\title{
Gianluigi Colalucci
}

\section{y su trayectoria restauradora}

Un viaje a través de las transformaciones en el mundo de la restauracion desde Cesare Brandi a nuestros dias

-VOLUMEN I-

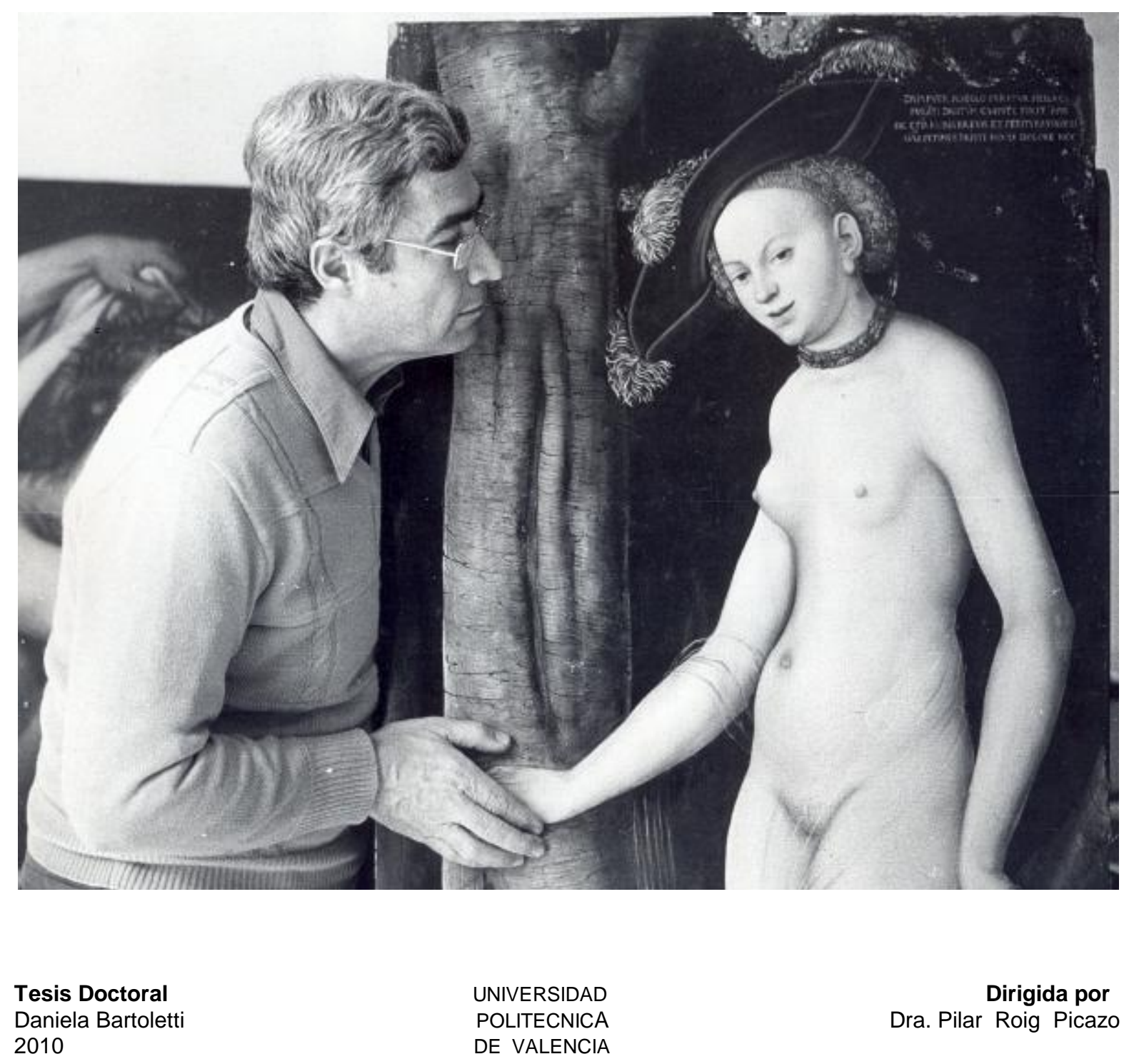




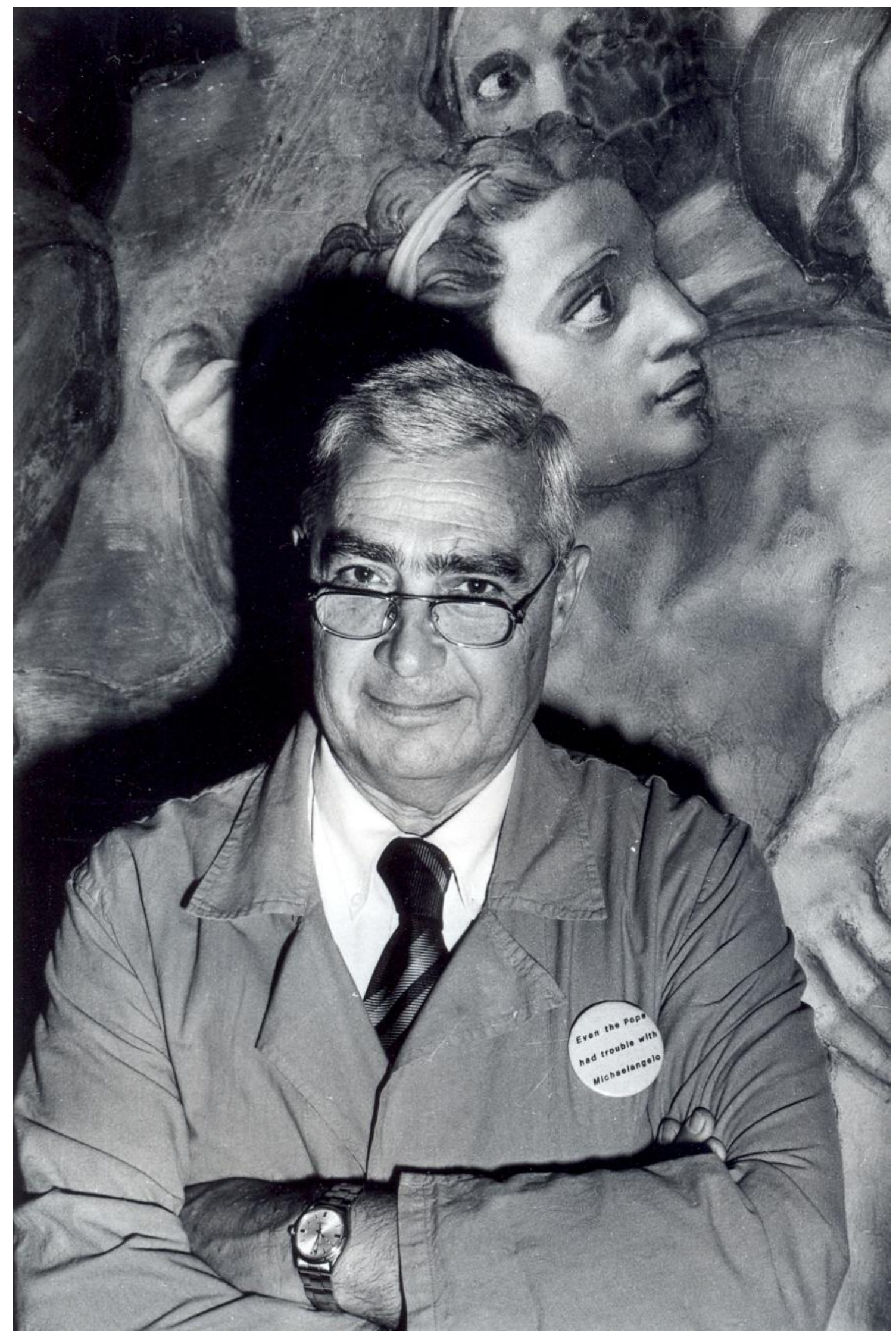

Gianluigi Colalucci durante il restauro del Giudizio Universale di Michelangelo 


\section{INTRODUZIONE}

$\mathrm{Nel}$ campo della conservazione dei beni culturali vi sono alcune figure di restauratori che con la loro opera hanno contribuito a scrivere pagine importanti della storia del restauro. L'interesse per questo argomento, che già da qualche anno è al centro di molte iniziative non sempre ben riuscite ${ }^{1}$, trova la sua espressione più interessante nel progetto europeo di un Archivio Storico dei Restauratori Europei, promosso dall'Associazione Secco Suardo di Bergamo,( si vedano a questo proposito i primi volumi dei "Quaderni dell'Archivio Storico Nazionale e Banca Dati dei restauratori italiani") $^{2}$. Attraverso l'acquisizione degli archivi di restauro, si cerca di ricostruire la storia della conservazione italiana ed europea del periodo compreso tra il $X V \| I^{\circ}$ e il $X X^{\circ}$ sec.

La presente tesi dottorale, dal titolo Gianluigi Colalucci y su trayectoria restaura dora si inserisce in questo contesto di studi cui Pilar Roig, Direttrice del Dipartimento di Conservazione e Restauro dei Beni Culturali dell'Università Politecnica di Valenzia e direttrice di questa tesi è particolarmente interessata, e si propone di rendere noto il profilo professionale di colui che nella nostra epoca ha meglio rappresentato e rappresenta, l'eccellenza del restauro italiano: Gianluigi Colalucci. Va inoltre sottolineato che proprio a riconoscimento di un percorso umano e professionale esemplare, la stessa Università Politecnica di Valenzia ha conferito nel 1995 a Gianluigi Colalucci una Laurea Honoris Causa in Conservazione dei Beni Culturali e nel 2003 gli ha intitolato una strada nel Campus Universitario. La Collaborazione di Colalucci con l'Università Politecnica inizia nel 1994 in occasione del restauro degli affreschi di Palomino nella Basilica della Virgen e continua oggi con il restauro della Volta dello Santos Juanes. Colalucci inoltre collabora stabilmente con la rivista R\&R,è professore assieme alla dott.ssa Pilar Roig del programma di dottorato in Scienza e Restauro del Patrimonio e del master ufficiale in Conservazione dei Beni Culturali. Inoltre ha sempre collaborato come consulente restauratore in tutte le iniziative che ha intrapreso e sviluppato il Dipartimento.

\section{OBIETTIVI}

II lavoro che viene presentato nasce con l'obiettivo di aprire una finestra su uno dei periodi più significativi della storia della tutela italiana, quello che va dall'Istituto Centrale del Restauro degli anni cinquanta, diretto da Cesare Brandi, ed arriva fino ai giorni nostri.

In primo luogo si cercherà di disegnare fedelmente il percorso professionale di Gianluigi Colalucci, e di fornire un profilo a tutto tond della sua complessa personalità di restauratore. Per raggiungere questo obbiettivo non ci limiteremo a trattare gli aspetti prettamente legati alle prassi esecutive degli interventi, ma cercheremo di fornire elementi interessanti alla comprensione di quelle complesse fasi evolutive che in questi ultimi sessant'anni hanno modificato radicalmente il mondo della conservazione italiana.

\section{TECNICA}

Per il raggiungimento degli obiettivi proposti è stata adottata una tecnica di indagine che ha unito la ricerca documentaristica eseguita nell'archivio e nella biblioteca di Colalucci, ai dati scaturiti dalla sua testimonianza diretta. 


\section{Ricerca}

L'indagine bibliografica si è basata sulla raccolta dei testi relativi alla storia del restauro italiana con particolare approfondimento di quelli relativi ai lavori svolti da Gianluigi Colalucci. Sono stati visionati libri, pubblicazioni, stampa e materiale su supporto audiovisivo.

\section{Studio dei documenti}

Lo studio presso l'archivio privato di Colalucci, ha preso l'avvio con la fase di riordino del materiale, da me eseguita tra il 2003 e il 2006. II materiale, una volta diviso per temi e divenuto facilmente consultabile, ha reso possibile la ricerca di tutte quelle fonti utili alla stesura della presente tesi. Sono state analizzate raccolte di corrispondenza, manoscritti, documenti, preventivi di restauro, contratti d'appalto, relazioni dei lavori, materiale fotografico, giornalistico ed audiovisivo. II risultato del lavoro di ricerca, ha contribuito a tracciare il profilo professionale di Colalucci dandomi la possibilità di mettere a fuoco l'evoluzione delle tecniche di restauro ed i materiali utilizzati nel corso di questi ultimi sessant'anni. Mi ha dato anche l'opportunità di individuare i cambiamenti di rotta del settore della conservazione, come quelli che riguardano il delicato equilibrio esistente tra l'indagine filologica dei materiali e quella scientifica.

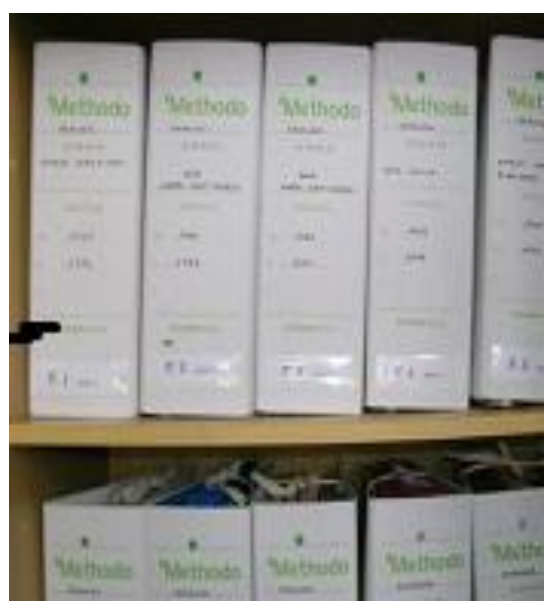

Una parte dell'archivio dedicata ai documenti

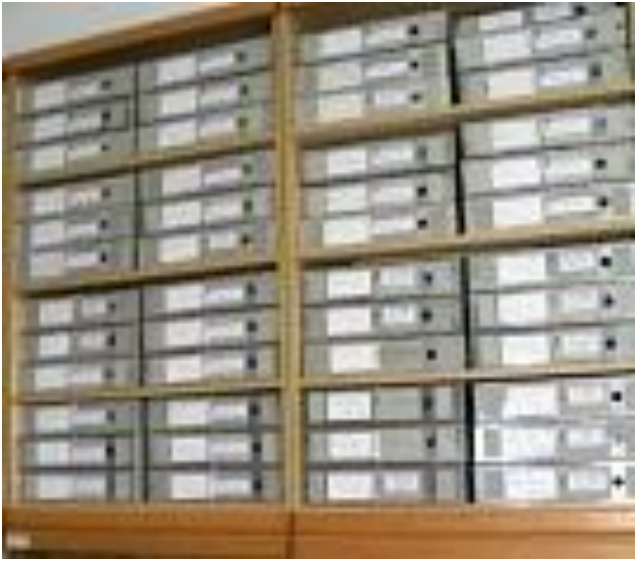

Una parte dell'archivio dedicata alle foto 


\section{ABSTRACT}

La tesi dottorale intitolata "Gianluigi Colalucci y su trayectoria restauradora" si propone di aprire una finestra su uno dei periodi più significativi della storia della tutela italiana, quello che va dall'attività dell'Istituto Centrale del restauro degli anni cinquanta, diretto da Cesare Brandi, ed arriva sino ai giorni nostri. Questa tesi, nata da un'idea di Pilar Roig, si inserisce nel contesto di studi e di ricerche sulle figure eminenti di restauratori che in questi anni stanno interessando la ricerca universitaria e registrano iniziative importanti come l'istituzione dell'archivio storico dei restauratori italiani e l'archivio storico dei restauratori europei, promosse dalla fondazione Secco Suardo. Atraverso lo studio della figura di Colalucci restauratore, si ripercorrono anche i progressi e le evoluzioni delle tecniche e della ricerca scientifica nel campo del restauro.

La tesi si articola in sei capitoli : il primo capitolo "gli anni della formazione", con gli inizi alla scuola dell' I.C.R. e l'insegnamento di Cesare Brandi; il secondo capitolo "il periodo siciliano", con il lavoro durissimo, per la poca esperienza, svolto da Colalucci a Palermo in Sicilia; il terzo capitolo "il Vaticano", dove si segue il percorso all'interno del laboratorio di restauro dei Musei Vaticani a partire dal 1960 e prima di affrontare il restauro degli affreschi di Michelangelo nel 1980 ; il quarto capitolo "Roma e le Soprintendenze dal 1965 al 1985", dove si analizza il lavoro eseguito da Colalucci parallelamente all'impegno nei Musei Vaticani; il capitolo quinto "la Sistina". Questo capitolo è dedicato interamente al restauro degli affreschi di Michelangelo nella Cappella Sistina, accompagnato da una forte polemica che la presente tesi analizza e documenta attraverso l'epistolario tra Colalucci e James Beck, accanito oppositore del restauro, e la stampa nazionale ed estera del tempo; il sesto capitolo "oltre la Sistina" dove si segue Colalucci nei lavori eseguiti dopo la conclusione della Sistina e dopo aver lasciato il Vaticano. Questo è un capitolo aperto poiché l'attività di Colalucci continua tutt'ora.

A conclusione del lungo percorso della vita professionale di Colalucci si evince che il periodo delle figure di restauratori eccellenti sta per concludersi, perché se è vero che questi sono stati un punto di riferimento per tante giovani leve, l'attuale appiattimento della società, la tendenza nel campo del restauro ad affidarsi sempre di più alle indagini scientifiche e sempre meno alle capacità di conoscenza e di capacità analitica dell'uomo, nonché leggi di assegnazione dei lavori di restauro che ignorano completamente la qualità professionale del restauratore, tolgono qualunque incentivo all'impegno durissimo e costante che questo lavoro richiede a chi voglia farlo seriamente e con coscienza, e soprattutto nell'esclusivo interesse del bene dell'opera d'arte. 


\section{RINGRAZIAMENTI}

Le persone che desidero ringraziare sono molte, poiché senza il loro aiuto la realizzazione di questa tesi sarebbe stata impossibile. Tra tutti coloro che a diverso titolo hanno reso possibile la realizzazione del mio lavoro va in particolare la mia gratitudine a:

Pilar Roig Picazo, direttrice del Dipartimento di Conservazione e Restauro dei Beni Culturali dell'Università Politecnica di Valencia (UPV) nonché direttrice di questa tesi, che mi ha spronato a realizzare questo lavoro;

Gianluigi Colalucci, poichè senza di lui non esisterebbe questo lavoro e perché mi ha affidato il suo archivio. Lo ringrazio particolarmente anche perché, durante la stesura della tesi, mi ha pazientemente assistito, sottoponendosi a continue interviste, rispondendo alle mie mille domande, e dandomi indicazioni affinché lo svolgimento della mia ricerca fosse mirato;

desidero inoltre ringraziare per il valido aiuto nella stesura della bibliografia la mia amica di lunga data e collega Fabiola Rubino, i miei fratelli Paolo e Roberto per le preziose indicazioni e l'assistenza informatica, e la dott.ssa Veronica Di Lullo per il lavoro di catalogazione dell'archivio. 


\section{I - GLI ANNI DELLA FORMAZIONE}

Questo primo capitolo abbraccia l'arco di tempo compreso tra la metà degli anni trenta e l'inizio gli anni cinquanta del Novecento, e affronta il periodo iniziale della storia di Colalucci. Si va dai precoci contatti con il mondo del restauro, dell'esistenza del quale prende atto già piccolissimo, alla formazione avvenuta presso l'Istituto Centrale del Restauro di Brandi, dove arriva grazie ai consigli del restauratore Augusto Cecconi Principi. Quello con Cecconi Principi è un'incontro fondamentale per Colalucci che a metà degli anni quaranta, è alle prese con la scelta del percorso da intraprendere dopo il liceo classico. Grazie alla testimonianza diretta di Colalucci, entreremo nel mondo "ovattato" dell'lstituto di quegli anni. Faremo un viaggio nel mondo della conservazione italiana che, per merito delle leggi sulla tutela varate alla fine degli anni trenta, aveva raggiunto un ruolo di prestigio. Tenteremo di mettere meglio a fuoco i metodi di insegnamento di Cesare Brandi, cercando di capire come gli allievi di quegli anni imparavano i fondamenti teorici del restauro, non ancora trasformati nella teoria vera e propria. Faremo un viaggio nell' Istituto dei Mora, di Giovanni Urbani, di Antonio Donghi, e di Augusto Werrmeheren che era stato chiamato da Brandi per dare all'insegnamento del restauro un'impronta più scientifica. Entreremo anche nel mondo affascinante delle storiche trasferte, organizzate nei primi anni cinquanta dall'lstituto a Napoli e a Messina, in occasione dei restauri al chiostro del Platano, a San Giovanni a Carbonara e per la mostra su Antonello da Messina e il '400 siciliano. 
I primi contatti col mondo del restauro e l'Istituto Centrale di Cesare Brandi

Gianluigi Colalucci nasce a Roma nel 1929 e trascorre i primi cinque anni della sua vita in una bella casa in via del Velabro ${ }^{3}$, situata accanto alla chiesa di San Giorgio e di fronte all'arco di Giano. Nel 1934 si trasferisce con la famiglia ${ }^{4}$ in via Cesare Beccaria $88^{5}$, nel più moderno quartiere Flaminio. Da piccolissimo, l'area archeologica del Foro Romano, diviene per lui un luogo familiare dove passare i momenti di gioco e dove prendere confidenza con i monumenti antichi. Ricorda che il contesto urbano attorno alla sua casa del centro di Roma, subiva rapidi mutamenti a causa degli sventramenti che cancellavano una dopo l'altra, piazza Montanara e piazza della Consolazione, per fare posto alla via del Mare ${ }^{6}$. Mi dice che in quegli stessi anni ricorda di aver avuto il suo primo contatto con il mondo del restauro. Camminava con sua madre ai piedi della scalinata dell' Aracoeli, quando vide dei restauratori al lavoro. Erano all'interno di una piccola abside, parte di quei resti medievali che, a ridosso del Vittoriano, ${ }^{7}$ erano scampati alle demolizioni del 1928. L'abside conserva alcuni frammenti di affresco raffiguranti un Cristo ed i simboli della Passione. Colalucci ricorda che i restauratori erano arrampicati su un ponteggio rudimentale e che

\footnotetext{
${ }^{3}$ La casa è tutt'ora esistente. Si tratta di un edificio costruito in stile vagamente rinascimentale, in voga fino agli anni 30 del '900. L'assetto urbano della zona circostante la casa è però notevolmente mutato nel tempo. Le strade e i terreni per esempio, negli anni 20 erano ad una quota assai più alta di quella attuale e Colalucci ricorda l'esistenza di piazza Montanara scomparsa successivamente con gli sventramenti del periodo fascista.

${ }^{4}$ I genitori sono Luisa Ferrari e Giuseppe Colalucci. I| padre è un avvocato che si dedica al giornalismo. II nonno materno era Colonnello dell'esercito, quello paterno era nell'industria dell'acqua minerale.

${ }^{5}$ Anche questa casa, che si trova nei pressi del lungotevere Flaminio, è tutt'ora esistente.

${ }^{6}$ Piazza Montanara era un luogo molto caratteristico di Roma, molto amato da Goethe. La piazza fu rasa al suolo nel 1931 come Piazza della Consolazione, per fare posto all'attuale via del mare. Per maggiori chiarimenti sull'argomento cfr. I. Insolera "Roma fascista, nelle fotografie dell'Istitito Luce" editori riuniti- Roma 2001 ; oppure Italo Isolera e Francesco Perego in "Archeologia e Città" ed Laterza, Roma 1983.

Ovvero il monumento a Vittorio Emanuele II ,opera di G. Sacconi, inaugurato il 4 giugno 1911.La complessa macchina che porterà alla costruzione del monumento e alla distruzione delle pendici nord del Campidoglio si era messa in moto subito dopo la morte del re avvenuta nel 1878. Per le complicate vicende che riguardano il Vittoriano si veda Primo Acciaresi G. Sacconi e l'opera sua massima 1911; G. Sacconi Relazione del progetto per il monumento a Vittorio Emanale II. 1883.
} 
la cosa lo colpì moltissimo perché era incantato dall'idea di poter vedere da vicino le pitture e di poterle toccare.

Qualche anno dopo, quando ha circa quattordici anni, si reca per la prima volta in visita ai Musei Vaticani e alla Cappella Sistina. Siamo all'inizio degli anni quaranta e la parete del Giudizio Universale è seminascosta da una grande impalcatura. Nuovamente torna a fantasticare sul mestiere del restauratore. Ora ha una consapevolezza diversa delle cose e riesce a mettere meglio a fuoco le ragioni della curiosità che prova verso quel lavoro così inusuale. Mi dice che si sentiva attratto dal rapporto privilegiato che i restauratori potevano avere con l'opera d'arte, e che era attirato dal lavoro in se ma molto meno dai restauratori, che gli sembravano tutti vecchi e burberi. Bisogna dire che al di là delle generalizzazioni, le sue impressioni non erano lontanissime dalla realtà, poiché all'epoca vi erano ancora dei restauratori di stampo ottocentesco che agli occhi di un adolescente dovevano apparire decisamente poco attraenti.

I ricordi giovanili di Colalucci legati al restauro ed all'arte, si concludono con il racconto delle frequenti visite che faceva con la madre alla chiesa del Gesù. Andavano esattamente nella cappella della "Madonna della strada", dove ci 
sono le tavole tardo-cinquecentesche con le storie della Vergine, dipinte dal Valeriano e dal Pulzone ${ }^{8}$. La madre lo portava in quella cappella nella speranza che la Madonna lo aiutasse a trovare una strada per il futuro. Oggi, a distanza di tanti anni, sappiamo bene che quella strada sarà trovata e brillantemente percorsa. Molti anni dopo Colalucci tornerà in quella cappella, non più come faceva da piccolo, ma da restauratore ormai affermato a restaurare, su incarico della Soprintendenza, proprio quelle tavole che da bambino aveva visto e ammirato tante volte. Verso la metà degli anni quaranta, ha terminato il liceo ed è in alto mare circa il proseguimento degli studi. Ha molti interessi, una passione per l'ingegneria meccanica, ed una buona attitudine per il disegno. Ricorda che ad un certo punto, per una serie di circostanze fortunate, scoprì che tra le amicizie della sua famiglia vi era il noto restauratore romano Augusto Cecconi Principi ${ }^{9}$. L'incontro con Cecconi si rivelerà determinante ai fini delle scelte future, poiché grazie a lui si appassionerà definitivamente al restauro ed arriverà anche all'Istituto Centrale. Cecconi Principi insegnava all'istituto Centrale del Restauro e aveva un bellissimo studio al n`54 di via Margutta, la strada degli artisti. Veniva da una famosa famiglia di restauratori, suo zio Lorenzo aveva lavorato nella volta della Sistina nel 1910.

\footnotetext{
${ }^{8}$ Giuseppe Valeriano (L’Aquila 1542- Napoli 1596)-Scipione Pulzone (Gaeta 1550- Roma 1598).

${ }^{9}$ A. Cecconi Principi, era uno dei restauratori chiamati da C. Brandi all'I.C.R ad insegnare tecnica del restauro. La conoscenza di Colalucci con i Cecconi avvenne attraverso una coppia di amici di sua madre Luisa, i sig.ri Panicali, vicini di casa nel condominio in via G.Vasari n.14 dove i Colalucci abitavano al terzo piano. Giulio Panicali era un doppiatore cinematografico molto noto poiché prestava la sua "voce" ad attori americani famosi come Tyrone Power o Clarke Gable. L'incontro tra Colalucci e Cecconi avviene tra il 1945/46.
} 
Colalucci ricorda che Augusto si faceva chiamare "Steno" dagli amici più intimi, ed era un tipo lontano anni luce dai restauratori che aveva visto da bambino.

Era elegante, dinamico, spiritoso e possedeva automobili sportive. Vedendo crescere il suo interesse verso il restauro, molti amici di famiglia si attivano per aiutarlo, in quegli stessi anni la mamma di un suo compagno di scuola gli regala una preziosa edizione del Secco Suardo ${ }^{10}$, mentre altri conoscenti gli presentano Mameli, altro restauratore romano molto noto. Mameli abitava in via Tevere ed era assai diverso da Cecconi, poiché apparteneva a quella tipologia di restauratori di vecchio stampo, diffidenti verso l'Istituto e convinti che il mestiere si potesse imparare solo con la pratica di "bottega" ${ }^{11}$. Pur trovandolo affascinante come personaggio, Colalucci è ormai in grado di valutare la situazione. Le idee di Mameli sul restauro e sulla formazione gli appaiono immediatamente arretrate, mentre si trova pienamente in sintonia con il pensiero di Cecconi e perciò, alla fine degli anni quaranta, avendo ormai deciso che il restauro sarebbe stata la sua strada, tenta l'esame di ammissione all'Istituto Centrale del Restauro. Arriva a sostenere l'esame di ammissione nell'ottobre del 1949 dopo essersi fatto preparare da Lori Tosi, nipote di Cecconi. Affronta I e prove d'esame con altri sette o otto candidati, e viene ammesso ai corsi con quattro di loro: Chiara Barberis, Arnaldo Blasetti, Laura De Lama, Guillermo Sanchez Lemus. L'esame si basava su tre prove : disegno,

\footnotetext{
10 |l manuale di G. Secco Suardo, "Il Restauratore di dipinti” terza edizione, Hoepli 1918, gli viene regalata da un'amica della madre. L'edizione, che contiene la prefazione di Gaetano Previati, è ancora conservata nella biblioteca di Colalucci.

${ }^{11}$ Mameli era anche molto critico nei confronti del tratteggio che si faceva all'I.C.R. tanto da definirlo in modo dispregiativo "un ritocco a righe". II tratteggio, come tecnica di reintegrazione delle lacune era stata messo a punto da Cesare Brandi in occasione del restauro degli affreschi di Lorenzo da Viterbo nella Cappella Mazzatosta in Santa Maria della Verità a Viterbo. I dipinti erano crollati in seguito ai bombardamenti del 1944 ed erano stati ricomposti dall'istituto che aveva integrato le parti mancanti con il tratteggio. Cfr. C, Brandi, "Il restauro Teoria e pratica”, a cura di M. Cordaro. Roma 1994,pp. 84-89.
} 
storia dell'arte, tecniche artistiche e tecniche di restauro. La commissione d'esame era formata da Cesare Brandi e da altri professori, tra cui Giovanni Urbani. L'innata attitudine per il disegno lo aiuterà a superare bene la prima prova, pur non avendo alle spalle una formazione artistica specifica, e ad essere ammesso alla seconda prova pratica e poi agli orali. Mi raccontahe all'esame orale interrogava direttamente Brandi, e che la prova era difficile poiché questo, per sondare il reale il grado di preparazione e di interesse per l'arte dei candidati, faceva domande che esulavano dal programma. Mi dice anche che all'epoca ignorava l'importanza di Brandi come studioso, e dunque poté sopportare l'interrogazione senza provare una soggezione particolare. Brandi gli fece domande sulla facciata del Duomo di Orvieto del Maitani, e sulla collezione della Pinacoteca Vaticana, chiedendogli di parlare dell'opera che lo avesse maggiormente emozionato. La scelta di Colalucci ricadde sull'affresco raffigurante "II Platina", dipinto da Melozzo da Forlì per Papa Sisto IV. Brandi incuriosito dalla scelta, gli chiese di seguito come fosse possibile che un affresco dipinto per la biblioteca di Sisto IV ${ }^{\circ}$ si trovasse nella Pinacoteca, dandogli lo spunto per parlare della tecnica dello "strappo". Colalucci fece un ottimo esame, tanto da risultare primo in graduatoria e guadagnandosi, grazie alla risposta sullo strappo, la fama di grande conoscitore del Secco Suardo cosa che non rispondeva affatto alla verità. 


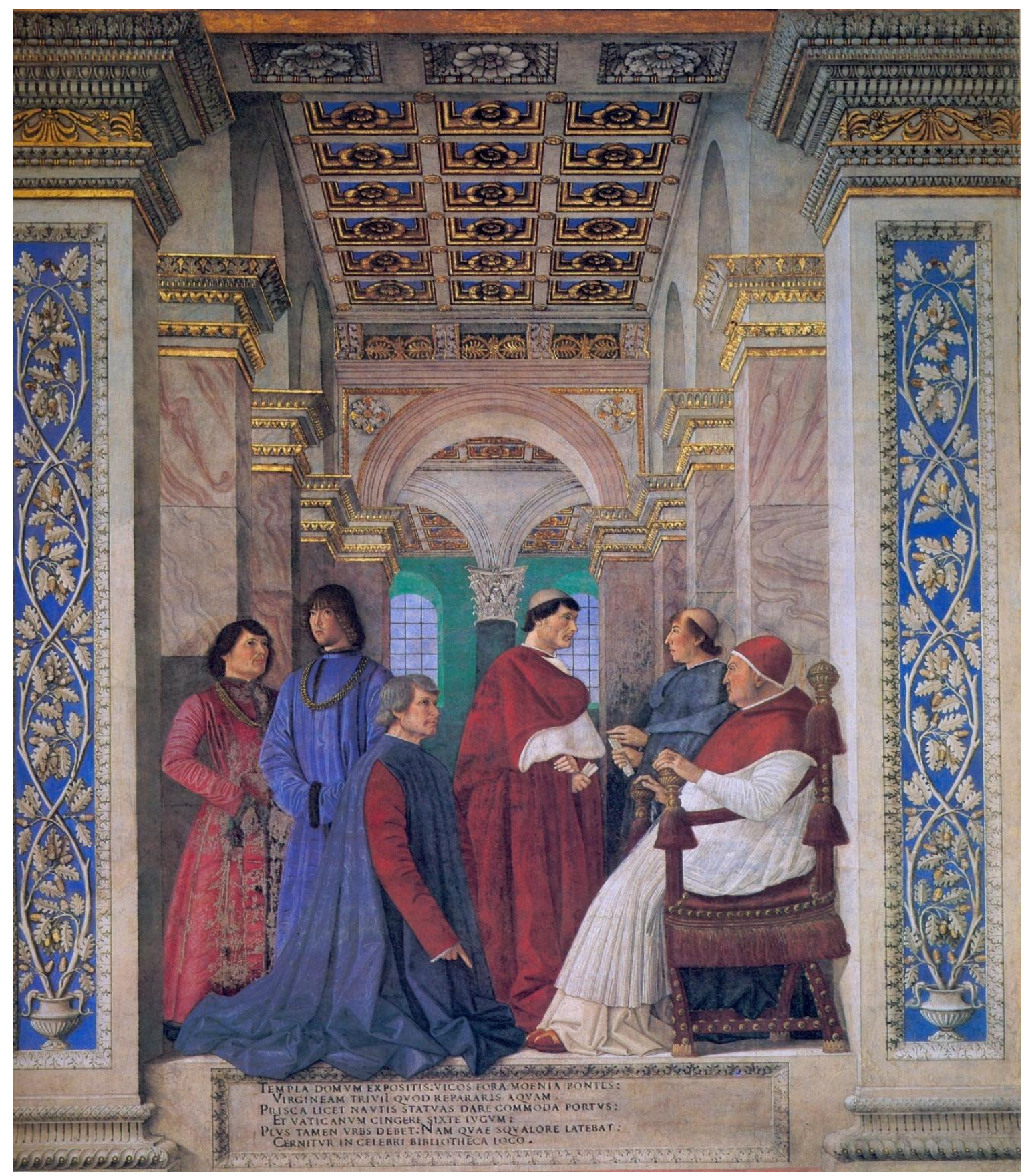

Melozzo da Forli "Il Platina" - affresco strappato- Pinacoteca Vaticana

I ricordi di Colalucci sull'Istituto di quegli anni, sono molto precisi. La sede è quella storica di Piazza San Francesco di Paola, nel grande ex convento magistralmente restaurato. Dice Colalucci : 
“.. L'Istituto aveva un fascino molto particolare. Era situato in un gran ex Convento,nella piazza di San Francesco di Paola, una piazzetta in una strada oggi come allora molto solitaria, pur essendo vicina al Colosseo e alla chiesa di San Pietro in Vincoli, dove si trova il Mosè di Michelangelo, luogo molto frequentato dai turisti. L'interno, molto elegante, era molto particolare per l'atmosfera rarefatta che si coglieva. Si incontravano poche persone, nessun rumore, nessun odore, anche se c'era molta gente che lavorava. L'interno dell'edificio era stato ristrutturato e arredato in modo moderno e con molto gusto. Quello che mi impressionava era l'ufficio del direttore, perché prima di entrare, in fondo ad un breve corridoio, sopra ad una pedana coperta da moquette marrone, stava la grande tavola della Pietà di Viterbo di Sebastiano del Piombo. II quadro di una altissima qualità materica e di una bellezza impressionante, era stato restaurato magistralmente e stava lì, quasi un simbolo della attività che si svolgeva in quel luogo. Per me questo è il simbolo dell'Istituto di Brandi degli anni cinquanta.(...) in quella biblioteca, in quei laboratori di chimica, negli studi dei restauratori, nel largo corridoio con i frammenti dell'affresco di Mantegna distrutto da un bombardamento, i restauratori, gli storici dell'arte i professori, formavano un mondo nel quale entravo con allegria (...) subito mi resi conto che mi trovavo in un centro creativo e di eccellenza destinato alla formazione di numerose generazioni di restauratori ben preparati e diverse quel modello tradizionale che ancora in quegli anni si formava nelle botteghe (..)."12

Al terzo piano erano gli ambienti più prestigiosi, appena salite le scale sulla sinistra, stava la Sala delle Mostre, voluta da Brandi come luogo espositivo per le opere restaurate. La sala era nata dalla collaborazione tra lo stesso Brandi, reduce dall'esperienza americana ${ }^{13}$, e l'architetto Silvio Radiconcini. Sulla scorta dell'esperienza vissuta, Brandi, appena rientrato in Italia, aveva voluto mettere in pratica quelle novità espositive che aveva assimilato oltreoceano. La

\footnotetext{
${ }^{2}$ I passi riportati qui e di seguito sono tratti dall'ntervista da me fatta a Colalucci e pubblicata sul n 108 di R\&RValencia settembre 2008 
Sala delle Mostre era stata pensata per essere un luogo con pochissime interferenze visive ed acustiche, in modo da favorire la concentrazione di chi guardava. Procedendo lungo il corridoio, oltre la Sala delle Mostre e sempre sulla sinistra, si incontrava la biblioteca Venturi e di seguito l'ufficio del Direttore. In fondo al corridoio stava come si è detto, la Pietà di Sebastiano del Piombo. La tavola era giunta all'Istituto nel 1945, ancora rinchiusa nella cassa di legno che l'aveva preservata dai danni della guerra ma che aveva messo a dura prova la stabilità del colore, e appena restaurata era stata scenograficamente esposta vicina alla Direzione, come un "maestoso biglietto da visita". Lungo il corridoio del primo piano, erano disposte le cassette che contenevano i frammenti degli affreschi di Mantegna provenienti dalla Cappella Ovetari ${ }^{14}$. Quei frammenti erano divenuti il simbolo delle distruzioni belliche, ed erano arrivati all'Istituto raccolti in grandi sacchi assieme a detriti di vario genere. In pochi mesi si era tentata, e realizzata, la ricostruzione parziale della scena con il "Martirio di San Giacomo", che aveva richiesto la messa in atto di soluzioni innovative, dando all'operazione il valore storico del "prototipo".l frammenti appartenenti a quel brano, erano stati applicati su un fondo costituito da una fotografia che riproduceva, a grandezza naturale, l'originale prima della distruzione. La foto era stata impressa su tela, e Colalucci mi dice che l'allora fotografo dell'Istituto Mauro Peleggi, per sviluppare la foto sulla tela preparata con la gelatina fotografica, aveva dovuto inondare di reagente il pavimento di

\footnotetext{
${ }^{14}$ La Chiesa degli Eremitani fu bombardata dagli aerei alleati nel 1944. Durante il bombardamento andarono distrutti quasi completamente gli affreschi della Cappella Ovetari dipinti dal Mantegna, da Giovanni d'Alemagna, da Bono da Ferrara, Ansuino da Forlì e Nicolò Pizzolo tra il 1448 e il 1452. Dal disastro si salvarono soltanto i due brani raffiguranti " l'Assunta" e "il martirio e il trasporto del corpo di San Cristoforo" staccati nel 1887 dal restauratore Bertolli, e che allo scoppio della guerra furono portati in un rifugio. L'evento, come si può bene intuire, colpì profondamente le sensibilità degli uomini di cultura e non e fu percepito come una ferita insanabile inferta al cuore della storia dell'arte. Tutti i frammenti che subito dopo il disastro furono raccolti tra le macerie, vennero inviati a Roma all'istituto Centrale, dove fu subito tentata la ricomposizione di alcune scene.
} 
uno dei locali al piano terra. L'intervento di restituzione estetica, aveva poi richiesto l'esecuzione di una sapiente reintegrazione pittorica a tratteggio "spinta al massimo", che era scaturita dalle complesse elaborazioni teoriche di Brandi sul tema del frammento. L'estremo tentativo di ricostruzione era intervenuto quasi a negare, sull'onda dell'emozione, la perdita di quello che è considerato uno dei principali capolavori del Rinascimento. Una perdita che, all'indomani del bombardamento, aveva fatto pronunciare al grande storico dell'arte Giovanni Fiocco parole che pesavano su tutti come un macigno: "La Cappella Ovetari è morta prima che fossero aperte le porte dei suoi segreti". Dopo le prime ricomposizioni, si era riusciti a restituire anche piccoli brani delle scene con le "storie di San Cristoforo", ma l'Istituto aveva deciso di non proseguire oltre, circoscrivendo la ricerca dei frammenti, alla pratica didattica per agli allievi appena entrati.

Tra il 1949 e il 1953, cioè nel periodo di permanenza di Colalucci l'Istituto era popolato da molte persone. Oltre a Brandi c'era un direttore della scuola che era Michelangelo Cagiano de Azevedo anche insegnante di archeologia. Giovanni Urbani insegnava storia dell'arte, Salvatore Liberti la chimica e Antonio Donghi ${ }^{15}$ il disegno. Anche Donghi colpiva molto la fantasia di Colalucci poiché era un personaggio singolare ed eccentrico che, nonostante il successo come artista, conduceva un'esistenza molto riservata.

La scuola si svolgeva più o meno come oggi. In quegli anni l'insegnamento 
delle tecniche di restauro era affidato ad Augusto Cecconi Principi al quale, nel 1950, si aggiungerà Augusto Vermeheren. Nel formare il gruppo di restauratori dell'Istituto Brandi, aveva attinto da molte parti, scegliendo le persone secondo un criterio di merito che oggi sarebbe impensabile. Da Bergamo aveva chiamato il celebre Mauro Pelliccioli, che era arrivato con un gruppo di collaboratori formato da Luigi Pigazzini, Stefano Locati, Tarcisio Spini e Francesco Pelessoni. Da Siena il doratore Giuliano Baldi, da Roma il restauratore Carlo Matteucci ${ }^{16}$. Da Rodi Brandi aveva chiamato il restauratore ${ }^{17}$ Alì Caravella, conosciuto durante l'esperienza fatta nel Dodecanneso, ed aveva fatto venire da Napoli il chimico Selim Augusti. Mi racconta Colalucci che Pelliccioli, si dimetterà quasi subito a causa delle profonde divergenze che esistevano tra lui e Brandi ${ }^{18}$.

L'arrivo di Augusto Vermeheren da Firenze, segna una importante svolta nel criterio di insegnamento dell'Istituto. Vermeheren possedeva un innato talento, che con la pratica aveva affinato, per ciò che riguarda la diagnosi radiografica applicata al restauro. Nel 1935 aveva costruito il prototipo di un sofisticato apparecchio che consentiva di ottenere delle immagini radiografiche selettive. Le novità da lui introdotte saranno così incisive, da far tornare sui banchi di

\footnotetext{
${ }^{16}$ Matteucci, era un restauratore romano che, come Cecconi aveva uno studio in via Margutta. Era dotato di grande capacità soprattutto nella reintegrazione pittorica. Colalucci ricorda che Matteucci andava a lavorare in Istituto la mattina molto presto verso le 7 e andava via alle 10/ 10,30. In quelle ore che trascorreva in Istituto spesso sistemava , senza essere visto, le reintegrazioni fatte da altri .

${ }^{17}$ All'inizio del periodo fascista, prima della dittatura, all'interno del partito vi era un gruppo dirigente costituito da quattro uomini di potere: B. Mussolini, C. De Vecchi, I. Balbo e De Bono. Ad un certo momento, e con varie scuse, Mussolini allontana dall'Italia De Vecchi, Balbo e De Bono facendo conferire loro incarichi di prestigio all'estero. De Vecchi viene nominato Governatore del Dodecanneso (il gruppo di dodici isole dell'Egeo divenute Italiane, la cui capitale era Rodi). De Vecchi persona di cultura, ostile e contrario a Mussolini, raccoglie e porta con se a Rodi alcuni giovani storici dell'arte antifascisti tra cui Argan e Brandi. I due giovani studiosi, durante la loro permanenza a Rodi, conoscono il restauratore Alì Caravella che in seguito faranno venire a Roma come insegnante, quando saranno chiamati a dirigere l' Istituto appena fondato con la legge Bottai.

18 Tra Brandi e Pelliccioli vi erano distanze incolmabili sul concetto di restauro e sull'idea della figura del restauratore. Pelliccioli aveva una visione ancora ottocentesca e un po' "romantica" del restauro che contrastava decisamente con l'indirizzo scientifico, anche se pur sempre storico-critico ,pensato da Brandi.
} 
scuola perfino i Mora, già diplomati pochi anni prima. Mi racconta Colalucci che in Istituto Vermeheren decise di perfezionare l'apparecchio che aveva già messo a punto anni prima ${ }^{19}$, e che mirava ad eliminare, dalle radiografie delle tavole, le interferenze delle parchettature, dei nodi o di altri elementi estranei al legno come i chiodi. Colalucci mi dice che vi riuscì alla perfezione tanto che, quando vide il risultato della prima radiografia, pensò che il fotografo Peleggi, che l'aveva sviluppata, avesse usato qualche metodo di correzione fotografica per cancellare le tracce delle interferenze.

Nel 1951, Colalucci è costretto ad interrompe il corso per un anno per svolgere il servizio militare ${ }^{20}$. Al rientro riprende il corso da dove lo aveva interrotto, ovviamente con compagni diversi da quelli che aveva lasciato l'anno precedente.

Lo svolgimento del corso comprendeva, allora come oggi, l'insegnamento di materie teoriche e l'insegnamento pratico delle tecniche di restauro. Durante le ore dedicate alla pratica, gli allievi affiancavano i vari restauratori nei lavori che questi via via svolgevano. Naturalmente, il numero dei restauratori interni all'Istituto cresceva con gli anni, poiché a quelli chiamati da Brandi inizialmente, si aggiungevano i diplomati più meritevoli. Uno dei primi lavori di Colalucci allievo, si svolge sotto la guida dei Mora, e riguarda il recupero della doratura originale, nelle cornici gotiche del trittico con la "Madonna col Bambino, Pietà e

\footnotetext{
${ }^{19}$ A. Vermeheren "sulle possibilità Stereo-Strato-Radiografiche..." in Bollettino I.C.R. 11-12 - 1952 pp.121/133 
Santi ${ }^{21}$ di Matteo da Gualdo. In seguito, lavora con Peppino Pittà al recupero dei frammenti degli affreschi di Mantegna, ed al trasporto di colore di una tavola proveniente dalla Cattedrale di Bari ${ }^{22}$. Con Paolo Mora lavora sugli affreschi a fondo nero del Museo delle Terme a Roma ${ }^{23}$, con Baldi agli stendardi di Città di Castello di Raffaello ${ }^{24}$, ed infine con Aldo Angelini alla cimasa "dell'Annunciazione" di Piero della Francesca ${ }^{25}$. Le tecniche di restauro si apprendevano lavorando prevalentemente sulle opere mobili o sugli affreschi staccati. All'epoca si facevano sperimentazioni di nuovi materiali, si affacciavano timidamente i materiali sintetici verso i quali c'era una grande attenzione. Alcuni di questi avranno uno sviluppo incredibile, altri saranno abbandonati quasi subito, come il Nylon liquido, che Colalucci ricorda di aver provato, insieme a Paolo Mora, sugli affreschi a fondo nero del museo delle Terme. L'insegnamento pratico veniva integrato dalle esperienze di lavoro nei cantieri di affreschi che l'Istituto svolgeva fuori sede, ed ai quali gli allievi partecipavano come aiutanti. Nei primi anni cinquanta l'Istituto aveva due importanti cantieri a Napoli. Colalucci partecipa con Aldo Angelini al restauro degli affreschi di Antonio Solario ${ }^{26}$ nel Chiostro del Platano, dove l'I.C.R. già nel

\footnotetext{
${ }^{21}$ II trittico proveniente dalla Chiesa di S. Maria Assunta di Casacastalda. Cfr. scheda di restauro a cura di G. Urbani in Bollettino I.C.R n 3-4 anno 1950, p. 109

${ }^{22}$ Anonimo meridionale del sec.XVI, "San Girolamo nello studio" San Nicola di Bari. Cfr. scheda di restauro a cura di G.Urbani, Bollettino I.C.R n $7-8$ anno 1951,pp 73

${ }^{23}$ M. C. de Azevedo "Provvedimenti conservativi per i dipinti della casa Romana della Farnesina" Bollettino I.C.R $n^{\circ} 7-8$ anno 1951, pp 33-34

${ }^{24}$ Stendardo processionale, opera di Raffaello raffigurante "SS. Trinità con i Santi Rocco e Sebastiano, Creazione di Eva”. Cfr scheda di restauro a cura di S. Liberti in Bollettino I.C.R n9-10 anno 1952, pp. 94-

${ }^{25}$ C. Brandi “ Restauri a Piero della Francesca” Bollettino I.C.R n¹7-18 anno 1954, da p.88 a p.97

${ }^{26}$ Antonio Solario detto lo Zingaro. Pittore della prima metà del 1500, di origini veneziane, attivo nelle Marche oltre che a Napoli. Il chiostro del Platano si trova nel convento dei Santi Severino e Sossio.
} 
1942, aveva effettuato una campagna di indagini scientifiche curata da Selim Augusti ${ }^{27}$, e con Raimondo Boenni ed Eliseo Zorzetto al restauro degli affreschi di Michelino da Besozzo nella Chiesa di San Giovanni a Carbonara. Sempre al chiostro del Platano tornerà una seconda volta assieme alle restauratrici Nerina Neri e Annamaria Sorace (che sposerà nel 1954). Partecipa anche alla trasferta di Messina, organizzata nel 1953 in occasione della mostra su Antonello e il ' 400 siciliano $^{28}$. La trasferta di Messina è un po' diversa dalle altre, poiché per restaurare gran parte delle opere che dovevano essere esposte nella mostra, l'Istituto sarà costretto a trasferirsi per alcuni mesi, e quasi al completo, nella città siciliana. Brandi era nel comitato scientifico della mostra, alla quale dedicherà un numero speciale del "Bollettino dell'Istituto"29. Per l'allestimento, il Soprintendente Giorgio Vigni aveva voluto l'architetto veneziano Carlo Scarpa, reduce dai restauri eseguiti tra il 1950 e il 1952 alle gallerie dell'Accademia a Venezia. Le scelte espositive di Scarpa si riveleranno coraggiose $^{30}$, poiché trasformeranno le spogli e sale del Palazzo Comunale di Messina, in una specie di interno di tenda araba . Colalucci mi racconta che Scarpa ottenne quel particolare effetto, sovrapponendo tra loro una grande quantità di teli di "velatino", la speciale garza che i restauratori usano per

\footnotetext{
${ }^{27}$ G. Urbani "Il restauro degli affreschi di Antonio Solaro nel Chiostro del Platano a Napoli" e S. Liberti "Analisi microclimatica dei campioni delle efflorescenze..." Bollettino I.C.R n 2 anno 1950

${ }^{28} \mathrm{Cfr}$. catalogo della mostra a cura di G. Vigni e G. Carandente, ed. Alfieri 1953 Venezia

${ }^{29}$ Cfr. n 14-15 del Bollettino dell'Istituto Centrale del Restauro 1953

${ }^{30}$ La mostra si svolgeva negli ambienti del Palazzo Comunale di Messina, nel salone centrale erano esposte tutte le opere di Antonello, nelle sale laterali le opere del 400 siciliano. Con una genialità singolare Scarpa nascose tutte le tristissime pareti e i soffitti del palazzo con drappi di "velatino" intrecciati tra di loro, in modo da far somigliare ogni ambiente all'interno di una sontuosa tenda araba. Invenzione di grande effetto e originalità (soprattutto se pensiamo ai tempi in cui fu realizzata) che evoca la cultura mediterranea e araba della quale la Sicilia è intrisa. E' divertente quello che racconta Colalucci a proposito dei velatini usati da Scarpa, che alla fine della mostra furono presi dai restauratori e vista l'enorme quantità, utilizzati per i lavori di molti anni successivi. Colalucci ne prese moltissimo e lo utilizzò fino agli anni 60.
} 
proteggere le pitture durante determinate operazioni. Brandi seguiva da vicino $\mathrm{i}$ lavori anche dal punto di vista museografico, un tema che continuava ad appassionarlo. Colalucci ricorda che il direttore, quando era in trasferta, a Messina come a Napoli, si rilassava e passava con gli allievi e i restauratori momenti assai piacevoli :

"Quando veniva a visitare i lavori in trasferta si rilassava. Mangiavamo tutti assieme. Gli piaceva molto la cucina e cucinava lui stesso. Una volta, quando eravamo a Napoli per lavorare al Chiostro del Platano, invitò Nerina, Annamaria e me, nella sua piccola casa nellisola di Procida. Dopo essere stati in barca (brandi remava e cantava brani dell'Orfeo e Euridice di Glouk) ci offrì un riso ai frutti di mare che aveva riprodotto dopo averlo assaggiato nel famoso ristorante "Corsetti" di Roma, che proprio in quell'anno, 1952, il famoso cuoco romano aveva elaborato.”.

In onore delle esperienze fatte durante la trasferta di Messina, Colalucci decide di preparare la tesi di diploma su Antonello. Già durante la preparazione della Mostra, aveva avuto l'opportunità di vedere da vicino il famoso "ritratto virile" di Cefalù mentre veniva restaurato, in Istituto a Roma, da Paolo e Laura Mora. Si ricorda di aver visto nascere, giorno dopo giorno, la rispettosissima reintegrazione pittorica che attenuava, senza cancellarli, $i$ segni dell'antico sfregio che deturpava gli occhi ed il volto del ritratto. Qualche tempo dopo a Messina, aveva avuto l'opportunità di tenere tra le mani la "Crocifissione di Sibiu" giunta nella città siciliana per la mostra. Alla fine del 1953, appena rientrato dalla trasferta, Colalucci sostiene l'esame di diploma e acquisisce il titolo di restauratore. 


\section{L'insegnamento di Cesare Brandi}

Le vicende che hanno portato alla fondazione dell'lstituto Centrale del Restauro, sono ampiamente note e più volte pubblicate. Si va dalle vicende storico-critiche sapientemente trattate da Licia Vlad Borrelli ${ }^{31}$, a quelle più prettamente burocratico- amministrative, riprese di recente da molti altri. L'Istituto, come è noto, nasce alla fine degli anni trenta del Novecento, dalle menti illuminate di un piccolo e determinato gruppo di intellettuali, tra cui spiccano i nomi di C. Brandi e G. C. Argan, sostenuti dall'allora Ministro della cultura Giuseppe Bottai. Nonostante la difficoltà del momento politico, il gruppo riesce a far varare nel 1939 due leggi cardine per il settore della conservazione del patrimonio culturale italiano: quella sulla tutela, e quella che permetterà la fondazione dell'Istituto Centrale del Restauro ${ }^{32}$. L'esigenza di riordinare il settore del restauro con nuove regole pratico-teoriche, si era manifestata in tutta la sua virulenza già un anno prima, in occasione dello storico Convegno dei Soprintendenti tenutosi a Roma. II discorso di apertura del giovane Argan aveva insistito con fermezza sulla necessità "improrogabile" di istituire un "Gabinetto Centrale del Restauro". Argan aveva anche ratificato, rimarcandone le differenze, le caratteristiche dei due tipi di restauro possibili : quello conservativo $^{33}$ e quello artistico ${ }^{34}$. Poco più di un anno dopo, il 10 ottobre del

\footnotetext{
${ }^{31}$ Cfr. L. Borrelli in "Attualità della teoria di cesare Brandi" atti del convegno su Brandi ,Siena 1998, ed. Silvana Editoriale Milano 2001

32 Giuseppe Bottai pur essendo ministro del governo fascista aveva in materia di tutela e conservazione idee moderniste. Le leggi in questione sono la n.1089 del 1 giugno1939, pubblicata sulla "Gazzetta Ufficiale" del 8 agosto $1939 n^{\circ} 184$ con il titolo "Tutela Delle Cose D'Interesse Artistico o Storico" e l'altra è la n.1240 del 22 luglio 1939, pubblicata sulla "Gazzetta Ufficiale" del 2 settembre 1939, n.205 col titolo "Creazione del Regio Istituto del Restauro presso il Ministero dell'Educazione Nazionale". 
1941, I'Istituto viene inaugurato, e affidato alla direzione di Cesare Brandi. Brandi ricoprirà il ruolo di direttore fino al 1961, quando passerà il testimone a Pasquale Rotondi che a sua volta lo lascerà a Giovanni Urbani.

L'attività iniziale dell'Istituto si svolge a ritmo ridotto per le difficoltà derivanti dalla guerra, anche se tra il 1942 e il 1946 Brandi organizza alcune Mostre di opere restaurate. Vale la pena di citare quella su Antonello da Messina ${ }^{35}$ e quella sulla ricomposizione dei dipinti di Lorenzo da Viterbo ${ }^{36}$. Nell'immediato dopoguerra, la struttura comincia a marciare a pieno regime, anche se deve fare i conti con un contesto urbanistico e un patrimonio artistico pesantemente danneggiati dalle vicende belliche appena passate, e continua a rendere conto della propria attività attraverso le mostre ${ }^{37}$. Saranno anni duri, ma gloriosi ed entusiasmanti, durante i quali l'Istituto sarà in prima linea a rispondere, con mezzi finalmente idonei, alla complessa realtà che gli si presentava. I nuovi mezzi si contrapponevano con fermezza, grazie all'autorevolezza di Brandi, all'inadeguatezza dei criteri empirici che fino ad allora avevano prevalso nel restauro delle opere d'arte, non solo con una unità metodologica, ma con una vera e propria teoria.

Colalucci frequenta la scuola negli anni in cui questi principi si sono ormai consolidati. L'Istituto è reduce dalle due grandi "ricostruzioni" del Lorenzo da Viterbo e del Mantegna. La tecnica di reintegrazione a tratteggio è ormai pratica acquisita e Brandi sta per pubblicare il primo numero del "Bollettino" in cui sancirà, attraverso il "fondamento teorico del restauro", il principio base della 
teoria che conosciamo oggi. Per capire in che modo gli allievi di allora imparavano ad applicare la regola brandiana, bisogna ascoltare le parole di Colalucci :

"Brandi dirigeva ma non dava lezioni. Per questo il suo magistero era molto incisivo ed ineguagliabile. Lo esercitava ogni mattina andando a vedere $i$ restauri in corso, dando opinioni, direttive, ragionando e argomentando le sue decisioni di fonte ai problemi, a volte complessi, discutendo cordialmente con i restauratori, interessandosi di tutto anche della loro vita privata. Il lavoro che si faceva era impregnato del suo insegnamento, per questo sostengo che è nel mio DNA. Proprio perché Brandi non dava lezioni, poterlo ascoltare era una cosa preziosa. Facevo in modo di ascoltarlo quanto più potevo per capire a fondo il suo pensiero. Quando entrai in Istituto, la Teoria del Restauro non era ancora stata pubblicata, però si parlava del tema, si discuteva e si applicava come se tutti l'avessero studiata. Nel 1950 con il primo bollettino dell'lstituto Centrale del Restauro, Brandi pubblicò "il Fondamento teorico del restauro". Quel libretto storico lo conservo gelosamente..".

La forza della personalità di Brandi ed il suo carisma si rivelavano vincenti all'esterno come all'interno dell'Istituto. Colalucci mi dice che tutte le persone che popolavano l'Istituto (dal primo degli ispettori all'ultimo degli operai), si sentivano gratificate dal contatto con Brandi, e che tutte vedevano in lui il punto di riferimento di quel luogo di eccellenza di cui erano fieri di fare parte:

"L'Istituto Centrale del Restauro non sarebbe stato quello che ho descritto se non ci fosse stata la figura di Cesare Brandi. Storico dell'arte di grandissimo peso, in eterno contrasto con un'altro grande come Roberto Longhi, Brandi era un uomo di intelligenza superiore, aveva una enorme e profonda cultura,era poeta, in quel tempo aveva pubblicato le "Elegie", 
musicologo e buon compositore, e anche un raffinato gastronomo. La figura di Brandi era carismatica: molto temuto dai suoi colleghi, per i suoi severissimi giudizi critici, era senza dubbio molto rispettato. Tutti noi, tanto dentro come fuori dell'Istituto, ci sentivamo un gruppo privilegiato anche perché la direzione di Brandi ci faceva sentire parte di un'elite privilegiata."

L'impronta dell'insegnamento brandiano sugli studenti di quegli anni è indelebile. II contatto diretto con lui, li rende diversi da tutti quelli che non hanno goduto della stessa opportunità. Uno dei segni più vistosi di questa impronta è rappresentato dalla capacità di analizzare a fondo l'opera. Brandi, come mi conferma Colalucci, aveva il dono di saper "leggere l'opera d'arte" come nessun altro. Attraverso una lucida e meticolosa analisi visiva dei materiali, arrivava a penetrarli. Alla sua osservazione non sfuggiva nulla, poiché era convinto che l'analisi minuta dei dettagli morfologici dell'opera, fosse l'irrinunciabile operazione propeteutica ad ogni restauro ben condotto, e alle campagne di indagini scientifiche "mirate" che non a caso considerava "controprove diagnostiche". Colalucci a questo proposito racconta:

"..Quando Brandi analizzava "leggeva" l'opera, ascoltarlo era un momento di alto apprendimento. Successe anche a me. Ero solo davanti al Polittico del Beato Angelico $^{38}$ della pinacoteca di Perugia, che era stato portato all'entrata dell'istituto per essere portato ad una mostra di opere restaurate dall'I.C.R. che si doveva svolgere a Palazzo Venezia, e in quel momento arrivò Brandi che si mise a guardare l'opera. Dopo pochi minuti di osservazioni cominciò a ragionare sul valore del colori, parlando dello spessore dei bianchi, della profondità dei neri, del timbro e degli accostamenti dei rossi, del valore del fondo oro. Una lezione intera per la

\footnotetext{
${ }^{38}$ Cfr C. Brandi "Mostra di dipinti restaurati- Angelico, P.Della Francesca, A.da Messina" Roma Palazzo Venezia 1953. pp.10-11
} 
mia formazione della quale non ho dimenticato nulla(..). Brandi era gentile e cordiale, anche se a volte poteva essere molto tagliente e severo. Commentava sempre tutto ed era un piacere ascoltarlo, però un suo rimprovero poteva segnarti per tutta la vita.(..)

Per concludere questo capitolo, riporto ancora una volta le parole di Colalucci, che racchiudono il pensiero lucido ed intelligente di chi, pure essendo passato alla storia, non dimentica l'origine dell'insegnamento che lo ha reso capace di affrontare ciò che definisce "la sua eccezionale avventura professionale" :

"Come maestro Brandi è stato tutto per me, mi ha insegnato a guardare un'opera d'arte, a capire la sua essenza e ha dare un senso ad ogni segno e ad ogni colore. Mi ha insegnato a ragionare molto prima di intervenire sulle opere, a dare una spiegazione logica a ogni decisione e ad essere molto critico con me stesso, in modo da farmi sentire alla fine forte e sicuro. Al magistero di Brandi devo la capacità che mi ha permesso di affrontare l'eccezionale avventura professionale che la vita mi ha riservato ${ }^{39}$. Mi faccio l'illusione di aver interpretato degnamente il modello di restauratore che egli stava formando per il futuro." 


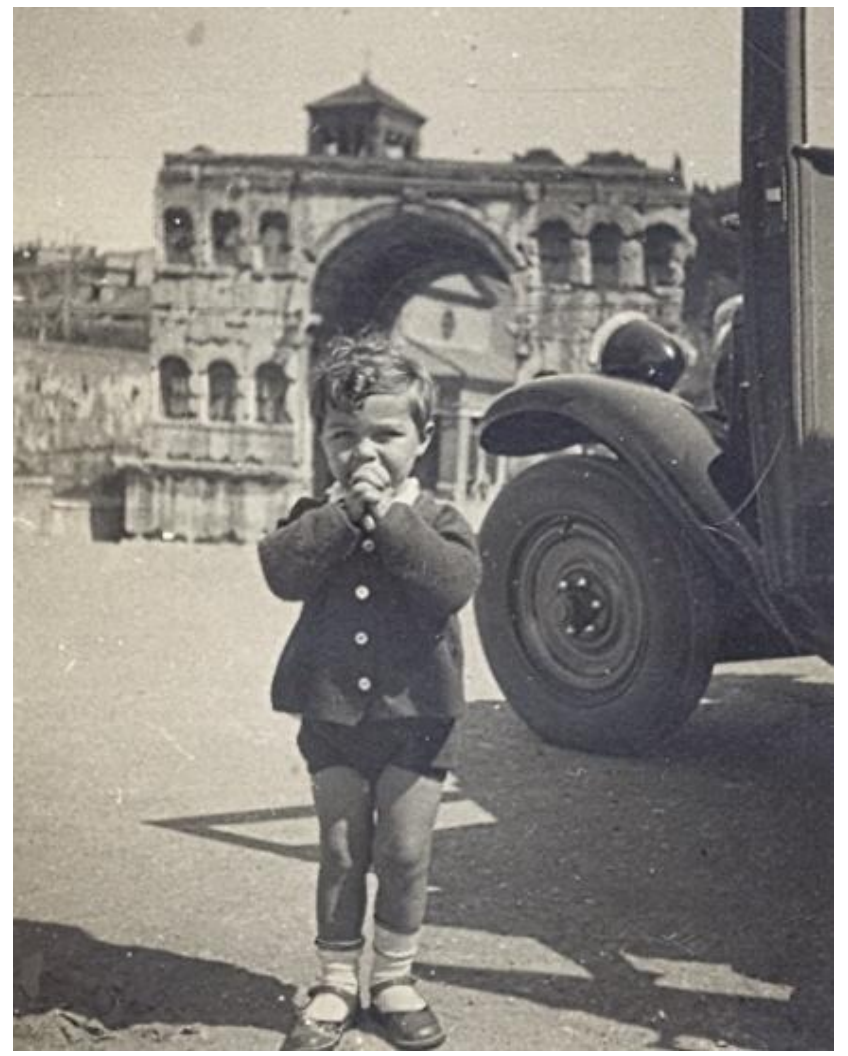

Fig 1- Gianluigi Colalucci all'età di cinque anni

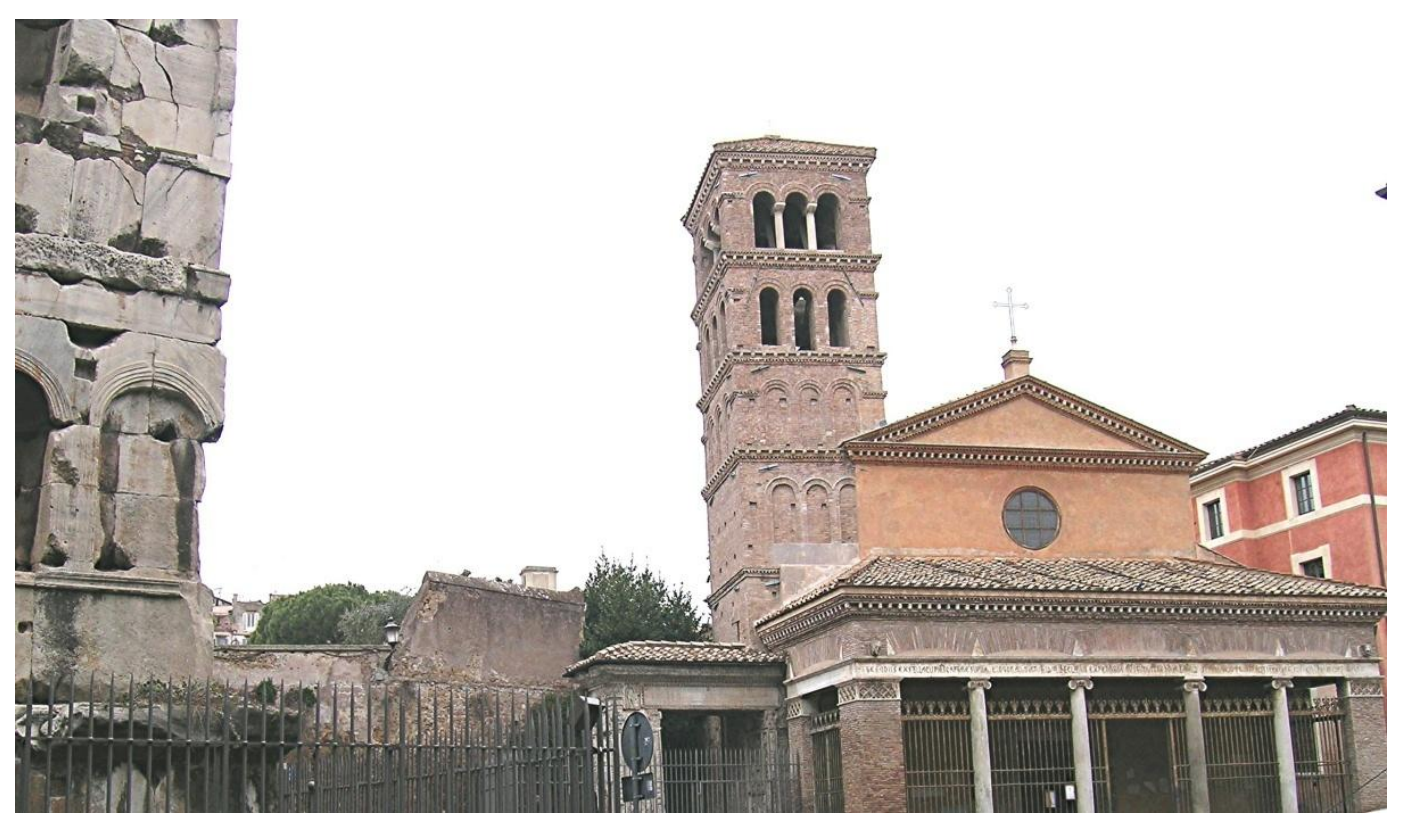

Fig. 2 - La chiesa di San Giorgio in Velabro vista dalla casa di Colalucci 


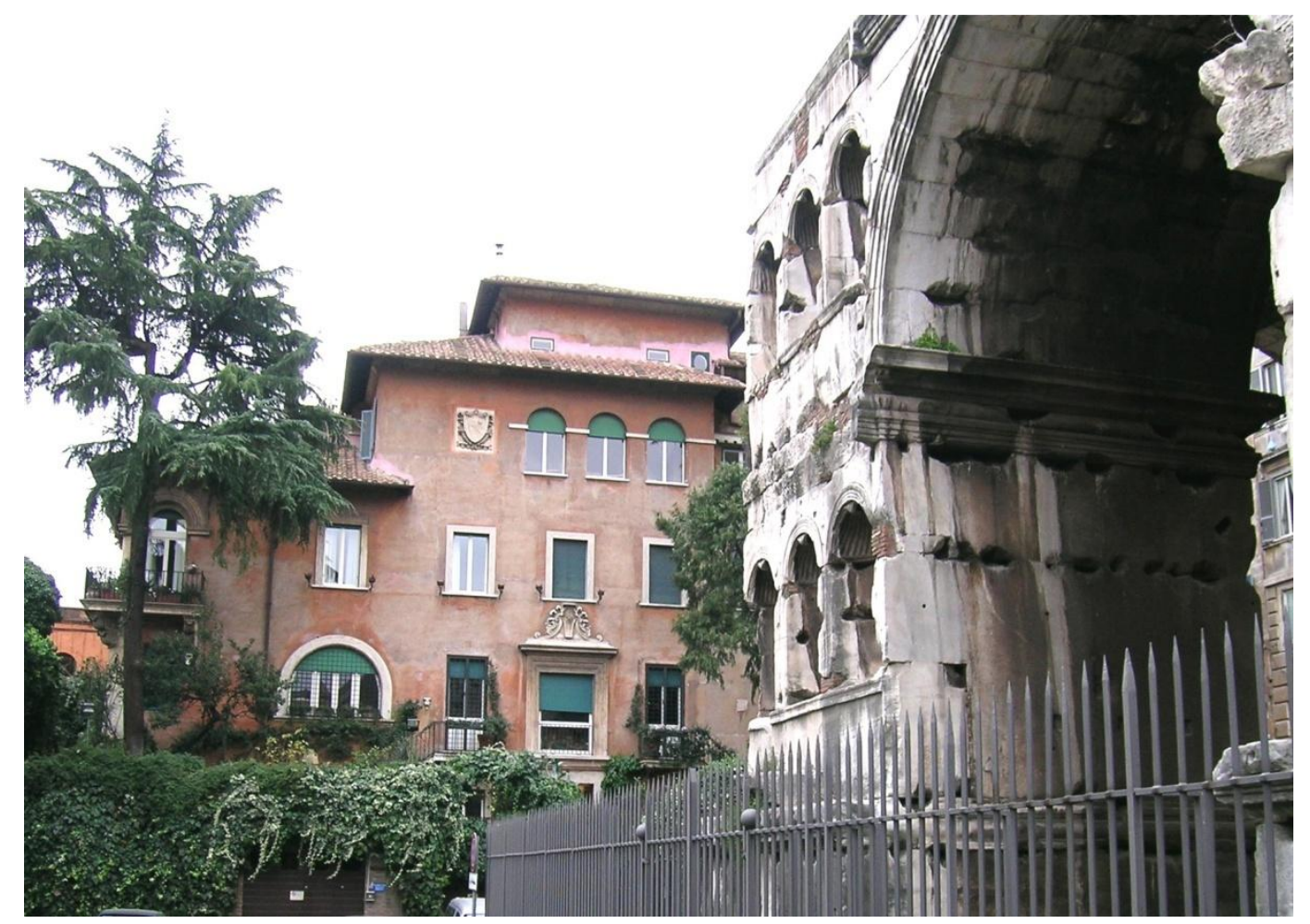

Fig. 3 - Una vista della casa con l'arco di Giano

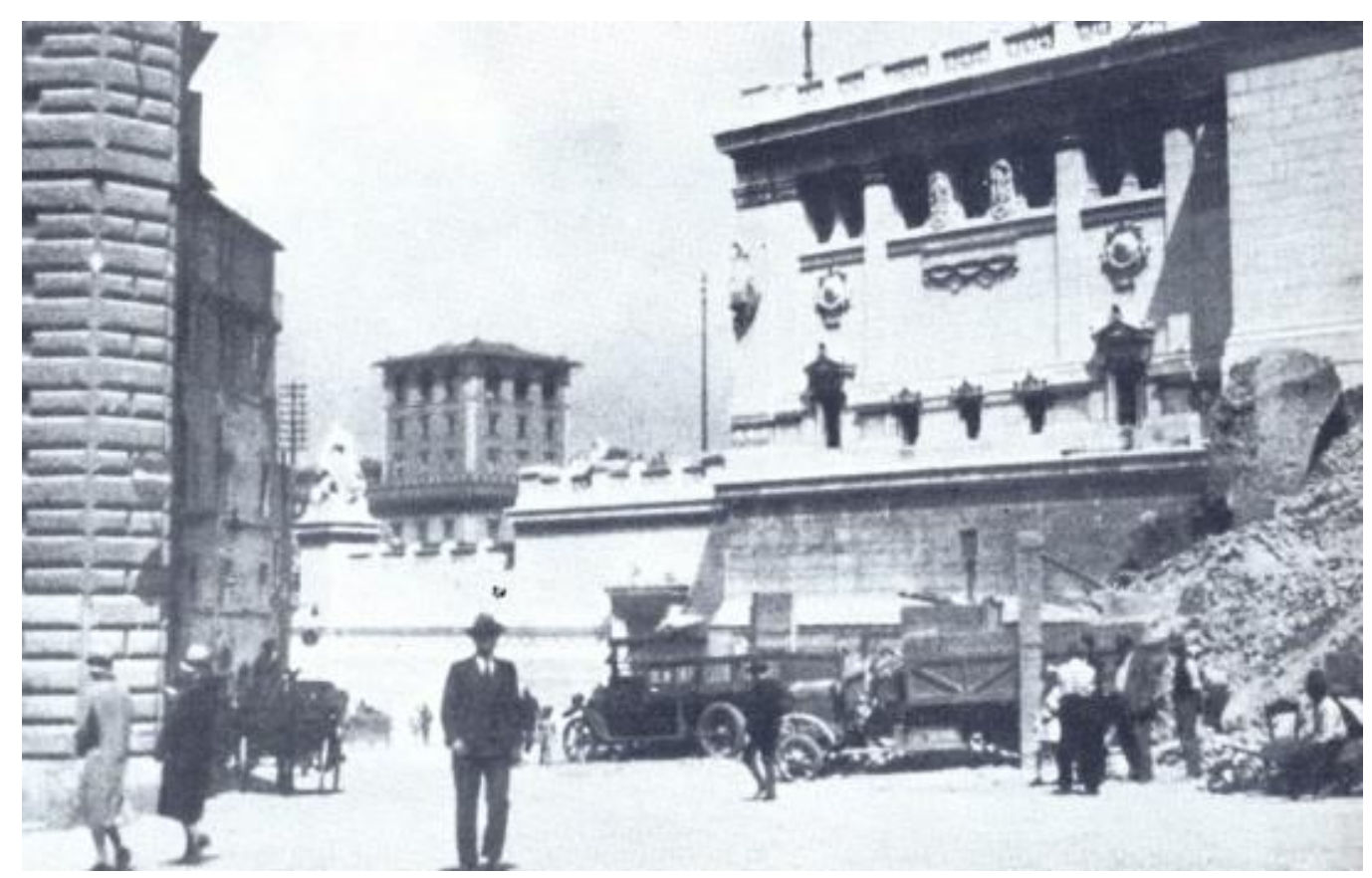

Fig. 4 - Una foto dell'inizio del Novecento che mostra i lavori a ridosso del Vittoriano 


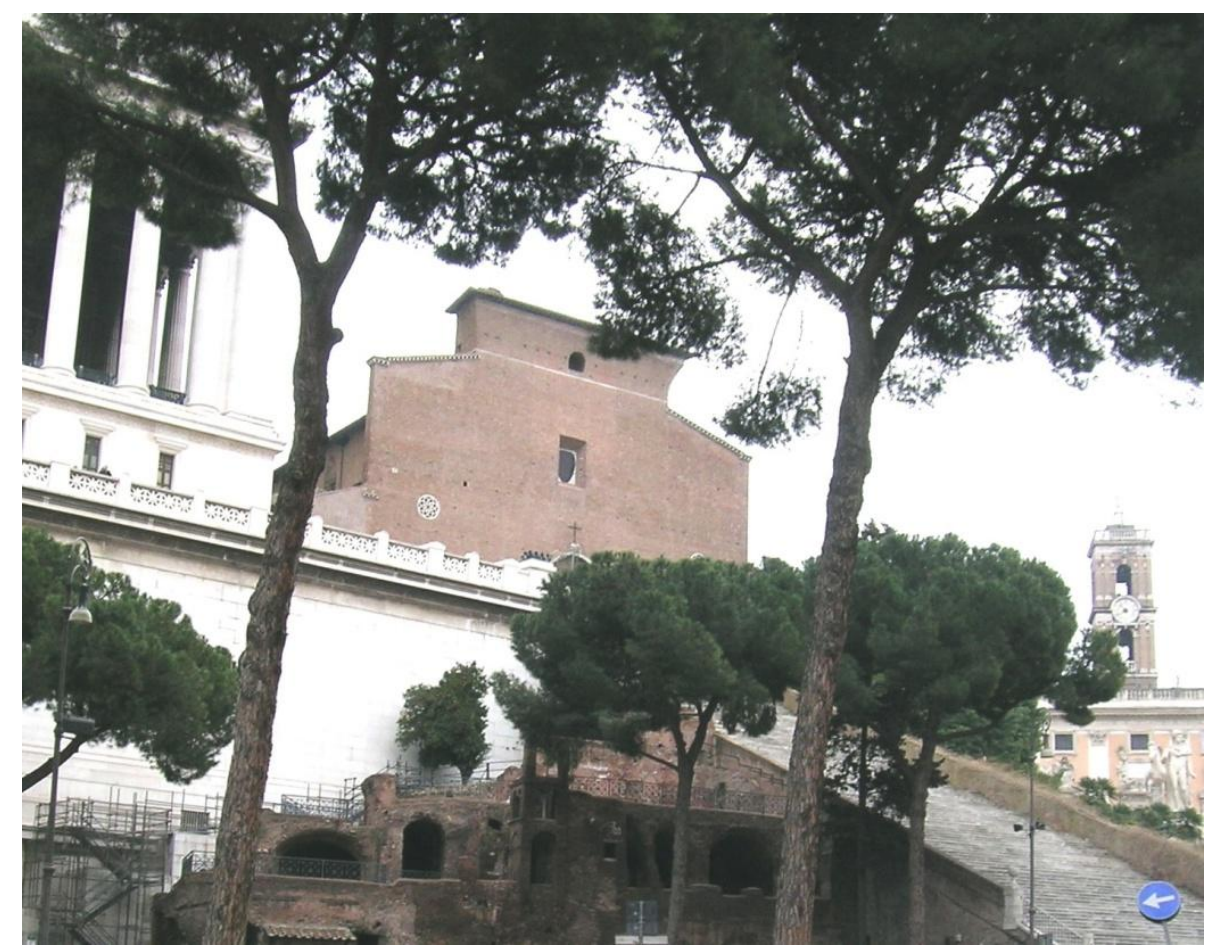

Fig. 5- I resti medievali ai piedi della scalinata dell'Aracoeli

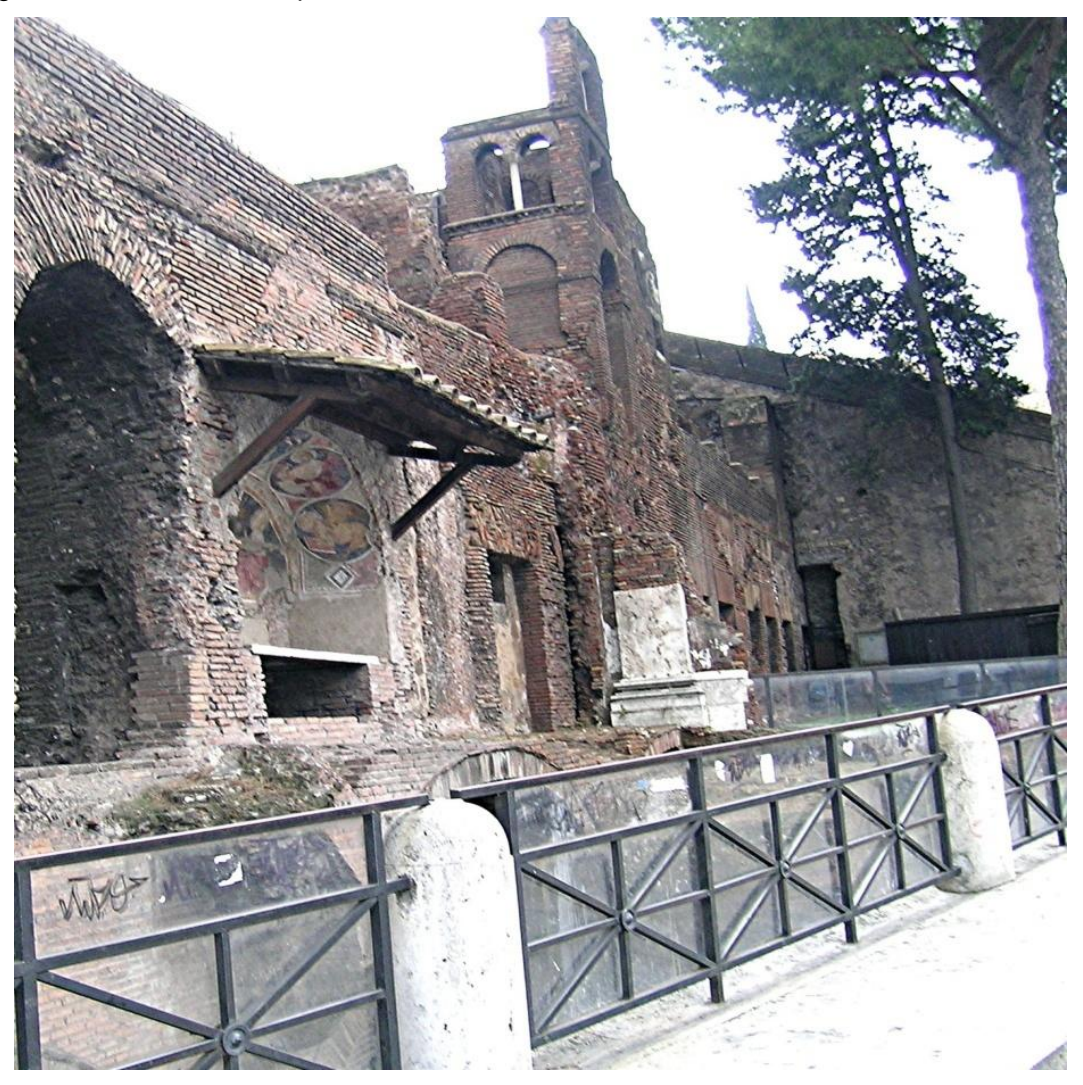

Fig. 6 - Una veduta laterale dell'abside medievale 


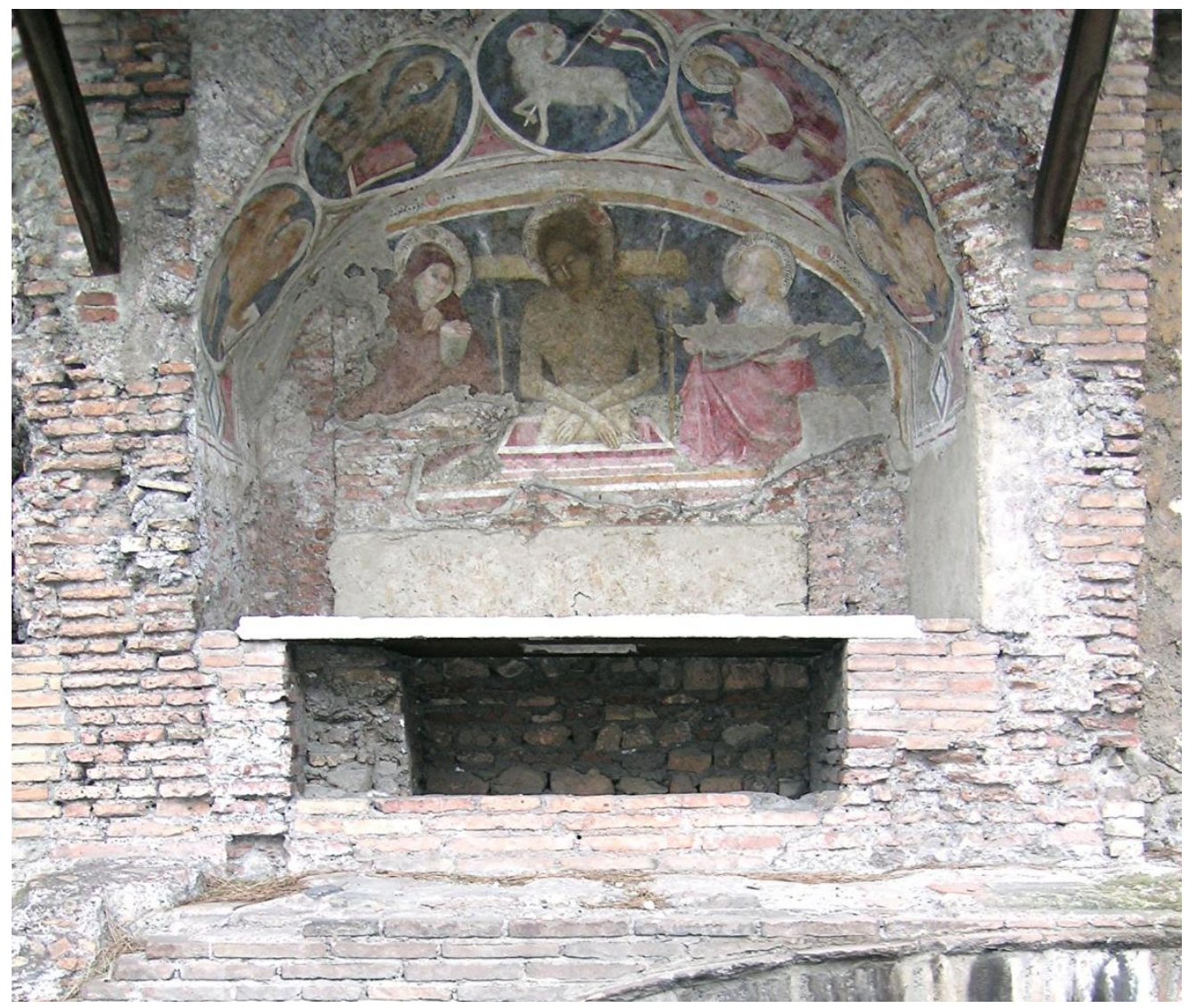

Fig. 7 - L'abside con i resti di affresco
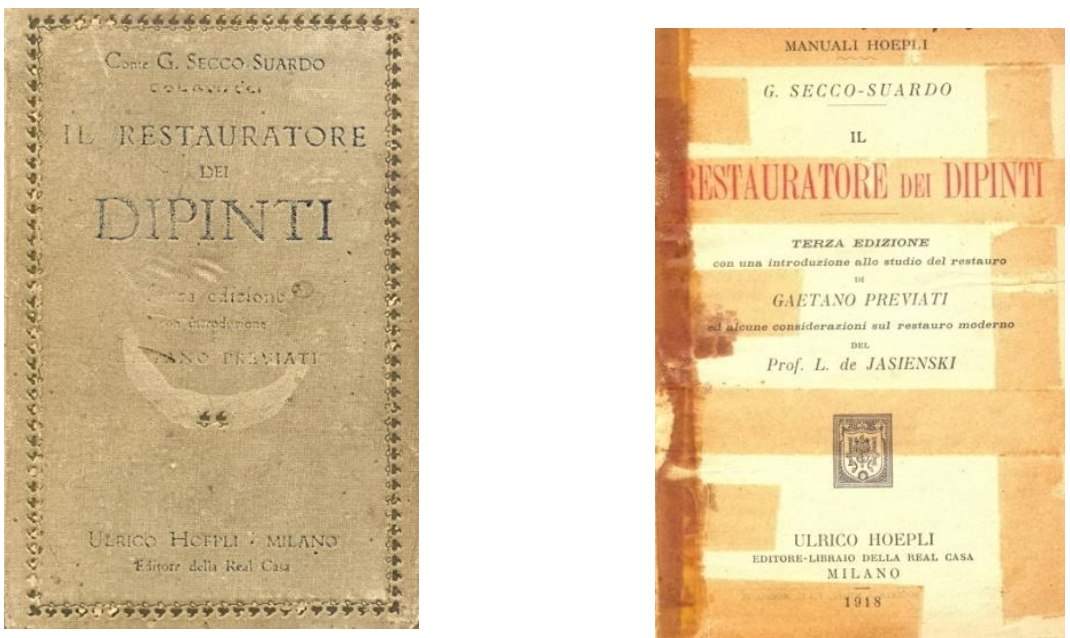

Fig 8-9 - L'antica edizione del Secco Suardo, avuta in regalo alla fine degli anni quaranta 


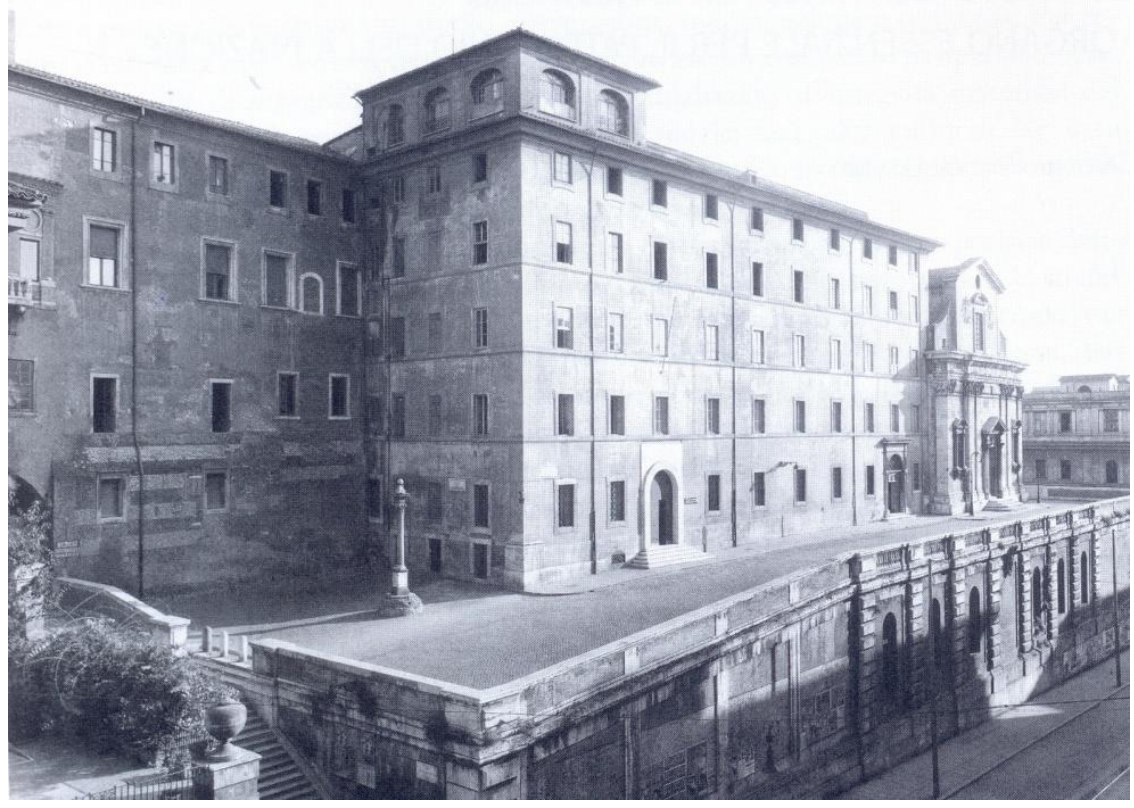

Fig. 10- Una veduta esterna dell'Istituto negli anni cinquanta

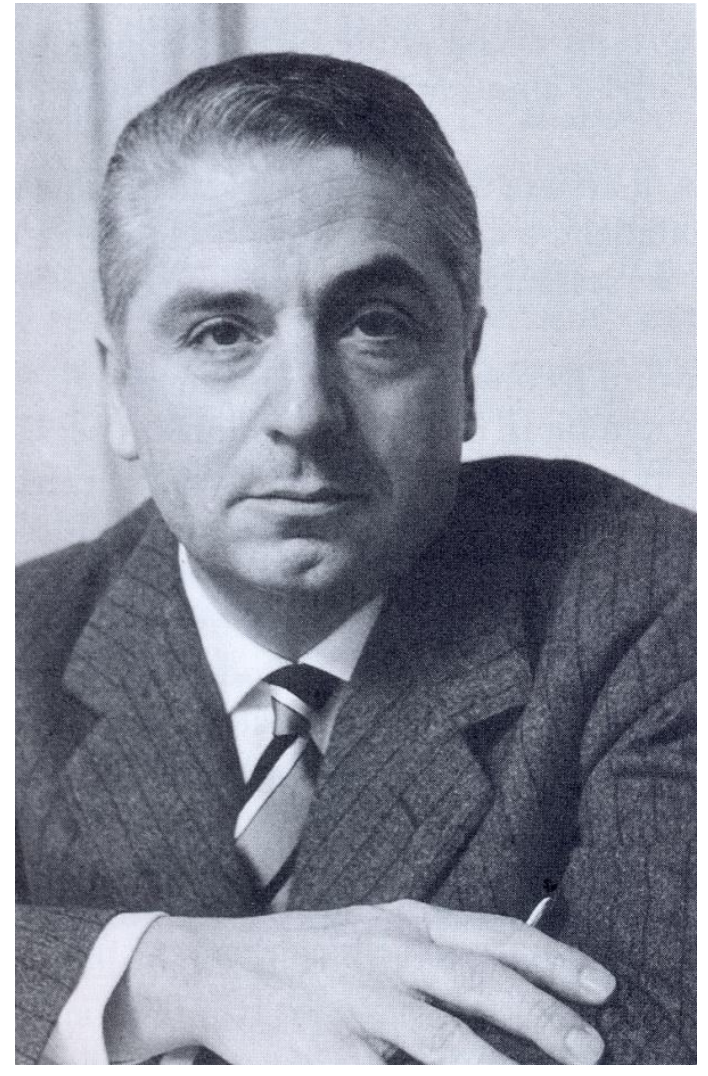

Fig. 11- Cesare Brandi negli anni cinquanta. 


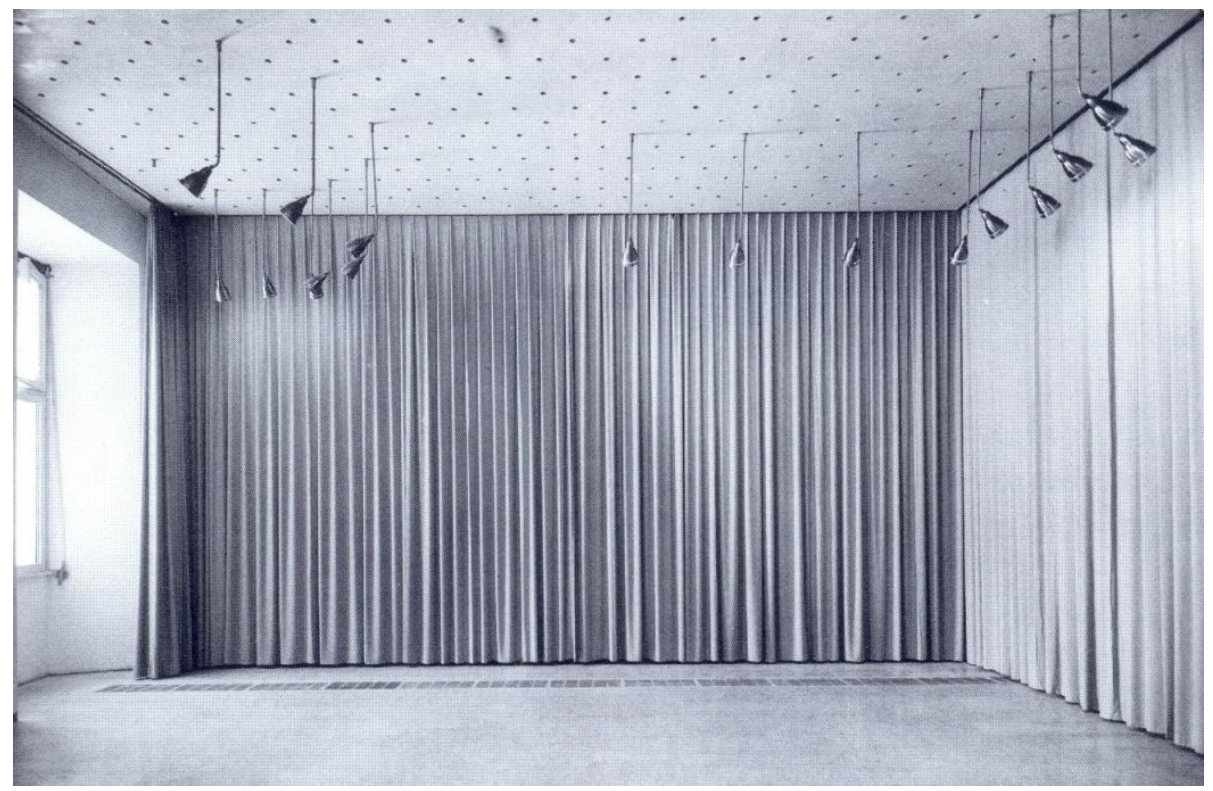

Fig. 12 - Una veduta della sala delle Mostre

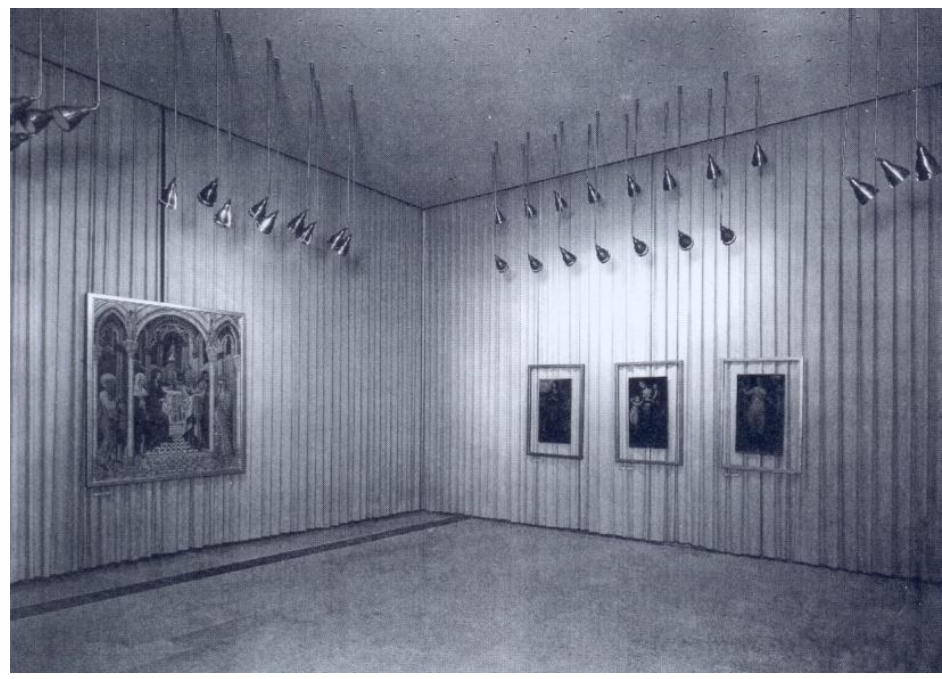

Fig. 13 - La Sala delle Mostre al terzo piano dell'Istituto 


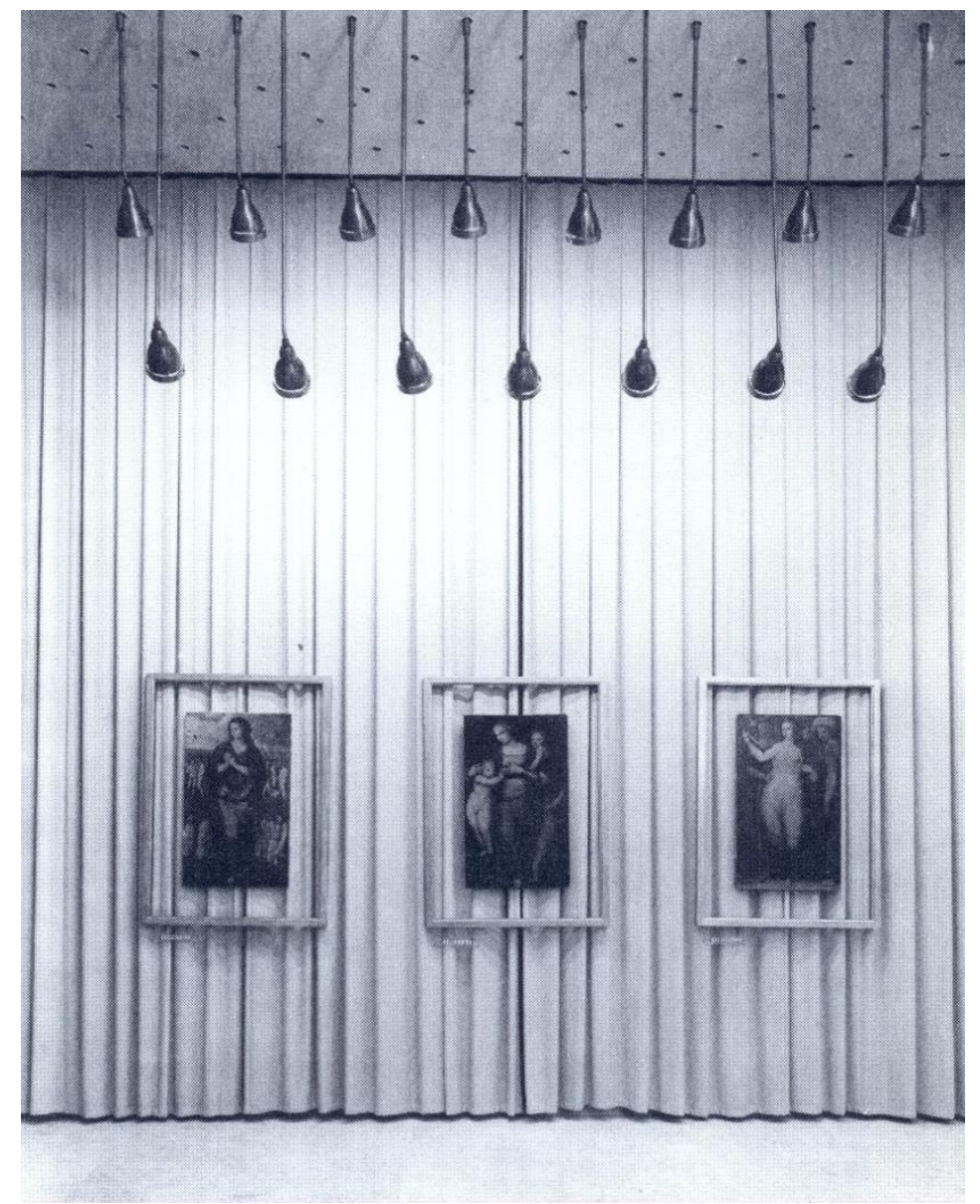

Fig. 14- Un'altra veduta della Sala delle Mostre, con il particolare sistema di illuminazione 


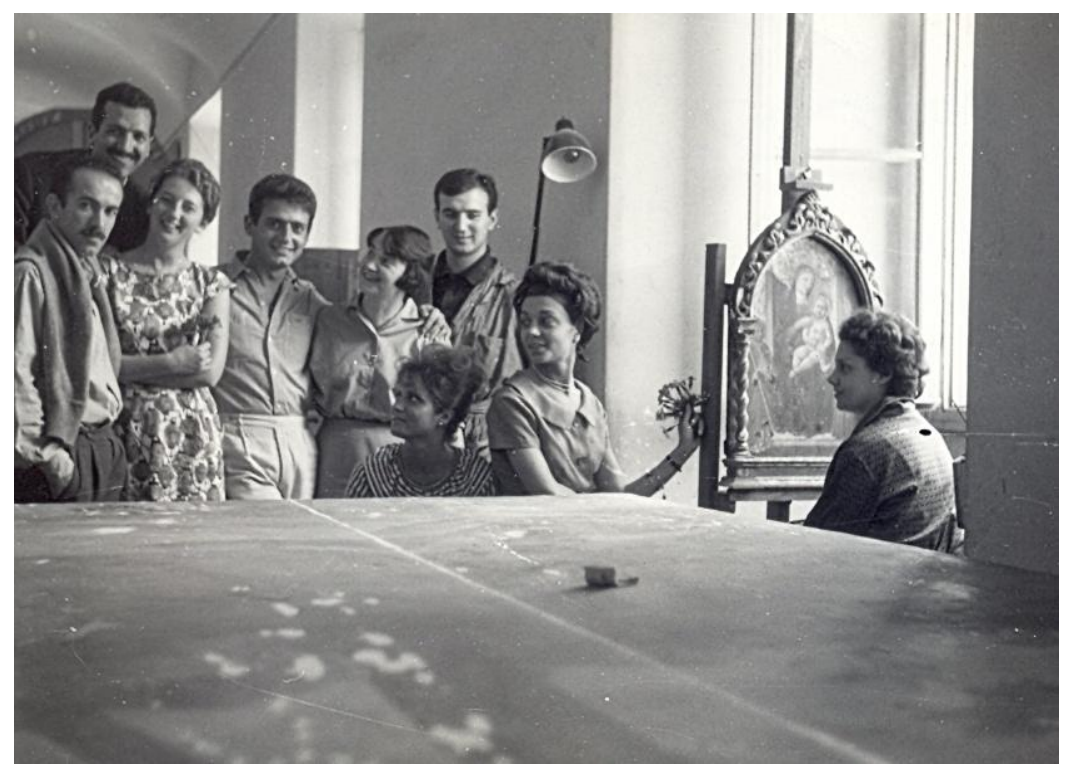

Fig. 15 - Una foto di gruppo di alcuni restauratori dell'Istituto negli anni 50

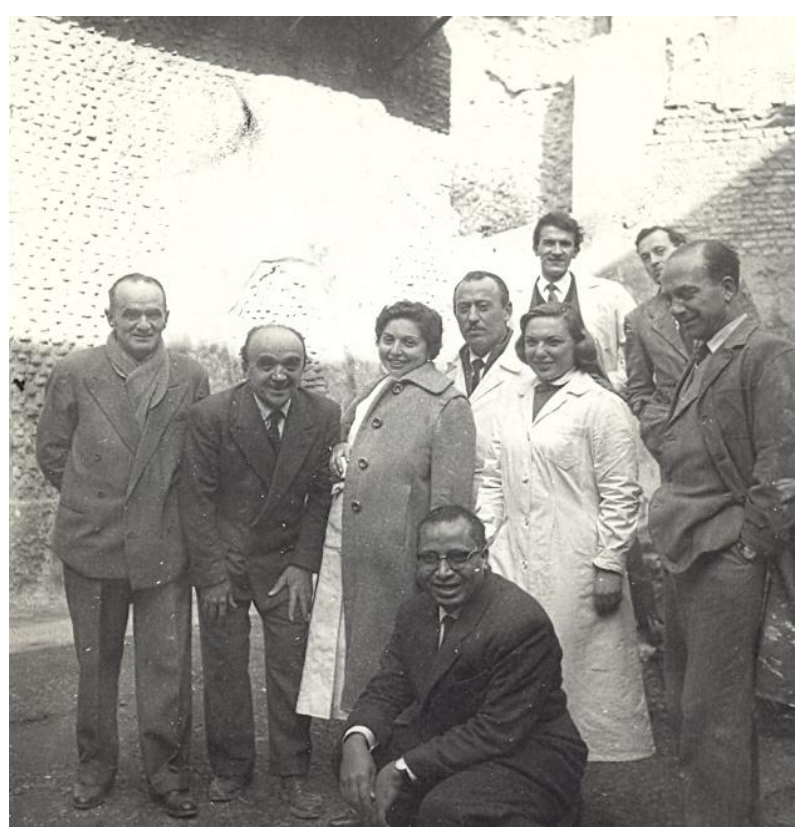

Fig. 16 - Un gruppo di restauratori dell'Istituto nel cantiere della Casa di Livia al Palatino. Da sinistra : T. Spini, C. Matteucci, E. Pagliani, alcuni allievi e sul fondo R. Vlad. 


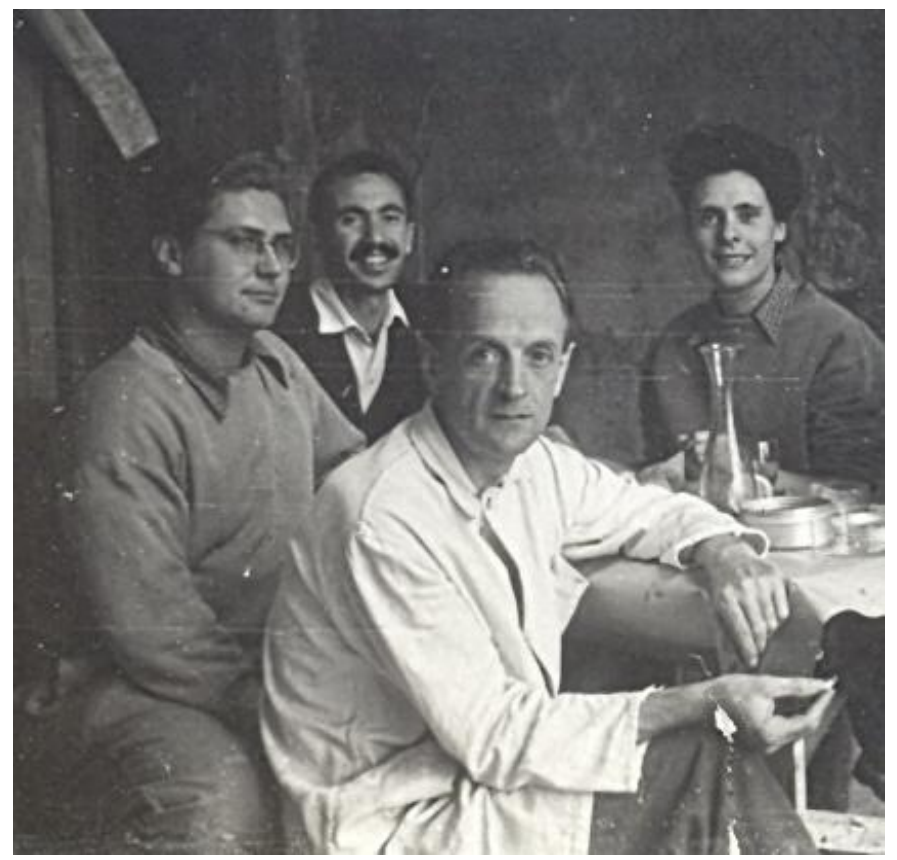

Fig.17 - Foto di gruppo dei restauratori in cantiere. In primo piano G. Baldi, in secondo Piano P. Pittà e dei giovanissimi Paolo e Laura Mora

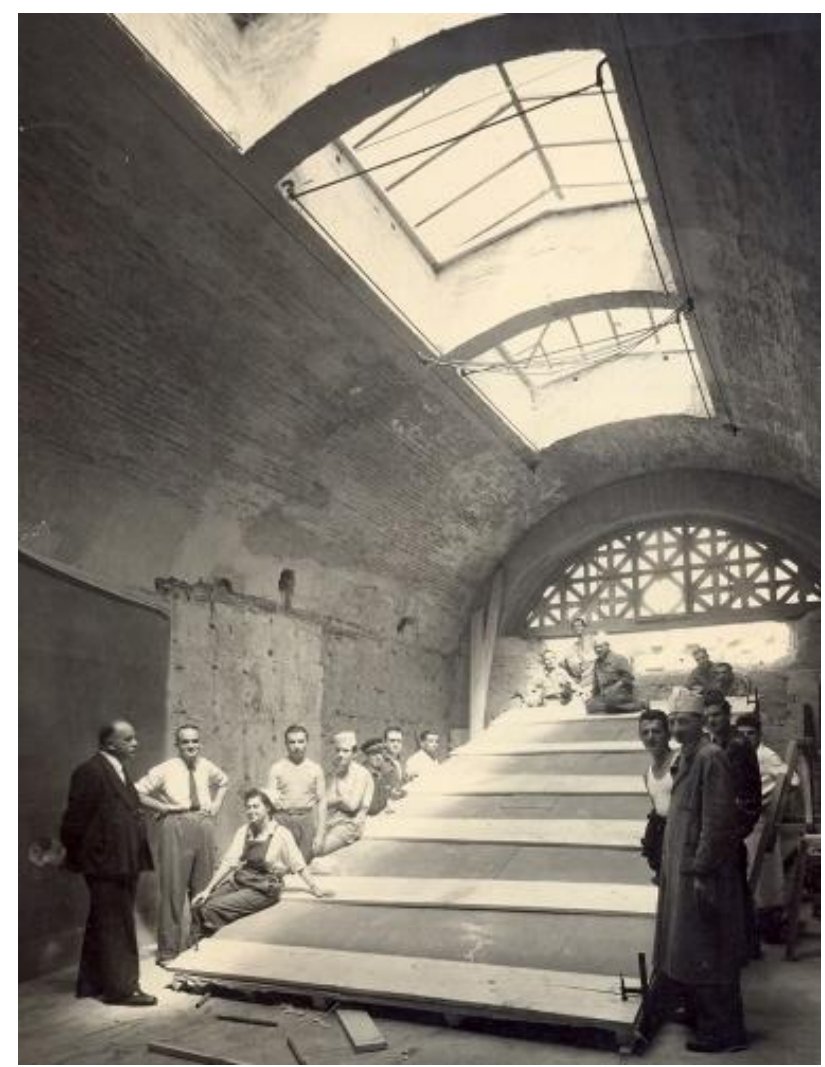

Fig.18 - Un'altra vista del cantiere della Casa di Livia al Palatino 


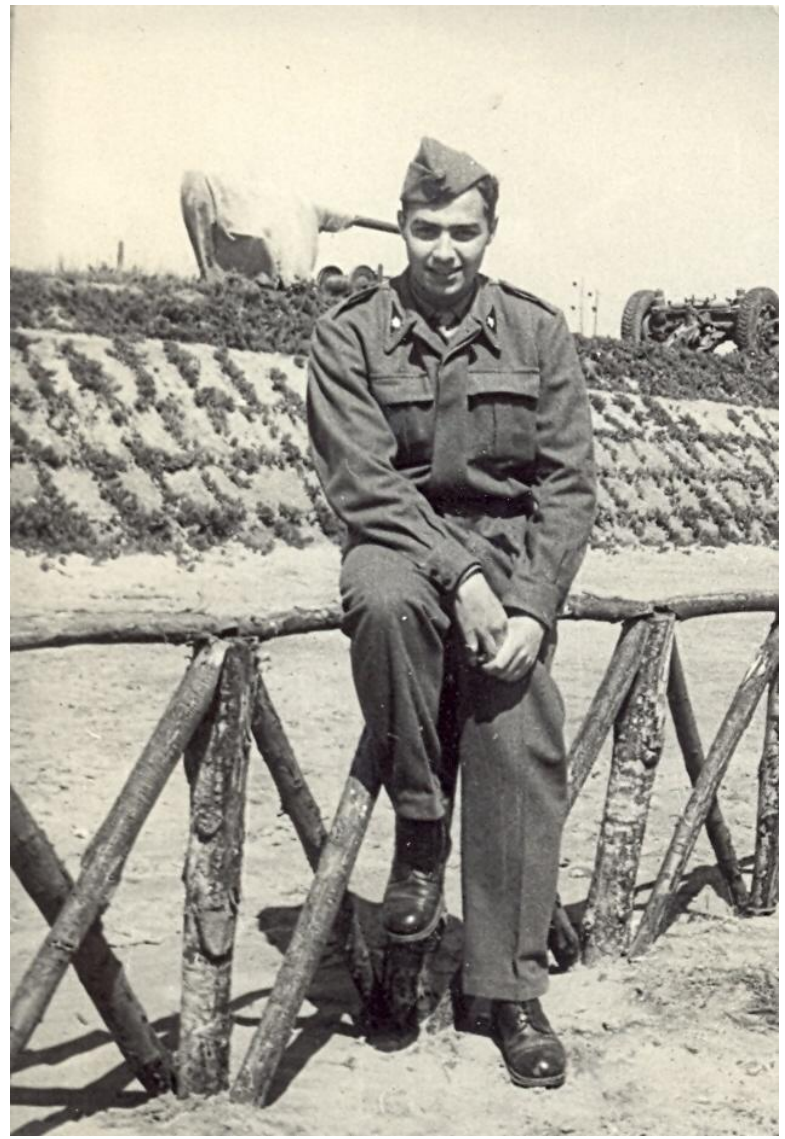

Fig.19- Gianluigi Colalucci a Sabaudia durante il servizio militare- 1951

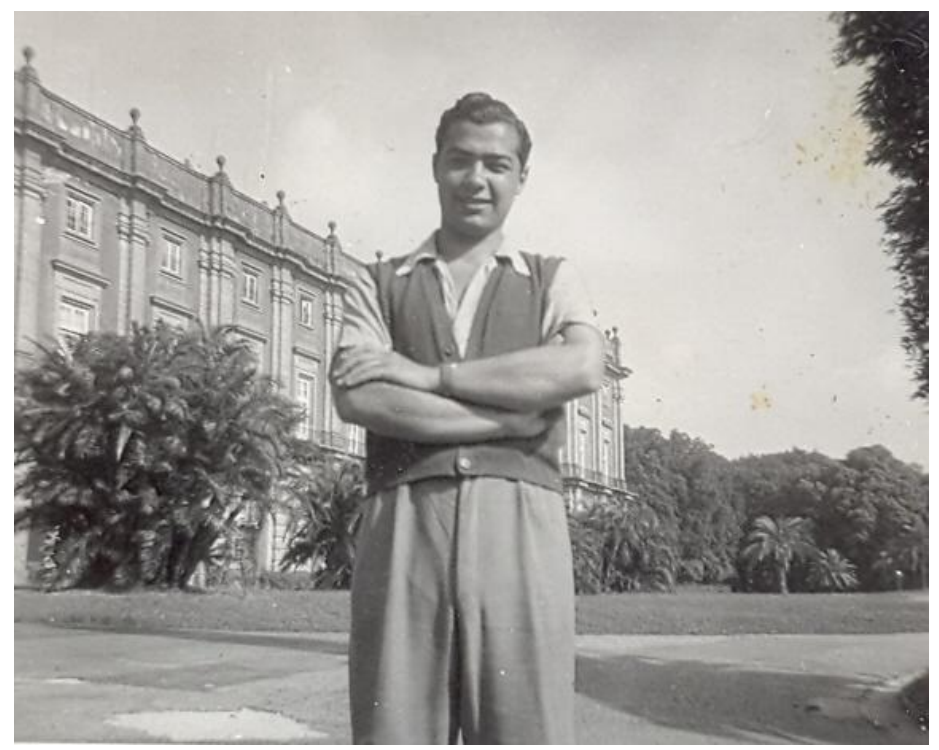

Fig.20 - G. Colalucci a Napoli nel 1950 durante la sua prima trasferta 


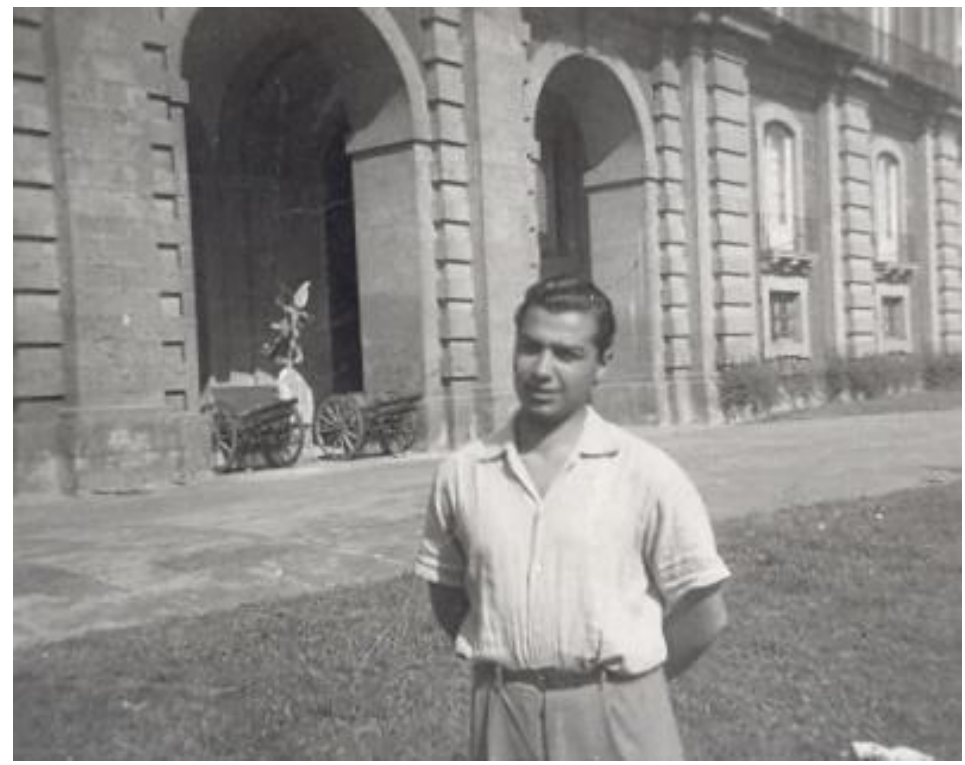

Fig.21 - Un'altra foto scattata durante la trasferta di Napoli

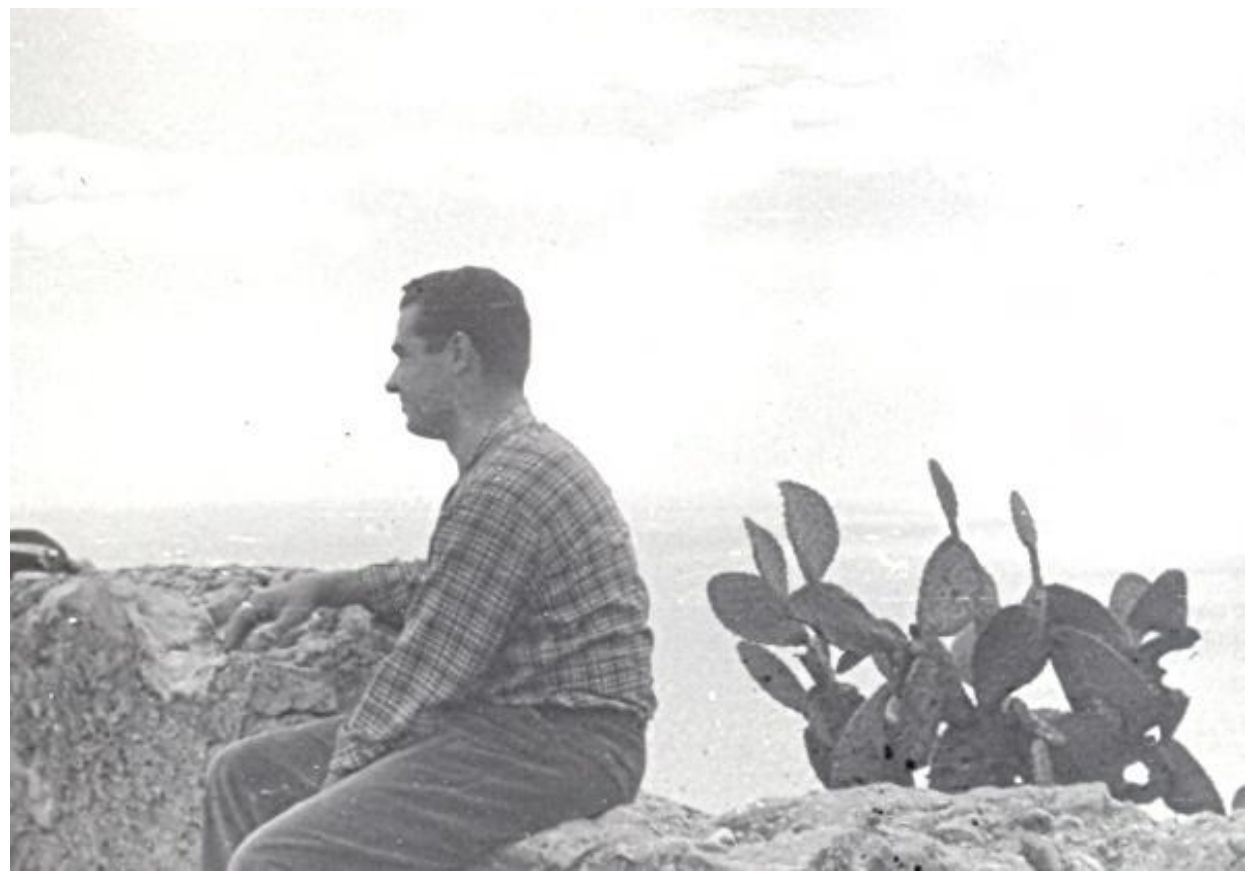

Fig. 22 - A Taormina durante la trasferta in occasione della Mostra di Messina nel 1953 


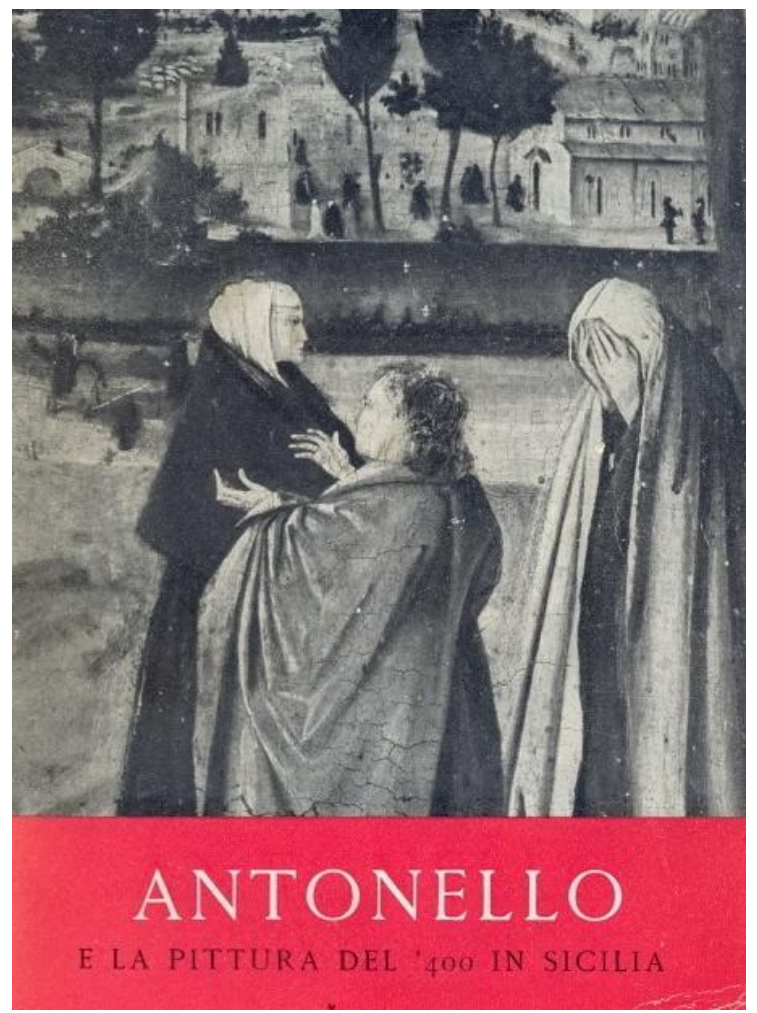

Fig.23 - La copertina del catalogo della Mostra di Messina

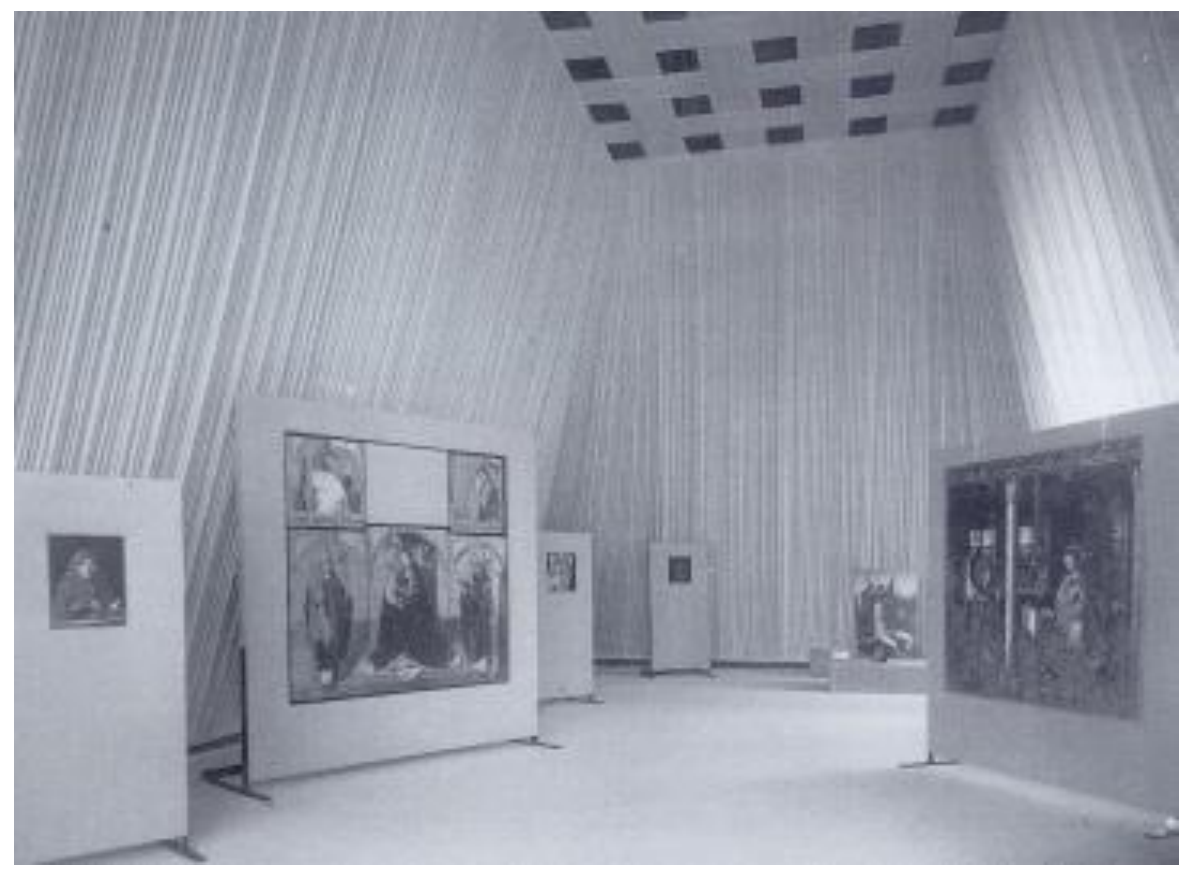

Fig.24 - Una delle sale della Mostra allestita da C. Scarpa-1953 


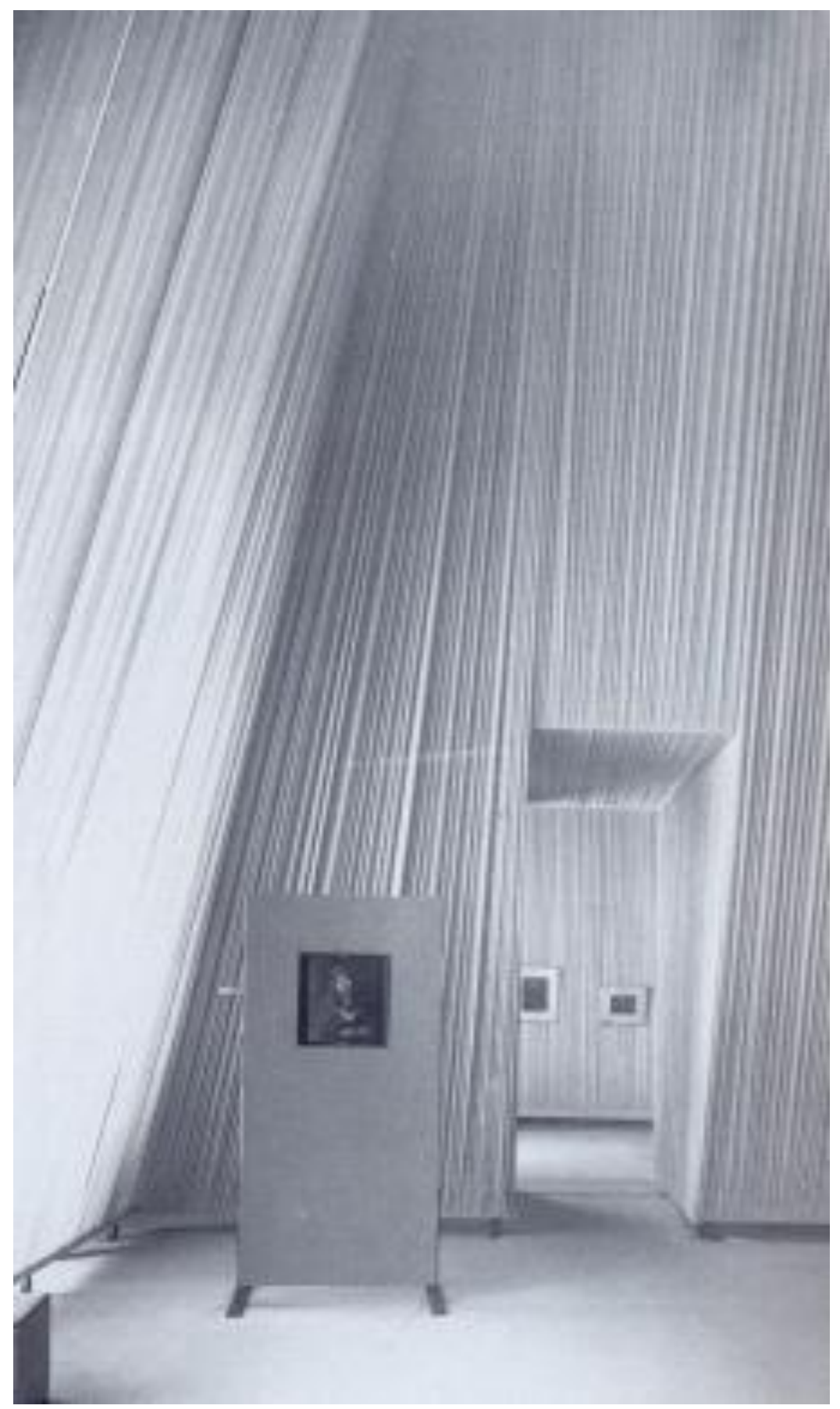

Fig.25 - Un'altra foto della Mostra su Antonello 


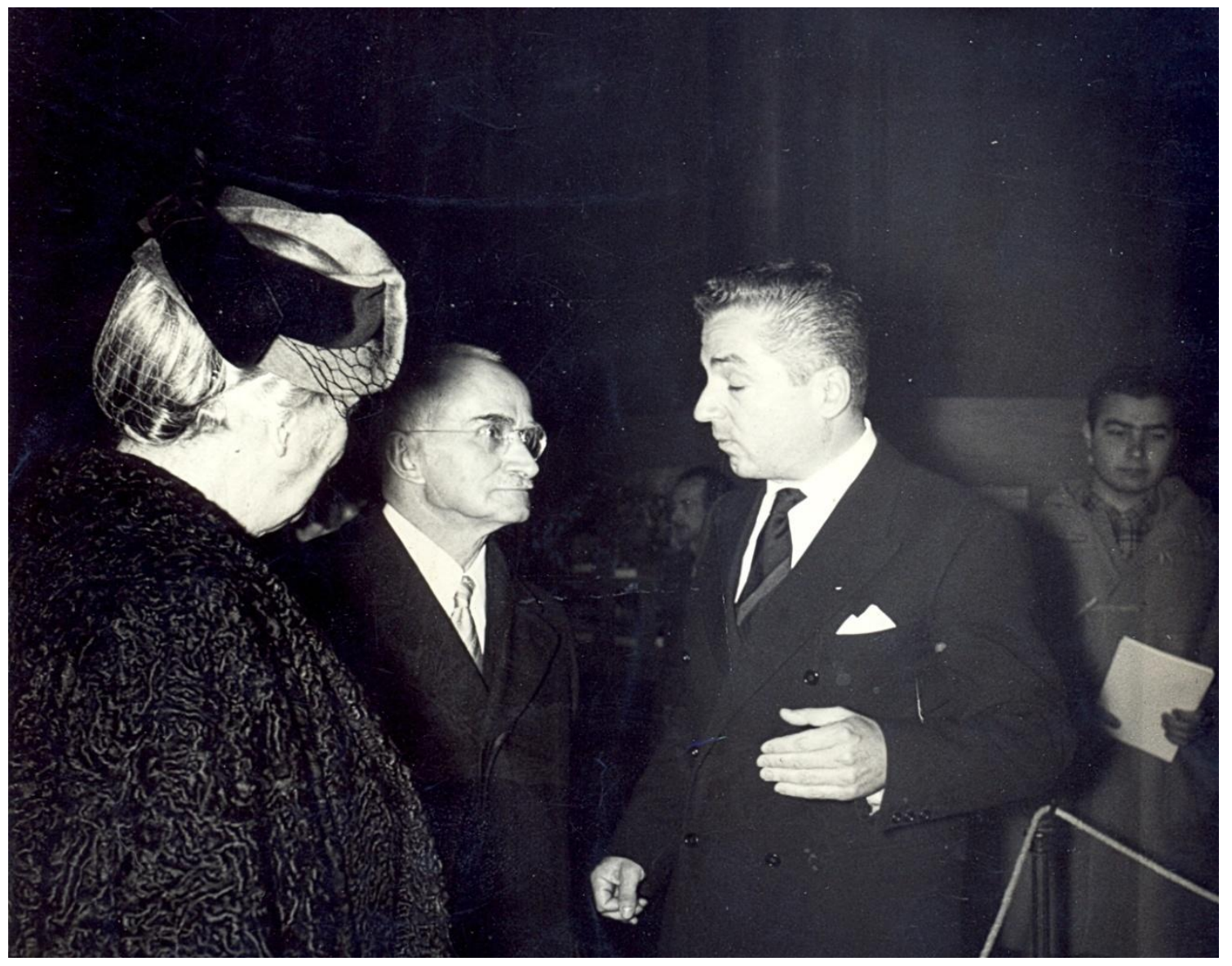

Fig. 26-L'inaugurazione della Mostra sui dipinti restaurati dall'Istituto, tenutasi a Palazzo Venezia nel 1953. Cesare Brandi fa da "guida" al Presidente della Repubblica Luigi Einaudi e alla moglie. Sul fondo, dietro Brandi, si vede G. Colalucci con i cataloghi della Mostra da distribuire agli invitati. 


\section{II - II PERIODO SICILIANO}

Subito dopo il diploma Colalucci torna in Sicilia, a Palermo, per eseguire, assieme ad altri due diplomati come lui, il primo lavoro come restauratore. Per una serie di circostanze fortunate riceverà altri incarichi e, lavoro dopo lavoro, rimarrà in quella terra fino al 1960.Gli anni siciliani saranno anni duri, soprattutto all'inizio, quando, rimasto solo, l'inesperienza e le difficoltà economiche lo costringeranno a ritmi lavorativi pesantissimi. Saranno anche anni stimolanti che lo porteranno a conoscere personaggi interessanti, come Carlo Scarpa, che nel 1953 sta restaurando Palazzo Abatellis, o come gran parte dell'aristocrazia palermitana, all'interno della quale viene introdotto dal giovane Giovanni Carandente, che a quel tempo era ispettore della Soprintendenza. Conoscerà Giuseppe Tommasi di Lampedusa, il pittore Bruno Caruso, il fotografo Enzo Sellerio e l'architetto Samonà. Lavora su opere difficili dal punto di vista conservativo, su opere di grande formato che lo costringeranno a risolvere problemi complessi grazie ai quali acquisirà un'esperienza fori dal comune. La Soprintendenza gli mette a disposizione un grande locale all'interno di Palazzo Abatellis da usare come laboratorio di restauro per le opere prelevate in giro per la Sicilia. Durante gli anni passati in Sicilia, compie anche alcuni lavori per conto di Cesare Brandi : a Creta, ad Assisi ed a Tolentino. Alla fine degli anni cinquanta decide di rientrare a Roma. 
Appena dopo la tesi Colalucci torna in Sicilia per eseguire, assieme ad altri due diplomati come lui, un restauro su incarico di Giovanni Carandente ${ }^{40}$. II lavoro riguarda la settecentesca pala d'altare conservata nella Parrocchia di Mondello a Valdesi. Terminato il lavoro i suoi colleghi tornano a Roma, e il Soprintendente Giorgio Vigni ${ }^{41}$, gli affida il restauro un'opera conservata nel Museo di Palazzo Abatellis ${ }^{42}$, un polittico raffigurante l'Incoronazione della Vergine attribuito al Maestro di Trapani. L'esecuzione del restauro, che si rivela da subito troppo complessa per lui, lo costringerà a ritmi di lavoro pesantissimi. Mi racconta che si sentiva inesperto e non riusciva ad ottenere risultati soddisfacenti nella reintegrazione pittorica, e dato che faceva fatica a completare il lavoro, iniziava ad avere gravi difficoltà economiche. Per uscire da quella situazione, andava a lavorare al mattino prestissimo e rimaneva in laboratorio fino ad sera inoltrata. Spesso si tratteneva a studiare le reintegrazioni fatte dal restauratore milanese Ottemi Della Rotta, sulle opere che erano conservate nel museo di palazzo Abatellis ${ }^{43}$. I suoi problemi nel lavoro erano ingigantiti dalla lontananza dall'Istituto e dalla solitudine, tanto che

\footnotetext{
${ }^{40}$ G. Carandente storico e critico d'arte col gusto per l'arte contemporanea.Per la biografia completa cfr "Dizionario biografico dei Soprintendenti Storici dell'Arte 1904-1974" ed. Bonomia University Press, Bologna 2007

${ }^{41}$ Per la biografia di Giorgio Vigni cfr. "Dizionario ...."op. cit

${ }^{42}$ Palazzo Abatellis, costruito alla fine del 1400 dall'arch. Matteo Carnelivari, è sede della Galleria Nazionale della Sicilia che fu Inaugurata il 23 giugno 1954. II suo aspetto attuale è il frutto del complesso lavoro di restauro compiuto da Scarpa con la direzione di Vigni. Cfr. "Palazzo Abatellis" a cura di Paolo Morello, ed Vianello spa 1989 Treviso 
si sentirà molto più sollevato all'arrivo di Aldo Angelini e Sergio Pigazzini, mandati a Palermo da Brandi a restaurare una parte del soffitto della Cappella Palatina. Mi dice che in quei restauratori, più grandi e più esperti di lui, vedeva un possibile supporto tecnico e un legame, anche se indiretto, con l'Istituto. Completato il restauro del trittico, ottiene altri lavori e la sua permanenza a Palermo diventa stabile. Durante il primo anno di permanenza ritrova l'architetto Carlo Scarpa ${ }^{44}$ impegnato, tra il 1953 e il 1954, nel restauro di Palazzo Abatellis. Colalucci lo aveva conosciuto a Messina, ma a Palermo ha modo di frequentarlo più assiduamente e soprattutto di vederlo all'opera. Sarà un'esperienza di fondamentale importanza per lui. Seguendo Scarpa al lavoro e nelle visite che questi faceva ai monumenti di Palermo, Colalucci impara a guardare l'architettura con occhi più consapevoli ed ad "affinare" il gusto per i materiali architettonici :

"Posso dire che l' incontro con Scarpa, durante gli anni in cui veniva a Palermo per restaurare palazzo Abatellis, fu per me fondamentale per capire ed amare l'architettura. L' insegnamento di Scarpa lo ho appreso vedendolo all'opera e seguendolo nelle sue visite ai monumenti della città. Vedevo come trattava la materia, come accarezzava la pietra, il marmo, il rilievo delle colonne tortili delle finestre di palazzo Steri. Un giorno mi disse: < Sai perché la facciata dello Steri è tanto diversa dagli altri palazzi di Palermo? Perché come Trinità dei Monti a Roma è in faccia al sole> .(..) Carlo Scarpa era geniale, però come persona era veramente singolare..(..)..scriveva normalmente al contrario, come Leonardo. Conservo una foto con la dedica scritta in questo modo. Per leggerla bisogna usare uno specchio.(..).Credo che già in quegli anni stava costruendo il personaggio che interpretò per tutta la vita. E a

${ }^{44}$ Cfr. AAVV "Carlo Scarpa" catalogo della mostra, ed. Electa. Milano 2000 
Palermo lo faceva con una eccentricità che a volte mi sembrava eccessiva, come quando gettò in una strada molto frequentata, due bicchieri di vetro. Stavamo mangiando in un ristorante di Corso Vittorio, il locale era situato al primo piano di un palazzo del XVII'sec. in gran parte distrutto da un bombardamento. Eravamo seduti ad un tavolo che si trovava su un terrazzo, quando improvvisamente e senza motivo fece volare di sotto un bicchiere di quelli che si dicevano infrangibili. Rimasi pietrificato, e poiché ero terrorizzato all'idea che potesse essere finito sulla gente che passava esclamai : < architetto è impazzito?> allora lui ne lanciò subito un altro per dimostrarmi che si poteva fare senza alcuna conseguenza"45

II Palazzo Abatellis restaurato si inaugura il 23 giugno del 1954, con un convegno sulla museografia, al quale partecipa anche Brandi. Poco tempo prima Colalucci, a Palermo, aveva sposato la restauratrice Annamaria Sorace ${ }^{46}$. Mi racconta che il Soprintendente Vigni, e il Marchese Guido de Pace, amico di Carandente, furono i testimoni di nozze. Inizia così un intenso periodo siciliano, fatto di esperienze professionali e di rapporti sociali che lo porteranno a conoscere, attraverso il Marchese de Pace, gran parte dell'aristocrazia palermitana custode di collezioni d'arte di altissimo valore. Le collezioni erano tenute per lo più nascoste, poiché all'epoca, tra le famiglie nobili, serpeggiava il forte timore di una presa di potere da parte dei comunisti. Le collezioni erano composte da pezzi pregiatissimi, si andava dai fondi oro trecenteschi alle opere fiamminghe del $\mathrm{XV}{ }^{\circ} \mathrm{sec}$., che i loro proprietari vedevano come "beni rifugio" in caso di fuga forzata. Grazie al Marchese de Pace e a Carandente, Colalucci

\footnotetext{
D. Bartoletti "Intervista a G.Colalucci" cit.

${ }^{46}$ A. Sorace, restauratrice dell'Istituto, momentaneamente "distaccata" presso la sede della Soprintendenza delle Gallerie della Sicilia di Palazzo Abatellis.
} 
ottiene la fiducia di queste famiglie, può entrare nei loro palazzi e restaurare gran parte delle loro collezioni. Lavora per la Principessa di Sciara, che aveva il palazzo a piazza Castello, per la Principessa di Gangi proprietaria del palazzo in cui fu girato il film di Visconti "il Gattopardo", per il Principe Bordonaro, con villa all'Addaura vicino Mondello, per i Principi Lanza di Mazzarino, proprietari dell'omonimo palazzo di via Maqueda, dove un tempo veniva ospitato il $\operatorname{Re}$ d'Italia quando era in visita a Palermo. Conosce e lavora per Giuseppe Tomasi di Lampedusa autore de II Gattopardo, per la Duchessa della Verdura e per la Principessa Moncada di Paternò che aveva una splendida villa a Bagheria. Ma la conoscenza di questa élite palermitana gli darà anche modo di frequentare un gruppo di giovani intellettuali composto dal pittore Bruno Caruso, da Enzo Sellerio, marito dell'editrice e bravissimo fotografo poi divenuto professore di matematica all'università, da Lanza Tommasi di Mazzarino divenuto professore di storia della musica all'università di Palermo, dal Barone Bebbuzzo Lo Monaco musicista, da Ignazio Moncada pittore, e dall'architetto Samonà, nipote del più celebre zio, professore alla Università di Venezia. La Principessa Topazia di Salaparuta madre della scrittrice Dacia Maraini, era la "chioccia" di questo gruppo che, per impegni vari, finirà per disperdersi alla fine del 1957. A proposito di Tommasi di Lampedusa Colalucci dice

(..) Conobbi molte persone, ma per brevità ricorderò solo Giuseppe Tommasi di Lampedusa autore del noto romanzo "II Gattopardo". II romanzo fu pubblicato dopo la sua morte, nel 1958, perciò, quando il principe mi chiamò per farmi vedere alcuni quadri non immaginavo 
che quando la mattina lo vedevo nella pasticceria Massimo o Caflisch in via Ruggiero VII, seduto solo in un tavolo, chinato sui fogli, in realtà stava scrivendo una opera destinata ad avere un successo mondiale (..). ${ }^{47}$

Gli anni siciliani vedranno Colalucci impegnato in molti lavori per la Soprintendenza. Nei primi anni di permanenza a Palermo, quelli che vanno dal 1953 al 1957, si occupa prettamente del restauro di opere conservate a Palazzo Abatellis o di quelli appartenenti a chiese o musei delle province di Palermo e Trapani. Dal 1957 alle province di Palermo e Trapani si aggiungeranno quelle di Agrigento, Enna e Caltanissetta e Ragusa. A Trapani si reca una prima volta nel dicembre del 1954, per fare la revisione dei dipinti della collezione del Museo Pepoli in occasione dell'inaugurazione delle nuove sale espositive. Tornerà a Trapani altre volte, sempre su incarico di Vigni, per visionare un affresco basiliano della chiesa di S.Antonio ad Erice per poi eseguirne il restauro. Mi racconta che quando andava a Trapani, il Direttore Vincenzo Scuderi lo ospitava negli uffici del Museo Pepoli, e che quando vi arrivò la prima volta con la "Litorina" da Palermo, in una giornata di forte libeccio, pensò di aver fatto un salto indietro nel tempo, come nei film di fantascienza, poiché alla stazione anziché i taxi, trovò ancora i Landeau a cavalli.

A Palermo lavora in un laboratorio all'interno di Palazzo Abatellis. Inizialmente, cioè prima dei restauri di Scarpa, gli viene affidato un locale ricavato nella torre. Successivamente avrà a disposizione un ampio laboratorio all'ultimo piano del 
Palazzo, mentre dal 1957 in poi, si trasferirà in un altro ambiente al piano terreno, ricavato nel Convento confinante con il Palazzo, e che dopo i restauri di Scarpa era stato adibito a Museo.

La permanenza siciliana di Colalucci è interrotta soltanto da alcune pause durante le quali svolge dei lavori su incarico di Brandi. II primo ha luogo tra ottobre e dicembre del 1956 a Creta nel Museo di Eraklion. Si svolge per conto della scuola archeologica italiana di Atene diretta da Doro Levi. II lavoro riguarda la ricomposizione dell'affresco minoico di Amnisos detto "dei Gigli", che si presenta diviso in 12 frammenti. Per rimontarlo sarà adottato un particolare metodo ideato personalmente da Brandi. II metodo, che prevedeva l'uso della cera, è dettagliatamente descritto nella relazione tecnica dell'intervento redatta da Colalucci a fine lavoro. Mi racconta che Brandi, poiché era in netto disaccordo con il metodo di reintegrazione-ricostruzione fino ad allora eseguito dal pittore Fanurachis, dette disposizioni affinché l'intervento si circoscrivesse al solo riassemblaggio. A tale proposito, a commento di una delle foto che documentano l'intervento, troviamo scritto da Colalucci:

"L'Istituto Centrale del Restauro non approva il sistema di reintegrazione pittorica adottato dai Greci e quindi a noi è stato tassativamente proibito di intervenire pittoricamente." 48

Il secondo lavoro per conto di Brandi si svolge nel 1957 nella Basilica inferiore di Assisi, e riguarda il restauro dell'affresco con la "Predica agli uccelli" del Maestro di S. Francesco. II terzo lavoro si svolge nel 1959/60 a Tolentino. II restauro riguarda gli affreschi del Cappellone di San Nicola, con le scene del

\footnotetext{
${ }^{48}$ Archivio G.Colalucci (sezione fotografica).
} 
"nuovo Testamento" e della "vita del Santo", all'epoca attribuiti al Baronzio e successivamente a Pietro da Rimini.

Il secondo periodo siciliano dal 1957 al 1959

Dopo la parentesi di Assisi, Colalucci rientra a Palermo e inizia a lavorare con altri due restauratori diplomati all'Istituto, Alberto Polidori di Perugia e Fausto Giannitrapani di Viterbo, entrambi conosciuti a Roma. Giannitrapani era stato mandato a Palermo dall'Istituto, in sostituzione di Annamaria Sorace, che nel frattempo era rientrata a Roma. Nei tre anni compresi tra il 1957 ed il 1960, data del rientro definitivo a Roma, Colalucci ed i suoi nuovi colleghi, lavoreranno ad un ritmo serrato. Una volta l'anno programmavano un giro per le province siciliane che erano di loro pertinenza. Durante il viaggio si facevano accompagnare da un camion in modo da prelevare tutte le opere indicate dalla Soprintendenza per la Sicilia, per portarle in laboratorio a Palermo. Dopo un anno riconsegnavano le opere restaurate e prelevavano quelle da restaurare. II Ioro raggio d'azione si estendeva a quasi tutto il territorio siciliano, fatta eccezione per le province di Catania e Siracusa che avevano altri restauratori di riferimento $^{49}$. A volte si presentava la necessità di eseguire dei restauri sul posto, come nel caso di Erice o di Castelvetrano, che costringevano a brevi trasferimenti. In questa ultima fase del suo soggiorno siciliano, Colalucci

\footnotetext{
${ }^{49}$ Nelle province di Siracusa e Catania lavorava il restauratore che si chiamava Giovanni Nicolosi . Nella zona di Palermo prima di Colalucci lavorava un pittore-restauratore di nome Giambecchina.
} 
acquista una grande esperienza poichè si trova a lavorare su opere difficilissime dal punto di vista conservativo. Mi racconta che, specialmente nei paesi, trovava opere che avevano subito restauri particolarmente invasivi dovuti all'intervento di maestranze improvvisate. Gli stessi restauri che Brandi in "Sicilia mia” descriverà con lucida severità :

“..S'era già visto al tempo della Mostra di Antonello : codeste tavole tartassate da liscivature feroci, si trovano in genere ricoperte da uno strato come di cinnamomo o di sandracca che le fa sospettare piuttosto che vedere. Quegli strati rossastri, avvampati, perversi, una volta rimossi rimettono in luce delle tragiche larve, epidermidi incartapecorite, impronte. Quando poi non vengono fuori dei falsi veri e propri."

Colalucci mi racconta che i restauratori improvvisati, venivano reclutati per lo più dai parroci delle chiese tra gli artisti del luogo, ma molto più frequentemente erano i sacrestani che finivano per esercitare, su dipinti e sculture, lo stesso tipo di manutenzione che riservavano ai legni dei confessionali o degli inginocchiatoi, dove venivano usate misture a base di olii, cere, mordenti, e spesso anche olio d'olivo. Durante gli anni siciliani Colalucci lavora spesso su tele e tavole di grande formato, che lo costringeranno ad affrontare problemi complessi, ma che gli faranno acquisire una notevole padronanza nella foderatura, e nella reitegrazione pittorica. Questi dipinti si trovavano spesso in condizioni pessime, avevano i supporti in tela lacerati e quelli in legno sfiniti dagli attacchi dei tarli. Tra i dipinti di grande formato restaurati da Colalucci ricordo: "la Natività" Pietro D’Asaro detto il Monocolo di Racalmuto, un olio su tela di m. 3,90 × 2,48; il "Sant' Ignazio in estasi" del sec. XVII', un olio su tela di 
m. 4, 56 × 2,73 ; " II trionfo della Chiesa" di Girolamo Mercurio, olio su tela di m 4,30 x 3,00 ; la "Madonna del Rosario" di Andrea Carreca, olio su tela di m. 3,82x 2,52. Restaura dipinti su tavola con problemi gravissimi ai supporti, come“/l San Leonardo" di Antonio Riccio, una tavola di m.3,60 x 2,30; "Ognissanti” di Giuseppe Bonfiglio, una tavola di m.3,60×2,35 ed una "lunetta con gli angeli" proveniente da Castroreale che richiese l'intervento radicale del trasporto di colore. Colalucci restaura anche fondi oro, molte opere fiamminghe di cui la Sicilia è ricca, ma anche affreschi stremati dall'umidità, come i citati dipinti basiliani della chiesa di S. Antonio ad Erice, le cui condizioni gli imporranno il ricorso allo stacco.

Questa importantissima fase del suo cammino professionale si interrompe nel 1960 per propria scelta. In parte a causa della difficoltà di conciliare il lavoro in Sicilia con gli impegni familiari a Roma, ma soprattutto per il prestigioso invito fattogli dal laboratorio di restauro dei Musei Vaticani. Non si interromperà però il legame affettivo con la Sicilia, dove ancora oggi sente il bisogno di tornare appena gli impegni glielo consentono. Non si interromperà il rapporto di amicizia e stima con alcune delle persone che aveva frequentato in quegli anni, come Carandente, o come Scuderi che per molti anni a venire continuerà a considerare Colalucci come restauratore di riferimento. Scuderi continuerà ad affidargli lavori fino a che, una legge regionale e i famigerati cambiamenti di rotta nelle amministrazioni pubbliche, renderanno impossibile ai funzionari delle Soprintendenze la scelta diretta del restauratore. 


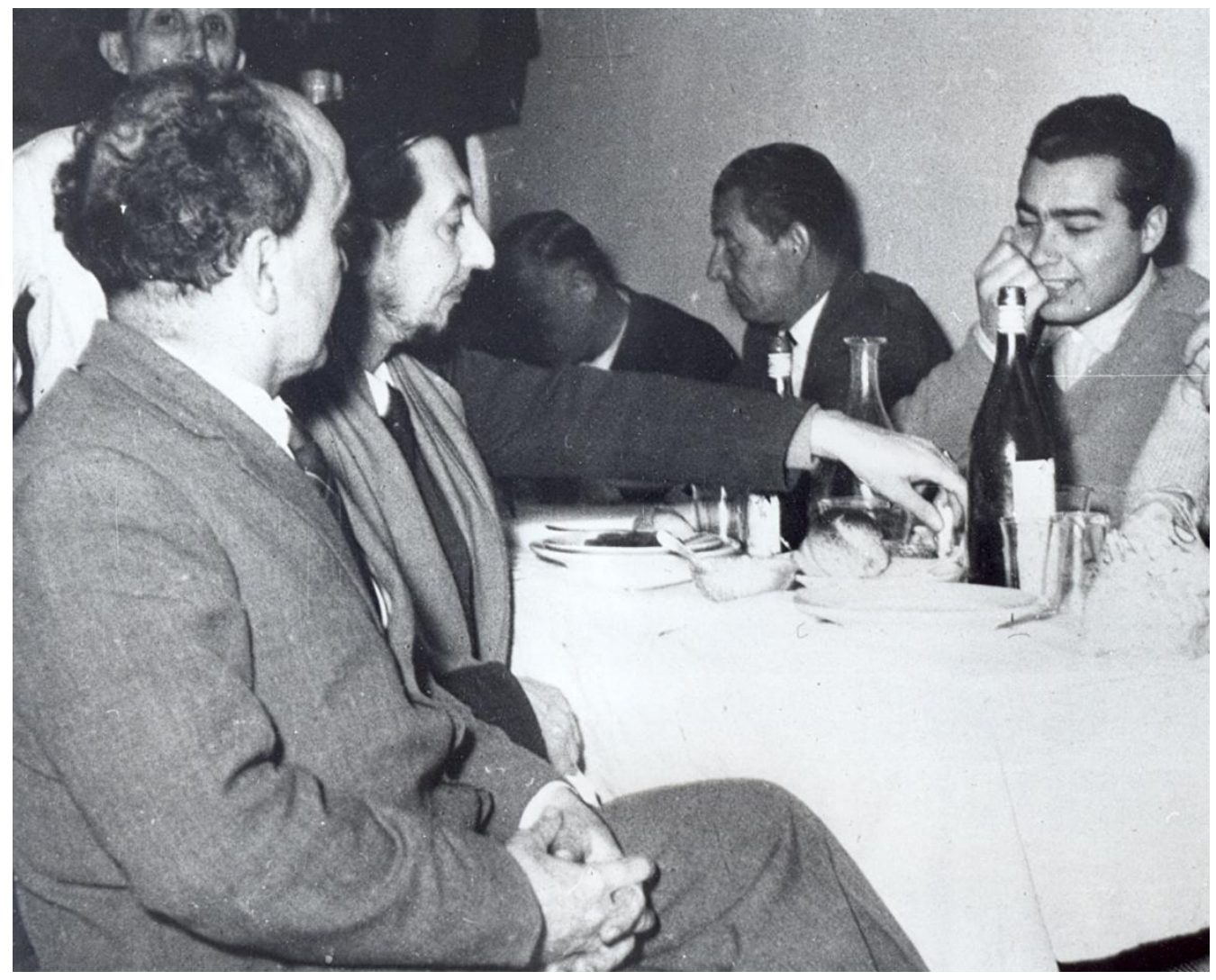

Fig.1- G. Colalucci a Palermo nel 1953 con l'architetto Carlo Scarpa

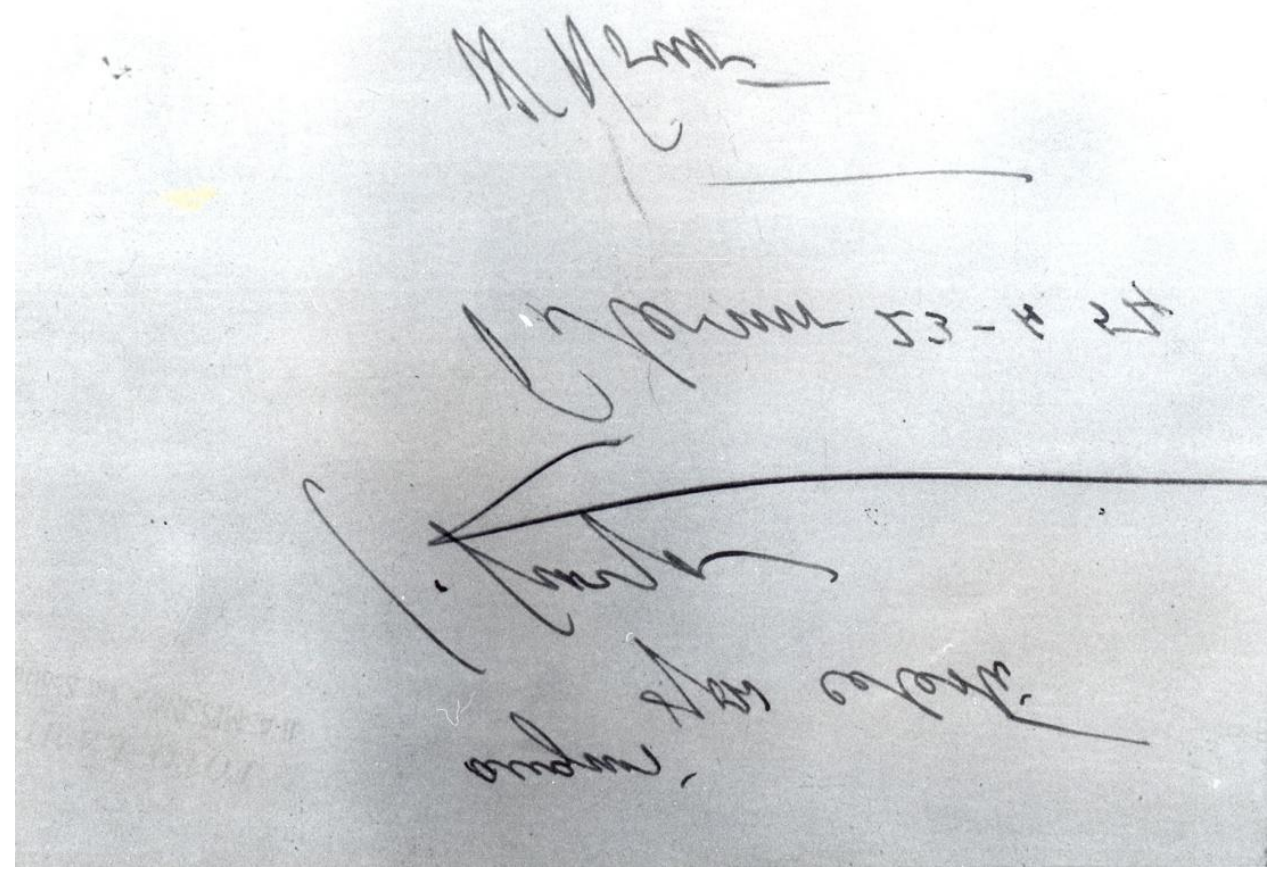

Fig. 2- La dedica di Scarpa sul retro della foto. Come si nota è scritta al contrario alla maniera di Leonardo 


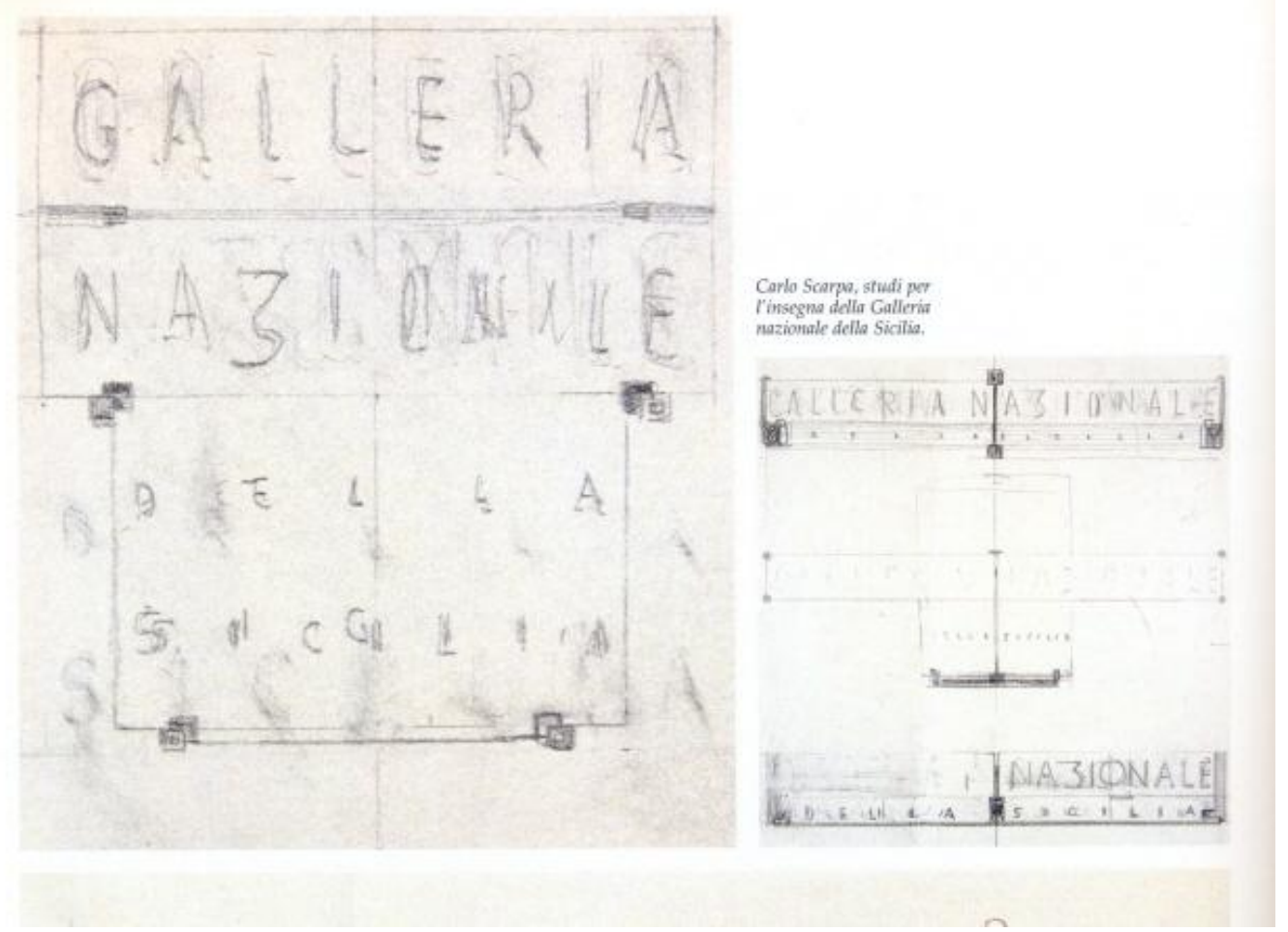

Fig. 3 - I disegni di Scarpa per il logo della Galleria di Palazzo Abatellis

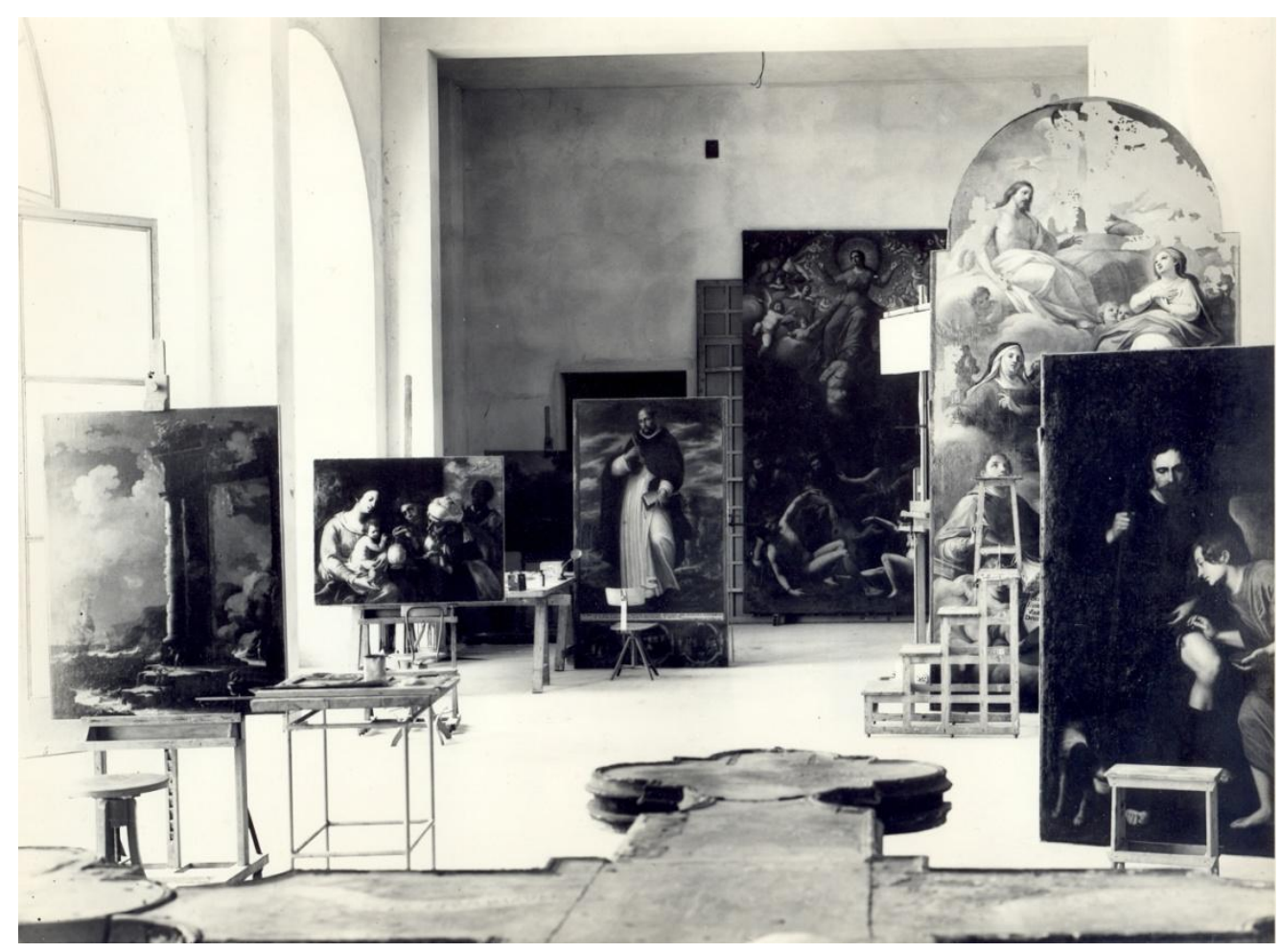

Fig. 4 II laboratorio di restauro di Palazzo Abatelis nel 1959 


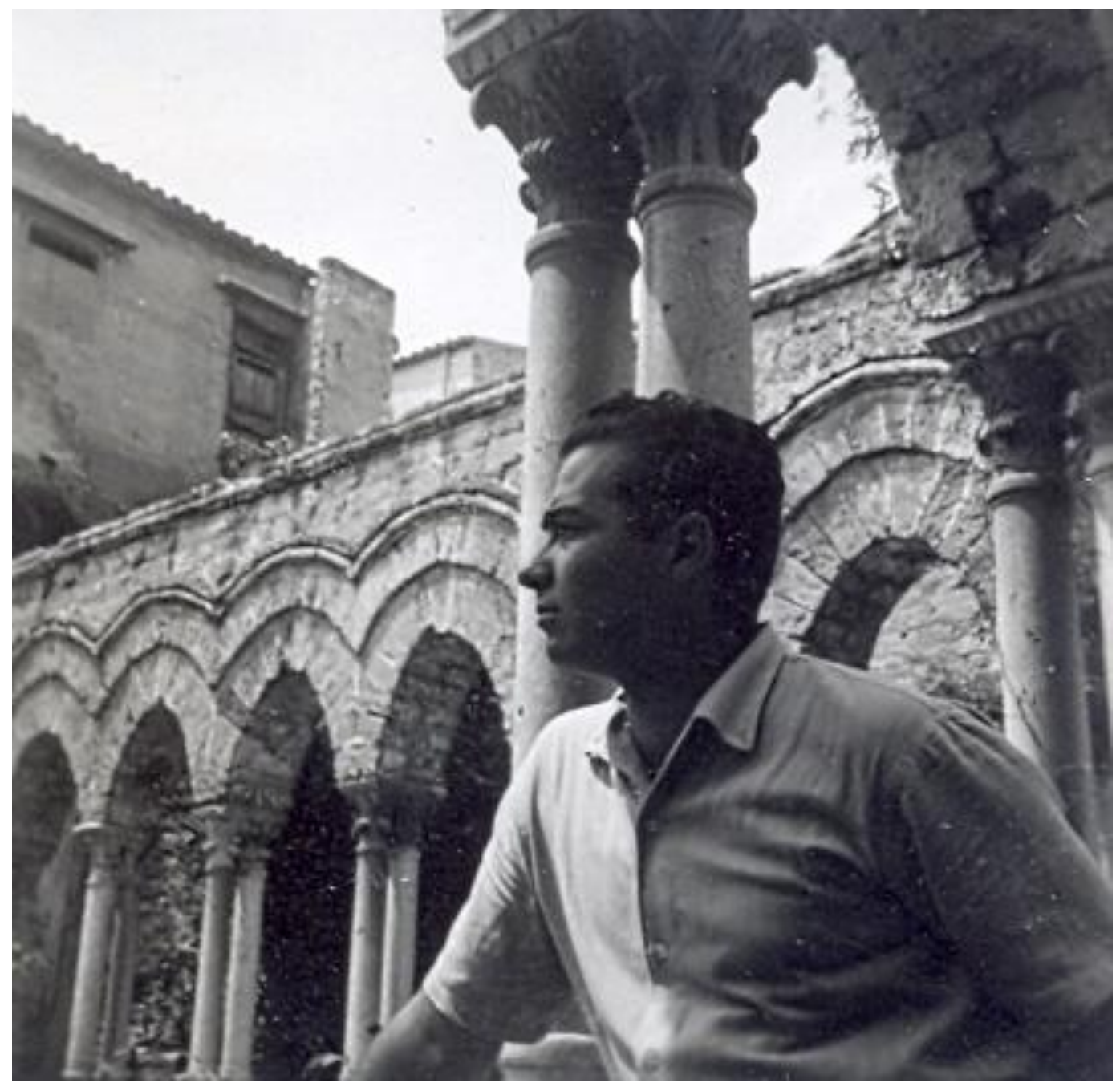

Fig. 5 -G. Colalucci nel chiostro di S. Giovanni degli Eremiti a Palermo-1953 


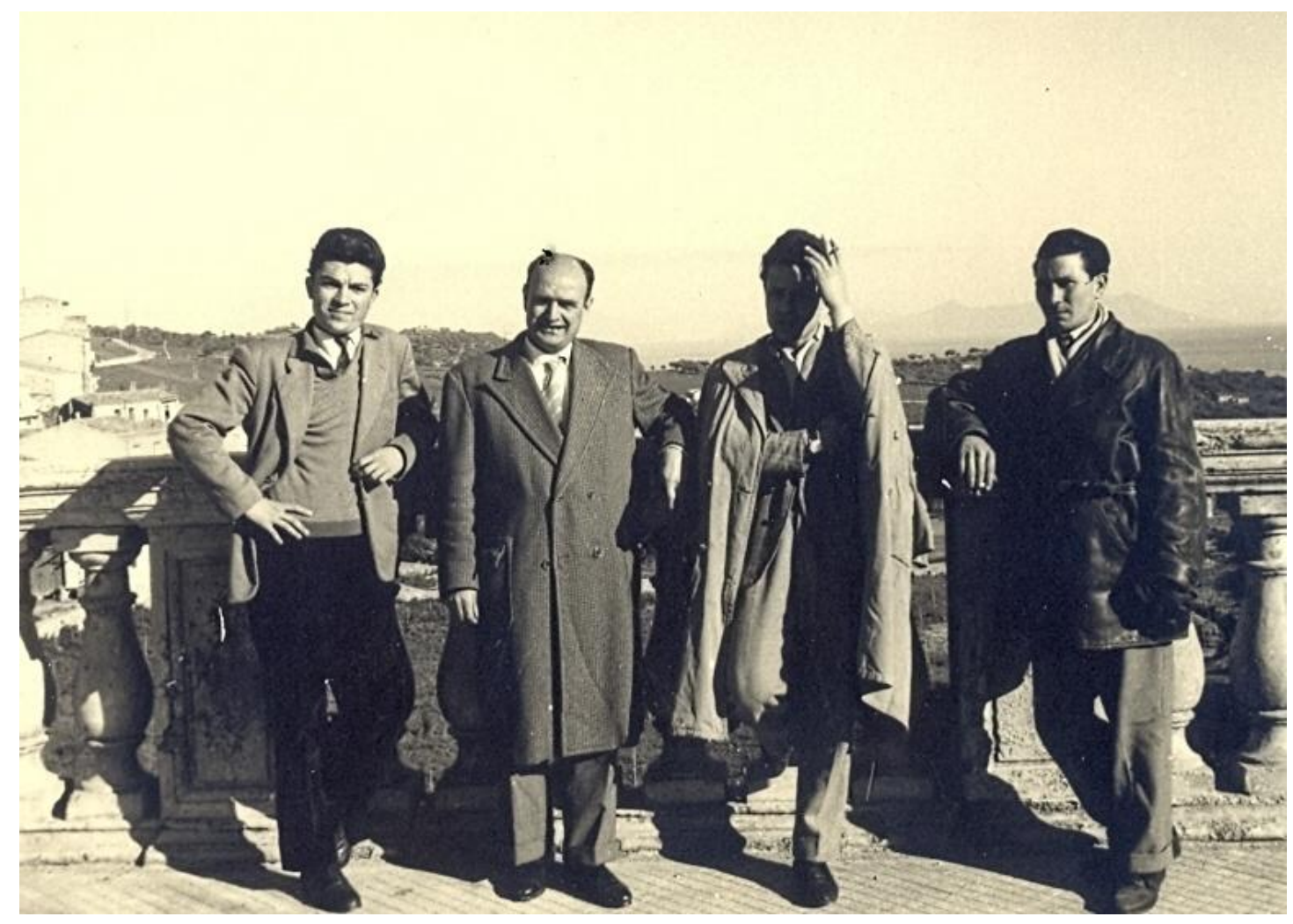

Fig. 6-1956, una foto che ritrae il falegname e l'autista della Soprintendenza Gemma e Pirrotta, durante uno dei viaggi fatti con Colalucci, all'interno della Sicilia, per prelevare le opere da restaurare. 


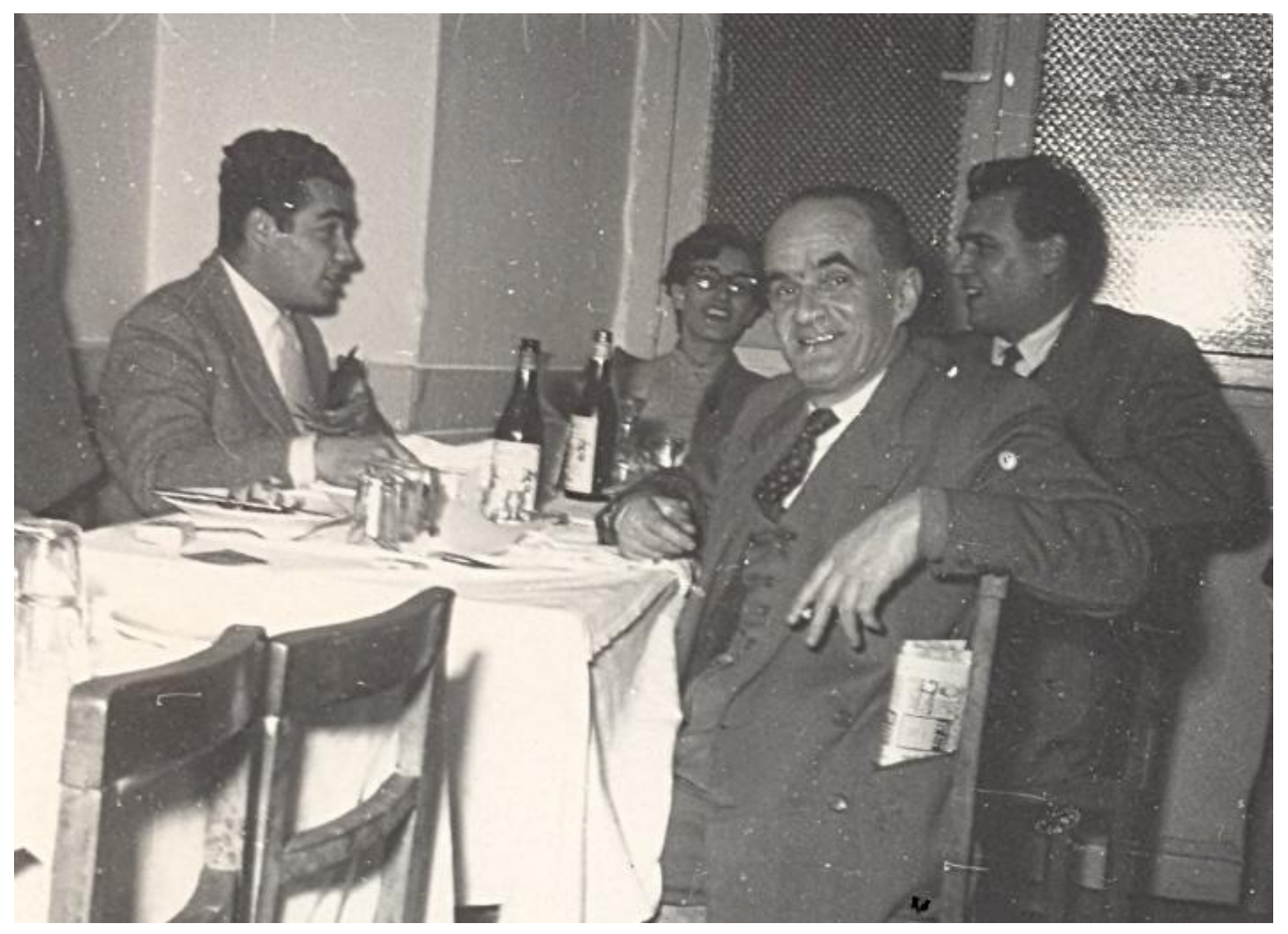

Fig.7- G. Colalucci a Palermo nel 1953. Sulla destra della foto T. Spini (in primo piano) e dietro di lui S. Pigazzini 


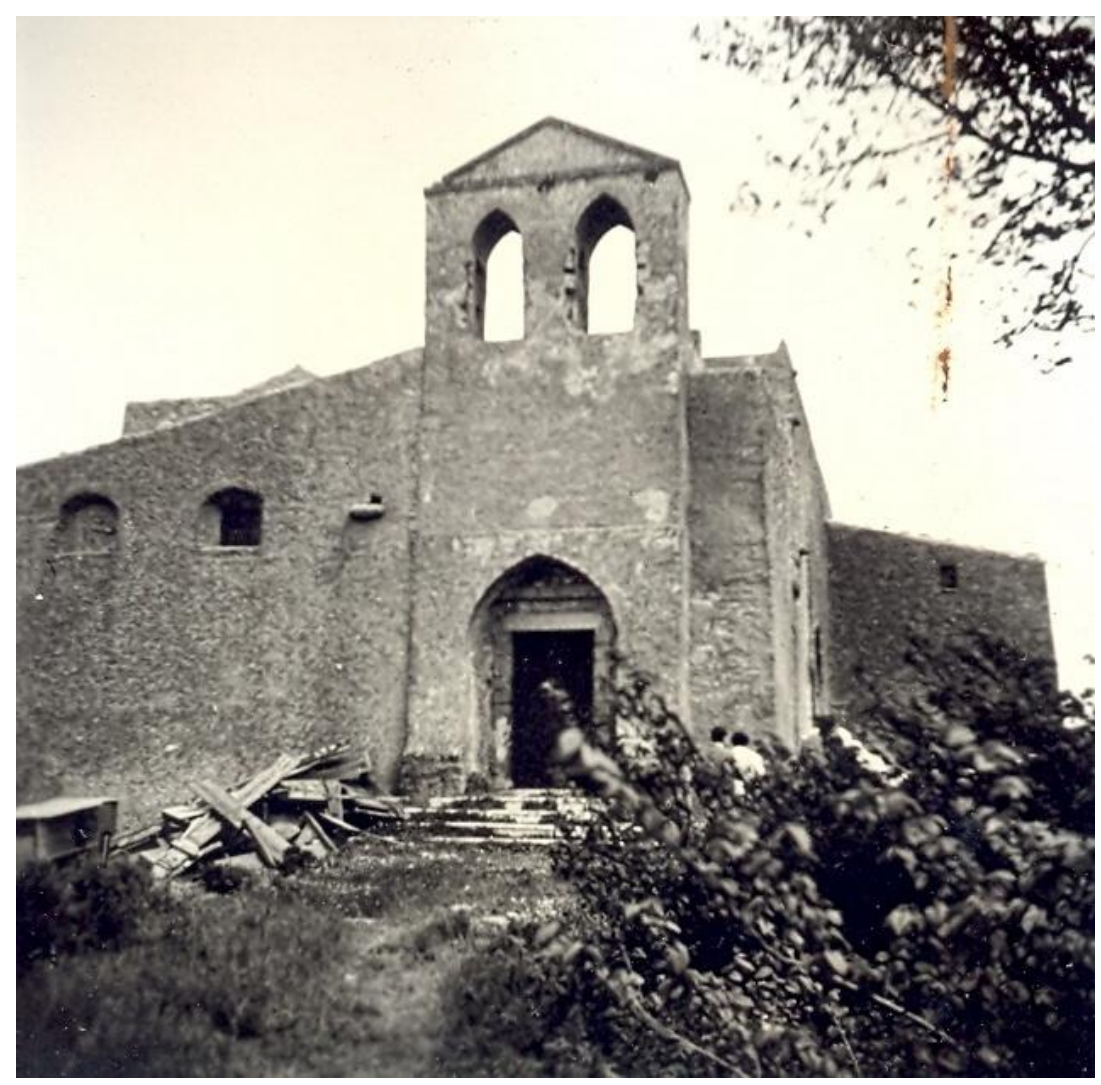

Fig. 8 - L'esterno della chiesa di S. Antonio ad Erice nel 1955

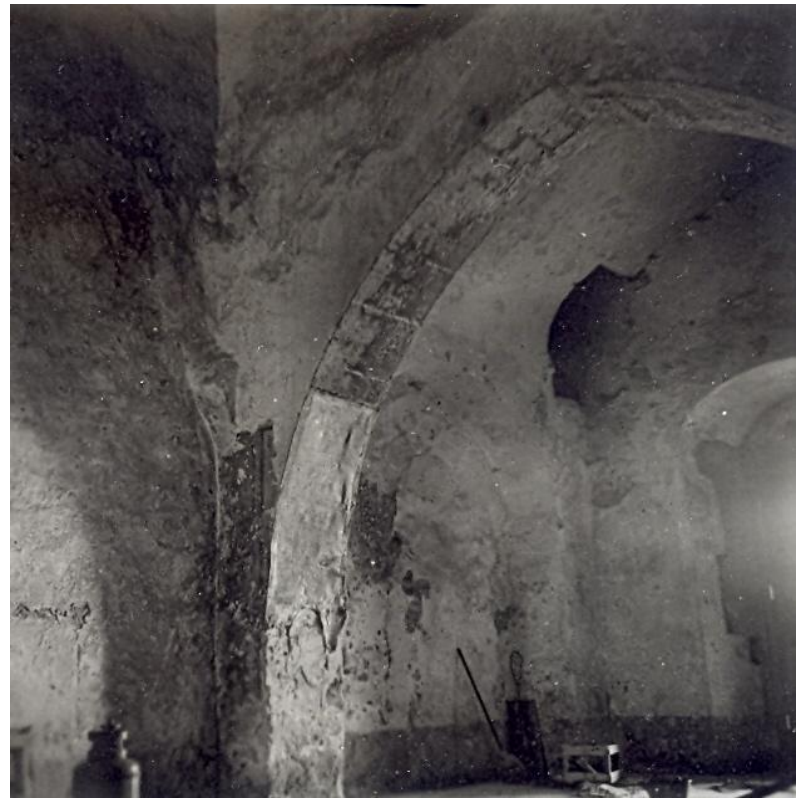

Fig. 9- Erice -Una veduta interna della chiesa con l'affresco basiliano preparato per lo stacco

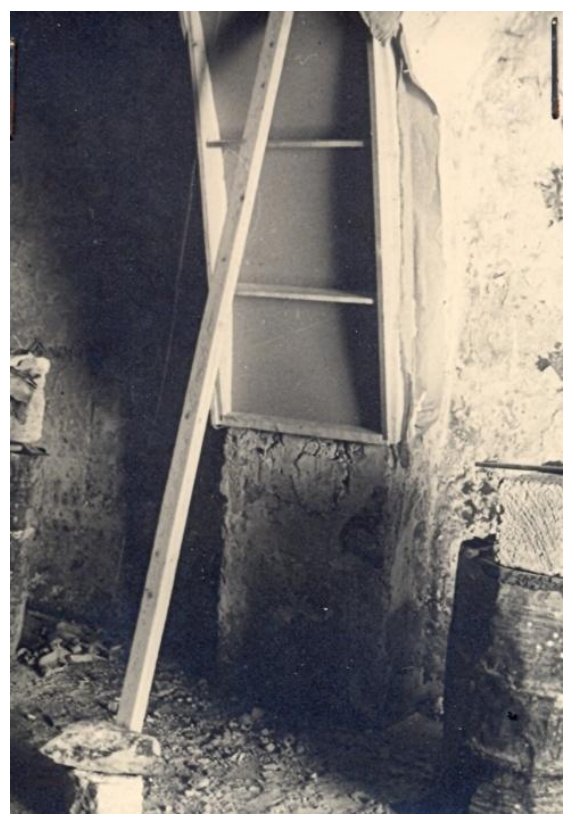

Fig. 10 - Erice- Un particolare della controforma 


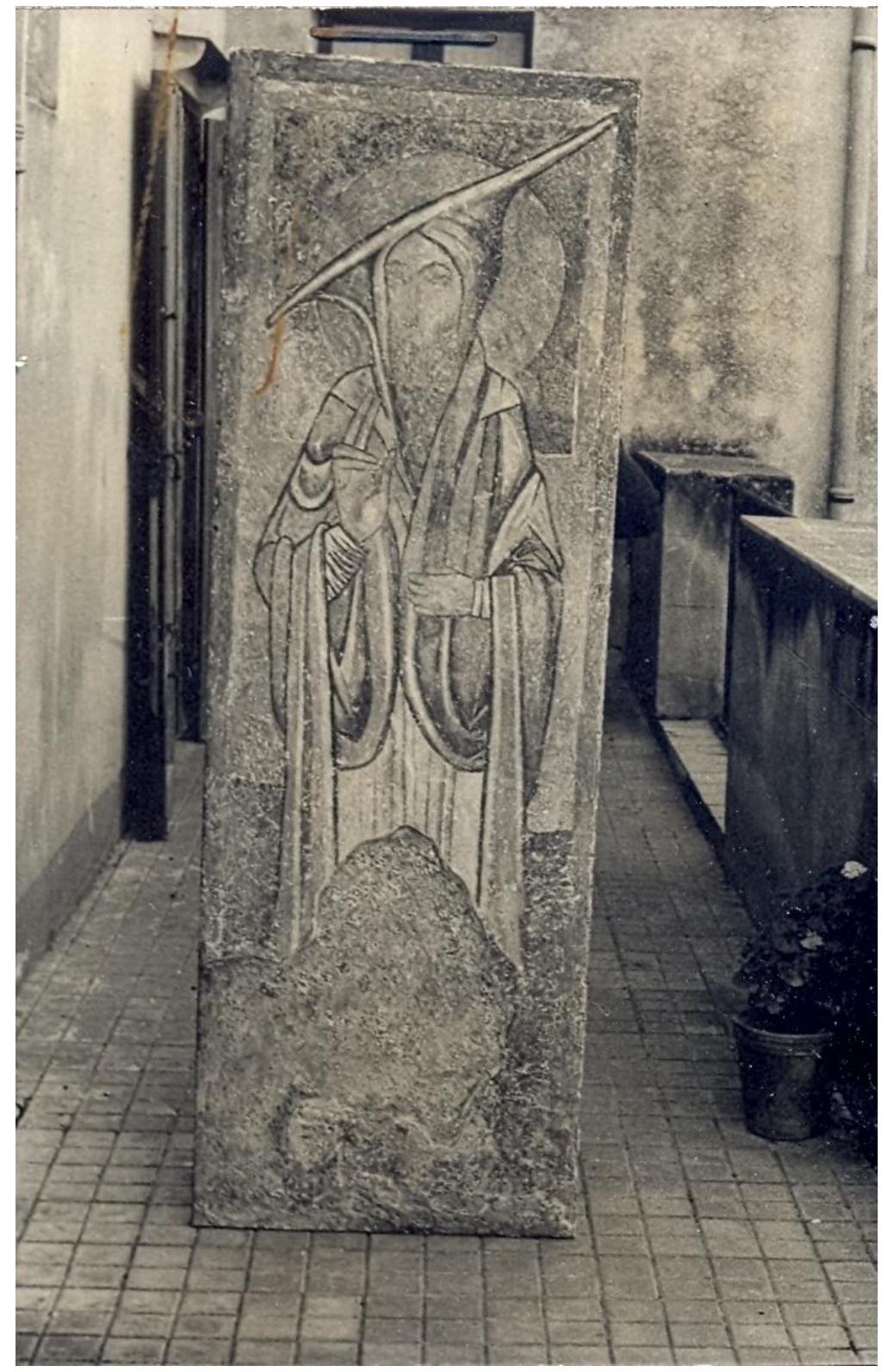

Fig. 11 - Erice - L'affresco dopo il restauro di Colalucci 


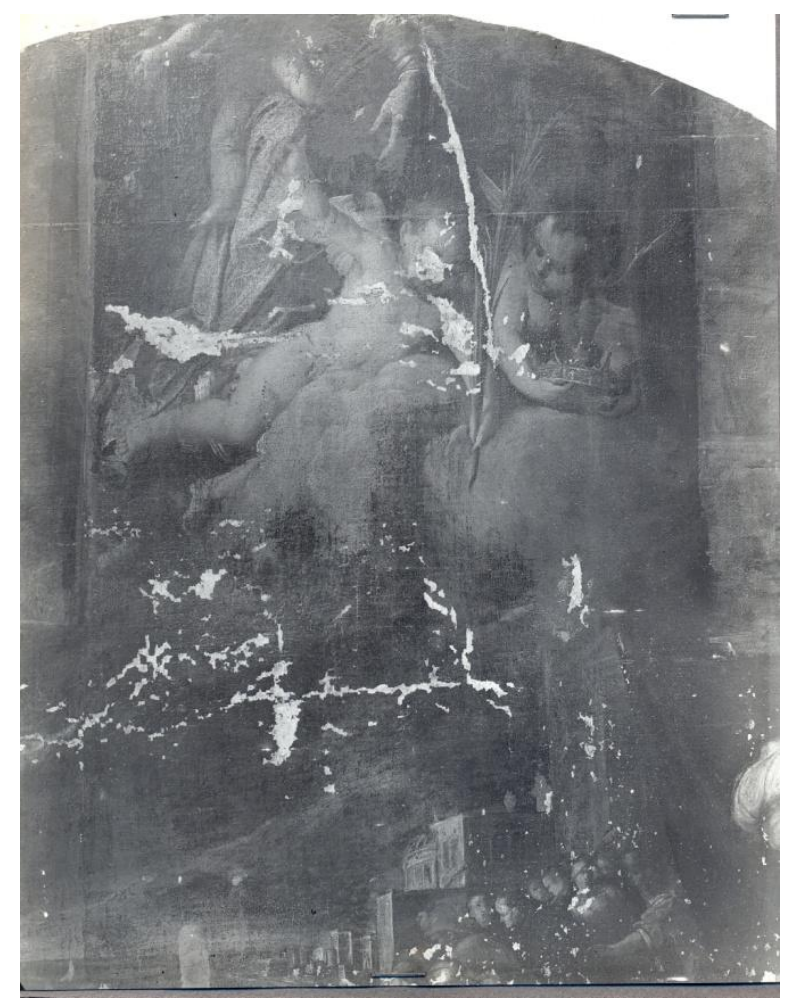

Fig.12-Un particolare della tela di F. Paladino con il "Martirio di S.Placido" durante il restauro di Colalucci

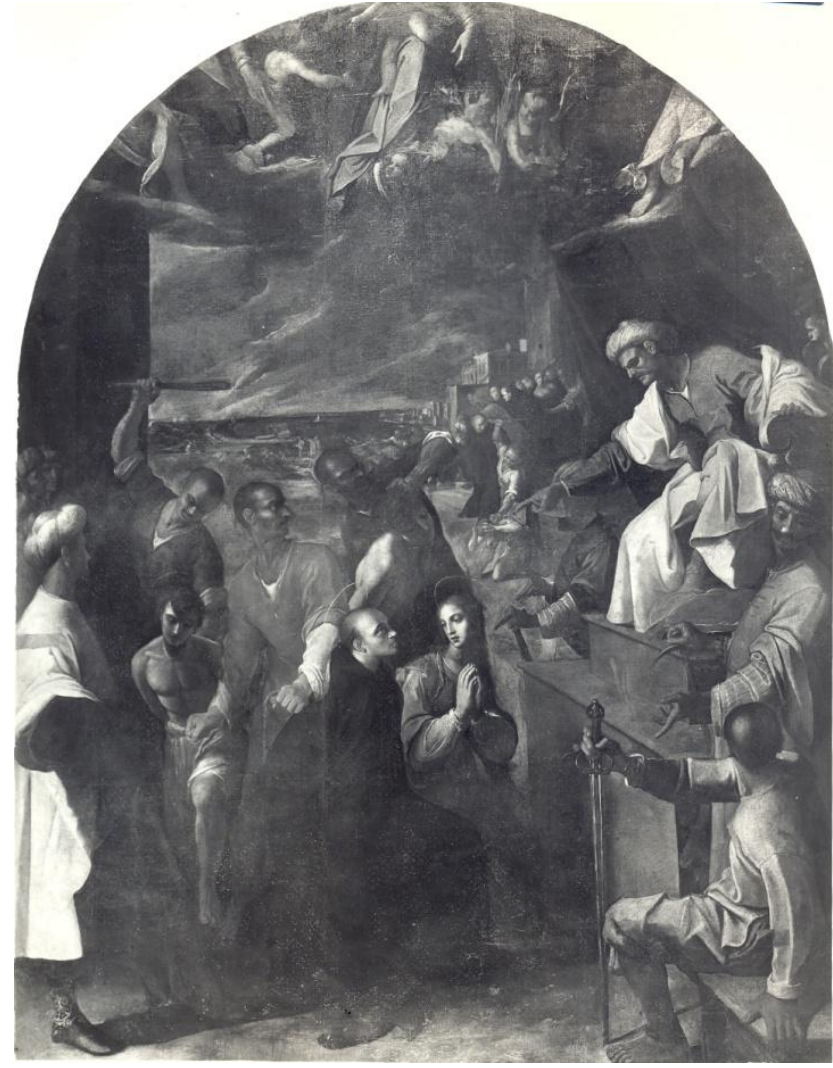

Fig. 13- La Tela di F. Paladino dopo il restauro. Olio su tela cm.406×311 


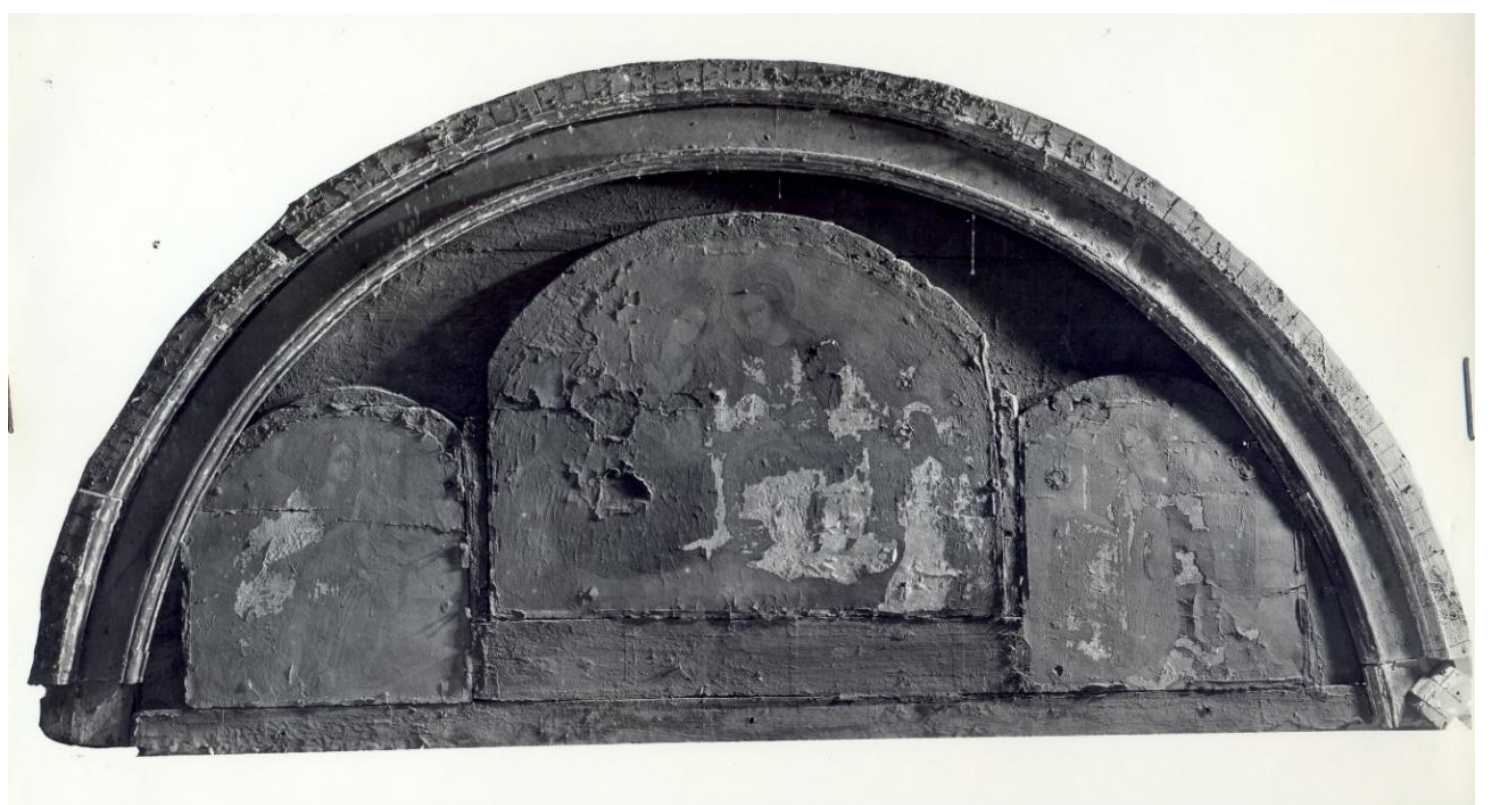

Fig. 14- Castroreale - Un dipinto su tavola di autore ignoto, raffigurante "I'Incoronazione della Vergine" Si nota il gravissimo stato della pellicola pittorica.

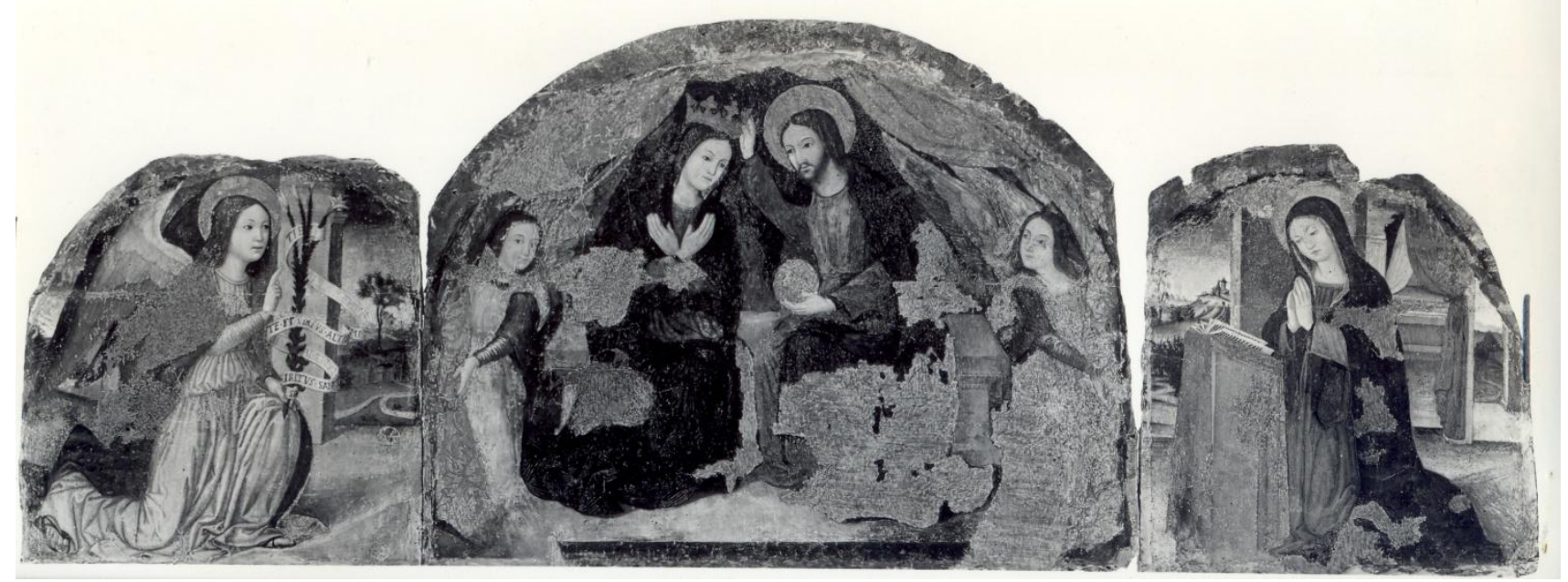

Fig.15- Castroreale - Lo stesso dipinto della foto precedente, dopo il restauro di Colalucci 


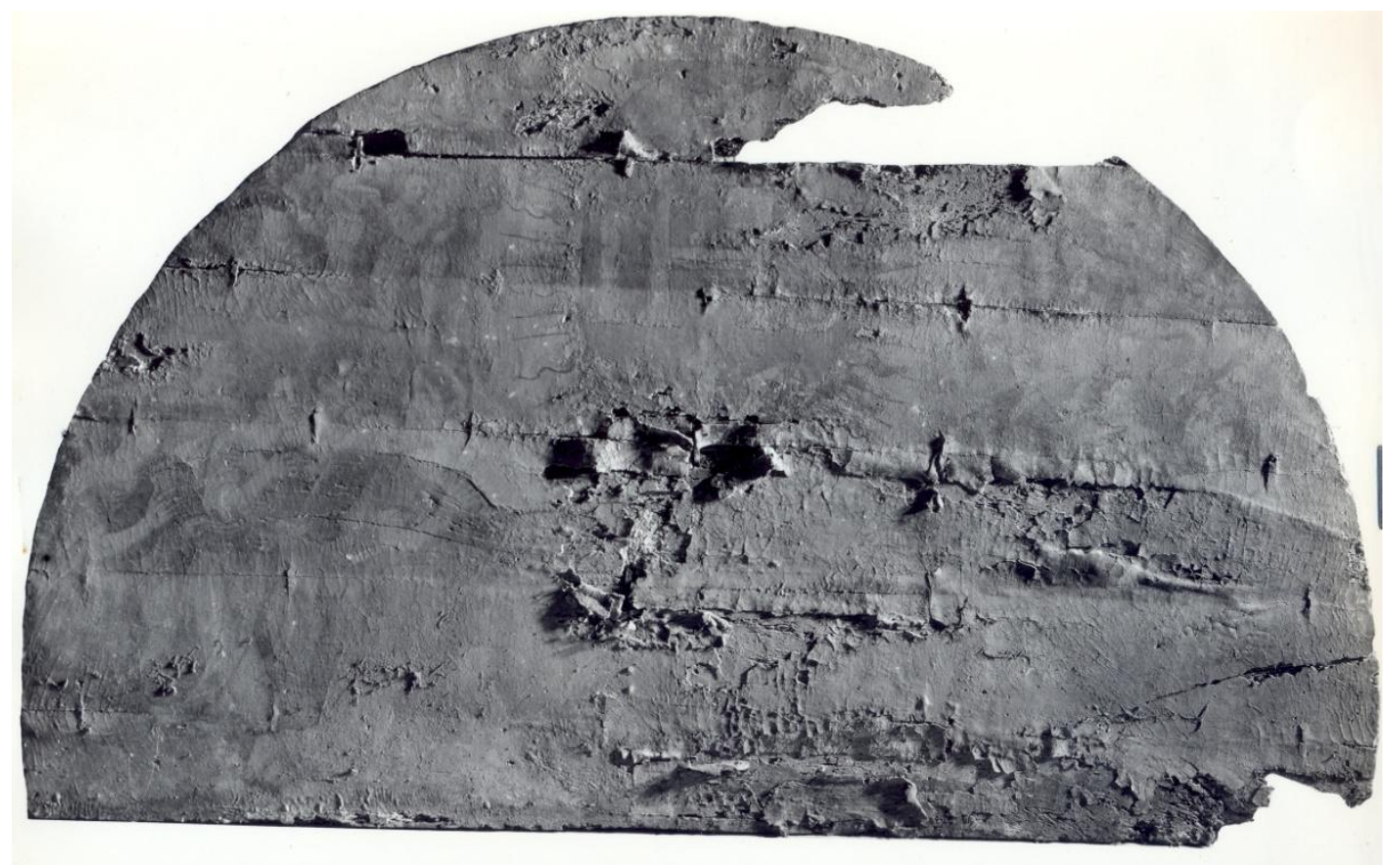

Fig. 16- Castroreale- autore ignoto "Angeli e IHS" - dipinto su tavola cm.230 x 205

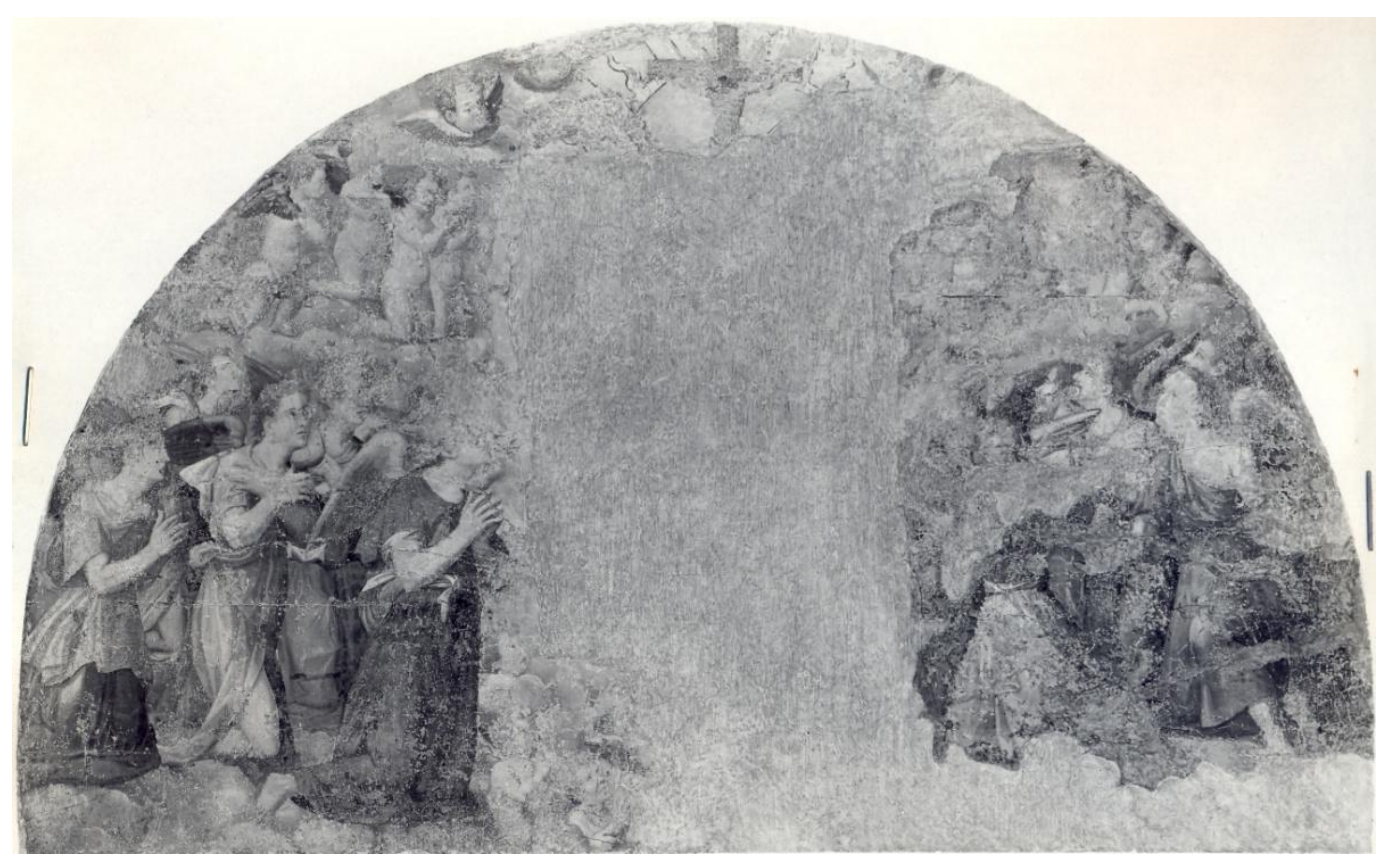

Fig- 17- Le figure 16-17, mostrano il dipinto prima e dopo il restauro eseguito da Colalucci. Lo stato di avanzato degrado del supporto richiese l'esecuzione di un trasporto di colore. 
Agira, ignoto catalano, "crocifisso". Dipinto su tavola cm.385x286

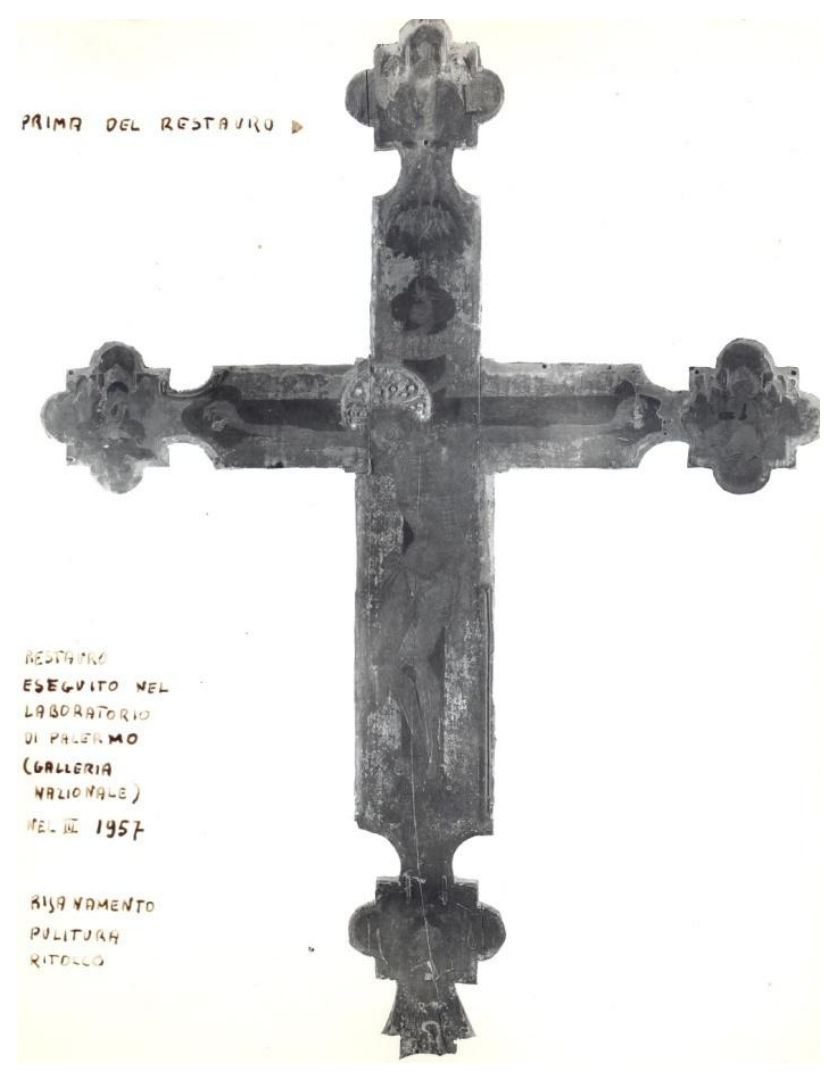

Fig. 18 - Prima del restauro

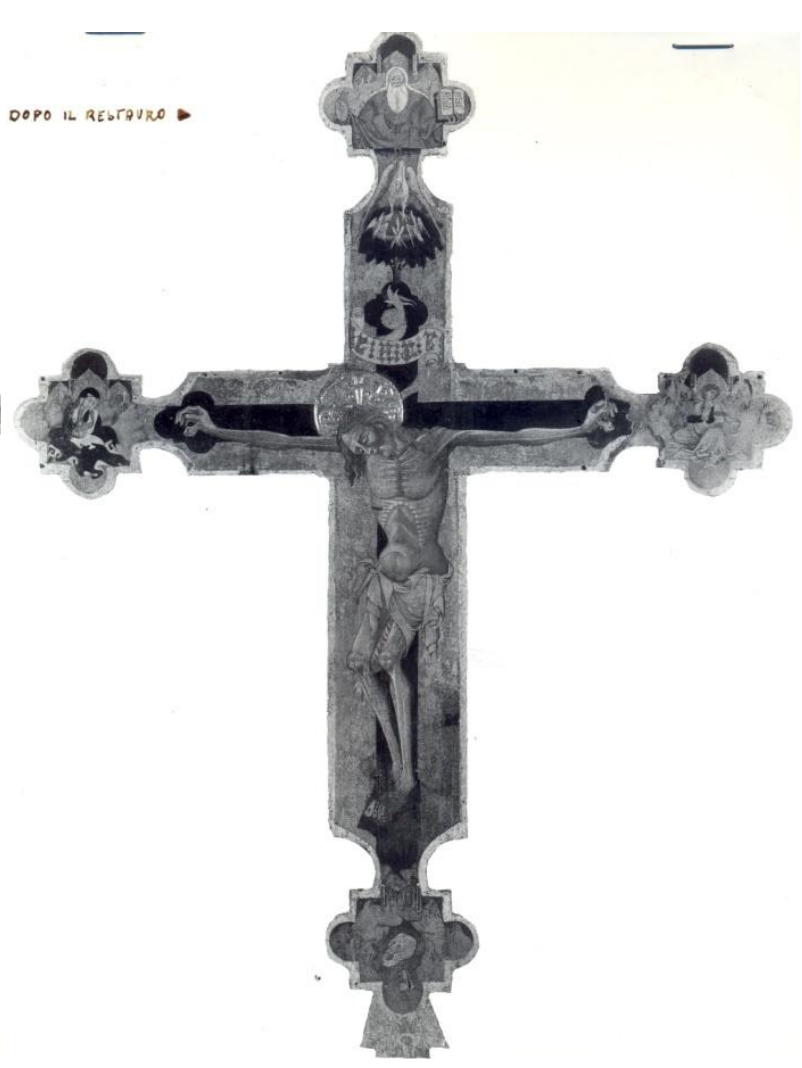

Fig. 19- dopo il restauro 


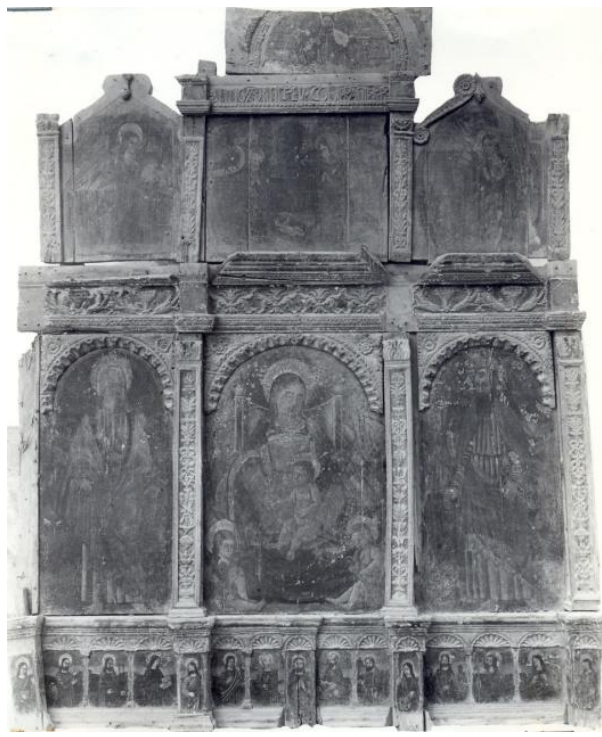

Fig. 20-prima del restauro

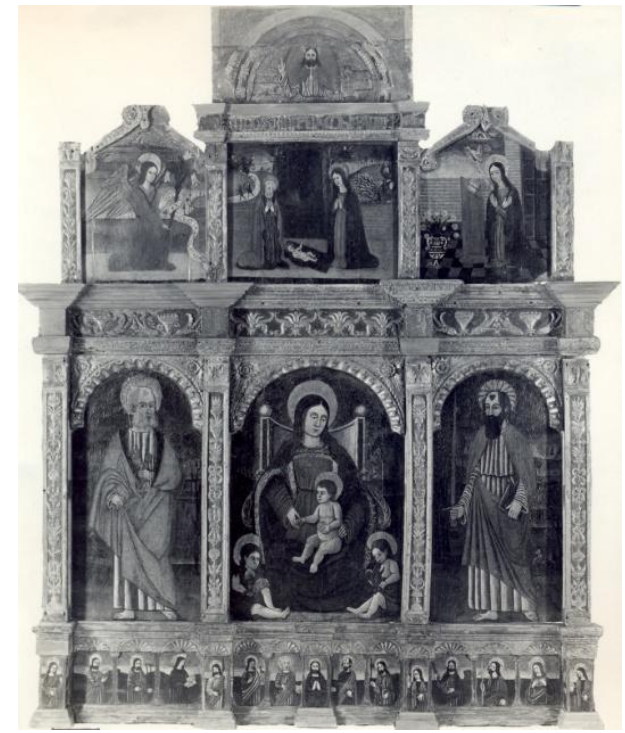

Fig. 21- dopo il restauro 
Molino- A. Riccio, “Madonna di Loreto"- dipinto su tavola

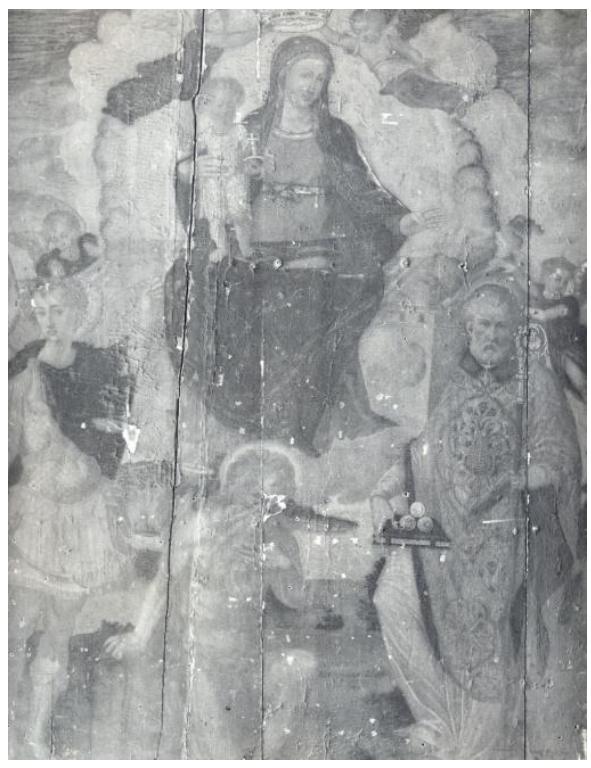

Fig. 22 - prima del restauro

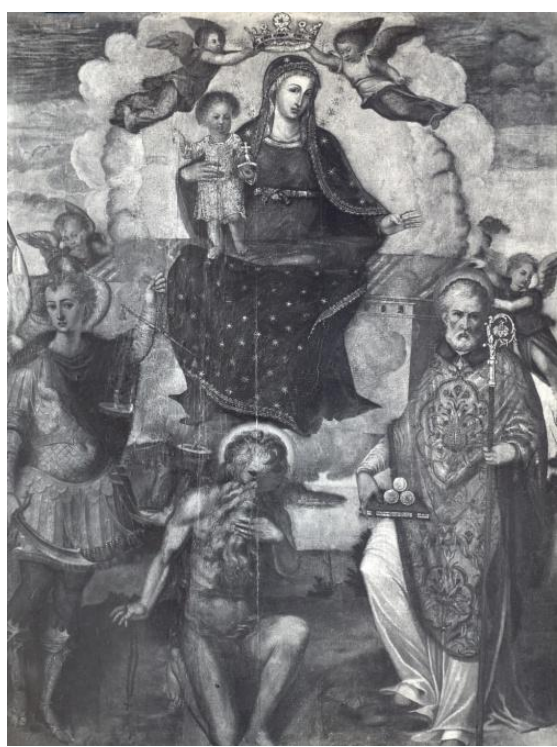

Fig.23- dopo il restauro

Butera - F. Paladino "Immacolata"

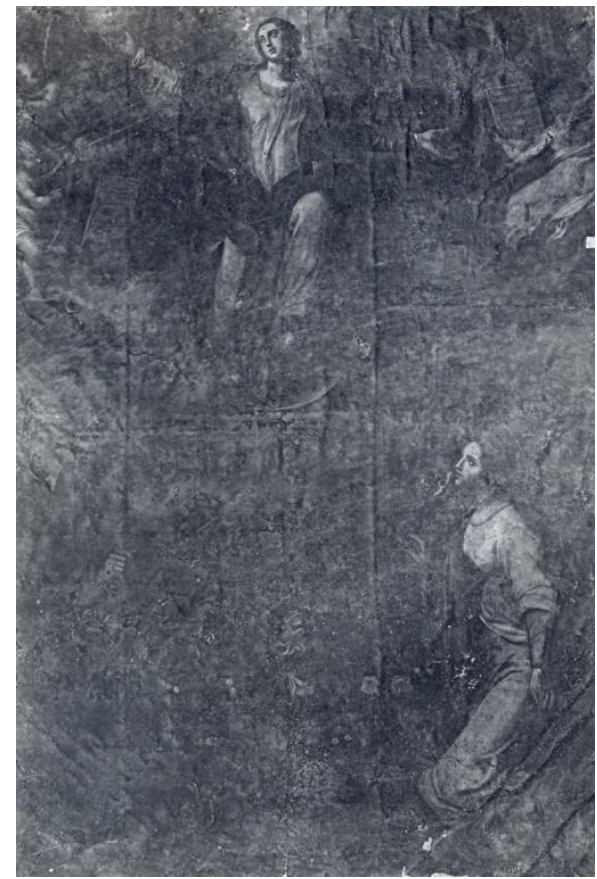

Fig.24- prima del restauro

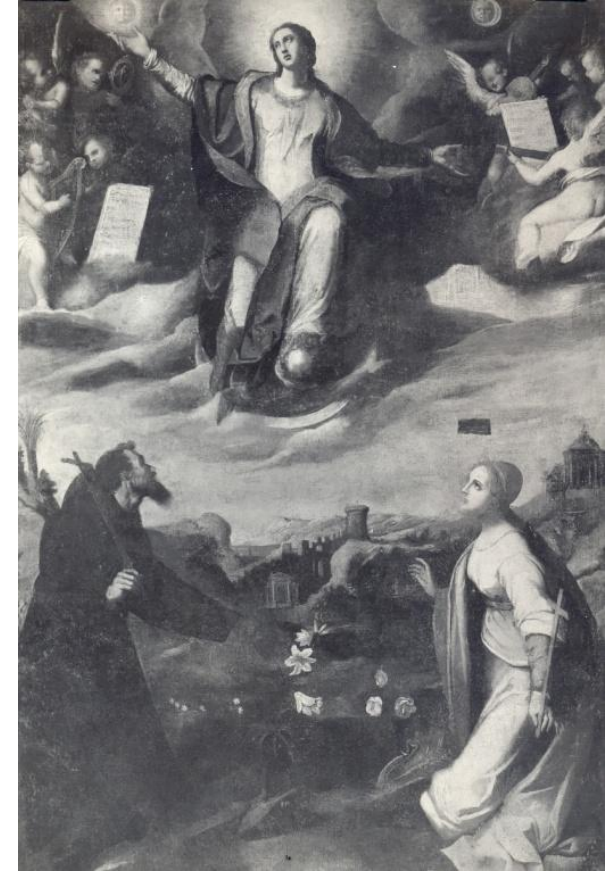

Fig. 25- dopo il restauro 
Caltagirone- F.Paladino "Deposizione"- olio su tela cm.300×200

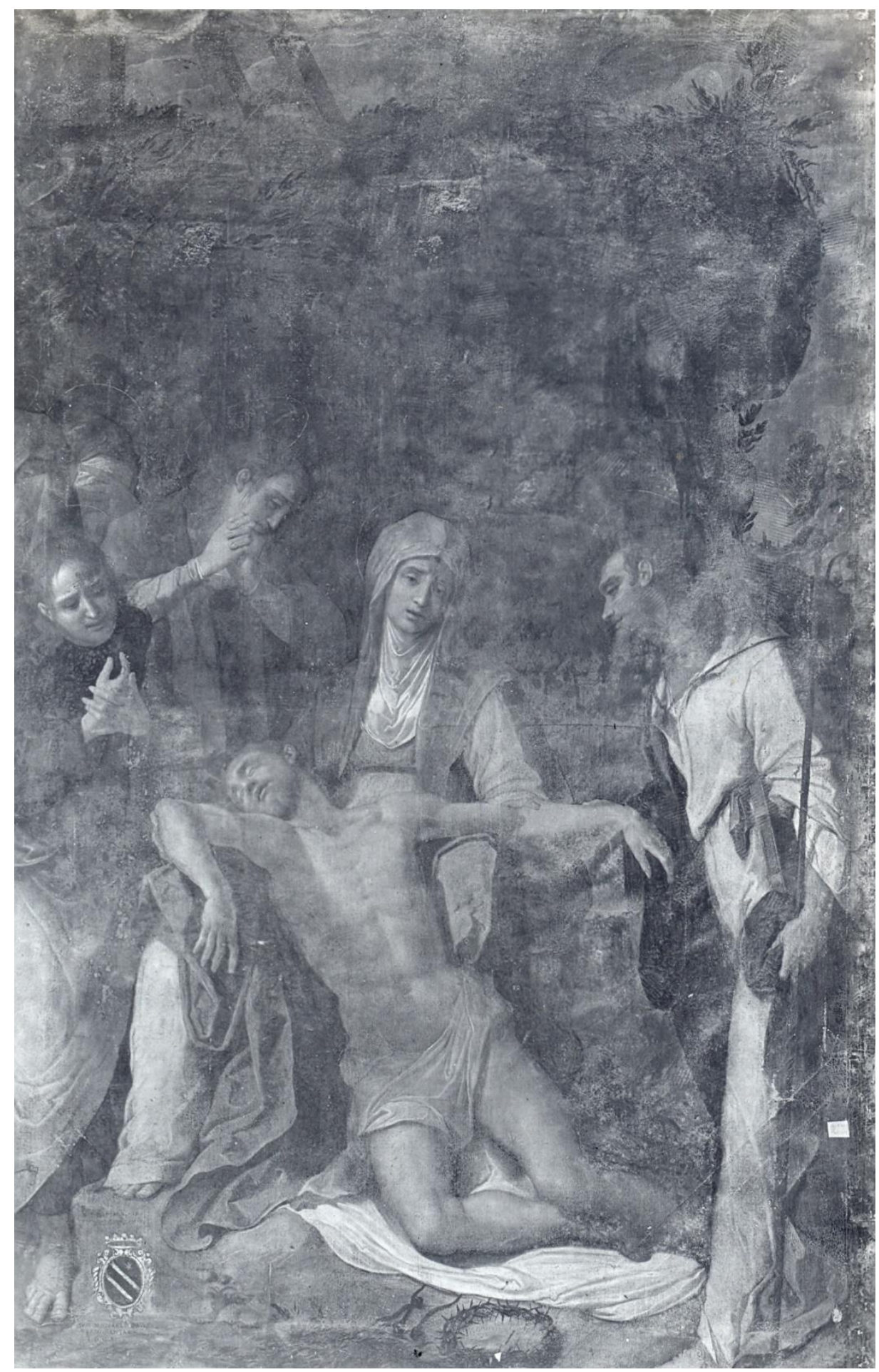

Fig. 26- il dipinto prima del restauro 


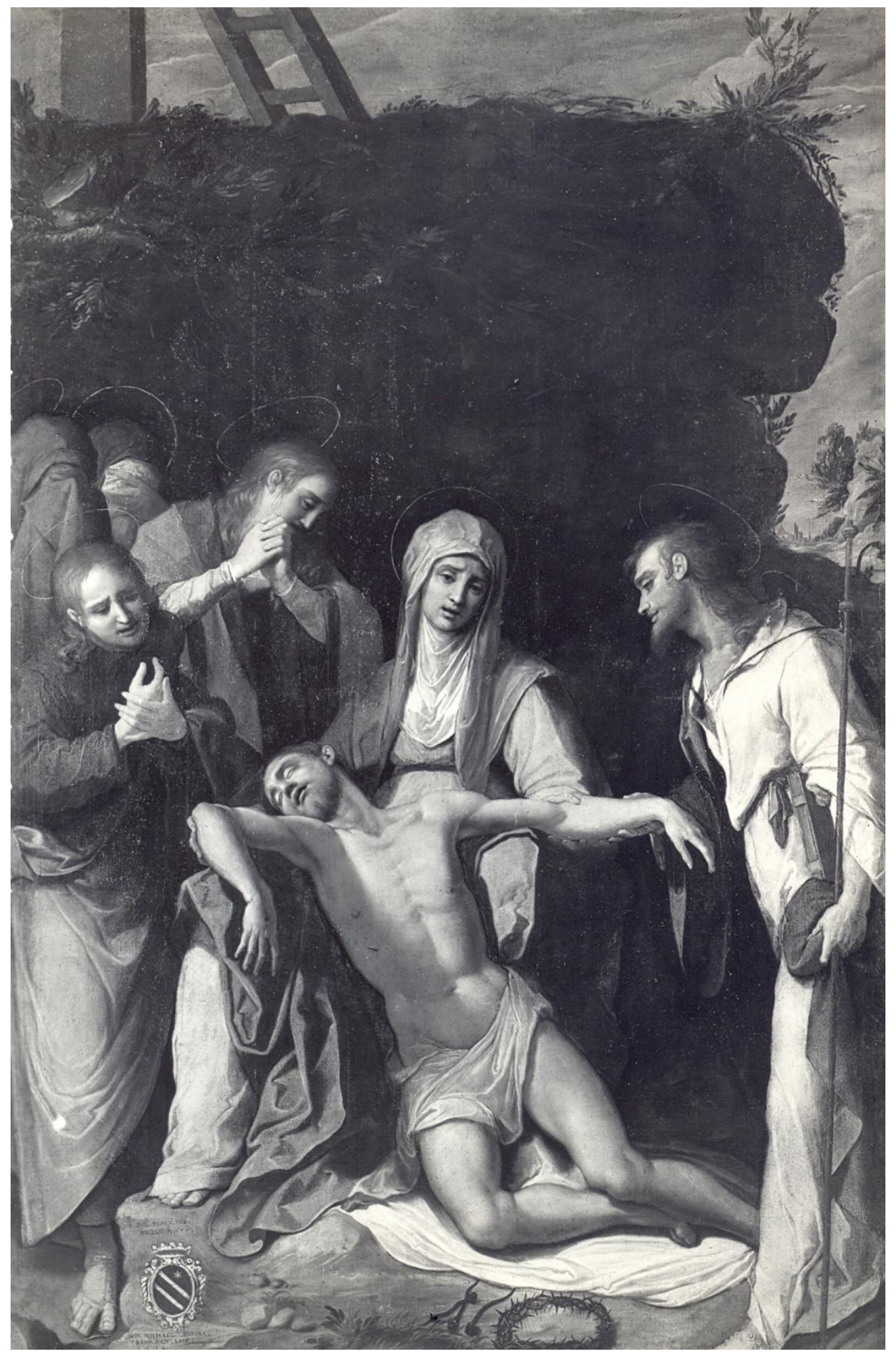

Fig. 27 - il dipinto dopo il restauro 


\section{III - II Vaticano dal 1960 al 1978}

Questo capitolo si apre con l'assunzione di Colalucci in Vaticano e continua con il racconto della sua attività nel laboratorio di restauro fino al 1978, anno in cui viene nominato capo restauratore. Attraverso la testimonianza diretta di Colalucci cercherò di "entrare" nel laboratorio Vaticano degli anni sessanta in modo da fornire una descrizione fedele di ciò che era la struttura in quegli anni. Una struttura che aveva avuto trascorsi gloriosi poiché negli anni trenta del Novecento aveva goduto di un certo prestigio grazie anche al gabinetto di ricerche scientifiche di cui era stata dotata, ma che poi, dopo la fondazione dell'Istituto Centrale del Restauro, era rapidamente invecchiata. L'Istituto entra nel mondo della conservazione con la duplice funzione di sviluppo e divulgazione, e già nel 1939, dunque molto prima della teoria di Brandi, fa apparire vecchio e superato tutto ciò che esiste nel campo del restauro. Le logiche chiuse ed autoreferenziate ed $i$ "segreti di bottega" che avevano distinto fino ad allora l'operato dei laboratori di restauro, sembrano improvvisamente appartenere ad un altro secolo. Quando nel cinquantanove il dottor Deoclecio Redig de Campos, direttore del Reparto di Arte Bizantina, Medievale e Moderna dei Musei Vaticani, decide di assumere un restauratore diplomato all'Istituto lo fa con l'intento preciso di portare nel laboratorio vaticano quel rinnovamento che mancava da troppi anni, un rinnovamento basato sull'acquisizione di una mentalità diversa oltre che sui metodi e sulle tecnologie. Nel 1960 il Pontefice è Giovanni XXIII ${ }^{\circ}$ al quale nel 1963 succederà Paolo VI che porterà nella Chiesa cambiamenti e modernizzazioni. Nel 1978, a Paolo $\mathrm{VI}^{\circ}$ succederà Giovanni Paolo ${ }^{\circ}$ che morirà un mese dopo ed al quale succederà Giovanni Paolo $\|^{\circ}$. Come vedremo Colalucci avrà qualche difficoltà ad inserirsi nell'ambiente del laboratorio anche se alla fine la sua mentalità ed i suoi metodi saranno adottati ed apprezzati da tutti gli altri restauratori. Si dedicherà a molti lavori e all'aggiornamento del laboratorio, e sarà testimone di momenti piacevoli ma anche difficili come quello legato alla vicenda della seconda loggia di Raffaello. Nel 1978 viene nominato capo restauratore da Carlo Pietrangeli, che sostituisce de Campos, andato in pensione, nella carica di Direttore Generale. La nomina di Colalucci a capo restauratore appare il logico riconoscimento al consolidamento della sua esperienza ed alla crescita della sua autorevolezza dentro e fuori dal Vaticano. 


\section{Il Laboratorio di restauro dei Musei Vaticani}

II colloquio preliminare per l'assunzione di Colalucci al laboratorio di restauro dei Musei Vaticani si svolge nel mese di ottobre 1959. Qualche tempo prima il direttore del reparto di arte bizantina medievale e moderna dei Musei dott. Deoclecio Redig de Campos, che era anche guardia nobile del Papa ${ }^{51}$, incontra in una cerimonia in Vaticano il Prof. Michelangelo Cagiano de Azevedo archeologo, anche lui guardia nobile e direttore dei corsi all'I.C.R.. de Campos vuole rimpiazzare un paio di restauratori anziani andati in pensione e al tempo stesso aggiornare le metodiche del laboratorio Vaticano e perciò chiede a Cagiano de Azevedo il nome di un bravo restauratore formato all'Istituto "...un restauratore abbastanza giovane ma con esperienza sufficiente per poter restaurare Raffaello". Cagiano de Azevedo gli indica Colalucci.

In una notte Colalucci prepara la documentazione da presentare la mattina successiva a de Campos. II colloquio va bene ma passerà un anno prima che Colalucci venga chiamato per prendere servizio ( ottobre 1960).

Al momento dell'assunzione di Colalucci, i Musei Vaticani erano retti dall'archeologo Filippo Magi che faceva la funzione di Direttore Generale, posto vacante dopo la morte dell'archeologo prof. Bartolomeo Nogara.

Il laboratorio di restauro dei Musei Vaticani fu costituito nel 1925 e, secondo l'abitudine del tempo, la gestione tecnica era affidata agli artisti. Basti pensare 
che perfino i custodi del Museo erano selezionati fra quelli che venivano definiti "artisti sfortunati". La sede attuale del laboratorio risale al 1932 e fu costruita contemporaneamente alla nuova Pinacoteca, che è quella tuttora esistente. L'organizzazione dei Musei era di tipo verticistico con un Direttore Generale al quale facevano capo il Direttore Artistico per le Pitture che era un artista, e un Direttore Artistico per le Sculture che era un archeologo. I Laboratori di restauro, divisi in: pitture (il più numeroso ed attivo); arazzi, mosaici, marmi, metalli e terrecotte, dipendevano dal Direttore Generale che si avvaleva della collaborazione del Direttore delle Pitture ${ }^{52}$ per i reparti di Pittura, arazzi e mosaici, il quale a sua volta si avvaleva dell'Assistente Tecnico (oggi capo restauratore), per il Laboratorio Restauro pitture. Questa figura tecnicoburocratica, che era sempre un restauratore di dipinti, aveva la responsabilità tecnica e disciplinare del Laboratorio Pitture. A capo degli altri settori vi erano i restauratori anziani. E poi c'era la figura simbolica del decano.

Nell'Archivio dei Musei è conservato un quaderno nel quale si trova un appunto scritto a mano dal pittore Biagio Biagetti, Direttore Artistico per le Pitture dagli anni Venti agli anni quaranta, in cui si legge "...io non ho bisogno diartisti ho bisogno di operai.." II che ci fa capire come l'errato concetto secondo il quale con una buona direzione il restauro possa essere eseguito da semplici maestranze ha radici lontane. Anche la tradizione e la legislazione sulla conservazione e la gestione delle opere in Vaticano hanno radici lontane 
che risalgono a quando lo Stato Pontificio si estendeva verso nord, oltre il centro Italia. I Musei attuali infatti conservano quelle che al tempo dello Stato Pontificio costituivano le collezioni Papali e un certo numero di opere sparse sul territorio di proprietà della Chiesa. Ricordiamo che ad occuparsi di queste opere nell'800 vi fu l'autorevole figura di Antonio Canova. Nel 1970, con la caduta di Roma e il completamento dell'unità d'Italia lo Stato Pontificio, perduti tutti i suoi possedimenti territoriali, cessa di esistere e il Papa Pio IX si chiude nei Palazzi Apostolici. Solo nel 1929, con la firma dei patti Lateranenzi, si costituisce lo Stato della Città del Vaticano, stato sovrano a tutti gli effetti. A quel punto il piccolo Stato si da una struttura e nasce la Direzione Generale dei Monumenti, Musei, e Gallerie Pontificie che da pochissimo tempo ha cambiato nome nel più familiare Musei Vaticani. Prima che il Vaticano diventasse uno stato con confini precisi, le strade di Roma portavano anche al cortile di San Damaso, oggi destinato esclusivamente all'arrivo dei Capi di Stato e Ambasciatori, per cui alla vecchia pinacoteca si accedeva da quel cortile il cui portone, tuttora sormontato dalla grande scritta Pinacoteca, era ubicato sotto la Loggia di Bramante e Raffaello.

In seguito alla ristrutturazione interna, nel 1932 fu costruita la nuova Pinacoteca alla quale si accedeva in origine da un solo portone aperto nelle mura dalla parte della loggia di Innocenzo VIII․

Nei nuovi localo troveranno la loro sede i Laboratori di Restauro e anche il 
Gabinetto Ricerche Scientifiche istituito proprio nel 1932 e dotato di apparecchi radiografici, raggi ultravioletti, luci ai vapori di sodio, e di tutte quelle altre attrezzature, per l'epoca modernissime e di avanguardia nel campo del restauro, soprattutto in rapporto a ciò che avveniva altrove.

Nel laboratorio Colalucci trova come assistente tecnico Francesco Bencivenga, buon pittore e decoratore esperto che si preoccupa più della disciplina che del restauro che lascia alla competenza dei suoi restauratori. Nessuno dei restauratori ha avuto una formazione specifica nel settore, ma provengono da scuole artistiche, sono cioè pittori o decoratori. Va detto che la forte presenza dei decoratori era determinata dalla necessità di dover intervenire frequentemente sugli apparati decorativi dei palazzi Pontifici che, quando danneggiati, dovevano essere ripristinati con le stesse tecniche e se possibile con la stessa abilità. Colalucci oggi riconosce che, pur nei limiti della situazione, quegli abili decoratori, nel restauro avevano acquisito un concetto "relativamente evoluto", che li aveva spinti a porsi il problema della riconoscibilità delle reintegrazioni e dei rifacimenti.

I restauratori che trova in laboratorio sono ancora quelli chiamati da Biagetti: Luigi Brandi, Igino Cupelloni, Francesco Mander, Gugliemo Mizzoni. Poi trova dei giovani che in alcuni casi avevano una formazione di "bottega" oppure nessuna formazione, e che erano stati assunti nel laboratorio grazie all'interessamento di qualche parente che lavorava in Vaticano. Questi giovani 
si chiamavano Giuseppe Segoni, Maurizio Rossi, Piergiorgio Bonetti, Maurizio Parodi, Biagio Cascone, Giovanni Grossi e Orazi. Come si intuisce, Colalucci si trova davanti un mondo abbastanza chiuso e fortemente autoreferenziato. Un mondo molto distante da quello che aveva conosciuto fino ad allora.

Queste persone praticavano il restauro secondo metodi appresi dai colleghi più anziani (i così detti vecchi), senza stimoli provenienti dall'esterno, ma preoccupati di riuscire ad inventare qualche cosa di nuovo che li mettesse in luce nell'ambito interno del Vaticano. Lo stesso Colalucci agli inizi fu molto criticato perché "non aveva inventato niente".

Appare più che motivata dunque l'esigenza di de Campos di portare, attraverso un restauratore formato all'Istituto, non solo le nuove tecnologie in uso nel mondo della conservazione, ma anche la mentalità Brandiana basata come sappiamo sul principio di riconoscibilità e di reversibilità. Chiedo a Colalucci :

D: tu vieni assunto in Vaticano per rinnovare il modus operandi del laboratorio e per introdurre il concetto brandiano. Pochi sanno che fino al tuo arrivo i restauratori vaticani, per quanto abili nel loro lavoro, operavano ancora secondo il concetto ottocentesco del restauro cioè si ponevano solo, e non sempre, il problema della riconoscibilità degli interventi. Viceversa come sappiamo il moderno restauro si basa sul duplice concetto di reversibilità e riconoscibilità. Sembra una differenza di poco conto ma in questo abbinamento sta il segreto della rivoluzione brandiana. Come sono stati accolti all'inizio i cambiamenti portati dal tuo modo di lavorare ?

R. "Chiarisco subito che sono stato assunto al laboratorio non per insegnare ma per lavorare secondo i criteri brandiani. Ho portato con me la mia formazione teorica e la tecnologia della quale disponevo che era quella dell' ICR . II laboratorio aveva un suo modo di lavorare che evidentemente il direttore de Campos giudicava invecchiato e dunque sperava che attraverso un ricambio generazionale ci potesse essere anche un rinnovamento delle tecnologie" 
D. Tuttavia il ricambio generazionale auspicato da de Campos si fermerà a te poiché $\mathrm{i}$ restauratori che verranno assunti dopo non avranno alcuna formazione specifica. Mi pare che bisognerà aspettare molti anni e precisamente fino alla direzione di Pietrangeli per avere finalmente restauratori diplomati all'ICR, o sbaglio ?

R. "No non sbagli. Devo dire però che il ricambio generazionale iniziato con me ebbe un seguito con l'assunzione di Sergio Pigazzini un'altro restauratore diplomato all'ICR, che purtroppo dopo circa un anno si dimise per ragioni personali. Dopo questo tentativo di rinnovamento qualitativo, il laboratorio si popolerà di nuove persone provenienti da altre amministrazioni del vaticano $o$ dall'esterno per motivi di parentela: figli o nipoti di dipendenti vaticani che potevano garantire le qualità morali del nuovo assunto, e quindi di persone ancora una volta prive di formazione specifica, destinate, quindi, ad imparare il mestiere sul campo, facendo gli aiutanti dei "vecchi".

D. La nobile iniziativa di de Campos perciò si esaurisce quasi subito?

R. "Si, soffocata dalle logiche amministrative e, come ho detto, da quella sorta di piccolo nepotismo che, se pure per presunte ragioni di sicurezza, in Vaticano ancora sopravviveva".

D. Come avveniva la formazione all'interno del laboratorio ?

R. Non era previsto "l'apprendistato" né retribuito né non retribuito, per cui $i$ giovani (tutti erano stipendiati), potevano imparare soltanto attraverso il servizio di manovalanza che prestavano ai restauratori più anziani. Lentamente, attraverso gli anni, passavano dalle mansioni più semplici a quelle un poco più complesse nelle quali potevano raggiungere anche punte di eccellenza, ma l'aspetto negativo di quella prassi era rappresentato dal fatto che, con l'andare degli anni, questi restauratori acquisivano anzianità di servizio senza mai completare la loro formazione, poiché finivano per essere impiegati nelle mansioni che meglio sapevano svolgere. Non è un paradosso dire che erano restauratori che vivevano la loro vita professionale sapendo fare benissimo un certo numero di operazioni ed ignorando completamente molte altre".

D. Senza contare la totale assenza della conoscenza teorica.

R. "Infatti, di quella non se ne parlava assolutamente". 


\section{Il rapporto con gli altri restauratori del Laboratorio}

Colalucci viene assunto come specialista del restauro dei dipinti su tavola e grazie al diploma dell'ICR, viene inserito al livello di "restauratore di prima classe", ovvero il grado che avevano raggiunto i colleghi più vecchi, in molti anni di lavoro, e che era subito al disotto dell'assistente tecnico. La cosa ovviamente viene presa malissimo e gli scatenano contro le antipatie di tutti gli altri restauratori del laboratorio. L'insofferenza dei colleghi è aggravata dal fatto che gli viene anche data la facoltà di prendere iniziative personali riferendone direttamente al dottor de Campos. I restauratori più anziani giudicano ingiusto essere equiparati ad un giovane, che per di più è guardato con sospetto poiché ha un modo di lavorare a loro del tutto estraneo. I colleghi più giovani si sentono invece scavalcati perché hanno molti anni di servizio alle spalle ed ora sono ad un livello più basso di quello del nuovo collega appena entrato.

Colalucci comunque trascorre i primi anni in laboratorio stando abbastanza isolato poiché quasi tutti gli altri restauratori lavoravano spesso in cantieri di affreschi, mentre lui lavora su tele e tavole. L'unico momento di contatto con i colleghi (in tutto poco più di una decina), era rappresentato dalla riunione che si teneva ogni mattina prima dell'inizio dei lavori, poi tutti gli altri si recavano sui vari cantieri mentre lui rimaneva in laboratorio.

II $1^{\circ}$ ottobre 1960 è il suo primo giorno di lavoro e viene messo subito alla prova con uno di quei restauri che richiedono molta abilità ed esperienza: il trasporto di colore da legno a tela del dipinti di forma ottagonale di Francesco Menzocchi (Forlì, 1502-74), raffigurante "La traslazione della Santa casa di Loreto". Quindici 
giorni dopo gli vengono affidati altri due dipinti su tela di scuola italiana del sec. XVI raffiguranti, uno "San Francesco", ${ }^{53}$ e l'altro "San Domenico" xe poi un' altra tela del sec. XVII raffigurante "San Giovanni Battista". Venti giorni dopo inizia il restauro di una grande tavola $(236 \times 149)$ di scuola di Giorgio Vasari, ed in seguito la tempera su tavola di scuola romana del sec. XII raffigurante un "Cristo Benedicente,54. Tutti lavori che Colalucci portava avanti contemporaneamente, con grande impegno e solerzia e che avevano avuto un buon esito e il plauso del Direttore, ma anche l'ostilità nascosta di un ambiente scosso dal suo torpore e timoroso delle novità.

Alcuni restauratori del laboratorio Vaticano cercarono di reagire tentando di espellere il corpo estraneo prima che fosse troppo tardi e quindi alla disperata si adoperarono per mettere Colalucci in cattiva luce con de Campos, presso il quale, invece, acquistava sempre più stima. Nell'aprile del 1961 costoro, approfittando delle difficoltà presentate dalla foderatura della grande tela (269x172) del Guercino ${ }^{55}$ raffigurante "Santa Margherita da Cortona", tentarono di far credere al Direttore de Campos che durante la foderatura Colalucci avesse causato dei gravi danni al dipinto. Dato che la mestica adoperata dal Guercino è molto ruvida e granulosa, questi colleghi cercarono di far credere a de Campos che quella superficie così scabra fosse il risultato di una stiratura troppo calda. Fortunatamente il tentativo naufragò quando, avvertito da Maurizio Rossi di quello che stava accadendo a sua insaputa, Colalucci chiese

\footnotetext{
${ }_{53}$ Olio su tela di scuola italiana raffigurante S. Francesco inv.2145 prot.4007- cfr F. Mancinelli in Arte Medioevale e Moderna, estratto dal Bollettino I,1- anni 1959-1974, pag. 143. 
al direttore di andare a vedere un'altra tela del Guercino esposta in Pinacoteca accanto a quella di "Santa Margherita da Cortona", e che, mai restaurata, presentava la stessa identica caratteristica preparazione. De Campos si convinse subito che il dipinto in questione non era stato danneggiato, e molto diplomaticamente disse a Colalucci: "Può dire a quelle persone che si sono sbagliate".

Tra le numerose opere restaurate da Colalucci in quegli anni vi sono moltissimi dipinti su tavola come la "Madonna col Bambino" di Cima da Conegliano, la "Vergine col Bambino" di Bernardino Daddi, il "San Pietro in Cattedra" e la "Resurrezione del figlio di Teofilo" di Jacopo di Cione, il "San Francesco" di Margaritone D'Arezzo, la "Madonna in trono" di Pietro Lorenzetti, quattro tavole con le storie di San Nicola da Bari di Gentile da Fabriano, "Madonna col Bambino" di p. del Casentino, II "Gesù Nazareno" ed il "Bacio di Giuda" di Antonio Vivarini ${ }^{56}$, "il Torchio Mistico" di Marco Pino, il "San Giorgio che uccide il drago" di Paris Bordone, "Io Sposalizio Mistico di Santa Caterina" del Garofalo, "il Redentore" di Bernardino Luini ${ }^{57}$. Restaura dipinti su tela come la "Fortuna trattenuta da Amore" di Guido Reni, quattro tele della serie delle "vedute astronomiche" di Donato Creti, "il martirio di San Pietro d' Arbuez" di Murrillo ${ }^{58}$. Si dedica anche al restauro di una importante scultura policroma come il "Crocefisso di San Paolo" detto del Cavallini e a quello di un frammento

\footnotetext{
${ }^{56}$ Tempere su tavola :C. da Conegliano, prot.4068 - B. Daddi, inv. 180, prot. 4085 - Jacopo di Cione inv. 107 prot. 74 e inv, 113 prot. 75 - Margaritone, inv, 2 prot. 79 - Lorenzetti, inv.170 prot.147 - G. da Fabbriano, inv.247 prot.468, inv.248 prot.468, inv.248 prot.469, inv.249 prot.470, inv.250 prot.470 - A. Vivarini , inv.525 e 525 b prot.150. op. cit. pp. $147 / 166$. 159. 
di affresco staccato della prima metà del sec. XII ${ }^{\circ}$ raffigurante il profeta "Mosè" ed a moltissime altre ${ }^{59}$ opere.

Durante quegli anni oltre a dedicarsi al restauro inizia a raccogliere documentazioni, a studiare i trattati e imposta il lavoro di controllo dello stato di conservazione di tutti i dipinti della Pinacoteca. Disegna le schede di rilevamento dati che poi furono stampate e che sono in uso ancora oggi. Costruisce un grande pannello sul quale riporta la pianta della Pinacoteca con tutti i dipinti; sotto ogni dipinto pone una casella che poteva contenere dei colori che variavano a seconda dello stato di conservazione dell'opera ( un po' come si usa oggi per le emergenze sanitarie) il colore verde distingueva i dipinti in buone condizioni, poi c'erano dei colori intermedi per i dipinti in condizioni variabili, mentre il rosso indicava l'urgenza del restauro. In questo modo, facendo il monitoraggio una volta l'anno (o più frequentemente per le opere contrassegnate dal codice rosso), si aveva sempre presente l'effettivo stato dei dipinti e il variare o l'evolversi degli eventuali problemi. Anche in questo frangente la sua formazione brandiana si impone prepotentemente, difatti mentre il capo restauratore, che nel frattempo era cambiato ed al posto di Bencivenga era stato nominato Luigi Brandi, sceglieva le opere da restaurare in base all'importanza del nome dell'autore ( prescindendo dalla reale urgenza di intervento), lui metteva in restauro esclusivamente le opere che ne avevano bisogno. Ad un certo punto, soffrendo di quello stato di chiusura mentale e di ripiegamento su se stessi in cui operavano i restauratori vaticani, presenta a de Campos un progetto di corsi di aggiornamento da tenersi all'interno dello stesso laboratorio allo scopo di dare 
uno stimolo all'ambiente e di far trovare un'atmosfera più vivace e impegnata ai giovani assunti i quali altrimenti avrebbero rischiato di diventare vecchi senza aver mai completato la loro preparazione, consapevole dei limiti e delle lacune che si nascondevano dietro un'esperienza maturata esclusivamente sul campo. Coinvolge i colleghi e ottiene di tenere le lezioni nella sala delle conferenze del museo Paolino. Luigi Brandi e Igino Cupelloni tengono un corso sulla pittura in affresco, Nazzareno Gabrielli un corso di chimica e Colalucci una serie di lezioni sul restauro dei dipinti su tavola. Vengono stampate le dispense di ogni corso di lezioni.

Oltre al controllo dello stato di conservazione delle opere della pinacoteca, prende l'iniziativa di effettuare un sondaggio presso alcuni musei stranieri a proposito dei sistemi di condizionamento delle sale espositive. Prepara uno schema di domande alle quali, i musei interpellati erano pregati, se volevano, di dare delle risposte. Le schede con le domande erano accompagnate da una lettera del direttore de Campos. Purtroppo le risposte non furono molte, probabilmente per la complessità del problema che veniva posto, basti pensare che per la Pinacoteca il tema del condizionamento delle sale di esposizione è ancora oggi aperto e non risolto. Durante quegli anni si aggiorna continuamente sull'evoluzione dei metodi di conservazione e sui materiali di restauro, all'interno del laboratorio è il primo restauratore che chiede e ottiene il permesso di andare ad un convegno. II convegno fu quello organizzato dall' ICOM a Venezia nel 1975, dove tra l'altro si dibatterono i problemi causati dalle foderature tradizionali e non, e dove fu presentata da Gustav Berger la BEVA 
$371^{60}$. Le aspettative del direttore de Campos vengono pertanto pienamente soddisfatte e anche se lentamente e tra mille diffidenze, il laboratorio comincia a marciare secondo i fondamenti brandiani senza però azzerare tutto quello che della tradizione poteva e doveva essere giustamente salvato. Oggi possiamo dire che forse è stata proprio la capacità di conciliare gli elementi innovativi con quelli dettati dalla tradizione, che ha portato il laboratorio di restauro dei Musei Vaticani, dalla fine degli anni settanta ad oggi, a competere e dialogare con $\mathrm{i}$ laboratori dei più prestigiosi Musei del mondo.

\section{Come vengono giudicate le innovazioni che porti in Vaticano dagli altri restauratori?}

R. "Il mio lavorare da solo non era fine a se stesso poiché era osservato dai restauratori che lavoravano sulle tele e sulle tavole. Questi, osservandomi modificano quasi subito due cose : aboliscono l'uso della "sodina" (ovvero la soda Solvaix diluita) per pulire i dipinti e l'uso dell'olio di lino per neutralizzare i solventi al posto dell'acqua ragia usata da me.

\section{Dunque iniziano a porsi il problema della reversibilità ?}

R. "Si perché pian piano si avvicinano ai miei metodi e cercano di capire come lavoro. Voglio sottolineare che tutto questo era affidato alliniziativa di ogni singolo restauratore poiché il Direttore, condizionato dai malumori provocati dall'avermi dato un livello alto e facoltà che gli altri non avevano, per non creare altri malesseri non obbliga alcuno a seguire i miei metodi di lavoro. Però i criteri ed $i$ mezzi che usavo suscitavano curiosità. L'uso

che facevo del Dimetilformammide e della Butillammina, al quel tempo solventi nuovi che davano grandi possibilità, attira l'attenzione anche del laboratorio di ricerche scientifiche. II chimico Vittorio Federici, che normalmente forniva lemetodiche e i solventi ai restauratori, prima si picca, ma poi si interessa al loro uso nella pulitura dei quadri".

D. Tu potevi usare sostanze chimiche senza la sua approvazione, come mai?

R. "Perché io, utilizzando materiali e metodiche testate dall'ICR, avevo avuto la facoltà di rispondere direttamente al Direttore di ciò che facevo e dei metodi che usavo senza passare per il Gabinetto Ricerche Scientifiche . Vittorio Federici,

\footnotetext{
${ }^{60}$ Beva come è noto è l'acronimo della composizione chimica del prodotto ( Etil-vinil-acetato ) preceduto dall'iniziale del cognome del suo scopritore : Gustav Berger
} 
però, quando si rende conto delle grandi possibilità dei nuovi solventi e delle metodiche che usavo le introduce in laboratorio come metodiche correnti."

D. Questo tuo essere tanto diverso come ti faceva vivere all'interno del laboratorio?

R. "lo avevo rapporti cordiali con tutti, ma facevo la mia vita e gestivo i miei lavori, per cui venivo considerato quasi come un restauratore autonomo al quale era riconosciuto un livello di professionalità tale da concedergli un alto grado di indipendenza e persino la facoltà di partecipare ai convegni a spese del Museo, fatto impensabile in quel contesto. Non ho mai imposto i miei metodi o la mia mentalità perché avevo fiducia dell'esempio dei buoni risultati. $E$ avevo ragione per ché alla fine sono diventato il punto di riferimento per tutto il laboratorio".

Voglio dire, per amore di verità, che io non mi sentivo il portatore di un "verbo" $e$ quindi ero aperto a tutte le esperienze fatte da altri e specialmente ai metodi del passato o a metodi diversi che potevano risultare interessanti. Li avrei potuto metabolizzare e, fatti rientrare nei miei principi di restauro, utilizzarli al momento opportuno.

D. Torniamo al modo di lavorare del laboratorio. Tu ad un certo punto istituisci $\mathbf{i}$ codici di urgenza per le opere da restaurare. Cosa ti spinge a farlo?

R. "Mi spinge il fatto che ad un certo punto mi rendo conto che mentre io facevo $i$ restauri necessari, il vecchio capo Luigi Brandi si dedicavaesclusivamente ai restauri delle opere più importanti. Tra l'altro nonostante io avessi introdotto il tratteggio, lui continuava ad evidenziare le reintegrazioni con un metodo ormai superato cioè segnando le lacune lungo i bordi esterni. Mi metteva in allarme anche il fatto che, poiché temeva il mio giudizio, quasi sempre iniziasse i lavori su opere importantissime quando io ero in vacanza."

\section{Raccontamene uno}

R. "Posso raccontare per esempio il caso della Trasfigurazione di Raffaello. Io ero in vacanza e dunque non so esattamente perché fu messa in restauro. So comunque che i problemi della tavola erano rappresentati dalla presenza di alcuni sollevamenti di colore lungo le giunture verticali delle assi in ciliegio che compongono il supporto. Viene deciso di fare un intervento sul supporto e il Direttore chiama l'ingegnere aeronautico che aveva realizzato la parchettatura per l'ICR sulla Maestà di Duccio di Buoninsegna."

D. Tu avevi già iniziato a porti il problema delle parchettature ?

R. "No inizio proprio con questa della Trasfigurazione. Notavo i lati positivi ma 
anche alcuni aspetti molto svantaggiosi. Mi sembrava un'ottima cosa il telaio metallico su cui poggia il dipinto, il sistema che la sorregge in modo che le traverse in acciaio non pesino sul legno della tavola e mi sembrava buono l'uso del TEFLON per rendere scorrevoli le traverse. I lati negativi erano rappresentati dalla rigidità delle traverse che mi appariva come un sistema molto invecchiato mentre io ero già incuriosito dai sistemi che lasciavano i supporti più liberi di muoversi.

D. C'è una innovazione in questa parchettatura ?

R. "No, nessuna innovazione, c'è solo il trasferimento di una tecnologia (barre rigide di acciaio) in una scala più ampia. La parchettatura è eseguita ancora secondo il sistema che costringe i supporti in strutture rigide."

\section{E le ricerche di Roberto Carità ?}

R. "Oggi quelle ricerche sono valorizzate ma a suo tempo le cose che ha fatto sono rimaste dei prototipi."

D. La tavola aveva anche problemi di imbarcamento ?

$\boldsymbol{R}$. "No, per questo ritengo che la parchettatura tutto sommato abbia retto bene negli anni. Bisogna anche considerare che sotto la gestione di Pietrangeli, in occasione della parziale ristrutturazione voluta da Fabrizio Mancinelli, la sala, detta appunto della Trasfigurazione, è stata climatizzata e dunque il dipinto non ha più subito stress termoigrometrici".

\section{La Sala Clementina}

Con il Papa Paolo $\mathrm{VI}^{\circ}$, come sempre accade, vi è un riordino dei concetti amministrativi in Vaticano, e con l'aumentare del costo dei dipendenti le Amministrazioni tendono ad avvalersi di imprese esterne per svolgere lavori ben definiti e limitati nel tempo. II restauro delle opere d'arte è considerato un settore 
dove il controllo dei costi può essere fatto agevolmente con l'assegnazione dei vari lavori a imprese di restauro. Per questo motivo all'inizio degli anni settanta il Laboratorio di Restauro dei Musei rischia lo smantellamento e la chiusura poiché considerato troppo costoso per il troppo personale improduttivo e per giunta "covo di sovversivi" (sic!). In quegli anni il Vaticano si trova nella necessità di provvedere al restauro della sala Clementina ${ }^{61}$. Gli imponenti lavori di consolidamento della struttura muraria, avevano imposto lo strappo di molti affreschi delle pareti dipinti da Cherubino Alberti, che erano poi stati restaurati e ricollocati al loro posto. II Vaticano decide pertanto di eseguire il restauro della volta della sala a completamento della campagna già iniziata. La Direzione Generale, in linea con la nuova politica amministrativa e memore dell'esperienza negativa che anni prima aveva caratterizzato il lavoro su alcuni affreschi della sala Regia (durato senza alcuna giustificazione ben sette anni), pone i restauratori del laboratorio di fronte a un vero e proprio ultimatum perché il lavoro sulla volta della Clementina deve concludersi nell'arco di nove mesi, dal gennaio a settembre 1976, pena la chiusura del Laboratorio di restauro pitture. Da quel momento in poi i lavori sarebbero stati affidati esclusivamente a ditte esterne.

I restauratori posti di fronte alle loro responsabilità ed al rischio di perdere il posto di lavoro, dopo consultazioni e discussioni interne, decidono all'unanimità di impegnarsi a eseguire il lavoro nei tempi stabiliti.

${ }^{61}$ Sul restauro della Clementina cfr F. Mancinelli e G. Colalucci in "Apoteosi di san Clemente di Giovanni e Cherubino Alberti -Bollettino dei Monumenti Muse e Gallerie Pontificie n IV- 1983 
Tutti vi partecipano, quindi anche Colalucci (anche se non aveva partecipato al restauro della Sala Regia), che per l'occasione entra in più stretto contatto con i suoi colleghi. Egli tuttavia, pur impegnandosi a fondo nel lavoro della sala Clementina, era rimasto abbastanza indifferente alle decisioni della Direzione a proposito del minacciato smantellamento del Laboratorio poiché parallelamente al lavoro del Vaticano (che adottava l'orario statale 8-14), nel pomeriggio continuava a svolgere la sua attività per le soprintendenze italiane, dato che per I'Italia il Vaticano è uno stato estero a tutti gli effetti e amministrativamente e fiscalmente il lavoro svolto in quella sede equivale a lavoro svolto all'estero. II Vaticano, a sua volta, non si opponeva a che qualche restauratore, oltre l'orario di servizio, facesse lavori all'esterno purché le due attività non confliggessero.

Dopo questo episodio, e fino all'inizio del restauro della Sistina, l'attività e la vita del laboratorio vaticano si svolgeranno secondo una normale routine, con una sola "spiacevole" parentesi collocabile alla fine degli anni Settanta, ovvero il problema del restauro degli affreschi di Raffaello della Seconda Loggia.

La vicenda, molto grave, sarebbe potuta restare negli archivi del Laboratorio di restauro dei Musei Vaticani senza interessare questa Tesi Dottorale se Colalucci fosse state estraneo ai fatti. Invece egli ebbe una parte molto importante nell'individuare le gravi controindicazioni di una nuova metodica di consolidamento dei dipinti murali introdotta al laboratorio dal chimico Federici, e nell'evitare che un pur grave problema divenisse una catastrofe. Parliamo della tecnica dell'alluminato di potassio usata nel restauro delle prime due campate 
della Seconda Loggia che ha procurato problemi tanto gravi da indurre la Direzione Generale dei Musei a istituire la figura del "Consulente" e a redigere un protocollo di comportamento al fine di regolamentare tutte le fasi che caratterizzano lo svolgimento di un lavoro di restauro. II regolamento, tutt'oggi in vigore, anche se nato in circostanze difficili, rappresenta un validissimo modello di gestione lavorativa. Le norme stabiliscono gli obblighi e le responsabilità delle professionalità coinvolte nell'intervento di restauro, disponendo che tutte le decisioni prese coralmente nelle riunioni preliminari ${ }^{62}$ a proposito delle tecniche 0 dei materiali da impiegare, non possano essere modificate se non dopo una nuova riunione. Tutti i restauratori responsabili dei lavori sono inoltre tenuti a tenere un diario di cantiere con pagine numerate sulle quali annotare le osservazioni e le operazioni eseguite quotidianamente, e sulle quali sono tenuti ad apporre la loro firma per presa visione ogni volta che visitano il cantiere o il singolo dipinti i direttori, i chimici, il capo restauratore il consulente. II che costituisce un prezioso documento d'archivio, ed un vero e proprio "diario di bordo".

\section{La seconda Loggia di Raffaello e l'alluminato di potassio}

La vicenda che scosse il Laboratorio di restauro vaticano prese l'avvio da una idea del Gabinetto di Ricerche Scientifiche che, adoperandosi per risolvere i problemi della decoesione delle pitture murali causati dall'umidità, mise a punto 
un prodotto inorganico a base di idrossido di alluminio, elemento molto igroscopico, già esistente in campo chimico e utilizzato industrialmente in tutt'altro ambito. Per testarne l'efficaci furono eseguite prove di consolidamento su vari affreschi fra cui quelli del Battistero di San Giovanni, afflitti da costanti sbiancamenti e da problemi di decoesione dovuti alla forte presenza di umidità. Le prove eseguite dettero dei risultati relativamente incoraggianti e sulla base delle sperimentazioni (che si riveleranno insufficienti), i responsabili del laboratorio di restauro si convinsero di poter adottare l'uso dell'alluminato con una certa sistematicità autorizzandone l'utilizzo su due importanti cantieri in esecuzione in quel momento, ovvero le volte della seconda Loggia di Raffaello e la stufetta del Bibbiena. Quasi subito però la sostanza evidenzia un gravissimo inconveniente poiché in alcuni casi anziché penetrare all'interno della pellicola pittorica e dell'intonaco precipita in superficie dando luogo ad uno strato bianco, opaco ed irreversibile ai solventi abitualmente in uso. Colalucci appena si rende conto dei gravi limiti del prodotto ne sospende immediatamente l'uso e, preoccupato del grave effetto collaterale chiede al dott. Nazzareno Gabrielli, assistente del Dott. Federici, spiegazioni circa il fenomeno e indicazioni specifiche su come asportare il precipitato bianco. II fatto che Gabrielli stesso si mostri preoccupato prendendo le distanze dalle decisioni adottate dal capo restauratore Luigi Brandi e respingendo ogni responsabilità sull'abilitazione dell'uso della sostanza sugli affreschi, lo lasciano tutt'altro che sereno. Inoltre apprende che il grosso punto 
irrisolto dell'alluminato consisteva proprio nella possibilità che, anziché penetrare in profondità, potesse formare in superficie un precipitato bianco a base di allumina rimuovibile esclusivamente con acido cloridrico. A quel punto risolve rapidamente il problema nelle parti trattate della stufetta del Bibbiena con grande preoccupazione ed estrema cautela. Capisce che l'alluminato, valido per alcuni versi, non è utilizzabile e chiude definitivamente con questo prodotto. Capisce inoltre che alla base dell'accaduto vi era la scarsissima comunicazione tra il laboratorio di restauro e la Direzione aggravata dall'abitudine dei restauratori vaticani di non rendere conto del loro operato tecnico. Contemporaneamente l'alluminato veniva usato sugli affreschi delle volticelle delle prime due campate della seconda loggia di Raffaello. Colalucci si informa circa le procedure che stavano adottando i restauratori impegnati nel restauro della loggia, e, come temeva, apprende che come prassi essi applicavano l'alluminato, e poiché quasi sempre si formava il precipitato a causa della impermeabilità della superficie dipinta, questo sbiancamento veniva rimosso con l'acido cloridrico, senza farsi molti problemi, perché in buona fede credevano nei vantaggi del prodotto, ma, non possedendo le necessarie conoscenze chimiche, non potevano capire la pericolosità di quello che facevano. Colalucci capisce di dover fermare l'uso dell'alluminato anche a costo di mettersi contro tutti, perché il responsabile dei lavori della loggia, il dott. Fabrizio Mancinelli, storico d'arte, molto giovane ed inesperto e da poco assunto ai Musei, dava per buona la metodica che gli era stata presentata come innovativa ed efficace. 
Conscio della gravità della situazione fa presente a Mancinelli i rischi e l'improponibilità di una metodica che prevedeva come prassi l'uso dell'acido cloridrico sulle pitture murali63. Mancinelli, capito pienamente il problema, impone ai restauratori di abbandonare l'uso dell'acido ed implicitamente l'uso dell'alluminato. A seguito di questa decisione, la seconda campata della loggia, con le scene del paradiso terrestre, trattata con il solo alluminato si presentava in gran parte deturpata dal precipitato bianco, mentre la prima campata trattata con l'acido non presentava più gli sbiancamenti.

In quel momento si vengono a creare delle forti tensioni interne poiché i restauratori responsabili delle logge continuavano ad apprezzare le doti dell'alluminato, sottovalutandone gli effetti collaterali, e per questo opponevano resistenza alla decisione della Direzione dei lavori, convinti di poter risolvere il problema degli sbiancamenti senza ricorrere all'uso dell'acido cloridrico. Si continuava perciò ad usare l'alluminato sulle zone sbiancate ingannati dal fatto che al momento dell'applicazione l'affresco, anche se per poco tempo, tornava ad essere leggibile grazie al fatto che lo strato bianco bagnandosi diveniva trasparente. Subito dopo però si aveva un nuovo precipitato e la pellicola bianca aumentava di spessore.

Più tardi, scoppiato il problema delle Logge, vedremo che i responsabili del G.R.S. declineranno ogni responsabilità facendole ricadere sui restauratori.

Nello stesso periodo, poco prima del problema delle Logge, i sostenitori di questa metodica avevano pensato di intervenire sul Giudizio Universale di 
Michelangelo con la speranza di risolvere il problema della pulitura, che era ritenuta quasi impossibile perché il grande dipinto era da sempre considerato eseguito quasi completamente a secco. Si pensava, infatti, di consolidare con l'idrossido di alluminio tutta la pellicola pittorica per poi pulirla con i metodi usuali.

Come si vede, tra i restauratori del Laboratorio ormai si era creata una pericolosa atmosfera di euforia attorno alla scoperta di questo prodotto che sembrava destinato ad essere usato su tutti i dipinti murali come una panacea per ogni male. Per di più l'alluminato alzava di tono tutti i colori con un effetto illusorio perché a causa della igroscopicità del potassio questi si esaltavano nelle giornate umide e si abbassavano nelle giornate di aria secca. Ma il fenomeno si è capito più tardi, quando ormai l'alluminato era stato bandito da tempo.

Sulla questione dell'alluminato si crea un forte contrasto tra Colalucci e quei restauratori del laboratorio che, mancando di una formazione scientifica, non erano in grado di comprendere la gravità del problema. Quando poi Colalucci, che in quel momento era alle prese con il precipitato bianco che si era formato sulla piccola volta della Stufetta del Bibbiena, ha sentore che sono imminenti le prove persino sul Giudizio, sente il dovere morale di andare direttamente dal Direttore de Campos per informarlo sui seri problemi che lui stava incontrando sull'uso dell'alluminato nella stufetta del Bibbiena. De Campos, che si aspettava 
molto dalle prove sul Giudizio, ascolta con apprensione quanto ha da dirgli Colalucci, prende atto dei fatti, lo ringrazia e decide di bloccare le prove sul Giudizio.

Però rimaneva irrisolto il problema della seconda loggia. II capo restauratore Luigi Brandi per problemi di salute ne era uscito da tempo incaricando ufficiosamente della direzione tecnica il suo vice Igino Cupelloni. II problema a quel punto esplode in tutta la sua gravità De Campos ormai è messo sull'avviso e va in seconda loggia a prendere visione del problema facendosi accompagnare da Colalucci il quale testimonia che de Campos, di fronte all'evidente biancore della volticella si sente quasi male e, sedutosi su una sedia del ponteggio, dice “..oggi con la chimica ci sono dei metodi che $i$ restauratori con formazione empirica non possono usare, poiché sarebbe come dare un bazooca in mano ad un arciere.."

Il lavoro viene immediatamente sospeso, ma nel frattempo le voci corrono, la notizia trapela e arriva alla stampa italiana.

Paese Sera, che in quel tempo era il giornale di riferimento della "intelligenzia" di sinistra, fa partire una campagna di stampa che denunciava i fatti avvenuti. Tuttavia la polemica si blocca pochi giorni dopo poiché l'attenzione dell'opinione pubblica viene polarizzata da un gravissimo fatto che scuote il mondo politico e tutta la società civile italiana e tutto il mondo: il rapimento dell'on. Aldo Moro, Presidente del Consiglio, da parte del gruppo terroristico "Brigate Rosse". 
Qualche tempo dopo sotto la direzione del nuovo Direttore Carlo Pietrangeli,

Colalucci sarà incaricato di risolvere i problemi alla seconda Loggia. A conclusione di un delicato e paziente lavoro durato circa sei mesi gli affreschi di Raffaello, sebbene parzialmente danneggiati, torneranno ad essere leggibili. Chiedo a Colalucci un parere sulla vicenda della seconda Loggia :

\section{Come è stata possibile una vicenda come quella della seconda Loggia ?}

R. "La risposta sta nella mentalità superata che era alla base della struttura del laboratorio, anche se siamo ormai agli anni settanta. C'era una convinzione di fondo che portava a questo. Ai restauratori più anziani, a prescindere dalla loro preparazione e capacità, venivano assegnati lavori importanti. Era un po' come una gestione familiare dove mancava totalmente l'abitudine a rendere conto al mondo di ciò che si faceva sulle opere del Vaticano. L'altro fattore scatenante di quella vicenda fu l'eccitazione per la scoperta dell'alluminato di potassio. Qui c'è già un problema di ignoranza scientifica perché i restauratori che avevano in mano l'opera e conoscevano il problema della metodica si sarebbero dovuti mostrare fortemente diffidenti verso una sostanza reversibile solo con acido cloridrico. Da ultimo il tipo di organizzazione del laboratorio, dove ai più anziani veniva accordata una fiducia eccessiva e molta libertà di intervento come si poteva fare ai vecchi tempi. Ma tutto stava cambiando e il Laboratorio Vaticano si è trovato a fare $i$ conti con un problema nuovissimo, che mai si sarebbe presentato se si fosse andato avanti ancora con colori, pennelli e i soliti solventi.

Purtroppo l'epilogo è stato tristissimo, per non dire altro, sul piano umano perché alcuni, come de Campos ed un bravo restauratore anziano hanno pagato di persona somatizzando quella enorme responsabilità, altri, non meno responsabili, sono riusciti a tirasi fuori dimostrando di essere a vario titolo estranei ai fatti, ed uno solo, il restauratore meno anziano è stato multato per non aver avvertito la Direzione dei Musei di quanto stava accadendo". 


\section{Con l'arrivo di Carlo Pietrangeli le cose cambiano?}

R. "Si con l'arrivo di Pietrangeli che era stato direttore dei Musei Capitolini, cambia radicalmente il peso dei Musei nel Vaticano. Pietrangeli era la persona ideale per ricoprire la carica di Direttore generale perché godeva di grande autorevolezza dentro e fuori del Vaticano.

Pietrangeli recupera il valore della funzione primaria dei Musei che era quella di Soprintendenza per la città del Vaticano e per i luoghi extraterritoriali che appartengono al Vaticano, come ad esempio le Basiliche. Infatti istituisce subito l'Ufficio per il Catalogo delle opere e censisce, anche quelle appartenenti alle nunziature apostoliche sparse in tutto il mondo".

\section{E per quanto riguarda il Laboratorio?}

R. "Pietrangeli si trova a dover gestire la scottante vicenda della seconda Loggia e nomina Pasquale Rotondi (già direttore dell'ICR) consulente per il restauro. Con lui istituisce un protocollo relativo alla conduzione dei restauri che serve ad evitare in futuro problemi di questo tipo".

D. Tra di voi c'è stata subito una buona intesa?

R. "Pietrangeli prima di arrivare in Vaticano era stato Soprintendente al Comune di Roma, perciò già mi conosceva e conosceva i miei maestri dell'l.C.R. come il Prof. Matteucci che stimava molto, dunque trovammo subito un'ottima intesa.

\section{E Fabrizio Mancinelli ?}

R. "Fabrizio era arrivato ai Musei da Milano, anche lui chiamato da de Campos. Non aveva un gran legame con l'ambiente degli storici dell'arte romani, ma era molto legato a quello estero.

Quando è arrivato a Roma non aveva esperienza di restauro, quindi se la è fatta sul campo a contatto di gomito con i restauratori. II rapporto tra me e Mancinelli si fece più stretto con il procedere dei lavori in Sistina poiché ci siamo trovati a dover fronteggiare insieme l'enorme peso di quel lavoro e di quello feroce polemica.

Da professionale questo rapporto si trasformerà in un rapporto di sincera stima reciproca e di amicizia"

D. Sotto la direzione di Pietrangeli ai Musei ed al laboratorio vengono fatte scelte di qualità. A proposito della assunzione dei nuovi restauratori, per esempio, riprende il discorso iniziato dal suo predecessore de Campos. 
R. "Si anche perché bisogna sottolineare che in quegli anni (a partire dalla fine degli anni settanta) sembrava inammissibile servirsi di restauratori che non avessero una specifica preparazione teorico pratica come quella dell'ICR".

D. Adesso come è la situazione del Laboratorio dopo Pietrangeli e dopo la gestione di altri due direttori, come Francesco Buranelli e Antonio Paolucci, tuttora in carica?

R. "La situazione è buona perché lo standard di qualità gestionale dei restauri è ancora alto come quello impostato da Pietrangeli a suo tempo, e sviluppato nei quattordici anni del restauro degli affreschi di Michelangelo della cappella Sistina Solo chi non vuole vedere non vede che quel restauro, che ha fatto fare un grande passo avanti alla gestione di tutti i restauri nel mondo per le ragioni che sappiamo, ha portato alla ribalta e ha fatto meritare rispetto e stima al Laboratorio di restauro dei Musei Vaticani. Un Laboratorio storico che però aveva bisogno, come ogni istituzione, di stare al passo con i tempi. Ritengo che l'obbiettivo sia stato raggiunto, anzi che sia stato superato poiché, per un certo tempo, era divenuto anche un punto di riferimento per molte istituzioni.

Oggi posso dire che lo standard continua ad essere alto, le attrezzature del laboratorio vengono ammodernate, anche se per questo basta avere i soldi.

L'importante è che si tenga alta la qualità professionale dei restauratori e dei direttori, poiché dopo il restauro della Sistina e per l'importanza delle opere che sono sotto la responsabilità dei Musei Vaticani, il Laboratorio è costantemente sotto l'occhio attento del mondo". 


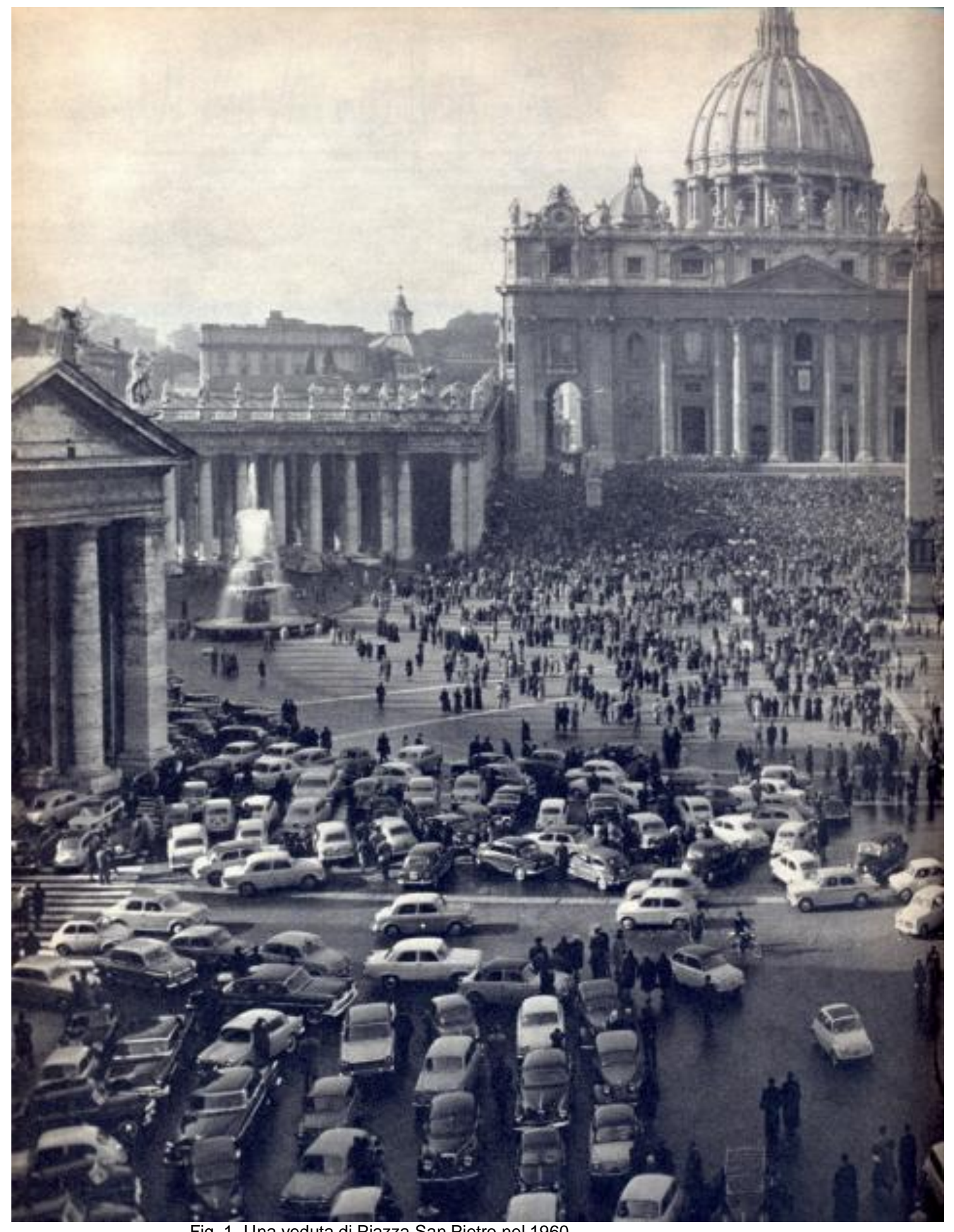

Fig. 1- Una veduta di Piazza San Pietro nel 1960 


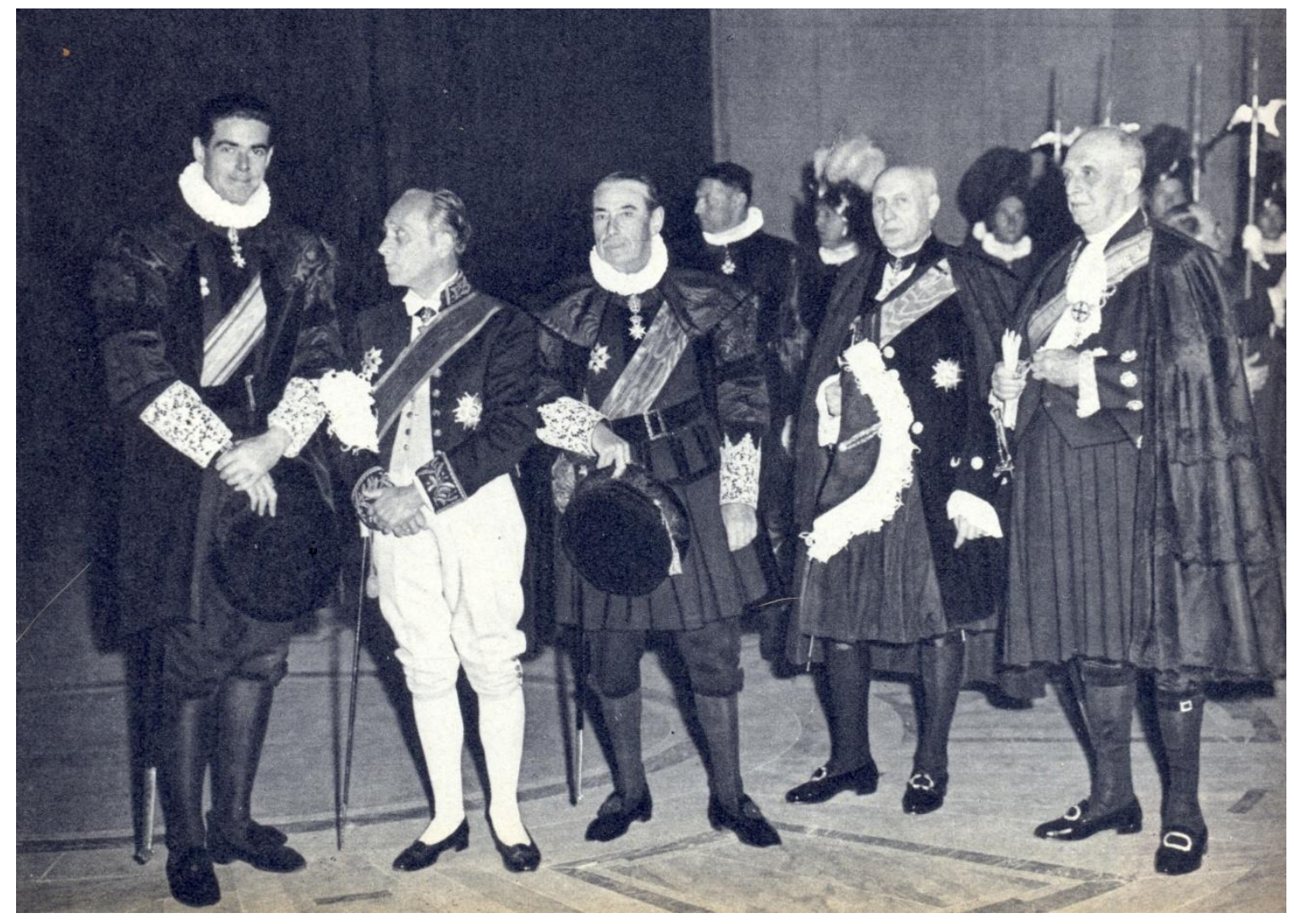

Fig. 2- Alcuni rappresentanti della Guardia Nobile del Papa in alta uniforme- 1960 


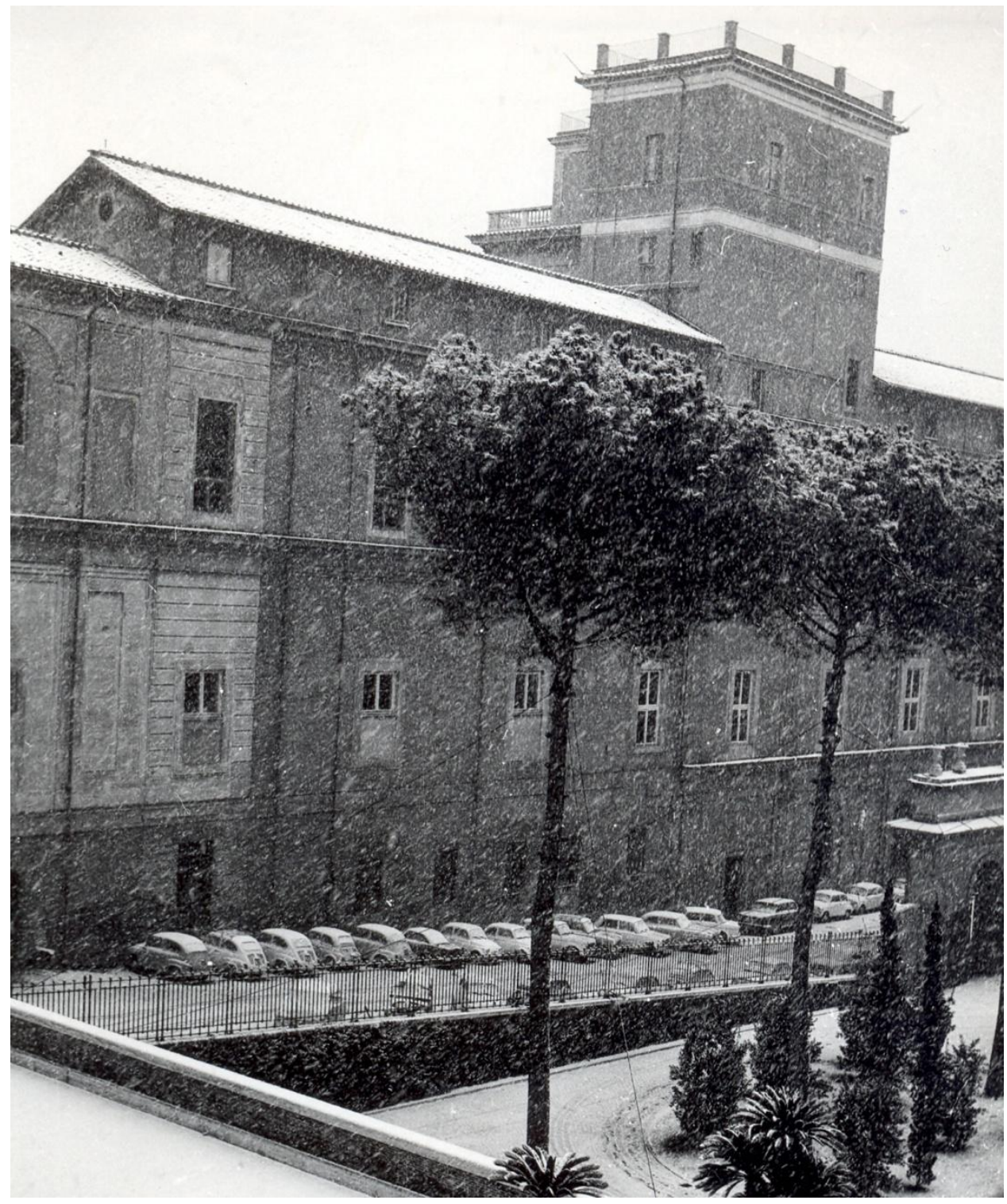

Fig. 3- Una foto della Pinacoteca Vaticana durante la nevicata della fine degli anni sessanta 


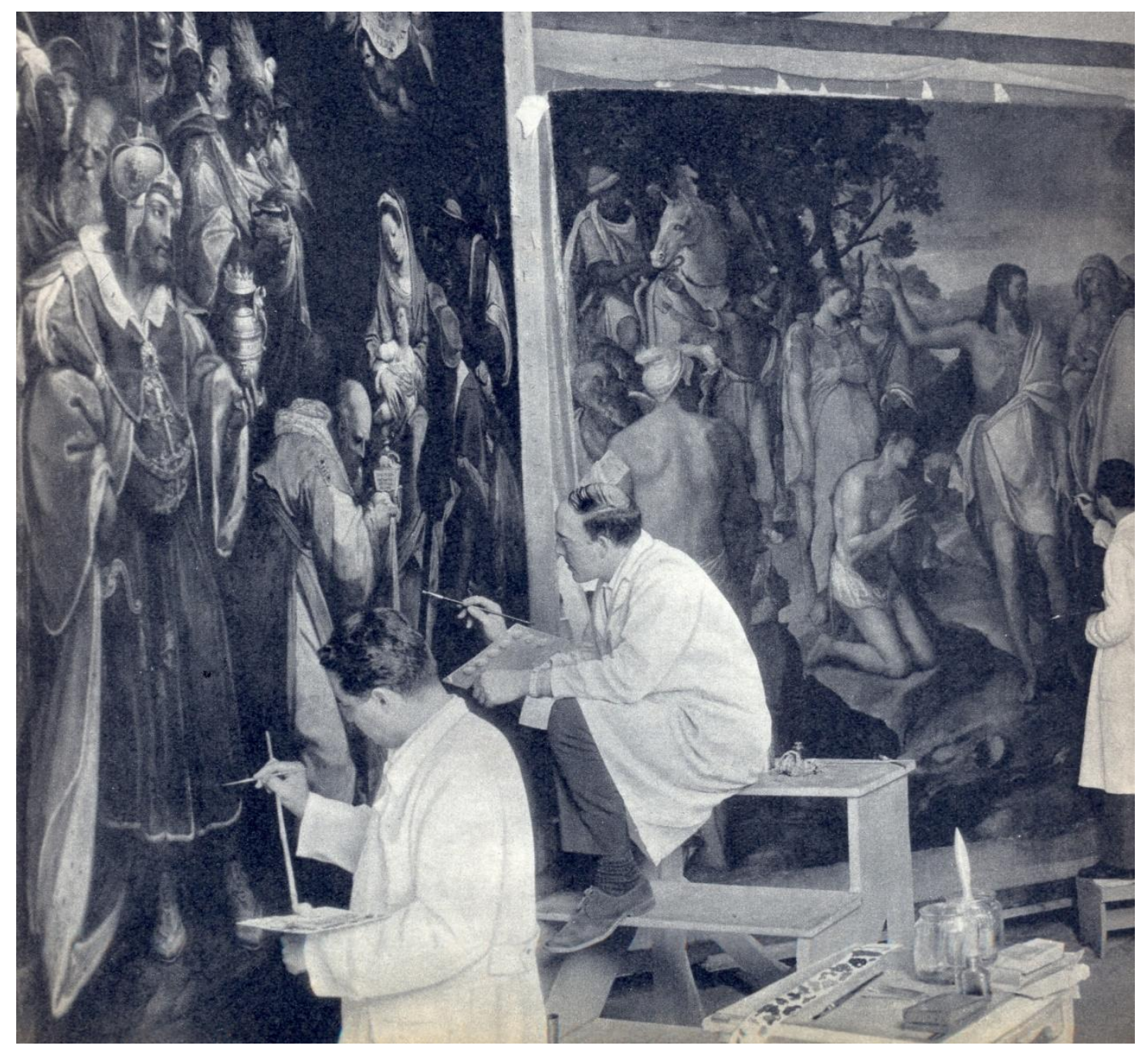

Fig .5- II laboratorio Vaticano nel 1961- Colalucci è in primo piano,dietro di lui G. Segoni 


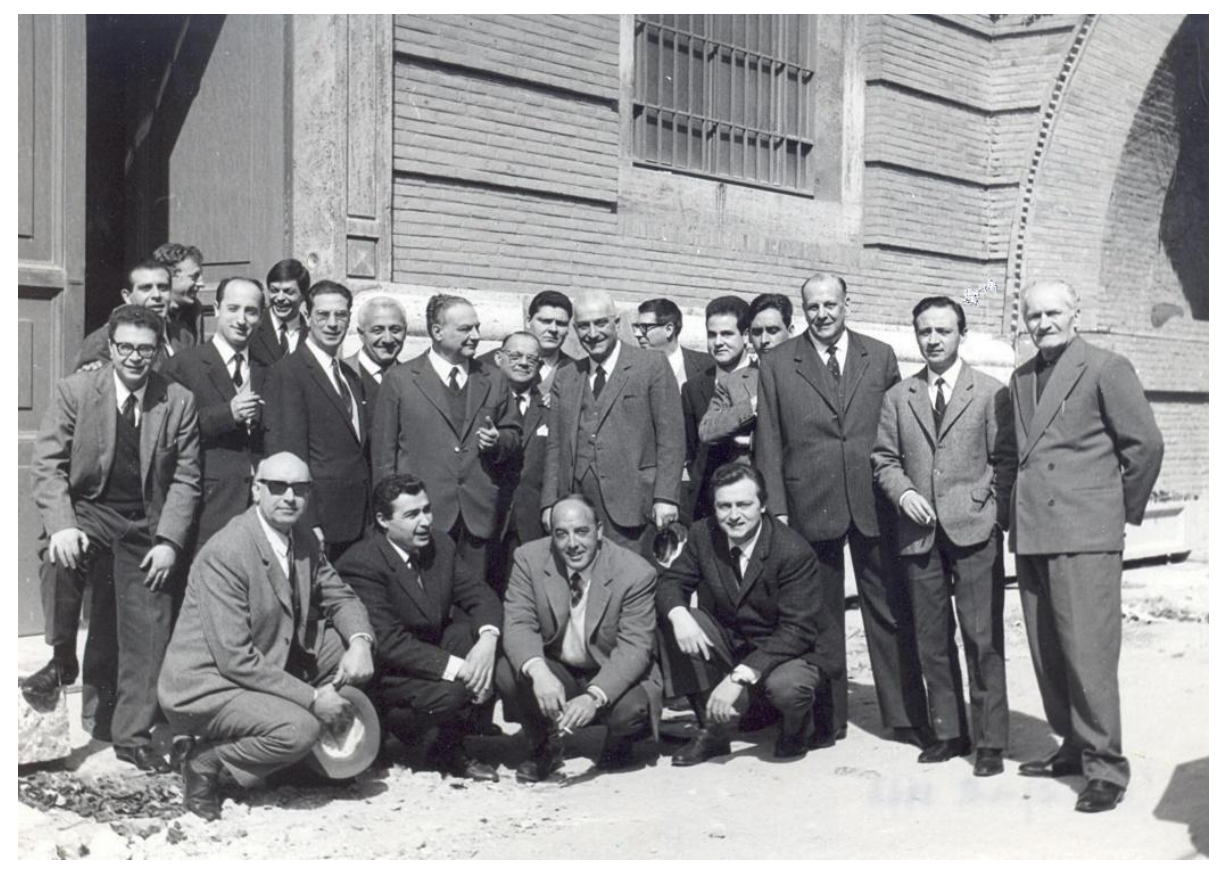

Fig. 6 - una foto di gruppo dei restauratori del laboratorio nel 1966-Al centro il Direttore de Campos e il capo restauratore Luigi Brandi.

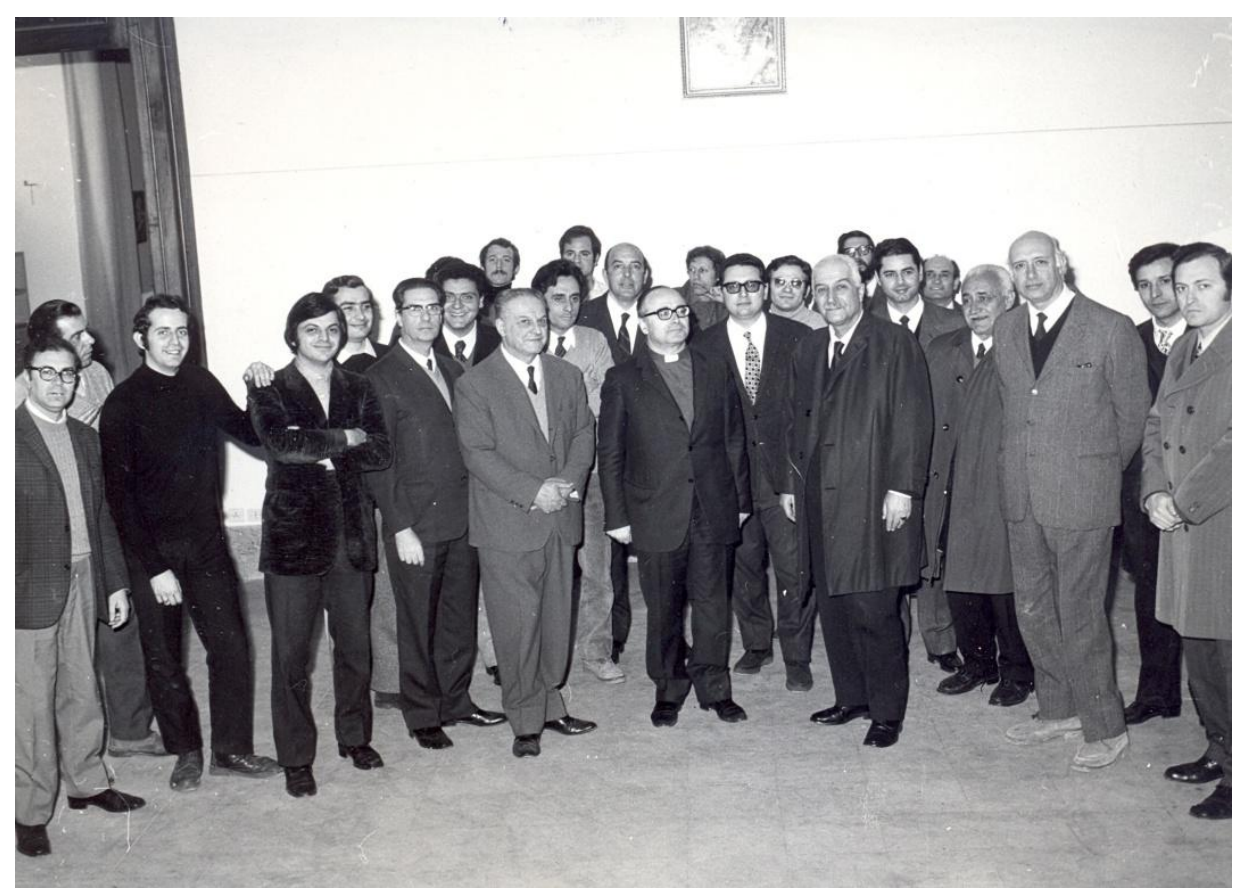

Fig.7 - un'altra foto di gruppo dei restauratori del laboratorio nel 1971 


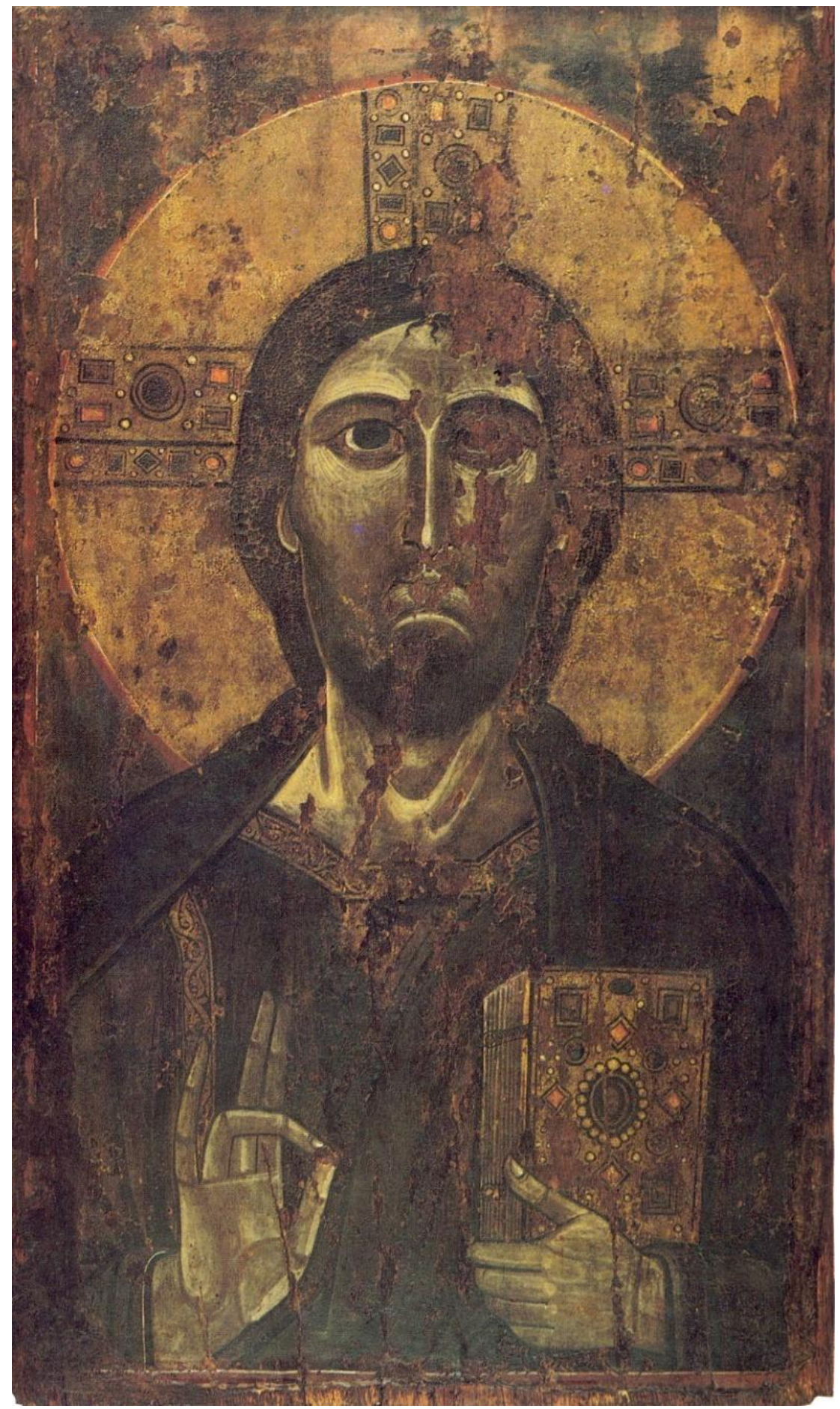

Fig. 8 -Sc, romana del sec. XII', " Redentore"- tempera su tavola -restaurato da Colalucci nel 1960 


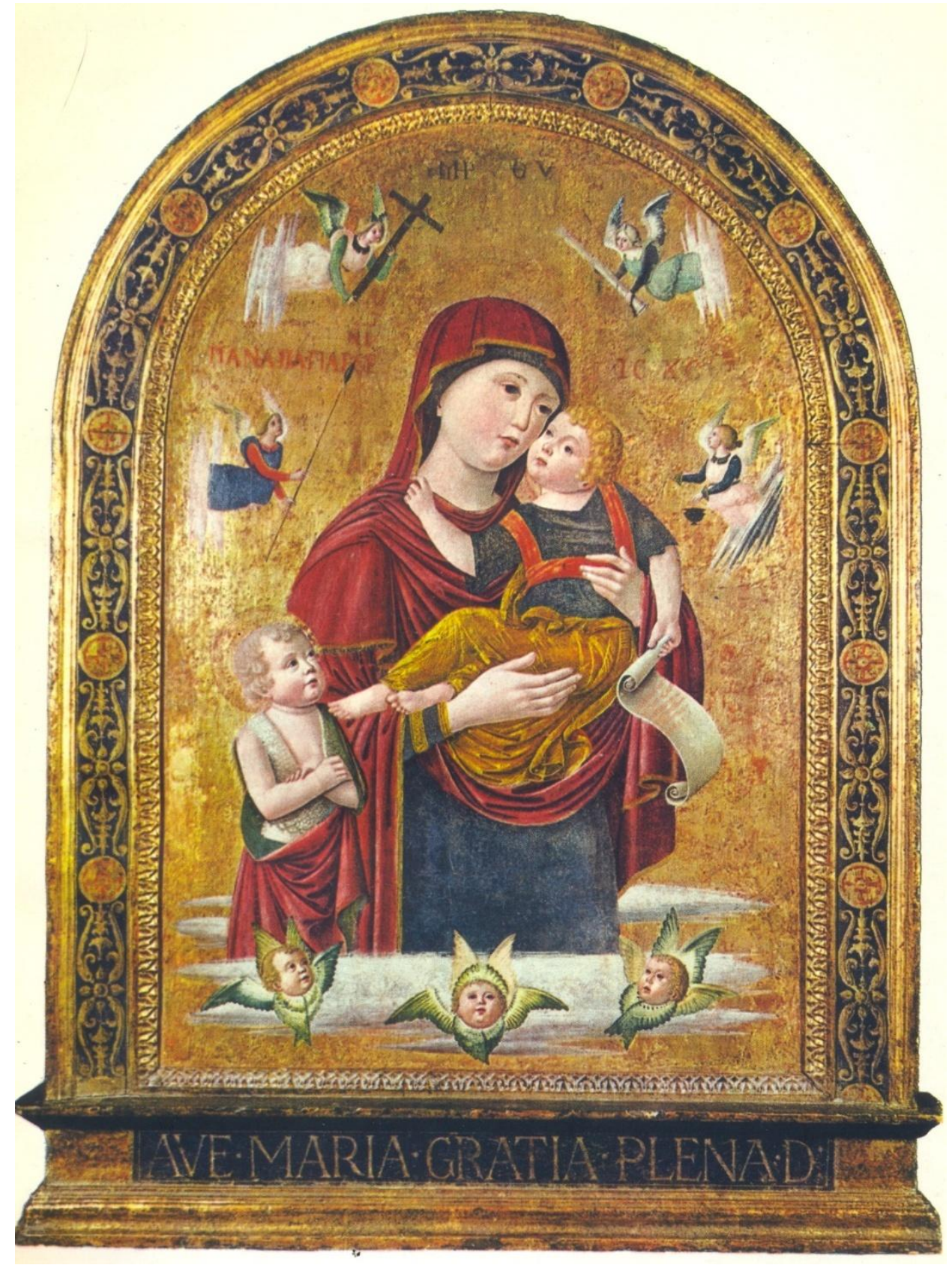

Fig. 9 - Cima da Conegliano, "Madonna col Bambino"- tempera su tavola, restaurato da Colalucci nel 1962 


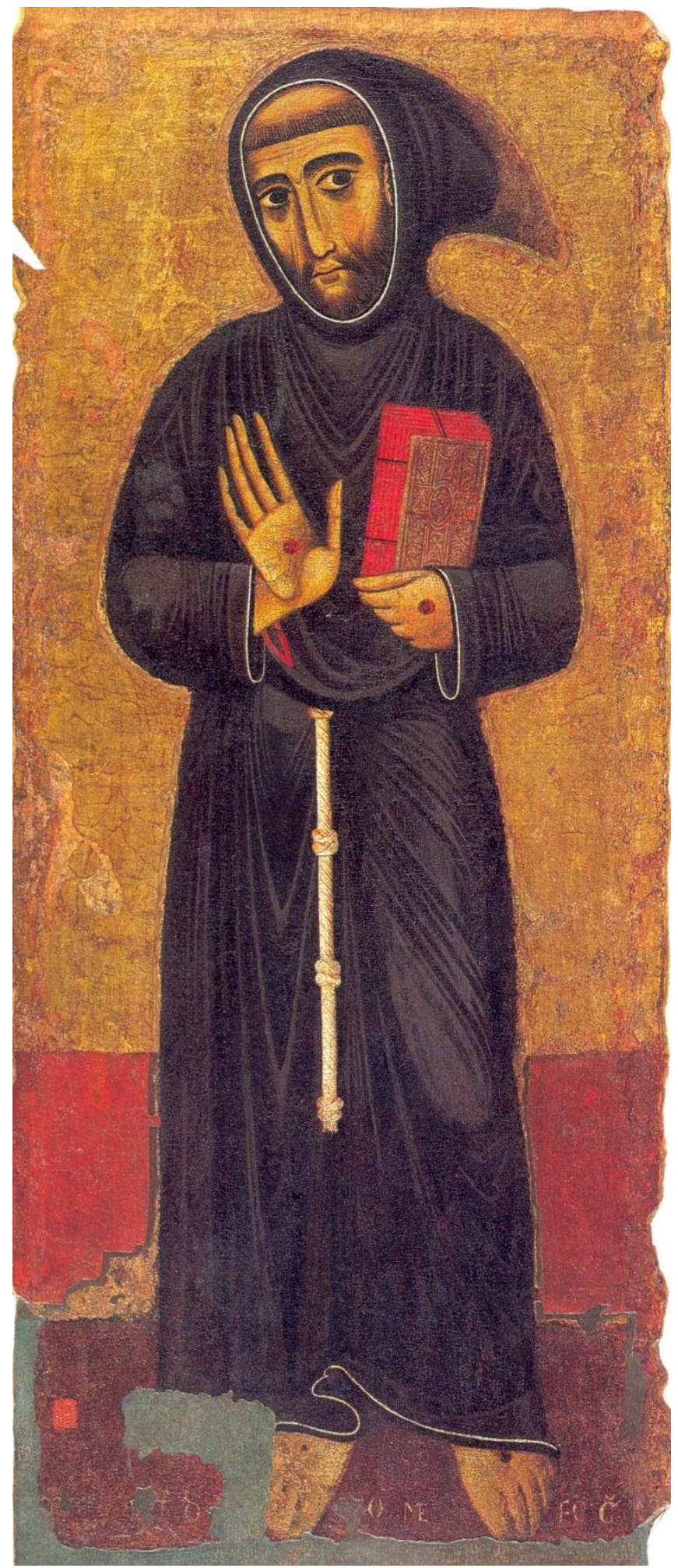

Fig 10- Margaritone d' Arezzo "S. Francesco"- restaurato da Colalucci nel 1965 


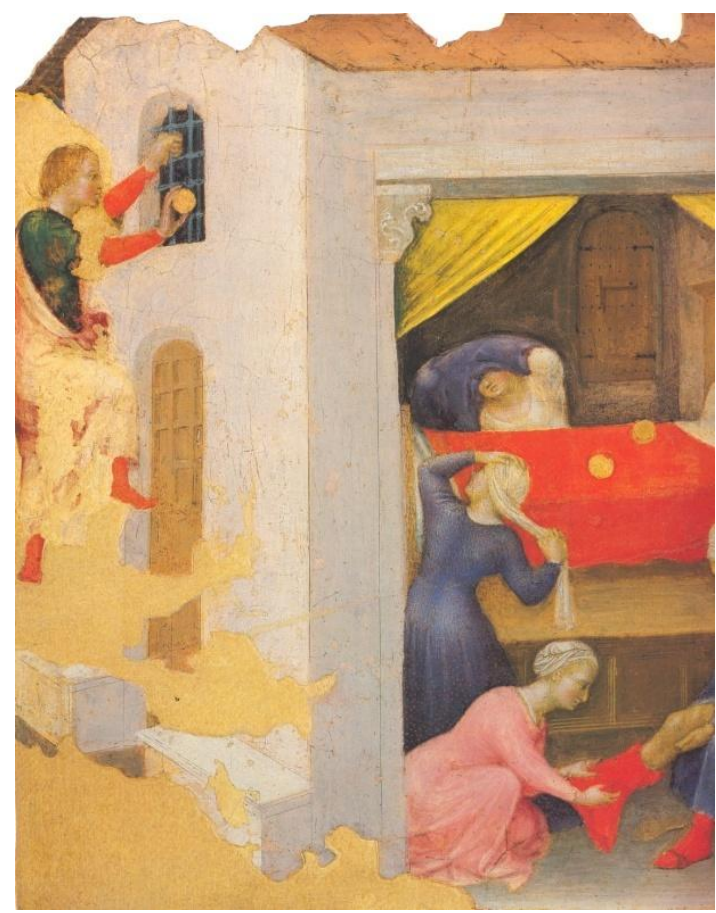

Fig. 11- part. dopo il restauro

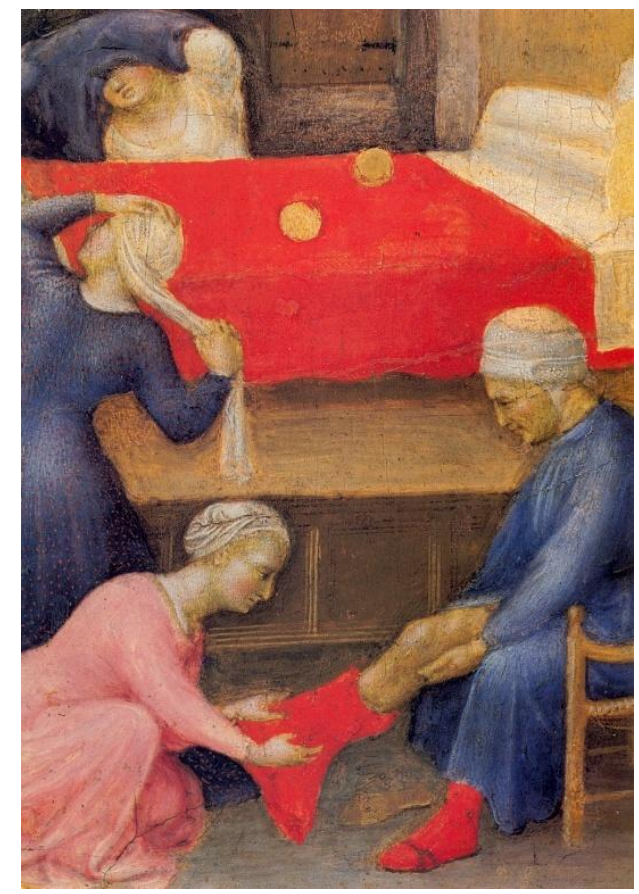

F.12- part. dopo il restauro

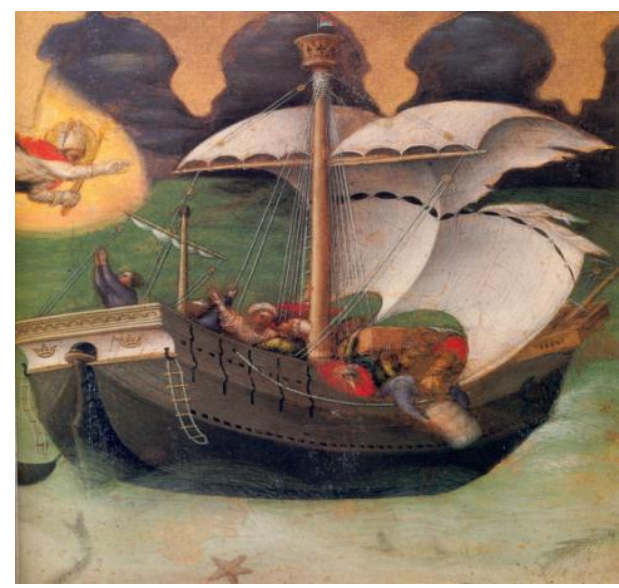

Fig.13-part. del dipinto dopo il restauro 

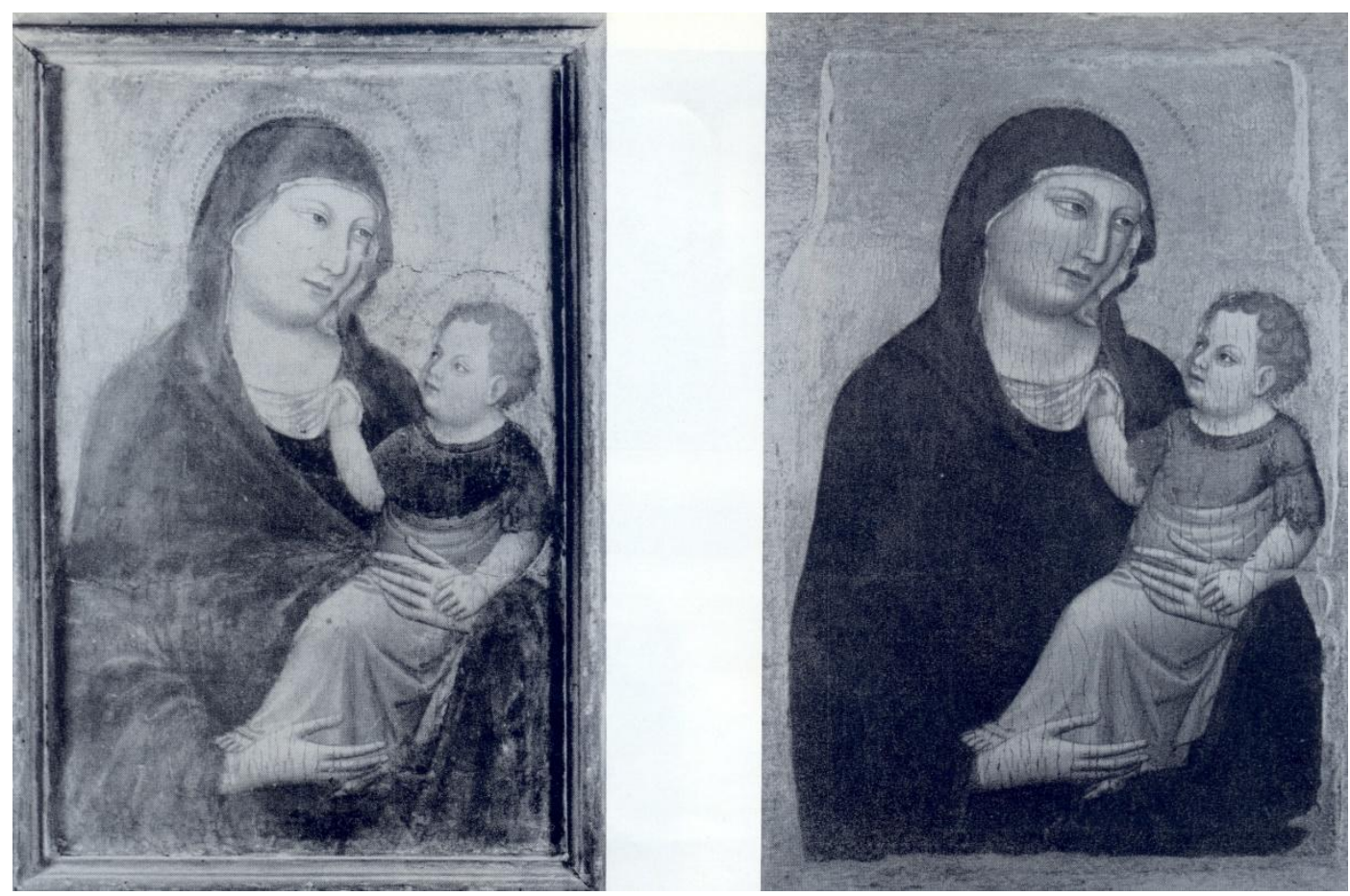

Fig. 14 - Jacopo da Casentino "Madonna col Bambino" la tempera su tavola- prima e dopo il restauro di Colalucci -1974 
P. Bordone- "San Giorgio che uccide il drago" olio su tela - restaurato da Colalucci nel 1969

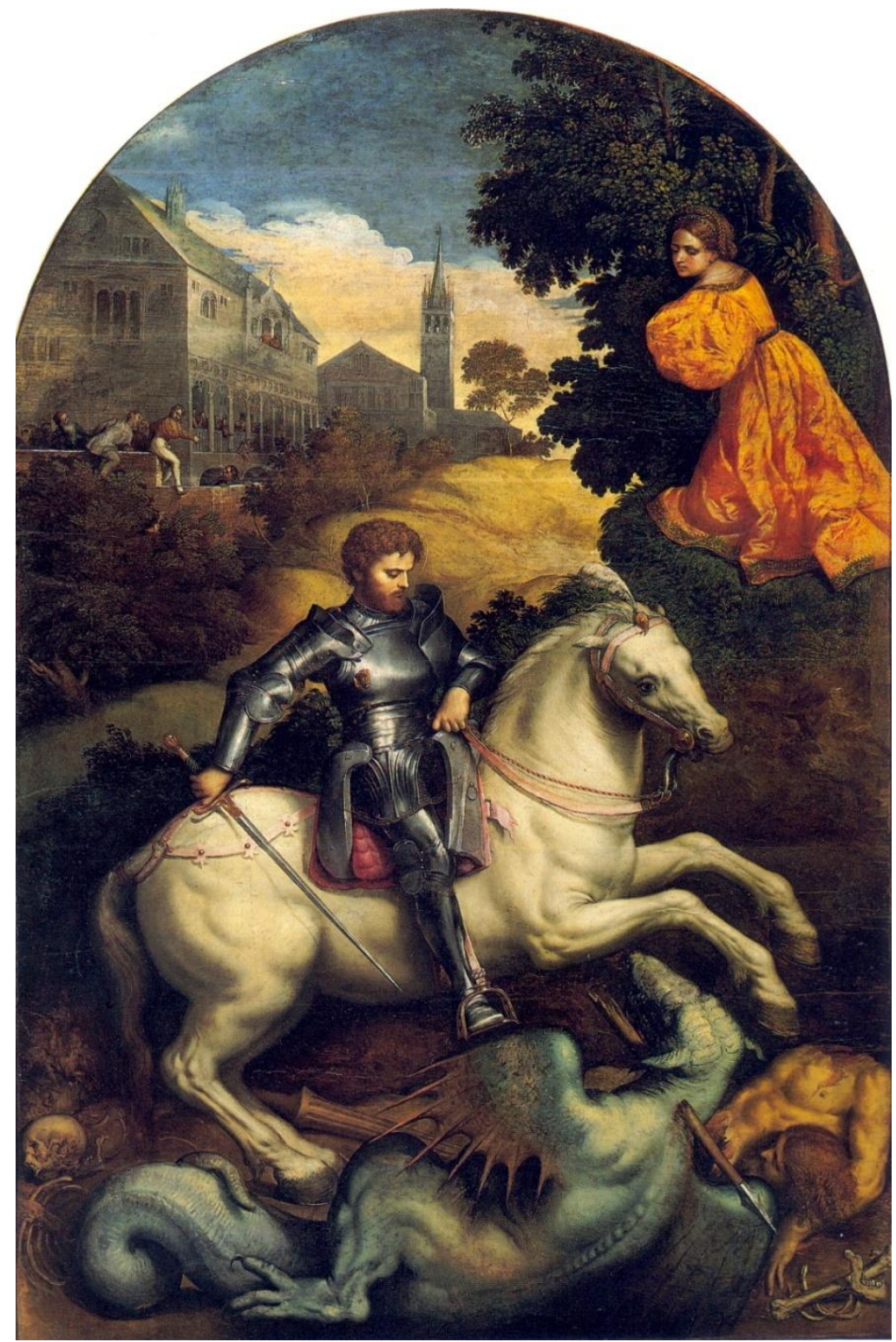

Fig. 15- il dipinto dopo il restauro

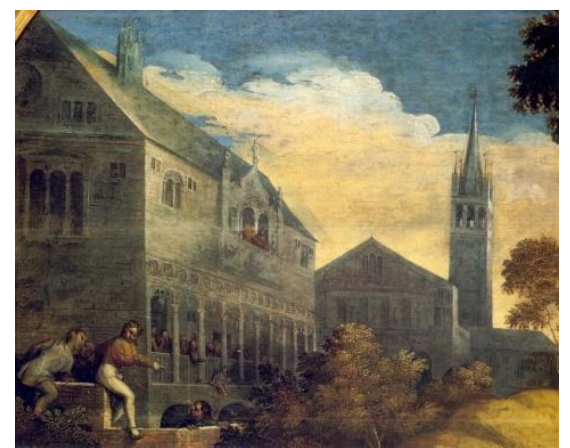

Fig. 16- un particolare del paesaggio dopo il restauro 


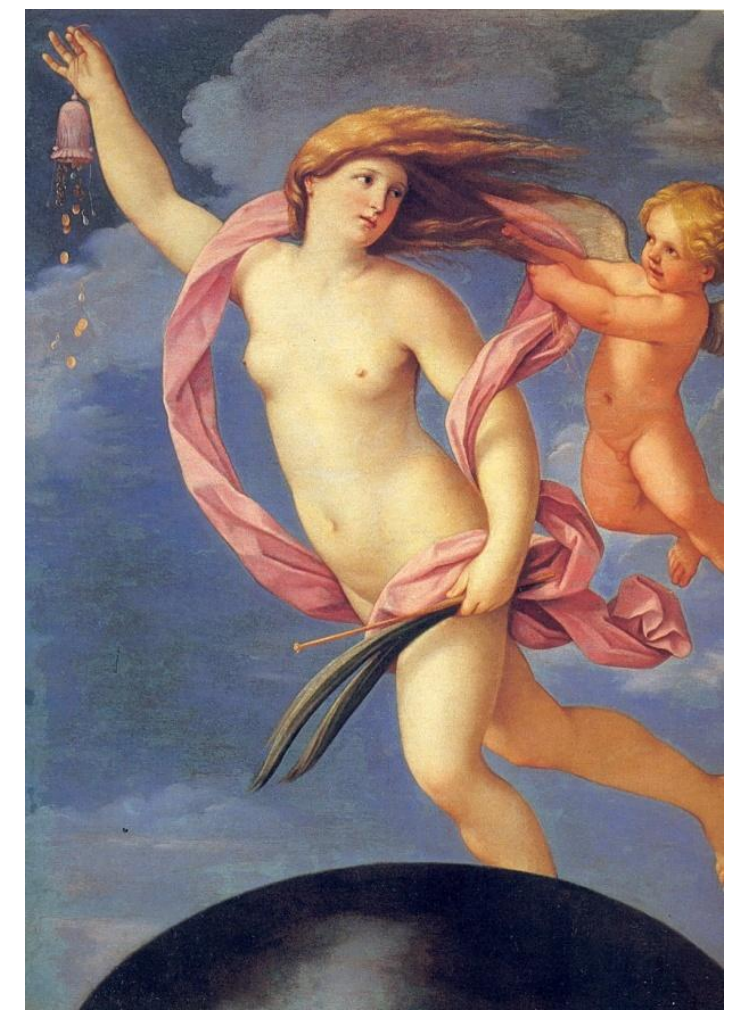

Fig. 17- G.Reni, "La fortuna trattenuta da Amore" Olio su tela, restaurato nel 1963

D. Creti, "Venere" e "La cometa", olio su tela restaurato da Colalucci 1969

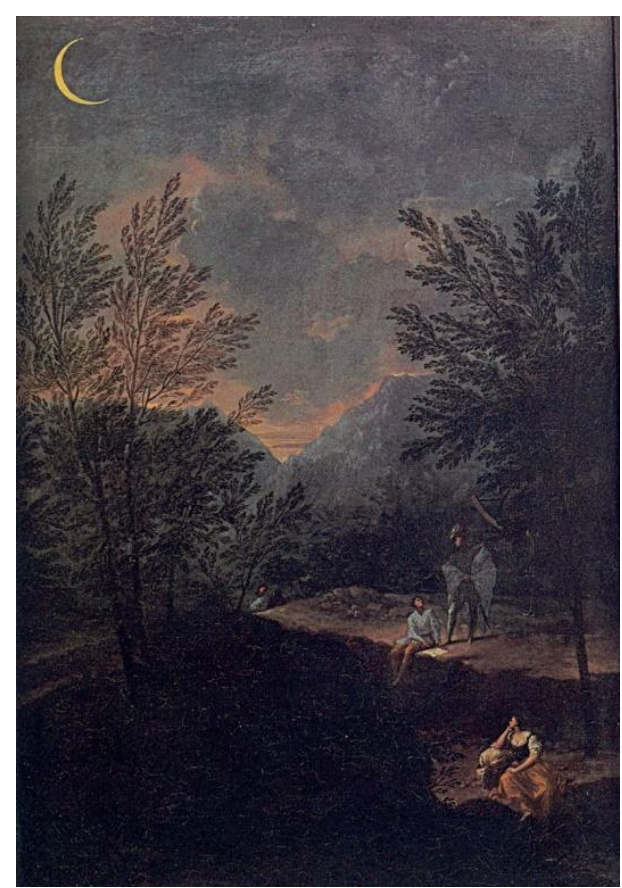

Fig. 18 - dopo il restauro

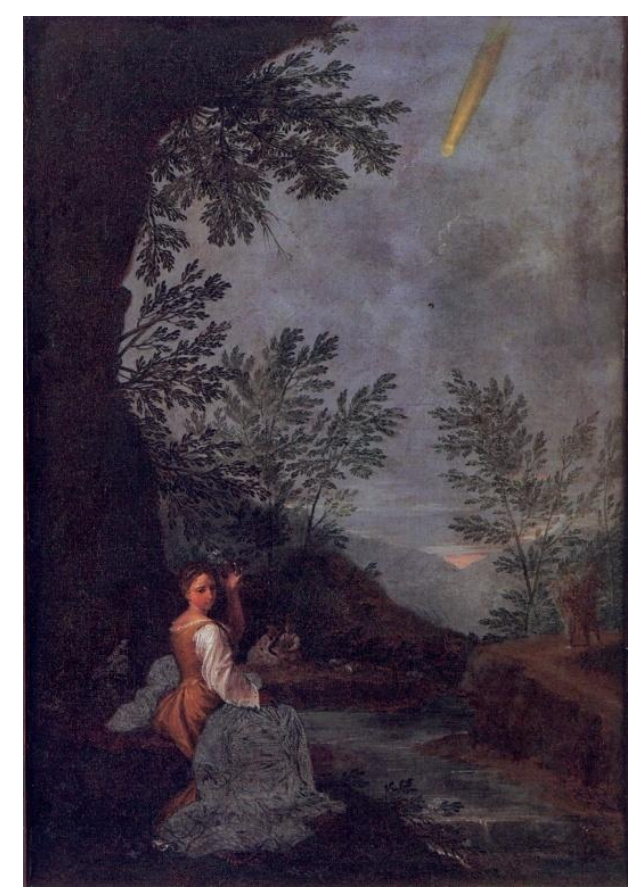

Fig. 19 - dopo il restauro 


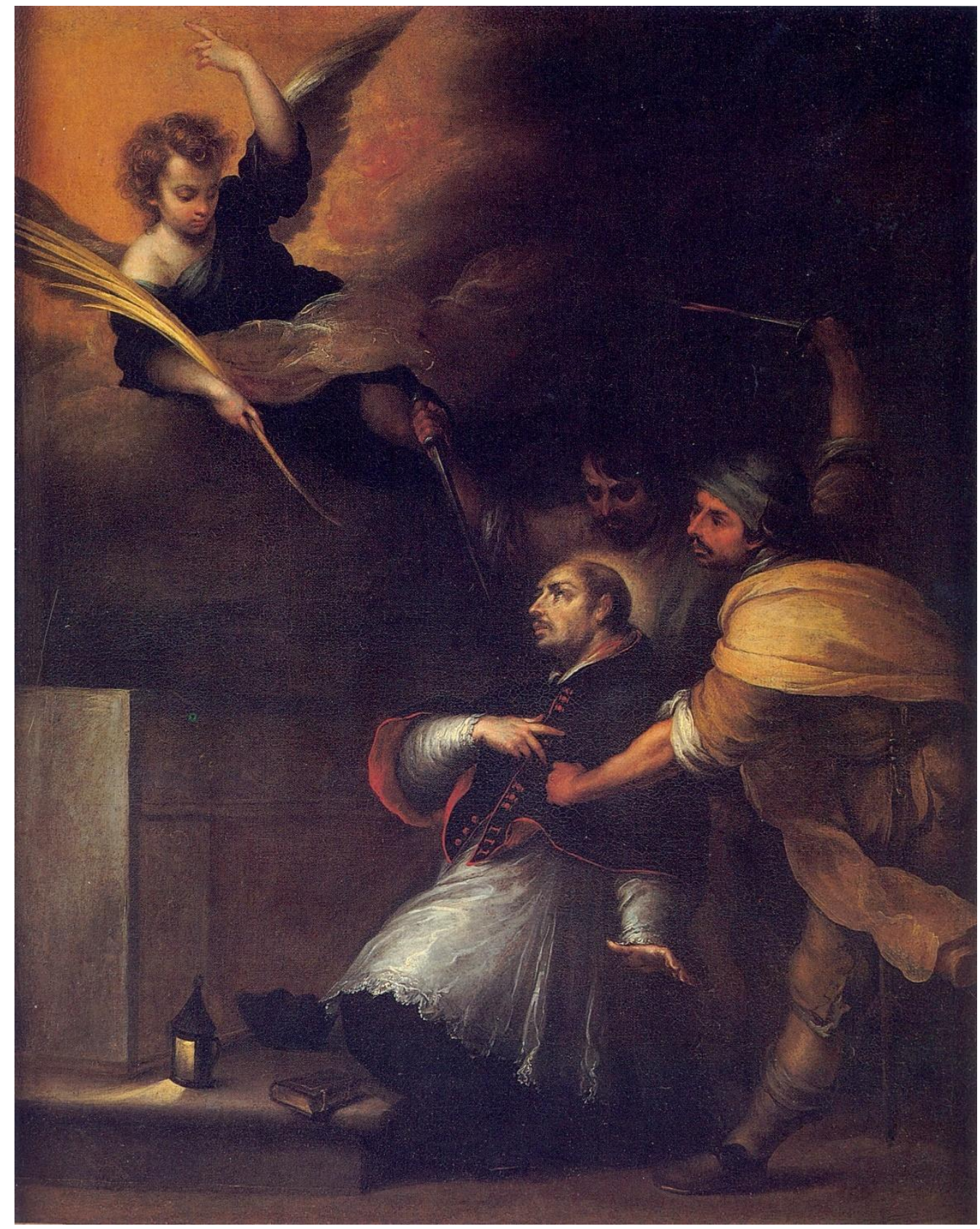

Fig. 20 - Murrillo "Il martirio di San Pietro d'Arbruez" - olio su tela, restaurato da Colalucci nel 1965 
Scuola tardo-romana sec.XIV ${ }^{\circ}$ Crocifisso di San Paolo detto del Cavallini restaurato da Colalucci nel 1974

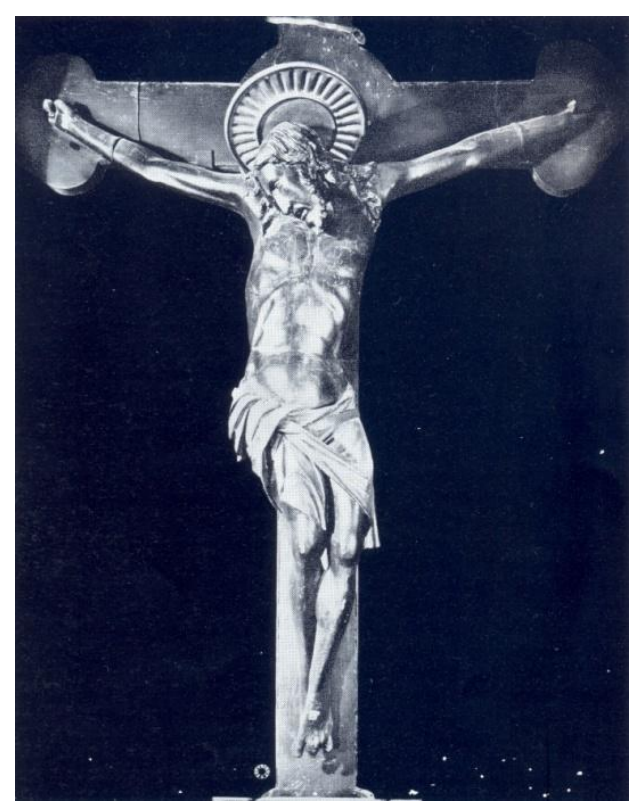

Fig. 21- II Crocifisso prima del restauro
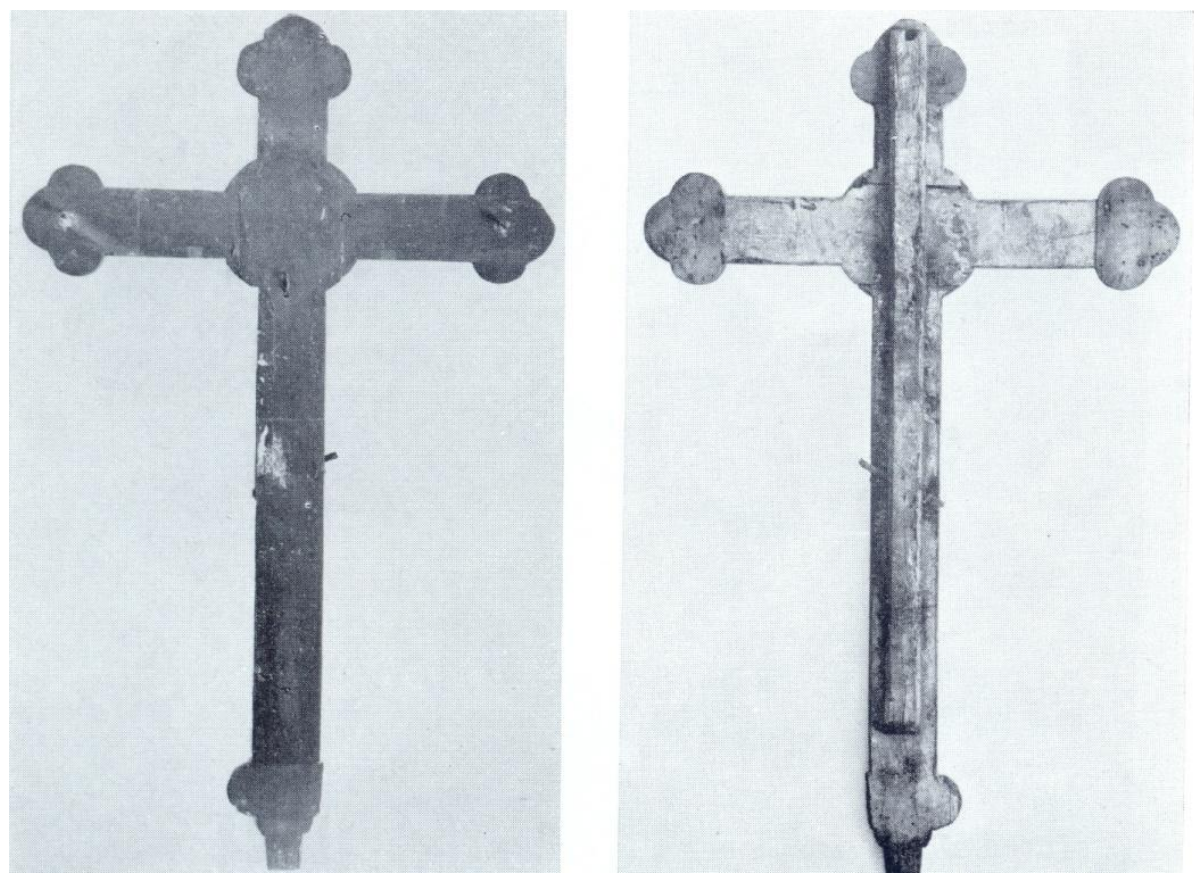

Fig. 22 - il recto e il verso della croce prima del restauro 


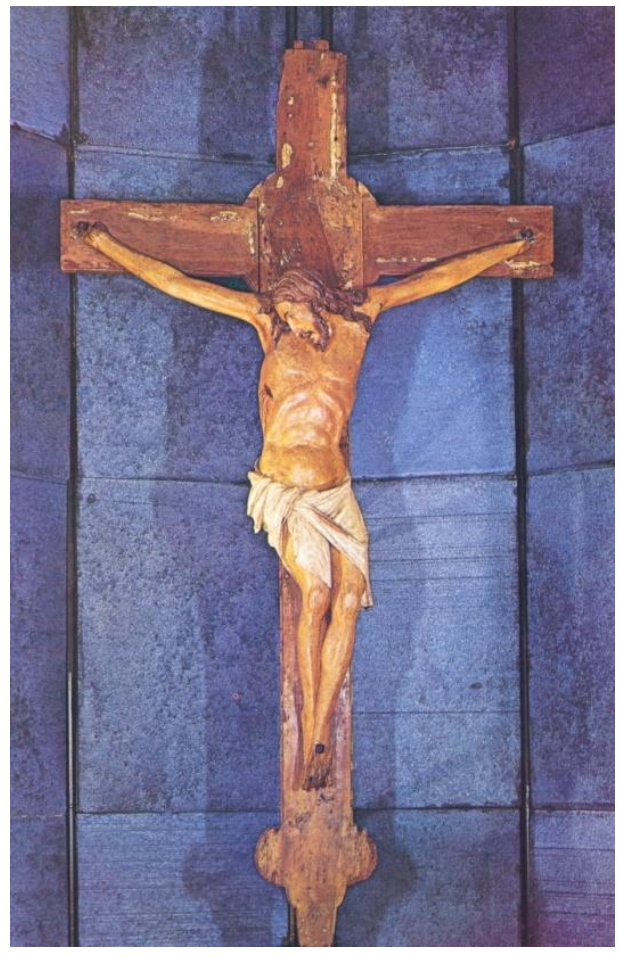

Fig. 23 - La scultura dopo il restauro

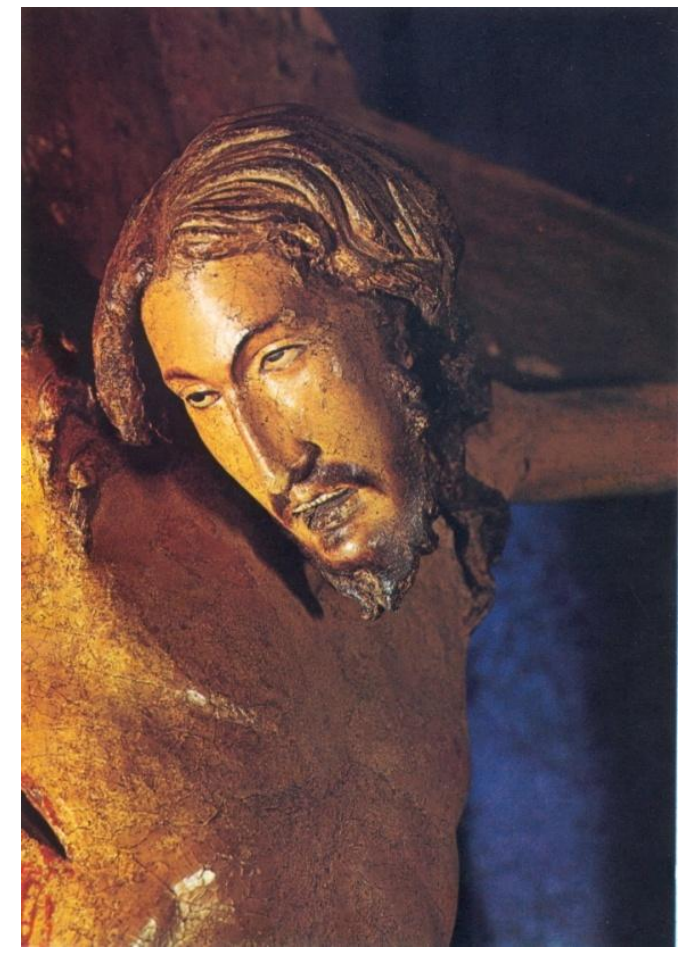

Fig. 24- part. del volto di Cristo dopo il restauro 


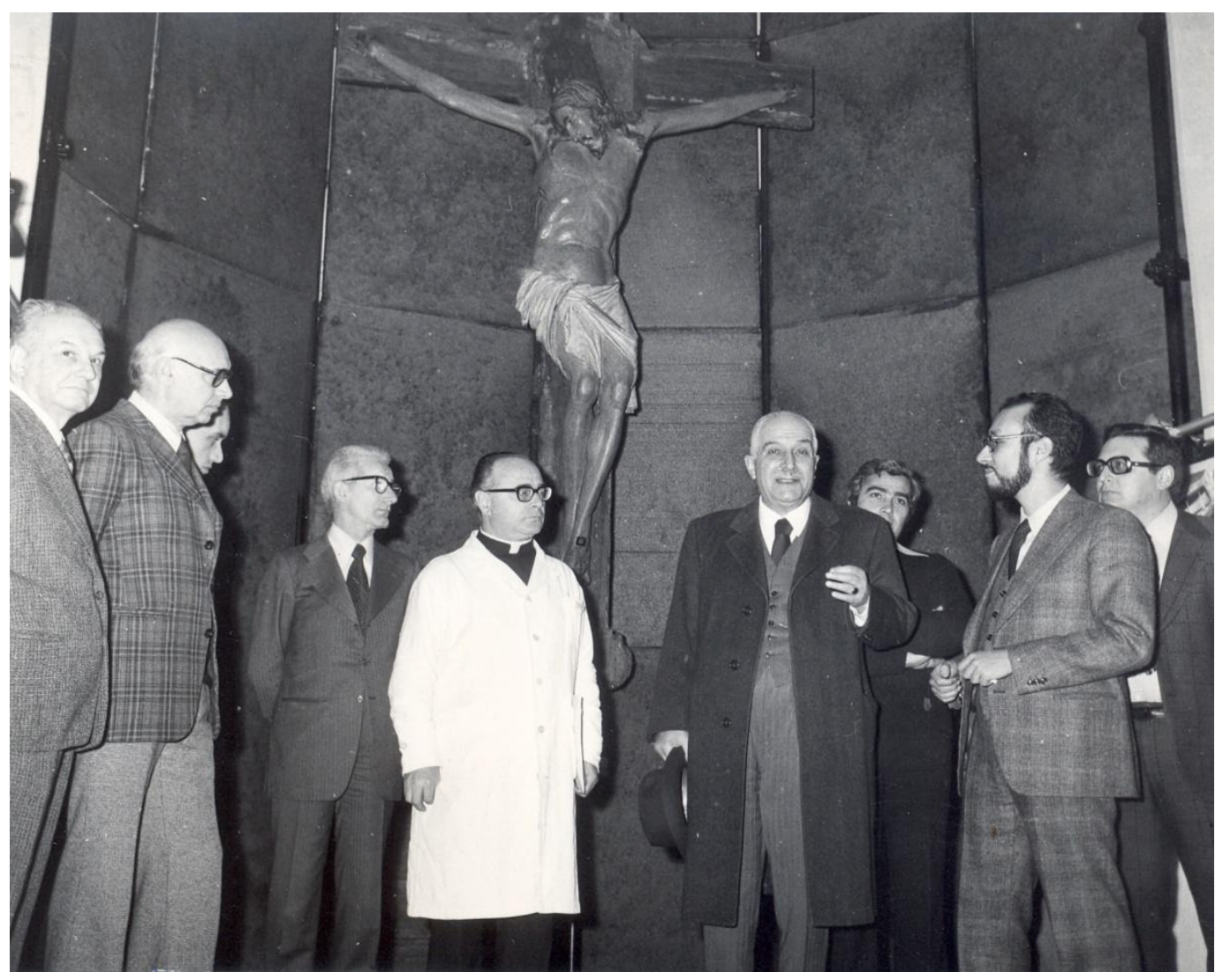

Fig. 25 -

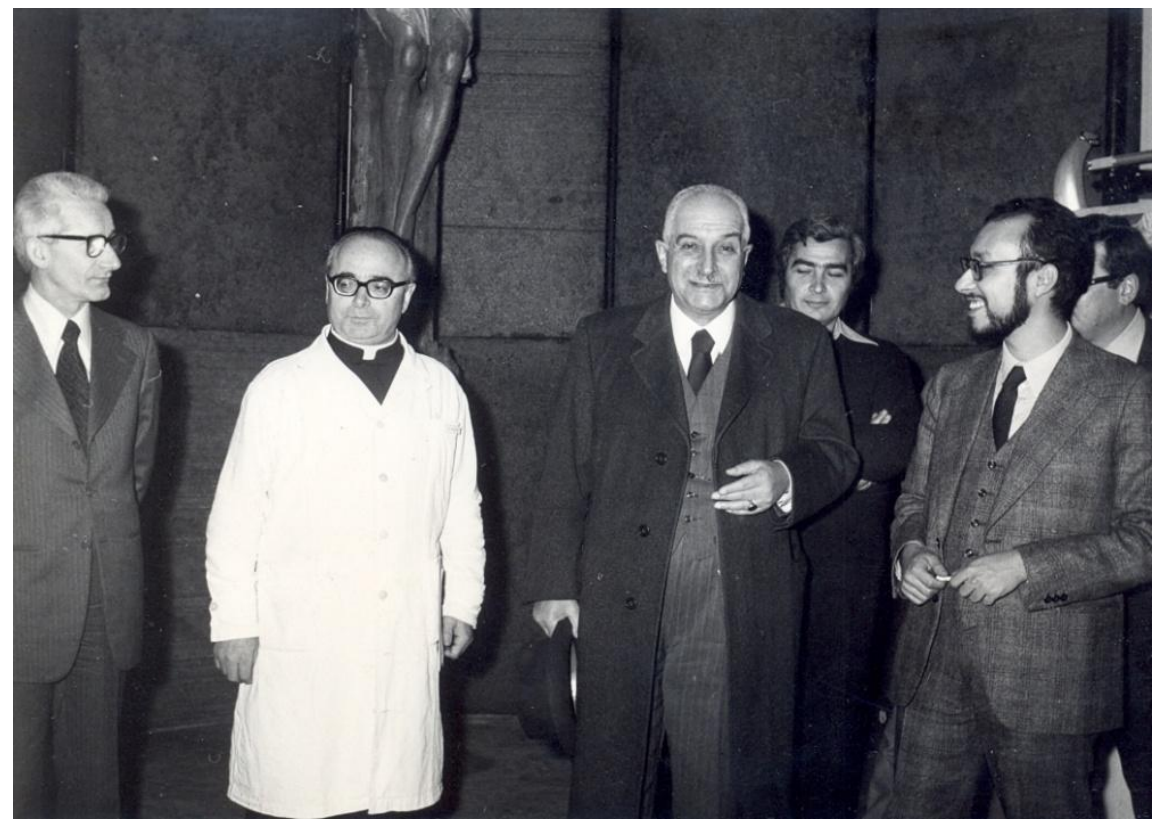

Fig. 26-

Le foto 25- 26 mostrano due momenti della presentazione del restauro del Crocifisso di San Paolo. Al centro il Direttore de Campos, a sinistra F. Mancinelli, Colalucci in secondo piano. Nella foto 25 il capo restauratore Luigi Brandi (a destra), Igino Cupelloni e il Segretario generale Walter Persegati 


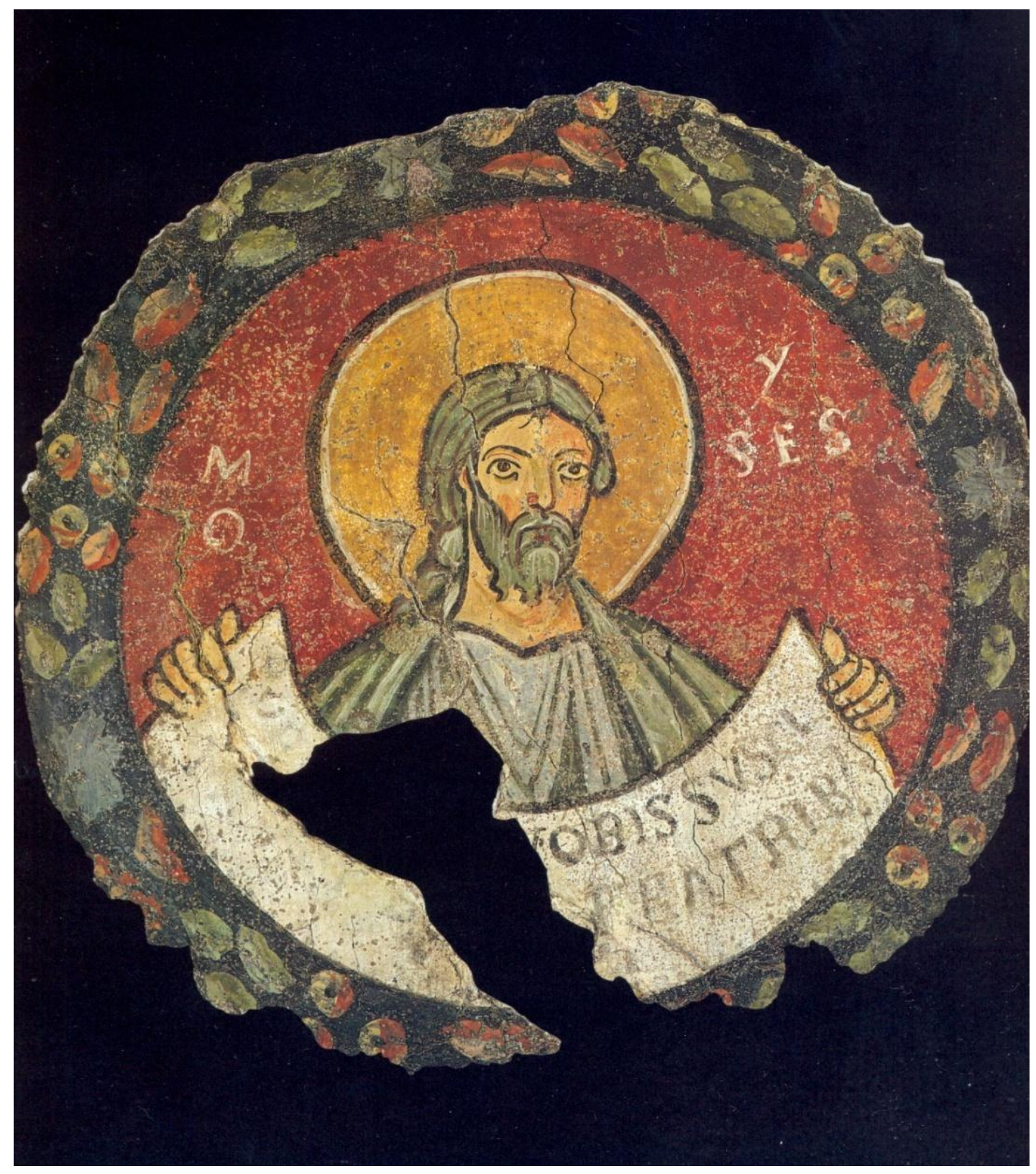

Fig. 27 - Sc. romana del sec. XII “ Mosé” - frammento di affresco staccato, restaurato da Colalucci nel 1973 


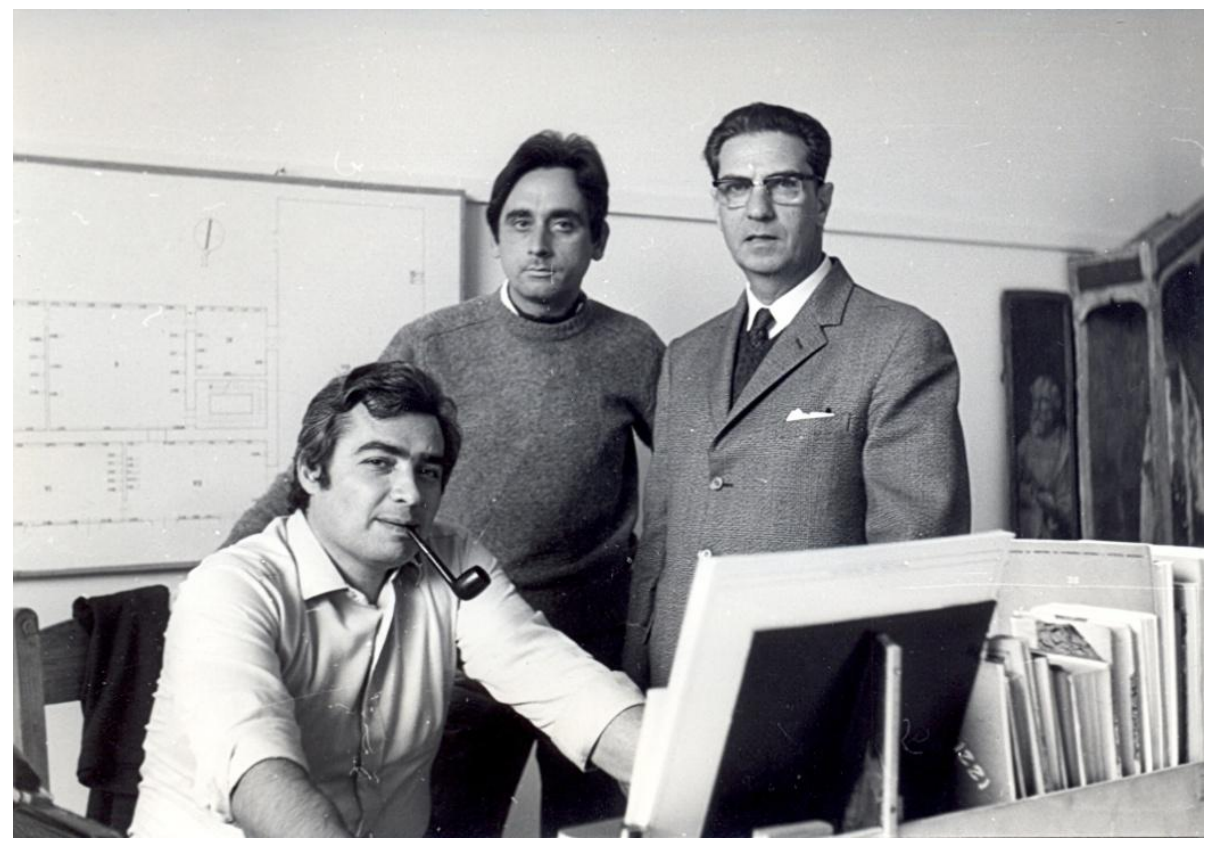

Fig 28 - Colalucci in laboratorio negli anni Settanta con il collega Enrico Guidi (al centro) e il restauratore di arazzi Bruno Grossi

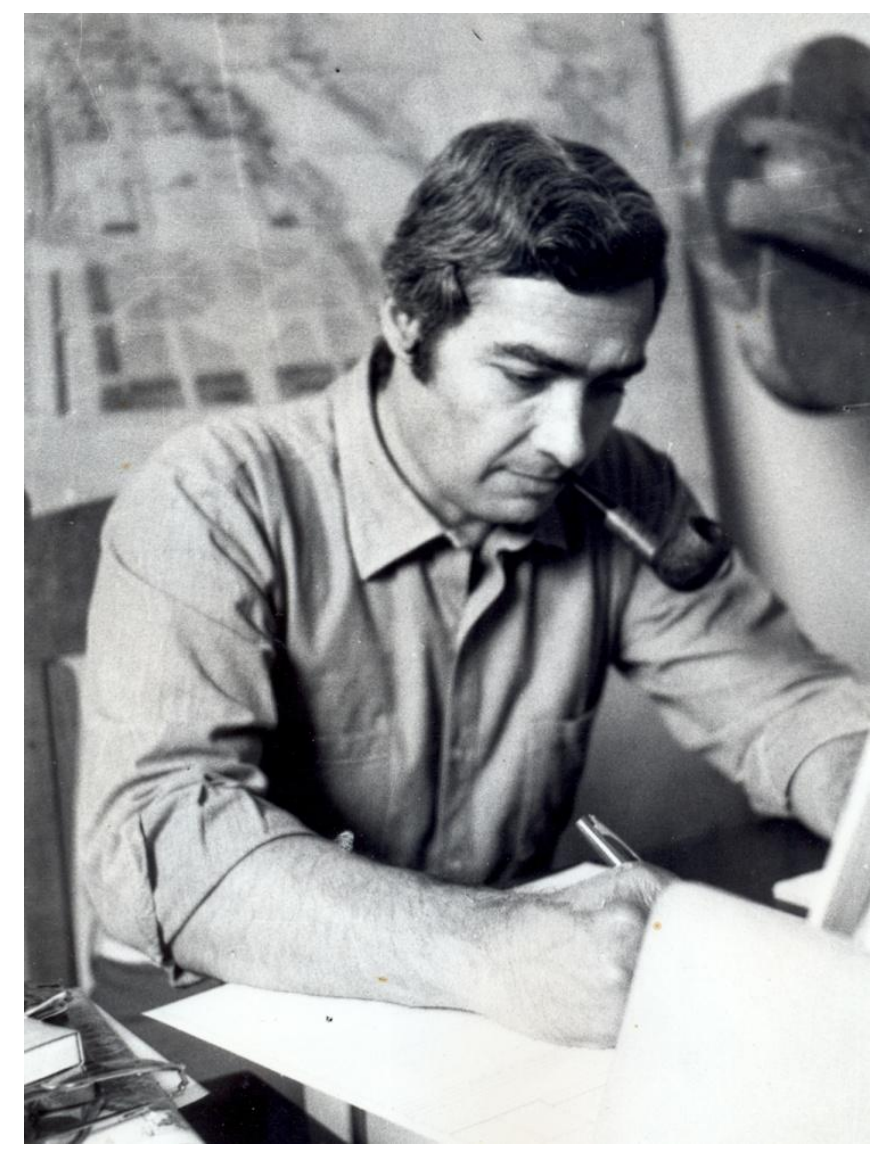

Fig. 29 - Un'altra foto di Colalucci in laboratorio negli anni 70 


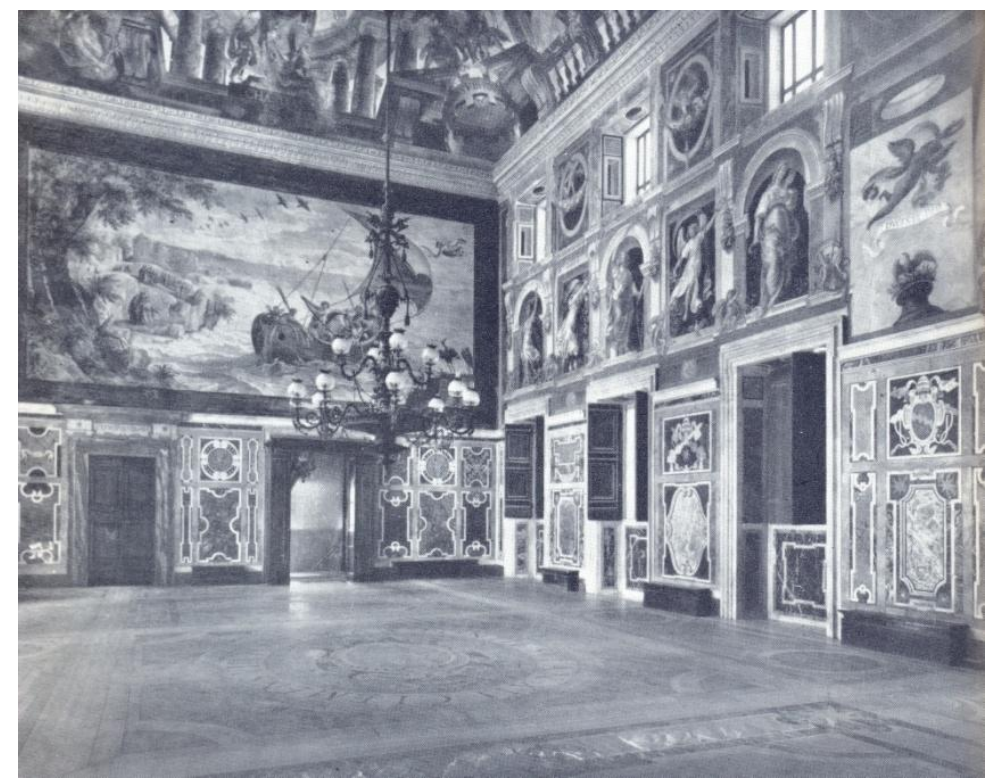

Fig. 30- La Sala Clementina in Vaticano

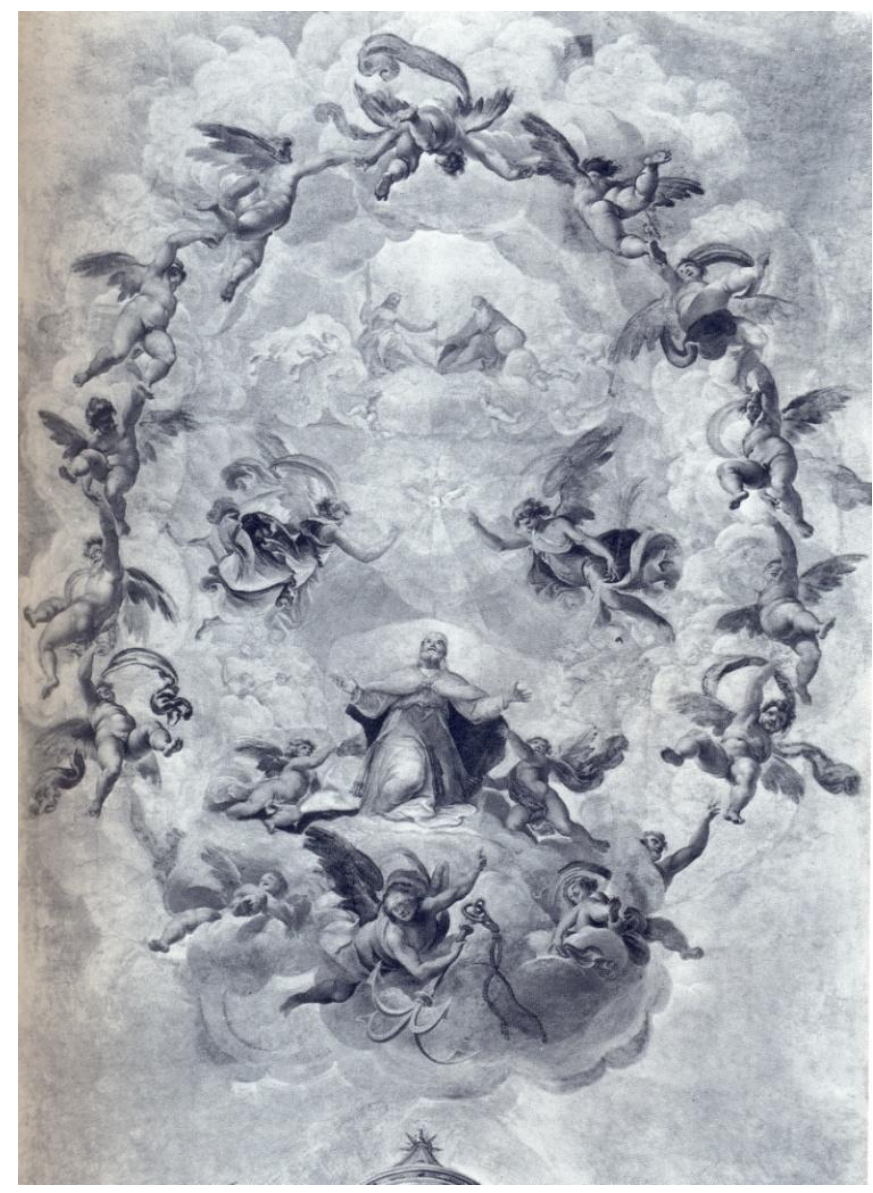

Fig. 31 -La Volta della Sala Clementina (C. Alberti) restaurata da tutti i restauratori del laboratorio negli anni 70 


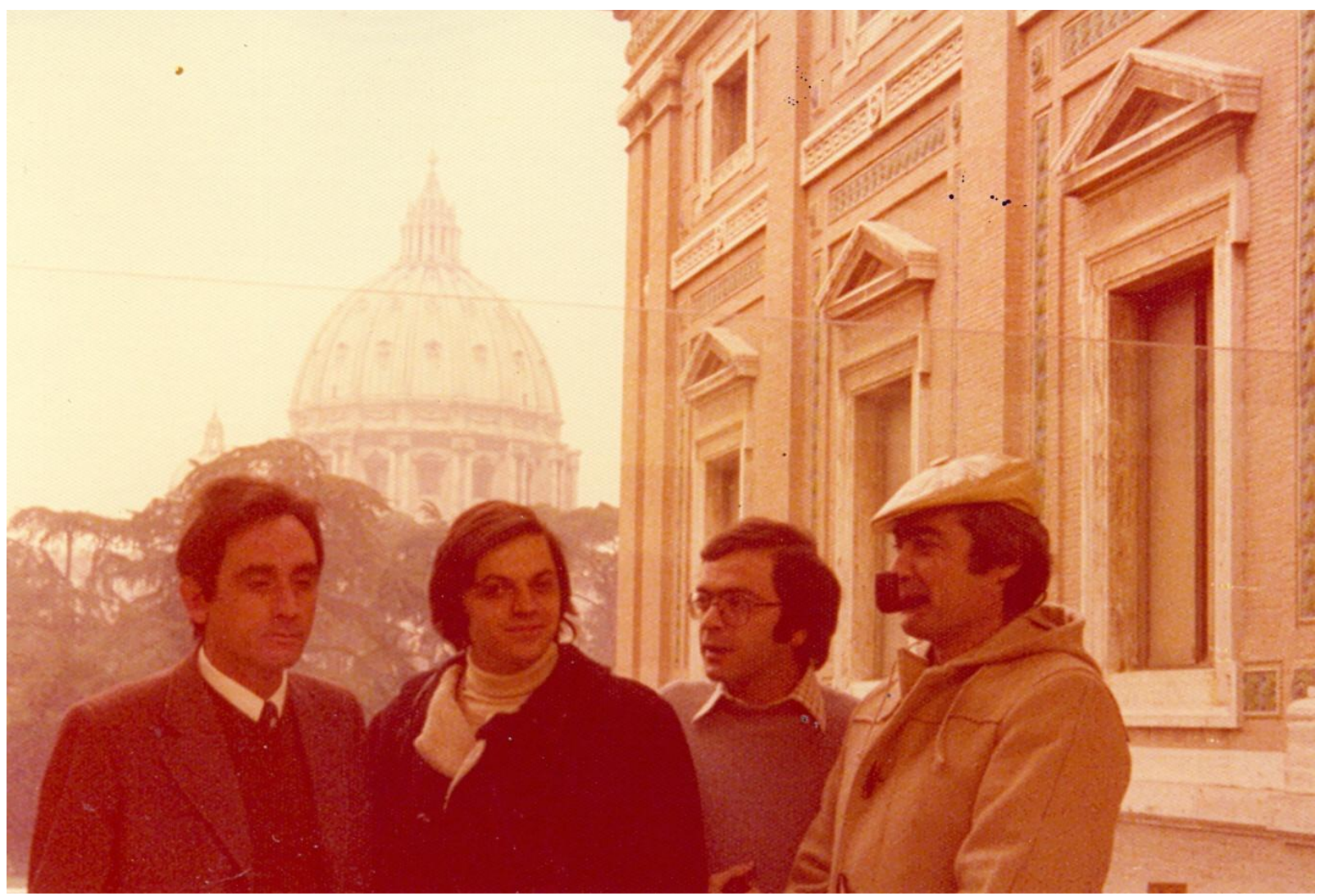

Fig. 32 - Colalucci con i colleghi E. Guidi (a sinistra) G. Properzi e M. De Luca, all'ingresso della Pinacoteca nel 1975 


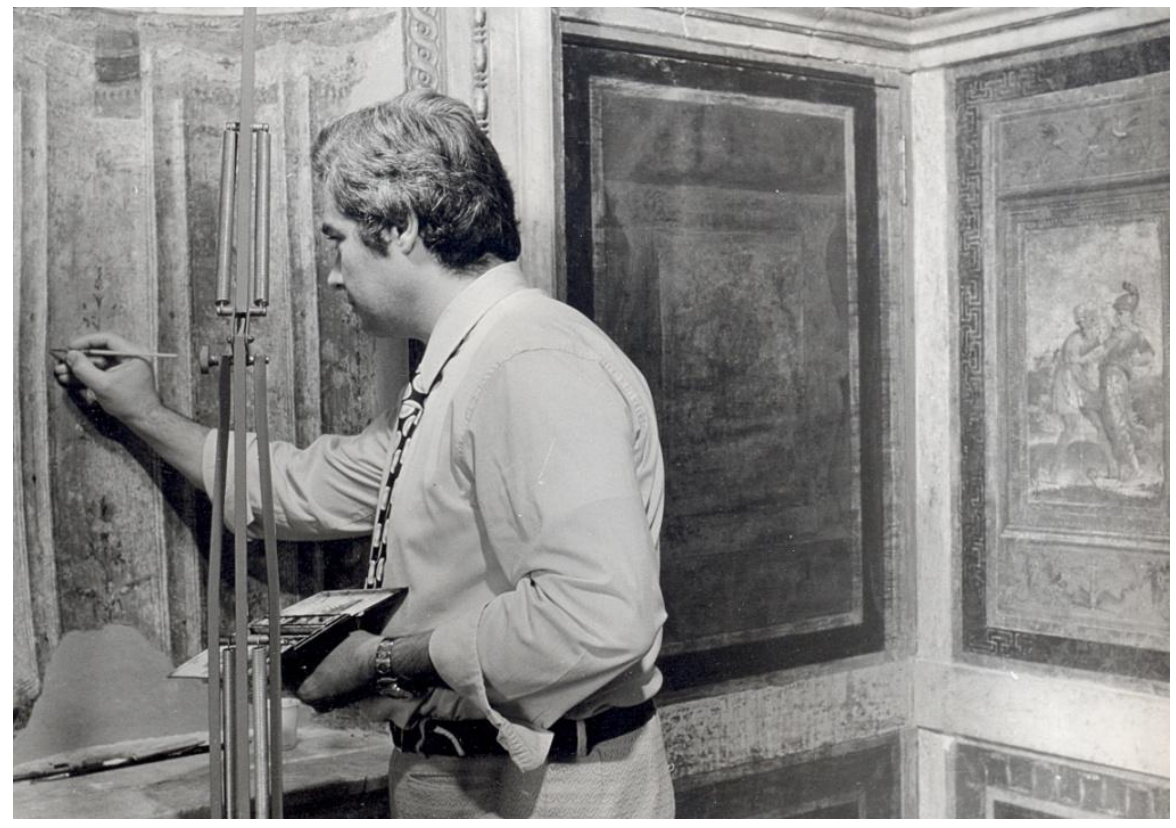

Fig. 33

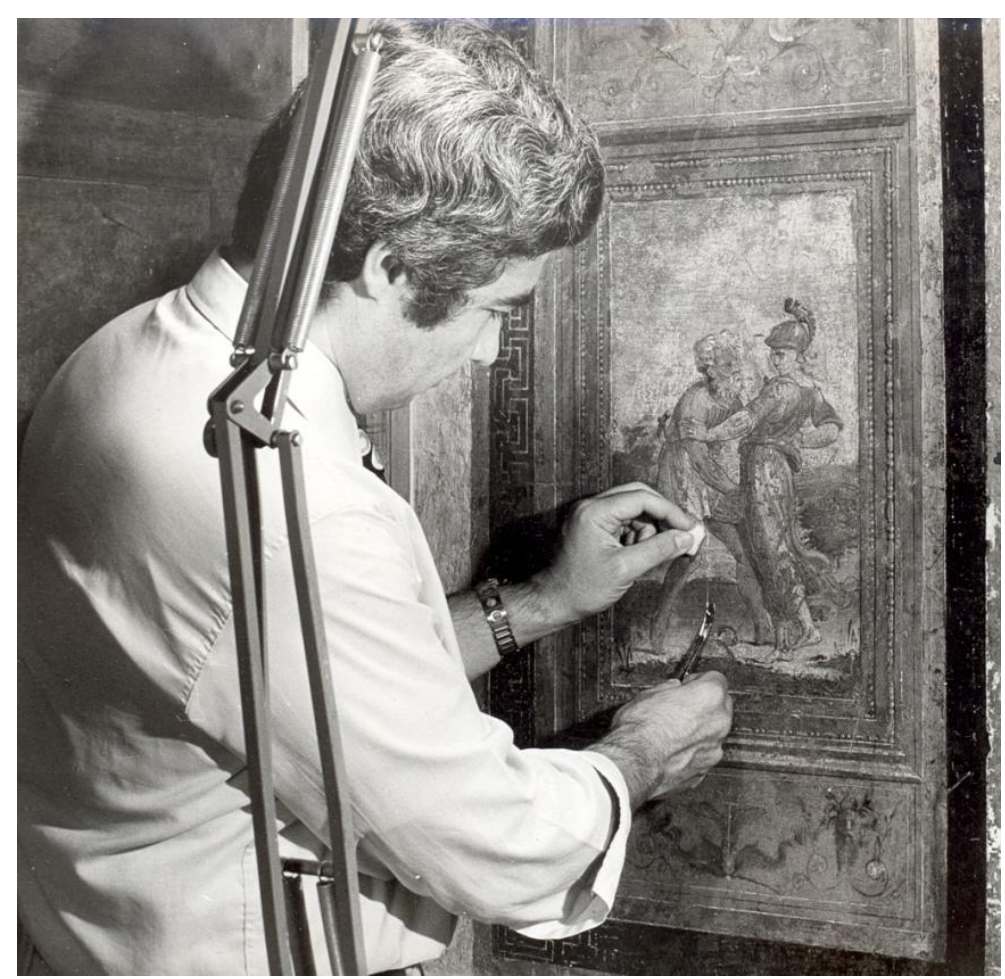

Fig. 34

Le figure 33-34 ritraggono Colalucci durante il restauro della stufetta del Bbibiena. Anni 70 


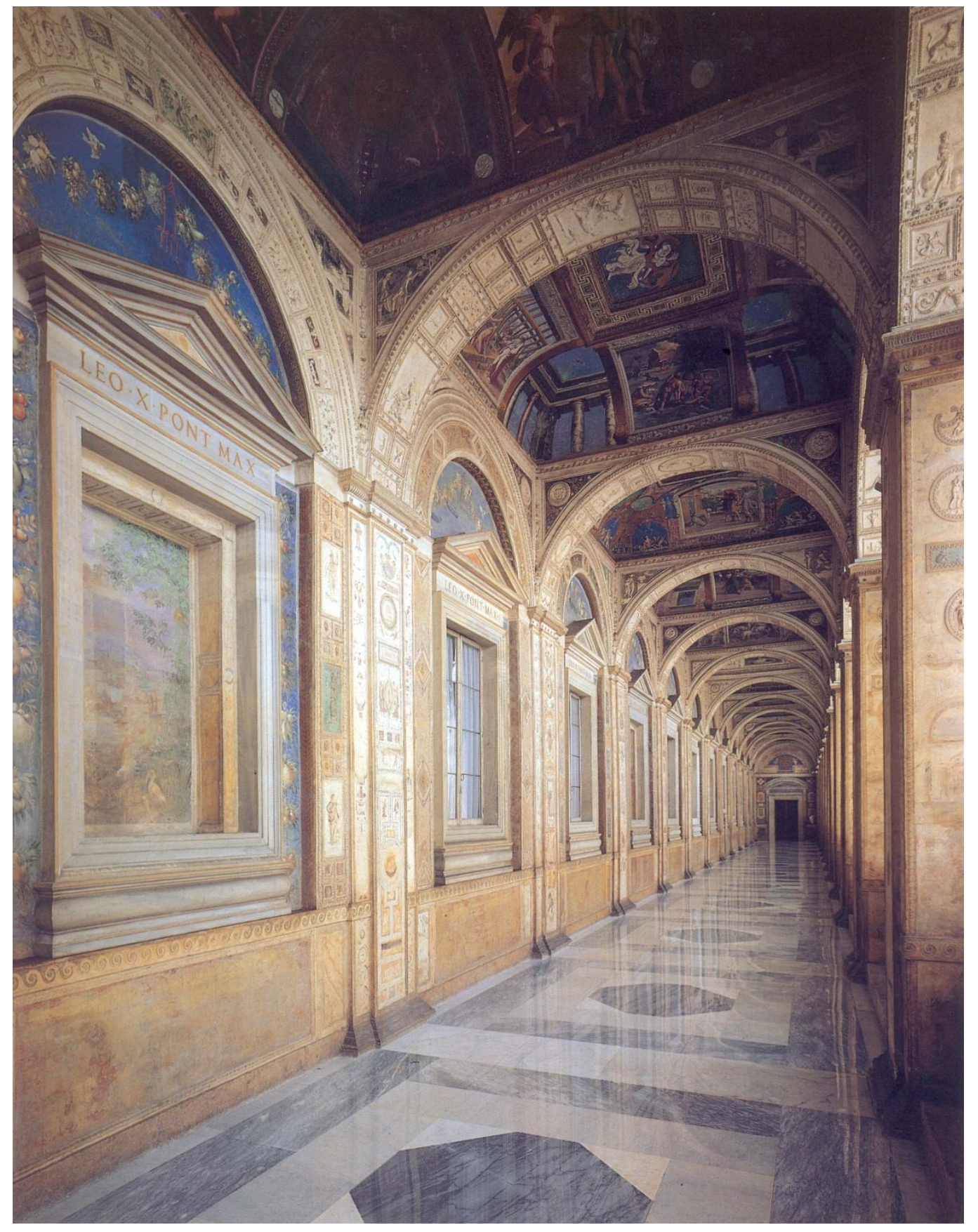

Fig. 35 - Una veduta d'insieme della seconda loggia di Raffaello, in Vaticano. 


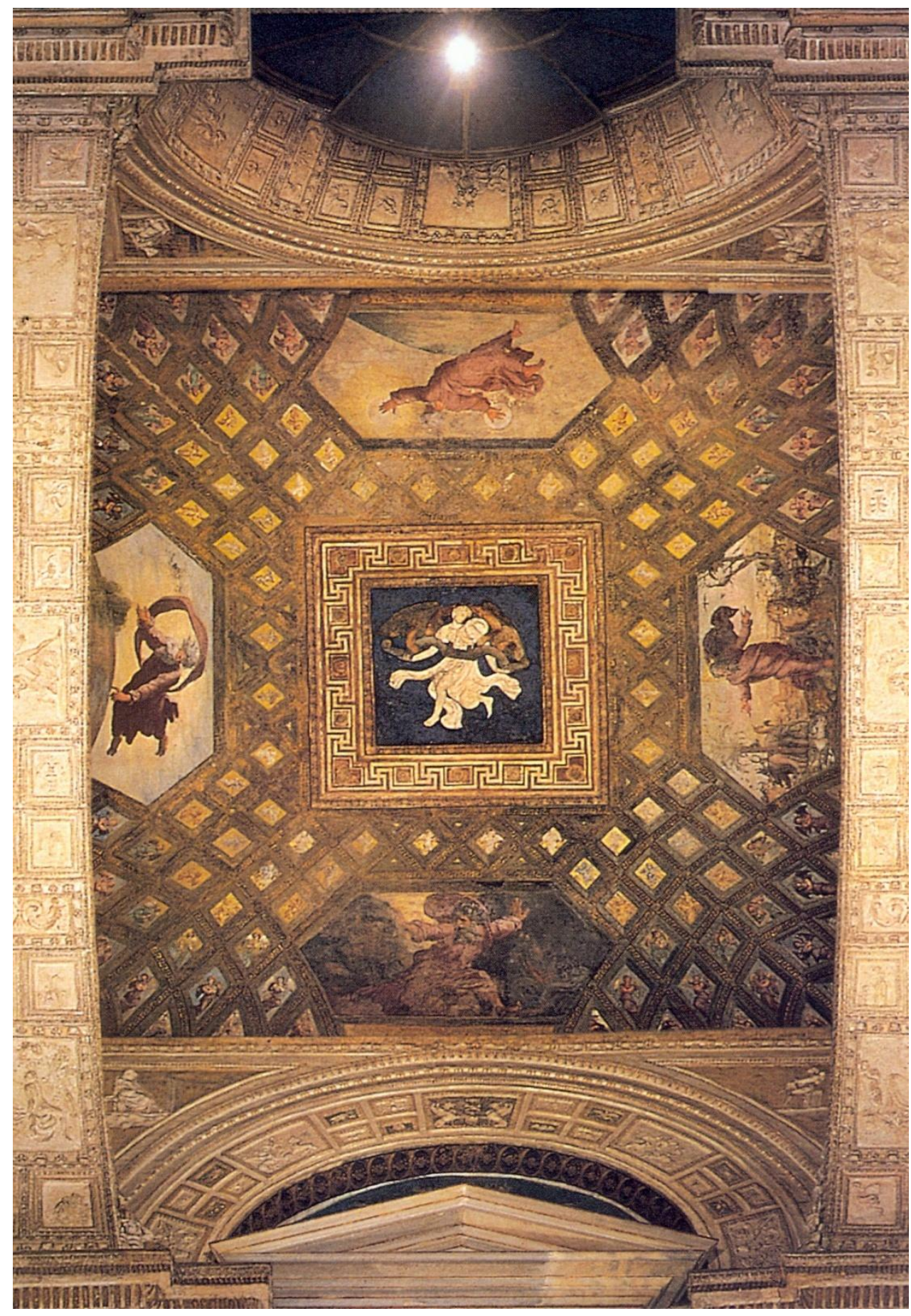

Fig. 36 - La volta della $I^{\circ}$ campata della Loggia, trattata con l'alluminato di potassio. 


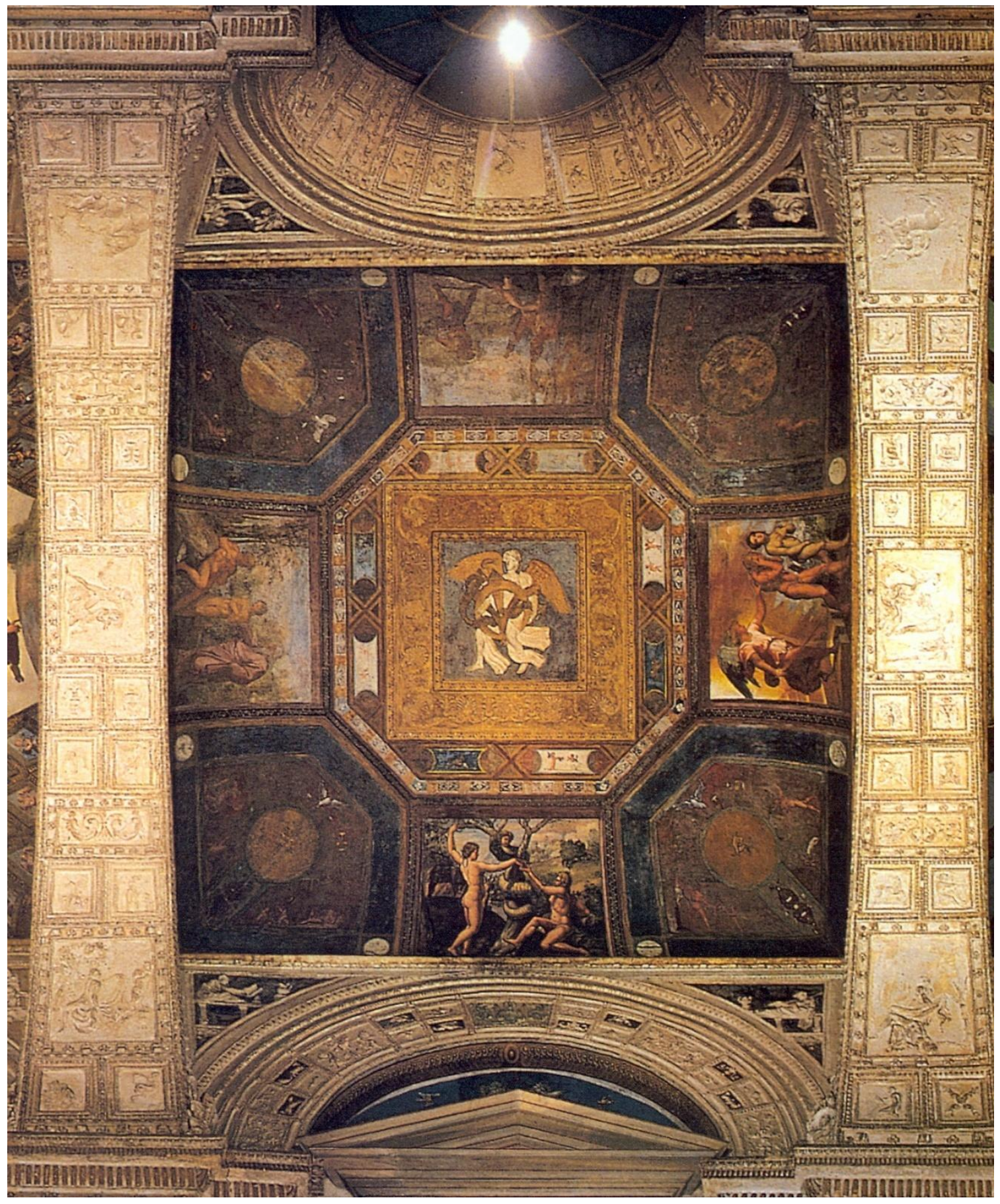

Fig. 37 - La volta della $I^{\circ}$ campata della Loggia, trattata con l'alluminato di potassio. 


\section{IV - Roma e il Lazio dal 1965 al 1985}

Dopo circa quattro anni dal rientro a Roma e dall'assunzione in Vaticano, Colalucci decide di allacciare rapporti di lavoro con la Soprintendenza di Palazzo Venezia. II lavoro al Vaticano lo assorbe fino alle due del pomeriggio, ed è un lavoro che per lo stato Italiano non esiste, poiché è svolto in uno stato estero, dunque Colalucci, nel pomeriggio, può tranquillamente dedicarsi all'attività indipendente. Siamo nel 1964 e l'ambiente delle Soprintendenze romane è monopolizzato da pochi restauratori, alcuni dei quali noti, che fanno quasi tutti i lavori. Colalucci, pur consapevole di questo, e conscio della difficoltà di entrare in un ambiente "chiuso", prepara il suo curriculum e chiede di essere ricevuto dal Soprintendente. II curriculum è corredato da una nutrita documentazione fotografica dei lavori svolti in Sicilia. L' ispettore che lo riceve si mostra inizialmente diffidente nei suoi confronti, ma appena si rende conto della qualità dei lavori che ha svolto, lo introduce immediatamente nell'ufficio del Soprintendente. Dopo qualche mese, arriva il primo lavoro e di seguito ne arriveranno moltissimi altri. In quegli anni le Soprintendenze affidano i lavori attraverso un criterio di tipo "discrezionale", basato cioè sulla qualità professionale del restauratore. Tra il restauratore e il Direttore dei Lavori, che molto spesso è uno studioso di alto livello, si instaura un rapporto di reciproca stima e grande collaborazione, un po' come accade tra medico e paziente. Tra l'altro, anche se ancora vi erano dei bravi restauratori con formazione artigianale che continuavano la loro attività, i diplomati dell'Istituto riscuotevano una sempre crescente fiducia da parte delle Soprintendenze. Colalucci, chiamato da eminenti studiosi, lavorerà per la Soprintendenza di Palazzo Venezia, per la Galleria Borghese e per Castel Sant'Angelo. Lavora essenzialmente da solo o con pochissimi aiutanti, uno o due al massimo. Verso la fine degli anni settanta, nel mondo del restauro, avvengono alcuni cambiamenti di pensiero. Nascono i primi gruppi di restauratori fortemente politicizzati e organizzati in cooperative o consorzi, che mirano a monopolizzare, attraverso gli appoggi politici, il mondo del restauro. La figura del singolo professionista perde popolarità ed il cambio generazionale,che nel frattempo si va verificando all'interno delle Soprintendenze, contribuisce al radicamento delle nuove concezioni . 


\section{La Soprintendenza di Palazzo Venezia}

Siamo nel 1964, Colalucci presenta alla segreteria della Soprintendenza di Palazzo Venezia ${ }^{64}$, la documentazione completa dei lavori eseguiti fino a quel momento. Viene ricevuto da Italo Faldi ${ }^{65}$, storico dell'arte, che ricopre il ruolo di ispettore. Faldi all'inizio si mostra diffidente nei confronti di Colalucci, credendolo uno dei tanti restauratori, di livello mediocre, che continuamente domandavano di essere inseriti nelle liste di fiducia della Soprintendenza. Vedendo la qualità del curriculum, cambia rapidamente atteggiamento e fa in modo che Colaucci venga ricevuto dal Soprintendente, che in quegli anni è Giorgio Castelfranco ${ }^{66}$. Qualche tempo dopo Colalucci riceve il primo incarico, ovvero il restauro della Sagrestia della Cappella Monthioni in Santa Maria di Montesanto $^{67}$ a Piazza del Popolo. La Sagrestia tardo seicentesca a pianta trapezoidale, interamente rivestita di stucchi dorati, e decorata con pitture murali del Baciccio. All'epoca del restauro l'edificio versava in uno stato di gravissimo degrado causato dalla forte e persistente umidità. Mi racconta Colalucci che i danni erano di tale entità da aver causato la perdita totale di un "San Francesco" dipinto ad olio su muro. II restauro si svolge tra giugno e ottobre 1965 sotto la direzione della dott.ssa Maria Vittoria Brugnoli ${ }^{68}$, e comprende il consolidamento degli intonaci e degli stucchi, la pulitura e la reintegrazione di

\footnotetext{
${ }^{64}$ Ovvero la Soprintendenza alle Gallerie del Lazio con sede a Palazzo Venezia.

${ }^{65}$ Ispettore in quegli anni poi ricoprirà la carica di Soprintendente, cfr. "Dizionario.." cit. .

${ }^{66}$ idem.

${ }^{67}$ Le chiese di Santa Maria di Montesanto e Santa Maria dei Miracoli si trovano sulla piazza del Popolo e dividono il cosiddetto "tridente" formato dalla via del Babuino, via del Corso e via Ripetta. Le chiese sembrano gemelle ma in realtà sono diverse per struttura, pianta e dimensioni. Entrambe iniziate dal Rainaldi furono continuate dal Bernini $\mathrm{e}$ completate dal Fontana, i campanili invece furono aggiunti nel Settecento. 
tutte le superfici decorate. Nella dettagliata relazione del restauro ${ }^{69}$, tra le molte annotazioni sulle tecniche esecutive, spicca quella che riguarda la decorazione plastica della Cappella. Leggiamo che gli stucchi, a base di calce e polvere di marmo ${ }^{70}$, risultano lavorati a spatola su uno scheletro grezzo eseguito a calco. L'altra annotazione interessante riguarda la tecnica delle dorature. La lamina d'oro è applicata a colla e non a "missione" come vorrebbe la regola, e ciò ha reso la superficie particolarmente sensibile all'umidità, anche se indubbiamente, come sottolinea Colalucci, la doratura a colla ha una resa estetica migliore di quella a missione. Oltre alla Sacrestia della Cappella Monthioni, Colalucci restaura, sempre per la stessa chiesa, anche un dipinto su tela di Ludovico Gimignani, raffigurante "La Vergine e S. Maria Maddalena de’ Pazzi”.

La stessa dott.ssa Brugnoli, qualche tempo dopo, gli affida il restauro di tre grandi dipinti su tela conservati nella chiesa di San Salvatore in Lauro : "Il trasporto della Santa Casa di Loreto" di G. Peruzzini "Santi marchigiani" di Pier Leone Ghezzi ${ }^{71}$, e il "San Carlo Borromeo e la Vergine" ${ }^{\text {"72 }}$ di Alessandro Turchi ${ }^{73}$. Di seguito gli affida il restauro di altri due grandi dipinti, questa volta appartenenti al Pio Sodalizio dei Piceni : "La Madonna della Misericordia" di Federico Barocci, e "San Gioacchino, Sant'Anna e San Giuseppe" di Pier Leone Ghezzi. Mi dice Colalucci che l'integrità di questi dipinti era fortemente

\footnotetext{
${ }^{69}$ Archivio G.Colalucci, sezione documenti F.1 (serie 1)

${ }^{70}$ Ossia quello che comunemente viene definito "stucco romano".

${ }^{71}$ Pittore romano (1674-1755).

${ }^{72}$ Cfr. Catalogo "Attività della Soprintendenza alle Gallerie del Lazio" Roma, aprile 1967 
compromessa da gravi danni ai supporti in tela, foderati o meno. Le superfici pittoriche erano alterate da ridipinture di pessima fattura ancora frutto di restauri "casuali". Nelle relazioni di fine lavori, Colalucci annota puntigliosamente ogni dettaglio. Leggiamo che il dipinto del Barocci per esempio, era scurito da una patina artificiale a base di zafferano ${ }^{74}$. La "Madonna della Misericordia" del Ghezzi invece, oltre agli strati di vernici scure che offuscavano completamente il timbro cromatico originale ${ }^{75}$, era alterata da un deturpante intervento con stucco colorato, che mirava a nascondere le il cretto originale tipico dei medium eccessivamente oleosi. Colalucci puntualizza che gli impasti troppo ricchi di olio, tendono a "scivolare" sulla mestica, producendo delle crettature anomale come aspetto ma del tutto "fisiologiche" nella sostanza, e che il risultato del rimedio è largamente peggiore del danno.

A questi lavori ne seguiranno molti altri, e Colalucci continuerà a lavorare per la dott.ssa Brugnoli, alla quale si aggiungeranno le dott.sse Luisa Mortari, ed Ilaria Toesca $^{76}$. Per quest'ultima oltre al restauro di una lunetta su tela di Francesco Vanni ${ }^{77}$ raffigurante "La morte di Santa Cecilia" conservata nel Convento di Santa Cecilia, e di un dipinto del Sassoferrato ${ }^{78}$ raffigurante " $\mathrm{La}$

\footnotetext{
${ }^{4}$ G. Secco Suardo nel paragrafo dedicato alle patine scrive "..purchè non se ne abusi, come fanno talora $i$ cattivi restauratori, i quali, sotto il folto velo di esse, tentano di nascondere l'imperizia della loro mano" e cita la ricetta fornita dal Déon a base di zafferano sciolto nell'acqua e mescolato a fuliggine, liquirizia nera e caffè. La miscela veniva stesa sul quadro, lasciata asciugare ed in ultimo verniciata. G. Secco Suardo "Il ristauratore dei dipinti" ed postuma ed. Hoepli, Milano 1894, pag 318 
Madonna del Rosario" conservato nella chiesa di Santa Sabina, Colalucci eseguirà, tra il 1966 ed il 1974 una importantissima serie di restauri su dipinti medievali.

Tra i restauri fuori dal comune vale la pena di citare quello eseguito nel 1970 per la dott.ssa Brugnoli su una grande tela della chiesa di Sant'Ivo alla Sapienza : "S. Ivo si fa avvocato dei poveri" di Pietro da Cortona . Si tratta di una grande pala d'altare centinata, alta più di otto metri e larga poco meno di quattro, il cui recupero già di per se impegnativo, fu gravato dai non facili problemi di movimentazione. Sempre per la Brugnoli, in quello stesso anno, compie il restauro dei dipinti del Passignano nella Cappella Barberini di Sant' Andrea della Valle eseguiti ad olio su muro, e ad olio su tavola. Nella relazione tecnica è descritta la successione stratigrafica dei dipinti ad olio su muro anche se come, Colalucci specifica, in mancanza di lacune apprezzabili, non fu possibile eseguire una ricerca capace di fornire risultati certi.

I dipinti medievali

Nel 1966 Colalucci viene incaricato da llaria Toesca di esaminare il crocefisso della chiesa di San Tommaso ai Cenci ${ }^{79}$. La storica dell'arte, è convinta che al disotto del colore bruno scuro che ricopre tutta la croce, si nascondano i resti di una pittura più antica. Mi dice Colalucci che l'idea della dott.ssa Toesca trovò

\footnotetext{
${ }^{79}$ La chiesa di San Tommaso ai Cenci, si trova nel ghetto di Roma ed è incorporata al Palazzo dei Cenci dal sec.XV. Prima di essere annessa al Palazzo era denominata San Tommaso a Capo delle Mole poiché si trova in prossimità della punta dell'isola Tiberina dove sul fiume, nel medioevo, stavano le mole.
} 
conferma sin dai primi risultati della pulitura. Ricorda che la pesante ridipintura ricopriva una pittura di altissima qualità e ancora leggibile, nonostante le corrosioni delle vecchie puliture a soda. Grazie al restauro, il testo pittorico recuperato sarà oggetto di un importante studio monografico, con il quale la Toesca porterà elementi utili al chiarimento del rapporto esistente tra Roma ed Assisi nell'arte italiana del Duecento. Lo studio mirerà anche a mettere meglio a fuoco gli anni della formazione di Giotto e l'identificazione della figura del Maestro d'Isacco ${ }^{80}$.

Dopo la croce di S.Tommaso ai cenci, Colalucci ottiene dalla Toesca un'altro importane lavoro. Si tratta del restauro di una tavola conservata nella chiesa di Sant'Angelo in Pescheria. Il lavoro, porta ad un nuovo importante recupero. Mi racconta Colalucci che la tavola, prima del restauro, era ricoperta da un'altra tavola dipinta di scuro che, come nelle icone, lasciava in vista soltanto il viso e le mani del dipinto sottostante. La pittura era alterata da orrende ridipinture, ma l'iconografia frontale, lasciava sperare che al disotto vi fosse l'immagine di una Madonna medievale romana. La pulitura, lunga e impegnativa, richiese l'uso del microscopio, acquistato da Colalucci per l'occasione. Durante il restauro furono identificati sei diversi interventi di ridipintura, la cui esecuzione disomogenea ne rese assai difficoltosa l'interpretazione. Mi dice Colalucci che alcuni degli interventi che alteravano l'immagine originale erano molto difficili da identificare poiché erano costituiti da piccole aggiunte messe per impreziosire il disegno, 
ma che davano all'immagine un aspetto più tardo. Ricorda anche che il momento più emozionante della pulitura, fu la scoperta della forma originale degli occhi della Vergine, coperti dalla ridipintura che li aveva allungati ai lati. La manomissione aveva stravolto quei canoni iconografici, rappresentati dalla forma più aperta degli occhi, che consentivano di datare il dipinto attorno al Duecento. L'immagine recuperata dal restauro, sarà identificata dalla Toesca come quella che anticamente a Roma veniva utilizzata per la processione "dell'inchinata". La cerimonia prevedeva che dal Sancta Santorum ${ }^{81}$ uscisse in processione la tavola col Redentore ${ }^{82}$, e da Sant' Angelo in Pescheria ${ }^{83}$ quella con la Vergine. Quando a metà strada le due processioni si incontravano la tavola con l'immagine del Redentore veniva fatta inchinare all'immagine della Vergine, dopo di che i due cortei tornavano alle chiese di partenza e le immagini sacre venivano riposte fino all'anno successivo. Durante il restauro di Colalucci l'opera verrà esaminata anche da Roberto Longhi, e nel 1969 i risultati dell'intervento saranno pubblicati a cura della Toesca, sulla rivista "Paragone"84. Un anno dopo, sempre incaricato dalla Toesca, Colalucci si occupa del restauro della "Madonna" di Santa Maria in Campo Marzio, e successivamente di quello della "Madonna avvocata" nella

\footnotetext{
${ }^{31}$ Ovvero la Scala Santa, oggi racchiusa in un edificio cinquecentesco fatto edificare da Sisto V (Peretti) nei pressi della Basilica di San Giovanni in Laterano. È il luogo più sacro di Roma e del mondo come dice l'iscrizione all'interno “ non est in toto sanctior orbe locus" non vi è in tutto il mondo luogo più santo.

${ }^{82}$ La tavola col Redentore ossia la famosissima immagine Archeropita (non dipinta da mano umana ma creata per intervento divino dalla mano degli Angeli), datata tra il VI ed il VII sec. sarà restaurata da Colalucci nel 1978, per conto dei Musei Vaticani.

La chiesa antichissima risale al sec VIII, e fu edificata in onore dell'apostolo Paolo, da Teodoto, sotto il Pontificato di Stefano III. II nome San'Angelo in Pescheria cioè (in foro piscium) deriva dal mercato del pesce che si teneva li vicino. Nel XII sec. era anche appellata S. Angelo iuxta tempum lovis, da basilica lovis, cioè il portico d'Ottavia. 
chiesa di S. Maria Maggiore a Tivoli attribuita a Jacopo Torriti, ma rivelatasi durante il restauro, un clamoroso falso del sec. XVIII ${ }^{\circ}$.

Negli stessi anni, e sempre nell'ambito dell'Imago Mariae, Colalucci compie per la dott.ssa Sara Stacciali, il restauro della "Madonna" di San Silvestro al Quirinale, e per la dott. ssa Luisa Mortari quello della "Madonna" della chiesa del SS. Nome di Maria.

\section{La Pala di Maranola e lo Stendardo di Lepanto}

Tra i lavori che Colalucci svolge per la Soprintendenza di Palazzo Venezia tra il 1972 e il 1974, vale la pena di citare quelli eseguiti su due opere molto singolari: il grande polittico della chiesa di Santa Maria dei Martiri a Maranola, e lo stendardo di Lepanto della Cattedrale di Gaeta.

La tavola di Maranola, di autore ignoto ma databile intorno alla prima metà del Cinquecento, è una sorta di "grande macchina" nata da un disegno unitario e composta da parti dipinte, e da parti scolpite policrome e dorate. Nella parte centrale della pala è raffigurata una "Madonna col Bambino tra i Santi Pietro e Paolo ed i Confratelli del Carmine", mentre nella parte alta sono rappresentate "L'Ascensione e l'Annunciazione". La struttura è composta da più assi tenute insieme da tre traverse scorrevoli con incastro a doppia coda di rondine, 
tutt'attorno vi è la grande cornice scolpita dipinta e dorata. Le cromie della cornice, sono a base di azzurrite applicata a tempera, mentre le dorature sono preparate con il bolo d'Armenia. Nella parte bassa, sulla base della colonna di sinistra, si legge la parola "anno", sulla base della colonna di destra, la parola "die XVII", più sotto alcuni frammenti suggeriscono la parola "Aprilis". Un vecchio intervento, eseguito nel tentativo di nascondere i danni causati da un principio di incendio, aveva provocato la perdita della metà inferiore delle basi delle colonne che probabilmente dovevano recare l'iscrizione dell'anno di esecuzione. Nella parte alta, in epoca relativamente recente, era stato inoltre applicato un baldacchino di fattura molto modesta che alterava notevolmente l'immagine originale dell'opera ${ }^{85}$. La presa d'atto della complessità costruttiva della tavola, porta Colalucci ad escludere l'ipotesi di smontare l'opera e di trasferirla a Roma, per eseguire il restauro nel suo studio. Nell'interesse del delicato equilibrio che la struttura lignea sembrava ormai aver raggiunto, dispone di eseguire il lavoro in loco. Per prima cosa esegue una meticolosa operazione di consolidamento del colore e dell'oro, e poi un lungo lavoro di pulitura. II pesante strato di colle oli e resine che era divenuto scurissimo, ricopriva un colore originale non particolarmente ritoccato ma danneggiato da vecchie puliture aggressive. Oltre alle operazioni sulla pellicola pittorica e sull'oro, il restauro comprenderà il risanamento del supporto ed il suo consolidamento. Nel luglio del 1973 a restauro concluso, durante la cerimonia di 
inaugurazione Colalucci terrà una conferenza ${ }^{86}$ alla presenza delle autorità cittadine per spiegare il lavoro eseguito. Vale la pena di sottolineare come la sensibilità da lui dimostrata nei confronti del dipinto in occasione del restauro, sarà totalmente vanificata anni dopo quando, per essere inviata ad una mostra, l'opera sarà completamente smembrata. Mi racconta Colalucci che, trovandosi per caso a visitare la chiesa di Santa Maria dei Martiri all'inizio degli anni novanta, si accorse con grande tristezza che la tavola giaceva smontata in un ambiente di servizio ${ }^{87}$ attiguo alla chiesa, senza alcuna precauzione per la sua conservazione.

Nel 1974 Colalucci si occupa del restauro dello Stendardo di Lepanto, un pezzo storico e artistico di grande importanza. L'opera, attribuita a Girolamo Siciolante da Sermoneta, e datata 1570 fu eseguita come vessillo di guerra su commissione di Papa Pio Vo, e fu issata da Marc'Antonio Colonna sulla nave ammiraglia della flotta Pontificia nella battaglia di Lepanto e successivamente donata alla città di Gaeta. Lo Stendardo è dipinto da entrambi i lati, e rappresenta il Crocefisso con i Santi Pietro e Paolo. II lato A, secondo l'iconografia classica, riproduce San Pietro alla destra del Cristo e San Paolo alla sinistra. Nel lato B l'impianto è invertito e di conseguenza San Pietro è alla sinistra del Cristo e San Paolo alla destra. In basso vi è una fascia recante il motto costantiniano "in hoc signo vinces” aggiunta alla fine del '700. Lo Stendardo è dipinto su seta color cremisi tinta secondo il metodo classico della tintura dei tessuti cioè per impregnazione.

\footnotetext{
${ }^{36}$ Quella tenuta a Maranola nella chiesa di Santa Maria dei Martiri , fu la prima conferenza di Colalucci. 
È dipinto a tempera grassa ${ }^{88}$ direttamente sulla seta senza preparazione anche se il tessuto molto probabilmente fu trattato preventivamente con acqua di colla per facilitare l'adesione del colore. L'uso della tempera grassa ha evitato che si producessero danni sulla seta non protetta dalla preparazione che, al contatto medium solo oleoso, si sarebbe macchiata e poi lacerata. L'uso di un medium puramente proteico invece avrebbe dato alla pellicola pittorica una secchezza eccessiva che l'avrebbe resa incapace di contrastare le sollecitazioni cui il supporto sarebbe stato inevitabilmente sottoposto, e dunque avrebbe finito con lo staccarsi. La pittura dello Stendardo è impreziosita da elementi dorati come i dardi fiammeggianti che simboleggiano il fuoco greco, le bordature dei panneggi e le aureole. I dardi sono posti a distanze regolari l'uno dall'altro e costituiscono un motivo ornamentale del fondo dello Stendardo. L'oro è applicato con la tecnica della "missione" ma al posto del mordente resinoso vi è uno strato di colla animale. A partire dal 1779 , per volontà del vescovo di Gaeta Carlo Pergamo, lo Stendardo fu trasformato in pala d'altare e posto sull'altare maggiore del Duomo. In quella occasione, l'esigenza di montare lo Stendardo su un telaio impose l'esecuzione di una foderatura che fu realizzata con una tela di canapa applicata con colla di farina. È singolare come in quella occasione, fu scelto di lasciare in vista il lato B dello Stendardo e di foderare il lato A, forse perché il lato B era in migliori condizioni di conservazione. Durante il restauro furono rifatte anche delle dorature e fu aggiunto il motto costantiniano "in hoc signo vinces" (nell'ambito del restauro eseguito da Colalucci fu ipotizzato che la seta usata per 
il motto sia stata prelevata da uno dei lati dello Stendardo che in origine aveva misure maggiori delle attuali). Nel 1779, contestualmente alla foderatura,furono anche eseguite delle stuccature ad olio, in buona parte tuttora presenti, poiché negli interventi di restauro successivi sono state conservate come documento storico. Nel 1943, durante la seconda guerra mondiale, lo Stendardo fu fortemente danneggiato dalle schegge prodotte da una bomba caduta sul Duomo.

Le schegge produssero grandi lacune all'interno dello Stendardo che, per interessamento di Papa Pio XII', fu messo al sicuro in Vaticano. Nel 1950 l'opera fu restaurata nel laboratorio di restauro degli arazzi del Vaticano. II restauratore Silvio Grossi asportò la canapa e foderò entrambi i lati dello Stendardo con seta applicata con colla di coniglio. Durante questo intervento fu anche deciso di spostare la fascia con il motto costantiniano dal lato B al lato A. Nel 1953, a restauro concluso, lo Stendardo fece ritorno sull'altare maggiore del Duomo, ma le condizioni ambientali, totalmente inadatte alla buona conservazione dell'opera, dettero in breve tempo l'avvio ad un nuovo pesante degrado. I problemi principali derivarono dalla colla usata in grande quantità dal Grossi per l'incollaggio delle sete, che con l'umidità, era divenuta molto scura trasformandosi anche in terreno di cultura per microrganismi di vario genere. Nei periodi di caldo-secco la stessa colla, ormai dura e vetrosa, causò gravissime deformazioni e lacerazioni della seta originale. II deterioramento provocato dai fattori descritti, rese necessario un nuovo restauro. Lo Stendardo arrivò a 
Colalucci in uno stato di avanzato degrado estetico e materico. La prima operazione che venne eseguita riguardò l'asportazione delle sete e della colla di coniglio applicate dal Grossi. Colalucci tuttavia pienamente consapevole che una buona percentuale della colla essendo penetrata all'interno del tessuto originale, non sarebbe stata asportabile senza causare ulteriori stress all'opera, nella relazione finale scriverà di aver rimosso la colla "ai limiti della resistenza della seta originale ${ }^{89 "}$. Dopo aver asportato le sete e la colla, Colalucci, in accordo con la Direzione dei Lavori, optò per la foderatura del solo lato B dello Stendardo, non più con uno ma con due teli di seta, scegliendo di lasciare totalmente libero il lato $A^{90}$. Durante il restauro fu anche scelto di distanziare dal lato inferiore la fascia con il motto per differenziarlo dal corpo originale del Vessillo. La scelta fu determinata dal fatto che, in seguito alle ricerche storiche e all'analisi ravvicinata dei materiali, risultò abbastanza chiaro che la fascia di tessuto recante il motto costantiniano, era stata ricavata da una banda di seta asportata dai lati dello Stendardo. L'ipotesi fu ulteriormente supportata, dalla fedelissima riproduzione dello Stendardo, fatta dal Vasari nell'affresco raffigurante la battaglia di Lepanto, dipinto nella sala Regia in Vaticano subito dopo la vittoria. Nell'affresco vasariano infatti il Vessillo appare con ampi margini attorno alla raffigurazione e soprattutto senza nessuna traccia del motto. Colalucci applicò le nuove sete di Lione ${ }^{91}$ con una emulsione acrilica stesa a freddo. Prima di giungere a questa soluzione fece una serie di prove con varie resine includendo nei test anche la Beva 371

\footnotetext{
${ }^{89}$ Cfr relazione dell'intervento, archivio G. Colalucci, sezione documenti F.1 (serie 1), 14.

${ }^{90}$ Come sottolinea Colalucci sarebbe stato impensabile lasciare lo stendardo senza alcuna protezione aderente alla seta originale che dopo le complesse vicende storiche e conservative era lesionata e fatiscente. Le dimensioni dell'opera $(3,20 \times 2,14)$ ne rendono difficile anche la sistemazione all'interno di due lastre di vetro o perspex. 
presentata al convegno ICOM di Venezia pochi anni prima. Compie dei test di trasparenza e reversibilità con resina Movilit D.M. 55 non diluita e con resina Beva 371 di Lascaux diluita in alcool puro. Le prove vengono eseguite applicando le resine su un unico velo di seta e poi su due veli sovrapposti. La Beva verrà scartata poiché ritenuta non sufficientemente trasparente e verrà scelta la resina Movilit ${ }^{92}$. II restauro comprese anche l'impianto di un nuovo sostegno metallico che potesse tenere l'opera in posizione verticale. Poiché il microclima del Duomo fu giudicato inadatto alla conservazione dello Stendardo, l'opera a restauro concluso, fu portata nel Museo Diocesano di Gaeta ${ }^{93}$.

II Guido Reni della SS. Trinità dei Pellegrini

Tra il 1981 ed il 1982, Colalucci restaura una grande tela dipinta nel $1625^{94}$ da Guido Reni per l'Altare Maggiore della chiesa della SS. Trinità dei Pellegrini ${ }^{95}$ a Roma. La tela, eseguita su commissione del cardinale Ludovisi, ha dimensioni imponenti ( più di cinque metri di altezza e tre di larghezza) e raffigura "il Crocefisso con la Trinità". I due angeli inginocchiati sulle nubi in basso,

\footnotetext{
${ }^{92}$ Ancora oggi il Movilit mantiene quasi inalterate le sue caratteristiche e svolge la sua funzione adesiva.

93 Nel 1988 lo Stendardo fu rimosso dagli ambienti del Museo Diocesano poiché il Palazzo de Vio doveva essere restaurato e fu portato nel centro culturale di Gaeta, dove rimase fino al 2006 anno in cui tornò al Museo. Durante i diciassette anni passati fuori dal Museo l'opera subì una serie di sollecitazioni anomale di tipo meccanico (ripetuti spostamenti). Subì anche degli stress termoigrometrici, poiché sottoposto a continue variazioni di temperatura e di umidità che generarono in breve problemi alla pittura originale e misero a dura prova anche la tenuta del restauro del '75. Nel 2007 l'opera è stata oggetto di un intervento di revisione eseguito da G. Colalucci e da D. Bartoletti. Successivamente è tornata al Museo Diocesano di Gaeta.
} 
fuoriescono dal disegno primitivo poiché furono aggiunti dal Reni ${ }^{96}$ in via di esecuzione, su suggerimento dei confratelli della chiesa. La tela aveva subito un restauro nel 1835, da parte di Lorenzo e Filippo Principi diretti da Vincenzo Camuccini, ed un altro restauro circa trent'anni dopo. Dal rilevamento sulla tecnica di esecuzione ${ }^{97}$, fatto da Colalucci in occasione del suo intervento, emerge che il dipinto è eseguito ad olio su una tela preparata con un imprimitura colorata. II modellato di base è costituito da toni scuri (terre- neribruni) a seconda dei colori ai quali servivano da sottofondo. I gialli e gli incarnati (tranne quello del Dio Padre) sono preparati con terra verde, l'azzurro con un colore bruno-rosso, i grigi ed il vestito dell'angelo inginocchiato a destra della croce con un colore bruno scuro e freddo tendente al blu, le lacche rosse ed il mantello viola del Dio Padre sono preparati in bruno. II modellato è ottenuto dal pittore partendo dalle ombre mezzane (per le quali sfrutta a volte il colore del fondo) e andando verso i toni più scuri e più chiari. Le ombre sono ottenute attraverso sovrapposizioni successive di velature, mentre le luci sono date con pennellate grasse e corpose. Reni ha dipinto per prima la figura del Dio Padre (prima la tonaca e poi il mantello) poi i due putti che reggono la croce, poi la croce e il Cristo. Per ultimi il mondo ed i due angeli inginocchiati. Durante il restauro, Colalucci individua alcuni pentimenti che riguardano la posizione delle braccia del Dio Padre (ora più basse e più corte), quelle del Cristo e la croce (ora più basse) ed un drappo del mantello di broccato del Dio

\footnotetext{
${ }^{96}$ L'artista percepì per l'opera un compenso di 800 scudi. 
padre (ora nascosto dal colore del fondo). II dipinto arriva a Colalucci in cattivo stato di conservazione con la tela originale lenta, anche se foderata, e montata su un telaio non originale. II supporto originale è poco aderente alla tela di rifodero ed è coperto di colla vetrificata. Il colore originale è offuscato da un pesantissimo beverone scuro a base di colla e da una vernice ingiallita ed annerita dai depositi di polvere e fumo delle candele. Per prima cosa Colalucci pulisce il dipinto. L'operazione si svolge in due tempi poiché le stratificazioni che ricoprono il colore originale sono di diversa natura. La vernice ingiallita viene asportata con Dimetilformammide mentre il beverone a base di colla richiede l'impiego di una soluzione leggermente basica. Poi procede passa alla foderatura. Per una serie di ragioni legate alle dimensioni del dipinto, ed alla presa d'atto che il vecchio telaio ligneo, anche se estensibile, non era stato in grado di garantire nel tempo il tensionamento del supporto, Colalucci decide di eseguire una foderatura termoplastica e di montare la tela su un telaio metallico. È molto interessante notare come decida di utilizzare proprio la Beva 371 che anni prima, per lo stendardo di Lepanto, aveva scartato ritenendola poco sperimentata e complicata da usare. A distanza di quasi dieci anni infatti, Gustav Bergher aveva reso la resina più versatile. L'uso più semplice del Beva 371 , aveva incentivato l'esecuzione delle foderature termoplastiche nel mondo e la conseguente costituzione di una soddisfacente letteratura scientifica sull'argomento, in grado di fornire ottime garanzie sul comportamento della resina nel tempo e sulla sua reversibilità. 


\section{Castel Sant'Angelo}

Un altro capitolo molto importante per la vita professionale di Colalucci, è rappresentato dagli importanti restauri svolti per il Museo Nazionale di Castel Sant' Angelo. In un arco di tempo di circa trent'anni (1966/1996), Colalucci restaura i cicli di affreschi cinquecenteschi della sala Paolina, della Biblioteca, della sala di Apollo, del corridoio Pompeiano, della stufetta di Clemente $\mathrm{VII}^{98}$, ed i soffitti lignei ed $\mathrm{i}$ fregi in affresco delle sale del Perseo e di Amore e Psiche $^{99}$. Lavora anche su numerose opere mobili ${ }^{100}$, su sculture marmoree e sulla settecentesca statua bronzea raffigurante l'Arcangelo Michele posta sul maschio del Castello. Durante gli anni trascorsi a Castel Sant' Angelo, Colalucci ha modo di instaurare rapporti di grande stima e collaborazione con i direttori che in quell'arco di tempo si succedono alla guida del Museo: il dott. Eraldo Gaudioso, la dott.ssa Filippa Aliberti (che aveva conosciuto giovanissima studentessa quando lavorava in Sicilia) il dott. Sabino lusco ${ }^{101}$ e l'arch. Liliana Pittarello. Ma instaura anche un rapporto di reciproca stima con il giovane ispettore Bruno Contardi, brillante allievo di Argan .

Lavorando sulle opere di Perin del Vaga, di Pellegrino Tibaldi, di Luzio Romano e Cristoforo Gherardi, Colalucci amplia la sua conoscenza sul restauro e sulle tecniche esecutive delle grandi decorazioni pittoriche e plastiche della Roma cinquecentesca. II modo di affrontare il restauro di cicli pittorici omogenei, se pure inevitabilmente manomessi da vecchi interventi, richiede doti aggiuntive al

\footnotetext{
${ }^{98}$ Cfr. AAVV "Quando gli Dei si spogliano" II bagno di Clemente VII a Castel Sant'Angelo e le altre stufe romane del primo Cinquecento, ed Romana Società- Roma 1984, pp. 98-100

${ }^{99}$ Per tutti i restauri sui cicli di affresco e sui soffitti lignei si rimanda al catalogo della mostra “

${ }^{100}$ Restaura tra gli altri il San Girolamo di Lorenzo Lotto, ed il polittico degli Zavattari. Per quest'ultimo cfr. relazione di restauro sul catalogo "Il polittico degli Zavattari" ed Centro Di- Firenze 1984 
restauratore che, durante il lavoro, pur non perdendo mai di vista il piccolo particolare, deve sempre tenere presente la visione d'insieme. Queste doti, così evidenti in Colalucci, si acquisiscono in anni di esperienza e di analisi approfondite. Nell'impegno che Colalucci impiega nell'affrontare il restauro delle decorazioni di Castel Sant'Angelo, si inserisce anche lo studio dei vecchi interventi di restauro di cui queste opere erano state più volte oggetto. Egli riesce a mettere a fuoco il modo di intervenire di alcune storiche figure di restauratori, attivi in ambito romano tra il '700 e I' 800 . Tra questi, quello che maggiormente cattura la sua attenzione, è il settecentesco Mazzuoli, per il singolare tratteggio che usava per ridare vigore alle ombre "appassite". Mi confida Colalucci che, l'essere riuscito in quegli anni a mettere a fuoco la tecnica d'intervento del Mazzuoli come pratica di reintegrazione, gli sarà di grande aiuto in seguito quando ritrovandola sugli affreschi di Michelangelo, potrà distinguerla dalla pittura originale senza particolari difficoltà.

A Castel Sant'Angelo, fino all'inizio degli anni '80, lavora per lunghi periodi da solo o al massimo con uno o due aiutanti. Questo era possibile perché all'epoca, i tempi per l'esecuzione dei lavori, erano assai dilatati rispetto ad oggi; dal 1980 in poi invece inizia ad avere un numero maggiore di collaboratori. Oltre alle vicende strettamente legate al lavoro, l' essere stato "inquilino privilegiato" di un luogo fuori dal comune come Castel Sant'Angelo ha regalato a Colalucci esperienze molto singolari. Gli anni di cui si parla erano assai diversi da quelli attuali tutto era più semplice e le procedure burocratiche 
erano assai più snelle di quelle in vigore oggi. II Museo di Castel Sant'Angelo, come tutti i Musei statali italiani, chiudeva alle 14. Si attendeva che i visitatori fossero usciti, poi usciva anche il personale degli uffici ed i custodi addetti alle sale, e rimaneva soltanto il custode che abitava in uno dei due torrioni fortificati sul ponte Sant'Angelo, quello di sinistra. Colalucci arrivava verso le 14,30 appena uscito dal Vaticano. Entrando trovava solo il custode che gli consegnava le chiavi della sala in cui doveva lavorare. Da quel momento e fino all'ora di uscita che generalmente era attorno alle 18, Colalucci restava praticamente solo all'interno della grande fortificazione, cosa che oggi sarebbe impensabile. Mi racconta che era come fare un salto indietro nel tempo, basti pensare che prima della posa in opera dell'ascensore, per accedere agli appartamenti Farnesiani, era necessario salire lungo la rampa diametrale passando dal ponte levatoio. La rampa immette nel cuore della Mole, un ambiente estremamente suggestivo che ricorda le famose incisioni di G. B. Piranesi ${ }^{102}$. A completamento di questa atmosfera, ${ }^{103}$ poiché gli ambienti del Castello venivano frequentemente usati come set cinematografici, mi dice che non era raro veder comparire attori nei panni di "Papa Giulio II" o, come fu nel 1991, Placido Domingo nei panni di Cavaradossi che si accingeva ad essere giustiziato sul terrazzo delle corazze.

Uno degli ultimi lavori che Colalucci esegue a Castel Sant'Angelo riguarda la settecentesca scultura bronzea del Werschaffelt che raffigura "I'Arcangelo Michele che rinfodera la spada dopo la pestilenza del 590”. La scultura è posta sul

\footnotetext{
${ }^{02}$ A tale proposito si veda M. Calvesi e altri in "Piranesi nei luoghi di Piranesi - Carceri, Mole Adriana, Vedute di Roma" cat. della Mostra, ed. Palombi, Roma 1979. 
maschio della fortificazione, è alta 4 metri, ha una apertura alare di 5 metri, e dal 1752 sostituisce il più antico Angelo di marmo di Raffaello da Montelupo ${ }^{104}$. L'Angelo, non è frutto di un unica fusione, ma è composto da 35 pezzi uniti da perni in bronzo. La scultura è sostenuta da un armatura metallica interna inserita in una base in muratura rivestita di blocchi di travertino. Nel 1982, fu avviata una campagna di indagini scientifiche e strutturali, atte a verificare lo stato di salute della scultura bronzea e della base marmorea. Poiché nell'ambito delle indagini emersero dati preoccupanti circa lo stato di conservazione dell'Angelo e della base in travertino, fu deciso di procede ad un radicale intervento di restauro. La statua mostrava allarmanti segni di adagiamento su se stessa, a causa della corrosione della armatura metallica all'altezza del colmo della zavorra ${ }^{105}$. Nel 1986 per eseguire il restauro del bronzo, e per poter sostituire l'armatura in ferro, fu necessario smontare completamente l'Angelo. Venne costruita un'impalcatura tutt'intorno alla grande statua da dove, tra l'altro, era possibile una vista su Roma letteralmente mozzafiato. II primo intervento fu quello di consumare la parte interna dei perni, salvando quella esterna per non danneggiare la filettatura originale. Alla fine di un lunghissimo lavoro tutti i 35 pezzi, alcuni dei quali di notevoli dimensioni ${ }^{106}$, furono smontati, separati ed imballati in attesa di essere trasportati al laboratorio di analisi dell' ENEA dove dovevano essere eseguiti gli esami metallografici. In quello stesso contesto doveva essere individuato il baricentro di ogni singolo pezzo necessario alla progettazione della nuova armatura metallica. Le casse in legno con i pezzi

\footnotetext{
${ }^{104}$ Anche l'Angelo di marmo, che ora si trova nel cortile detto dell' Angelo, è stato restaurato da Colalucci .

105 L'armatura originale era costituita da tre barre verticali interne e da due barre orizzontali esterne. Era inserita in una zavorra costituita da mattoni legati con malta pozzolanica inglobati in una colata di malta e mattoni tritati. La zavorra riempiva la base dell'Angelo fino ad una quota di circa m.1,60 corrispondente all'altezza delle ginocchia

106 Solo il torace pesa ben $646 \mathrm{~kg}$. Tutta la scultura, esclusa l'armatura interna, pesa $1636 \mathrm{~kg}$.
} 
venivano stoccate nel terrazzo delle corazze in attesa del trasferimento. Siamo a metà degli anni ' $80 \mathrm{e}$, nel mondo della conservazione, l'impatto del restauro della Sistina è fortissimo. Di quella risonanza però, che nasceva spontanea attorno alla unicità dell'opera che si andava restaurando, ne viene fraintesa l'essenza, e di quel successo, dovuto aggiungo io, alla preparazione ed al carisma delle persone che se ne occupavano, si cercherà di imitarne solo l'aspetto esteriore. Da quegli anni in poi il mondo del restauro non sarà più lo stesso, e si assisterà ad un aumento esponenziale di "eventi costruiti ad hoc" per coinvolgere la stampa, e portare al centro della cronaca culturale, anche lavori che si sarebbero potuti svolgere senza alcuna pubblicità. Si inventerà di tutto, e la spasmodica ricerca di visibilità arriverà fino ai giorni nostri con punte che si commentano da sole, cito per tutti "i restauri on-line" o quelli eseguiti di fronte ad un pubblico di visitatori paganti. A questa logica non sfugge l'Angelo del Werchaffelt. Come ricorda Colalucci, tutto ebbe inizio dalla singolare idea di una architetta della Soprintendenza per i Beni Ambientali ed Architettonici del Lazio, che all'epoca collaborava con la Direzione del Museo di Castel Sant'Angelo. L'architetta, ipotizzando erroneamente che l'Angelo fosse fuso in un unico blocco, pensò che la statua, con una idonea imbracatura, potesse essere sollevata e portata con un elicottero, al laboratorio di indagini scientifiche, distante da Roma circa $25 \mathrm{~km}$. Proviamo ad immaginare solo per un istante questa scena: un Angelo di bronzo del peso di una tonnellata e mezza che, tenuto da un elicottero, sorvola Roma come la Madonna Pellegrina della "Dolce Vita" di Fellini... 
Nonostante i pareri nettamente contrari del direttore dei lavori e di Colalucci, l'idea riuscirà a fare breccia nei vertici dell'allora Direzione Generale del Ministero, che evidentemente intravedeva in quella azione spettacolare, un'occasione di visibilità. L'uso dell'elicottero piacerà al punto che, anche di fronte all'impossibilità oggettiva di sollevare l'Angelo in un'unica soluzione, sarà comunque usato come mezzo per calare le casse contenenti pezzi della statua smontata, dal terrazzo delle corazze fino a terra. Vorrei aggiungere che, durante questa operazione, una delle casse urterà pesantemente una parte della balaustra in travertino del terrazzo, facendola crollare. Le casse contenenti i 35 pezzi dell'Angelo, raggiungeranno successivamente il laboratorio di indagini, a bordo di un camion. A parte l'esordio un po' movimentato, Colalucci mi dice che il restauro si svolse senza problemi fino al momento del rimontaggio della statua sul maschio del Castello. Mi dice che nel luglio del 1986, l'allora Direttore Generale del Ministero ${ }^{107}$, visitò il cantiere. L'intervento sull'Angelo è praticamente concluso, ma il rimontaggio della statua è rallentato dal protrarsi dei complicati lavori di consolidamento della base marmorea. I problemi tecnici interessano poco il Direttore Generale che ha pensato di far tornare l'Angelo sul maschio del Castello per il giorno di San Michele ${ }^{108}$, in modo da farlo benedire dal Pontefice ${ }^{109}$. Per soddisfare il desiderio del Direttore, l'Angelo verrà montato due volte, con costi aggiuntivi per l'amministrazione pubblica. In occasione della festa di San Michele, sarà costruita una gabbia fatta di tubi

\footnotetext{
${ }^{107}$ Francesco Sisinni

108 II giorno di San Michele si festeggia il 29 settembre.

${ }^{109}$ Va detto che da poco tempo il Ministero dei Beni Culturali si era trasferito nel Complesso monumentale del San Michele a ripa. II Direttore Generale aveva fissato la data di una visita del Papa Giovanni Paolo II alla sede del Ministero in modo da farla coincidere con la festa di S. Michele.
} 
metallici in modo da sostenere l'Angelo privo di armatura interna. Durante i festeggiamenti con i fuochi di artificio, ai quali i restauratori non saranno invitati, un candelotto finirà sul terrazzo delle Corazze dove era stata stoccata la cassa contenente una delle ali, che non era stato possibile sostenere con la gabbia metallica. Colalucci mi racconta che osservando lo spettacolo pirotecnico dal ponte Sant'Angelo, si accorse dell' incendio che si andava sviluppando ai piedi della statua. Cercò di entrare al Castello, senza riuscirci a causa della folla, per avvertire i custodi di ciò che stava accadendo. Mi dice che all'arrivo dei vigili del fuoco, il materiale plastico all'interno della cassa, con il calore si era fuso e depositato sull'ala di bronzo, e che questo richiese I' esecuzione di una pulitura supplementare del pezzo. Conclusa la festa, la statua e la gabbia di sostegno saranno smontate, e dopo la messa in opera di una nuova impalcatura l'Angelo tornerà definitivamente al suo posto nel $1987^{110}$

\section{Palazzo Falconieri}

Nel 1977 con il lavoro di Palazzo Falconieri ${ }^{111}$, l'attività di Colalucci subisce un radicale cambiamento. L'imponente entità del restauro, da eseguirsi in soli 10 mesi, gli imporrà l'ingaggio di una vera e propria squadra di collaboratori, cosa per lui assolutamente nuova visto che fino a quel momento aveva lavorato

\footnotetext{
${ }^{110}$ Per le notizie tecniche sulla statua e sul restauro cfr "L'Angelo e la Città" catalogo della mostra, ed. Fratelli Palombi settembre 1987. 
quasi sempre da solo o con pochissimi aiutanti. Palazzo Falconieri che si trova in via Giulia e che dal 1927 è sede dell'Accademia di Ungheria, tra il 1640 ed il

1651 fu ampliato e restaurato da Francesco Borromini. Suo è l'ampliamento della facciata su via Giulia, quello del braccio verso il Tevere, e quello dell'altana, e sue sono le decorazioni a stucco di alcuni soffitti del Palazzo. Nel 1977, nell'ambito di un radicale risanamento dell'edificio iniziato nel 1975 , Colalucci viene incaricato del restauro degli stucchi di Borromini e delle decorazioni murali ottocentesche all'interno del Palazzo ${ }^{112}$. Negli anni ottanta del Settecento in occasione del matrimonio di Costanza Falconieri con Luigi Braschi nipote del Pontefice Pio $\mathrm{Vl}^{\circ}$, l'interno del Palazzo era stato restaurato ed "abbellito" con decorazioni e dorature. Altri interventi di abbellimento e decorazione a tempera da quel momento si ripeteranno per tutto l'Ottocento. Quelli documentati coincidono con eventi storici importanti come quello del 1878 in occasione dell'elezione a Papa, col nome di Leone XIII', del cardinale Gioacchino Pecci inquilino del Palazzo. In quel contesto una saletta con stucchi borrominiani venne interamente decorata a tempera. Sono inoltre documentati interventi nel 1896/97 in coincidenza della costruzione degli argini del Tevere, con i quali il Governo Italiano pose fine alle frequenti e devastanti inondazioni che nei secoli avevano pesantemente degradato il sottosuolo della città. II restauro che Colalucci nel 1977 si trova a dover affrontare è anomalo, poiché fuoriesce da quei canoni di intervento all'interno dei quali era abituato a muoversi. Si trattava infatti di restituire integrità e godibilità a decorazioni

112 Poiché il Palazzo è sede dell'Accademia di Ungheria e poiché il restauro fu interamente finanziato dal Governo Ungherese, la competente Soprintendenza svolse esclusivamente il ruolo di "Alta sorveglianza" previsto in questi casi. 
pittoriche inserite in un contesto di uso corrente pur operando secondo i criteri del moderno restauro.

La ristrettezza dei tempi che ha a disposizione per portare a compimento il restauro lo induce a mettere in piedi un gruppo di lavoro composto da giovani restauratori allievi dell'I.C.R guidati da alcuni colleghi del laboratorio vaticano molto esperti nel restauro delle decorazioni murali a tempera e delle dorature e da una collega restauratrice Ninetta Ferrazzi. Quel cantiere molto difficile sarà per i giovani allievi dell'istituto un'occasione unica di apprendimento per tutto ciò che concerne la tecnica esecutiva ed il restauro delle decorazioni murali a tempera, campo nel quale quei restauratori vaticani erano veri e propri "maestri". La relazione dell'intervento di restauro ${ }^{113}$ contiene come al solito anche il rilevamento della tecnica esecutiva, che in questo caso fornisce interessanti particolari sulle decorazioni plastiche del Borromini. Siamo a cavallo tra la prima e la seconda metà del Seicento e gli stucchi, pur mantenendo la composizione base di calce e polvere di marmo, iniziano a presentare piccole percentuali di aggiunge di altri materiali, in questo caso di caseina. Dalle analisi chimiche fatte eseguire da Colalucci, risulta che la qualità della polvere di marmo usata dal Borromini, varia a seconda della tonalità che l'artista vuole ottenere nell'impasto. Per un tono caldo adopera il travertino di Tivoli, per un tono freddo il marmo bianco di Carrara. II modus operandi di tutti gli elementi decorativi quali i fiori, i frutti e i piccoli animali della simbologia ermetica sorprendentemente modellati in opera dunque direttamente sulle volte,

${ }^{113}$ Archivio G.Colalucci (sezione documenti) F.6 (serie 1) -9 
sottolinea la grande capacità e la genialità dello scultore. Le cornici, eseguite fuori opera e poi applicate in situ, se pure di fattura eccellente rientrano nei normali canoni esecutivi.

I temi iconografici adottati da Borromini per le decorazioni dei soffitti di Palazzo Falconieri, derivano dalla simbologia ermetica. Al centro del soffitto di una sala ${ }^{114}$, pone un gruppo plastico formato da simboli: l'acqua, la terra, il serpente che si morde la coda (vita), la colonna (saldezza), e l'occhio (protezione), mentre ai lati quattro falchi, tutti in posizioni diverse, poggiano su festoni di foglie di quercia e di alloro. Nei quattro angoli rappresenta delle cornucopie (con coda di serpente) piene di frutta, e le tipiche scale a scacchi dello stemma Falconieri. In un'altra sala l'artista rappresenta un sole raggiante inserito in tre cerchi formati dall'intreccio di corone di alloro che simboleggiano la "Trinità", con conchiglie angolari che poggiano su una cornice d'imposta a meandri. Molto singolare è la soluzione architettonica che usa in altre due sale ${ }^{115}$ del Palazzo dove, sulle cornici d'imposta quadrate corrispondenti alla pianta dei due ambienti, poggia una seconda cornice d'imposta circolare dalla quale fa partire una volta semisferica molto ribassata. Alla base di una delle due volte pone una grande corona di foglie di quercia nella quale inserisce dei fiori, ottenuti dall'intreccio di foglie e di bacche, alternati a gigli. Nell'altra sala "inventa" un modulo decorativo formato da una modanatura a "toro" circolare avvolta da un nastro e da fiori, bacche, frutti, e piccoli animali tratti ancora una volta dalla simbologia ermetica.

\footnotetext{
${ }^{14}$ Denominata sala 109. 
Le difficoltà del restauro che Colalucci si trova ad affrontare, non provengono tanto da problemi tecnici quanto da problemi estetici. Pur avendo la certezza della non autenticità delle dorature (alcune addirittura a porporina) che alteravano grossolanamente i ritmi delle decorazioni plastiche borrominiane, prima di intervenire con il restauro, va a studiarsi le altre opere del maestro in modo da mettere meglio a fuoco quale doveva essere l'esatta scansione dei ritmi tra le parti bianche e quelle dorate. L'intervento alla fine sarà condotto in modo da restituire solidità alla materia attraverso tutte quelle operazioni di consolidamento normalmente in uso. La leggibilità sarà recuperata attraverso l'asportazione delle manomissioni più recenti, mentre saranno conservate quelle di fine-settecento che pur fornendo una totale rielaborazione dell'impianto seicentesco originale, rappresentano un intervento oramai storicizzato.

Concludo il racconto di questo restauro chiedendo a Colalucci alcuni chiarimenti sul nuovo modo di organizzare il lavoro :

D. Con il cantiere di Palazzo Falconieri cambi radicalmente l'assetto organizzativo del tuo lavoro poiché inizi ad avere un bel numero di collaboratori. Cosa ricordi di quel cantiere storico?

R. "Premetto che mi sono buttato in quel lavoro anomalo per vastità e complessità e molto diverso da quello che fino ad allora avevo affrontato, con quella incoscienza che fa parte del mio carattere (o forse chiamo incoscienza ciò che invece è una sicurezza di sé nascosta, o meglio ancora una convinzione di farcela). Allinizio avevo l'esigenza di fare esperienza per un'impresa di quel genere. Ricordo per esempio il peso delle preoccupazioni che mi impediva di dormire la notte. Avevo iniziato il cantiere con restauratori giovani studenti (tu eri una di loro) con una buona preparazione teorica ma con pochissima esperienza pratica, mentre il 
lavoro richiedeva una conoscenza specifica ed una particolare abilità nel restauro degli stucchi e delle tempere su muro. Dopo poco tempo ho capito che $i$ restauratori giovani dovevano essere guidati da persone più esperte. Allora ho mobilitato tutti i restauratori del laboratorio Vaticano che, come ti ho spiegato, avevano imparato quelle tecniche molto specifiche dai restauratori più anziani abilissimi nell'arte della decorazione murale. Tecnica che già a quel tempo si era quasi completamente perduta. Ricordo che questo incontro nel cantiere di Palazzo Falconieri tra le giovani generazioni dell' ICR e i restauratori del Vaticano, ha reso possibile uno scambio di esperienze che ha arricchito tutti. Per i restauratori del laboratorio Vaticano, abituati ad una realtà diversa, più chiusa e fatta $d$ soli uomini, trovarsi tra persone giovani e giovani ragazze cui trasmettere la loro conoscenza è stato inizialmente complicato. I giovani da parte loro, dopo una diffidenza iniziale, hanno cominciato a capire che da quella esperienza pratica avrebbero potuto imparare tecniche preziose. Alla fine il lavoro è stato concluso con la soddisfazione di tutti, sono stati risolti problemi difficilissimi ( come il restauro di delle tempere e delle dorature ottocentesche di una saletta la cui preparazione era completamente distaccata dalla muratura ). La soddisfazione per i risultati raggiunti in quel cantiere fu tale che a conclusione del lavoro, il governo Ungherese, a quel tempo ancora comunista, mi ha insignito di una "stella rossa" per meriti del lavoro, una onorificenza molto prestigiosa che io ho trasmesso a tutti i collaboratori."

\section{La Galleria Borghese}

Nel 1976, Colalucci inizia una lunga collaborazione con la Galleria Borghese di

Roma. Per la Galleria, e sotto la direzione di varie ispettrici di quel Museo, restaurerà una importante serie di dipinti su tela e su tavola. Ne cito solo alcuni "La Resurrezione” di Marco Pino, alcuni dipinti del Garofalo, "I'Apollo e Dafne” e 
"l'Adorazione del Bambino" di Dosso Dossi, il "San Giovannino ed il San Girolamo" di Caravaggio, alcune opere di Andrea del Sarto, un “Sansone” del Guercino, “l' Adorazione dei pastori" di Pellegrino Tibaldi, e la "Venere e Amore" di Cranach. Come al solito i lavori sono accompagnati da dettagliate relazioni tecnicoscientifiche e documentati da eloquenti campagne fotografiche. Uno dei primi lavori eseguiti tra il 1977 ed il 1978, riguarda la tavola di Lucas Cranach detto il Vecchio, raffigurante "Venere e Amore”. Dalla relazione del restauro, si apprende che il supporto in legno di pioppo dello spessore di cm.1,5 è composto da sette assi (di larghezze diverse) ${ }^{116}$ assemblate tra loro. I lati lunghi del dipinto sono segnati una striscia di assottigliamento, larga circa $\mathrm{cm} .1,4$, praticata sulla tavola per poterla alloggiare nella cornice. Tutto il supporto, inoltre, in un vecchio restauro aveva subito un generale assottigliamento, come dimostra "l'apertura" delle gallerie scavate dai tarli. È attribuibile, probabilmente, a quello stesso intervento l'applicazione della parchettatura trovata da Colalucci sul dipinto al momento del suo restauro. II sostegno era composto da cinque elementi fissi paralleli alle fibre del legno, utilizzati come sede di alloggiamento di dieci traverse scorrevoli ${ }^{117}$, che con il tempo si erano bloccate a causa della pressione esercitata dal legno della tavola che tendeva ad imbarcarsi. Colalucci rileva, nella parte centrale del dipinto, un innesto originale in legno applicato dall'artista in sostituzione di un nodo. Ne rileva anche alcuni non originali e molto tarlati, applicati in passato per risanare le parti angolari del

\footnotetext{
${ }^{116}$ Ossia : cm.4,5-cm.10,2-cm.12-cm.9,8-cm.11-cm.10,5-cm. 11 
supporto evidentemente danneggiate. L'innesto originale con il tempo aveva segnato la superficie pittorica provocando una leggera depressione del colore. II vecchio restauro degli anni sessanta aveva lasciato sul dipinto uno spesso strato di vernice ormai ingiallita, "scolata" durante l'applicazione lungo la parte bassa delle gambe della Venere. Oltre alla vernice vi erano numerosi ritocchi ad olio e a tempera che chiudevano le lacune della pellicola pittorica, della preparazione e una fenditura formatasi nel punto di giuntura di due assi in corrispondenza della gamba sinistra della Venere. Per quanto concerne la tecnica esecutiva, risulta che il dipinto è realizzato con una tecnica mista, cioè ad olio e a tempera, su una preparazione di tono ambrato che ricopre a sua volta la sottile mestica di gesso e colla. Un particolare molto interessante è dato dalla piccola figura di drago, disegnata con un colore chiaro sul tronco sotto la mano della Venere, poiché questa figura ( che risulta comunque completata da vecchi ritocchi) potrebbe essere la firma dell'artista. II restauro di Colalucci prende l'avvio dal risanamento del supporto. Viene rimossa la parchettatura e viene eseguita la disinfestazione e il consolidamento del legno. L'impianto della nuova parchettatura viene preceduto dalla messa in opera di piccoli innesti di legno di balsa e dall'esecuzione di stuccature con pasta di legno nelle parti polverizzate dai tarli. Lo schema della nuova parchettatura rispecchia chiaramente i modelli già sperimentati da Colalucci da diversi anni, che non miravano a impedire i movimenti del supporto ma ad assecondarli, pur 
svolgendo una azione di sostegno. A proposito delle parchettature chiedo a Colalucci :

\section{Come sei arrivato a mettere a punto questo validissimo schema di parchettatura:}

R. "Sono partito dai risultati negativi visti su parchettature relativamente recenti, parliamo comunque degli anni 50/60. A quel tempo anche all'I.C.R.ci si rendeva conto dell'insoddisfacente risultato delle parchettature correnti tanto che Roberto Carità, storico dell'arte appassionato di fisica e di tecnologia, aveva delle idee nuove sull'argomento. Ricordo che la filosofia che fino ad allora aveva dettato l'impianto delle parchettature si basava sul principio di correzione delle deformazioni delle assi attraverso operazioni di costrizione del supporto che però davano effetti molto negativi. Anche parchettature celebri come quella eseguita sulla Maestà di Duccio era ancora legata al concetto antico. Carità si rende perciò conto che i sistemi in uso erano molto invecchiati ed esegue una serie di prototipi. Esegue modelli di telai e di tensionamento delle tele sui telai ed un prototipo di parchettatura sulla tavola con la Madonna della Misericordia di Santa Maria in Trastevere. $\dot{E}$ il primo, quantomeno in ambito romano, ad intuire che le tavole non andavano costrette ma sorrette, e che l' impianto di sistemi rigidi era da evitare. A distanza di anni ho rivisto delle parchettature fatte dall'I.C.R. con i sistemi antichi, che nel tempo avevano dato cattivi risultati, ed allora mi sono messo a riflettere sulla validità delle idee di Carità, e cioè sul fatto che i supporti lignei non andassero bloccati o costretti in strutture rigide ma che dovessero essere sorretti da parchettature in grado di assecondarne i movimenti. La gestazione è stata lunga, poiché per mancanza di tempo non potevo dedicarmi alla sperimentazione, ed è andata avanti fino a che anche le committenze iniziarono a mostrarsi favorevoli all'idea di mantenere le tavole con le loro deformazioni, in linea con la tendenza che mirava a rendere gli interventi sulle opere meno invasivi. Siamo agli inizi degli anni Settanta ed a quel punto inizio a studiare più approfonditamente il comportamento dei legni cercando di capire, con un amico ingegnere, se vi fossero delle regole fisse. Studiando scopro che le assi che compongono e tavole hanno un imbarcamento diverso a secondo del punto del tronco da cui sono state tagliate, e perciò mi rendo conto che una tavola composta da molte assi si modifica 
in molti modi. Studio anche la meccanica di tali comportamenti e mi rendo conto che le cosa è molto complessa perché la presenza dei nodi modifica il comportamento delle assi. In questo studio trovo l'aiuto di uncollega restauratore del Vaticano Enrico Guidi, con il quale mi trovo in sintonia circa la necessità di impiantare delle parchettature che tengano conto dei diversi comportamenti del legno e che siano appropriate a ciascun caso, partendo dal principio che le traverse scorrevoli debbano rimanere sempre tali e non bloccarsi nel tempo, e debbano adattarsi alle deformazioni stabilizzate. Faccio costruire in Vaticano un modello di supporto con la sezione a forma di $S$ e faccio applicare delle doppie traverse in alluminio alternate ad un nastro di teflon e appoggiate su tacchi di teflon. Le traverse vengono messe di piatto e non di taglio e sono trattenute da "gattelli" in legno. Ancora oggi a distanza di quasi quaranta anni quelle traverse sono in grado di scorrere seguendo la deformazione del modello.

\section{Perché non ha mai pubblicato questa tua tecnologia ?}

R. "Probabilmente ho sottovalutato l'importanza di questo lavoro, anche perché pensavo che per presentarlo ad un convegno dovessi approfondire gli studi sul comportamento dei legni. Non avevo il tempo di farlo e dunque mi sono limitato a realizzare questo modello di parchettatura per i miei lavori e, anche a distanza di anni, ho sempre avuto ottimi risultati."

Tra la rimozione della vecchia parchettatura e l'impianto di quella nuova, il dipinto di Cranach (opportunamente protetto sul fronte ) viene lasciato libero di riprendere la naturale deformazione che il sostegno rigido aveva a lungo contrastato con gravi ripercussioni sulla stabilità del colore ${ }^{118}$. La parchettatura pensata da Colalucci è composta da traverse scorrevoli realizzate con coppie di aste di allumnio flessibili ${ }^{119}$, rivestite di TEFLON, che è un materiale lubrificante. Le traverse sono sostenute da "gattelli" ossia da ponticelli in legno di mogano,

\footnotetext{
118 La preparazione, costretta nella parchettatura rigida, aveva subito una riduzione della superficie d'appoggio mettendo a serio rischio la stabilità del colore. Una volta liberate dal sostegno rigido, le fibre del legno hanno gradualmente riacquistato la leggera deformazione dovuta alla fisiologica perdita di umidità, permettendo così alla mestica di recuperare la superficie necessaria alla completa adesione.

${ }^{119}$ Perché messe di piatto e non di taglio.
} 
applicati direttamente sulla tavola ${ }^{120}$, e scorrono su una guida fatta da piccoli segmenti di TEFLON anche questi applicati direttamente sulla tavola ${ }^{121}$. La pulitura recupera il timbro freddo della pittura al disotto del pesante strato di vernice ingiallita. Vengono rimossi anche i ritocchi ad olio e a tempera che però non portano al recupero di materia originale poiché eseguiti su vecchie lacune. II restauro si conclude con la reintegrazione ed una nuova verniciatura. Tra il 1982 e il 1983 è la volta del restauro dell' "Apollo e Dafne" di Dosso Dossi, un dipinto che la storiografia colloca tra gli anni venti e trenta del Cinquecento. L'opera, che arrivò a Roma da Ferrara come dono del Marchese Bentivoglio a Scipione Borghese, nel Sette-Ottocento era stata più volte manomessa da interventi invasivi quali puliture aggressive e ridipinture. L'intervento più recente risaliva al 1945, era stato condotto da Carlo Matteucci e diretto da Aldo De Rinaldis $^{122}$.

Quel restauro aveva portato alla rimozione della ridipintura ottocentesca che ricopriva il manto verde di Apollo, molto danneggiato da precedenti puliture. In quello stesso contesto furono però conservate altre ridipinture, probabilmente coeve di quella che ricopriva il manto, e che Colalucci dunque trova ancora sul dipinto. II Matteucci aveva poi eseguito una sommaria sverniciatura della superficie lasciando quasi intatto lo strato di sporco che la ricopriva, in modo da non creare scompensi tra le zone riportate in luce sotto le ridipinture e quelle non toccate.

\footnotetext{
${ }^{120}$ La parte dei gattelli a contatto con le barre metalliche è di forma semicircolare ed è rivestita anch'essa di teflon. ${ }^{121}$ I rivestimenti in teflon servono ad assicurare la massima scorrevolezza delle traverse evitandone il blocco in caso eccessivo movimento del supporto. 
Le foto del dipinto prima del restauro degli anni quaranta mostrano, come sottolinea Colalucci nel rilevamento dello stato di conservazione ${ }^{123}$, quanto la ridipintura grigio-verde ottocentesca alterasse pesantemente il modellato originale del drappo. Le tracce di questo intervento, ancora presenti sul dipinto al momento del restauro di Colalucci, ne dimostravano la pesantezza e la stesura al disopra dello strato di resinato di rame, prodotto dalla naturale alterazione del verde originale. Le ridipinture che Matteucci non aveva rimosso invece, interessavano il terreno scuro alle spalle di Apollo, la sua corona di alloro e le ciocche di capelli che ricadevano lungo le spalle. Come sottolinea Colalucci, pur non essendoci dubbi sulla natura non originale di questi interventi (le sezioni stratigrafiche mostravano infatti la presenza di consistenti strati di vernici già invecchiate tra il colore originale e i detti interventi), la decisione di asportarli fu presa soltanto a pulitura conclusa. In quel momento infatti apparve chiarissima anche la loro estraneità estetica al testo originale recuperato sotto lo sporco e le vernici alterate. Le manomissioni, poiché dipinte in epoca posteriore e dunque con un timbro cromatico in accordo con l'invecchiamento delle vernici e dello sporco depositatosi sulla superficie pittorica, stonavano completamente con la tonalità dei colori originali. Anche le annotazioni sulla tecnica esecutiva sono molto interessanti ${ }^{124}$. Apprendiamo che l'opera è dipinta su un supporto in tela a trama piana, stretta e a fili sottili, formato da due teli uniti da una cucitura a cerniera che attraversa il dipinto verticalmente.

\footnotetext{
${ }^{123}$ Cfr. relazione del restauro, archivio G. Colalucci, sezione documenti, F.6 (serie 1) -5

124 Tutte le puntualissime osservazioni ed i rilevamenti fatti da Colalucci nel corso del restauro da lui eseguito tra il 1982 e il 1983, e riportate nella relazione del restauro, costituiscono la fonte dalla quale provengono le notizie pubblicate da A.Coliva nella scheda 28. Apollo "Note Tecniche" in "Dosso Dossi- pittore di corte a Ferrara nel Rinascimento" a cura di A.Bayer, ed.SATE, Ferrara 1998.
} 
Quando Colalucci rimuove la tela di rifodero trova sul supporto originale un disegno raffigurante il busto di un uomo di profilo con mantello e copricapo, e nell'angolo in basso a destra, rovesciato rispetto al disegno, il monogramma $\mathrm{H}$ B. Rileva anche i segni lasciati sulla tela dal telaio originale più stretto di quello applicato in occasione della vecchia reintelatura. L'imprimitura bianca di gesso e colla è coperta da uno strato di colore bruno-nero legato con medium a base di colla e olio. La preparazione è di colori diversi a seconda delle zone, il cielo per esempio è preparato in azzurro, gli incarnati ed il paesaggio con il cielo tempestoso e la città in grigio, il terreno attorno alla figura di Apollo in brunoscuro, mentre la parte bassa con il boschetto in verde. II drappo verde è stato preparato in ocra gialla, modellato con lumeggiature verdi e bianche ed infine velato con lacca verde. In ultimo è stato dipinto il gallone giallo con ombre e riflessi rossi ad imitazione dell'oro che pure appare in tracce sui bordi del drappo verde. II legante pittorico è costituito da colla animale emulsionata con olio. La lacca invece è legata con un emulsione di olio e resina. Molto interessante è la nota relativa alla tecnica esecutiva del fogliame, degli arbusti e degli alberi, dipinti per ultimi e con un medium colloso che oltre ad aver fatto scivolare la pittura sulla superficie grassa del quadro, dando ai bordi di questi elementi una forma frastagliata ed irregolare, fornisce al colore un aspetto "grumoso". Colalucci sottolinea che il dipinto doveva essere stato accuratamente preparato su un cartone (di cui però non v'è traccia), poiché la sicurezza con cui sono stesi i colori preparatori e la mancanza di correzioni lascerebbe intendere una precisa delineazione del disegno. II fatto che di un 
eventuale cartone dell'Apollo non si abbiano notizie e dunque che non vi sia un riscontro oggettivo della fase "gestatoria" del dipinto, rientra in quel problema tuttora aperto che riguarda proprio l'uso che l'artista fece dei disegni preparatori su carta ${ }^{125}$. Nell'Apollo e Dafne, i colori di preparazione si accostano ma non si sovrappongono e formano dei sottili cordoli di pigmento rappreso. La "lira da braccio" invece è stata eseguita in ultimo. Come emerge dalle annotazioni degli appunti di cantiere e dalla relazione finale, gli interventi di Colalucci scaturiscono sempre da analisi molto approfondite e dei problemi, e le sue azioni sono sempre il frutto di complesse valutazioni. Aspetta ad asportare le ridipinture fino a che non completa la pulitura dell'intero dipinto, nonostante l'esito delle indagini stratigrafiche ${ }^{126}$ non lasciasse dubbi sulla loro falsità. Con la stessa prudenza si ferma invece di fronte ai "ritocchi" che interessano i denti di Apollo, perché non ritiene probante ai fini di una presunta falsità, quello strato di vernici che le stratigrafie evidenziano tra il pigmento dei denti e quello della bocca. Un attento conoscitore delle tecniche come lui, sa infatti che quegli strati potrebbero essere il risultato dell'alta percentuale di olio e resina con cui i pittori in antico usavano stemperare la lacca di garanza. Si ferma anche di fronte alle tracce di colore arancio presenti sulle gote di Apollo ritenendole possibili finiture originali parzialmente rimosse durante un vecchio restauro.

Concludo questa carrellata dei lavori alla Borghese con il restauro eseguito da Colalucci tra il 1982 ed il 1983 sul "San Girolamo scrivente" di Caravaggio, opera

\footnotetext{
125 Anche perché nelle sue opere non v’è traccia dei metodi usuali di trasferimento del disegno, cioè la quadrettatura, lo spolvero o altro. 
dipinta per il cardinale Scipione Borghese e databile, secondo il Bellori, tra il 1605 e il 1606. II supporto del quadro è costituito da una tela di canapa con fili medi e tessuta a trama larga. L'imprimitura è a base di gesso impastato con terra rossa, legato con colla e olio, ed ha un colore, come nota Colalucci, che si avvicina alla tonalità della terra di Siena bruciata pallida. Poiché lo strato preparatorio ha uno spessore sottile, la trama tessile del supporto appare evidente su tutto il dipinto. La costruzione del quadro prende l'avvio con il trasferimento del disegno del San Girolamo e con la campitura del fondo attorno al Santo con grandi pennellate oblique. L'artista poi esegue la figura al suo interno finendo con la stesura dei massimi chiari e dei massimi scuri. II San Girolamo viene poi ulteriormente scontornato dall'artista con il colore di fondo nelle fasi finali dell'esecuzione durante le quali stende anche le pennellate chiare nella parte destra del quadro. Dall'analisi di Colalucci risulta che il dipinto è "povero" di pigmento cromatico, il che significa che il colore ha poco spessore ed è molto "tirato" sulla superficie. Anche le pennellate con più corpo in realtà hanno anch'esse uno spessore minimo. L'opera arriva al restauro di Colalucci già alterata da vecchi interventi, già foderata e montata su un telaio non originale, ma nuovamente allentata. La superficie del colore è ricoperta da un pesante strato di vernice ingiallita ed ossidata, ed è fortemente danneggiata da vecchie puliture. Le parti più corrose e più ritoccate, corrispondono alla parte bassa de I dipinto ed interessano in particolare i I tavolo ed il manto rosso del 
Santo. Colalucci rileva anche sulla parte destra del fondo in alto l'inizio di una vecchia pulitura aggressiva, poi nascosta con un ritocco, che aveva fatto affiorare il colore ocra-rossicio della preparazione. II restauro comprenderà la esecuzione di una nuova foderatura con relativa sostituzione del telaio fisso con uno estensibile, la pulitura e la reintegrazione pittorica.

Questo capitolo ha toccato soltanto alcuni dei restauri svolti da Colalucci per le Soprintendenze romane. Con la scelta presentata ho cercato di dare un'idea completa e fedele della sua attività, attraverso l'arco di tempo trattato, scegliendo quegli interventi che si distinguono per entità o difficoltà, o perché rappresentativi dal punto di vista organizzativo. 


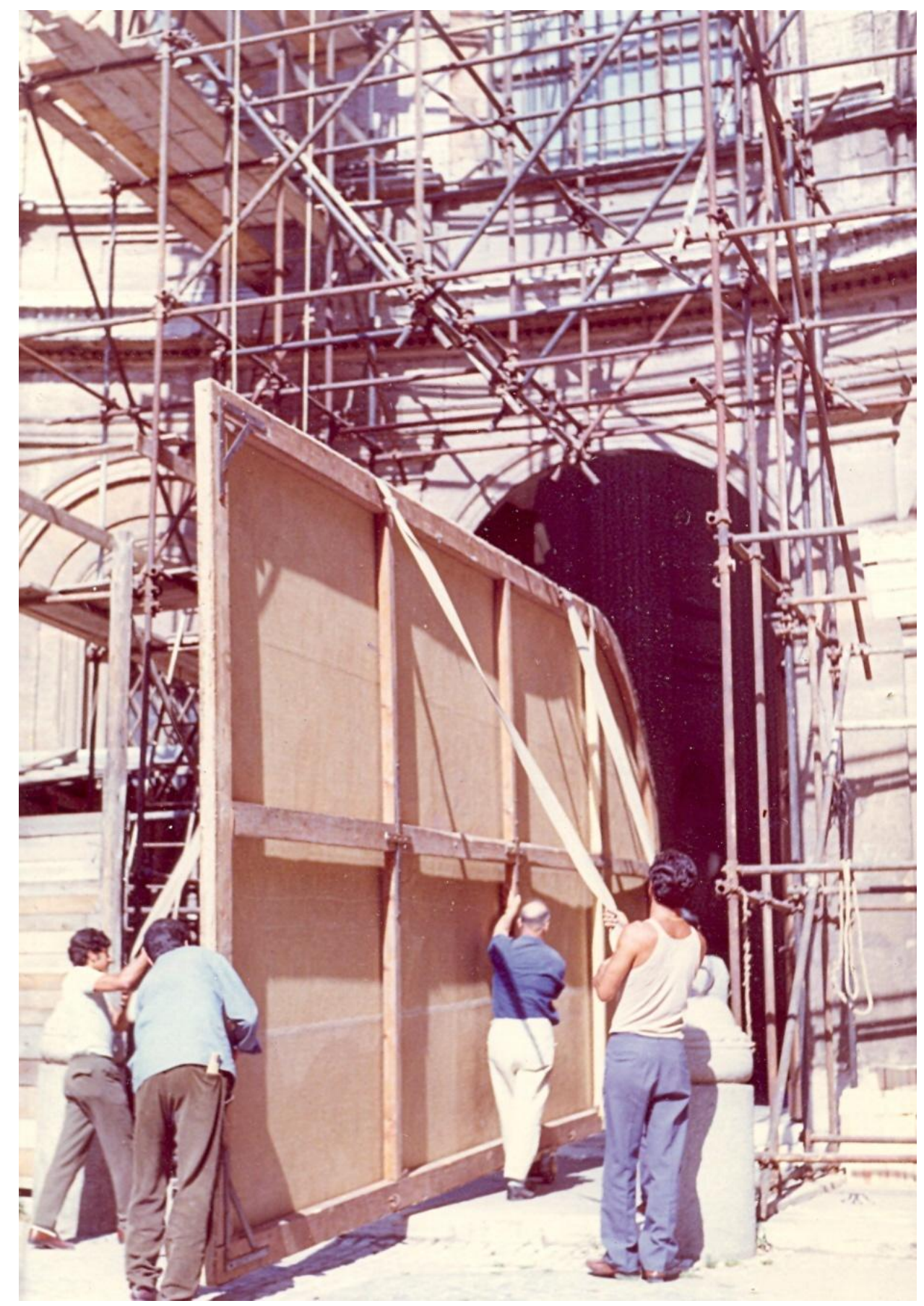

Fig. 1 - Roma, chiesa di Sant'Ivo alla Sapienza- La movimentazione della grande tela di

Pietro da Cortona "S. Ivo si fa avvocato tra i poveri", in occasione del restauro.

La tela restaurata da Colalucci alla fine degli anni 60 , è alta m.8,25 e larga m. 3,75 


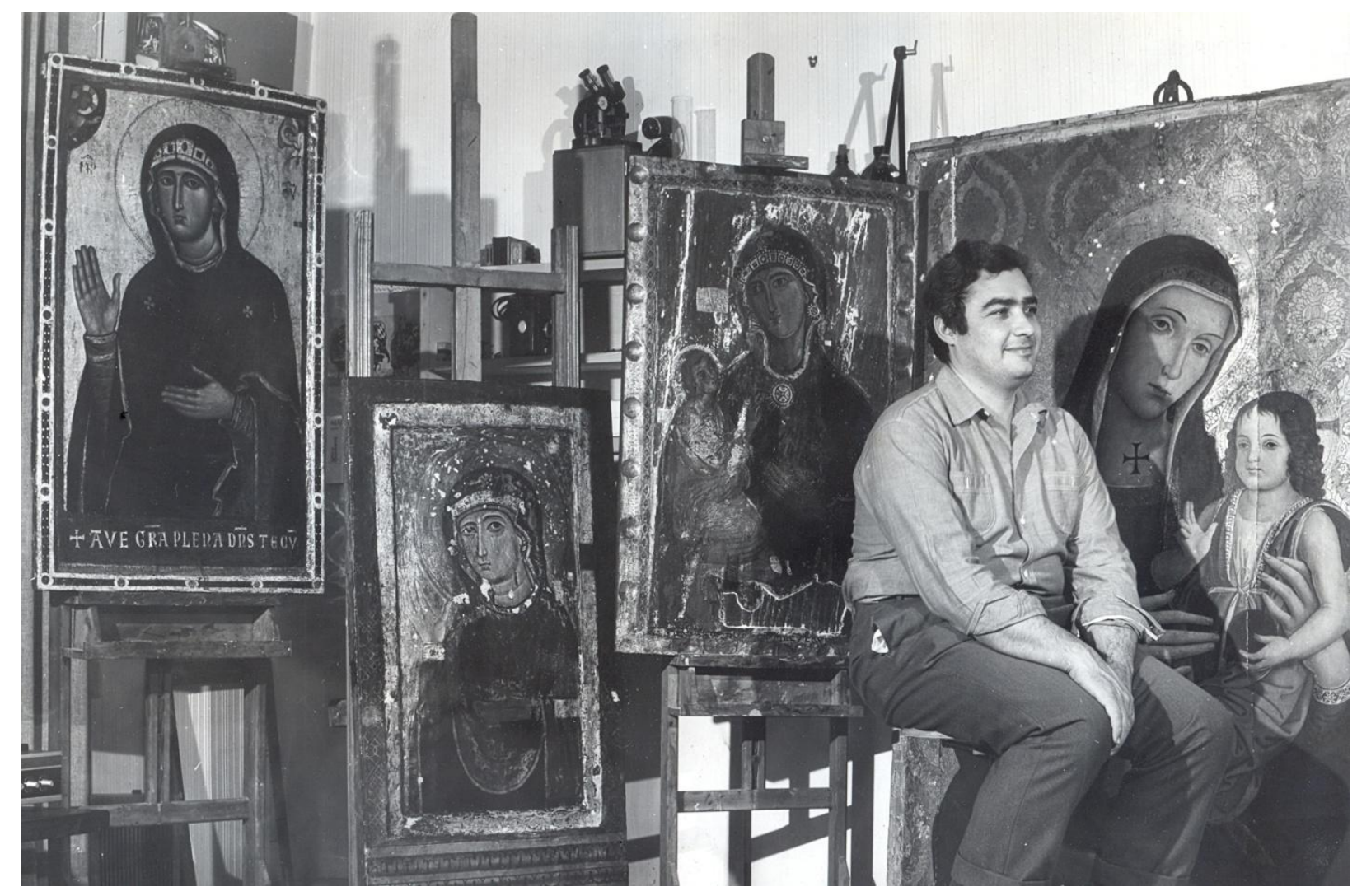

Fig. 2 - Colalucci nel suo studio di Roma negli anni 60. Dietro di lui la "Madonna col Bambino" della chiesa del Nome di MariaRoma, e le "Madonne Avvocate" delle chiese di S. Maria in Campo Marzio (al centro) Roma,e di S. Maria Maggiore Tivoli. A destra la "Madonna col Bambino" (di A. Romano) della chiesa dei Santi Apostoli a Roma. 
Maranola- Chiesa di Santa Maria dei Martiri "Madonna col Bambino e Santi". Restaurata da

Colalucci nel 1971

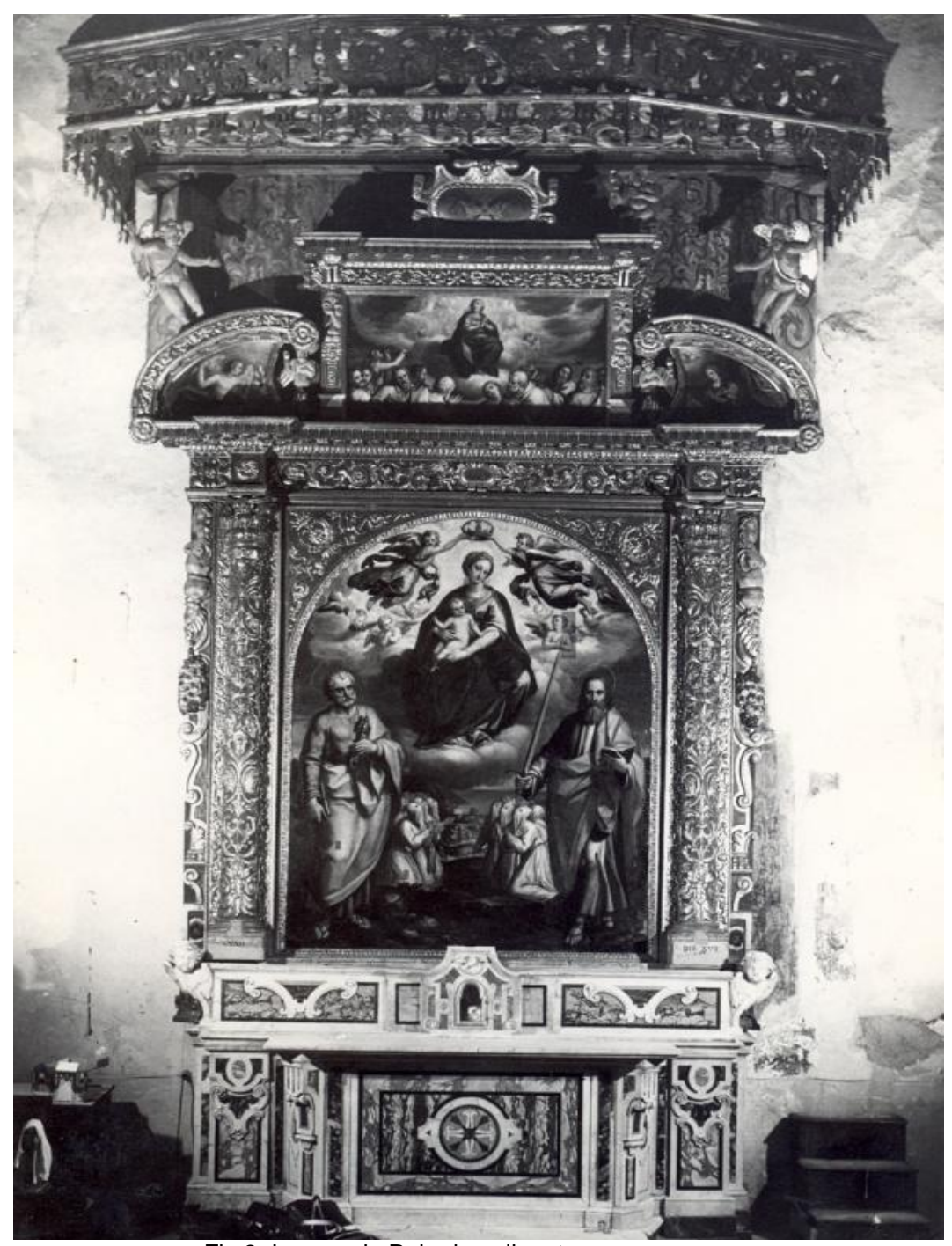

Fig.3- La grande Pala dopo il restauro 


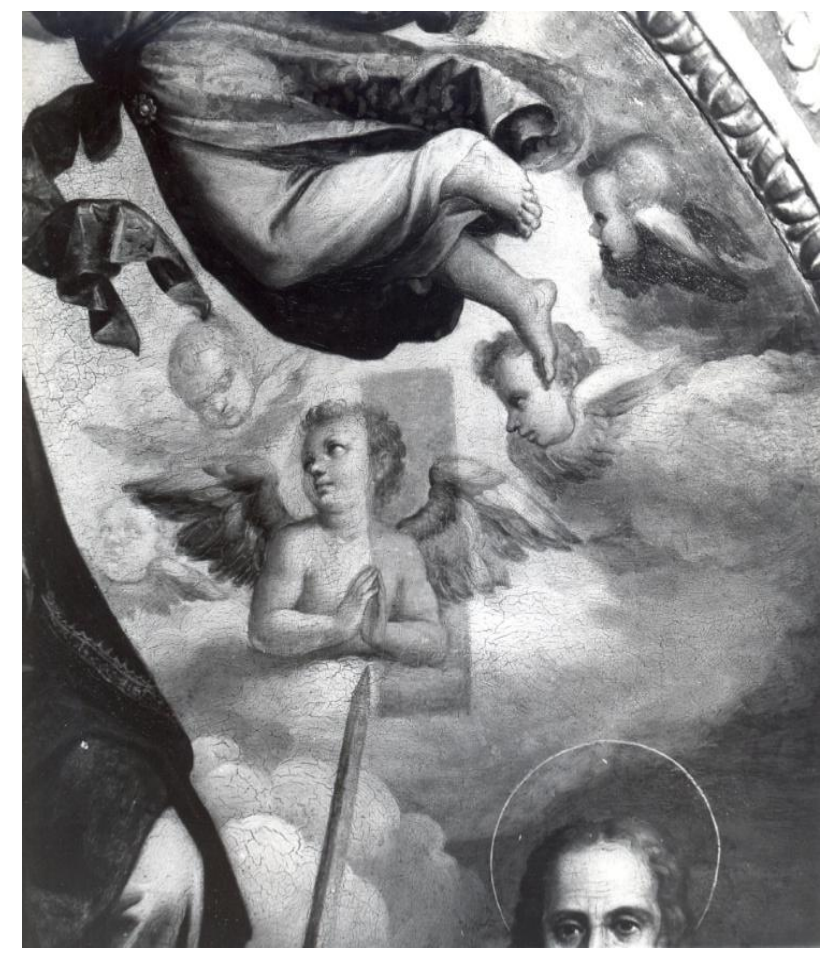

Fig.4 - particolare degli Angeli durante la pulitura

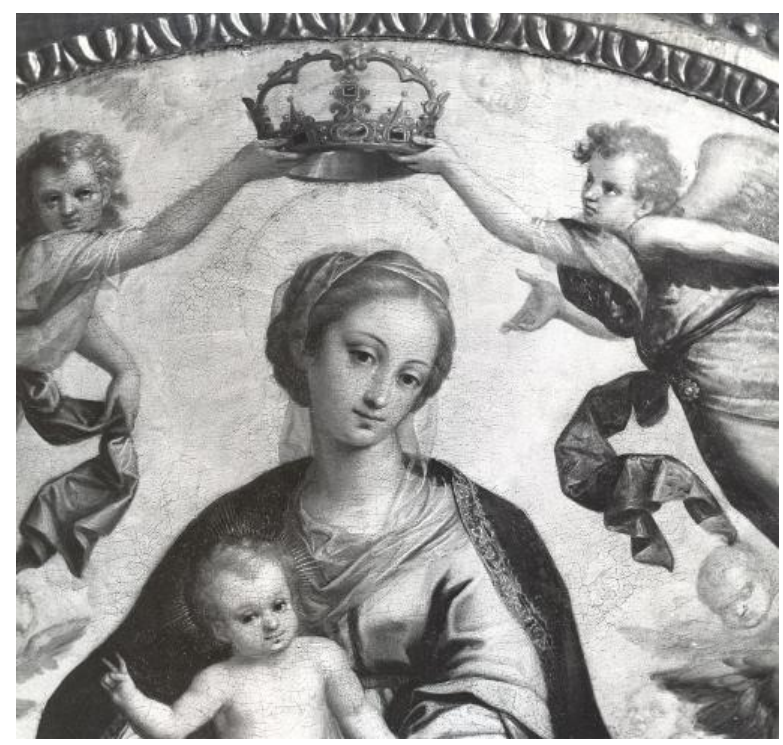

Fig.5-Un particolare della Vergine dopo il restauro 


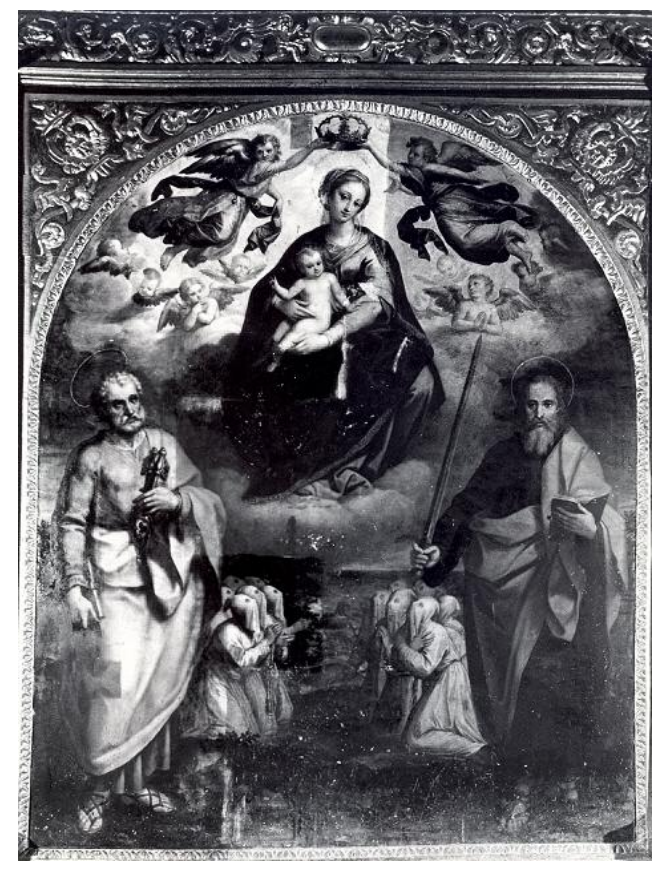

Fig.-6-La tavola durante la pulitura

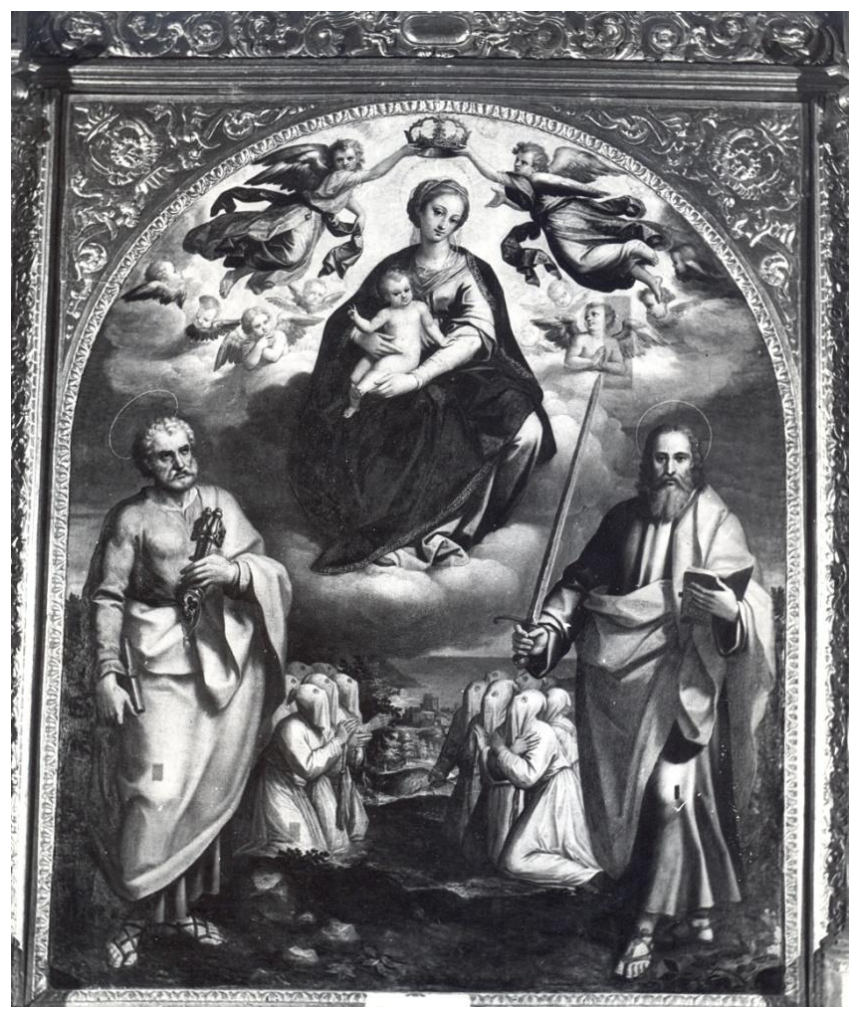

Fig.7 - la parte centrale della Pala dopo il restauro 


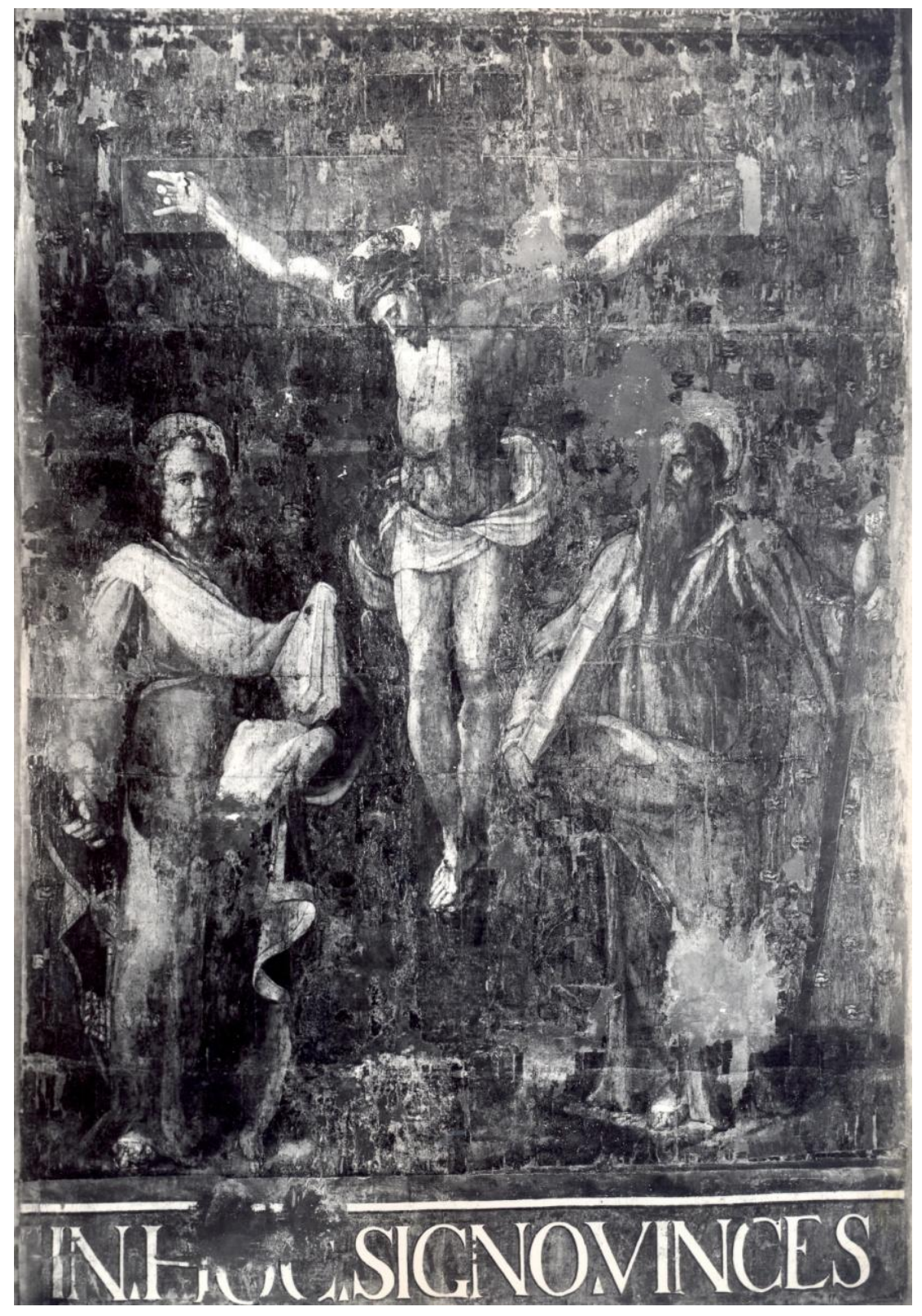

Fig. 8 - Lo stendardo prima del restauro 

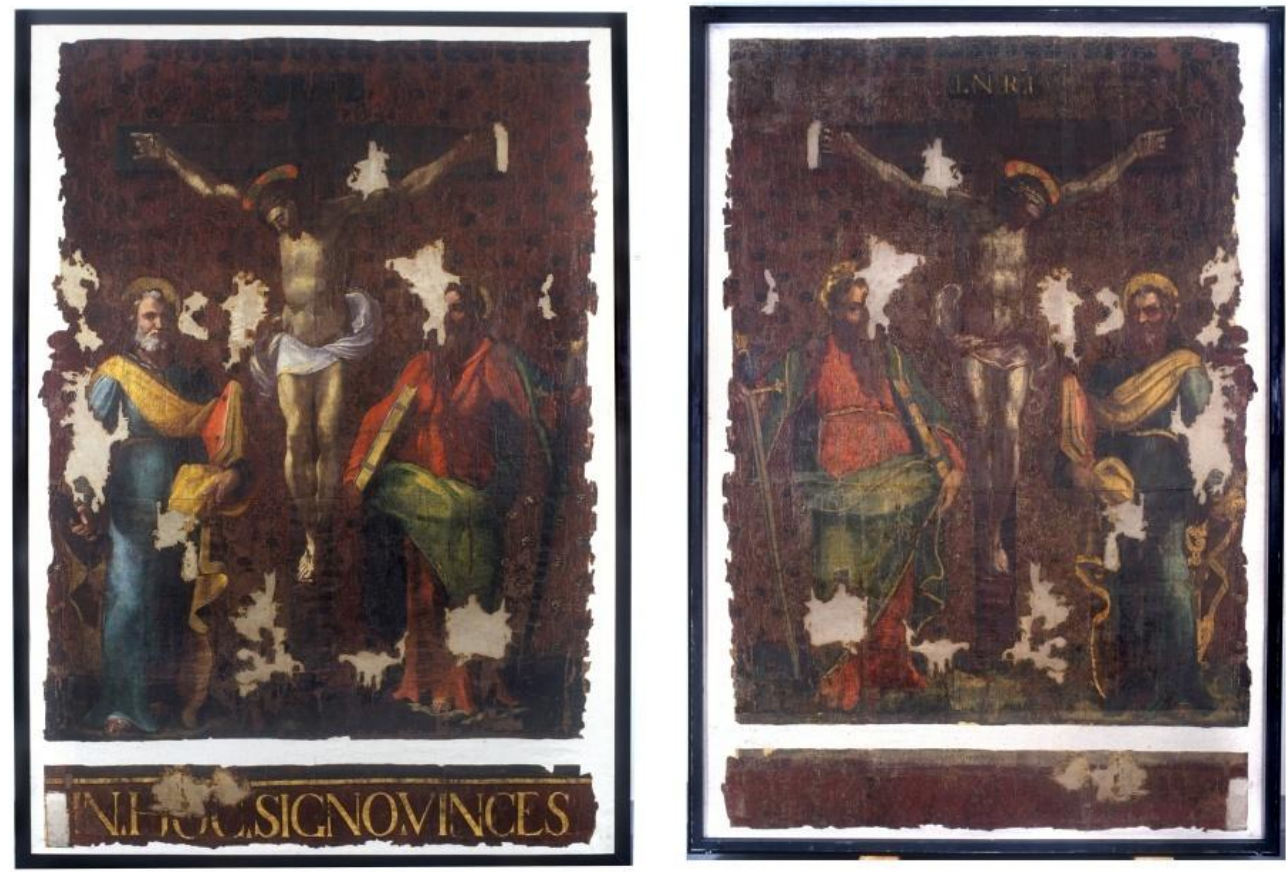

Fig. 9 10- la faccia A e B dello Stendardo oggi

Dopo il radicale restauro del 1975, Colalucci è intervenuto nuovamente sull'opera tra il 2006/07 per una revisione. Le foto a colori mostrano lo stato attuale dell'opera dopo la revisione. 
Roma- chiesa della Trinità dei Pellegrini, G. reni -“La SS.Trinità. L'opera è stata restaurata da Colalucci nel 1982

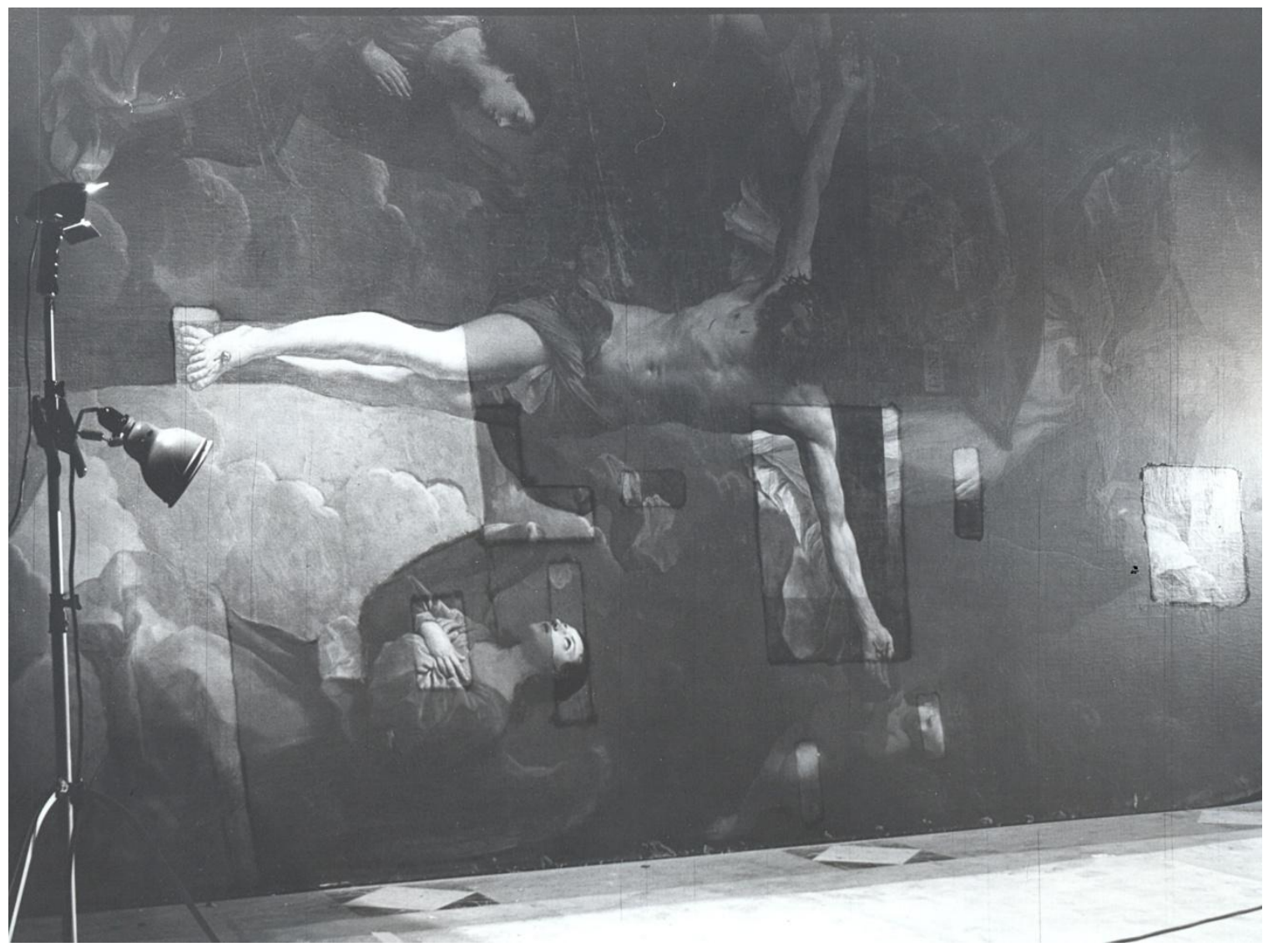

Fig 11- La grande tela del Reni durante la pulitura 


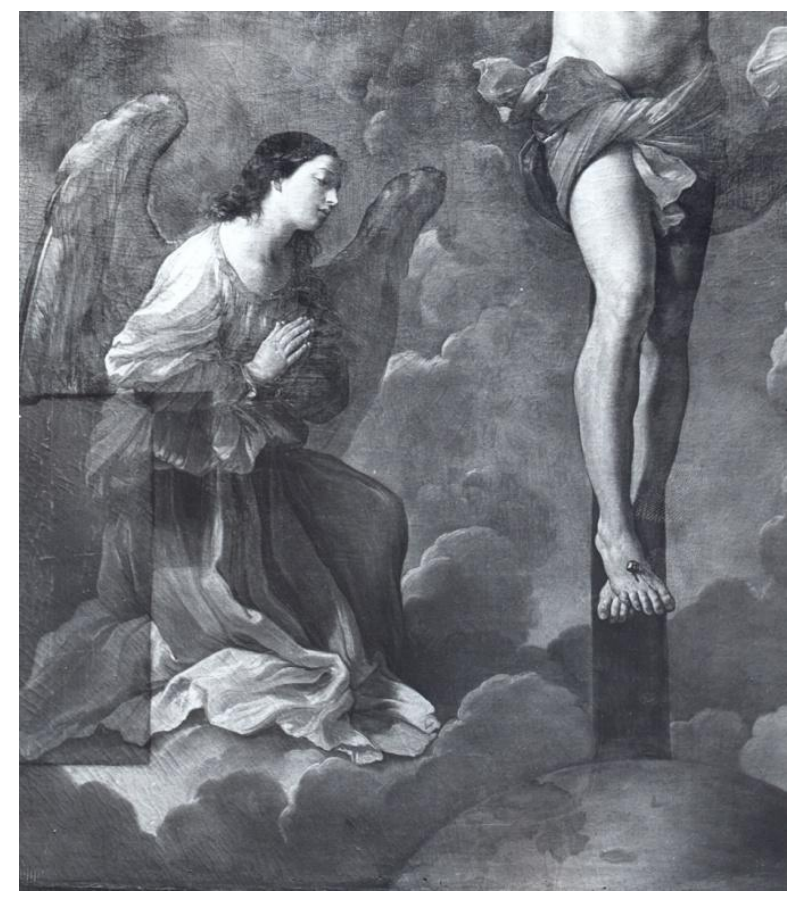

Fig. 12 -un particolare durante la pulitura

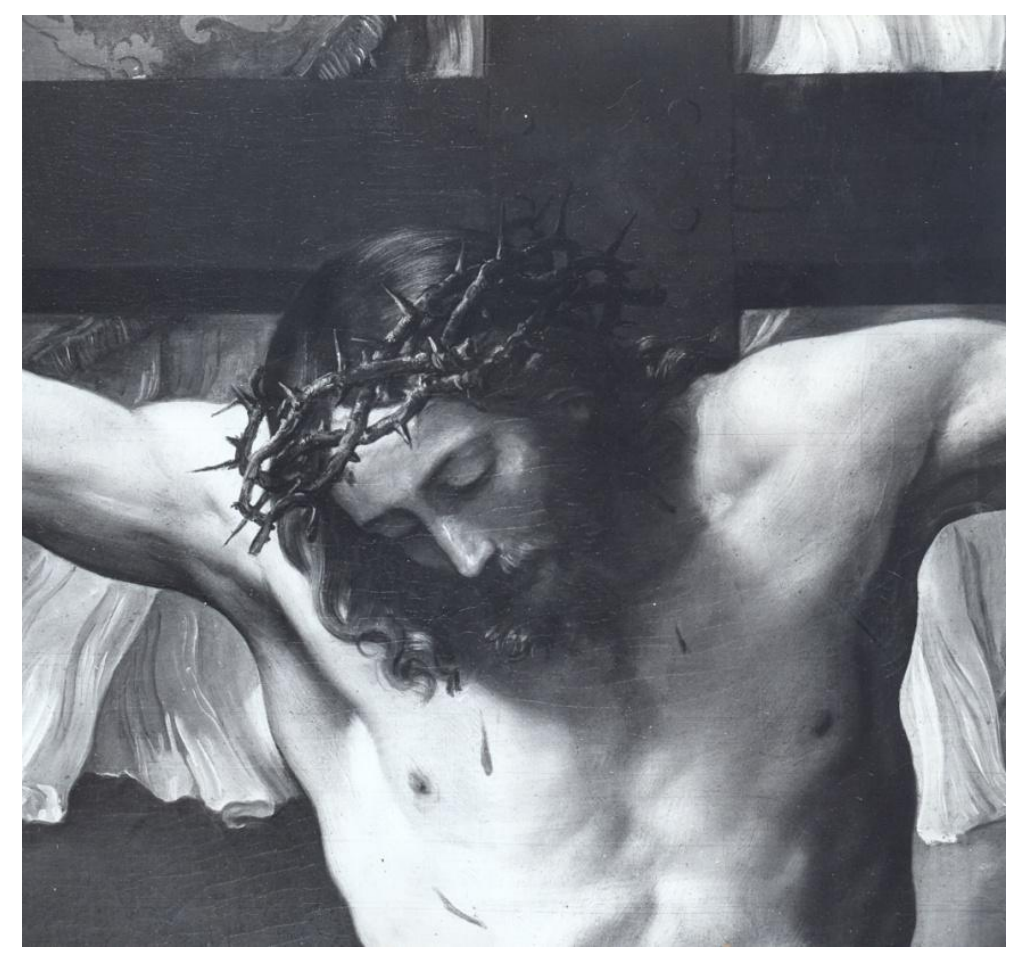

Fig. 13 - II volto del Cristo dopo il restauro 


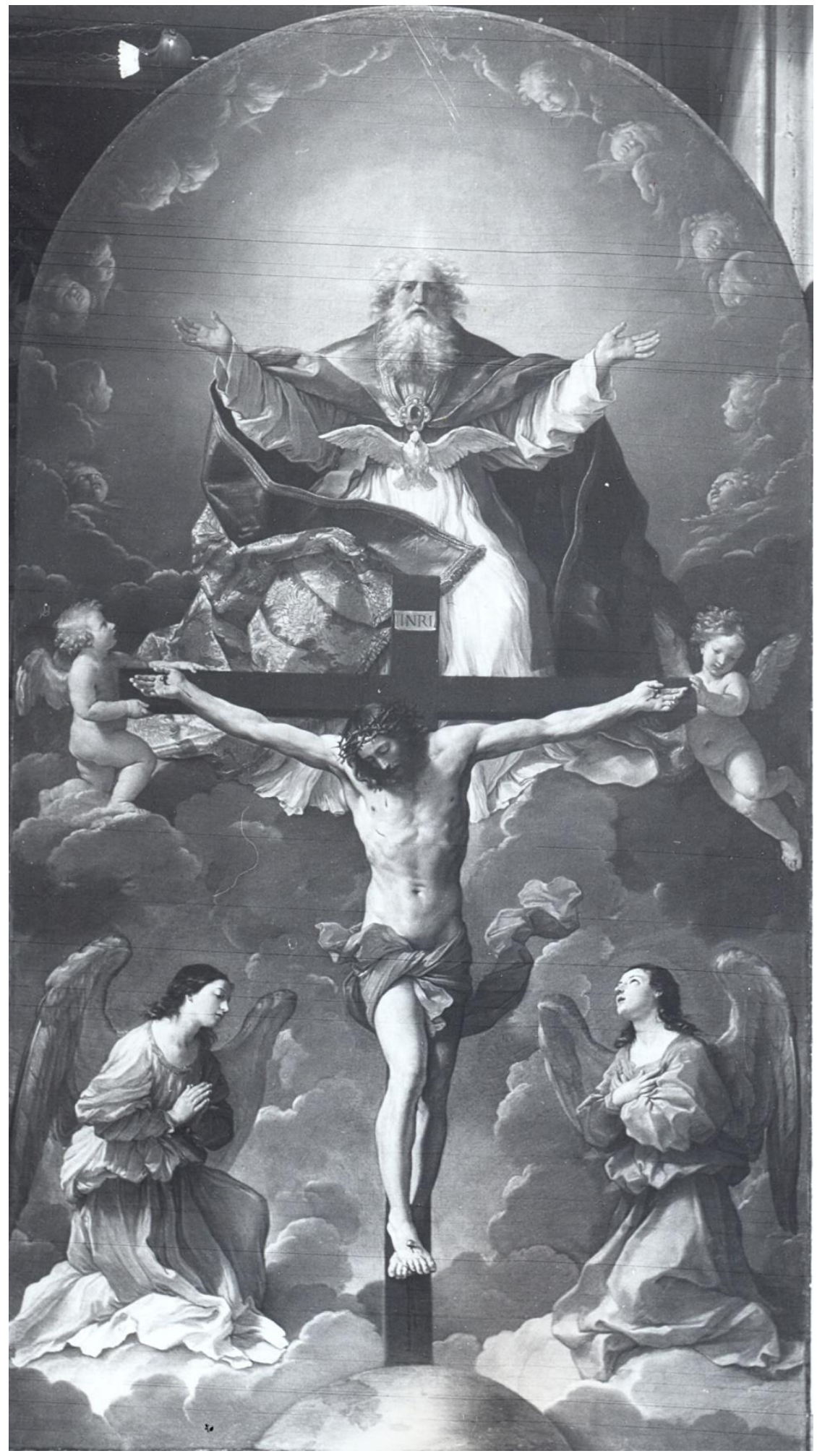

Fig. 14 - II dipinto dopo il restauro 
Roma- Castel Sant'Angelo - la Sala Paolina. Restaurata da Colalucci a più riprese tra il 1972 ed || 1983.

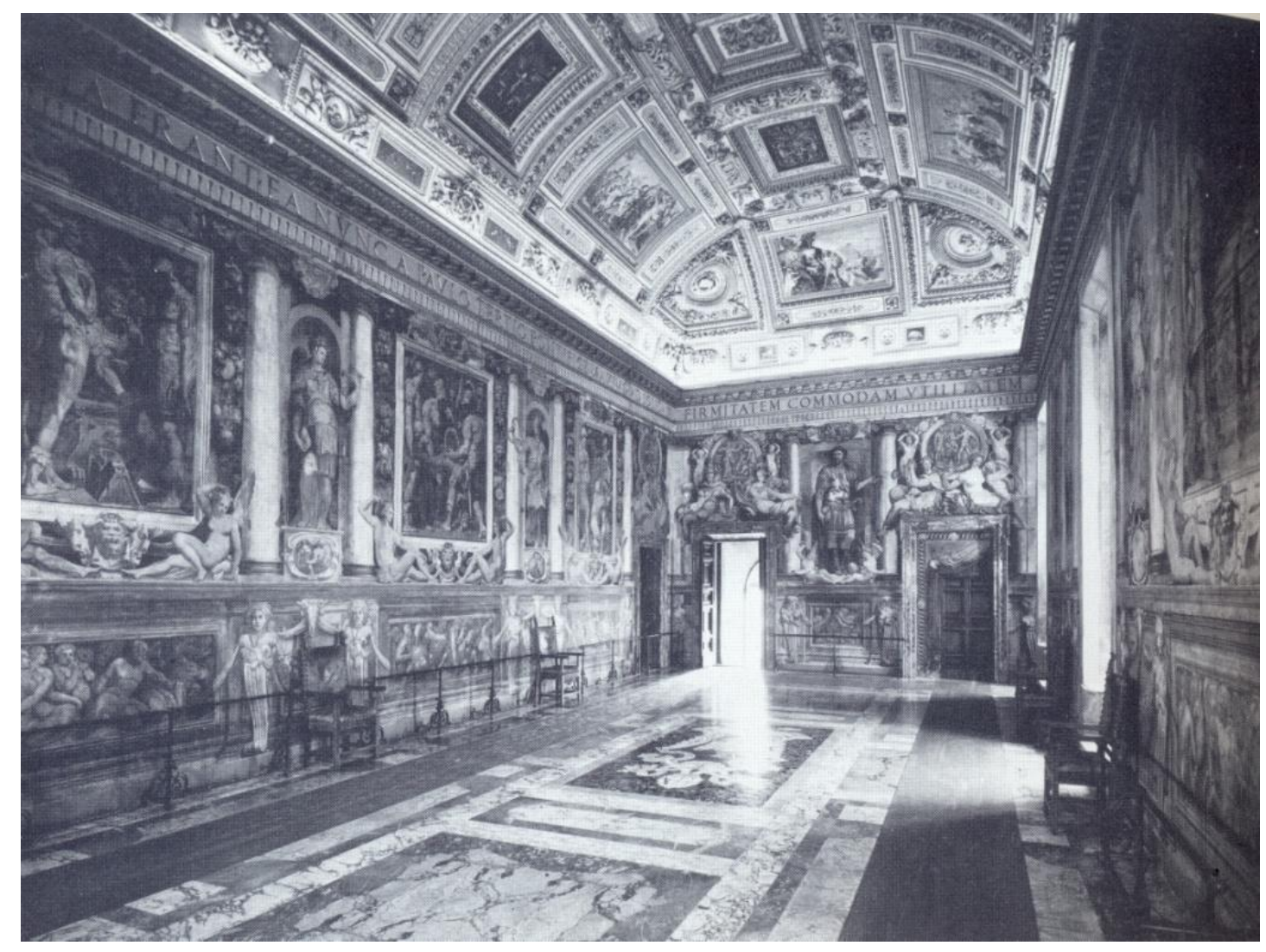

Fig. 15- una veduta della Sala dopo il restauro 


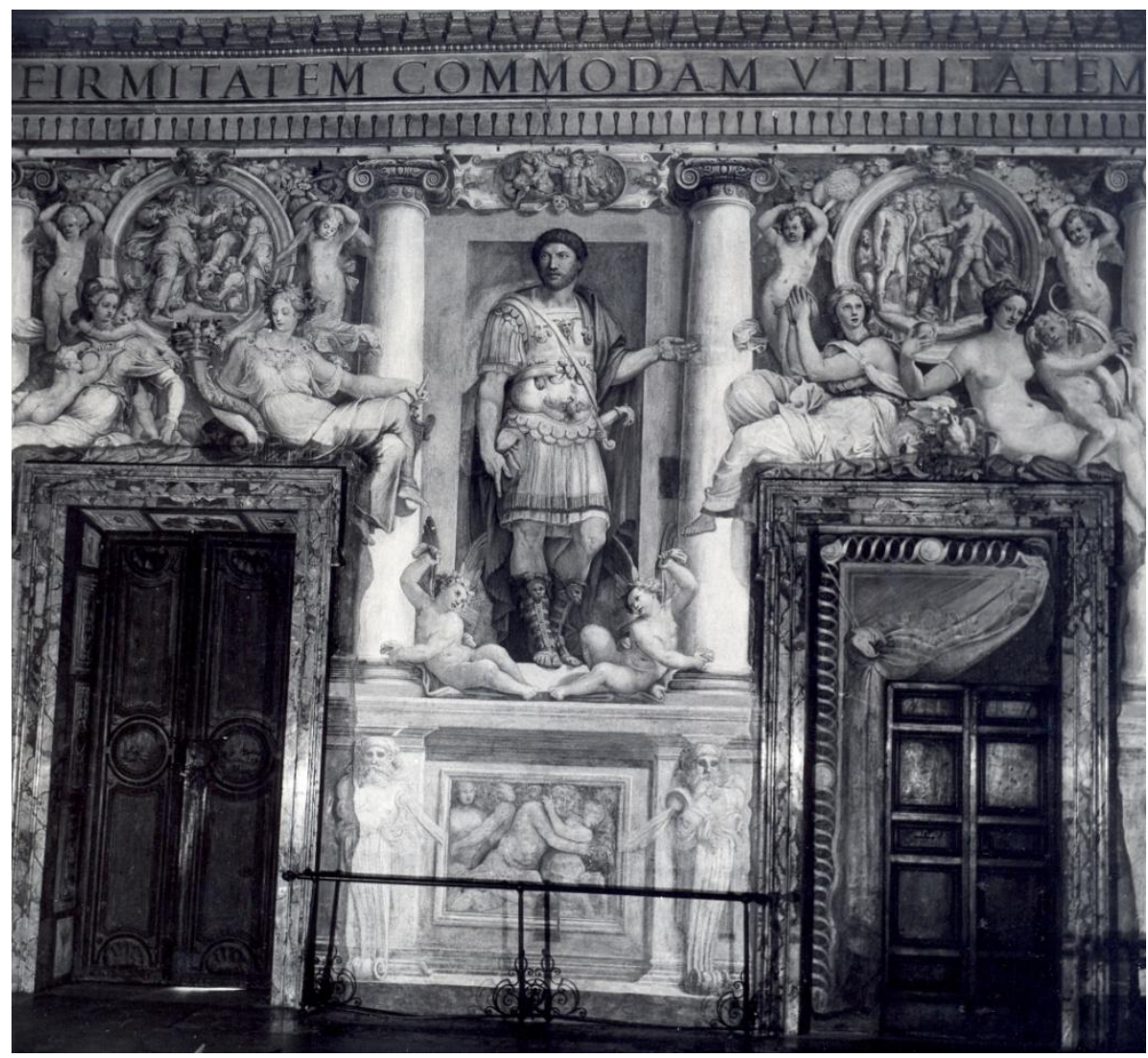

Fig. 16 - un particolare dell'Imperatore Adriano dopo il restauro

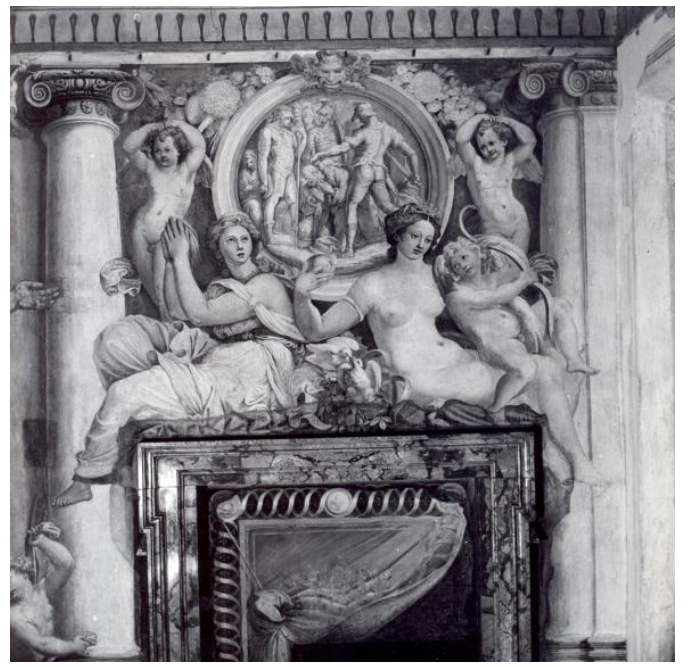

Fig. 17 - particolare dopo il restauro

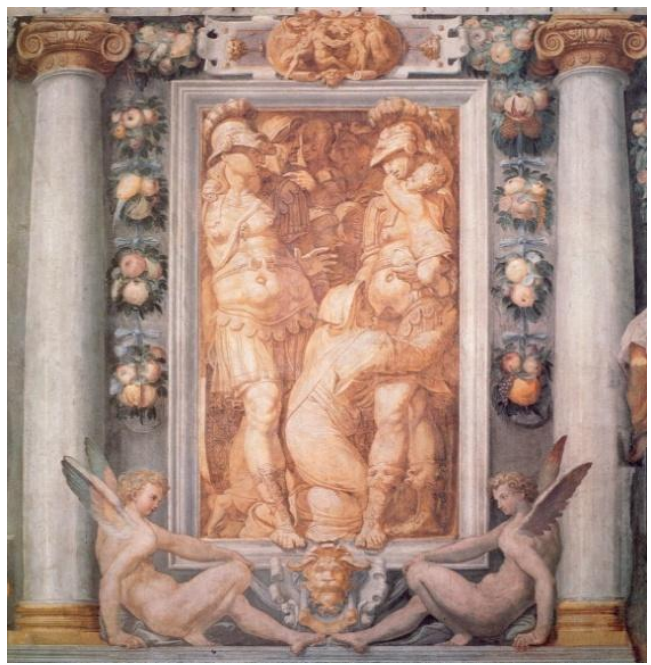

Fig. 18 - particolare dopo il restauro 
Roma- Castel Sant'Angelo- Volta della Biblioteca. Restaurata da Colalucci nel 1978

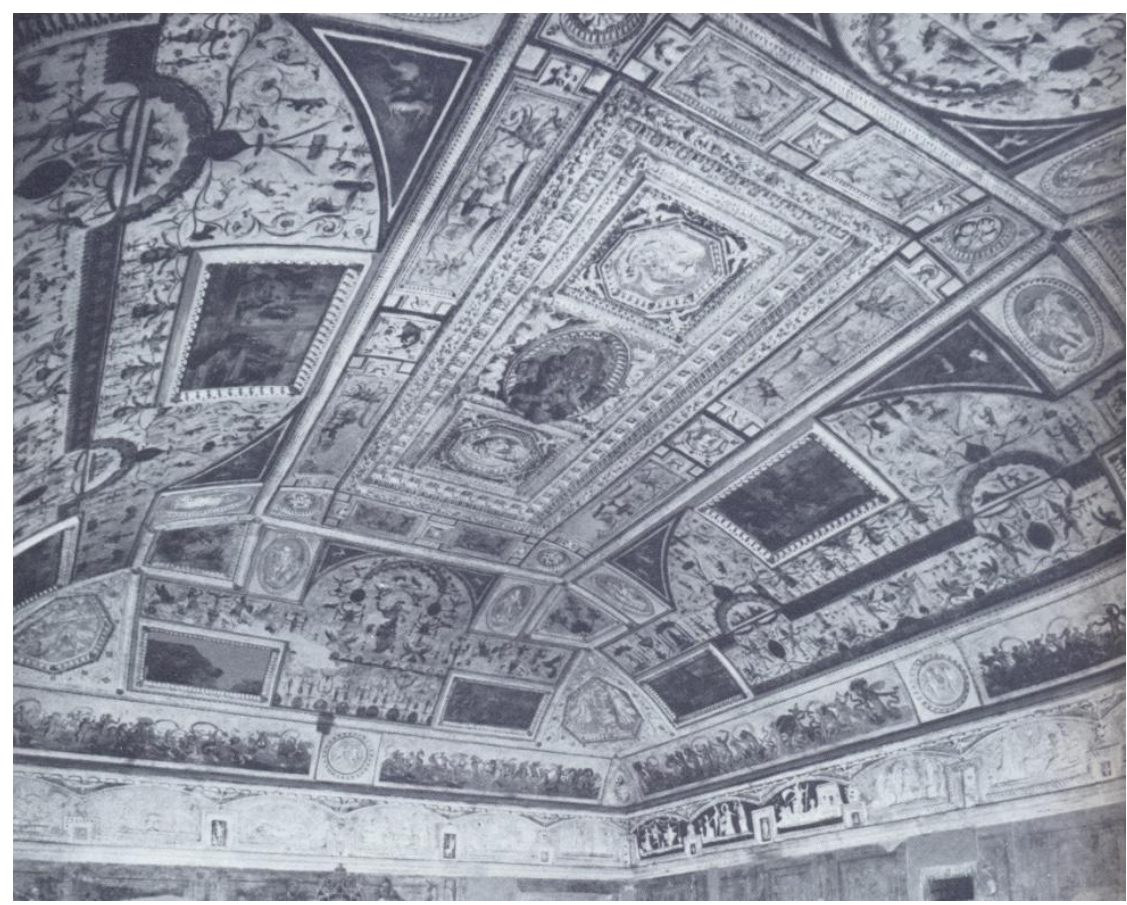

Fig. 19 - una panoramica della Volta dopo il restauro

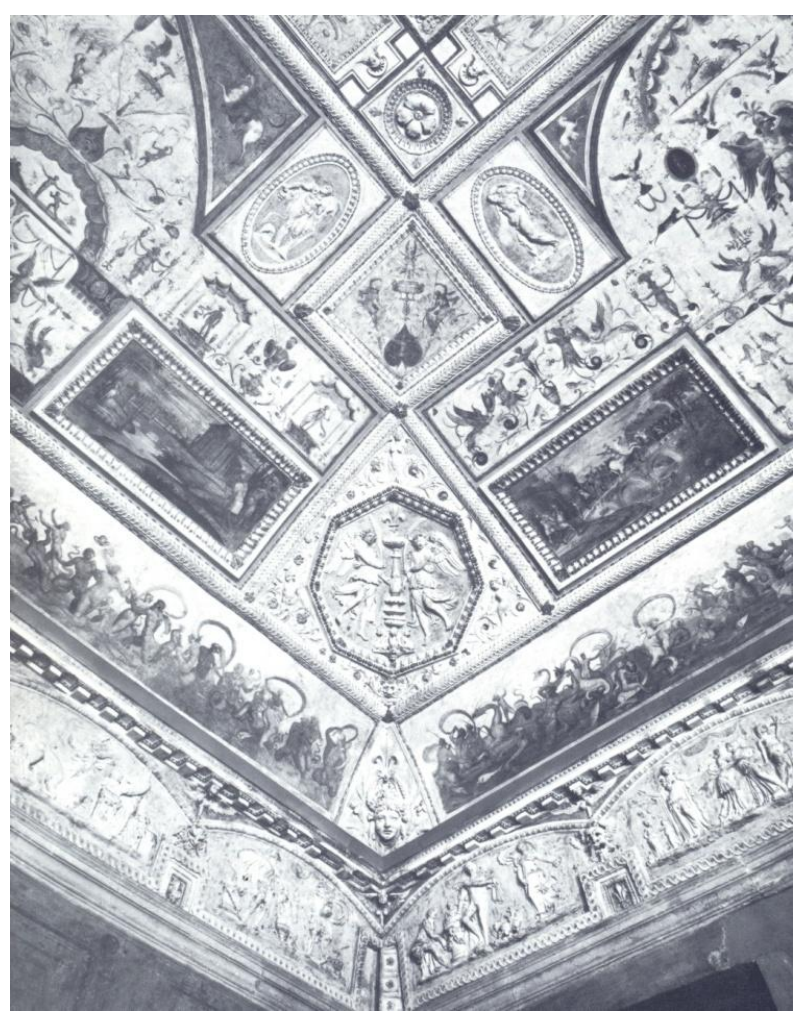

Fig.20 - Un particolare della Volta dopo il restauro 


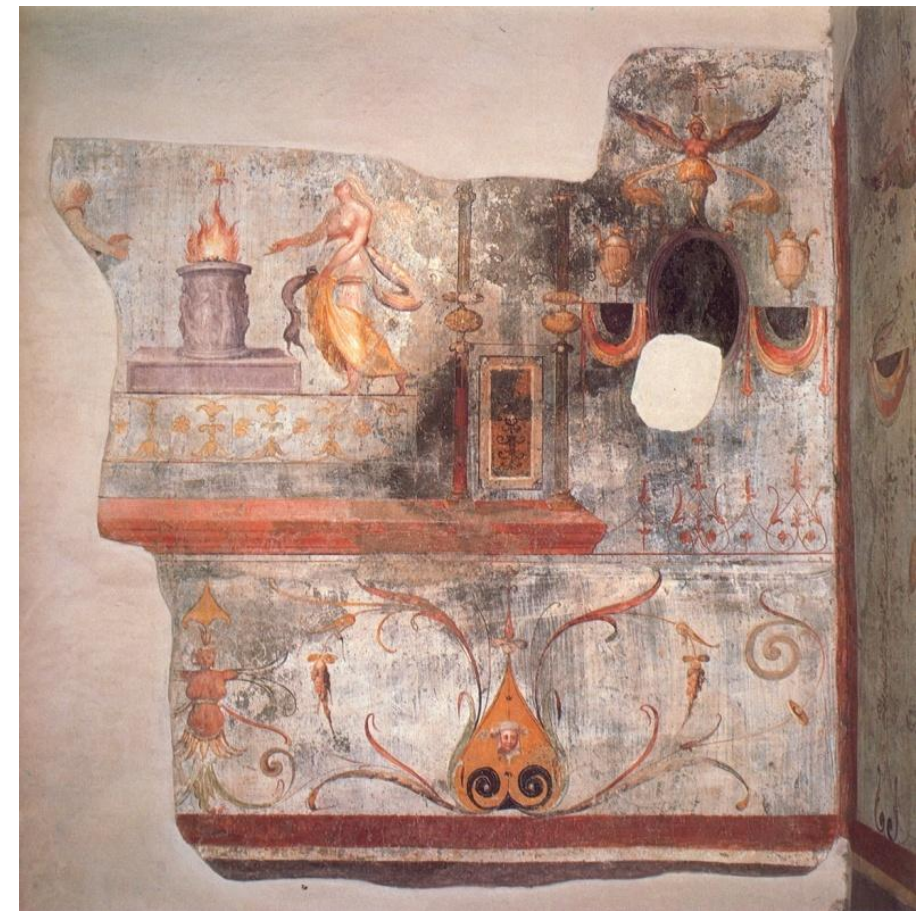

Fig.21-un particolare degli affreschi del vestibolo della Biblioteca, durante il restauro

Roma- Castel Sant'Angelo- Sala d'Apollo. Restaurata da Colalucci nel 1975

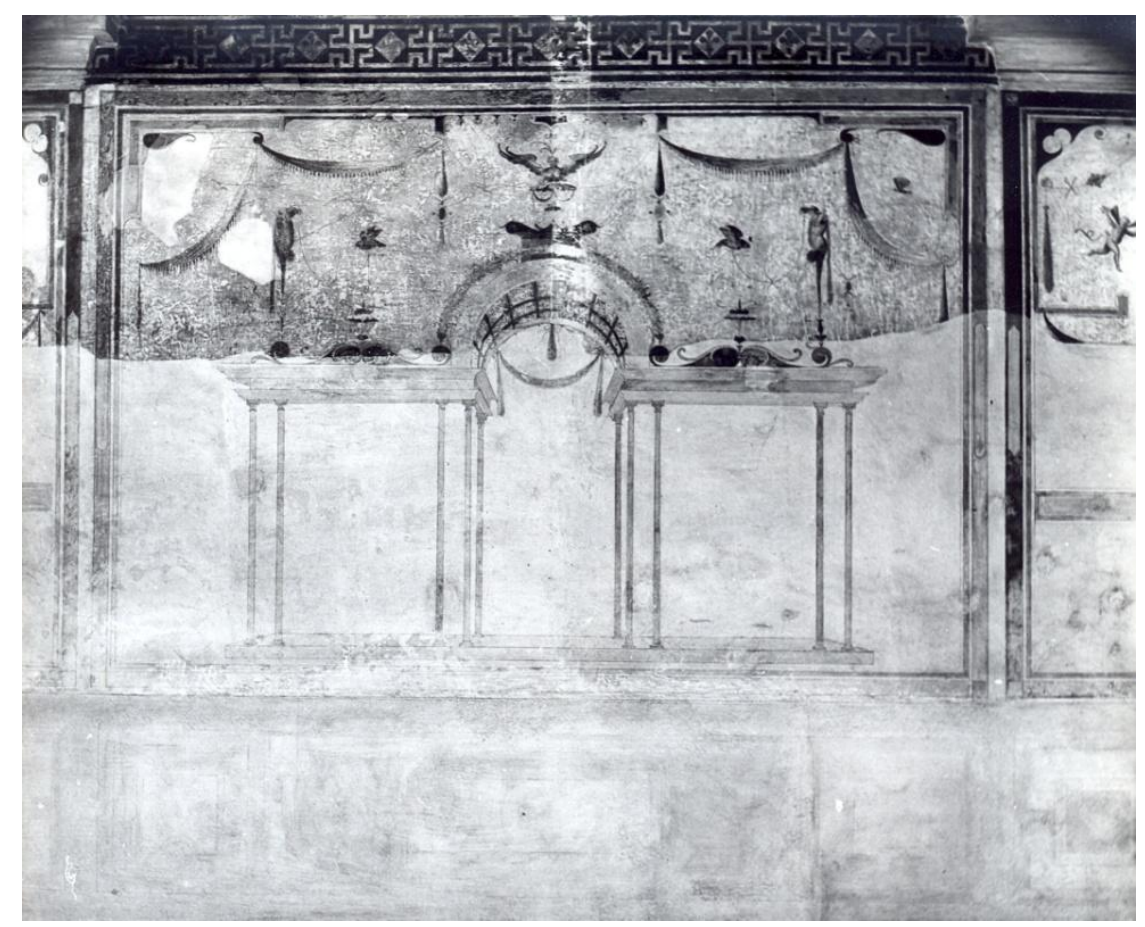

Fig.22- un particolare delle pareti prima del restauro, con l'intervento del restauratore Buttinelli (anni 40) 


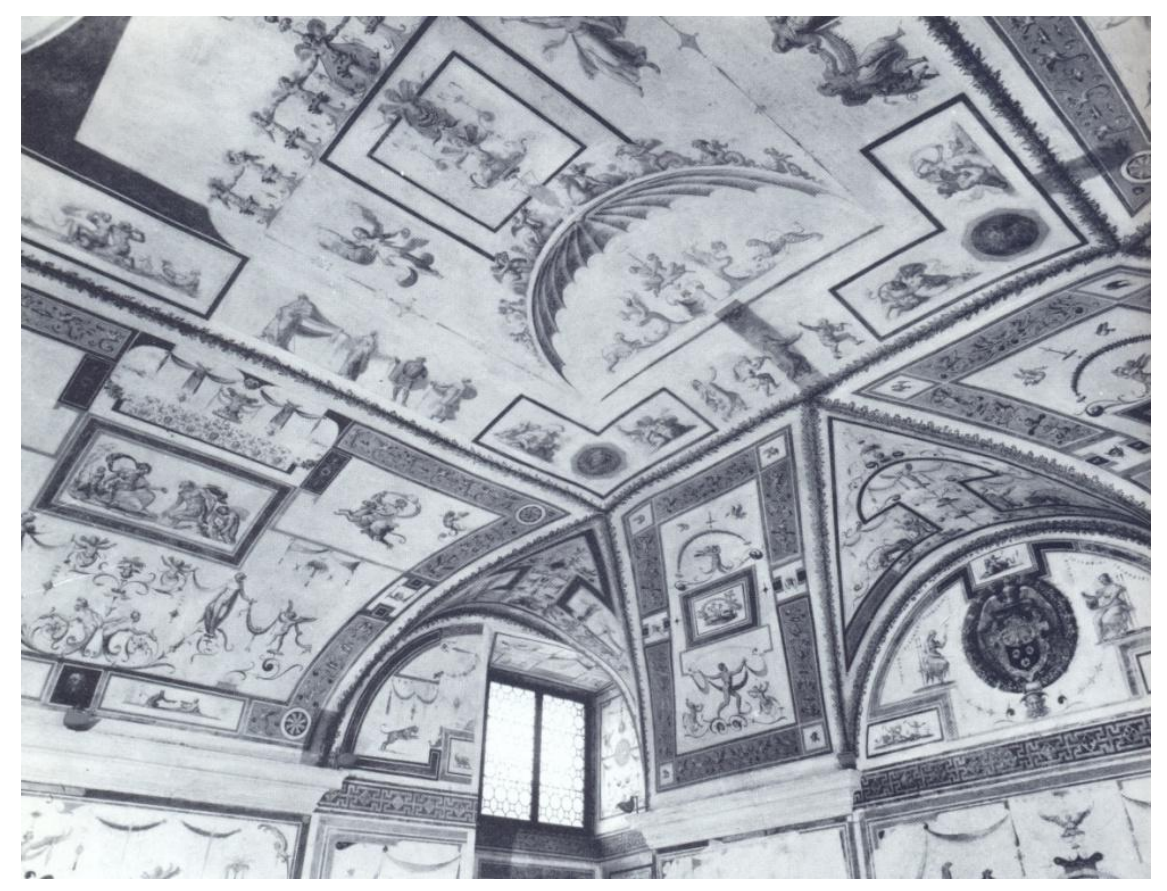

Fig. 23 - particolare della Volta dopo il restauro

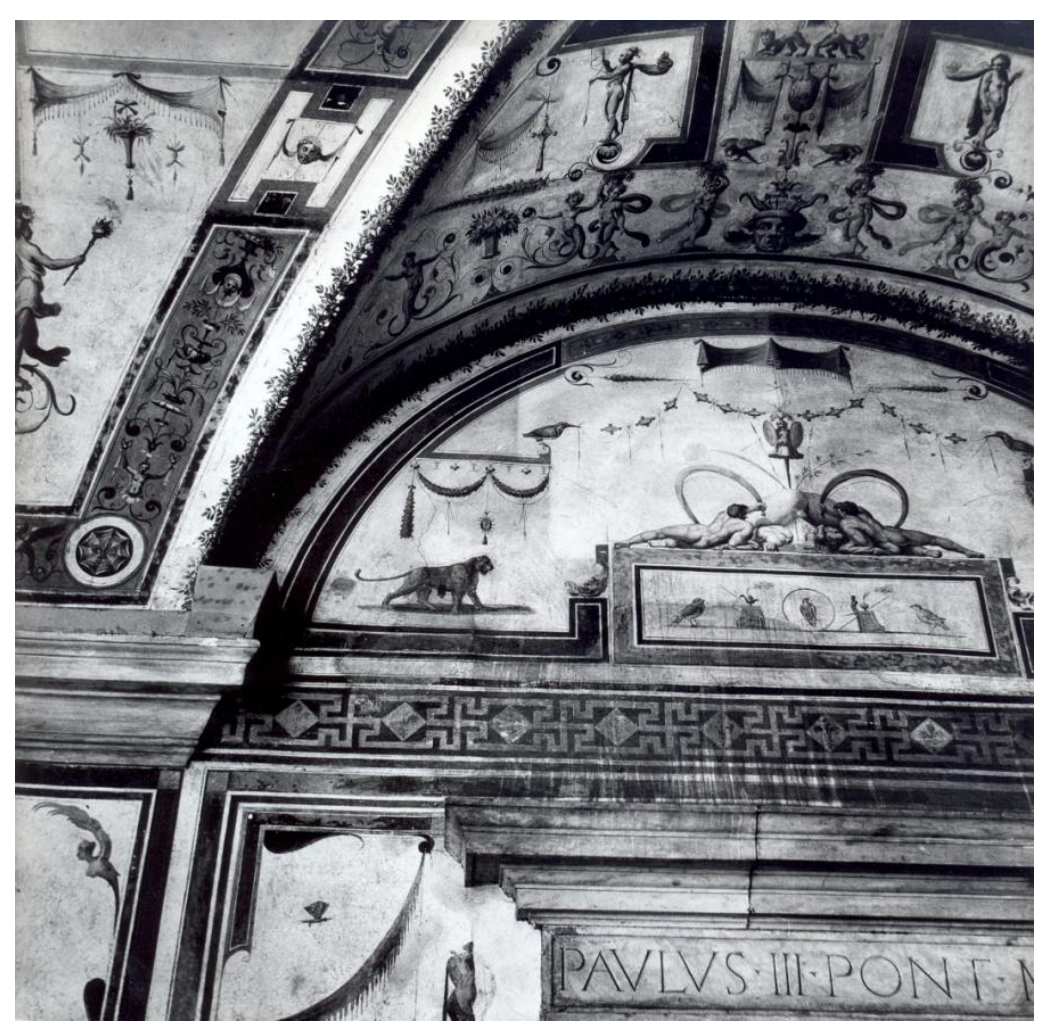

Fig.24 - un particolare delle pareti della Sala d'Apollo durante la pulitura 


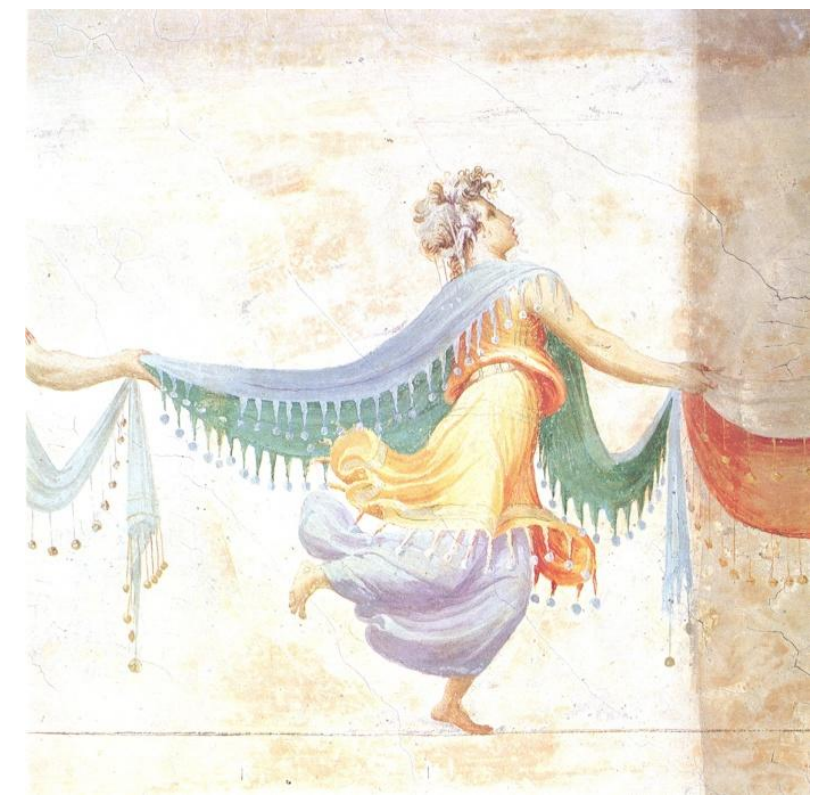

Fig. 25 - particolare delle pareti durante la pulitura

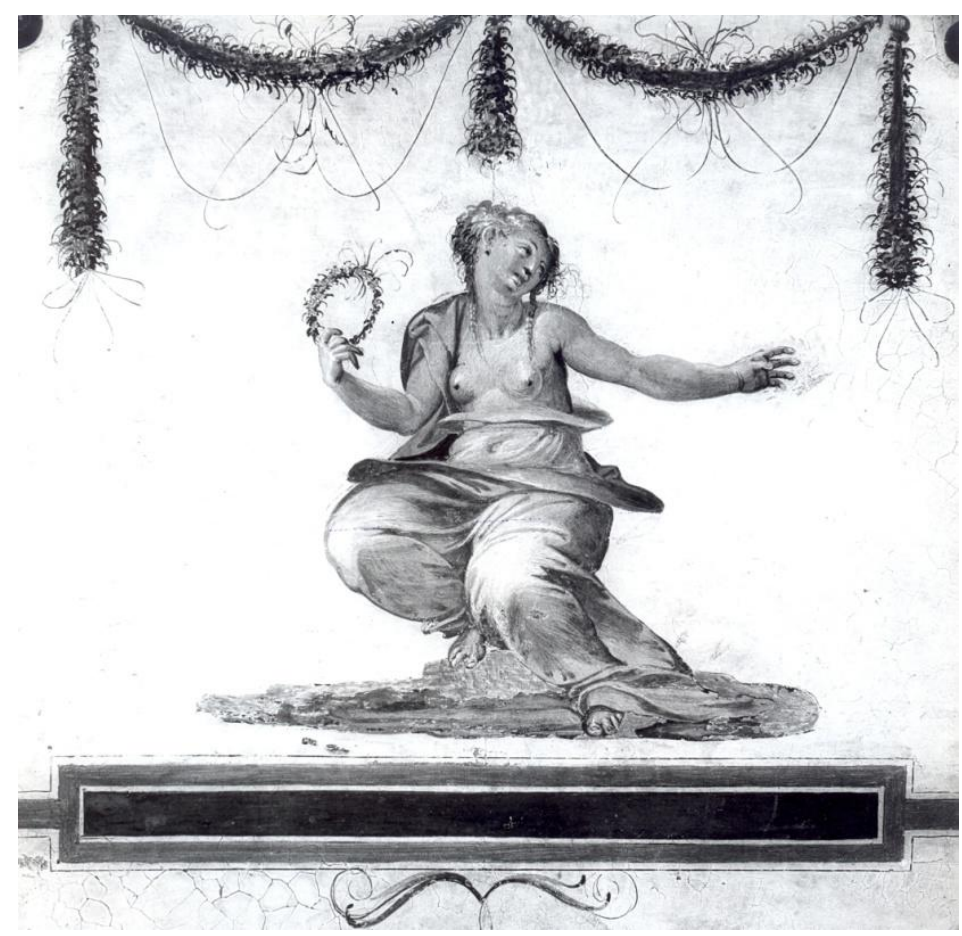

Fig. 26 - particolare degli affreschi della Sala d'Apollo dopo la pulitura 


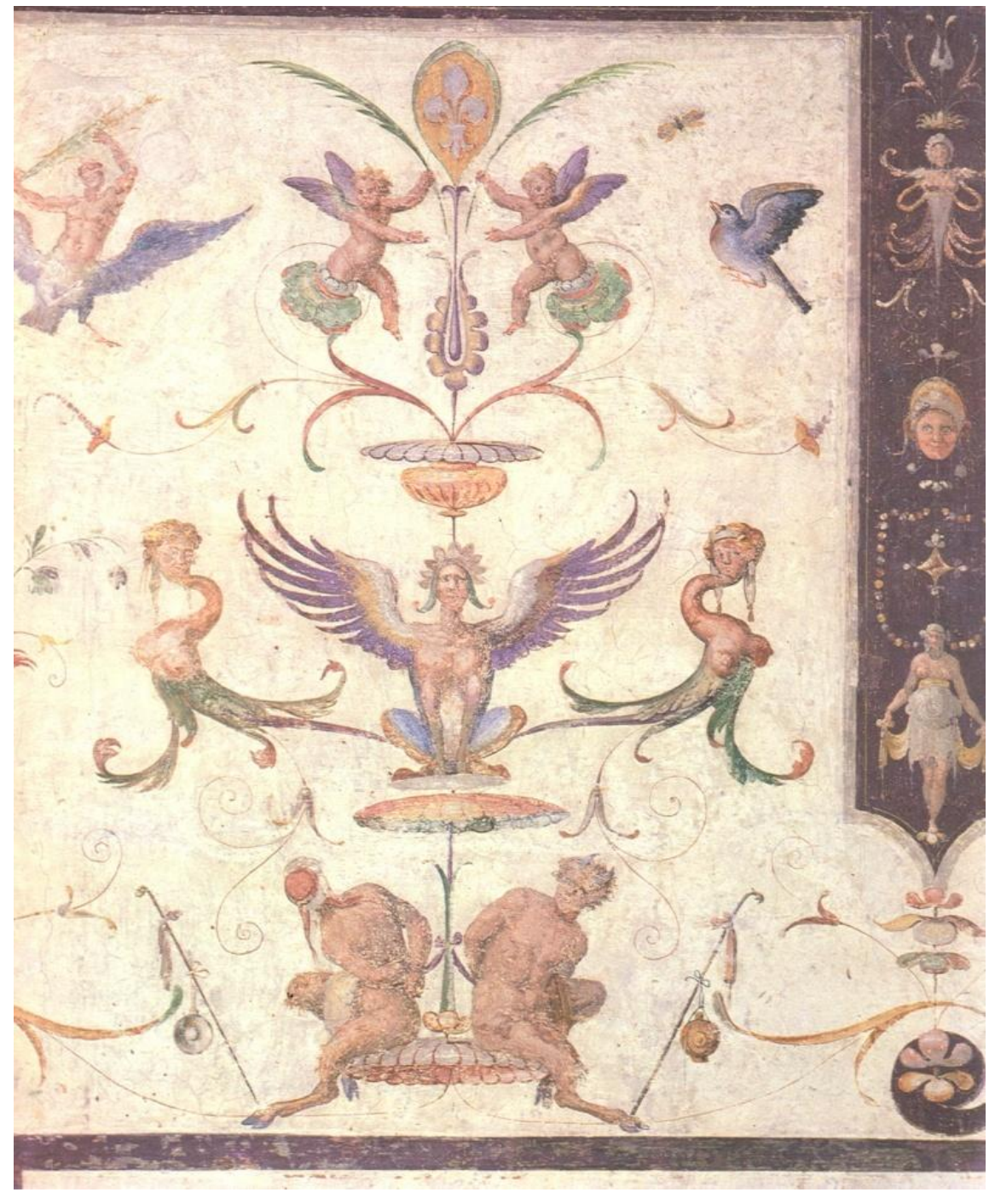

Fig.27 - particolare delle pareti della Sala d'Apollo dopo la pulitura 


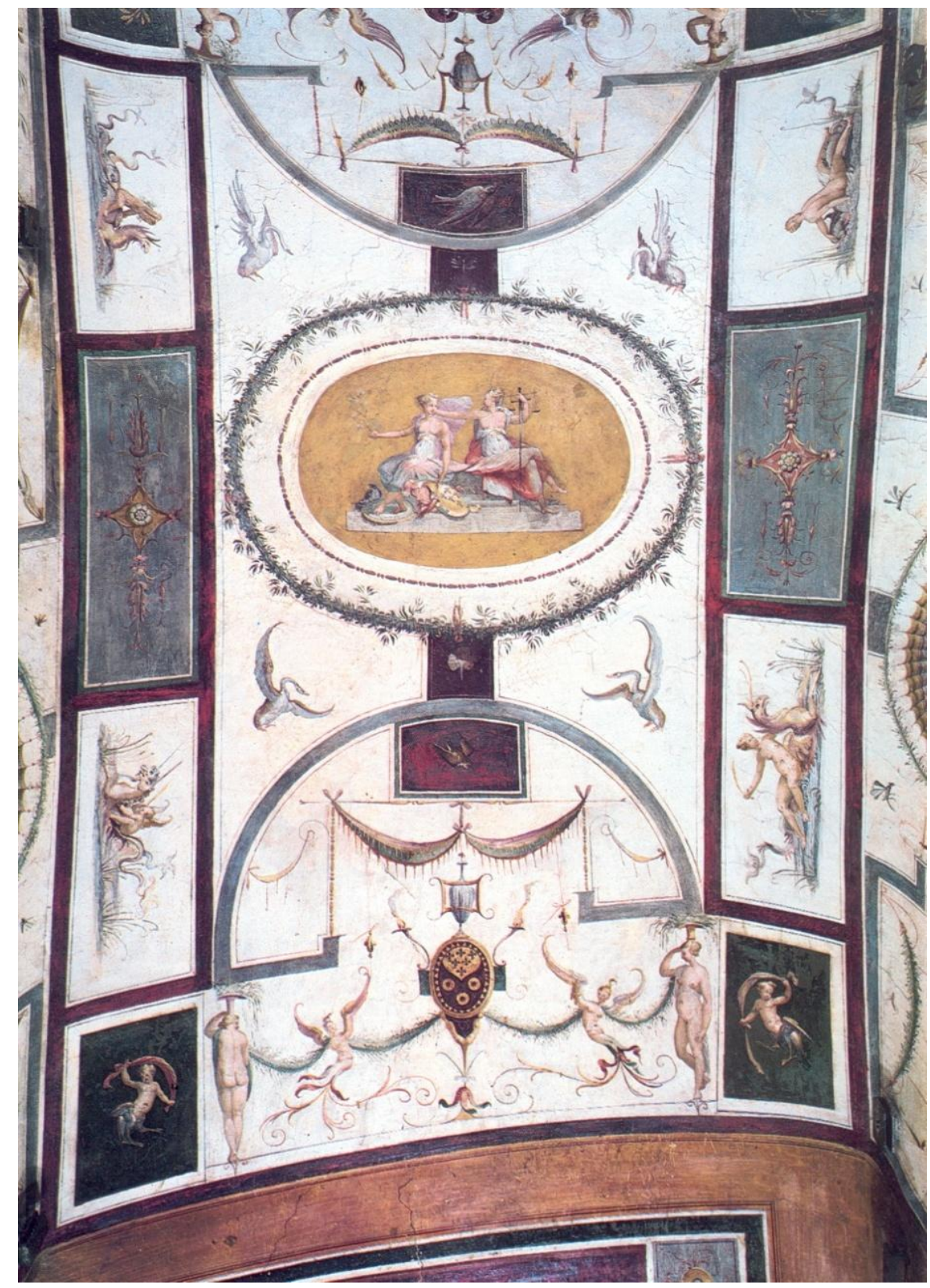

Fig.28 - la Volta del Corridoio Pompeiano dopo il restauro 


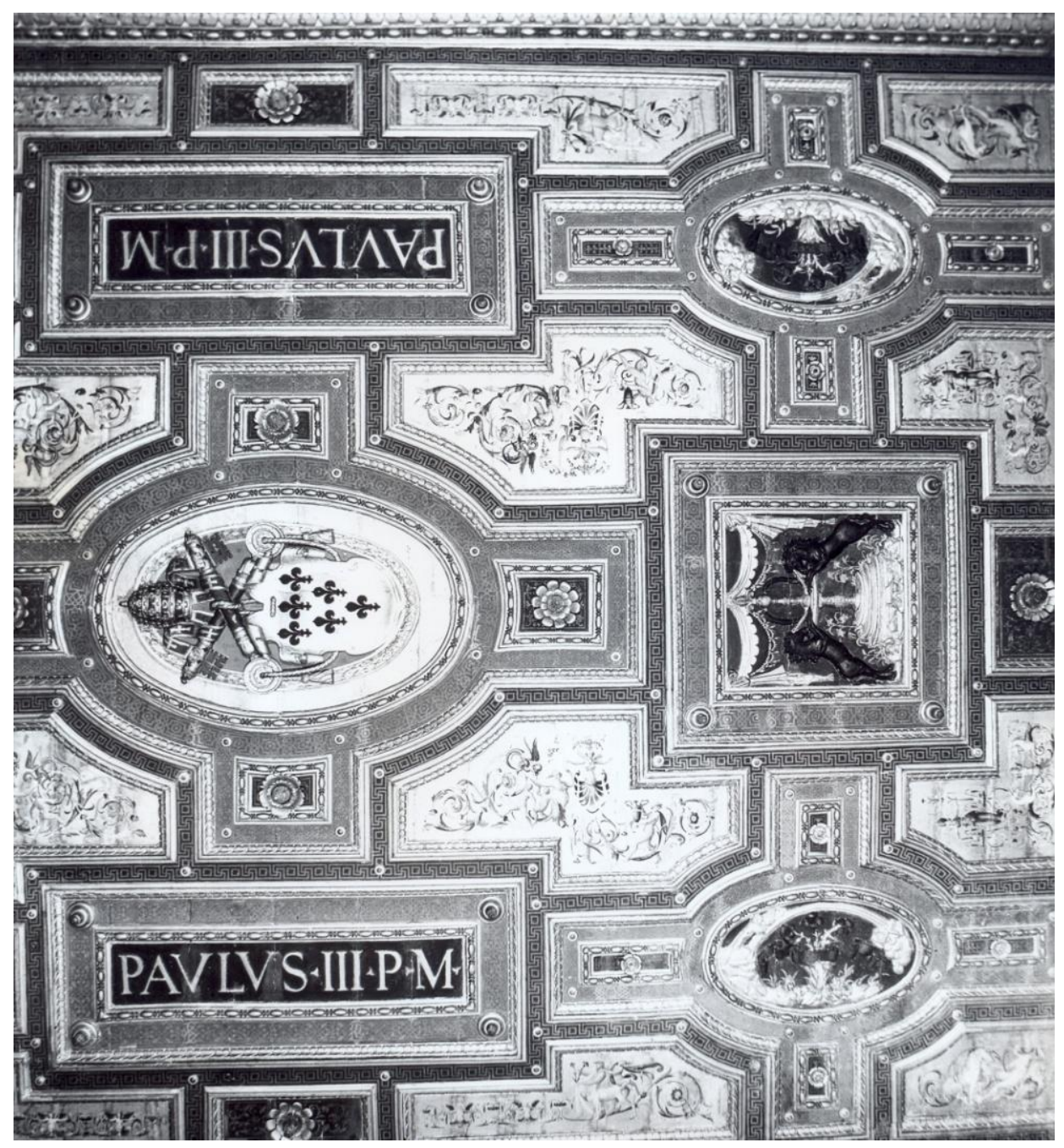

Fig.29- Castel Sant' Angelo- Soffitto della Sala di "Amore e Psiche" dopo il restauro di Colalucci -1985 
Roma- Castel Sant'Angelo - Arcangelo Michele. Restaurato da Colalucci tra il 1985 e il 1987

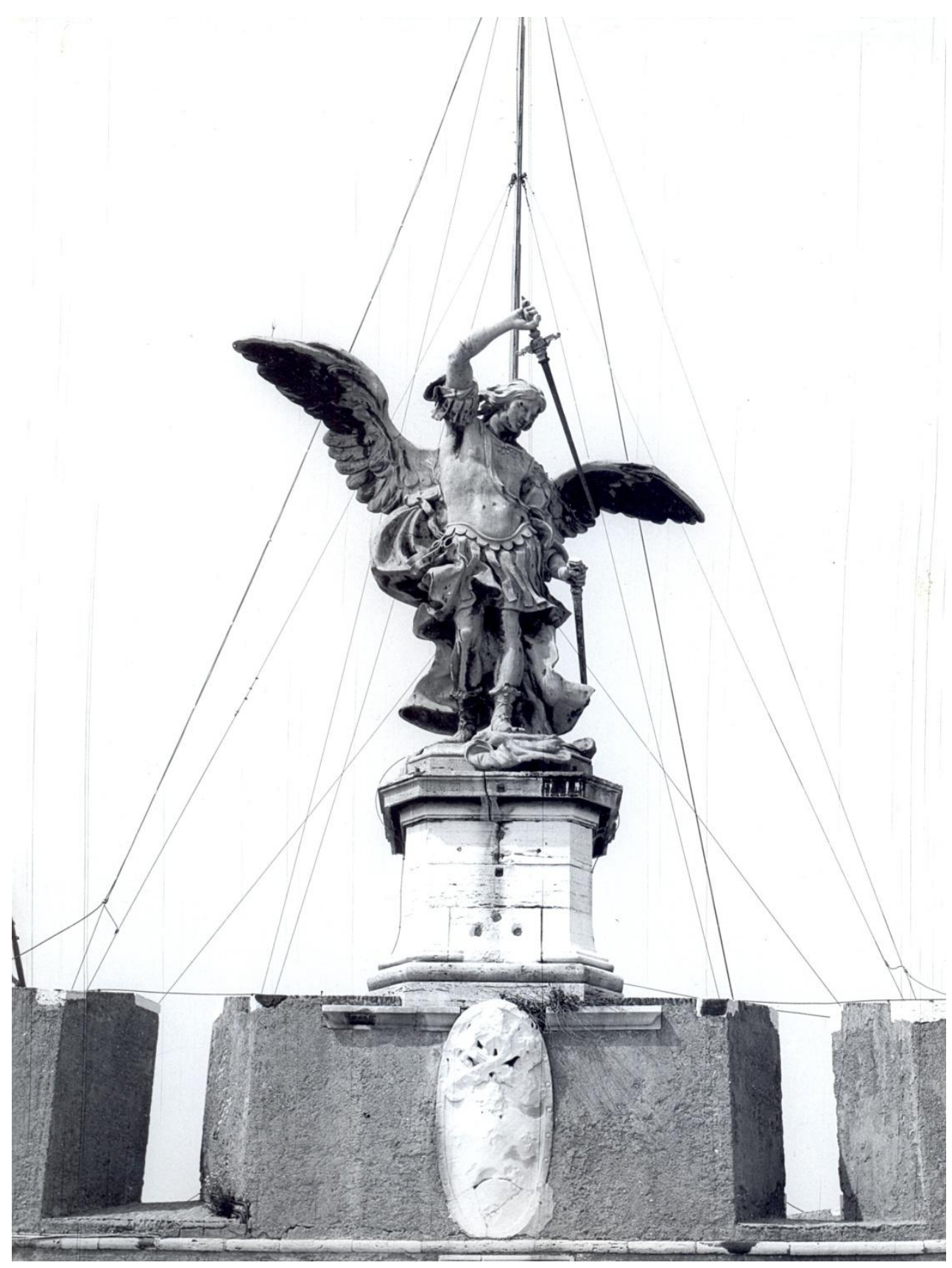

Fig. 30- L'Angelo del Verchaffelt prima del restauro 


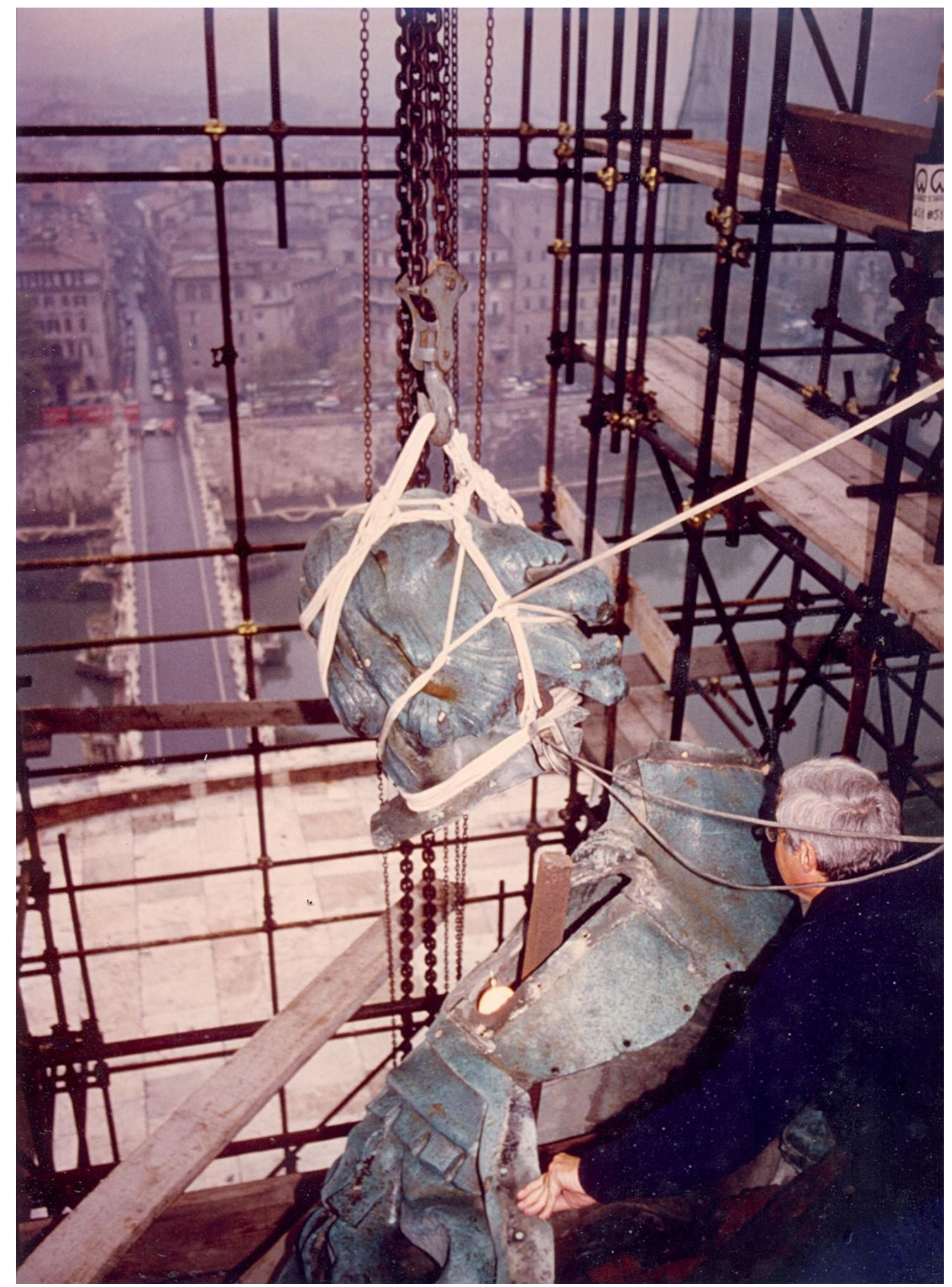

Fig. 31- Colalucci durante lo smontaggio della testa dell'Angelo 


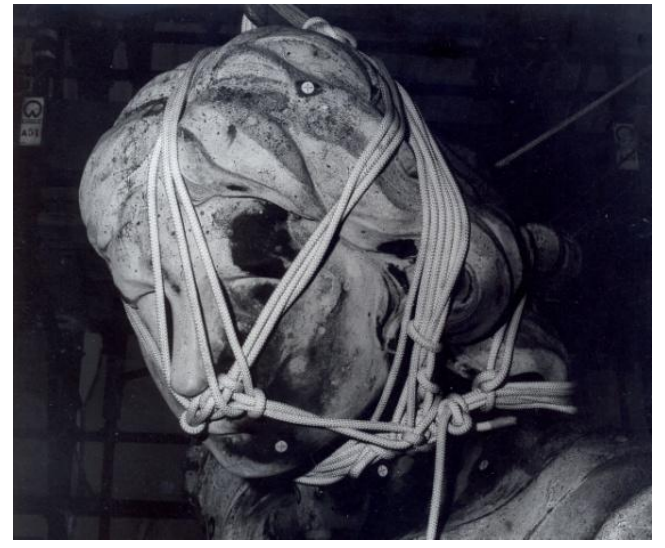

Fig. 32- lo smontaggio della testa

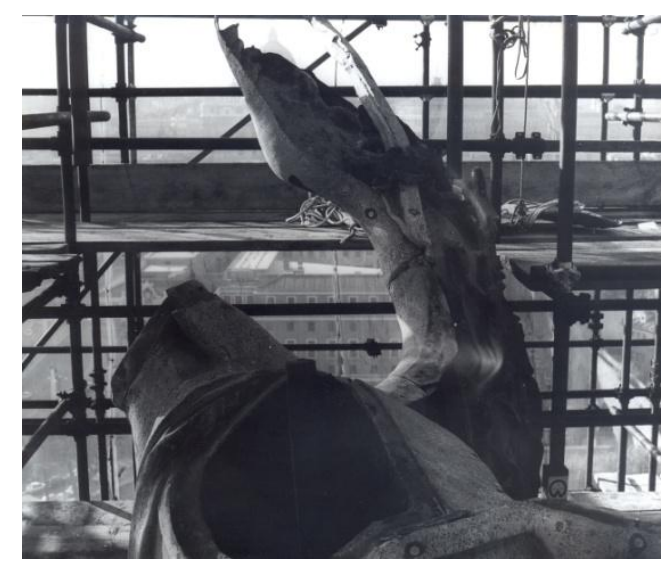

Fig. 34- alto particolare dell'Angelo

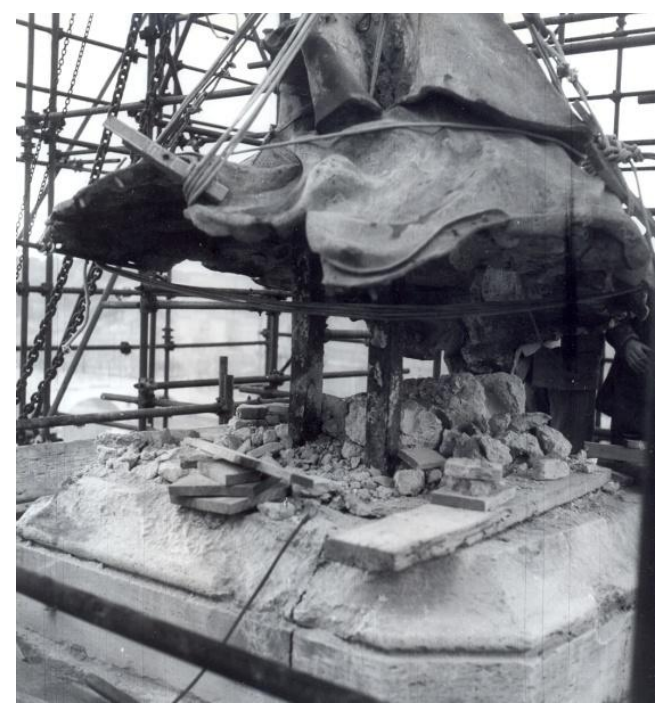

Fig. 36- lo smontaggio della base

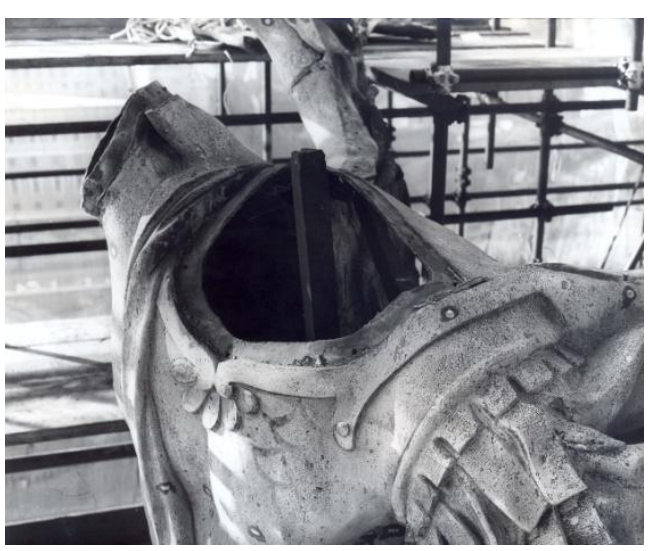

Fig. 33- l'Angelo senza testa

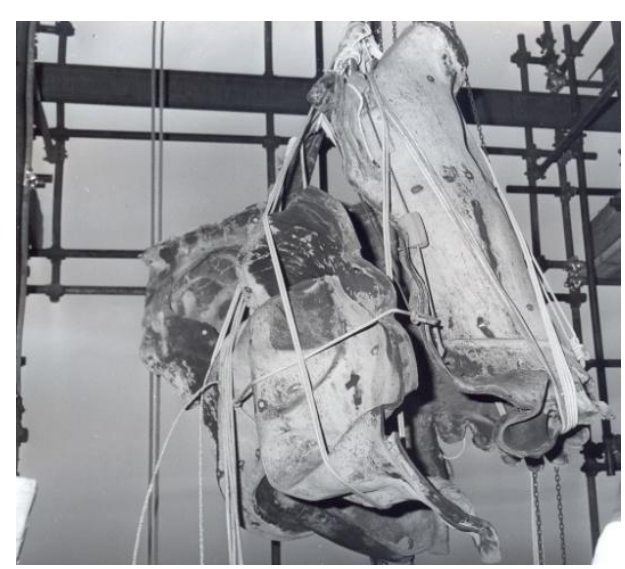

Fig. 35- lo smontaggio di una parte del manto

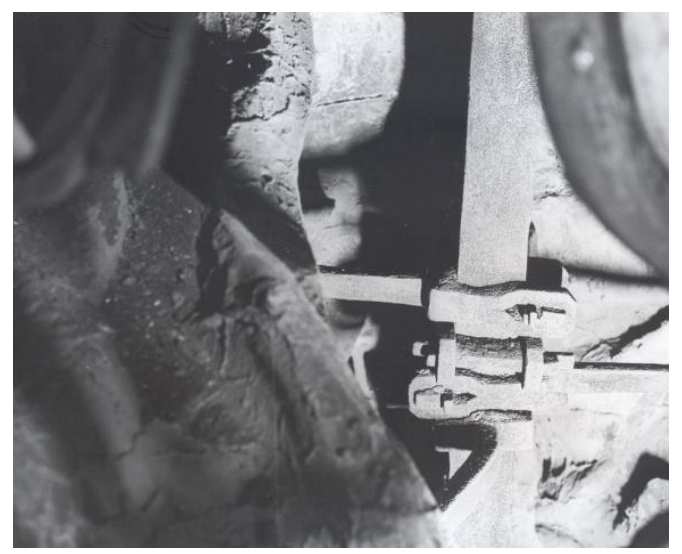

Fig. 37- un particolare della vecchia armatura 


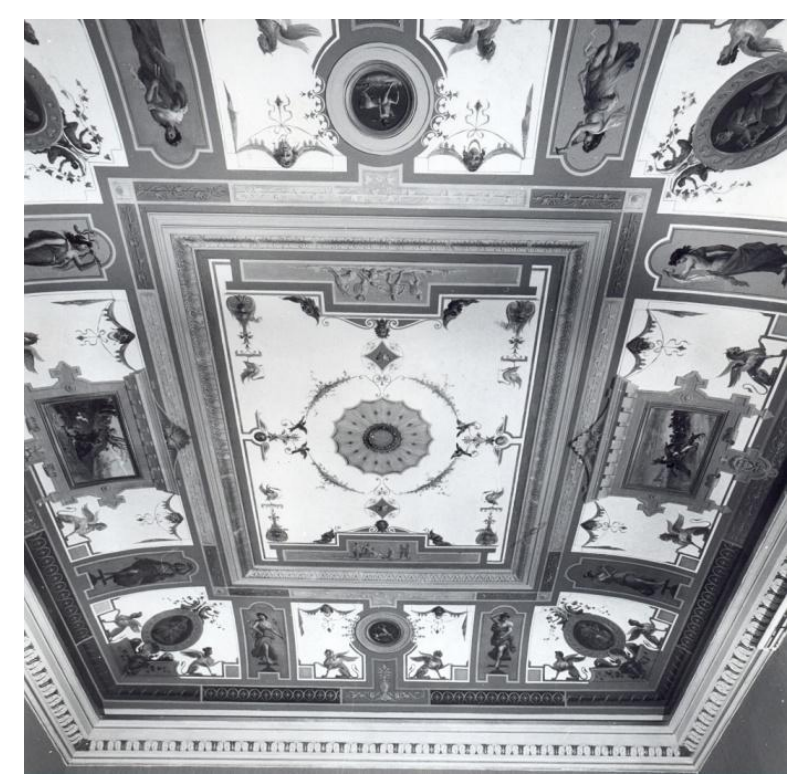

Fig.38- la Sala 256 dopo il restauro

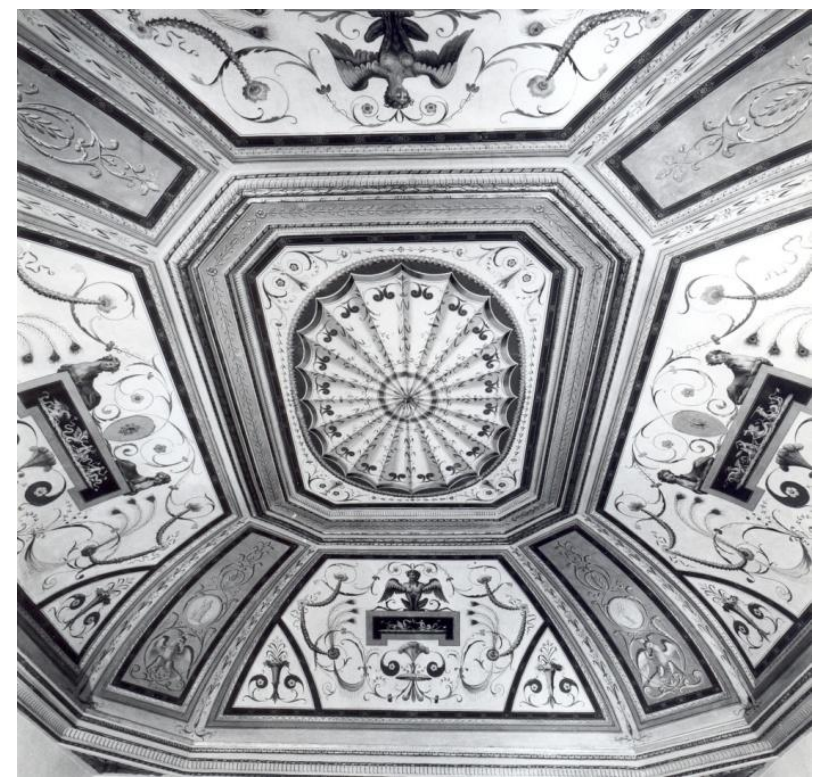

Fig. 39 - la Sala 272 dopo il restauro

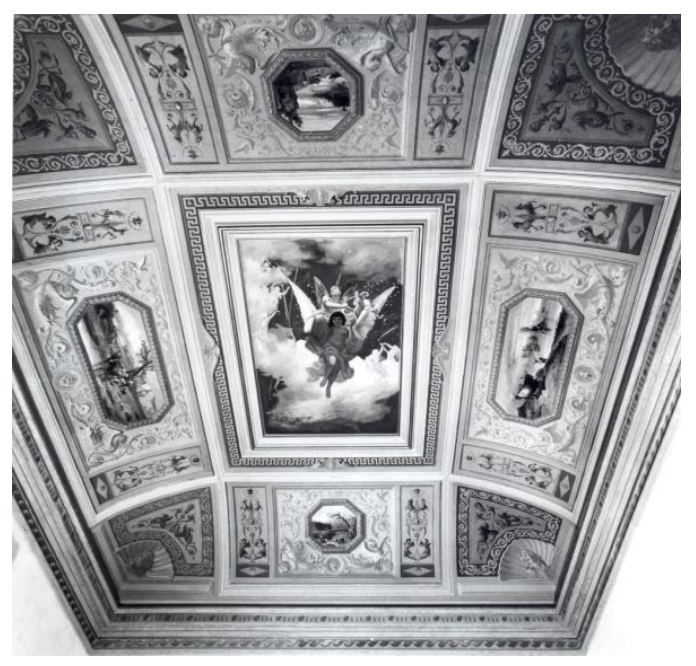

Fig. 41- la Sala 254 dopo il restauro 


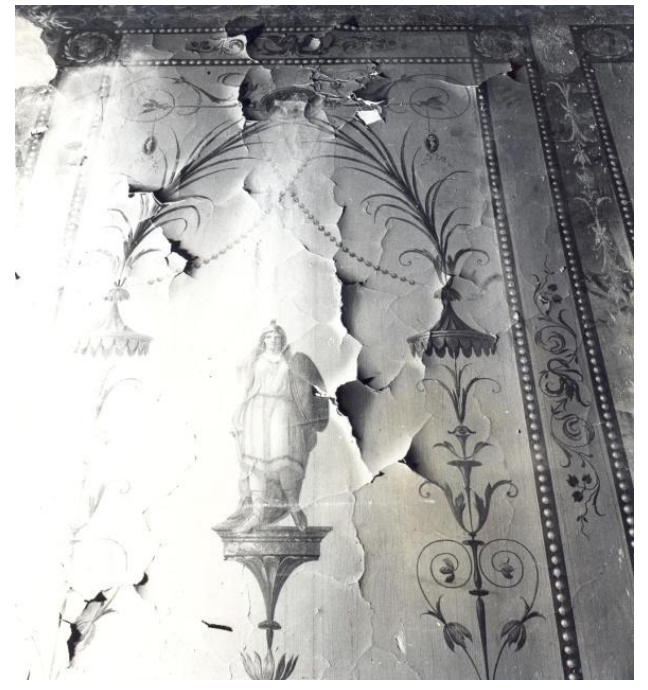

Fig. 42 - sollevamenti di colore nella Sala 118

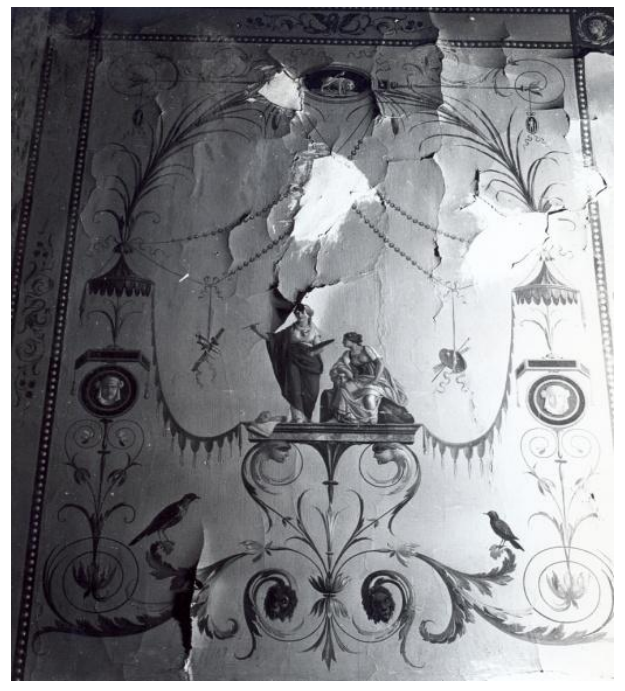

Fig. 43 - sollevamenti di colore nella Sala 118

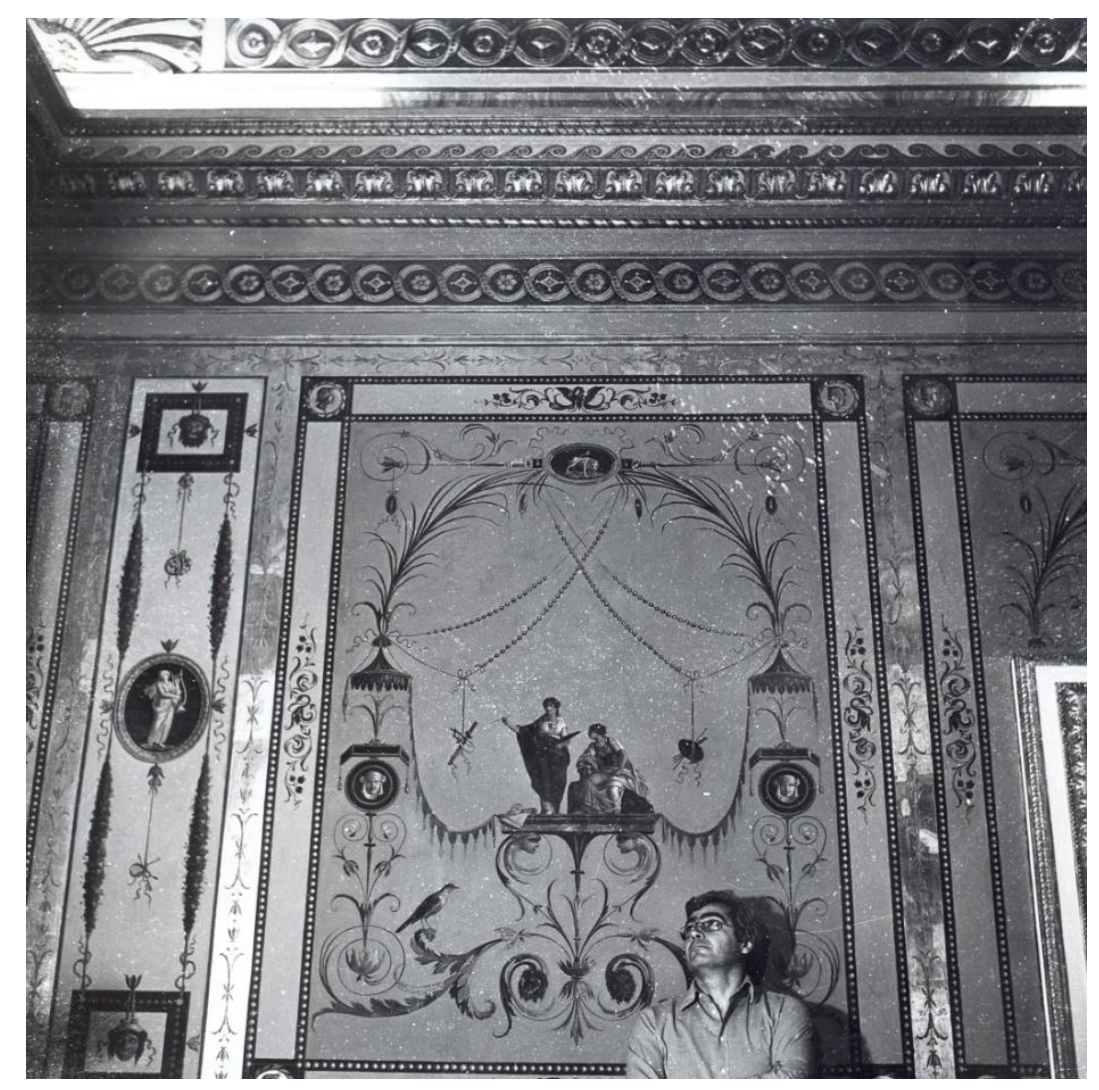

Fig. 44- Colalucci nella Sala 118 restaurata 


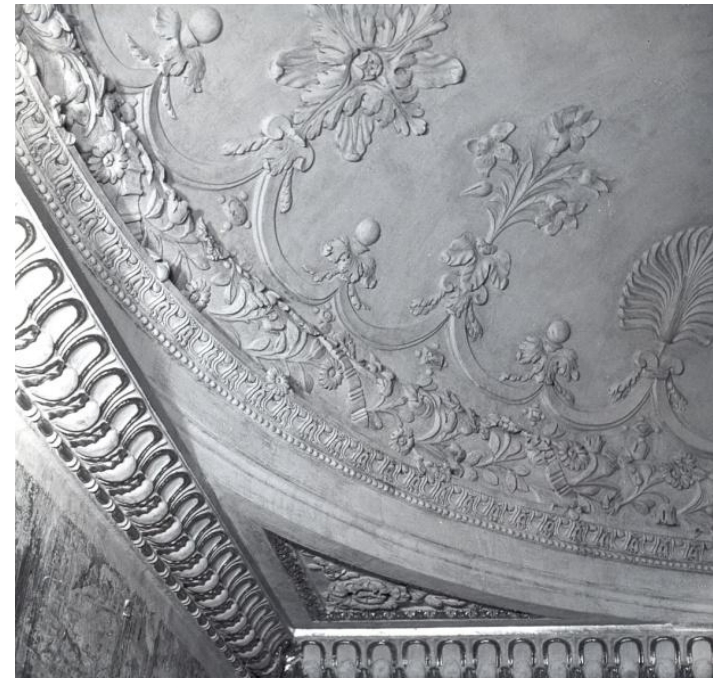

Fig. 45- gli stucchi di Borromini nella Sala 106

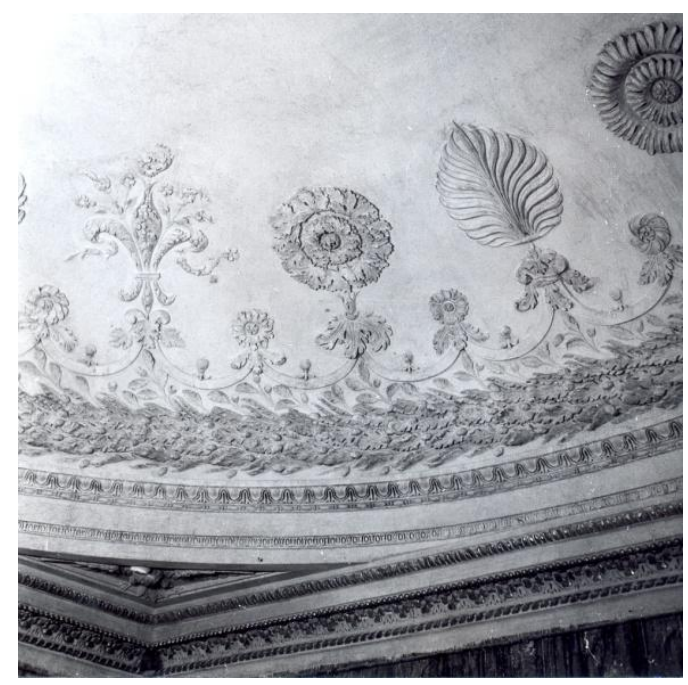

Fig.46 - Gli stucchi di Borromini nella Sala 107

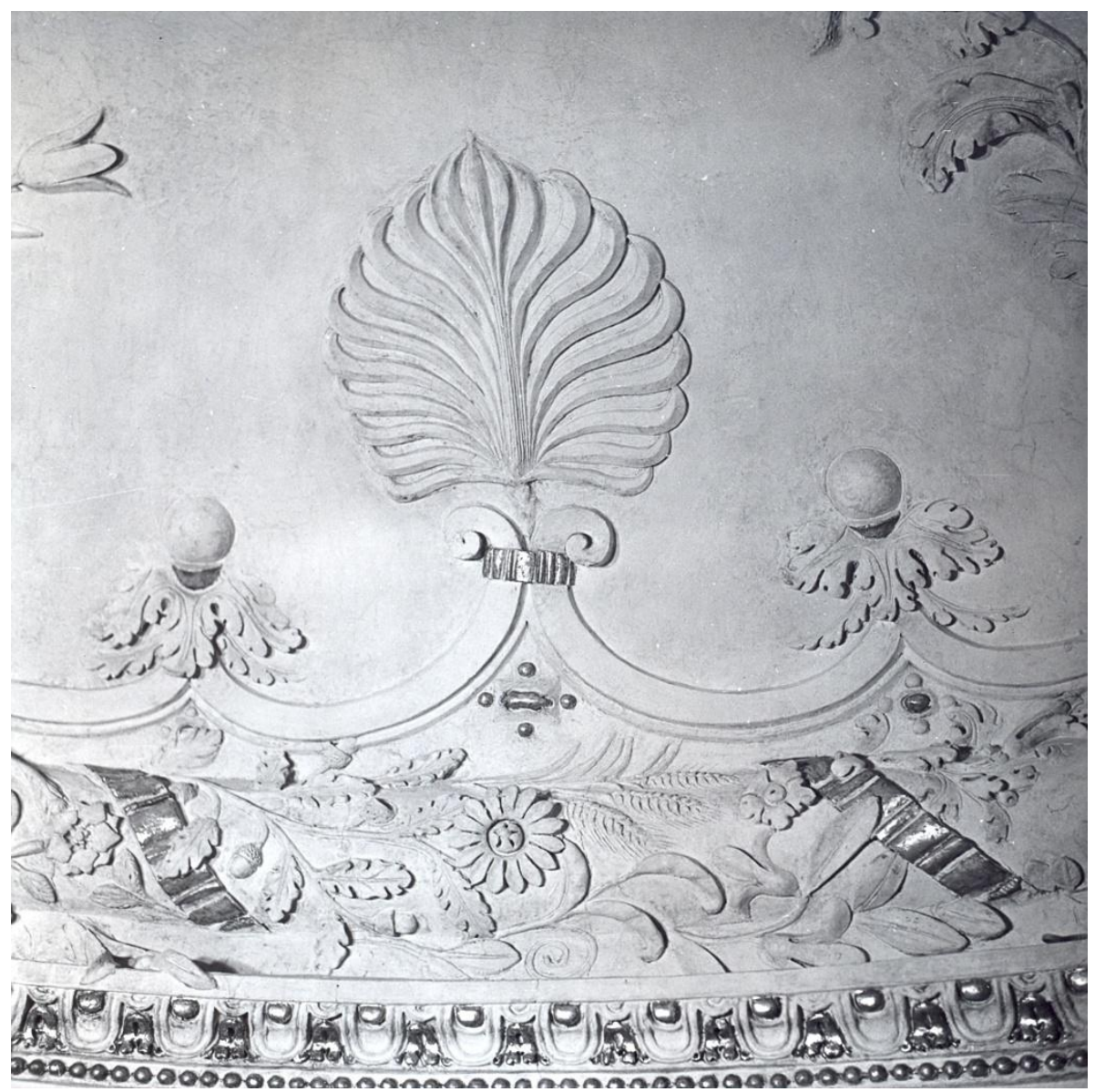

Fig. 47 - gli stucchi della Sala 106 dopo il restauro 
Roma - Galleria Borghese. Alcuni dipinti restaurati da Colalucci

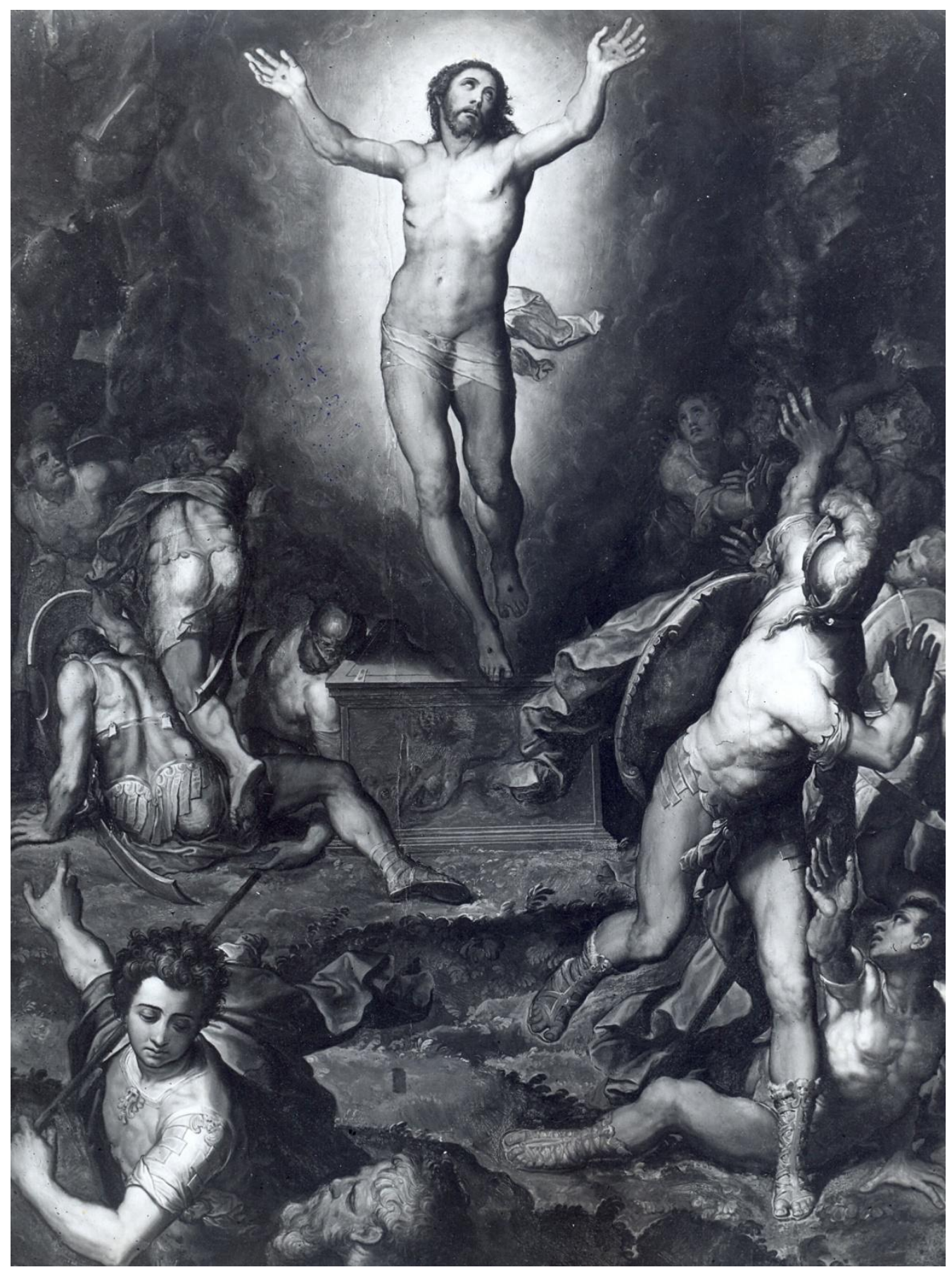

Fig. 48 - MarcoPino "Resurrezione" dopo il restauro di Colalucci- 1976/77 


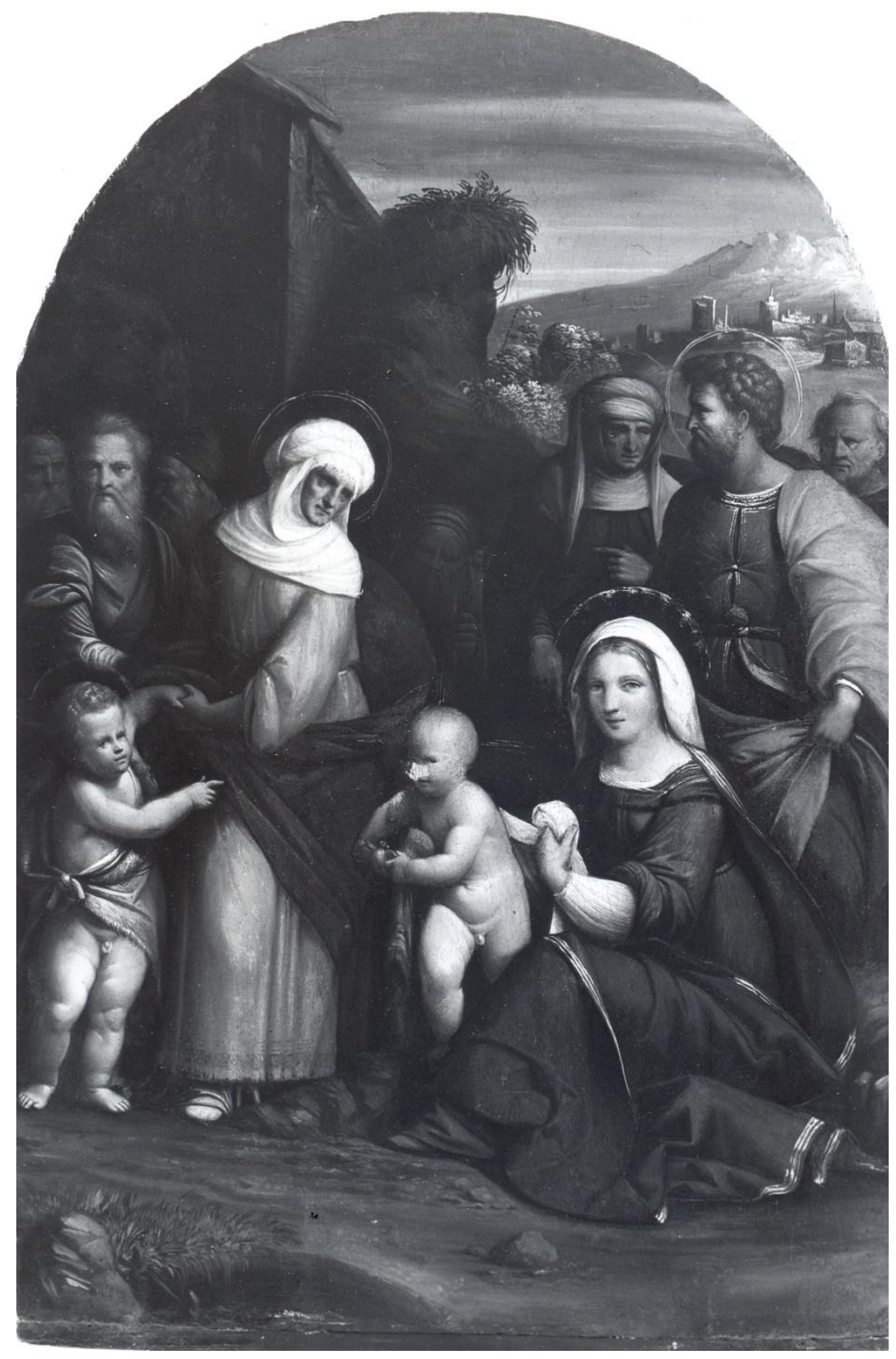

Fig.49- Garofalo "Sacra Famiglia” restauro eseguito da Colalucci nel 1978 


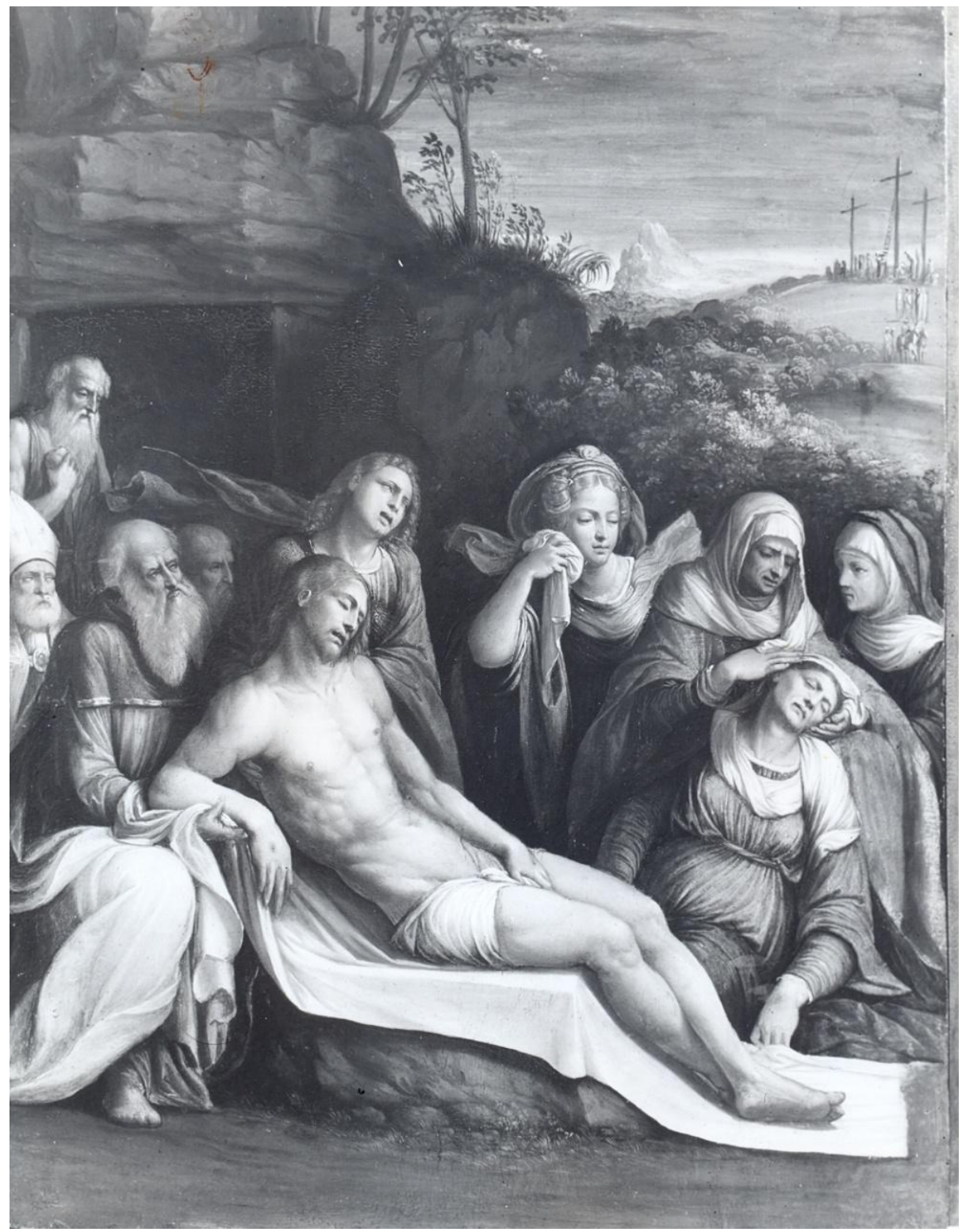

Fig. 50- Garofalo "Pianto sul Cristo morto" restauro eseguito da Colalucci nel 1978 


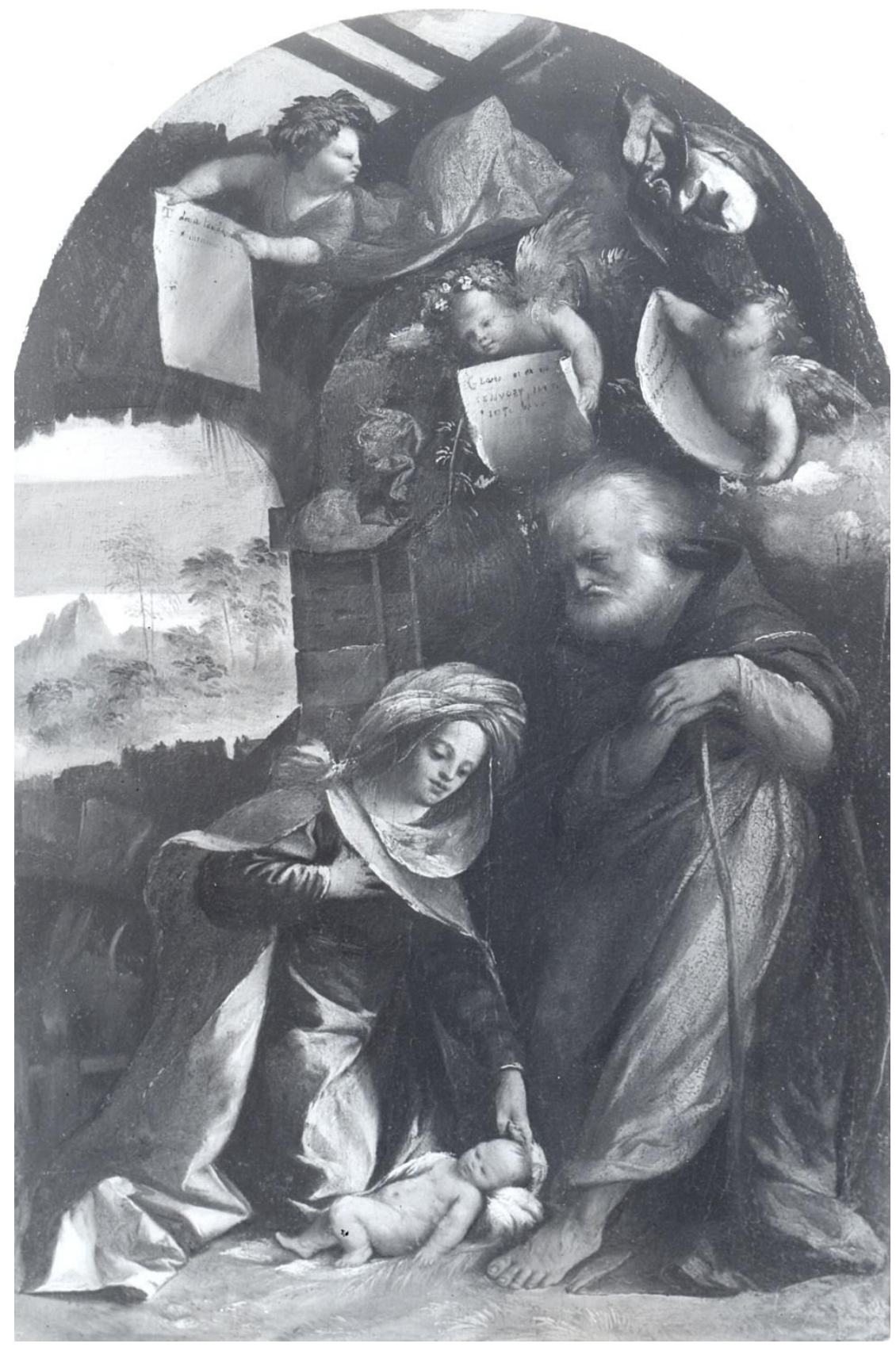

Fig. 51 - D. Dossi “Adorazione del Bambino" restauro eseguito da Colalucci nel 1978 


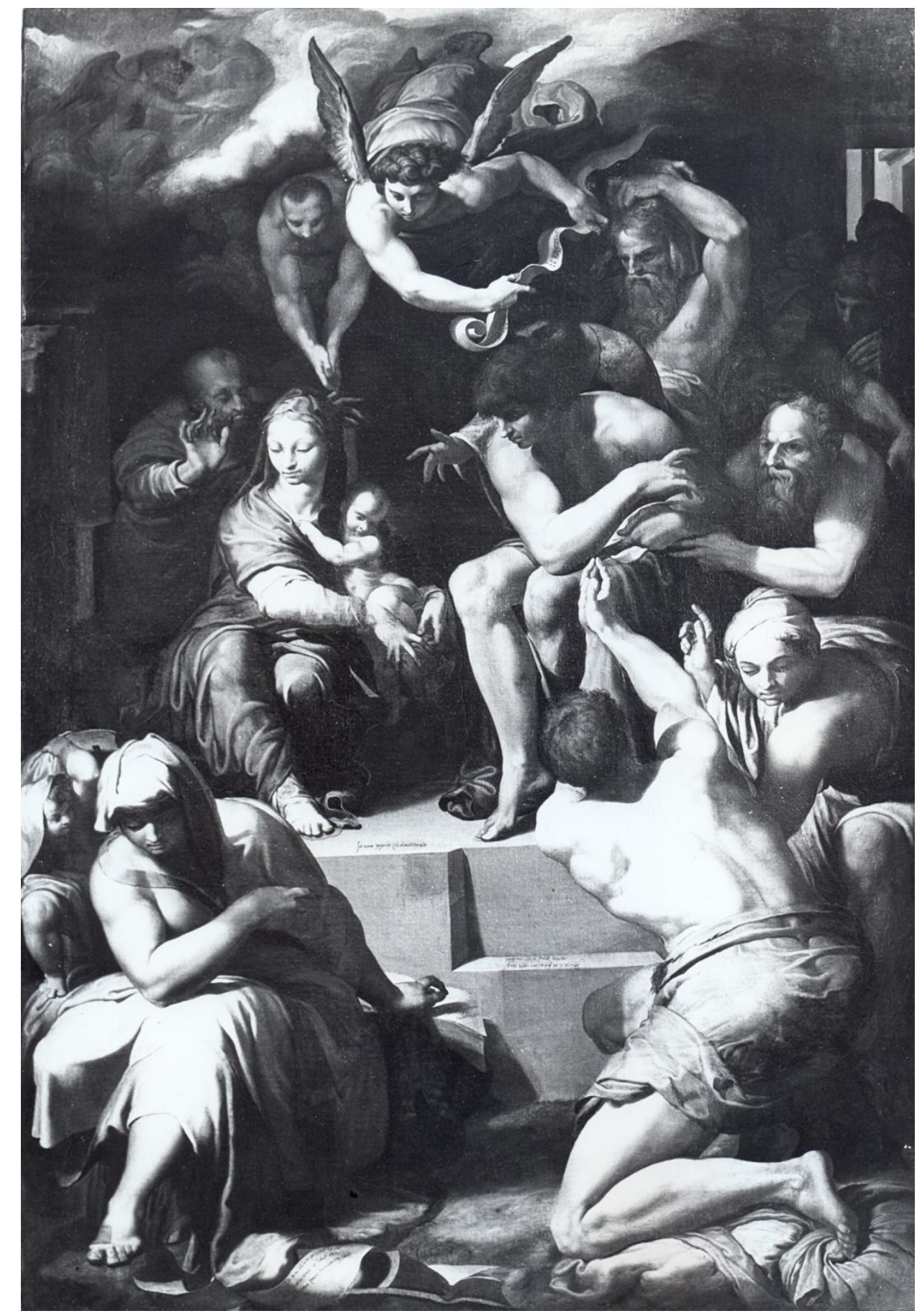

Fig. 52 - Pellegrino Tibaldi "Presepio" restauro eseguito da Colalucci tra il 1973 e il 1974 


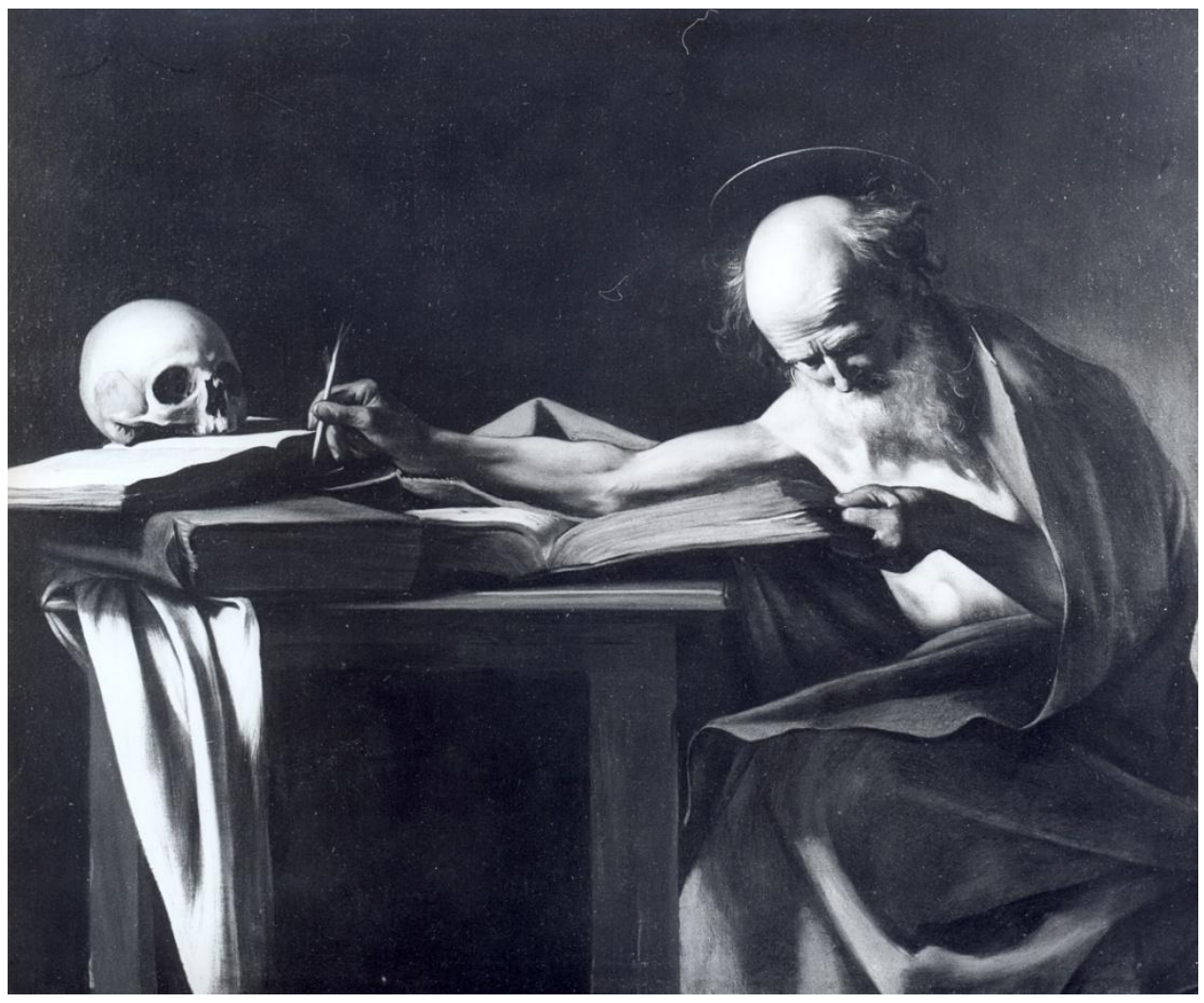

Fig. 53 - Caravaggio "San Girolamo" restauro eseguito da Colalucci nel 1983

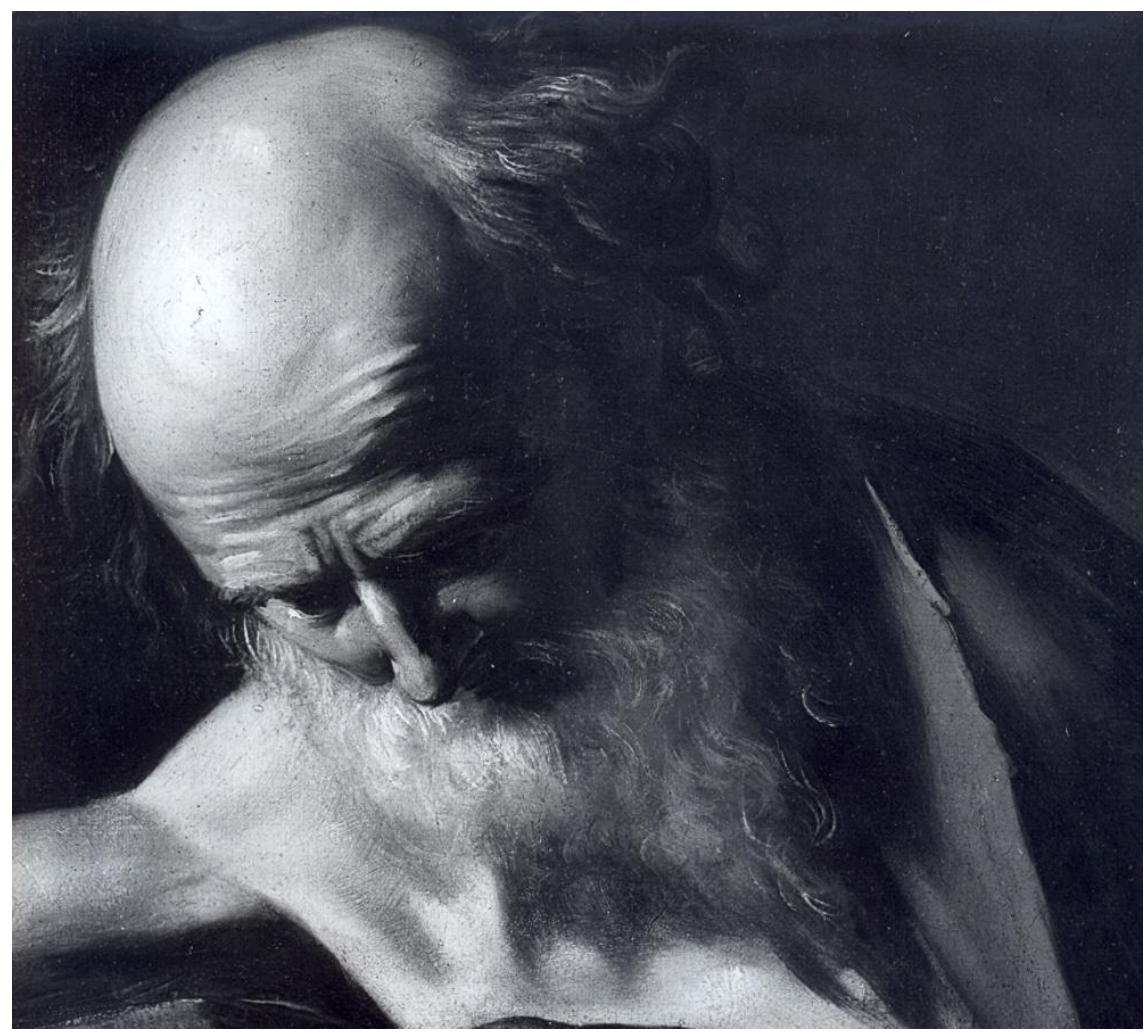

Fig. 54 - Caravaggio, particolare del volto del Santo 


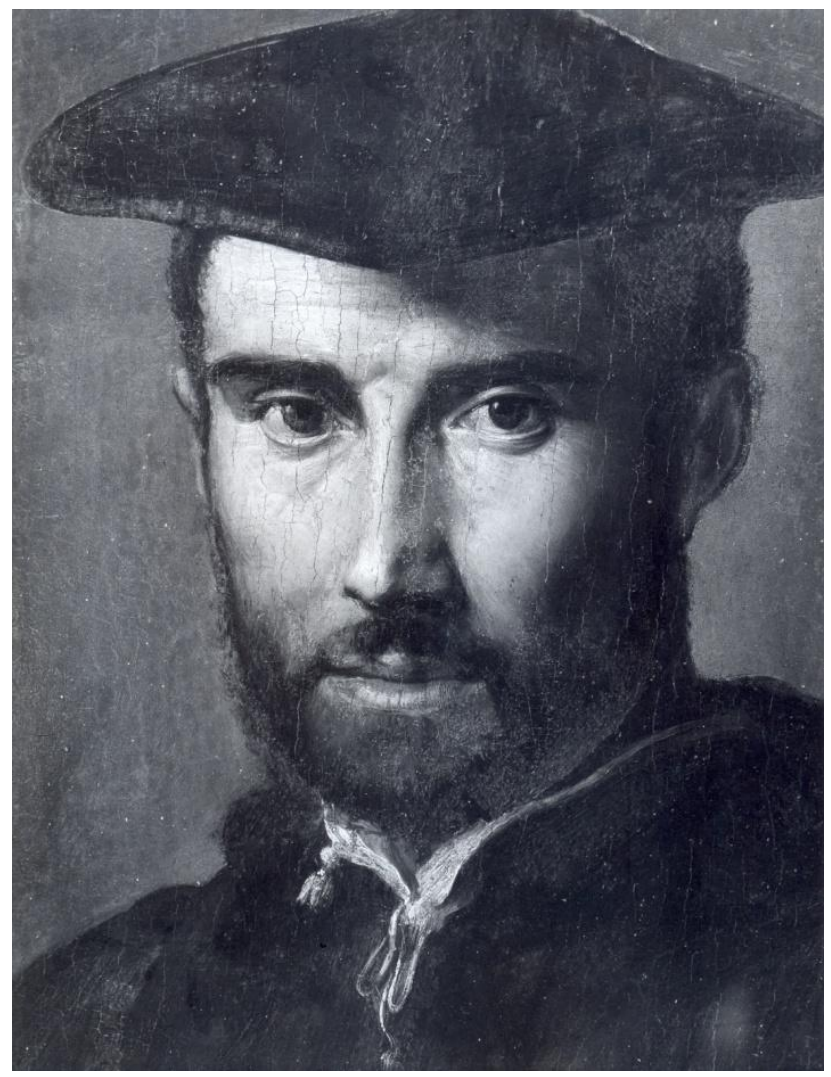

Fig. 55- Parmigianino "Ritratto d'uomo" restaurato da Colalucci nel 1984

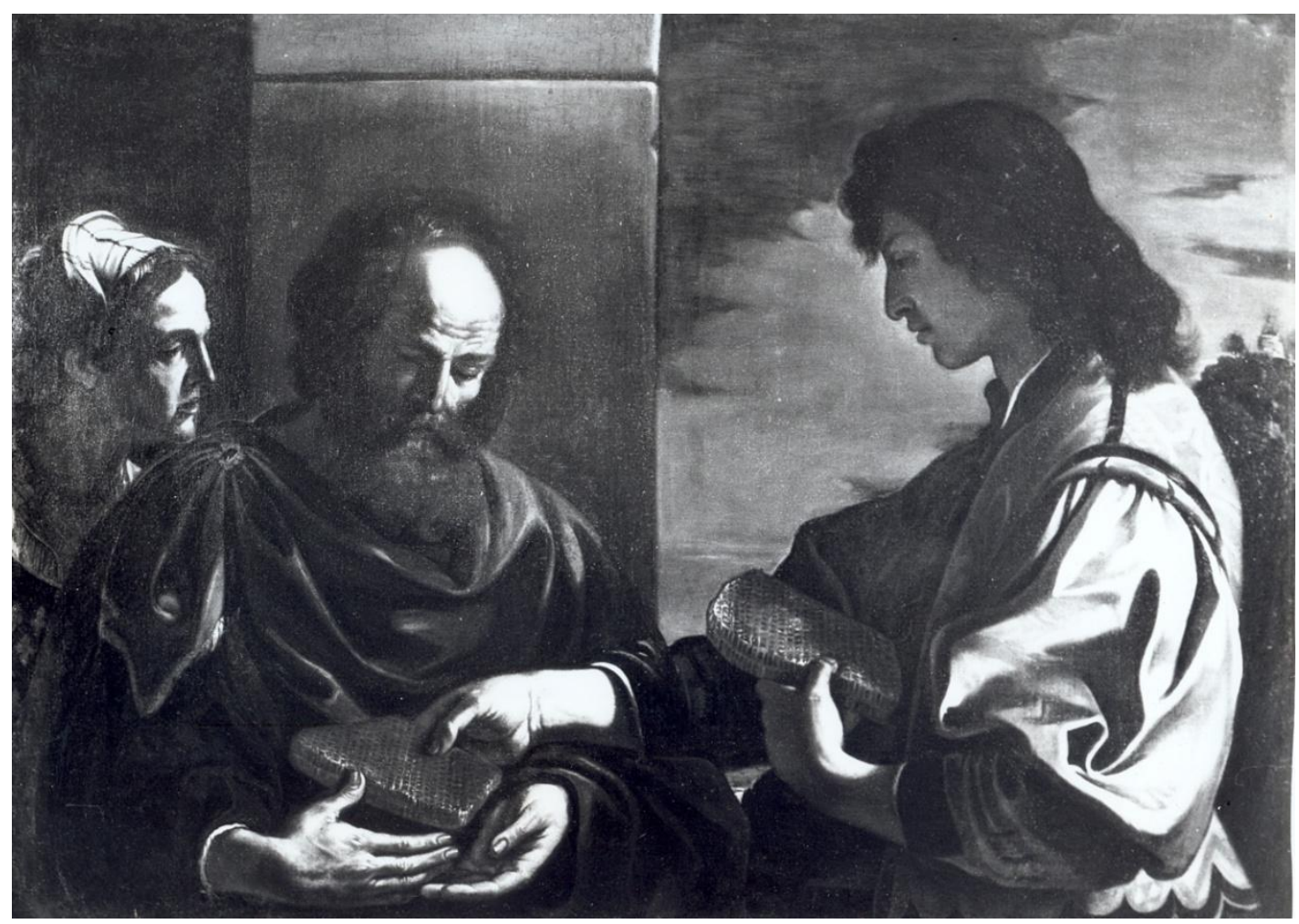

Fig. 56 - Guercino “ Sansone offre un favo ai genitori” restaurato da Colalucci nel 1985 


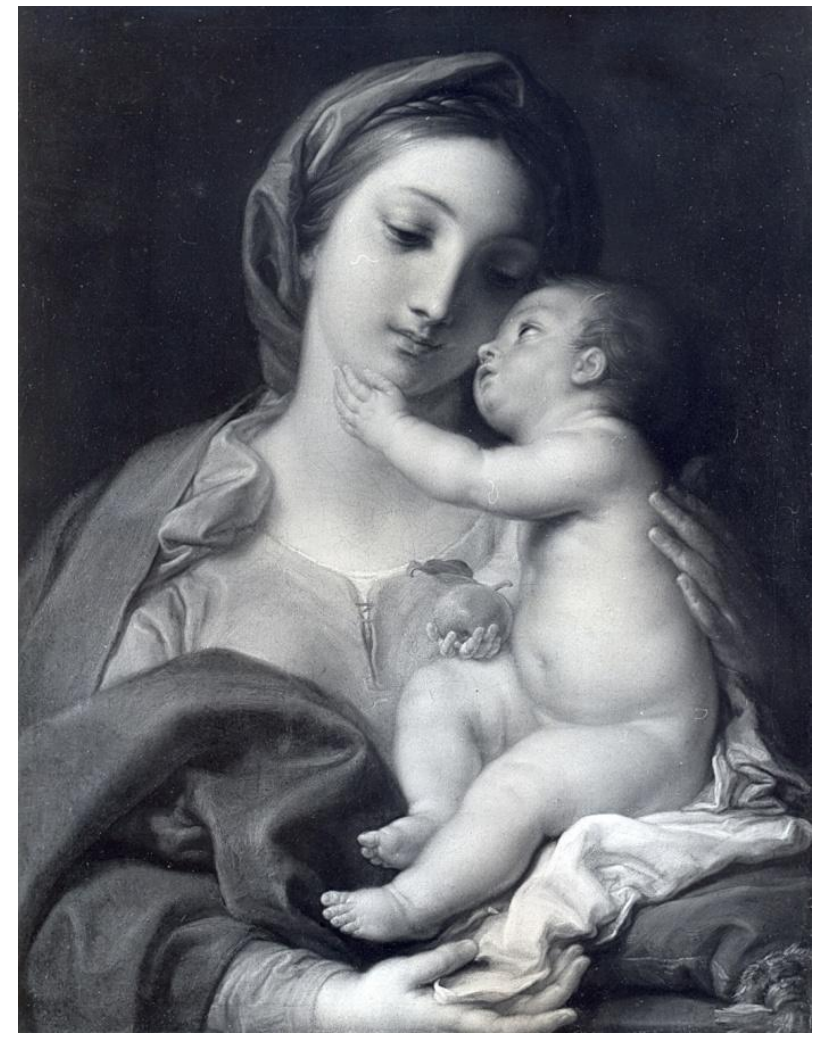

Fig. 57- P. Batoni “ Madonna col Bambino” restauro del 1984

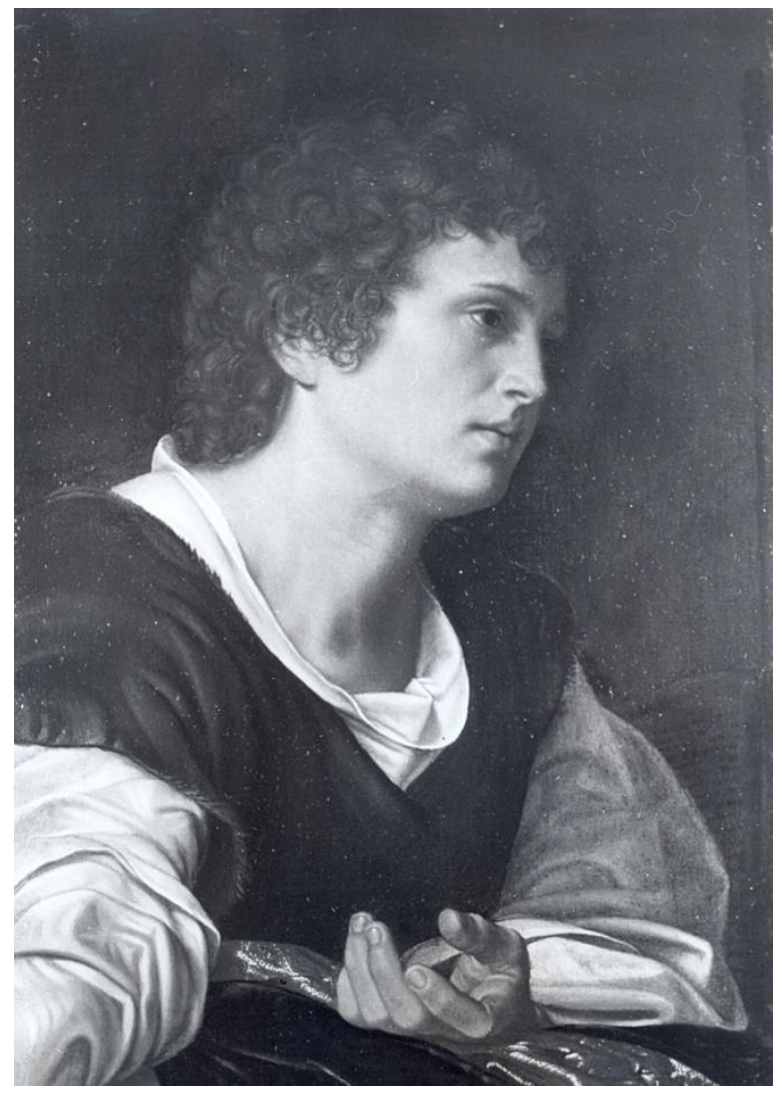

Fig. 58 - Savoldo "Ritratto di giovane" restauro del 1985 


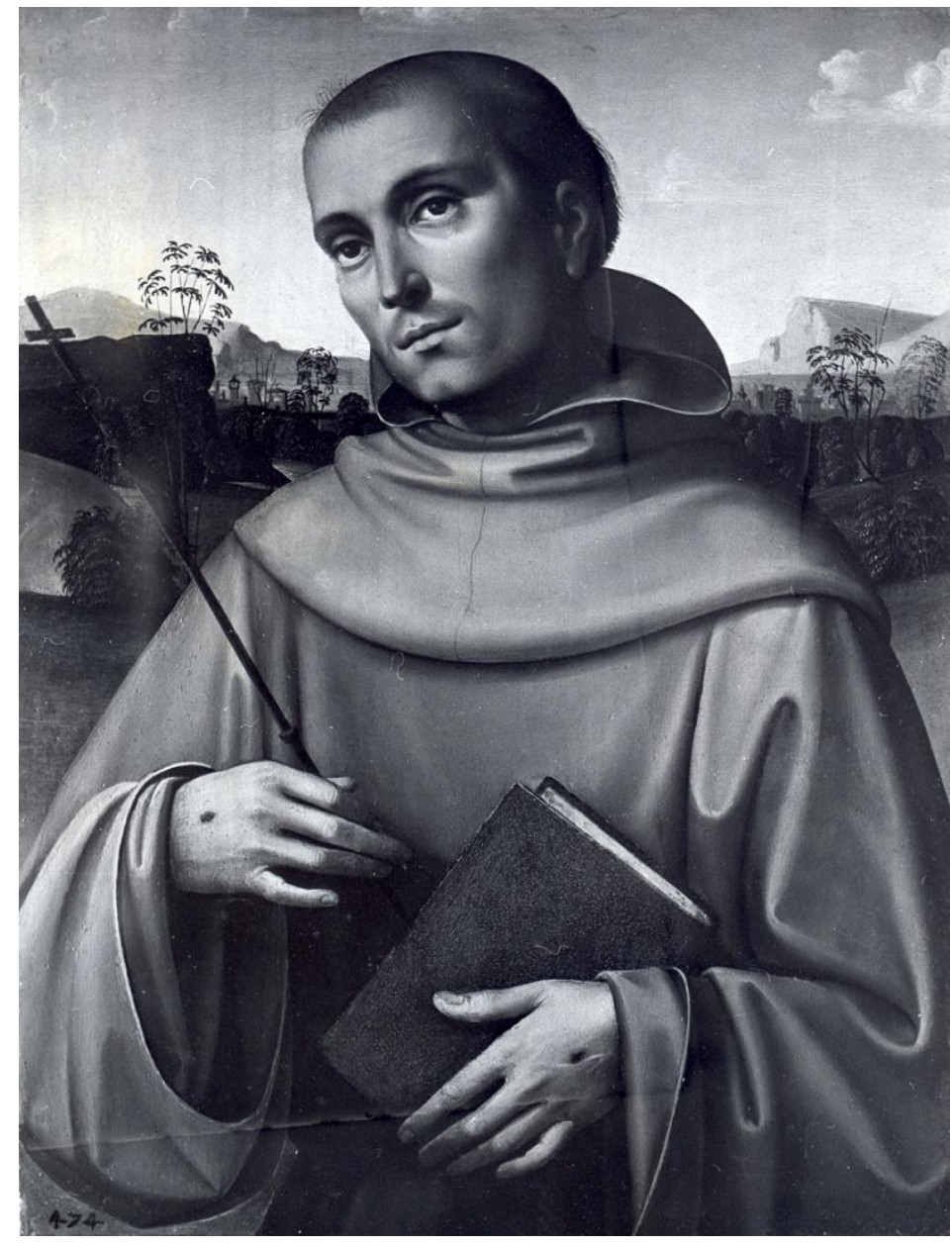

Fig. 59 -F. Francia "San Francesco" restaurato da Colalucci nel 1985 


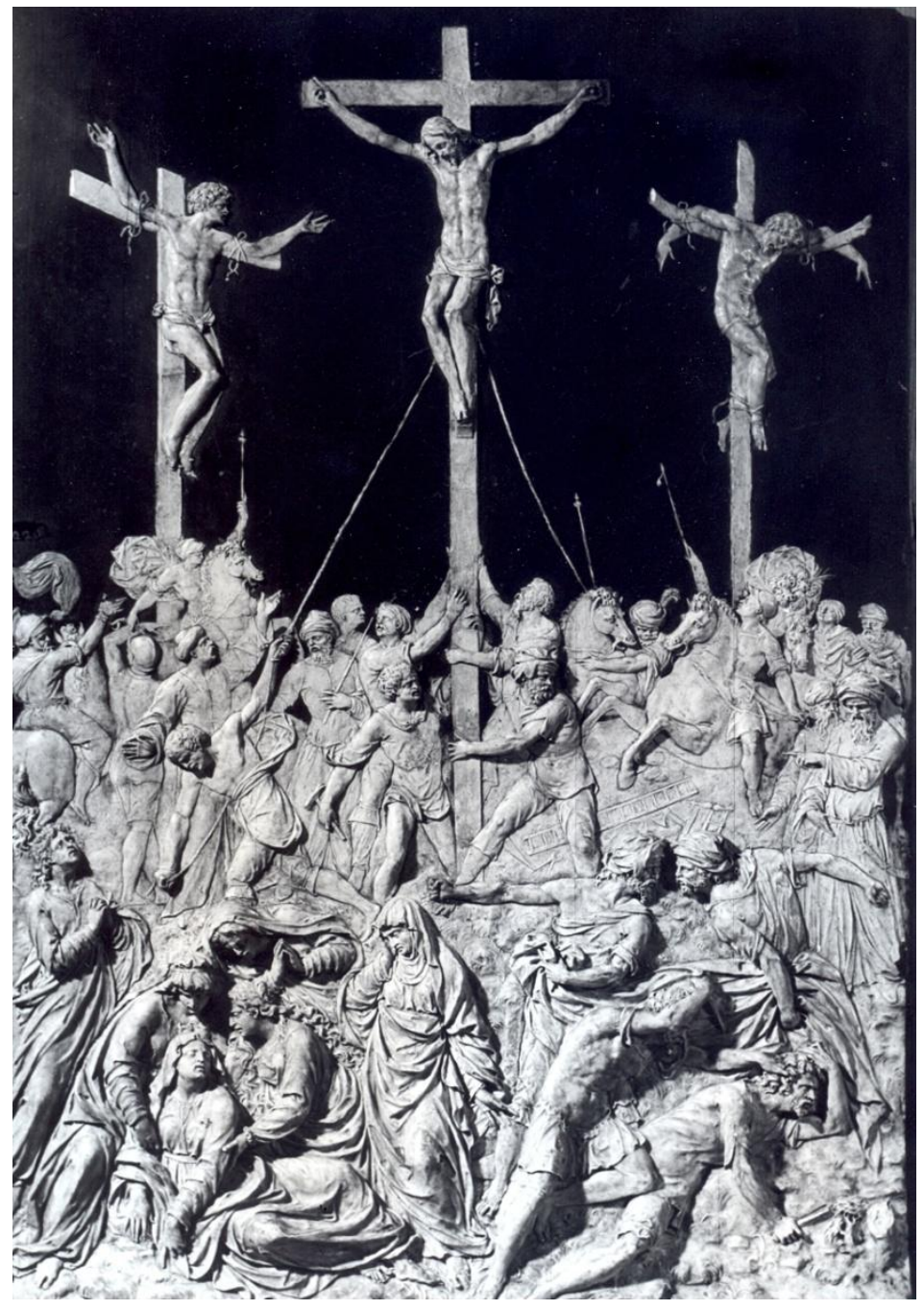

Fig.60 - G. Della Porta “ Crocifissione” restauro del 1985

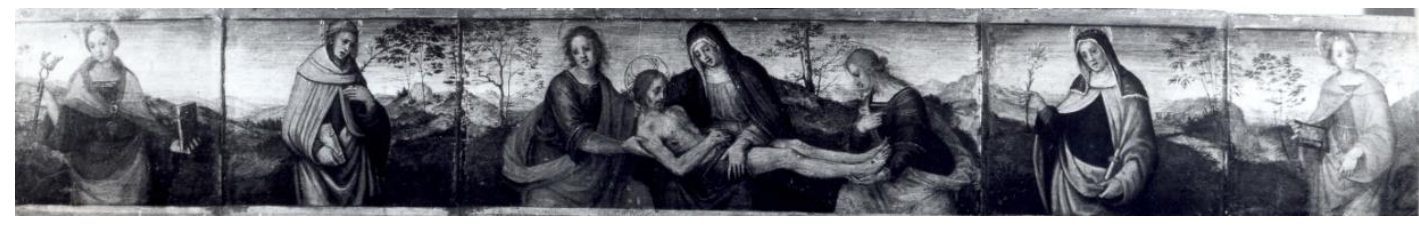

Fig. 61 - A. del Sarto - predella “Pietà e Santi” restaurato da Colalucci nel 1985 


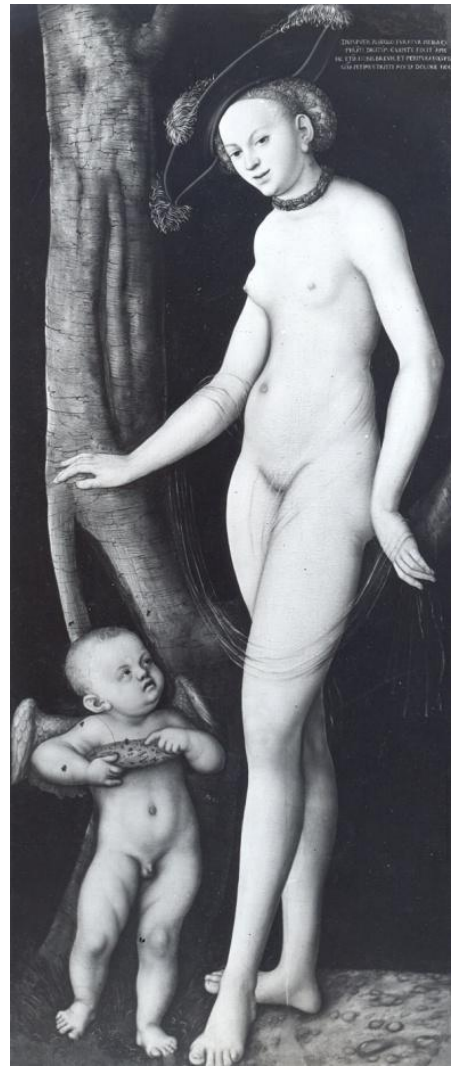

Fig.62 - Cranch " Venere e Amore

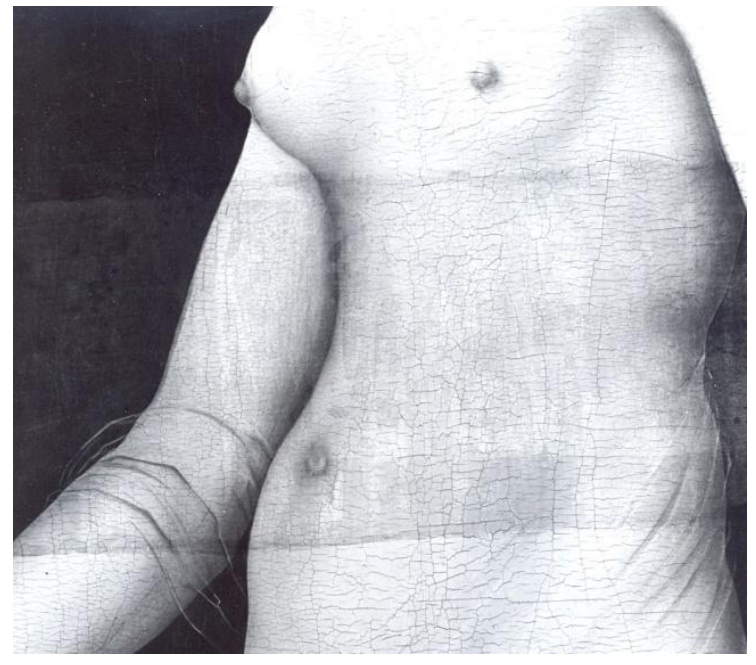

Fig. 63 - particolare durante la pulitura

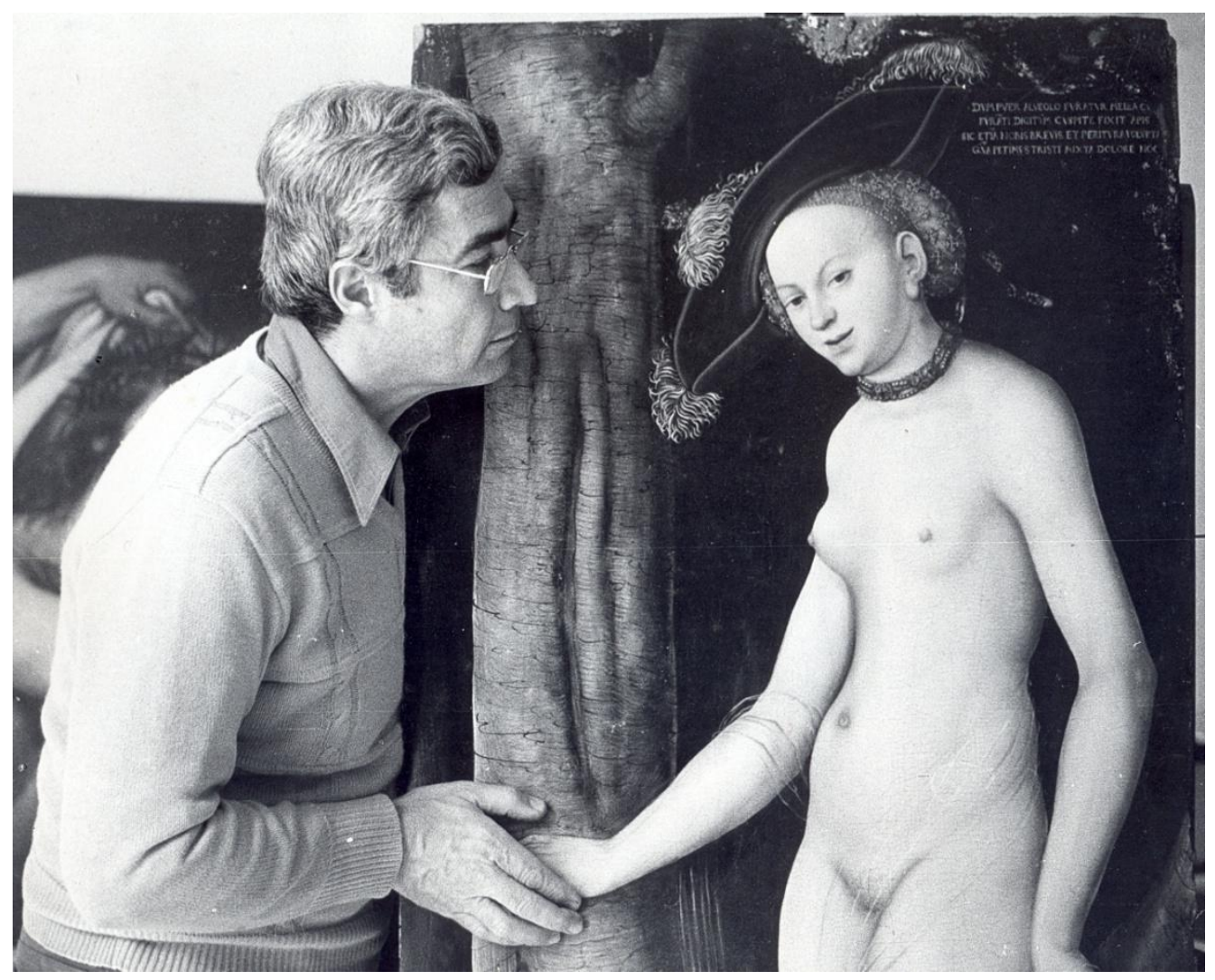

Fig. 64 - Colalucci e la "Venere" 


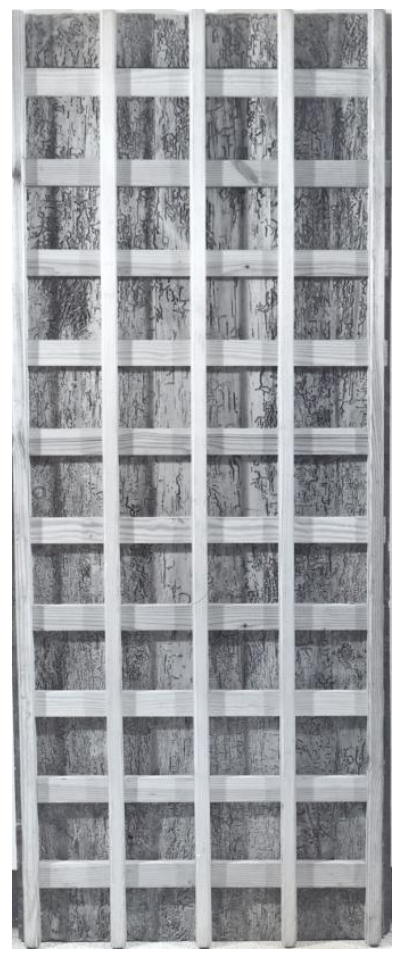

Fig. 65- la vecchia parchettatura

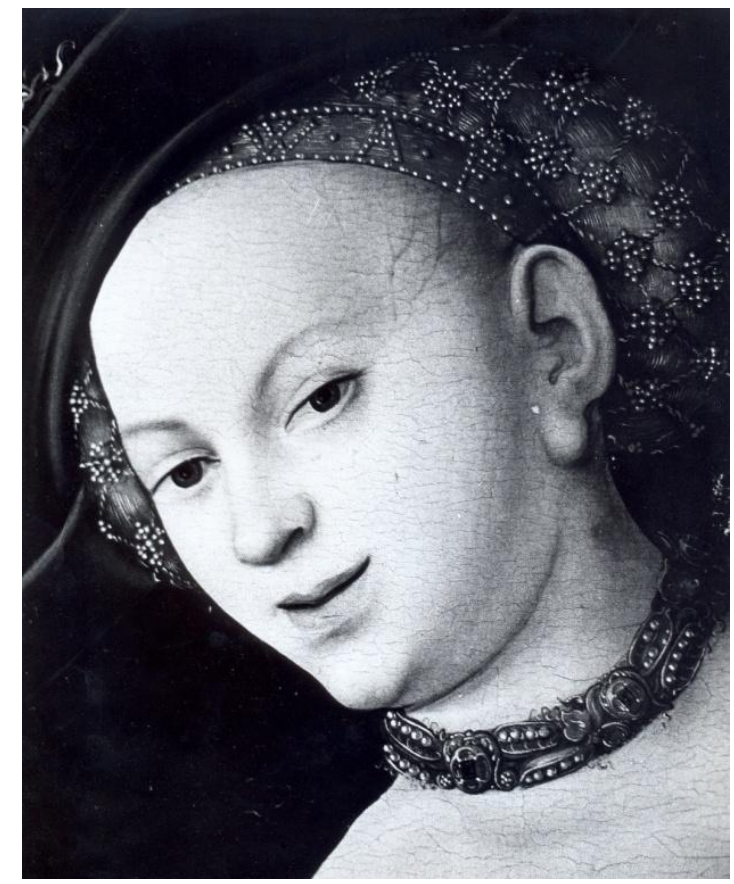

Fig.67- un particolare del volto della Venere dopo II restauro

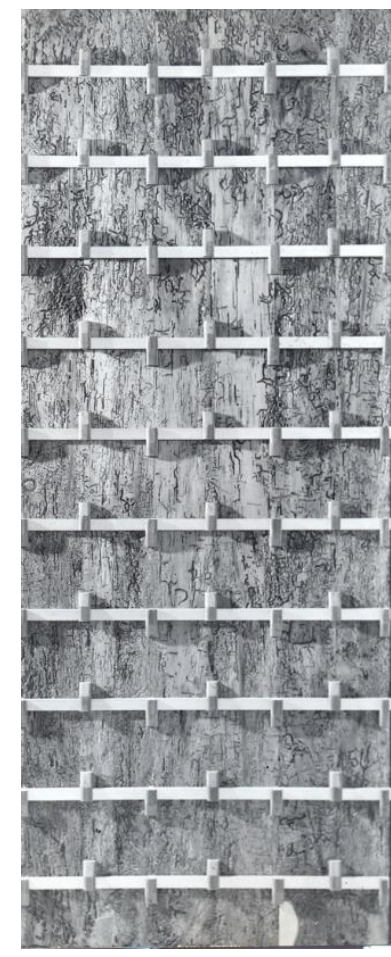

Fig. 66- la nuova parchettatura

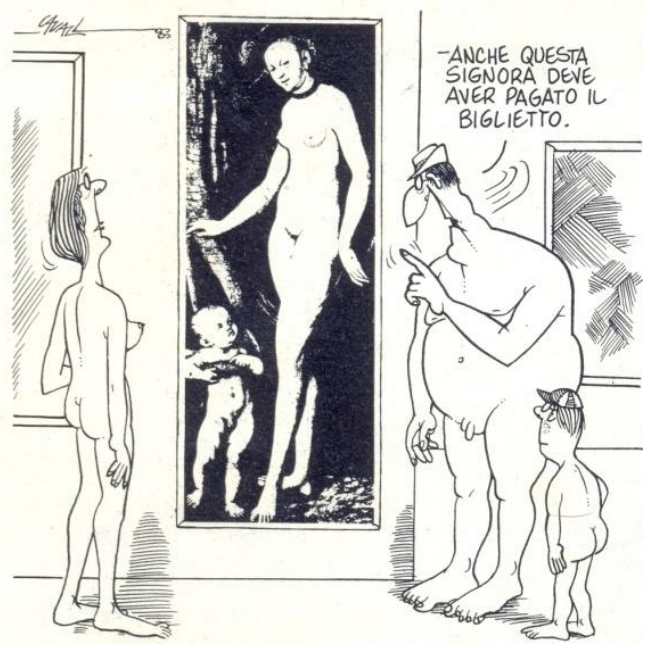

Fig. 68- una curiosa vignetta dell'epoca del restauro 


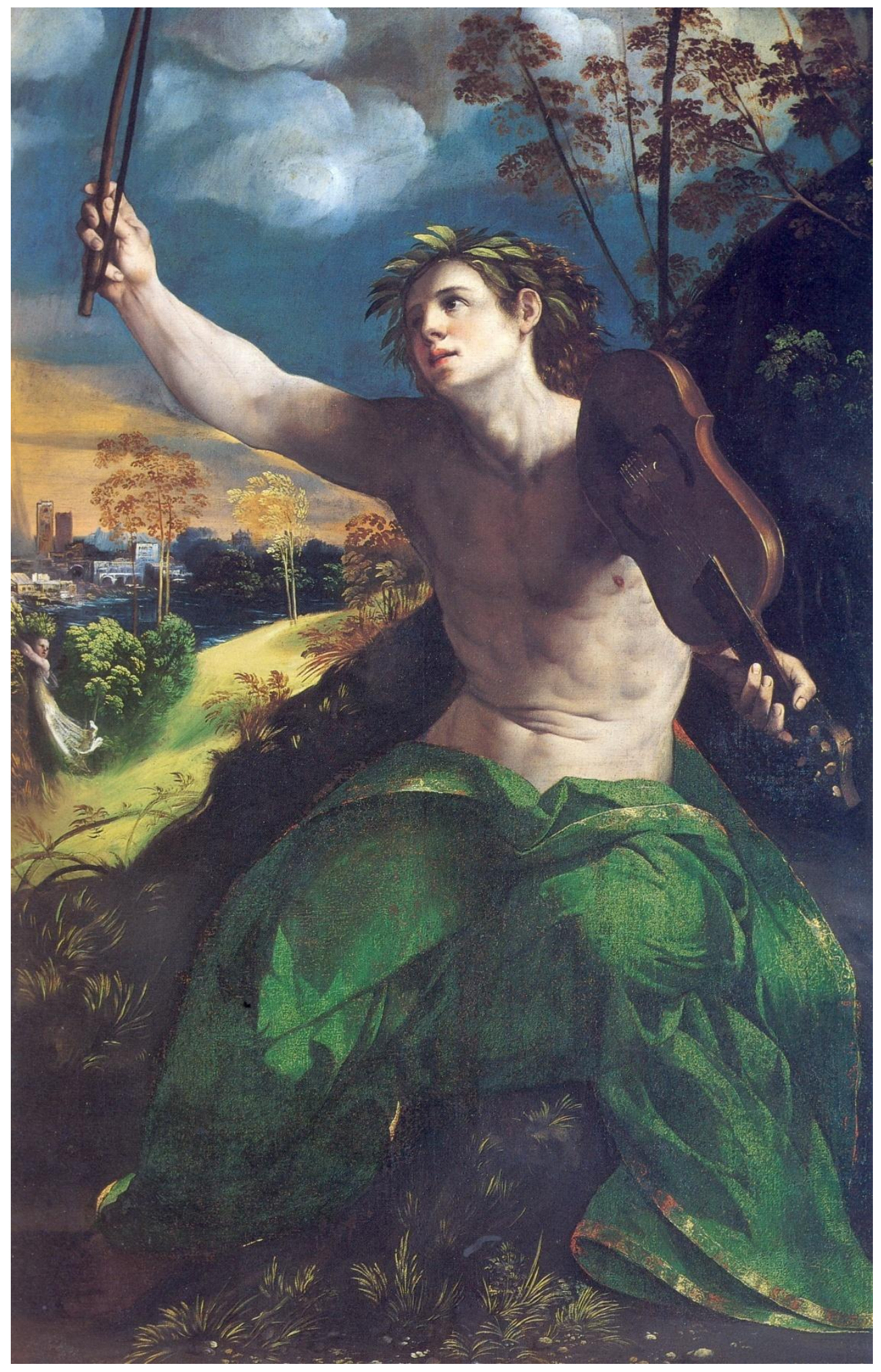

Fig. 69 - Dosso Dossi “ Apollo e Dafne” restaurato da Colalucci nel 1982 


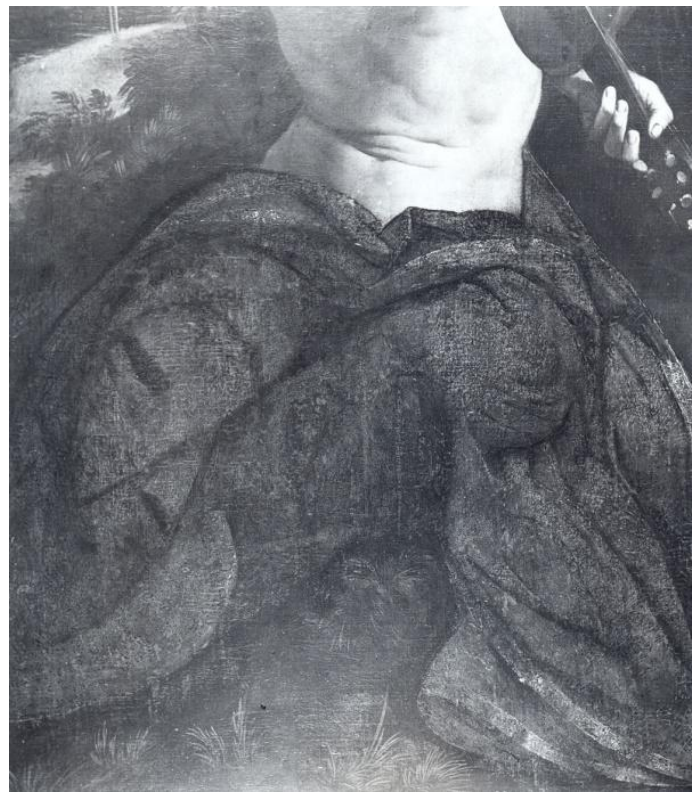

Fig. 70 - il manto di Apollo

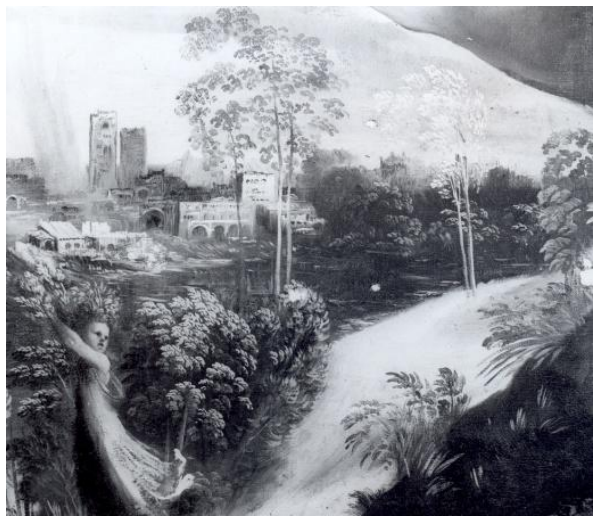

Fig. 71 - la figura di Dafne

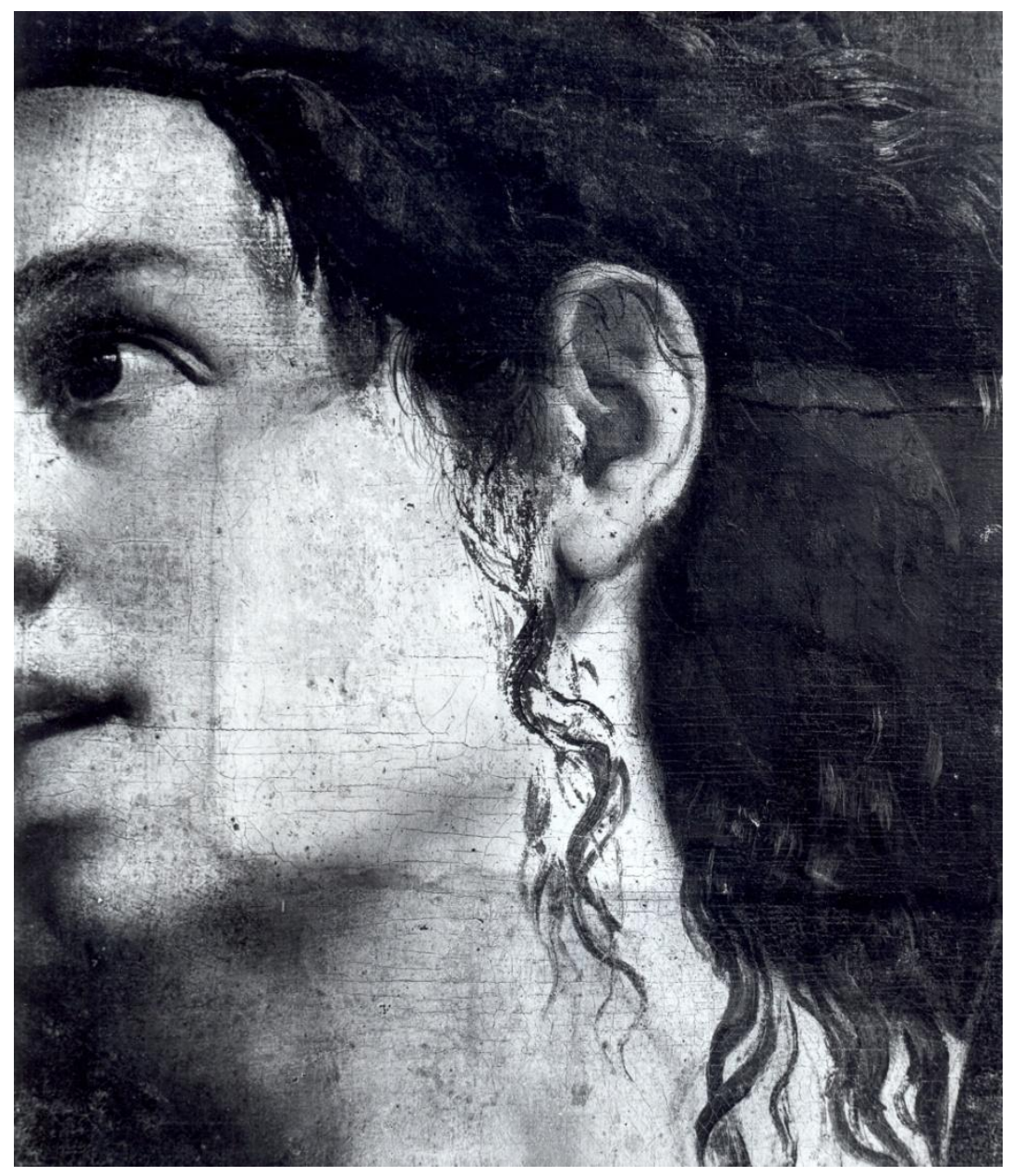

Fig.72- i riccioli falsi di Apollo durante la pulitura 


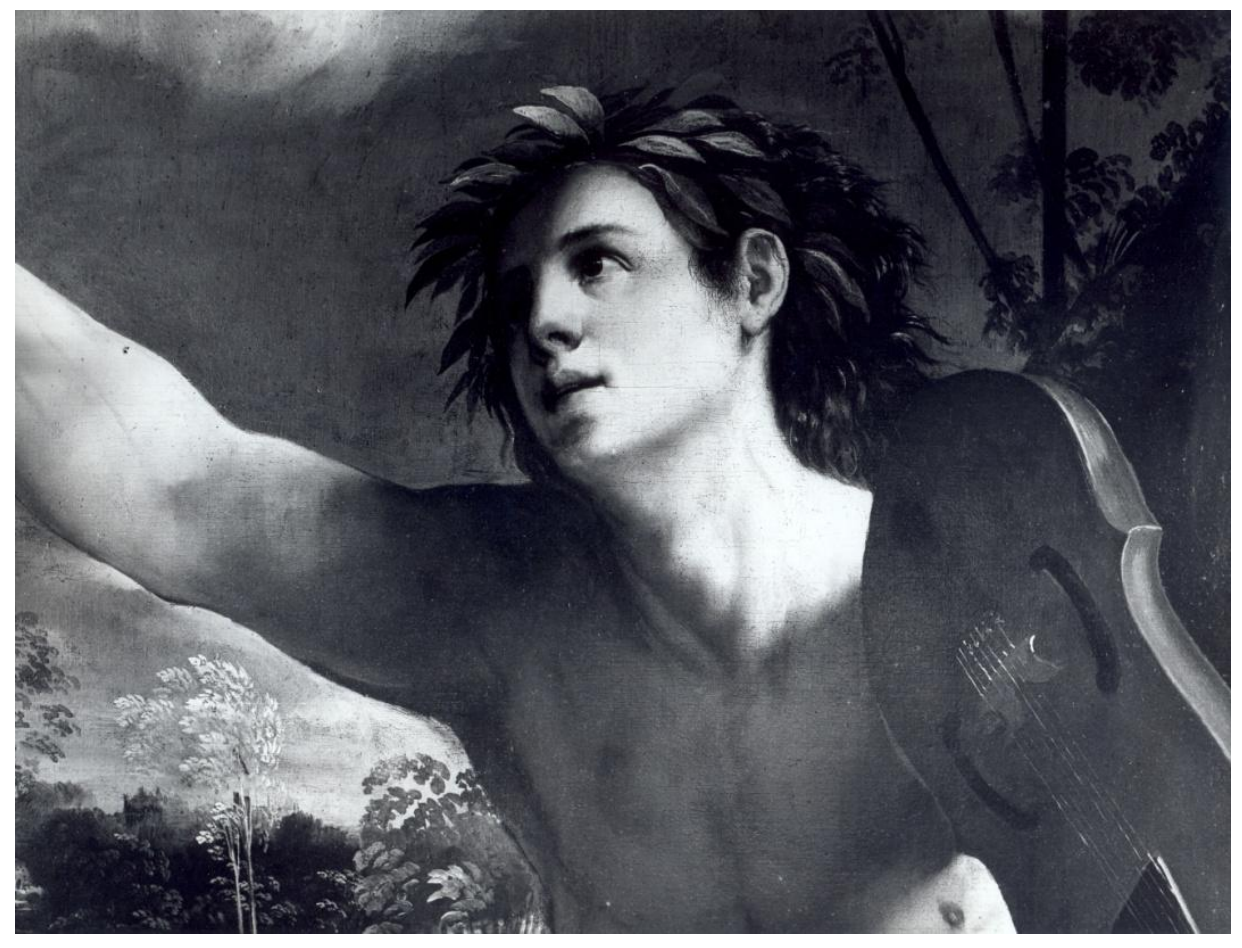

Fig. 73 - Apollo dopo il restauro

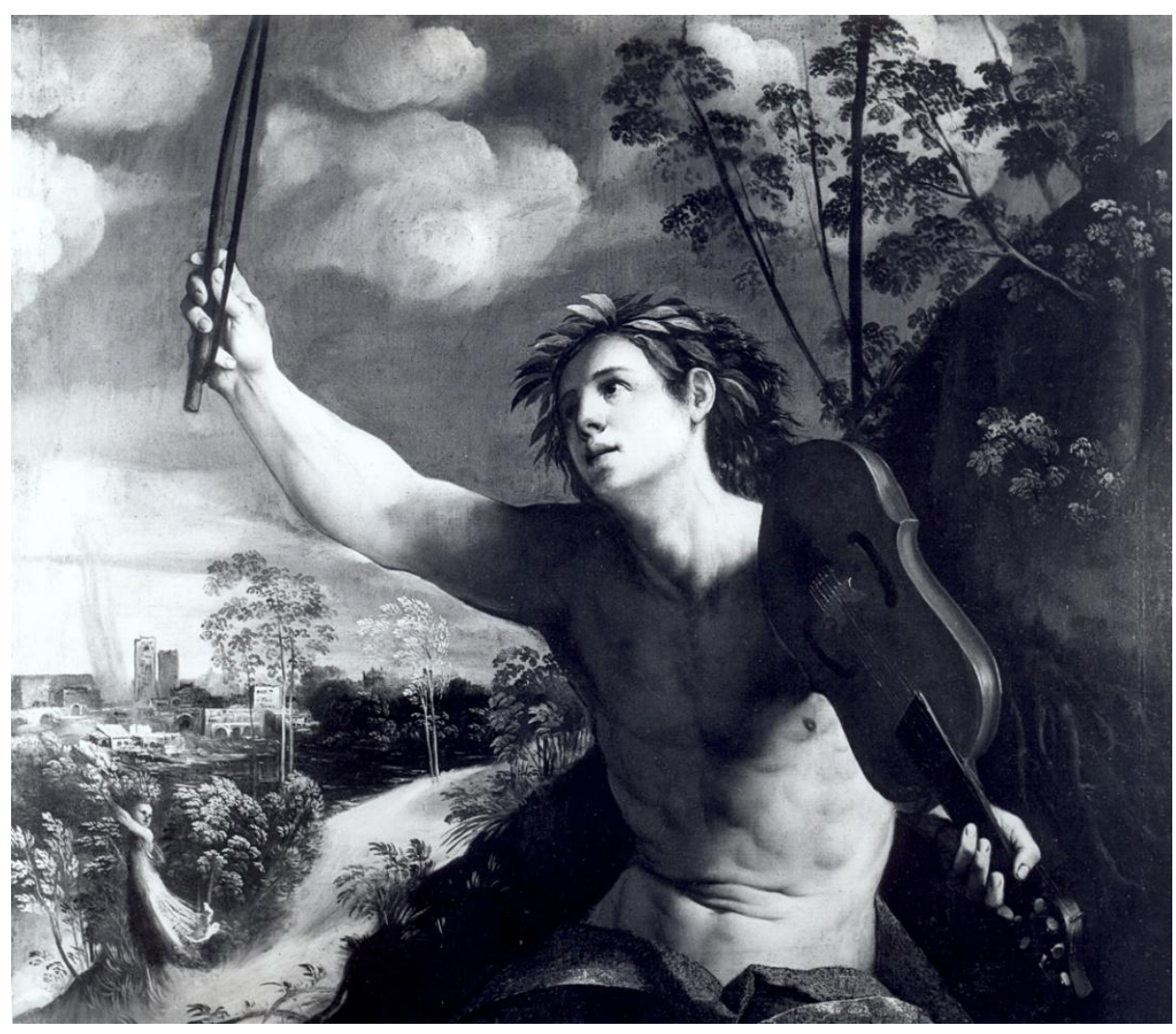

Fig. 74 - Apollo e Dafne dopo il restauro 


\section{V - La Cappella Sistina}

Questo capitolo affronta la complessa vicenda del restauro della Cappella Sistina. L'impresa più importante e imponente della storia del restauro. Per capire a fondo come sia stato possibile realizzarla dobbiamo iniziare il nostro viaggio nel mondo della conservazione vaticana ed italiana dalla fine degli anni settanta e rimanerci fino alla metà degli anni novanta.

Ai musei Vaticani è arrivato da poco il nuovo Direttore Carlo Pietrangeli e Colalucci è appena stato nominato capo restauratore del laboratorio. Pietrangeli proviene dalle Soprintendenze romane è una figura autorevole che porta molti cambiamenti nella gestione dei Musei ed in quella del laboratorio di restauro. Finalmente quel rinnovamento iniziato molti anni prima da de Campos trova le condizioni per essere pienamente attuato.

Pietrangeli e Colalucci hanno rapporti con l'Istituto di Urbani e dei Mora, che in quegli anni vive, come tutto il mondo del restauro, un clima di rinnovato entusiasmo. Le domande di iscrizione all'Istituto si moltiplicano, superare l'esame d'ammissione diventa difficilissimo ed il diploma diviene un titolo prestigioso. Si intensifica la divulgazione in campo conservativo ed il confronto tra chi si occupa di restauro diviene una consuetudine. Adesso il Vaticano di Pietrangeli, Mancinelli e Colalucci è finalmente pronto ad interagire e a dialogare con le realtà esterne. La grande impresa della Sistina nasce dunque sotto questo auspicio e con la piena consapevolezza che le scelte conservative debbano essere condivise con le comunità scientifiche e storiche di tutto il mondo. Colalucci è conscio che un lavoro come questo non può lasciare spazio al minimo dubbio, e sa che nulla può essere lasciato al caso. Per quattordici anni il cantiere della Sistina diventa un luogo di incontro aperto a tutti coloro che condividono l'interesse per l'opera michelangiolesca. Pietrangeli in quanto direttore dei Musei, Mancinelli e Colalucci aprono le porte di quel luogo straordinario tutti, anche a chi non è d'accordo con il restauro.

II restauro della Sistina va avanti per quattordici anni, la popolarità dei Musei Vaticani cresce parallelamente a quella del lavoro e dei suoi protagonisti. Colalucci e Mancinelli vengono invitati in tutto il mondo a riferire e a raccontare i risultati di quella prodigiosa impresa. In quegli anni in Italia si svolgono altri due importanti restauri quello sull' Ultima cena di Leonardo eseguito da Pinin Brambilla, e quello sugli affreschi di Masaccio nella chiesa del Carmine a Firenze a cura dell'Opificio delle pietre dure. 
Pochi anni dopo, mentre il lavoro della Sistina procede con successo e il laboratorio vaticano marcia verso l'adozione di criteri sempre più vicini all' Istituto, anche per quanto riguarda la selezione dei nuovi restauratori da assumere, il mondo del restauro italiano comincia a mostrare i segni di quella gravissima crisi che di lì a poco passerà come uno schiacciasassi, su tutto quello che da Brandi fino ad allora era stato costruito. Uno dei primi allarmanti segnali di questo degrado, si ha nel 1984 con le dimissioni di Giovanni Urbani dall'Istituto, in polemica con le politiche del Ministero. l'Italia inizia così la sua corsa verso il basso. Una corsa che passerà attraverso le scriteriate leggi sugli appalti pubblici - responsabili dell'accesso al restauro di persone prive di formazione e delle imprese edili - e culminerà con le disastrose normative sulla formazione dei restauratori. Iniziano a proliferare corsi e corsetti di durata variabile (si va dai due anni ai tre mesi o addirittura alle due settimane) che insegnano il restauro a chi non intende sottoporsi alla esame di ammissione all'Istituto Centrale o a chi non riesce a superarlo. Purtroppo gli esclusi dall'lstituto, al quale nel frattempo si è aggiunto l'Opificio delle Pietre dure di Firenze, sono in numericamente più forti di coloro che riescono a superare l'esame. Si organizzano in sindacato e rivendicano il diritto di parità professionale con il diplomati I.C.R. I governi di quegli anni, intravedono in quella massa di giovani un facile serbatoio di voti, li assecondano a scapito di quella che quasi con fastidio viene considerata un'elite, cioè i restauratori I.C.R. e O.P.D. Durante questi quattordici anni il mondo della conservazione perde alcuni personaggi illustri come Cesare Brandi, Pasquale Rotondi e Giovanni Urbani. Muore anche un grande nome della Storia dell'arte come Giulio Carlo Argan che aveva condiviso con Brandi il progetto di fondazione dell'Istituto Centrale del Restauro. II 27 agosto del 1993 due bombe della mafia danneggiano gravemente la Basilica di San Giovanni in Laterano e la chiesa di San Giorgio in Velabro. Verso la fine del restauro della Sistina, si ammala gravemente e muore poco dopo, Fabrizio Mancinelli. Nel 1995 a restauro ormai Concluso Colalucci va in pensione, Pietrangeli morirà qualche anno dopo. La crisi entra inevitabilmente se pure in ritardo anche in Vaticano. 
Le prime prove di pulitura

Alla fine degli anni 70 Carlo Pietrangeli decide di mettere in programma il restauro dei due affreschi raffiguranti "La resurrezione di Cristo" e "La Contesa sul Corpo di Mosè", che Hendrick van den Broeck e Matteo da Lecce dipinsero nel tardo ‘500 sulla parete di fronte al Giudizio. Con questo progetto Pietrangeli intende completare la campagna di restauri avviata dal laboratorio tra il 1965 e il 1974 sulle opere del ' $400^{127}$. L'impalcatura di fronte ai due dipinti cinquecenteschi viene montata all'inizio di gennaio 1980 in modo da consentire l'esecuzione delle indagini scientifiche, della documentazione fotografica e dare inizio al restauro ${ }^{128}$. La consueta riunione preliminare si svolge il 9 gennaio sul ponteggio, di fronte ad alcune prove di pulitura eseguite su entrambi gli affreschi. Al di là delle considerazioni di routine relative al restauro ed allo stato conservativo delle opere, durante la riunione viene disposto di sondare l'intonaco sottostante gli affreschi cinquecenteschi nella speranza di trovare traccia delle antiche pitture di Signorelli e Ghirlandaio. II sondaggio sarà puntualmente eseguito ma darà purtroppo esito negativo. Durante il rilevamento dello stato di conservazione delle pitture di van den Broeck e di Matteo da Lecce, Colalucci nota molte situazioni simili a quelle che aveva più volte riscontrato sul Giudizio Universale di Michelangelo, a lui ben noto poiché ogni anno ne eseguiva la spolveratura.

\footnotetext{
${ }^{127}$ La campagna aveva compreso il restauro del cantiere quattrocentesco della Sistina con le opere di Botticelli, Ghirlandaio, Perugino, Signorelli e Cosimo Rosselli. Dal restauro erano rimasti fuori i ritratti dei pontefici. 
La tradizione vaticana della spolveratura del Giudizio si ripeteva dal 1543 , da quando cioè Papa Paolo III Farnese istituì la figura del "mundator". Colalucci mi racconta che la spolveratura del Giudizio rappresentava per lui un momento "magico" perché nel silenzio della Cappella Sistina chiusa ai visitatori riusciva ad avere con quell'opera tanto misteriosa un rapporto esclusivo. La spolveratura era anche una occasione di studio perché gli dava modo osservare da vicino la pittura di Michelangelo. Mi dice che la pittura del Giudizio vista a distanza ravvicinata aveva da subito suscitato in lui un grande interesse. Si rendeva conto che vi erano alcune anomalie tecniche che, per puro interesse professionale, aveva anche documentato fotograficamente. Si trattava di elementi che apparentemente sembravano estranei all'affresco ma che non potevano essere inquadrati con certezza come interventi di restauro. Quando finalmente si trova a tu per tu con gli affreschi tardo-cinquecenteschi di van den Broeck e di Matteo da Lecce, dipinti circa 50 anni dopo il Giudizio, e sui quali riscontra lo stesso tipo di pennellate anomale che aveva visto sull'affresco di Michelangelo, inizia ad ipotizzare la presenza della mano di un restauratore. L'ipotesi lascia gradatamente spazio ad una quasi certezza quando la pulitura del Matteo da Lecce rivela con precisione i caratteri di un massiccio intervento di restauro.

A questo punto si pone delle domande anche sulla volta che a differenza del Giudizio non conosceva da vicino, poiché dal 1942 cioè da quando fu ultimata la campagna di consolidamento degli intonaci avviata dal Biagetti nel 1923, in quella parte della Cappella non erano più stati montati ponteggi. L'occasione di 
vederla da vicino si presenta appena finito il restauro del Matteo da Lecce e del van den Broeck, poiché per raggiungere le effigi dei Pontefici si alza l'impalcatura. Sui piani alti del nuovo ponte riesce a vedere la parte bassa delle lunette di Michelangelo, non soddisfatto però chiede ed ottiene che il ponte venga alzato ulteriormente in modo da vedere agevolmente tutta la lunetta con Eleazar. La situazione che si presenta ai suoi occhi è completamente nuova. La lunetta non presenta nessuna traccia di ciò che aveva visto e studiato sul Giudizio. Vede una superficie dipinta ricoperta da una sostanza scurissima color cuoio. La sostanza è compatta e vetrosa, anche al tatto non è particolarmente liscia ed è ricoperta di polvere e fumo. Osservando più attentamente la pittura Colalucci si accorge che la massa scura ricopre senza soluzione di continuità la pittura di Michelangelo, una zona sulla sinistra della lunetta particolarmente corrosa da vecchie infiltrazioni di acqua, ma anche il basamento sul quale poggiano i piedi dei due antenati di Cristo che era stato intonacato e dipinto nel 1700. Inoltre, come la lunetta, anche le effigi dei Papi recano lo stesso strato scuro che ricopre la pittura quattrocentesca e le parti ridipinte nel 1700.

Sulla scorta di questi elementi si decide di avviare una campagna di indagini scientifiche, e di effettuare un test di pulitura, della grandezza di un francobollo, sul manto della figura di Eleazar. Nonostante le esigue misure del tassello, la sorpresa per l'alta qualità del colore che affiora dallo strato di sporco è indescrivibile. II colore è vivace, compatto ed in perfetto stato di conservazione. Colalucci si rende conto che il risultato ottenuto non può essere ignorato ma che 
anzi merita uno studio più approfondito e mirato. Appoggiato da Mancinelli (che in un primo momento si era mostrato scettico di fronte allidea di toccare Michelangelo ma che preso atto dell'esito della prova aveva cambiato idea) chiede al direttore l'autorizzazione per un saggio di pulitura più esteso. Nel frattempo arrivano i risultati delle analisi chimiche. I campioni dello strato scuro depositato sugli affreschi risultano composto da una colla animale tenacissima a base di cheratine. È singolare notare che questi risultati forniti dal gabinetto di ricerche scientifiche, convalidino quelli delle indagini effettuate quasi quarant'anni prima nell'ambito della campagna Biagetti ${ }^{129}$. La nuova apertura viene eseguita seguendo un linea orizzontale in modo da comprendere più colori e misura circa $3 \mathrm{~cm}$.di altezza ed è lunga $40 \mathrm{~cm}$. Con questo sistema Colalucci cerca di comprendere meglio lo stato conservativo della pittura ma intende anche mettere in evidenza i rapporti cromatici tra i vari pigmenti. II risultato che ottiene è al di sopra delle aspettative, pone la Direzione dei lavori e lui stesso, di fronte alla necessità di prendere una decisione non facile, sulla prosecuzione 0 l'interruzione del lavoro. Tutti sono combattuti tra la legittima curiosità di scoprire la vera pittura di Michelangelo, ed il timore di restituire un'opera completamente diversa da quella conosciuta ed amata da tutti. Si trovano a dover decidere tra due opzioni: ricoprire le prove di pulitura ignorando i risultati ottenuti; o andare avanti nel lavoro mettendo in conto una serie di problemi di non facile soluzione. Le riunioni per arrivare ad una decisione condivisa si fanno davanti alle prove di pulitura, e gli interrogativi più comuni non riguardano l'aspetto tecnico del lavoro 
che non presenta difficoltà, ma l'aspetto storico-critico. Un risultato come quello svelato dalle prove pone inevitabilmente l'accento sul rischio di andare a modificare la lettura del colore michelangiolesco e di conseguenza di un intero periodo della storia dell'arte. L'affresco di Michelangelo, fino a quel momento considerato povero di colore e quasi monocromo, appare coloratissimo e prezioso. Dopo lunghe discussioni si arriva a decidere di eseguire la pulitura di tutta la lunetta con Eleazar, in modo da avere un intero brano di pittura, ampio ma comunque circoscritto, pulito da presentare agli studiosi ed all'opinione pubblica. Si decide anche che durante i lavori, il cantiere sarà un cantiere "aperto" a tutti gli studiosi ed esperti nel campo artistico e conservativo.

Colalucci decide di eseguire la pulitura della lunetta da solo, in modo da controllare l'intero lavoro e rispondere in prima persona ad eventuali contestazioni, senza coinvolgere il lavoro di altri restauratori. La stima di cui Colalucci gode nell'ambiente del restauro ha un ruolo determinante nell'evoluzione della situazione, perché diversamente la Direzione dei Musei, non avrebbe rischiato di proseguire nell'avventura della Sistina. Egli aveva quelle doti che servivano a reggere l'impatto di un lavoro imponente e problematico: preparazione, capacità organizzativa ${ }^{130}$, diplomazia e abitudine alla divulgazione. 


\section{La lunetta di Eleazar}

II 20 giugno del 1980 inizia la pulitura della lunetta di Eleazar. Al disotto dei pesanti strati di colle e nerofumo che lentamente e con estrema cautela vengono rimossi dalla superficie, emergono i colori vivacissimi di Michelangelo. Sul diario di cantiere vengono annotati giorno per giorno e con estrema precisione, i particolari della tecnica di esecuzione, le operazioni compiute sull'opera, e le considerazioni sui risultati del lavoro, con l'intento preciso di lasciare un documento fedele di tutta l'evoluzione dell'intervento.

Colalucci dispone anche che lo stesso diario di cantiere venga usato per raccogliere le firme dei visitatori. II 16 giugno, qualche giorno prima di iniziare il lavoro vero e proprio, scrive sullo stato di conservazione della lunetta. Descrive l'aspetto e la consistenza del pesantissimo strato di polvere che ricopre la pittura, rileva le tracce dei vecchi consolidamenti di intonaco con le stuccature dei fori di iniezione, e le stuccature delle crepe più ampie. Individua ritocchi di vario genere, ne nota alcuni a puntini che vanno a integrare le sgranature dello strato di colla e nerofumo, trova i graffi dovuti alle antiche spolverature e le piccole sbavature della pellicola collosa. Riesce a distinguere la meccanica delle "mani incrociate" del pennello con il quale era stata stesa la colla ${ }^{131}$. II risultato delle prime aperture è entusiasmante ma prima di andare avanti si vuole il parere dell'Istituto Cenrale del Restauro. Il primo ad essere invitato è

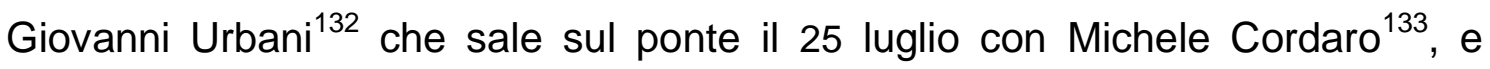

\footnotetext{
${ }^{131}$ Poiché la colla, scurendo, aveva accentuato la differenza tra le parti trattate e quelle risparmiate. 
Mara Nimmo. Tutti approvano pienamente metodi e risultati ed incoraggiano Colalucci a proseguire nella pulitura. Quattro giorni dopo l'inizio della pulitura, torna Cordaro con Giuseppe Basile ${ }^{134}$, Gabriele Borghini ${ }^{135}$ e Rosalia Varoli Piazza ${ }^{136}$.

II 18 luglio tornano Paolo e Laura Mora, che già avevano visto ed approvato i risultati delle prime prove di pulitura. L'appoggio dell'stituto è un elemento in più che alimenta la volontà di proseguire nel lavoro. Dopo questa fase iniziale il cantiere della prima lunetta, che durerà circa otto mesi, viene visitato da 117 persone (studiosi, restauratori e artisti) fra i quali : Michael Hirsht ${ }^{137}$ il 24 settembre, Filippo Trevisani ${ }^{138}$ il 17 dicembre, Eraldo Gaudioso ${ }^{139}$ con la moglie Filippa Aliberti il 3 gennaio 1981, Maria Andaloro ${ }^{140}$ torna l'8 gennaio, Fabrizio Clerici ${ }^{141}$ il 13 gennaio, Bruno Zanardi ${ }^{142}$ il 17 gennaio, Bruno Mantura il 21. Angiola Maria Romanini ${ }^{143}$ il 6 febbraio. II 10 febbraio, viene presentata ufficialmente la parete restaurata e la lunetta di Michelangelo con Eleazar e Mathan. È un successo, e anche la stampa come gli ambienti culturali italiani

\footnotetext{
${ }^{133}$ Storico dell'arte, allievo di Cesare Brandi. All'epoca era insegnante all' ICR. Cordaro in seguito ricoprirà la carica di direttore della Calcografia di Roma e successivamente quella di direttore dell' ICR.

${ }^{134}$ Storico dell'arte, insegnante all'ICR

${ }^{135}$ Storico dell'arte già Ispettore alla Soprintendenza di Palazzo Venezia a Roma, oggi Soprintendente a Siena.

${ }^{136}$ Storica dell'arte, già insegnante all' ICR, e successivamente funzionaria dell' ICCROM.

${ }^{137}$ Storico dell'arte inglese. È forse il più grande studioso dei disegni di Michelangelo

${ }^{138}$ Storico dell'arte già ispettore all'ICR, oggi Soprintendente a Mantova.

139 I coniugi Gaudioso entrambi storici dell'arte, avevano ricoperto la carica di direttore al Museo Nazionale di Castel Sant'Angelo, dunque conoscevano entrambi Colalucci da molti anni.

${ }^{140}$ Maria Andaloro è stata allieva e assistente universitaria di Cesare Brandi, attualmente dirige la facoltà di Beni Culturali dell'Università della Tuscia a Viterbo.

${ }^{141}$ Artista, nasce a Milano nel 1913..

${ }^{142}$ Restauratore, allievo di Giovanni Urbani. Autore di numerosi testi e di restauri eccellenti, attualmente è docente di teoria del restauro presso l'Università Carlo Bò di Urbino. 
ed esteri reagisce con grande favore. Gli articoli sul "Il Tempo", "La Stampa", il "Corriere della Sera" "La Repubblica" "L’Espresso" "Panorama" ma anche il "New York Time" o il tedesco "Stern" parlano ${ }^{144}$ di un Michelangelo ritrovato.

La prosecuzione del lavoro

Preso atto del generale consenso, la Direzione decide di far preparare a Colalucci un progetto per il restauro di tutti gli affreschi Michelangioleschi della Sistina, compreso il Giudizio Universale. II progetto viene redatto in base ai tempi ed alle metodologie impiegate per il lavoro sulla prima lunetta, e prevede una esecuzione in tre tranche. La prima comprende le rimanenti tredici lunette, la seconda tutta la volta, e la terza il Giudizio Universale. Per ogni tranche vengono previsti quattro anni di lavoro, dodici complessivi. Dopo l'approvazione partono i lavori sulla lunetta di lacob e loseph accanto a quella di Eleazar per proseguire poi alternativamente lungo le pareti comprendendo di volta in volta due lunette ed i pontefici sottostanti. Dal punto di vista tecnico, salvo qualche piccola variazione della metodica dovuta a elementi contingenti, il lavoro procede secondo il programma stabilito. Subito dopo l'avvio della prosecuzione

\footnotetext{
${ }^{144}$ Cfr. D. Petrocelli "Un inedito Giudizio Universale nella restaurata Cappella Sistina” il Tempo, merc 11 febbraio 1981 - L. Storoni "Gli affreschi della Sistina ritrovano il loro splendore" La Stampa, 11 febbraio 1981, p. 6 - "Michelangelo va in restauro" Corriere della Sera, 11 febbraio 1981 - D. Cimagalli " 12 anni per lavare il Giudizio Universale" Gente, 6 marzo 1981 pp.128/130 - Henry Tanner “Restoration Reveals Mchelangelo’s Gifts” New York Time, 31 marzo 1981- F. Bellonzi "Conosciamo un nuovo Michelangelo" II Tempo 8 aprile 1981 p. 3 - "In Vaticano fanno toilette gli affreschi della Sistina" La Repubblica, 28 giugno 1981 - "Zwolf jahre kur fur Michelangelo" Stern, 3 luglio 1981 - " All of Michelangelo's work will have to de restudied" Art News, ottobre 1981.
} 
dei lavori Rotondi inizia a pensare che per una impresa come quella che si stava compiendo non fosse sufficiente la sola documentazione fotografica ma che ci volesse anche una ripresa cinematografica. Colalucci aveva provato con la sua cinepresa $8 \mathrm{~mm}$ a fare delle riprese "amatoriali" ma si era subito reso conto della non fattibilità della cosa. La Direzione dei Musei inizia a cercare qualcuno che possa fare le riprese dell'intera fase della pulitura. Tutti coloro che rispondono, compresa la Rai italiana, vengono scartati poiché interessati a filmare solo una porzione del lavoro mentre il Vaticano ha l'esigenza di documentarlo per intero. La ricerca continua fino a che una società giapponese, proprietaria di case editrici, di giornali, e di una rete televisiva di Tokio, si offre di fare le riprese di tutta la pulitura e di altre fasi del restauro a campione. I giapponesi offrono le riprese cinematografiche -che saranno fatte da una troup televisiva della NTV- chiedendo in cambio i diritti sulle immagini filmate e su quelle fotografiche. L'accordo raggiunto prevederà la concessione dei diritti in cambio di una somma di denaro. All'inizio del lavoro sulla terza e quarta lunetta arriva il primo gruppo di giapponesi a vedere il cantiere, portano dei cameraman italiani e fanno delle riprese di prova. Successivamente arriverà la troup definitiva composta da dieci persone ${ }^{145}$.

\footnotetext{
145 Se consideriamo i molti rifiuti che il Vaticano ebbe da parte delle numerose televisioni interpellate, le obbiezioni sollevate in seguito da alcuni organi di stampa circa la scelta di affidare l'incarico ad una tv giapponese sono totalmente fuori luogo.
} 
Il secondo giornale di cantiere della Sistina inizia il 29 aprile del 1982. In quello stesso giorno visitano il cantiere 20 persone provenienti dai più prestigiosi Musei del mondo, come il Fine Arts Museum di San Francisco e il Metropolitan Museum di New York. La stampa estera aveva già iniziato a dedicare al restauro articoli importanti come quello di Philippe Pons su "Le Monde" ${ }^{146}$, o quello di Clara Hemphill sul "Daily American"147. All'inizio di gennaio in Italia era uscito sul settimanale "L'Espresso" un pezzo assai significativo sui risultati del restauro e su Colalucci ${ }^{148}$ come restauratore. L'articolo aveva avuto un forte impatto sugli ambienti culturali perché al suo interno recava un importante intervento di $\operatorname{Argan}^{149}$ sul colore di Michelangelo riportato alla luce dal restauro. "Quel pennello furioso" così lo storico aveva intitolato il suo pezzo che pur nella sinteticità di articolo giornalistico possedeva tutta la forza di un piccolo saggio di storia dell'arte. Scrive Argan:

\begin{abstract}
"La volta della Sistina è scura per vecchie colle e nerofumo di ceri, che $i$ restauratori finora non hanno saputo od osato levare. Le prime tre lunette pulite da Colalucci provano che un restauro più spinto è possibile. Anche per motivi dottrinali la Cappella era chiara..(...) Le lunette con lagenerazione di Cristo secondo Matteo sono l'ultimo atto della prodigiosa impresa..(...)..Michelangelo le dipinse d'impeto e per sfida o per dispetto dopo un battibecco con Giulio II che non voleva rimandare l'inaugurazione di Ognissanti del 1512(...) Dipingendo di furia (tre giornate per lunetta) aveva modellato direttamente nel colore come, quando scolpiva, nel
\end{abstract}

\footnotetext{
${ }^{146}$ Cfr. P.Pons "Les lunettes de Michel-Ange" in Arts et Spectacles, Le Monde, 15 aprile 1982, p.15.

${ }^{147}$ Cfr. C. Hemphill "Sistine Chapel's facelift successfully underway" in Daily American 14 febbraio 1982, p. 10

${ }^{148}$ Fabrizio Dentice "I colori del Giudizio" e G. C. Argan "Quel pennello furioso" su L’Espresso, 24 gennaio 1982, pp. 91/97.

${ }^{149}$ Ricordo che Argan aveva visitato il cantiere accompagnato da B. Contardi.
} 
marmo..(...) Con la riapparsa violenza del nativo "furor" cromatico le lunette provano che fu proprio Michelangelo a trovare quella teoria manierista del colore, fondata su dissonanze quasi dodecafoniche, che pochi anni dopo apparirà già matura nelle opere del Pontormo e del Rosso. Poi il Vasari s'adoperò ad occultare il cromatismo del maestro per riconoscere ai toscani il primato del disegno ed ai veneti quello del tono. La distinzione giusta del era invece tra due concezioni del colore : timbrico o qualitativo in Michelangelo, tonale o quantitativo in Tiziano. Una filosofia dell'essere-in-se e una filosofia dell'essere-in-relazione mondo".

II queste poche righe Argan trova il senso storico a quella pittura che il restauro rivela "inedita" e apre nuovi orizzonti sull'origine del colore manierista.

Al consenso degli ambienti scientifici e storico artistici, si contrapponeva già a quel tempo, lo scontento di alcuni isolati gruppi di artisti. A loro, abituati a guardare una pittura poco leggibile, quei colori vivi proprio non piacciono. Non piacciono al punto tale che, col tempo, trasformeranno quel pensiero legato al gusto personale, in un feroce attacco al risultato del restauro e alle metodologie adottate per eseguirlo. Bisogna dire che il primo sintomo del dissenso si era manifestato già alla presentazione della lunetta di Eleazar.

II pittore Toti Scialoja -che all'epoca era direttore dell'Accademia di Belle Arti di Roma- in quella occasione aveva mostrato forti perplessità sui risultati della pulitura, perché dava per scontato che il beverone asportato con il restauro fosse una finitura originale di Michelangelo. II pittore si era anche mostrato resistente al dialogo con i restauratori rifiutando qualsiasi spiegazione 
sull'origine tarda della patina e restando aggrappato alle sue convinzioni personali. La tesi arganiana sull'origine manierista del colore di Michelangelo trovava Scialoja totalmente in disaccordo perché secondo lui, come avrà modo di scrivere in seguito "Un grande creatore non è mai manieristico".

Dopo quella prima esternazione pubblica, l'artista aveva cominciato a cercare alleati per condurre una campagna di sensibilizzazione contro il restauro. Nella fase iniziale aveva trovato Venanzio Crocetti un pittore che in gioventù era stato "aiutante" 150 al laboratorio dei Musei e che per questo vantava grandi conoscenze nel campo del restauro. A questi due artisti si aggiungeranno in seguito altre persone che troveranno un canale di visibilità attraverso il quotidiano romano "Paese Sera". Come avremo modo di vedere in seguito, gli attori principali della campagna contro il restauro sono in qualche modo tutti legati tra loro. Dunque anche nel momento in cui la polemica diventerà più violenta e quando gli attacchi al restauro ed a Colalucci sembrano provenire da molti ambienti diversi, in realtà si tratterà sempre dalle stesse persone.

II 6 maggio 1982, Colalucci fa il punto della situazione ed annota sul giornale di cantiere che le lunette con Azor-Sadoch e Josias - Salathiel sono completamente pulite, consolidate e trattate con il metodo C80 (ossia Paraloid al 4\% in diluente, che poi viene rimosso dalla superficie con diluente ed acqua distillata), ed in via di stuccatura in attesa della reintegrazione. Scrive che nella parte bassa delle lunette è stata asportata la stuccatura che nascondeva le buche pontaie

\footnotetext{
${ }^{50}$ Colalucci mi racconta che Crocetti era stato aiutante al laboratorio di restauro, dove aveva svolto sempre incarichi secondari. In seguito aveva intrapreso la carriera di "artista". Crocetti apparteneva a quella categoria di persone che un tempo venivano assunte al laboratorio di restauro pur non avendo alcuna formazione specifica. Egli come molti artisti aveva la convinzione di conoscere a fondo le tecniche pittoriche antiche.
} 
dell'impalcatura michelangiolesca. Nell'intonaco che ricopriva la buca ai piedi della figura di Josias, uno dei restauratori (Maurizio Rossi) trova alcuni frammenti di antiche carte da gioco -questi reperti poi saranno trattati con glicerina e conservati sotto vetro. II rilevamento della situazione prosegue con la descrizione delle asole metalliche inserite negli intonaci all'epoca del Biagetti, come aggancio delle traverse di appoggio ai pressatoi. Poiché le asole, fatte di sottili fili di rame, non risultano dannose o fastidiose dal punto di vista estetico, si decide di conservarle come documento storico.

Nel frattempo gli organi di stampa continuano ad interessarsi al lavoro, il 26 aprile era uscito sul "Messaggero" un articolo di Aldo Ricci ${ }^{151}$ che aveva seguito quello di Marco Borina sul "Corriere della Sera"152. Proseguono anche le visite le visite, e l' 11 maggio 1982 sale per la prima volta sul ponte James Beck docente alla Columbia University di New York city. Beck contrariamente a ciò che si può pensare, in quella occasione non mostra alcuna perplessità sul lavoro, tanto che una settimana dopo scriverà a Bruno Contardi che lo aveva accompagnato in Sistina una lettera di ringraziamento ${ }^{153}$. Lo studioso rimarrà per qualche tempo "silente" e si disinteresserà al restauro per poi risvegliarsi improvvisamente alla conclusione del lavoro sulle lunette.

Qualche giorno dopo la visita di Contardi, è la volta di Pinin Brambilla che lascia un commento scritto $^{154}$. Le visite proseguono nei giorni successivi con gruppi dell' I.C.R, della Virginia University, dell'stituto Svedese, di quello finlandese. II 22

\footnotetext{
${ }^{151}$ A. Ricci "Michelangelo senza veli” || Messaggero, 26 aprile 1982 p.6.

${ }^{152}$ M.Barina "Con i restauratori sui ponteggi della Sistina sembra di sentire la presenza di Michelangelo" Corriere della Sera, mercoledì 27 gennaio 1982.

${ }^{153}$ Archivio Colalucci ,sezione documenti (F.9 - serie 6) La lettera fu regalata a Colalucci dallo stesso Contardi . Vedi allegati Doc.B.1/82 
maggio salgono Caterina Bon, Paul Schvartzbaum dell' ICCROM assieme ad altre persone. II 6 giugno dalla Soprintendenza di Milano arriva Carlo Bertelli ${ }^{155}$ che conosce bene Colalucci da molti anni, e cosi via fino al 9 giugno quando viene smontato il ponte su queste due lunette. II ponte viene rimontato qualche giorno dopo davanti alle lunette con Ozias, loatham, Achaz. II 5 luglio, dopo la riunione preliminare, Colalucci inizia a pulire in ripresa diretta davanti alle telecamere dell' NTV, le due teste del gruppo di sinistra di Ozias. Prosegue il lavoro e continuano le visite di persone provenienti da tutto il mondo : dalla Germania, da San Francisco, da New York. Torna con una certa frequenza Michael Hirst . Vengono i restauratori del Museo Pusckin di Mosca assieme ai funzionari dell'ambasciata di Russia a Roma. Alessandro Parronchi da Firenze, che tornerà più volte, e via dicendo. II lavoro va avanti di fronte alla cinepresa della TV giapponese che documenta la pulitura per intero. Colalucci non perde mai la concentrazione, nonostante sul ponteggio vi sia un continuo afflusso di studiosi e tecnici, tiene fede a quello che oggi si definirebbe cronoprogramma, ed annota tutto ciò che accade in cantiere. Le fasi del lavoro, i problemi, le riflessioni sui risultati e i minimi dettagli della tecnica e dello stato degli affreschi divengono così un lungo e circostanziato racconto. Con le visite delle molte personalità del mondo della storia dell'arte e del restauro, il consenso per il risultato del lavoro si va consolidando. Siamo ancora lontani dall'avvento di internet ma l'eco del restauro del Michelangelo della Sistina arriva ovunque. 
Nel frattempo il lavoro prosegue parallelamente al procedere della ricerca storica e scientifica per non lasciare spazio al minimo dubbio. Colalucci ogni volta che affronta un nuovo brano di pittura non da mai niente per scontato ma continua ad indagare sulla tecnica e sulla materia. Alle mille domande che si pone cerca sempre delle risposte plausibili lasciando da parte ipotesi o teoremi. Mi racconta che un giorno, durante una conferenza stampa, un giornalista della televisione italiana che gli aveva fatto domande sui problemi del restauro, dopo che ebbe ascoltato le risposte gli chiese in tono polemico se fosse una persona senza dubbi, quando Colalucci rispose che al contrario di dubbi ne aveva avuti moltissimi ma aveva fatto in modo di toglierseli tutti, il giornalista spiazzato replicò con un elegante : "Tousché".

Nel 1983, il primo aprile, Colalucci riceve una lettera ${ }^{156}$ da un artista americano di nome Frank Mason. Mason è un pittore muralista che ricopre la carica di "Second Vice President" in una associazione dal nome altisonante :la "National Society of Mural Painters" fondata a New York ${ }^{157}$ nel 1895. L'artista si dichiara preoccupato dai risultati della pulitura. La sua preoccupazione è nata dopo aver visto le foto della lunetta di Eleazar restaurata, pubblicate dalla rivista "Connoisseur Magazine" ${ }^{158}$. Mason è convinto che la pulitura abbia portato via le finiture a secco di Michelangelo. La lettera è accompagnata dalle foto di Eleazar prima e dopo l'intervento- sulle quali l'artista ha sottolineato a penna tutti quei particolari che, secondo lui, la pulitura ha cancellato. La risposta è cortese ma estremamente ferma poiché Colalucci tentando di spiegare a Mason la fragilità

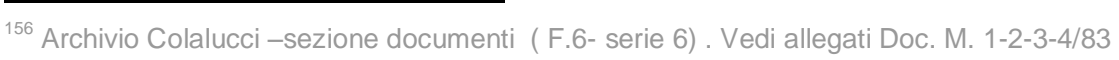
${ }^{157}$ La sede dell'associazione è al n. 41 East 65 th Street a New York - N.Y. 10021 
delle opinioni basate esclusivamente su riferimenti fotografici, smonta punto per punto tutte le obbiezioni del pittore. I particolari che nelle fotografie di Connoisseur vengono interpretati da Mason come ombre, altro non sono che macchie di colla e nerofumo o restauri sette-ottocenteschi. Colalucci spiega a Mason che in Michelangelo l'ottenimento del volume non avviene attraverso l'uso delle ombre nere o brune, ma con il gioco del colore che è la vera novità scoperta dal restauro in corso. La lettera si conclude con un invito a visitare il cantiere: "La invito a venire a vedere i lavori di restauro direttamente sul ponteggio nella Cappella Sistina.(..) Le assicuro che vedere Michelangelo da vicino, per un artista sensibile come Lei, sarà una emozione indimenticabile" ${ }^{\text {"159 }}$.

Nel frattempo continuano ad uscire articoli sulla stampa italiana ed estera sempre di più interessata al lavoro, come testimoniano i pezzi su "l'Express", "La Stampa", "Il Tempo", o “'Avvenire”, ma anche all' accordo che il Vaticano ha stipulato con la NTV di Tokio $^{160}$ a proposito della documentazione cinematografica dell'intervento.

Il terzo giornale di cantiere inizia il 20 giugno 1984. Si lavora sull'ultima lunetta del ciclo, quella di Salmon e Aminadab. A marzo era uscito un bell'articolo sul settimanale Epoca ${ }^{161}$ e ad aprile uno su la Repubblica ${ }^{162}$. Proseguono le visite da tutto il mondo e contemporaneamente al lavoro di restauro- che sulle lunette si sta quasi concludendo- si provvede a fare gli interventi sulle antiche buche

\footnotetext{
${ }^{159}$ Archivio Colalucci, sezione documenti (F.9 - serie 6). Vedi allegati Doc. M. 5/83

${ }^{160}$ F. Santini "Michelangelo tra dollari e yen" La Stampa, 17 dicembre 1983, p.3 - D. Petrocelli "Un Mecenate venuto dall'oriente" II Tempo, 23 novembre 1983 p.6 - Vanja Luksic “ Les Japonais de la Sixtine "l'Express, 16 dicembre 1983.

${ }^{161}$ Cfr. G. Massari "C'è voluta una pennellata di giallo" Epoca, 9 marzo 1984, pp. 72/78. 
pontaie $^{163}$ per predisporre gli agganci del ponte sospeso che servirà per il restauro della Volta. II 9 luglio la Rai italiana fa alcune riprese televisive sul ponteggio a completamento di quelle che in un primo momento sarebbero dovute servire per confezionare un piccolo servizio televisivo per la rubrica "Tamtam". Visto il risultato del restauro la Rai aveva poi deciso di integrare le riprese per confezionare uno "speciale" ${ }^{164}$ della durata di un'ora. II 13 ottobre si conclude definitivamente la prima fase del restauro degli affreschi di Michelangelo- quello delle lunette- i restauratori sono pronti a passare alla prima fetta della Volta. Si fanno le prove di carico delle mensole che dovranno sorreggere il ponte sospeso, ed il 7 novembre tutto è pronto per quello che nel diario di cantiere Colalucci definisce "il secondo grande viaggio" cioè il restauro della Volta della Cappella Sistina. Tra novembre e dicembre escono altri importanti articoli giornalistici sui risultati del restauro ${ }^{165}$ tra cui quello di

\footnotetext{
${ }^{163}$ Le buche pontaie originali sono state utilizzate per l'ancoraggio del carro ponte usato per il restauro della Volta. Per fare questo, le buche sono state rinforzate con fodere di acciaio fissate con speciali resine.

164 II giornalista Nino Crescenti, autore televisivo ed inviato di TV 7, era andato a parlare con Colalucci per fare un piccolo inserto di dieci minuti da inserire nella rubrica televisiva "tamtam" che all'epoca curava. Quando aveva visto l'entità dei risultati del lavoro chiese ed ottenne di fare una trasmissione interamente dedicata alla Sistina. Si veda "Michelangelo rivelato" in Speciale TG1 a cura di Nino Criscenti, produzione RAI, Roma 1984

165 R. Stenge "A new glimpse of Michelangelo" Time, 24 dicembre 1984 - R. Lane" Michelangelo plain" Washington Post, 23 dicembre 1984 - F. Miracco "Ne dipinse di tutti I colori” L'Europeo 22 dicembre 1984, pp.100/104 - "Dalla Sistina il restauro del Secolo" Repubblica 18 dicembre 1984 - F. Minervino "Michelangelo riserva una sorpresa : il colore" Corriere della Sera 19 dicembre 1984- "Altri otto anni di lavoro alla Cappella Sistina" Repubblica 13 dicembre 1984 - A. Donati “Alla ricerca di una volta perduta” Repubblica 27 dicembre 1984

${ }^{165}$ Cfr. G. Carandente "La Sistina cambia pelle" II Giornale 13 dicembre 1984, p.3.
} 
Giovanni Carandente ${ }^{166}$. Lo studioso riprende il discorso già aperto da Argan due anni prima, a proposito del colore di Michelangelo:

"I magnifici colori.." dice Carandente " non permettono più di considerarlo il disegnatore più forte ma il coloritore più fiacco..(..) E Michelangelo va ristudiato daccapo, tanto è sconvolgente la scoperta, così diverso risultando il pittore del quale si era osato scrivere che nella Sistina aveva adoperato colori che tiravano tutti al mattone e al grigio...(...) incapace di imitare il colorito di natura, di variare le tinte. I fiumi di inchiostro stampati per descrivere il groviglio di corpi senz'ordine né colore sulla volta della Cappella papale, dovranno essere fra breve cancellati dalla storia dell'arte.(.)E' questa la prima fase del restauro iniziato il 10 febbraio 1981, che ora si è conclusa e che Carlo Pietrangeli ha presentato l'altra sera alle televisioni di tutto il mondo. Si tratta di un restauro eccezionale e memorabile.....) una televisione giapponese..(..) filmerà ogni centimetro quadrato di intonaco dipinto, durante le operazioni di pulitura eseguite magistralmente da Gianluigi Colalucci .....) Abbiamo visto l'altra sera un campione del film..(..) quindici minuti girati nel giugno 1983 ad una delle lunette. Era come stare lassù, a quindici metri dal pavimento della Sistina a seguire il gesto e il ritmo pacato di Colalucci che pazientemente, in un atmosfera senza tempo - un muto, magico colloquio con il capolavororimuoveva il film nerastro di nerofumo e colle animali...(..)L'incantesimo di aver visto risorgere da quello strato nerastro le figure solidamente plasmate e vivacemente colorate di Michelangelo può essere difficilmente descritto con le parole. Era come intessere un dialogo con quel burbero di un Fiorentino che, proprio quando portava a termine quest'opera gigantesca e sublime, scriveva al padre, in sconsolata modestia : < e vivo con grandissime fatiche e con mille sospetti. E sono stato cosi circa quindici anni e mai ebbi un ora di bene >...(..) Le figure hanno una plasticità maestosa e anche, nelle pose sciolte e spontanee, una straordinaria morbidezza.......) Con i materiali e le tecniche avanzate di oggi, il ponte in acciaio e legno corre ora su un doppio binario e $i$ sostegni usano gli stessi fori per i sorgozzoni che usò Michelangelo..(..) C'è da augurarsi di poter ripetere nel 1992 (cioè la data ipotizzata per la fine del restauro) anche noi prostrati, la celebre frase di Giulio II : < Dio, quanto è terribile il tuo giorno del Giudizio ! >”. 
La parte di volta che viene affrontata per prima coincide con l'inizio della decorazione michelangiolesca, e comprende la vela con Davide e Golia, quella con Giuditta ed Oloferne e la figura del profeta Zaccaria. Sulla Volta ricominciano gli studi, i test di pulitura e le ricerche scientifiche. Si presenta subito un problema sulla figura di Zaccaria. La figura appare molto diversa rispetto alla pittura delle lunette. Sembra molto ritoccata e corretta, il manto verde è ricoperto da tratteggi incrociati verdi e bruno -neri che sembrano estranei all'affresco. II viso è appesantito da ombre che alterano la stesura sottostante e la manica gialla dell'abito ha un aspetto poco cinquecentesco. Cercando di capire meglio la situazione si fanno indagini aggiuntive mentre si procede con il lavoro nelle zone che non presentano problemi. Colalucci mi dice che in questa prima parte della Volta Michelangelo apporta alcune correzioni alla proporzione delle figure poiché evidentemente deve prendere dimestichezza con la nuova superficie. Sempre sul manto verde di Zaccaria per esempio vengono individuate due correzioni che Michelangelo fa su una rasatura di calce applicata su una parte di intonaco che aveva precedentemente raschiato in superficie. Le correzioni sono abbastanza evidenti poiché hanno un aspetto superficiale granuloso molto diverso da quello smaltato dell'affresco, sono anche meno resistenti e richiedono un trattamento consolidante prima della pulitura. II 29 gennaio 1985 Colalucci annota sul diario che sono riusciti ad individuare come falsi i tratteggi neri sul manto di Zaccaria ma che vi sono ancora delle incertezze su quelli verdi, dunque continua la ricerca. Qualche 
giorno dopo in cantiere ha luogo una riunione con il Direttore, il consulente Rotondi, Mancinelli, Gabrielli e naturalmente Colalucci. Si discute anche del problema del manto verde di Zaccaria. Alla fine si decide di continuare le ricerche, procedendo con il lavoro sulle zone che non presentano problemi come la vele. II 17 aprile 1985 dopo quasi due anni dall'invito che Colalucci gli aveva rivolto, Mason arriva in Vaticano. II pittore si rifiuta però drasticamente di salire sul ponteggio per vedere gli affreschi da vicino e continua a sostenere che il restauro sta danneggiando la pittura di Michelangelo. L'artista incontra Pietrangeli, Mancinelli Colalucci e Gabrielli ma nessuno di loro riesce a fargli cambiare posizione, tanto che appena tornato in America organizza una manifestazione di studenti della "Art Student of N.Y." davanti al consolato italiano di New York per fermare il restauro. In quella occasione Mason, in rappresentanza dei manifestanti, consegna al viceconsole Roscigno una petizione ${ }^{167}$ per fermare "I'orribile distruzione subita con il lavoro già completato sulle lunette". C'è un articolo firmato da John Cappelli sul quotidiano "Il Progresso"168 che riporta la notizia della manifestazione e comprende un intervista a Mason. L'artista rilascia questa dichiarazione :

"Noi (cioè i muralisti d'America) riteniamo che Michelangelo lavorò a secco prima di diventare un maestro insuperato dell'affresco." Prosegue Mason “..il dott. Colalucci si oppone strenuamente alle nostre argomentazioni negando l'essenza vitale del materiale su cui lavora (...) ho scoperto ben altro, e cioè che la spinta

\footnotetext{
${ }^{167}$ Archivio Colalucci-sezione documenti (F.9- serie 6). Vedi allegati Doc. M.5/85 
del restauro viene in non piccola parte da almeno tre milioni di dollari pagati dalla Nippon TV per i diritti di filmare per prima il nuovo Michelangelo.."

Qui addirittura si cerca di dare al restauro una valenza politico-commerciale. L'articolo continua su questo piano toccando punte che potremo definire esilaranti quando viene accusato Colalucci "di eseguire la pulitura con criteri modernistici che distruggerebbero parte dell'anatomia e con preparati chimici capaci di dare un risalto psichedelico alle forme" Allo stesso modo esilaranti sono le scritte dei cartelli usati dagli studenti nel corteo "Svegliatevi italoamericani e unitevi a noi per salvare la Sistina!" oppure: "Dio è già pulito non ha bisogno di Colalucci".

Per Mason, l'intervista al Progresso, è anche una succulenta occasione di promozione professionale, poiché l'articolo di Cappelli non manca di dare ampio spazio alle opere eseguite dal pittore per le chiese di New York. Chissà forse Mason ha la segreta speranza di poter un giorno dipingere un affresco in Vaticano? In occasione della consegna della petizione, l'artista invia una lettera aperta al New York Time ed una al Segretario di Stato del Vaticano Cardinale Casaroli. Tra il mese di maggio e giugno arriveranno in Segreteria di Stato alcune lettere aperte contro il restauro: quella di Dean Fauset Presidente dell'associazione di cui Mason è vicepresidente, quella di Donald Weston Presidente della "Fine Art Federation of New York", e quella di Alexandre Eliot 
art editor di Time Magazine ${ }^{169}$.

Siamo ad un anno dalla conclusione del restauro delle lunette, il lavoro procede normalmente, disturbato soltanto dalla polemica che non accenna a mollare e sembra farsi più pressante.

Nell' ottobre del 1985, il magnate americano Stillman organizza nella sua tenuta di Wethersfield, vicino New York, una settimana di studi sulla Sistina. Stillman è un collezionista, dunque è molto vicino all'ambiente degli artisti contemporanei. Nella casa di Wethersfield ci sono delle decorazioni murali del pittore Pietro Annigoni, un artista italiano molto abile nel disegno, che in età matura si è avvicinato alla tecnica dell'affresco, con risultati discutibili. Per la settimana di studi sulla Sistina, Stillman ospita a Wethersfield un selezionato gruppo di storici dell'arte e restauratori per discutere sul restauro in corso. A rappresentare il Vaticano ci sono Persegati, Mancinelli, Colalucci e Gabrielli. Al termine della prima giornata di incontro viene fatta un'esposizione nell'auditorium del Metropolitan Museum di New York. Oltre al gruppo del Vaticano vi prendono parte il capo restauratore del museo di Los Angeles, la storica dell'arte Eve Borsook, il restauratore Paul Schwartzbaum dell' ICCROM, il restauratore Andrea Rothe del Getty Museum di Malibu e la Weil Garris Brandt docente di storia dell'arte alla New York University e consulente dei Musei Vaticani per l'arte rinascimentale. Due giorni dopo questo incontro pubblico se 
ne organizza un altro nella sede della Frick Collection di New York. Questa volta il pubblico è più ristretto di quello del Metropolitan ma molto selezionato. Ci sono alcuni personaggi celebri del mondo della conservazione newyorkese, come Mario Modestini, Diane Dwyer del Metropolitan Museum, e Marco Grassi, ma c'è anche James Beck. Alla discussione finale, cui molti partecipano per esprimere la propria opinione sul restauro, Beck polemizza sul solito problema delle finiture a secco. Il tono della contestazione del professore della Columbia University è inasprito da una evidente rivalità esistente tra lui e la Weil Garris Brandt docente alla N.Y. University, che è li presente nella veste ufficiale di consulente per i Musei Vaticani. Due autorevoli rappresentanti di due prestigiose università : uno escluso dalla grande impresa Sistina, l'altra coinvolta come consulente.

La presenza a New York del gruppo del Vaticano risveglia la "fantasia" di Mason. L'artista non può lasciarsi scappare l'occasione per riprendere il discorso sul restauro di Michelangelo, e decide perciò di invitare, nel suo circolo privato, Colalucci e gli altri per parlare della Sistina. Le idee e le azioni dell'artista contro il restauro sono arcinote, ma nonostante ciò, l'invito viene accettato nella speranza di poter avere, una volta per tutte con Mason e i suoi seguaci, un confronto corretto e costruttivo. Non sarà così poiché il dibattito assumerà subito un carattere di inaccettabilità. Agli argomenti storici, tecnici o scientifici portati dall'equipe della Sistina a supporto delle scelte fatte, Mason e i 
suoi seguaci contrappongono soltanto teoremi senza nessun fondamento scientifico. Mi dice Colalucci che l'artista continuava ad evocare l'immagine del "Genio melanconico" che sporca con il nerofumo (addirittura in seguito si parlerà dell'atramentum $)^{170}$ l'affresco appena finito, ${ }^{171}$ e rifiutava di accettare la lettura più realistica di Michelangelo alle prese con le regole del "buon fresco" cinquecentesco. La riunione organizzata da Mason metterà a dura prova anche la pazienza della Weil Garris Brandt, presente alla conferenza che, con una dura replica alle accuse del pittore, porrà fine allincontro. Dopo la chiusura della settimana di Wethersfield, Beck, con l'aiuto del giornalista italiano Lucio Manisco -corrispondente del quotidiano romano "II Messaggero"- e anche molto legato a Scialoja, scriverà sul New York Times un articolo contro il restauro

II quarto giornale di cantiere della Sistina inizia nel novembre 1985. Dopo quasi un anno di ricerche si sta ancora lavorando sulla figura di Zaccaria. II problema questa volta è quel colore a tempera che altera la forma della manica gialla.

Ha l'aspetto di una ridipintura poiché è scurissimo e molto diverso, per proporzioni ed aspetto, dai pentimenti michelangioleschi. Colalucci però in assenza di prove oggettive sulla sua non originalità non vuole asportarla. I| 27 novembre si svolge una miniriunione con Gabrielli per discutere alcune novità emerse dal procedere della pulitura dello Zaccaria e stabilire l'esecuzione di nuovi prelievi. Circa due settimane dopo si fa una nuova riunione con 
Pietrangeli, Mancinelli, Rotondi, Colalucci e Gabrielli finalizzata alla decisione di rimuovere o meno la ridipintura. Grazie agli elementi emersi dallo studio archivistico e dai test di pulitura si riesce ad inquadrare l'intervento nell'ambito del restauro eseguito dal Mazzuoli nella prima metà del Settecento. Finalmente si può procedere alla sua rimozione. Le correzioni sul collo e sulla manica del Profeta risultano invece originali e ovviamente vengono conservate. Nel frattempo il cantiere continua ad essere teatro di visite. II 14 dicembre salgono sul ponte Basile, Cordaro, Andaloro, e Varoli Piazza. Due giorni dopo arriva da Venezia Trevisani, e altre persone, e così via fino alle fine del 1985 per riprendere con l'inizio del nuovo anno. II 13 gennaio 1986, davanti alle telecamere della NTV, Colalucci procede alla rimozione delle ridipinture sul profeta Zaccaria, schiena, ginocchio, manica gialla e piega del manto verde. Pulendo scopre che lo strato bianco dato dal restauratore come preparazione per l'intervento fatto sulla schiena del profeta e sopra le correzioni di Michelangelo, entra in una grande lacuna del colore originale.

Questa è la conferma definitiva della non originalità dell'intervento che sta rimuovendo.

II 24 gennaio in cantiere si festeggiata la conclusione della prima porzione di volta. È tutto completato, comprese le riprese cinematografiche, le documentazioni grafiche e quelle fotografiche. Si aspetta soltanto di lasciare definitivamente il ponteggio in attesa della grande inaugurazione. II 4 febbraio 
alle 17,30 di fronte a circa settecento persone, e di fronte agli organi di stampa, radio e televisioni di tutto il mondo, la prima porzione della volta restaurata viene presentata ufficialmente. E' un trionfo.

Colalucci, qualche giorno dopo, racconta l'evento nel diario di cantiere. Parla della grande emozione provata nel vedere gli affreschi restaurati per la prima volta dal basso. Si dice soddisfatto del risultato del lavoro e sollevato circa la sua omogeneità, mentre è assai critico sulla qualità dell'illuminazione. Secondo lui la sera dell'inaugurazione gli affreschi erano stati eccessivamente illuminati .Racconta infatti di aver fatto spegnere, il giorno successivo, quasi tutte le lampade piazzate ${ }^{172}$, lasciandone accese soltanto due.

La cerimonia dell'apertura della prima porzione della Volta restaurata fa il giro del mondo e, attraverso gli organi di stampa, le immagini degli affreschi arrivano nelle case di tutti. Cresce la curiosità attorno al lavoro e cresce il consenso per i risultati ottenuti. La popolarità di Colalucci è in rapida ascesa. Quando in Vaticano percorre il lungo corridoio delle carte geografiche per recarsi in Sistina, i turisti lo fotografano come fosse un divo del cinema. Alcuni gli chiedono l'autografo. A tutti piace il suo modo pacato di parlare del lavoro. Trasmette sicurezza senza mai mostrarsi arrogante, e fa sembrare semplice anche ciò che non lo è. Le visite si in cantiere si moltiplicano. Per vedere gli affreschi da vicino arrivano persone dalle più prestigiose istituzioni di tutto il mondo : da San Diego California, dalla Università del Michigan, da quella del

${ }^{172}$ La sera dell'inaugurazione erano state piazzate diciotto lampade Osram-Philips, anche per consentire alle televisioni di effettuare le riprese degli affreschi. 
Wisconsin, dall'Accademia Britannica, da quella Germanica, dalla Sorbona di Parigi. Gli Storici dell'arte ed i restauratori italiani amano visitare il cantiere con una certa frequenza, e seguono il lavoro -che intanto prosegue nella seconda porzione della Volta comprendente la scena con il Diluvio Universale- con grande partecipazione. È ancora una volta il diario di cantiere a lasciarci la traccia dell'emozione immediata dei numerosi visitatori. Molte e lusinghiere le annotazioni che tanti di loro lasciano accanto alla firma "..una esperienza nella vita che non si può dimenticare" lascia scritto Gombrich ${ }^{173}$. Peridis il noto vignettista de El Paìs, disegna una scenetta che rappresenta Colalucci impegnato nella pulitura della volta osservato dal Papa che gli dice "..va bene così maestro"174. Lo scultore Arnaldo Pomodoro scrive :".. è per me un giorno particolare; è davvero emozionante trovarmi al posto di Michelangelo e vedere da vicino come ha lavorato! Un' opera gigantesca, stupenda e vadano gli elogi a chi se ne prende cura. Grazie e tanti auguri”, Umberto Baldini commenta :"Grazie per questo ritorno allo spazio della visione".

Nel frattempo in Segreteria di Stato arrivano altre lettere a proposito del restauro. Questa volta a scrivere è l'Arcivescovo di Milano Carlo Maria Martini $^{175}$. II Cardinale trasmette una lettera del presidente della Corte d'Appello di Milano che raccoglie "alcuni rilievi critici di un gruppo di artisti" sul restauro della Sistina. Ancora una volta le perplessità si alimentano nell'ambiente degli artisti, in questo caso il gruppo è di Bergamo e fa capo al pittore Mario Donizetti. Gli argomenti vertono come al solito sulla rifinitura a secco dell'affresco

\footnotetext{
${ }^{173}$ Vedi allegati Doc. D. 4/86 ${ }^{174}$ Vedi allegati Doc. D. 7/86 
michelangiolesco. La lettera è accompagnata da un articolo che il pittore ha scritto per il trimestrale "Ricerca" ${ }^{176}$. Donizetti si avventura in campi che non gli sono propri, come quello della storia dell'arte, del restauro e della chimica, pretendendo di dare lezioni a chi di quelle materie se ne occupa in maniera professionale. II pittore sostiene per esempio, che l'azione del solvente usato per la pulitura ( $A B$ 57) sia dovuta alla soda caustica e all'ammoniaca, scambiando il bicarbonato di sodio per soda caustica ed il carbonato d'ammonio per ammoniaca. Parla del Condivi traendo conclusioni personali. Si scaglia contro la rimozione dei ritocchi dalla figura di Zaccaria accusando i restauratori di aver agito con leggerezza ed ignoranza, quando abbiamo visto che gli studi sui problemi del Profeta hanno impegnato tutta l'equipe per più di un anno. Donizetti prosegue l'articolo parlando della fuliggine, secondo lui usata da Michelangelo per nascondere i colori troppo brillanti dell'affresco appena dipinto. II pittore avverte che la fuliggine -non avendo una definizione in formula chimica - può essere scambiata per lo sporco prodotto dalle lampade. Dando ad intendere che i restauratori ed i chimici siano incapaci di distinguere il sedimento di sporco dalla materia originale. Ma il restauro della Sistina non sarà l'unico bersaglio di Donizetti che successivamente sparerà a zero anche contro il restauro del Cenacolo, incolpando la restauratrice Pinin Brambilla di aver : "asportato dal Cenacolo le finiture a secco di Leonardo". II pittore termina l'articolo su "Ricerca" con una descrizione molto personale, e senza alcun riscontro scientifico o storico, della tecnica pittorica di Michelangelo. 
“.. Michelangelo concepì a priori il raggiungimento del risultato finale non intieramente a solo fresco, ma a tecnica mista. Anche per la scarsità delle sue conoscenze di tecnica a fresco adottò questo metodo misto che gli procurò ovviamente le difficoltà che sono non solo note ma storiche”.

II 9 dicembre 1986 visitano per la prima ed unica volta il cantiere, Toti Scialoja e Alessandro Conti ${ }^{177}$. Nessuno dei due, prima di questa data, ha mai visto la pittura di Michelangelo della Sistina da vicino ${ }^{178}$ anche se Conti, pochi giorni prima, ha mandato alle stampe ${ }^{179}$ un testo dal titolo "Michelangelo e la pittura a fresco"180. II libro deve essere presentato di li a qualche giorno, e questa singolare visita in exstremis gli serve per poter dire di aver visto la pittura di Michelangelo da vicino. Non importa quando. Lo studioso si fida del fatto che nessuno metterà in relazione la data della sua visita in Sistina con quella della stampa del libro.

Nel diario di cantiere, c'è il racconto di questa strana visita. È un racconto duro e critico fatto da Colalucci e sottoscritto da Mancinelli. Apprendiamo che Conti e Scialoja si sono fermati sul ponteggio per una stringata mezz'ora, e che hanno osservato gli affreschi in un clima di estrema freddezza, senza mai cercare il dialogo con i restauratori. Nessuna domanda, nessuna apertura al dialogo. Concludendo il racconto di questo episodio Colalucci si sofferma sul problema dell'insegnamento delle tecniche artistiche. Conti, come nota, è abituato a studiare le opere sulle riproduzioni fotografiche, le tecniche solo sulle fonti, e non ha nessuna abitudine al contatto diretto con la materia. Un metodo di studio

\footnotetext{
177 Vedi allegati Doc. D. 8/86

${ }^{178}$ || che è molto strano dal momento che il lavoro andava avanti da quasi cinque anni. II cantiere era aperto a chiunque facesse richiesta di visitarlo.

${ }^{179}$ Finito di stampare nel novembre 1986 presso la Grafica Lito di Firenze.

${ }^{180}$ Cfr. A. Conti “Michelangelo e la pittura a fresco" con prefazione di Toti Scialoja, Firenze 1986.
} 
discutibile che si presta ad interpretazioni spesso lontane dalla realtà 0 quantomeno lacunose. Oggi che a più di vent'anni di distanza dalla pubblicazione del testo di Conti, abbiamo acquisito la consapevolezza che lo studio delle tecniche esecutive - per fornire dati credibili- deve essere condotto a diretto contatto con l'opera d'arte, le riflessioni di Colalucci ci sembrano quanto mai appropriate. All'epoca però gli scritti di Conti, anche se da molti illustri studiosi furono subito definiti "marginali e fantasiosi", fecero in tempo a finire sui tavoli di molti studenti. Vi era l'aggravante che lo studioso rivendicava il suo ruolo universitario presentandosi come "L'unico titolare della Cattedra di Storia e Tecnica del restauro" a Bologna. In realtà insegnava al DAMS una sorta di facoltà sperimentale dedicata all' insegnamento delle varie forme di arte e spettacolo e che in quegli anni, altro segno della crisi che avanzava, aveva da poco incluso tra quegli insegnamenti la "storia e la tecnica del restauro" 181.

Il quinto giornale di cantiere inizia il 19 gennaio 1987, con un lungo elenco di firme. Tra visitatori c'è Paul Philippot. Si sta lavorando alla scena della Cacciata dal Paradiso terrestre. In cantiere c'è una novità : il 23 gennaio è stato istallato dalla società E.C.G. il compiuter ${ }^{182}$ per la raccolta e archiviazione dei dati relativi alla documentazione grafica. Fino a quel momento le basi grafiche erano state eseguite manualmente ${ }^{183}$ partendo dalle tavole fotografiche Alinari. Con il procedere del lavoro, e la crescita dei dati da acquisire e da rendere

\footnotetext{
${ }^{181}$ Conti si era laureato con una tesi sulla "storia del restauro" che poi aveva trasformato in testo scolastico- Colalucci definisce "insulso" questo testo poiché ritiene che non si possa parlare di storia in quanto si tratta di una raccolta disorganica di metodi di restauro.

182 Si tratta di una stazione Apollo D.N. 3000 con processore Motorola 68020, 4 megabytes di RAM e hard disk da 330 megabyte, monitor 19 pollici a sedici colori ad alta definizione. II sofware di base è un series 5000 (S5k9 della Auto Trol Tecnology di Denver ), il software applicativo, fornito dalla E:C:G: è stato successivamente modificato ed adattato alle esigenze della raccolta dati dalla stessa equipe di restauro. Si veda F. Mancinelli "Sistemi di documentazione nel restauro della Cappella Sistina” in Atti del Convegno Internazionale di studi, marzo 1990- Ed. Istituto Geografico De Agostani, Novara 1994. PP. 263/265.
} 
soprattutto consultabili facilmente anche in futuro, nel corso del 1986, si era deciso di ricorrere allinformatica. È questa la prima volta che un compiuter viene istallato in un cantiere di restauro. II compiuter, per tutta la durata del restauro, sarà manovrato da Filippo Petrignani.

Intanto continua l'opera di divulgazione dei risultati del lavoro. L' 1 febbraio, all'indomani di una affollatissima conferenza di Mancinelli al Poldi Pezzoli di Milano, il quotidiano la Repubblica, pubblica una lettera aperta di Beck a Colalucci. La lettera da inizio ad un vero e proprio botta e risposta tra i due che avrà luogo sui giornali e che si protrarrà per qualche tempo. La cosa è anomala poiché Colalucci-come tutta l'equipe vaticana-aveva sempre cercato di dibattere i problemi del restauro nelle sedi idonee, tenendosi lontano dalle polemiche spicciole tanto care ai mass media. In questo caso particolare però, poiché tirato personalmente in ballo, sarà costretto a rispondere pubblicamente.

La lettera aperta di Beck a la Repubblica si apre così :

"Caro Colalucci in questo mondo alienato e frettoloso dove le azioni sono coperte dal velo dell'anonimato, le battute ad effetto sono di rigore e le alleanze più spurie portano a strane compagnie ${ }^{184}$...(.) ..quando il New York Time ha pubblicato la corrispondenza da Roma di Mary Davis Suro ${ }^{185}$ .....)..basata essenzialmente su una sua intervista, ho preso atto che le mie osservazioni non erano rimaste inascoltate..(...)..lei Colalucci, un restauratore con esperienze decennali sta incominciando a nutrire gravi dubbi anche se è stata una sola la voce del mondo accademico (cioè la sua) che si è levata per contestare il restauro da lei diretto...(..) malgrado

\footnotetext{
${ }^{184}$ Potremmo dire che questa "criptica apertura" più che al lavoro di Colalucci sembrerebbe riferibile alla natura di quell' ArtWatch, di cui Beck è a capo.

${ }^{185}$ Beck si riferisce all'articolo di M. D. Suro "Il restauro della Sistina : guai in Paradiso" New York Time, 4 gennaio 1987 e ripreso poi dall’ International Herald Tribune.
} 
l'osannante consenso di tanti emeriti storici dell'arte..(..) mi sembra che una singola voce abbia avuto su di lei un impercettibile effetto.."

La letterà di Beck prosegue con uno stile alquanto discutibile quando, dopo aver fatto raccomandazioni elementari, incita Colalucci a non farsi "trarre in inganno da amici che le rivolgono elogi forse generosi ma sicuramente acritici e retorici ( evidentemente per Beck sono retorici i commenti di Argan, Bertelli, Brandi, Briganti, Chastel, Gombric, Urbani, e di tutti quanti hanno scritto a favore del restauro ).." Poi getta quasi un anatema :

“..quando verrà il momento sarà lei e non questi personaggi, a dover rendere conto del suo operato alla posterità...(..) si schieri dalla parte degli angeli.."

II 2 febbraio, in cantiere ci sono trenta giornalisti inviati dai giornali e dalle TV più importanti del mondo : Le Figarò, Ya- Madrid, N.C. News, "La Nazione", Agenzia Asca, Afp, “Il Giornale”, “Il Tempo”, “Avvenire”, “Corriere della Sera”, DjN, "Voice of America”, Televista-Messico, “La Repubblica”, BBC, TG.3 Rai, Agenzia Italia ed altre. Si continua il 5 con AP, EFE, "Daily News", Europa Press- Spagna, ANSA, Agenzia France Press, NPR, "La Stampa", "II Messaggero", "El Pais", "Sonijay Tribune", GR 324 ore. Si sta lavorando sulla scena della Cacciata dal Paradiso Terrestre.

Ancor prima della risposta di Colalucci a Beck su la Repubblica, esce sul

\footnotetext{
${ }^{186}$ Beck costruisce un ipotesi fantasiosa, partendo da alcune considerazioni personali su Colalucci, con le quali la Suro aveva colorito il suo articolo sul New York Time. La giornalista aveva scritto che Colalucci ,gravato dalle responsabilità del lavoro,gli era apparso teso ed improvvisamente invecchiato. Tutto qui, tanto che in seguito resasi conto che il suo pezzo era stato usato scorrettamente da Beck per gli articoli qui riportati, si scuserà personalmente con Colalucci.
} 
Corriere della Sera un commento di Carlo Bertelli dal titolo emblematico : "Michelangelo sporco dura di più ?" . Bertelli risponde sostanzialmente a Beck difendendo il restauro della Sistina e criticando coloro che esprimono giudizi su lavori che non conoscono. Sul contenuto del testo di Conti Bertelli è molto severo :

'E' dunque un segno interessante di costume il fatto che sia stato possibile scrivere un intero libro contro il restauro della Sistina senza che l'autore dimostri mai un' osservazione diretta e soltanto cucia notizie stampate a ipotesi non dimostrate" ${ }^{m 187}$.

La feroce stroncatura di Bertelli al metodo di ricerca di Conti non passa inosservata, tanto che la polemica si inasprisce ulteriormente. Tra le varie testate giornalistiche italiane ed estere, che si occupano dell'argomento, spicca il quotidiano romano Paese Sera che conduce la polemica in maniera molto scorretta. C'è da dire che il quotidiano romano, dopo un passato glorioso è ormai in grave crisi editoriale - tanto che di lì a pochi anni chiuderà i battenti definitivamente - e probabilmente cerca di vendere quante più copie possibile con titoli sensazionalistici. Paese Sera diviene la voce pubblica delle opinioni personali di un ristretto gruppo di persone : Manisco, Scialoja, Conti e Bek cioè un giornalista un pittore e due storici dell'arte ). Più aumenta il successo del restauro nel mondo, più la polemica assume i caratteri di una caccia alle streghe, contro il Vaticano prima e contro Colalucci poi. 
Manisco è l'autore di un pezzo uscito il 5 febbraio $^{188}$ su Paese Sera. L'articolo lunghissimo è un inno alla faziosità. Si sofferma sul solito testo di Conti annunciandone la traduzione in inglese. Manisco definisce l'appello di Beck su la Repubblica "Accorato e civile" mentre giudica "polemico e denigratorio" il modo di rispondere di Colalucci e di Mancinelli. La falsità di tali asserzioni trova un facile riscontro nell'intervista rilasciata da Mancinelli al Corriere della Sera e nella lettera di risposta di Colalucci a Beck, entrambe pubblicate il 7 febbraio.

"Caro Beck, lei mi offende" così si apre la lettera di Colalucci ${ }^{189}$,che prosegue:

“....La sua affermazione secondo la quale io incomincerei a nutrire gravi dubbi sul mio lavoro di restauro mi sorprende e mi sbalordisce, tanto essa è contraria alla verità...(..).. no professore, io non sono né angosciato né preso da incertezze, sono solo pienamente conscio delle responsabilità che pesano su di me così come pesano su tutti coloro che condividono le decisioni relative alla campagna di restauro in corso...(..)...Ciò che più mi sorprende nella sua lettera è che lei possa pensare che le domande più elementari che oggi mi pone, non siano state da noi considerate prima ancora di dare inizio al lavoro. Mi sembra ovvio che quesiti quali : è necessario procedere alla pulitura? Ė urgente? Siamo sicuri della bontà del metodo nel tempo? Esistono rifiniture originali a secco di Michelangelo ? ecc. vengono posti come premessa di qualsiasi operazione di restauro. Dubitandone, professor Beck, lei offende la nostra professionalità ed il nostro senso di responsabilità...(.) risposte a questi problemi...(..)..sono già state date da noi attraverso pubblicazioni scientifiche ed altre di larga diffusione. Ma lei sembra volerle ignorare. Quanto alla pausa da lei invocata, le faccio presente che le pause di riflessione sono per noi normale prassi di lavoro e durano tutto il tempo necessario...(..) ritenevo importante la sua opinione, ma la sua lettera mi ha profondamente deluso.

\footnotetext{
${ }^{188}$ L. Manisco "Ora anche dagli usa <fermate i restauri>" Paese sera 5 febbraio 1987, p. 11. 
Quanto al suo invito, ad effetto, a schierarmi <dalla parte degli angeli > mi pare di esservi ormai da oltre sei anni. E lei professore ?".

Mancinelli invece risponde alle domande di A. Debenedetti dalle pagine del Corriere della Sera. Alla domanda sulla pausa di riflessione invocata da Beck Mancinelli risponde:

"Sono d'accordo con Beck che, lavorando su Michelangelo, la prudenza è indispensabile. Sono d'accordo sul fatto che il tempo in operazioni di questo genere non deve avere importanza. Però le pause di riflessione si fanno quando ci sono dei motivi validi. Nel nostro caso, le pause sono già state moltissime anche se il professor Beck non ne è informato. Ci siamo fermati ogni volta che lo abbiamo ritenuto necessario.."

Quando il giornalista chiede quali consensi ha avuto il lavoro Mancinelli risponde :

"In molti si sono espressi a favore pubblicamente : da Urbani a Bertelli, da Argan a Calvesi, da Briganti a Zeri, da Chastel a Raggianti a Baldini, da Hartt a Shearman, dalla Weill-Garris alla Borsooc. E mi fermo agli storici dell'arte.." Poi alla domanda sul dissenso di Scialoja riprende : "Gli artisti hanno un rapporto estremamente soggettivo -ed è giusto- con l'opera d'arte e la trasformazione operata dalla pulitura è stata indubbiamente shoccante. Non tutti gli artisti però, hanno reagito allo stesso modo.."190

Pochi giorni dopo un nuovo articolo su la Repubblica con ulteriore replica di Beck :

"il professor Colalucci mi ha sfidato ad un dibattito pubblico chiedendomi < da che parte sta lei professore?> La risposta è semplice - dalla parte di Michelangelo..." 
l'intervista riporta sempre gli stessi argomenti contro il restauro basati sulle solite fonti : l'ormai noto passo del Condivi e le improbabili teorie contenute nel testo di Conti ${ }^{191}$. L'articolo si conclude con la risposta di Colalucci, interpellato a proposito della lettera aperta contro il restauro inviata al Papa da una quindicina di artisti americani tra cui Christo, Rauschenberg e Andy Warhol -che pare avesse aderito poco prima di morire-. Dice Colalucci :

"Noi non ci mettiamo in allarme, e nemmeno il Papa, altrimenti si sarebbe mosso da tempo. Ho l'impressione che qualcuno di questi firmatari non abbia neanche mai visto che cosa stiamo facendo".

A difesa del restauro ed a proposito della protesta degli artisti americani Giuliano Briganti scrive su la Repubblica un articolo dal titolo "Quando si firma al buio" 192 Dice Briganti :

"Credevo fosse una consuetudine tutta italiana quella di firmare lettere aperte, quasi sempre per telefono, avendo solo un'idea molto vaga del contenuto delle medesime. Ma vedo che non è così. Non so davvero cosa abbia condotto artisti come Rauschemberg, Cristo, Rosenquiste e il defunto Andy Warhol a firmare, insieme ad altri artisti americani (quindici in tutto) una lettera a proposito del restauro della Sistina...(..) proponendo al Vaticano la sospensione dei lavori..."

Briganti ritiene dunque totalmente fuori luogo la levata di scudi di quelli che definisce "antichi eroi della Pop Art" e rivela che ha sempre pensato, senza tuttavia dirlo, che i pittori anche i più grandi, non fossero le persone "più adatte a capire gli altri pittori e i grandi che li hanno preceduti", e a tale proposito cita

191 Bisogna dire che Conti, polemizzando con il restauro della Sistina, trova il modo di portare continuamente alla ribalta il suo libro che con ogni probabilità, in altro contesto, sarebbe passato inosservato. Conti fa, come si direbbe oggi, pubblicità a costo zero. 
Federico Zeri che gli aveva ricordato quanto misera, e basata su attribuzioni sbagliate, fosse la collezione di quadri antichi di Picasso. Briganti si chiede che autorità abbiano i firmatari della lettera per parlare, visto che la loro opinione si basa sul sentito dire, poiché nessuno di loro ha mai visto il lavoro da vicino ed ha forse "solo sbirciato fotografie di giornali o poco più". Briganti si sofferma anche sulla provenienza degli attacchi e sul fatto che da questi :

"reiterati attacchi contro questo meraviglioso restauro della Sistina - attacchi che provengono tutti, diciamo anche questo, sempre dalla stessa fonte - non emerga mai nulla di nuovo. Se studiamo bene gli argomenti degli oppositori non vi troviamo, in fondo, nessuna accusa precisa, nessuna manomissione $o$ danno documentato : solo accuse, gravissime si, ma generiche e che insistono sempre e soltanto sulla distruzione di presunti ritocchi a secco, di pentimenti, di aggiunte, di velature a colla e di <ultime mani >, la cui esistenza non è, a mio vedere, in alcun modo dimostrata nei fatti. Sono accuse basate soprattutto su di un giudizio estetico che presuppone un' immagine di Michelangelo che personalmente non mi sento affatto di condividere..."

Colalucci è reduce da un viaggio in Canada dove ha fatto una conferenza. Continuano le visite. II 9 marzo visita il cantiere Antonio Cederna noto per le sue campagne di stampa volte a sensibilizzare i lettori sulla salvaguardia dell'ambiente e del patrimonio culturale ${ }^{193}$. Assieme a Cederna salgono sul ponte Desideria Pasolini dall'Onda, e Maria Antonelli, due personalità di spicco di "Italia Nostra"194, l'associazione che dal 1955 si occupa della difesa del territorio. Il 10 marzo Colalucci inizia la pulitura della testa di Eva. Pochi giorni

\footnotetext{
193 Cederna, dagli anni cinquanta del Novecento in poi (era nato nel 1921 e morirà nel 1996) aveva condotto molte battaglie per la salvaguardia del territorio, scrivendo su riviste e giornali come "il Mondo", "il Corriere della Sera", "la Repubblica", e "L’Espresso". Dal 1980 era presidente della sezione di Roma di "Italia Nostra". Nel 1987 viene eletto in Parlamento dove rimarrà fino al 1992 e dove contribuirà alla stesura di leggi a favore della tutela e della difesa del territorio. Si veda tra l'altro A. Cederna "Sritti per Roma" Ed. Palombi, Roma 2008. 
dopo esce sul Corriere della Sera un' altro articolo di Bertelli dal titolo “Lassù in cima alla Sistina"195. In questo articolo Bertelli racconta l'ultima delle molte visite fatte in Sistina e coglie l'occasione per parlare del contenuto di una lettera recentemente inviatagli da Beck. Sul ponte viene accolto da Mancinelli e da Colalucci "..sono sorridenti come li ho sempre visti.." dice lo storico che chiede loro " non sapevo che Beck fosse stato due volte qua" Mancinelli e Colalucci rispondono "oh si, l'ultima volta nel novembre scorso. Si congratulò con noi, partì e poi ci scrisse che non era d'accordo e che dovevamo sospendere i lavori.." Lo storico mette al corrente Colalucci e Mancinelli di aver ricevuto anche lui una lettera da Beck che mira a convincerlo ad andare dalla sua parte:

“..poiché come sai loro (cioè i restauratori) stanno togliendo tutta la colla, fatta come i tuoi amici hanno detto, di colla animale <made from animals $>$ infatti io credo che certi strati di colla siano stati posti da Michelangelo come preparazione per ritocchi a secco e per dare unità all'insieme, come pensa anche Conti che ha maggiori conoscenze tecniche di me".

Un tentativo che fallisce ovviamente e che anzi spinge Bertelli a scrivere questo interessante articolo che entra nel merito delle obiezioni sollevate da Beck, analizzandole e smontandole una ad una. C'è un passo molto significativo in cui lo studioso circoscrive la ragione di tutta quella bagarre ad un argomento preciso :

“.. né Beck né Conti hanno individuato un punto preciso, in tutta la Pittura di Michelangelo finora restaurata o in via di esserlo, dove si trovino colle apposte 
da Michelangelo e non dai suoi restauratori. Conti, l'autorità tecnica cui fa ricorso Beck, nella copertina del suo libro riproduce la testa del profeta Daniele, che non è ancora restaurata, ma che dal ponteggio si può vedere da vicino e appare come un vero campionario di imbratti e grossolani ritocchi.."

Bertelli torna a criticare il testo di Conti, puntando il dito sulla debolezza delle fonti cui l'autore ha basato le sue teorie :

" La fonte cui a sua volta fa riferimento Conti non è rappresentata dall'osservazione diretta delle sezioni <sondaggi dello spessore dell'intonaco dipinto >..(..)..né altri rilievi al microscopio, ma l'autorità d'un manuale scritto nel tardo Cinquecento da un mediocrissimo pittore, Giambattista Armenini. Quello sì che aveva bisogno di colle e nerofumo con cui mascherare le sue magagne...(..) ...in quanto poi allipotesi che uno strato di colla fosse stato steso da Michelangelo per poi dipingervi sopra, non esiste proprio nessun supporto per sostenerla. Un ritocco a tempera si fa <stemperando> i pigmenti nella colla, non dipingendo su uno strato di colla"

Bertelli analizza anche l'ambito culturale che ha generato l'assurda polemica attorno al restauro ed il fatto che essa sia nata in ambito universitario non gli sembra casuale poiché dice quello è "il mondo delle diapositive”. Poi affronta il problema del gusto degli artisti contemporanei ad avvolgere di mistero opere simbolo dell'arte come la Gioconda o la stesa Cappella Sistina. Conclude citando il caso dell'icona di Damasco, un opera veneratissima ma che è proibito vedere :

“..Anche certe icone del nostro tempo, la Gioconda, o la Sistina, debbono esistere invisibili per permetterci di parlarne. In fondo anche l'ultima opera di Andy Warhol non è stata eseguita sulle immagini dell'ultima cena di Leonardo, ma della copia, perduta, che ne aveva eseguito Giuseppe Bossi. C'è da riflettere." 
Più le posizioni a favore del restauro ${ }^{196}$ vengono da voci autorevoli più i dissensi sembrano alimentarsi. II 25 marzo Paese Sera ${ }^{197}$ pubblica un altro pezzo di Manisco, che questa volta tra i suoi bersagli include anche tutti quelli che si sono pronunciati a favore del restauro : dall'Istituto del Restauro al restauratore Tintori ed allo stesso Bertelli che, secondo il giornalista, da Soprintendente avrebbe permesso restauri distruttivi sulle opere di Brera. Ma naturalmente il bersaglio più appetito da Manisco è Colalucci, che tra le altre cose diviene l'oggetto della vignetta satirica al centro della pagina. Credo che prima d'ora nessun restauratore avesse goduto di "tale onore". Manisco nell'articolo usa un discutibile stile da "giornalista d'assalto" cercando di gettare discredito su coloro che accusa. Evidentemente non gli resta altro. Ecco perciò che Colalucci diviene colpevole di aver distrutto- prima di Michelangelo- gli affreschi di Perin del Vaga a Castel Sant'Angelo e la Trasfigurazione di Raffaello. Per la cronaca sottolineo che la pulitura degli affreschi di Perin del Vaga fu rispettosa al punto da conservare tutto l'intervento settecentesco del Mazzuoli, e che la Trasfigurazone di Raffaello non fu restaurata da Colalucci né, come abbiamo visto nel capitolo 3- egli ebbe alcun ruolo in quel lavoro.

L'ultimo articolo di Bertelli evidentemente non passa inosservato neanche oltreoceano, al punto che alcuni degli artisti firmatari della lettera aperta al Papa -probabilmente anche in seguito al duro commento di Briganti su la Repubblica - decidono di andare in Sistina per vedere gli affreschi da vicino.

\footnotetext{
196 Oltre agli articoli citati si veda : D. Del Rio "Quattro passi in paradiso" la Repubblica 8/9 febbraio 1987 - O. Petrosillo "Torna il vero Michelangelo dagli affreschi della Sistina" II Tempo 8 febbraio 1987 - P. Consagra "Un pugno dall'aldilà" il Giornale 8 febbraio 1987 - F. Zoccoli "Sotto il velo c'è proprio Michelangelo" ne II resto del Carlino del 21 febbraio 1987 - A. Pinelli "i colori della disputa" in II Messaggero del 26 febbraio 1987 - Cfr. anche in la Repubblica 8 marzo 1987 G. Del Re "Dall'America nessuna scoperta" A. Pinelli "Ciò che Beck non ha tenuto presente" F. Clerici " non confondiamo l'olio con l'acqua" . Anna Guaita "Il restauro della Sisina è ok" II Messaggero, 17 aprile 1987- Fabio Isman "Achi piace sparlare di Michelangelo" II Messaggero, 2 giugno 1987. 
Dal diario di cantiere del 5 maggio : "Nei giorni passati sono venuti sul ponte alcuni pittori americani e galleristi, di quelli che hanno firmato la petizione al Papa per fermare il restauro." Con queste parole, Colalucci inizia a raccontare la visita degli artisti americani, e prosegue :

"Dialogo tra sordi ed io non ho più pazienza (...) hanno vecchie idee che noi (con Cesare Brandi) abbiamo superato da più di cinquanta anni. Questa gente è fissata per "l'esperienza materica" e ama perciò le muffe, la sporcizia, la casualità delle macchie e dei colori. Vuole ghettizzare Michelangelo in un area quanto più possibile lontana da noi. La sua arte deve essere corposa e misteriosa. Hanno paura forse della mente lucidissima e razionale che ha concepito una Volta complessa nella quale la visione architettonica di Michelangelo si unisce al suo senso plastico, tutto costruito in funzione di un cromatismo sentito sulle grandi superfici e nei grandi spazi. Trovo terribilmente riduttivo costringere Michelangelo ai nostri poveri schemi e alle nostre povere capacità tecniche...(...) Questa esperienza con i pittori americani mi ha lasciato un senso di pena perché ho visto stimati artisti che si lanciano dilettantescamente in un campo, quello del restauro, che non conoscono assolutamente e del quale forse sino a ieri non conoscevano neanche l'esistenza. Ė penoso vedere fino a che punto siano ignoranti in tecnica pittorica (antica) e in tecnica di restauro, di come siano totalmente disorientati pur senza accorgersene, nel vedere per la prima volta da vicino un affresco antico e soprattutto come siano totalmente all'oscuro di una cosa che si chiama teoria del restauro...."

A settembre sulla rivista l'Illustrazione Italiana esce un bellissimo commento sul restauro firmato da Argan "La Sistina come risposta alla Cena"198. Argan legge il nuovo Michelangelo. Si dice certo che il recupero della cromia originale della Sistina possa finalmente portare alla ricostruzione della teoria del colore di Michelangelo. Mette a confronto Michelangelo con Leonardo anzi lo mette quasi in concorrenza:

\footnotetext{
${ }^{198}$ G. C. Argan "La Sistina come risposta alla Cena" a cura di Sabina Orlandi su L'Illustrazione Italiana N ${ }^{\circ} 46$ settembre 1987, pp.22/27
} 
"Probabilmente la volta della Sistina è stata dipinta in diretta polemica a Leonardo , come risposta fiorentina alla Cena di Milano, che era la più famosa delle pitture murali del tempo.."

scrive Argan, e pone l'accento sulle diversità culturali che erano alla base della formazione dei due grandi artisti. Leonardo infatti era un avversario di quel movimento neoplatonico fiorentino al quale invece Michelangelo era vicino dai tempi di Lorenzo il Magnifico. Questa, spiega Argan, era stata la causa della fuga di Leonardo da Firenze alla volta di Milano dove l'artista sentiva di poter affermare la sua visione dell'arte più vicina alla tecnologia ed alla sperimentazione tecnica, che alla filosofia

\begin{abstract}
"Michelangelo non conobbe direttamente la Cena di Leonardo, e non immaginava che la tecnica usata avrebbe portato il dipinto come lo vide il Vasari: poco più di una macchia..(..).Leonardo e Michelangelo avevano già avuto in passato il modo di confrontarsi nella pittura murale : il dipinto di Leonardo rovinò prima di essere compiuto..(..) meno di cinque anni dopo, nella Sistina Michelangelo volle dimostrare che sul muro si poteva dipingere solo a buon fresco.."
\end{abstract}

L'11 settembre sale sul ponte la principessa Margaret d'Inghilterra.

Nonostante le testimonianze di stima che continuano ad arrivare da tutto il mondo, la Segreteria di Stato Vaticana decide di fare fronte agli attacchi violenti (che sembrano non avere tregua), nominando una Commissione di massimi esperti. La Commissione con il proprio appoggio avrà il compito di supportare l'equipe vaticana durante tutta la prosecuzione del lavoro. Gli esperti per questo 
delicato compito vengono scelti tra gli esponenti delle più alte istituzioni nel campo del restauro e della conservazione., italiane ed internazionali :

Prof. Umberto Baldini, Già direttore dell'Istituto Centrale del Restauro, Roma.

Prof. Carlo Bertelli, $\quad$ Università di Losanna.

Prof. André Chastel, $\quad$ Storico dell'arte, membro de l'Institut de France

Prof. Alfio Del Serra, Restauratore Capo del Laboratorio di Restauro di P. Pitti, Firenze.

Prof. P. Luigi De Vecchi, Storico dell'arte, Università di Milano.

Prof. Sidney j. Freedberg, Chief Curator National Gallery of Art, Washington

Prof. Luitpold Frommel, Direttore della Biblioteca Hertziana, Roma

Prof. Micael Hirst, University of London, Courtanld Institute of Art.

Prof. P. Schwartzbaum, Chief Curator Guggenheim Museum di New York Venezia, già Restauratore Capo dell' ICCROM, Roma.

Prof. Norbert Baer, $\quad$ Director Conservation Depart. Inst. of Fine Arts, N.Y. University.

Prof. John Sherman, Harvard University.

Prof. Giovanni Urbani, già Direttore dell'l. C. R. Roma.

Prof. K. Weil-Garris, Institute of Fine Art, New York University.

Prof. Matthias Winner, Freie Universitat Berlin. 
La Commissione si riunisce per la prima volta il 27 novembre 1987, i lavori durano due giorni. Il cantiere è sulla zona che comprende la figura del profeta Ezechiele e quella della Sibilla Cumana. L'apertura dei lavori si svolge nella sala dei Paramenti appositamente preparata con quattro tavoli messi per fare quadrato. Ci sono due proiettori per diapositive $6 \times 6$ e $35 \mathrm{~mm}$ con i relativi schermi . Il discorso di saluto viene fatto dal Card. Baggio. Sono presenti oltre ai Commissari il Marchese Sacchetti, Mons. Marcinkus, il prof. Pietrangeli, il dott. Mancinelli, il dott. Gabrielli e Colalucci. Ci sono inoltre il Segretario Persegati, e la dott.ssa Edith Cicerchia, storica dell'arte e organizzatrice del pranzo di fine lavori ${ }^{199}$. II Card. Baggio chiede ai Commissari di dare a fine lavori un parere preciso sui seguenti punti :

qualità del lavoro, validità delle tecniche di restauro, correttezza della conduzione scientifica, qualità e sufficienza della ricerca scientifica, risultati del restauro. Ai Commissari viene richiesto di dare anche dei suggerimenti. Dopo il discorso di apertura si trasferiscono tutti sul ponteggio in modo da vedere da vicino la campata con la nascita di Eva già restaurata e quella con la creazione di Adamo non ancora toccata. Questo per permettere ai membri della Commissione di valutare in pieno ed attentamente le condizioni degli affreschi prima dell'intervento e la qualità dell'intervento stesso. La seconda tappa della visita è il laboratorio di ricerche scientifiche dove Gabrielli ha allestito sul grande diafanoscopio a parete un pannello illustrativo con le foto a luce di Wood, a 
raggi infrarossi, le stratigrafie e i diagrammi delle analisi chimiche delle colle, delle resine e di tutte le sostanze estranee presenti sugli affreschi. Alla fine della mattinata la Commissione elegge all'unanimità Chastel Presidente che decide di riprendere la riunione nel pomeriggio chiedendo ai responsabili del restauro di preparare nel frattempo alcune integrazioni alle documentazioni già esposte. Chastel chiede notizie su altri restauri simili a quello in corso in modo da prendere visione degli aspetti positivi o negativi delle metodiche adottate.

Bertelli chiede di vedere le documentazioni fotografiche della tecnica pittorica di Michelangelo, in particolare delle zone difficilmente visibili dopo il restauro. Inoltre viene richiesto di vedere le stratigrafie accoppiate alle foto delle zone di prelievo. Colalucci sceglie come zona da presentare la Sibilla Cumana mettendo insieme le foto delle aree di prelievo con i particolari dei punti e le relative stratigrafie. Per quanto riguarda i restauri simili a quelli riscontrati su Michelangelo Colalucci prepara le foto del suo archivio privato con i particolari degli interventi del Mazzuoli da lui documentati nella sala di Amore e Psiche a Castel Sant'Angelo, e gli interventi censori nella sala di Amore e Psiche a Palazzo Spada. Decide anche di mostrare le ridipinture della sala dei Paramenti in Vaticano. Per quanto riguarda i particolari da mostrare a Bertelli sceglie le foto dei capelli degli ignudi,delle orecchie delle mani, dei visi ecc. Prepara anche la serie di dias delle gambe della Sibilla Eritrea con i problemi dei danni dei ritocchi e delle ridipinture. 
Durante il pomeriggio la Commissione si reca sul ponte per vedere gli affreschi illuminati esclusivamente con la luce di Wood in modo da osservare attentamente le zone da restaurare e quelle già restaurate. Vengono chieste delucidazioni sull'uso del Paraloid e sulle intenzioni per la futura conservazione degli affreschi. Colalucci spiega tutto sul Paraloid e sulla metodica che usa per applicarlo in Sistina mentre Gabrielli ne illustra le caratteristiche chimiche.

Alla fine della seconda giornata di lavori tutti si riuniscono nella sede dei Cavalieri del santo Sepolcro per la lettura della relazione finale fatta da Chastel. Sono presenti il Cardinale Baggio, il marchese Sacchetti e monsignor Marcinkus, oltre ai rappresentanti del laboratorio. Tutti sono soddisfatti perché il giudizio sulla conduzione del lavoro e sui risultati è molto positivo. La Commissione, su suggerimento di Mancinelli, propone che a fine lavori sulla Volta, prima dell'inizio del restauro sul Giudizio, venga organizzato un convegno di studi. Viene anche deciso di mantenere sul progetto il massimo riserbo, per dare modo agli organizzatori di lavorare con la tranquillità necessaria. In quella stessa sede Urbani propone di aggiungere alle indagini scientifiche le misurazioni colorimetriche, ${ }^{200}$ da effettuarsi prima e dopo la pulitura, in modo da avere una dato in più per mettere a tacere le contestazioni.

Con l'inizio del nuovo anno iniziano le prove di pulitura sulla scena con la Creazione di Adamo. Qui la situazione è diversa dalla parte di volta fin ora restaurata poiché coincide con la seconda pontata affrontata da Michelangelo. Colalucci appunta che l'intonaco sembra diverso, come impasto e lavorazione, 
e rileva un più ampio uso dell'incisione indiretta rispetto allo spolvero, utilizzato maggiormente nella prima campata. II 19 gennaio 1988 Colalucci annota sul diario di cantiere la notizia della morte di Cesare Brandi, avvenuta il giorno prima. Scrive anche alcune righe in ricordo del suo grande maestro e sottolinea il profondo dispiacere per la sua perdita, con Brandi se ne va irrimediabilmente una parte fondamentale della storia del restauro.

L'8 febbraio torna la troupe dell'NTV. Si sta lavorando sul Dio Padre della Creazione. Colalucci nota che la pulitura di questa campata crea meno problemi rispetto alla parte di volta fin ora affrontata. Gli sembra di essere tornato alle lunette. L'affresco è forte e smaltato, non ci sono pentimenti né rifiniture a secco. La sera prima Colalucci ha parlato al telefono con Carandente, da poco nominato direttore della XLIII Esposizione Internazionale d'Arte, la Biennale di Venezia, che è interessato ad un progetto da realizzare per il giorno dell' inaugurazione della mostra. Carandente vorrebbe proiettare, nel salone con la cupola dipinta da Galileo Chini, che è propriamente l'ingresso del Padiglione Italia, alcuni momenti del restauro della Sistina portando il restauro di Michelangelo tra i pittori moderni. Vedremo in seguito che il progetto sarà realizzato. Intanto in Sistina si sta mettendo l'impianto di illuminazione nuovo. A Colalucci non piace perché la luce è eccessiva e verdastra. E' convinto che nelle giornate di sole la luce artificiale sia inutile, ed appunta di fare una nota in proposito al Direttore ed a Mancinelli. II 15 fa il programma per il proseguimento della pulitura sulla Creazione, disponendo di continuare con la 
testa di Adamo, con il braccio e l'avambraccio sinistro, con i gruppi di putti, con la figura attorno al Dio Padre, con il mantello, e con il Dio Padre. Programma di terminare la pulitura con il particolare delle "dita che si toccano". Nel frattempo il giorno 19 iniziano le operazioni di allestimento delle apparecchiature per il prelievo dei campioni di aria che serviranno per l'analisi dei gas inquinanti. Le dita che si toccano, vengono pulite il 25 febbraio davanti alle cineprese della NTV e a un piccolo gruppo di persone tra cui il prof. Pietrangeli, Rotondi, Mancinelli e monsignor Marcinkus, poichè Colalucci ha pensato di dare rilievo all'avvenimento. Del resto il dettaglio delle dita costituisce il pezzo più famoso di tutta la volta anche se non è un brano di pittura particolarmente alto (tra l'altro le due falangi dell'indice e le prime due del medio e dell'anulare della mano sinistra di Adamo sono il frutto del restauro del Carnevali). Pochi giorni dopo, sul ponte ci sono il fotografo ed una inviata della rivista americana Life che conta di pubblicare un articolo sul restauro nel mese di giugno ${ }^{201}$. II fotografo è Enrico Ferorelli che, terminato il servizio, lascia scritta sul diario questa riflessione : "I pellegrini, i religiosi, gli storici, i romani ed i fotografi vi saranno grati del vostro lavoro per secoli ; finché la polvere non risporcherà noi, voi ed il dipinto. Con ammirazione"

II giorno 24 marzo, mentre si procede alla rimozione della stuccatura che taglia longitudinalmente la base del collo dell'ignudo alla sinistra della Sibilla Persicha eseguita dal Carnevali, il restauratore Maurizio Rossi scopre un frammento di affresco originale affogato sotto la malta. Poiché il Carnevali è intervenuto nel 1570, il frammento, che proviene dalla zona in ombra dell'ignudo, testimonia 
l'effettivo stato dell'affresco a quella data. Naturalmente il frammento risulta in tutto simile, nei colori e nella superficie, a quello che si va recuperando con la pulitura. Questa è un ulteriore prova della correttezza del lavoro in corso. II frammento ritrovato misura circa $5 \mathrm{~cm}$ per lato ed è trattenuto da chiodi in ferro normalmente adoperati dal Carnevali per armare la malta usata per i risarcimenti. Data l'importanza documentaristica del ritrovamento, Colalucci propone di lasciare il frammento così come è stato ritrovato, sistemando di conseguenza la lacuna attorno, per renderla esteticamente accettabile.

Il 10 maggio iniziano le riprese per il filmato destinato alla Biennale. La regista è Anna Zanoli, che è anche storica dell'arte, il direttore della fotografia è un mostro sacro del cinema Carlo di Palma (il preferito di Woody Allen). II film viene realizzato con la concessione della Nippon Television N.T.V che ha l'esclusiva sulle immagini ${ }^{202}$. Circa due settimane prima dell'apertura della mostra di Venezia, su la Repubblica esce un lungo articolo-intervista a Carandente. La giornalista Natalia Aspesi ${ }^{203}$ apre così :"La vecchia Biennaled'arte, edizione $n^{\circ} 43$ e tra sette anni centenaria, avrà il suo scoop" poi lascia spiegare a Carandente di cosa si tratterà :

"Nei giorni della vernice..(..)..attraverso otto monitor, potremo vedere la pulitura degli affreschi di Michelangelo e Gianluigi Colalucci, mentre riporta ai suoi veri colori il Padre Eterno. Così quelli che hanno protestato contro $i$ restauri saranno zittiti e resteranno incantati".

\footnotetext{
${ }^{202}$ La N.T.V detiene l'esclusiva mondiale sulle immagini fotografiche e cinematografiche delle pitture di Michelangelo nella Cappella Sistina. La N.T.V mette a disposizione gratuitamente per questa iniziativa l'archivio del materiale grezzo girato sulla Creazione d'Adamo. 
Nell'introduzione al catalogo ${ }^{204}$ intitolata "/l luogo degli artisti" Carandente specificava : "il brano Michelangiolesco che appare sul video è quello della Creazione dell'uomo, un tema che gli artisti contemporanei troveranno di agevole riferimento alla loro stessa ininterrotta nel tempo creatività" E ad apertura del catalogo della mostra mise come prima immagine una foto di Colalucci al lavoro sull'affresco della Volta. Questo coinvolgimento degli artisti, dai quali erano partite alcune delle contestazioni, a verificare per mezzo del video, portato nel luogo deputato delle loro mostre, le operazioni di restauro della Sistina, ebbe uno straordinario effetto di chiarificazione. L'iniziativa di Carandente ebbe un successo enorme. I visitatori che venivano intervistati dalle televisioni e dalla radio all'uscita della mostra, si dicevano estasiati ed emozionati di fronte ai risultati della pulitura. Qualcuno paragonò la visione della testa di Adamo che emergeva poco alla volta dallo sporco, attraverso i gesti calmi e ritmati delle mani di Colalucci a quella di un parto.

II video registrato rimase visibile a ciclo continuo per tutta la durata della mostra, e fu visto da 300.000 visitatori. Nel video era presentata e nominata tutta l'equipe vaticana che lavorava con Colalucci e Mancinelli, di cui non si disse più che fosse giapponese. II commento fuori campo era fatto da Colalucci stesso. Anna Zanoli gli chiedeva di chiarire, sulle immagini che scorrevano, quelle operazioni che descritte con le sole parole sui giornali avevano creato dei dubbi. Nel video si chiarì per esempio che l'aspetto innaturale della superficie 
dipinta, che a volte il pubblico dal basso coglieva, era il frutto dell'effetto delle luci di servizio o delle lampade termiche ${ }^{205}$.

II settimo diario della volta inizia il 30 maggio 1988, si sta lavorando alla scena della separazione della terra dalle acque. La scena è attraversata da una serie di crepe di varia misura fino a quella che ha prodotto sulla mano sinistra del Dio padre una larga caduta di intonaco reintegrata in affresco dal Carnevali in due giornate ( una per il cielo, ed una per la mano).

Verso la fine dell'anno Beck torna ad animarsi dalle pagine del settimanale l'Espresso ${ }^{206}$. Lo storico usa lo "stile" e gli argomenti di sempre, ma questa volta chiede addirittura di essere ricevuto dal Papa. Dalle pagine del settimanale lancia un appello :

“Dal 1980 a oggi i restauratori della Cappella Sistina hanno rifatto le pareti della Cappella. Chiedo a tutti, a partire da Giovanni Paolo II, che, prima di incominciare a ripulire il Giudizio Universale, i restauri si fermino per qualche anno..”.

E' assai interessante notare come la stampa, anche quella generalmente seria, riesca ancora a dare spazio a Beck, e a divulgare notizie senza l'opportuna verifica. Nell'articolo in questione per esempio Beck accusa direttamente il Vaticano dicendo :

"Qualche anno fa i giapponesi hanno avvicinato i responsabili delle collezioni d'arte vaticane, ed hanno proposto di finanziare il restauro della Sistina ..."

\footnotetext{
${ }^{205}$ Cfr. Anna Zanoli "Il tradimento della luce" Giornale dell'Arte, luglio-agosto 1988 
Una notizia totalmente falsa che il giornalista Melega avrebbe avuto il dovere di verificare prima di pubblicarla. Come abbiamo visto infatti, il Vaticano cercò una televisione, disposta a documentare l'intera fase di pulitura, soltanto a lavoro già iniziato e dopo la presentazione ufficiale della prima lunetta restaurata. Quanto ai giapponesi, la NTV fu scelta dopo i ripetuti rifiuti avuti dalle TV italiane, i cui interessi non coincidevano con l' esigenza di documentare per intero la fase di pulitura degli affreschi. Poi Beck continua :

"Convinti di far bene, quei responsabili hanno detto di sì, e il Papa si deve essere fidato. Poi i lavori sono cominciati, circondati da grande segretezza.."

Anche in questo caso le accuse sono facilmente smontabili confrontando date e firme sui diari di cantiere. Se il giornalista avesse verificato, avrebbe scoperto che il cantiere della prima lunetta fu visitato da 117 persone, e che tra quelle persone vi erano stati gli storici ed i restauratori dell'Istituto Centrale del Restauro e molti altri, con i quali in quegli otto mesi di lavoro, Colalucci ed $\mathrm{i}$ responsabili del restauro avevano ripetutamente cercato il confronto. L'articolo di Melega si dilunga sulle ormai note accuse, riprese anche nella scheda di Toti Scialoja pubblicata al centro pagina. Ormai Beck e suoi seguaci sono costretti ad alzare i toni delle accuse per avere spazio e per tentare di trascinare nella bagarre i responsabili del restauro. Naturalmente non ci riusciranno e con il passare del tempo rimarranno sempre più isolati. Viene spontaneo mettere a confronto lo stile ed il contenuto dell'articolo appena citato con quello apparso 
sullo stesso settimanale quasi sei anni prima e firmato da Fabrizio Dentice e da Giulio Carlo $\operatorname{Argan}^{207}$.

Nella primavera del 1989, quando i lavori della Volta sono arrivati alla fine, Anna Zanoli realizza un servizio ${ }^{208}$ per una delle rubriche più seguite della RAI : Tg1 sette. Le riprese riguardano la pulitura di una delle scene più spettacolari della Volta : "La separazione della luce dalle tenebre" che con i suoi forti contrasti di colore offre lo spunto per affrontare il tema dell'origine del cangiante. II confronto, offerto nel servizio, con il Tondo Doni dipinto da Michelangelo prima della Sistina, riesce a chiarire anche i dubbi più persistenti.

Per celebrare la fine del restauro della volta, viene realizzato anche un altro servizio televisivo a cura di Nino Criscenti dal titolo "Dentro la Sistina" ${ }^{209}$ che vede coinvolti come voci a favore del restauro personaggi come E.Gombrich, G. Briganti e F. Zeri, e come voci contrarie J. Beck.

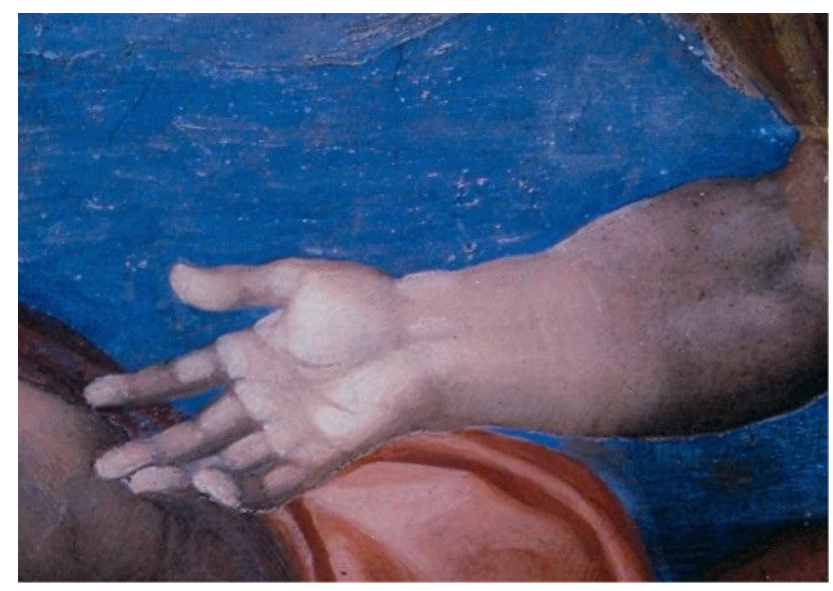

Michelangelo -un particolare del Giudizio Universale

\footnotetext{
207 Op. cit.

208 |l servizio dal titolo "Il colore di Michelangelo" andò in onda su RAI 1 il 2 maggio 1989 alle ore 20,30 


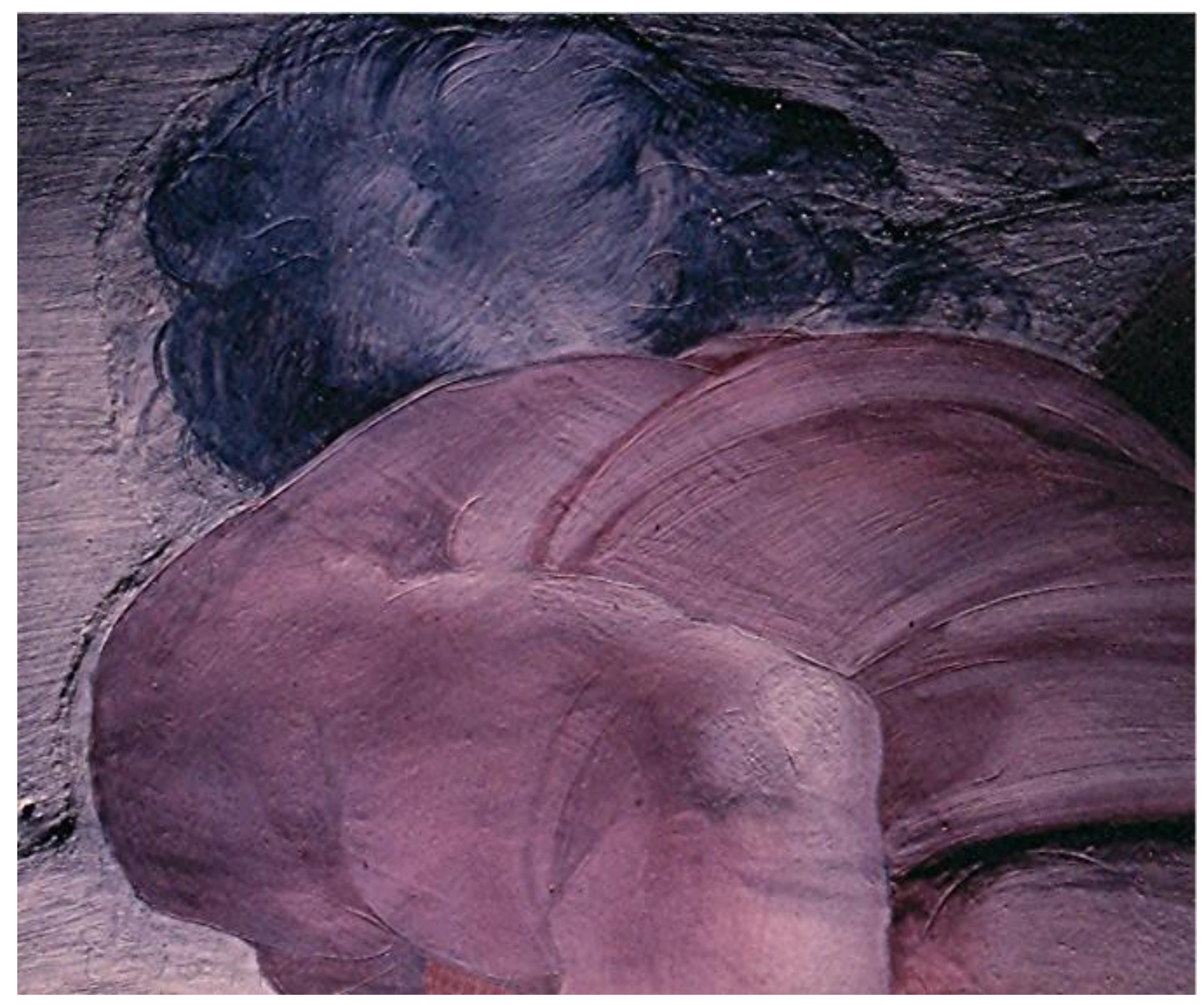

Michelangelo "La separazione della luce dalle tenebre" particolare della figura del Dio Padre a luce radente 


\section{Giudizio Universale}

II primo dei tre diari del Giudizio inizia il 23 novembre del 1989, con il verbale della riunione preliminare tratto dall'ultimo diario della volta. I tre diari coprono l'arco di tempo lungo quattro anni che si conclude il 24 marzo 1994 con la fine del lavoro.

Davanti al giudizio c'è una intelaiatura di tubi che servirà a sostenere i piani per eseguire alcune prove di pulitura da mostrare nel corso dell'imminente Convegno. Il Convegno internazionale di studi si svolge nel marzo del 1990 con lo scopo di creare un raccordo tra quanto fatto, cioè il restauro della volta, e quello che dovrà venire, cioè il restauro del Giudizio. È organizzato in grande stile, sotto il patronato dei Musei Vaticani, con il contributo finanziario della NTV, e la collaborazione dell'Istituto della Enciclopedia Italiana, della Wethersfield Foundation, della Kress Foundation e della Texas Instruments Corporation. Vi prendono parte i più alti specialisti nel campo della conservazione degli affreschi, della scienza del restauro e gli studiosi di Michelangelo. Nel corso di una settimana, si susseguono gli interventi di Baer, Baldini, Bertelli, Botticelli, Chastel, Cordaro, Dalai, Del Serra, De Vecchi, Freeberg, Frommel, Giantomassi, Hartt, Hirst, Sherman, Tabasso, Weil Garrii Brandt, Winner, e molti altri oltre a quelli dei responsabili del restauro Mancinelli, Colalucci e Gabrielli $^{210}$. La giornata di apertura è pubblica e si svolge nella sala dei "Cento Giorni" nel Palazzo della Cancelleria. Le altre giornate, nella Biblioteca di Sisto

\footnotetext{
${ }^{210}$ Per la lista completa degli interventi si veda "Michelangelo la Cappella Sistina" Atti del Convegno internazionale di Studi - marzo 1990, a cura di Kathleen Weil Garris Brandt, ed. Istituto Geografico De Agostini, Novara 1994.
} 
IV in Vaticano, si svolgono di fronte ad un pubblico di invitati. II compito di aprire la conferenza plenaria tocca a Chastel, decano degli studi sul Rinascimento. II suo discorso introduttivo è un capolavoro di stile e vivacità intellettuale. Colalucci parla alla fine della mattinata. II suo forse è l'intervento più atteso. La sala è pienissima, ci sono persone in piedi e molte altre accalcate fuori che non riescono ad entrare e che cercano di vedere e di sentire qualcosa. Come al solito Colalucci non legge la sua relazione ma parla "a braccio" e questo rende la sua esposizione più viva. Illustra il lavoro fatto fino a quel momento con l'aiuto delle diapositive che monta, come di consueto, su due proiettori per avere contemporaneamente le immagini prima e dopo il restauro. Parla con tranquillità e trasmette la sicurezza di chi, come gli diranno in seguito, "ha la materia nelle mani". Il silenzio si rompe ogni tanto con le esclamazioni di ammirazione del pubblico, quando sullo schermo scorrono le immagini dei particolari della Volta restaurata. Le spiegazioni di Colalucci non sono mai scontate, sono chiare e dettagliate senza essere noiose. Non è scontato neanche il modo in cui chiude la sua relazione, dedicando i nove anni di quel lavoro alla memoria del suo maestro Cesare Brandi da poco scomparso.

Dopo il Convegno, gli studi preliminari sul Giudizio e le relative prove di pulitura, terranno impegnata tutta l'equipe per circa sette mesi. Per l'identificazione delle figure Colalucci decide di seguire lo schema fatto dal Biagetti che divide il giudizio in 11 zone corrispondenti ad altrettante lettere dell'alfabeto. Nello schema, le figure di ogni zona sono siglate con numeri progressivi, dunque ogni 
personaggio è identificato con la lettera della zona cui è inserito ed il numero di appartenenza. Alle 10,45 del 4 dicembre Colalucci inizia la prima prova di pulitura sulla figura 24 del settore C. La prova è eseguita con ammonio carbonato e carta giapponese. I tempi di contatto del solvente sono brevi, circa due minuti, ed i risultati sono subito entusiasmanti. Due giorni dopo, le prove vengono esaminate ed approvate da Pietrangeli, Mancinelli e dalla W. Garris. Per sottolineare l'avvenimento e dare inizio ufficialmente alle prove di pulitura in cantiere si brinda.

Nel frattempo, anche per l'impatto mediatico seguito al Convegno ed alla presentazione della volta restaurata, Beck visita la Sistina e poco dopo scrive a Colalucci $^{211}$. Colalucci, nonostante tutto, risponde in modo gentile allo studioso, dicendo che considera sempre positivo il dialogo e lo scambio di idee, anche se queste nascono da posizioni inconciliabili come le loro.

"Il lavoro del restauratore" scrive Colalucci a Beck "si incentra nello studio della materia di cui si compone l'opera d'arte e da questo studio egli trae le sue conoscenze, rifuggendo, per quanto possibile, da interpretazioni personali. (..)..il nostro lavoro in Sistina è stato attentamente e liberamente seguito da storici dell'arte e da restauratori che ci hanno aiutato con stimolanti e preziosi pareri, per questo motivo ho sempre preso in considerazione anche le sue obiezioni e le sue critiche, che, depurate da quelle accuse in cui mi era impossibile riconoscermi, ho sottoposto a puntuale verifica..(..)Mi sarà gradito incontrarla ancora in una atmosfera più serena e responsabile per dibattere $i$ temi che ci stanno a cuore" 212

Vedi allegati Doc. B.2/90

La lettera di Beck è datata 13 luglio 1990 , la risposta di Colalucci 26 luglio. Archivio Colalucci - sezione documenti (F.9 - serie 6) vedi allegati Doc. B.3/90 
Un mese dopo Colalucci riceverà una nuova lettera di Beck, sempre con gli stessi appelli a fermare il restauro ${ }^{213}$.

II 12 novembre 1990, davanti alle telecamere della NTV Colalucci inizia a pulire la figura B 5 corrispondente all'angelo di sinistra del lunettone destro. La pulitura viene effettuata con ammonio carbonato in carbossilmetilcellulosa con un tempo di contatto di circa 9 minuti - lavaggio con acqua satura di ammonio carbonato- lavaggio finale con acqua distillata. Naturalmente il metodo di pulitura nel corso del lavoro subirà alcune variazioni dovute alle diverse situazioni presenti sul Giudizio, più complesse di quelle incontrate sulla Volta. II Giudizio è più ritoccato e più danneggiato. Oltre ai celebri interventi censori di Daniele da Volterra vi sono le ridipinture di Domenico Carnevali, quelle del Camuccini ${ }^{214}$, gli interventi del Mazzuoli ecc. Nonostante ciò la materia che affiora da sotto lo sporco è sempre fonte di grande emozione per tutti. A dicembre Colalucci comincia ad affrontare il problema del cielo di lapislazzuli. Un problema che lo terrà impegnato per molto tempo e che richiederà la messa a punto di un metodo di pulitura molto particolare e delicato . II 2 gennaio 1991 sul diario viene riportata la notizia della morte del Prof. Rotondi.

In cantiere si lavora attorno al problema dell'azzurro del cielo. Colalucci scrive che bisogna fare altre indagini stratigrafiche e microscopiche, e che bisogna indagare a fondo su uno strato di azzurro nerastro che giace a tempera

\footnotetext{
${ }^{213}$ Vedi allegati Doc. B. 4/90 
sull'azzurro in affresco. II 5 febbraio, appena rientrato da Leningrado, inizia a pulire -davanti alle telecamere della NTV- la figura A21 e le teste delle figure A16 e A18. La messa a punto del metodo di pulitura dell'azzurro presenta ancora delle difficoltà che richiedono tempo e riflessione. Vi è ad un certo momento, una diversità di vedute tra il chimico Gabrielli e Colalucci.

Il primo non vede di buon occhio l'uso dei metodi acquosi per la pulitura del cielo, mentre Colalucci è convinto che il problema non sia dovuto all'uso dell' acqua quanto l'azione meccanica degli strumenti adoperati per stendere il solvente.

II 15 febbraio Beck scrive nuovamente a Colalucci ${ }^{215}$. II tono della lettera è aspro poiché lo storico dice aver appreso da un "amico pittore" che Colalucci nasconderebbe alla stampa le sue numerose visite in Sistina. La replica non si fa aspettare. Con il solito stile pacato ma fermo Colalucci risponde a Beck dicendo:

"..a tutti coloro che me lo hanno chiesto, giornalisti compresi, ho sempre parlato delle sue visite sui ponteggi e più recentemente del nostro incontro in Cappella Sistina. Francamente farei un torto più a me stesso che a lei se dovessi ricorrere alla menzogna o alla denigrazione nei suoi confronti, per sostenere la bontà del mio lavoro. Temo che lei abbia incontrato persone che si divertono a farla arrabbiare..(..) ella ha dimenticato di dirmi il nome dello stimato artista gentiluomo che le ha detto una simile falsità. Posso capire il suo stato d'animo ma le minacce se le poteva risparmiare, e per favore non scendiamo sul piano personale! ?216. $^{216}$

\footnotetext{
${ }^{215}$ Vedi allegati Doc.B.5/91
} 
Qualche giorno dopo Beck risponde ringraziando Colalucci, e dicendo anche che non gli sembra il caso di rivelare il nome del pittore, perché con lui in realtà non ha mai avuto un rapporto diretto ma sempre mediato da altre persone... ${ }^{217}$ Lo storico chiude la lettera chiedendo a Colalucci un parere sull' articolo appena scritto per il Giornale dell' Arte ${ }^{218}$. L'articolo "spara a zero" sul restauro italiano e contiene una singolare "bozza per la difesa delle opere d'arte" pensata dallo stesso Beck

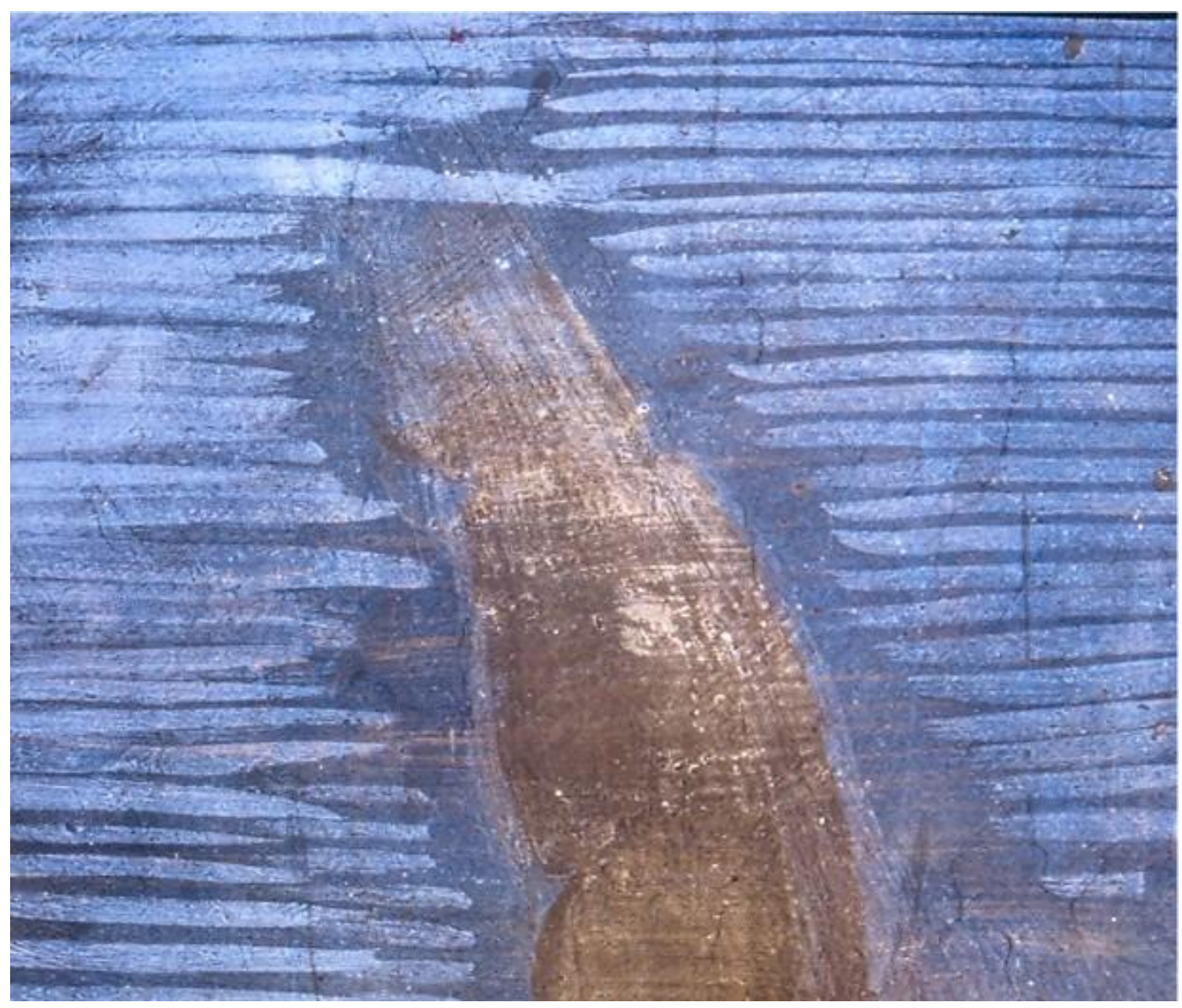

Michelangelo- "Giudizio Universale" particolare delle striature chiare del cielo di lapislazzuli

\footnotetext{
${ }^{217}$ Vedi allegati Doc. B.7/91

${ }^{218}$ Cfr. Beck "la mia carta dei diritti delle opere d'arte" e "ll decalogo di Beck" in Giornale dell'Arte, n 87, marzo 1991, p.38.
} 
II punto più terrorizzante della bozza riguarda la possibilità di dividere le opere d'arte in fasce d'importanza (corrispondenti a categorie $A-B-C$ ), in base alla quale le opere di classe $\mathrm{C}$ possono venire sacrificate, per essere rimpiazzate da opere contemporanee. Risponde Colalucci:

"Egregio Professor Beck..(..)..io che sono uno dei più vecchi allievi di Cesare Brandi, ritengo che per bene operare e fare scelte corrette sia sufficiente attenersi al dettato della sua teoria del restauro. Quella di Brandi è un filosofia tuttora insuperata e lo stanno a dimostrare $i$ successivi tentativi di aggiornamento che, se pure apprezzabili sul piano dell'intenzione, sono risultati a parer mio vuoti di contenuto quando non addirittura dilettanteschi. La sua idea di dividere le opere in categorie mi sembra molto rischiosa, specie per la categoria $C$ che, se ho ben capito, potrebbe essere sacrificata per fare posto ad opere moderne. Un concetto del genere potrebbe avere effetti devastanti specie in architettura e in urbanistica. Infine per quanto riguarda l'idea di una super commissione e della sua stravagante formazione, ho il sospetto che anche lei la consideri più una provocazione che una via praticabile e valida. lo personalmente se mi ammalassi non vorrei essere curato da un'equipe formata da un avvocato, un sociologo un senatore un padre di famiglia..(..).. ma sceglierei un buon medico e poi in caso chiederei un consulto dei migliori specialisti. ${ }^{219}$

A marzo Colalucci e Mancinelli vanno a Parigi per una conferenza e una tavola rotonda sul restauro. All'inizio di aprile il lavoro prosegue con la rifinitura della pulitura del lunettone di sinistra per poi passare alla rifinitura di quello di destra. Colalucci si occupa personalmente del cielo. II 4 maggio visitano il cantiere i reali di Svezia.

${ }^{219}$ Lettera del 21 marzo 1991. Archivio Colalucci - sezione documenti ( F. 9 - serie 6 ) vedi allegati Doc. B.8/91 
Contemporaneamente al restauro in Sistina si stanno facendo le operazioni preliminari per il posizionamento dei sensori che serviranno a controllare il ricambio dell'aria. II 29 maggio Colalucci riceve a New York la laurea Honoris Causa of Doctor of Fine Arts alla N.Y. University. La seconda laurea Honoris Causa gli sarà conferita nel 1995 dalla facoltà di Conservazione dei Beni Culturali della Università Politecnica di Valencia a riconoscimento di un percorso umano e professionale esemplare, la stessa Università nel 2003 gli intitolerà una strada nel campus universitario.

Continuano le visite da tutto il mondo, l' 11 settembre visita il cantiere la principessa Margaret d' Inghilterra, e qualche tempo dopo il 22 novembre è la volta della regina Sofia di Spagna ${ }^{220}$.

Il secondo diario del Giudizio inizia il 2 dicembre 1991. Si lavora sulla figura D 21. Colalucci è concentratissimo e come sempre, oltre ad occuparsi del lavoro, deve coordinare gli spostamenti della troup della NTV. II 9 marzo 1992, si affronta la figura D72 corrispondente alla pelle di San Bartolomeo. È dipinta in buon fresco con pennellate rapide con pennello grande a setole aperte. La parte della giornata successiva verso il basso, comprende parte delle gambe ed è dipinta a secco sul cielo. II colore a secco sale anche verso l'alto, sulla destra del braccio -a destra di chi guarda- e lungo la gamba di sinistra. Si rileva anche lo stato di conservazione di altre figure tra cui la M41 corrispondente al Biagio da Cesena. La figura ha un aspetto untuoso, scuro e presenta delle ripatinature 
di parti più chiare - fronte ,naso, bocca, guance e spalla destra- come se li fossero state fatte delle prove di pulitura poi ricoperte. Nei mesi successivi si procede con la pulitura e la rifinitura. Subito dopo l'estate, all'inizio di settembre, di fronte alle telecamere della NTV si pulisce il gruppo degli angeli tubicini.

II 10 settembre torna la principessa Margaret d'Inghilterra.

II 12 e 13 ottobre si riunisce il Comitato internazionale per prendere visione dell'andamento dei lavori. Colalucci prepara il suo intervento corredato da diapositive e organizza il ponte per accogliere i commissari per la discussione davanti all'affresco. Il giudizio del Comitato sul lavoro sarà molto favorevole.

Desterà invece qualche preoccupazione il sistema di controllo della climatizzazione per il quale verrà richiesto un perfezionamento.

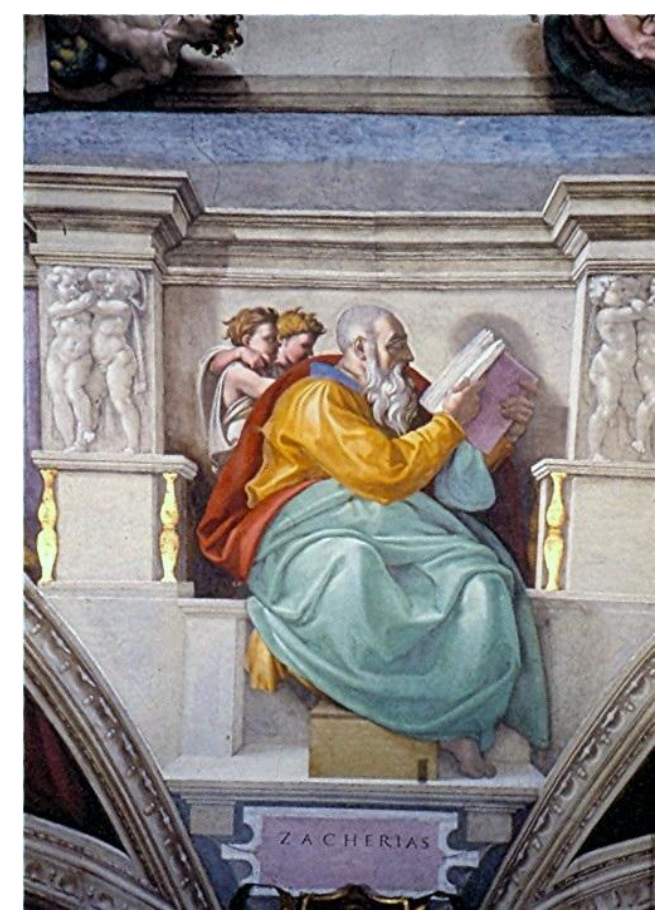

Michelangelo -II Profeta Zaccaria 


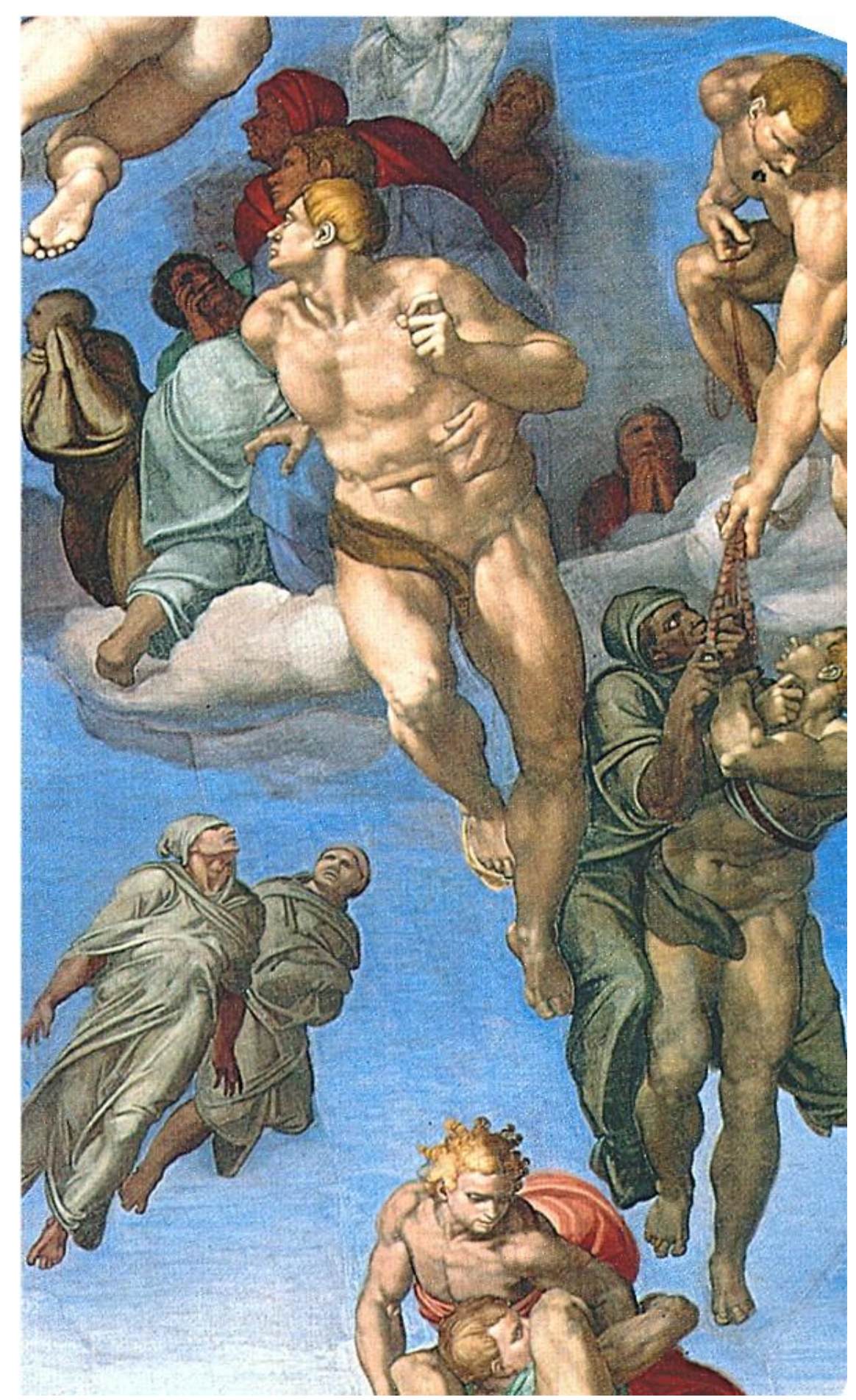

Michelangelo- Giudizio Universale particolare 
Il terzo diario del Giudizio inizia il 15 febbraio 1993, si sta procedendo al rilevamento delle figure $\mathrm{H} 25$ ed $\mathrm{H} 26$. Colalucci un mese prima ha ricevuto un importante testimonianza di stima da un "mostro sacro" della storia dell'arte : John Pope-Hennessy. Lo studioso scrive a Colalucci una lettera di ammirazione per i risultati del lavoro 221 . Colalucci risponde :

"..le sue parole rappresentano per me e per tutti coloro che insieme a me sono impegnati in questo lavoro di restauro, il più alto riconoscimento ad un impegno che ci ha visto talvolta nella bufera delle incomprensioni e delle critiche sferzanti, amplificate da mass media assetati di scandali ..."222.

II 16 febbraio, Colalucci continua a pulire il cielo sulla sinistra della figura di Caronte. Bagnando il manico del remo, chiaramente ridipinto, appaiono le lettere D.C. ed una data che sembra essere 1566 - forse la firma di Domenico Carnevale ${ }^{223}$ - La figura di Caronte scrive sul diario Colalucci :

"..è veramente impressionante con questo suo colore verdastro e nerastro. Ricorda i demoni enormi che sono piazzati in quei padiglioni coperti, davanti ai templi buddisti in Giappone. Quelli però sono un po' caricaturali e direi, ironiciquesto invece è drammatico."

La pulitura di Caronte continua nei giorni successivi e prosegue sulla barca del demone. La barca è in cattive condizioni perché è molto modificata nella forma

\footnotetext{
${ }^{221}$ Vedi allegati Doc. P-H 1/93

${ }^{222}$ La lettera di Pope-Hennessy è datata 9 gennaio 1993, la risposta di Colalucci 30 gennaio 1993. Archivio Colalucci - sezione documenti (F.9 - serie 6 ) vedi allegati Doc.P-H 2/93 
e nell'aspetto dai numerosi interventi di restauro. II 22 vengono fatti dei prelievi sul cielo dal prof. Chiari dell'Università di Torino.

Il 13 marzo visitano il cantiere i reali d'Olanda in compagnia di Gianni e Marella Agnellii ${ }^{224}$.

Il 16 si sta ancora cercando di identificare la natura del solvente all'origine delle striature biancastre che segnano orizzontalmente il cielo. Su suggerimento del prof. Chiari, Colalucci prova a riprodurre il sistema antico della pulitura con la cenere, ma ottiene un risultato scarsissimo. II chimico consiglia di aumentare la basicità della cenere bollendola. II risultato questa volta è leggermente più incisivo anche se, come nota Colalucci, è decisamente lontano da quello della pulitura settecentesca. II 25 giugno si rileva lo stato di conservazione della figura D 60 corrispondente al Cristo giudice, ed il 30, davanti alle telecamere, si inizia la pulitura partendo dalla mano e dall'avambraccio. Sul ponte, oltre alla troup giapponese ed al fotografo Okamura, ci sono i fotografi di National Geografic. II giorno seguente Colalucci inizia la pulitura della testa di Cristo precedentemente oltre al braccio aveva pulito metà petto e la parte alta dei capelli. 


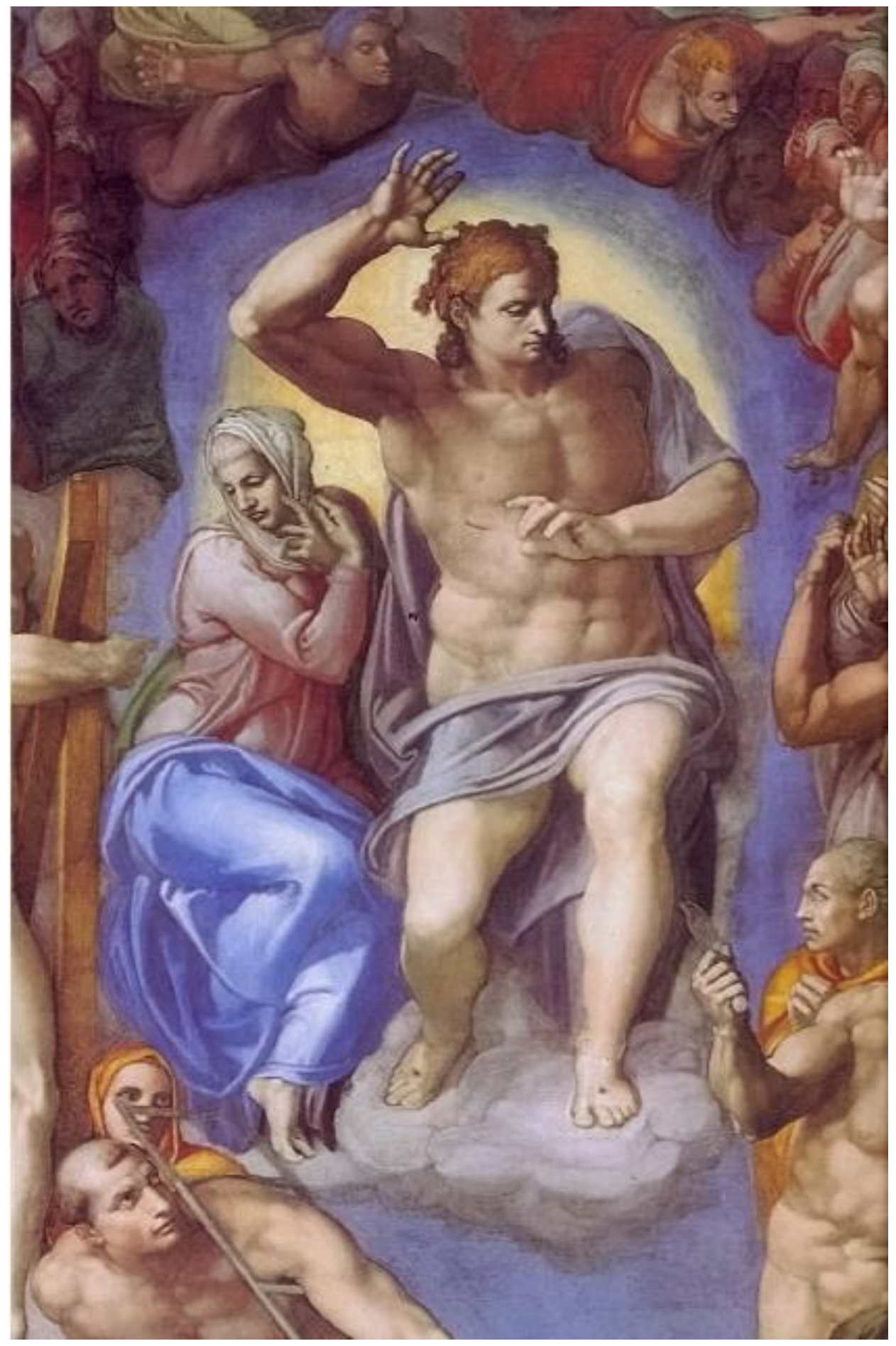

Michelangelo - "Il Cristo Giudice "del Giudizio Universale 
La pulitura si conclude il 7 , ed il giorno seguente in cantiere si festeggia l'avvenimento.

Durante l'estate di quell'anno, precisamente la notte del 23 luglio, la mafia fa esplodere due bombe a Roma che danneggiano gravemente la Basilica di San Giovanni in Laterano, e la chiesa di San Giorgio in Velabro. E perciò da quel momento in poi Colalucci, dovrà aggiungere alla sua già impegnativa attività di capo restauratore (poiché oltre al cantiere della Sistina che lo impegna quotidianamente, deve mandare avanti la normale attività del laboratorio di restauro e gestire le emergenze) si andrà ad aggiungere la progettazione e l'organizzazione del restauro della Loggia della Basilica Lateranense. Per il Laboratorio, tra l'altro, si sta occupando di un altro importante lavoro, cioè la pulitura del San Girolamo di Leonardo.

L'8 settembre visitano il cantiere l'Imperatore e l'Imperatrice del Giappone, ed il 13 torna ancora una volta la principessa Margaret d'Inghilterra. II 27 novembre sale sul ponte Carlo Azelio Ciampi (che sarà Presidente della Repubblica dopo Oscar Luigi Scalfaro). Nei mesi che seguono, il lavoro continua a ritmo più sostenuto. Si cominciano le rifiniture e le revisioni delle parti già finite, in vista della chiusura definitiva. Purtroppo in questo momento tanto importante il cantiere si trova privato del supporto fondamentale di Fabrizio Mancinelli che all'inizio del 1994 si ammala gravemente. II 2 febbraio il diario riporta il verbale della riunione tenutasi in cantiere per decidere, in base agli studi condotti, la 
rimozione degli interventi censori. Pietrangeli decide di esaminare le braghe una per una in modo da stabilire quelle da rimuovere e quelle da conservare. Per facilitare l'identificazione si utilizza un grafico preparato dal Gabinetto di ricerche scientifiche, che riporta gli interventi censori siglati con un numero. Dopo aver ascoltato il parere di tutti, viene deciso di conservare interamente gli interventi cinquecenteschi, e di rimuovere quelli sette/ottocenteschi, lasciandone quattro come campione storico. Colalucci riprende a scrivere il diario il 27 febbraio, è domenica ed è al lavoro. La fase conclusiva del cantiere è come sempre molto impegnativa, purtroppo Mancinelli è ancora malato e fa fatica a riprendersi e tutti sono molto preoccupati per lui. Colalucci in particolare vive questa vicenda con molta ansia, poiché è molto legato a Mancinelli. Trova profondamente ingiusto il fatto che, per la malattia che lo ha colpito, Mancinelli non possa avere la serenità di raccogliere i frutti di quei lunghi quattordici anni di lavoro. In cantiere nel frattempo si riducono di misura i tasselli di sporco, che erano stati lasciati come campioni. In questo momento le visite si intensificano perché si sa che quelli sono gli ultimi giorni per poter vedere da vicino il Giudizio. Colalucci lavora mattina e pomeriggio e, ancora durante la fase di smontaggio del ponte, con Bonetti e Rossi fa gli ultimi ritocchi. L'11 marzo la Rai 1 riprende gli affreschi da vicino prima dello smontaggio definitivo del ponte, così da avere il materiale da mandare in onda in occasione dell'inaugurazione. Mancinelli nel frattempo si è leggermente ripreso e 
fortunatamente, anche se con molta fatica, riesce a trovare la forza di andare in cantiere per l'intervista con la RAl, anche se tre giorni prima aveva dovuto rinunciare all'intervista con Anna Zanoli all'interno di un servizio da lei realizzato per la rubrica "Bellitalia" a cura di RAI 3. In questo servizio furono intervistati Gabrielli e due studiosi di Michelangelo il teologo Romeo De Majo e lo storico dell'arte Pierluigi De Vecchi. II video, realizzato negli ultimi giorni prima dello smontaggio delle impalcature, ebbe come guida Colalucci che, man mano che scendeva dal piano più alto del ponte, segnalava ai telespettatori gli elementi più significativi della tecnica di Michelangelo che potevano ancora essere ripresi da vicino. Colalucci rispondeva anche alle curiosità e ancora una volta, mentre passava da un piano all'altro, indicava i restauratori al lavoro e come aveva sempre fatto in ogni pubblica occasione, li nominava tutti con la loro qualifica.

Il 17 marzo tutti i sei piani alti del ponte sono smontati e Colalucci lavora sul piano basso. II 28 marzo il ponte è completamente smontato e Colalucci ha finalmente la visione completa del Giudizio restaurato. Scrive sul diario : "..lo trovo impressionante perché è al di fuori della pittura.." Scrive anche che la data ufficiale del termine del restauro del Giudizio è il 26 marzo 1994 e che in tal senso ha scritto una lettera al prof. Carlo Pietrangeli.

Le cerimonie per l'apertura della Sistina restaurata, iniziano alle ore 9 di venerdì 
8 aprile, con la S. Messa di Papa Giovanni Paolo II. Mancinelli, Gabrielli, Baratti, Rossi e Petrignani, portano le offerte al Papa. Colalucci invece, commenta assieme alla giornalista A. Buttiglione, la cerimonia in mondovisione, con Guido Cornini per i quattrocentisti. Con la sua voce calma Colalucci spiega, passo per passo, i segreti di quell'opera tanto misteriosa che, per quattordici anni, è passata centimetro dopo centimetro sotto le sue mani. Spiega anche il suo lavoro cercando parole semplici, poiché sa che quelle parole stanno entrando nelle case di tutto il mondo, e dunque devono essere comprese da tutti.

Alle ore 12 , si svolge la conferenza stampa nella Sala della Benedizione, cui sono presenti i giornali e le televisioni di tutto il mondo. Alle 19,30 Colalucci rilascia un'intervista al telegiornale della $3^{\circ}$ rete della Rai.

La prima giornata di celebrazioni si conclude con la grande cena offerta dal Marchese Sacchetti al circolo della caccia, alla quale prendono parte tutti coloro che si sono occupati del restauro, ed i membri del comitato scientifico internazionale. II giorno seguente alle ore 18, un concerto di musica sacra nella Cappella Sistina restaurata, conclude ufficialmente le celebrazioni.

Ora, come disse Freedberg già al convegno di quattro anni prima, si può soltanto stare :

“in rispettosa ammirazione dell'opera d'arte più grande del Rinascimento italiano che sia stata sottoposta a restauro. II risultato di questo sforzo è stato il recupero, a un grado che ha del miracoloso, dell'aspetto degli affreschi allo stato in cui si trovavano quando Michelangelo li esegui”. 


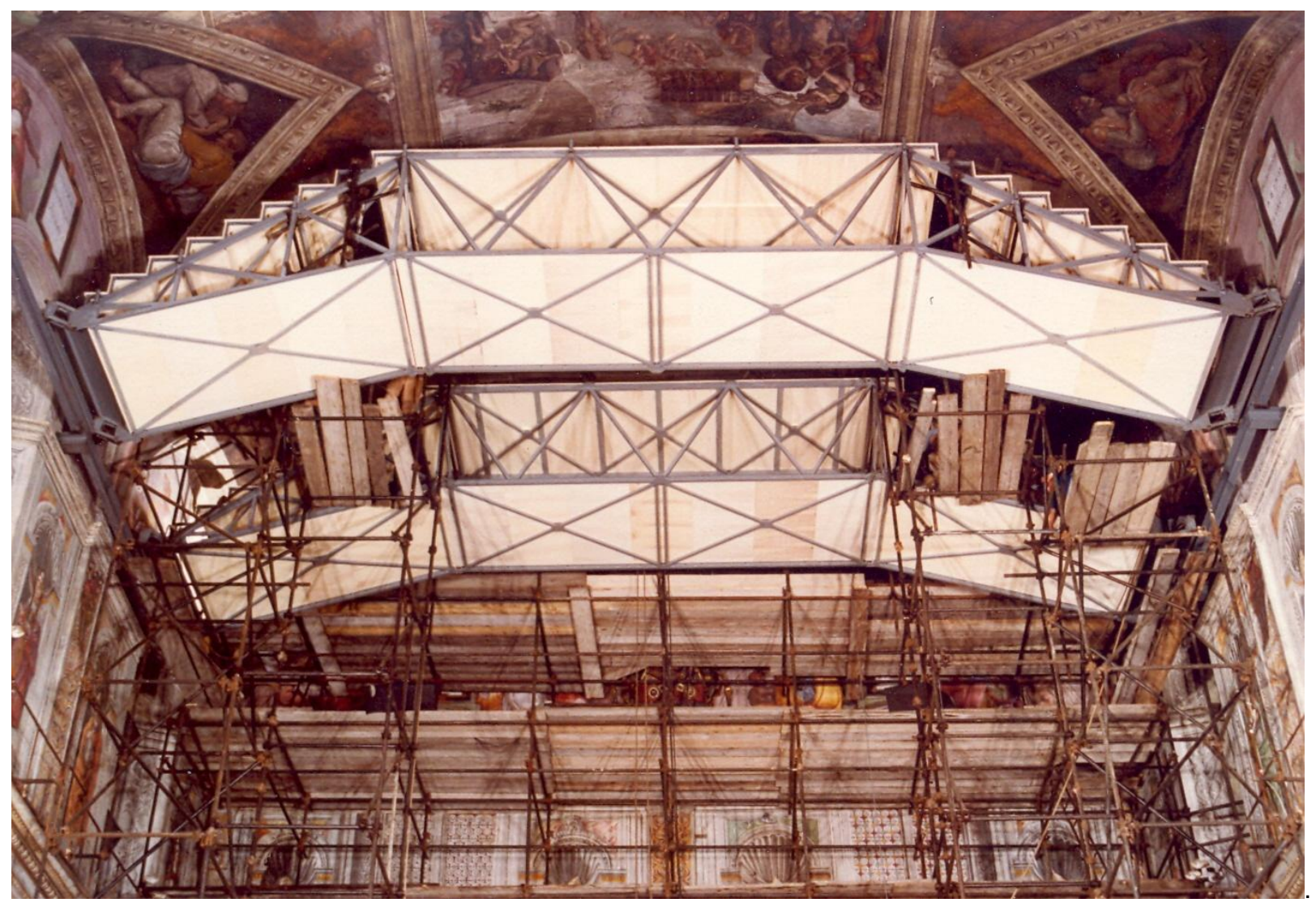

Fig.1- una panoramica del carro ponte sospeso 


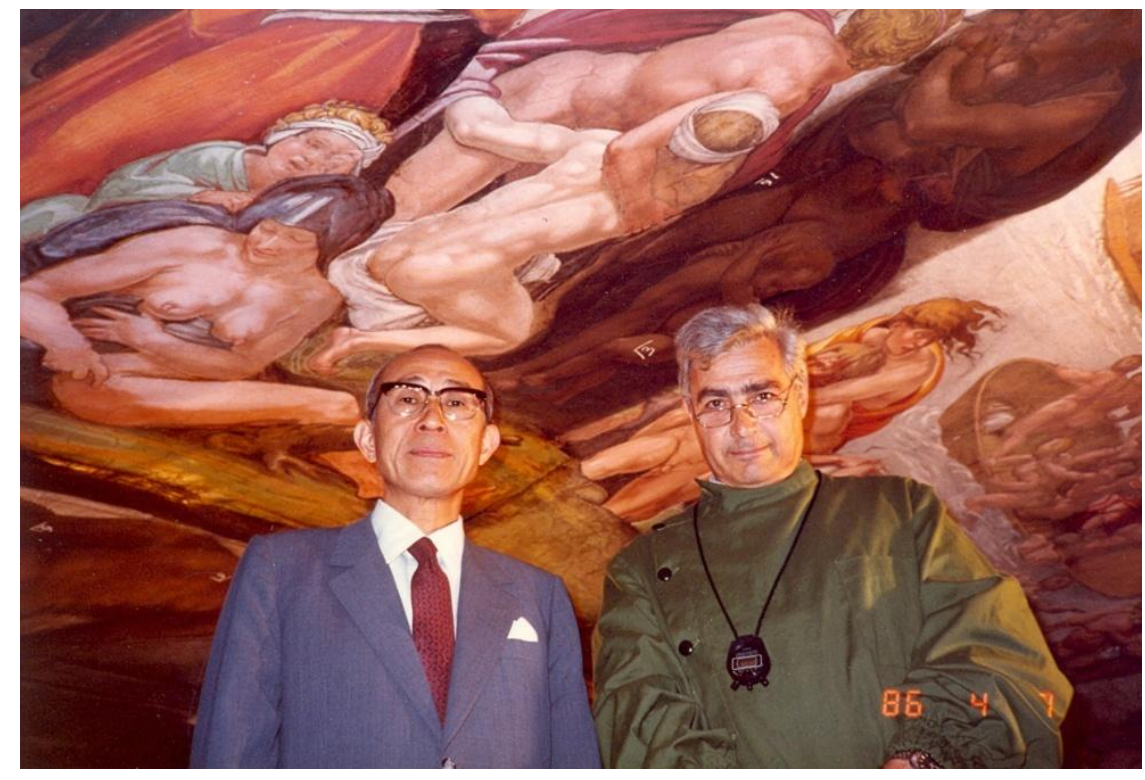

Fig. 2 - Colalucci con uno dei capi della NTV di Tokio

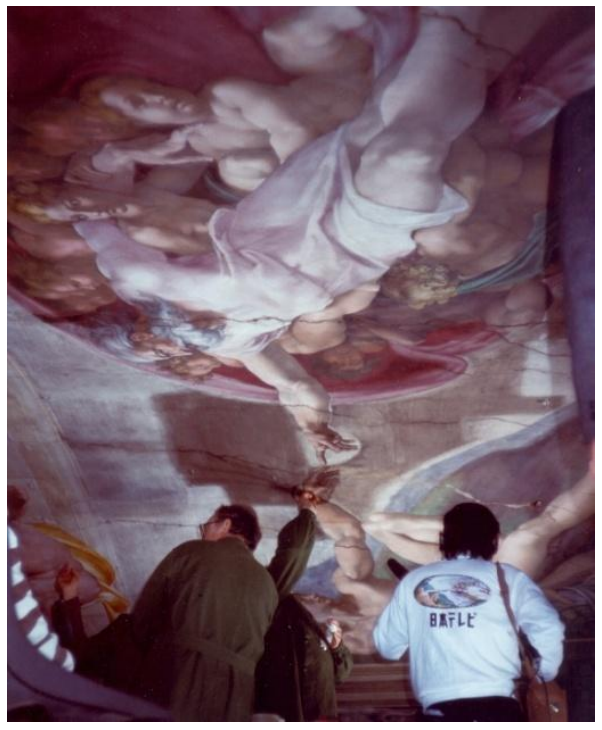

Fig. 3- durante le riprese

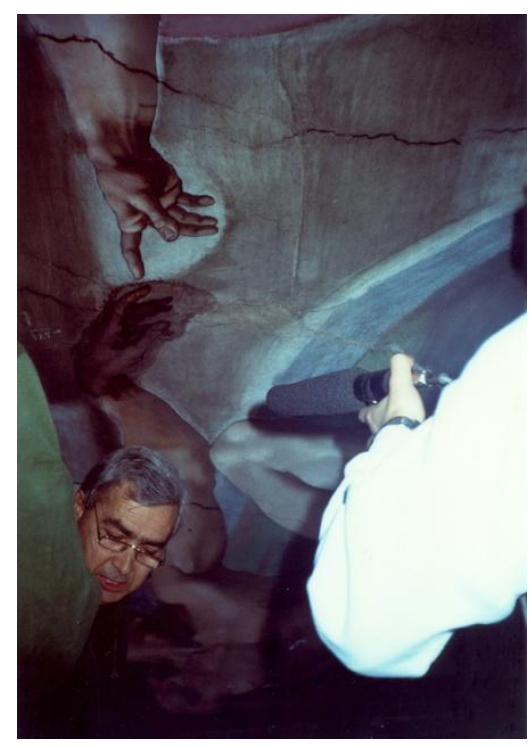

Fig. 4 - durante le riprese 


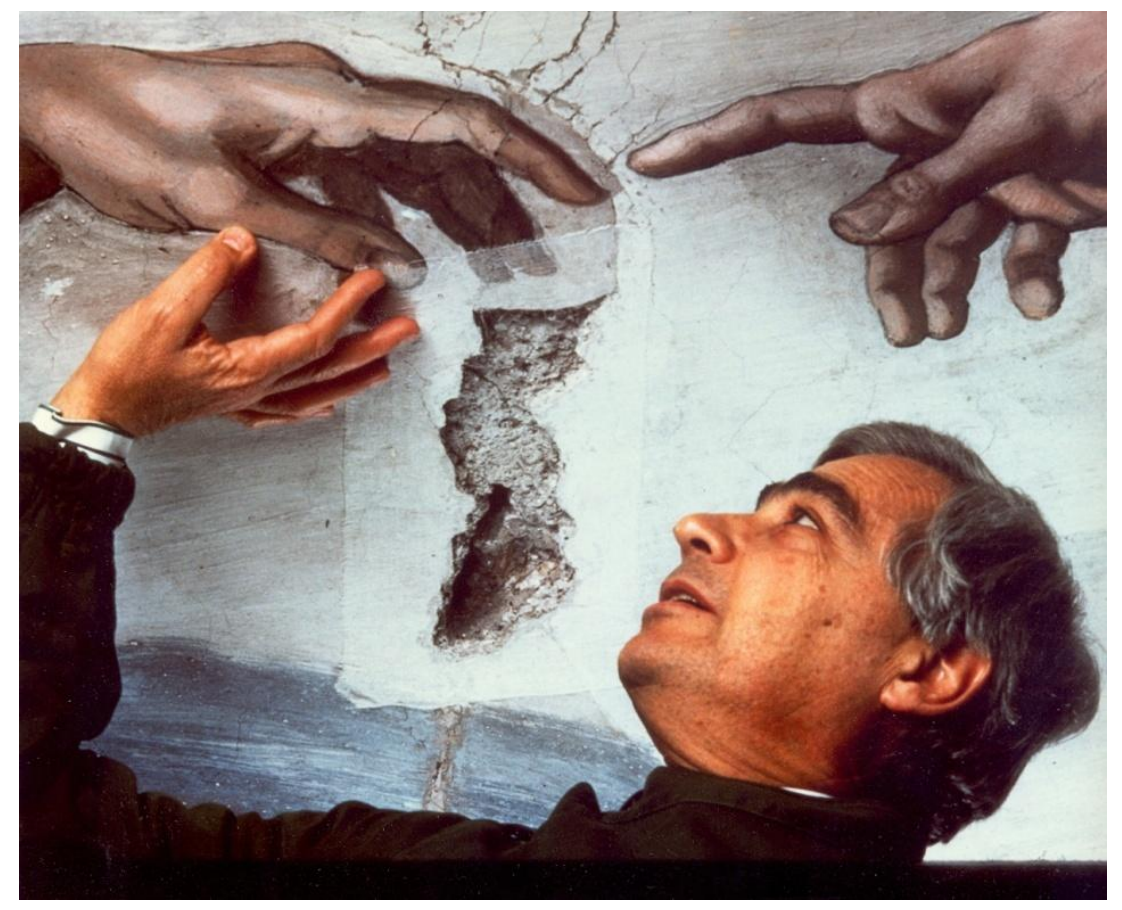

Fig. 5- Colalucci davanti alle "dita che si toccano"

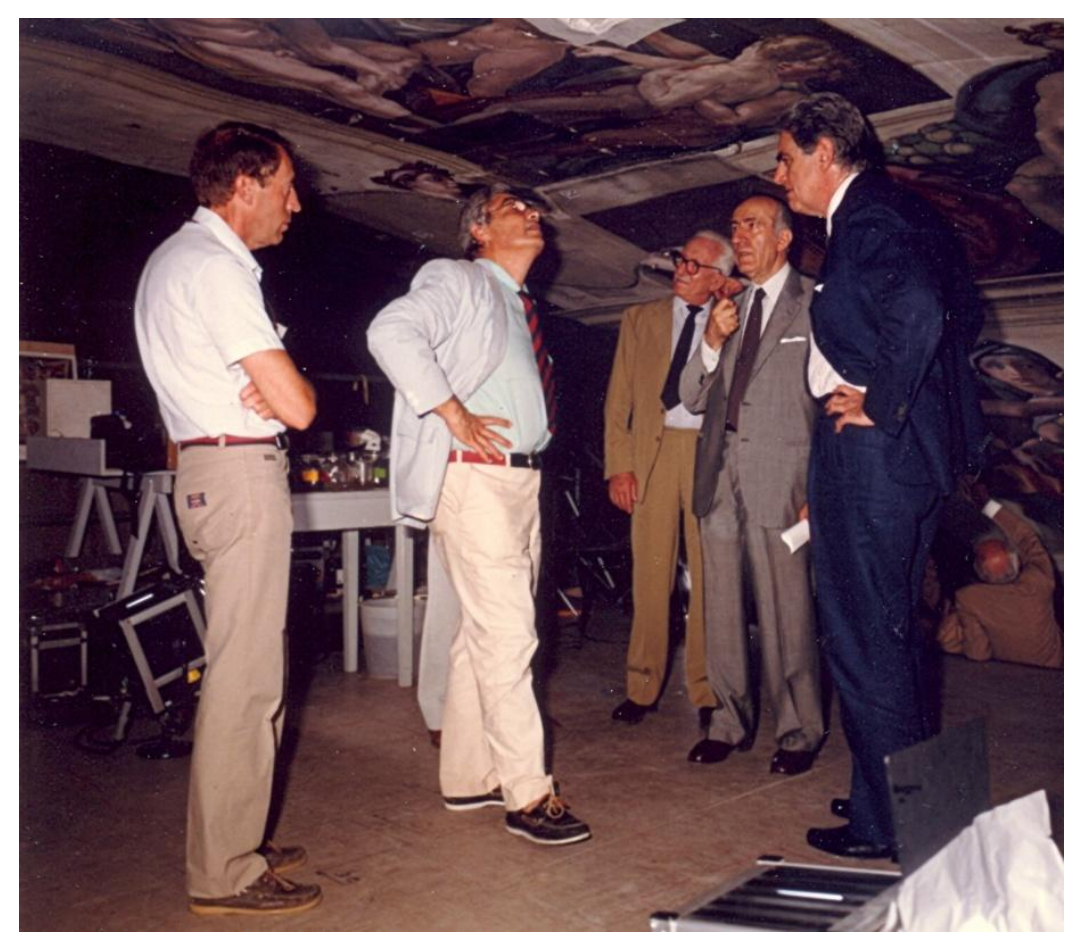

Fig.6 - Colalucci con il Marchese Sacchetti (a destra) il Direttore Pietrangeli Rotondi e Giorgio Bonetti (a sinistra) 


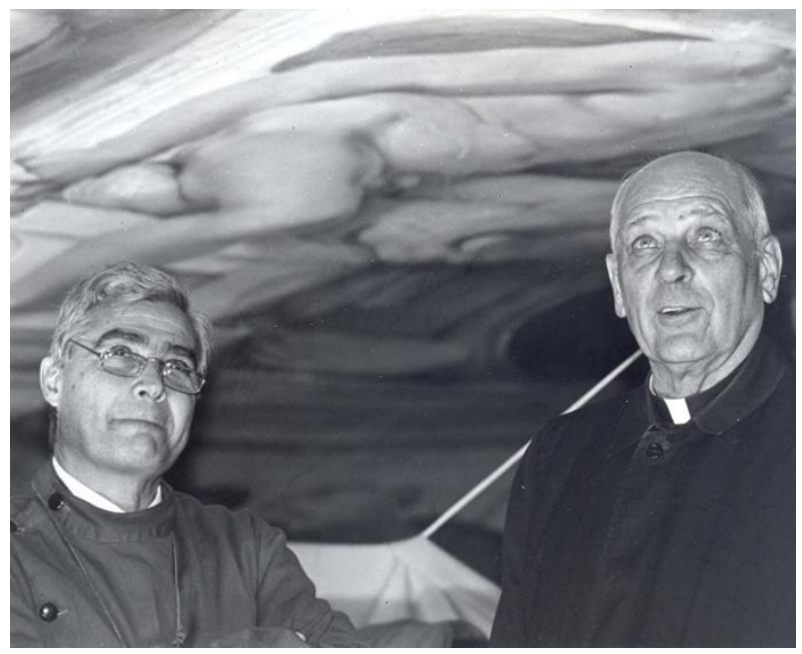

Fig. 7- Colalucci con monsignor Marcinkus

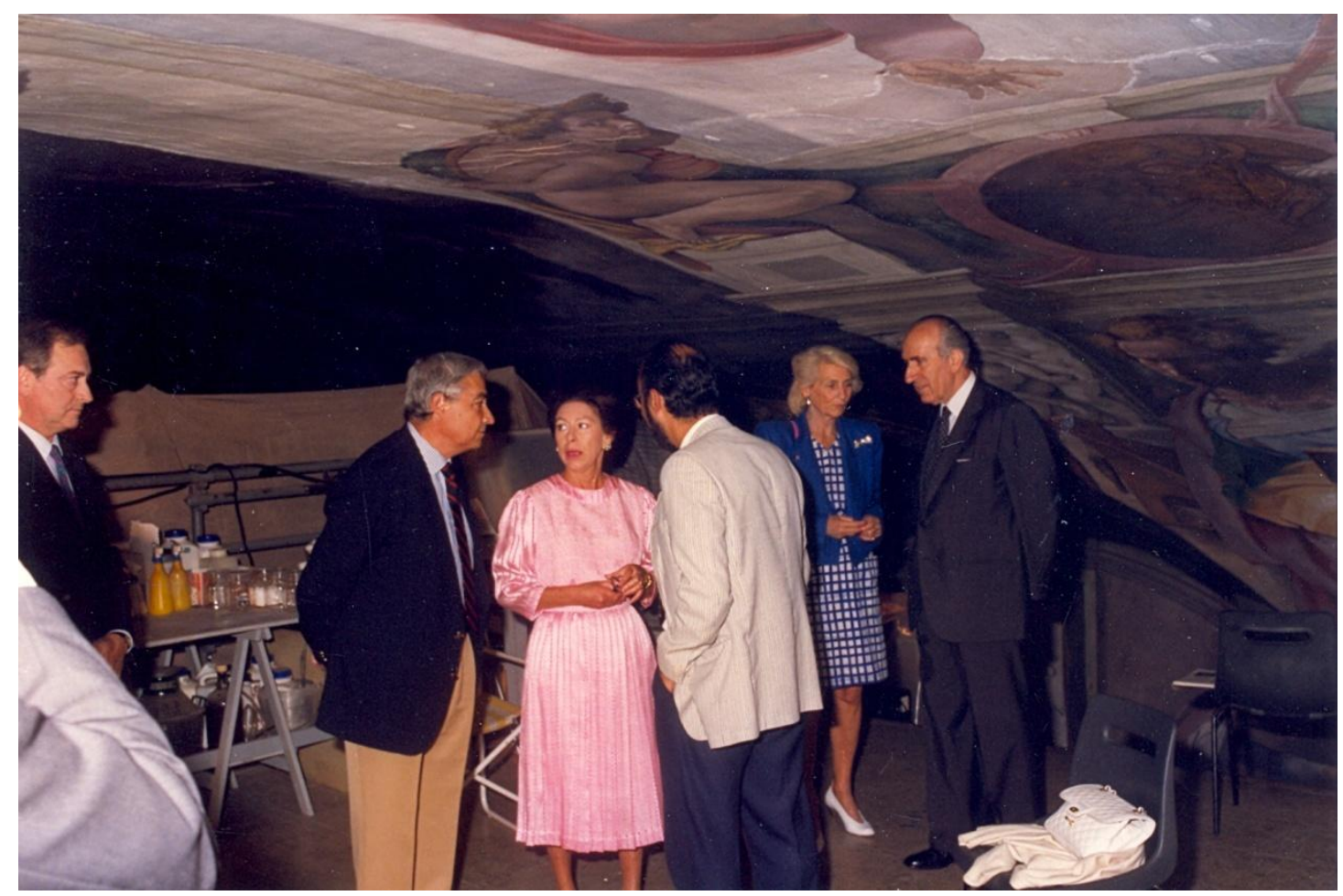

Fig. 8- la Principessa Margaret d'Inghilterra in una delle frequenti visite al cantiere 


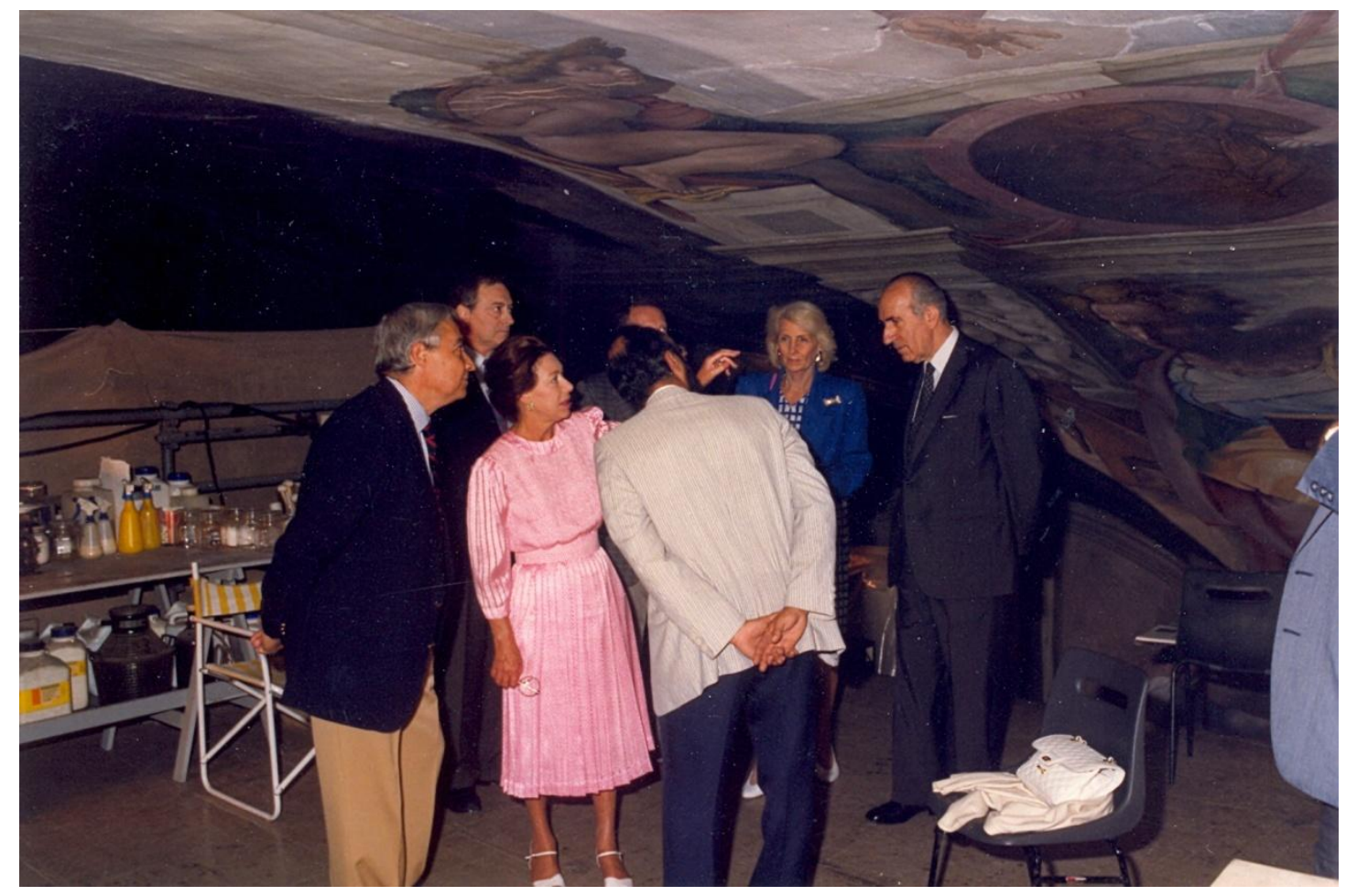

Fig. 9- la Principessa Margaret in un altro momento della visita

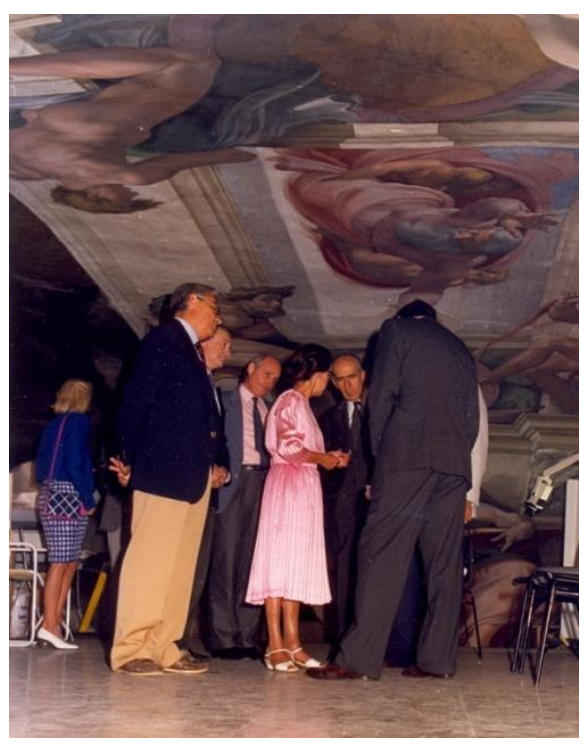

Fig. 10 - la Principessa Margaret 


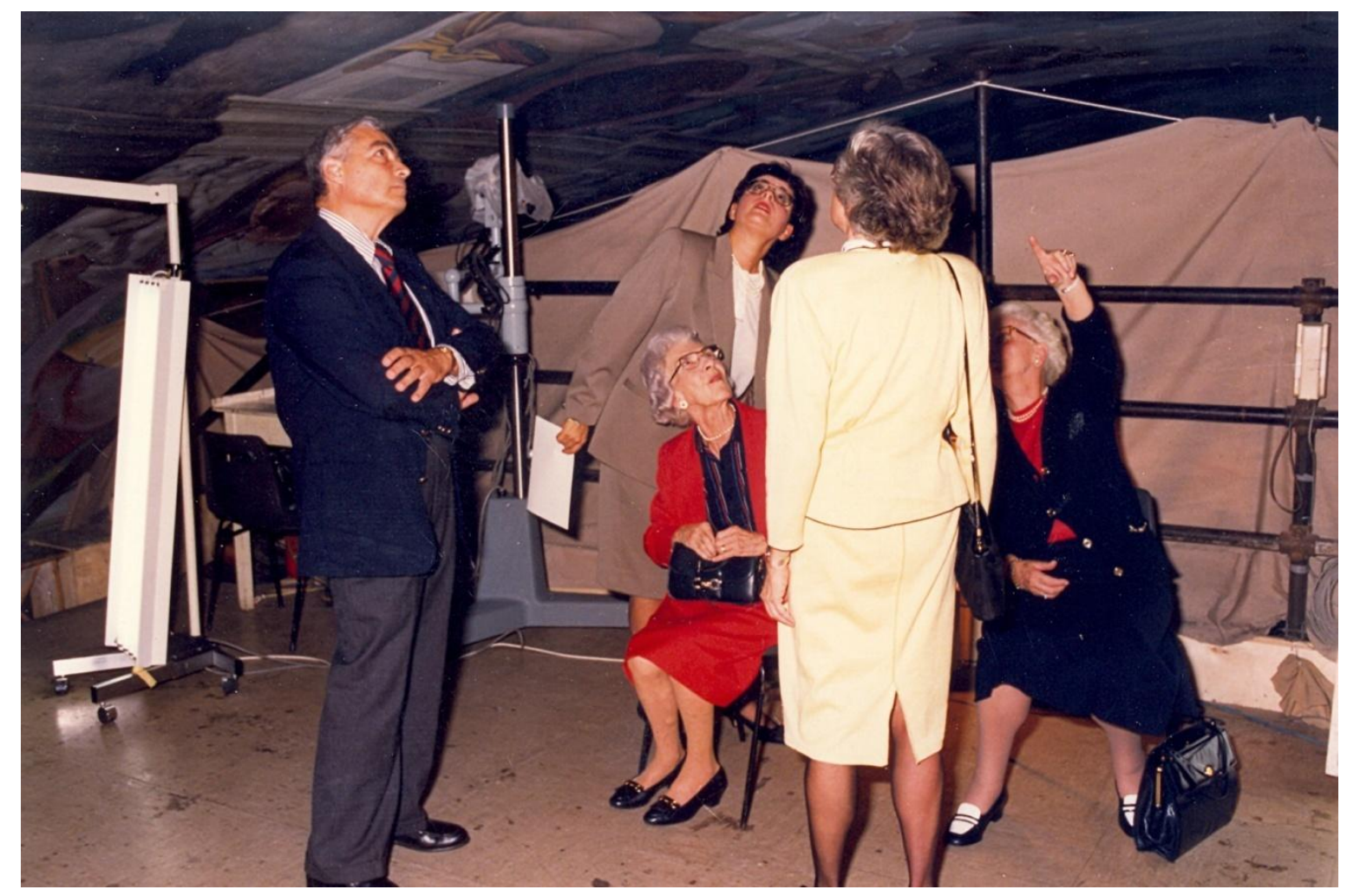

Fig. 11- Colalucci con la Regina di Danimarca (di spalle) 


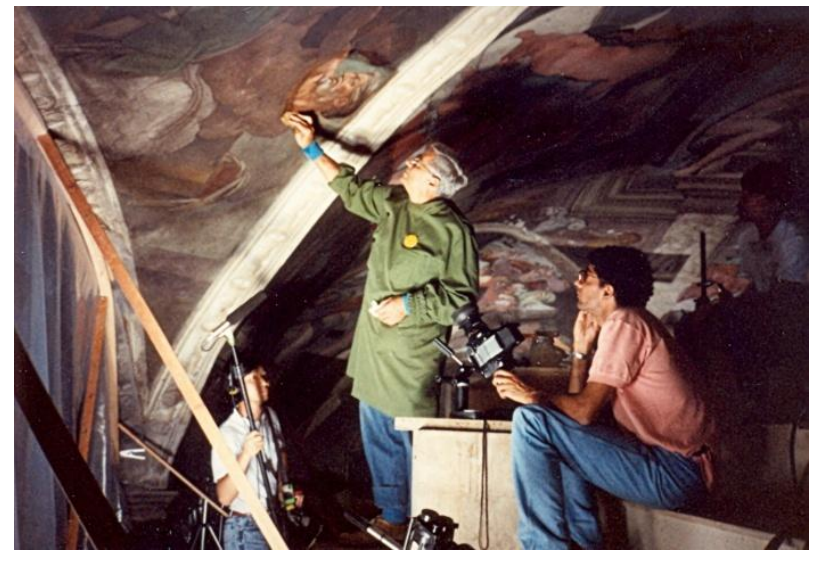

Fig. 12

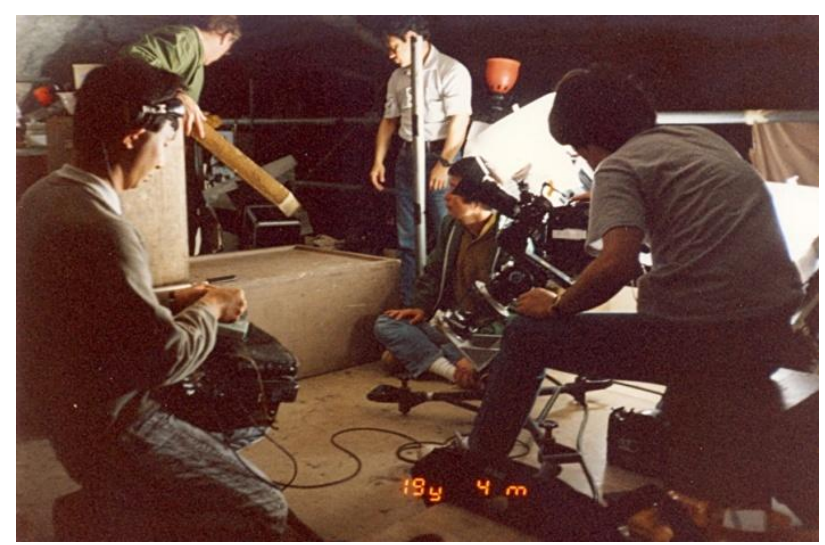

Fig. 14

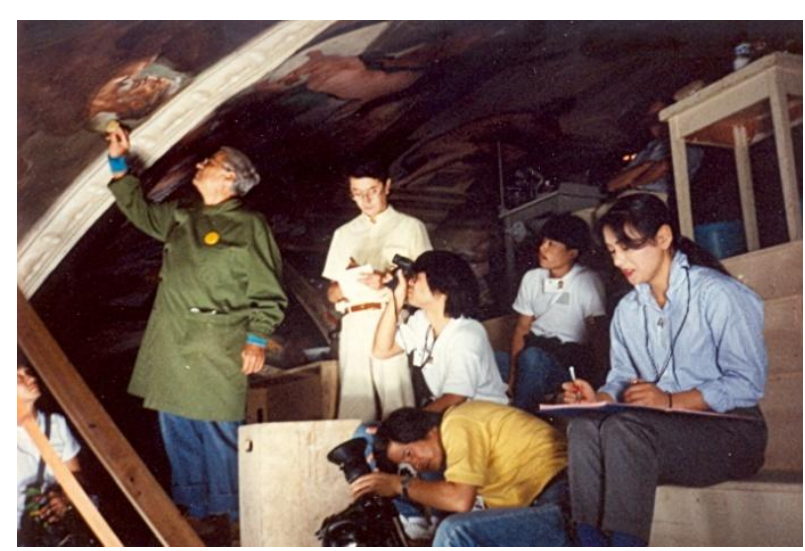

Fig. 13

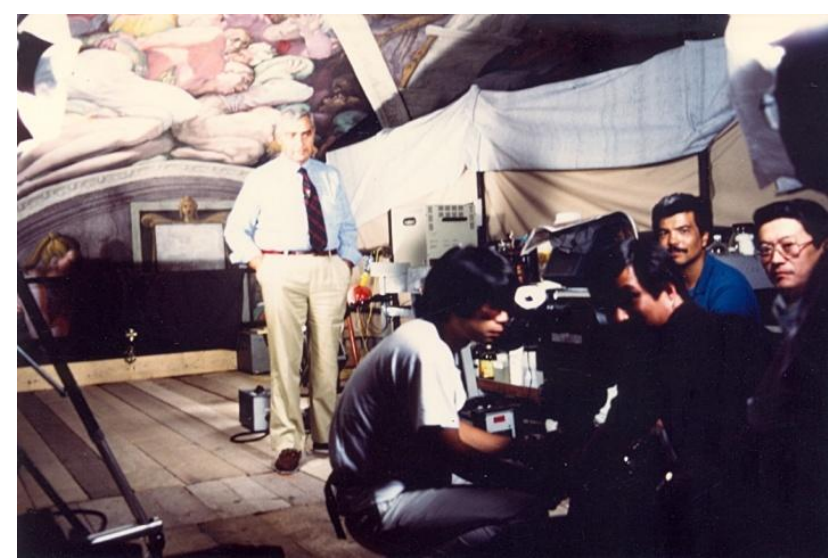

Fig. 15

Le foto $12-13-14-15$, mostrano alcuni momenti del lavoro durante le riprese della NTV 


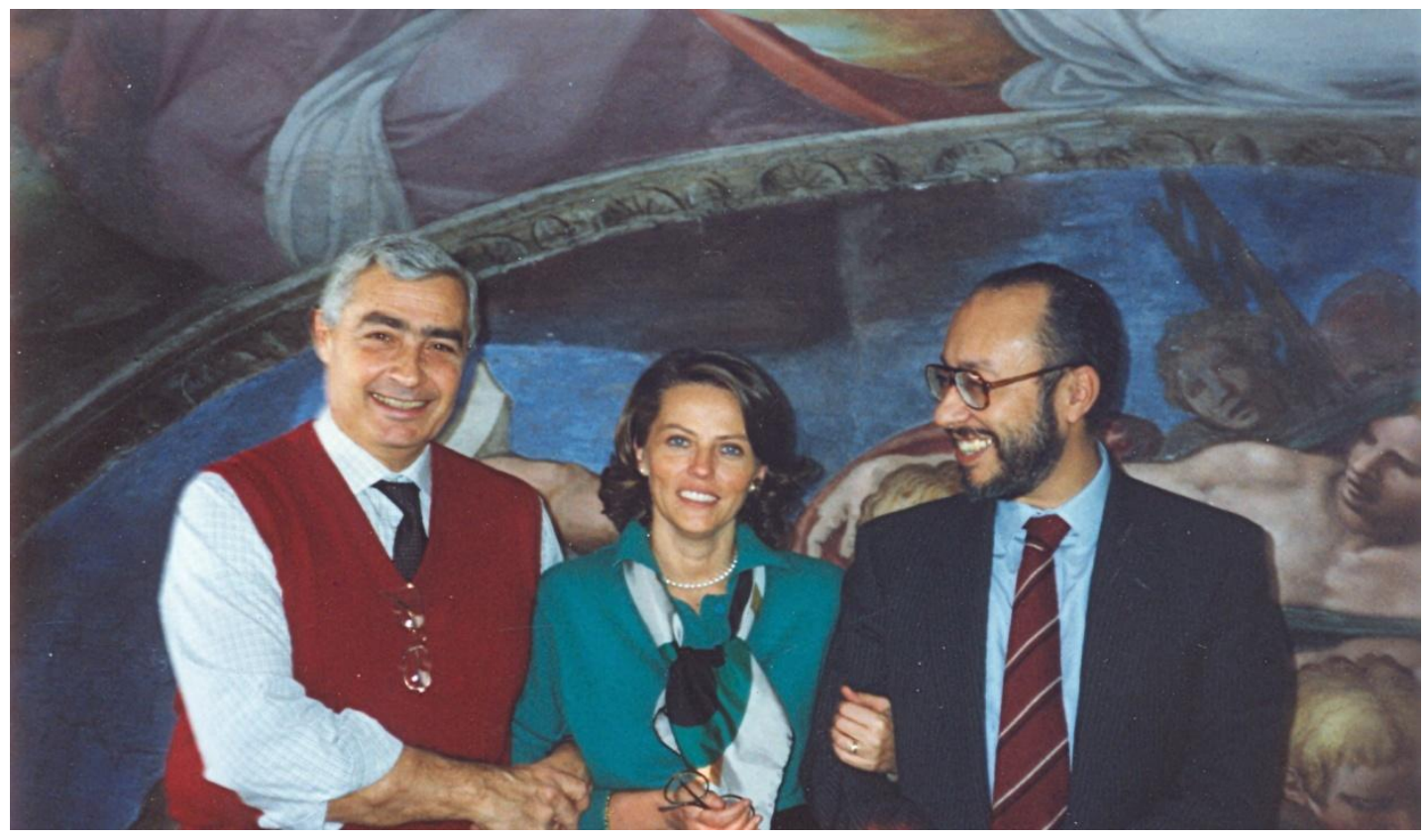

Fig. 16 - Colalucci con la dott.ssa De Strobel e F. Mancinelli

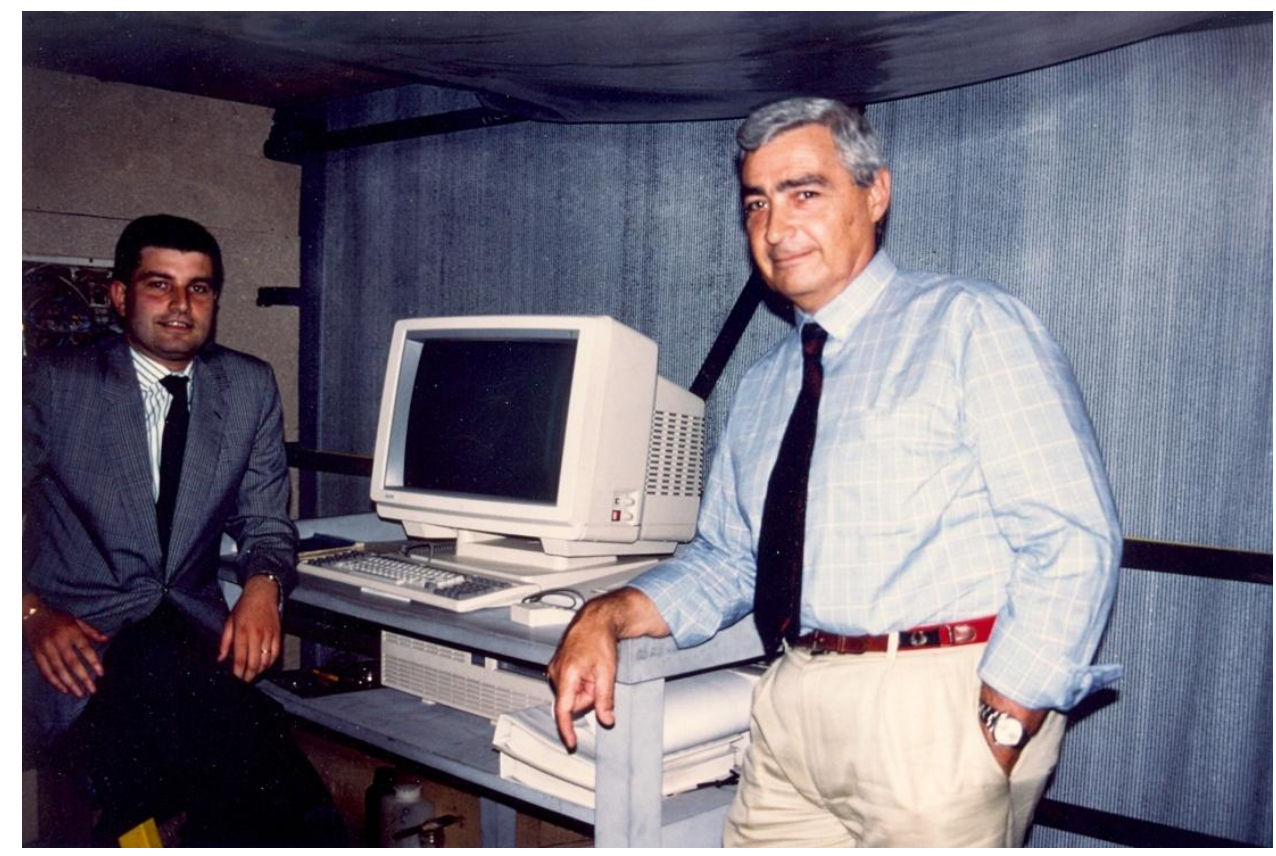

Fig. 17- Colalucci con Filippo Petrignani 


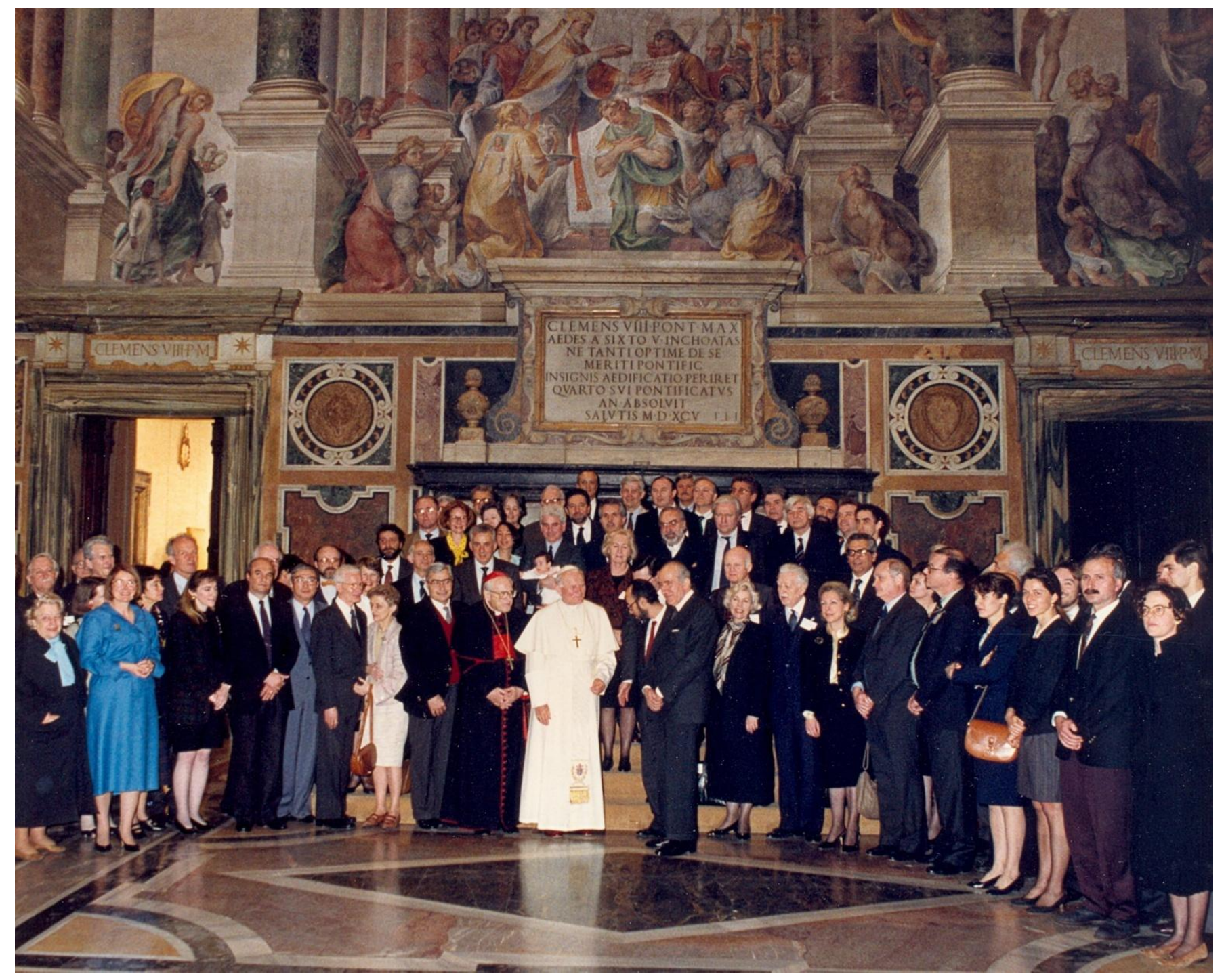

Fig. 18 - La foto di chiusura del Convegno del 1990 con il Papa Giovanni Paolo II 


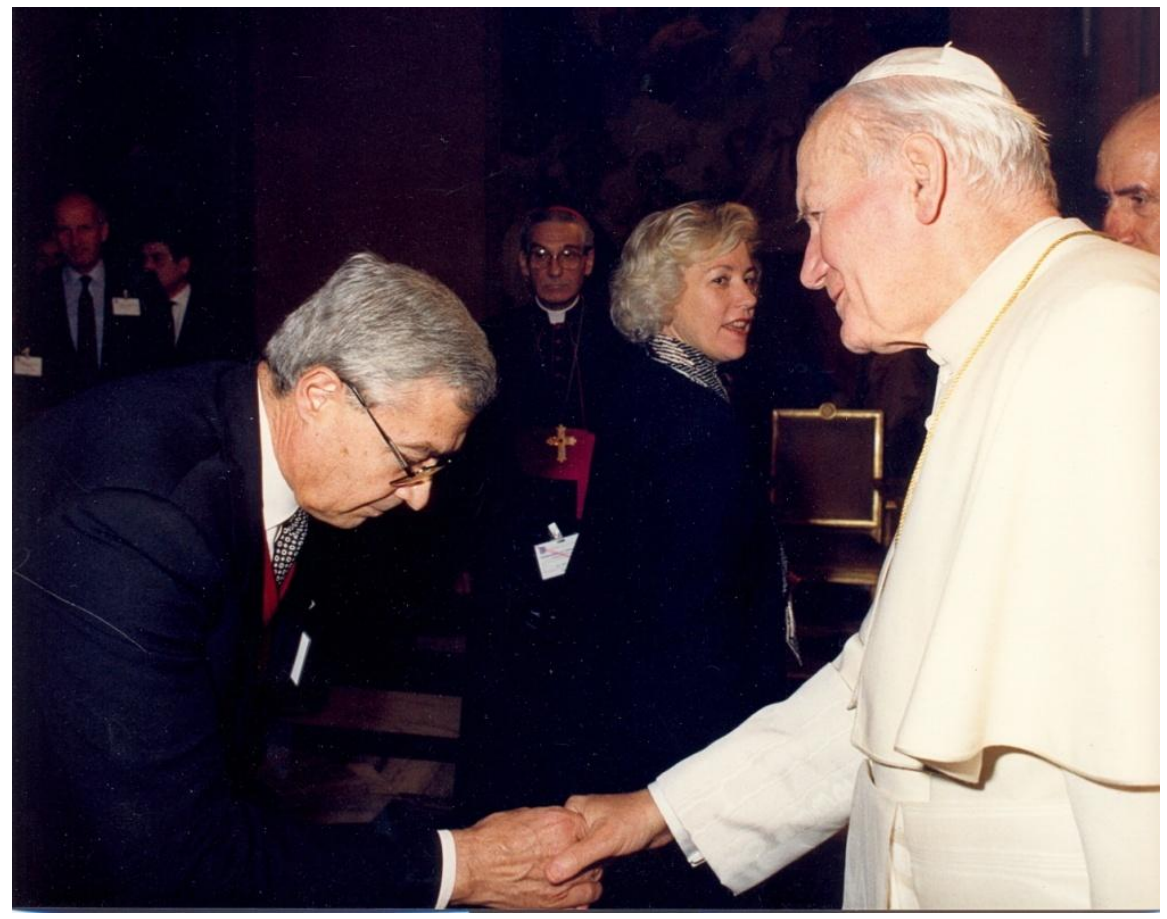

Fig. 19- Colalucci con il Papa durante la cerimonia di chiusura del Convegno

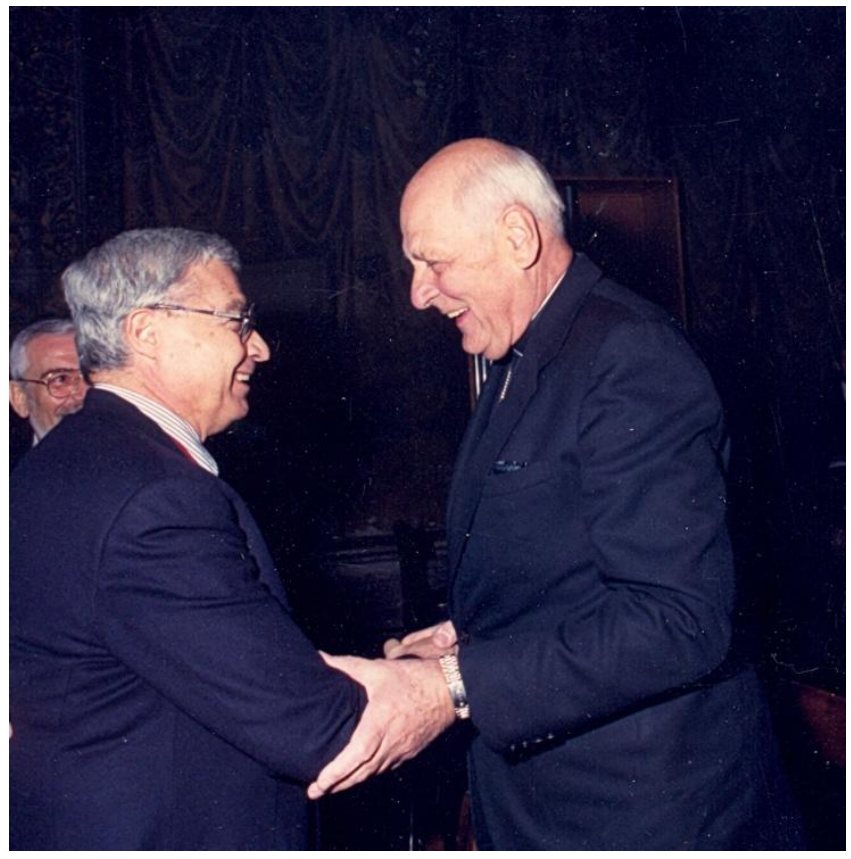

Fig. 20- Colalucci con monsignor Marcinkus 


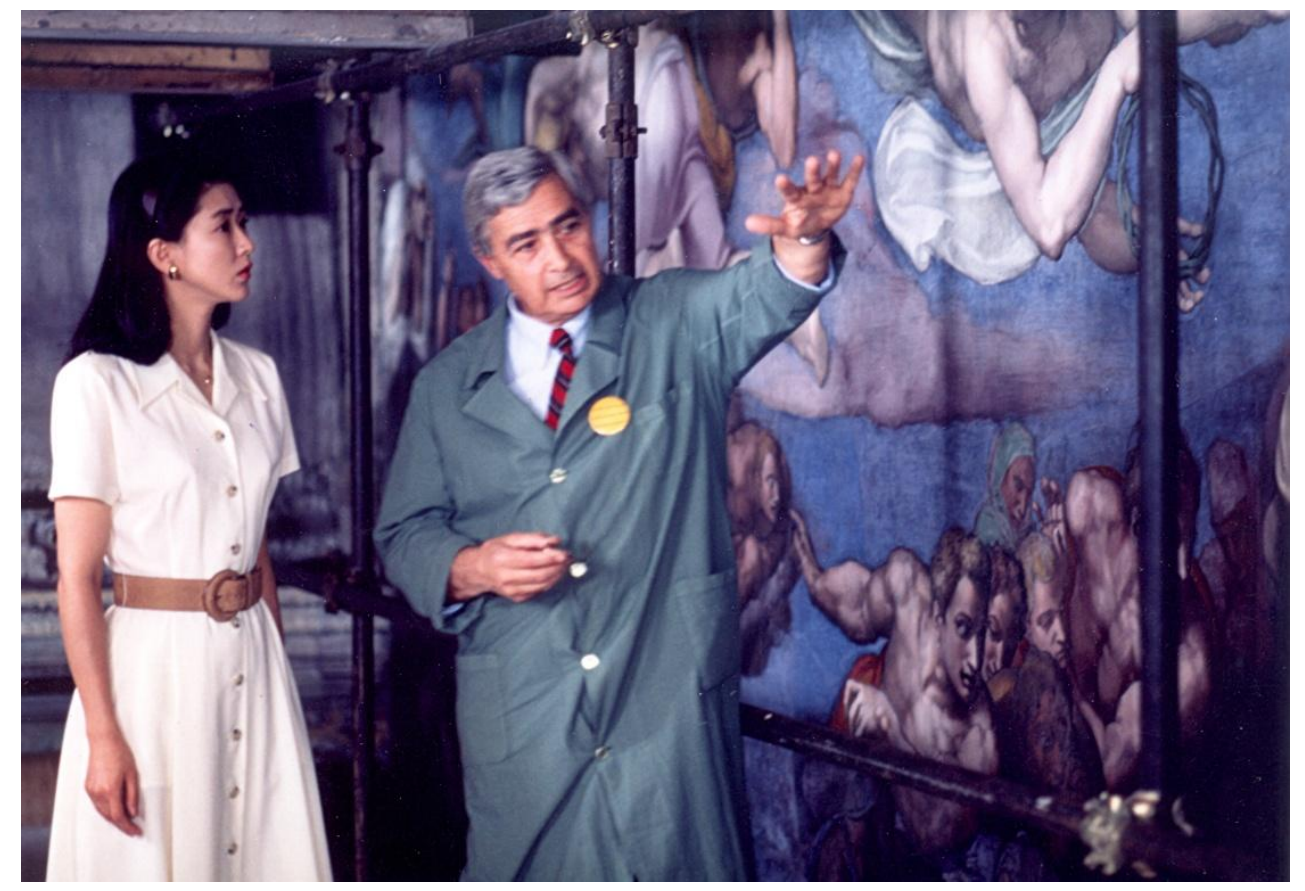

Fig. 21

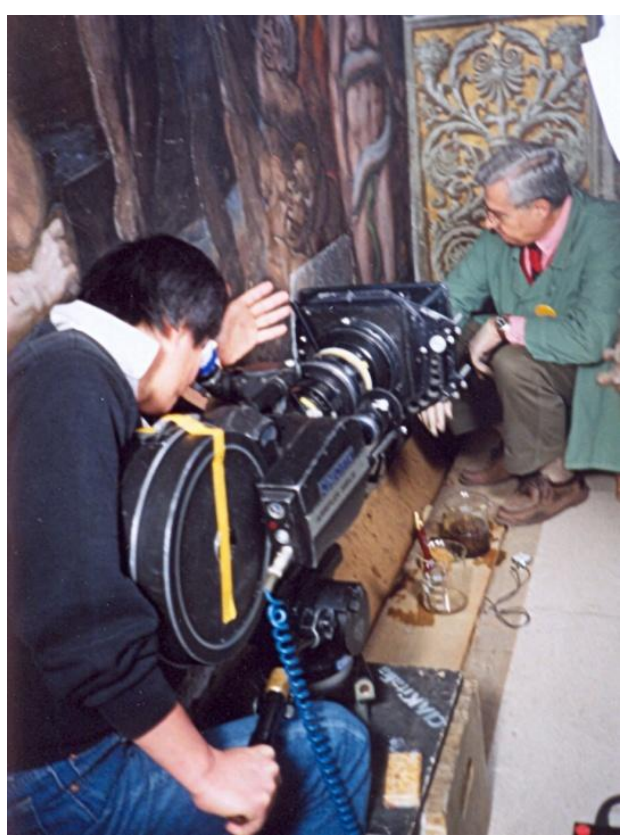

Fig. 22

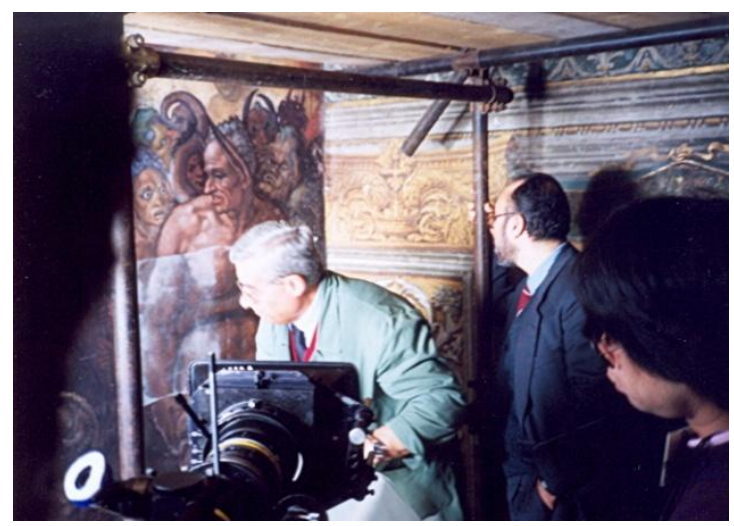

Fig. 23

Le foto 21- 22- 23 mostrano alcuni momenti del lavoro di Colalucci sul Giudizio Universale di fronte alle telecamere della NTV 


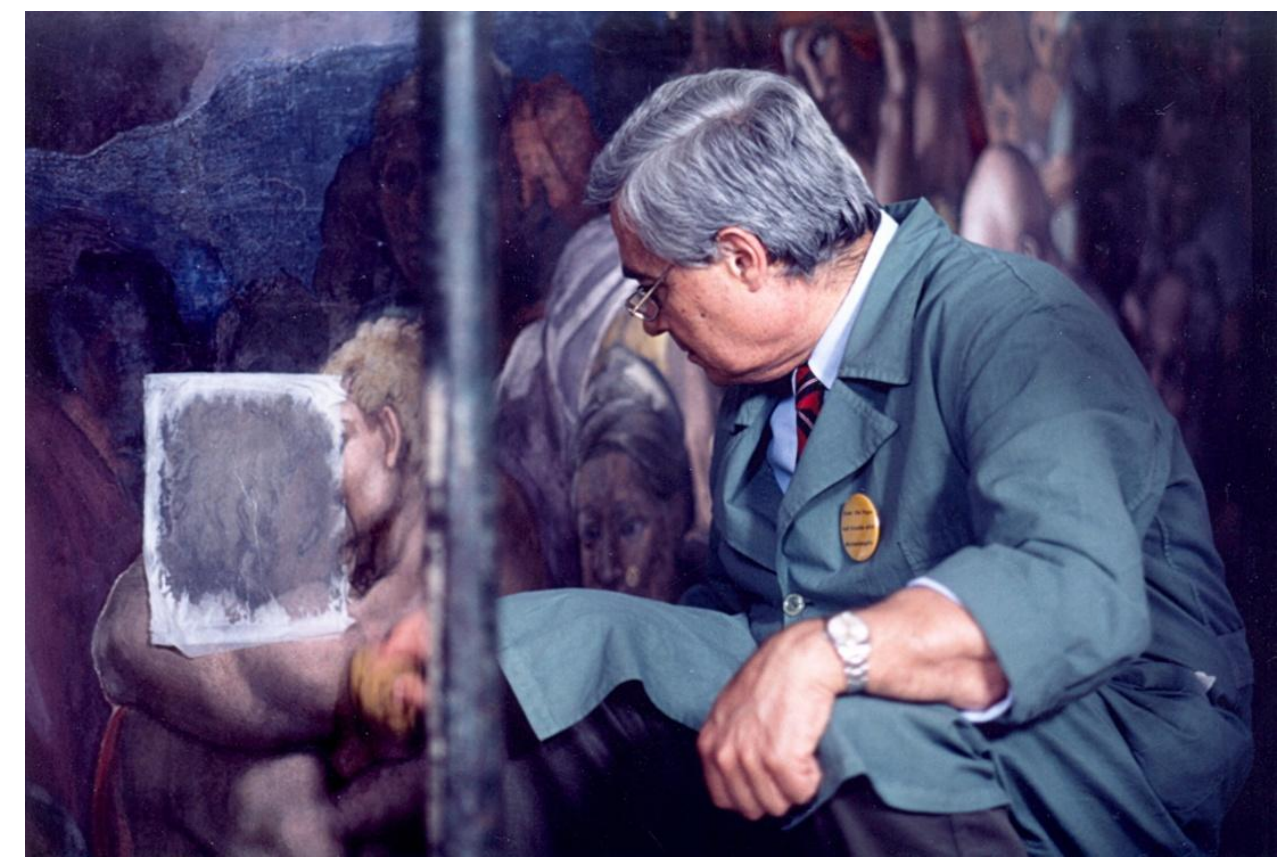

Fig. 24 - Colalucci durante la pulitura del Giudizio Universale

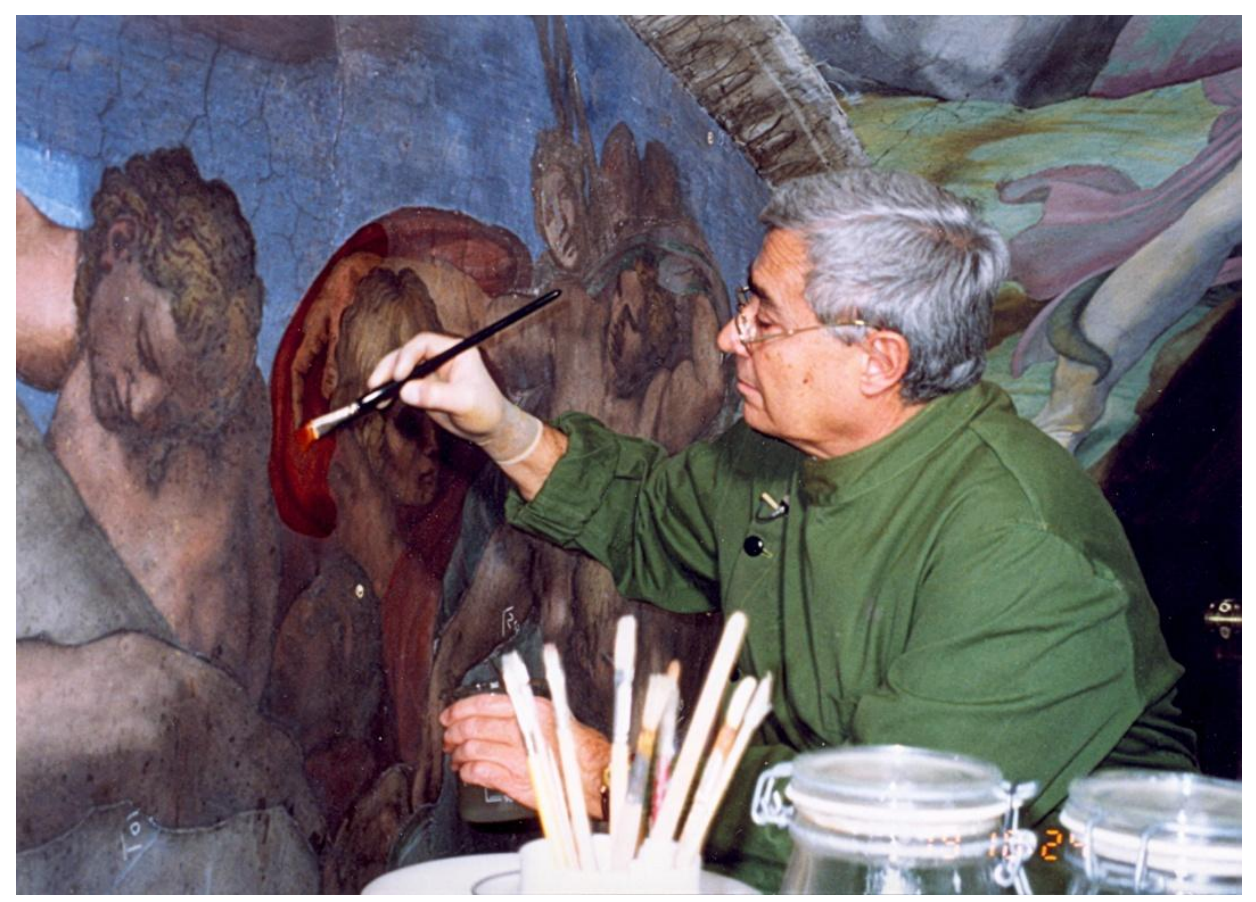

Fig. 25 - Colalucci durante la pulitura 


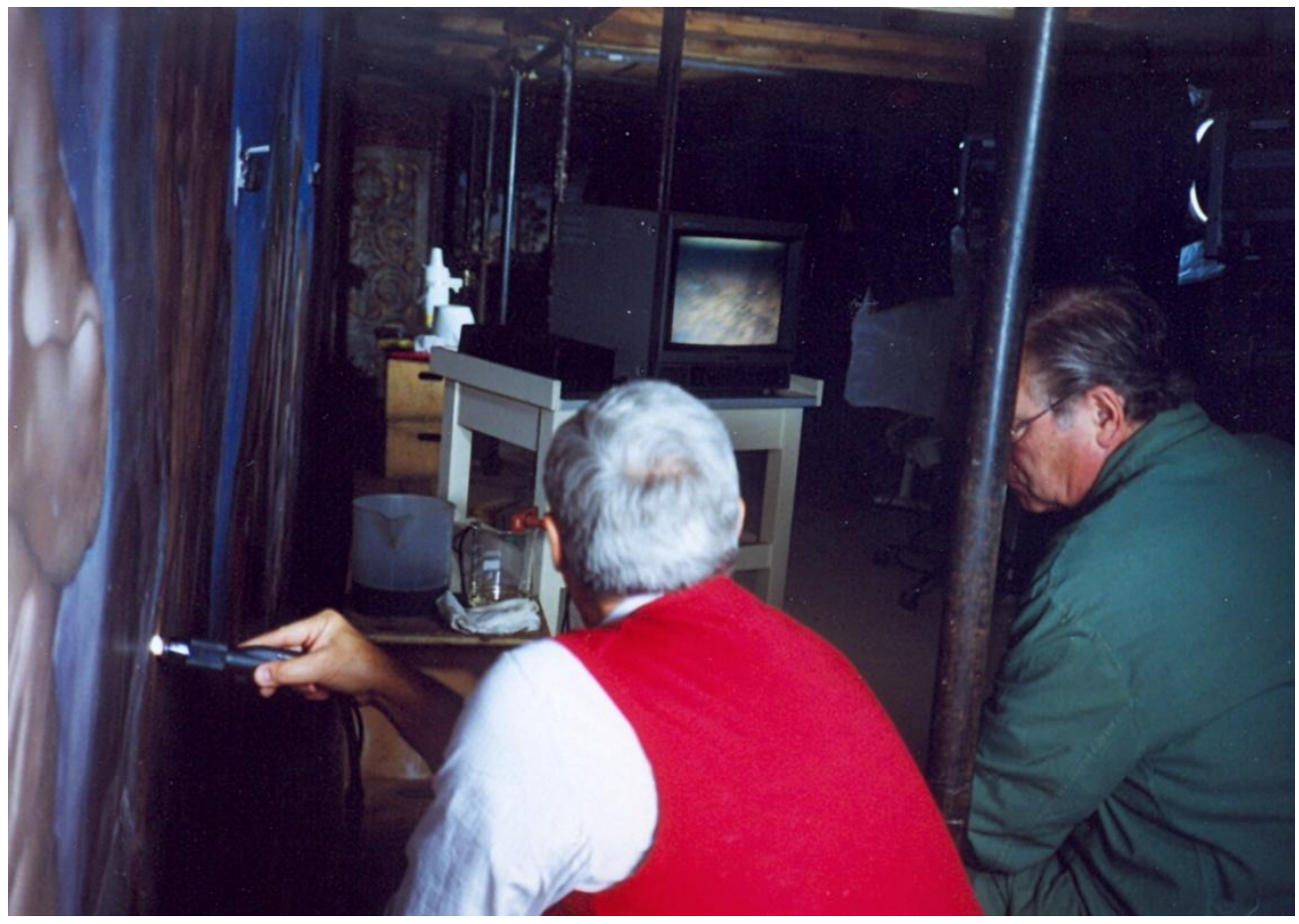

Fig. 26 - Colalucci osserva l'affresco con il microscopio a fibre ottiche, accanto a lui Maurizio Rossi

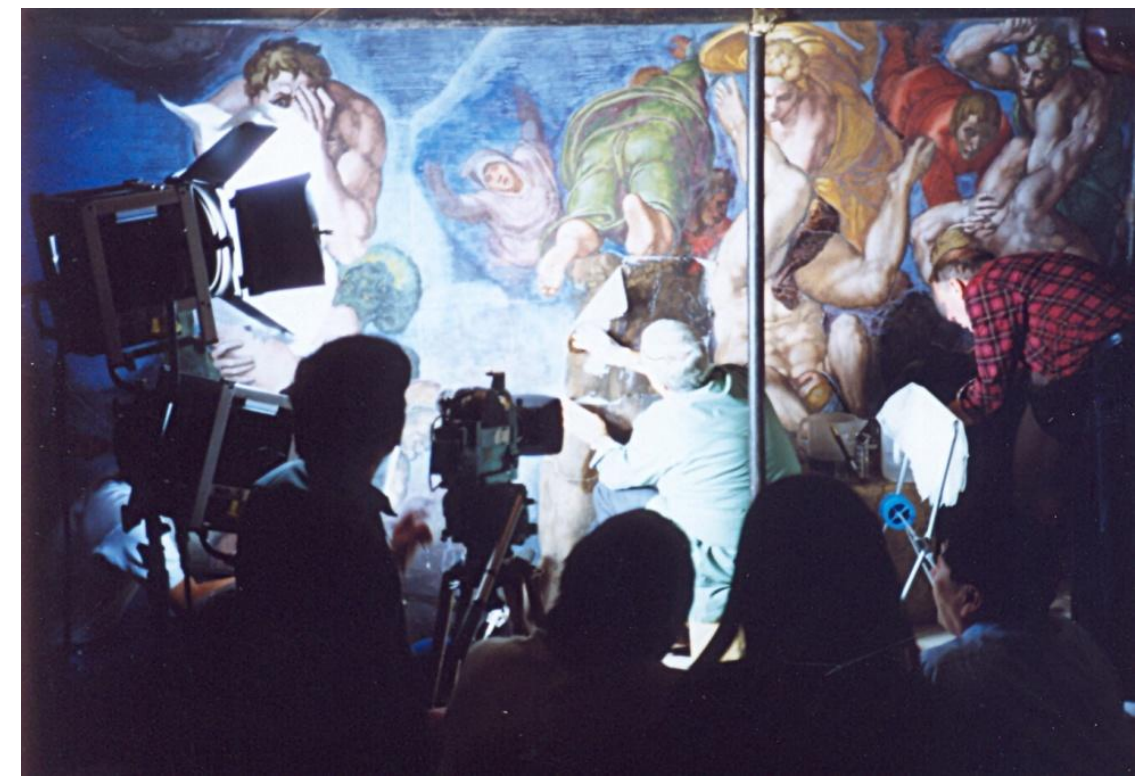

Fig. 27 - Un momento della pulitura del Giudizio 


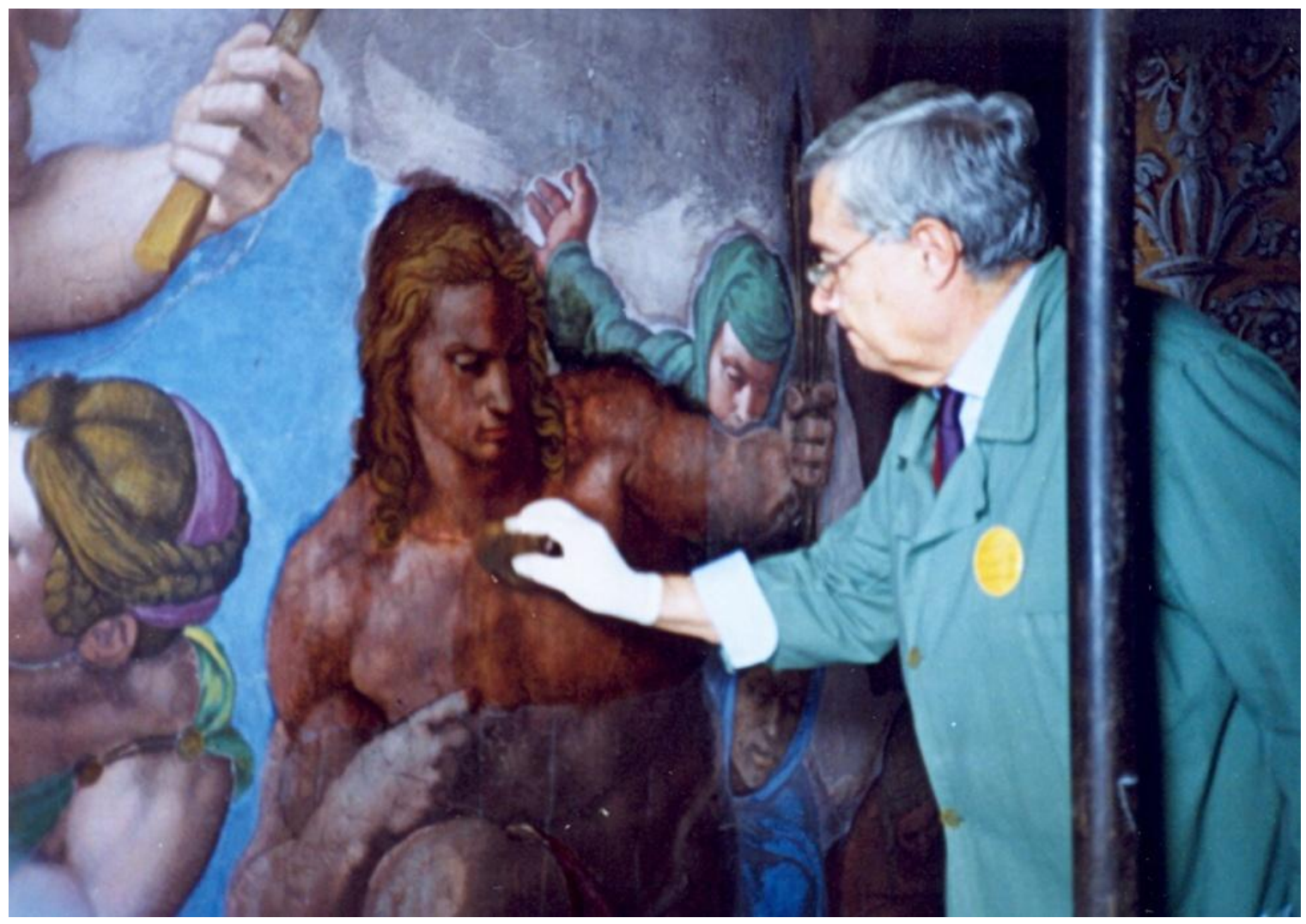

Fig. 28- La pulitura del San Sebastiano 


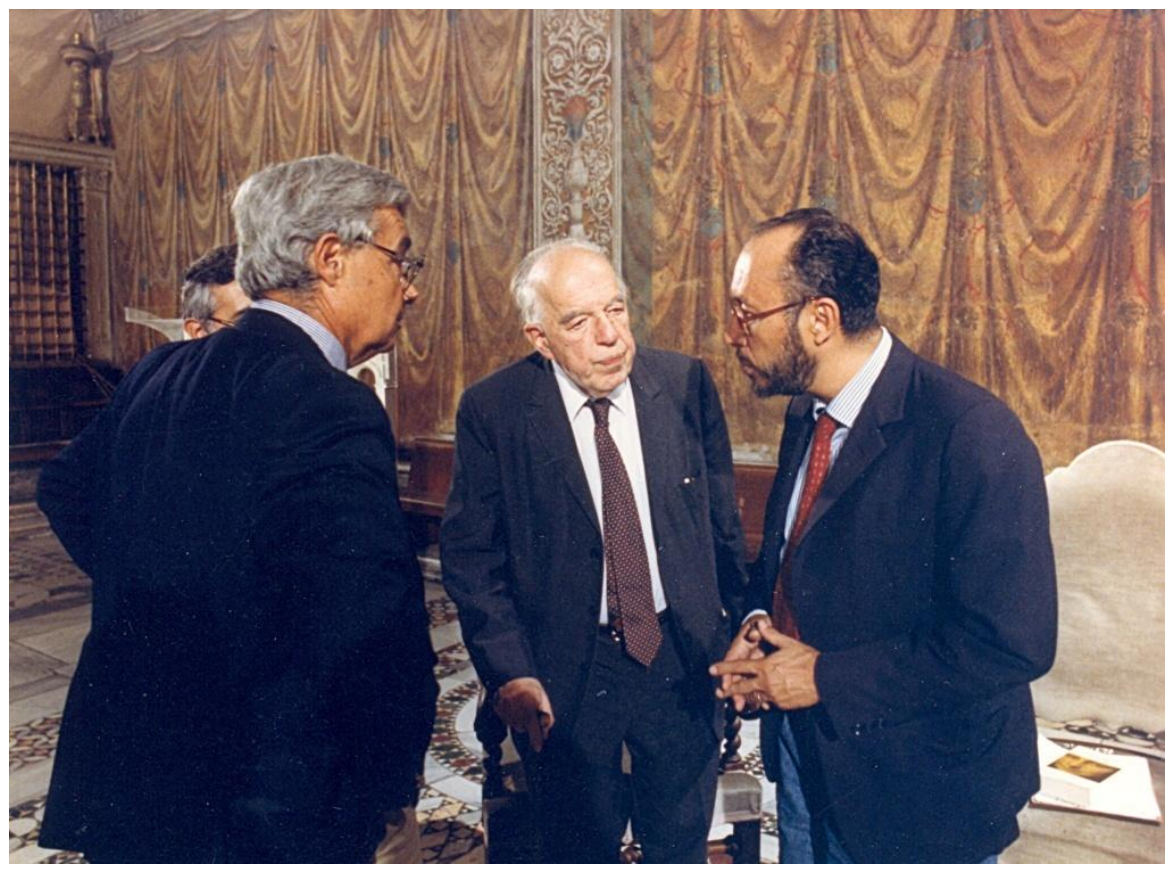

Fig.29 -La trasmissione della RAI curata dal giornalista Nino Criscenti sui risultati del Lavoro. Colalucci e Mancinelli sono con Ernst Gombrich - è il 1989

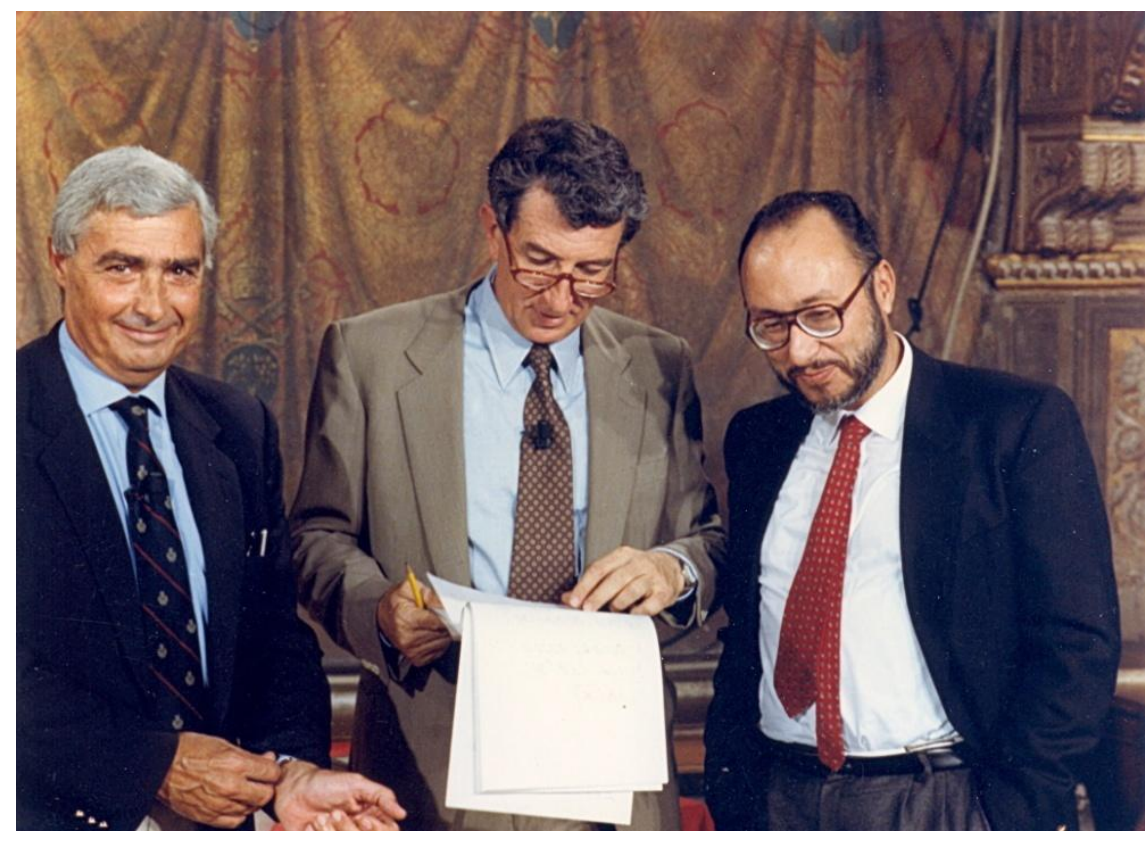

Fig.30- Un altro momento della registrazione della trasmissione. Al centro,tra Mancinelli e Colalucci il conduttore Corrado Augias 


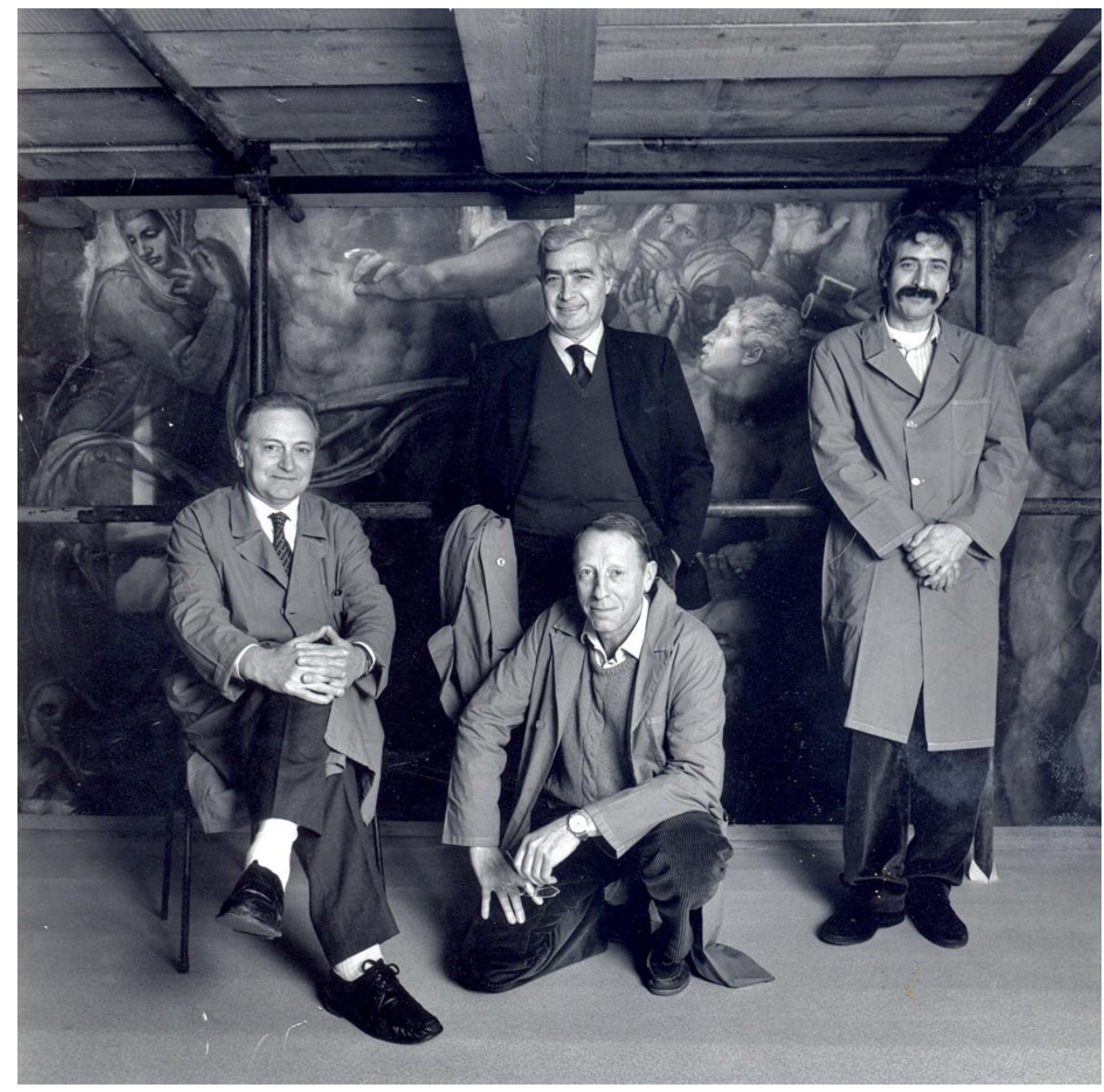

Fig. 31 - II gruppo dei restauratori della Sistina al completo. A sinistra seduto M. Rossi, in ginocchio G. Bonetti, a destra B. Baratti, al centro Colalucci

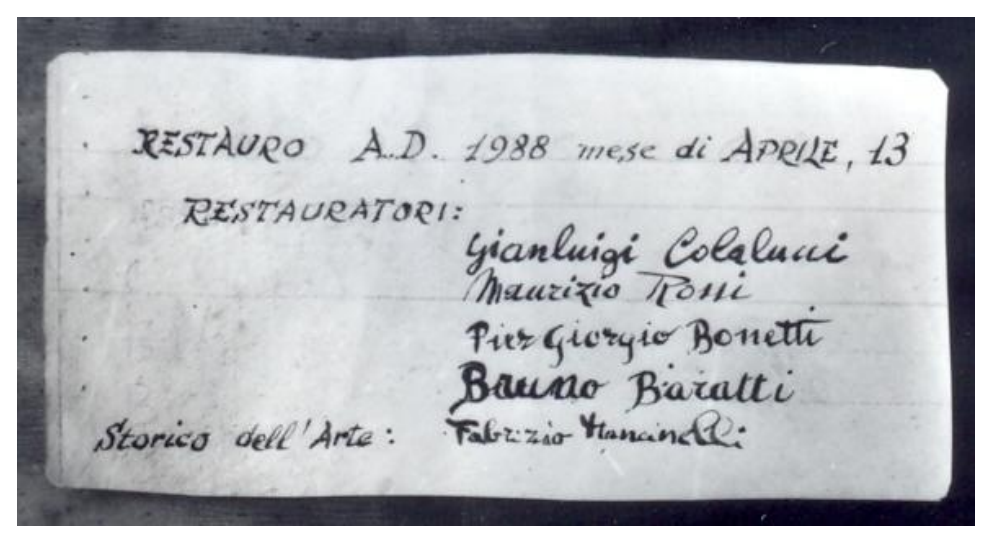

Fig. 32 -ll cartiglio con i nomi dei restauratori e di Mancinelli, inserito all'interno di una lacuna, al centro della Volta 


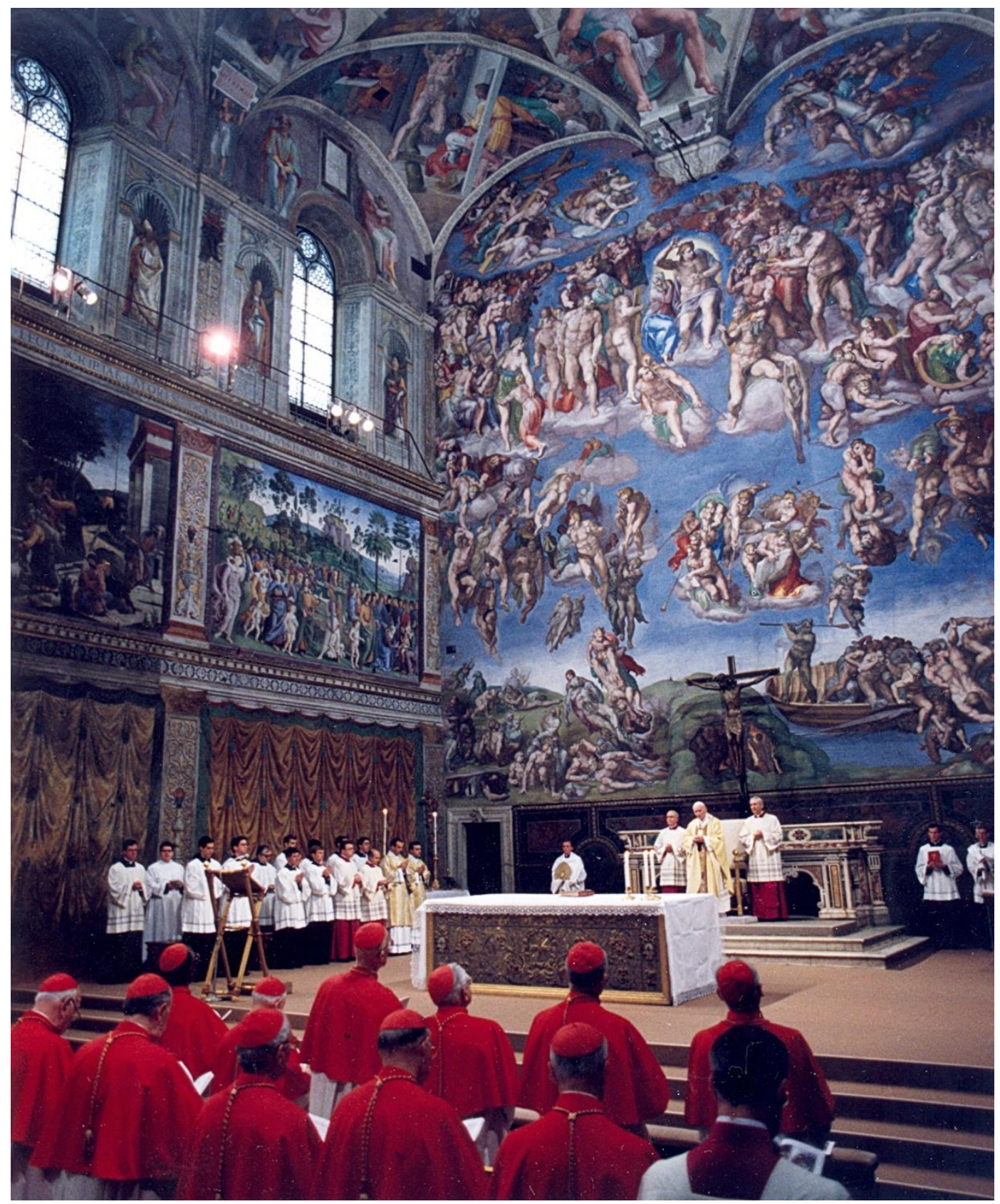

Fig. 33- La messa del Papa Giovanni Paolo II in mondovisione, per l'inaugurazione della Sistina restaurata 


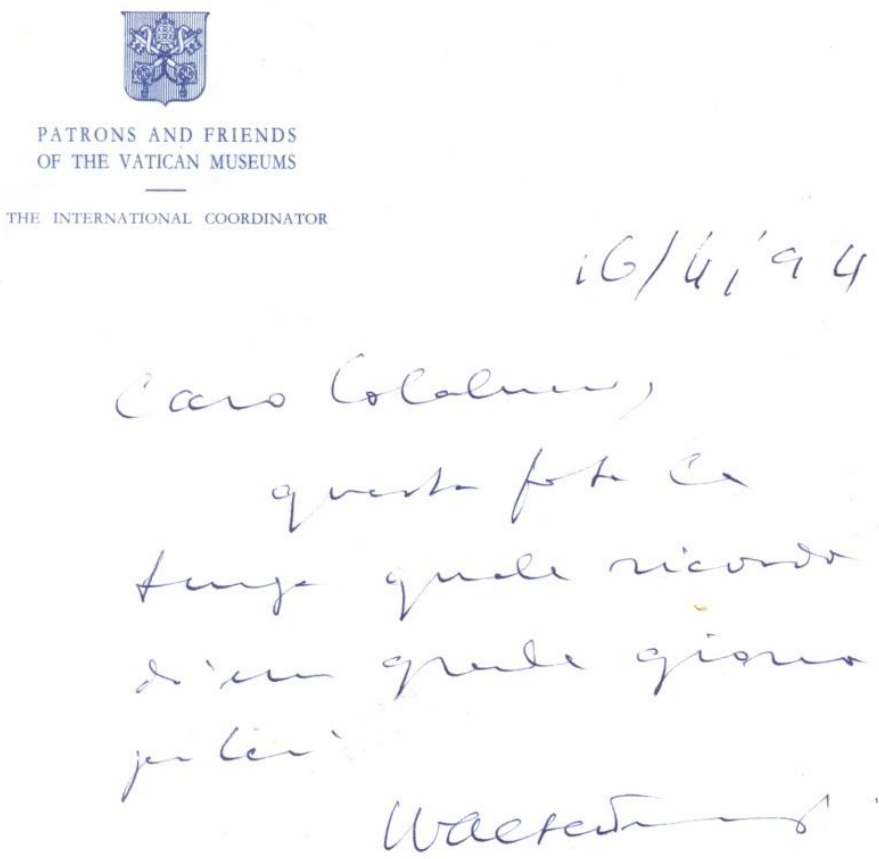

Palazzo San Calisto - I 00120 Città del Vaticano - Vatican City State Tel. (06) 698.7113 - FAX (06) 698.7262 - TELEX 2024 DIRGENTEL VA

Fig.34- II retro della foto 33, con la dedica a Colalucci da parte del Segretario Generale dei Musei W. Persegati 


\section{VI - OLTRE LA SISTINA}

Contemporaneamente al restauro della Sistina e dopo la sua conclusione, Colalucci svolge la sua normale attività privata presso le Soprintendenze. Lavora come abbiamo visto per la Galleria Borghese, per la Soprintendenza di palazzo Venezia, ma anche per la Soprintendenza di Mantova, per quella del Veneto e per quella di Napoli. I lavori divengono sempre più imponenti ed iniziano i grandi cantieri anche in virtù di alcune tragedie ambientali come il terremoto dell'Irpinia. Per fare fronte agli impegni fuori sede, Colalucci decide di formare il suo gruppo di restauro, riunendosi in consorzio con quattro giovani restauratori già suoi allievi. II consorzio si chiamerà "Eleazar" in omaggio al personaggio della lunetta di Michelangelo da cui è partito il restauro della Sistina. Con il suo gruppo Colalucci svolgerà alcuni importanti lavori a Roma a Napoli e a Padova. All'inizio degli anni novanta il gruppo si scioglie poiché ognuno dei componenti sceglie di seguire una sua propria strada. Nel 1993 dalle ceneri del consorzio nasce la società "Conservazione e Restauro" in seno alla quale ancora oggi svolge la sua attività. Ma nel frattempo sono arrivate le leggi sugli appalti pubblici che impediscono alle amministrazioni di scegliere a chi affidare i restauri. II curriculum del restauratore finisce all'ultimo posto nella classifica dei requisiti utili all'ottenimento dei lavori, mentre vengono messi in primo piano i requisiti economici e ciò spalanca le porte del settore alle imprese edili. 
Gli affreschi di Tiziano a Padova

Uno dei più prestigiosi lavori che Colalucci svolge agli inizi degli anni ottanta, riguarda i tre affreschi di Tiziano nella Scuoletta del Santo, a Padova. Gli importanti dipinti sono sotto la giurisdizione della "Veneranda Arca del Santo" l'antichissima associazione che dal XIII ${ }^{\circ}$ sec. si occupa della conservazione e della gestione dei beni mobili ed immobili appartenenti al Complesso Monumentale della Basilica di Sant'Antonio che è di proprietà della Santa Sede. II rapporto tra Colalucci e l'Arca del Santo, inizia nel 1982 quando in qualità di capo restauratore dei Musei Vaticani, viene mandato dal direttore Pietrangeli a studiare il serio problema di "sbiancamenti" che affliggeva da tempo gli affreschi di Tiziano. L'allora Presidente capo dell'Arca, l'architetto Danilo Negri, pur avendo fatto restaurare pochi anni prima gli affreschi, era preoccupato che non si riuscisse a debellare ciò che veniva scambiato per salificazioni, e temendo che il problema provenisse dall'umidità delle pareti, aveva chiesto a Pietrangeli un parere circa la possibilità di staccarli.

Gli affreschi rappresentano i miracoli di Sant'Antonio e sono inseriti in un ciclo pittorico eseguito nei primi anni Cinquanta del 1500, da vari pittori attivi in ambito padovano. Gli affreschi di Tiziano, rappresentano " il miracolo del neonato " quello del "Santo che riattacca il piede.." e quello con "il marito geloso che pugnala la moglie”. Quando Colalucci analizza i dipinti si rende conto che lo stesso fenomeno di sbiancamento del colore che tanto preoccupava l'architetto 
Negri, e che aveva richiesto l'esecuzione di una serie di interventi sugli affreschi di Tiziano ( l'ultimo risaliva alla metà degli anni 70), era presente anche su un frammento di affresco (non appartenente a Tiziano) e già staccato anni prima. II problema dunque non era attribuibile ai sali, che pure erano presenti, ma a qualcosa di diverso. Studiando meglio i dipinti, Colalucci vede che la superficie dei tre affreschi, ha un aspetto traslucido ed intuisce che nell'ultimo restauro era stato applicato un forte quantitativo di fissativo (poi risultato una resina acrilica ad alta concentrazione), che impediva il naturale scambio di umidità tra lo strato pittorico e l'ambiente. Al disotto del film di resina si depositava in modo anomalo l'umidità, ed i sali tendevano a esercitare una forza meccanica che finiva per creare piccoli ma diffusi sollevamenti di colore. Dopo una serie di procedure amministrative, il direttore Pietrangeli incarica Colalucci di occuparsi personalmente del restauro dei tre dipinti di Tiziano, ma non qualità di restauratore dei Musei Vaticani, bensì come libero professionista. Per portare avanti il lavoro Colalucci, essendo tra l'altro Padova distante circa cinquecento chilometri da Roma, deve mettere insieme una piccola squadra di allievi che, in sua assenza possa portare avanti le fasi meno delicate del lavoro. Colalucci usa i suoi giorni di ferie al Vaticano ed i fine settimana per eseguire la pulitura.

Colgo l'occasione per chiedere a Colalucci un commento sul Paraloid e sull'uso o l'abuso che di questa resina si è fatto in passato. Chiedo anche il suo giudizio sul fatto che spesso l'uso del Paraloid si contrappone 
erroneamente a quello del solfato di Bario, pur essendoci tra le due sostanze differenze sostanziali :

R. "Il Paraloid ha molti limiti e tra l'uso dei due materiali esistono delle differenze concettuali. II Paraloid secondo me ha anche delle buone qualità ma spesso viene usato male o a sproposito. Per esempio l'abitudine a dare comunque il Paraloid sugli affreschi dopo averli puliti o sulle salificazioni per farle diventare trasparenti li considero errori gravi. Sono invece d'accordo nel considerare l'uso del Paraloid utile in casi molto specifici, anche se bisogna fare in modo che non rimanga in superficie o formi un film. Questa è la ragione che mi ha portato a mettere a punto una metodica che consente l'uso del Paraloid come consolidante della pellicola pittorica senza avere l'inconveniente del film superficiale. Per il Bario vale lo stesso discorso può essere molto utile ma soltanto dove vi siano salificazioni di solfato superiori all' $82 \%$. Sono invece radicalmente contrario all'uso indiscriminato del Bario. Mi lascia ancora molto perplesso la preparazione delle superfici destinate ad essere trattate con il solfato di Bario. Per favorire la penetrazione del Bario la pellicola pittorica viene resa molto porosa e dunque la materia tipica dell'affresco cambia aspetto e questo non mi piace."

D.Tuttavia nonostante queste tue perplessità, ad un certo punto apri uno spiraglio all'uso del Bario in Vaticano

R. "Si perché non avevo e non ho pregiudizi ma piuttosto una attenzione al fatto che questa metodica in alcuni casi può dare risultati interessanti. Ho chiesto alla Direzione dei Musei di far venire a Roma il restauratore Guido

Botticelli da Firenze, per trattare con il Bario un affresco di Guido Reni (molto danneggiato dai solfati), che si trova nella Cappella Sistina della Basilica di Santa Maria Maggiore. In questo modo ho fatto in modo che alcuni giovani restauratori del laboratorio imparassero il metodo di applicazione. Tuttavia rimango convinto che il consolidamento con il solfato di Bario debba essere considerato come l'ultima spiaggia per il salvataggio di un affresco o di parte di esso e non come metodica di routine." 
Il lavoro sui dipinti di Tiziano impegnerà Colalucci dal 1982 al/1985 (circa tre mesi l'anno per ogni affresco). La pulitura riuscirà a risolvere in maniera definitiva quel problema che, non capito, aveva fatto sottoporre gli affreschi a continui restauri esponendoli anche all'ipotesi estrema dello stacco.

I lavori con il consorzio Eleazar e con la società Conservazione e Restauro

Nel frattempo Colalucci ha già formato il suo primo gruppo di lavoro, il consorzio "Eleazar", con il quale esegue molti grandi lavori importanti: si va dal restauro del tempio dei "Dioscuri" al foro romano, ai dipinti ad olio su muro e su lavagna di Siciolante da Sermoneta nella Cappella Cesi di Santa maria Maggiore, al grande soffitto ligneo di Teodoro d'Errico fiammingo della chiesa di "Dommaromita" a Napoli. A Padova con il consorzio restaura il trecentesco ciclo di affreschi di Giusto de' Menabuoi nella Basilica di Sant'Antonio, il ciclo cinquecentesco "dell'Oratorio di San Rocco" e quello del "Odeo Cornaro".

Quando nel 1990 il consorzio si scioglie, Colalucci fonda la "Conservazione e Restauro" con la quale eseguirà tra gli altri, il restauro del grande dipinto ad olio su ardesia di Francesco Vanni raffigurante "La caduta di Simon Mago", e quello del trecentesco ciclo di affreschi di Altichiero da Zevio nell'Oratorio di san Giorgio a Padova. 
Nel frattempo il mondo del restauro si è profondamente modificato, l'Italia è stata travolta dalla vicenda di "mani pulite" che ha portato all'entrata in vigore di leggi "capestro" nel settore degli appalti pubblici. Alla guida del Ministero dei Beni culturali (che in pochi anni cambierà più volte nome) si avvicendano Ministri totalmente inadeguati a gestire i gravissimi problemi che nel frattempo hanno travolto il settore. Vengono fatte scelte populiste, come quelle che in occasione dei lavori per il giubileo del 2000, consentiranno alle imprese edili (o a imprese di restauro con velleità imprenditoriali) impegnate nei grandi restauri messi in piedi dallo stato italiano o dal Vaticano (restauro della facciata della Basilica di San Pietro e tanti altri grandi lavori eseguiti in quella occasione senza una vera e propria necessità) di formare mano d'opera a costo zero. Quella stessa mano d'opera che oggi rivendica la qualifica di restauratore.

In questo desolante panorama dove l'esperienza e la preparazione sembrano non avere più alcun senso, lavorare per le Soprintendenze diviene praticamente impossibile.

I funzionari delle Soprintendenze quando vogliono evitare di ricorrere al sistema delle gare al massimo ribasso imposte dalla legge e scegliere $\mathrm{i}$ restauratori in base alla qualità professionale devono sempre più spesso ricorrere ai finanziamenti privati. È così che ancora oggi Colalucci viene chiamato ad occuparsi di alcune importanti opere. Tra il 2003 e il 2007 Colalucci si occupa del restauro del ciclo pittorico di Giulio Campi nella chiesa di Santa Margherita a Cremona, interamente finanziato da Giovanni Arvedi noto industriale dell'acciaio. Anche il lavori di cui si sta occupando attualmente come la ricomposizione dei frammenti degli affreschi di 
Mantegna $^{225}$ a Padova e il restauro della Cappella del Rosario nella chiesa dei Santi Giovanni e Paolo ${ }^{226}$ a Venezia, sono interamente finanziati da capitali privati.

Molto spesso Colalucci viene chiamato come "protezione preventiva contro le polemiche" in alcuni importanti cantieri, da quegli stessi funzionari che non sono in grado, nella routine, di affidargli direttamente i lavori. E' il caso del cantiere della Cappella degli Scrovegni a Padova il cui restauro, in base al protocollo d'intesa siglato II 31 maggio del 2000 tra il Ministero per i Beni e le attività culturali ed il Comune di Padova ${ }^{227}$, era stato affidato all'Istituto Centrale del Restauro ${ }^{228}$ e sul quale incombeva lo "spettro" di Beck. Beck si era risvegliato perché aveva intravisto, in una battaglia contro il restauro di Giotto, un ulteriore occasione di visibilità. La paura di delle critiche, ed i tempi strettissimi per l'esecuzione del lavoro, avevano indotto il direttore dei lavori G. Basile, a chiamare tre restauratori dalla fama inattaccabile: Colalucci, Pinin Brambilla e Carlo Giantomassi. Presto i timori di Basile nei confronti di Beck si riveleranno infondati poiché come si sa, se pure sommo pittore, Giotto non è Michelangelo, e questo farà sgonfiare la polemica sul nascere. II lavoro presenta tuttavia notevoli problemi tecnici soprattutto nella pulitura, che il progetto esecutivo prevedeva di eseguire con le resine a scambio ionico. Rapidamente l'esperienza di Colalucci, Brambilla e Giantomassi, porterà al

\footnotetext{
225 |l lavoro è sponsorizzato dalla Fondazione Cassa di risparmio di Padova e Rovigo.

${ }^{226}$ II lavoro è finanziato dalla stessa parrocchia.

${ }^{227}$ La Cappella degli Scrovegni è di proprietà del Comune di Padova dal 1880.

${ }^{228}$ II protocollo è pubblicato in Giotto, C. Scrovegni, verso il traguardo- Quaderno n 2 pp. 30-34 a cura di G. Basile, gennaio 2001
} 
cambio di procedura riuscendo a far pulire $\mathrm{i}$ dipinti con mezzi molto più semplici come l'acqua tiepida ed il carbonato d'ammonio. II lavoro sarà eseguito nei tempi stabiliti, anche perché alle prime ditte chiamate dall'Istituto se ne aggiungeranno altre 10. Nonostante l'impegno messo da tutti i restauratori per portare a termine il lavoro nei tempi stabiliti, alla inaugurazione del cantiere nessuno di loro sarà invitato alla cerimonia.

Qualche anno dopo, quando Colalucci e Giantomassi saranno impegnati nel complesso intervento sui frammenti degli affreschi di Mantegna, verranno duramente attaccati da Basile ${ }^{229}$ che metterà in dubbio proprio quelle doti indiscusse di preparazione tecnica ed onestà intellettuale che nel cantiere di Giotto aveva usato come scudo

${ }^{29}$ Basile trascinerà di fronte alla giunta comunale di Padova, i restauratori impegnati nel difficile "Progetto Mantegna" accusandoli di agire con leggerezza ed in funzione dell'inaugurazione finale. In quella stessa occasione, cercherà di avere in uso il sofisticato sistema informatico messo a punto dalla facoltà di fisica dell'Università di Padova per la ricerca dei frammenti. Un sistema avanzato che è riuscito nel Mantegna dove ad Assisi dopo il terremoto, il CNR. di Bari chiamato da Basile aveva totalmente fallito. 


\section{CONCLUSIONI}

Lo studio dei documenti d'archivio e la registrazione delle testimonianze dirette di Gianluigi Colalucci, hanno permesso di tratteggiare il profilo di un restauratore che certamente ha rappresentato e rappresenta, il modello immaginato da Cesare Brand e da Giulio Carlo Argan alla fine degli anni trenta del Novecento, e realizzato da Brandi attraverso i corsi a numero chiuso dell'I.C.R. a partire dalla seconda metà degli anni quaranta.

Si può obbiettare che, poiché la vita professionale di Gianluigi Colalucci è stata caratterizzata dalla esecuzione di un restauro assolutamente fuori dell'ordinario, come quello degli affreschi michelangioleschi della Sistina, la visibilità che ciò gli ha regalato in tutto il mondo,impedisce di considerarlo un modello sul quale fare valutazioni circa il livello della formazione media impartita da Brandi.

lo penso che il "modello Colalucci", pur escludendo la lunga parentesi Sistina, rappresenti ancora oggi il restauratore pensato molti anni fa per il futuro. Probabilmente la sua esperienza è tra le più ampie e complete che un restauratore possa acquisire nel corso della vita. La singolare duplice posizione di restauratore dipendente dei Musei Vaticani, a tutti gli effetti considerati territorio estero, e di restauratore libero professionista in Italia, lo ha messo nella condizione particolarissima di conoscere tutti i problemi, e di fare tutte le esperienze che le due "vesti", molto diverse tra loro dal punto di vista gestionale, comportano. Ha forgiato la sua esperienza spaziando in ambiti diversi tra loro, ed occupandosi del restauro di dipinti, ma anche di opere in bronzo e lapidee, il che gli ha dato la possibilità di ampliare ancora di più la sua conoscenza sui materiali e sulle tecniche. Per questo l'attuale tendenza in campo formativo, all'eccessiva specializzazione in ambiti sempre più circoscritti o peggio ancora abbinati per tipologie di supporto, lo vede in totale disaccordo, poiché considera questo un grave limite alle conoscenze del restauratore. Proprio per questo considero Colalucci il restauratore attraverso il quale è possibile studiare l'evoluzione di questa attività che da "mestiere" è stata trasformata in professione.

Colalucci rappresenta alla perfezione questo cammino, quasi un "traghettamento" che fino ad oggi si è rivelato molto faticoso e pieno di insidie.

Naturalmente sarebbe sbagliato pensare che in una professione vi possano essere solo picchi di eccellenza. L'eccezionalità, può infatti rappresentare un modello cui fare riferimento, ma niente di più. Penso che sarebbe assurdo pretendere da tutti $\mathrm{i}$ restauratori formati sulla linea di Brandi, quella sensibilità o quella capacità di approccio con l'opera d'arte, che possono avere acquisito soltanto alcuni di coloro che lo hanno saputo cogliere, come ha fatto Colalucci, direttamente dal padre del moderno restauro. Penso anche però che il buon livello medio raggiunto attualmente nel settore del restauro, non sia sufficiente a scongiurare il pericolo di ritorno al "mestiere". La gravissima crisi dell'Istituto Centrale del Restauro, che dopo Urbani e i Mora non ha più avuto figure carismatiche di riferimento, e la pericolosa tendenza a minimizzare l'importanza di una formazione di alto livello, da parte di chi la possiede di livello basso o non la possiede affatto, rischia di vanificare il cammino fino ad ora percorso. 
L'abitudine sempre più diffusa ad affidare alla diagnosi scientifica ciò che dovrebbe scaturire dalla lettura morfologica dell'opera d'arte e dall'elaborazione critica della sua storia conservativa fatta dal restauratore, non è un segno del progresso che avanza, ma un pericoloso segnale di "ritorno alle origini". Quelle origini che, come abbiamo visto, avevano reso possibile ad un laboratorio scientifico di antica fama e tecnologicamente avanzato come quello Vaticano, di mettere nelle mani di restauratori non adeguatamente preparati, una sostanza pericolosa come l'alluminato di potassio e di arrivare così alla gravissima vicenda della seconda loggia.

Con ciò non intendo certo sminuire l'importanza della diagnostica scientifica nel restauro, che considero parte indispensabile dello studio dell'opera, ma ritengo che il mezzo scientifico debba essere uno strumento nelle mani del restauratore e non il restauratore uno strumento nelle mani della scienza.

Del resto, come dice spesso Colalucci, per attrezzare alla perfezione un moderno laboratorio di restauro basta avere molti soldi, per attrezzare alla perfezione la mente del restauratore serve molto di più. 


\section{BIBLIOGRAFIA}

P. Acciaresi, "G. Sacconi e l'opera sua massima" 1911

M.Andaloro (a cura di) "La teoria del restauro del novecento da Riegl a Brandi" atti del convegno di studi, Viterbo Novembre 2003, ed. Nardini 2006

AA.VV "Cesare Brandi, teoria ed esperienza dell'arte" atti del convegno- Silvana editoriale, Siena 1998

AA.VV "Dizionario biografico dei Soprintendenti storici dell'arte"ed Bonomia University, Bologna 2007

AA.VV " Storia fotografica di Roma, 1919-1929" ed Intra Moenia, Napoli 2002

AA.VV "Carlo Scarpa" catalogo della mostra, ed. Electa, Milano 2000

AA.VV "Attività della soprintendenza alle gallerie del Lazio" catalogo della mostra ed De Luca,Roma,1967

AA.VV "Mostra dei restauri in Vaticano" bollettino M.M.G.P n IV ,1983

AA.VV "Michelangelo La Cappella Sistina- Rapporto sul restauro del GiudizioUniversale" ed. Musei Vaticani e Istituto Geografico De Agostani, 1999.

AA.VV " Archivum Arcis" ed. Romana Società editrice, Roma 1987

G. C. Argan "Occasioni di critica" ed. Riuniti, Roma 1981

G.C. Argan B.Contardi "Michelangelo architetto" ed. Electa, Milano 1990

M. Armellini "Le chiese di Roma" tomo I , ed. R.O.R.E. Città di Castello 1941

G. B. Armenini "De' veri precetti della pittura" ed. Einaudi, Torino 1988

S. Augusti "Natura e cause delle efflorescenze bianche che si producono sugli affreschi" Napoli 1948

AA.VV " Quando gli Dei si spogliano" a cura di B. Contardi, ed. Romana società editrice, Roma 1984

AA.VV "L'Angelo e la Città" ed. Palombi, Roma 1989

D. Bartoletti, "Intervista a G. Colalucci" in R \& R n 108-Valencia, settembre 2008

A.Bayer (a cura di) "Dosso Dossi pittore di corte a Ferrara nel Rinascimento" scheda n 28 su l'Apollo- ed. Sate, Ferrara 1998

G. Basile, Giotto,Cappella degli Scrovegni,verso il traguardo, Quaderno n 2 pp.30/34,gennaio 2001

B.Biagietti "La volta della Cappella Sistina, primo saggio di indagini sulla cronologia e la tecnica delle pitture di Michelangelo" estratto dai rendiconti della Pontificia Accademia Romana di Archeologia,vol.XII Roma 1936

C. Bon Valsassina "Restauro made in Italy" ed Electa, Milano 2006

S. Boscarino "Sicilia Barocca" ed Officina, Palermo 1986

C. Brandi "Mostra dei dipinti di Antonello da Messina" catalogo della mostra I.C.R. Roma, novembredicembre 1942

C. Brandi "Mostra dei frammenti ricostruiti di Lorenzo da Viterbo" I.C.R., Roma, maggio 1946

C. Brandi “ VI ${ }^{\circ}$ Mostra dei restauri" catalogo, I.C.R., Roma, marzo 1949

C. Brandi "Mostra di dipinti restaurati" catalogo della mostra di Palazzo Venezia,Roma, marzo 1953

C. Brandi "Restauri a Piero della Francesca" bollettino I.C.R. n 17-18 anno1954

C. Brandi "Mostra di opere restaurate"in occasione delVII Congresso internazionale di Archeologia

Classica, I.C.R. Roma settembre 1958

C. Brandi "Teoria del Restauro"- ed Piccola Biblioteca Einaudi, Torino 1977

C. Brandi "Il Restauro" a cura di M.Cordaro- editori Riuniti, Roma 1994

C. Brandi "Carmine o della Pittura" ed Vallecchi, Firenze 1942

C. Brandi "Il restauro dell'opera d'arte secondo l'Istanza estetica o dell'artisticità" in Bollettino dell'I.C.R n० 13 pp.3-8, Roma 1953

C. Brandi "Viaggio nella Grecia antica" ed. Vallecchi Firenze 1954

C. Brandi "Sicilia mia" ed Sellerio, II ${ }^{\circ}$ edizione, Palermo 2005

M. Cagiano de Azevedo "Provvedimenti conservativi per una casa romana.." bollettino I.C.R. $n^{\circ}$ 7- 8 1951 pp.33-34

M. Calvesi "Piranesi nei luoghi di Piranesi-Carceri,Mole Adriana, Vedute di Roma" Catalogo della mostra ed. Palombi, Roma 1979

M. Carboni "Cesare Brandi” Editori Riuniti, Roma 1992

M. I. Catalano "Brandi e il restauro" ed Nardini, Firenze 1998

C. Cennini “Il libro dell'Arte” con pref.di L. Magagnato, ed. Neri Pozza, Vicenza 1971

A.Chastel " La grottesca" ed. Einaudi, Torino 1989

G. Colalucci "Relazione del restauro..." II Polittico degli Zavattari , Firenze 1984 pp. 101

G. Colalucci et altri "La Cappella Sistina : i primi restauri" "La Volta restaurata" "La Cappella Sistina"ed.

Istituto Geografico De Agostini - I vol. 1986- II vol. 1992-III vol.1997

G. Colalucci "la tipologia dei cartoni e la tecnica esecutiva della volta della Cappella Sistina" e "Test e Informazioni disponibili sul Giudizio: lo stato di Conservazione e la tecnica esecutiva" in atti del Convegno internazionale di studi, marzo 1990-ed. Istituto Geografico De Agostini 1994 
G. Colalucci "Lo stato di conservazione degli affreschi di Michelangelo sulla volta della Cappella Sistina e l'intervento di restauro" in Rapporto sul restauro della volta- ed. Istituto Geografico De Agostini 1994

G. Colalucci "Tecnica e metodologia operativa di Michelangelo sul Giudizio Universale"e "Lo stato dell'affresco prima del restauro" in Rapporto sul Restauro del Giudizio Universale - ed. MuseiVaticani

Istituto Geografico De Agostini 1999

G. Colalucci "Le lunette di Michelangelo nella Cappella Sistina" in Tecnica e stile (a cura di E. Borsook e

F. Gioffredi) ed. Silvana Editoriale , Firenze 1986

G. Colalucci et altri "Mchelangelo e la Sistina- la tecnica il restauro il mito" ed.Palombi, Roma 1990

G. Colalucci "Il restauro della volta e del Giudizio della Cappella Sistina e la tecnica nella pittura ad affresco di Michelangelo : nuove riflessioni" La Sistina e Michelangelo (a cura di F.Buranelli;

A.M. De Strobel ; G. Gentili ) Silvana editoriale, Milano 2003

G.Colalucci "Lunette con Eleazar-Mathan; Jacob-Joseph; Achim-Eliud;Azor-Sadoc;Josias-Jeconias

Salathiel" in Bollettino dei Musei Monumenti e Gallerie Pontificie, IV 1983

G. Colalucci e P. Bonometti (a cura di) "Le chiese delle Sante Margherita e Pelagia" ed.Silvana editoriale, Milano 2008

G. Colalucci, D. Bartoletti, L. Baggio "Altichiero da Zevio nell'Oratorio di san Giorgio- il restauro degli affreschi" ed. De Luca, Roma 1999

G. Colalucci e D. Bartoletti "Appunti sulla tecnica esecutiva degli affreschi di Altichiero nell'Oratorio di S. Giorgio a Padova" in II Santo XXXIX, 1999, fasc. 1-2

A. Conti, Storia del restauro e della Conservazione delle opere d'arte ed. Electa, Milano 1988

A. Conti, Michelangelo e la pittura a fresco- tecnica e conservazione della Volta Sistina" Firenze 1986

B.Contardi e A. Gentili “ II San Girolamo di Lorenzo Lotto a Castel Sant'Angelo"ed. Romana Società editrice, Roma 1983

B. Contardi e G. Curcio "In Urbe Architectus" ed Argos, Roma 1991

M. Cordaro (a cura di) "II Restauro" ed. Riuniti, Roma 1994

A.M. De Strobel "Documenti per la Cappella Sistina » in Michelangelo, cat. della mostra ed. Fratelli Palombi, 1990

De vecchi, Guazzoni, Girardi "Michelangelo pittore ,scultore e architetto e rime”, ed .Jaca Book

R. De Maio "Michelangelo e la Controriforma" ed. Sansoni 1990

M. Fagiolo dell'Arco "La festa barocca" ed. DeLuca, Roma 1997

A.Forcellino"Michelangelo Buonarroti, storia di una pasione eretica" ed,Einaudi 2002

U. Forni "Manuale del pittore restauratore" studi per la nuova edizione (a cura di G. Bonsanti e M.Ciatti) ed. Edifir, Firenze 2004

E. Gaudioso "I lavori farnesiani a Castel sant'Angelo" ed. libreria dello stato, Roma 1979

E. Gaudioso e F. Aliberti " Gli affreschi di Paolo III a Castel Sant'Angelo" ed. De Luca, Roma 1982

A. Gentili "Da Tiziano a Tiziano" ed. Bulzoni, Roma, 1988

Goethe "La Teoria dei colori" con introduzione di G.C. Argan, ed. II Saggiatore, Milano 1979

M. Hirst "Michelangelo and his drawings" London 1988

M.Hirst "Michelangelo, i disegni" (traduzione Casadei e Ornella Francisci Osti)

I.Insolera "Archeologia e città" ed. Laterza, Roma 1983

I.Insolera "Roma, Immagini e realtà dal x al xx secolo" ed. Laterza, Roma 1980

I.Insolera " Roma fascista" ed. Riuniti, Roma 2001

D. Levi "Cavalcaselle" il pioniere della conservazione dell'arte italiana, ed. Einaudi, Torino 1988

S. Liberti " Stendardo processionale opera di Raffaello.." bollettino I.C.R. n 9-10anno 1952

S. Liberti, Analisi microclimatica dei campioni delle efflorescenze degli affreschi di A. Solario" Bollettino

I.C.R. n² - Roma 1950

Nogara "I musei e le gallerie Pontificie nell'anno 1925/1926" in rendiconti della Pontificia Accademia Romana di Archeologia, anno IV 1926

C.Malvasia, "Vite dei pittori bolognesi" Bologna 1678

F. Mancinelli e G. Colalucci," Apoteosi di S .Clemente di Giovanni e Cherubino Alberti"- Bollettino dei Monumenti ,Musei e Gallerie Pontificie no IV-1983

F. Mancinelli "Arte medioevale e moderna" bollettino dei monumenti, musei e gallerie pontificie, estratto del volume I -anno 1959/1974

F. Mancinelli (a cura di) "Michelangelo- La Cappella Sistin") rapporto sul restauro degli affreschi della volta, vol. II- ed Istituto Geografico De Agostini,1994

F.Mancinelli A. De Strobel "Le lunette e le vele della Cappella Sistina" ed. Leonardo-De Luca, Roma 1992

P. Morello "Palazzo Abatellis" ed. Vianello, Treviso 1989

C.Pietrangeli F.Mancinelli "I recenti restauri.."- in Rassegna dell'Acc.Naz. di S Luca- Roma

C. Pietrangeli "Premessa al Bollettino dei Monumenti, Musei e Gallerie Pontificie" n 1-3-anno 1979 
G. Piva"Il restauro dei dipinti nel sistema antico e moderno" ed.Hoepli, Milano1961

G. Piva "Manuale pratico di tecnica pittorica" ed. Hoepli III ed, Milano 1964

G.Sacconi, "Relazione del progetto per il monumento a Vittorio Emanuele II" 1883

F. Scoppola "Normativa e restauro, alla ricerca di un orientamento nella definizione delle procedure da adottare" in Giotto, Cappella Scrovgni, II progetto di Restauro, quaderno 0 - maggio 2001

V. Scuderi "Mostra dei dipinti restaurati del Museo Nazionale Pepoli di Trapani" cat. della mostra, ed cartograff- Trapani maggio 1955

G.Secco Suardo "II restauratore di dipinti" con pref. di G. Previati, ed. Hoepli, Milano 1918

G.SeccoSuardo "II restauratore di dipinti" ed.postuma- ed.Hoepli, Milano1894

S. Settis "Italia S.P.A." ed.Einaudi,Torino 2002

I.Toesca "una croce dipinta romana" bollettino d'arte n 51, Roma 1966

I.Toesca "L'antica Madonna di Sant'Angelo in Pescheria a Roma" su Paragone n²27, 1969 pp.3-18

M.E. Tisserant "Une Vierge Italo-Bizantine de Cima Da Conegliano" Biblioteca Apostolica Vaticana 1964

G. Urbani "Intorno al restauro" ed. Skira, Milano 2000

G. Urbani " II restauro degli affreschi di Antonio Solario" bollettino I.C.R. n 2 anno 1950

G. Urbani "Problemi di Conservazione" ed. Compositori, Bologna

G. Urbani "Il trittico della chiesa di S.Maria Assunta di Casacastalda" bollettino I.C.R n`3-4- 1950

G. Urbani "San Girolamo nello studio" bollettino I.C.R. n 7-8 p. 73, anno 1951

P.Vandenberg "il complotto della Cappella Sistina" ed.Sugarco1998

G. Vasari “Le vite...” nell'edizione di L. Torrentino Firenze 1550 - A cura di L. Bellosi e A. Rossi- ed. Einaudi, Torino 1986

L. Venturi "Storia della Critica d'arte" ed Piccola Biblioteca Einaudi, torino 1964

G. Vigni e G. Carandente "Antonello da Messina e la pittura del " 400 in Sicilia" catalogo della mostra ed. Alfieri, Venezia 1953-e ancora in Bollettino dell'I. C. R. n 14-15, Roma 1953

A.Vermeheren "Sulle possibilità Stereo-Strato-Radiografiche ecc...." in Bollettino dell'I.C.R. $\mathrm{n}^{\circ}$ 11-12

Roma 1952 pp.121-133

A. Zalapì "Dimore di Sicilia" ed. Arsenale, Verona 1998

\section{STAMPA}

D .Petrocelli, Un inedito Giudizio Universale nella restaurata Cappella Sistina ,II Tempo, merc. 11 febbraio 1981

L. Storoni, Gli affreschi della Sistina ritrovano il loro splendore, La Stampa,11 febbraio 1981,p,6

"Michelangelo va in restauro", Corriere della Sera, 11 febbraio 1981

D. Cimagalli, 12 anni per lavare il Giudizio Universale, Gente, 6 marzo 1981,pp.1287130

Henry Tanner, Restoration Reveals Michelangelo's Gifts ,New York Time,31 marzo 1981

F. Bellonzi, Conosciamo un nuovo Michelangelo, II Tempo, 8 aprile 1981,p.3

"In Vaticano fanno toilette gli affreschi della Sistina", La Repubblica, 28 giugno 1981

"Zwolf Jahre kur fur Michelangelo", Stern, 31 luglio1981

"All of Michelangelo's work will have to derestudied", Art News, ottobre 1981

F. Dentice, I colori della Sistina, L'Espresso, 24 gennaio 1982,pp.91/97

M. Barina, Con i restauratori sui ponteggi della Sistina sembra di sentire la presenza di Michelangelo, Corriere della Sera, merc.27 gennaio1982

C. Hemphil, Sistine Chapel's facelift successfully underway, in Daily American, 14 febbraio 1982,p.10

P. Pons, Le lunettes de Michel-Ange, in Art set Spectacles, Le Monde,15 aprile 1982,p.15

A. Ricci, Michelangelo senza veli, II Messaggero, 26 aprile 1982,p.6

Patricia Corbett, After centuries of Grime, Connoisseur Magazine, maggio 1982

D. Petrocelli, Un Mecenate venuto dall'oriente, II Tempo, 23 novembre 1983,p.6

F. Santini, Michelangelo tra dollari e yen, La Stampa, 17 dicembre 1983,p.3

Vanja Luksic, Les Japonais de la Sixtine, L'Express, 16 dicembre 1983

G. Massari, C'è voluta una pennellata di giallo, Epoca, 9 marzo 1984,pp.72/78

Clara Valenzano, Michelangelo a colori sotto il fumo e la colla, Repubblica, 24 aprile 1984,p.15 
"Altri otto anni di lavoro alla Cappella Sistina" Repubblica, 13 dicembre 1984

G. Carandente, La Sistina cambia pelle, II Giornale, 13 dicembre 1984,p.3

"Dalla Sistina il restauro de/Secolo" Repubblica, 18 dicembre 1984

F. Minervino, Michelangelo riserva una sorpresa:il colore, Corriere della Sera, 19 dicembre 1984

F. Miracco, Ne dipinse di tutti i colori, L'Europeo, 22 dicembre 1984,pp.100/104

R. Lane, Michelangelo plain, Washington Post, 23 dicembre 1984

R. Stenge, A new glimpse of Michelangelo, Time, 24 dicembre 1984

A.Donati, Alla ricerca di una volta perduta, Repubblica, 27 dicembre 1984

M. D. Suro, II restauro della Sistina:guai in paradiso, New York Time, 4 gennaio 1987

C. Bertelli, Michelangelo sporco dura di più?, Corriere della Sera ,4 febbraio 1987

L. Manisco, Ora anche dagli USA "fermate i restauri", Paese sera, 5 febbraio 1987,p.11

G. Colalucci, Caro Beck lei mi offende, Repubblica 7 febbraio 1987

A.Debenedetti, Per la Sistina non c'è bisogno di pause, Corriere della Sera, 7 febbraio 1987

P. Consagra, Un pugno dall'aldilà, II Giornale, 8 febbraio 1987

G. Briganti, Quando si firma al buio, Repubblica, 8 marzo 1987

D. Del Rio, Quattro passi in Paradiso, Repubblica, 8/9 febbraio 1987

O. Petrosillo, Torna il vero Michelangelo dagli affreschi della Sistina, II Tempo,8 febbraio 1987

E. Porta Cuando se confunde misterio con mugre El Pais, 17 febbraio 1987

F. Zoccoli, Sotto il velo c'è proprio Michelangelo, II Resto del Carlino, 21 febbraio 1987

A.Pinelli, I colori della disputa, II Messaggero,26 febbraio 1987

P. Morison Michelangelo in his true colurs The Daily Telegraph, 3 marzo 1987

G. Glueck Halt Urged in Work on Sisine and Last Supper The New York Times, 6 marzo 1987

A. Pinelli, Ciò che Beck non ha tenuto presente, Repubblica, 8 marzo 1987

G. Del Re, Dall'America nessuna scoperta, Repubblica , 8 marzo 1987

F. Clerici, Non confondiamo l'olio con l'acqua ,Repubblica, 8 marzo 1987

J. Russel Conservators Endorse Sistine Restoration The New York Times, 16 aprile 1987

A. Chastel La nouvelle palette de Mchel-Ange Le Monde, 24 aprile 1987

R. Hughes Out of Grime, a Domain of Light Time, 27 aprile 1987

F. De Azuca "Miguel Angel,blanco y negro, o color?" El Pais, 2 luglio 1987

J. Pope-Hennessy Storm Over the Sistine Ceiling The New York Revivew, 8 ottobre 1987

A. Zanoli “ II tradimento della luce” Giornale dell'Arte luglio-agosto 1988.

J.Beck ,"La mia carta dei diritti delle opere d'arte" e "Il decalogo di Beck", Giornale dell'Arte n 87 ,marzo 1991, p.38

C. A. Bucci intervista Colalucci “Questo è il vero Michelangelo" L'Unità 7 gennaio 1994

G. Fabre intervista R.De Maio "Ok, il Giudizio è giusto" Panorama 21 gennaio 1994

A. Sandoval "La restauracion de los frescos de la Capilla Sixstina finaliza tras catorci anos de trabajos" La Vanguardia, 31, gennaio 1994

J. Arias “El Juicio Final de la Capilla Sixtina restaurado tras cuatro anos de trabajo" El Pais 14 febbraio 1994

C. Salvadè "Devant le Jugement dernier de la Sixtine, comme au premier jour" e "Quatorze ans de travail à quatre » Le Noveau Quotidien 1, marzo 1994

J. Arìas "El verdadero rostro de Dios" El Pais semanal, 6 marzo 1994

M. Legris "La renaissance de Michel-Ange » L' Esxpress, numéro spécial, marzo 1994

L. Ventura " II Giudizio dai ponteggi" La Gazzetta di Modena, 13 marzo 1994

O. Madelin "La gloire de Michel-Ange" Le Spectacle du Monde n 385- aprile 1994

R. De Maio" Nel giorno del Giudizio" La Voce, 5 aprile 1994

T. Abate "I pro e i contro del restauro- colloqui con Scialoja, Carandente e Beck" La Voce, 5aprile 1994

M.F.Apolloni "Alla fine restarono tutti in mutande" La voce 5 aprile 1994

C. Strinati "Gli stivali di Michelangelo" la Repubblica.7 aprile 1994

P.Vagheggi "Uno Choc a colori" la Repubblica, 7 aprile 1994

L. Storoni "Nudi da discutere" la Repubblica, 7 aprile 1994

P. Vagheggi "La Sistina ritrovata" la Repubblica 9 aprile 1994

M. N. De Luca «A colpi di spugna contro le offese dei secoli »la Repubblica, 9 aprile 1994

F.Isman "Un Michelangelo mai visto prima" il Messaggero,9 aprile 1994 
P. Conti ed E..Tadini "Michelangelo il cielo sopra Woitjla" Corriere della Sera 9 aprile 1994

F. Gianfranceschi "II Giudizio Universale rivelato" II Tempo, 9 aprile 1994

C. D'Onofrio "La Sistina nacque cosi" II Tempo 9 aprile 1994

S. Sereni "Rinasce il Giudizio Universale" Epoca, 12 aprile 19994

A. Mammì intervista G. Colalucci "La mia vita con Michelangelo" L'Espresso, aprile 1994

P. Conti "Beck? Va rinviato a Giudizio- la replica di carandente" Corriere della Sera, 23 aprile 1994

E. Tadini "Quello è il colore di Michelangelo" Corriere della Sera, 23 aprile 1994

P. Badaloni " E venne il giorno del Giudizio" Radiocorriere TV, maggio 1994

VIDEO

N. Criscenti "Michelangelo rivelato" video in Speciale Tg1, produzione RAI 11984.

N. Criscenti "Dentro la Sistina” video con E. Gombrich, G.Briganti e F. Zeri, RAl 1989.

N. Criscenti "Michelangelo : il Giudizio Rivelato" video, produzione RAI 1, trasmesso il 18 maggio 1994.

A. Zanoli "La creazione dell'uomo" film $16 \mathrm{~mm}$. riversato su video, fotografia di C. di Palma, produzione Biennale di Venezia settore Arti Visive, con l'apporto dell' Archivio delle immagini N.T.V 1988.

A. Zanoli "Il colore di Michelangelo" video, produzione RAl 1 trasmesso in Tg1 sette il 2, maggio 1989.

A. Zanoli "Il restauro del Giudizio Universale" video, produzione RAI in Bellitalia 12 aprile 1994. 


\section{Gianluigi Colalucci}

\section{y su trayectoria restauradora}

Un viaje a través de las transformaciones en el mundo de la restauraciòn desde Cesare Brandi a nuestros dias

-VOLUMEN II-

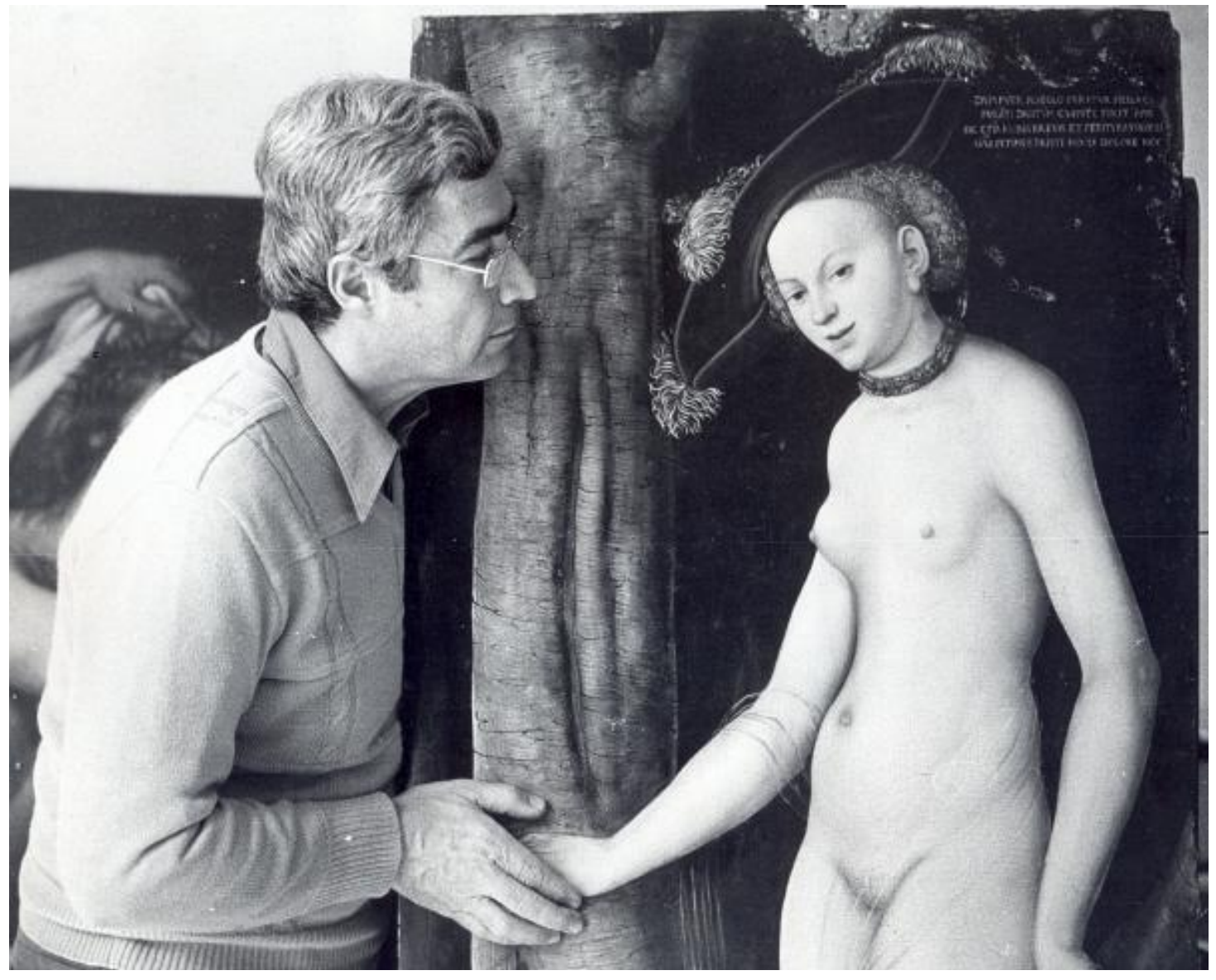

Tesis Doctora

Daniela Bartoletti 2010
UNIVERSIDAD

POLITECNICA DE VALENZIA
Dirigida por Dra. Pilar Roig Picazo 
DOCUMENTI POPE-HENNESSY - ( Archivio Colalucci- sezione documenti- F.9 serie 6)

28 VIA DE' BARDI 50125 FIRENZE
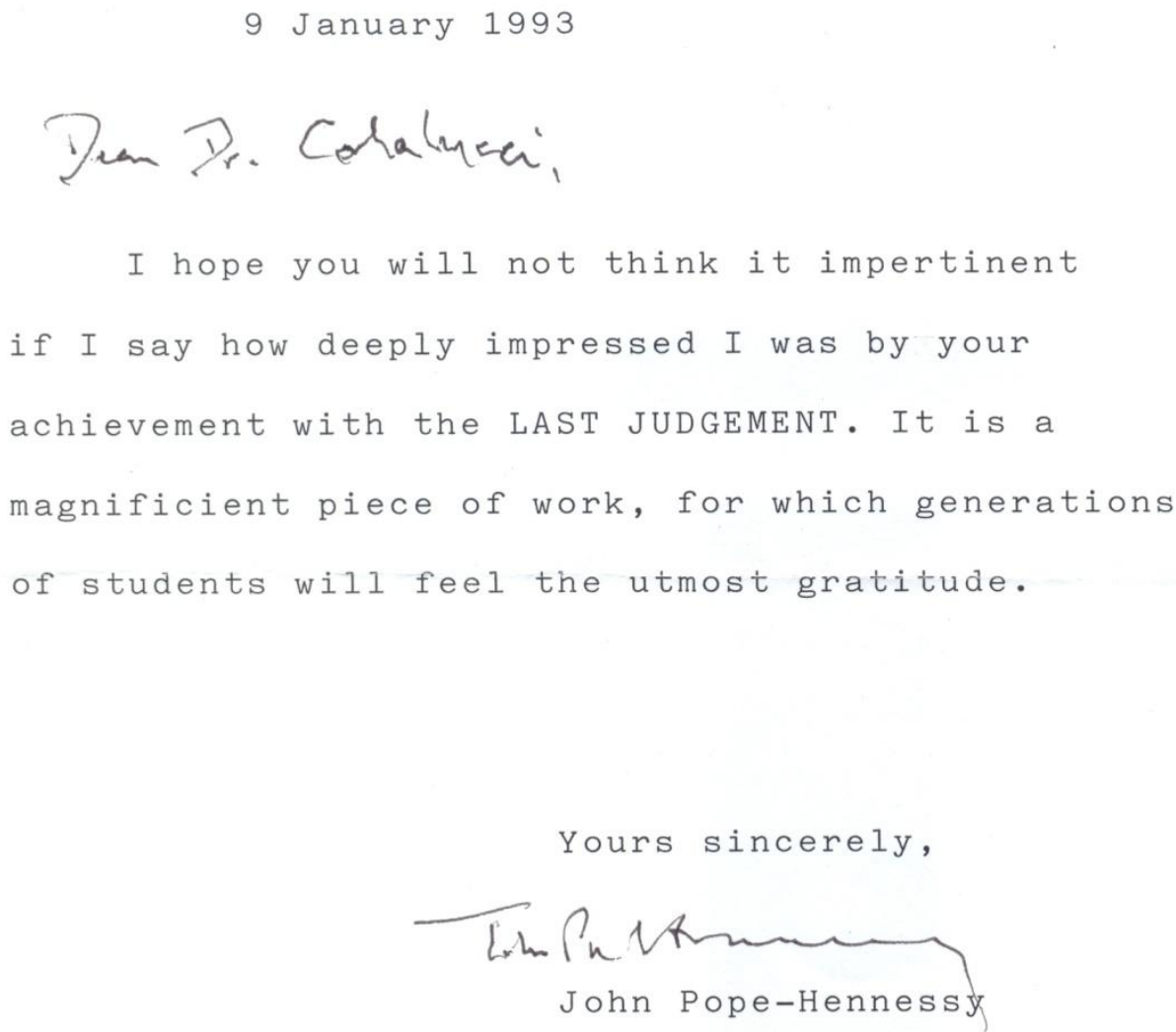

Doc. P-H 1/93 
Chiarimimo Prot. John Paje Menneny.

Le sono grato per l'apprezzamento lusinghiero che Ella ha voluto parteciparmi, circa il mio lavoro sugli affreschi michelangioleschi della Cappella Sistina.

Le Sue parole rappresentano per me e per tutti coloro che insieme a me sono impegnati in questo lavoro di restauro, il più alto riconoscimento ad un impegno che ci ha visto talvolta affrontare la bufera delle incomprensioni e delle critiche sferzanti, amplificate da mass media assetati di scandali.

Con gratitudine, e con l'augurio di incontrarla ancora sul ponteggio del Giudizio Universale, Le porgo i miei più deferenti saluti.
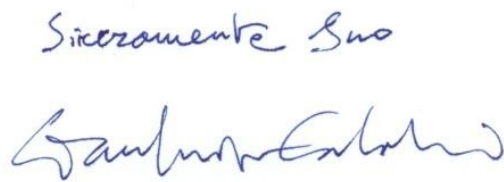

Gianluigi Colalucci

Doc. P-H 2/93 
DOCUMENTI MASON (Archivio Colalucci - sezione documenti- F.9 serie 6)

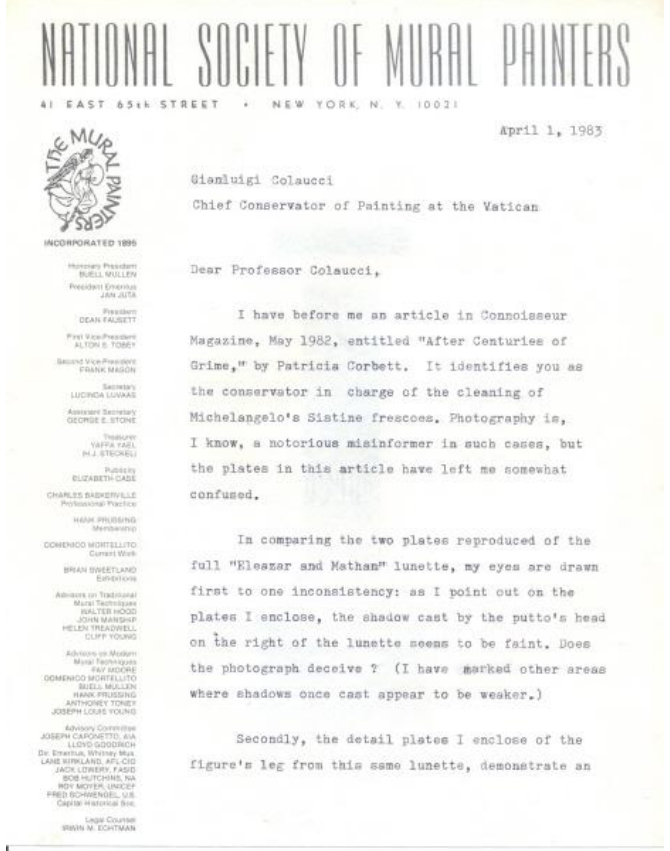

Doc. M. 1 /83

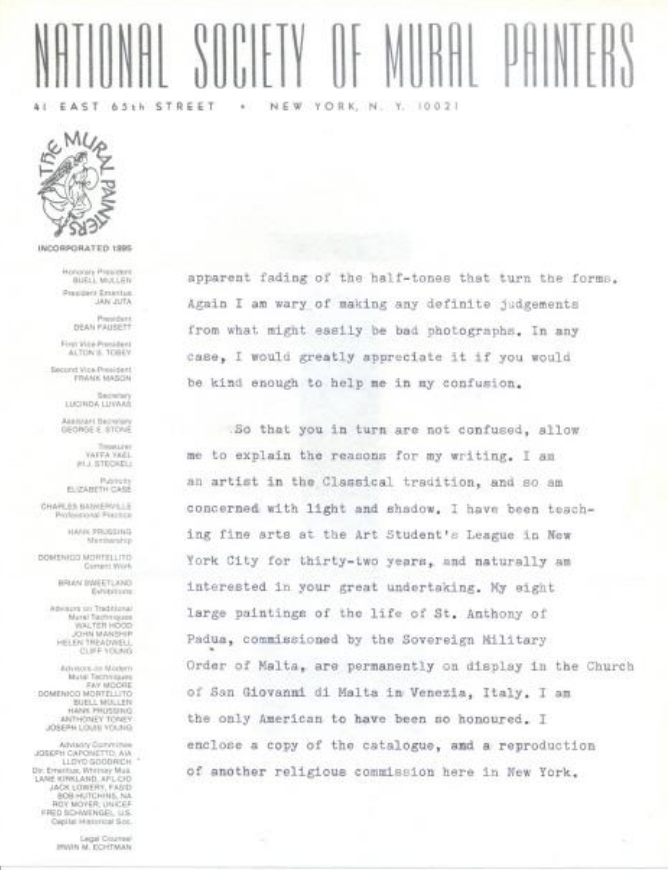

Doc. M. $1 / 83$

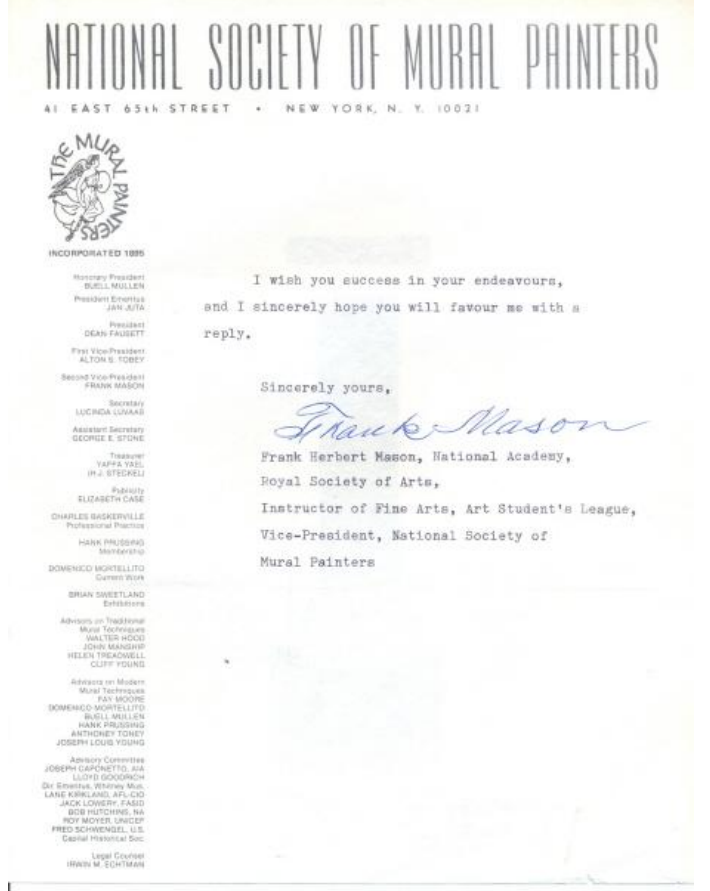

Doc. M.1/83 


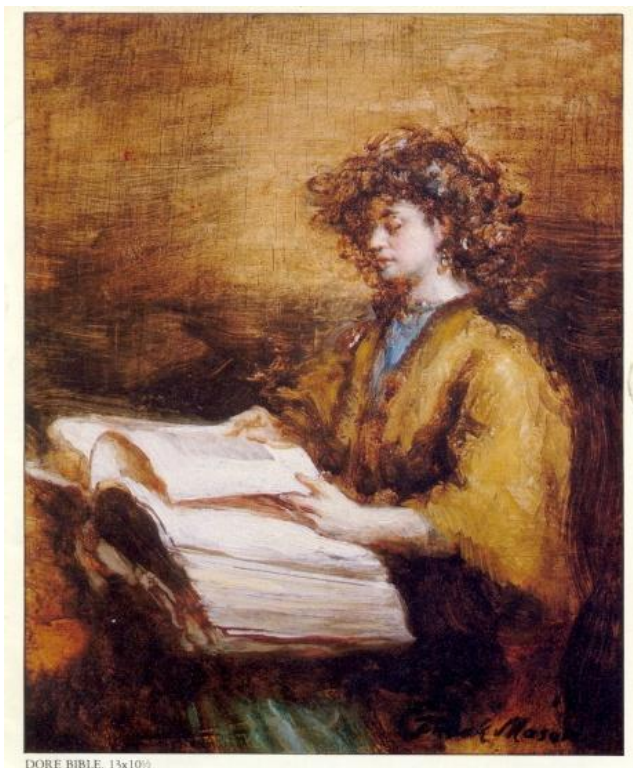

FRANK MASON, N. A.

Doc. M. 2/83

\section{EAST PAINTS WEST}

FRANK HERBERT MASON, N.A.

David L. Bell

\author{
O'MEARA GALLERY, LTD. \\ OF \\ SANTA FE \\ proudly presents
}

\section{FRANK MASON, N.A.}

YOU ARE CORDIALLY INVITED TO THE OPENING RECEPTION

Saturday, October 15, 19836 p.m. - 8 p.m.

THE ARTIST WILL BE PRESENT

Demonstration and discussion of the artist's technique and research will be

EXHIBITION CONTINUES THROUGH NOVEMBER 1, 1983
When critics and collectors speak of a renaissance of landscape and figure painting, they mean, as much as anything else, that they have reawakened to its existence. For a tradition
as central to western civilization as representational art can hardly be supposed to have perished because a few generations of artists and theoreticians have rebelled against it. It is true that science has changed our view of life, but it has not changed the nature of life which
is the subject of art And for that matter, the Hellenistic and Renaissance worls hed their science too, the forerunner of our own. What the undeniable philosophical shifts of modem life do require is adaptation of tradition, and that in turn calls for enlightenment, which is to say education about the past
and an honest eve focused on the present. Without education, we labor to reinvent the and and. And without honest vision, we produce art that mocks the past. Tradition can
when perhaps best be defined as a balance of continuity and change. The life and work of Frank Herbert Mason are most readily understood in that context of
living tradition A painter in what is sometimes called "ellasscell" style, Mason has made living tradition. A painter in what is sometimes called a "lassical" "tyle, Mason has made
landscapes, religious paintings and portraits, including a "Portrait of the Artist" in Renaissance garb, that have the light, space and brushwork we associate with the art of the past. Yet he has equally conferred those qualities in portraits of contemporary personages
including black militant Melvin Van Peebles, in including black militant Melvin Van Peebles, in a present-day genre painting such as
"Scene from Little Italy,"and in New England and Southwestern landscape work that would "Sardly be taken as from the Renaissance or even the American 19 th century, yet verifies the link between the two and from them to the present. Nor is Mason's "Gloria in Excelsis Deo" likely to be mistaken for a 16th century Venetian
painting though its gestural composition and brilliant but suffised light immediately bring painting, though its gestural composition and brilliant but suffused lightimmediately bring
to mind the vision of Tintoretto. The point is that, far from doing an imitation of the great Mannerists, Mason has aligned himself in spirit with the sources of his predecessor's inspiration, and from that starting point has taken the matter forward on his own. Not
incidentally, he is in posession incidentally, he is in possession of the technical mastery to do so. That fact has to do with
Mason's early life and education, with his dedication to the belief that Renaissance Mason's early life and education, with his dedication to the belief that Renaissance
consciousness remains the animus of modern man, and with the informed determination to embrace and extend that consciousness

Born in Cleveland in 1921, Frank Mason was the son of parents with artistic interests, the father a collector of 19th century paintings, the mother a musician and painter. His New York City mayor Fiorello La Guardia and at the age of twelve, Mason was a prorenticed to Manuel Reyes, the Spanish painter and poet, at the newly-founded New York City Music and Art High School

The particular nature of his artistic gift was confirmed by confrontation with a and that Mason's budding work was plagiarism. At the age of sixteen. Mason transfered to the no less distinguished tutelage of classicists Frank Du Mond and George Bridgman at the
Art Students League. The criticism had been valuable, for it alerted Mason to the dangers of

Winning a scholarship for what proved to be the first year of a long affiliation, Mason
studied with Du Mond until the latter's death in 1951, following which he took his teacher's

Doc. M. 2/83 


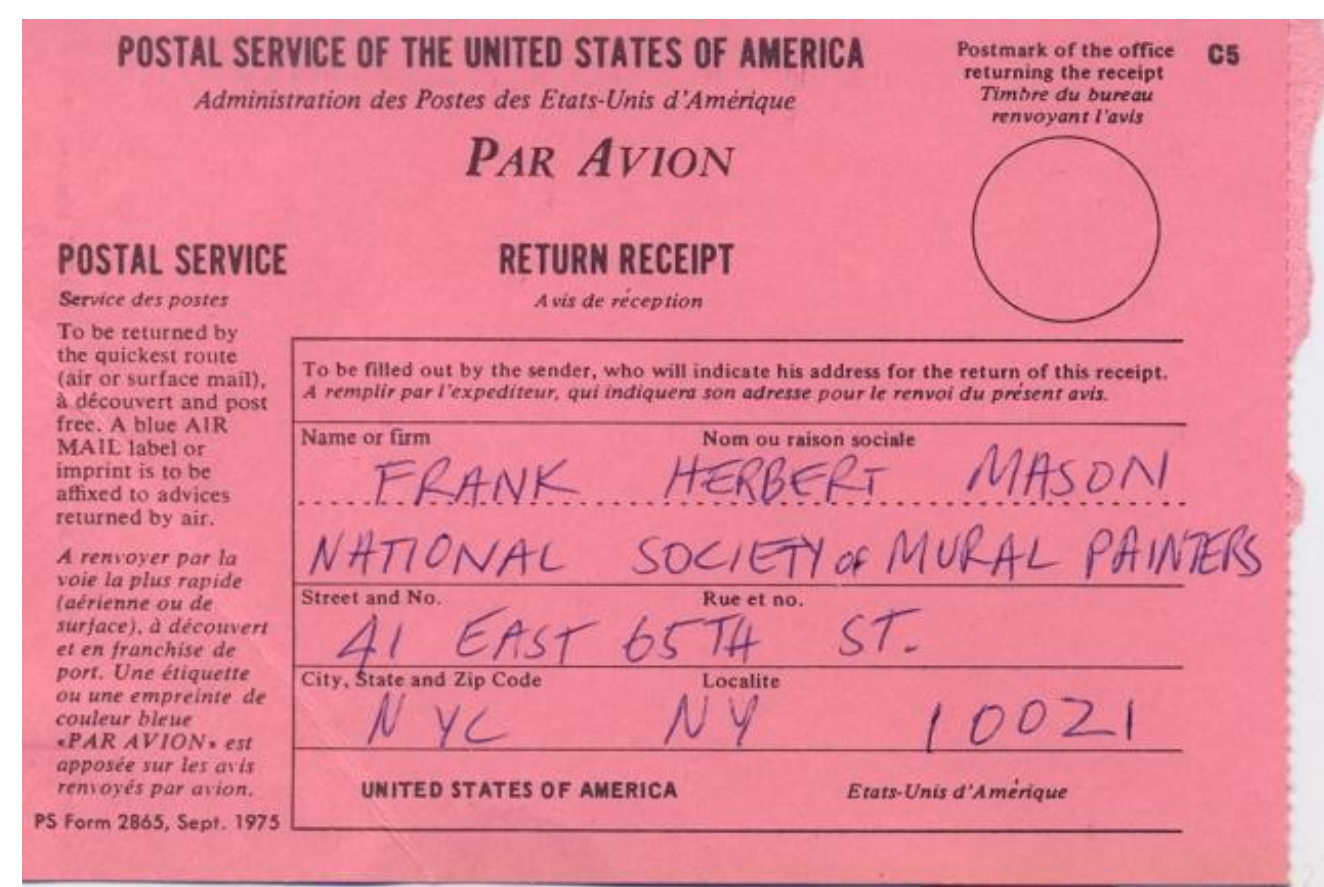

Doc. M. 3/83

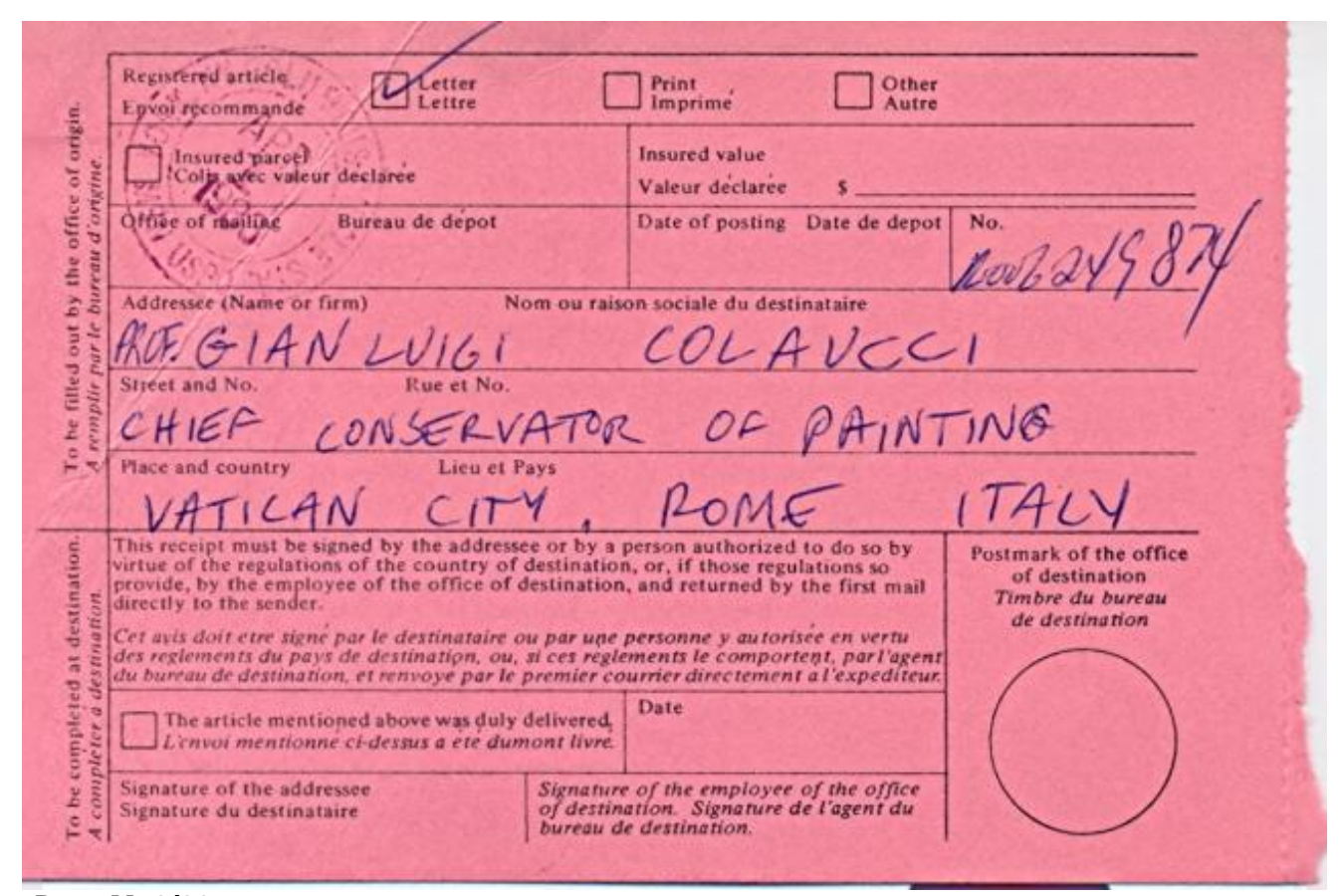

Doc. M. 3/83 


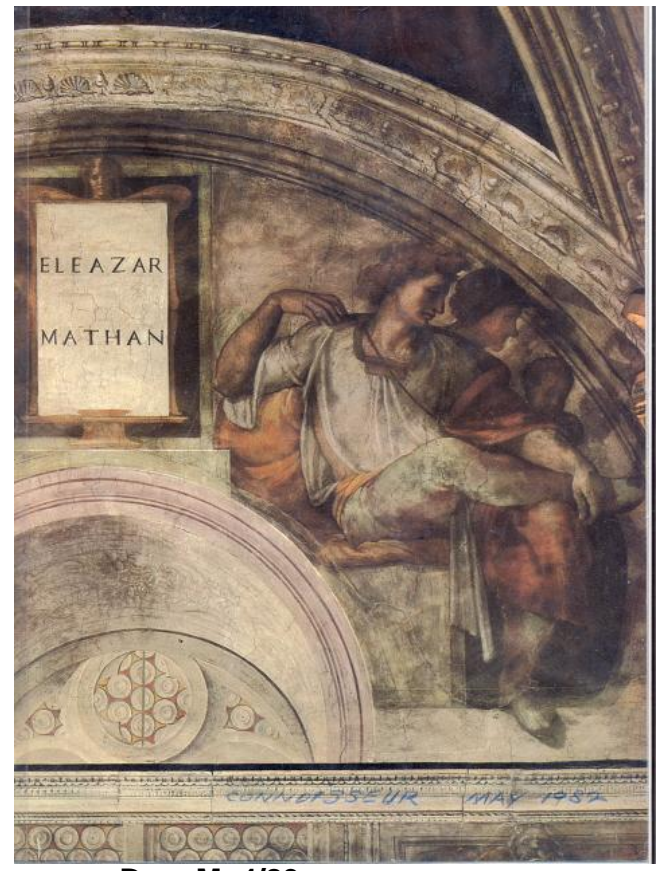

Doc. M 4/83

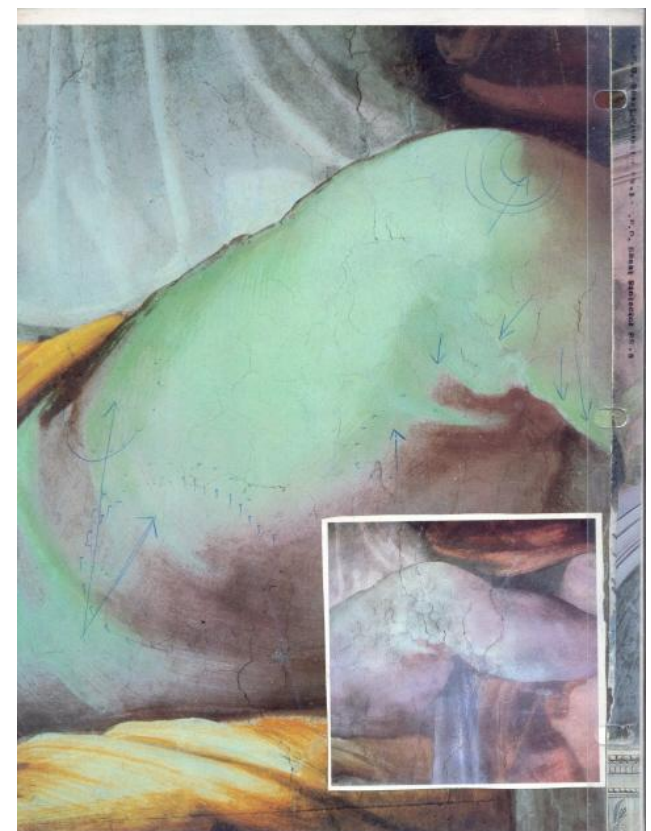

Doc. M. 4/83

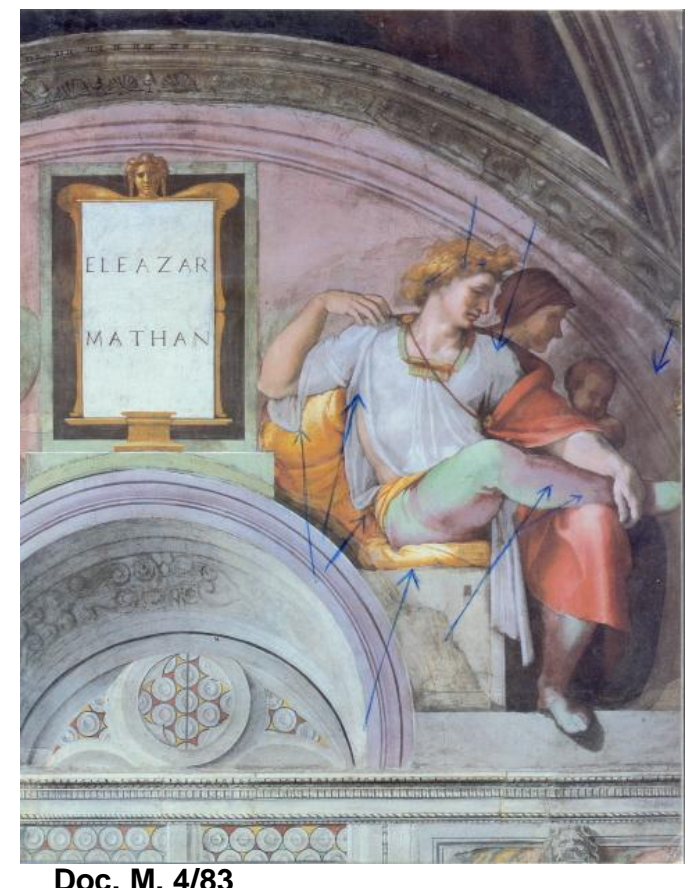

Doc. M. 4/83

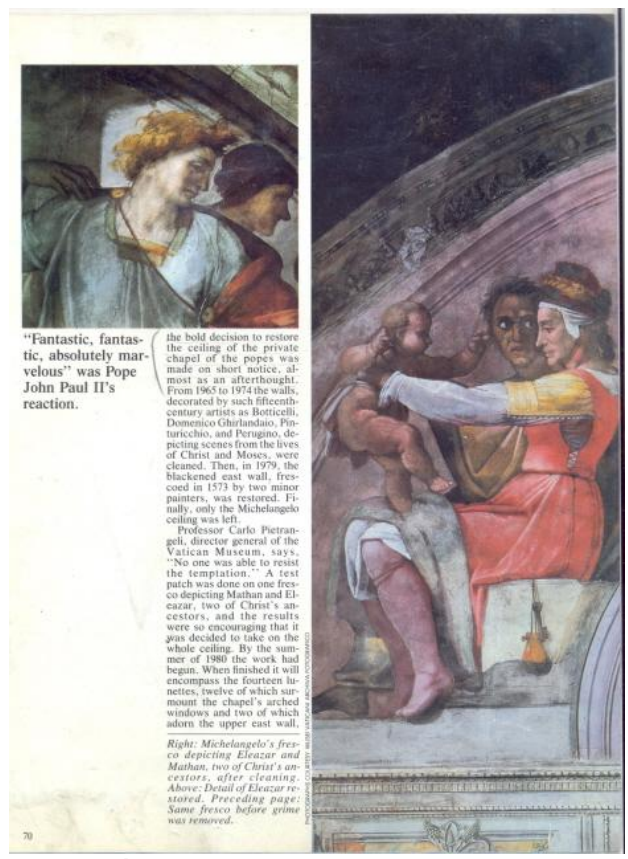

Doc. M. 4/83 


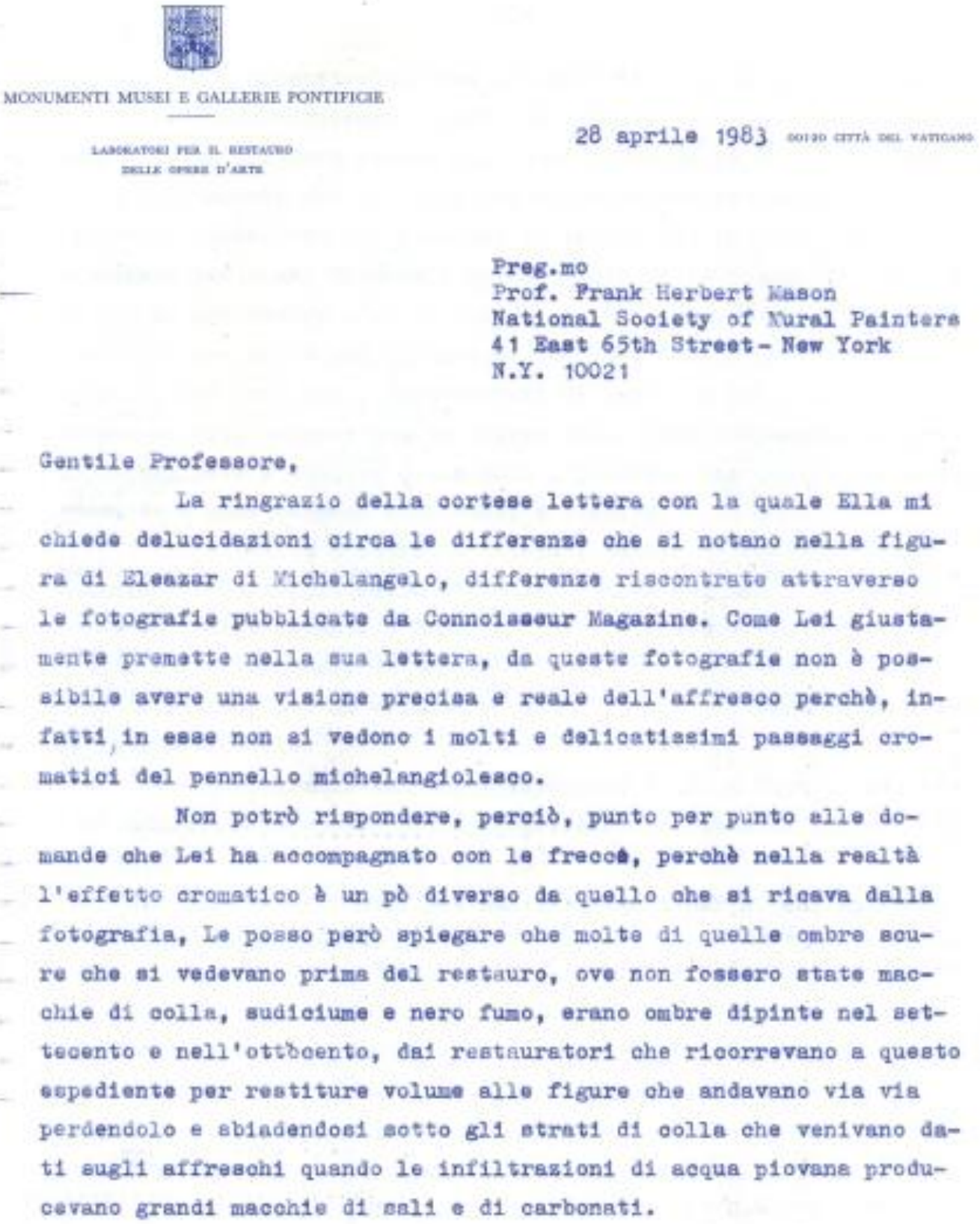

Doc. M. $5 / 83$ 
Non dizentiohiamo ohe la eduoszione oromatice di Vichelangelo quattroeentesoa, quindi egli non ha mal diplnto ombre nere o brune per dare volume alle aue flgure na 10 he bempe fatto eaclualvamente con 11 gloco del color1 eon un perticolare uso della panneliate che posalamo definire come la vere acoperta d1 questo restauro. Purtroppo tutto questo dslle fotografie atempete non 51 pub vedere e $n 1$ diaplace ohe Lel non ebble potuto venire a sentire uns delie due conferenze ohe ho tenuto a novasbre a a marzo In New York per 1 dipartimenti di restauro del Netropoliten Xuseum af Art. Avrebbe potuto vedere delle fedell diapositive nolto dettagliate e sent1re quald sono 1 problem che questo reatauro presents e come vengono affrontat1 e risolt1.

Le invito a venire a vedere 1 lavori d1 reatauro direttamente aul pontegglo nella Cappella S1etina nel caso che tol venise in Italla durante 1 proseimi anni (11 levoro durera aino al 1992). Pus telefonerat al 6985384 . Le seeloura ohe vadere vichelan-

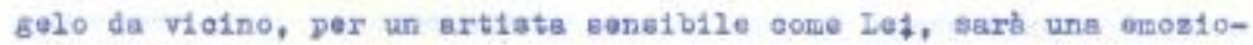
ne indimenticabile.

La ringraxio della pubblieazione e della fotografia de1 auo1 affresoh1 verenente nolto intereseant1 e plen1 di splritualita.

Le facolo 1 miel p1a aentit1 augur1 per 11 guo lavoro e La seluto oordisinente.

Doc. M. $5 / 83$ 


\section{A $\underline{\text { PETITION }}$ \\ PRESENTED TO}

THE ITALIAN CONSULATE, NEW YORK CITY, MAY 16th, 1985

We represent a growing number of concerned artists and citizens the world over--of which number the undersigned are only a fraction-who protest and abhor what we feel to be a destructive over-cleaning of Michelangelo's frescoes in the Sistine Chapel. For the past few years we have followed closely the progress of the restoration of the lower lunettes depicting the geneology of Christ, watching in horror as these once powerful, mysterious, and three-dimensional compositions were reduced by Professor Colalucci and his staff of restorers and chemists to mere ghosts of their former selves. They now appear to us to be bland and weak, robbed of Michelangelo's pre-eminent artistic attribute, sculptural form.

We have written Professor Colalucci and have met with him and other Vatican Museum officials; we have researched both sclentific and aesthetic interpretations of this masterpiece extensively; we have reviewed the scholarship of over 400 years, most of which sits solidly in our corner; we have written a letter to Pope John Paul II, and received a confirmation that he has seen it; we have also written to most major newspapers in Italy and the rest of Europe. In the process, we have discovered that the restoration was given a ljttle boost of at least $\$ 3,000,000$ (Assoc. Press figure) from the Nippon Television Network Corporation of Japan, in return for film rights to the "new" Michelangelo.

The results of our hard work have been very reassuring: Support has poured in steadily for our cause, as an increasing group of artists, church people, restorers, journalists and others can attest. Many have seen the ceiling personally; not only Americans, but Italians and other Europeans as we11.

And yet the destruction continues unabated. The "official scourers" dare to suggest from their lofty chemical perches that the scholarship of 400 years was sadly misguided, and that the qualities that gave the ceiling its theological and aesthetic genius were "simply a matter of dirt". This is the cultural poverty of our time, that one of the greatest human achjevements of any age should be perceived as a mere accident of nature: A statement made to the press by Professor Colalucci sums up his point of view: "Some people, especially the older generations, would like to stick to the black and white idea of Michelangelo. The younger generation, on the other hand, seems much more interested and appreciative of this new version of Michelangelo." Why then, we would like to ask, are there so many young people interested in stopping this kind of cleaning?

Therefore we have come to you, representatives of the Italian people here in New York, to urge that you pass on our concerns to those you represent. Urge them, in turn, to visit the Sistine while there is still time. Already the scaffolding is in place, and the attack on the vault is beginning. If they agree that the frescoes are being overcleaned, then let them join in our outcry. Our goal is a moratorium on further cleaning until world discussion can lead to less destructive restoration methods.

We approach you that the Italian populace might approach the Vatican, demanding that the guardianship of this matchless National Treasure be shared among all its rightful inheritors. Otherwise, some three million dollars will have changed hands, and with what benefit to Italy? And at what a cost to all of us? The greatest visual expression of the Christian faith, the greatest momument of art in Christendom, the masterpiece of Italy's most famous son, will have passed forever from the earth.

Doc. M. 6/85 


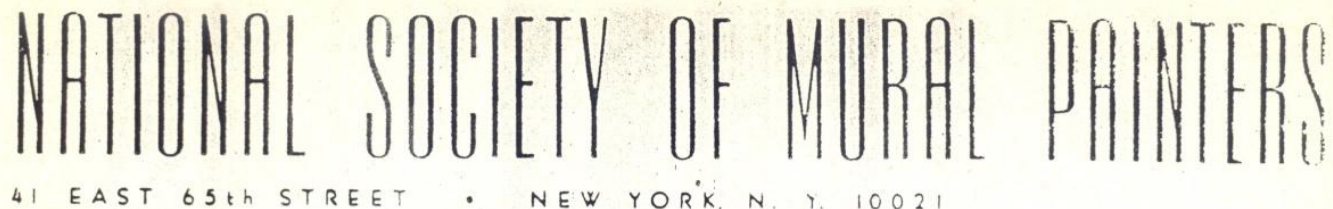

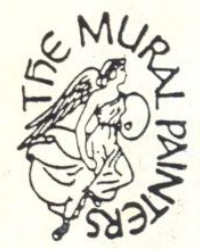

INCORPORATED 1895

Honorary President

President Emeiffus

JAN JUTA

Presicen:
Jati FAUSETT

First Vice.Presiden:
ALTON: S TOEEY

ALTON: S TOEE

Fecono Vice.Presiden:
FRANK MASON:

Secreary
LUCINDA LUVAAS

Assistan: Secre:ary
GEORGE E, STOHE

Treasurer

YAFFL YAEL
STECKEL

Publicity
ELIZAGETHCASE

CHARLES BASKERVILLE

HATh PRUSSINO

Perroersnis

DOMENICO MORTELLITO
CUITENI ViOrh

BRIAN SWEETLANO

Exhibitions

Advisors on Traditional

WALTER HOOO

OHN MANSHIP

CLIFF YOUNG

Advisors on Moderr

MUral Techniques
FAY MOORE

DOMENICO MORTELLITO
BUELL MULLEN

HANK PRUSSIN:

JOSEPH LOUIS YOUEY

Advisory Committe

H CAPONETTO. AIA

LLOYO GOODRICH

ANE KIRKLAND AF MUS

JACK LOWERY FASIO

$B O B$ HUTCHINS. NA

ROY MOYEP. UNICEF

CRED SCHWENGEL, U.S

Legal Counse!
M. ECHTMAN

Open Letter

His Eminence Agostino Cardinale Casaroli

Segretario di Stato

Citta del Vaticano

00120 Roma, Italia

Your Eminence:

Having been President of the National Society of Mural Painters and having appeared before the joint Congress in special sessions dealing with mural painting in the Capitol of the United States, I wish to assert very strongly the support of all the experts in the National Society of Mural Painters for the heroic stand and expertise of my colleague for many years and Vice-President of the Society, Frank Herbert Mason.

Mr. Mason, avarded the Cross of Merit Prima mural murals permanently hung in the Church of San Giovanni di Malta, Venice, has clearly brought to the attention of the world our position concerning the possible face mural paintings on the cern of the earth and in any civilization. Our concern is so great that we will take any steps to help preserve the aesthetic beauty of that magnificent work of Art, Michelangelo's masterpiece, the frescoes of the Sistine Chapel and to prevent their destruction by removal of actually finished work of Michelangelo from the underlying frescoes. We will pursue this until a conclave of reputable restorers has had a chance to evaluate the potential tragedy if the present cleaning and stripping of the frescoes is continued.

Every great artist in the world aspires to view these inspiring paintings of the world's greatest muralist, sculptor and architect. As artists concerned with their restoration, it is our concerted feeling that what has been shown to us to date is totally destroyed from the artistic point of view.

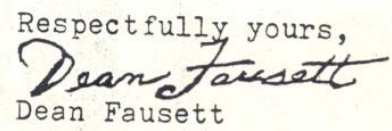

Doc. M. $7 / 85$ 
Open Letter to His Eminence Agostino Cardinale Casaroli

385 Broome Street

New York, New York 10013

U.S.A.

May 20, 1985

His Eminence Agostino Cardinale Casaroli

Segretario di Stato

Citta' del Vaticano

00120 Roma, Italia

Your Eminence:

This letter is sent to Your Eminence with the most grave concern for the future of the Sistine Chapel. I am an expert in the field of classical painting in the Renaissance manner. My work may be seen in Venice hanging with Giovanni Bellini. I am spokesman for members of three major organizations here in the United States: the National Society of Mural Painters, the National Academy of Design, and the Art Students League. Enclosed is a letter from the President of the National Society of Mural Painters as well as information regarding a protest demonstration sponsored by the Art Students League. We cannot believe that so large a body of professional opinion will be ignored by Your Eminence in your position as Secretary of state of the Vatican.

On April 17, having travelled to Rome for that purpose, I met with Sig.ri Carlo Pietrangeli, Walter Persegati, Fabrizio Mancinelli, Gianluigi Colalucci, and Nazzareno Gabrielli of the Vatican Museum. At the opening of our discussion Sig. Mancinelli stated the position of the Museum staff that nothing painted by the hand of Michelangelo has been removed from the Sistine Chapel frescoes. I contest this statement and intend to prove that more than grime and dirt has been removed due to present cleaning methods. I am enclosing photographs with notations made during my April visit. Using these, Your Eminence may check the validity of my position.

St. Franci"s was the inspiration for the return of the humanities into art, and Giotto of the Florentine school is given credit for bringing form and a life-like quality into painting following centuries of flat symbolism. Michelangelo carried this philosophy to its highest in his Sistine Chapel frescoes. The works of this school were not conceived in pieces as are the works of the 20th century. There were delicate relationships of light and shade which created unity within each painting. This is not rhetoric. This is documented historical and artistic fact. It is my contention that

\section{Doc. M. $8 / 85$}


this philosophy of form and light relationships has been totally ignored in the cleaning to date.

Here in the United States we wrote to the Vatican Museum to request color photographs of the currently restored lunettes and were informed that only black and white photographs are available. Consequently, to use the enclosed color plates, it will be necessary for Your Eminence to visit the Sistine Chapel (with binoculars) to compare them to the lunettes as they now stand. We realize that time is precious. However, since Michelangelo's Sistine Chapel is the greatest artistic work in Christendom, we would hope there will be time found for this effort. You will see that the lunettes are in psychedelic pieces. Areas that should be subdued--pillows, background areas, pant legs, hands, putti figures between lunettes-are now brilliant and leap from the wall. The Renaissance sense of light relationships is completely destroyed. Please notice that the figures are now flat and lack the form that vias characteristic of the Florentine philosophy.

The Director of the Accademia delle Belle Arti in Rome, Toti Scialoja, strongly agrees with our point of view. I am sure he would be willing to discuss this matter if contacted. I am certain he would be honored to visit the Sistine Chapel to serve as guide for our point of view.

Within the Vatican itself Your Eminence has a film shown here in the United States in 1968 on ABC television. A letter from its author, Alexander Eliot, is here enclosed. A showing of that film, completed at close range, would allow a better comparison of "before and after" than these still photographs can provide.

During my April discussion with the Vatican Museum staff their main point of emphasis was that everything is being done within the realm of science. Your Eminence, I would caution that none of the scientists involved would be capable of painting the Sistine Chapel. They are seeing at close range what Michelangelo envisioned as being seen from the floor below. Science did not paint the Chapel!

I understand that the position of Secretary of State of the Vatican carries authority over the Vatican Museum. We would again caution Your Eminence that this period in Vatican history may very well be remembered as the time when the Sistine Chapel was destroyed.

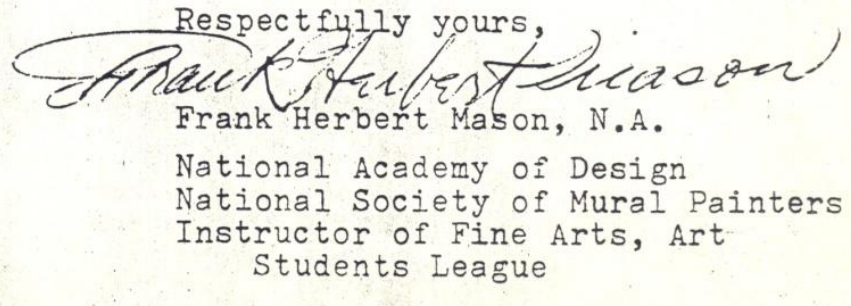

Doc. M. 8/85 
His Eminence Agostino Cardinale Casaroli

Segretario di Stato

Citta' del Vaticano

00120 Roma, Italia

Your Eminence:

Art restorers themselves insist that their own incompetent predecessors damaged 99\% of the world's older paintings. Is the new breed of cleaning technicians a trifle better qualified at this occult trade? Maybe yes, and maybe no. So when it comes to irreplaceable masterpieces, let's wait and see--why not?

$$
\text { While filming the Sistine ceiling }
$$

years ago (for the American Council of Catholic Bishops, Capitol Cities, ABC Network, and 75 million viewers, all-told), I spent six weeks atop a wheeled tower to come within touching. distance of each section. Except for cracks crisscrossing the plaster, almost the whole surface was in excellent shape back then. But now the bottom rim of the ceiling where Michelangelo depicted the Ancestors of Jesus, has been forever ruined.

The wealth of meaningful details was difficult to make out from the floor; so they've been scrubbed away, irretrievably. The equally significant, very subtly modulated interaction of gosamer color has been replaced by flat, posterish glare. The exquisite contours are gone, obliterated by black outlines which "you can see more easily". All this, in the name of so-called "cleaning" which is still going on. Let's stop it there!

The Vatican Collection contains a print of my film. I beg Your Eminence to view

\section{Doc. M. 9/85}


this yourself. Have it stopped at images of the Ancestors. Compare what it proves was there

against what's left today.

Your humble servant and friend of Michelangelo,

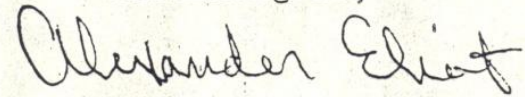

Alexander Eliot

25 Main Street

Northampton, MA 01060 - USA

Art Editor, Time Magazine, 1945-1960

Guggenheim Fellow, 1960

European Correspondent, Art in America

and Iife International, 1960-1970

Film Author, The Secret of Michelangelo: Every Man's Dream

Active Member, Society of American

Travel Writers, 1969-present

Book Author: 300 Years of American

Painting, Sight and Insight,

Earth Air Fire and Viater, Myths, etcetera

References: Who's Who in America

Who's Who in the World

Doc. $M .9 / 85$ 


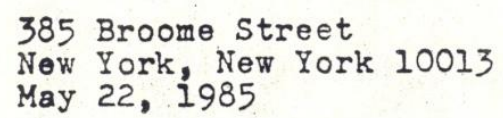

Sig. Massimo Roscigno

Vice Consul of Italy

Consulate General of Italy

690 Park Avenue

New York, New York 10021

Dear Sig. Roscigno,

Vie would like to thank you for your graclous reception on May 16 when the representatives from the Art Students League marched to show the1r concern for the future of the S1stince Chapel frescoes by Michelangelo. Enclosed Is the II Progresso article written by John Cappelli.

On May 17 we met w1th Archbishop Giovanni Chel1 who agreed to take letters to Agostino Cardinale Casarol1. Enclosed are coples of those letters as well as earlier letters sent to His Hollness Pope John Paul II and Monsignor Francia.

We have been in touch w1th museums, restorers and newspapers throughout the Unfted States and Europe. Recentiy the Society of Western Artists, an organization with 1200 members, jolned our protest. Vie are by no means alone in our thinking.

We 111 greatly appreclate any pressure your office may be able to bring to bear in this matter. Our concern is that there are no artists of the classical point of view directiy 1nvolved. The scientific approach must be used w1th artist1c guldance to prevent the destruction of the rest of the Sistine Chapel equal to that of the Iunettes already completed.

S1g. Tot1 Sclaloja, Director of the Accademia delle Belle Art1, 222 Via Ripeta, Rome, is in complete agreement with our position and would be interested in discussing this issue if contacted.

Respectfully yours,

Frank Herbert Mason

Doc. M.10/85 
Letters to the Editor

New York Times

229 W. 43 Street

New York, New York 10036

To the Editor:

Thank you for your coverage of our march to and demonstration day, May 16. However, as the Italian Consulate on Thursgrotesting the controversial lo's frescoes controversial restoration of Michelangeaspects of our point of view werel, I feel certain key nately. I was speaking with Vicere overlooked. Unfortutime your reporter was wice Consul Roscigno at the for comment.

comment in the foremost, contrary to Professor Steinberg's test in restorer infightin, we do not represent the laartists. And it is as ang. We are not restorers; we are the High Renaissance as artist painting and teaching in against the insance manner that I have long spoken out ration. For example, I led and abuses of scientific restoMuseum in 1976 to voice led a march on the Metropolitan articles.)

brilliance, ad fact that for all their intellectual

days have been trained scholars and conservators these examine. This fact was borne in works they so meticulously weeks ago when I met with the ch upon me all the more a few Colalucci, and other Vatican the chief restorer, Gianluigi I was told that a "new" Michel one, I might add, not in keeping of scholars and restorers oping with the interpretations too, were men of "extreme devotion past 400 years. Those, question raised by the devotion to Michelangelo." The this: to which

gelo do you pledge allegiance?

Does Professor Steinberg really see the restored Iunettes as being in relationship with the subtle power Judgement? outs could have ins really believe that these flat cutof Raphael, Rubens and

\section{Doc. M. $11 / 85$}


Tintoretto? As an artist, my hope is that the answer to these questions must be a resounding "No."

For too long the devotion, intelligence and expertise of artists like myself have been deprecated or ignored. Now we wish to reclaim, for ourselves and for the public, the Michelangelo of 400-odd years of connaisseurial and artistic acclaim. After all, it was an artist who painted the Sistine, not a scientist.

For the record, the solvent being used is $A B-57$. Also, the term we used to describe Michelangelo's "a secco" overpainting was "glue washes", and not "gouache" as per your article. This is a crucial point, as the glue that Michelangelo painted with would be chemically inseparable from the "l8th century glue" the restorers claim to be removing from the fresco surface. As we contend, in attempting to clean off what they see as later "dirt" (however euphemistically defined by Steinberg), Colalucci et al are destroying the great master's finishing touches and leaving the world the largest underpainting in art history.

Hoping for a moratorium and futher public debate, Respectfully yours,

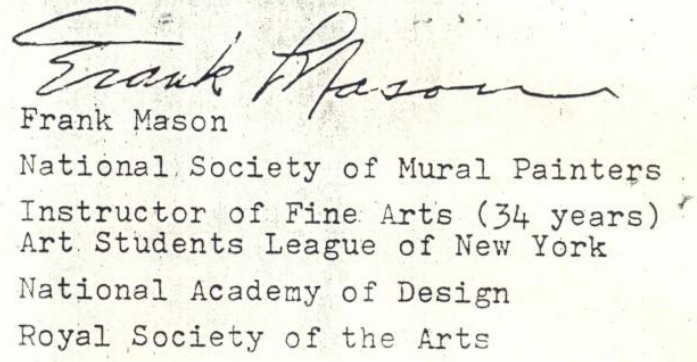

Doc. M.11/85 
OPEN LETTER

385 Broome Street

New York, New York 10013

September 3, 1985

\author{
Dr. Carlo Pietrangeli \\ Direttore Generale \\ Museo del Vaticano \\ Citta' del Vaticano \\ 00120 Rome, Italy
}

Sir:

My wife and I would like to thank you and your staff for the consideration and time given our interview this past April. We have listened to your point of view with interest. However, we believe that art is a realm other than science and that science alone is incapable of painting or restoring the Sistine Chapel. Aesthetics are pararount. It is possible to have a successful scientific operation but a dead patient.

The results of the current restoration of the Sistine Chapel lunettes no ionger show the genius of Michelangelo. The anatomy has been disturbed, and the relationships of light and shade have been destroyed. In many cases figures appear to have been cut out with scissors?

Can you give us an exact dating between the layers of glue that you claim have been applied through the centuries and that you have now removed from the lunettes? If, as we artists claim, Michelangelo worked 'a secco' on many areas of the Sistine Chapel, how is it possible to remove eighteenthcentury glue without removing Michelangelo's 'a secco' work underneath? Is a painter in the school of Michelangelo, I cannot accept the statement that the delicate modeliing of light and shade which created form and relationships now missing was done through the application of glue by secondrate artists in later centuries. Nor can I accept that the effect which overwhelmed the great artists and anatomists of Michelangelo's day--Raphael and Tintoretto, for example--Was created by dirt that is now being removed. These men would consider the 'new' lunettes amateurish and would not give them a second look. One has only to study their paintings to know that a flat tour de force, regardless of the brighter colors, would not have impressed then.

DOC. M. $11 / 85$ 
The vision of an artist is not always the vision of a scientist. While he worked on the scaffold, Michelangelo was seeing the painting in his mind's eye from a distance of sixty-five or more feet. It appears that the current restoration is being carried out from a very close, almost microscopic distance. We artists now find anatomical defects and changes in foreshortening that are unbearable to the eye and that are the direct result of restoration that ignores the neo-Platonic philosophy of the age of Michelangelo.

We implore you to reconsider your method of restoration and to include as consultants artists who can prove that they paint or sculpt in the great classical tradition. I would suggest your own Professor Toti Scialoja, Director of the Accademia di Belle Arti, Rome. There is in Oslo, Norway, another classical painter of great talent--odd Nurdrum--whom I feel sure would be interested. You know from the catalogue of my St. Anthony paintings in Venice that I would be capable of serving as a consultant, and I would happily volunteer my services.

We are greatly saddened that, in our opinion, Pope John Paul II will not be remembered through history for his good works and attempts to unite the world but, rather, for being the Pope who presided over the scientific destruction of the devine poetry of Michelangelo's Sistine Chapel.

Respectfully

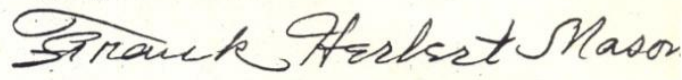

Frank Herbert Mason

s: Sig. Gianluigi: Colalucci

Doc. M. $12 / 85$ 


\section{THE FINE ARTS FEDERATION OF NEW YORK}
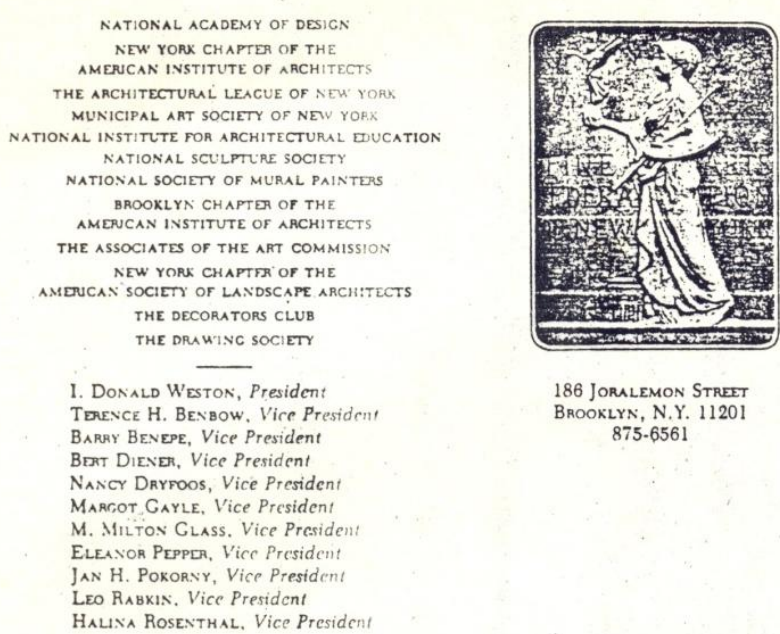
186 JORULEMON STREET
BROOKLYN, N.Y. 11201 875-656
NEW YORX STATE CHAPTER OF THE

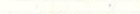
NEW YORX METROPOLITAN CHAPTER OF THE AMERCAS ABSTRCT ARTISTS AMERCA. ABSTRACT ARTIS
SCILPTORS GUILD HARLEM CULTURUL COUNCIL, INC. NEW YORX METROPOLITAN CHAPTER OF THE AMERUCAN PLANNING ASSOCIATION THE AMERTCAN FEDERTION OF ARTS THE PARKS COUNCIL

ARTISTS EQUITY ASS ACIATION OF NEW YORK INC NEW YORK SCCIETY OF ARCHTECTS NEW YORK LANDMARKS CONSERVANCY PUBLIC ART FUND, INC.
PUBN

MARON RoLLER, Secretary MiNor L. Bishop, Treasure Dodie ACKLIE, Director HELEN L. GRANGe, Directo LISA Nives, Director Hank Prussiva, Director RENATA Schicget Director NANNE S. Wollmani, Director

June 10, 1985

His Eminence Agostino Cardinale Casaroli

Segretario Di Stato

Citta Del Vaticano

00120 Roma, Italia

Døar Cardinale Casaroli,

The Fine Arts Federation of New York has for the last 75 years been concerned about the preservation of New York City's art heritage. Whereas this concerm has been exclusively about art matters that affected New York City, the Federation feels moved to comment when a work of art as renowned as Michaəlangelo's Sistine Chapel frescoes may be endangered.

This matter was brought to our attention by the National Society of Miral Painters who believe that the present methodology for restoring this magnificant work is in fact removing forever an essential part of the art work. If this is true, or "even has a remote possibility of bəing true, it behooves the Vatican to immediately stop the present work for a sufficient period of time to thoroughly investigate the possibility that there may in fact"be a loss of this irreplaceable nasterpiece.

The Fine Arts Federation urges you to have an open forum of experts on both sides of this issue prior to continuing with the work. All art lovers throughout the world will listen and learn and be satisfied that Michaelangleo's great masterpiece will not be jeopardized by hasty decisions.

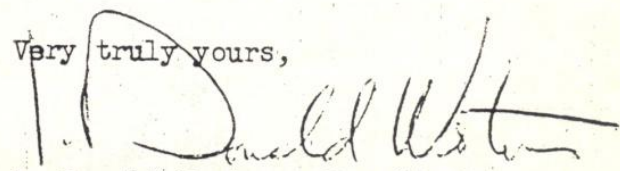

I. Donald: Weston - President

IDW/ss

Doc. M. $13 / 85$ 
IL. CARDINGLE CARLO MARIA MMn..

ARCIVESCOND OH ULLWNO

Misane, 14 aprite 1986

Eccellenea Reverendissima,

11 Presidente della

Corte a'Appeilo al Milano, Prof.Plero Pajardi, al ha consegnato una doeumentazione relativo ai lavori al restauro della Cappelia sistina e contenente sleuni rilievi critici di un gruppo di axtiati.

Mi permetto di eramettere a Lei questo materlale affinche' possa essere analizato dalle persone eompetent1.

profitto volentieri della elfcostanza per confermaral, con senel di dietinto os aquio

$$
\begin{aligned}
& \text { Aell"Eeciza Voetra Rev,na } \\
& \text { dev }=0
\end{aligned}
$$

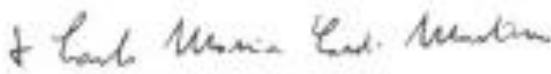

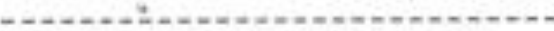

Eccellenza Reverendisaina

MOAL. BDUARDO MARTINEZ SOMALO

Segreteria al stato

00120 CTTTA' DEL VAFICANO

Doc. M. $14 / 86$ 


\section{Cara Eminenza,}

mi trovo nella singolarissima situazione di doverLe fare una pressante segnalazione che esula del tutto dalla mia competenza (...nè invoco presuntuosamente l'alibi "le vie del Signore...").

Un gruppo di amici di Bergamo, di tutta serietà,mi chiede di farLe giungere, tramite me, la loro accorata invocazione perchè con la Sua Autorità chieda un ripensamento ai Responsabili.del restauro della Cappella Sistina. Essi sono convinti professionalmente che si stia perpetrando un "misfatto" artistico e ne offrono negli allegati un principio di prova,pronti peraltro a contribuire ben maggiormente se richiesti. Essi ritengono che ciò che appare frutto dei dispetti del tempo sia in realtà,almeno in parte, appannaggio del tipo di tecnica di affresco proprio dilMichelangelo.

Eminenza,mi creda,sono in imbarazzo e non so che dirle. Ma in fondo l'errore umano è sempre astrattamente possibile e un atto come questo di umile collaborazione in chiave di critica costruttiva non può nuocere a nessuno.

Gradisca i miei saluti cordiali.

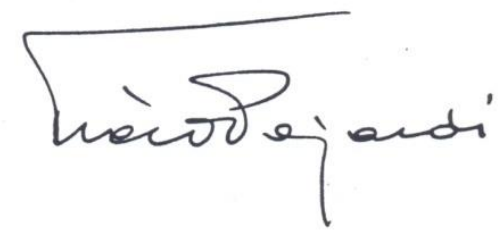

175.205

Doc. M. 15/86 

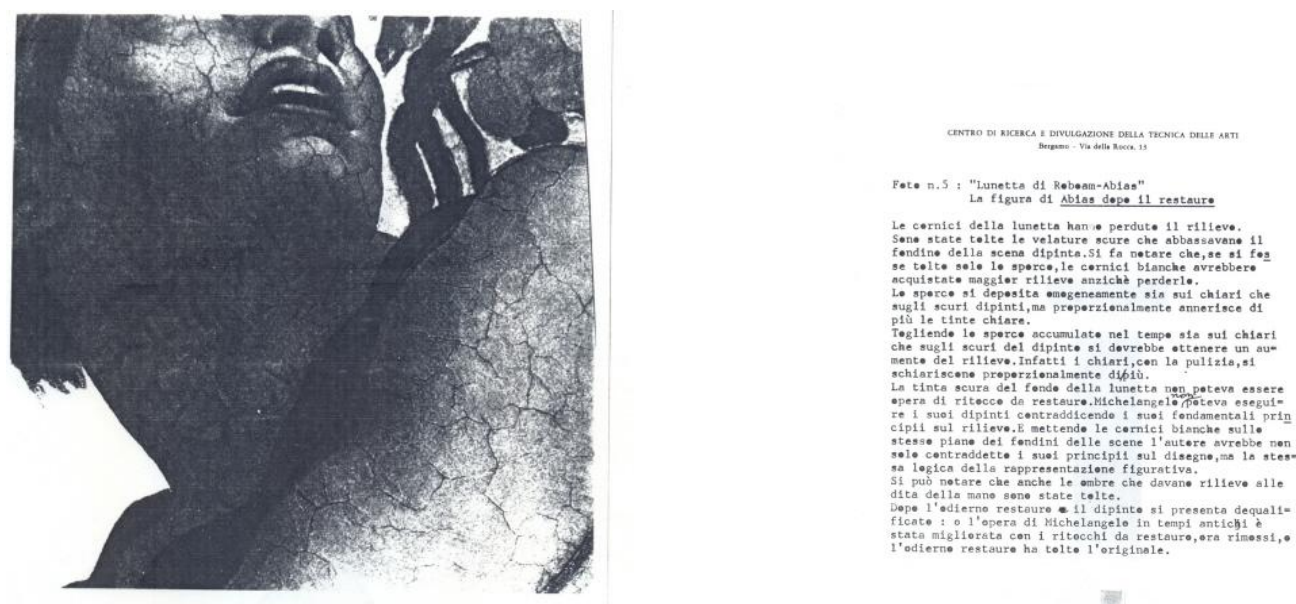

Fote n.1: Gioma

La figura in corrispondenza delle part1 in
- mbra presenta crepe nell' 1 ntentace che han=

ombra presenta crepe nell intenace che han=
ne un alone scuro. Nelle parti chiare 10 cre
pe nell' ne

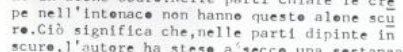

scuro, autore ha steso a secco una sost
verniciante per dare pili profondità ag11
scur1 - contrasto e rilievo alle luc1.
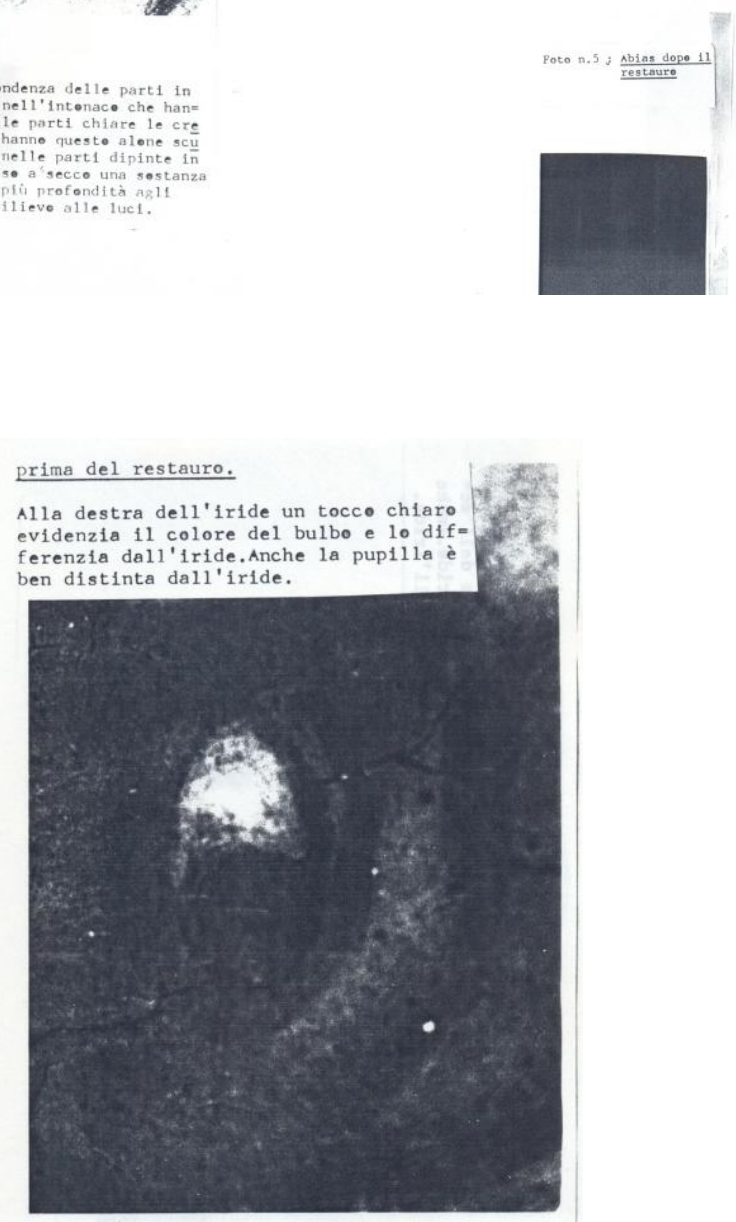

Doc. M.16/86

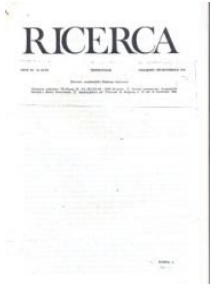




\section{CAPPELLA SISTINA 1980,1986 \\ E CONTRONOTA SUL CANGIANTE}

E' cliamato $A \cdot B 57$ it solrente usato per la pritizia f la rimozione dei ritoccbi da re. stasto della volta deila Cappitla Sistina diputte da Micbelangelo.

Cont questo solvente si opera tun lavrggion che coinvolge tutte le rifiniture a "secco" eseguite sopra il lavoro a fresco considerate opera di anticc restauro.

$E^{\prime}$ stato tolto interameate il panneggio verde del projeta Zaccaria che era ridipinto a tempera pius scaro specialmente nelle ombre.

Tolto questo rifacimento, a comparso un panneggio pia ebiaro eseguito a fresco. Qpesto panneggio $k$ intatio, senza abresioni nè alteraziont. La morfologia delle per. zellate del ritocco era identica, ma si é crefuto di dover asportare il ritocco interpretando questa morfologia come lavoro di perfetta integrazione del restawo cont il resto originale.

Vale a dire che un restauratore, sul panneggio originale in perfetto stato di conserva. zione, ne ba ridipinto un alsro premurandosi di imitare la morfologis delle pennellate per integrare il suo intervento con l'originale.

Devo far notare cbe la morfologia delle penmellate à leggibile solo se la si osserva a forte lace radente e a pochi centimetri di distanza,

Micbelangelo non ba eseguito le pitture solamente a fresco, ma ba rielaborato tutto it lavoro a "secco". La maggior parte dei ritoccbi sono autografi. Salva la estremamente necessaria rimozione dello sporco cbe potrebbe restituire il cromatismo originale è da contestarsi la legittimita di questo intervento cbe sta per essere catusa del pith grande disastro mai accorso nella staria dei danneggiamenti da restaturo.

Sono convinto che it restauratori, grazic alla loro assoluta buonta fede, lascino in sito sna camplonatura delle sovrapitture cbe stanno togliendo. Con guesta campionatura non impediranno un gindizio storico sul loro operato.

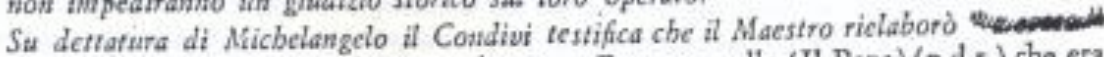
tutta loopera dopo averla dipinta a fresco. a E come quello (Il Papa) (n.d.r.) che era. di.natura veemente e impaziente d'aspettare poishè fu fatta la metà, ciò̀ dalla porta fino a mezzo la wolta, volle ch'egli la scoptisse sncorchè fosse imperfetta e non avesse avuto l'ultima mano * - Condivi, a Vita di Micbelangelo *.

Da. questo brano si può bene capire che Micbelangelo concepisce il lavoro di pittura Jcils wolta non semplicemente a fresco altrimenti non avrebbe detto al Condivi cbe disfece il ponte ancorcbè la melà della volta gia dipinta non avesse "avuto l'ultima mano ๖. L'affresco non si può ritoceare a tresce nemmeno al giomo dopo. Micbilangelo provocavd l'impazienza del Papa indugiando nei ritoccbi, nei rifacimenti

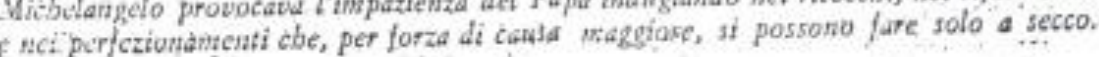

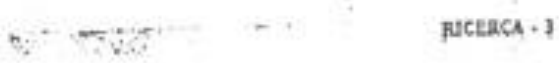

Doc. M.17/86 


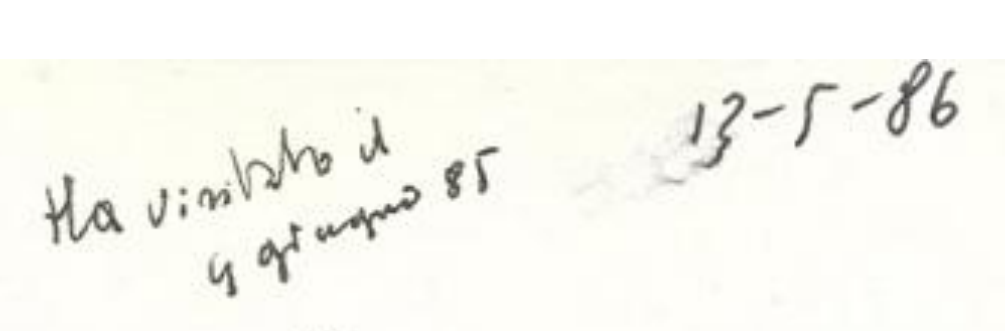

Bel roggso. pecato he non $\sqrt{5}$ oblira menar la reats in concune con la

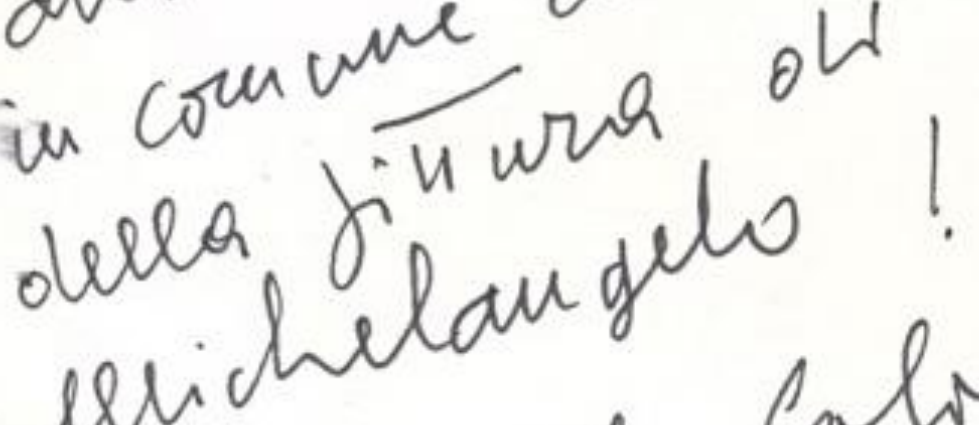
sh colow Doc. M.18/86 


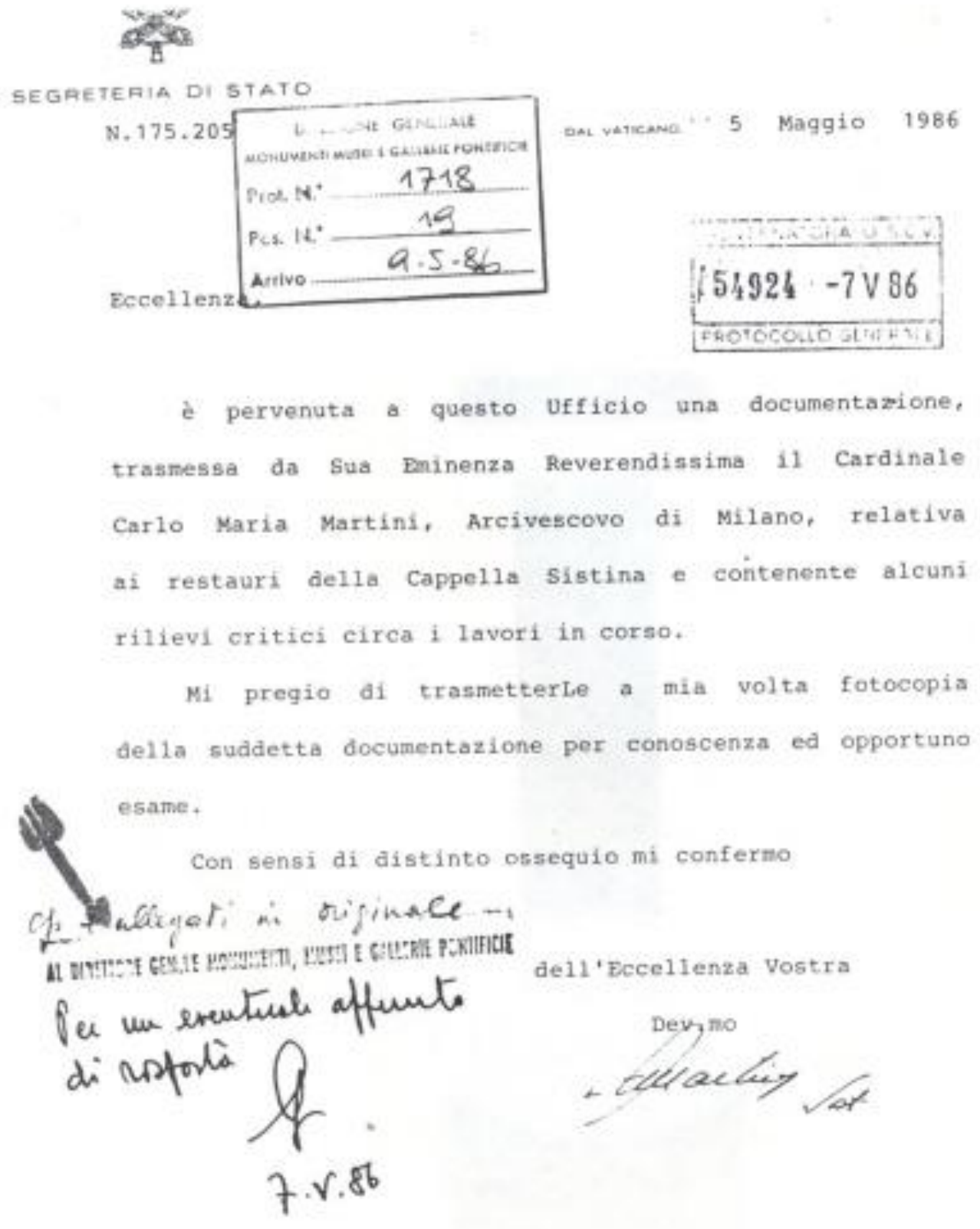

A Sua Eccellenza

Dott. Cav. Marchese Don GIULID SACCHeTT1

Deleqato 5 peciale

della pontificia Commissione

per lo stato della

CITTA* DEL VATICANO

Doc. M. 19/86 


\section{THE WETHERSFIELD INSTITUTE}

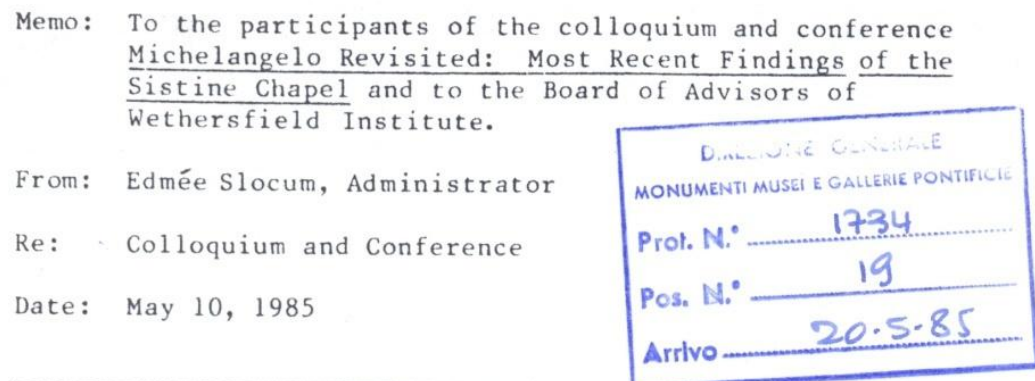

1. The dates of the colloquium and of the conference have been changed: The colloquium at Wethersfield House will now be on Saturday and Sunday, October 19 and 20 and the conference will be held on Monday October 21.

2. We are in the process of drawing up lists for the invitations to the conference. Please send us names of colleagues or of

other interested persons who might lik. to attend the conference on October 21 .

3. Technical experts from the Vatican will come to wethersfield on October 23 and 24 to discuss their restoration work with specialists from the United States. Their findings will be presented to the press and to a selected public at a conference in the Frick Collection auditorium on friday. October 25. If you would like to attend this conference, pleas let us know as soun as possible as the capacity of the Frick collection auditorium is $1 \mathrm{imited}$. 


\title{
THE WETHERSFIELD INSTITUTE
}

May 16,1985

\author{
Mr. Gianluigi Colalucci \\ Chief Restorer \\ The Vatican Museums \\ Citta del Vaticano \\ Rome 00120
}

Dear Mr. Colalucci:

You are aware that the Wethersfield Institute plans to welcome to its house the leading scholars of the world in the field of Michelangelo studies as well as the most important restorers world wide. We are pleased, indeed, to learn from Dr. Persegati that you may be available for those meetings.

Because of the extraordinary interest in the restoration techniques, we thought that it would be imnprtant for you to attend the scholarly sessions of art historians at Wethersfield as well as the technical colloquium we had originally planned.

May I then formally invite you to join us at Wethersfield House in rural New York State for a colloquium on the subject of the recent restoration in the Sistine Chapel on Saturday and Sunday October 19 and 20th, 1985. Besides yourself and Mr. Gabrielli, there will be six participants: Professor Andre Chastel, Professor Michael Hirst, Dr. Fabrizio Mancinelli, Professor Pieroluigi de Vecchi, Professor John Shearman and Professor Kathleen Weil-Garris Brandt.

It is our plan that after the group has had an opportunity to exchange its views, you will join us at the Art Institute of New York University where the scholars will deliver a brief paper before an audience of several hundred people, carefully selected, who will be interested to hear their views on the subject of the Sistine Chapel. That seminar will take place on Monday, October 21 st.

The Colloquium will continue at Wethersfield House on October 23rd and 24 th with a public meeting at the Frick Collection on October the 25 th.

(continued...)

445 East 80th Street, New York, N.Y. 10021 (212) 734-9284

Doc. W. 2/85 
page two

Mr. Gianluigi Colalucci

May 16, 1984

We will shortly send you details regarding your visit to Wethersfield and New York but, in the meantime, I hope we have sent you enough information for you to indicate that you will be with us at the Wethersfield Institute. The Wethersfield Institute will be most honored to welcome someone of your renown and we know that our auditors will share in that sentiment.

All the expenses of your travel and activities will be cared for by the Wethersfield Institute over those days and they are pleased to offer you a $\$ 1,500$ stipend.

Sincerely yours,

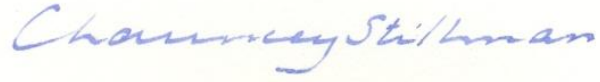

Chauncey Stillman

President

cc: Dr. Walter Persegati

Dr. Fabrizio Mancine11i

Louis B. Warren, Esq.

\section{Doc. W. 2/85}




\title{
THE WETHERSFIELD INSTITUTE
}

Monday August 19, 1985

\author{
Mr. Gianluigi Colalucci \\ Chief Restorer \\ The Vatican Museums \\ Citta del Vaticano \\ Rome 00120 \\ It aly
}

Dear Mir. Colalucci:

Time is fast approaching to finalize the travel arrangements for your trip to New York for the meetings sponsored by Wethersfield Institute.

In order to take advantage of the APEX fares, we would like to buy your ticket as soon as possible. We would therefore like to know what travel dates would be most convenient for you.

I would suggest that you plan to arrive in New York on Friday, October 18. You would be met at the airport and driven directly to Wethersfield House.

As you know, there will be two days of colloquia at Wethersfield House, Saturday October 19 and Sunday October 20. The public conference will take place in New York on Monday the 21st of October at the Metropolitan Museum.

You would return to Wethersfield House on Tuesday evening, October 22 to be ready for the meetings on October 23 and 24 . You would return to New York on the evening of the 24 th as the conference at the Frick Collection is on Friday the 25th.

I vaguely recollect your mentioning that you would be travelling in the US either before or after the conference. Please let me know what you plans and dates are at your earliesi couvenience.

If I do not hear from you to the contrary, I will reserve a ticket leaving Rome and arriving to New York on October 18 and leaving New York on October 26 and arriving in Rome on October 27.

It was a pleasure to meet you last month on the scaffolding and I very much enjoyed my tour. Thank you!

Yours sincerely,

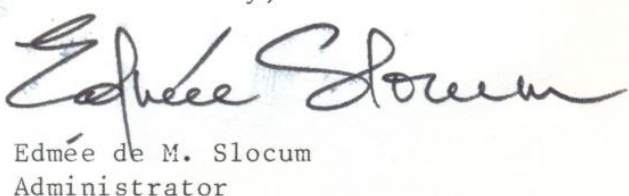

445 East 80th Street, New York, N.Y. 10021 (212) 734-9284 

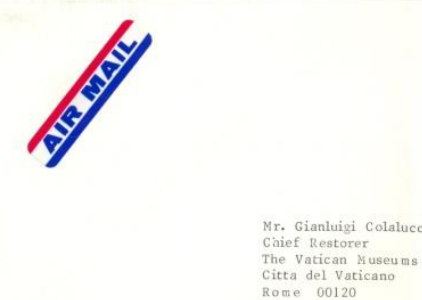

Rome 00120
Italy

Doc. W. $4 / 85$

\section{THE WETHERSFIELD INSTITUTE}

Friday, October 4, 1985

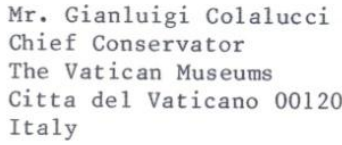

Enclosed please find your ticket which has been changed to reflect the change in plans.

When you arrive in New York on October 17 with Dr. Mancinel1i you will be met by a driver (who will be looking for you as you leave customs and who will have a sign wiht Mancinelli on it) to take you to your hotel, the American Stanhope (on Fifth Avenue at 81st Street, New York, NY 10028 Tel: 212-288-5800.)

As things stand now, a press conference will be held on Friday morning. On Friday afternoon you will be taken to Wethersfield House and to the Willows Motel in Amenia where you will be staying (Tel: 914-373-3090) as there is only room for the five speakers at Wethersfield House. Transportation will be available to shuttle back and forth easily from Wethersfield to the Motel.

The meetings and the meals will be at Wethersfield House (RR1 Box 440 Tel: 914-373-8037). You will remain in Amenia from Friday evening to Sunday afternoon, at which time you will be return to the Stanhope Hotel.

The conference at the Metropolitan Museum will take place on Monday the 21 st and on Tuesday the 22 nd at 10.30 A.M. we will meet with Mr. Mason. Tuesday afternoon you will return to Wethersfield House where you will stay until Thursday evening. Friday is the Frick Collection conference and I have booked your return flight for Saturday 0ctober 26.

Please call me at the number listed below if there are any changes or if you have any questions.

I look forward to seeing you again and wish you a most pleasant journey.

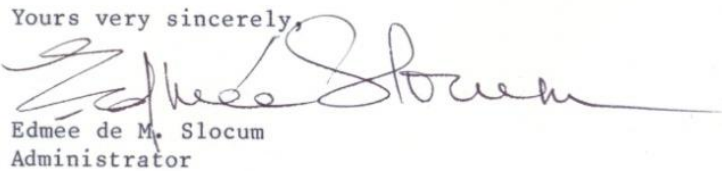

445 East 80th Street, New York, N.Y. 10021 (212) 734-9284

Doc. W. $4 / 85$ 


\section{THE WETHERSFIELD INSTITUTE}

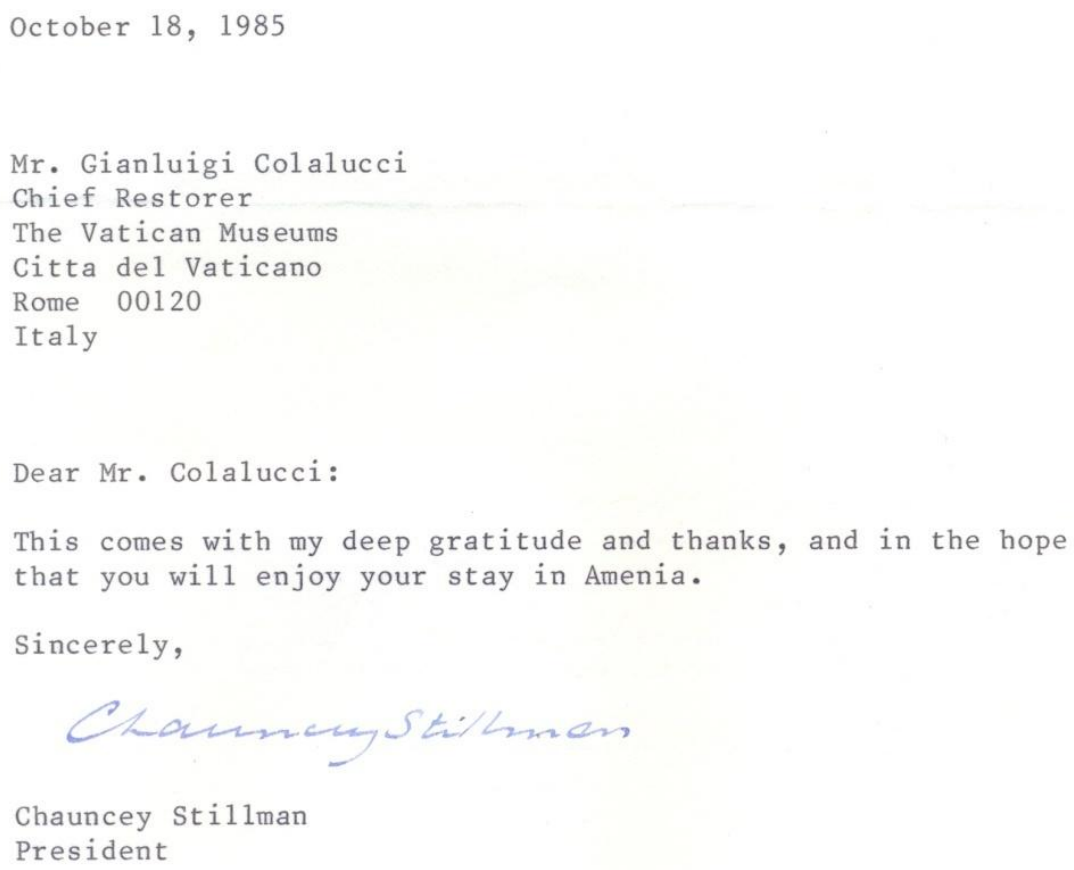

Chauncey Stillman

President

445 East 80th Street, New York, N.Y. 10021 (212) 734-9284

Doc. W. 5/85 


\section{WETHERSF IELD INSTITUTE}

Wethersfield Institute, founded in New York in 1984, is committed to the growth and study of Christian culture in its widest sense. This aim will be pursued through the study of Christian culture in all its aspects, from philosophy to archeology; art, history, languages based on latin and problems in ethics. Particular emphasis will be put on these areas of learning and culture that will strenghten the ties uniting the Cahtolic Chruch in this country with the Holy See.

\section{BOARD OF ADVISORS}

Mr. Chauncey Stillman

President

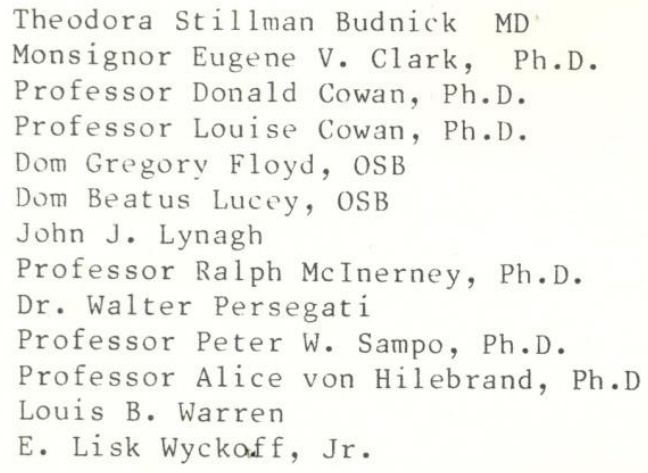

E. Lisk Wyckoff, Jr.

Doc. W. 6/85 
WETHERSFIELD INSTITUTE

PROGRAM FOR MEETINGS 10/22-10/25

\section{Tuesday October 22, 1985}

10.30 AM Meeting with Mr. Mason and Mr. Elliott

Meeting at Knickerbocker Club (2 East 62 nd Street)

4.00 PM Meet at Stanhope for trip to Wethersfield House

(circa 2 hours drive) Number of Wethersfield House 914-373-8037

" Willows Motel 914-373-8090

Wednesday October 23, 1985

Wethersfield House all day

Thursday October 24, 1985

Return to New York circa 6 PM

Friday October 25, 1985

10.30 AM Frick Collection Conference

12.30 PM Lunch Knickerbocker Club (2 EAst 62nd Street)

4.30 P.M. End Conference

5.30 P.M. Farewe11 Buffet Supper Union Club

(101 East 69th Street)

$* * * * * * *$

Doc. $7 / 85$ 


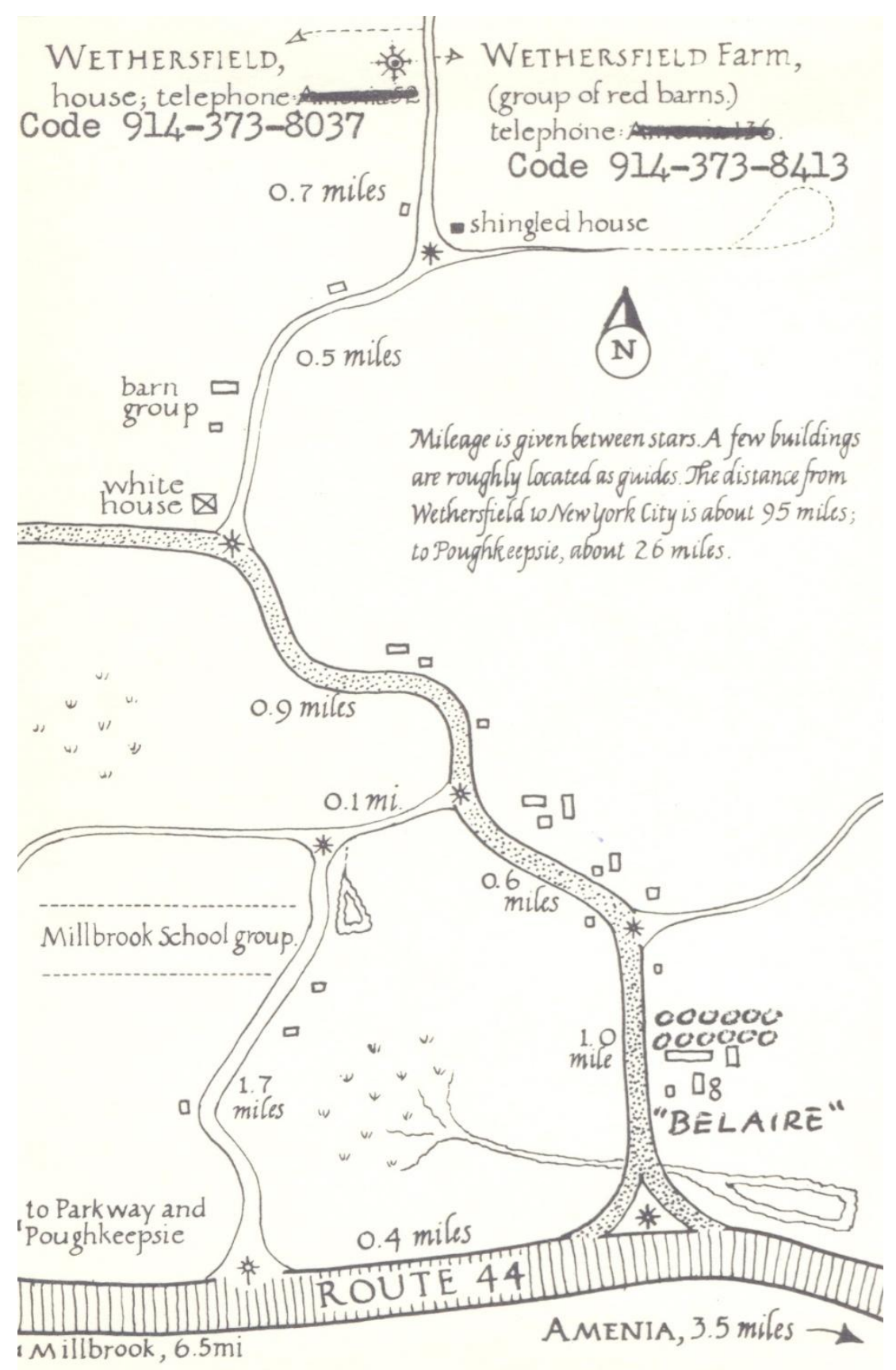

Doc. W. 8/85 
WETHERSFIELD INSTITUTE

PRESENTS

MICHELANGELO REDISCOVERED;

\section{LATEST FINDINGS IN THE SISTINE CHAPEL}

THE FRICK COLLECTION

Friday October 25, 1985

PROGRAM

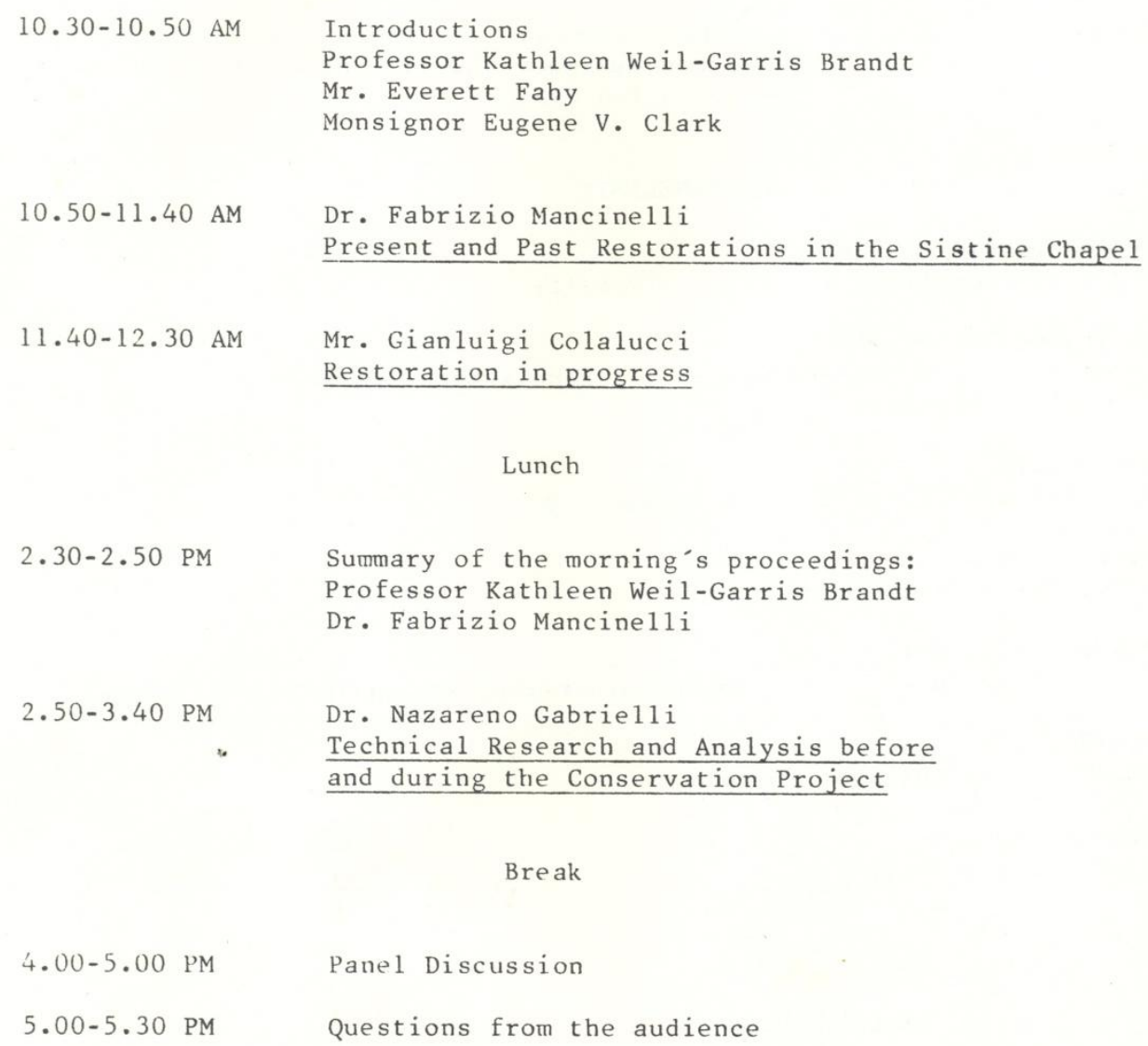

DOC. W. 9/85 


\section{Wethersfield Institute \\ requests the fleasure of youx company at a conference on conservation questions}

$$
\begin{aligned}
& \text { Michelangela Rediscovered; } \\
& \text { Most Recent Findings } \\
& \text { in the Sistine Chapel }
\end{aligned}
$$

Friday, Octolew 25th, 1985

The Frick Collection

$$
\begin{gathered}
\text { 10:30 A. M. to 5:30 P.M. M. } \\
1 \text { East roth Sireet } \\
\text { Newe York City }
\end{gathered}
$$

\footnotetext{
RYVP

by enclosed cand
}

Doc. W. 12/85

\author{
Resenvations will be \\ held at the doon \\ in the ondex in which \\ they ane received.
}


Non Transterabti

The Board of Directors of the Patrons of the Arts of the Vatican Museums cordially invite you

to honor the officers of the Vatican Museums and hear and $1 \varepsilon \varepsilon$ their report on the splendid restoration of the Sistine Chapel at the University Club Thursday, October 24, 1985 at 7:30 P.S.

for dinner

Doc. W. 13/85

Doc. W. 13/85 


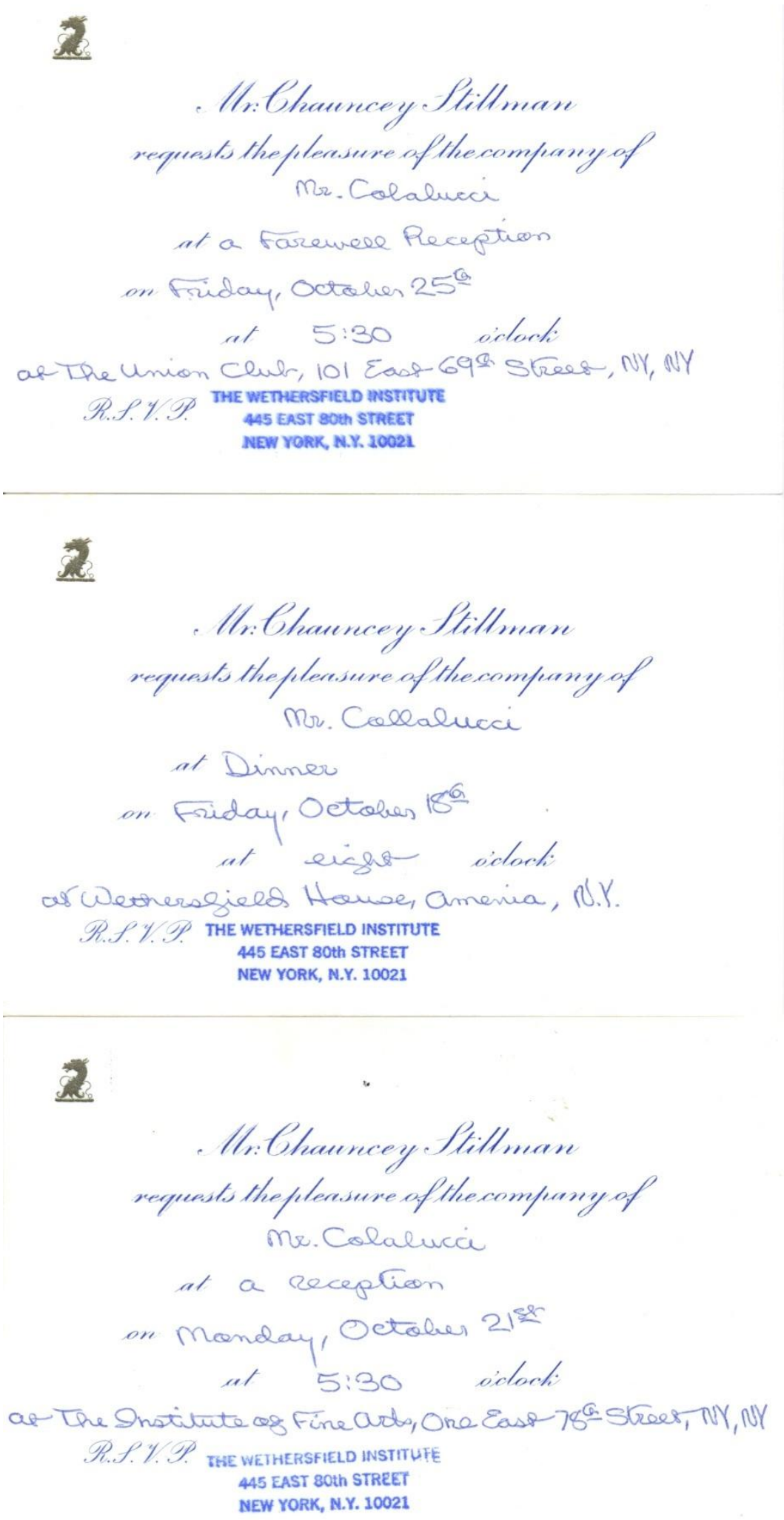

Doc. W. 14/85 


\section{Wethersfield Instiute}

A conference on consereation questions canstitutes the second part of a weeklongmeeling Nichelangela Rediscosered; Most Recent Findings in the Sistine Chapel. Exprerts in the field of conservation will meet for two days of colloquia at Wethersfield House in Dulchess Counly. Neve York and will veconvene on October 25 la shave the resulls of their discussions with an insiled audience. Wethersfield Institute plans to hold further confevences, devoled to the study of Christian cullure in all its aspects, on a yearly basis.

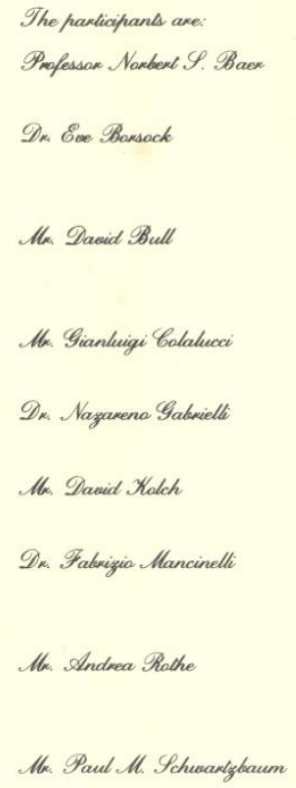

Neus Mank Unisensily Insitule of Fine Stas Reseanch Associale Valla I Talli, Howence Head of Painting Conservation Washinglen, $\mathscr{D} \mathscr{C}$. The Vatioan Meseums, Vatican Cily Head of Reseanch Labonatory The Vatican Mtuseums, Vatioan Gily Consenoation Deparment And Institute of Chicaga Curatere of Byzantine, Medienal and Modewn Ant The Vatioan Museums, Vatican City Painlings Cansereatore The \& Paul Selty Museum
Malibur Chief Ganservatar Restaver

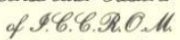
MU. V.E.S.C.O.) Rome

\section{Wethersfield Institute}

Wethersfield Institule, founded in New Yook in 1984, is committed to the growth and study of Christian culture in its widest sense. This aim will be pursued through the study of Christian culture in all its aspects, fram philasophy to archeology; ard, hisloxy, languages based on Latin, and problems in ethics. Parliculaw emphasis will be put on these aveas of learning and culture that will strengthen the ties uniting the Catholic Church in this country with the Holy See.

\section{Chauncey Sillman President}

$$
\text { Baand of Advisons }
$$

Theodona Sillman Budnik, M.D

Mansignos Eugene V. Clark

Professox Donald Cousan, Ph. D

Professor Lovise Cousan, $\mathscr{P h} \mathscr{D}$.

Dam Gregary Flayds OSPB

Dom Bealus Llucey, OSPB

Ghn I. Synagh

Professan Ralph tha Tnewney, Ph. D.

Dr. Waltex Pexsegati

Chanles Scribner, II, Ph. D.

Professar Pelex V. Sampa, Ph. D.

Professar Alice wan Hildebrand, Ph. D

Lovis $\mathscr{B}$. Wawen

E. Lisk Wyckoffs Ia

Doc. W. 15/85 
New York University

A private university in the public service

Institute of Fine Arts

1 East 78th Street

New York, N.Y. 1002

Telephone: (212) 772-5800

November 8,1985

Mr. Gianluigi Colalucci

Chief Restorer

Vatican Museums

Vatican City 00120

Rome, Italy

\section{Dear Gianluigi,}

It would be difficult to thank you enough for your heroic and untiring contributions to Wethersfield. I feel that you sustained the brunt of the whole thing. You knew it would be strenuous and provoking but I wonder if even you anticipated quite how much would be asked of you.

As a result of your work and patient good humor much was accomplished. I still hear your praises sung every day. I hope, once you have recovered, you will think it was all worthwhile. I certainly do think so and I believe that you have laid the foundations for new attitudes and greater understanding in the world outside and perhaps even inside the walls of the Vatican.

Finally I want to thank you on my own account for the support and kindness you showed me throughout. I look forward eagerly to seeing you on the scaffolding this spring.

Your friend,<smiles>CCC[C@@H]1CCCC[C@@H]1C(C)(C)C</smiles>

Kathleen Weil-Garris Brandt

Doc. W. $16 / 85$ 


\section{THE WETHERSFIELD INSTITUTE}

November 13,1985

Mr. Gianluigi Colalucci

Chief Restorer

The Vatican Museums

Citta de1 Vaticano 00120

Italy

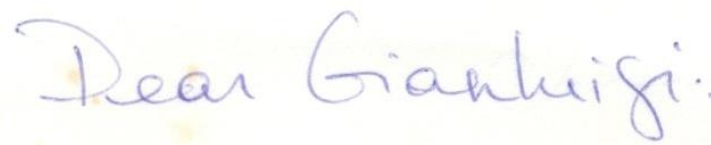

Now that the dust has settled I do want to thank you for your participation in the Wethersfield meetings. Your unfailing good humour and hard work helped the meetings run smoothly both at Wethersfield House and at the Frick Collection. I look forward to receiving a copy of the lecture you delivered at the Frick Collection.

It was a great pleasure to see you again and I hope that next time I come to Rome I will get a new tour of the scaffolding! Until then, this comes with my wishes for an excellent fall and winter and once more, many thanks.

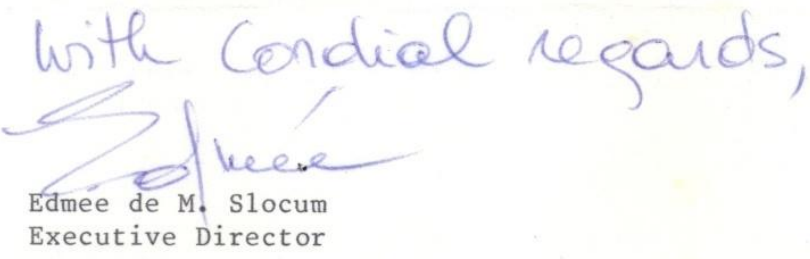

445 East 80th Street, New York, N.Y. 10021 (212) 734-9284

Doc. W. $17 / 85$ 
Gentile Signora

Edmee de M. Slocum Executive Director The Wethersfield Institute 445 East 80th Street New York, N.Y. 10021

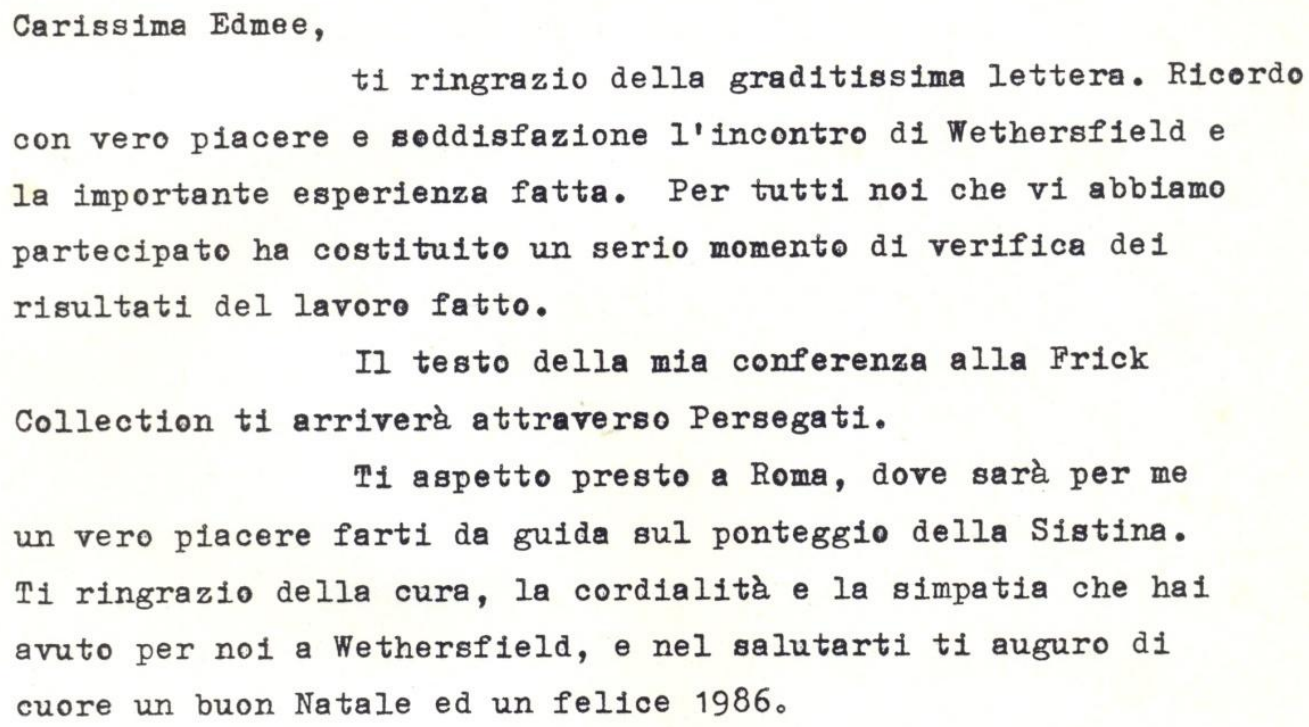

Doc. W. $18 / 85$ 
DOCUMENTI BECK (Archivio Colalucci- sezione documenti-F.9 serie 6)

Columbia University in the City of New York

DEDARTMENT OH ART HISTOAY

ANO ANCHACOLOOY

Schermernorn Hail
New Vork, N.V. 10027

Caroprume Quvanix. 18 magize

Qrazce di nuove per l'ecperieura ensea che ho anuto alla fistuia.

Saro, come ho detto, a

Frume dal 16 quagno if por e zpero che rencte su. Voglio vedere anele "Peruzgi." Peuso di cundore a Roure verso la fine quingo, re ri esco trovore da dermire da anici (chedero (alveri). Aroyid di mono, Jtemetses Doc. B. 1/82

344 


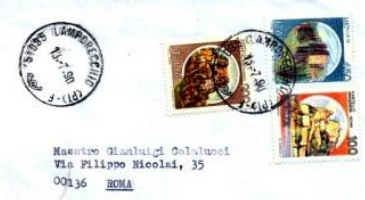

Doc. B. 2/90

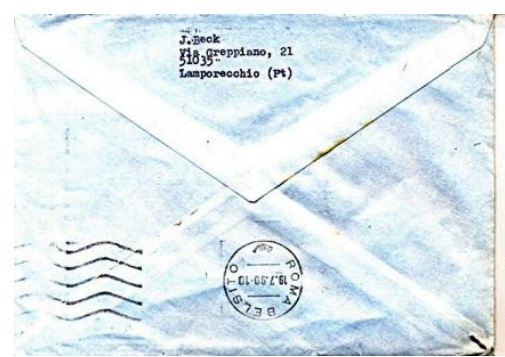

Doc. B. 2/90

Columbia University in the City of New York | New York, N.Y. 10027

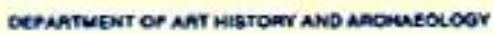
Ja1y 13,1990

Dear Naestro Colalucel,

I vould $11 \mathrm{k}$ o to thenk you for greeting me along with xike Doley at

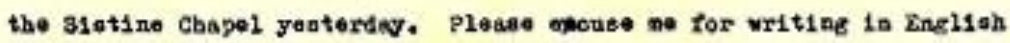
but I a1d not vant to be mleunderatood. on a bunan level I bope we ona obtas a friendly rolationablp, and $I$ an vell avare of your reputstion ae a ribe perbon.

On a profosilobal level, howerer, we appear to be at completely oppoeite eides, certaif fyth regand to the rork dobe on the ceiliag. I any this Do that there can be no niatake sbout my postioa. Perhape sa vark procobds on the Leet Judgegent, Wbiob I hope will be potponed until many more studiea oan be aede, ve oan agree on that projeot. I hope that we can meet agaln at nere lekoure sometine in the fall, 11 not eooser, and I giro my Itakien teleptone number ( waioh I nay not have witten oorrectly on the oard I eave yon): exscr $0573-92695$.

Fia orepsano, 21

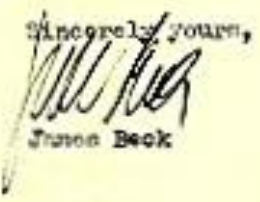

51035 LANPORSOCHIo \{Pt

Doc. B. $2 / 90$ 
Prof.Janes Beck
Via Greppiano, 21
\$1035 Lamporechio
Caro Professor Beck,
La ringrazio della Sua gentile lettera.

Considero positivo il nastro incontro nella Cappella Sistina. perche credo nel rapporto diretto, nel dialogo e nello scambio di idee, anche se contrastanti ed inconciliabili, purche lontano dal elanore delle poleniche giornalistiche.

Sinno su sponde opposte per quanto riguarda il lavoro fat to nella volta della sistinat evidentenente abbiamo percorso strade molto diverse che oi hanno porteto contrastanti convincinenti. I1 lavoro del restauratore $s i$ incentra nello studio della materia di cui si conpone l'opera d'arte o da questo studio exli trae le sue conoscenze, rifuggendo, per quanto possibile, da interpretazioni personali. Ho coscenza di aver fatto tutto ció con la riflessivita - la cautela che la circostanza richiedeva.

Il noatro lavoro in Sistina stato attentamente e liberanente seguito da storici d'arte da restauratori che ci hano alutato con atinolanti e preziosi pareri, per questo notivo ho sempre preso in seria coalderazione anche le sue obiezioni e le Sue oritiche, che, depurate da quelle accuse in cui ni era inpossibile riconoscermi, ho sottoposto a puntuale verifica.

La consapevolezza di aver lavorato in profondit su ogni ninimo dettaglio e dubbio ai non aver sottovelutato niente e nessuno. mi ha dato nagsiore forza norale e mi ha reso più sereno. pernettendomi di sostenere la grande responsabilita di cui sento tut to il peso.

La stessa linea di condotta sarà tenuta per il lavoro sul Giudizio Universale la cui fase di studio, di documentazione a di sondaggio durera tut to 11 tempo necessario a nettere in chiaro - dare soluzione tutti i probleni che il grande affresco presenta.

Hi sara gradito di incontrarla ancors in una atmosfera più serens - responsabile, per dibattere 1 temi ohe ci stanno cuore.

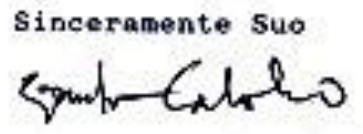


August 26,1990

Dear Maestro Colalucei.

I returned from my holidays in the nountains to find your grocious letter of 26 July in my noilbox. I have to sdnit that 1 an honored that you took the time to vrite to me and that vau are preparod to continue to discuss with me issues that are of the greatest interest to both of us. You are absolutely carrect in pointing that that they should take Dlsce suoy frow the rhotoric of the daily neuspopers and tho press. Again excuse me for witing in English, but uhile I con nanago in Italian, I feel much nore confortable in English, ond bore preciso in my bouning.

May $\mathrm{I}$ nake of observation: I an oreoared to believe that art historians and, in particular, one art historian gave deternining advice and orecious opinions. Unfortunstely for a variety of ressons, sony art historians due to an orientation that hos led them ausy fros direct confrontations with the art works, tond to "see" with their intellects ond not with their eyes, I am very dissabointwent in how poarly the estabilishment art historians act when it cones to restorgtions of majar nasteroisces whether the disastrous cloanings at the London National Gollery, at the Yale University Gollery of Art, at the Metrodolitan, or uhorever. Either they are often cowards or they are bilind or their interest lie elseuhere. You and $\mathrm{I}$ know that in every restoration, there is bound to be same losses, and these must be weighted againet the nesessity for sreservation of the art object. But when tho balance swings too far, the specialists nust spesk out. Certainiv we can disuess this issue together, and $I$ beliove that ve agroe, at least in orinciole.

On this line, I beliove that to a certain extent you have been victinized by these scholare and so-called specialiste, who obtein prestige and honors by being clasely assadiotod with the restorstian. Furtihermore they have brivileges about getting inforastion, seeing otheir work being done in the Votican, and obtaining photographs, etc. Mony of theil se not students of oainting in the first place, more speciolized in sculpture and architecture ol thaugh "poverful", and if they aro devoted to painting, they have nevor realiy atudied Michelangelo in barticular. They have for the nost part been nore eoncerned with Raphael and $h i s$ 'school, which offors very different questions and ultiwately have a disinterested viou of Hichelangelo. The ane wajor scholor vith a cloin of being a Hichelangelo specialist ts on elderlv Aaerican, who has beon at the sawo time as he has been singing the praises of the Sistine raztoration and publicizing it has been deepty envolved sit the sale of a so-colled nodel of the David but which is a elearcut forgery, fron uhich he will benefit financially. In other words, you nay have been to a certain ontent betrayed by your friends. as it vere. In cases such os this one, what you really needed fron these people was horsh, constructive eritician and not sveet and ignorsht praise, in ay opinion. Then you could have acted upon the points raised.

I Dlan to write very little more on the vaults of the sistina. It does soen to se, again fron Wy point of view, thet the dowage has been done and thot the only thing left to do is monitor the ceiling very carefully to hake sure that the chenicals are not stili st work, and that the

Doc. B. $4 / 90$ 
stuogphoric changes that can occur nou that the auriace has been denuded of its old erotestive coatings aro sonehow cantralled. I do not see any pucpose, consequentiy, in beating a deod horse, as the soying goes, except that I wild write a Briaf paper on the romoval of a major pentimento to clear the air and a brief goneral statonont for a popul or weekly.

As for the Gukdizio Unaversale, whilo I am tranquilizod that AB 57 and the Parblloid will not be used. I still aaintain that tho bost trostnont i. nothing more that what nov be required by conservation alone. Thus a vory, vory light eleaning, even a oroper dusting, ot this time is all that is calied for thare is aluays tine in the future far a deas eleuning, for now I would go very lightly indeed, Best of all would be no intervention at all at this time, but colitically thot mav be overy diffleult course sonsisering the sponsor and the stated positions of the Watican tean ue until very recently.

Let me repeat, caro maestro. that I do not oretend to be an expert on restorstian, on the chenical probloms, of the teshniques of cinauecento fresco painting. I do have a fatr understanding of the docuwentary evidence on the ane hand, and the art histarical evidence on the other. Furthermore, I believe that I have a very large anount of common sense and I think I have been able to see the entire averatian within the contest of the scholarly, oalitical and econowic factors, bath within ItaIr and more widely. I regret that a nan of your integrity has been

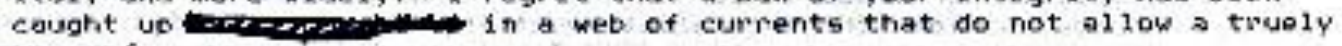
free range of

sction. If you did have such a range of action, I an guite sure yous wauld suggost a postponament of the intervention at the sltar wall, at least until the now atmosphoris controls are not only aperatiansl but that sisficient tests have been nade to detornino tho proper sottings and suoervision of the controls. To my knowledge thera $3 \mathrm{~s}$ not much previnus axporience to go on: the heat of kome and the yast number of visitors to the gallery makas it a unique cose.

I hope that within the next fow wooks or nonths I shall get to fone and verhaos we can speak agaxh. In the nenatire, wara yau to sane to

Florence for other business. I would be most pleased to soo you here. Finaliy, if $Y$ hove anything to say, $I$ will say it, and $I$ would be ansteful if you did the aane in ay regard.

Prof. Janes Beck:
Via Grepoiana, 21
Sioss Lanoarecehio (Pt)

Doc. B. $4 / 90$ 
Fobruarv 15, 1991

Dear Maestro Calolucei.

It has recentiv cane to wy attention again that you oersonally have beon reparted as claiming that beck has never been on the scaffolding of the Sistina. This is an old gtary invented by the Public Relations people surrounding the restoration, but you know perfectly well that I was uD, since I say you and you $s$ ar we and greeted we up thore, on ay second viait to the ceiling. Since this infornation was reported to a paintor in fowe whose art I respect, I expest you to correct this situation inhediatoly. If in fact you have actually said I was never on the scoffold. I shall publically call you liar. If not I expect you ta correct the situstian

If you do not recall the occaslan i was brought up by Professor Kanicelli. hivielf and you wight consult hill. It is one thing to have your opirion and I have wite, and for us to disagree, but for you to actualy lie, seons to me a situation $I$ do not olan to tolorato.

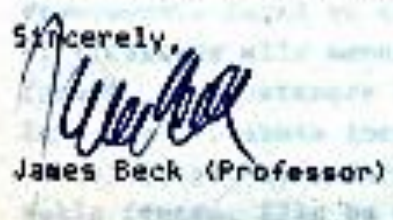

I

C. P, No, B

51035 Lawoorecch10 (Pt)

Doc. B. $5 / 91$ 
Prof.Janes Beck

C.P.N ${ }^{\circ} 8$

51035 Lamporecchio (FT)

\section{Caro Prof.Beck,}

sono letteralaence ceduto dalle nuvole nel leggere le sua lettera, perchè a tutci coloro che me lo hamo ehiseco, glornalisti compres1, ho senpre parlato delle Sue due visite our pontege \& piul recentemente anche del nostro incontro in Cappella 518cina.

Francamente farel un torto plù a ne stesso ebe Lei se dovesa1 ricorrere alla nenzogna o alla denigrazione nel suot confront1, per sostenere la'bonta del alo laworo.

Teno che let abbla incontrace pergone stuplde o disonegte che 81 divertado a farla arrablare.

Ne11a fretta, E1la ba dimenticato di diraf 11 noue dello stiace extiata gentiluono che ba decto une sinile falsità. Posso esplre 11 suo stato d'anino, ns le alnoce se le poteva risparaiak, a per favore non scendfano ov1 piano personale!

\section{Sinceranente}

Groilucalin

Gianlutgi Colaluec1

Doc. B. $6 / 91$ 


\section{VILLA I TAT TI}

\section{Februerv 26, 1991}

Kaestro Gianluigl Colslucei

$V$ is Antonio Mordint 14

00195 Rons

Cora Haestro colalucel.

Sona walta lioto di avera le sue parole con la quala chído la quastione. Io non perisa, perá, sha o giusto the dfco il nowe del pittore percho ho sentita trabite un altra porsona, Del resto, anche io nan sento ad non voglie scendere sul piano parsonate.

In oltre, curiasunente of in un strano garo gells storis, nai si gno in qualche nofo legato. Con questo nan voglio dire che io sappig i prablent coue Lei, o che tho lo esperionza cone Lef, o che ho lo preparazione coue Le1. Ka per bene o per wala sono pasti quasi sei anni che seguo o studia 1. cose agni giorno.

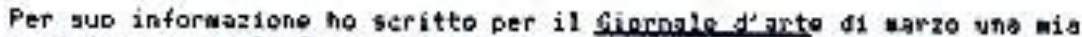
posizione generalo tnan sulia Sistinal che sard grato di suara suo 1 reazioni.

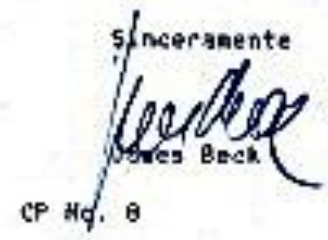

\$1035 Lasporecchio (Pt) 
Prof.James Beck

C.P. n. 8

81035 Lanporechio

Egregio Professor Beck,

Ho letto il Suo articolo riguardante 1 problemi della conservazione e del restauro, pubblicato dal giornale dell'srte di marzo tho ricevuto anche is rotocopial, e poiché Ella ne ne chiede 11 parere, io Gilelo do con tutta fraschezza.

Trovo senz'altro condivisibile la prooccupazione, del resto anpianente diffusa negli ambionti responsabili, per i rischi oggettivi che corrono le opere d'arte nel viagsiare, cosi come mi trova concorde il timore che la cospicua quantita di denaro privato, peraltro più che necessaria, che datfluita o che sta affluendo in questo delicato settore, non venga usata nells misura dovuta per $l$ meno spettacolari na più necessari interventi di pura conservazione. A guesto proposito voglio ribadire che contrariamente a quello che Lei pensa, il regtauro della sistine ¿ stato deciso per motivi tecnico-scientifici ed è cominciato molto tenpo prina della ricerca del finanziamento il quale è legato all'altra esigenza scientifica quale quella di disporre in archivio di un filn che mostrasse in tenpo reale la pulitura di tutti sli affeschi della sistina.

Dal Suo scritto appare evidente tutta la sfiducia che Ella nutre nel confronti degli Organi e delle persone responsabili a tutti i livelli in questo settore. Qui non sono doltutto d'accordo. perché io che vivo dal didentro 1 mille problení del nostro lavoro conosco un gran nunero di persone ben preparate, oneste, degne della nasina stima che si injegnano a fondo nel lavoro senza mire di lucrosi quadagni e non credo che persone esterne potrebbero fare meglio. Del resto to che sono uno dei piu vecchi alliovi di cesare Brandi, ritengo che per bene operare e fare scelte corrette sis sufficente attenersi al dettato della sua "teoria del restauro". Quella di Brandi d una fllosofia tuttora insuperata e lo stanno a dinostrare 1 auccessivi tentativi di rimaneggiamento, di riadattamento, di agkiornanento, tentativi che se pur apprezzabili sul piano dell'intenzione, sono risultati a perer mio vuoti di contenuto quando non dilettanteschi.

La Sua idea di dividere le opere in eategorie mi sembra nolto rischiosa, specie per la categoria $C$ che, se ho ben capito, potrebbe essere sacrificata per fare posto ad opere noderne. Un concetto del genere potrebbe avere offetti devastanti specie in architettura e in urbanistica.

Infine, per quanto riguarda 1 'idea di una super conmissione e della sua stravagante formazione, ho il sospetto che anche Loi la eonsideri più una provocazione che una via praticabile e valida. Io personalmente ge ni amalassi non vorrei essere curato da una equipe formata da un avvocato, un sooiologo, un senatore e da un

Doc. B. $8 / 91$ 


\begin{abstract}
padre di fabiglia ohe en cose ai fanno i tigli: ari banalo, ma ia sceglierei prian di tutco un buon nedico pol chiederi un convulto dei aiglior1 apeoindist.

L'argobento de Lil toceato vaeto ed articolate, per cui $m$ ne potrebbe discutere all'infinito as io ho cercato di essere nol to alntetico - posibilmento shiaro.

Distintanente La valuto
\end{abstract}

\title{
Gienluig1 Colalued
}

Doc. B. $8 / 91$ 


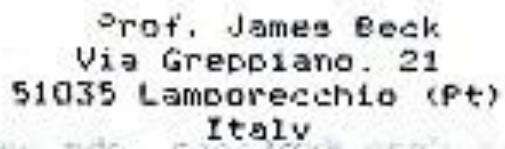

Io sto cercando di portare le discussione sul lovelo internazionalo, perché i problemi nan sona limitati sus Italia; anzi, $m i$ sembre simile problemi [a poggio] si trovana dapertutto, Gerania, in particulare, mi dicono, ma ancho USA Cper me, gravissiato par i guardi, come al Metropoliton, Washington Nationol Gallery, per eseapioJ.

Nel caso della Sistina, to penso che vostro neaica più grande era la hass Media, 11 Public Relations, e, perfine, i storici d'arte, ed invece di vori discussioni aperti, tutto ors controllato e manipesato [non certo da Lei, sono nisuro]. C'sono ormai wolto, secondo came capisco le cose, 
specialmente in Gran Brotagna, cho vanno avanti fino a fondo sul argamento. Io ho scritto ila ultima pensiero sulia volta che in in via di stanpa...,pol basta. Per ne, a questo punto, sara tranquilisato di sapere che 11 Giudizio sarb salvato.

Io ho intenzione di venire a Rono presto, a spero di poter salutarla. Ia trova pensante "Egregio Professor, Beck" perehe non "Cara Back," o "Caro James?"

Saluti cordiali,

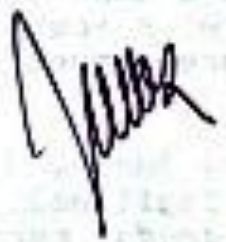

Doc. B. $9 / 91$ 


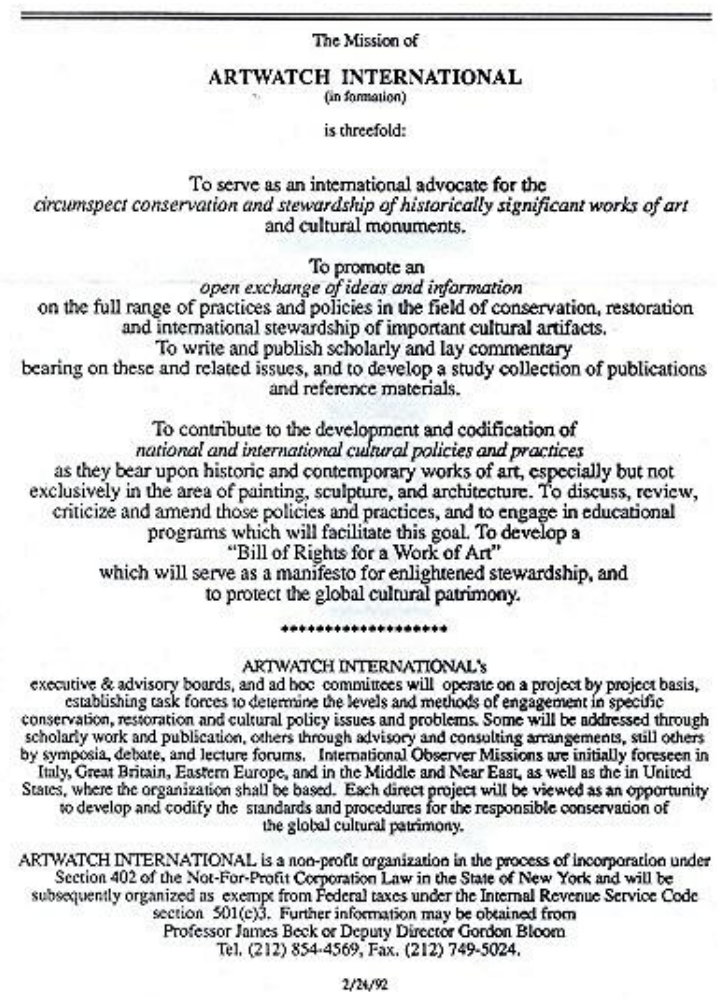

DOC. B. 10/91

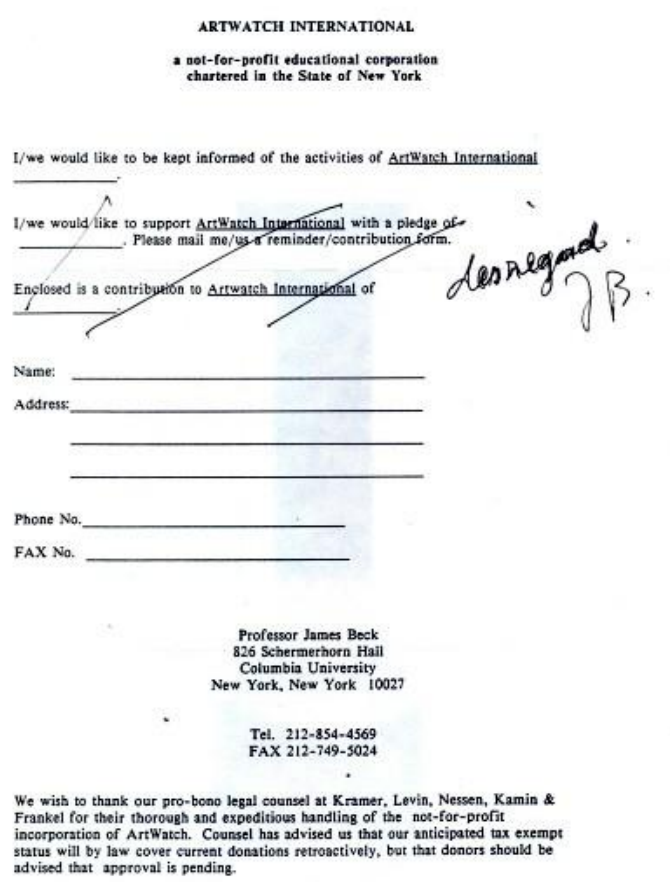

Doc. B. 10/91 


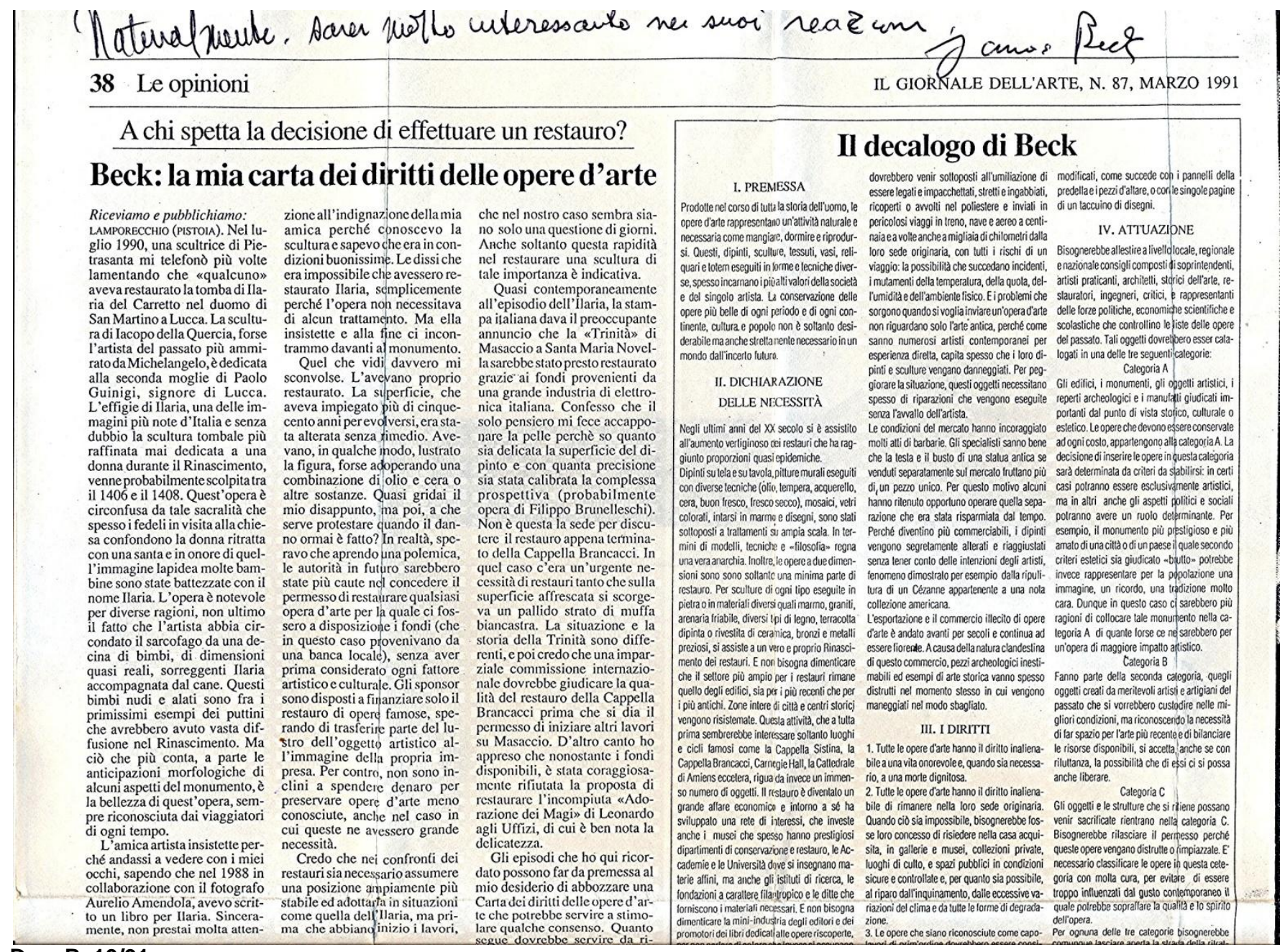

Doc. B. 10/91 


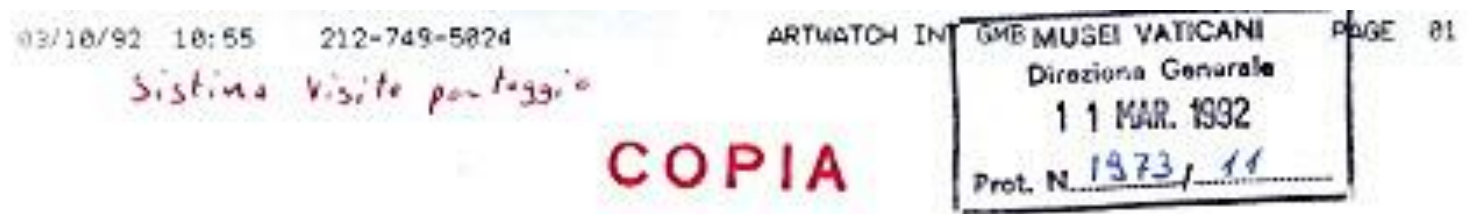

Columbia University in the City of New York | New York, N.Y. 10027 DEPARTMENT OF ART HISTORY AND AFCHUEOLOCY From James Beck: FAX, 212-854-7329. Tel, 212-316-0912

Narch 5, 1992

Frofegsor Gianluigi Colaluoci Care of Vatican Museuma

vis F. Hiccolai, 35

00136 , Rome, Italy

Dear Gianluigi,

I am sorry that you are not ablo to come to kosts in May, but I bope we shall neet Bocn, anyway. In fact, I an writing to ask you whether I might not cone to the siatina on Friday morning March 27the to have a look at the "Last Judgenent," as it is now unfolding, ard to exchange a fer words with you. I shall be arriving in Italy on the 26 th of Narch, to attend a symposiun at the Facilty of Mrchitectural pertoration the thiversity of Rone, and I ahall also give a paper wyalf. I thall be bpeaking obout cerception of nowers art (n,b., not the slstina), and would be moet gratiffed if I could both see you and the "Giudizfo."

For your information. I am sending on to you some saterial about the tormation of enteiatch Internaticnal, of which. I am the pirector and the Pounder. Naturaliy. as alwaye, I an interested in your coservations asd. to be gure, criticion. In any event, with luck, I whall have the pleacure of greeting you personally in koms in the near future. I am,

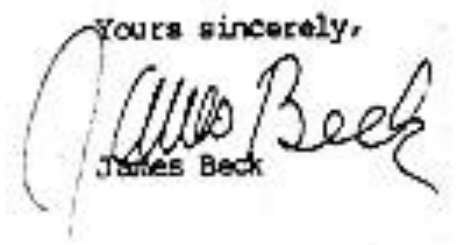

g26 Schermerhorn pall Columbia Ondveraity kew York, yes York 10025

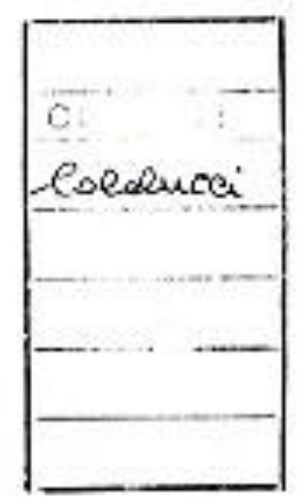

Doc. B. $11 / 92$ 
CIANLUIGI COLALUCCI

$2243 / 11$

Prof .Jsans Beck

826 Scherserhorn Ball

Coluabia University

New York, Kew York 10025
Basa 13 marzo 1992

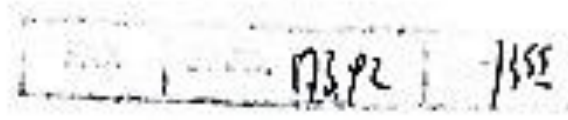

COPIA

Cara Beck,

avrei nolto placere di incontrarti o di postrarti il leworo abe atiano facendo ool Givdizio na 11 periodo di tine nerso per ae non va bene perche so oon gard a Boae ed 11 ponteggio sarab inaccesarbile gato che verrd in parte nodoficato. D'altra parte, to vorrel eseerel quando tu visitera1 11 Giudizio.

T1 prego quind1 di sclegliere un altro periodo, lasciando passa-

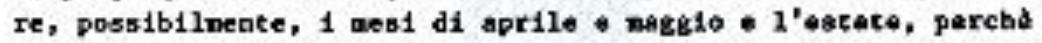
1o sarò a Rona bolo baltuarianente cause del aolti fapegei di lavoro fuori * le vacanse.

Se non ti diapiace of perneteo d1 suggerirti la flae di ottobre - I primi di novenbre, percbè a quel teapo saró floso a Rona 11 aío lavoro sarà un pó plù avanti e tu avrai di one piu ampia per siudicare.

Nel fratteapo ayrato aodo di rigentikef, aperando che tu voglia cortesemente aderire al afo invito.

In attega delle infornazioni cirea 11 tuo Artuateh Internatoari. ti invio cordiali salved.

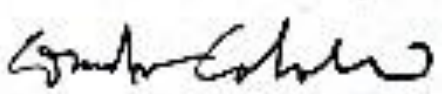

Gianluigi Colăluce1 
Columbia University in the City of New York | New York, N. Y. 10027

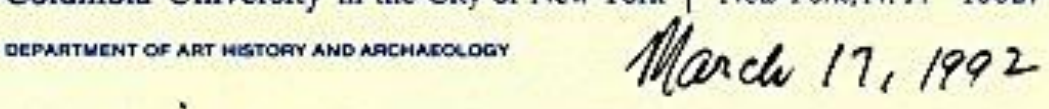

Cono quarlinge.

quasi per la tua.

Cectamente un far vero in

sett. $O$ t. Se non pruma.

chland partero lo sterso Qla tisteni vendi mattino, el 27. per un numunto. Se th par lareaise detho the nenco. Gol uns asertade per reden, se persible, andre lo caprelle faolud, narograto.

Pes resto,

Daluti Cronali

Tames

Doc. B. $13 / 92$

360 
Prof. Jakes Beck

C. P, No, 8

31035 LAMPORECCHIO (PE) ItalY

Karch 10, 1993

Caro Kaestro Cololucei,

I a finally in a position to take up your offer to show ae what is going on with the Lant Judgenent. I wonder if at date like Kay 4 or May 5 or May 6 would be possible? Or. would a date in late April be better for you, say the 26 or 27 th? I could get there reasonably ear 14,$10 ; 30$, by leaving very, very early fron Tuscasy,

As conncidence vould have it, I have been asked to do a little book on Raphoel's Stanza dello Sognetura, and would be honorod to havo a look at the roon with you.

I an constantly aware that by soee odd irony of history, we have bean throun together.

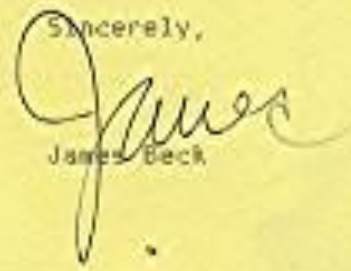

Doc. B. $14 / 93$ 


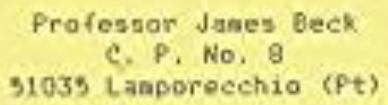

(Te1: 0573-81698)

Maestro Gianluigi Colalucci, via Antonio Kordint 14.

C0195 Ron

Caro Maestro Colaluced,

ho la tua nolto gradito del 3 aprile, e sard nolto lieto di venire a Roma al1a Cappella Sistina, olla ora 10:30 el giorno 3 Maggio per poter visitare il ponteggf del Giudizio con te. Ricanosco o prendo un iwgegso furmate e di gestuluavo ol no pubblicaro nulla sulla nia visita al Giudizio, sino a quando la pirezione Generale dei Kusei Vanticai non aprira 11 ponteggio anche alla stampa.

Inoltre, riconosco la tua generosita di pernitteral questa posribilita, e ti ringrazio in'anticipo.

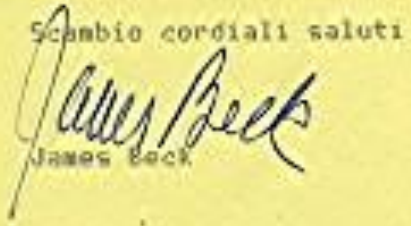

Lanporecchio, il 16 Aprile, 1993

Doc. B. $15 / 93$ 


\section{ArtWatch Internationdi (Inc.) \\ 931 Schermethom \\ Columbin Utwivering \\ New York New Yock 1000 s}

Dear Gianduigi,

I am sorry that I did not thank you of 1 - $1311 y$ sooner for allowing me to seo tho Last Jugenent with you last month. In tho meantime. I had to go to New Yonk and I an now back. But I havo often thought of your generosity in pernitting me an opportunity to viow the work up close, and for your explanations. Again. nay I thank you with hopo that we can remain, at least on a porsonal and on a human levol, friends.

As I indicated to you last month, my new book on restorations will be coming out in the late summer in England and in tho United states, and thero aro soveral chapters devoted to the sistine ceiling. As you are aware we do not see eye ta eye on many of the things that happened there ovor the past ten years. I also mentioned to you wy opinion that the mass modia which has been manipulated in favor of the Vatican position on $a$ worldwide basis $i=$ roally not very holpful in the discourse. Latoly I read that with the new air conitioning the sistine frescoes w11 be preserve "etornaliy." Whot nonsense. An what will happen if there is a power failure as hopponed for example in the Brera or in Bologna a faw years ago? But that is the least of it.

What $I$ am trying to say is that whatever the judgements may be of my book, and whatever your reactions might be, I shall continuo to regard you with warmth, as a person who has always been open to

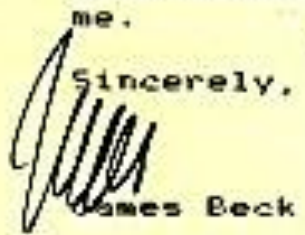

C.P. No,

51035 Lamporecchio (PT)

Doc. B. $16 / 93$ 


\section{Professor James Beck \\ C. P. No. 8}

51035 Lamporecchio (Pt) Italia

Tel/fax: -0573-81698

18Giugno 1995

Caro Maestro Colalucci,

Ho l'intenzione di venire a Roma per vedere dinuovo la Sistina la mattina del 28 di Giugno (mercoledi') prossimo, verso lora 10:00. Saro' molto contento di potere vederla a quell'ocassione per avere le sue explicazioni o almeno un saluto. Se Lei non po' venire, forse posso incrontrare uno suo assistente ed anche il chimico Gabrielli, che nel passato mi ha invitato di trovarlo. (Non ho ne' numero del telefono ne' indirizo.) In questi giomi ho anche parlat" col amico comune, Leonetto Tinori.

So benissimo che Lei non e' tanto contento di quello che scrivo, ma mi sembra utile lo stesso per tutti i due di avere un rapporto civile.

Suo con distinti saluti,

$$
1 / \operatorname{lig}, \mathrm{hab}
$$

Doc. B. $17 / 93$ 


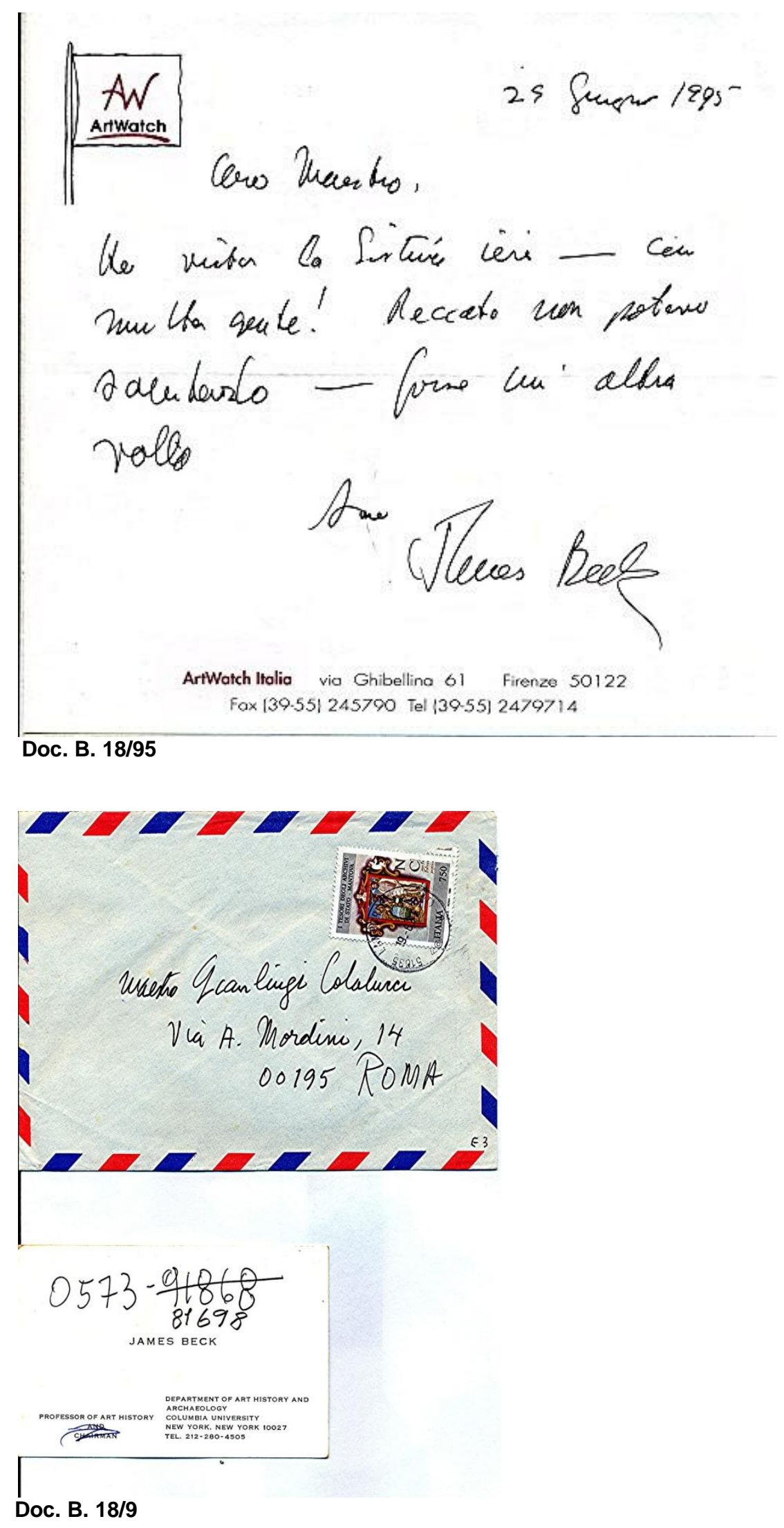

365 
DIARI DI CANTIERE DELLA SISTINA (archivio Colalucci- sezione documenti F. 13 serie 6-F. 14 serie 6 )

we Boneti vuple asjentare iforiche unanca dow

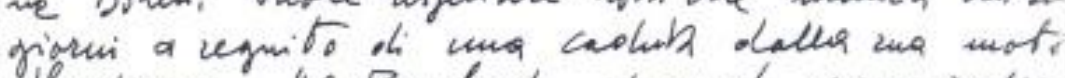
Houds 400 - de Paraloid, ofuowolo sune uspir. fa male at finco, zfecie wh stonaco, it bo e pus for voure allergre in pust. o wen siom alle kones, ofmudi i there he ofue

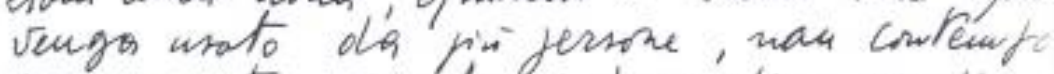
raveanente, for hewi torivolic zenpe con l'wto sleith mantiere ot wi ziano twi. ofotati -

allo finc of magyso raremuno couseymase it laraso e seriamo he non vi rians cumflication

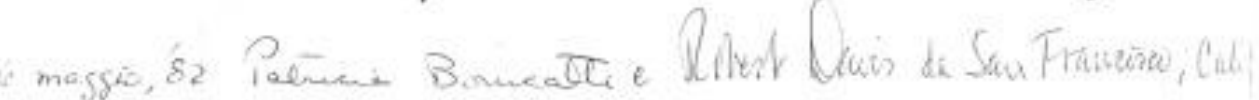

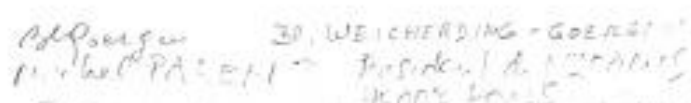

8 Moygio 82

Saen thace.

fancis Hackell.

cuszc thes.

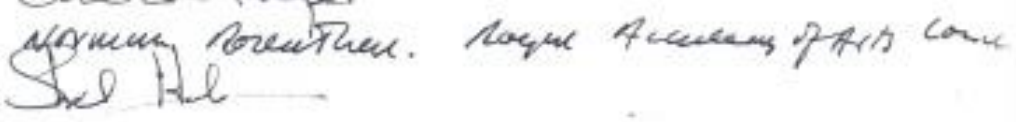
Y. Sartiorowien

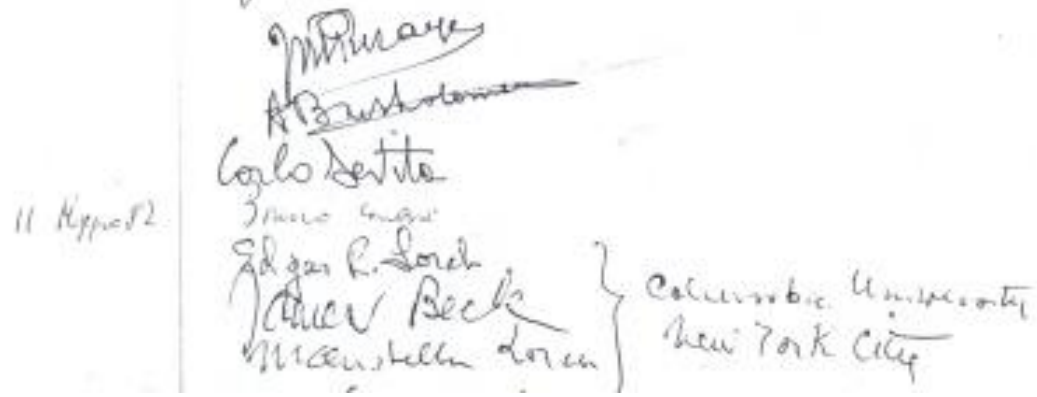

Doc. D. 1/82 - la prima visita di Beck, accompagnato da Bruno Contardi (data 11 maggio 1982) 


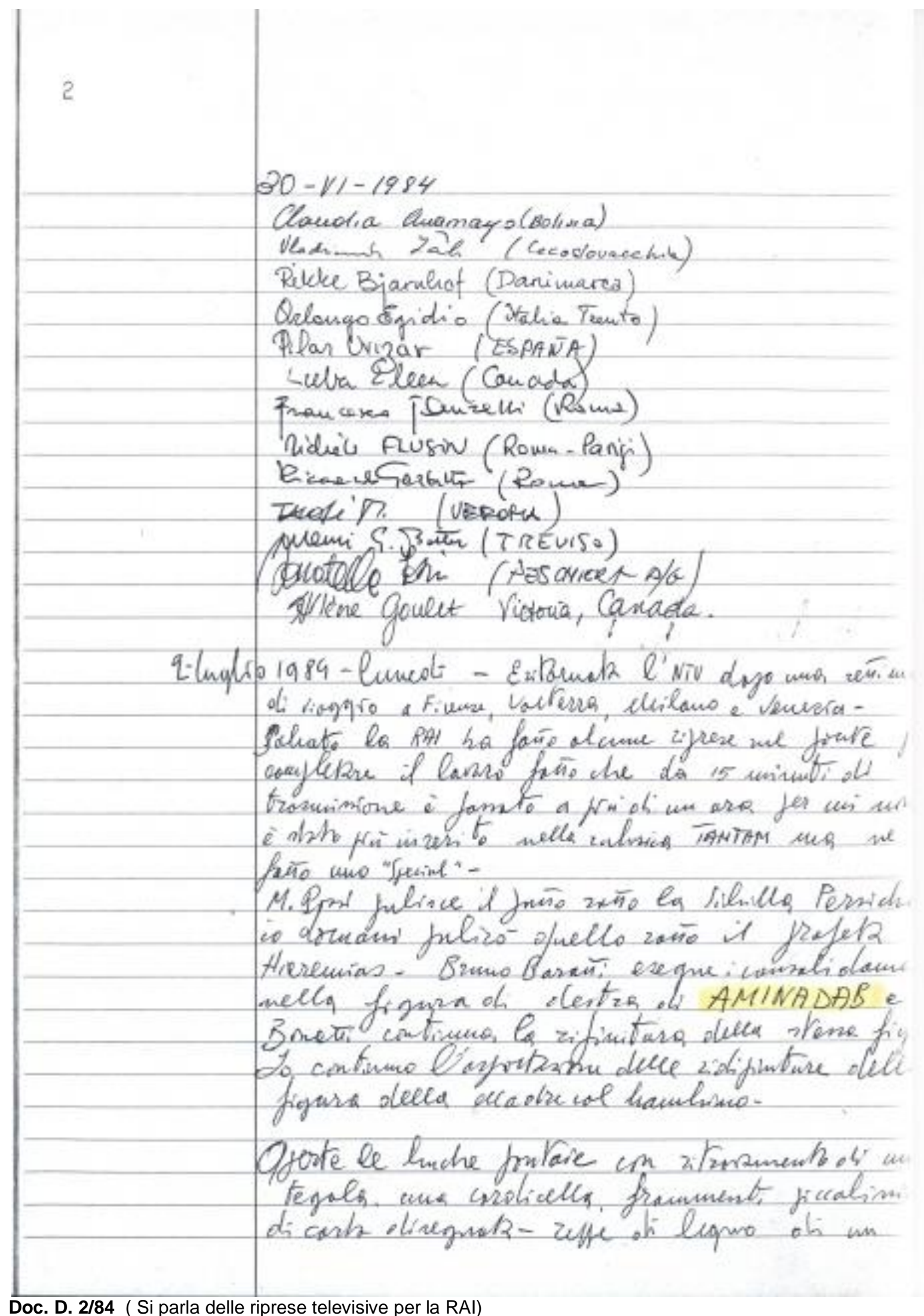

Doc. D. 2/84 ( Si parla delle riprese televisive per la RAI) 
unreoledi 7 noveulire 1984

atle ore to portians iffer if seconds grande naggto: if untauro della Wta dela ceffello sintrues -

Eseguo is prino test di pulitura con la nola da 195 unumti - Druacis enequizo il recoudo intervento L'NT ha filueto l'arrenimento. Elaws con me ellaurivo Roni, Pir Giargro Bonent. e Girovaui Grom -

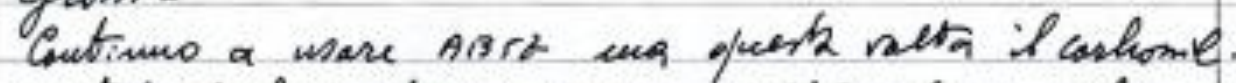
until cellubsa doria mere nalto oluro altimats soals enaledertaneute.

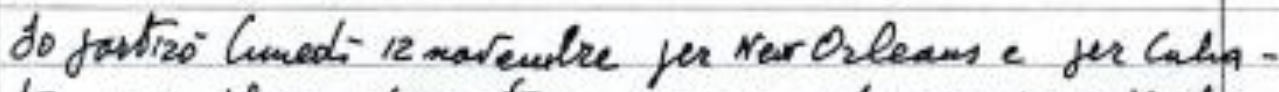
tormero- it ea dello of eno were - La zimuione frel:minare non so se cizarel frime della sia jurtena o al uio ritaru-

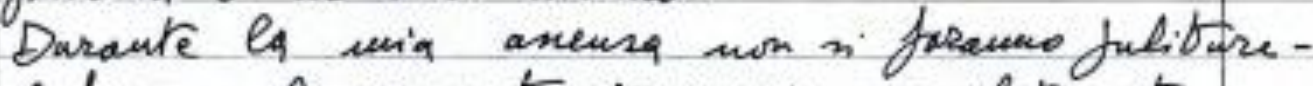

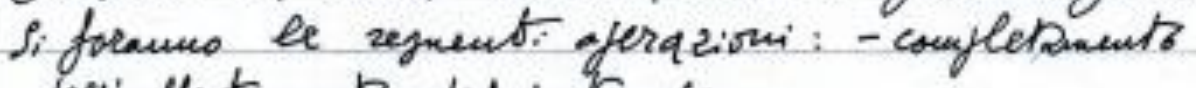

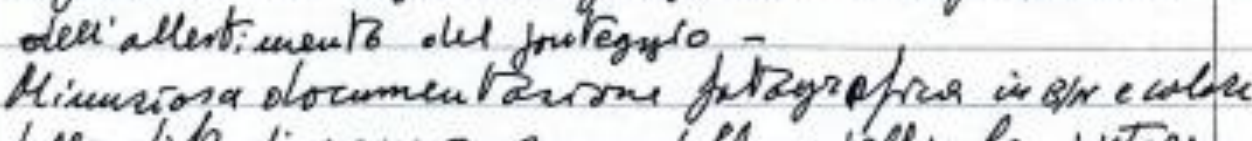

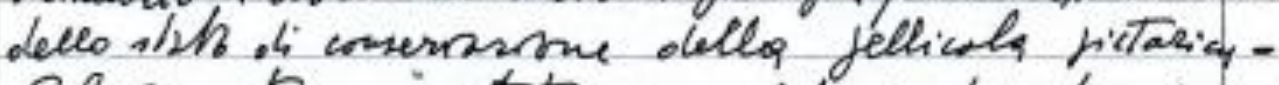
Rilevanunto e zentitusome grefices dei dowiRilerments e untifurme jefica delle tecuide diesecunsone -

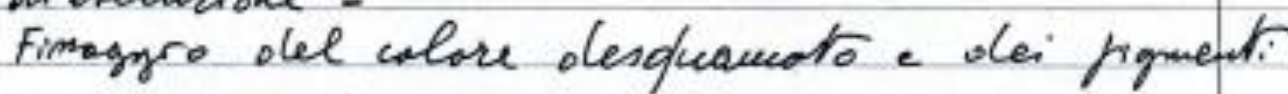
a varsa coestone Prelievi fer andini dei colari, dere sontans entranee 2 delle matte (i) Pulievi jer esacui itrotigrafici -

Doc. D. $\mathbf{3 / 8 4}$ (inizio del restauro della Volta) Giveluir Cololun 
23

7.16-1986 michel-Ange arant et apis I'ope'nation de la cataracte-

neweillew - medéfiosond

amme Fronad

Eolabh ercerchiv hiwo cfpesasi'

jit de frichen

21-4-86 Terminata le julitara e la zifiuttura ad ercesione della finure deda vadre con: olue houhivi - Verso es concherime crasolidamenti e ituccatire - Couching trañament e Corapro

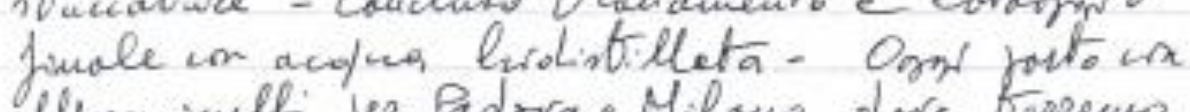
Mouvinell jer Padora e Milowe dare ferreno tre crufereure, nua oliniversils di Podora e

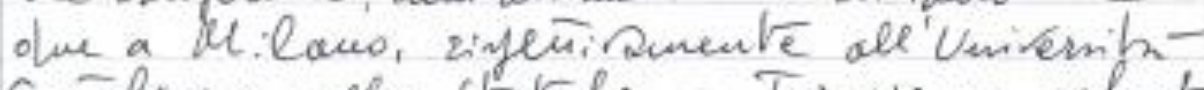
Cañolica e alls tratale - Toruereno rabato. Venerdi arriverá I'NTV - Duraute $l_{a}$ unimuana iniziera $e$ oferosiome di teintegrome grosica- Cha

$1 / 4 / 86$

\&I $\quad \operatorname{arata}$

und spuning alh wha cle me is pio dimentiare

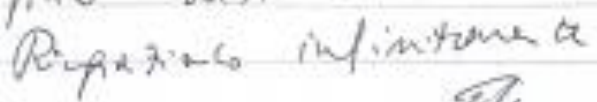

the Fombive. \&4.

In me curd.

Doc. D. 4/86 ( il commento di Gombrich.: una esperienza nella vita che non si può dimenticare)

369 


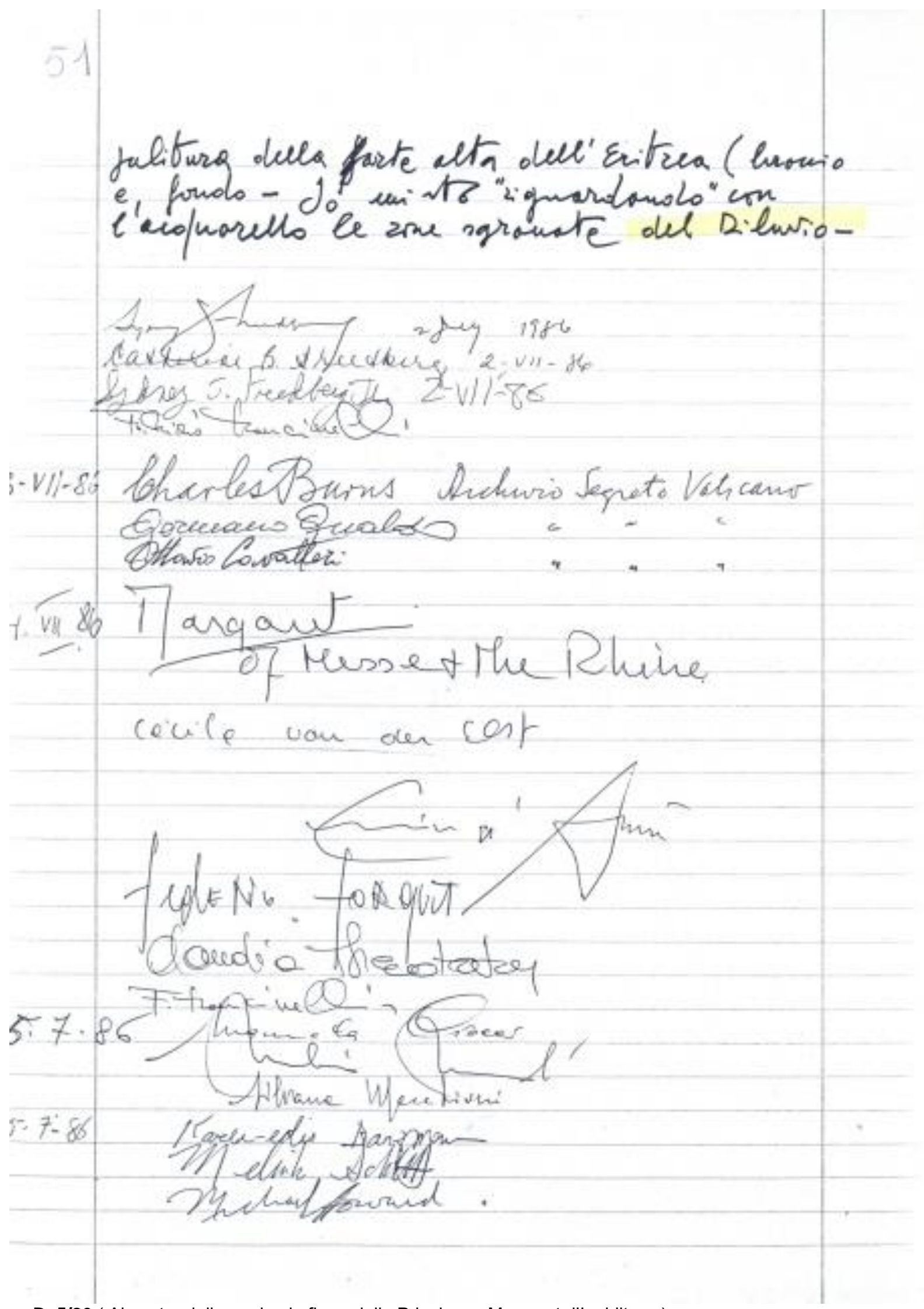

Doc. D. 5/86 ( Al centro della pagina la firma della Principesa Margaret d'Inghilterra)

370 


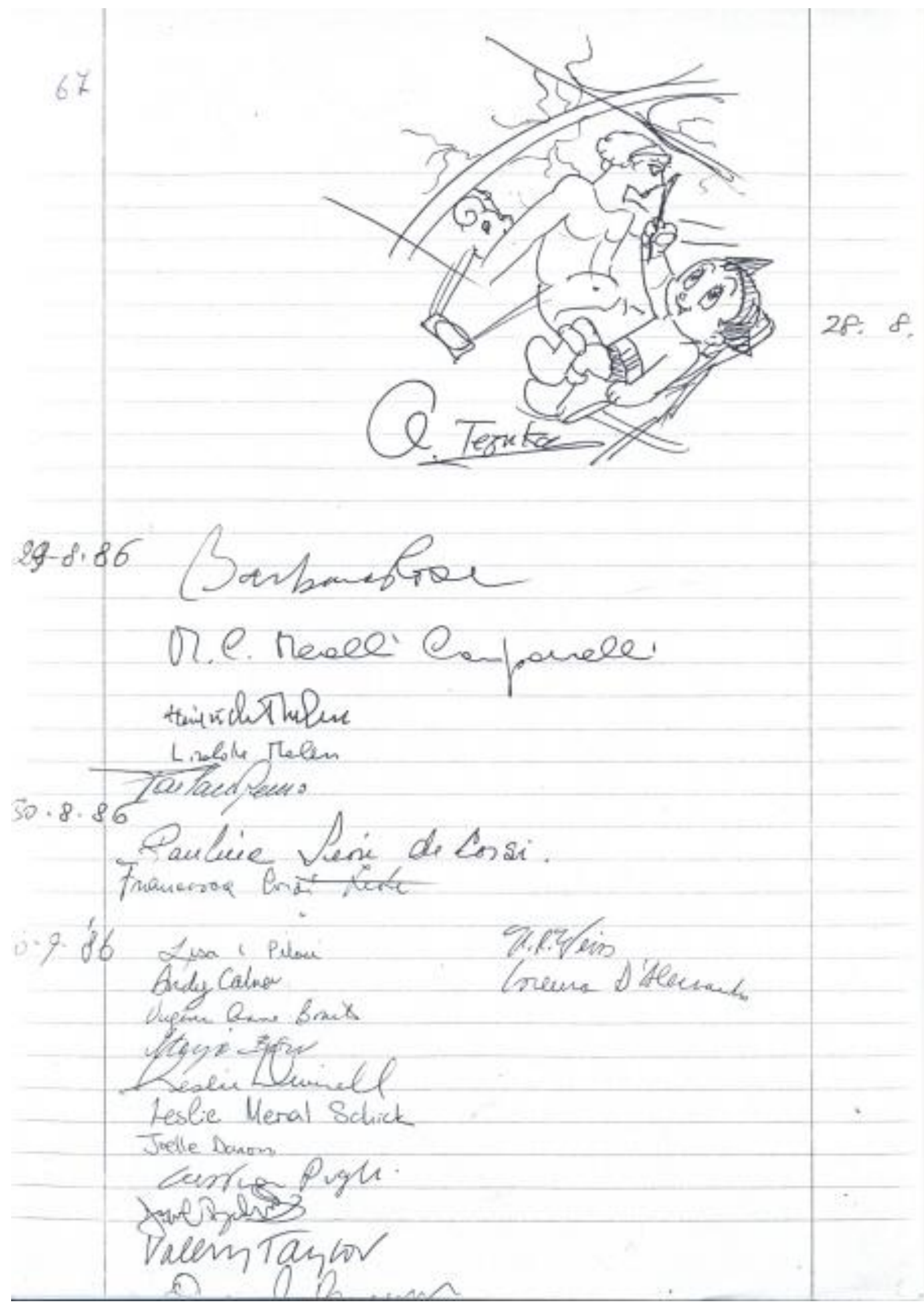

Doc. D.6/86 (Una vignetta di un noto disegnatore giapponese)

371 
44

mai prosate of accuntuate - Pursiann ol vino della

48

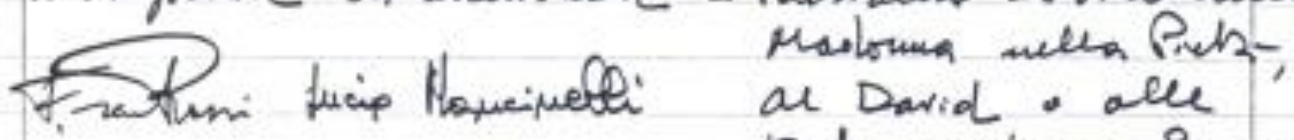

toulhe Mulotice - Rusiano

a pulle enjesfici lerigetimine e moolente cin'ble renitilih- che auche inpotuño und unarlida foute luminosa le fa vilizare - Ed - marma! La jüura di Miluelangelo ì la tena cosa, una suet usa zirettik di colare. ofuinali un le fene susilitimine delicatione-

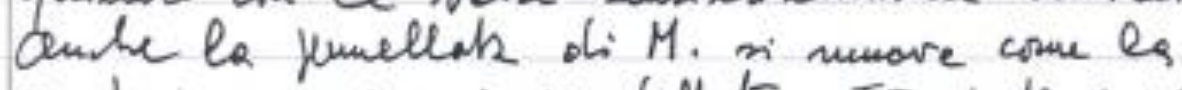

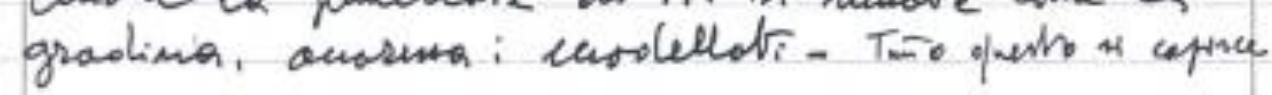

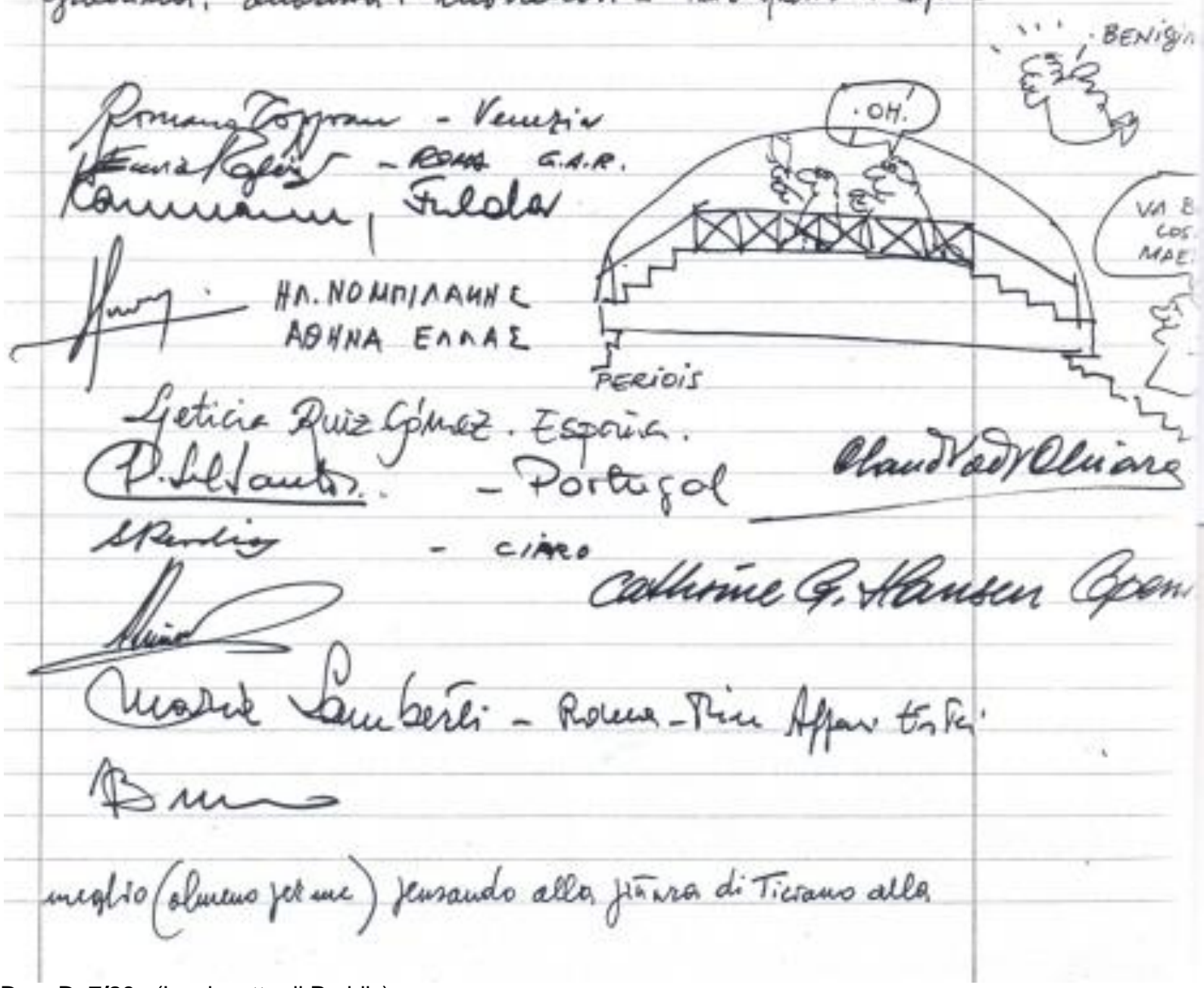

Doc. D. 7/86 (La vignetta di Peridis)

372 


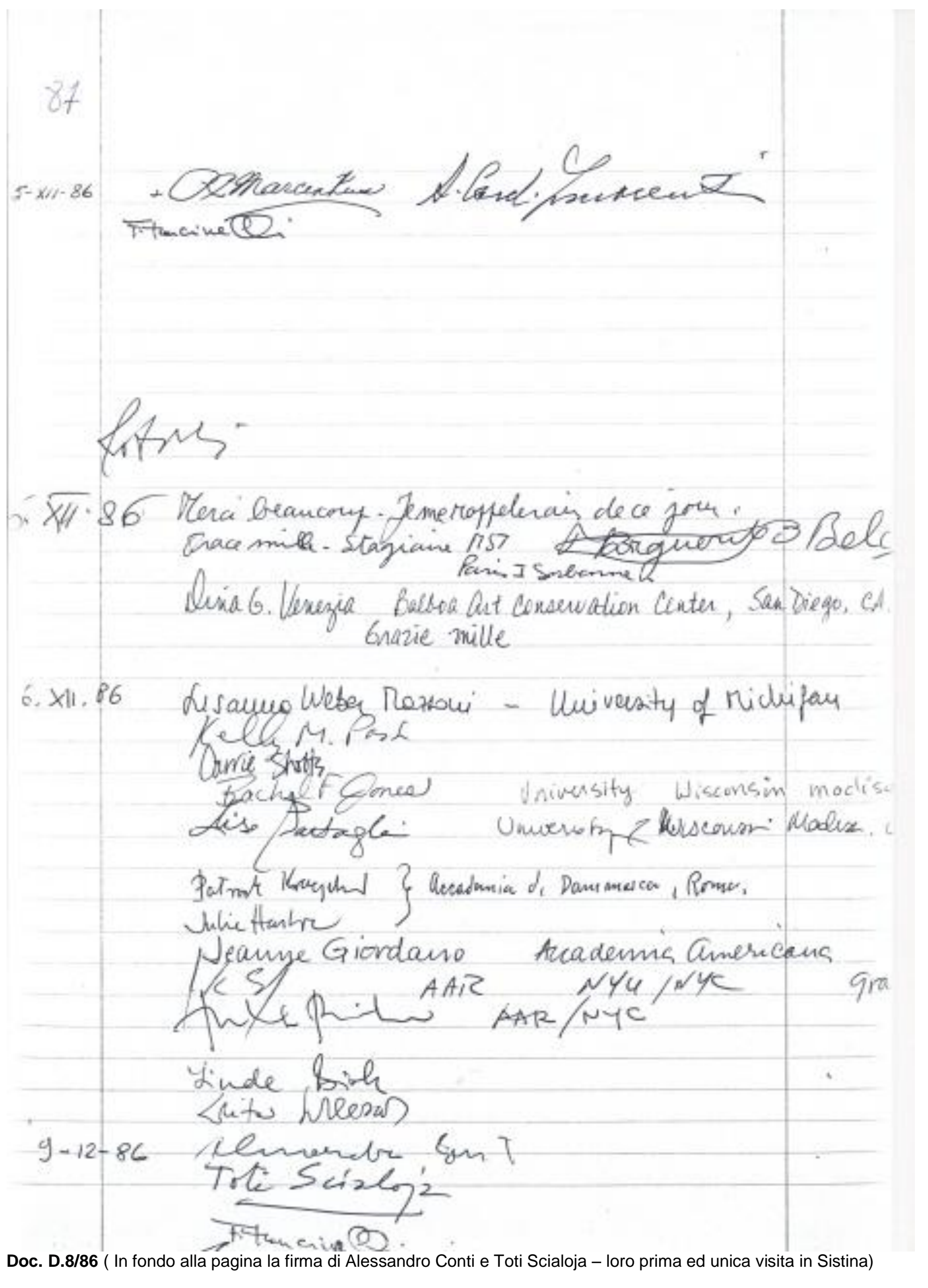

373 


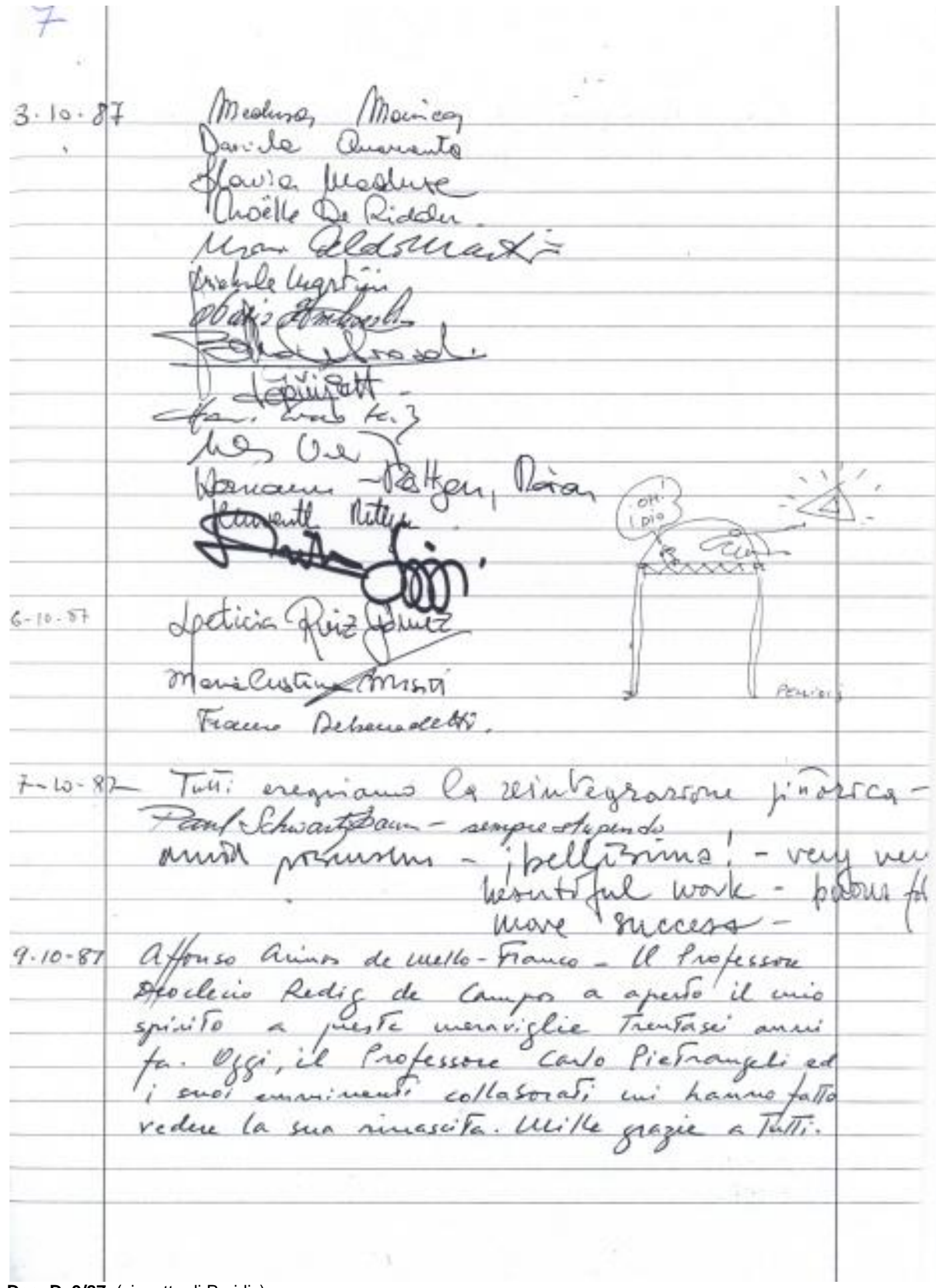

Doc. D. 9/87 (vignetta di Peridis) 


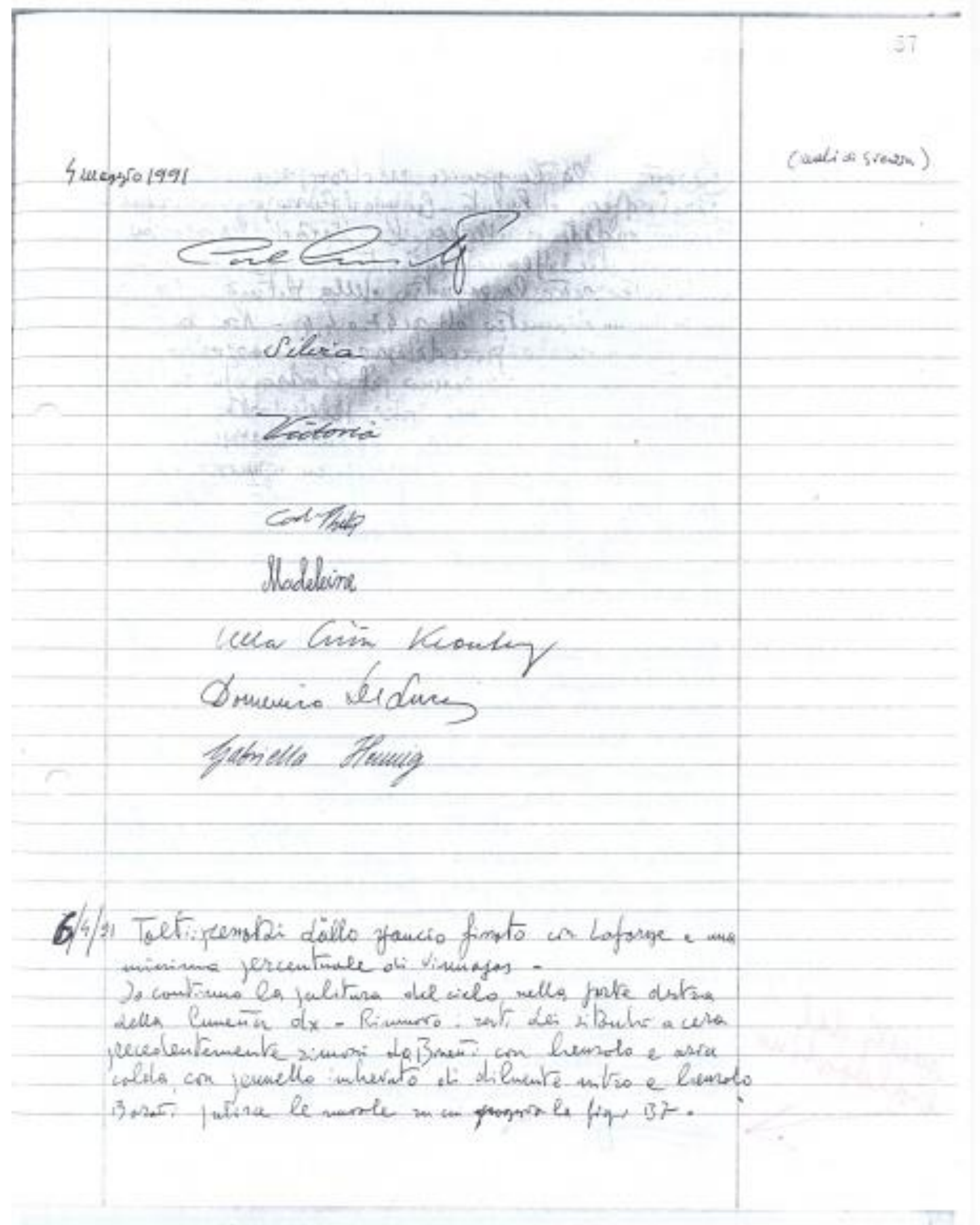

Doc. D. 10/91 (Le firme dei Reali di Svezia) 


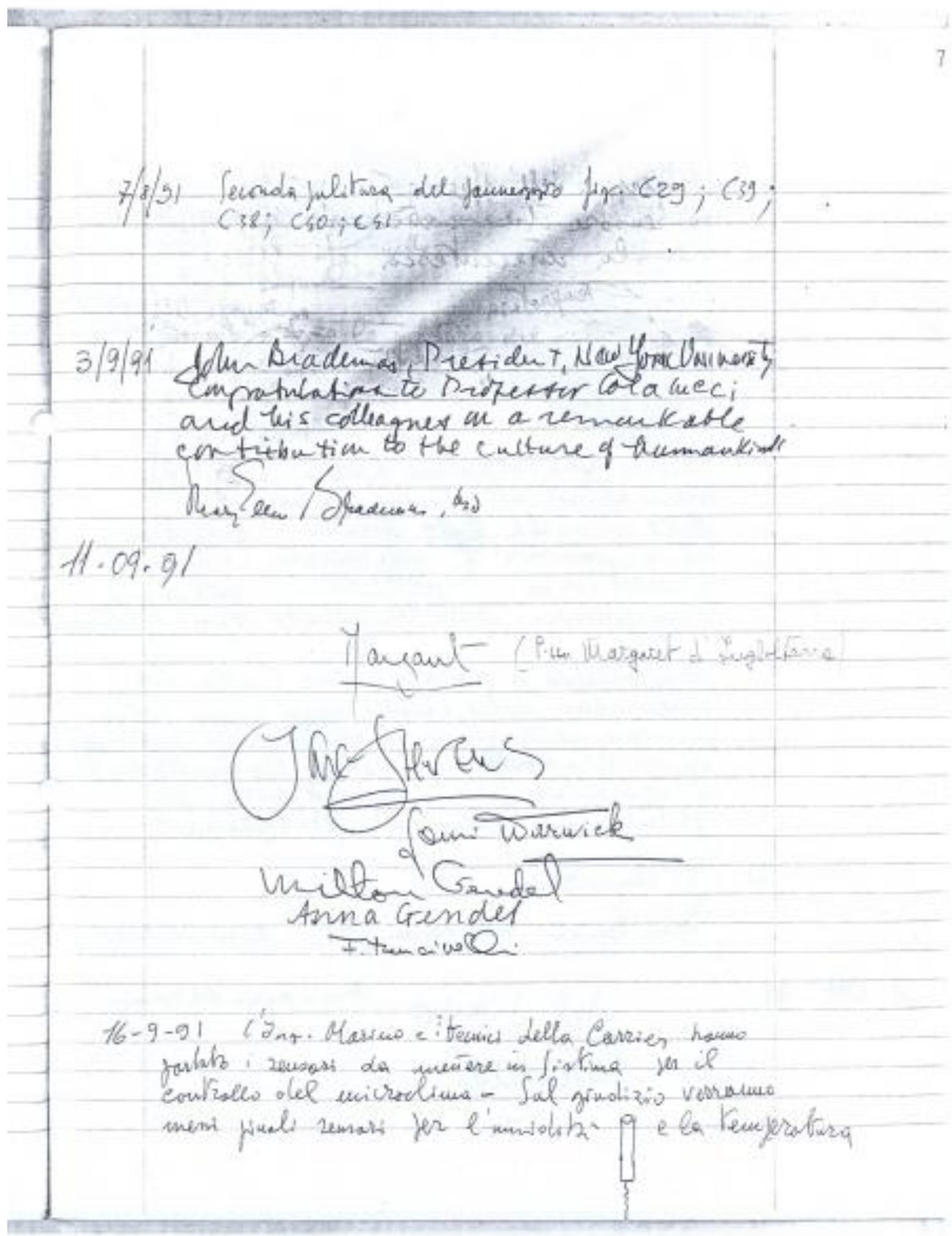

Doc. D.11/91 (La firma della Principessa Margaret d'Inghilterra in occasione di una delle sue numerose visite ) 


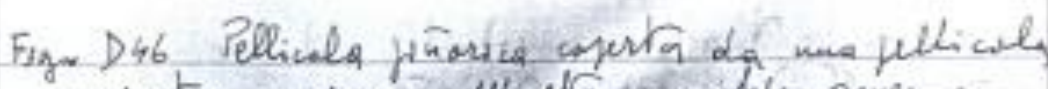

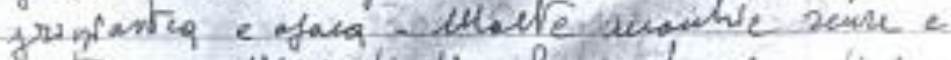

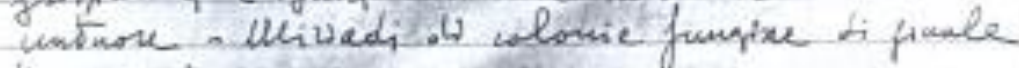
dismentoni - is Joba

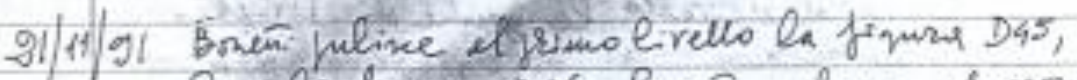
Rond es firara D46-Baran pulize al serndo

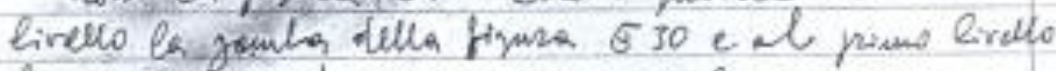
if caypo seluo jigure $\in 39$, zino al jesizoma -

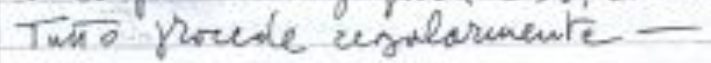
22/uaveabee/1991

22/noviablen/1991 coprel canno

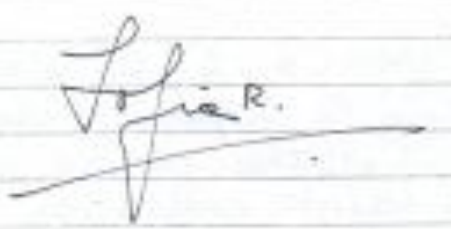
23.11 .91 .

\section{T tencies}

on hem bethe hel

Efiwinco la julitira della fizara dis. Gianawi Batiota -

Doc. D.12/91 ( la firma della Regina Sofia di Spagna) 


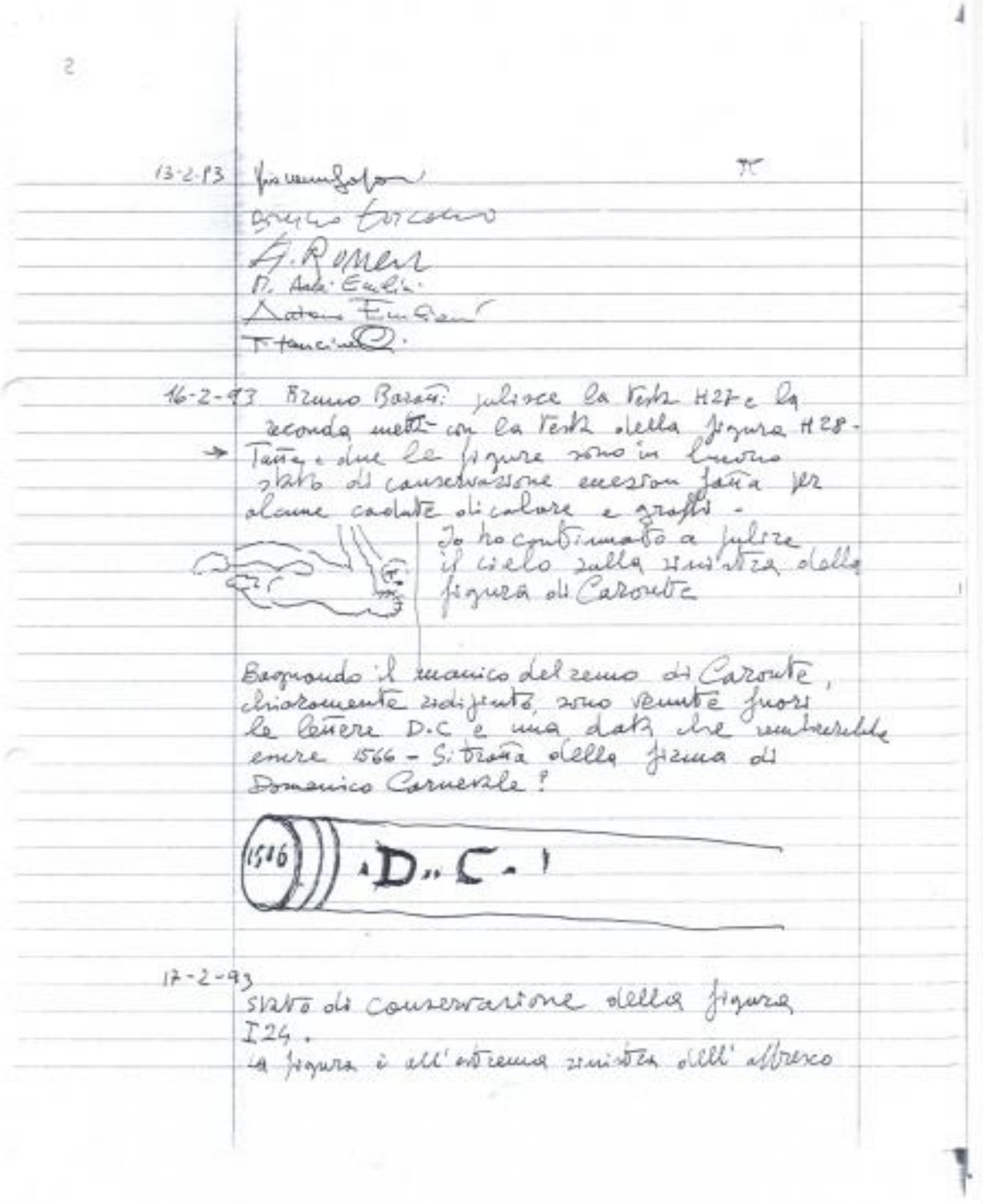

Doc. D. 13/93 ( la sigla D.C. forse Domenico Carnevali, rinvenuta sul remo di Caronte e la data 1516) 


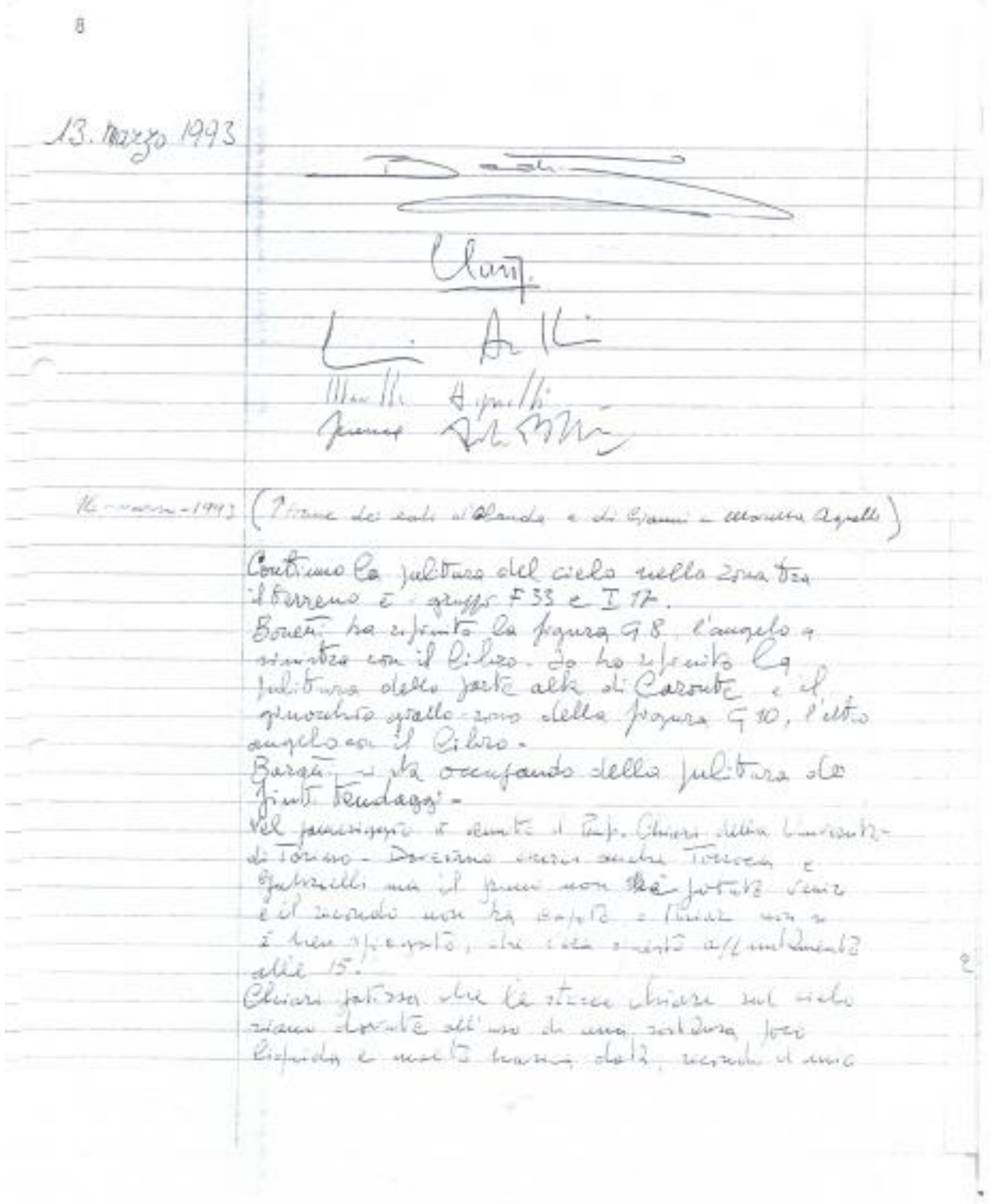

Doc. D.14/93 (le firme dei Reali d'Olanda e quelle di Gianni e Marella Agnelli) 


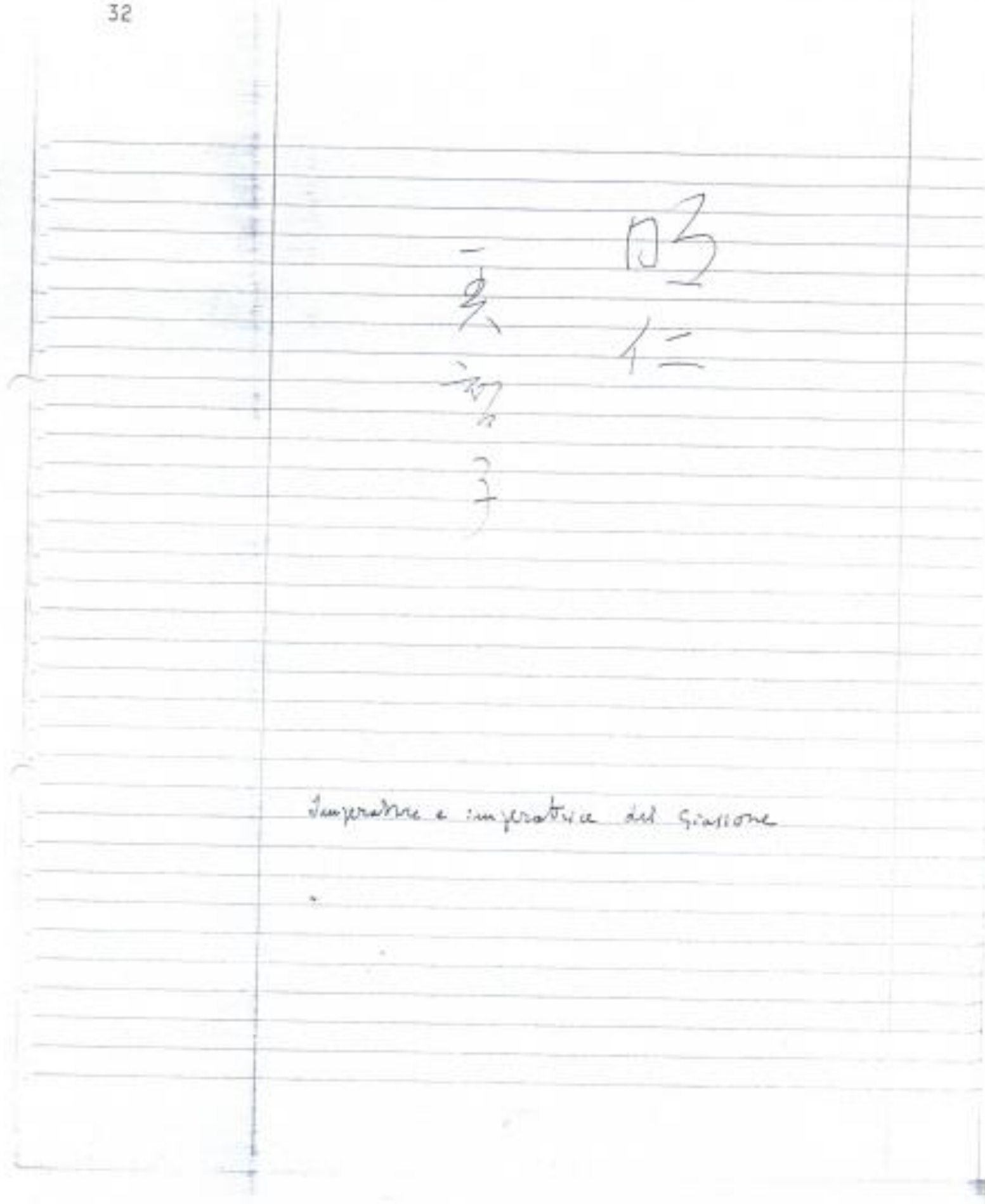

Doc. D. 15/93 ( le firme degli Imperatori del Giappone) 


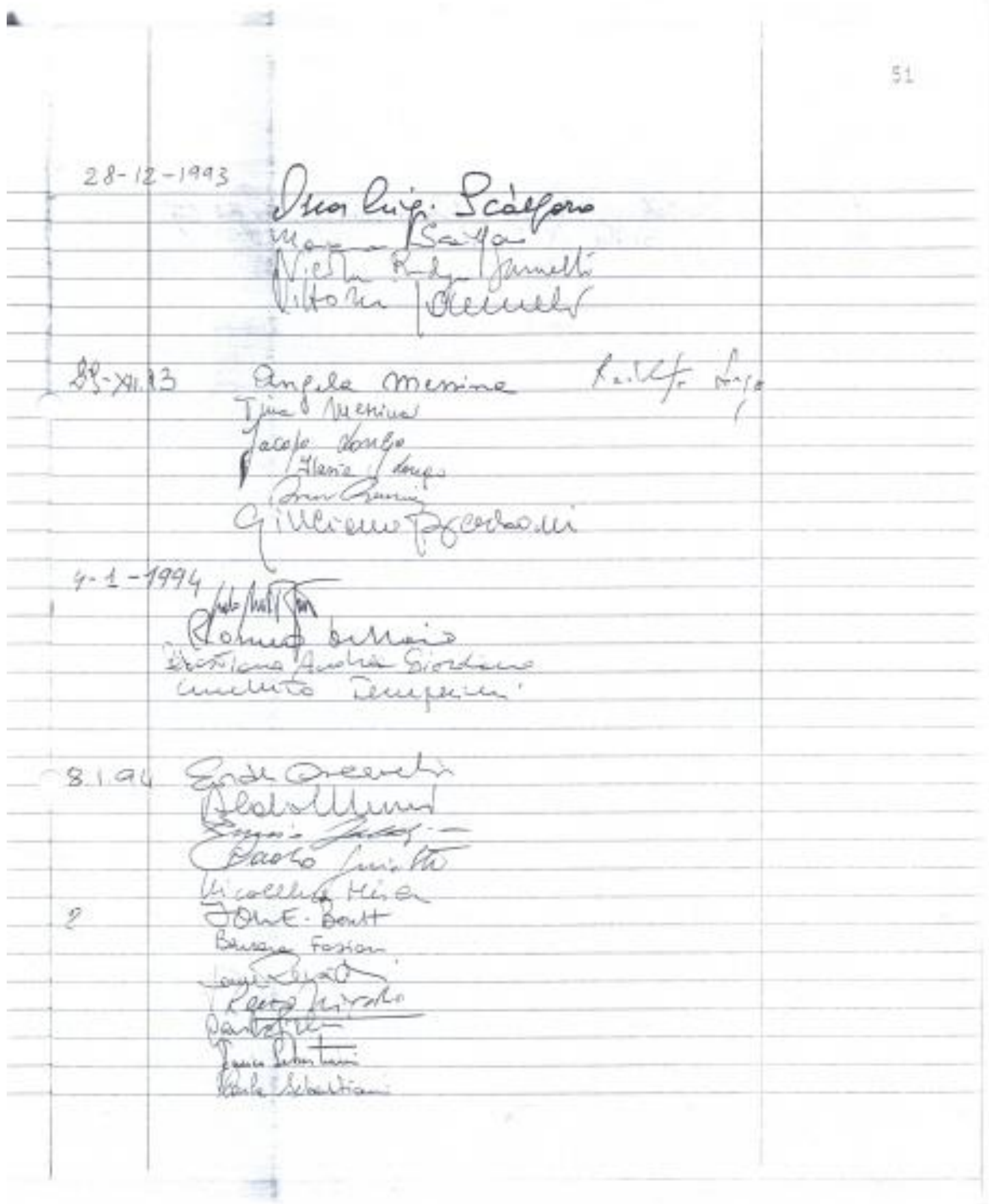

Doc. D. 16/93 (La firma del Presidente del Presidente della Repubblica Oscar Luigi Scalfaro) 


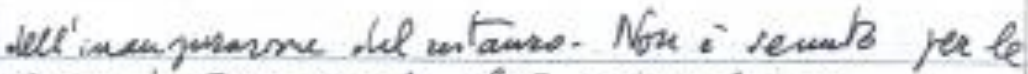

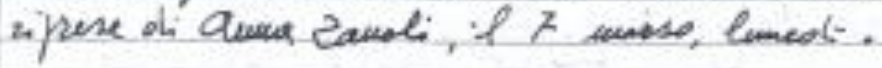

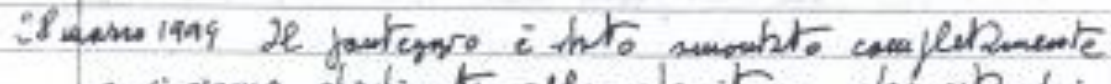

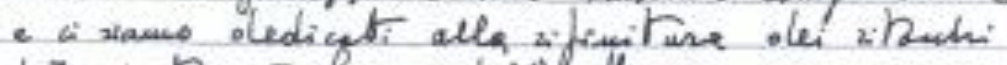

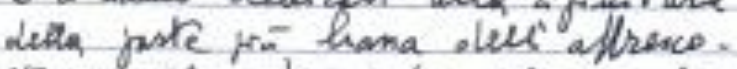

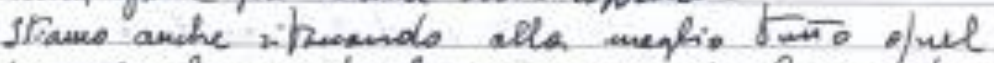

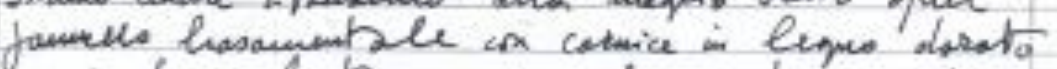

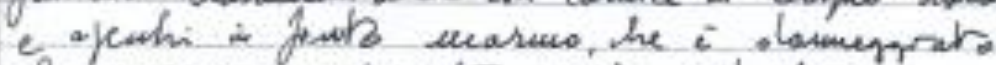

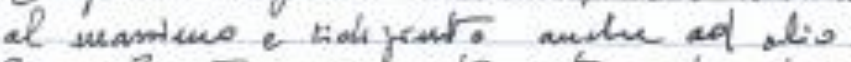

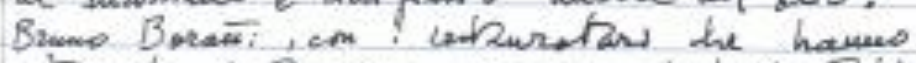

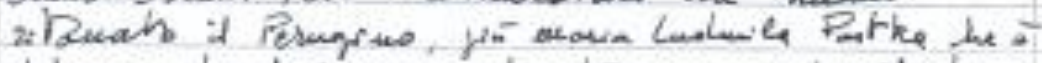

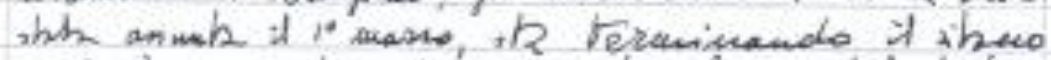
$e$ if "jatiments deves jaste hama del jinto

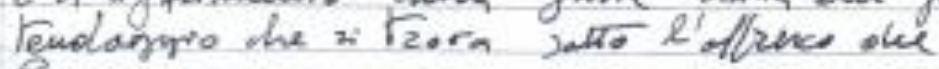
Perugino -

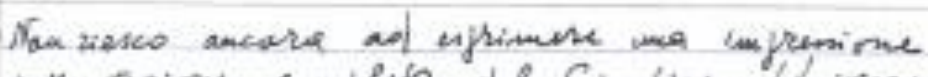
ath risione coupleith dil Gindisid Warverdale.

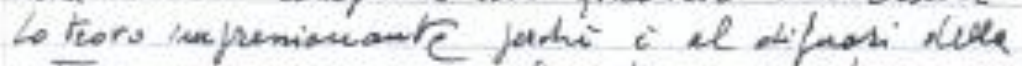

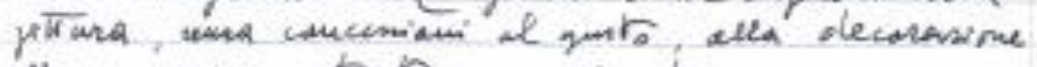

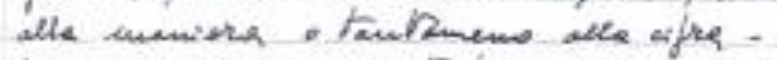

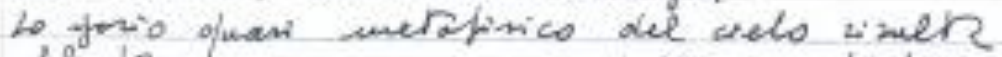

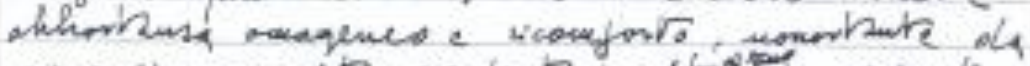

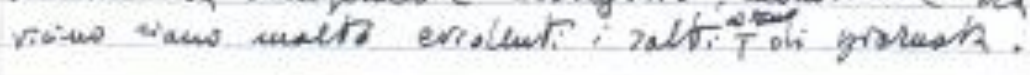

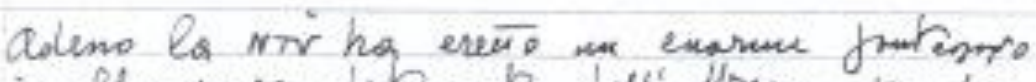

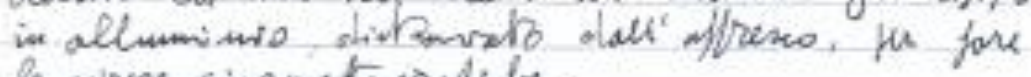
ic siphe cinemate grapiche-

LADATA VEFIEIALE DEL TERMINE DEL RESTAURO \& I 26 MAR2O 1994

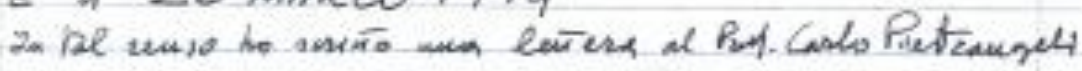

inamincalabuat

Doc. D. 17/ 94 (La pagina con la data della fine del restauro della Sistina) 


\section{Sistine Chapel's facelift successfully underway}

By CLARA HEMPHILL VATICAN CITY (AP) .. Restoration experts have finished work on part of the Sistine Chapel and Michelangelo's brilliantly colored muscular fresco that and barely visible grimy, gray "The expectacions," Fabrizio Mancinelli, director of the restoration work told reporter Tuesday. "It was wonderful to find the detailed work under the dirt."

It will take 12 years to com plete the restor 15 th century chapel, finish with the Last Judge, finishin the the Last Judgment behind the altar.

Next to the restored fresco on the back wall is another by Michelangelo, still sooty and drab with decades of dirt. The figures are flat murky shadows. The details are invisible. The colors are merely different shades of gray.

The restored fresco, showing Eleazar and Mathan, ancestors of Ch rist, seems to sparkle with green, red, yellow and blue clothes draped over robust sinewy bodies. Every detail is visible: the curve of the lips, a purse attached to a belt, a few keys.

The works are cleaned with paste made of several solvents. The paste is applied, allowed to dry, and then gently brushed off. The process is repeated until the work is clean.

The cracks in the chapel, some caused by an explosion of gunpowder in a nearby Vatican storeroom in the 18 th century, remain. But the restoration experts say the cracks have 'stabilized' and it is better to leave them as they

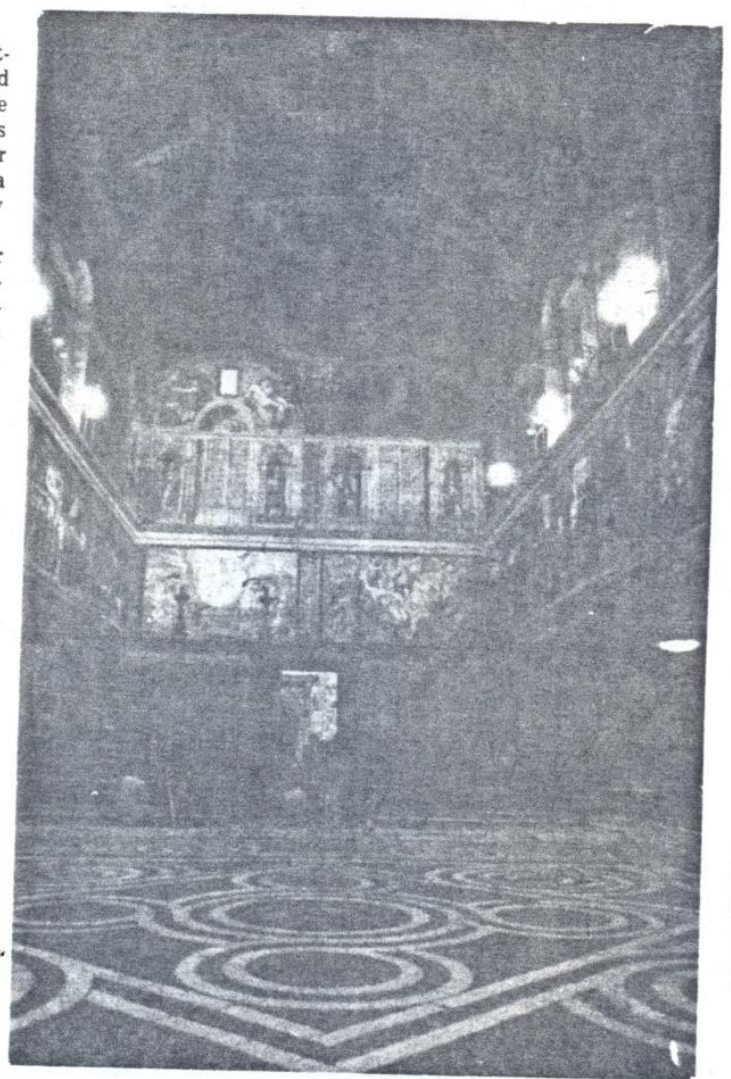

are.

"We try to do as little as "possible," said Gianluigi Colalucci, who is in charge of restoring the Michelangelo frescos. "Every operation might be the source of new damages,"

Where the paint has flaked off, the restorers have touched up small areas with water color in narrow, vertical lines in a slightly lighter tint than the original. The water color the be wiped off with a wet sponge, and doesn't affect the original.

"We don't do retouching in the old sense, where entire frescoes were completely

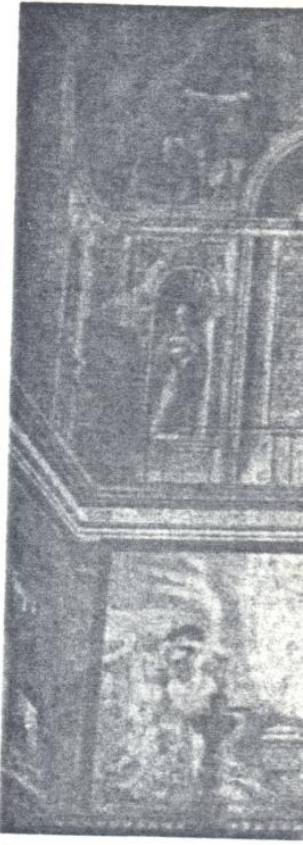

Photo at left:

Partial view of Michel. angelo's frescoes in the Sistine Chapel. The four rectangles at center and the arch at left are the sections restored up to now. Photo above: Semigeneral view of the Sist ine Chapel taken when the press was invited to watch the status of the restoration works (AP)

painted over," Mancinelli sai "What we do is help $t$ damaged part. From far aw (on the floor) you can't

Mancinelli said the reston will probably leave the cloths draped over the priv parts of the figures privi Last Judgment, additions ma

\section{US nurses' survival instincts to the fore}

IT DAVC Th AT 


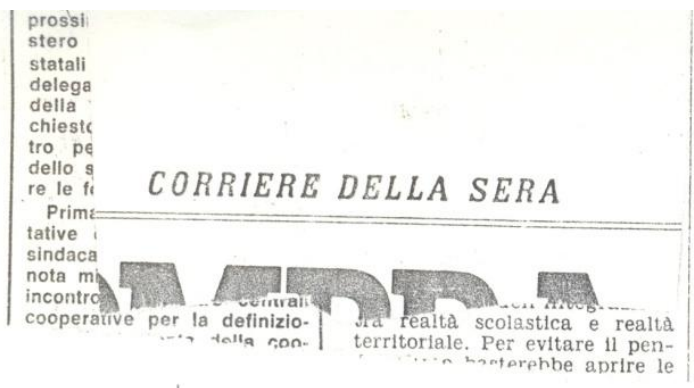

\section{Michelangelo va in rostauro}

\section{Mercoledì 11 febbraio 1981}

plinare I camipeyg.,
svolto un incontro tra l'as-
sessore regionale all'urbani-
stica Pietro Santi ed I pro-
prietari e gestori dei cam-
peggi.
I proprietari del campeggi
hanno chiesto un riesame
della legge di salvaguardia
dalle coste, che possa per-
mettere linstallazlone di
nuovi campeggi e contem-
poraneamente la sanatoria
per I campeggi gia esistenti,
aicuni da oltre 15 anni, che
si trovano in zone prospi-
centi i lidi marini o lacustri.

annuveran... spitata in una citta di cu vene a conoscere la storla, 'ambiente naturale, 1 monument, le fabbilche ecc. e a sua volta ospita una class

uccesso incredilara la Pinto ma 11 provveditorato impugnando una circolare ministerlale, dice che 1 professori non si possono allontanare dalla scuola per più di 2 glorni. Quel che si fa a Milano. Bologna, Torino e in altri $\mathrm{CO}^{-}$

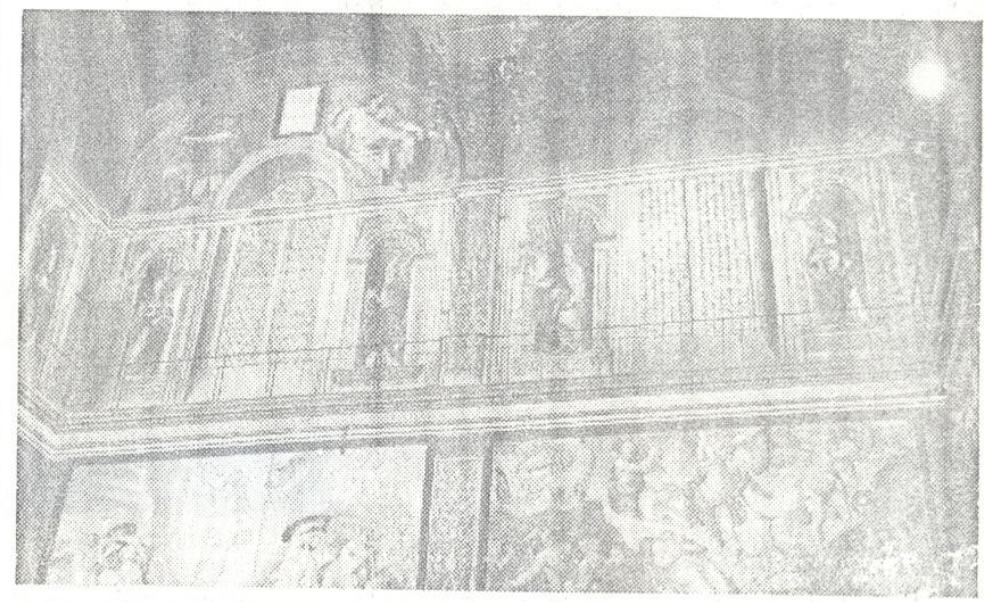

Entro it 1993 I grandf affreschl micheiangloleschl della Cappella Sisina saranno tutti rostaurati. Carlo detto leri il dirattore gonarale del Monumentl, musel e gallerle pontiflcie, il profossor uitiml 12 mesil, presentando a giornalisti e studlosi la prima parte del dipinti restaurati negll te vi 12 mesi sulia parete d'Ingresso di fronte al wGludizlo universalsm. Fra lo opero reatauraCristo una delle quattordicl lunette sifrescate da michelangolo e raffigurante dua entensill di stauro dello due Eleazaro. I programma del lavori prevede per i prossiml quattro anni II re.

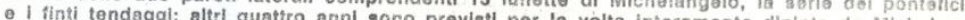

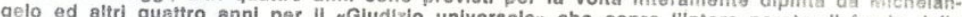
Cappella. Per l'esecuzione del restaurt verramersaien che copro lintera paroto dl pondo della re ai visitatori solo la parte Interessata man mano dal lavori la Cappella Stolina ro da togliedi sempre aperia al pubblico. Nells foto: 


\section{A DI ROMA}

\section{SINDACALI \\ yrgsol}

Inti 75.000 iscritti oblemi della città

fasce più o meno peso pic o meno: un zo dall'industria; un dai servizi. Scarsa la rappresentanza del agricolo

ngresso romano, che stagione delle assiferiche, in vista della zxione dell'VIII connazionale, saranno 1 anche numerose de in straniere. In prito rappresentanti del rnoser il segretario IT di Madrid, il rapante del Sindapemocratico di Vienello di Malta e gli ppresentanti dei sindemocratici dell'Eriel Tigrai e di molti dell America latina. o, ovviamente, pre1. lavori anche deledei movimenti sine dei partiti demo-

cosa la UIL offre iacato, alla società e ta per gli anni 80 zione che Brumo nenome della Segresvolgerà ne che tocca tre punamentali: l'analisi devenimenti succedutis rande vittoria delle (1) nelle amministraomunali e regionali solidarietà nazionale uelle attese - avverino - sono andate in arte delusen); lo stamovimento e i rapndacato deve rivedeproprig strategia in providenti contrad1. infine la situaziola città di Roma. soprattutto su queinto che la relazione rino e la riflessione IL assumono una dine critica di estremo La UIL riconosce,
come positivo il «me-

RESTAURATI I FAMOSI AFFRESCHI DI MICHELANGELO

Dodici anni di lavori alla Cappella Sistina

A titolo sperimentale già eseguitì con successo alcuni lavori - Le opere d'arte hanno cinque secoli di vita - Usato un solvente di nuova fabbricazione

Gli affreschi di Michelangelo nella Cappella Sistina vengono lavati, asciugati attentamente osservati centimetro per centimetro. quindi restaurati, a quas primo esecuzione. Ia notipria è esunta zia è giunta oggin vaticastauro tuno-dei piu specislizzati del mondo, al termine della felice ripulitura della prima delle 14 lunette dipinte dallartista fiorentino in cima alla parete dingresso della famosa Cappella, voluta da Papa Sisto IV Della Rovere per le grandi solennita di curia ed affre1541, in due randi fasi diverse, da Michelangelo. II primo restauro, eseguito con successo mediante solventi approvati anche dalla Sovrintendenza italiana ai monumenti, è stato alla lunetta di Eleazaro e Mathan, antenati di Gesù, dipinta 470 anni fa.

Gli affreschi erano molto sporchi e per evitare che, lavandoli, altri danni si aggiungessero a quelli del tempo, I'Istituto Vaticano che li ha presi in cura li ha fatti ripulire con il solvent "AB57", un prodotto speried autorizzato anche dall'Istituto centrale italiano per il restauro.

La prima ripulitura, fatt da una squadra di otto spe-

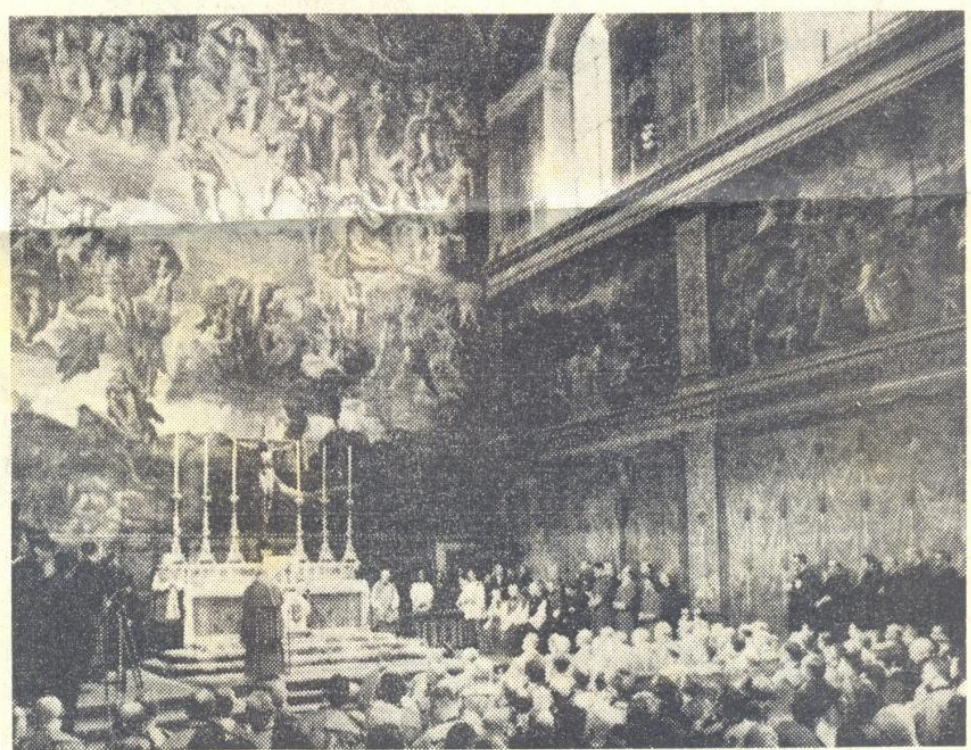

dalle autorità vaticane, do- un periodo dai dieci ai dodi- ci, capo del Laboratorio, e po il non felice esito, qual- ci anni. Gli affreschi della seguiti pure giorno per giorche anno fa, di un tentativo Cappella comprendono del no, dal direttore della sedi restauro di alcuni alfre- resto, oltre alle fatto peró con altri materia- di dipinti di artisti prece- brizio Mancinelli.

li. Per ripuline la prima lu- denti, come Botticelli, il Pe- I primi lavori eseguiti e 11. Per ripulire la prima lu- denti, come Botticelli, il Pe- I primi lavori eseguiti e mesi, per fare l'intero re rori e mesi, per fare lintero re- vori sono diretti personal- nente resauro saranno illucomprensibile trepidazione esperti vaticani prevedono ratore" Gian Luigi Colaluc- braio in Vaticano,

NELL'ANNIVERSARIO DELLA MORTE

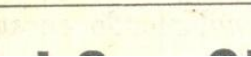

LA POLEMICA SULL'IACP 
pigiato il pulsante elettrico, ha saltato un muretto, è scomparso".

Solo fortuna allora?

"Sì è stato proprio fortuna- carcere - ha detto Tina Lagostena - e per quale motivo si trovava in un carcere normale e non in un carcere di massima sicurezza come previsto per tutti $i$ detenuti che si sono resi responsabili di un tentativo di evasione di una rivoltaw. Le femministe hanno poi rivolto un appello alle donne deputato perché si rechino immediatamente nel carcere di San Gimignano per svolgere un'inchiesta. soldi in $\mathrm{t}$ trate nel evasione di suscit terrogati

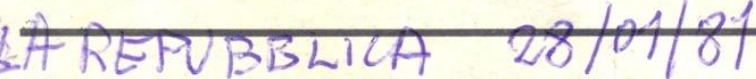

\section{Cominciato il restauro ai famosi dipinti di Michelangelo}

\section{In Vaticano fanno toilette gli affreschi della "Sistina"}

CITTA' DEL VATICANO Gli affreschi di Michelangelo nella cappella Sistina fanno "toilette". A quasi mezzo millennio dalla loro prima esecuzione $\mathrm{i}$ dipinti vengono lavati. asciugati e attentamente controllati centimetro per centimetro. La notizia è arrivata dal laboratorio del restauro vaticano, uno dei più specializzati del mondo, al termine dlla felice ripulitura della prima delle quattordici lunette dipinte dall artista fiorentino in cima alla parete d'ingresso della famosa cappella voluta da papa Sisto quarto Della Rovere per le grandi solennità di curia ed affrescata poi, tra il 1508 e il 1541, in due grandi fasi diverse, da Michelangelo.

Il primo restauro, eseguito con successo impiegando solventi approvati anche dalla sovrintendenza italiana ai monumenti. è stato effettuato sul la lunetta di Eleazaro e Mathan, antenati di Gesù, dipinta 470 anni fa. Gli affreschi secolari erano molto sporchi e per evitare che, lavandoli, altr danni si potessero aggiungere a quelli già causati dal tempo. l'istituto vaticano che li ha presi in cura li ha fatti ripulire con il solvente "A B 57", un prodotto già sperimentato con successo per il delicato restauro di altri capolavori ed autorizzato anche dalle autorità italiane.

La prima ripulitura, eseguita da una squadra di otto spe cialisti, è stata seguita con comprensibile trepidazione dalle autorità vaticane dopo l'esito non certo felice, verificatosi qualche anno fa, di un tentativo di restauro di alcuni affreschi di Raffaello nelle Logge. Quel lavoro, che come precedente negativo aveva fatto nascere qualche perplessità sull'opportunità della nuova operazione, era stato però portato a termine con altri materiali. L'uso del «A B 57» sulla lunetta di Eleazaro e Mathan ha garantito un buon risultato e dovrebbe permettere un completamento perfetto dei restauri.

Per ripulire la prima lunetta ci sono voluti alcuni mesi. Per portare a termine l'intera operazione di restauro degli affreschi della cappella Sistina gli esperti vaticani prevedono un periodo di lavoro che va da un minimo di dieci anni a un massimo di dodici. Gli affreschi della famosa cappella comprendono, del resto, oltre alle ben note opere di Michelangelo, grandi dipinti di artisti precedenti come il Botticelli, il Perugino e il Signorelli. I lavori sono diretti personalmente dal «maestro restauratoren Gian Luigi Colalucci, capo del laboratorio, e seguiti giorno per giorno dal direttore della sezione d'arte moderna dei musei vaticani, Fabrizio Mancinelli.

I primi lavori eseguiti dall'equipe ! otto specialisti e i crite- ri adottati per il completamento dell'imponente restauro saranno illustrati dalle autorità vaticane, il prossimo dieci febbraio, nel corso di una conferenza stampa convocata nella stessa cappella Sistina. Finora, assieme alla prima lunetta di Michelangelo, sono stati restaurati ventiquattro ritratti dei primi papi dipinti alla fine del quattrocento (alcuni dal Botticelli e dal Ghirlandaio tra una finestra e l'altra delle porte laterali) assieme a due grandi affreschi, ritenuti di mediocre valore, dipinti dopo la morte di Michelangelo sulla parete di ingresso e rappresentanti una "resurrezione" e una "contesa sul corpo di Mosèm, opera rispettivamente di Hendrik Van Der Broek (Arrigo il fiammingo) e di Matteo da Lecce.

- CITTA' DEL VATICANO Il papa visiterà la Sicilia, e in particolare la valle del Belice. per incontrarsi con le popola zioni colpite dal terremoto del 1968. Secondo l'agenzia Ansa. che afferma di avere appreso la notizia da "fonte certa", il viaggio nell'isola avverrà entro quest'anno, probabilmente nella seconda metà del 1981 .

"La mia visita verrà 13 anni dopo il terremoto, ma la situazione è sempre difficile e verrò sempre volentieri in Sicilia", ha detto Wojtyla giovedi scorso in un discorso ai terremotati del Belice.
Rad le de

ROMA ri sarann segno di 1 to preser la Difesa paghe dei gradı pa in ser ti e rich guenti: c al comur all'avier le, al con all'avier caporale po di ma Per que! zio conti paga sal re dal tr lire al gi Quest! ordinari tari di $\mathrm{t}$ me spec gli allier litari, c Pubblic: nanza e li: trem: ruolame servizio dodicesi settemil ventiqu mila da se di sel La $r$ ghe int giovani vante I futura ] liardi d 


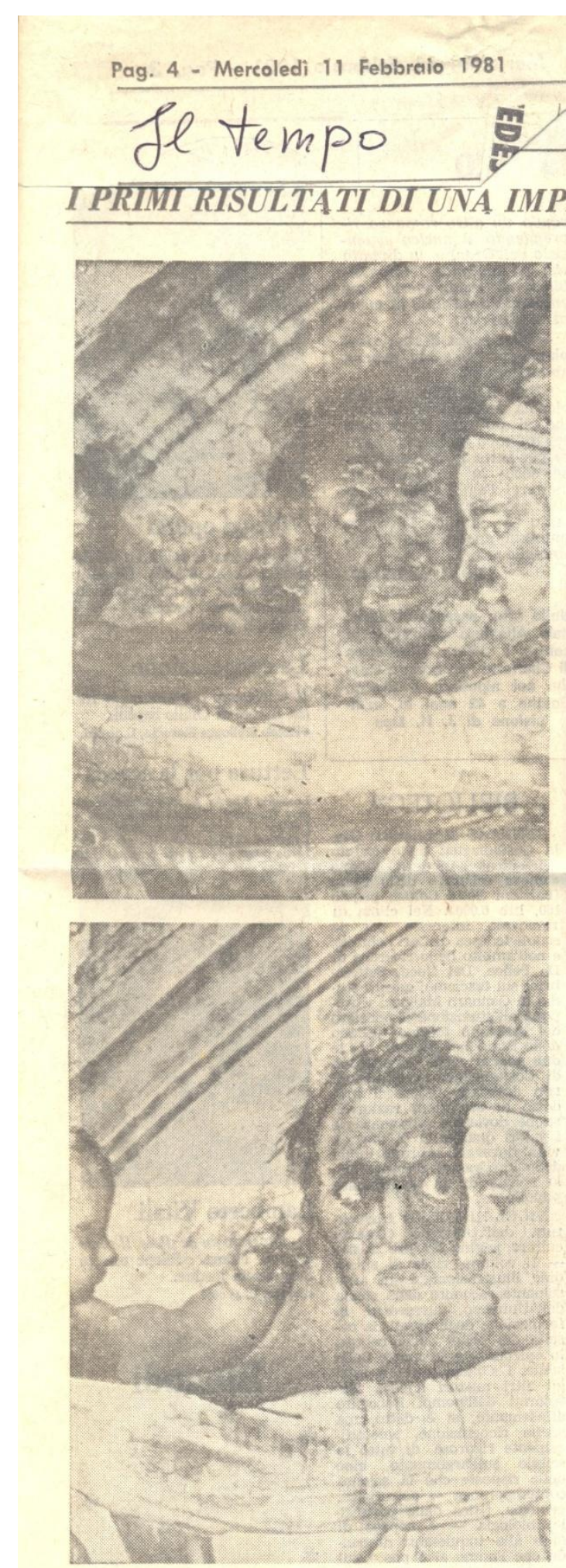

La lunetta prima e dopo il restauro
2) La liberazione dei Fori mperiali è opera pensata din dal primo decennio del secolo e ds lui portal avanti. Il fascismo - che conto on tutto c1o, ve ne e Isolato dal traffico nella giusta misurar apperire le antica vestigia nenzionista misura le in- Dobbiamo dire if v strade di certi "sfascia- sono molto frequent straden. Intanto, il nostro se perché si prefe BRUNO PALMa zona senza addentr

\section{Un «inedito» Giud nella restaurata $\mathrm{C}$}

In dodici anni di scrupolosissimo lavoro (più di quanti ne pittorici) verranno interamente ripuliti, consolidati e fissa

Come avevamo anticipato col dovuto rilievo su queste colonne (v. Il T empo, 28 gennaio us.), si e pasto mano a uniopera di totale restausaggio del colore e dove corra reintegrazione pittorica (tuttavia eseguita soltanto all'acquarello e "sottotono n) di quello che è sinumento pittoricon di tutt i tempi; e che appare vertiginoso anche come "progetto ", prima ancora di lasciare stupefatti per la sua diamo alla Cappelia Sistina. me si sa stupendi affresch me si sa stupendi affresch ticelli, del Ghirlandaio, Luca Signorelli e di altri artisti insigni, ma soprattutto limmensa volta e la decorazione della parete dell'altare, interamente destinata al Giudiato Universate, ed mano, quella suprema di Michelangelo.

A quest'opera di restauro, resa necessarla dal progres. sivo scurimento delle pitture, per di piú deteriorate in vari punti per infiltrazioni d'acqua e crepe negli intonaci, e di cui ieri sono stati presentati 1 primi emozionanti risultati, e impegnato dei Museitorio di Restauro dei Musei Vaticani, e la cura gono può essere testimoniata dalla circostanza che per l'intero restauro sono previsti dodici anni di ininterrotto lavoro: più di quant ne occorsero a Michelangelo per i suoi due grandiosi cicli pittorici (quattro anni
per la volta e cinque per il per la volta e cinque per cui si puô ritenere che $i \mathrm{ri}$ schi insiti sempre in ogni intervento di restauro siano, in questo caso, del tutra di pulitura consolidamento e fissaggio del colo\begin{tabular}{l|l|l|l} 
re naturalmente pseguita con & (facenti parti delle 28 figu- & rali della Cappella) \\
tecniche raffinatissime & ie del primi Papi che deco- & Con il prof. Pietr
\end{tabular}

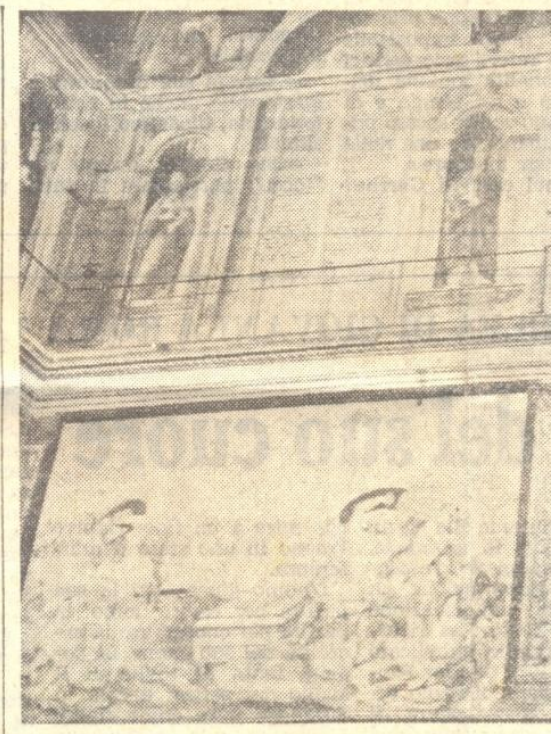

piu moderni ritrovati scien- rano tre pareti della tifici, consentirà di ammira- la), dovute al Ros re una Cappella Sistina "ine- Ghirlandaio e a ur dita”, cioe restituita allo mo del Cinquecen splendore ch'essa aveva a grandi affreschi (de meta dei Cinquecento. dei "Fatti della Vit che sono stati presentati ieri di Mosè ") dovuti dal prof. Carlo Pietrangeli. da Lece (La con direttore generale dei Mo- corpo di Mosél numenti. Musei e Gallerie drick van den Bro Pontificie riguardano gli af- Resurrezione di C freschi dipinti sulla parete che sono le uniche della Cappolla che è quella eseguite dopo che opposta al Giudizio Uni- pella Sistina era st versale. vale a dire, una del- mata (e infatti fu le quattordici lunette affre- rifacimento integra scate da Michelangelo sotto affreschi preesiste la volta, e che rafrigura gli chirandaio e di leazaro terzo figlio di Aron- un crollo di quella ne e Mathan nonno di San e infine i finti ten Giuseppe, entrambi ritratti affresco che si tro con le mogli e altre figure; base della parete st cinque figure di pontefici me delle altre par 


\section{Un «inedito» Giudizio Universalt nella restaurata Cappella Sistina}

In dodici anni di scrupolosissimo lavoro (più di quanti ne occorsero a Michelangelo per i suoi grandiosi ci pittorici) verranno interamente ripuliti, consolidati e fissati tutti gli affreschi che decorano la stupenda s

Come avevamo anticipato col dovuto rilievo su queste colonne ( $v$. Il Tempo, 28 gennaio us.), si e pasto mano a unopera di totale restauro, inteso come pulitura, fissaggio del colore e dove occorra reintegrazione pittorica (tuttavia eseguita soltanto all acquarello e " sottocuramente if maggiore umonumento pittoricon di tutt i tempi; e che appare verti. ginoso anche come " progetto ", prima ancora di la. sciare stupefatti per la sua mirabile realizzazione: alludiamo alla Cappeila Sistina. Nella quale si ammirano, come si sa stupendi affresch del Perugino, di Sandro Botticelli, del Ghirlandaio, di Euca Signorelli e di altri artisti insigni, ma soprattutto razione della parete dell'altare, interamente destinata tare, Gintizio Universale. entrambe dovute a un'unica mano, quella suprema di Michelangelo.

A quest'opera di restauro, resa necessaria dal progressivo scurimento delle pitture, per di più deteriorate in vari punti per infiltrazioni d'acqua e crepe negli intonaci, e di cui ieri sono stati presentati i primi emozio-
nanti risultati, è impegnato il Laboratorio di Restauro dei Museí Vaticani; e la cura che i suoi esperti vi ripongono puo essere testimoniata dalla circostanza che per l'intero restauro sono previsti dodici anni di ininterrotto lavoro: più di quanti ne occorsero a Michelangelo per i suoi due grandiosi ci-
cli pittorici (quattro anni per la volta e cinque per il Giudizio Universale). Per cui si può ritenere che $\mathrm{i}$ rischi insiti sempre in ogni intervento di restauro siano, in questo caso, del tut-
to irrilevanti, laddove l'ope$\mathrm{ra}$ di pulitura, consolidamento e fissaggio del colo-

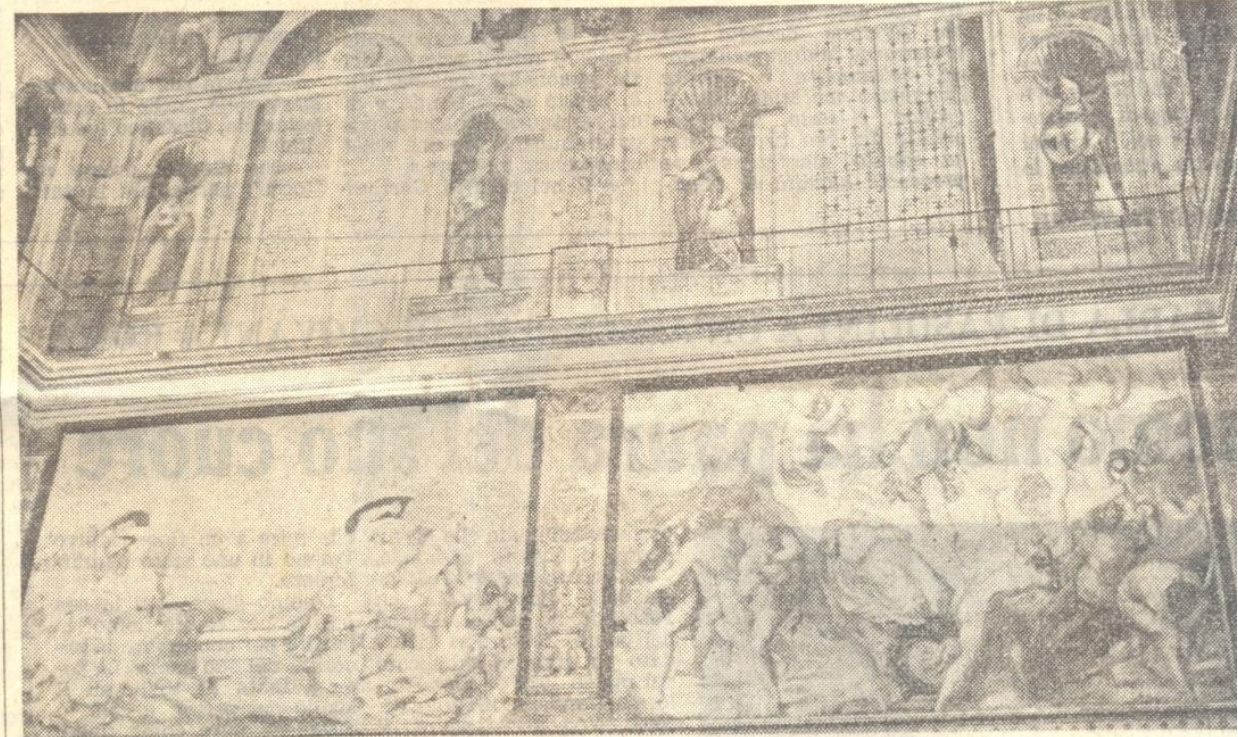

piu moderni ritrovati scienifici, consentirà di ammiraditan, cioè restituita allo splendore ch'essa aveva metà del Cinquecento.

I restauri gia realizzati, e che sono stati presentati leri direttore generale dei Monumenti, Musei e Gallerie Pontificie riguardano gli affreschi dipinti sulla parete della Cappolla che e quella opposta al Giudiato Universale. Vale a dire, una dele quattordici lunette affrescate da Michelangelo sotto la volta, e che raffigura gli eazaro, terzo figlio di Aronne e Mathan nonno di San Giuseppe, entrambi ritratt con le mogli e altre figure: cinque figure di pontefic (facenti parti delle 28 figure dei primi Papi che deco- rano tre pareti della Cappella), dovute al Rosselli, al mo del Cinquecento; due grandi affreschi (delle serie dei " Fatti della Vita di Cristo " e dei "Fatti della Vita di Mosè n) dovuti a Matteo da Lecce (La contesa sul corpo di Mosè) e ad Hendrick van den Broeck ( $L a$ che sono le uniche pitture eseguite dopo che la Cappella Sistina era stata ultirifa ime infatti furono un affreschi preesistenti del Ghirlandaio e di Luca Signorelli, andati perduti per un crollo di quella parete) e infine $i$ finti tendaggi ad affresco che si trovano alla base della parete stessa (come delle altre pareti laterali della Cappella) rano anche, ad illustrare con note tecniche e col sussidio di diapositive i restauri eseguiti, il dott Fabrizio Manc1nelli, che sovrintende allintero restauro con la consuondi, e prof Pasquale RoColalucei prof, Giantuigs 1 restauro degli affreschi di Michelangelo; e che si è valso dell'opera dei maestri restauratori Maurizio Rosst. vanni Grossi, e dei restauratori Claudio Rossi de Gasperis, Carlo Mazzarini Brung Baratti Il programma di restauro come si detto prevede una durata di dodici anni: quattro per restauro delle pareti laterali comprendenti anche 13 iunette di Michelangelo), attri quattro per la volta michelangiolesca. e quattro an- sale. Dodici anni in bene anche perché lavoro verra eseguits tori, e a mezzo di che la Sappella Sist verri mai preclus pubblico, soprattutt risti, che quotidianar si affolla, né alle ce DOMENICO PETR

\section{Minimaratona}

di Torpignattara

Domenica 8 marzo la sesta uMinimaraton Centro Attività Social maso, con il patroci st'anno, del nostro g Sono previsti due ta di $\mathrm{Km}, 8$ e 20

Per informazioni dirino 170 , telefono

is . 


\section{II restauro della Cappella Sistina}

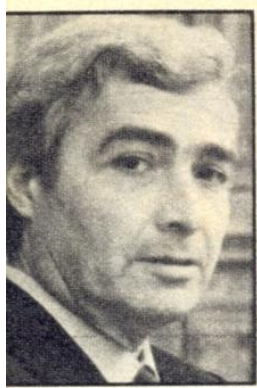

aestro restauratore pror Gianluigi Colalucci: a nella Cappella Sistina.

DINO CIMAGALL

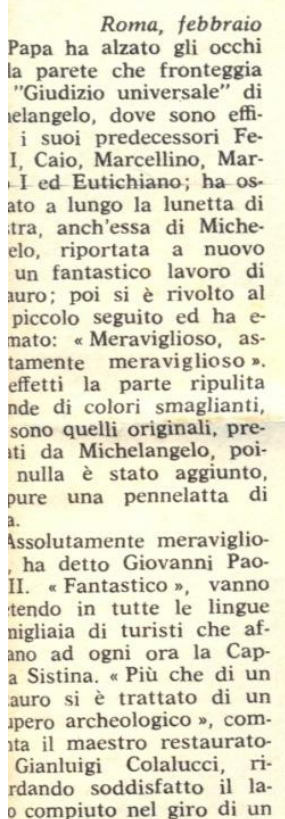

compiuto nel giro di un

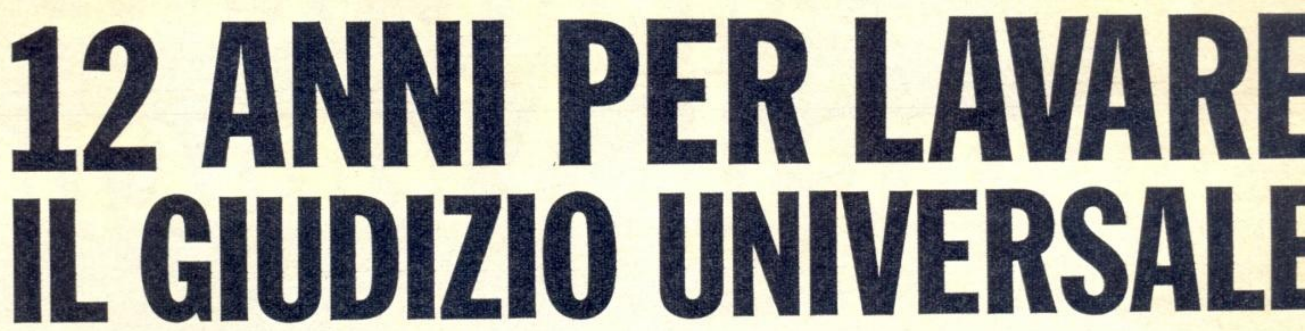

Lavorando a venti metri di altezza, i maestri restauratori hanno già riportał al primitivo splendore una meravigliosa "lunetta" di Michelangelo - Come perché gli affreschi sono diventati sporchi - Le tecniche più moderne segui per compiere perfettamente il "miracolo" - Le difficoltà e i programmi del r stauro dei dodicimila metri quadrati dipinti sulle pareti della celebre Cappel

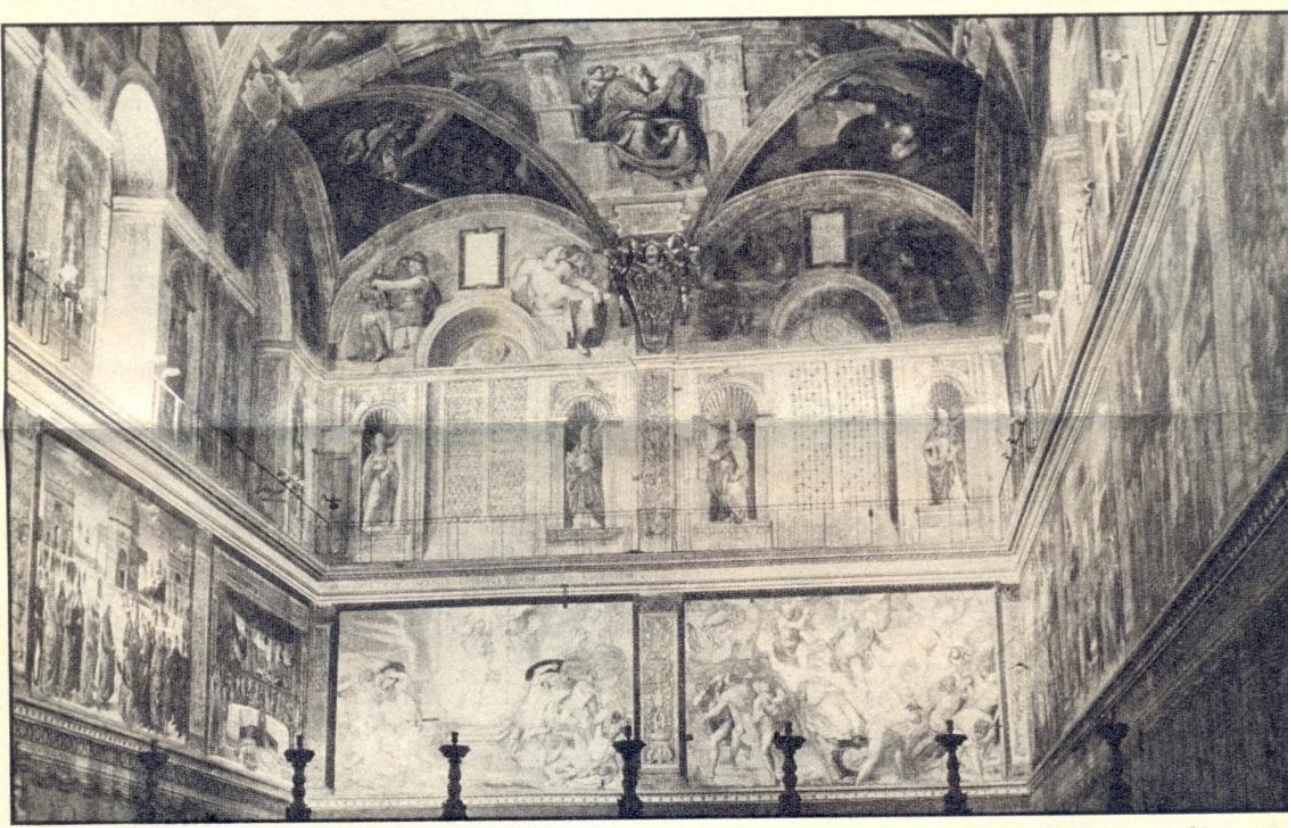

LA PARETE RESTAURATA Città del Vaticano pella Sistina sulla quale sono stati eseguiti $\mathrm{i}$ restauri. In a sinistra, la "lunetta" di Michelangelo già ripulita. Al ce le figure di alcuni Papi, dipinte nel XV secolo. In bass sinistra, "La resurrezione di Cristo" di Van den Broeck, destra "La contesa sul corpo di Mosè" di Matteo da Le

anno insieme con i suoi col-

Colalucci, 51 anni, frequen to i corsi dell'Istituto cen trale di restauro dal 1949 al 1953; poi lavorò in Sicilia con puntate a Creta, ad Assisi, a Tolentino. Dal 1960 nell'organico della Città del Va ticano oggi è a capo di una équipe di quindici "estauratori, sezione pittura

Colalucci ha lavorato per un anno su un ponteggio tipo Innocenti alto venti me tri, articolato su sette piani $\mathrm{Si}$ era fatto portare fin lassù (a) kes) 0 (1)

" "LUNETTA" PULITA Città del Vaticano. Ecco come appare la "lunetta" di Mi- gelo e dei grandi maestri passato.

Quando è iniziato il lav COLALUCCI: « Nel gen 1980. Avevamo comincia da Lecce e Van den Br ta mai eseguita negli u cinquant'anni, mentre in era stato restaurato il Il direttore, professor Pietrangeli, aveva decis completare il restauro,
minciando dalla fascia di restauro di due affresch basso sulla parete, oper due pittori del 500: M Quest'operazione non era dei pittori quattrocente 
Una colorata sorpresa sotto la polvere e il fumo della Cappella Sistin: Michelangelo? Tutto da scoprire

Gli affreschi di Michelangelo nella Cappella Sistina verranno integralmente restaurati. Con una conferenza stampa il Vaticano ha reso nota la storica decisione presentando i lavori già eseguiti ed illustrando le successive fasi del programma: un'operazione che richiedera altri dodici anni. Per la prima volta dopo più di quattro secoli sarà possibile rivedere i famosissimi dipinti in tutta la freschezza di quando erano appena terminati.

Fumo di candele, polvere, infiltrazioni d'acqua piovana cominciarono molto presto ad annerirli. E' vero che già alla fine del Cinquecento veniva nominato un amundator 0 "pulitore" per curarne la manutenzione, ma la stessa grandezza dell artista incuteva soggezione facendo da deterrente; ci si limitava all'asportazione superficiale della polvere $e$ all'uso protettivo dei cosiddetti aravvivantin, colle calde che ridavano tono al colore ma che con il tempo si alteravano scurendo sempre più il dipinto. D'altro canto $i$ danni irreversibili sono sporcizia gli affreschi restano quasi intat-

Un primo stupefacente assaggio lo fornisce l'affresco ora restaurato, sulla parete di fronte al Giudizio Universale; si tratta della lunetta di Eleazar e Nathan, una delle 14 nelle quali sono ritratti gli antenati di Cristo. Ne è emerso un Michelangelo sconosciuto: colorista, pittore. Accostamenti di verdi e rossi, tonalità cangianti, che annunciano le cromie intellettuali di un Pontormo o di un Rosso Fiorentino; ombre usate con discrezione, leggere, colorate (erano state scurite nel ' 700 per accentuare $i$ contrasti): estro e immediatezza di soluzioni (l'intera lunetta fu eseguita in tre sole "giornaten e senza cartone, tracciando con un pennello il disegno preliminare direttamente sull'intonaco). Come già affermano molti studiosi, occorrerà riscrivere un intero capitolo della storia dell'arte.

"Non è solo un restauro, è una scoperta archeologica* mi dice Gianluigi Colalucci. archeol laboratorio di restauro dei musei vaticani, durante una lunga chiacchierata- intervista. Il problema centrale - spiega il maestro restauratore, che dirige $e$ in gran parte eseque personalmente $i$ lavori - è stato quello di stabilire il livello di pulitura, eliminare cioè le macchie sovrapposte e tirar fuori tutta la pittura di Michelangelo senza mai andare oltre e rischiare di perderne anche una sola pennellata. Diviene cosi pienamente godibile il modellato michelangiolesco ottenuto con una tecnica quasi fotografica: incisiva messa a fuoco di un punto preciso e progressiva sfocatura di tutto ciò che è su piani diversi, senza però che le immagini perdano mai di consistenza.

Lavorando sull'impalcatura a diretto contatto con l'opera, si scoprono particola$r i$ invisibili dal basso, che il Buonarroti, di ciò ben consapevole, eseguiva solo per se stesso: capelli sfuggenti a una treccia e dipinti usando solo qualche pelo di un grosso pennello, il microscopico fiocco del nastrino che sorregge un sacchetto di soldi nella figura a sinistra (pare si trattasse di una tirchiona).

Se oggiè stato possibile affrontare un'impresa che appena venti anni fa sarebbe apparsa inconeepibile, non è soltanto per apparsa inconcepibile, non è soltanto per di più sicura affidabilità ma perchè è stato perchè è stato rimosso quel blocco mentale che impediva di "mettere le mani» su Michelangelo. Scomparsi gli ultimi residui del romantico feticismo per l'opera d'arte misteriosa, remota, seminascosta dalla "patinan, si è sentito che i tempi erano ormai maturi per un'operazione di franco recupero. A questa decisione comunque, successivamente confortata da pareri favorevoli dell' Istituto centrale del restauro e di numerosi storici dell'arte, non si sarebbe giunti senzal'entusiasmo del prof. Carlo Pietrangeli, direttore generale dei musei vaticani e del Dott. Fabrizio Mancinelli, responsabile del settore dell'arte medievale e moderna.

Salutandolo chiedo a Colalucci di riassumere in una frase le sue impressioni. Mi risponde senza esitare: «Michelangelo è superiore alla sua fama”.

Franca Zoccoli

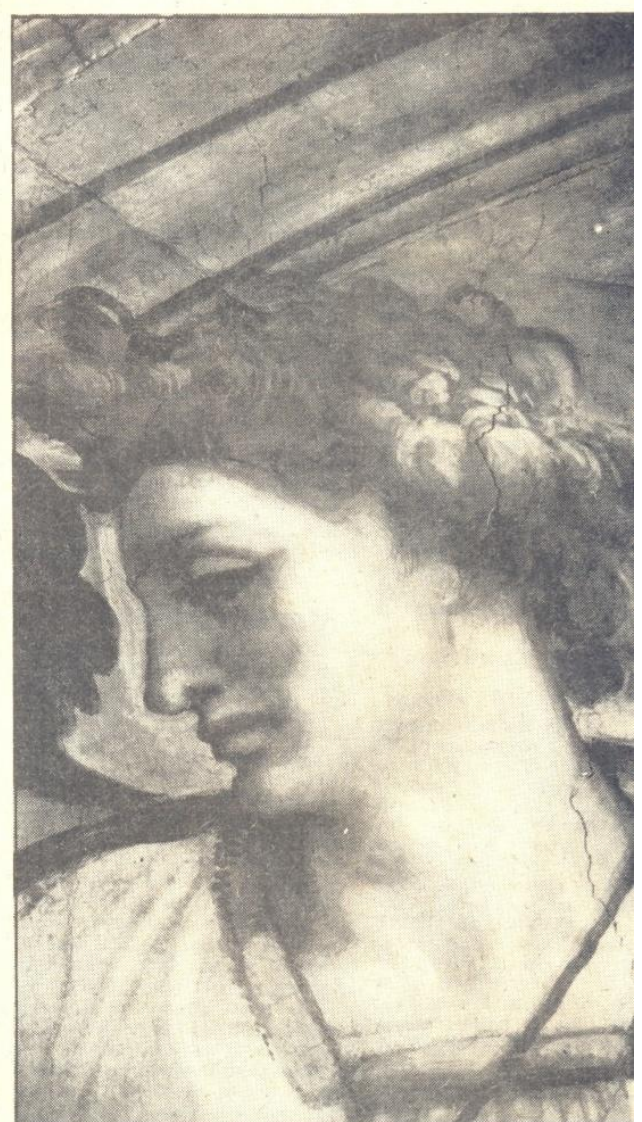

Un «primo piano» di Eleazar che dimostra la tecnica quasi fotografica del modellato michelangiolesco.

civile» ci vuole, ma non illudia moci di poter cancellare ogni margine di risch - 


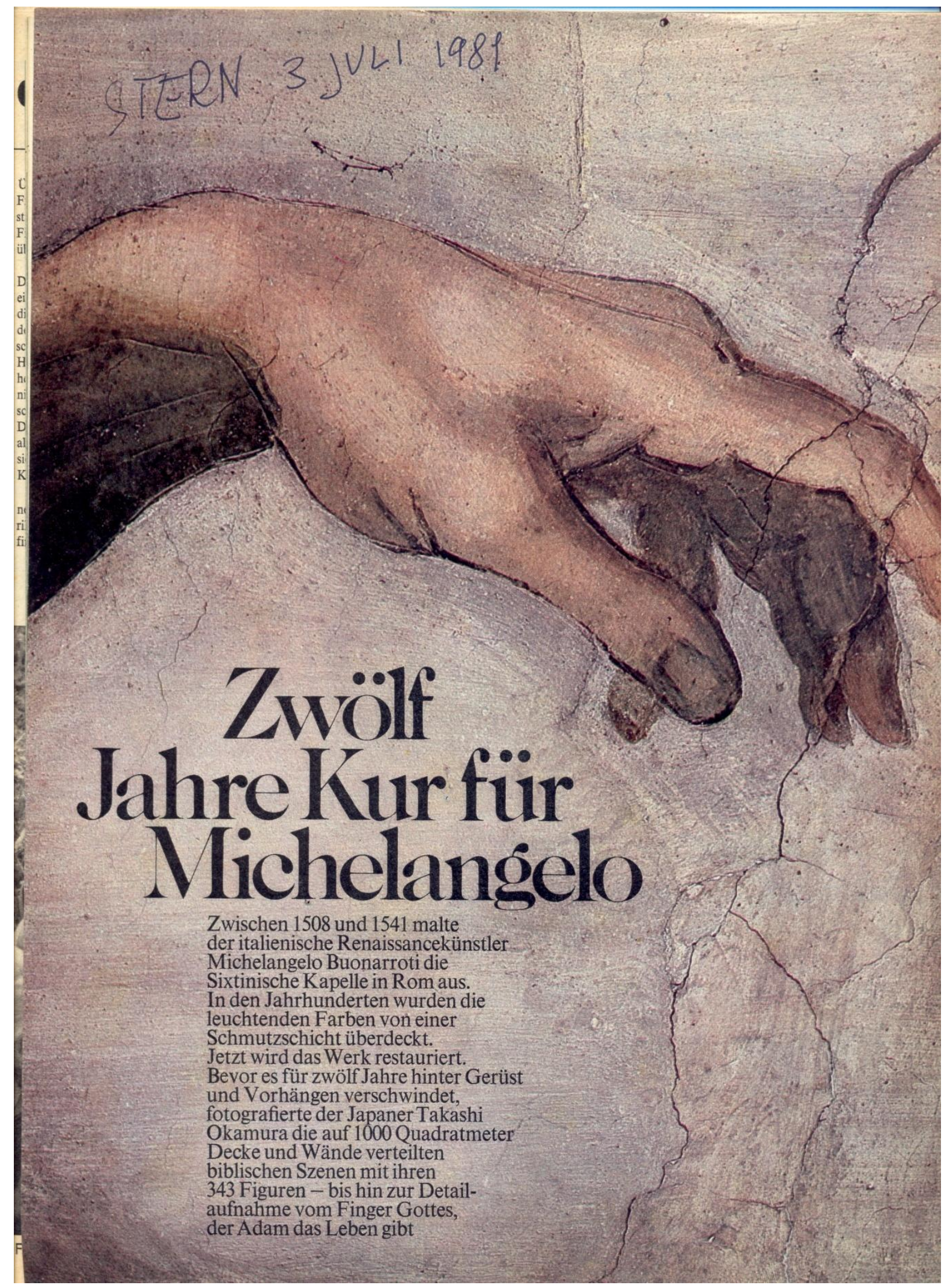




\section{„Es ist die Kunst, die mich stets gequält hat, und meine Kinder sind dieWerke"}

Michelangelo am Ende seines Lebens

\section{Ein Bericht von Henning Klüver mit Fotos von Takashi Okamura}

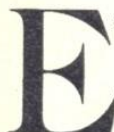
ist wie die Reise zum Mond. Danach wird die Welt verändert sein", sagt Professor Gianluigi Colalucci, Meisterrestaurator des Vatikan. Und Dr. Fabricio Mancinelli, Chefkonservator im Dienst der römischen Kurie, fügt hinzu: „Das Ergebnis wird schockieren. “

Die beiden Sachverständigen sind verantwortlich für eine Arbeit, die nicht nur Kunstgeschichtlern als Jahrhundertereignis gilt: Die Fresken, mit denen Michelangelo Buonarroti vor über 450 Jahren die Sixtinische Kapelle in Rom ausmalte, werden jetzt restauriert.

Zwölf Jahre lang.

Wie danach Decke und Altarwand der Sixtina aussehen werden, zeigen Mathan und Eleazar, die bereits restauriert sind. Statt in matten Farben strahlen die beiden Vorfahren Christi (nach dem Matthäus-Evangelium) in kräftig-buntem Glanz.

,Jetzt erst wird verständlich", erklärt Mancinelli, "wieso seinerzeit viele Künstler, zum Beispiel $\mathrm{Ca}$ ravaggio, die kräftigen Farben des Meisters rühmten und sie zum Vorbild nahmen. Das gilt besonders für die Altarwand, die das ,Jüngste Gericht' zeigt. Jahrhundertelang hat die Wissenschaft zeitgenössische Kopien wie etwa die Daniele da Volterras - heute in Neapel —, die voller Far benpracht ist, als eigenwillige Interpretation eines verirrten Michelangelo-Schülers abgetan. Im 19. Jahrhundert - und zum Tei auch heute noch - fußt die gesamte Michelangelo-Interpretation auf der matten, dunklen Farbgebung. Ei- gentlich war die wissenschaftliche Beschäftigung mit ihm abgeschlossen. Neues gab es kaum noch zu sagen. Das wird sich jetzt ändern."

Die Gemälde Michelangelos zogen jährlich Hunderttausende Touristen, Kunstund Kirchenpilger in die unter Papst Sixtus IV. (1471 bis 1484) erbaute Kapelle. Der plumpe, architektonisch eher mißlungene Bau war seitdem die Hauskapelle der Päpste, die auch zum Konklave, zur Wah des neuen Pontifex, benutzt wird. An den Längswänden haben Botticelli, Ghirlandao, Signorelli, Perugino, Pinturicchio u. a. - toskanische und umbrische Meister der ausgehenden Frührenaissance - Fresken geschaffen, die allein schon den Weltruhm der Kapelle begründet hätten. An die

Decke aber hat Michelange10 in 20 Meter Höhe das Meisterfresko der Hochre naissance gemalt: Auf gut 1000 Quadratmetern erzählen 343 Figuren die Schöpfungs- und Sintflutgeschichte. „Eine so große Vorstellung von Gott in Aktion haben neben Michelangelo nur noch Johann Sebastian Bach in seinen beiden Passione und Dante in seinem ,Inferno" entwickelt", kommentiert Michelangelo-Forscher Harald Keller.

Gottvater mit silbrigem Bart teilt Licht und Finsternis, wie es bis dahin noch nie von christlicher Kunst als manueller Schöpfungsakt dargestellt worden war. Wie in einem überdimensionale Comic strip schwebt Got von rechts heran, um Sonne und Mond zu schaffen, links fliegt er nach voller Dre-

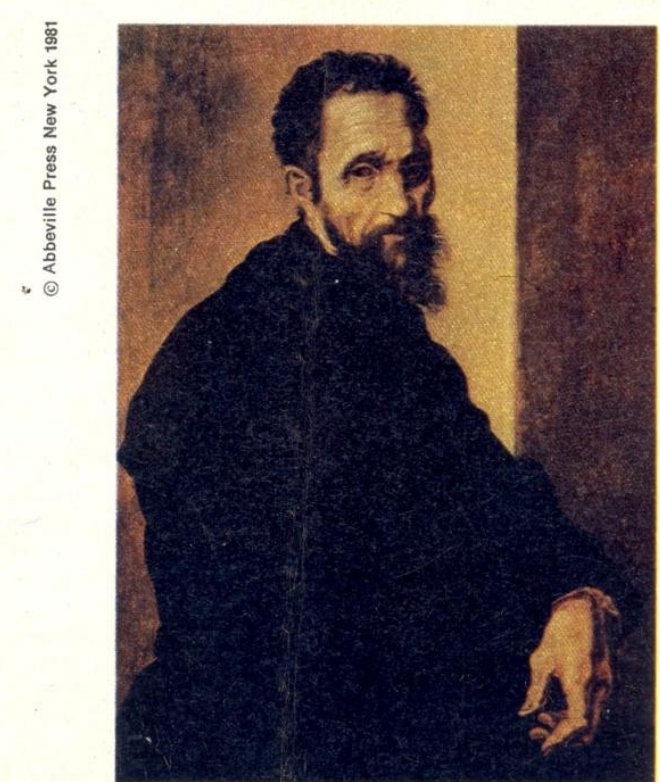

Bildhauer, Maler, Architekt: der Italiener Michelangelo Buonarrot 1475 bis 1564), gemalt von einem unbekannten Zeitgenossen hung zu neuen Schöpfungstaten weiter. $\mathrm{Er}$ beseel Adam, der Gottvater den Zeigefinger der linken Hand sehnsuchtsvoll entgegenstreckt - man meint, es müsse jeden Augenblick blitzen, als spränge ein Funke über. Im Sündenfall verführt Eva nicht Adam, statt dessen brechen beide gemeinsam die Früchte vom Baum der Erkenntnis. In der Sintflutgeschichte liegt, von seinen Söhnen verhöhnt, der trunkene Noah satt katertvoreinemgroßen Weinbottich. Beim Sieg Davids über Goliath, beim Stammbaum Christi, bei den Propheten und Sibyllen wie auch den nackten "Füllfiguren": Immer ist Michelangelo auf der Suche nach unverwechselbaren Menschentypen, die er plastisch wie Skulpturen malt, während er für den Hintergrund nur wenige Pinselstriche übrig hat

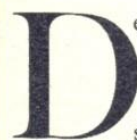

nn Michelangelo 475 bis 1564), der Superstar der Hochrenaissance, war vor allem Bildhauer. Berühmt sind seine Pietà, sein David, sein Moses, seine Grabmäler. Aber er war auch Architekt, Stadtplaner und Dichter: In Sonetten besang er sowohl seine leidenschaftliche Liebe zum schönen, jungen, römischen Edelmann Tommaso Cavalieri wie seine platonische zur philosophierenden Witwe Vittoria Colonna. Michelangelo entwarf $\mathrm{Fe}$ stungsanlagen, baute StraBen, Plätze, Stadttore und schuf die Kuppel von St. Peter, der wichtigsten Kirche der Christenheit. Aber er war sich in jungen Jahren auch nicht zu schade, für einen seiner vielen Herren und Auftraggeber, Piero de' Medici, im Winter Schneemänner zu bauen.

Michelangelo war ",von mittlerer Größe, hatte breite 


\section{Den Bart reckich \\ gen Himmel,derweil der Pinsel immeriberm A $1 \hat{o}^{\prime}$ ". " \\ Michelangelo in einem Sonett über seine Malerel in der Sixtina}

Schultern, die jedoch in richtigem Verhältnis zu seinem Körperbau standen. Als er alt wurde, trug er Stiefel von Hundefellen monatelang über den bloßen Füßen, so $\mathrm{da} \beta$ oft, wenn er sie endlich ausziehen wollte, die Haut mit herunterging". schrieb sein erster Biograph. Giorgio Vasari, in den ,Lebensbeschreibungen" (erschienen 1568). Michelangelo war kein armer Mann Ihm gehörten Häuser und Grundstücke in Rom und Florenz, und allein die Einnahmen aus einer Po-Fähre bei Piacenza, die ihm Papst Paul III. 1535 auf Lebenszeit übertragen hatte, ergaben jährlich 600 Golddukaten (nach heutigem Kaufwert rund 60000 Mark). Michelangelo lebte einfach und notierte eigenbrötlerisch seine täglichen Ausgaben an die Wand des Schlafzimmers. Als er am 18. Februar 1564 ,zur Stunde des AveLäutens" starb, „übergab er Gott seine Seele, der Erde seinen Leib, seine Besitztümer den nächsten Anverwandten" (Vasari).

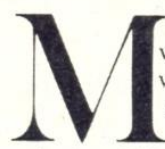

ichelangelo wußte, was er wert ist. Das zeigte er auch im Umgang mit den Machtigen seine Zeit. Als ihn Papst Julius II (ein Neffe von Sixtus IV.) einmal nicht sofort empfangen wollte, reiste der halsstarrige Künstler umgehend nach Florenz ab. Und als ihm später Julius den Auftrag für die Malarbeiten in der Sixtina gab, maulte Michelangelo: .,Ich bin Bildhauer, nicht Maler." Und: „Hier verliere ich nur meine Zeit!" Auch über den Inhalt der Bilder stritten sich Papst und Künstler so lange, bis Julius entnervt aufgab: „Mach, was du willst!“

Das tat Michelangelo. Doch was er nicht wußte:
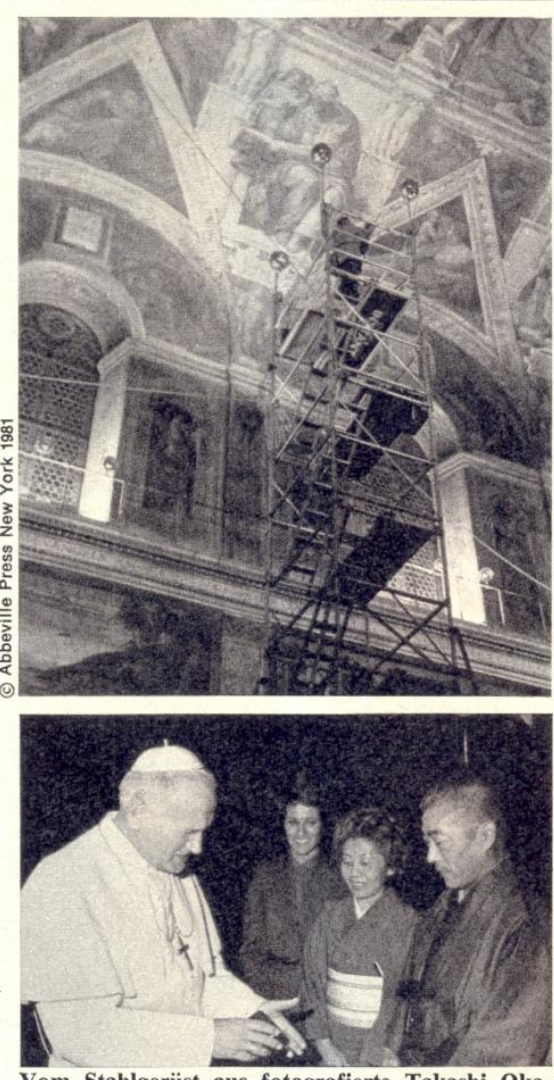

Yom Stahlgerüst aus fotografierte Takashi Okamura sechs Monate lang die Fresken Michelangelos in der Sixtinischen Kapelle. Johannes Paul II. verlieh dem Japaner (rechts mit Ehefrau) einen Orden

Den Plan, die Decke der Sixtina ausmalen zu lassen, hatten zwei seiner berühmten Zeitgenossen und ärgsten Widersacher ausgeheckt. Der Architekt Bramante und der Maler Raffael wollten den Bildhauer, der seit der Aufstellung seiner David-Skulptur in Florenz berühmt war, eins auswischen; "wohl berechnend, da $\beta$ er, sobald er malen müßte, wegen Mangel an Erfahrung im Fresko, ein minder rühmliches Werk zustande bringen würde" (Vasari). 1508 begann Michelange- lo mit der Arbeit in der Six tinischen Kapelle. Seine Gehilfen schickte er bald we gen Unfähigkeit fort. E malte ,a fresco“, das heißt, in den frisch aufgetragenen Putz. War die Stelle trocken, konnte nichts mehr verändert, hinzugefügt, verbesser werden; es sei denn, man schlug den Putz wieder ab. So konnte Tag für Tag jeweils nur ein kleines Stück der Decke gestaltet werden.

Michelangelo arbeitete -

im Gegensatz zur Legende - nicht im Liegen, sondern stehend, „das Gesicht nach oben gekehrt, wodurch er sich die Augen also verdorben hatte, da $\beta$ er mehrere Monate lang nur von unten nach oben Briefe lesen und Zeichnungen betrachten konnte" (Vasari). Michelangelo beschreibt es in einem Sonett so: „Den Bart reck ich gen Himmel, mit dem Nacken / rückwärts gelehnt, und mit HarpyienBauch, derweil der Pinsel immer überm Aug'/ ein schön Mosaiko kleckt auf die Backen."

nfang Oktober 1512 war das DeckenWerk vollbracht. 1 wurde die Kapelle für den Besuch geöffnet. Die Hoffnung seiner Widersacher hatte sich nicht erfüllt, denn ,alle erstaunten und verstummten" (Vasari). Der Papst war zufrieden, belohnte Michelangelo mit 6000 Dukaten und reichen Geschenken. Mit einem "Nebenwerk" stand der Bildhauer, der zum Malen "gezwungen" worden war, auf dem Gipfel seines Ruhms. Dazu der Kunstsoziologe Arnold Hauser: „Es vollzieht sich die letzte Wendung in seinem Aufstieg; nicht mehr die Kunst, er selbst wird zum Gegenstand der Verehrung - wird zur Mode. Die Welt, deren Ruhm er zu künden hatte, kündet jetzt seinen Ruhm.“

Michelangelo sah es am Ende seines Lebens so: „Nur zuviel habe ich mit einer Frau zu schaffen gehabt, das ist die Kunst, die mich stets gequält hat, und meine Kinder sind die Werke, die von mir zurückbleiben, die, wenn sie auch nichts taugen, doch eine Zeitlang leben."

Das Überleben eines seiner bekanntesten und umstrittensten „Kinder“ war lange Zeit in Frage gestellt: das "Jüngste Gericht" an der Altarwand der Sixtini- 


\section{'All of Michelangelo's Work will have to be Restudied'}

THE SISTINE CHAPEL,

AFTER THE UNVEILING OF THE

FIRST PHASE OF A COMPLETE RESTORATION, RADIATES A SPLENDOR THAT HASN'T

BEEN SEEN FOR THREE CENTURIES. THE ENTIRE PROJECT WILL TAKE AT LEAST ANOTHER DOZEN YEARS

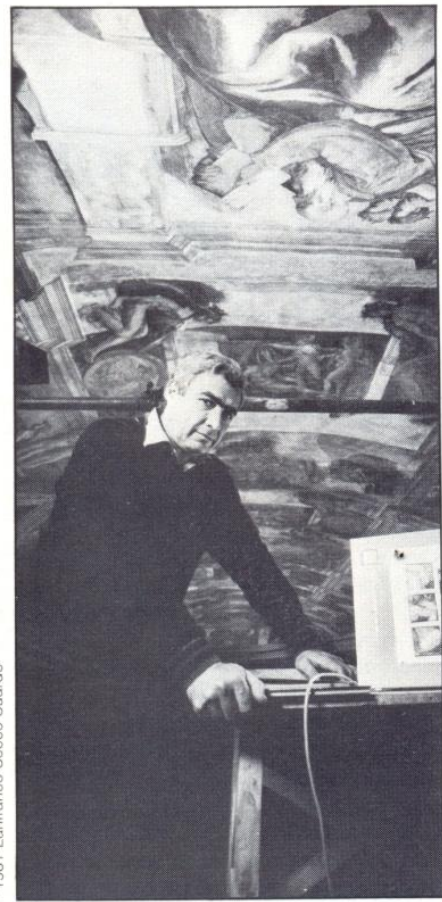

Chief painting restorer Gianluigi Colalucci.

114 / A R T NEW
O n February 10, 1981, the Vatican inveiled the first phase of what is to be a complete restoration of the Sistine Chapel. This monumental undertaking, begun in 1980, is expected to take at least another dozen years. It started with the east wall and included not only Michelangelo's lunette of Eleazar and Mathan, two of Christ's ancestors, but also portraits of five early popes painted by Cosimo Rosselli, Ghirlandaio, their pupils and an anonymous artist of the 16th century; two large frescoes, The Resurrection of Christ by Hendrick van den Broeck (also known as Arrigo Paludano) and The Fight Over the Body of Moses by Matteo da Lecce, both painted in 1571-72, nearly a century later than the other twelve scenes from the lives of Moses and Christ; and the trompe l'oeil "leather" curtain on the wall below them. In 1966, a team of restorers had already started cleaning the scenes from the lives of Christ and Moses, not painted by Michelangelo, on the north and south walls. (Perugino, Botticelli, Luca Signorelli, Pinturicchio and Piero di Cosimo also worked in the Sistine Chapel.)

It was a revelation to see the chapel without scaffolding, and the east wall radiated a splendor that hadn't been seen for three centuries. Carlo Pietrangeli, director-general of the Vatican Museums, reinforced one's sense of the importance of the occasion when he welcomed the gathering. "In this holy place," he said, "in this unique and unrepeatable setting, authorities, scholars and the press have gathered here to see the results of the recent work of the Vatican Museums Laboratory: the nearly completed restoration of an entire wall of the Sistine Chapel."' His welcoming speech was followed by an understated artistic commentary from Dr. Fabrizio Mancinelli, curato of Byzantine, medieval and modern art and director of works, and a slide show narrated by Gianluigi Colalucci, chief painting restorer, who is solely responsible for those parts of the chapel by Michelangelo.

The Sistine Chapel was without scaffolding for only two weeks before work continued on the rest of the east wall: Michelangelo's lunette of Jacob and Joseph. It is estimated that this and the dozen remainin Michelangelo lunettes of Christ's ancestors, plus the remaining 21 papal portraits (four of the original 30 were obliterated by $\mathrm{Mi}$ chelangelo when he painted the Last Judgment on the west wall) and the rest of the trompe l'oeil "leather" curtain, will take a good four years. The ceiling will require four more years as well as the study, be tween now and 1985, of a scaffold with an eventual movable platform that may ride on rails, which won't obscure too much of the public's view. There will probably be a flexible reclining back support so that Cola lucci will not have to restore the ceiling while lying on his back, the way Michelangelo is thought by some to have painted it. That, says art curator Mancinelli, "would have been physically impossible. The dis 

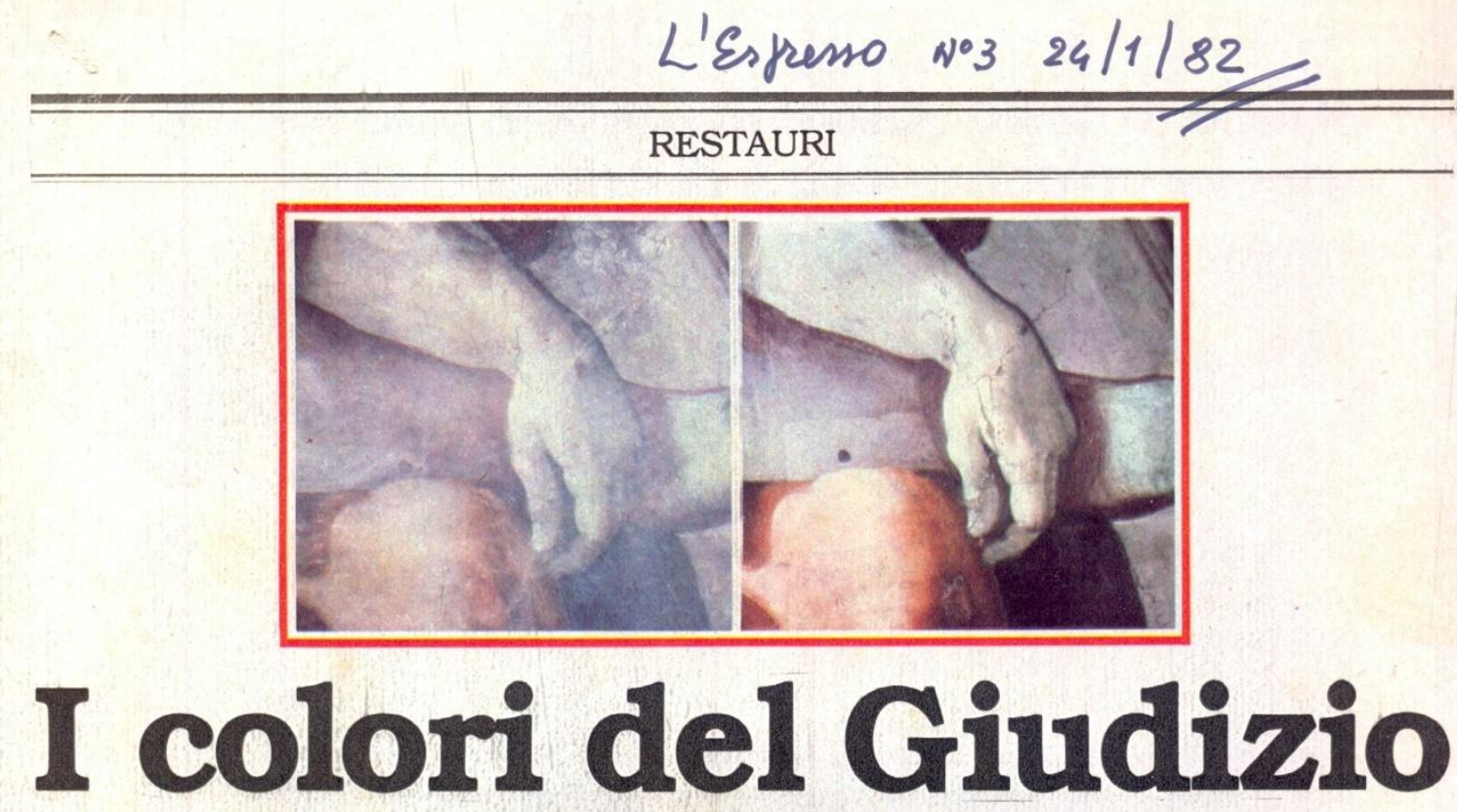

Roma. Chissà come sarà la Cappella Sistina nel 1994... Guardando in su alle tre lunette già pulite l'im. maginazione si sbriglia e vorrebbe anticipare il gran giorno in cui, tolta l'ultima impalcatura davanti alla parete del Giudizio, l'intero ciclo michelangiolesco ci apparirà coi suoi veri colori. Perché questo ac. cada sono preventivati dodici anni di lavori: quattro per le lunette e i sottostanti ritratti dei primi papi, quattro per la volta, ed altrettanti per il Giudizio. $\mathrm{Ne}$ sono trascorsi finora me. no di due, e già quello che si vede confonde molte idee che ci eravamo fatti su Michelangelo pittore riluttante, e aggiunge luce alla nostra immagine della intera Cappella.

La prima delle quattordici lunette raffiguranti gli antenati di Gesù era visibile dopo la pulitura fin dal febbraio scorso. Con le altre due scoperte in questi giorni, la fascia alta è completata sulla parete di fondo ed iniziata sulla parete lun. ga che sta a sinistra

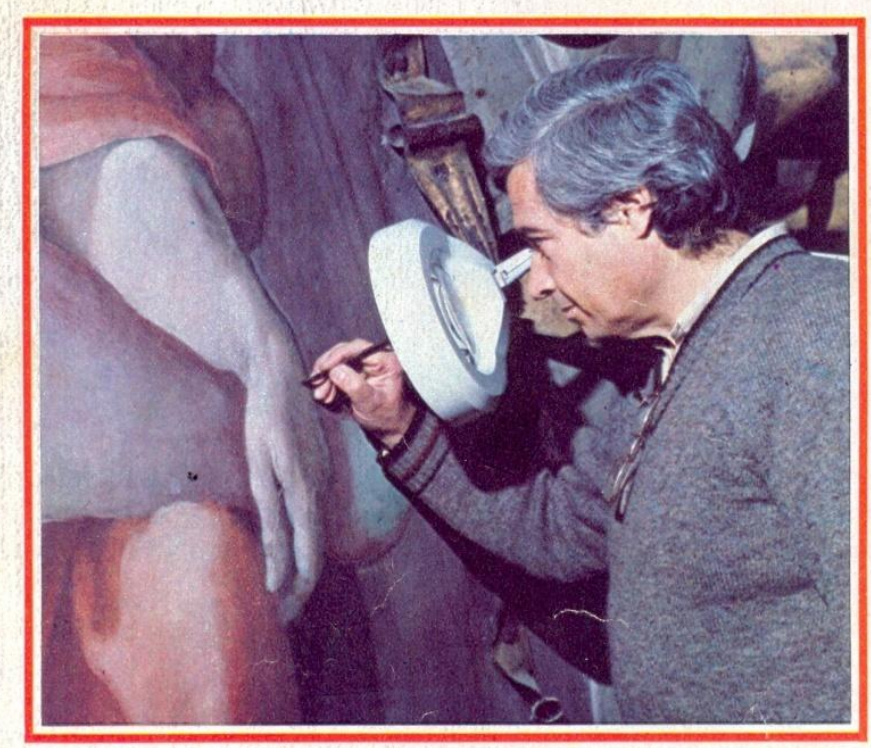

Roma. Gianluigt Colaluccl mentre restaura la mano di Mathan in una delle lunette della Cappella Sisting In alto, a sinistra, il dettaglio della mano prima del restauro e, a destra, dopo. di chi guarda l'altare. Non si capisce perché, rispetto a tutto il resto della Cappella proprio questa fascia si fosse sporcata di più: certo è che s'era annerita al punto da risultare dal basso quasi indecifrabile. Non solo le figure dei discendenti di Davide che formano la genealogia di Cristo al principio del Vangelo di Matteo erano completamente oscurate e i cartigli resi illeggibili, ma da quella zona spenta era come se si sprigionasse un velo di neb. bia, a smorzare i con trasti e le vibrazioni luminose di tutta la pittura circostante. Solo adesso, vedendo le figure di Mathan ed Eliazar, di Achin ed Eliud, di Jacob Joseph restituite alla luce nelle tre lunette pulite, ci si rende conto di come in tutta la Sistina il colore fosse benvenuto cantasse a gloria di Dio.

Gianluigi Colalucci lavora in Vaticano da ventun anni. Vi entrò da maestro restauratore, ed ora, con la qualifica di assistente tecnico, è il responsabile dei restau》) 


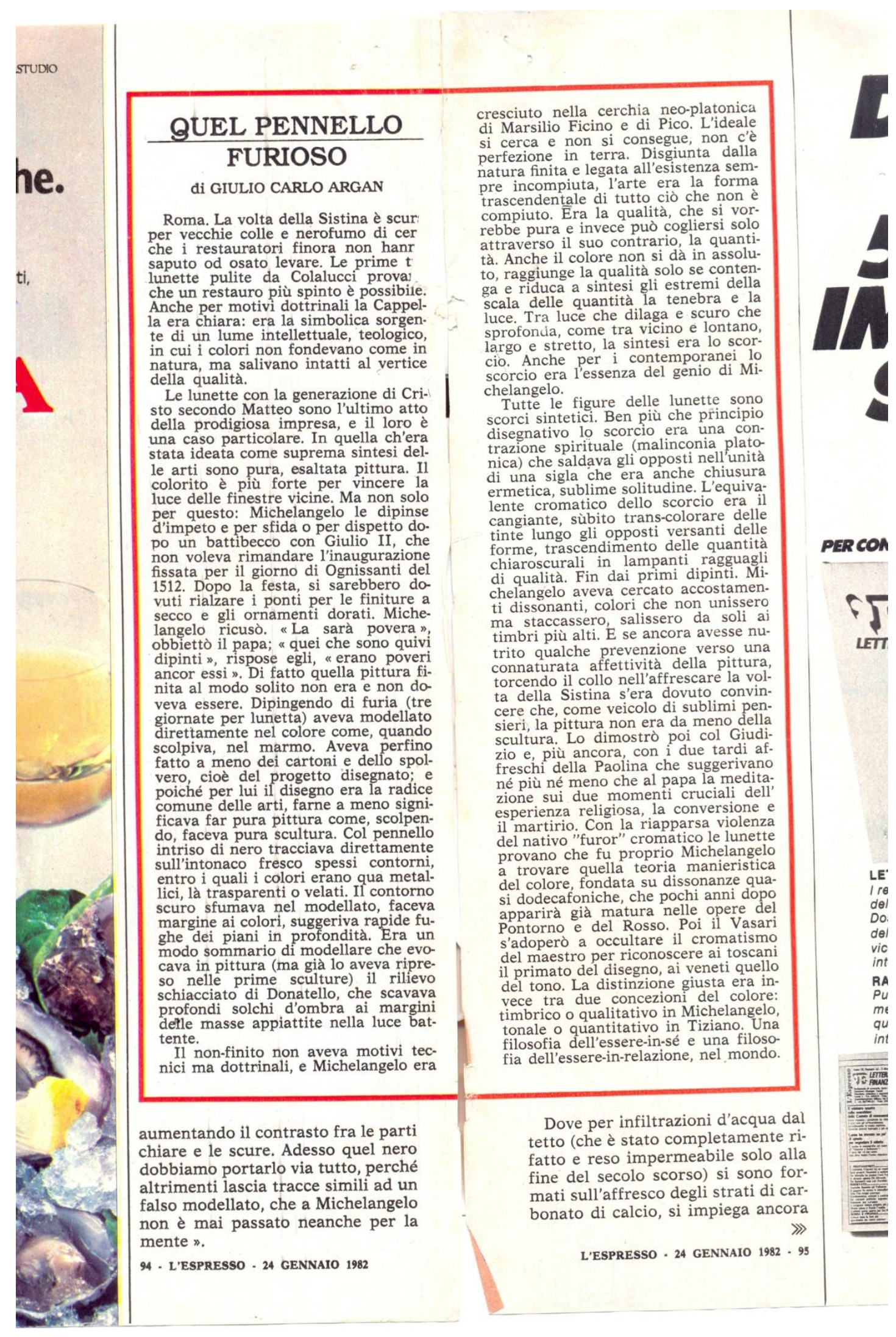




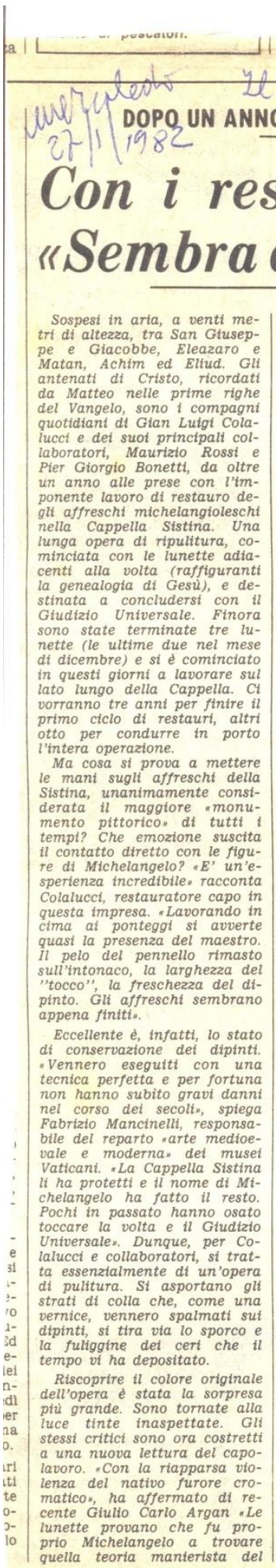

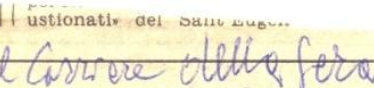

DI LAVORI È GIÀ TERMINATA LA RIPULITURA DI TRE LUNETTE ADIACENTI ALLA VOLTA

Con $i$ restauratori sui ponteggi della Sistina: "Sembra di sentire la presenza di Michelangelo"

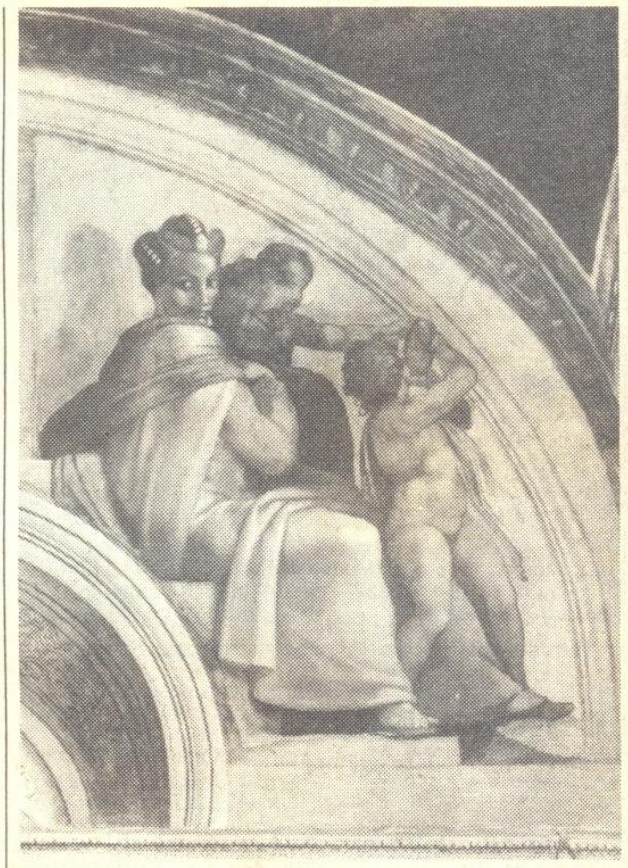

Lunetta di "Giacobbe e Giuseppe" dopo il restauro colore, fondata su dissonanze che anni dopo apparird gid matura nelle opere del Pon-
tormo e del Rosso. Su in alto, in cima all'imdell'intervento restaurativo sorprendente. Colalucci sta adesso lavorando alla lunetta di Josia, Jeconia e Salatiel tempi della deportazione in Babilonia). Solo la parte su-
periore é finita. In basso, inperiore e finita. In basso, in-
vece, le tinte multicolori dei corpi e delle vesti si confondono sotto uno strato di sporco in cui e difficile distinguetro del dipinto il cartiglio, con $i$ nomi degli antenati rore con le iscrizioni delle lunette adiacenti, mentre il colore smagliante del travertino romano compare da una proscandiscono la volta. $E^{\prime}$ - che bile immaginare cosa sard Sistina a lavoro ultimato? "Difficile dirlo,, afferma Colachio "Anche per chi ha liocsempre una scoperta. L'emozione è quella dello scavo artd. "Cl siamo accortin, spiegelo dipinse le lunette senza l'ausilio di cartoni preparato$r i$, come invece avvenne per tista, insomma, cred di gett soli giorni per ogni lunetta. Se si pensa alle dimensioni metri, si resta impressionat dalla furia creativa del pitto-

Circa mille e duecento metri langelo impiegó nove anni per gni staranno in cima ai ponteggi per un periodo più lungo. Che effetto fa? . Be, una comitiva di giapponesi mi ha dieci annin, risponde Colalucci con un sorriso, "Chi lo sa?
Per ora non c'e certo il tempo di annoiarsi. E poi, avere da vanti il Giudizio Universale Marco Barina
Trenta chili di travertino lasciano piazza San Pietro

Un pezzo di travertino di $30 \mid$ probabilmente infiltraziont di chill, che faceva parte del fregio di uno stemma pontificlo dr plazza san Pletro, per rimose dai vigill del fuoco vaticani durante una periodica ispezione, evitando cosi che potesse cadere. Lo stemma si trova a oltre 30 metri d'altezza sul colonnato di destra, al piazza vicino al quale solitamente stazionano carrozzelle pubbliche per 1 turisti.

Altri quattro frammenti soaltrettante statue baroche che, da oltre tre secoli, sono collocate sul colonnato e sulla sommità della Basilica. Si tino raffiguranti martiri, padino raffiguranti martiri, pascolpite dagli allievi del Bernini durante 1 lavori per la realizzazione del colonnato, che dal 1656 al 1667.

Le statue, che al pari del colonnato furono commissionate da Papa Alessandro VII
Chigi, soffrono di vecchiaia e Chigi, soffrono di vecchiaia e
specie nei periodi di freddo specie nei periodi di freddo
intenso si possono sgretolare. A provocare il fenomeno, seacqua piovana che, penetrando nella pletra porosa, riesce robusti sostegni di ferro.

E' probabile ora che, sulla base di un dettagliato rapporto che I vigiti hanno redatto a conclusione dell ispezione, duticane decidano di sottoporre e statue a speciall trattamenti conservativi, anche ricorrendo a resine sintetiche. Intanto una piccola porzione di piazza San Pietro, In corrispondenza con lo stemma di stato rimosso il pezzo da chili, è stato transennato. Non è la prima volta che questo accaden, ha detto un Vaticano da 35 anni, ma per cortuna non è mal accaduto che qualcuno abbia subito danni per la caduta di frammenti di travertino.

Alcuni anni fa, durante un volento temporale, un fulmne colpi un altro stemma po opposto della piazu suavocando la caduta dil diverst grossi pezzi. Lo stemma fu

\section{Ricordato in Campidoglio} il consigliere de Ricciotti quadri di affreschi attendono
II sindaco Vetere ha sospeso ieri dopo pochi minuti dalla sua la morte del rappresentante della DC, Benito Ricciotti. Sullo scranno occupato da Aicciotti so sto posto un maxzo di fiort di campo. Vetere ha annunciato che nei prossimi giorni si terre in consiglio fa commemorazione ufficiale, presente la famiglia delí scomparso. If sindaco ha ricordato le circostanze drammatiche in seguito alie quail consigliere ha trovato la morte. Come en noto. va un bagno nella propria abitazione. leri pomeriggio si sono svolti i funerali dello scomparso, a spese del Comune, nella chiesa di $\mathbf{S}$. Ambrogio in via viteil. Nell cevuto l'omaggio dei colleghi, degli amici di partito, di rappresen. tanze sindacali. Vigili urbani in alla unilorme hanno reso gli ono-

Intanto, continuano gli accertamenti da parte dei tecnici dell'E. NEL, per stabilire come si sia potuto verificare "I tragico incidente che ecostato la vita al consigliere Ricciotti. Mentre non sie

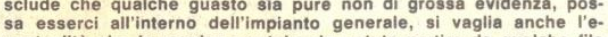
ventualita che la scarica mortale sia potuta partire da qualche tilo scoperto, esistente sotto la muratura.

Si tratta, comunque, di indagini complesse e che pretendono attrezzature anche abbastanza sofisticate. Quel che è certo, nello stabile vivissima la preoccupazione di quanti vi abitano. 


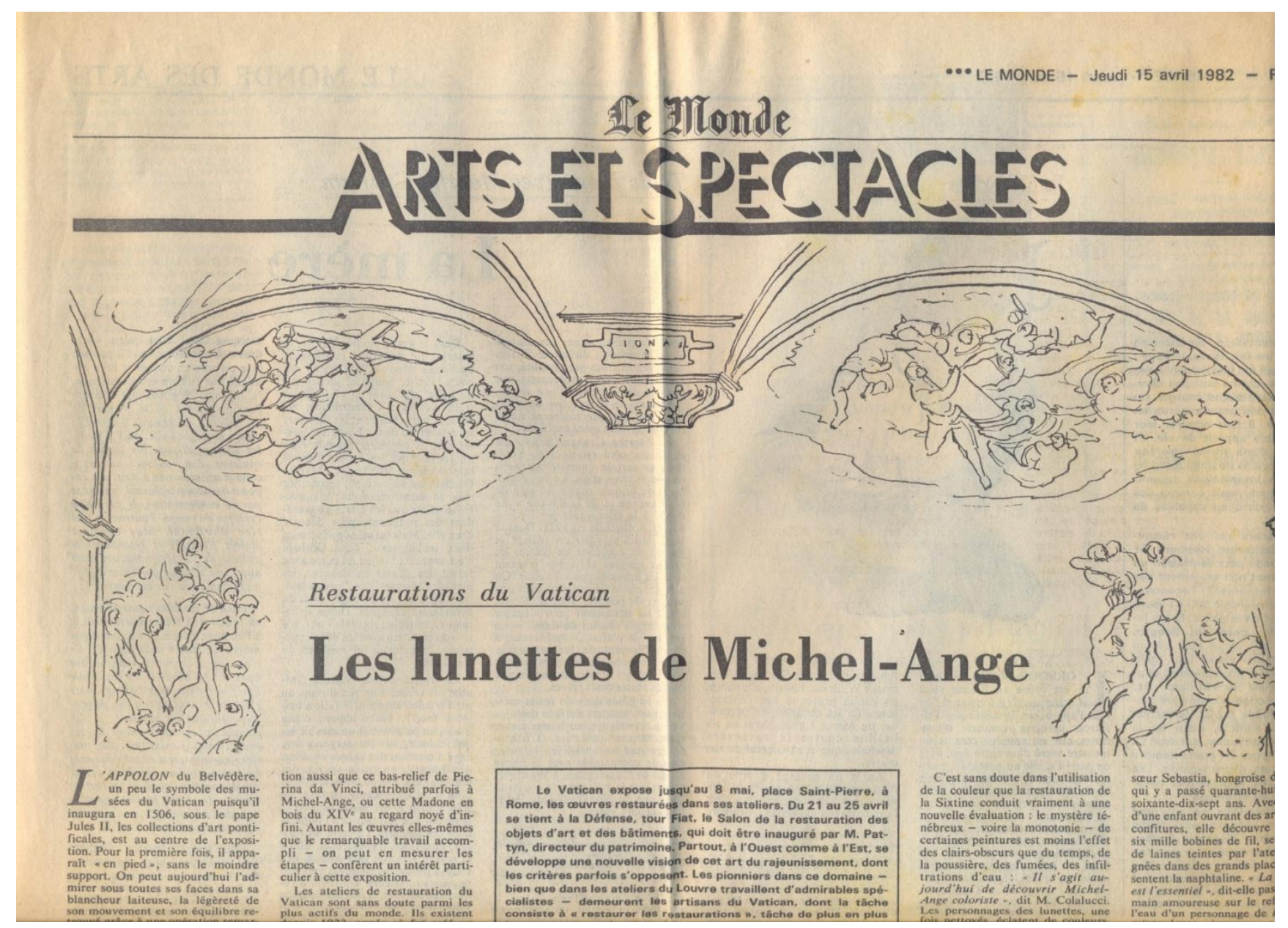




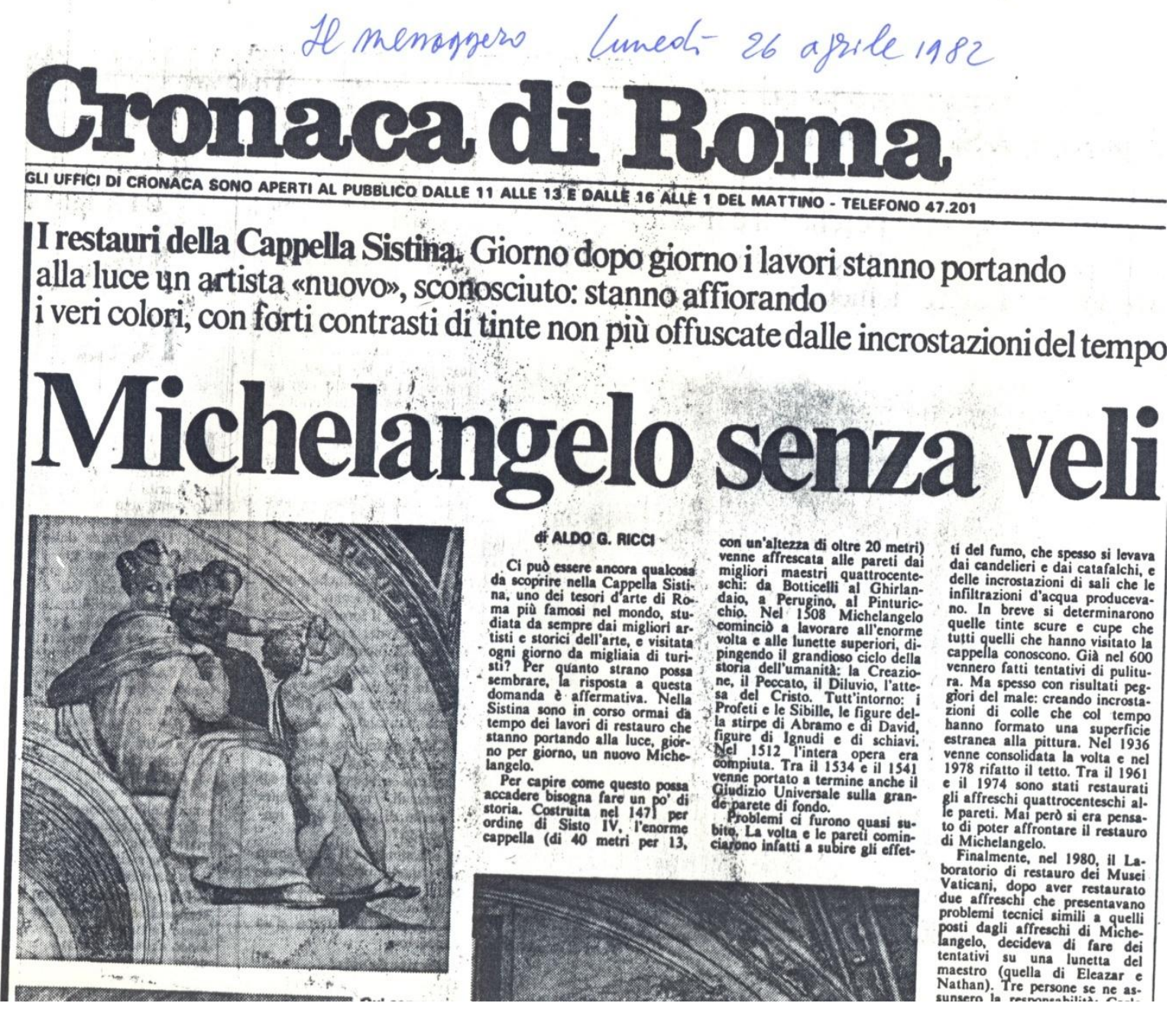



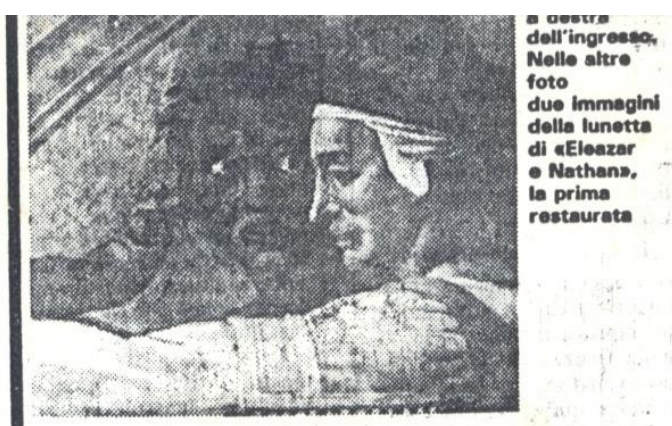

\section{Il responsabile dei lavori svela i segreti dell'opera di restaule che sit concluderà attorno all' 92}

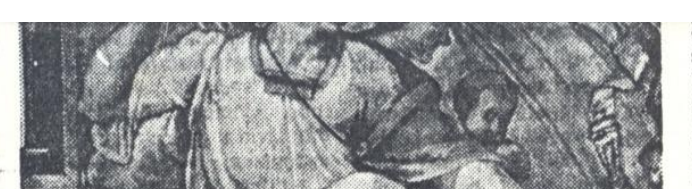
t'ultimo eseguiva personalmencele braio dell'81, la lunetla veniva ufficilamente presentata ag esperti. Da quelia data, tecnici dell'Istituto del restauro e di molti altri Paesi, studiosi come Brandi e Argan, si sono arrampicati sulle scale che portano 20 metri da terra, dove si trova no le lunette. Si deciso $\cos 1$ portare a termine dichelan gelo nella Sistina. Parallelamente al restauro vengono condotte delle ricerche sul -microclima della cappella (temperatura umidita, polvere) per studiare mezzi più efficaci per evitare gli inconvenienti del passato. Tuti lavori vengono eseguito preparando, passo passo, una comple zioni, corredata da foto $e$ film in modo che $\mathrm{i}$ restauratori del futuro possano regolarsi con la massima precisione. Anche io, informato del lavoro da un amico esperto, ho potuto visitare il cantiere di restauro accompagnato dal responsabile tecni ha fornito tutte le informazioni necessarie, e vedere da vicino le tre lunette ormai ultimate $e$ le due in corso di lavorazione. Sono entrato nell'incastellatu-
ra coperta che nasconde i lavori, mi sono arrampicato fortunosamente fino in cima, ho potuto parlare con in sei restauratori che hanno in cura gli affresch e, sopratlutho, verifcare da vicino qua Michelangelo che sta venendo alla luce. L'impatto, anche per un profano, sconvolgente. Le figure che una-critica romantica aveva descritto come oscures, evelates, emisterioses. s'impongono invece con una nitidezza di modellato, con una forza di colore che nessuno poteva provede costanze estranee dalle interpretazioni deformanti, riemerge oggi un Michelangelo del tutto sconosciuto. Riemerge grazie alle moderne tecniche di restauro, ma anche a un atteggiamento nuovo del mondo deg. esperti. E' una lunga e affascinante aventura quella che cco minciata due anni fa nella cap pella Sistina, un arve fard molto discutere e molto scrivere. Tra dieci anni la Sistina sara qualcosa di completamente nuovo diverso, qualcosa che nessuno aveva piu visto da oltre quattro A.G.R. secoli.
Cimitiamo a togliere le incrosrazioni. formate da carbonati, fumo e colle, e fissare i colori più delicati.

- Ma come?

52) Usiamo un particolare solvente (l'AB 52) che viene lasciato sulla superficie per
3-4 minuti. Il calcolo del tempo à imporvia. Naturalmente qui la tensione spesso ti residui Dopo 24 ore si ripete. I carbonastate molte polemiche? mandarlo in profondita lasciando pulita la to. col sistema tradizionale e poi asciuga lo col solvente. Erano rimaste delle tracce sultato fu ottimo. Quindi, un po casua mente, abbiamo individuato abbiamo poi adotato nel lavoro successivo.

langelo al restauratore? torni disegnati. Michelangelo le modella direttamente dalla prima stesura. La lunetta a divisa in tre parti: due gruppi digura corrisponde a una giornata di lavoro perché questi si servono di aiuti o dipingono a settori una piccola porzione pe Michelangelo no. Modella un'intera figuii Michelangelo. Gli affreschi di altri auanni dovrebbe essere tutto finito. Ocorre bile una parte della Cappella. Non si pud polavoro come la Sistina. Questo biar tecniche questo pud influenzare Abbiamo intrapreso una lunga dificie tro per il Giudizio Universale. ma affascinante avventura 
I lavori di restauro dureranno 12 anni Gli affreschi della Sistina ritrovano il loro splendore

ROMA - Sono stati presentati oggi alla stampa gli affreschi eseguiti negli ultimi dodici mesi dal Laboratorio di Restauro dei Musei Vaticani che ha la cura di tutti gli edifici appartenenti al Vaticano - basiliche, palazzi Lateranensi, della Cancelleria, di Castel Gandolfo - nonché delle opere in essi contenute, af freschi, sculture, ceramiche, bronzi, dipinti di ogni genere: per la Cappella Sistina, si prevede un lavoro di ripulitura e ripristino che durerà per i prossimi dodici anni.

E' già un privilegio salire alla Cappella che Sisto IV fece costruire nel 1475 sulle dimensioni indicate dalla Bibbia per il Tempio di Salomone - per la Scala Regia, immergersi in questa prospettiva continuamente rinnovata di arco in arco, nella concezione ritmica del Bernini che ha un parallelo solo nella musica coeva; sostare nella Sala Regia, adorna di stucchi che riprendono, insieme agli stemmi papali, motivi classici degli ovuli e delle foglie d'acanto; trovarsi infine nella Cappella senza il fiume ininterrotto di turisti che l'affollano e guardare la volta e le pareti a proprio agio, con l'illuminazione adatta.

La lunetta restaurata, nella parete d'ingresso, di faccia al Giudizio, rientra nello schema ideologico di Michelangelo, che la dipinse, come le altre, tra il 1508 e il 1512 e volle rappresentarvi gli antenati di Cristo come sono elencati nel Vangelo di Matteo. Qui si tratta di Mathan, di sua moglie e del bambino (che diventerà il padre di $\mathbf{S}$. Giuseppe) e di Eleazar; e ci accorgiamo per la prima volta dell'esistenza di queste figure stupende, come se in una stanza buia irrompesse per la prima volta una luce abbagliante: a confronto, la lunetta attigua e assolutamente invisibile.

Sotto la lunetta, sono stati restaurati i ritratti dei papi, figure compassate e quasi convenzionall, a paragone con l'impeto che travolge quelle michelangiolesche: esse appartengono alla scuola del Ghirlandaio e a Cosimo Rosselli; due altri affreschi sottostanti, la Resurrezione di Cristo e la Disputa sul corpo di Mosé, erano stati dipinti da Luca Signorelli e dal Ghirlandaio, ma il crollo della parete ne impose il rifacimento nel 1571 ed esso fu affidato a due tardi manieristi di scarsa fama, Matteo da Lecce ed Heinrick van den Broeck. Anche questi dipinti, completamente bui prima del restauro, sono luminosi e vividamente colorati: quattrocento anni a lume di candela li avevano coperti di una fuliggine di cui sono stati conservati dei tasselli-campione, per stati conservati dei tasse.
indicare il lavoro fatto.

indicare il lavoro fatto.
Ed eccoci improvvisamente a tu per tu Ed eccoci improvvisamente a tu per tu sue pennellate rapide, asciutte, con i suo pentimenti, le cancellature, le ombre cangianti da uno ad altro colore e le luci che colpiscono un volto piegato, una ciocca di capelli, un ginocchio e le pennellate di concapelli, un ginocchio e le pennellate di con-
torno per profilare le sagome; il prof. Pietrangeli, direttore dei Musei, il dr. Mancinelli e l'assistente tecnico del restauro, G. Colucci, spiegano la tecnica applicata, il lavoro compiuto; $\mathrm{ma}$ in chi guarda si fa un gran silenzio; ci si trova soli con il grande vecchio aspro e chiuso nel suo tormento intento senza aiuti al suo lavoro titanico, teso a lodare Dio con il pennello e con lo scalpello e, al tempo stesso, torturato dal rimorso di amare troppo quell'arte che era la sua vita («conosco or ben - com'era d'error carca...); e si vorrebbe chiedergli perché quel volto abbronzato ha uno sguardo puardo dista di profilo serba gelosamente legate alla cintura la borsa e le chiavi e quale pensiero piega il profilo di Eleazar malinconicamente verso terra.
Implicazioni

\section{Rinviafa /e per le mav.}

Tokyo ha chiesto che le quando fanno scalo - Co:

DAL NOSTRO INVIATO SPECIALE | dell'a GENOVA - La «Freccia tenz Blun, destinazione Palermo, è Ma ferma nel porto di Genova: la tare Pia Costan destinazione averc "Pia Costan, destinazione aver Stati Uniti, non leva le anco- re in re; si arrestano nei porti del giun Mar dei Caraibi le navi italia- «Finr ne che prestano servizio cro- ca d cieristico; incrociano le brac- Tries: cia ad Hong Kong i marittimi $\propto$ Med della aMediterranea e a Sin- ponic gapore quelli della Nipponi- sciope gapore quelli della Nipponi- sciope ca n irritando le autorita loca- un inv no lo sciopero di 72 ore indetto $\quad$ L'ins no lo sciopero di 72 ore indetto
dai sindacati confederali per danti dai sindacati confederali per
il rinnovo del contratto:
privat obiettivo la "stabilità del italian rapporto di lavoro al posto Giapp

Elezioni: nessuna rante decisione astens \begin{tabular}{l|l} 
per le date & $\begin{array}{l}\text { contra } \\
\text { pedito }\end{array}$
\end{tabular}

ROMA - Negli ambienti "Llo del ministero dell'Interno si esse) precisa che le notizie pubbli- sorzi cate da alcuni quotidiani cir- in $\mathrm{E}$ ca le date delle elezioni ammi- da sc nistrative sono destituite di tede: ogni fondamento.

Kon Nessuna decisione e stata to un finora presa anche per quan- chiar to riguarda la data di svolgimento dei referendum popolari. Entrambe le consultazio- conta ni debbono comunque aver sinda luogo tra il 15 aprile il 15 giu- mode luogo tra 115 aprile e il 15 giu- tica, gno in due distinte domeni- me h che. "E una vertenza sindacale", si affrettano a dire tutti "Orig: Chiuso per sciopero il casinò di St.-Vincent 
EPOCA 9 MAR20 1984

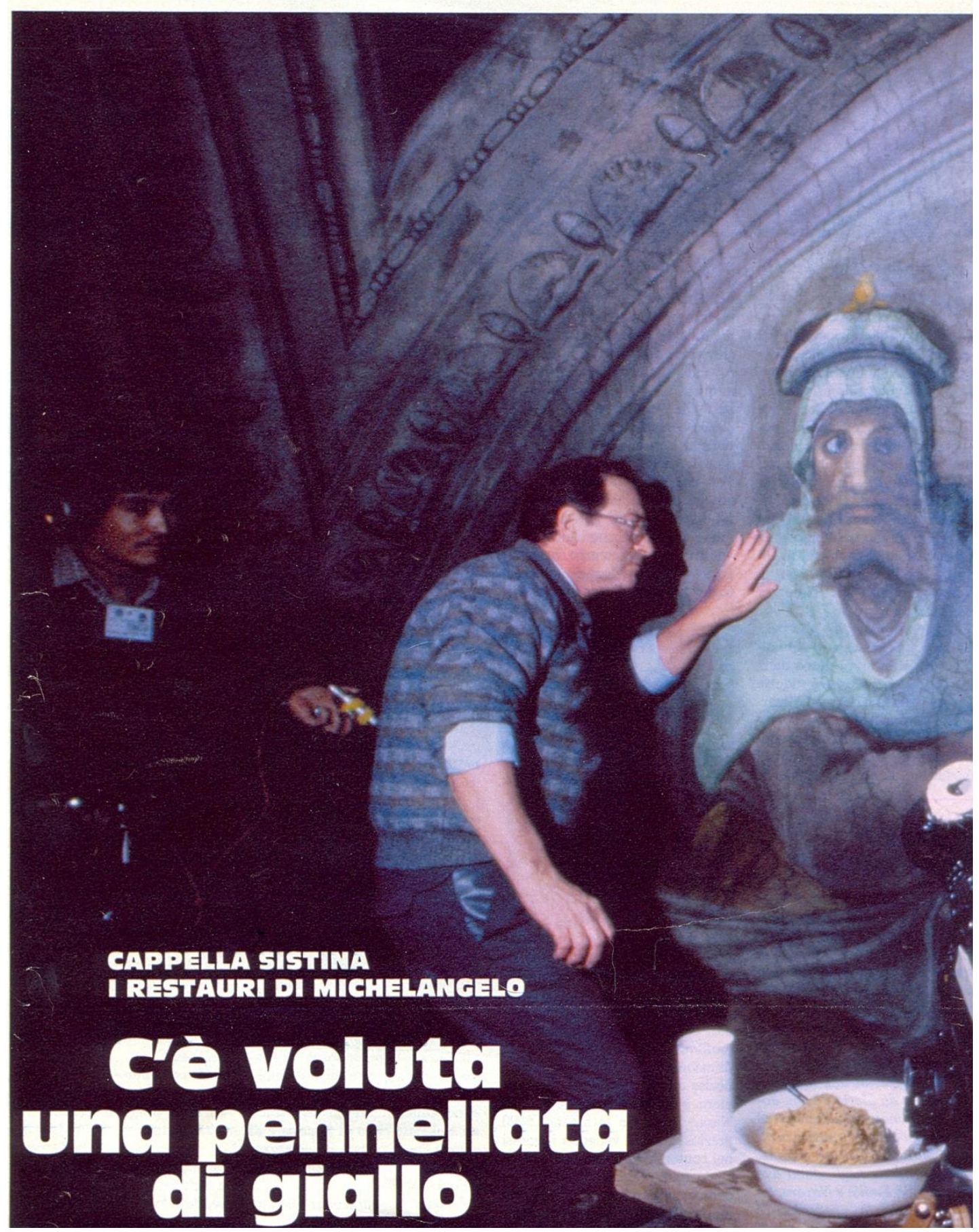




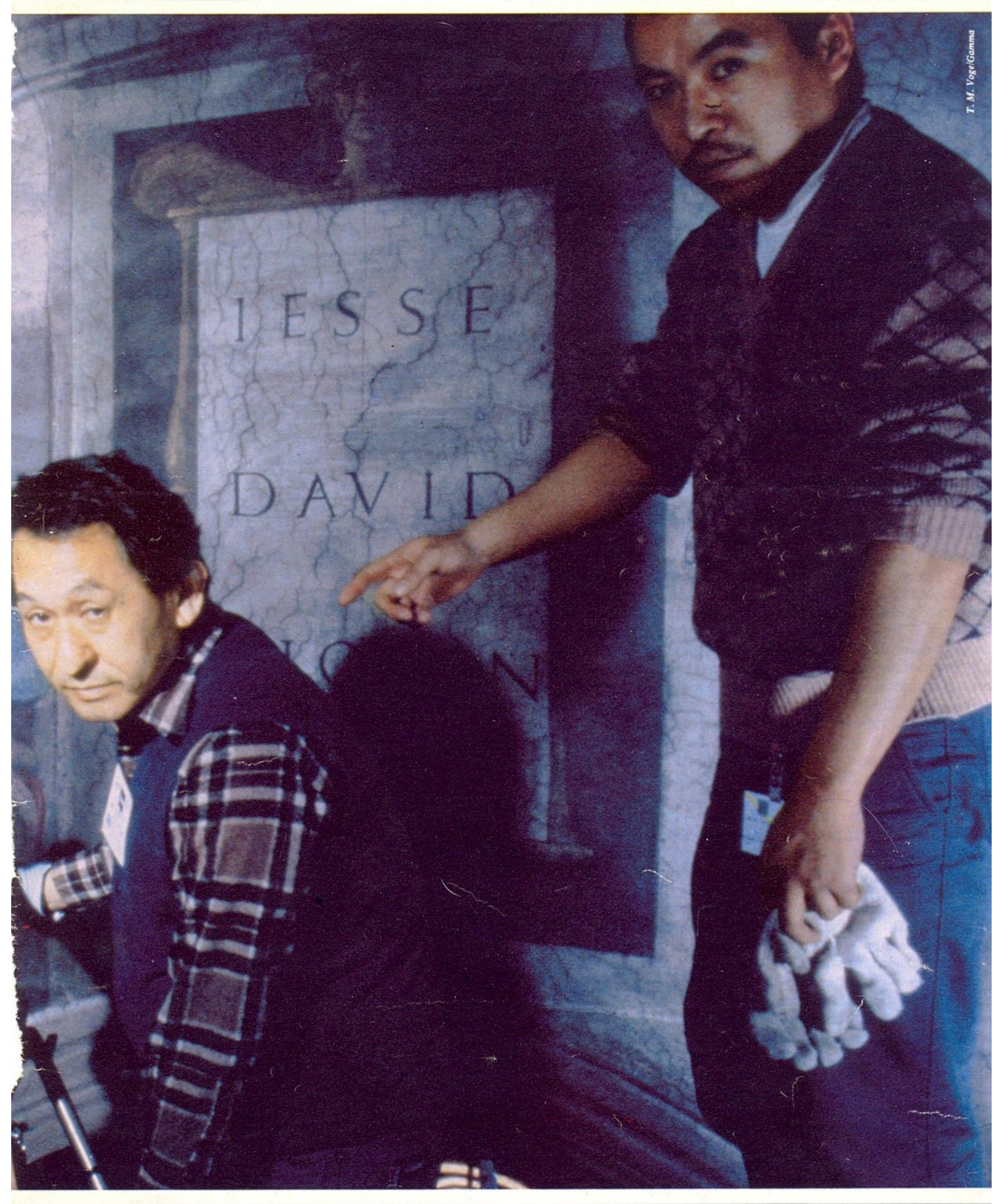

che controlla i risultati degli interventi sulla "lunetta" rappresentante Re Davide. 


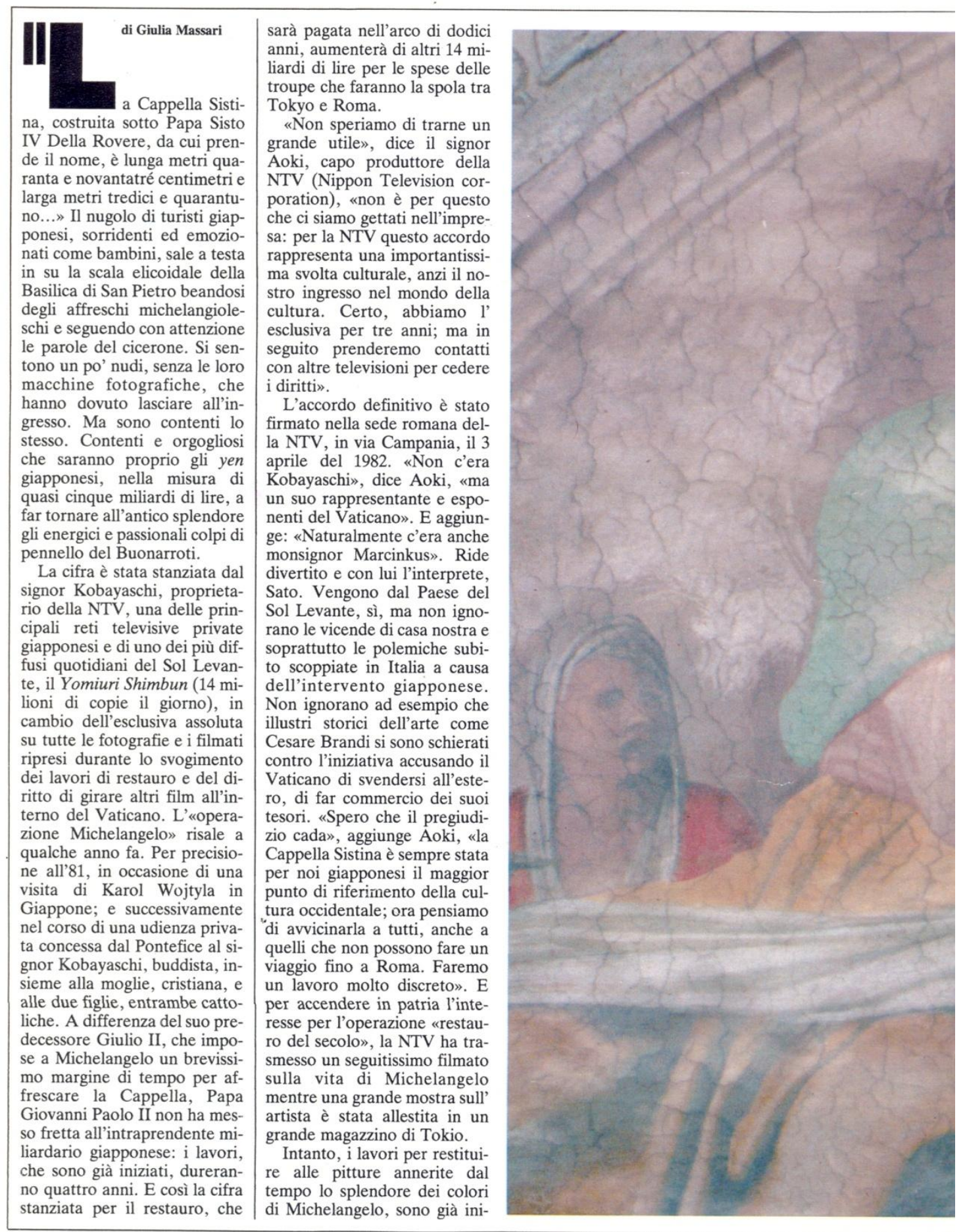

II re Davide prima e dopo il restauro. La figura del grande " 


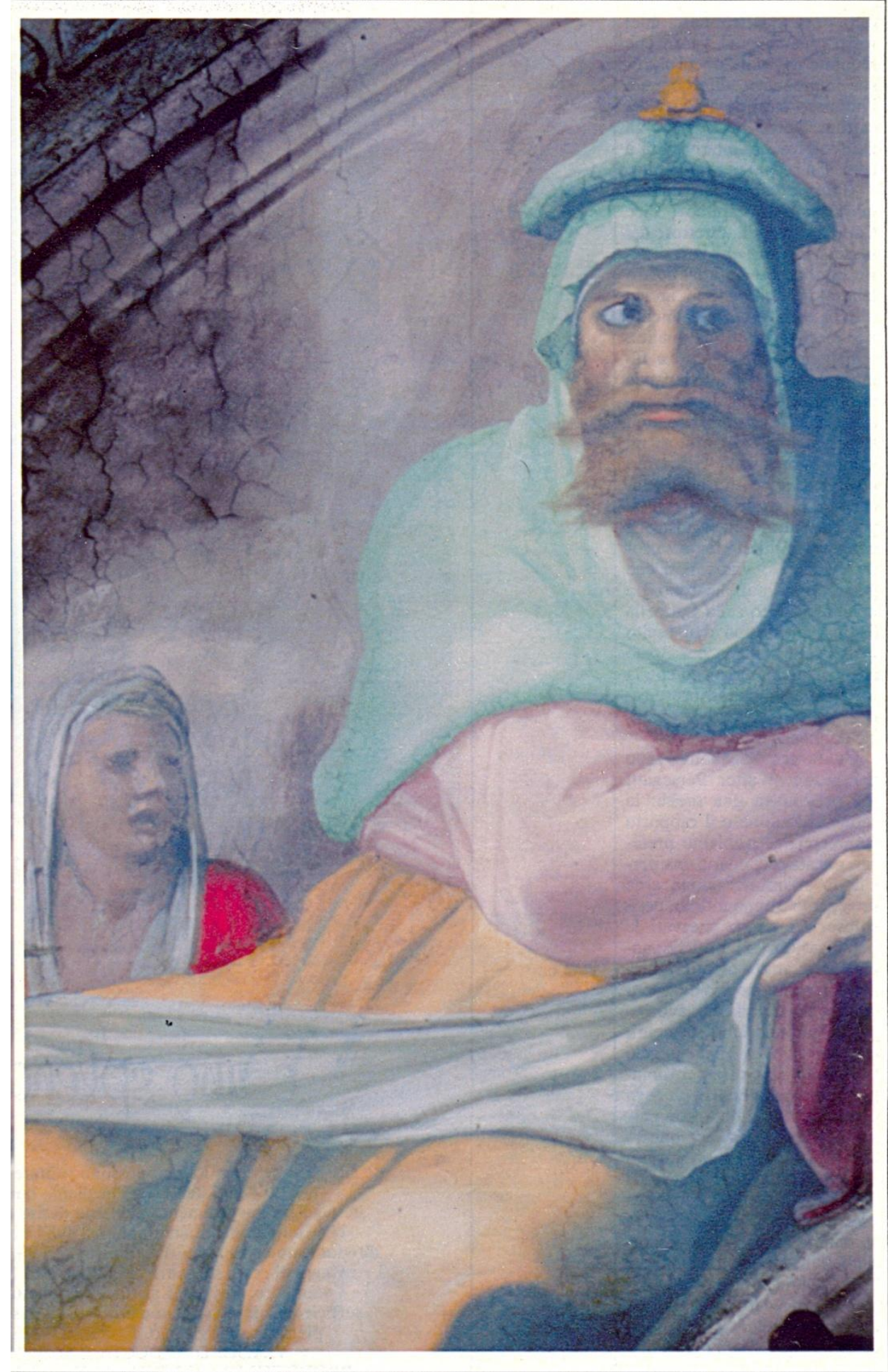

gelo, occupa la seconda lunetta a destra della Sistina. RE DAVIDE TORNA A GUARDARCI DOPO 4 SECOLI 
Italian art

\section{Milk shake for Michelangelo}

Michelangelo probably climbed in through a window each morning at dawn to paint his supreme masterpiece-the ceiling of the Sistine chapel in the Vatican. The popular can. The popular image of the Florentine height of just under 21 metres, to work on height of just under 21 metres, to work on
his creation seems to have been disproved his creation seems to have been disproved by the discovery of two holes next to each of the 12 windows (orginally there were support his working platform, which could have been reached by an outside catwalk at window level.

Michelangelo's holes will be used again, later this year, to support a platform for the restoration of the frescoed

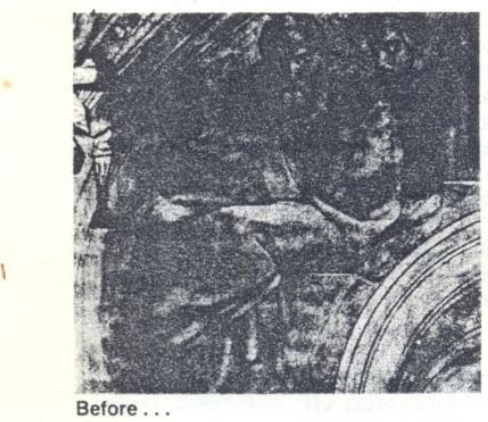

ceiling. The chief restorer, $\mathrm{Mr}$ Gianluigi Colalucci, says he plans to use the holes to build a metal track, running the length of the chapel on each side, which will carry a mobile platform for himself and his two assistants, Mr Maurizio Rossi and Mr Pier Giorgio Bonetti, when they are ready to take on the ceiling. They, too will crawl in from the windows. The platform will have no structure at ground level.

The discovery of those holes is but one of the revelations made by the Vaticah restorers working in the Sistine chapel. In the next six months or so, they will have completed the restoration of all of $\mathrm{Mi}$ chelangelo's frescoes in the chapel's lunettes and spandrels (the areas between the windows and the ceiling proper). which depict Old Testament prophets. sibyls, Jesus's ancestors (according to S$$
\text { sibyls, Jesus's ancestors (according to St }
$$

months have seen the results and. even though the space already restored is far from insignificant (each lunette, for instance, measures about 2.15 by 4.30 metres) and is more difficult to view than the ceiling, the effect is startling. For the Michelangelo riginal colours are to be seen. Since this is bound to be true of the ceiling when it is cleaned and will certainly be true of "The Last Judgment", when work starts on that in 1988, as Michelangelo's last fresco in the Sistine is today barely visible because of grime. art scholars may have to rewrite of grime, art scholars

Traditionally, they have said that the Traditionally, they have said, that the
Sistine frescoes "offer a harmony of rare. Sistine frescoes "offer a harmony of rare,
pale tones, a sort of diffused light". The colours, they say, are restrained, almos opaque-in short, what the modern layman would call pastel shades. All wrong. Michelangelo's original colours are so vivid they almost leap out from the walt. The British Museum holds man. sketches that Michelangelo did before sketches that Michelangelo did before
painting the Sistine's ceiling. (He considered wall painting was for sissies. He wa a sculptor by trade. he insisted.) However, he obviously felt sure enough of his wall technique that when he painted the area now under restoration, he did it wishout sketching on the wall first. There is no trace of any designs beneath th: vast and flawless painted surface. He is known to have worked alone, fast, an furiously and completed everything bu "The Last Judgment" (done at a later time) in only four years.

Mr Colalucci's two-man team is not restoring the Sistine frescoes in the generally accepted sense of the word. They are cleaning the walls of centuries of lampblack, which came not only from the candles used at the altar (beneath "The Last Judgment"), but from the flaming torches that, before the invention of electricity, were used for illumination even during the day.

Since it had no heating, braziers werc set at the feet of the old cardinals when conclaves were held. The roof was often leaky, causing a calcium roof to form on the frescoes. Perhaps the only thing th: has protected the frescoes from totia destruction, particularly from the pollution of the moter car and Romesobit-fired plants. was the animal pplied over the past three pplied over the past three
lier Vatican restorers. lier
of glue have darkened trick has been to remove hout removing the painted plaster underneath

The Vatican restorers are applying to the frescoes a kind of poultice, known as AB-s7. which was concocted about 12 years ago by a husband-and-wife team. Laura and Paolo Mora, of Rome's Institute for Restoration. The numerals 57 refer to the number of experiments they made before hitting on the right formula. It consists of water, bicarbonate of ammonia bicarbonate of soda. Desogen (a Gieigy pharmaceutical product) and Cigy phas methyl cellulose. (The last is also used to give that "wholesome thickness" to milk shakes served by at least one multinational fast-food chain.) AB-57 is an odourless, colourless jelly. The Vatican approach has been to wash a small area, about the size of a man's hand, with distilled water allow it to dry and then apply the $A B-57$ to the area for about apply the AB-57 to the area for about one minute, removing it and repent

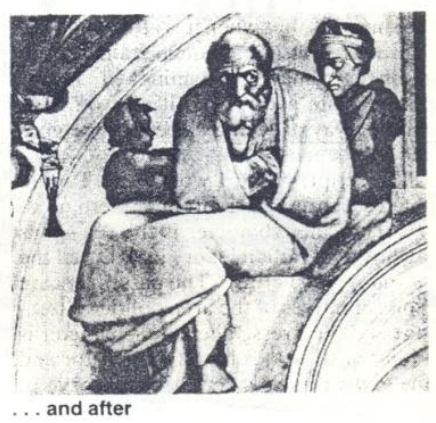

A remaining problem is how to protect Michelangelo's frescoes now that his nudes are doubly so- that is, without the glue's protection in this dirty modern world If visitors to the chapel could hold their the most of them stay, pollution and humidity could be considerably reduced, but of course that cannot be. Mr Colalucci plan to put nothing over the frescoes, which is risky, but those frescoes cleaned so far show no signs of damage after two years of breathing Rome's atmosphere.

Japanese television has brought the rights to film, photograph and record the various stages of the restoration. It paid an initial $\$ 975,000$ for the privilege in June, 1982, when that sum was deposite with Chase Manhattan in New York. in the account of the Istituto per le Opere di Religione (IOR), now better known the Vatican's bank. That was he ars the vaticans bank. That was ibe first instalment of a payment from the Nippon television network. Which, at specified times over the next 12 years, will give the IOR an additional $\$ 2 \mathrm{~m}$. According to the terms of the contract. the Vatican will

\section{con cordiali saluti GEORGE ARMSTRON
ROME CORRESPONDENT}

THE GUARDIAN THE SUNPAY Tines Loxpos 


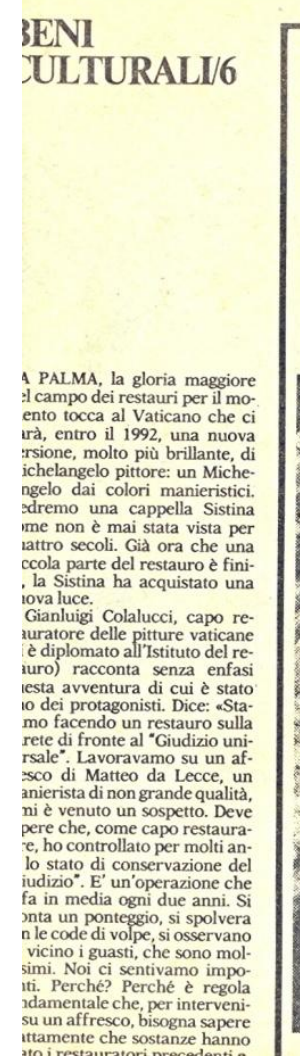

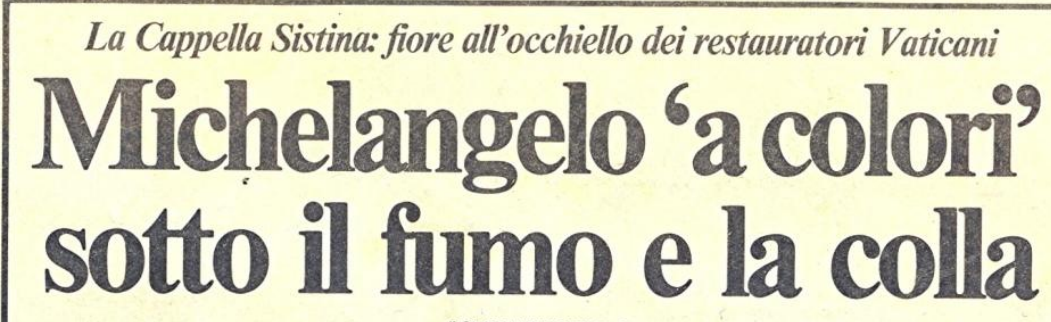

di CLARA VALENZIANO

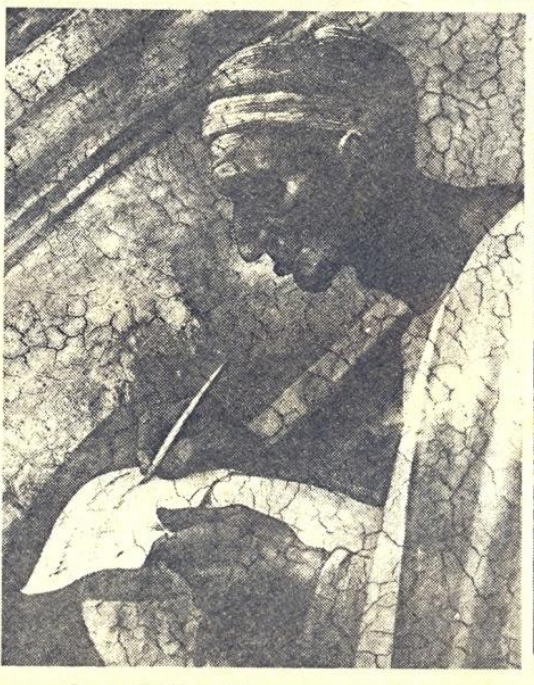

Nelle foto picocole qui
fianco: 2 lunette tra

piú deteriorate. Con

Obeth quella in alto:

col Principe Aming
quelle in besso. $A$

particolare con

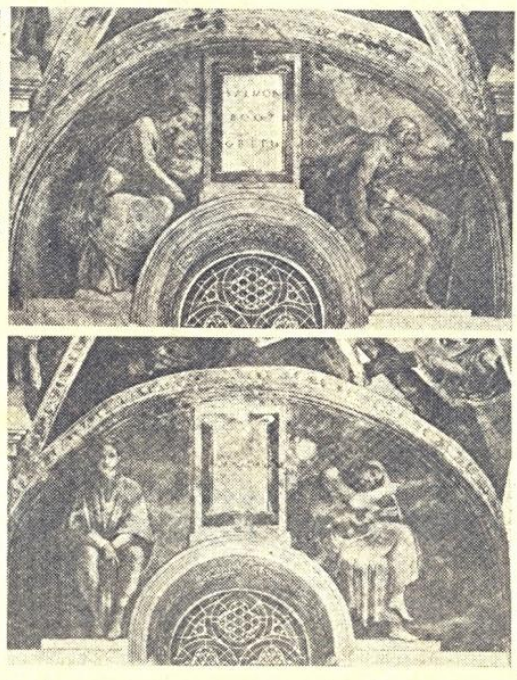

a invisibile dicera, è stato trasferito nel Cortile delle Corazze, i] primo per chi entro nel museo
(ma pochi si accorgono che li c'é

Il Vaticano ha, inoltre, instauframmentidi vasigreciconiare sei di New York e Berlino (per faclitarne la ricostruzione). Infine, rà il quinto centenario di Raffaello: aprira una mostra in settembre. Tra i restauri importanti che verranno presentati in questa $\propto$ -
casione ci sarà quello del quadro della Madonna di Monteluce, minciato da Raffaello e finito dai suoi allievi. Il restauro ha messo in evidenza un fatto singolare: dipinti quarrsi, eormato di due insieme. Il dipinto ha una storia faceva parte delle opere d'arte rapinate da Napoleone e restituiecasione il nel 1816. In quella non rimetterle nei loro posti d'origine, chiese e sacrestie, ma di raccoglierle in un apposito $\mathrm{mu}$

Un tetto per il tempio 


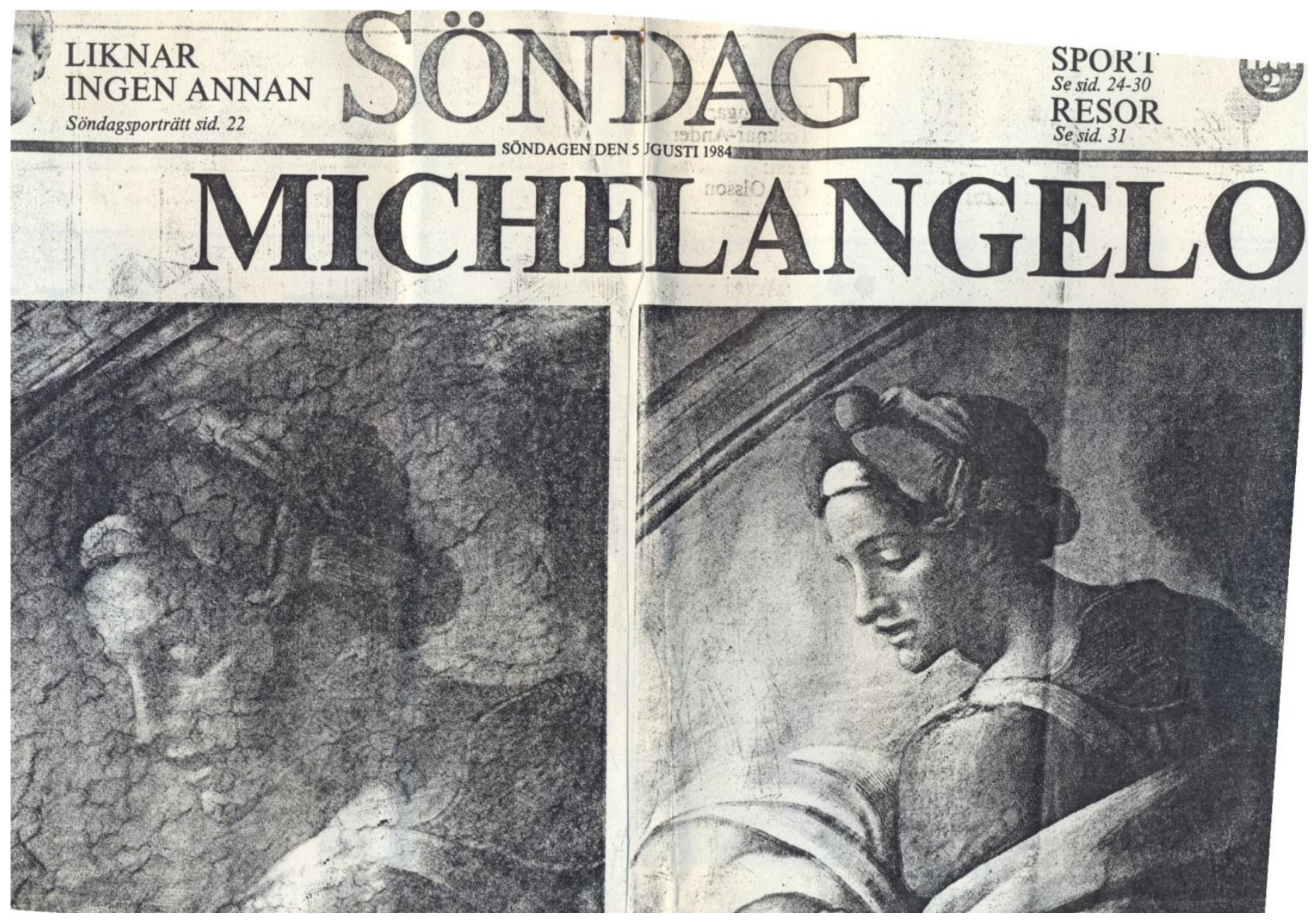




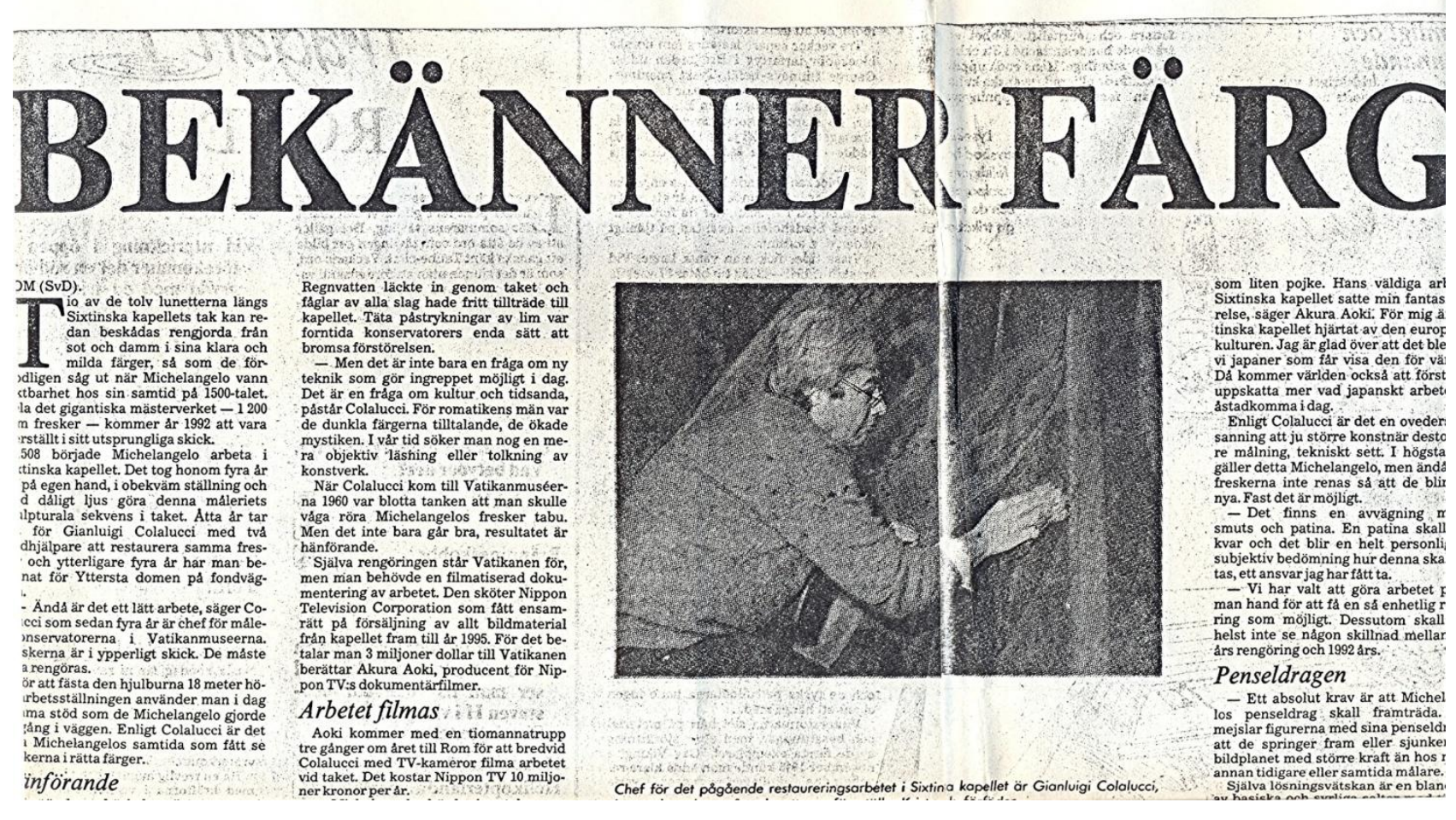




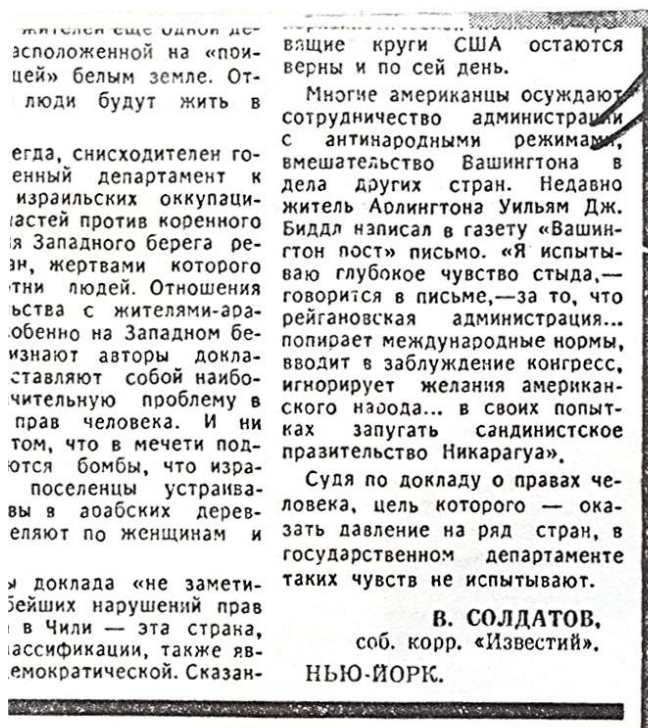

ем достоянием общеи стала воспроизвеазетами 49-я страница ывшего председателя начальников штаженных сил США генедда С. Джонса, на комешены карты Фактивероятных американ-
ных баз в Индийском ных баз в Индийском lа второй карте Трин-

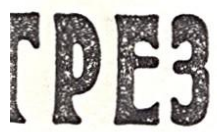

значены военные базы. 4 прессе появилось неважных разоблачений,

явным вопиющее чие между словами и ашингтона. Ему пришс о Тринкомали. илов, населяющих этот роза создаяия в нем жой военной базы имеони против нее чуть ем все прочие чители ганизаторы стопкнове мо, налеялись поймать

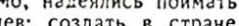
чую обстановку крато огила бы Вашингтоолила бы Вашингтозаранее запугать района тринкоматтвратить его массо зсты.

после серия вспышек Шри Ланке туда починистр обороны США р. Затем Копомбо поІециальный представиэрезидента Рейгана зернон уолтерс. Ланстали, по-видимому, опасностью, которая ейся ситуации может ходить от Индии, поих резко увеличат юджет. Им стали уси?язывать дополнитель- ны». Стремление США заполучить базу в Тринкомали стали скорее всего объяснять ланкийщам как попытку "защитить» остров. Беззастенчиво спекулируя на экономических трудностлх UЈри Ланки и на внутрипоинтической напряженности, связанной с недавними столкновениями, Пентагон тянется к Триноомали. Многие на острове хорошо понимают эту тактику. Резкс осудил наращивание американского военного присутстС०ийся на днях в Коломбо масЛанки. В последнее время в печать ряда стран просочилось сообщение о том, что Пентагон не только жаждет обладания тринкомали, но и подумывает о переводе туда Центрального командования СШа (Сентком). Все это не гицо опасность того,-замечаст индийская газета "Пэтриот»,что Шои Ланка превратитса в Своеобразный «южноазиатский Ливан", и есе прибрежные государства должны принять $к$ сведению ход событий в этой стране». Усиленное проникновение Вашингтона в экономическую и политическую жизнь Шри Ланки продолжаетса. В обмен на навязанную ей "военную помощь» США потребовали от правительства Шри Ланки разрешения на строительство на острове шести мощных радиотрансляционных станций "Голоса Америки». Дело не только В том, Что С помощью этих станций будет вестись подрывная пропаганда против ряда стран Азии. Дело еще и в том, что создаваемый радиокомплекссамьй мощный в этом районе мира - в любой момент может быть использован и для военных целей.

Трудное время переживает остров грез.

А. ТЕР-ГРИГОРЯН. рия в Индийском океане состосозый Митинг осщественности, может не настораживать. "На-
Новые краски Микеланджело

Итальянские путеводители у верлдают. что знаменитея Сикстинская капелла о Ватикане соорухсена в конце XV века по распоряженик папік римского Сикста IV. Эта прямоугольная зала co сводчатым потолком высотоп почти в 21 метр расписана зна менитьми итальянскими худох киками эпохи Возрохоения: Бот тичелли, Перуджино. Синьорелли и другими. Но главное, что в ней скульптора, жсивописца и архискульптора, живописца

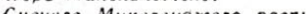
Сначала Микеланожело распиcan потолок Сакстинской капелcozdon zuzourcoryo co

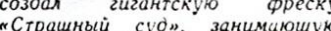
площад в двести зандадратных метров. Сеичас теорения мuкеМuкеде зтоі уникальрй работы а поnросил рассказать duректора $B$ a просии рассказать оиректора Варандасели, одного Карло Пьет раножели, ооного из крупнешиших ве которого и начались реставро чионные работь в Сикстинской капелre.

Отвечая на мой вопрос, почему решились на такой смельй и да рания всемирно uзsectubax рация всемирно известныс фре рандхели сказел:

- Микеланджело был выдаю-

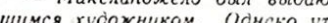
вероилось мнение, что в чветово

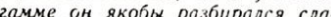
бее. Так ли это на самом деле? мы провели мнохество исследо ваний и убедились, что художник превосходно чувстбовал чветовую гамму, писал яркими, сочньеми красками. Однако эти краски скрыть от глаз слоем вековой пыли, кнешнтим загрязнением, копотью свеч и кадильниц. Это открытие, перевернувщее устоявшееся мнение о Микеланджело как о живописце, нагляоно подтверухдают реставрачионние ра боты в Сикстинской капелле.

Они началисо в 1980 zоду u рассчитаны на двенадцать лет. Летом этого года закончится их первыL̈ этал. Вот посмотрите на деа снимка одной и той же жен ской фигуры с ребенком на ру ках. Один сделан до реставрачии, другой - после. Видите, какая огромная разница? На первом снимке краски тусклье, на втором - кркLе.

पто же касается риска, то мо гу заверить, что он исключен. Прехсде чем приступить к работам. мы тщательно исследуем ррески, опрєделяем, гое краски самого худохтика, а гое после дуюије наслоения и грязь. Надо сказат, 4то сама фрески Мuнеланджело превосходно сохра-

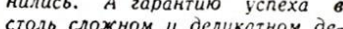
столь сломном u деликатном деcтве наuнu рестовраторо мастер$$
\text { н. ПАКЛИН, }
$$

соб. корр. «Известий
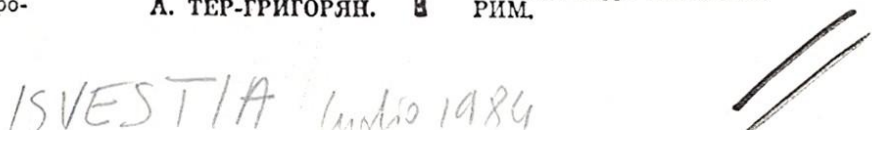


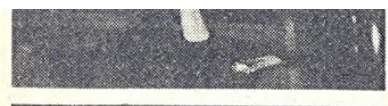

aupo aver ucciso per legituma ditesa sl
ritrova a vivere, sapendo in partenza che Festa Campanile, espone una volla sua è una partita persz come una be-

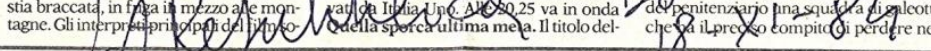

sonnia. A troio ar cunosita segnainamo, sempre perdomani(alle 20,25, Retequa (980) inson, una vila tha stori no piace caldom.

Speciale Tg1 sul "Michelangelo ritrovato" domani sera alle 22,20 su RaiUno

\section{Dalla Sistina, il restauro del secolo}

PER TRE milioni di dollari (quasi sei miliardi di ad assicurarsi l'esclusiva delle riprese. Ma un piccolo ascoop", a proposito dei lavori di resta dei turisti le lunette michelangiolesche dell Cappella Sistina l'ha fatto anche la Ty italing il sei garticolare, la troupe di Speciale Tgi, che il sei giugno scorso è entrata per la prima vo precisi accordi, però con ripulitura di un paio dilunettedella partesinistra della Cappella, quelle rispettivamente intitola quali il restauratore capo della Cappella, Gian-

luigi Colalucci e i suoi collaboratori Maurizio tre mesi, da giugno appunto al 15 settem per Ecorso. leit motival servizioche Speciale Tgl dedicadomani sera $(22,20$, RaiUno) al Michelangelo ri trovato: poco meno di un' or a di servizio, firmata da Nino Criscenti, con la fotografia di Angelo montaggio di Massimo Branchesi.

Quattordici lunette, la volta, il Giudizio Universale: sono la meta, quotidianamente, di una media di settemila visitatori. La loro ripulitura
già è stata battezzata come ail restauro del seco-

lon. E, in effetti, I'obiettivodeirestauratoriè ass cols ernici stessc usate dai «restauratorin dei secol corsi che si sono stratificate sugli aff resch. Domani sera, grazie a Speciale Tg1 avrem insoma un primo assaggiodelrestauro. Un as. a televisione giapponese non $h$ a potuto negrer un'autorizzazione ad una troupe che non aveva intenzione di «rubare" le immagini di un documentario d'arte, ma realizzare un servizio gio
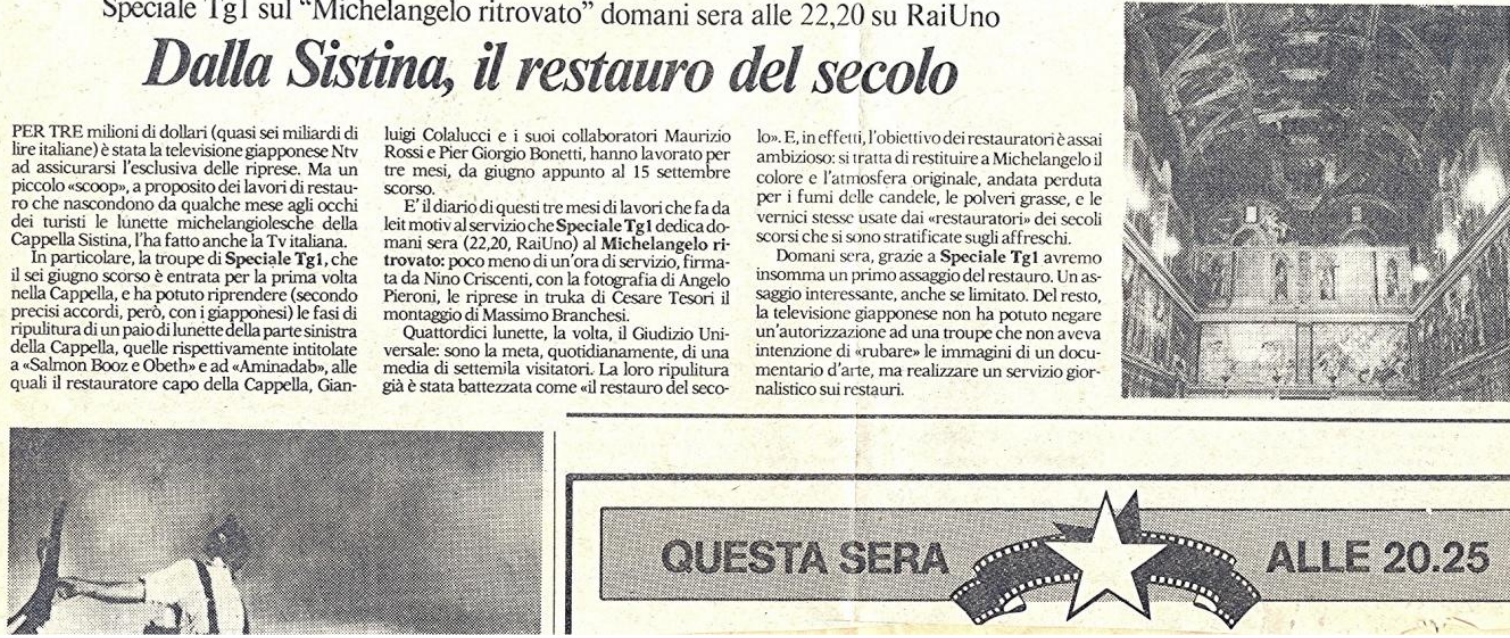

Quiaccanto, Scorciodella sotto, Cadice. un 'immagine delle alto, a sinistra, arilyn Monroo in caldom. All'attrice Retequattro special; adestra,
Liv Uilmann in specchion
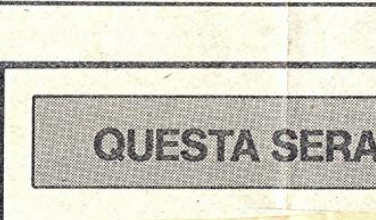

ALLE 20.25 


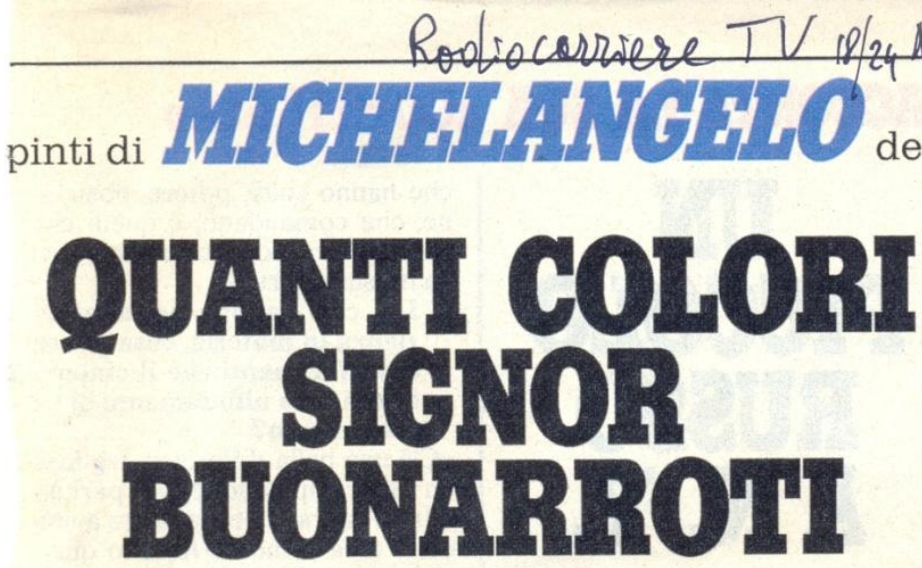

giapponese che si è aggiudicata, per tre milioni di dollari, l'esclusiva di tutte le immagini del restauro, in film e in fotografia, fino al 1995. Ogni giorno, insieme ai tre restauratori, salgono sul ponte a venti metri d'altezza i dieci giapponesi della troupe televisiva per riprendere, in una spettacolare sequenza, ogni istante del restauro. Una copia di tutto il materiale filmato è riservata ai Musei Vaticani che dispone così di una documentazione capillare di tutte le fasi importanti del lavoro.

Per qualche giorno è stato permesso anche a noi di salire sul ponte del restauro. Insieme con l'operatore Angelo Pieroni siamo arrivati nel giorno in cui Colalucci e i suoi hanno cominciato a pulire le due ultime lunette, quella denominata «Salmon, Booz e Obeth», con una donna con bambino a sinistra e un vecchio con bastone a destra, e quella di «Aminadab», con un giovane a sinistra e una ragaz-

\section{Alcune fasi del}

delicato lavoro di ripulitura condotto da Gianluigi

Colalucci (sotto e a sinistra) con Maurizio Rossi e Piergiorgio Bonetti

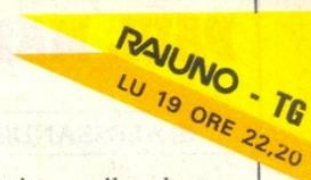

za che si pettina sulla destra. Nel corso dei giorni abbiamo visto emergere, dal grigio che li copriva, i rossi, i verdi, i gialli, i bagliori dei colori di Michelangelo che aspettavano solo di essere liberati da strati di sudiciume e dalle durissime vernici a base di colle animali passate nel ' 700 con la buona intenzione di proteggere gli affreschi e nascondere i dann delle infiltrazioni d'acqua, in realtà col risultato di renderli scuri $e$ opachi.

Abbiamo osservato come Colalucci, Bonetti e Rossi riescono a rimuovere fumi e colle, con qual strumenti, con quali prodotti. E siamo stati sorpresi dalla semplicità di un lavoro da grandi artigiani, che nasconde in realtà una profonda esperienza e lunghe ricerche ed è costantemente controllato dal Laboratorio di analisi dei Musei Vaticani. Siamo tornati più volte su quel ponte fino $\mathrm{a}$ vedere, nei giorni scorsi, le due lunette così come le aveva colorate Michelangelo.
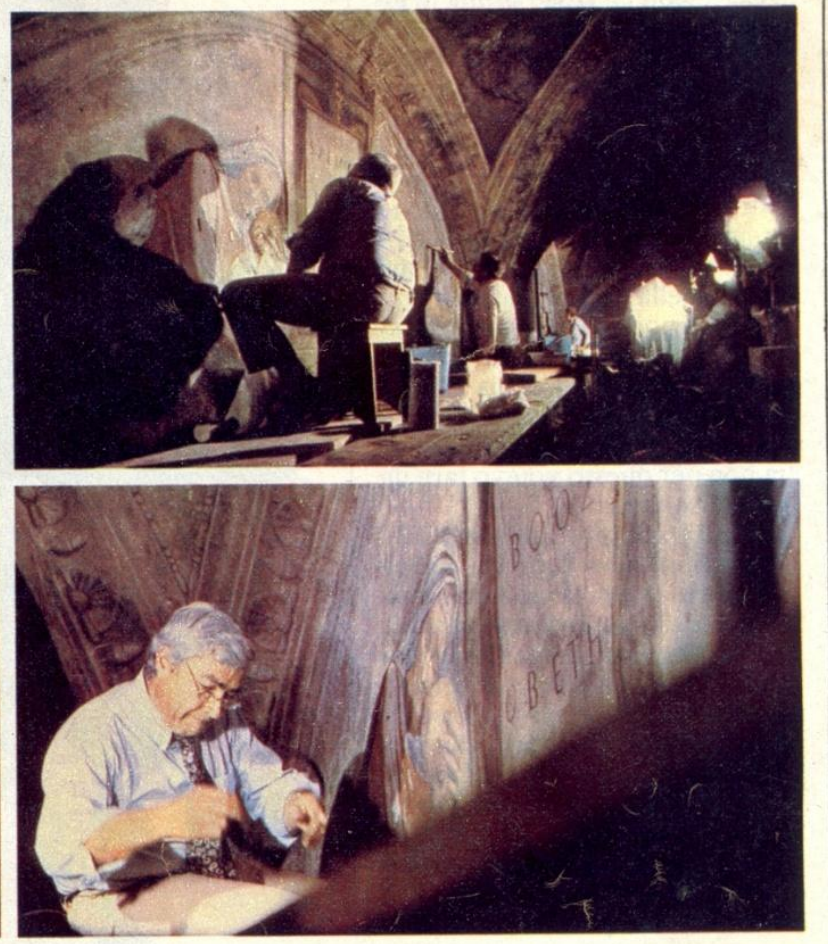

RadiocorriereTV 89 
ThA

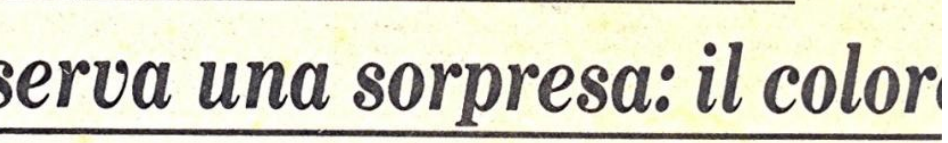

pubblico piu vasto oltre che stretto. E certo aggiunge fo scino all'operazione l'innocenza di coloro che, come Criscenti, si meravigliano che a eseguire il delicatissimo restauro siano pochissimi personaggi: tre esecutor sui ponti e tre analisti che raccolgono le gocce d'acqua che cadono man mano che la spugna umida passa sulle d'o ate al colore dovranno cora cadere prima che anstauro del gigantesco dipinto (in tutto 1200 metri quadrati) sia finalmente concluso?

Il restauro, in sé, non è difficile. Non lo è per due ragioni. Primo: perche il luogo scelto per gli affresch non soffre così a fondo dell'umidità e degli altri malanni drammatici che fin dall'inizio afflissero, mettiamo, "Ulima Cena" di Leonardo. Secondo: perche Michemerimen a diferenza dello preoccupava degli impasti si della loro capacità di durare nei secoli. Ed è certo curioso, nei secoli. Ed e certo curioso, di recente il Vasari o il Lomazzo, avere la conferma che il "colorista" Michelangelo non era da meno in fatto di ecniche e di soluzioni. Proprio lui che, nel 1509, mentre dipingeva la Sistina da un anno, scrisse al padre: $* \mathrm{El}$ avoro mio non va inanzi modo che a me ne paia meintare. E questa e la difficolta del lavoro, e anchor el non sionestone. E pur perdo

In pratica, quando gli esperti cominciarono gli ro, si accorsero subito che i danni safferti dai dipinti, a

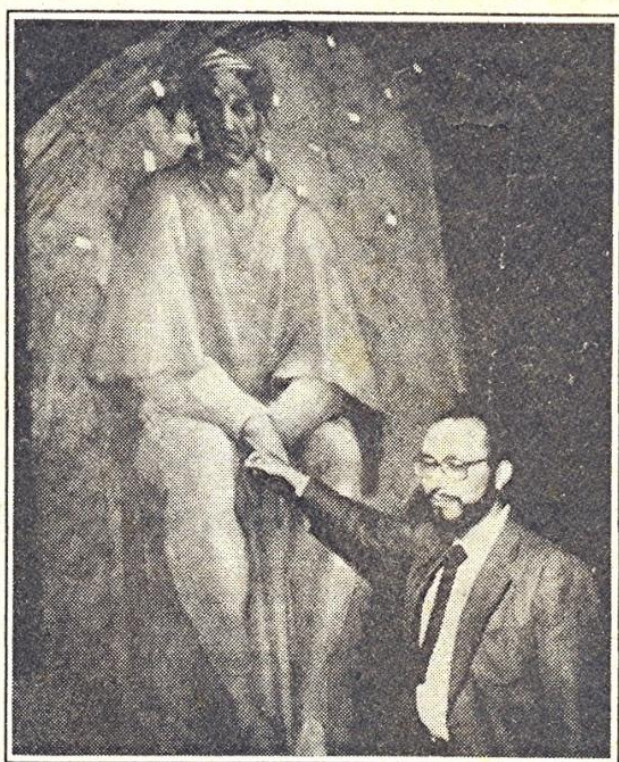

I professor Mancinelli, direttore del restauro della Cappella Sistina, indica la figura di Aminadab.

qualche infiltrazione d'ac- davvero prodigioso. Ma la qua e soprattutto le ridipin- novità vera e il grande prete date nei secoli, erano risol- gio di questo restauro, come vibili e bastava una energi- si è detto, è di restituire al ca, oculatissima pulitura completo un Michelangelo no nelle lunetornasse, alme- $\begin{aligned} & \text { colorista vividissimo e } \\ & \text { straordinario capace di cro- }\end{aligned}$ n risultato è stupefacente, matismi stridenti, traspaspecialmente se si bada alla renze inattese, manierismi e circostanza che Michelange- contrasti che creano movilo dipinse quelle lunette, ral- mento e spazio - uno spazio Cristo fino ad Abramo, quasi tro il quale possono - vivendi getto ratori, utilizzando anche il tomie. colore dell'intonaco con un Cade così la leggenda di un senso naturale della prospet- Michelangelo creatore di senso naturale della prospet- Michelangelo creatore di un genio, ma come scata e oppressa da mor conferma, allo stesso te che il vivacissimo "T Doni", dipinto da Mich gelo a partire dal 1504 , sarebbe rimasto senza si to nella sua tumultuosa riera di artista poliedri multiforme. E' un contri gia apprezzabile per $u$ stauro ancora agli inizj contributo che costring studiosi a rimeditare l'il percorso del genio mich

A questo punto la tras sione si chiude. Ma è gié porte la volta e poi il " $\mathrm{G}$ prema dell'artista sessal ne, ed è probabile che d: verranno altre sorprese, novità per gli storici d plica anche ben altre spera, siano risolte $c c$ stessa perizia dimostra nora. Una perizia che sarà indispensabile a mento in cui dovrannc toni" controriformisti scati o scalpellati per ra di censura già nel $\mathrm{Ci}$ cento e nel Seicento. mano potrà sciogliere colori duri stesi da cu cigni e da mani pesan questa la domanda o esaminato perni che primi lavori e ha vist noi il filmato $E$. "Certo il "Giudizio" è più gravi condizioni de nette, in talune parti ac tura rifatto, spaccato d qua e da altri malanni ra bisognerà, davvero, tare, probabilmente: $p$ che riguarda la tecnic restauro.

Fiorella Miner 
Paolo Portoghesi - Dibattiti e fi- cessione (giugno '83).

Cappella Sistina. Conclusa la prima fase dei restauri alle Lunette. Adesso tocca alla volta

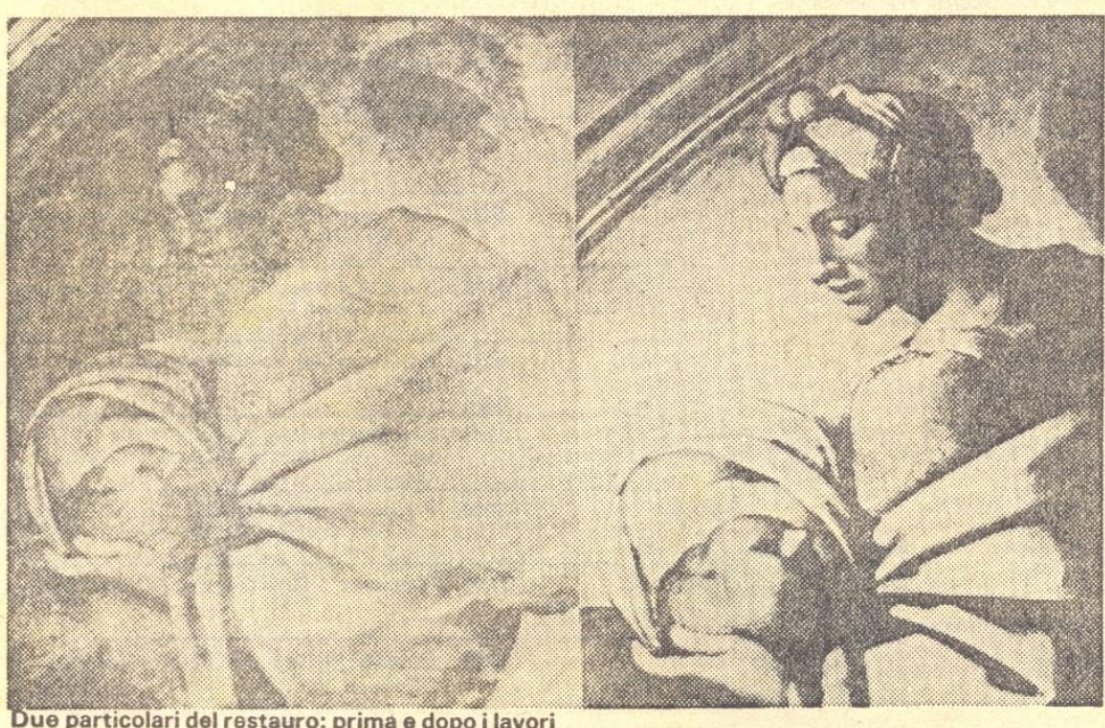

\section{Un incanto la «scoperta» dei colori di Michelangelo}

Arancio, verde smeraldo, rosa intenso. Colori brillanti e luminosi. Entrare nella Cappella $\mathrm{Si}$ stina e alzare gli occhi verso le Lunette di Michelangelo appena Lunette di Michelangelo appena finite di restaurare, dà un'emozione inattesa. Si era abituati alPatmosfera grigia e cupa delle tinte: -Si ma il colore sommesso e spento era dovuto a sovrapposizione di materie estrance, a un impasto di sudicio, di fumo di candele, di colle animali passate più volte sull'affresco nel corso dei secoli. E noi abbiamo deciso di pulire, anche se Michelangelo sembrerà diverso e se dovremo rivedere alcuni giudizi sulla sua pitturas, spiega Carlo Pietrange. pitturas, spicga Carlo Pietrangesei e Gallerie pontificie, presensei e Gallerie pontificie, presentando il risultato dei lavori di restauro condotti nel corso di quattro anni nelle 14 lunette affrescate da Michelangelo e raffiguranti gli antenati di Cristo, e del le 28 immagini di pontefici dipinti tra il 1481 e il 1483 dal Bot- ticelli, dal Perugino, dal Ghirandaio, dal Signorelli e dalle lo ro botteghe (604 metriquadri restanti, 30 mila ore di lavoro).

Con le lunette si è conclusa la prima delle tre fasi che, per complessivi dodici anni, vedranno restauratori vaticani al lavoro nella Cappella Sistina; ora toccherà alla volta e, fra quattro anni, alla parete di fondo dov'è dipinto il Giudizio Universale* Sulla testa degli osservatori, ieri. tutti calamitati dall'incanto della *scoperta* dei colori di Michelangelo incombeva la struttura acciaio progettata e costruita per eseguire $i$ lavori costruita per ponte (15 mila chili, a ponte (IS mila chili, a 15 metri da terra), permettera di procedero un quinto della superficie ro un quinto della superficie rimarrà nascosta alla vista dei visitatori, i quali potranno continuare ad accedere alla Cappella rendendosi conto *in diretta" del procedere del lavoro e dei risultati già ottenuti.
Sceso per un momento dalla sua piattaforma aerea dove ha già cominciato a lavorare sugli affreschi della volta, Gianluigi Colalucci, restauratore capo de Musei vaticani e autore, insieme con Maurizio Rossi e Piergiorgio Bonetti, del restauro risponde alle domande dei giornalisti, numerosissimi gli stranieri, spiega tecniche e materiali usati, illustra il grande lavoro compiuto dal gabinetto di ricerche scientifiche dei Musei a monte del restauro vero e proprio. E fa da speaker mentre passano su uno 位 uti su decine di migliaia di metri di pellicola girat dalla NTV giapponese, lo sponsor dei lavori) che lo ritraggono al lavoro: la spugna passa leggera sull'affresco e porta via l'impasto scuro: e spuntano $\mathrm{i}$ «colori di Michelangelo*.

L.Go.

un so 
Oggi serrata-bis di mezza giornata (24 of in alcune città) per protestare contro la riform:

Negozi chiusi

un'altra volta

Ma supermercati aperti

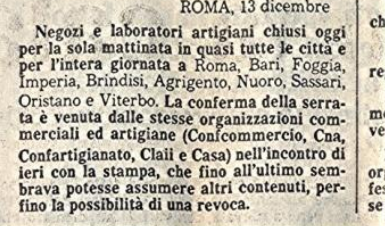

tutti gli esercizi rimarranno però

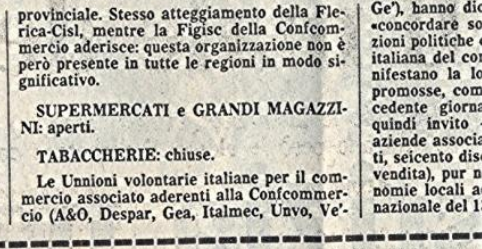

Rivoluzionario restauro della Cappella Sistina: sotto

crosta di sporco emerge un pittore insospettato Michelangelo, questo sconosciuto

Quattro anni di lavoro (pagato dai giapponesi) hanno messo in evidenza gli smaglianti colori di 14 lunette
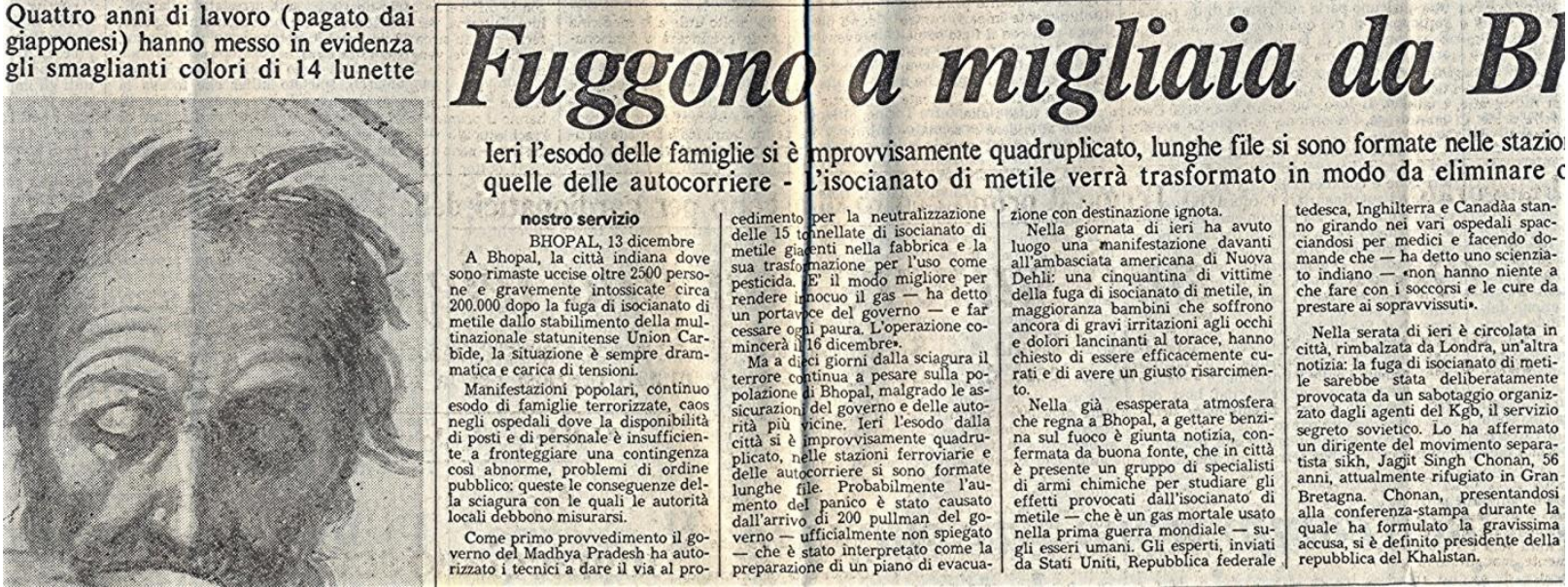

Ieri l'esodo delle famiglie si è mprovvisamente quadruplicato, lunghe file si sono formate nelle stazio quelle delle autocorriere - fisocianato di metile verrà trasformato in modo da eliminare c

nostro servizio

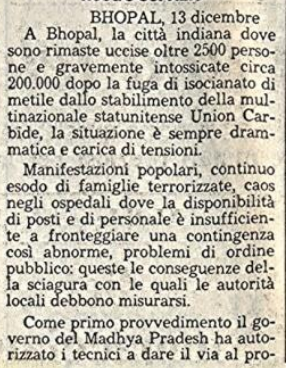

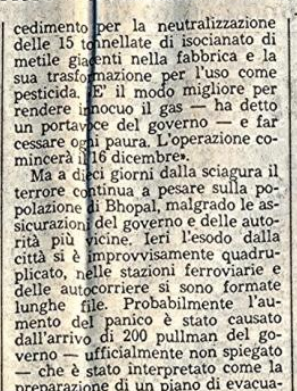

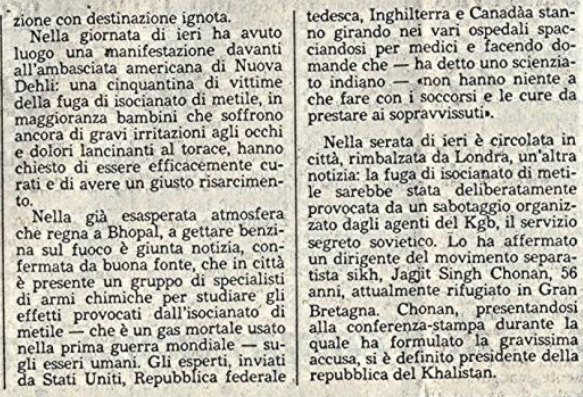




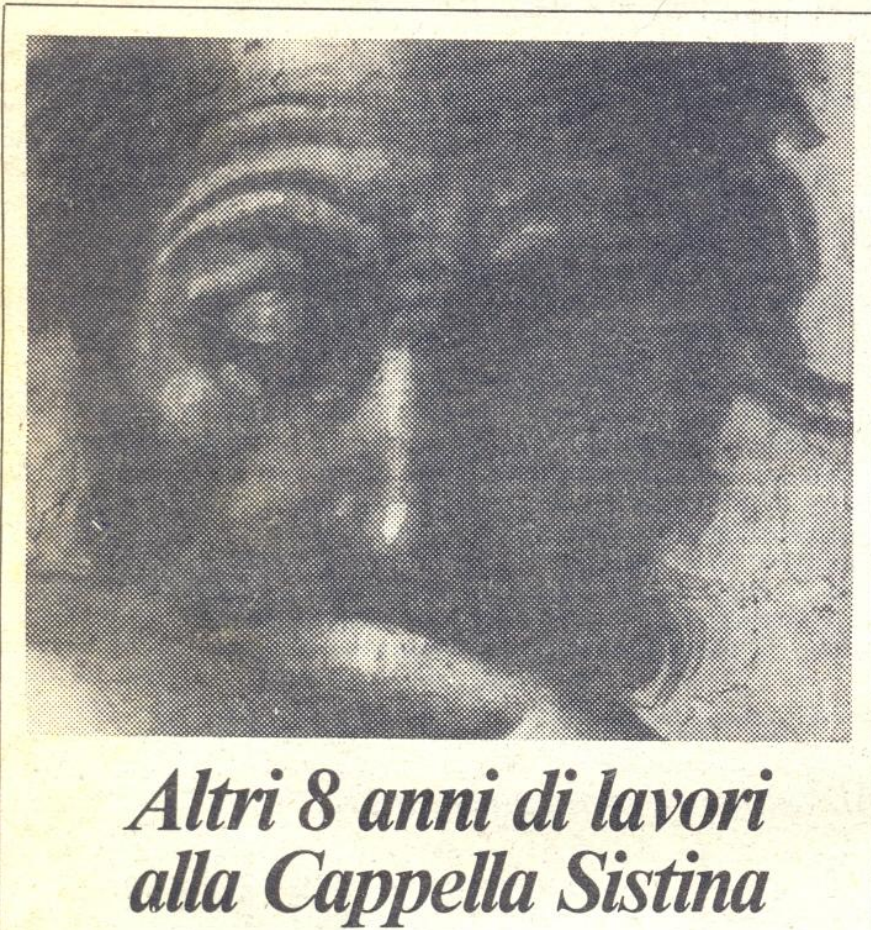

DAI SEICENTO metri quadrati restaurati nella Cappella Sistina con le trentamila e più ore di lavoro degli ultimi quattro anni è emerso anche un autoritratto di Michelangelo (nella foto). Scoperto in una delle 14 lunette dipinte dall'artista, a giudicare dal nastro, che il Buonarroti non aveva certo così regolare, si tratta, dicono gli esperti, di una visione idealizzata sotto le spoglie di AzorSadoch, nella serie dei profeti. Il restauro finanziato dalla Nippon Television Network di Tokio (che si è così assicurata i diritti esclusi-

\section{Il caos ieri si è estes Sul Lung}

E LUNGHE file di automobiL li paralizzano il Lungotevere. Subito dopo aver superato un discreto martedi di assestamento, la zona di Ponte Umberto e piazzale della Libertà ha ritrovato un mercoledi di grande caos. Perfino Corso Vittorio che prima di ieri non era stato coinvolto nella congestione è rimasto intasato dalle 9 di mattina alle sette e mezzo di sera. Su Corso Rinascimento, invece, neogioiellino varato dall'assessorato capitolino a traffico, la corsia preferenziale si modella sui diritti dei pedoni e, come ripetevano ieri i vigili urba$\mathrm{ni}$, «funziona bene perchè non $\mathrm{ci}$ passa quasi nessuno...n.

I guai della circolazione, a due settimane da Natale sono cominciati alle sette di mattina: chi aveva deciso di raggiungere gli uffici, le scuole, i laboratori, i negozi con la macchina è rimasto intrappolato sul Lungotevere per quasi due ore insieme a bus e taxi. E il punto contagiato è sempre il solito: Ponte Umberto (a senso unico), piazzale della Libertà, Tor Di Nona fino a Trastevere. Mezzi pubblici e veicoli privati restano stretti in una morsa. «Bisogna tener presente», dicono in

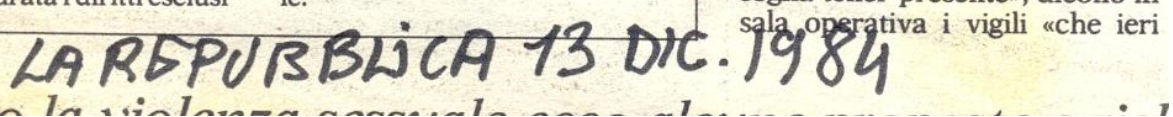


Conclusa la prima fase di lavoro i tecnici passano alla ripulitura della vòlta

\section{Un film racconta il restauro della Sistina Com'era il ponteggio usato da Michelangelo}

Per la prima volta il «trattamento» di un'opera d'arte viene documentato in presa diretta - L'artista impiegava tre giorni per dipingere una lunetta - Uno «schizzo» consente un'ipotesi sul ponte

Ignorava tutto ciò che ri-
uarda il colores (De Piles varda il colore (De Piles, nza effetto, il colore tira mattone e al grigion (De alande, 1768). SUn ammasconfuso di figure senz'o ine nè colores (Bergeret de rancourt, 1773). «Non sapeimitare il colorito della aturas (Della Valle, 1791. sembrava fra tutti il dise ator piu forte, ma il colo295). guire fino a poche più renti, e si riferisce piomuue agli affreschi di Michengelo nella Cappella Sistia. Come dimostrano i re auri in corso, a cura de ase i ad avere capito fu Wilon, nel 1893: «Gli affresch no stati criticati per l'intozione sommessa. Questo a quando furono dipint ano vigorosi e brillanti ulite, liberate dai fumi di ndele, dalla polvere, dagl rati di sbeveronis, compodi colle animali e di assi, le lunette della Sisthanno mostrato lo splen ore del propri colori.

La prima fase del restauaurata quattro anni, orsi, durante un incontro Vrs1, durante un incontro
Vaticano, dal direttore i Monumenti e Musei Ponfici, Carlo Pietrangeli, dal rettore dei lavori, Fabrizio ancinelli, e dal Capo re auratore dei Musei Vatica4, Gianluigi Colalucci. Sono ate anche annunciate ce prossime lasi, che dure pulitura della vòlta e poi restauro della parete su i è affrescato il Giudizio niversale. Di tutto cì̀, orriere della Sera si è ocpato, anche con un artico di Cesare Brandi, mercodì scorso. Tuttavia, almen 1 punto di vista tecnico, eso. In primo luogo, si de-

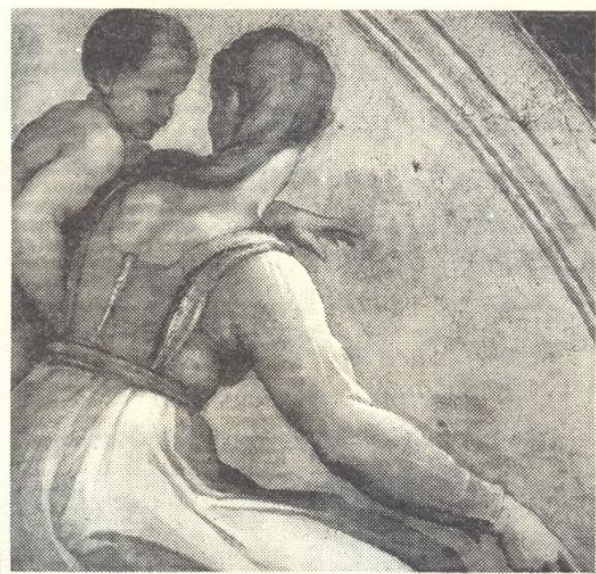

Michelangelo: Lunetta nella Cappella Sistina

ve fare cenno dell'canteprimax alla quale è stato possicontro in Vaticano: una mezz'ora circa di spezzoni, ne cinematografica completa che la NTV, la Nippon television network corperation di Tokyo, ha girato sull integuito. L NTV corresponsione di un gruo compenso, si è assicurata i diritti esclusivi di riproduzione degli affreschi restaurati, per un periodo di tre anni dalla fine di ciascuna fase di lavoro. Ci sono sempre stati documenti dedicati ai restauri: le tre ento i cataloghi, le immagini fotografiche Con la Sistina però si assiste forse per la prima volta a un documento canimatos che racconta il restauro nel momento stesso dell esecuzione, minuto per minuto, secondo per secon- ralmente, senza possibilità Sull'affresco, il restauratore Sull affresco, il restauratore
stende con gesti lenti, ierati1 cui nome di ebattaglia» AB57. Il solvente resta depositato soltanto per tre minuti, poi viene tirato via con una spugna imbevuta di acqua distillata e, rimosso. trascina con se la materia ha di sporcizia che per tan to tempo ha ricoperto i colori. Là dove passa la spugna, disegnando sulla superficie innumerevoli forme geome triche, circoli, rettangoli rombi e trapezi, appaiono allimprovviso altrettante aureole di colori brillanti, purnisiode altro: un lavoro mo, da ripetere fra le quattro pareti di casa. $\mathrm{E}$ li stanno il limite e al tempo stesso la bellezza segreta de film: il quale non ci racconta nulla di tutto il lunghisci, una miscela trasparente quasi domestico, semplicissi- di analisi, di ricerche, di | alto a sinistra, uno schizzo studi scientifici, che hanno variamente interpretato: vi preceduto lenti giri delle appare un personaggio in mani armate di spugna. La piedi su una struttura ad arsono nel fatto che esso cor- $\begin{aligned} & \text { co, gradinata, che termina ina } \\ & \text { una piaforma su cui gia- }\end{aligned}$ risponde veramente all'ani- ce una figura accosciata. La ma giapponese: le sue imma- figura in piedi ha il braccio gini ci descrivono la parte destro steso in un gesto larmimetica del rapporto con go, come di chi stesse dipin-

$\begin{array}{ll}\text { lopera d'arte, hanno tutto } & \text { gendo. E sulla sua testa pas- } \\ \text { lo stile calligrafico dei capo- } & \text { sano una serie di linee cur- } \\ \text { ve, come di una volta }\end{array}$ lavori calligrafico dei capoche nascono da secoli nell' sola dei vulcani e dei fior pallidi.

Prima di passare sull'affresco un nuovo strato di miscela solvente, i restauratori attendono ventiquattro ore. Un'eternita se si pensa che Michelangelo, com'e stato accertato, dipingeva ni: uno per ciascun gruppo ni: uno per ciascun grupp zione centrale. E dipingeva direttamente sull'intonaco fresco, senza spolvero n cartoni, servendosi di rapid appunti. Nelle prime lunette eseguite, il disegno e il colore erano molto più studiati. Poi, per assecondare la fretta del Papa, il colore si sempre piu sottile, lintonadiventa granuloso con effet$\mathrm{ti}$ di rifrazione luminos completamente diversi. I materie usate per i color sono soprattutto terre, oss di, che dimostrano la grand capacità di Michelangelo ne1o scegliere ciò che garant. sce la solidità, la durata. Poca malachite, niente lapi-
slazzuli.

Durante i lavori di resta ti in luce $i$ fori, che eran chiusi con muratura usati per la costruzione del ponte su cui Michelangelo affrescò la volta e le lunette. Il tipo di ponteggio usato è sempre stato un argomento di dibattito fra gli studiosi. Agli Uffizi è conservato uno studio che presenta, nell'angolo in
Dice Fabrizio Mancinelli: cIo credo che sia qui raffigurata la sezione di metà de dipingere la vollta della $\mathrm{Si}$. stina. Le informazioni fornite dal disegno e quelle date dal restauro consentono alcune ipotesi precise. L'elemento base del ponte era costituito da una struttura gradinata, coronata da una piattaforma e sostenuta da tanti, entrambi realizzat probabilmente come una priata. Nello schizzo, il sistema di capriate non com pare; perché il disegno serviva, probabilmente, solo a indicare al epontarolos che la struttura gradinata doveva seguire landamento della volta, cosi da consentire il stesso non doveva essere troppo accostata alla vòlta perché altrimenti il pittore si sarebbe trovato nelle condizioni di disagio della figura in piedi o di quella acco-

Calcolando il numero delle finestre, si pensa che $\mathrm{Mi}$ chelangelo abbia fatto co struire sei strutture gradina te. Con questo sistemas, direalizzare il suo immenso affresco. Con la piattaforma superiore dipinse le storie le immagini al centro della volta, con le gradinate laterali diede vita alle Sibille ai Profetis.

Pietro Lanzara superficie ogni punto delia 
LEUROPEO 22 DIC. 1984

\section{Cultura}

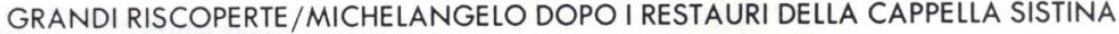 Ne dipinse di tutti i colori}

\| primo «spolveratore» ufficiale fu il domestico di Buonarroti. Da allora la Sistina fu più volte aggiustata e imbellettata. Adesso, a finanziare il più grande

restauro di tutti i tempi sono arrivati i giapponesi. E si vedono cose mai viste prima

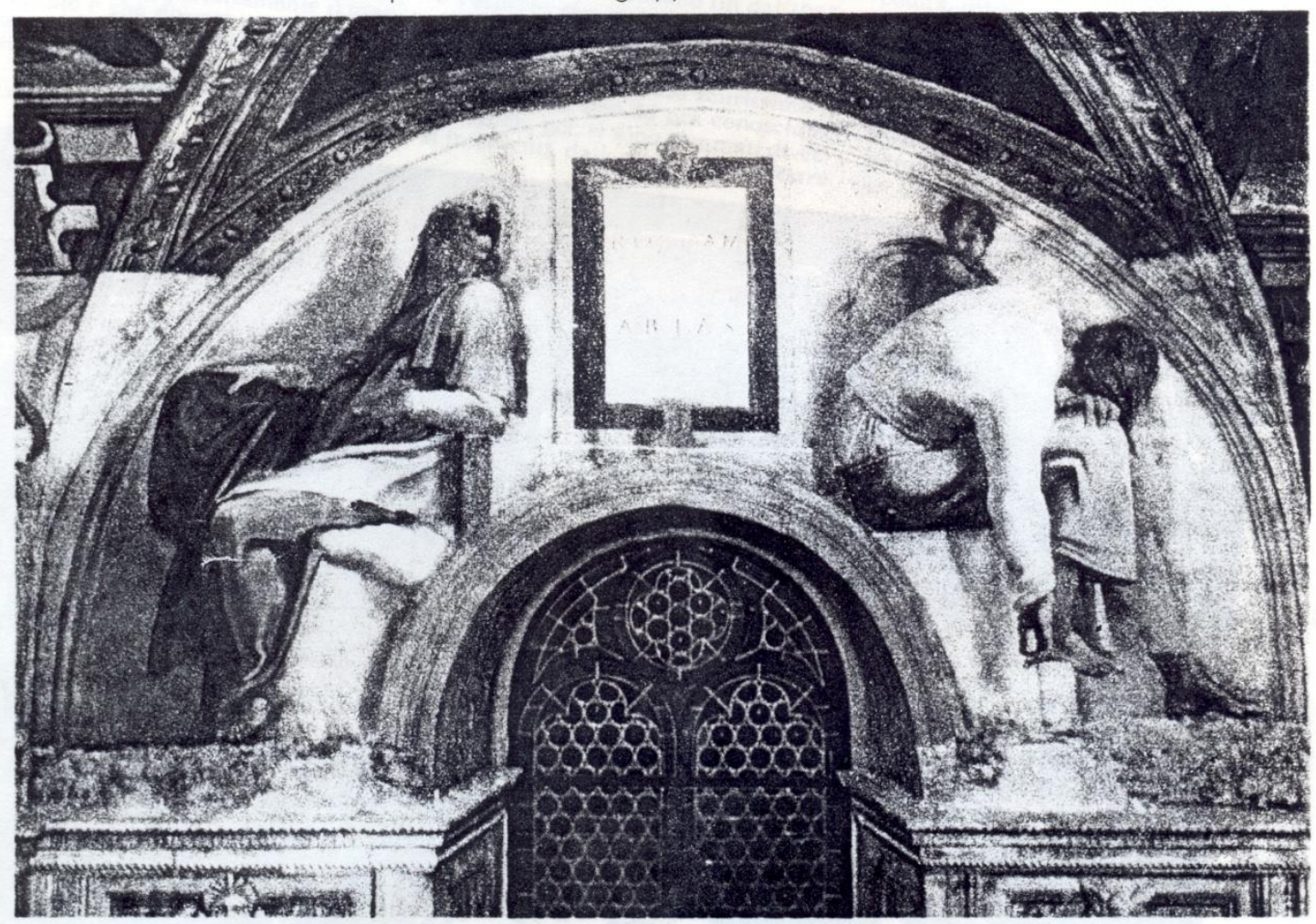

La lunetta «Roboam Abias» della Cappella Sistina. Ecco come appare dopo i lunghi, sofisticatissimi lavori di restauro,

\section{di Franco Miracco}

Stiamo vivendo quel decennio in $S$ cui sarà possibile ancora vedere per l'ultima volta assieme, in un incredibile accostamento, il vecchio e il nuovo Michelangelo, durerà fino al 1992 tutto il restauro della Cappella Sistina, iniziato nel 1980. Il lavoro è ancora lungo: mentre sono appena finiti i lavori per il restauro degli affreschi poco noti delle lunette stanno per avere inizio i restauri della volta. Per vedere i ponteggi intorno al grande Giudizio Universale bisognerà, invece, aspettare il 1988.
Cosi piano piano, negli anni Novanta, Michelangelo ci sarà restituito tanto autentico, quanto a noi inedito e sconosciuto. "Ora a restauro delle 14 lunette appena completato possiamo finalmente dire di trovarci di fronte a una grande scoperta. Le lunette, infatti, erano sporche e di fatto illeggibili: d'ora in poi, non potremo più capire Michelangelo avendo nella mente la "vecchia Sistina"”.

Comincia così, conversando con $\mathrm{Fa}$ brizio Mancinelli, storico dell'arte dei Musei Vaticani e responsabile dei lavori di restauro della Cappella, questo primo e inedito viaggio alla riscoperta del "vero" Michelangelo.
Ma facciamo un passo indietro: l'impresa di Michelangelo Buonarroti cominciò il 10 maggio del 1508 e fu portata a termine il 31 ottobre 1512 . Durante quest'arco di tempo furono affrescate le lunette e la volta. Solo 23 anni dopo giunse il momento del Giu. dizio Universale. La fatica michelan. giolesca conobbe fasi alterne di frenetica attività e di soste forzate, dovute a problemi tecnici, ad interruzioni nei pagamenti, ad assenze del papa a fa stidi causati dallo stesso, che poi stidi causati dallo stesso, che poi era natura veemente ed im. pazienten, troppo frettoloso per rispettare i tempi e le necessità dell'artista e, quindi, già con il naso per aria, 


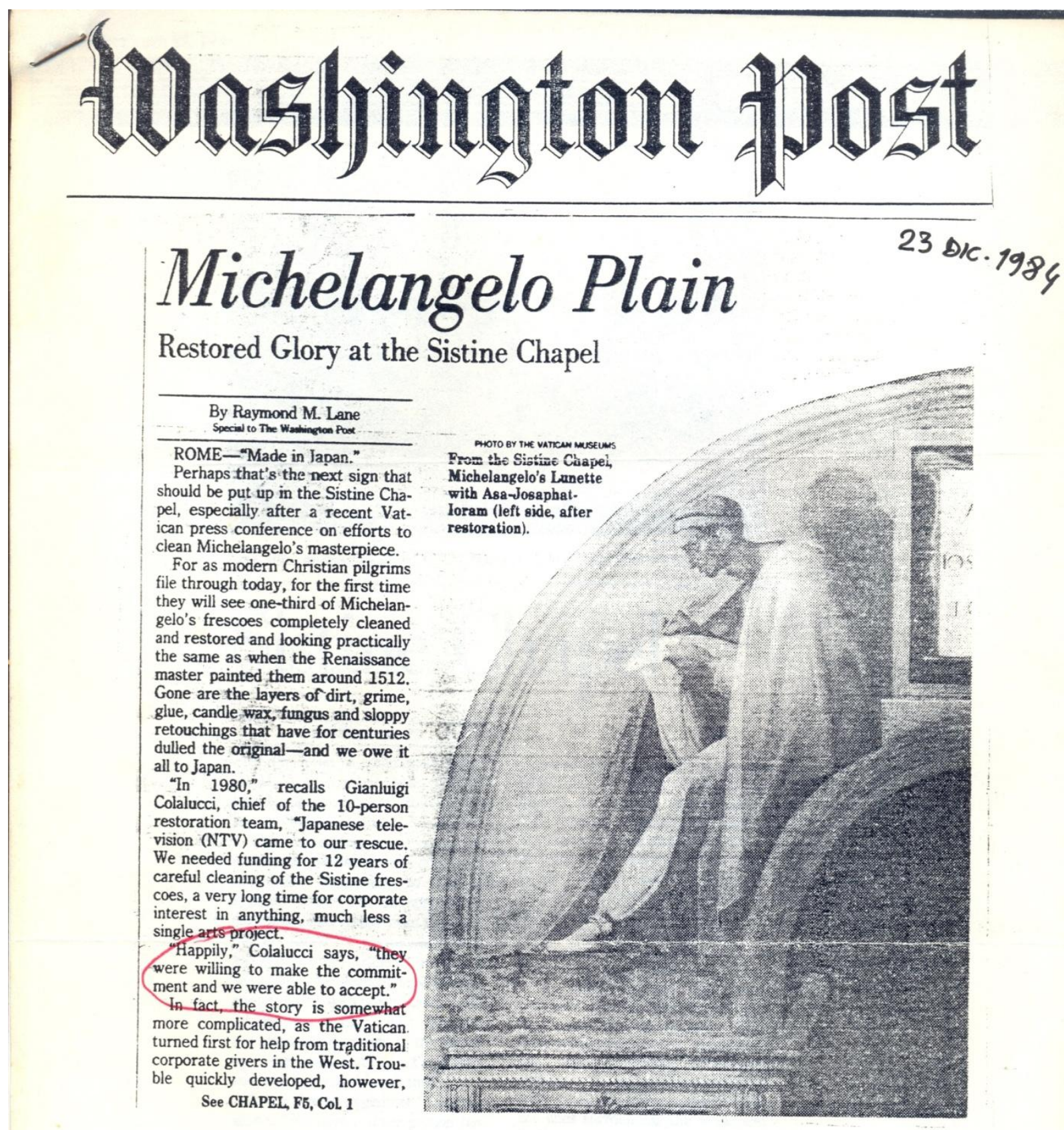




\section{Art}

\section{A New Glimpse of Michelangelo}

\section{Restoration of the Sistine Chapel proceeds—with stunning results}

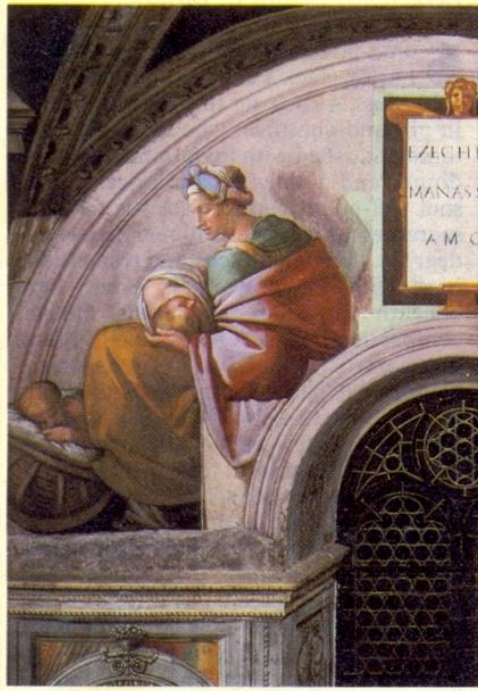

$t$ was nothing short of a revelation. Five years ago, Gianluigi Colalucci, director of the Vatican Museum's Painting Restoration Laboratory, applied a dollop of a chemical cleaning solution to a postagestamp-size portion of Michelangelo's fresco of Eleazar over one of the arched windows in the Sistine Chapel. There, beneath five centuries of grime from smoky candles, incense, glue and assorted retouchings, he found color-fresh, radiant, vivid color. It was, says Colalucci, "like opening a window on another world,"

After the dramatic impact of that first experiment, Colalucci, 54, launched a twelve-year, three-stage program, financed in part by a \$3 million grant from the Nippon Television Network of Japan. The goal: to rejuvenate all of Michelangelo's frescoes in the Sistine Chapel. After four years of painstaking work, the first stage has been finished, and the world of Michelangelo that it reveals is dazzling. The restoration has not only transformed the chapel but also spurred a reconsideration of long-cherished conceptions about its creator. It reveals a Michelangelo who, contrary to his traditional depiction as a shadowy, tenebrous painter, was a bold and brilliant colorist.

The first phase of the project, covering the upper part of the chapel's three walls, includes the restoration of 14 "lunettes," crescent-shaped murals above the windows. The before-and-after contrast is striking: a small square in one lunette has been left unrestored and appears, by comparison, to be pitch black. Another area,

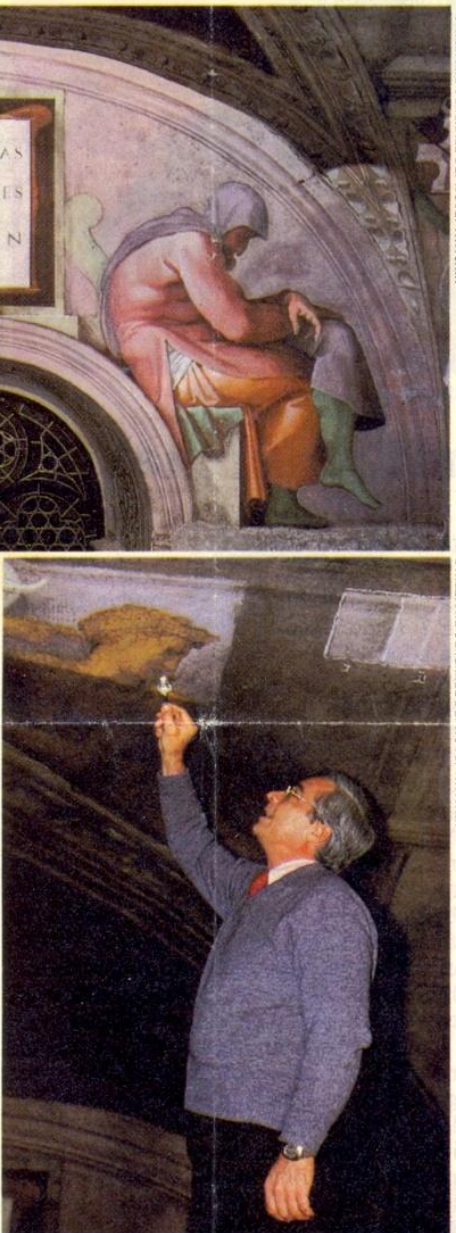

A restored fresco in the Sistine Chapel, above: Head Restorer Colalucci demonstrates his deft touch

showing the murky, undefined figure of Naasson, an ancient sibyl, with only one hand and dark hair clearly visible, became a sharp aquiline profile of a woman, her hair bound by a bright blue filet, with a previously obscured earring dangling from her ear. The second stage of what is being ury will be devoted to the ceiling. It has already begun and is scheduled to take four more years. The last four years, appropriately, will be dedicated to the matchless Last Judgment on the wall behind the altar. So far, according to Professor Giulio Argan, a noted ar historian and a former mayor of Rome, "the results are exceptional and are deserving of the highest praise."

The actual restoration is performed by Colalucci, with the help of Piergiorgio Bonetti and Maurizio Rossi, both of whom have been restoring Vatican paintings for 30 years. The threesome works on a mobile, 20-ft.-wide steel bridge, modeled on the scaffolding used by Michelangelo, $49 \mathrm{ft}$. above the chapel floor. From their perch atop the bridge, they are the first men to glimpse the work of the master in its near original condition. The elixir that magically wipes away the detritus of the ages is a viscous liquid called AB57. Developed more than a decade ago by Rome's Central Institute for Restoration, it consists of water, bicarbonate of ammonia, bicarbonate of soda, desogen and methyl cellulose.

The restorers carefully apply the solution with a camel's hair brush to a handkerchief-size portion of the fresco at a time. After about three minutes, the liquid is gently wiped off with a natural sponge and distilled water. AB-57 removes only dirt, not paint, but if left on too long, it could harm the natural colors. Colalucci discovered that except for some leaking of salts like calcium carbonate through the plaster, the frescoes were in remarkably good condition. After each stage of the cleaning, a microscopic survey is made to determine whether further scrubbing is necessary. Typically, three cleanings are made of each fresco.

The restoration has not only disclosed the brilliance of Michelangelo's original colors, it has also shed light on his methods. The artist often complained that he was not really a painter but a sculptor; still, he worked with astonishing speed and deftness, painting each of the last three of the 11 -ft.-high lunettes in a day. The restorers have found hairs from Michelangelo's brush, which he apparently did not have time to remove, imbedded in the plaster, Unlike his work on the Sistine ceiling, the wall frescoes were painted directly on the damp plaster, without benefit of full-size drawings. The layer of color is so thin, according to Curator Fabrizio Mancinelli, that any sketches would show through.

So far, the restorers have encountered few problems, but they acknowledge that the most difficult stage will be the final one, The Last Judgmen pt touchups of the work by earlier restorers will have to be removed, and because tapers once burned on the wall above the altar, the painting is particularly sooty. If the program lives up to expectations, the great Sistine vault will eventually bea true heaven of color, a shimmering blow to the senses. For hundreds of years, it was considered blasphemous to tamper with Michelangelo's masterpiece. Colalucci's restoration clearly shows that it would have been a sacrilege not to - By Richard Stengel. Reported by Walter Galling/Rome 


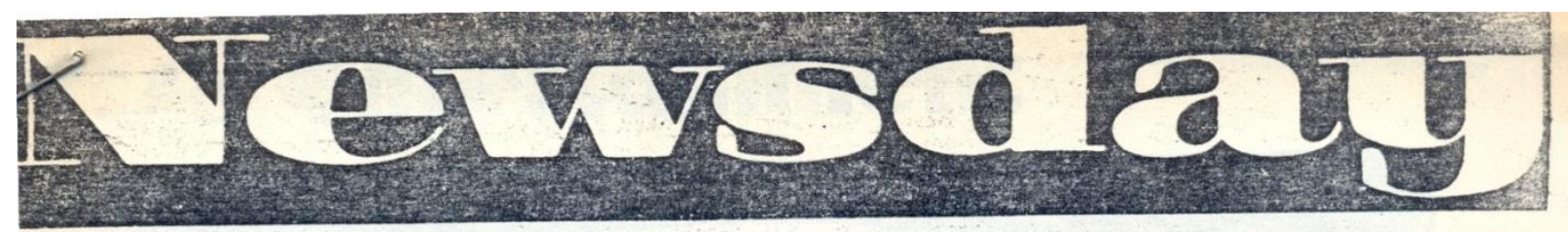

E LONG ISLAND NEWSPAPER O AHURSDAY, DEC. 27,1984030 CHNIS O SUFFOIIK

\section{Yistine renaissance 'made in Japan}

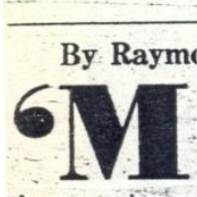

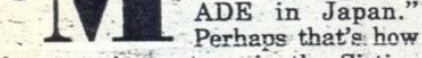
Chapel should read. As visitors file through the chapel during the holidays this year, they will see some Michelangelo frescoes, that have been cleaned for the first time. One-third of Michelangelo's frescoes were completely cleaned and restored; they look almost the same as when the Renaissance master painted them around 1512. Gone are the layers of dirt, grime, glue, candle wax, fungus, and sloppy retouchings that have for centuries dulled the originals.

And we owe it all to a Japanese television station.

"In 1980," said Gianluigi Colalucci, chief restorer of the Vatican's 10-person project team, "Japanese television came to our rescue. We needed funding for 12 years of careful cleaning and restoration of the Sistine frescoes, a very long time for corporate interest in anything, much less a single arts pro ject. Happily they were willing to make the commitment, and we were able to accept."

In fact, the story is somewhat more complicated, since the Vatican turned first for help to traditional western corporate givers. Trouble western corporate givers. Trouble issue of commercial rights. Could they advertise beer, tires or tennis balls using the Sistine Chapel, they wanted to know.

The answer was no, of course, so another 30 companies were considered, according to Vatican sources. American network television was not interested. The Japanese TV company made an offer the Vatican couldn't refuse: It would spend $\$ 3$ million on the restoration project, and film the cleaning process from start to finish with newly created cold lighting that wouldn't hurt the paint; the station

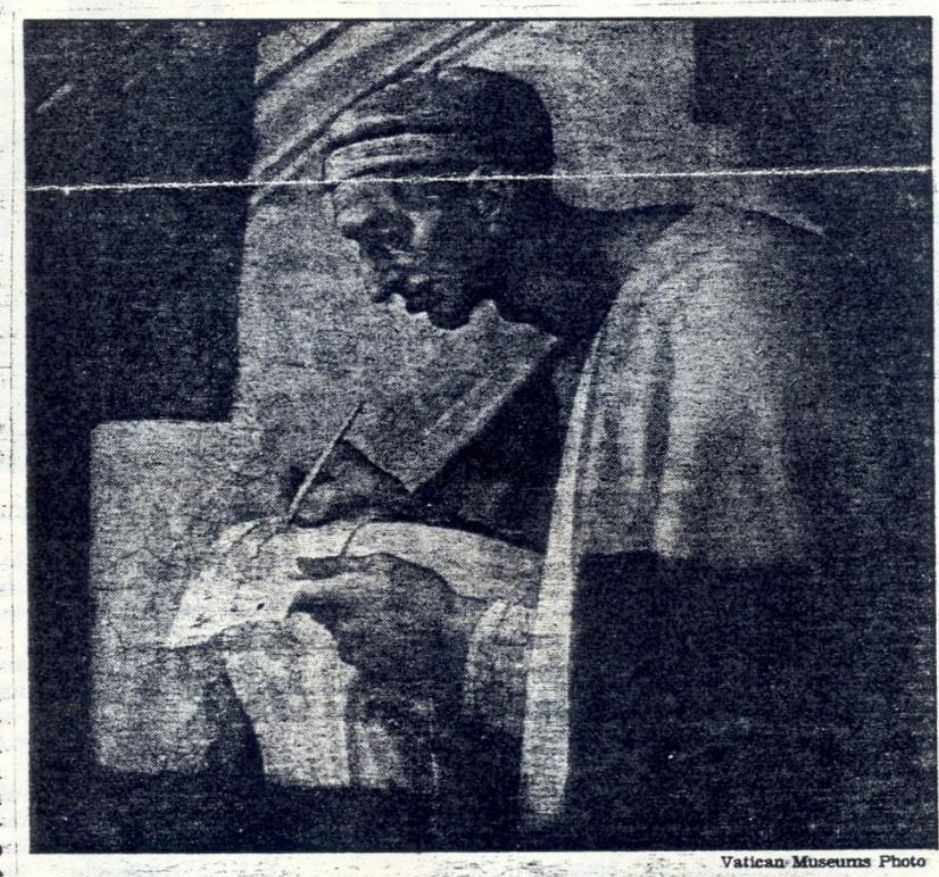

Michelangelo's Sistine Chapel fresco of Asa Josaphat loram during cleaning

would relinquish the copyright to the film after three years:

"It's a nice arrangement," Colalucci sard. "We have a three-person Japanese film crew on the scaffolding with us from 9 to 1 every day, and as.we clean they record the process."

The exercise is by no means empty, either, as the restorers soon discovered cleaning the lunettes, the lower frescoes depicting the 40 generations from Adam to Christ's birth. They learned that Michelangelo painted very quickly and without stencils or sketches of his subjects.

"It fairly boggles the mind," Colalucci said, "to think that he could do a fresco the size of say, a Chevrolet station wagon in a single painting ses- sion, with complete fidelity to all the colors, subject matter and lines surrounding the work. Why, that's amazhis artistic skills."

The Vatican also has unveiled the next part of the cleanuptoperation: next part of the ceiling itself, with a lightweight metal bridge for rect copy of the wooden bridge $\mathrm{Mi}$ chelangelo invented for the job, even using the same holes sunk into the walls in 1509 to anchor the contraption. With water, electricity and a portable toilet, however, it's a far cry from the wall-to-wail basketball court-sized planking Michelangelo laid down for the original three-year ing, and deepens our appreciation of with a lightweight metal bridge for
the restorers to stand on. It's a di- 
Dopo quattro anni di lavoro ripulite le quattordici lunette. Ora prosegue il restauro della Cappella Sistina

\section{Alla ricerca di una Volta perduta}

E sotto lo sporco sco Michelangelo dai grandi colori

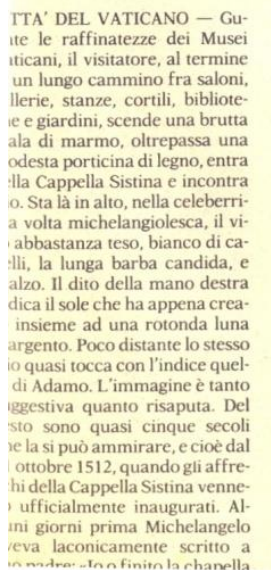

La storia di centinaia di metri affrescati controvoglia, fra litigi, incomprensioni; litigi, incomprensioni;
protagonisti il grande
pittore, papi, artisti pittore, papi, artisti invidiosi, storici d'arte.

Ouando censurarono

il Giudizio universale

di ALFREDO DONDI
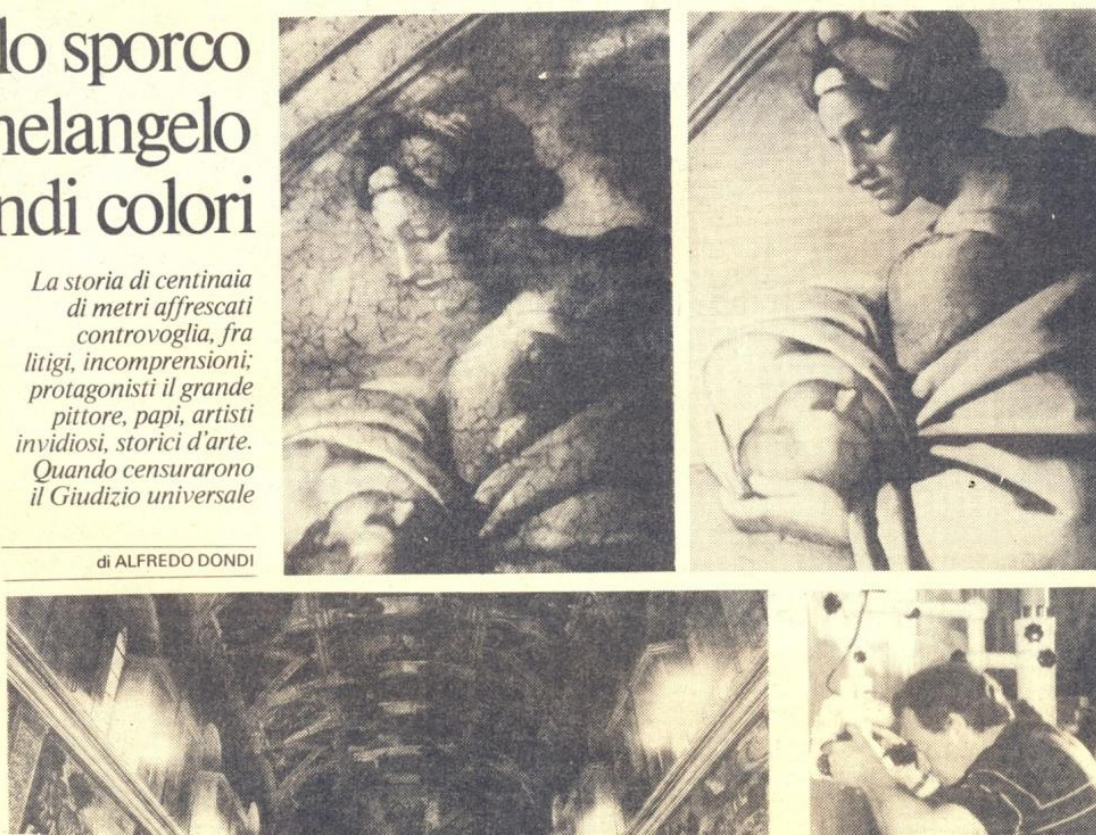

Particolare diun
lunetta prima e

dopo il restauro, di
fiancoe, sotto, da

sinistra, uno

Cappella Sisting

Cappella Sistina.
con le lunette e le
grande votta e eur

grande volta

tecnico

restaur
lavoro

cile. Per delle ragioni tecniche ed ambientali è molto più difficile ragioni tecniche si riferiscono al fatto che l'affresco si esegue su una superficie appositamente preparata con calcina, sabbia, intonaco e malta ancora umida (fresca, appanto) eicolori si in sti induriscono. Ovvie sono le ra. gioni ambientali Un quadro se esposto alle cattiverie del tempo lo si sposta in un luogo sicuro. Un affresco quasi mai, soprattutto se di grandi dimensioni come quelli della Cappella Sistina. Liè nato, 1 i deve rimanere nei secoli, magari a subire Tonta del fumo e della polvere $\mathrm{c}$ ancor pia quella delle lettanti i quali, nel passato, hanno ricoperto i dipinti con colle animali nel tentativo di rendere impermeabili le pitture cambiando ne cosi le tonalità.

Una scoperta 
tu per tu con la persona che non ha avuto remore ad affrontare uno dei restauri più impegnativi e rischiosi

\section{"Ilo e Michelangelo", tutti i segreti Hel restauratore della Sistina}

ome Gianluigi Colalucci è arrivato al capolavoro cinquecentesco - Le anomalie di un lavoro che non sembrava possibile sli affreschi originali erano ben diversi da quelli che eravamo abituati ad ammiraren - Le polemiche ir una presunta alterazione: "Si tratta di fatti, non di idee" - Oggi è impegnato al Carmine di Padova
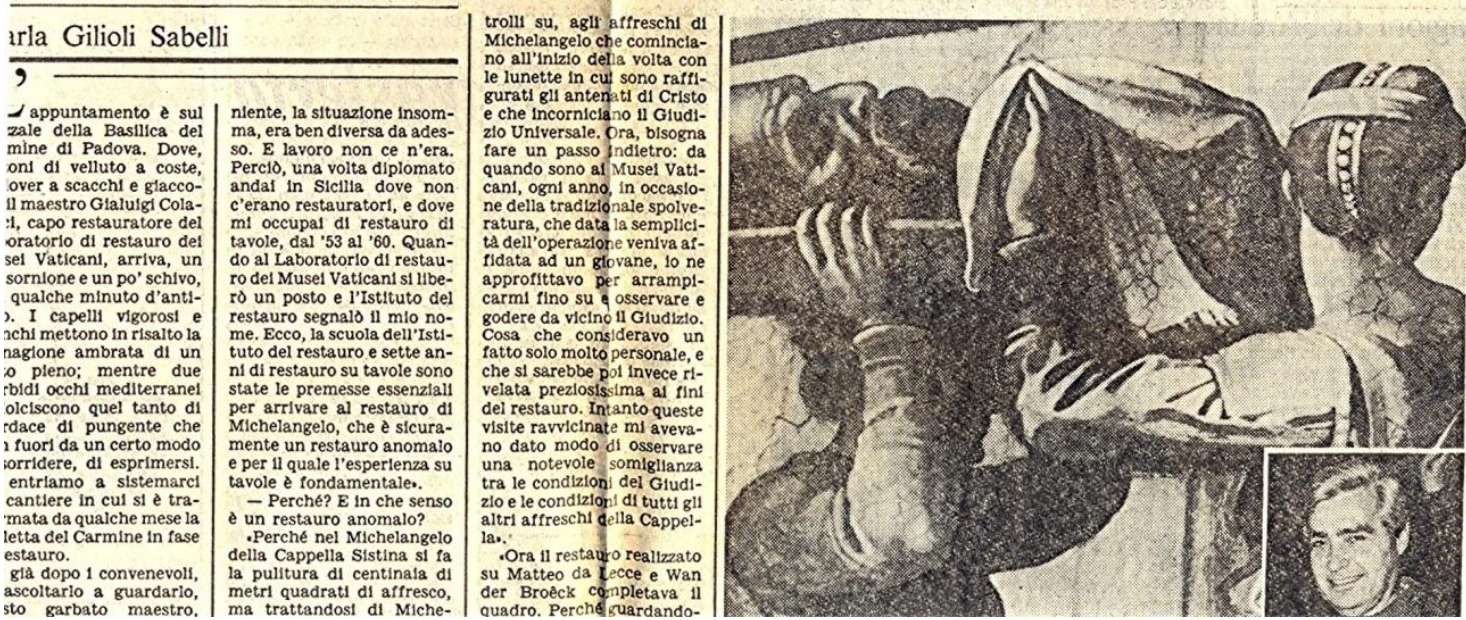

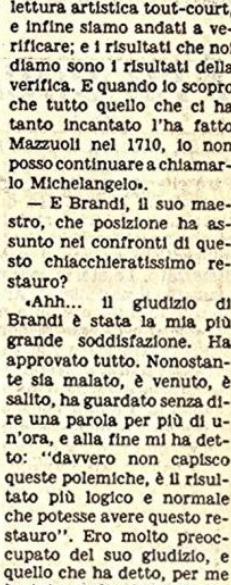




\section{Gazzetta di Parma di venerdí 16/1/87

GRONACA DELLA CITTA

DOMANI UN DIBATTITO AL CENTRO CAVAGNARI

Restauri della Cappella Sistina: una vicenda che fa discutere

Ne parleranno il restauratore prof. Colalucci, il regista Criscenti e il prof. Quintavalle L'iniziativa della Cassa di risparmio alle 16,30

Si dice, ed è probabilmente vero, che il restauro gelo nello Cappella Sistin gelo nella Cappella Sistina Non servono parole per dire come questi dipinti siano forse il massimo vertice d'arte raggiunto dall'uomo: com'è stato scritto, misurando qui Michelangelo addirittura la propria creativita con quella di Dio, le cui fatiche per la Creazione del mondo gli affreschi sistini appunto illustrano.

Molte parole e molte immagini durante i lavori servono invece per spiegare, restauro che in questi anni estauro che in questi anni Restauro che ci sta restituendo una immagine del turto nuova del Michelan tutto nuova del Michelangelo che da sempre dato isto. Grigio, cupo, a esitonzialen, il secondo; chiari, spechiante di cangian-

forza plastica quello che la
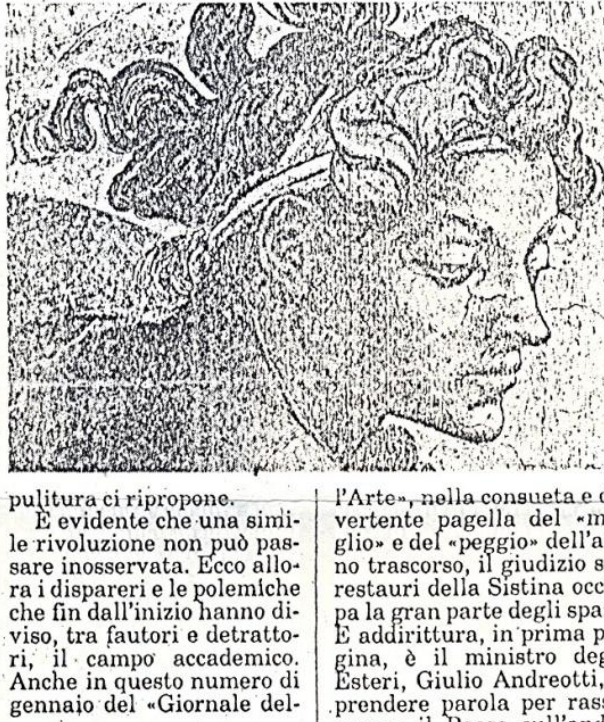
gennaio del "Giornale dell'Arte", nella consueta e di-
vertente pagella del *me-
gliow e del "peggio" dell'an-
no trascorso, il giudizio sui
restauri della Sistina occu-
pa la gran parte degli spazi.
E addirittura, in prima pa-
gina, e il ministro degli
Esteri, Giulio Andreotti, a
prendere parola per rassicurare il Paese sull'andamento dei lavori.

La Cassa di Risparmio di Parma, in collaborazione con l'Associazione *Sponsor e Cultura", ha organizzato presso il "Centro Cavagnarin, domani, sabato alle ore rin, domani, sabato una conferenza sui 16,30, una conferenza dal restauri della Sistina dal lato".

Saranno presenti, l'autore dell'intervento, prof. Gianluigi Colalucci, e il re gista Nino Criscenti del 1 , che su questo restauro ha girato un avvincente documentario. A presentare il tutto sara il preside della facoltà di Magistero della nostra Università, prof. Carlo Arturo Quintavalle. Farà gli onori di casa il presidente della Cassa, prof Alessandro Duce.

L'occasione si presenta di straordinario interesse per la città. Il documentario di Criscenti sulla prima parte dei lavori eseguito sulle lunette con i profeti, le diapositive di Colalucc sul restauro della volta, po- 


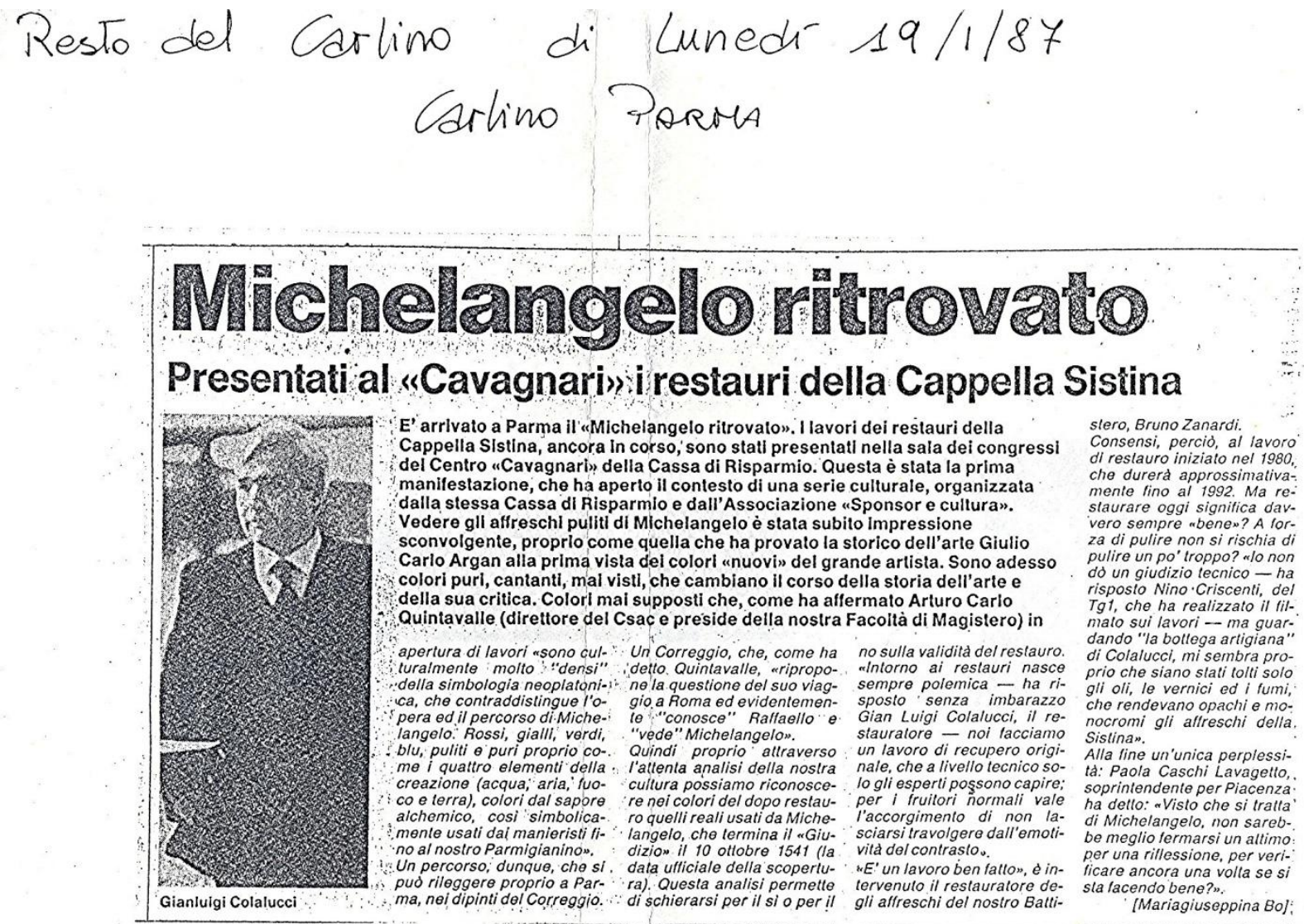


asciata a $\mathrm{Ka}$ nmette gli er ase della rivoie con il Pakinolto vicino.

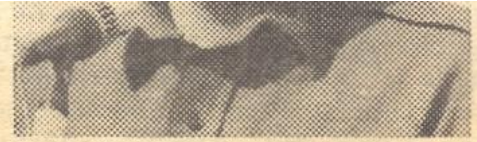

APAGINA 9 mentre trovano conferma le voci secondo cui Terry Waite, l'emissario della Chiesa anglicana è prigioniero della Jihad islamica. Ieri il leader druso Jumblatt si è offerto come ostaggio purché Waite venga rimesso in libertà.

A PAGINA 10 CON UN SERVIZIO DI ENRICO FRANCESCHIN na il giallo resta sacrare aliani"

\section{edalla Tass}

ALBERTO STABILE

ss insiste: l'eccidio dei duemila solspoli non è un'invenzione. E cita le Mi trovavo vicino alla zona boscosa - dice Yulia Moskal chealla finedeleva 16 anni - Una lunga colonna si è avvicinata insieme con un conlcuni suonavanola chitarra. Solola che si preparava a compiere l'eseava dagli italiani. Mi sembrava di ire. Mentre scappavamo abbiamo e delle armi automatichen. Ma dei li italiani citati dalla «Tass» non c'è nivi del Ministero della Difesa. Spazioni dei dispersi chiedono che Mole un approfondimento su tuttiica-

A PAGINA 7
REPUIBSLICA.2.72/82

Dagli esperti Usa un invito alla cautela Cappella Sistina "Bloccate subito quei restauri..."

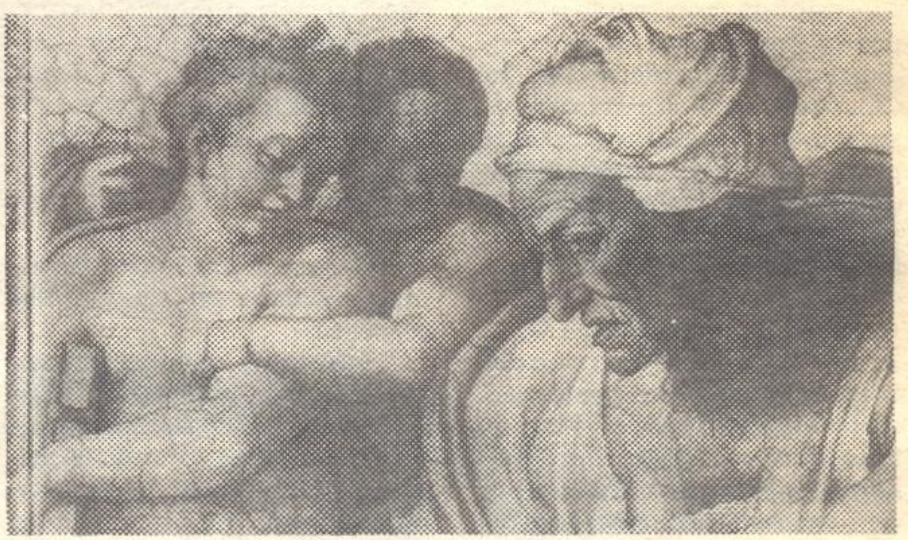

Un particolare della Cappella Sistina

di JAMES BECK (titolare della cattedra di Storia dell'Arte all'Universita di Columbia)

- NELLE PAGINE DELLA CULTURA 


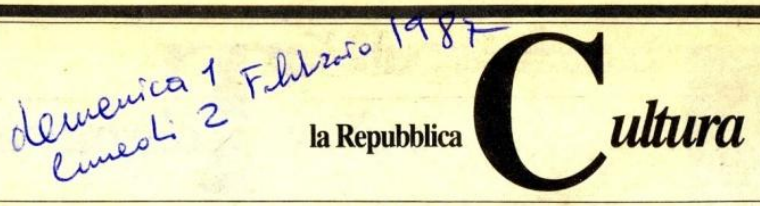

Pubblichiamo la "lettera aperta" che un autorevole studioso americano indirizza al professor Gianluigi Colalucci, direttore dei restauri della Cappella Sistina

\section{Angeli in pericolo?} LALETTERA apertadel professor James Beck, titolare dellacattedra
di storia dell'arte alla Columbia University - lettera che compare
oggi anche sul New York Times - rilancia una polemica che negli ultimi mesiaveva vistola maggioranza deglistoricidell'arte (1) particolar modo da Toti Scialoja e da Alessandro Conti. Proprio queste ultime settimane è uscito presso La casa Usher un volume prefazione di

di JAMES BECK

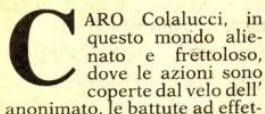

finire questi interventi «i re-
stauri più belli di questo secolon - mi sembra che una singo-
la voce dissenziente abbia avutosudi Leiun percettibileeffeto. Al centro delle sue preoccupiú spurie portano a strane cuno a cuiè dia ruolo antagonistico. Quando i thistina:guan in paradiso

cato da Il giornale dell'Arte de

settembre 1986 e da Arts Mag

anno va identificato non tan il miogiudizio personale qua to quellodella Storia: un giudi zio cioè che potrebbe far ric diavere compromessol'affla unitario che pervade l'affresco

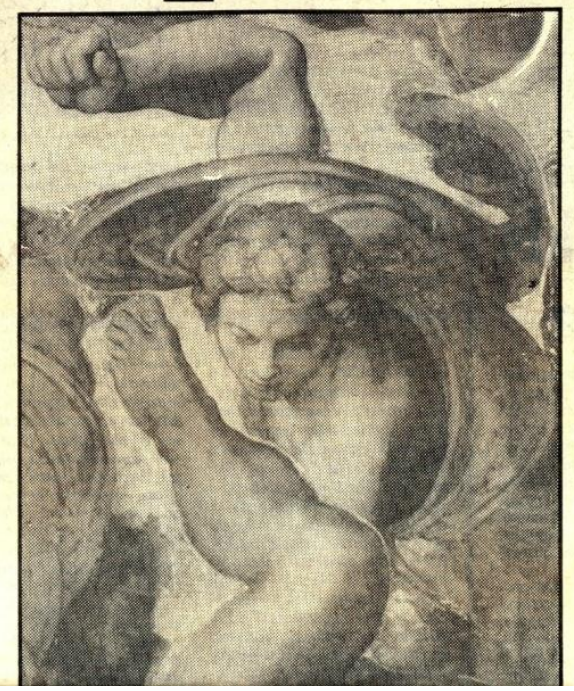

Michelangelo:
IIG Giudizio Universale
(particolare) appresentano mai poch freschi che risalgono a 475 (reschich

Equestinon sono isoliinterogativi a cui tutti noi dobbiacile forseè dinaturamoralee filosofica: a chi appartien questo capolavoro? Papa Giu-

di ricorrere al più intuizione

più difficile artista del temp per immortalare la Cappeli possono ora i suoi eredi di- 


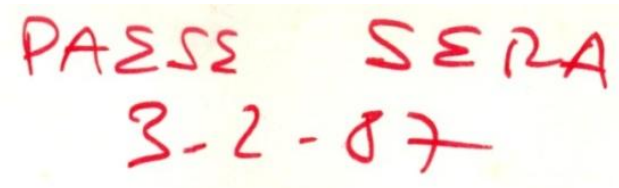

erta- rale Antonio Riccnezza.
nenti Per lui, che ha pubblicato

nenti Per lui, che ha pubblicato
veri- cinque volumi sulla cam-

veri- cinque volumi sulla cam-
i Leo- pagna di Russia, l'episodio

Leopoli diventano sempre

piu esigui. Tutto, o quas
tutto, era stato raccontato,

lov e Vassilli Romanovski.

Già otto anni prima la "Li- spettando la rormazioue ux teraturnaja Gazetan aveva

\section{SISTINA: NIENTE DUBBI REPLICA DAL VATICANO}

\section{Enrico Fontana}

ROMA. Giornalisti invitati a salire su mpalcature e ponteggi per accertare a ubontà dei lavorin. Febbrile lavoro di documentazione sui restauri in corso, quelli sulla volta, che dovrebbero essere ultimati nel 1988. La macchina organizzativa che accompagna i restauri vaticani alla Cappella Sistina di Michelangelo reagisce così alla lettera aperta di James Beck; titolare della cattedra di Storia dell'arte alla Columbia University, pubblicata domenica scor-

15 sa dal New York Times. Destinatario, il direttore del laboratorio, Gianluigi Colalucci. "Caro Colalucci - scrive lo studioso americano - lei, un restauratore con esperienze decennali, sta in-

bi- cominciando a nutrire gravi dubbin.

ine Secca escontata è arrivata la smentita

(iniziati nel 1980 e diretti da Fabrizio Mancinelli). "Non so da dove James Beck abbia tratto l'impressione che io sia preoccupaton. Eppure lo studioso americano stato esplicito nel citare la fonte che ha ispirato la sua lettera. una corrispondenza da Roma di Mary Davis Suro, pubblicata dal New York Times lo scorso 4 gennaio. Titolo: II Restauro della Sistina: guai in Paradiso". "Una corrispondenza - scrive Beck - basata essenzialmente su una Sua intervista (al Colalucci ndr). Nella replica Gianluigi Colalucci af ferma anche che "quando Beck nel

novembre scorso sali sul ponteggio della Sistina ci manifestò il suo com piacimento". "Ora, evidentemente è di parere diverson. Peccato che sempre James Beck, proprio su Paese Sera, abbia espresso gli stessi dubbi di oggi, lo scorso 14 ottobre. "La mia impressione di fronte al loro aspetto attuale (quello dei restauri, ndr) è che ora questi affreschi sono quasi spentin. Dubbi e perplessità noti nello stess mondo accademico tanto che Corrado maltese titolare ria dell' rte Modern all'Università riversita di Roma confessa, il 4 novembre, in un intervista al nostro giornale "d Ques Quale Osservaticon attenzione da terra (e non a distanza ravvicinata) gl affreschi restaurati perdono "peso definizione spazialen, come scrive Tot Scialoia nel suo manifesto-denuncia pubblicato dal nostro giornale il 5 ottobre dello scorso anno.

Le analogie tra il primo intervent di Beck e quest'ultima lettera son impressionanti. Allora, come oggi, in vita i restauratori alla prudenza, "Che fretta c'è - scrive Beck a ottobre nessuno ha maidetto che gli affresch siano in pericolo imminente". "Non sarebbe più opportuno - prosegue lo studioso americano - aspettare, an

che per una generazione se necessario, quando le tecniche non saranno cosi perfezionate da garantirci che anche lo strato più sottile di sostanze applicate da Michelangelo venga conservato?n. E questo infatti, le cosidette "velature a seccon, il nocciolo della polemica. Inesistenti, per i curatori del restauro. Parte integrante dell'arte michelangiolesca per chi chiede la sospensione dei lavori (con James Beck in testa). Sotto accusa finisce il solven te usato. L'Ab57 di cui si occup te usto L'Abs di cui si occupa, sul nostro giornale (111 ottobre dell' 86 ) Alessandro Conti, titolare della cattedra dienza e tenica del restauro all Universita di Bologna. Un potente agente chimico da usare "con precise raccomandazioni e per interventi ben circoscrittin, scrive Alessandro Conti. E non, come sta avvenendo, in tutti i 750 metri quadrati della Volta michelangiolesca.

"Se esistono scadenze contrattuali nell'ambito dei diritti di riproduzione - scrive James Beck - non sarebbe certo eccepibile modificarle o abrogarlen. E il riferimento, esplicito, al contratto miliardario firmato dal Vaticano e dalla compagnia televisiva giapponese Nippon Tv Corporation: In ballo l'esclusiva mondiale dei diritti di riproduzione, da qui fino al 1992 , quando dovrebbero terminare i restauridel Giudizio universale.
PERUGIA (A.F.). Il progetto è ambizioso. Si tratta di salvare dal degrado una delle pagine piu preziose della pitto di svelare un mister che è rimasto tal nontante eli sforzi di nonostandi studiosi. Li generazion taggio riguarda gli saffeschiche si trovano all'interno di una chiesa di Toscolona piccolo centro del comune di Avigliano Umbro. Il mistero da chiarire, inve$\mathrm{ce}$, riguarda il loro autore che per ora è conosciuto con il nome convenzionale del maestro dell'annunciazione Gardner. Un nome che gli esperti hanno tratto dallopera maggiore di questo artista, una annunciazione

\section{RESTAURI IN UMBRIA. CON LA CHIMICA ALLA RICERCA DELL'AUTORE PERDUTO}

dettero all'inizio del secolo alla collezionista americana Isabella Gardner. Tutta l'operazione sarà portata avanti dalla sovrintendenza ai beni culturali con la sponsorizzazione dell'Alcantara. L'azienda dell'Eni- lioni) metterà a disposizion i suoi laboratori per tutte le ricerche di natura fisica chimica sui materiali e su colori che saranno necessarie. Gli affreschi di Toscolano sono stati scoperti per caso nel 1984 da un restauratore di Todi, Marcello Ca- scarso valore. Ora sono stati rivalutati a utesto pittorico inedito, riconducibile al la cultura rinascimentale umbro-toscana" un'opera da salvare. Appena scoperto il valore effettivo degli af freschi (è un ciclo che narra della salvezza attraverso l'intercessione della Madonna e dei santi) la soprintendenza, con procedura d'ur genza, ha effettuato un primo intervento di consolida mento. Poi e cominciata l'attesa dei finanziamenti ne cessari per completare l'opera ma anche per scoprire la vera identità del maestro dell'annunciazione Gardner. Per ora c'è solo un'ipotesi: potrebbe essere Pier- 


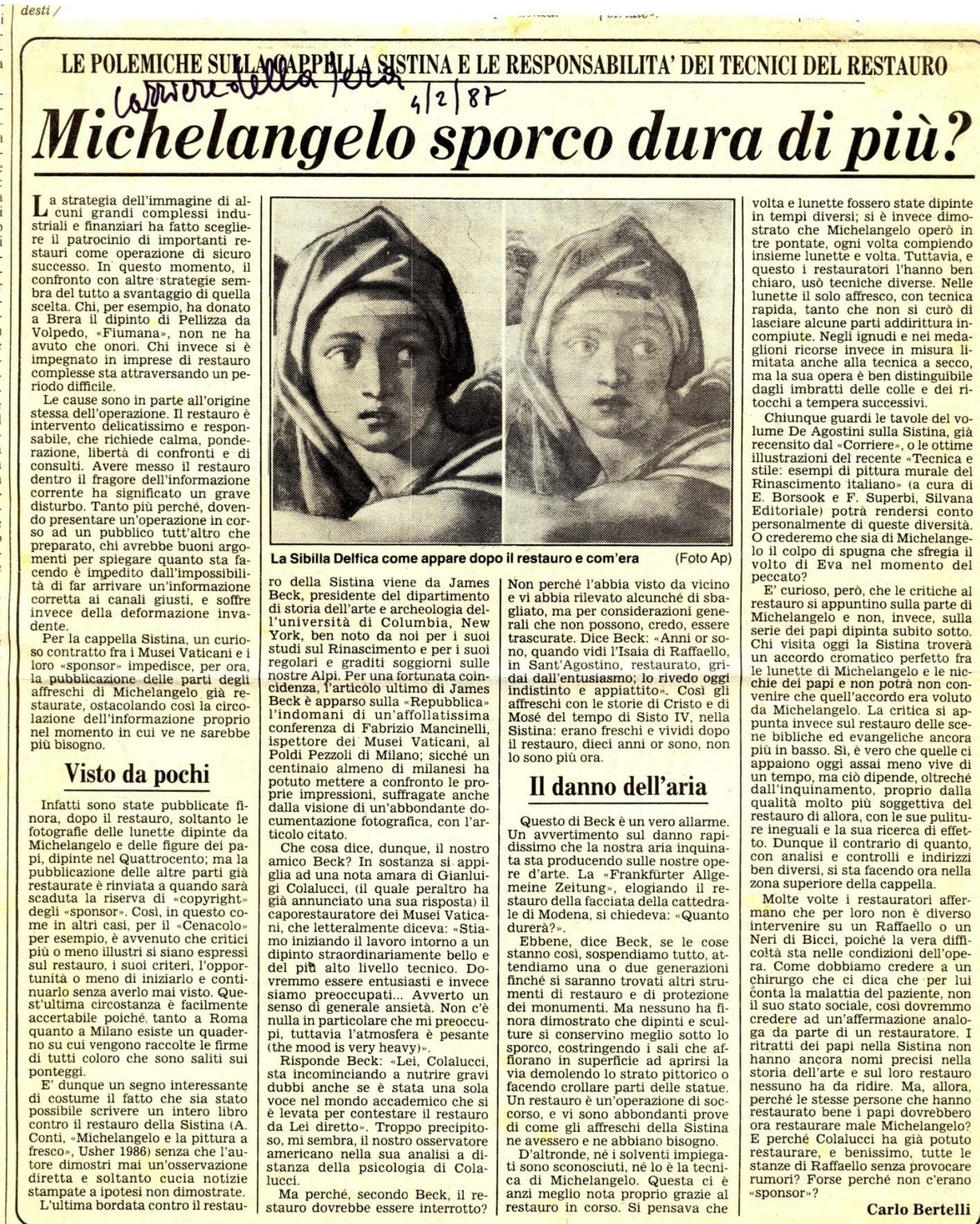




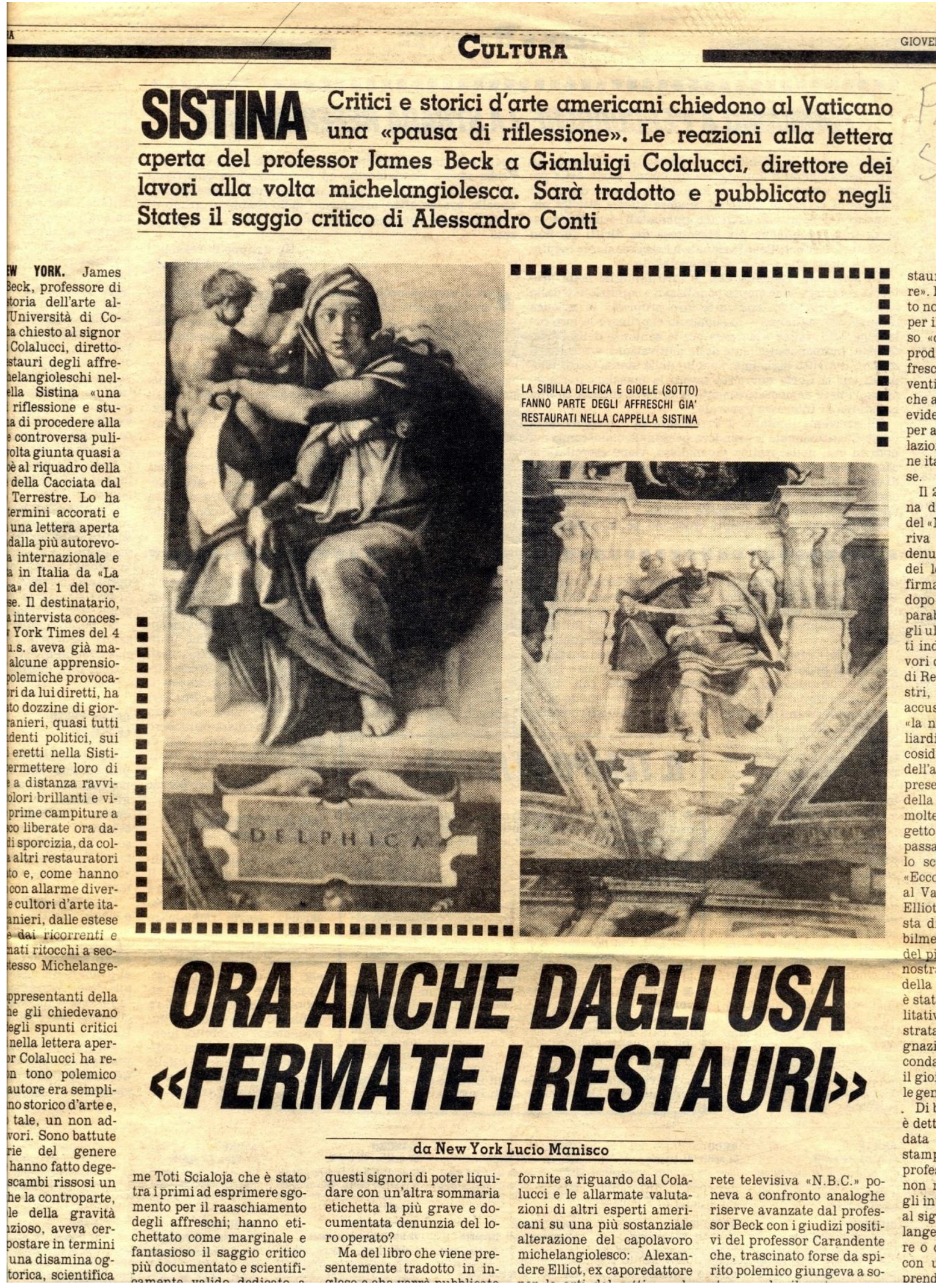




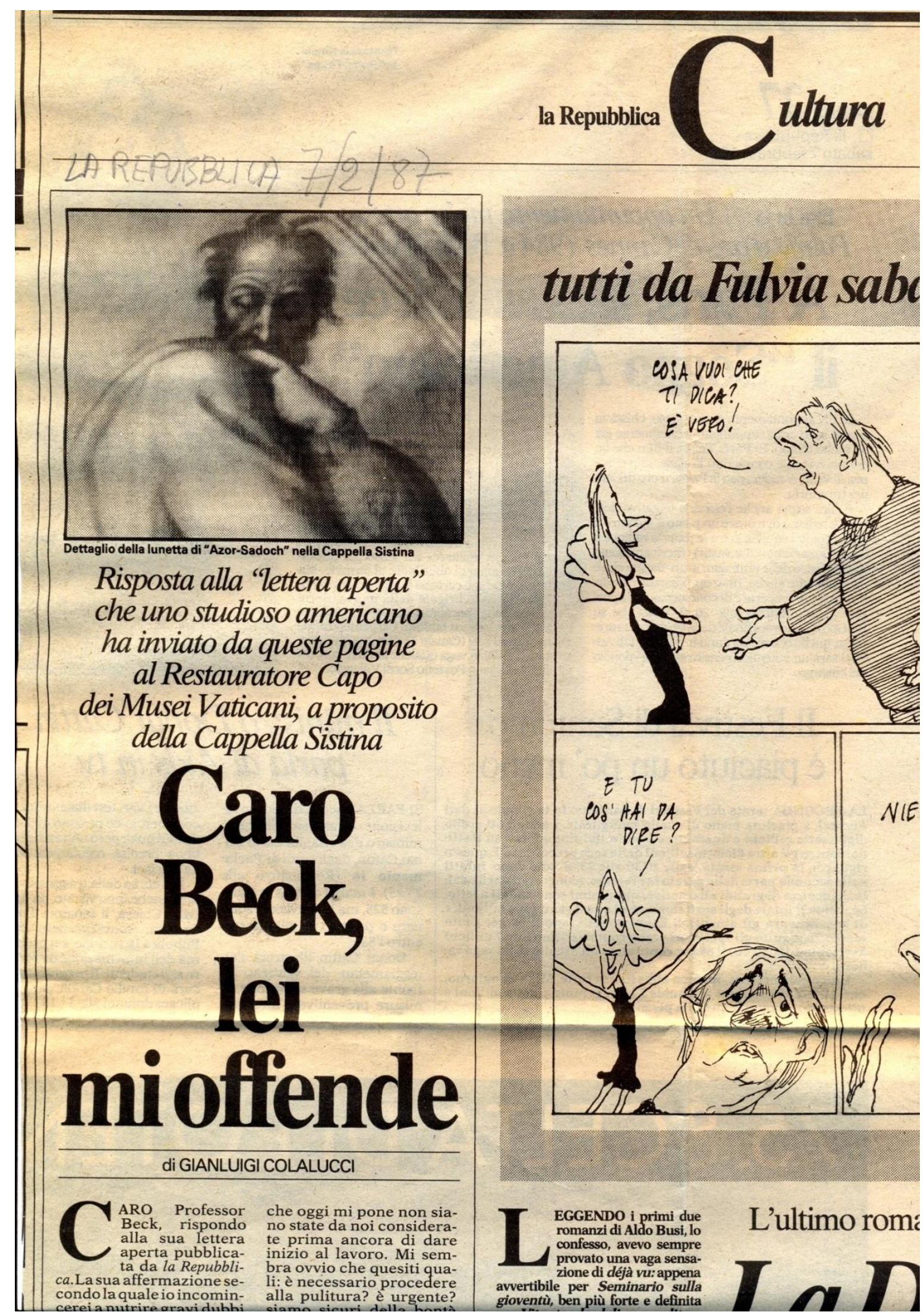


no fino al punto in cui siamo oggi, era già stato eseguito al tempo di Seltz (1904) e di Biagetti (anni ven tidotto al $\mathrm{min}$ ritocco, poi, e ridotto al min mo, riguarda essenzialmente le lacune viene eseguito a tratteggio verticale e incrociato. Aggiungero che e sempre ad acquarello, la tecnica - nel tempo

- Il restauro, secondo lei, è questione oggi prettament scientifica o anche estetica? «Il restauro adesso è molto complesso: comprende un fat tore estetico, un fattore storico e un fattore tecnico. Il restauro è oggi le tre cose insieme: un tempo era invece una questione essenzialmente estetica".

- Quali studiosi avete interpellato prima di intraprendere i lavori?

"Abbiamo sentito molti studiosi. Quello della Sistina d'altronde, fin dal primo gio no, un restauro aperto: son saliti sui ponti, a oggi, oltr della specialisti fra storici dell arte e restauratori, a cotuto Centrale del Restauro.

- Quando la Sistina nacqu aveva i colori brillanti, molt intensi di adesso?

"Allorché la decorazione fu eseguita, Michelangelo adott una tecnica (e questo risult chiaramente dal lavoro fin qui svolto) che era quella dei suoi contemporanei. Intendo dire cioè, con tutte le eccezioni previste dalla norma: in particolare, con pentimenti e parti secco, che non abbiamo trovato sulle lunette ma abbiamo trovato sulle volte Questa tecnica, c'è da aggiungere, Miche-

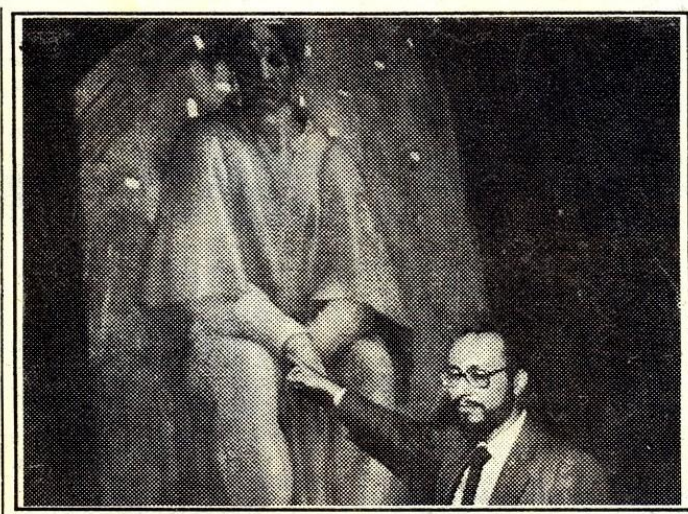

II professor Mancinelli, direttore del restauro della Sistina langelo la interpretò in modo particolare: il colore viene steso a velatura in modo da lano dei colori applisati in precedenza cedl'inza e spessissimo anche re di Michelangelo luminosisrimo fatto per lu visto in simo, fatto per essere visto in qualsiasi condizione di luce. In maestro sapeva benissimo che la Sistina non avrebbe mai no, sal livelli di illuminazione grosi la lu di illuminazioprattugi la luce elettrica, soprattutto se eccessiva, appiattisce le immagini

- Il professor Beck della Columbia University, attraverso una lettera inviata ai giornali. vi ha esplicitamente invitati alla prudenza. Ha chiesto se, allo stato delle cose, si può essere sicuri che nulla di Michelangelo si sta perdendo.
Beck, invitandovi a una pausa di riflessione, ha scritto: "Un leve ritardo nel completare la pulitura non può arrecare nocumento fisico agli affreschi”. Che cosa risponde a tutto questo, professor Mancinelli?

"Sono d'accordo con Beck che, lavorando su Michelangelo, la prudenza è indispensabile. Sono anche d'accordo sul fatto che il tempo in operazioni di questo genere non deve avere importanza. Però le pau se di riflessione si fanno quando ci sono dei motivi validi. Nel nostro caso, le pause sono già state moltissime anche se il professor Beck non ne è in formato. Ci siamo fermati ogn volta che lo abbiamo ritenuto necessario. Questa volta non necessario. Questa volta non rispondo a Beck per quanto mi compete. Credo che le stesse parole potrebbe dirle Colaluc ci, che non mi risulta abbia il mento dei lavori.

- Quali consensi hanno avu to i lavori?

"In molti si sono espressi a favore pubblicamente: da Urbani a Bertelli, da Argan Calvesi, da Briganti a Zeri, da Chastel a Ragghianti a Baldini, da Hartt a Shearm, dall Weill-Garris alla Borsooc. E m fermo ai soli storici dell'arte. Anche tra i restauratori i consensi pubblicamente espress sono stati decine".

- Come spiega professor Mancinelli, che molti artisti, cominciare da un pittore come Toti Scialoja, respingono
sultati del vostro restauro?

"Gli artisti hanno un rapporto estremamente soggettivo, ed è giusto, con l'opera d'arte la trasformazione operata dalla pulitura è stata indubbiamente choccante. Non tutti g stesso pero, hanno reagito allo stesso modo. Sono inoltre molto pochi quelli che hanno visto quell da vicino, sul ponte. quello del far vedere da vicino e normalmente il nostro argocente".

- Quando si concluderanno i lavori?

- Abbiamo fatto una tabella di marcia, che si basa sui tempi di pulitura di Eleazar. Sulla volta però abbiamo trovato problemi diversi: i tempi, cosi. si sono allungati. Probabilmente finiremo nel 1989 anzché nel 1988. Per il "Giudizio Universale" sono stati poi previsti quattro anni. Si vedrà".

Antonio Debenedetti 
eneva tutesplicitasione». La Iva ovvia: rassimo di to, ma nelon voleva gouache l'aveva donata a me, io l'avevo donata a mia volta a Graziella Lonardi, ma poi si era deteriorata a causa di un incendio e io avevo chiesto a Renato di rifarla. Si può interpellare la stessa Lonar-
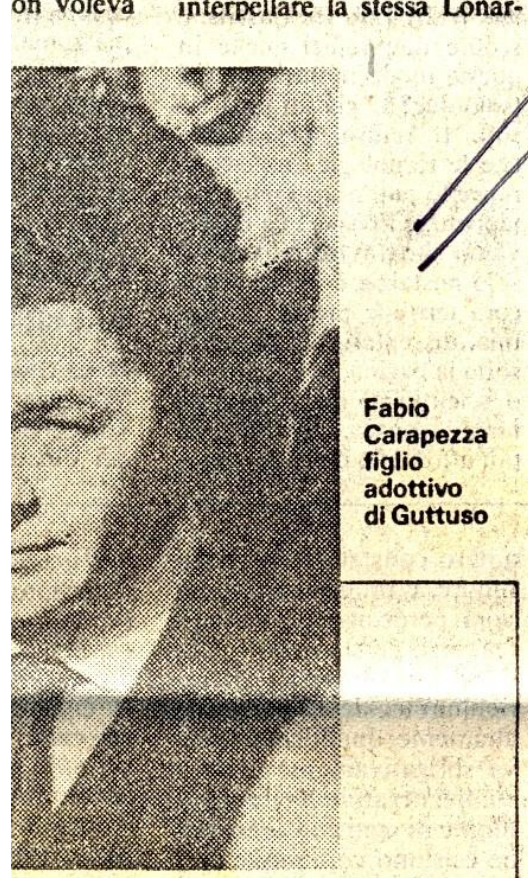

now. Il portiere di Palazzo del Grilio le disse che fra le chiavi ce n'era una che non funzionava.

Le avevano dato quelle chiavi apposta o no? La stessa Magrotto non è sicura che quell'evento imprevedibile che va sotto il nome di innamoramento, mentre il pittore la rassicura dicendole che intende improntare $\mathbb{N}$ Joro kapporto ad una «estremapurezzav).

\section{hiede l'eredità}

a, Nell'interpretazione della memoria Renato e Mimise Gutuso", aggiungenche occorrerà «concordare la più agele intesa per intraprendere, in cordiale nonia di intenti, la realizzazione di ei programmi che Guttso, ancora di :ente, aveva solennemene formulato al e di fare della fondazione stessa un ntro propulsore di vitalità artistica e Iturale».

consiglio di amministrazione della idazione (del quale fa parte anche il nite di Mimise Guttuso, Giampiero tti, che però non era presente), ha ane chiesto che, nell'istruttoria per il rinoscimento della fondazione, siano zcisati quali mezzi finanziari gli enti bblici metteranno a disposizione.

\section{Alla Cappella Sistina \\ Aveva elogiato i restauri vaticani}

Dovremo ancora aspettare qualche mese per vedere completamente rimessi a nuovo gli affreschi della Cappella Sistina. I1 direttore dei Musei Vaticani, Carlo Pietrangeli, lo ha ammesso conversando con i giornalisti con cui era salito sul ponte mobile che porta ai lavori. Tra la schiera di entusiasti per il restauro c'era anche Renato Guttuso, il pittore recentemente scomparso, che aveva clogiato con una lettera all' "Unità» i restauratori vaticani «per avere rimosso la intercapedine ingannatrice, aiutandoci cosi a vedere ed a capire quel che di Michelangelo è veramente terribile: il suo animo impetuosoly.

La upulitura» di 514 metri quadrati (su 750) di affresco della volta ancora da trattare potranno essere completati entro il 1988 (come da programma), per i 200 metri quadrati del "Giudizio Universale» occorreranno ben più di quattro anni. "Quando si tratta di restauri pittorici che hanno sulle spalle affreschi con secoli di esistenza - ha spiegato Pietrangeli - è davvero difficile preventivare sin dall'inizio tutte le difficoltà e tutti gli imprevisti ai quali si andrà incontrom. Pietrangeli, dopo aver rifatto passo passo tutte le tappe dei lavori, arrivati olíre la metà del cammino (degli iniziali 1554 metri quadrati, ne restano 714 ) ha aggiunto che saranno necessari quindicidiciotto mesi ancora per arrivare alla fine del restauro, sempre che non sorgano altre difficoltà impreviste.

"Voglio precisare - ha detto Pietrangeli - che questo ritardo non è affatto legato a quella che alcuni hanno chiamato una pausa di riflessione, dovuta a problemi inaspettati e che richiederebbe ulteriori studi. No, non c'è nessun problema, si tratta soltanto di tempi tecnici che si sono allungatis.

Da parte sua il capo dei restauratori, Gianluigi Colalucci, chiamato direttamente in causa come colui che ha voluto "l'alt» ha preannunciato che per chiarire tutte le polemiche, manderà una lettera aperta alla stampa. Colalucci ha aggiunto: «ll nostro è un cantiere aperto, chi lo vuole vedere può farlo subito e toccare con mano quello che stiamo facendo. Come è noto i restauratori hanno aperto il cantiere tre anni fa, con la sovvenzione di circa quattro miliardi di lire offerti dalla «Nippon Televison Network».

$$
\begin{aligned}
& \text { LMESSASSERO } 8 / 2 / 8 H \\
& \text { (LAMORTE DI GUITVSO) }
\end{aligned}
$$


Sulle impalcature dei restauratori che stanno restituendo splendore agli affreschi della Sistina

\section{Quattro passi in Paradiso Lassù, sottola volta, a contemplare Michelangelo}

di DOMENICO DEL RIO CITTA' DEL VATICANO Sono stato nel Paradiso TerreMale, facia faccial Bene edel ed Eva. Ho guardato negliocch il Serpente Il Paradiso Terrestre è quello di Michelangelo, sulla volta della Cappella Sistina. Sono salito lassu, a contemplare da vicino gli affreschi meravighiosi che, sotto le mani dei splendore dei colori. Non son un esperto, non sonoun tecn Sonosoltanto uno che, perpiùd un ora, siè nutritodimeraviglia. Giù, la Sistina brulica dei solii turisti, tedeschi, american giapponesi. Guardano, conlatesta sollevata in alto, "trasecolati descrivevale persone che perla prima volta erano rime per cantate davanti agli affreschi di Michelangelo. Un professore tedesco afferma solenne: "Questo restauro e il più civile e glorioso avvenimento che chiude il no-

\section{Il terribile Giulio II}

Ci stacchiamo dal pavimento con un piccolo ascensore metal suun'impalcaturasimileaqu la che aveva inventato
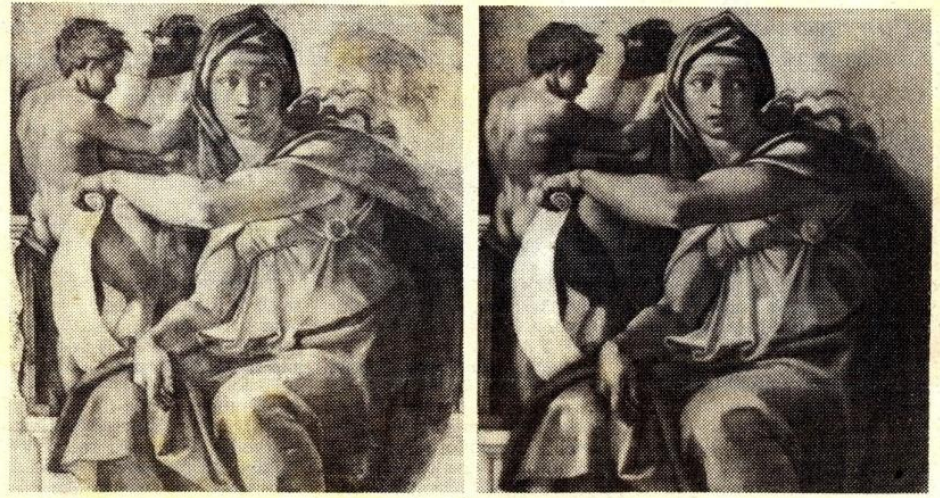

Sull'impalcatura di adesso none mai salito, invece, Giovanbottega dipittori mon cè una torio di chimica e di elettronica. Iresponsabilie gli espertivaticani del restauro (Pietrangeli, Persegati, Mancinelli, Gabrielli, Colalucci, Rossi, Bonetti) si muovono tra apparecchi video, frarossi boccette di vetro formule chimiche. Loro dicono, non tolgononiente aicolori, fan no solo pulizia, sciolgono la colla che fu applicata sugli affresch e che si e annerita a causa de fumo delle candele e dei bracier. Tnnatricen, come Guttuso cheerasalitoa conter testa a Oloferne. Davide taglia la testa a Golia. Noè, bianco vetre figli, nudi, lo coprono con un velo sottilissimo. L Sibill fica spalanca i suoi grandi occhi incantati, mentre il vento le gonfia il manto rosso e azzurro. La Sibilla Eritrea, muscolosa, si mmerge nella lettura di un libro.l prore Zaccaria, la barba parillate, e avvolio nella sua che bibliefebi giganteschi dalle membra perfette. La loro carne è morbida, color della pesca, come la carnediuna fanciulla. Unoè qui. stre Lo tocce con la mano. soilfruttoproibito. La sua carne nudaè sottolo strato sporco de Soltggineedella vecchiacolla. scende un piccolo spazio a cuneo di antico colore chiaro. Adamo, con la sua nudità neracontro il Serpente e afferra un ramo dell Albero come a scuotero. il serpente fa spiccare volto rossiccio e ambiguo donna come una figura misteriosa di un affrescopompeiano. Dall'altro lato dell'Albero, cacciati dalla spada di un angelo rosso, Eva e Adamo sono gia ripuliti. Eva è impaurita. Adam a un gesto di difesa, ha i tra
La Sibilla delfica
prima e dopo il restauro

prima e dopo iil resta
(foto Ntv-Tokyo)

della terra, Dio che separa luce dalle tenebre.

Là in fondo, sotto Giona spaventato dalla balena, c è l'imversale con le sue trecento figre. Annerito anch'esso dal fum edalla polvere grassa finirà co mostrare i colori originari forse 1992 o nel 1993. Oltre i coloanche i suoi mudi così come aveva dipinti Michelangelo, dimiranti, dibeati, di angel, di dannati? A Firenze, per Cappella Brancacci è già stato decisoditogliere le foglie, applicatenel Seicento, ainudidiAd mo ed Eva sia del Masaccio ch di Masolino. Accadrà cosi an-

\section{La questione} morale

La questione è duplice: tecnica e, diciamo, «morale». Per la parietecnica, diconoirestaurale coperture risulteranno soltanto superficiali e non sarann diventate tutt'uno con l'affresco. E per la parte "morale" Chi deciderà sarà il papa, naturalmente, cosi come furono 


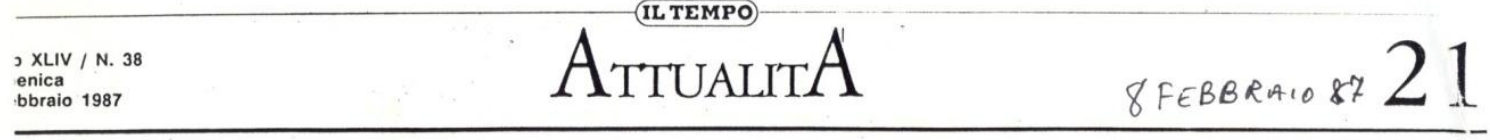

Visita sul ponteggio per osservare da vicino i lavori di restauro in corso sulla volta

\section{Torna il "vero» Michelangelo dagli affreschi della Sistina}

E riappaiono squillanti i colori originari, velati per secoli

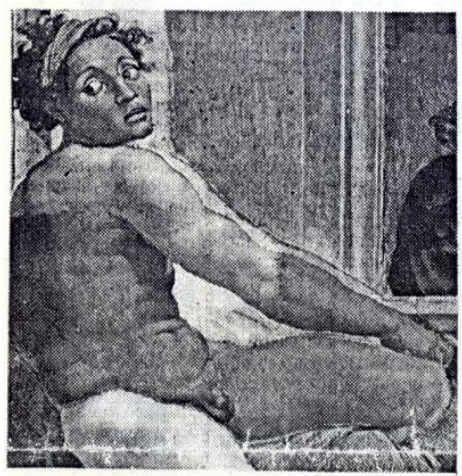

Un Ignudo

della volta

della cappe

prima (qui accanto)

e dopo (sotto)

il restauro

che it tecnici

stanno compiendo

dal 1980 le foto

sui lavori

sono pubblicate

per concessione

che finanzia

SALIRE sui ponteggi della quasi incisi a strette strisce sibile effettuarlo fino ad Sistina è come imbattersi sul bianco dello sfondo per una ventina di anni fa,
nello spirito di Michelange- dar loro lucentezza, o la leg- perché non si disponerano nello spirito di Michelange-
lo. Lo sfiorare con la mano gera ciocca della chioma di $\begin{array}{lll}\text { la superficie levigata dell'af- Eva, che spunta da sotto le } & \text { re il tenace strato di colla } \\ \text { la }\end{array}$ fresco, dà un brivido. E' braccia, sembrano comuni- di sporco, senza intaccere qualcosa di płù misterioso e care riservatamente a noi colori. coinvolgente di un contatto un brano del messaggio pit-

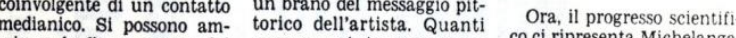
mirare le figure create dal avranno potuto osservare, a co ci ripresenta Michelangegenlo, alla stessa distanza cosi breve distanza, questo ri dal vivo. Sfata la leggenda mentre le dipine guardava giolesco nei suoi quasio cin- del Buonarroti non pittore e testa buttata all'indietro, a que secoli di esposizione? ce lo rende, invece, in tutta distanza ravvicinata, senza poter avere lo sguardo d'in- Lalo è torlo colpa, sul mezzo pittorico, dal colore sieme, ma con la forte emo- pente-donna zione del particolare incom- misoginicamente che $a$ ten- tenuti sourapponendo ot bente e forse anche con rat- tazione è femmina, segna latura due colori adiacenti e tesa attualmente il confine con con accostamenti audaci Qu>i co.pi dininti sono lc sporco. Vista da vicino, la tornati jivi, liberats dal suha opacino che per secoli li ti da lungo tempo abbruniper conuncare misteriosa- fusca la pittura, molto pormazione relativa agli at Acconto non appaia a chi di riportare tali datitura. sciate sull'intonaco fice della zona di affresco più di 475 anni fa, dal poggiamano di Michelangelo, uno spicchio dit colore, pie 


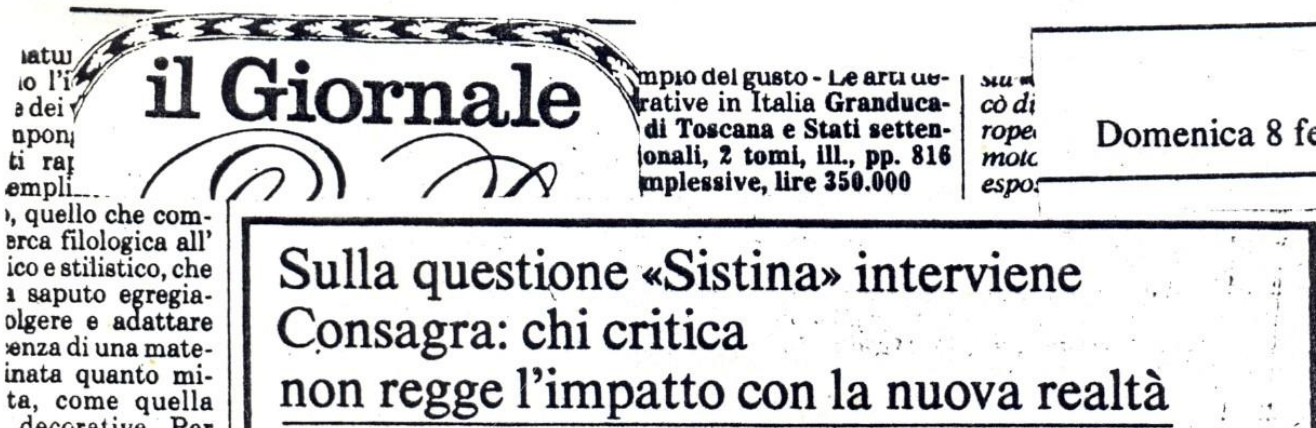
parati siano duntti studiati ed eteoccasioni che ne rminato la stesucritti possono teumente il luogo di leta e generale storica perché di imile essi sono il upposto criticato.

che è servito per questo risultato nente descrivibiimunque ricorda3 almeno un'ides te di chi lo ha in sistematizzato, in disciplina. Gli I mostrano facilcumenti e gli insono la base di che storiche. Ant antiche carte, ovate con abilità on parlano facille se non quando che notizie che si Inell'incerta grainchiostri 0ssidasse esattamente in on le mobilie, gli i ricchi oggetti a riferimento. Que3i dopo secoli, sono ue rintracciati nelariate collezioni e private del monluti, ce li rammen) qualche disegno suto e fortunosaentificato oppure escrizioni che ne aciato gli antichi i più curiosi e at-

paziente restauro arduo di per sé, è 1 difficile da farsi nche per altre raccano da vicino le iche, talvolta un e, della nostra iturale. Un primo superarsi era ingiudiziale ideali-

\section{Un pugno dall'aldilà}

Pietro Consagra
La polemica sui restauri della volta michelangiolesca nella Cappella Sistina di Roma, ospitata a varie tappe sul Giomale Lettere \& Artin, ha visto profilarsi due apar titiv: favorevoli alle operazioni di restauro si sono dichiarati critici come Ragghianti e Carandente; contrari, invece, gli artisti Tot Scialoja e Carlo Guarienti. Ecco ora una testimonianza dello scultore Pietro Consa gra, che si schiera invece apro-restauro.

ono stato gentilmente ospitato sul ponte da cui si va restaurando la volta della Cappella Sistina di Michelangelo.

Prima di dichiararmi un artista contrarío allo scandalo sollevato da altri artisti che si sono schierati dalla parte dell'opposizione, volevo farmi testimone del sapiente lavoro che stanno eseguendo $i$ dotti del restauro. L'opposizione é basata sulla ipotesi che puiire significa sempre togliere integrita al colore e soprattutto l'operazione sarebbe più grave riguardo alla volta perché l'artista avrebbe usato velature a secco che sparirebbero con il grasso del fumo che si vuole eliminare. L'enfasi su un Michelangelo tenebroso non mi ha mai adescato, e quando $i$ giornali hanno dato spazio all'allarme su una presunta alterazione dei colori che ora puliti sarebbero diventati da carta velina, capil bene di cosa si trattava. I contrari al restauro si sono trovati di fronte a un Michelangelo che non combaciava più con il michelangiolesco dei tormenti e sofferenze.

L'affresco della volta, prima di tutto, è un impianto decorativo ordinato dentro uno schema geometrico molto presente. Decorazione, come decorazione sono i frontoni del partenone con le sculture di Fidia per esaltare la partecipazione degli dei alle vicende umane. Un artista della classicità è tale perché mantiene un equilibrio molto centrato tra artificio formale e passione.

Dopo l'affresco della volta Michelangelo tende a spostarsi da tale equilibrio in opposte direzioni: nell'affresco del Giadizio Universale sottomette la geometria specchiante dei gruppi alla deter ne drammatica mentre nelle tombe medicee di S. Lorenzo a Firenze le sculture molto intense e-vigorose sono sospese in un contesto leggiadro.

La pittura della volta con la pulitura dei colori sta ritornando al suo primario valoconciso, vaporoso e acuto, come deve essere un'opera per un massimo prestigio. Alla smagliante apparizione della volta restaurata già per metà si arguiscono motivi del rigetto da parte della critica negativa. Il tempo con le sue intemperie negativa. Il tempo con le sue intemperie rio tranquillizzante, un allontamento dal presente che non vuole essere insidiato da ciò che è stato. Ci sono motivi di disagio per "climinizione deilis dimensione tempo. La richiesta di lasciare l'affresco invecchiato e offuscato dal fumo che si è aggregato, proviene da un ingorgo psichiuna realtà che giunge direttamente come un pugno dall'aldila.

Sospettare che le intenzioni dell'artista siano state edulcorate diventa involontariamente un rimbalzo negativo verso un Michelangelo che non sapeva sempre bene quello che faceva.

Michelangelo mi è sempre apparso un artista pratico che ha saputo vivere le spaccature del suo tempo, nei conflitti tra le parti politiche e religiose, facendo le mosse giuste per uscirne partecipando a tutto. I suoi pensieri riflettono l'insofferenza umana ad accettare quello che ci accade e ci circonda fuori da ció che si desidera. Ma egli ha ottenuto molto di ció che ha desiderato e certamente invecchiare non avrebbe voluto. Non avrebbe voluto affogare «né moccis.

Michelangelo poteva e non poteva essere fatto santo. Forse l'artista e sempre un manipolatore blasfemo. re di fasto, brillante e morbido, estroso e co che rifiuta lo shock dell'impatto con
Amico di poe Alberti, da Borg modo, a Carrier ha sempre cercat sia nei colori $e$ Questo anche se l'hanno costante citato, e talora ad passionato, pero dolo deragliare ce primaria de uomo (i suoi ba darsene) e persi nisti e gli eventi sua emozionant divengono sosta di pittore di Ro sformandosi in qualcosa che qu chi.

Con un detern tinuo approfona strumenti, quas flessione sui m del dipingere, ch anni ha indotto nare ripetutame dell'autoritratto: nello studio, in mitissimo e si dio, archivio, $r$ madio, creden sopra il brulich ria milanesen, Alberico Sala, a ta, presentarid mostra antologi ca Galleria d'Ar Gallarate gli ha care.

Nelle sale del istituzione - c ta, ricorda il di Zanella, ha fattc all'abituale pr presentazioned vanti, ma non o dire, storicizza possibile veder sintesi del lur Rossi, dalle com solidi geometri Trenta e Quara insieme al rigor ed alla corposi sino ai citati aut ultime preziose contempo god ture morte.

Attilio Rossi, C d'Arte Moder te, fino al $28 \mathrm{fe}$ 
La polemica della Sistina

\section{Michelangelo senza veli (difficile im maginarlo a passare la colla)}

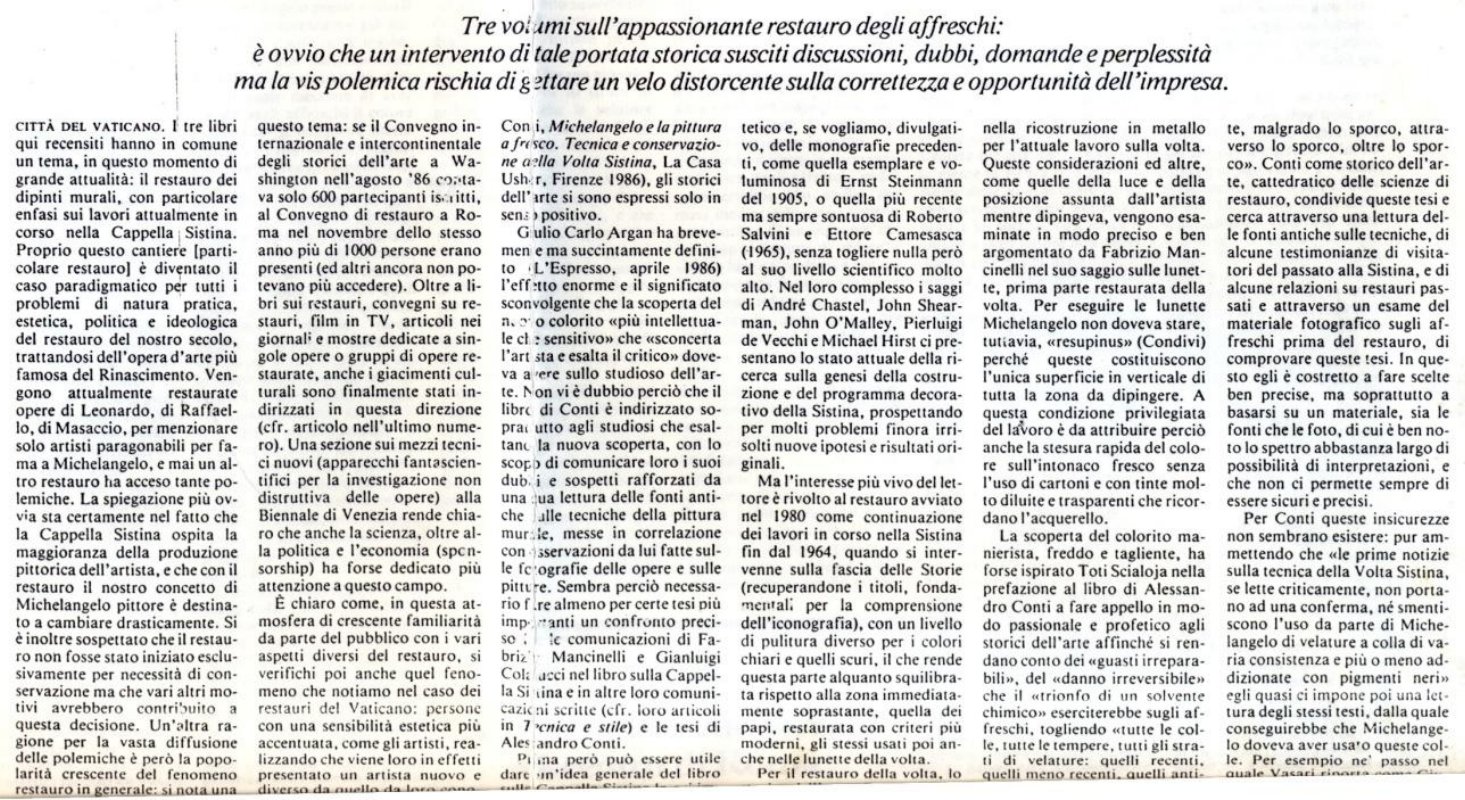

di un pollo, si recitano determinate tormule e poi si butta l'osso nel fuoco. Lo sterno stro.
brucera, torcendosi in mille spasimi he

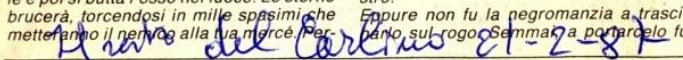

eventi, con occhio disincantato, scientifi- copiato a piü non posso. E non dimentico. Scientifico del Medioevo, s'intende: chiamo che Cecco ha precorso in
per esempio riteneva la grandine un fatto to la moderna fisiognomonia".

nicata, infine uccisa da Carlo III zo. Non proprio una bagascia,
meno uno stinco di santo.

\section{Sotto il velo c'è proprio Michelangelo}

\section{Visita ravvicinata ai discussi e delicati lavori di restauro della Cappella Sistina}

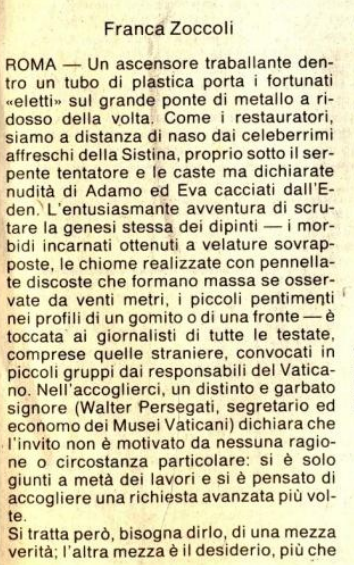

la lettura

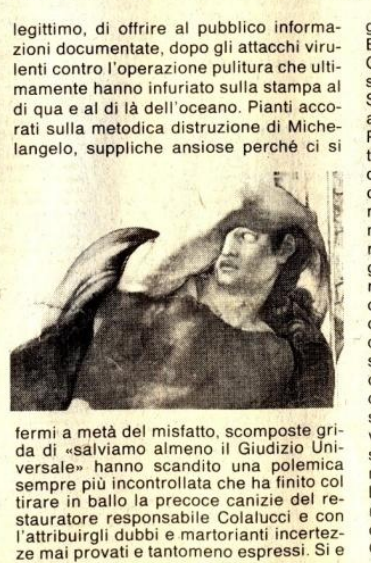

gettato nella mischia perfino il professor

Beck, capo del dipartimento d'arte dell

sembra, dell'estroso ma prudente Meyer Shapiro che dirigeva quel dipartiment all'epoca in cui vi studiavo. Piu volte si e scritto sui meccanismi scaenanti cosi appassionate reazioni: $\mathrm{M}$ deve essere diverso da quello che abbiamo sempre conosciuto e amato. Ma veniamo ai fatti: Fabrizio Mancinelli (direttogenerale dei Monumenti, Musei e Gallerie Pontificie) e Gianluigi Colalucci sono qui sul ponte per spiegare, per rintuzzare ogni accusa, per dissipare ogni timore, sottolineando soltanto che quasi nessuno dei detrattori è salito quassú, mentre i pochi che ci sono venuti hanno guardato senza voler vedere. Sotto il profilo emoti-
vo ogni atteggiamento è comprensibile. sotto quello tecnico - ribile

La principale imputazione è che la pulitura asporterebbe anche velature di mano di Michelangelo. almpossibile - afferma
Colalucci - ci si dimentica infatti che la

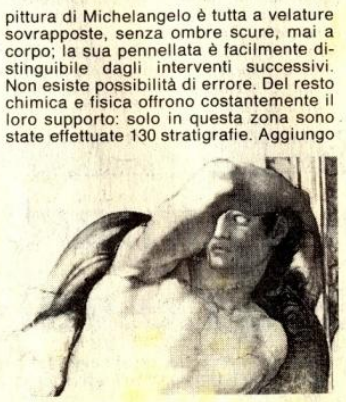

che le tecnichye usate non sono nuove ma collaudatissime, essendo giá state impiegate dall' 'stituto del Restauro per quasi rezza, ci si ferma con la pulitura appena un poco prima che tutto lo sporco sia stro infinitesimo, proprio per non ri Guardiamo il serpente che si av bero, non più grigiastro ma cor me bianche velate di giallo, ver
Adamo ed Eva con i corpi morb Adamo ed Eva coni garpi veri ro tappeto d'erba Vicino, dove ancora intervenuti, appaiono ch e livellanti ombre scure delle vapposte neisecoli perfidare rapido annerimento. sara fra 400 anni? chiede un me oggi - risponde tranquillo - poiché sono state eliminate pali cause di degrado, come le ni di acqua piovana e l'uso di ca croclime eviand inoltre contro del tasso di umidità e riduceno mo l'inquinamento dell'aria. I b a fresco non si alterano e Mich ricorso pochissimo al secco; cor e le pesanti ridipinture di antich una protezione sia pure falsa 


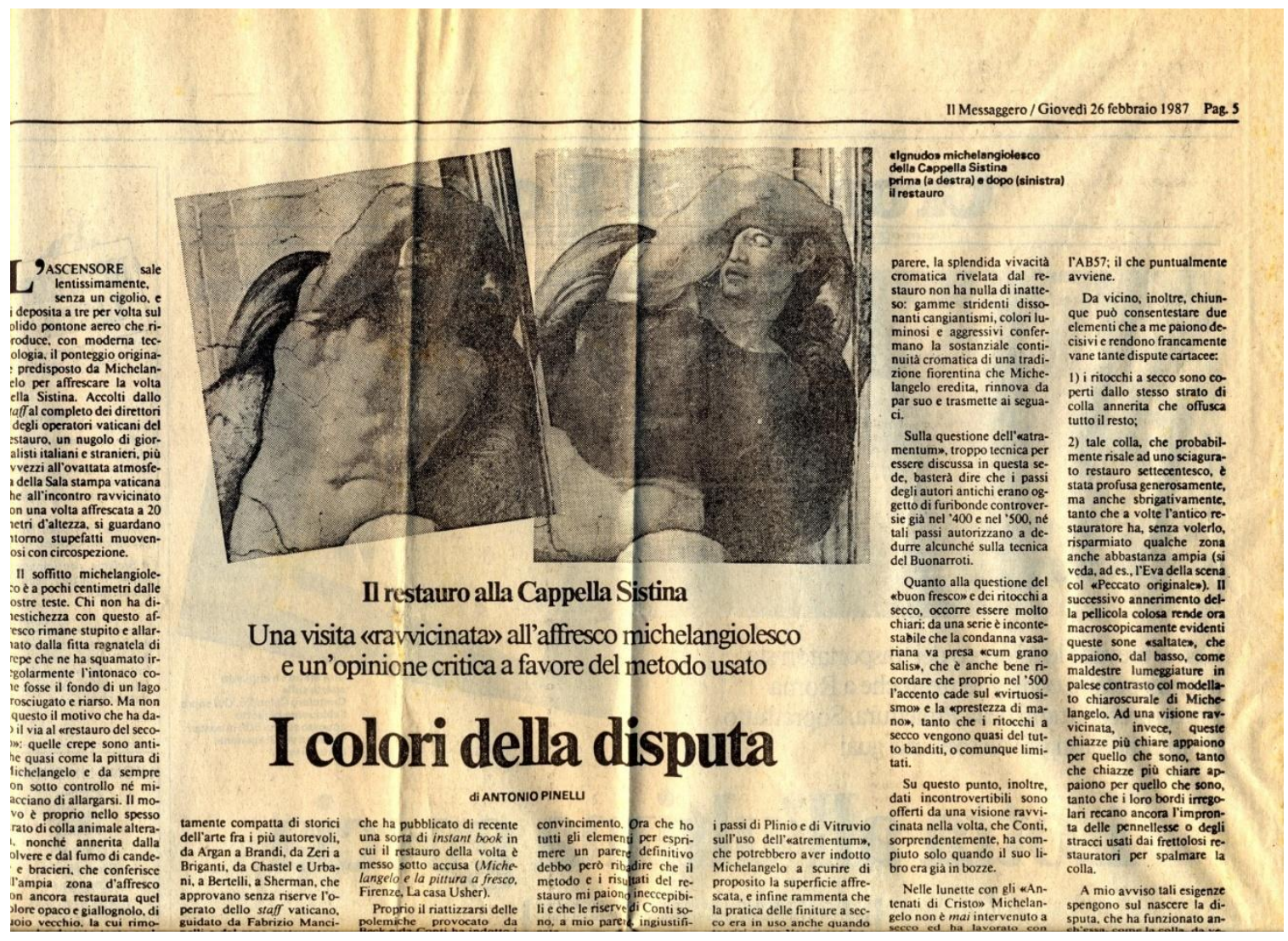

la Repubblica
venerdi 6 marzo 1987 CrOnaCa

ori furono iniziati i presunzione che lpresunzione che
elangelo non abbia ato niente" dice rico dell'arte, c'è una prova che abbia maiapplicato ati che rimuovete?" lucci risponde: "No siamo in allame"

ostro corrispondente lYORK(e.f.) - Lacrociata
icana per fermare il re icana per fermare il re
o della Cappella Sistin Ioltiplicandole sue forze.
sssor James Beck, docente
uria dell'artealla Columbias 'ersity, l'illustre studioso so con una lettera a Repub-
l, ha inviato un second saggio al nostro giorna it Colalucci, restauratore i artisti degli Usa (da Chri1 Rauschenberg, da Rosent a Andy Warhol che aveva
ritoall'iniziativa pochigior-
rima dimorire) hannoscritVaticano proponendo $\alpha \mathrm{r}$. rosamenten una pausa de
ri, perc consentire un'anal-
bale dei risultati. obale dei risultati.
firmatari hanno inviato un lirmatari hanno inviato un
logo messaggio a Rosalba
tito sorintendente alle fito messagintendente all
eArtidiBrera, perbloccar nardo. ta di James Beck: :ll pro-
or Luigi Colalucci, direttoClle operazioni di restauro ad un dibattito pubblico
dendomi:" dachepartesta,

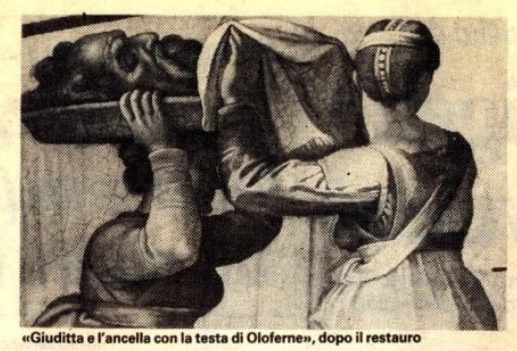

Eintantoilprofessor Beckreplicaaldirettore deirestauri Gli artisti americani
scrivono al papa
'Nontoccatela Sistina'

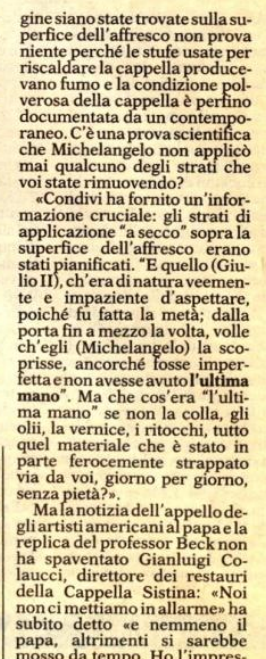


é solo una formula di tranizione, per sua stessa natua perciò labile e precaria, roprio questo rende insiene più difficile e più necesario evitarne la dissoluziote in un momento in cui non la ancora assolto il suo ompito "storico".

Da questo punto di vista, ,li sbocchi che si possono potizzare sono in fondo solanto tre.

Sulla carta ci sarebbe anora l'ipotesi che la crisi si oncluda con una riconferna e un rilancio della coaliione uscente. Basterebbe ornare all'accordo sottocritto l'estate scorsa: come ostiene la Democrazia critiana, attestata su una posiione che ha il suo punto di orza proprio in questo, nel atto cioè di richiamarsi a un npegno comune preso di omune accordo da tutti i artiti alleati. Dato però il lodo in cui Craxi si è diiesso - apertamente e inznzionalmente in contrasto on quell'accordo - si trat1 ormai dell'ipotesi meno robabile.

Resta allora da vedere se 1 vicenda della crisi prendeì una piega per cui la tela el pentapartito ne risulterà efinitivamente e irrimediailmente lacerata, oppure omporterà soltanto uno rappo che, dopo le elezio$i$, potrebbe essere ancora cucito.

Per il aiomento, in questa rima fase, tutti si stanno luovendo in modo da no rovocare guasti irreparabiLo stesso Craxi, con uno i quei gesti "double face» re sono tipici del suo stile olitico, è uscito da Palazzo higi sbattendo la porta ma sciandola aperta, badando oè a non dichiarare ormai onsunta l'esperienza del entapartito. Tutto sta a veare come si metteranno le sse quando la crisi arriverà passaggi più rischiosi. levisione alla nazione in questi toni di autocritica.

All'indomiani del discorso - in cui Reagan ha ammes so -ci sono delle ragioni.per quello che è accaduto, ma non ci sono scuse. Fu un er rore. e ha aggiunto *come dicono in Marina, è accadu. to nel mio turno di guardia. concludendo quindi "quan do uno sbaglia prende $i \mathrm{col}$ pi, impara la lezione, e poi va avanti* - per quanto l'Irangate non sia dimenticato, la più grave crisi di quello che fino a poco tempo addie. tro era uno dei più popolar presidenti degli Stati Uniti viene inquadrata in una luce differente, più. possibi-

La risposta psicologica, a

Casa Bianca.

A quanto afferma la rete televisiva per via cavo della Cnn, dalle conversazioni che il colonnello North credeva di avere cancellato ma che hanno ascoltato $i$ tre inquirenti del rapporto Tower, risulterebbe infatti che North come anticipato in dicembre dal piccolo giornale de Massachusetts *Lowell Sun*) dirotto fino a 5 milion di dollari, pari a 6 miliardi e mezzo di lire, provenient dal ricavato delle vendite di armi all'Iran e destinati secondo il piano clandestino principale ai contras, a 15 organizzazioni repubblicane di estrema destra, che avreb. bero utilizzato parte della somma per screditare con la

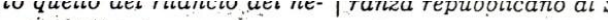
Giudicata "molto positiva» dai sovie la risposta americana sugli euromis

NEW YORK - Il presidente Reagan ha detto ieri accordo per l'eliminazione dei missili a medio-raggi l'Eordo per leliminazione dei missili a medio-raggi momento di grandi speranze per tutta l'umanita discorso dination. Washington, il capo della Casa Biana Associatic mutamento di posizione del Cremlino - he hatlo c negoziato sui missili tattici crepri - che ha separi esperimenti americani sulle uropel dalle limitazioni sentato un passo molto importante nel neria - ha ra La proposta sugli euromissili presentata. Uniti a Ginevra è stata giudicata «molto positiva sovietici. Lo ha detto il portavoce del ministero Esteri, Gennady Gerasimov.

\section{Ma la «pop-art» non c'entra con la Sistina e il Cenacolo}

\section{di GIOVANNI TESTOR}

E', certo, un bene inalienabile della società democratica quello di concedere a ogni uomo d'esprimere la propria opinione su ogni tema che, in un modo o in un altro, lo riguardi; tuttavia, per onorare tale libertà, sembra necessario che quant intendono riferire il loro parere qun intervenire su quei temi, ne conoscano nei modi plù concreti e profondi, i var soggetti. Da anni assistiamo a una sort di match pro e contro un determinato restauro, come se si trattasse d'una partita a tennis.

L'*ultiman, a proposito dei due restauri più celebrati e contrastati, quello della Sistina e quello del Cenacolo, ci arriva dall'America. A scrivere la lettera che invoca la loro sospensione è un gruppo d'artisti, quasi tutti appartenenti a ciò che fu la pop-art. E' curioso come anche 1 maestri dell'arte più prossima alle chiassosità e alle violenze strapazzate e strapazzanti dei "median, quando si chinano vori dell'arte antica rivelino d'amare monocromie l'oma re lindistinzione grigiume e, forse non lo lindistinzione, il quel pattume che tom sanno, il pattume; quel pattume che tempo e umana incuria sti, prima di firmare un Ma, questi artisti, prima di firmare un simile appello, come son se, alle volte, proprio anche Michelangiolo per diverse ragioni, tessero desiderare, e volere che un a por- ro fosse azzurro e non azzurro-sporco e un rosa, rosa, e non rosa-sporco?

Personalmente ho già espresso il mio parere, interamente positivo, sulle due operazioni in corso. Questo, pero, l'ho fatto avendo prima riconosciuto cio che mi sembra una palmare verità; palmare ancorché possa parer umiliante. Tale ver: tà è la seguente: per mezzi tecnici che s'abbia a disposizione ogni restauro por ta sempre, e ineluttabilmente, con sé segno del tempo in cui e stato ese su questo senso, un buon conoscitore di cose dell'arte dovrebbe essere in grado di-sta bilire la data e persino la regione d'esecuzione d'ogni restauro proprio dall'aurea zione d'ogni restauro proprio dallaurea te, certo inconsapevolmente, trascina con sé e, dunque, evoca. Tale ineluftabilità permarra perà lasciato robotizzare; finomo non sl non sarà insomma diventeto lumo Sventura ben più grave della totale spari zone della Sistina, del Cenacolo e d'ogni alto segno dell umano cammino. Solo partendo da tale umanta cam base e possibiper per quanto concerne in restauro, come conce concer si parte dalla superia dintervenire nel piu assoluto e i i tallo si parte dalla totale esclusione della propria cultura, della propria intelligenza e della propria sensibilita, l risultati po-
A pagina 13 Andrea Bor
Parla il vesco

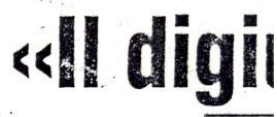

DAL NOSTRO INYLTTO SPECL REGGIO EMILIA mincia con una piccola gia della suorina: "Il ves non c'en. E invece c'e. diato dai giornalisti che rebbero intervistarlo. di portarlo sotto i rifle di portarlo sotto 1 rife per uno special del Tg1. berto Baroni, ll vescovo televisivo dersi dall' 'cerca di di media Sera. racconta perché $h$ ciso di ammonire i te contro l'overdose di vide

siamo entrati in Que

Siamo entrati in Qua ma, abbiamo quaranta cieta lita di baldoria piú ina sce le sorgenti e piu ina cosi ho indicato nell'eler na nella preghiera riuno" strade da perce giuno le strade da perc Pasqua*.

- I digiuni ormai li fa Pannella. Va piư di mod sciopero della tane

dero slamo arivati lndigestioni. Di cibo e d tavola e poi tutti insegu

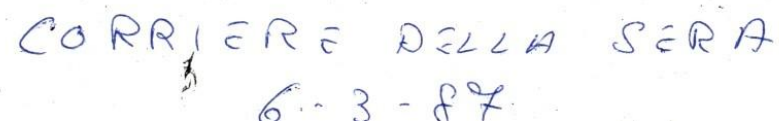


I restauri alla Cappella Sistina: il punto dopo il nuovo «siluro» di artisti e studic

langelo scoperto

to? A tinte

oppure a tutta luce?

re della polemica

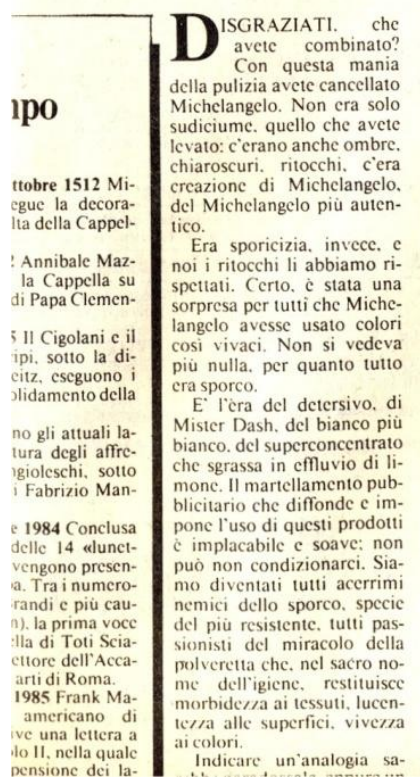

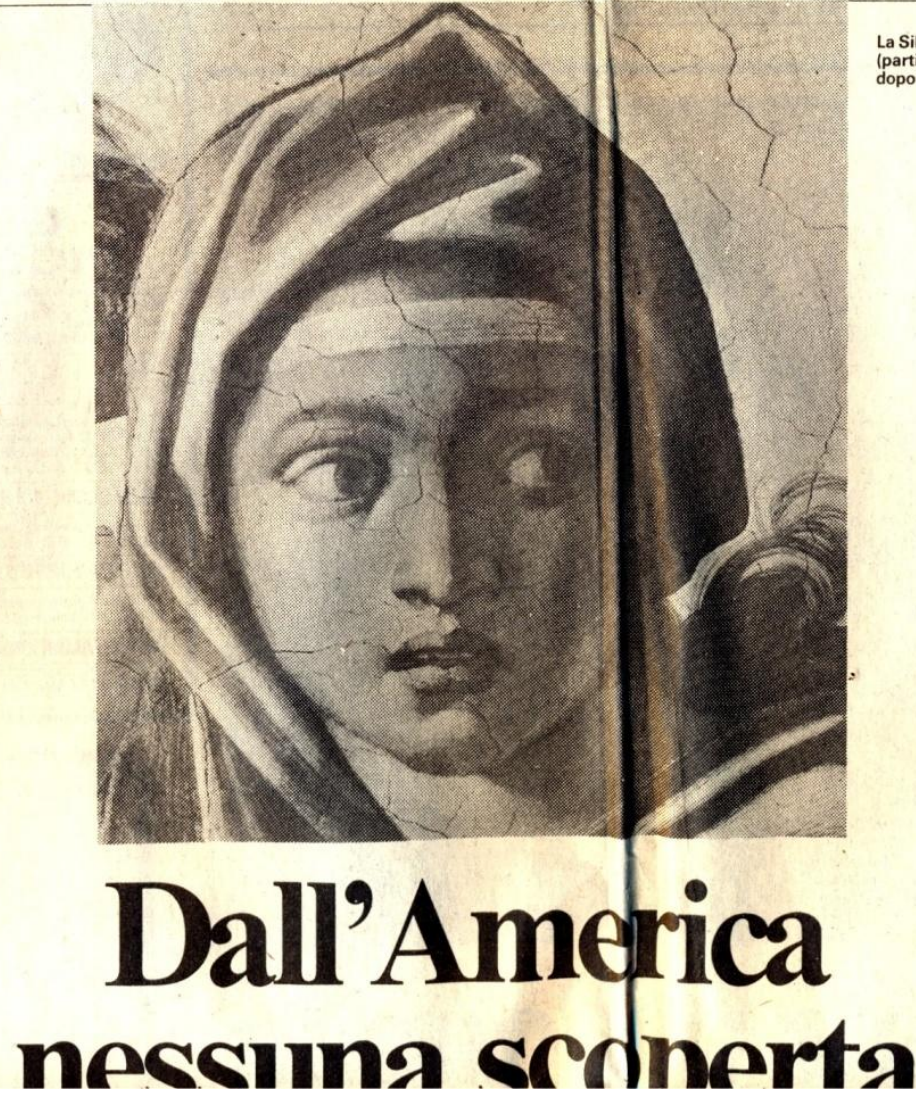

La Sibilla Delfica

(particolare)

L'c

Ciòc

te

ottenere la sospensione dei lavori. Succede cosi che Miin ogni caso immaginario. tutto cupezze e foschie, ven ga difeso dall'usurpazione $\mathrm{d}$ parte di un Michelangelo inedito e sorprendente, tutto Eci contrastasti e colori. E' curioso che tra i firma tari della petizione, i paladni del Michelangelo, diciamo gurino avanguardisticome la bonanima di Andy Warhole. udite udite, quel Christo che mpacchetta monumenti co eli di plastica. Per bizzarric capitoline. I'ufficio è a Rome. de me cbe a disposiziodecina d'anni prime era riuscito a farlo al Festival di Spoleto. impacchettando tra 'altro la fontana di Piazz delrorologio. Sul lato sin stro della fontana, cera un piccolo alloggio dove abitava Ricordo il caldo pomerige. di luglio in cui l'opera di Christo fu parzialmente

squarciata per dare aria alappartamentino. Nello squarcio apparve una loggetcillo giovane donna. incinta gros-

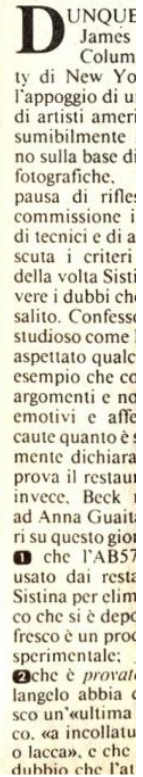




\section{„o il nuovo «siluro» di artisti e studiosi Usa}

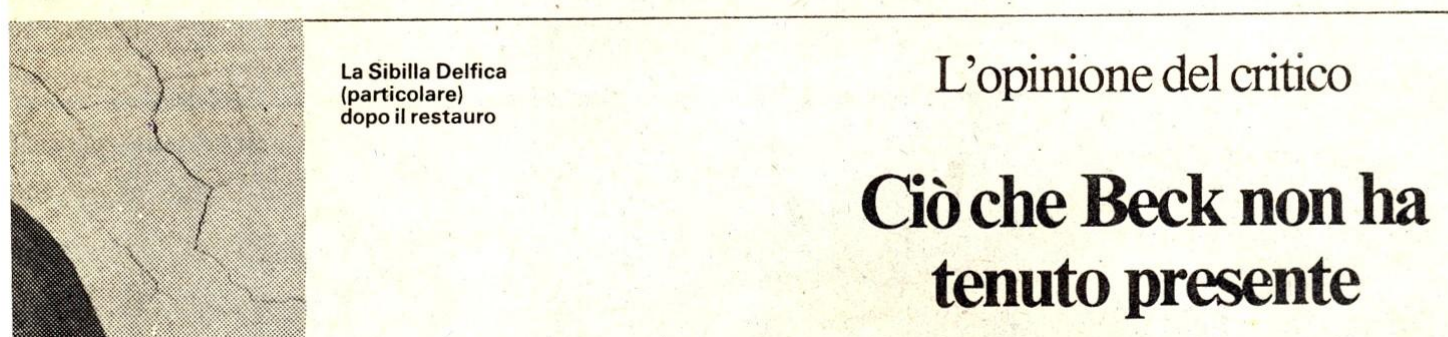

di ANTONIO PINELLI

ottenere la sospensione dei lavori. Succede cosi che Michelangelo, un Michelangelo in ogni caso immaginario, tutto cupezze e foschie, venga difeso dall'usurpazione da parte di un Michelangelo inedito e sorprendente, tutto luci e contrastasti e colori.

E' curioso che tra i firmatari della petizione, i paladini del Michelangelo, diciamo cosi. della conservazione, ficosi. della conservazione, figurino avanguardisti come la
bonanima di Andy Warhol e bonanima di Andy Warhol c,
udite udite, quel Christo che impacchetta monumenticon teli di plastica. Per bizzarrie capitoline. I'ufficio è a Roma, dove ebbe a disposizione le mura Aureliane, e una decina d'anni prima cra riuscito a farlo al Festival di Scito a farlo al Festival di Spoleto. impacchettando tra l'altro la fontana di Piazza dell'Orologio. Sul lato sinistro della fontana, c'era un piccolo alloggio dove abitava un dipendente del Comune. Ricordo il caldo pomeriggio di luglio in cui l'opera di Christo fu parzialmente squarciata per dare aria alsquarciata per dare aria alsquarcio apparve una loggetsquarcio apparve una loggetSulla loggetta ansimava una giovane donna, incinta grossa. pallida, lc occhiaic incavatc, il sorriso della sopportazione. Tutto bene, per carità. ognuno ha il diritto $\mathrm{d}$ pensare e dire ciò che vuole su tutto, naturalmente anche su Michclangelo, ma che centri Christo con i restaur della Cappella Sistina lo sanno solo il professor Beck c il no solo il
buon Dio.

Michclangelo scoperto o tradito: la polemica, come si suol dirc, divampa, ma non guasta, anzi si può dire se sia guasta. anzi si può dire se sia provvidenziale. Se non fosse stata polemica, questa
imponente, paziente, sapienimponente, pazicnte, sapien-
te opera di finissimo artigiate opera di finissimo artigia-

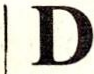

NQUE, il professor James Beck della James Beck della ty di New York, forte dellappoggio di una quindicin di artisti americani che presumibilmente si pronunciano sulla base di riproduzion fotografiche, invoca una pausa di riflessione e una pammissione internazionale di missione internazionale ditecnici edi artistiche ridiscuta 1 criteri del restauro della volta Sistina per dissovere i dubbi che lo hanno as salito. Confesso che, da un studioso come Beck, mi sar aspettato qualcosa di più, a esempio che contestasse con argomenti e non con appel cmotivi e affermazioni in caute quanto è stato ripetutacaute quane stato ripelutamente dichiarato da chi approva il restauro. Cosa dice, invece, Beck nellintervista ad Anna Guaita riportata icri su questo giornale?

(1) che l'AB57, il solvente usato dai restauratori della Sistina per eliminare lo sporco che si c̀ depositato sull'affresco è un prodotto nuovoc sperimentale:

2che è provato che Miche2che erovalo che Michelangelo abbia dato all affresco un "uultima mano" a secco, «a incollatura, olio, colla o laccam, c che èc il fondato dubbio che l'attule restauro, oltre alla sporcizia, rimuova anche questo strato originale:

3 che s'impone una commissione di studiosi espertio di studiosi esperti estranci all attuale restauro. perché finora gli studi suir risultati sono stati condotti solo da coloro che hanno parte in causa nel restaurostesso.

Ebbene, tutte e tre queste affermazioni di Beck sono destituite di fondamento:

- I'AB57 è tutt'altro che un prodotto sperimente un prodolto sperimentale, giacche vine usato con (2) non c"c alcuna prova che fatto e che sono perfettamente visibili guardando da vicino la volta. Nessuno ha mai negato che questi ritocchi nesistano (tranne nelle lunette con li (trantenti di Cristom. con gli «Antenati di Cristo», condotte interamente "a buon frescon). Sono rari, limitati, ma esistono; chiunque abbia un po' di esperienza li può riconoscere per la diversa consistenza della materia e la differente reazione alla luce. Ci sono, $\mathrm{e}$ infatti vengono correttamente trattaticon le dovute cautele trattati con le dovute cautele cue sostanze diverse da quelle usate sulle parti ad affresco (giacché, come è noto, sono ben più delicati e alterabili)

C'è poi il problema dello spesso strato di colla animale che copre l'intera volta e che, annerendosi col tempo anche per via del fumo di candele e bracieri. le ha conferidele e bracieri, le ha conferio quel color acuoro vecchio bisunto" cui i detrattori de! restauro sembrano tanto af fezionati. Più cauto di Beck. Alessandro Conti (l'unico altro storico dell'arte che si è pronunciato contro il restauro attuale) non nega che tale strato colloso possa essere anche composto di sporcizia c di colle incautamente spalcili coll incautamente spal mate durante i restauri ne secoli scorsi, ma aggiunge anche che probabilmente una prima stesura risale a Michelangelo in persona. che cosi avrebbe voluto ottcnere un abbassamento dei toni troppo vivi

Ma su questo, come ho già avuto occasione di scrivere. csistc un riscontro decisivo. che si può compiere agevolche si puo compierc agevolmente salendo sui palchi do $\checkmark c$ in corso il restauro. Da vicino, infatti, si vede chia ramente che tale strato $d$ colla fu applicato con generosità (c sopra i ritocchi a secco originali). ma anche sbrigativamente, tanto che 

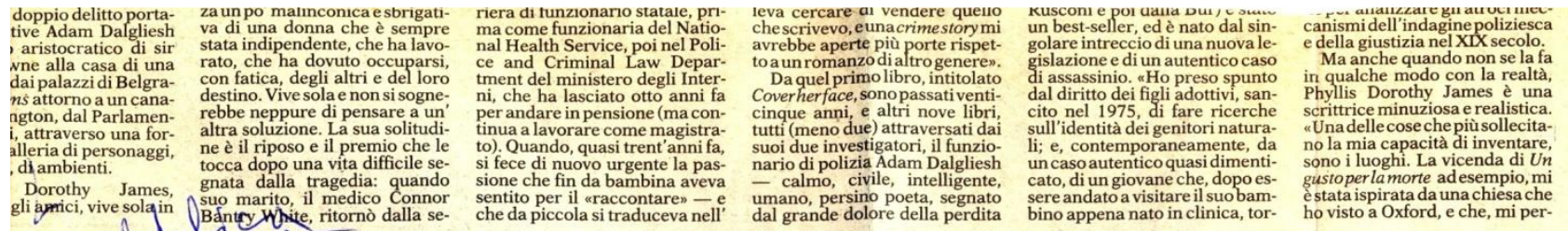

story america
hard-boiled, of za le paure, $c$,
traverso un pe cariamente, e
il senso di in "giallo" ogni p In qualche mo delitto immag differente alle

umano, persino poeta, segnato sere andato a visitare il suobam-

रिए wa A proposito della protesta di quindici artisti americani per i restauri della Sistina

\section{Quando si firma al buio}

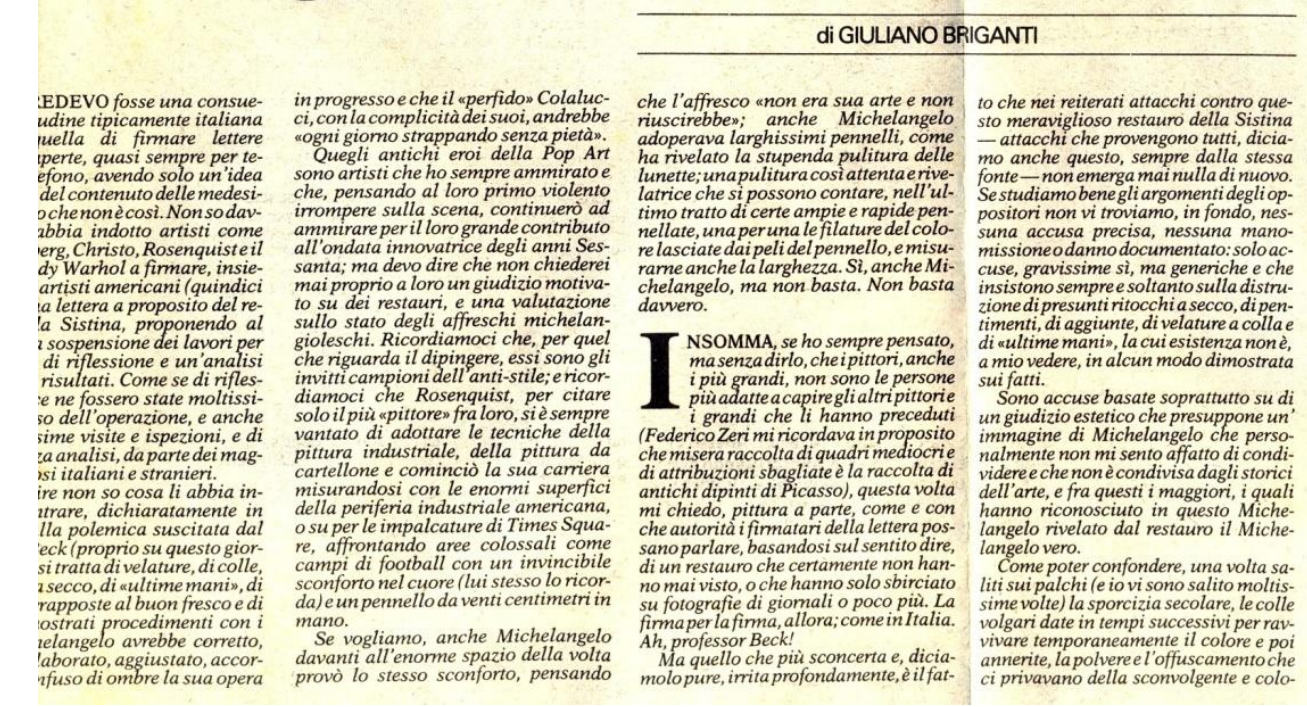

ratissima immagine di Michelangelo, con accorgimenti indimostrati e indiMichelangelo quando iniziò un'opera cosi colossale senza aver pratica dell af-
fresco? Certo ci fu: ma seppe superarla fresco? Certo ci fu: ma seppe superararla alle lunette con gli antenati di Cristo dipinte di getto, in sole tre giomate di lavoro, una per ogni figura e una per la targa con i nomi, e dipinte senza canone, con una sicurezza che spaventa,

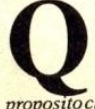

ANTO ai ritocchi, alle veature, certo, none detto che see in qualche casovelasse. Ma bisogna ricordare in ènecessario, perchéil ale, che il colore sia distribuito nell giomata, cioè quando l'intonaco è anre sul dipinto ottenendo che il colore si impasti con lintonaco ancora umido che quindi raggiunga una medesima ro solvente (ché si tratta di un leggero solvente) come l' affresco.
Molte altre cose po risposta ai dubbie ai accuse del professore
do sia questa la sede particolari tecnici. N fermare il mio giudi stauratori, sia in chi Posso aggiungere tu sempre il massimo preoccupa per la co opered arte quindi a passato, sono stati per Vorreiperòinvitar a rivedere nuovamen cantee appiattentede cante e appiattente de
contro il parere stess e della direzione dei poste sotto gli affres giomo di rivedere co ticare la straordinar vita e di grandezza $c$ luce crudele da to emanava dalla volta. parte dovuto propri
piattente di quella giudizionegativo del
dichicondivide le su

\section{PAPA ECOIOGISTA:}

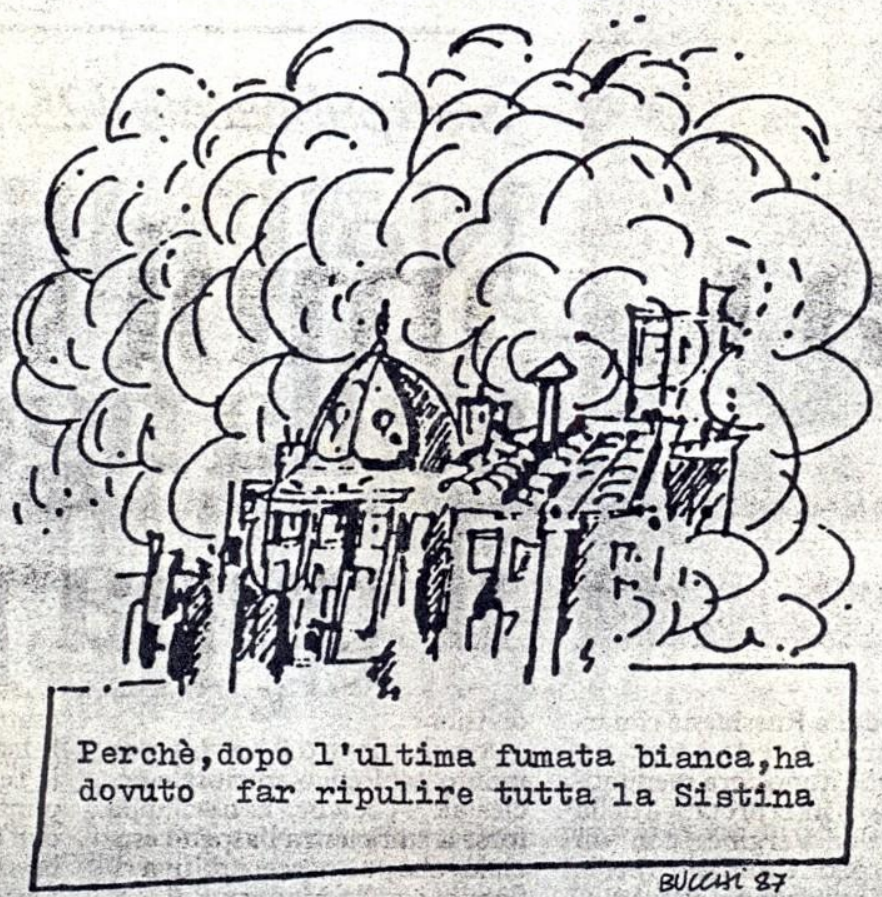

BuCCAt 87 
Visita ai restauri della Cappella per rispondere alla polemica sollevata dall' american

\section{Lassù, in cima alla Sistina Michelangelo inventò metodi nuovi di stendere il colore}

di CARLO BERTELLI

ه ulla piattaforma eretta sotto la volta della Sistina, in corrispondenza della scena con il «Peccato Originale», Fabrizio Mancinelli, direttore della Pinacoteca Vaticana, e Gianluigi Colalucci, il capo restauratore, mi aspettano. Sono sorridenti come li ho sempre visti. "Non sapevo che Beck fosse stato due volte qua", dico. "Oh, sì, mi rispondono; l'ultima nel novembre scorso. Si congratulò con noi, partì e poi ci scrisse che non era d'accordo e che dovevamo sospendere i lavori». «Ma anch'io ho una lettera di Beck!» esclamo e la tiro fuori.

In sostanza James Beck mi scrive: «Forse, il punto cruciale di questo restauro è il seguente: ci sono porzioni o strati di "colla" posta dallo stesso Michelangelo? Poiché, come sai, loro stanno togliendo tutta la colla (fatta, come i tuoi amici hanno detto, di colla animale, made from animals)". Infatti, dice sempre Beck: "Io credo che Michelangelo come preparazone Michelangelo come preparazione per ritocchi a secco (to prepare for secco adjustements) e per dare unita all'insieme (for unifying purposes), come pensa anche Conti, che ha maggiori conoscenze tecniche (expertize) di mem.

Senonché né Beck né Conti hanno individuato un punto preciso, in tutta la pittura di Michelangelo finora restaurata 0 in via di esserlo, dove si trovino colle apposte da Michelangelo e non dai suoi restauratori. Conti, l'autorità tecnica cui fa ricorso Beck, nella copertina del suo libro riproduce la testa del profeta Daniele, che non è ancora restaurata, ma che dal ponteggio si può vedere da vicino e appare come un vero campionario di imbratti e grossolani ritocchi. La forte cui a sua volta fa riferimento Conti non sono osservazioni dirette delle sezioni (sondaggi nello spessore dell'intonaco dipinto che permettono d'individuare, come in una fetta di torta a più strati, le vicende successive d'un dipinto e quindi di distinguere le sostanze originali da quelle sovrapposte), né altri rilievi al microscopio, ma l'autorità d'un manuale scritto nel tardo CinqueGiambattista Armenini. Quello sì che aveva bisogno di colle e di fumo con aveva bischo di colle di fumo con cut ribuire lo stesso attribuire lo stesso procedimento a fich ficato. «L Amenin, si obietta seriosamente, è una fonte pià valida di Vasari, proprio perché, artista piu modesto, Vul dire he pare ricette a Gualtiero Marchesi ma al pare ricette a Gualtiero March

In quanto poi all'ipotesi che uno strato di colla fosse stato steso da Michelangelo per poi dipingervi sopra, non esiste proprio nessun supporto per sostenerla. Un ritocco a tempera si fa "stemperando" i pigmenti nella colla, non dipingendo su uno strato di colla. Argomenti che da quassù, a contatto con la volta affrescata, perdono ogni consistenza. Michelangelo fu un grande sperimentatore anche nell affresco. Dipinse ogni lunetta in mai più di tre giornate e invento modi nuovissimi stendere il colore, acquoso e trasparente, talvolta premendo il pennello largo perché, così scorrendo, lasciass un segno aperto, l'equivalente in pittura di ciò che era la gradina nel marmo. Dall'alto, si osservano cose impensae. La volta è quasi modellata da diverso spessore degli intonaci e dove le vele sopra le lunette s'incontran con l'imbotte e formano un piccolo rialzo a uncino, ì Michelangelo ha collocato i suoi bucrani grigi rilevati col bianco di San Giovanni. E' di una scultura dipinta, poiché in quelde la plastica, mentre qui un rilievo plastico en base stereometrica del tutto l'architetura che divetamorfosi delerso la pittura.

Le giunture fra le giornate si avvertono appena; Michelangelo non ha avuto quasi mai la necessità di ritoccare la parte già fatta per accordarla con la nuova, poiché era riuscito a tenere gli stessi valori cromatici passando da una giornata dintonaco alla successiva. E anche nelle scene, ha lavorato con una decisione impressionante: la figura di Eva dopo il peccato, per che sembra dipinta in polemica con $\mathrm{g}$ studi di Leonardo per la «Leda», è stata realizzata tutta in un sol giorno. Nell'altra figura di Eva, quella accovacciata, lincarnato ha una luminosita e una delicatezza del tutto femminili, in contrasto con la pelle più ruvida scura di Adamo. Immaginare che $\mathrm{Mi}$ chelangelo ottenesse questi risultati per poi coprire il tutto con un beverone scuro è davvero un po' forte.

Quando fu tolto il primo palco dal restauro della volta palco che coincideva con la posizione che aveva occupato il primo palco per la pittura, disse che certamente Michelara, gurs a d a propria opera dal avrebbe modificato la tavolozza schiorendola ulteriormente. E' quello che pud constrore puluvion, dove la montagna in do piano appare di granito grigio rosa. Ancora più dimpra Ancora più impressionante e il vero zione degli "Ignudi»; le prime due coppie hanno colori e luci in rapporti dicato più $\mathrm{d}$ assai più minuti del fare largo e unito meno). Ne dei successivi. Certo, nei medaglioni a mondo de oro che sono presso gli "Ignudi" Mi- Omertà? chelangelo usò la tempera, ma la sua Chi conos sperimentazione come frescante non si vi si pratica rivolse, come avrebbero fatto Leonar- Direi che la do o un lombardo come il Sodoma, alla tuttora press cucina, ma a tutt'altro, come abbiamo rata che è pr

Eppure la polemica che è stata susci- certo olio tata intorno a questo restauro meravi- icone del n glioso, e che presto sarà dimenticata, da», o la ? contiene elementi di riflessione di invisibili per grande interesse. E' nata nell'ambito In fondo, l' delle università, e cioè nel mondo delle rhol non è st diapositive, e degli artisti che, special- ni della "Ce mente in America, non sono lontani copia, perdu dalle università (Dan Cameron ha de- Giuseppe Bc
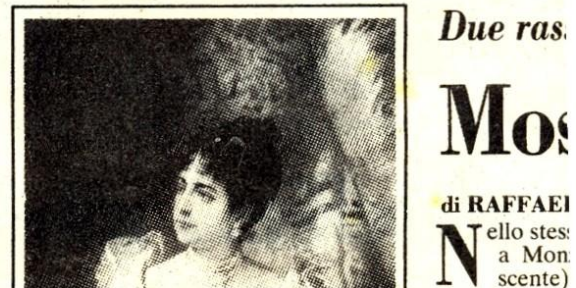
1 a Mon 169 dipinti pii (1840-1904) (1840-1904) a stanno per an dalla collezior sio. Un grand sio. Ungrandi pea per que ricorda in ver delle rare e state organizz: quella ordina nel 1924 nella scente Villa $\mathrm{R}$ Non è tutt tante opere d esposte al put sè Bianchi è facondo, ha piaciuto di fa porsi come il do di passags e il pieno nat

Ne consegu la presentazio ede una scelt oggi far sbuca vere e propric padre in fig padre in fig patrificabili Mosè Bianchi: «Ritratto di Giulia Lucini
Colombani», olio su tela, Ospedale Maggio-
quindi più di
commercio. Mosè Bianchi: «Ritratto di Giulia Lucini
Colombani», olio su tela, Ospedale Maggio-
quindi più dicabili
commercio. 


\section{TACCUINO}

di Milena Milani

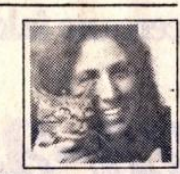

"

\section{La volpe}

La ragazza con il suo loden verde, che arrivava oltre i polpacci, venne avanti nello stretto destra, in prima fila. In bigliettaio che stava in piedi, voltato verso i passeggeri, la saluto in dialetto e lei rispose pronta, ridendo a pien ragazza inalberava sulla spalla, con la coda lunghissima condolante, disse. Oggi non mornimale si voltò verso di me che seguivo scena, poi, mentre si accomodava nello spazio prescelto, tiro sul suo grembo quella stola inocchia, come si trattasse di una volpe viva. parte, notai che gli occhi finti, di vetro, luccicaano to una volpe fulva piu o meno come quella, che mia madre metteva intorno al collo, sopra il suo cape nordesse, perche aveva anche 1 denti in vista, tra le gengive colorate.

La volpe è furba, mi raccontavano, quando quella testolina che sembrava vera, nè d horare le quattro zampe che pendevano, due chermine madre si allacciava la stola, cercavo di tirarne

Gli affreschi di Michelangelo alla Sistina Gratta gratta ecco la luce

Parla il restauratore capo professor Gianluigi Colalucci

Prima, per illuminare
quell'immenso respiro $d$ orme e di colori ci volev a forza di 28.800 watt. Tan o occorreva per vincere tempo. Adesso, una volta terminati ilavorisara suffi rivelare la pe del sole Sibilla Eritrea, del diluvio Quello degli affreschi di Sistina è stato definito gin tamente il restauro del se1980 terminerd, con gli in terventi sul Guudizio onienorme che ha aperto sipario sul mistero Miche langelo rivelando una di. ta della sua arte e sollevar che entreranno di sicuro nella storia di questa ecce peroartistico. Dai restauri finora ese langelo dai colori acces valche volta addirittura
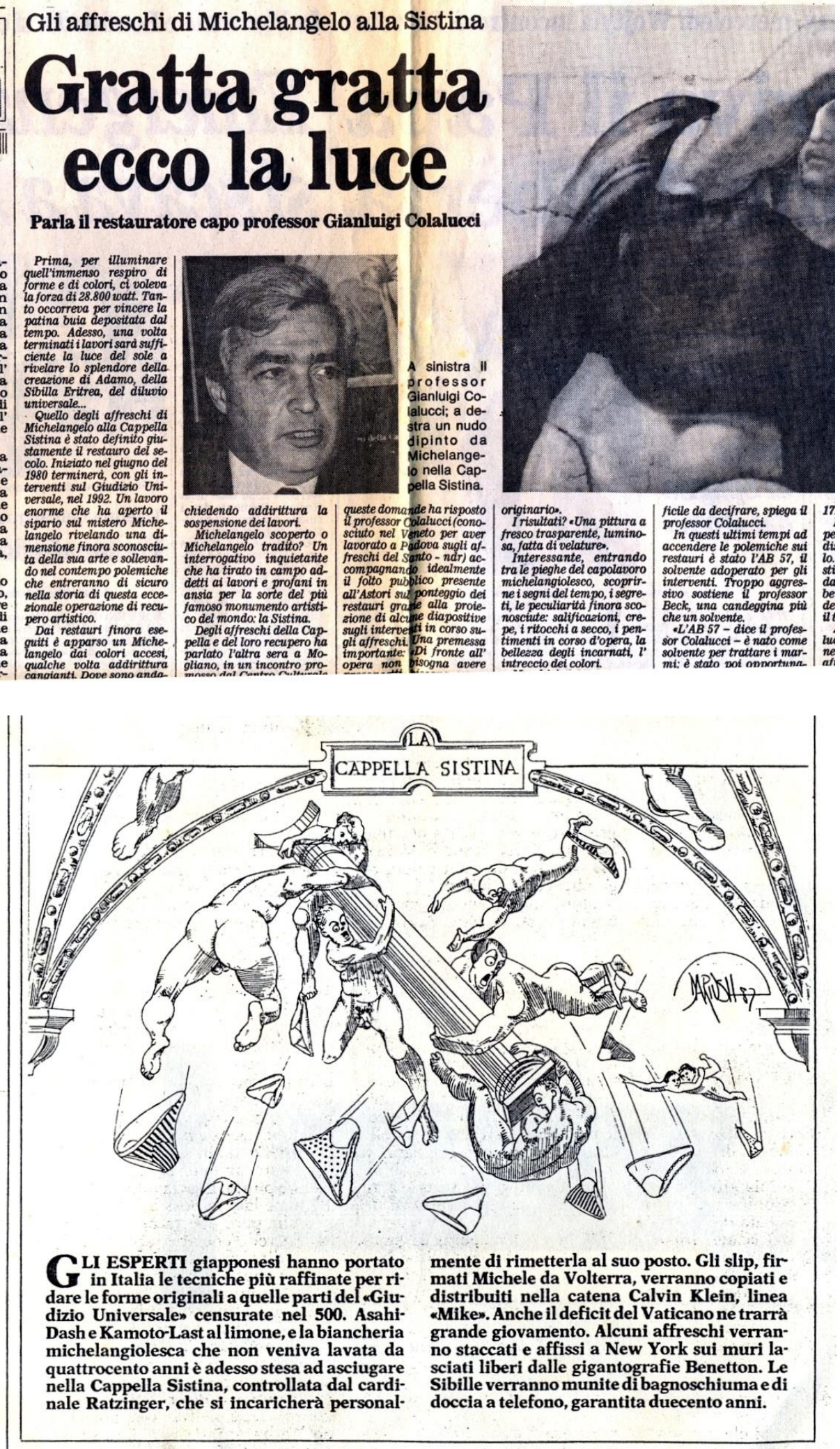


\section{«ll restauro della Sistina è ok»}

Un gruppo di 7 americani esperti del restauro

è stato inviato a Roma

per valutare

i lavori in corso in Vaticano

Il loro entusiasmo

ha scatenato tante polemiche

di ANNA GUAITA NEW YORK - voli ai lavori e quello dei contrari, le loro parole di aperta a delle forme nella Cappella approvazione hanno subita istina sono totalmente in sin- zioni da entrambe le parti. Poel sedicesimo secolo e dimo- co più di un mese fa quindici strano il pieno maestoso fui pitori americani, frat splendore della creazione di James Rosenquist e Robert Michelangelom. La categorica Rauschenberg, avevano invia政 il restauro michelangiolesco Fondazione nuovayorchese venisse interrotto «per un Samuel Kressn allo scopo di pausa di riflessionen. La provalutare i lavori in corso al posta si riallacciava a quella Vaticano: «Non è nelle nostre mes Beck preside della intenzioni prendere posizione distoria dell'arte della Colum nella polemica che circonda i dia University, studioso recisare la rande prestigio e nemico givrato dell'operazione. Adesso, Ackerman - Abbiamo inviato sull'onda del rapporto pubbliquesti esperti perché la Kress cato dagli esperti della Kress, si è sempre occupata della qualcuno di quei segnatari conservazione dell' arte italia- dice «rassicuratom e disponibia, e perché volevamo dare ai le a ritirare il proprio nome angerion esperti americani di dalla protesta. Non conving, ese che si è manifestato ne mondo intorno alla questione Sebbene i sette membri del- si dice invece ancora il profesmissione non avessero co- sor Beck: "La squadra er me obbiettivo ufficiale di con- c7mposta tutta da restaurato fibuire a dirimere la contro- - commenta, in una breve in
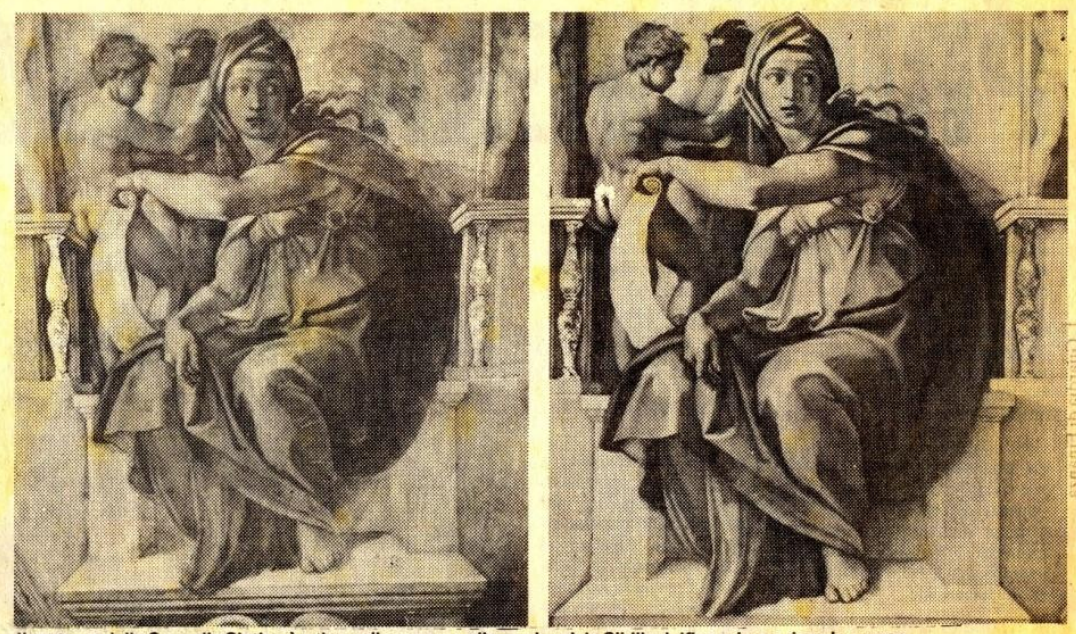

II restauro della Cappella Sistina è «okey» dicono pure gli americani: la Sibilla delfica prima e dopo la «cura»

tervista telefonica - Certo, se andiamo a chiedere a un gruppo di ingegneri atomici se sono a favore dellenergia atomiondano: sil!

(1) ri sponsorizzata dalla Fondazione Kress si trovano in effetti solo rappresentanti del mondo del restauro, anche se si tratta dei nomi più illustri David sul mercato. Da David Bull, dilla National ad Andrea Rothe, del Museo Paul Getty di Malibu fino Leonetto Tintori, restauratore degli affreschi di Giotto a $\mathrm{Pa}$ dova e di Piero della France sca ad Arezzo, l'opinione su- l'andamento dei lavori è stata unica: si tratta di un'ottima realizzazione, condotta da siancarlo Colalucci con usenstante la ripulitura degli affreschi comporti la rimorione udi vari strati accumulati $d$ sudiciume, colla e agoiunte dovute a passati restaurim, in complesso l'operazione viene giudicata "essenzialmente buona" ed eseguita "nel rispetto delle correzioni a secco operate dall artista stessom. Alon giudizio finale della cpedizione: «Devo chiarire che in $g$ nere non credo alle gruppo - ha detto il noto re- stauratore, che ha al sưo attivo gnosi resta sbagliata, e il pala ripulitura di quasi tutti $\mathrm{i}$ ziente muoren: per il professoquadri al Metropolitan Mu- re della Columbia insomma seum, oltre ai Mantegna con- rimane ancora senza risposta Vela la domanda originaria: chi ci a che due restauratisitisce che la ripulitura pensano non stia asportando anche Tuttavia questa volta siamo Tultima mano a incollatura rimasti tutti stupefatti. Non è che Michelangelo stesso rimasta alcuna riservay. -Mettiamola in questo modo - ribatte non convinto Ja- plicano all'opera è irreversibimes Beck - mmaginiamo che pe, non si potrà più togliere. sbagliare razione sull base di diagnosi. Coperaziond gli rie- dovremmo invece ispirarci alsce magnificamente bene, e le proposte dei «verdi», a una tutti i suoi colleghi gli fanno $i$ mentalità veramente consercomplimenti. Tuttavia la dia- 


\section{mi, le lettere}
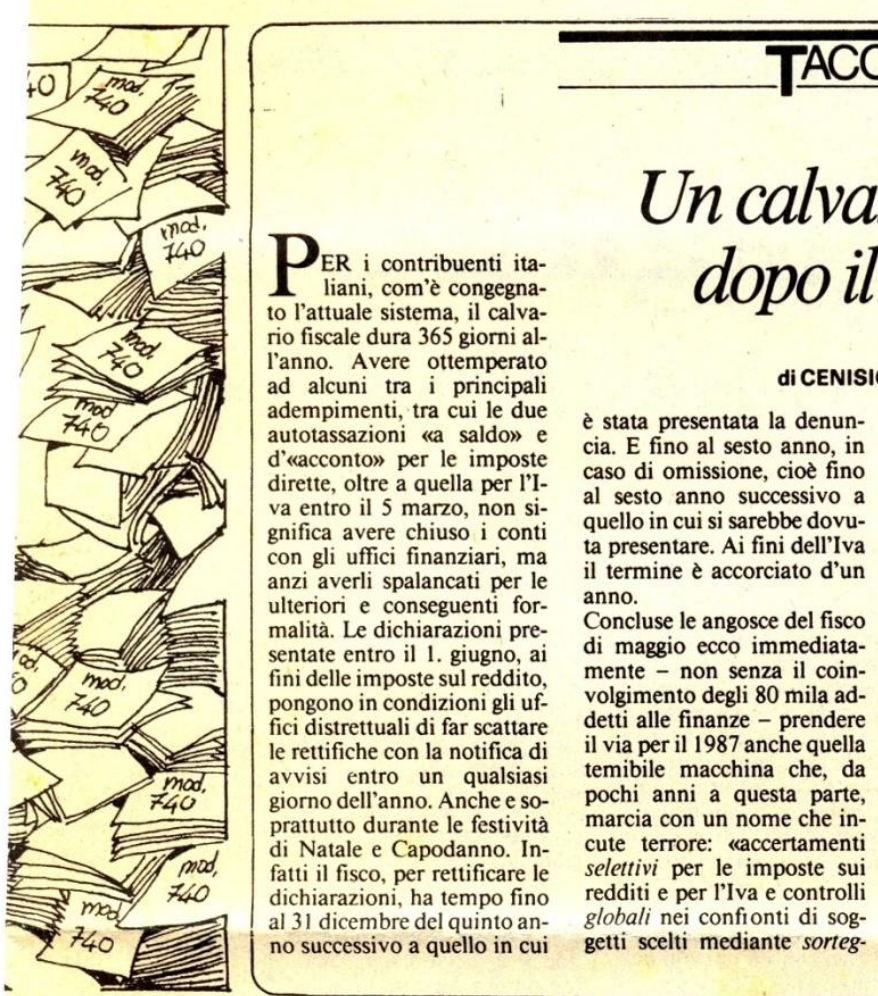

\section{ACCUINO}

\section{Un calvario fiscale dopo il «740»}

\section{CENISIO ZOPPIS}

Gion.

che però non può sostituirsi che però non può sostituirsi
con altro più breve, salvo con altro più breve, salvo menti numeri $4,5,6 \mathrm{~m}$. E cioè $i$ tre tipi di revisione che ormai il fisco può eseguire dopo quella analitica, induttiva e sintetica. Ve ne sono poi altri due: il settimo, costituito drall'accertamento in dall'accertamento in compar. ni. E l'ottavo, un immediato raschiatutto che si chiama "Art. 36 bis". E' la norma emanata per far correggere in via breve, dagli uffici e dai centri di servizio, gli errori materiali e di calcolo compiuti in sede di dichiarazione.
Il nostro ordinamento è il più ricco di leggi, decreti e regolamenti di ogni altro al mondo. Ma proprio per tale record si rende pesante, assai record si rende pesante, assai spesso contraddittorio, tanto che migliaia di leggi non mancano di essere invalidate dalla giurisprudenza delle Commissioni e delle più alte magistrature, a cominciare dalla Corte $\mathrm{Co}$ stituzionale.

Quali le conseguenze? I funzionari addetti agli accertamenti e controlli, pochi e male retribuiti, non riescono ad effettuarne neppure il due per cento (in rapporto alle dichiarioni). Con un'amministrazione più attrezzata in uomini e mezzı, più «ristrutturatas come vien chiesto da vent'anni ai geverni, ma anche con una normativa phì semplice e chiara, gli 85 mila miliardi di evasionn potrebbero diventare un rieordo d'altri tempi.

\section{DIARIO|TALIANO}

\section{A chi piace sparlare di Michelangelo}

\section{di FABIO ISMAN}

e che non si occupa di a bensi di pitture mura1 , una delegazione $d$ americani protestant ell'arte) è stata invitata na, fatta salire sul pondella Sistina, fatta colure con i maggiori esper: si occupano del «reidel secolom, e la queret) del secolom,

nbrava chiusa. e no: qualcuno ronza a attorno a Michelangeco gli importa che quefreschi abbiano compiua sorta di miracolo, met, d'accordo forse per la a volta due autentic ri sacri come (in ordine etico) Carlo Giulio ArFederico Zeri, entrambi convinti circa la bontà restauro del secolom; nuldell'Istituto centrale del $\mathrm{Re}$ stauro, Umberto Baldini, af fermi: «Finora, il risultato è perfetton, che anche altre autentiche autorità del settore, da Giovanni Carandente Carlo Bertelli, da André Cha stel a Giovanni Urbani, a un stel a Giovanni Urbani, a un riconosciuto maestro dei restaurator come Ottorin Nonfarmale trovino ineccepibile il lavoro svolto: a Beck continua a non piacere. (Con facile gioco di parole, si potrebbe dire che, nella vicen$\mathrm{da}$, il docente americano continua, appunto, a mettere il Beck).

I colori del Michelangelo risplendenti: arrendersi all'i- la lo interessa che il direttore trovato gli sembrano troppo dea che il pittore, ritenuto finora cupo, del terribile Giudizio universale fosse il precursore dei manieristi, si capisce che - alla fine - può non essere del tutto facile. Eppure, anche il Tondo Doni, restaura che il Tondo Doni, restauraassai diverso da ieri; la Pricertamente quella che abbiamo studiato a scuola; e gli stessi Masaccio e Masolino della Cappella Brancacci alla Chiesa del Carmine di Firenze - con e senza le foglie sul sesso di Adamo - ono indubbiamente di un'insospettata brillantezza. Già: il professor Beck non ci pensa e non li critica; del resto, come potrebbe? Protetti per secoli da un fre oggi un Buonarroti mavera del Botticelli non è altare mai rimosso, dalla rientranza di una finestra la brava restauratrice Ornella Casazza ha riesumato due piccoli volti che restituiscono - appunto - l'esatto «livellow di colore: proprio quello che Beck contesta.

«Noi siamo quasi a metà dell'opera - dice in Vaticano il direttore dei musei, Carlo Pietrangeli - e non interia mo affatto sospendentendiamo Siatto sospendere i lavoi. Siamo confortati dal consenso di tutti gli esperti, e sono i maggioni, che abbiamo chiamato a vigilare sull'opera, cominciando dal professor Pasquale Rotondi. Se qualcuno non è ancora soddisfatto ci può dispiacere, ma non di piùm.

Il «restauro del secolo», sponsorizzato da un network giapponese, non si concluderà prima del 1992, e raggiungerà sicuramente il suo culmine quando l'équipe diretta da Gianluigi Colalucci affronterà $\mathrm{i}$ duecento metri quadrati di affresco del Giudizio: tempo per nuove polemiche, dunque, non ne manca e non ne mancherà davvero. Anzi, l'osservatore di queste «beghe» - se è lecito chiamarle così - già paventa quanto potrà capitare: se tanti dubbi, tante proteste, tanti ronzii si levano oggi, figurarsi che cosa accadrà quando sarà il momento, anche qui, di far cadere le ubraghe" di tante nudità. In fin dei conti, parlare di Michelangelo - e forse soprattutto lo sparlarne - rende famosi: sarebbe davvero pis difficile trovar posto nelle York York Times parlando (o sparlando) di qualche pittore minore, non é vero? 
delle tingue $\dot{e}$, per cosi dire. na provocazione per il pensiero. La traduzione è sempre dime: ione di polisemia, che
puó $t$ ere fonte di ambiguità:
le co. lingue differenti. Pẹciè é pos- terprete rivela Tindicibile, laladuzione. Com- vora su una zona did confine prendere, interpretare... sono tra il dicibile e l'indicibilen.

\section{Lungo e inquietante elenco di capolavori distrutti da interventi di riparo}

Y e esiste un'avversione preconcetta ai restauri delle grandi opere d'arte come sostengono i difensori della radicale pura degli affreschi di Michelangelo nella CapSistina cosa mai la ha ingenerata? Forse concerione sacrale e irrazionale dell'invecdel passato, 0 non anto ei precede3nti drammatici e traumaanti, tali cioe da giustificare ampiamente sta avversione e Pallarme che ne consegue? assare in rassegna alcuni di questi precedenpiù gravi, non si può non convenire che la onda alternativa sia l'unica valida.

na rassegna del genere va rigorosamente oscritta ai guasti irreversibili apportati dai lauratori negli ultimi decenni ad opere fase che per ammissione generale dei critici e li storici 'arte sono state manomesse, grail ste 'arte sonte. in poste valulazioni: Der citadue soli esempi, rientrereboero in questa seda, gremita categoria aai restauri "spinti rati sugli affreschi di Perin del Vaga a Castel it'Angelo dal professor Gianluigi Colalucci. dirige la pulitura della volta michelangiolenella Cappella di Papa Sisto, ed anche que energico intervento sulla Trasfigurazione di ffaello nella Pinacoteca Vaticana che a detta qualche critico avrebbe alterato gli equilibri matici tra i diversi piani dell'opera.

on sono comunque precedenti di questo geonelli che motivano lallarme sconfinante ? altre devastazion siscussione anche se icoed ormai fuori discussione anche se i codetti esperti non amano parlarne. Quella che ue è una rassegna elic piú sommarie, limitat tempo, che attinge alla memoria frammen a ma indignata di un non addetto ai lavori. en poco è rimasto della Zingarella o Ma ina del Correggio a cui mise mano negli anni ta Stanislao Troiano per portare incautante via la seconda stesura del Maestro e cosa la deliziosa figura di un coniglietto.

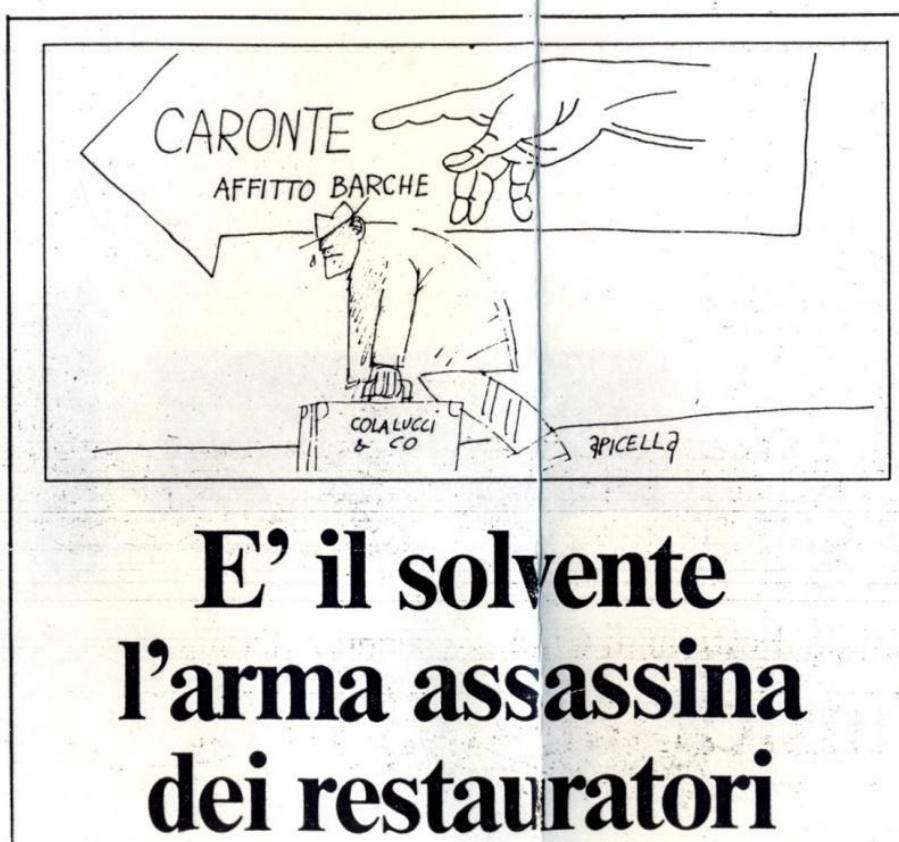

di Lucio Manis so

mento: tralasciamo il Battesimo di Cristo rovi- ritocs a secco di Piero, è andato distrutto l'e nato negli anni sessanta o l'opera di Brera ma- (a quilit,io igroscopico tra la parete e la pittura nomessa in data piu recente quando era sovrin- fresce, il degrado dell'opera non può più essere tendente alle belle arti il Bertelli che ora difende ferms:o.

a spada tratta i restauri della Sistina, soffer- Ma ${ }_{b}$ rado ripetuti interventi in ertremis non
Su un altro capolavoro di Paolo Uccello, la Madonna di Dublino, intervenne negli ann Sessanta il solito istituto centrale del restauro asportando un pentimento dell'autore, quel meraviglioso manto azzurro concui egli aveva voluto affilare l'eccessiva rotondità del viso.

Due opere di Giovanni Bellini sono uscite sfigurate dalle mani dei restauratori: uno di questi, il Ruehmann, negli anni Sessanta rimos- se con un eccesso di solvente lo ciglia dal ritratto del Doge Loredan della National Gallery: nella Madonna di Alzano Mageiore a Brera, nella Mador quadro parialmente ridipinto nell'Onocento. un recente saggio di pulitura ha lasciato un vero e prio buco mella pancia del Ba Risalgono all'inizio degli anni Ottanta i gua sti apportati da Renato Pasqui agli affreschi del Correggio nella Cupola del Duomo di Parma ora più di quella del Correggio si può vedere mano del Pasqui che ha ridipinto a tempéra e di gran lena gran tratti dell'opera.

Alla fine degli anni Cinquanta rivediamo a

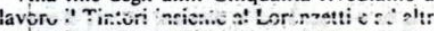
sugli affreschi i Buffalmacco e di Piero di Puccio nel Camposanto di Pisa:- sbagliano malamente la rimozione a strappo, usano per il Piero di Puccio supporti impropri, disperdono le fasce decorative, provocano l'erosione di sali che si mangianointeri tratti degli affreschi.

E' dello scorso anno il maldestro intervento di Edo Masini sulle Storie di Giuseppe di Andrea Sarto nella Galleria Pint: ha rimosso 作 olio scambiandolo per sporco e la pittura ap-

Dulpito di Donatello a Prato. negli anni Cinquanta Pier Sampaolesi applico un trattamento impropriodi silicati provocando il istacco delle superfici marmoree.

Chiudiamo questa obnubilante e spaventos rassegna con uno degli episodi piủ sconcertanti. la scomparsa del piccolo affresco delle Storie Adamo ed Eva di Raffaello nelle Logge del $\mathrm{Va}$ icano: scomparsa è if termine esatto perché nel 1977 venne cancellato del tutto da un errore de restauratori. 1 dirigenti del Laboratorio Vatica- 


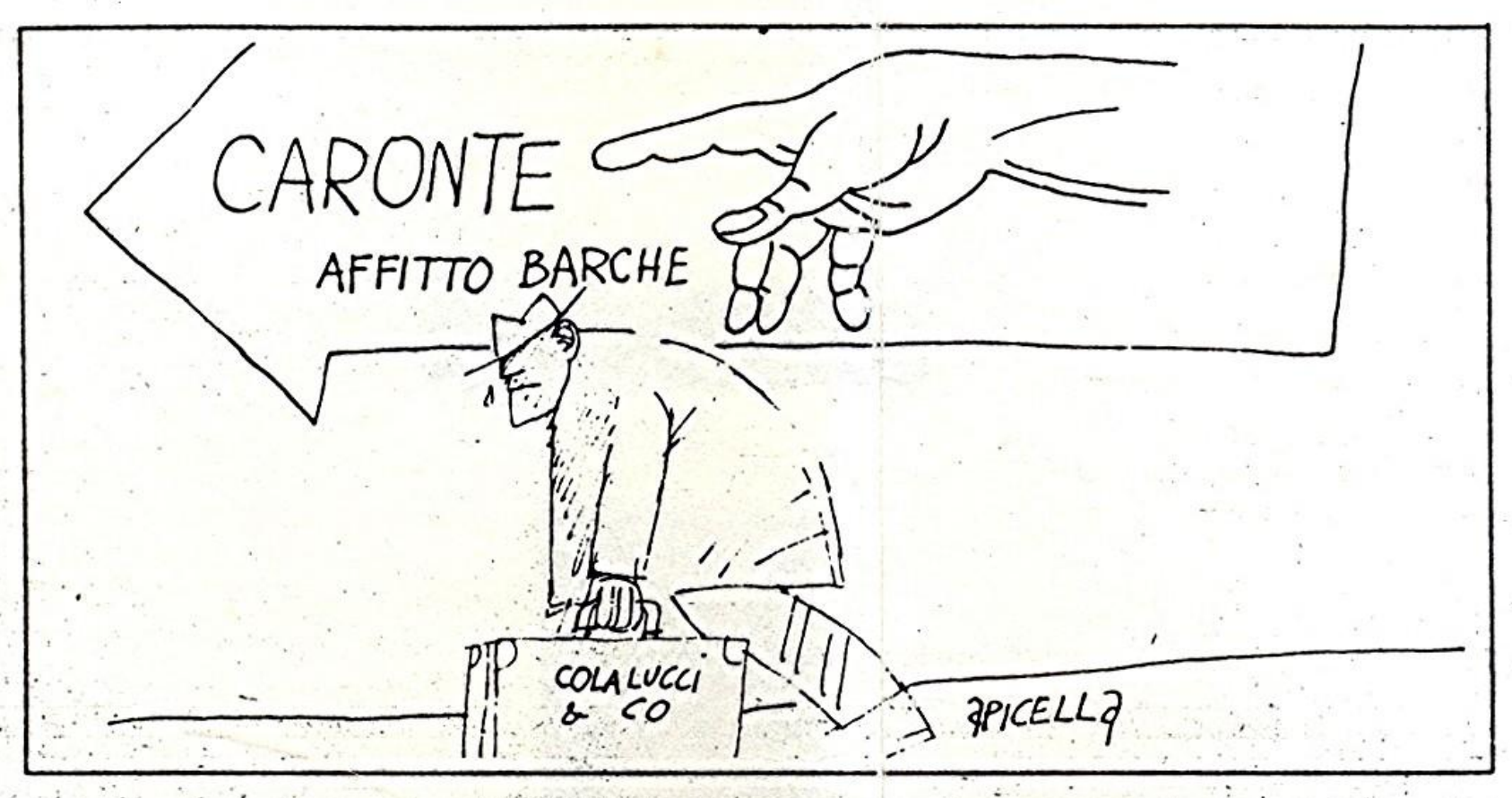


TRA LE MOLTE usanze italiane quelia diil settito di in prossimità di Natal in prossimita di Natal ntra nel numero del adizionis, fortunatamenin regresso. Infatti, in ossimita delle feste natal : la quantità dei libri-ogtto (troppo spesso «poets* gonfiati e inutili) im essi sul mercato, si è decimente ridotta. Tuttavia, $r$ cio che concerne talune se editrici che per necesà di programma debhono rre in circolarione $i$ proi prodotti in questo perioi prodotti in questo periodellanno, considerato me oggi si riscontri, sonte, uninversione. di tennza, con luscita di volumi esso di qualità molto eleita. Tra questi (evidente utto di una lunga prepazione) è da segnalare $* L a$ ippella Sistina, i primi rezuri la scoperta del colo-, presentato dall'Tstituto eografico De Agostini. II sto yuole essere una prima intualimzarione su quanto crso dalla pulitur freschi dell'intero ciclo ranos iamente, la parpreponderanie e dedicata capolan dichelan10. .7 . compitout critch redatts stuajasi e spectalist nelle tir e nelle tecniche rinascentalis sono improntati al assimo rigore scientiffico. panorama filologico sull' nbiente culturale romano, a il 1480 e il 1540 , è dato da ndré Chastel, mentre, ihn Sherman, oltre a indaure 1 valori del contesto orico-artistico in cul sanno realizzati Gli a razmi no reallo raflallo per la Cappella stina, opone un riesae degli anteratti dell imesa michelangiolesca, cioe 28 custruzione della capllla e la prima decorazione tempo di Sisto IV. (1) spa che fece edificare quei Vaticano e che gl! dette il: ome).

A Pierluigi De Vecchi si sve, invece, il bel saggio sul siudizio Universale: fonti onografiche, reazioni, inrpretazionis. Vale a dire: lichelangelo dopo l'impat, ancora giovanile, con la istina, alla luce delle deluoni per la mancata esecuone della sepoltura di Giu, II e delle lancinanti espe-

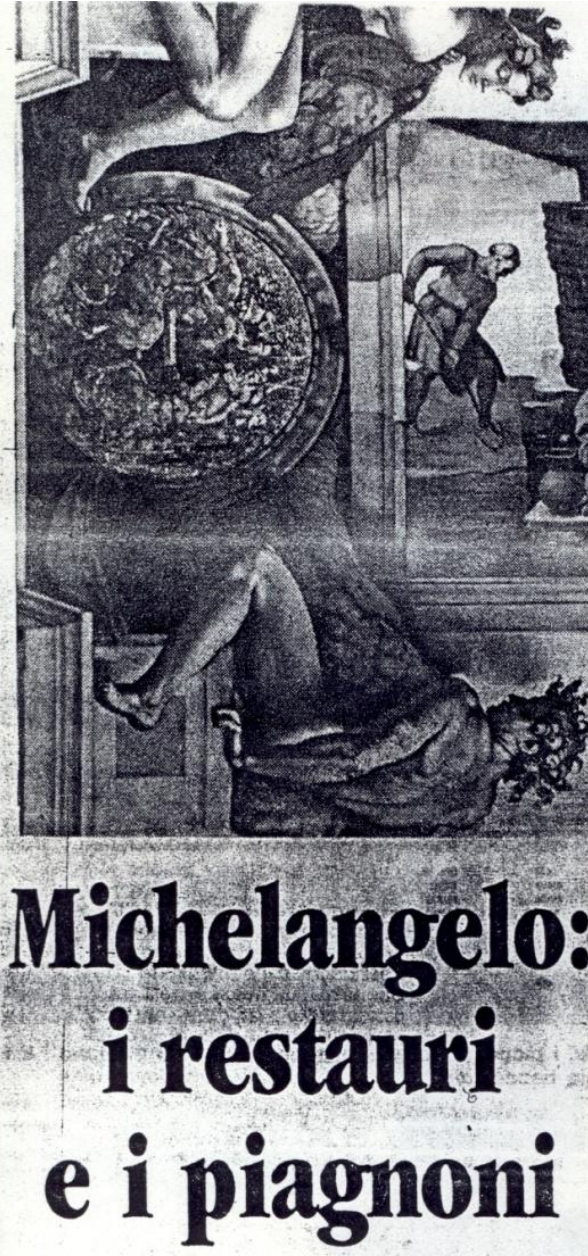

In un volume della De Agostini raccolti i contributi critici di studiosi Jell'arte che contrastano le tesi degli "amanti del sudicio»

quando è l'ossequio fideisti- chelangelo all'opera: tecnica colores, da Gianluigi cocollociche del reni; per affrescare l'ultima stauron) e, infine, particolarmmensa, parete del luogo mistero della volta. Gli afdelle sue prime esperienze freschi di Michelangelo alla pittoriche. luce del pensiero teologico

Tuttavia, a mio modo di del Rinascimenton. Tutto vedere, le pagine piu solleci- questo lavoro non vuole, cotanti di questo volume sono munque, essere solo un nuoquelle scritte da Michael vo modo di rileggere o di riHirst- (aIl modo delle attitu- considerare fatti e docudini. Il taccuino di Oxford menti inerenti la Sistina, l' Ure (II restauro de! Giudizio
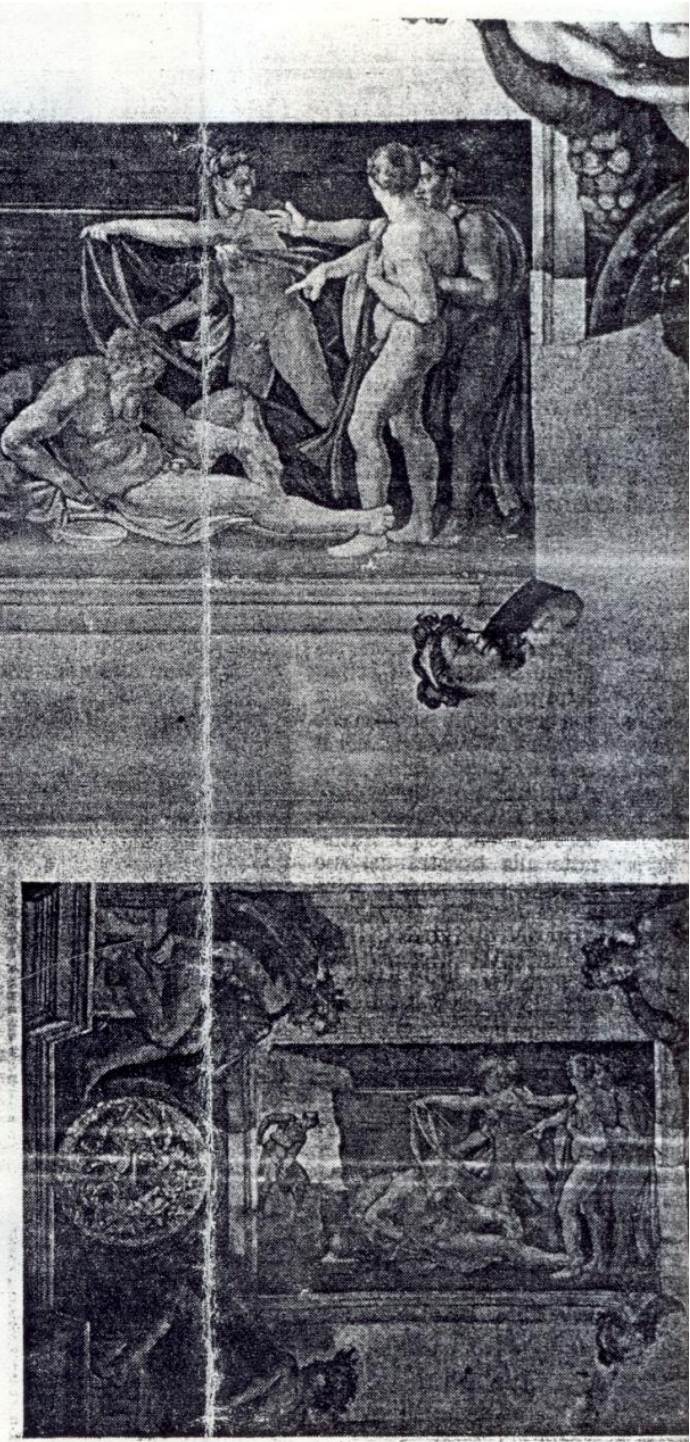
propor. certa- tivo la perceslone figurativa squil mente ulterior elenenti di di una luce minerale dalle tato orma e conterintc che im- iridescenze del cristallo. certa orranno nue:e ar. $3^{\prime}$ lazioni nterpretative). nella sua mente sublime, langic , e il risultato ottenuto dell'alba del primo giorno sibiliti lla luce (è il ter line più della Genesi, aleggiante poi rare idoneo) della valutazione su turto il *Creato. dellimprescindibile esistenarmail sono quasi inguar- compo si è investito del ruclo di *di- che illustrano la volta pri- dimen 
ESCLUSIVO - La clamorosa denuncia del pittore bergamasco Mario Donizetti contro l'équi

\section{Quanti schiaffi a Michelangelo}

"Con un metodo rozzo e approssimativo deturpano e snaturano i colori del capolavoro di Buonarroti» sostiene Donizetti. "Alcune figure hanno già perso l'antica grandiosità e assomigliano a sgargianti mascheroni». Perplessità e allarme anche tra gli studiosi americani

di ANTONELLA AMENDOLA - Foto di GIANNI GELMI

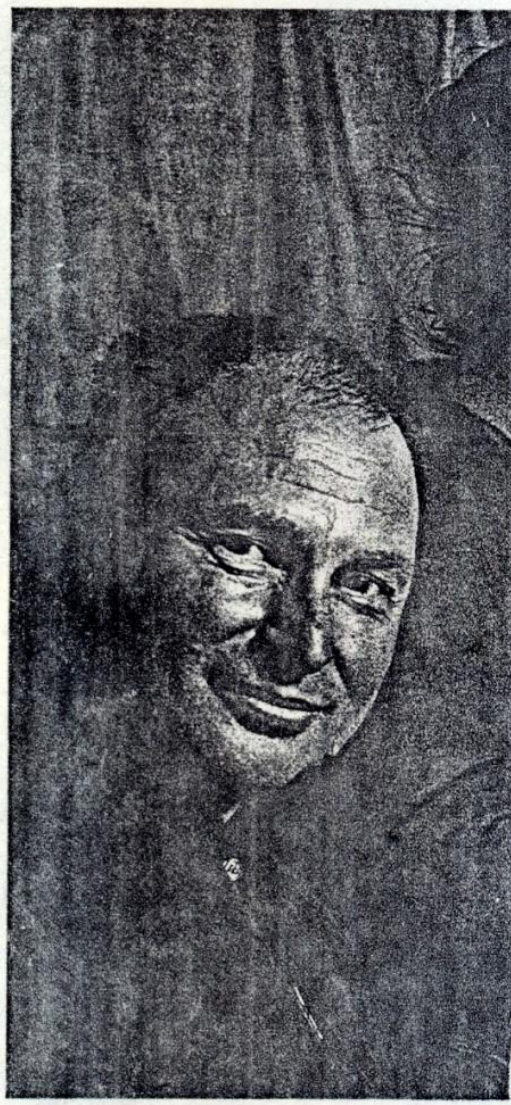

\&Fermiamo questo crimine»

Bergamo. Mario Donizetti, 54 anni, davanti al ritratto della moglie da lui dipinta. «Sono disposto ad assumermi tutte le responsabilità

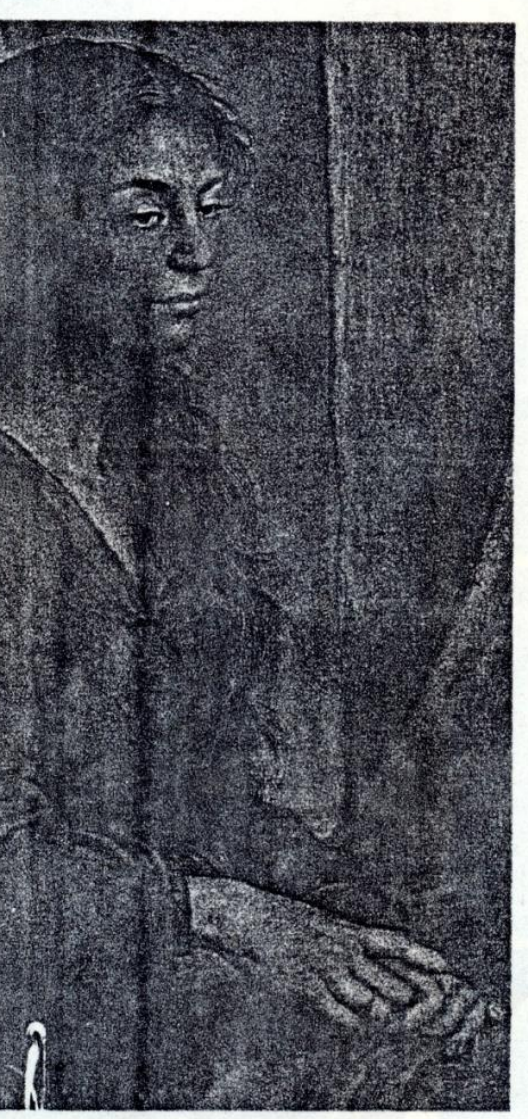

delle mie accuse» dice il pittore. «Ma fermiamo Mario Donizetti è noto in tutto it mondo per aver ripristinato la tecnica rinascimentale delle tempere con il tuorlo d'uovo. in tempo questo crimine contro l'umanitàn.

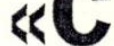
edo di avere la Rrova, giugne e inconfutabile che il cosiddet to restauro della Sistina non è che un di. sastroso scempio. In ogni caso mi assume coerentemente la responsabilità di aveı fornito ai lettori della Domenica del Cor. riere gli ingrandimenti fotografici da quali risulta il pressappochismo dei re. stauratori vaticani. Sono pronto a rispon. dere di persona ad ogni polemicam.

Chi parla in tono fermo e deciso è $\mathrm{Ma}$. rio Donizetti, cinquantaquattrenne arti. sta bergamasco noto in tutto il mondc per aver ripristinato la tecnica rinasci. mentale della tempera con il puro tuorlc d'uovo. Ma, senza dilungarci in una lun. ga scheda biografica, Donizetti, di cu sono attualmente visibili alcune opere al. la Pinacoteca ambrosiana, è l'unico arti. sta italiano che la prestigiosa rivista ame. ricana Time ha gratificato con un tripli. ce quanto inusitato onore: per ben tre volte infatti suoi quadri di Giovanni Paolo II, lady Diana e Indira Gandhi ne han. no illustrato la copertina.

Che cosa sta succedendo? Perché Ma. rio Donizetti è tanto turbato e come lui lo sono moltissimi artisti italiani, da Annigoni a Scialoja, da Guccione a Vespignani, da Clerici ad Attardi?

Procediamo con ordine

A quello che gli storici deli'arte considerano un gioiello unico, cioè la Cappella Sistina, Michelangelo mise mano in una ridente giornata, esattamente il $10 \mathrm{mag}$. gio 1508 , all'età di 33 anni: alla fine del. l'ottobre 1512 i circa 700 metri quadrati della volta, con le caratteristiche campa. te e lunette, furono resi pubblici in un $\mathrm{CO}^{-}$ ro di unanime estasiata meraviglia.

"Tuttavia” osserva il pittore Luigi Ghersi, animatore di un comitato romano pro Michelangelo, *il destino non doveva essere benevolo con il grande genio, Mentre egli era ancora in vita, seppe che i suoi nudi sarebbero stati camuffati e velati con singolari brachettoniw.

Restauro selvaggio o affascinante scoperta di un Michelangelo colorista precursore dei manieristi? L'interrogativo inquietante serpeggia da un continente all'altro, dagli Stati Uniti all'Italia, in un tam tam di concitate dichiarazioni che sta mettendo a soqquadro il paludato mondo dell'arte, di solito sonnacchioso e polveroso. La grande disputa che ormai coinvolge in partiti rissosi e fieramente avversi critici, storici dell'arte, restauratori, artisti, ha preso il via qualche anno fa quando le competentî autorità vaticane stabilirono che lo stato di degrado dell'edificio voluto da Sisto IV era arrivato al punto massimo di tollerabilità.

"Dopo accurate ispezioni" spiega il dottor Gianluigi Colalucci, responsabile dei restauri vaticanensi ariscontrammo 
STAMPA 1988

\section{Il grande storico dell'arte inglese scende in campo a difesa dei contestati restauri della Cappella Sistina} Caro Michelangelo, vestito di nuovo

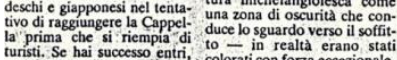

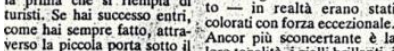

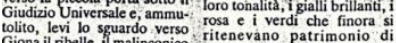

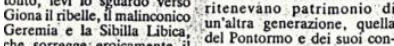
che sorregge eroicamente if
suo libro colossale. Ma circa a mareti corre unplia, palcatura corte Fabrizio Mancinelli, in un
puovo libro informativo dedia distoffe color senape, tra le

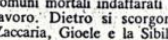
lato, quasi, del peneello di
altro artista, piu'vivace $e$ e La pulizia della Cappe
istina istina e il piu importante
tauro che sia mai stato te a piu grande pittura mai ese- se, ma che hà determinato. stata giudicata come il picoo, loro ricezione e valutazione, thsun altro intice al quale nai potuto arrivare, Dall'ep
a dello sviluppo dei proces Ia Genesi, ic Profetet, questic figure, generalmente

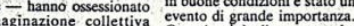
II umanita. Milioni di per- Quando si e de dimostrato che larsi l'atto divivalonta col qua
ii mondo in cui vivong

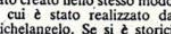
lell'arte, e essenzaiale liberarsi
lai vincoli affettivi professioproprieta dello storico del-
arte piu di quanto la Nona

Fenditure

dell'intonaco Una breve storia e inevita-
ile, La Cappella Sistina e
:mpre stata un problema. impre stata un problem.
lichelangelo comincio con
usare lintonaco sbagliato

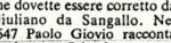

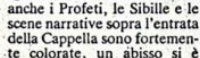
spalancato tra coloro che sono
nmasti tenacemente atteocal alla vecchia concezione della dalla stampa americana in ter
mini ampiamente polemis.
Ne sono scaturite manifesta zioni e si sono levate vivaci
proteste, sia nel monde vacci mico che in quello artistica. Le punto di spiegare Yenza di due giorni a New ro ei datit sum quali si bastas.
Naturalmente,
americane sono rimbalitiche
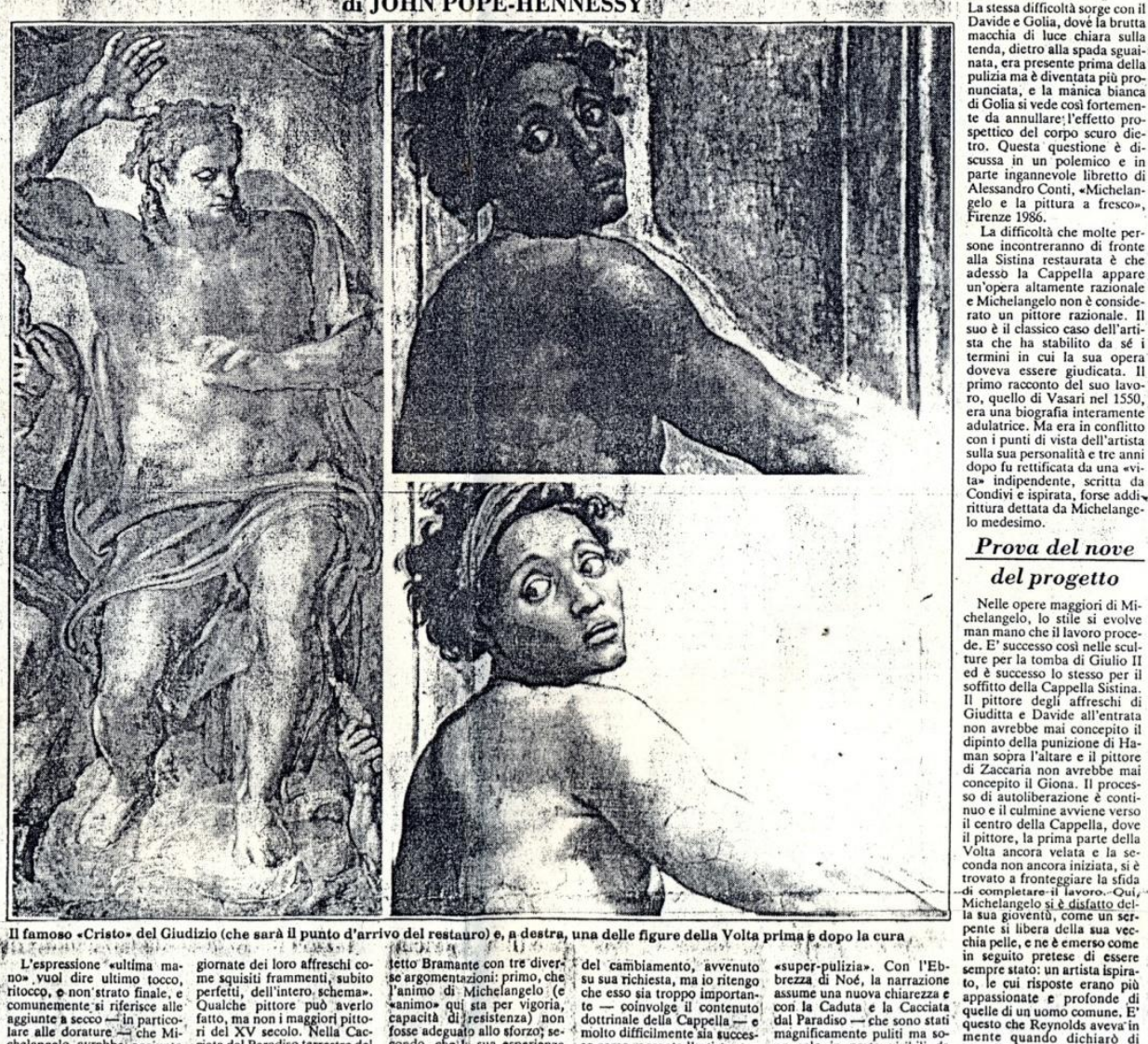

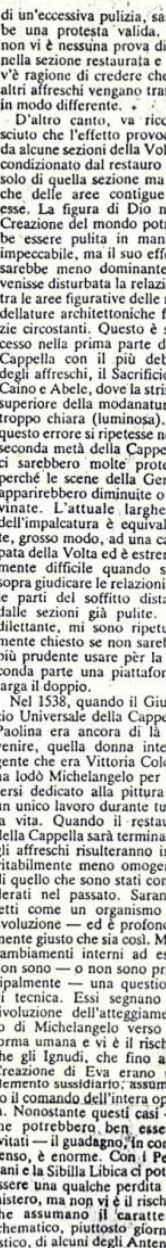

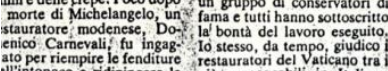

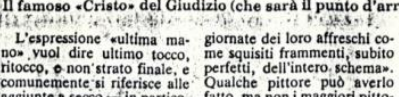
o del restauro) e, a destra, una delle figure della Yolta prima po dopo la cura,

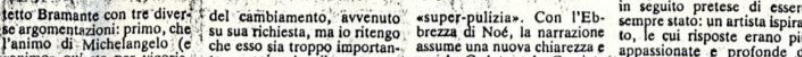

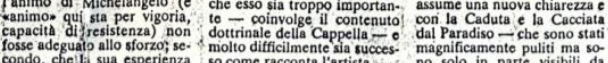




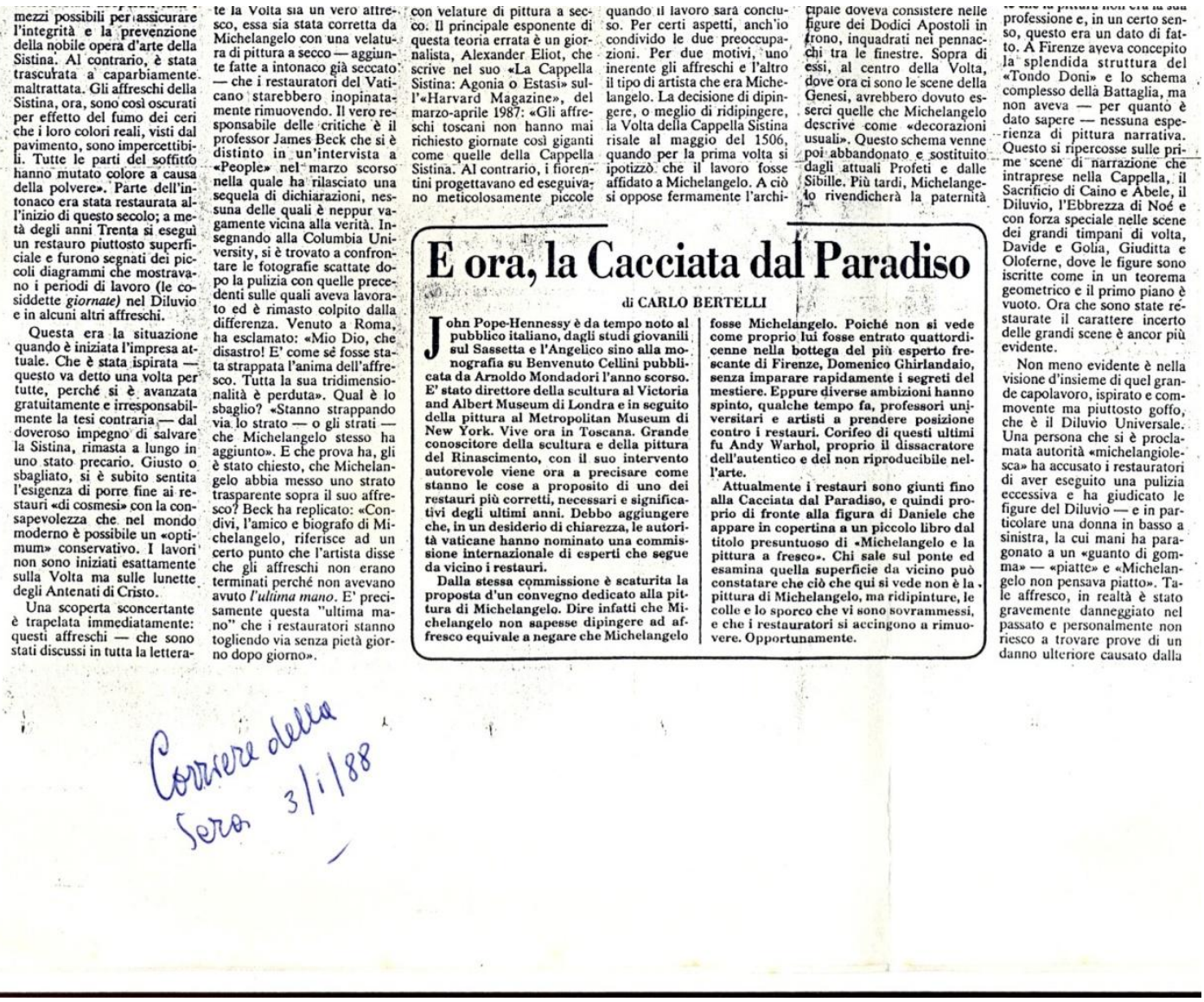




\section{El Diario}

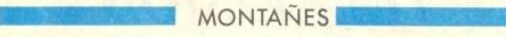

DECANO DE LA PRENSA CANTABRA (FUNDADO EN 1902)
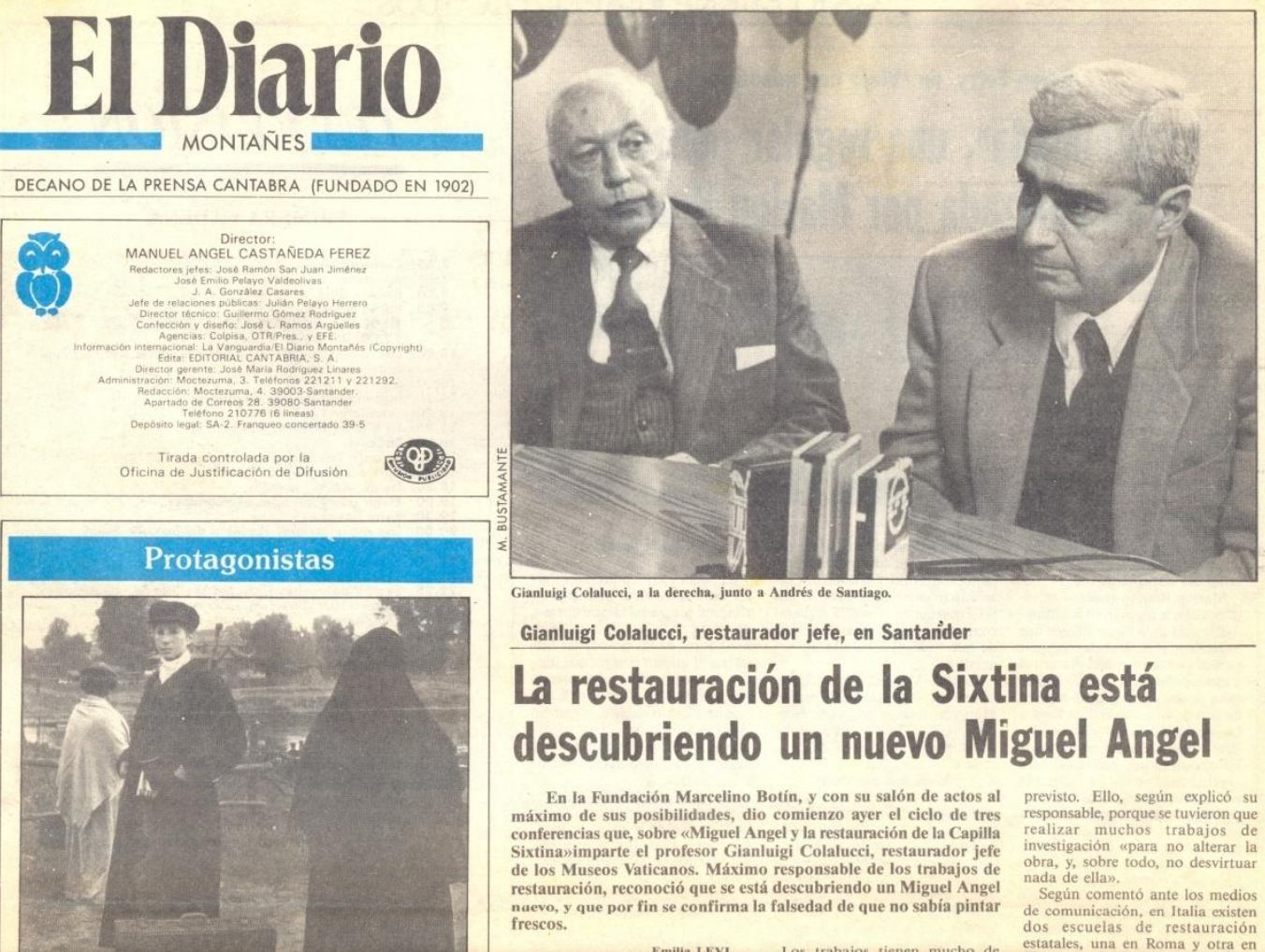

Gianluigi Colalucci, restaurador jefe, en Santanider

\section{La restauración de la Sixtina está descubriendo un nuevo Miguel Angel}

En la Fundación Marcelino Botín, y con su salón de actos al previsto. Ello, según explicó su máximo de sus posibilidades, dio comienzo ayer el ciclo de tres responsable, porque se tuvieron que conferencias que, sobre «Miguel Angel y la restauración de la Capilla $\begin{array}{r}\text { realizar muchos trabajos de } \\ \text { investigación «para no alterar la }\end{array}$ Sixtinamimparte el profesor Gianluigi Colalueci, restaurador jefe livestigacion weara no alterar la de los Maseos vaticanos. Maximo responsabe de los trabajos de nada de ella.

rescos frescos.

de comunicación, en ltalia existen dos escuelas de restauración
estatales, una en Roma y otra

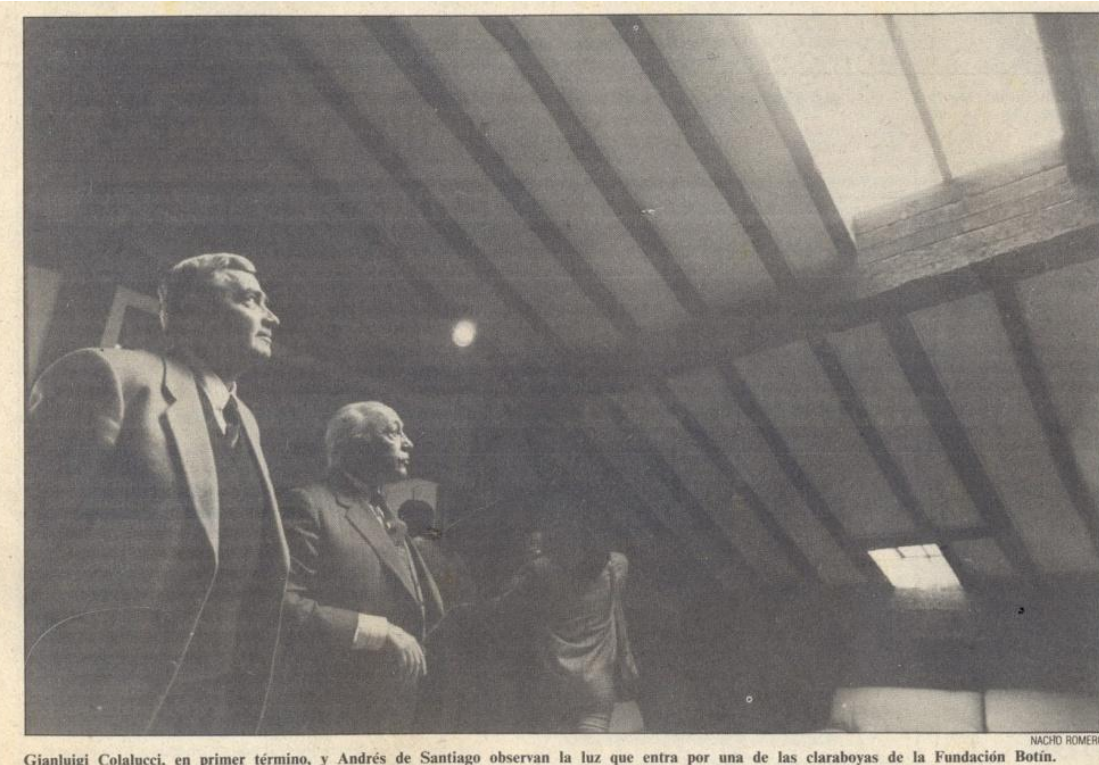

\section{El restaurador de Miguel Angel}

Gianluigi Colalucci dirige la restauración de la Capilla Sixtina, cuyos trabajos finalizarán en 1993
PERSONAS

Herbert von Karajan, director de orquesta, abrió anoche el vigésimo segundo Saltzburgo con una nueva or questación y escenificación de la ópera Tosca, de Puccini. El éxito artistico de la re presentación colmó todas las expectativas, $y$ Karajan, promotor de los Festivales de Primavera, obtuvo una vez dad natal de Mozart segin la agencia austriaca APA E mexicano Luis Lima y la italiana Fiamma Izzo d'A. mico cantaron los papeles protagonistas de Cavaradossi $y$ Tosca.

Katalyn Kantor, bailari na de 10 años, fue la estrella de la octava edición del Festival de Primavera de Budapest, clausurado el domingo. y que contó con la asistencia de cientos de miles de perso-
nas, informó ayer la Prensa nas, informó ayer la Prensa Kantor, que bailó el papel principal del ballet El señor de los sueños, de la obra de Tchaikovsky Cascanueces, tiene una disciplina y dotes
sobresalientes para la dan$z a$, un talento magistral y una irradiación personal que daran mucho que hablar en 


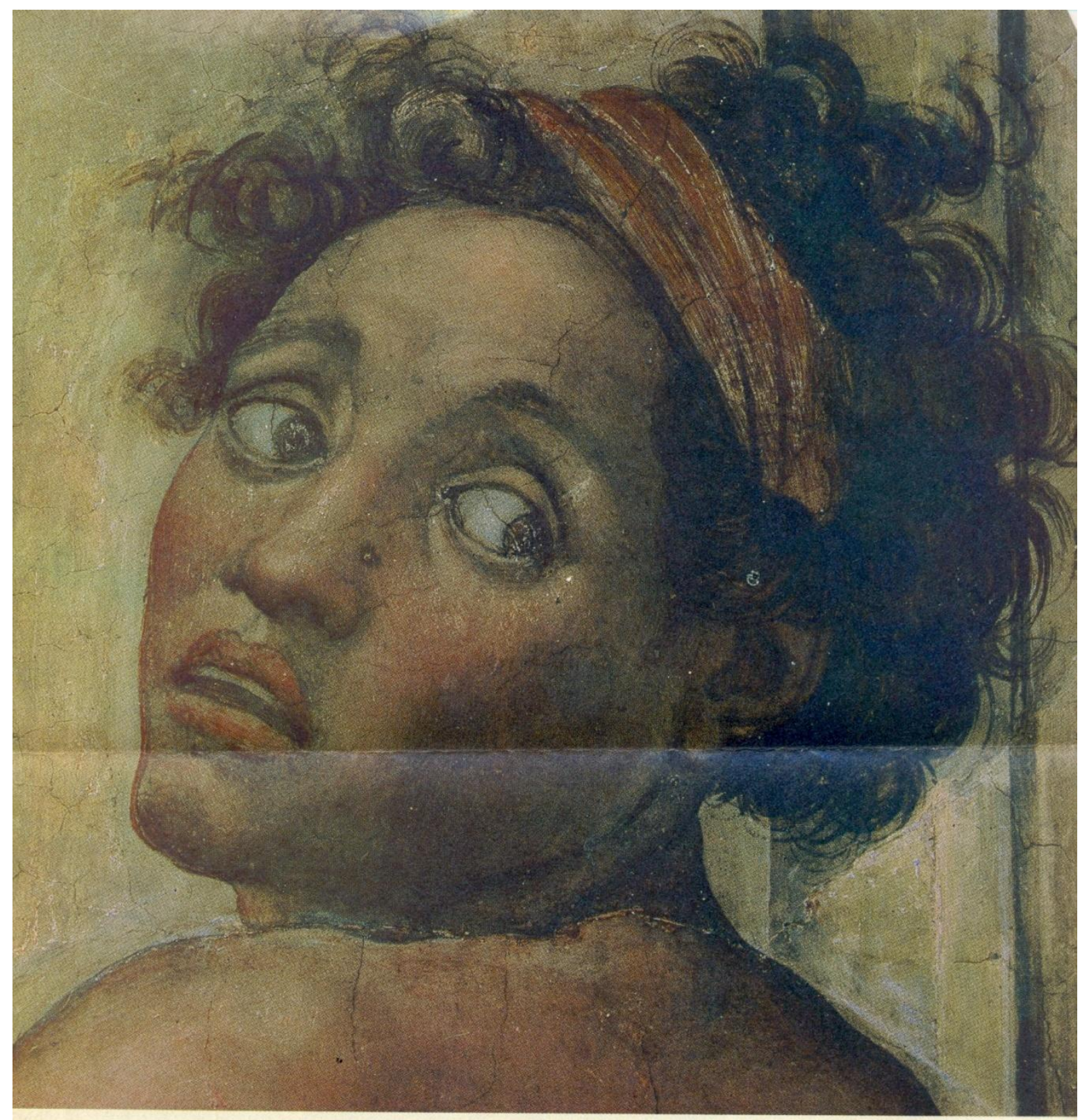

\section{Michelangelo gjenoppstår}

Århundrers sot fjernes fra taket i det sixtinske kapell. Michelangelos fresker dukker frem i sterke farver. Overraskende sterke, mener noen. Er mesteren gjenoppdaget eller forråd $\left.\left.30\right|^{\prime \prime} A^{\prime \prime} \cos 20\right) 73 / 2 / 88$

Tekst: Kristin F'lood. Foto: NTV/Vatikanet 

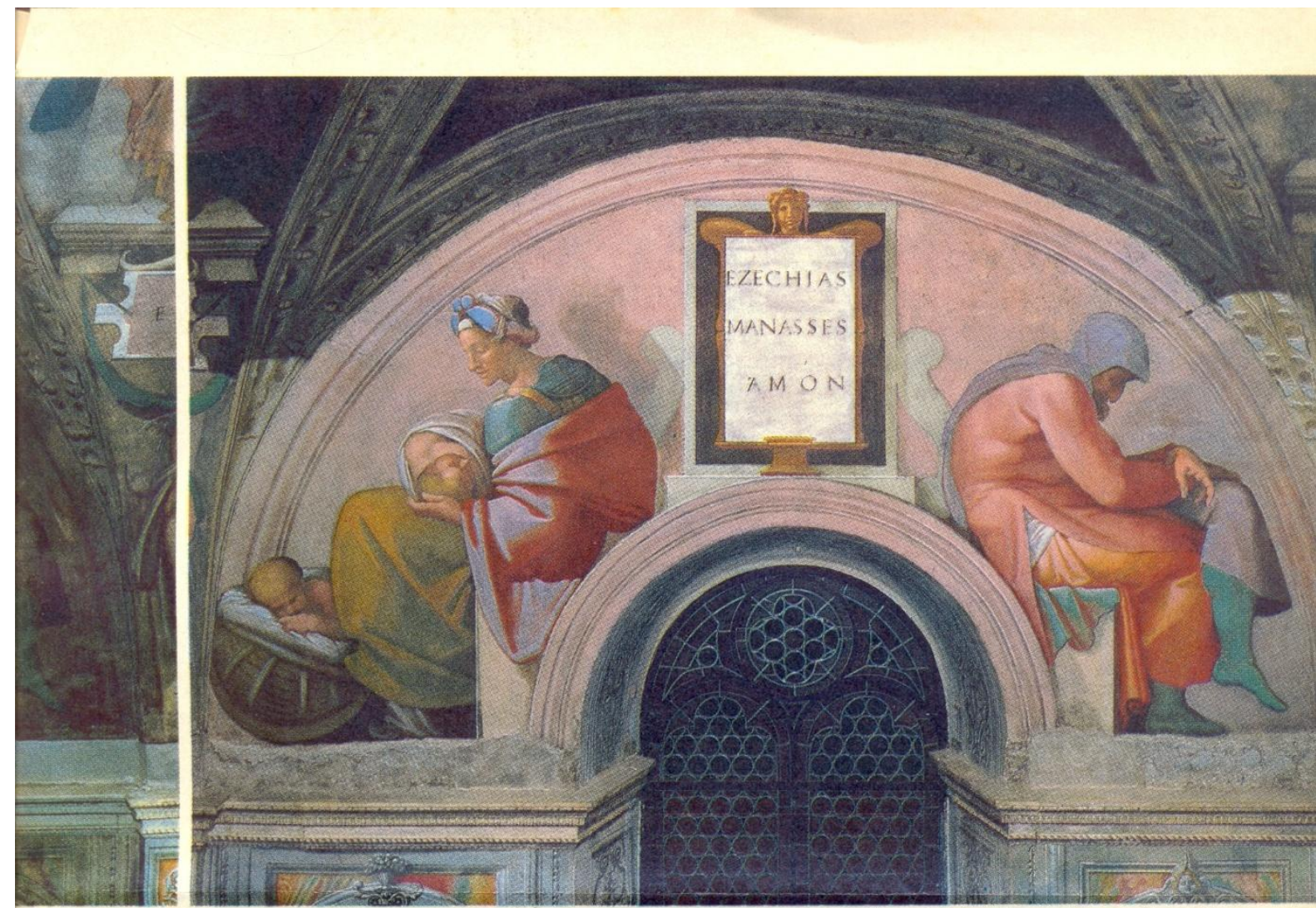

Personlig liker jeg de kraftige farvene, jeg ser jo bedre fra gulvet. Men jeg ville ikke ha beordret restaurering. Her er for mange usikre faktorer. Jeg ville latt tvilen komme bruntonene til gode, sier Sinding. Larsen.

Fantastisk! Jeg kan røre ved Vårherres panne! - Her oppe blir jeg nesten litt smårar. Men du og du hvor viktig det er å få ren set dette skikkelig. Det er slik man virkelig kommer kunstneren nær. Og nettopp dette må jo være poenget å finne og vise oss den opprinnelige Michelangelo.

Sier Thomas Thiis-Even sen, arkitekt og dr. philos., som ihøst fikk godkjent sin estetiske plan for Norges estetiske plan for Norges hovedstad. Sammen med A-Magasinet har han fått
audiens til restauratørenes aller helligste, og han gispe over forandringene mens han flytter blikket fra den urestaurerte Skapelsen av natt og dag til den nyvaskede og nyfødte Eva.

- Det er en sterk opplevelse å se takmaleriene så krystallklare, så farverike, i nesten naive farver som minner om 1800-talls pastellmalerier. Og efter min mening er jo himmelen slik, lys, lett og farverik, ikke tung, grå og bombastisk, sier Thiis-Evensen.

13 års arbeide. En utgift på fem milliarder lire. $\mathrm{Og}$ på fem milliarder lire. Og alt festes til filmen. Det jatar opp restaureringen på video. I tillegg har de bivideo. I tillegg har de bidrat med 20 millioner kroner for eneretten til alle fotografier mens arbeidet pågår og. tre år efterpå.

Og stillaset knirker i festehull fra 1500-tallet, mens datamaskinen under Edens have registrerer alle funn og detaljer. Og vi daler i

åpen heis fra Michelangelos himmelske far tilbake til de jordiske turistmasser.

$$
\left.A^{11} \cos 20\right) 132 / 88
$$

Sjefrestaurater Gianluigi Colalucci finpusser den nyrestaurerte Sibylle Delfica $i$ Vatikanets sixtinske kapell.

Et av områdene mellom vinduene for og effer restaurering.

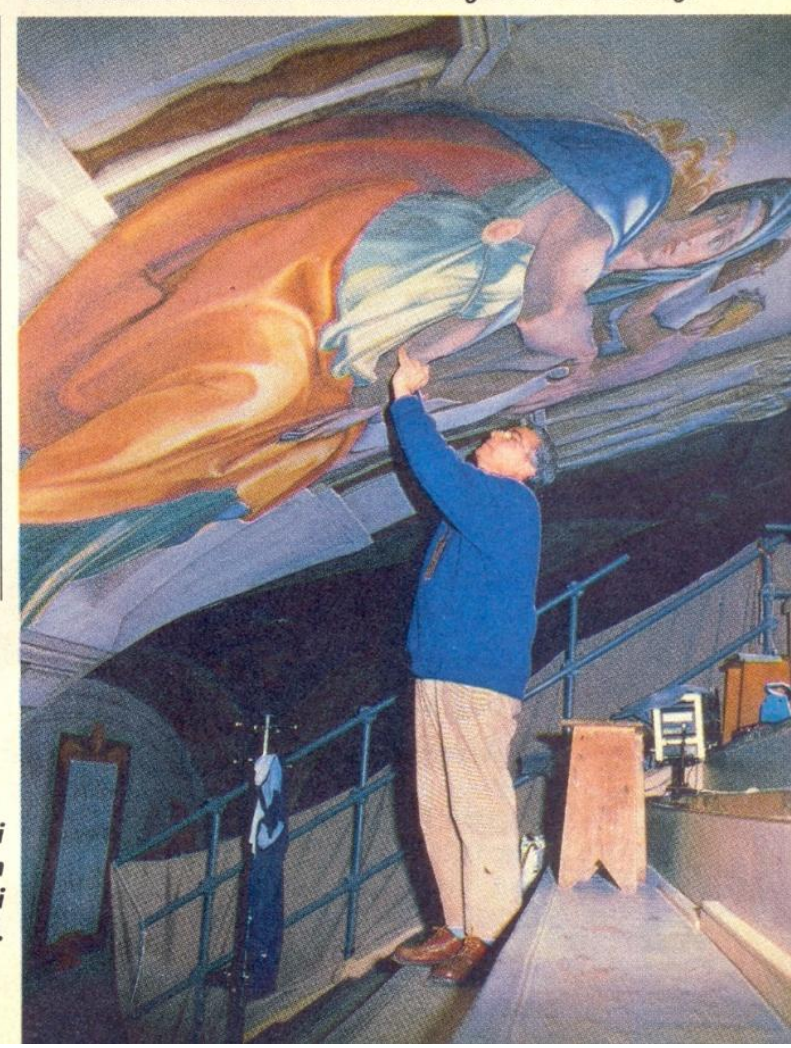


Mercoledl 23 marzo $1988<v$

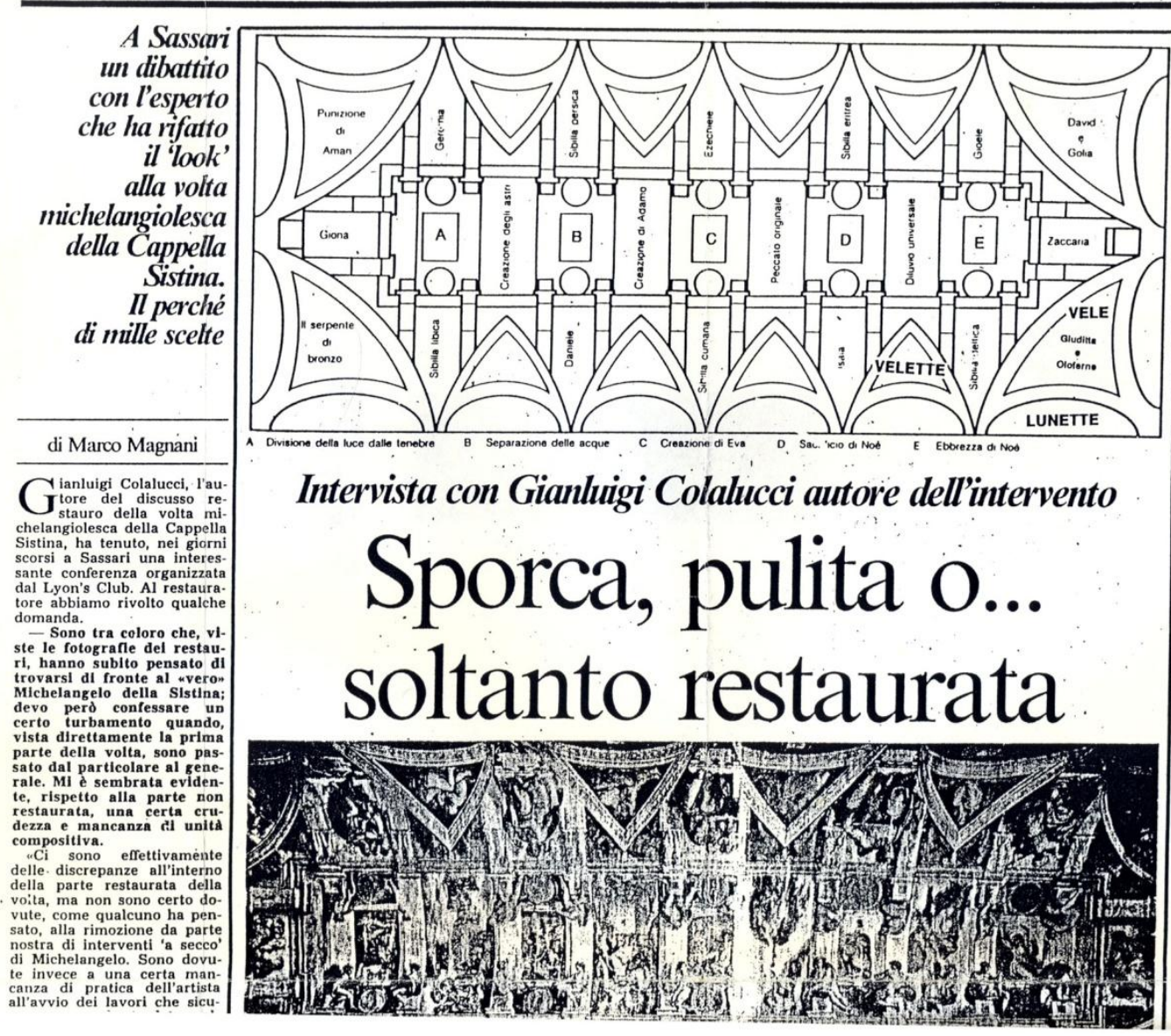

Un'Immagine della volta della Cappelia Sistin

e ll confronto
'prima' e 'dopo' II discusso

intervento di ripulltura

diseussioni tra gli addetII

allavori e anche.

Ma é plù 'vero' o quello rimesso a nuov
dillo

Ho avuto l'impression nute, molto pensate e ripensate, che ci fosse cioè una
specie di timidezza nei confronti dell' impresa iniziata. I partimenti architettonici, a
differenza di quelli successivi più grigi, si presentavano
molto chiari, quasi gessosi. I nostri critici forse avrebbero per compensare, per correg. avorare non è questo. Bisoscompensi. Non fare come certi artisti che, abituati an dare alle vernici e a criticare,
sembrava che fossero venuti a vedere Michelangelo che esponeva. Non è serio". molto avanti, pud conferparne l'effetiva necessiti colla che ricopriva gli affre schi e operava dei minu recati dalle infiltrazioni d'acqua presenti nella volta. Non no ha detto per i soldi della tv giapponese che in seguito 


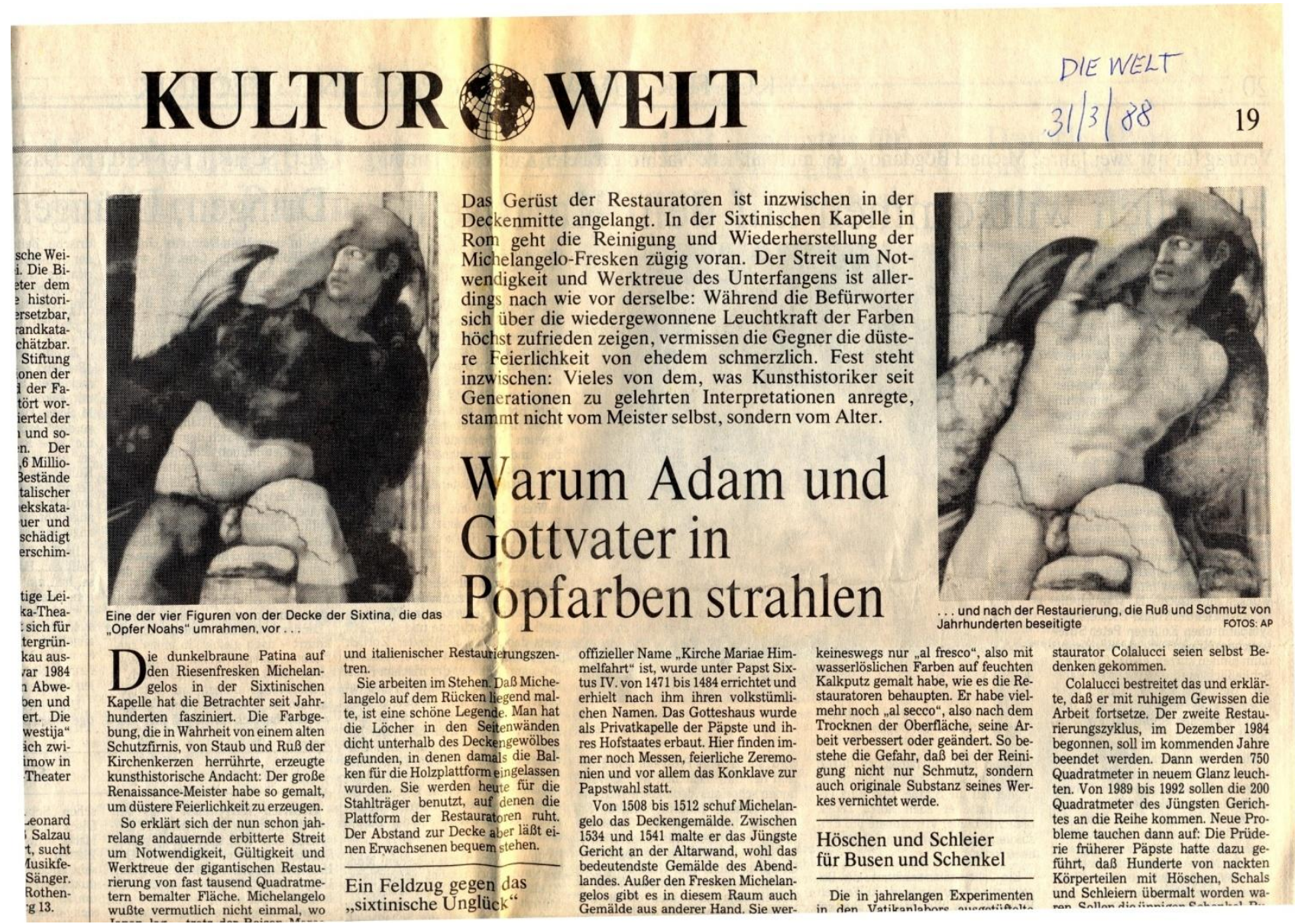




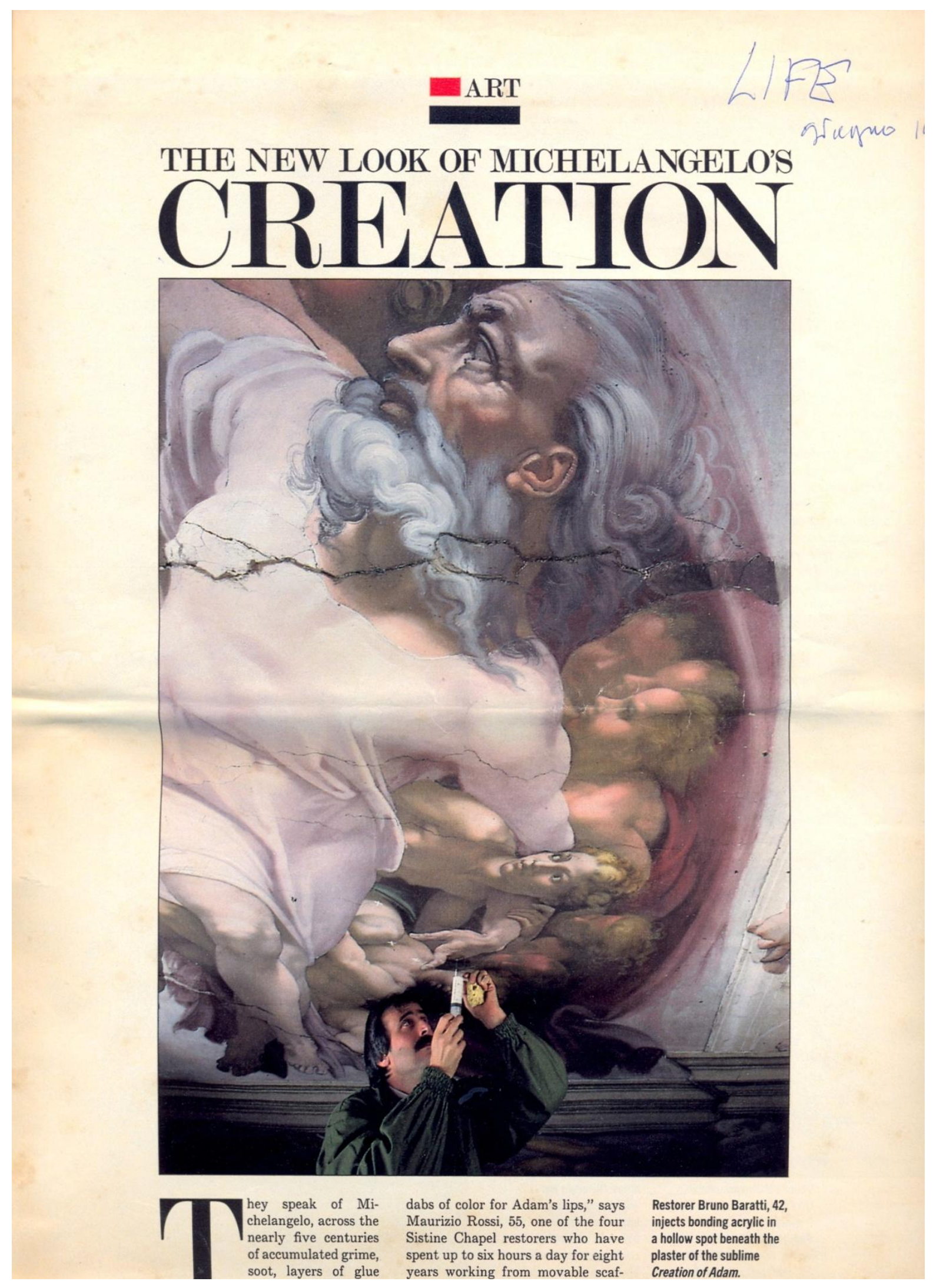


A detailed computer log of the restoration, checked by

Filippo Petrignani, 26, is part of the Vatican's long-term preservation scheme, as is

the elaborate humidity and dust control system being designed for the chapel, which has more than 6,000 visitors a day.
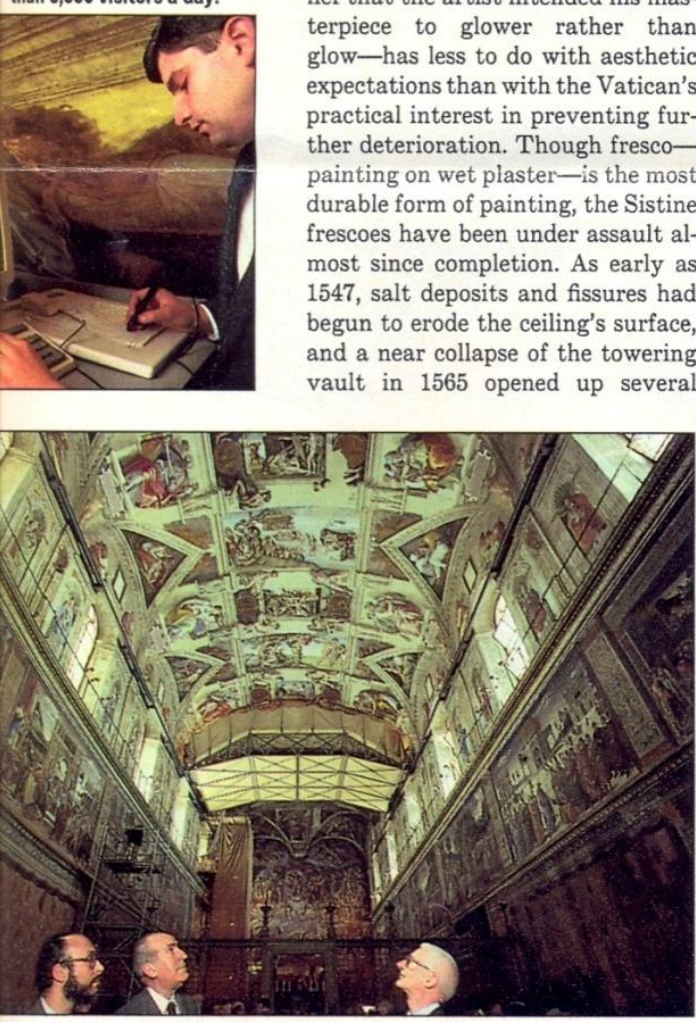

Vatican Museums officials

Dr. Fabrizio Mancinelli, 47

Professor Carlo

Pietrangeli, 75 , and $\mathrm{Dr}$.

Walter Persegati, 67, note

the contrast between the

cleaned and the uncleaned foot uncovered there comes further promise of surprise. "With our experience," says restorer Pier Giorgio Bonetti, 52, "we often try to imagine what is under the dirt. But then in relity, Michelangelo is always superior to any expectation."

That this revelation should occur now-after half a millennium of belief that the artist intended his masterpiece to glower rather than glow-has less to do with aesthetic expectations than with the Vatican's practical interest in preventing further deterioration. Though frescopainting on wet plaster-is the most durable form of painting, the Sistine frescoes have been under assault almost since completion. As early as 1547 , salt deposits and fissures had begun to erode the ceiling's surface, and a near collapse of the towering vault in 1565 opened up several ing of the chapel in the vatican. "This flesh," says Rossi, "has blood running in it-so fresh it looks like Michelangelo just put down his brushes. When we remove this mud, it is like seeing a baby being born."

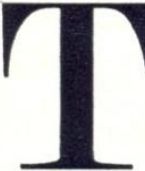

at is perhaps the ideal metaphor for this most monumental-and, for a time, controversial-of rescrim of centuries has been sponged away, a whole new idea of Michelangelo the painter rather than the sculptor has been discovered-a Michelangelo who is master of color as well as form. And with each square

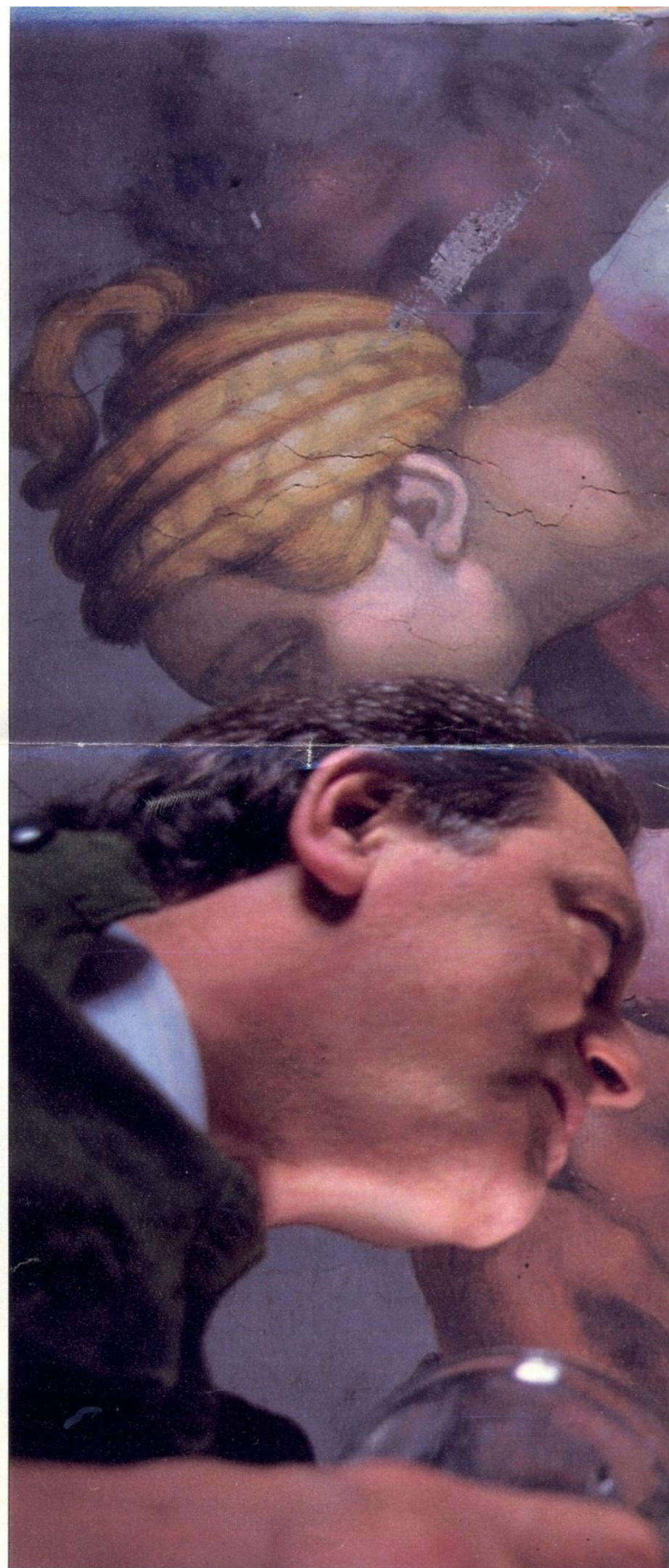


Bonetti points to evidence of the artist's spontaneous correction of his original engraving for Adam's right

leg and foot; at bottom, Colalucci examines the unexpected dividend of a hurried smoothing of plaster 477 years ago- the master's thumbprint.

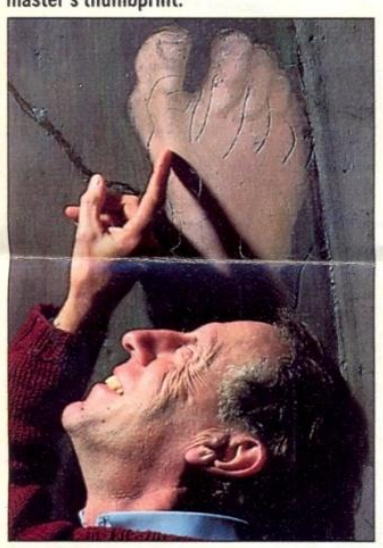

cracks, including one that destroyed the first three fingers of Adam's left hand, later retouched. But the greatest damage has come from wate seepage and repeated coats of glue meant to brighten the color. In time, this thick overcoat began to shrink, slowly pulling away tiny pieces of pigment. The current restoration, made possible by improved technology and partially backed by $\$ 3$ million from Nippon Television Network (in exchange for exclusive rights to pictures of the chapel for three years following the restoration) is in fact nothing more than the painstaking removal of several layers of glue and debris.

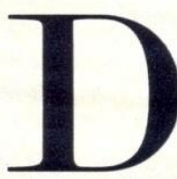

ling with one 12 inch square at ime, the restorers sponge the surface with distilled water, then apply a solution called AB-57, which is left on for three minutes exactly. The surface is again cleaned with distilled water, and 24 hours later the process is repeated. $A$ secco areas, in which paint was applied to dry rather than wet plaster, are cleaned without water. Now within 18 months of completing the ceiling, the restorers wil turn next to The Last Judgment, on the wall behind the altar, which Michelangelo undertook 24 years after the ceiling. It is expected to take four years to clean.

No one connected with the project yet speaks of fatigue, only of privilege. As head restorer Gianluigi Colalucci, 58 , wrote in his diary, "Today I cleaned the head of Adam, a section to leave you breathless. . . Does a male nude such as this exist in the history of painting?"

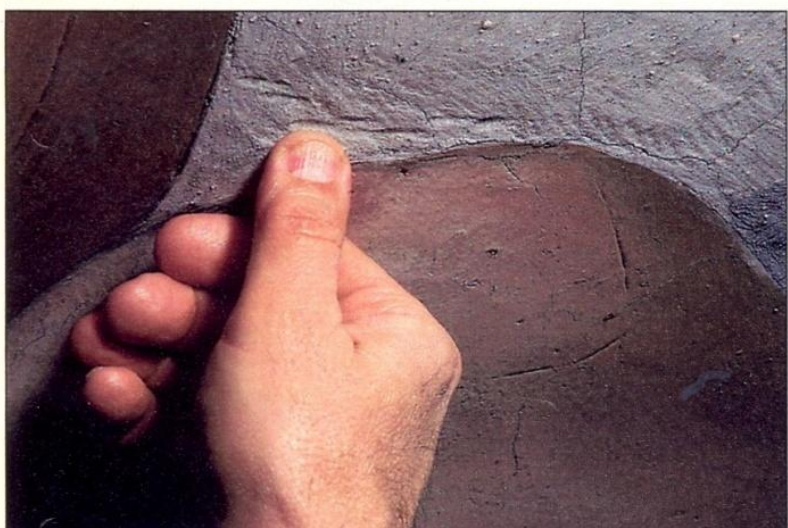

Right: "From a technical point of view, and from the point of view of the are in good condition," says head restorer Colalucci with results, the restoration of Michelangelo is particularly easy because the frescoes cial Terutaka Hashimoto. The microscope is for examining minute cross-sections of fresco.

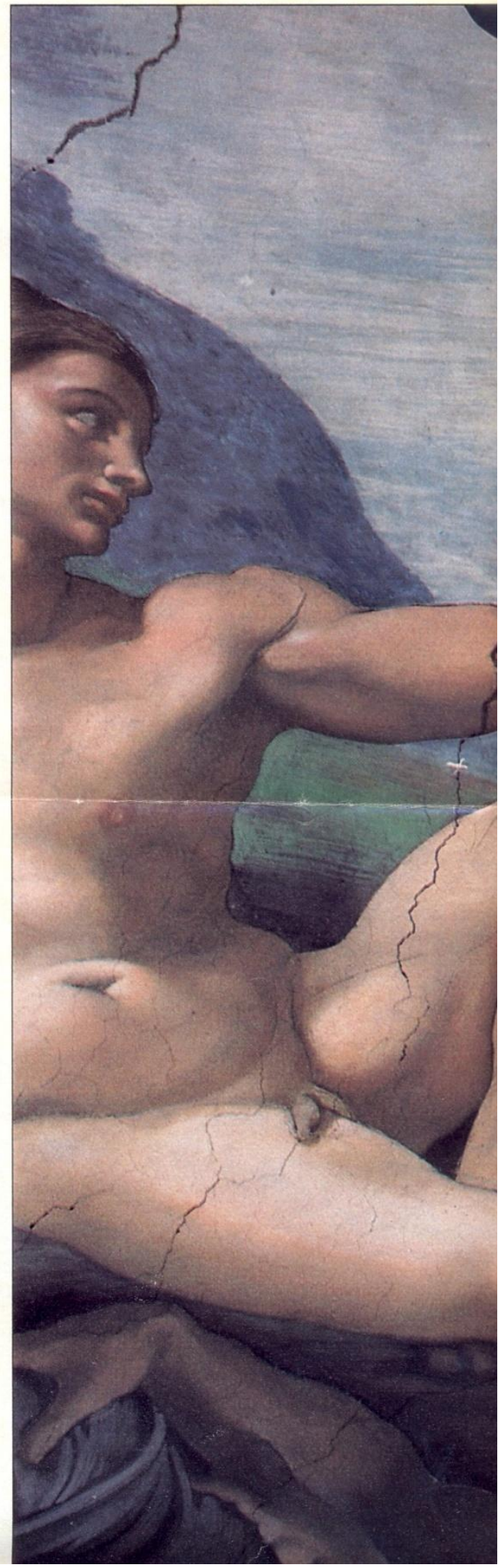




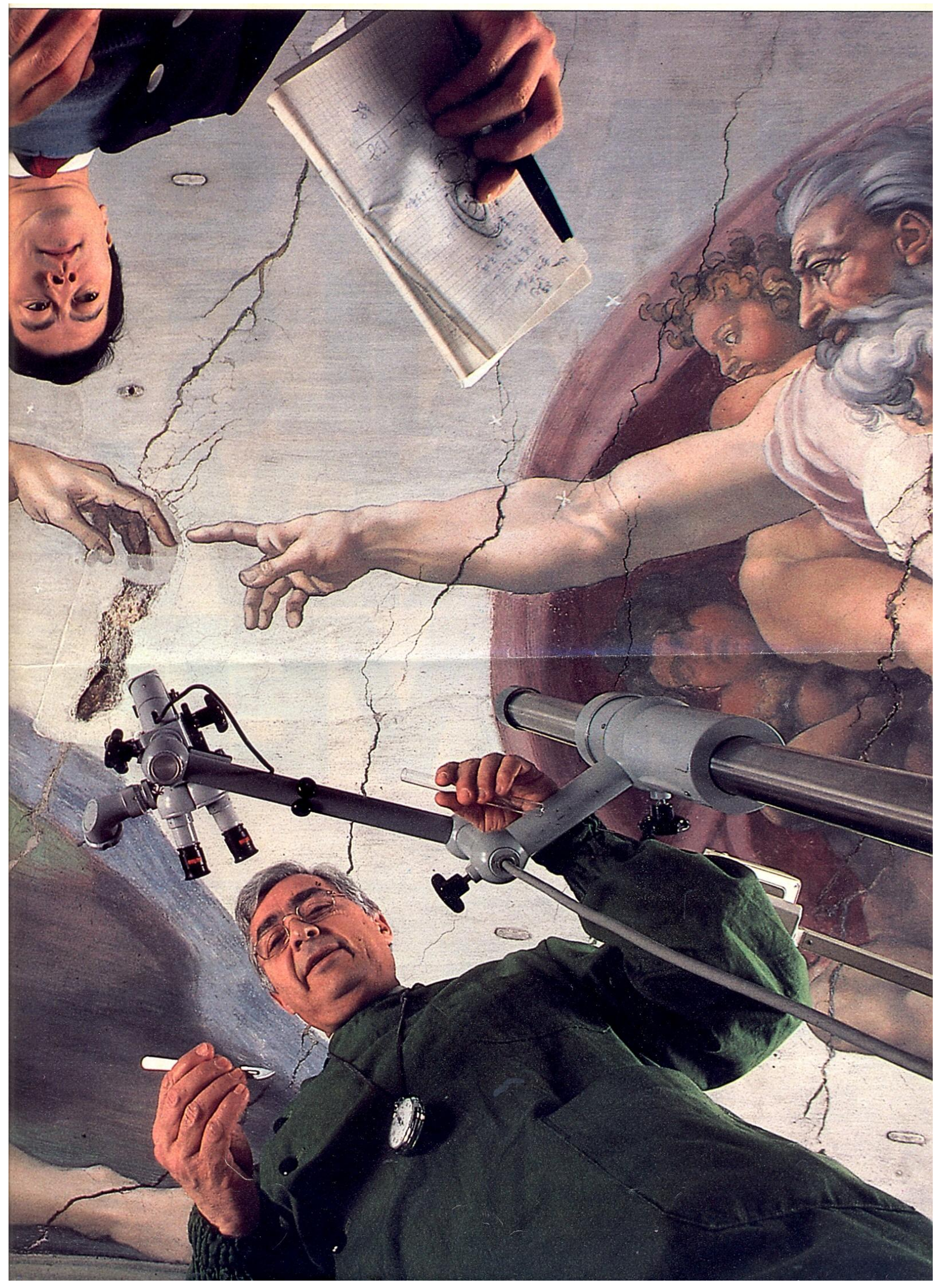


La Torre dell'Orologio dell'Oratorio dei Filippini

e muratura. Non solo. Sul torrino dell' $\mathbf{~}-$
rologio si sono aperte delle vistose crepe

Inoltre, lestanze sottostanti il torrinodell

AH REPOBBLICA $28 / 6 / 88$

Alla requisitoria del New York Times si aggiunge una denuncia dei sindacati

\section{Irresponsabili custodi d'arte Roma"censurata"dagliUsa}

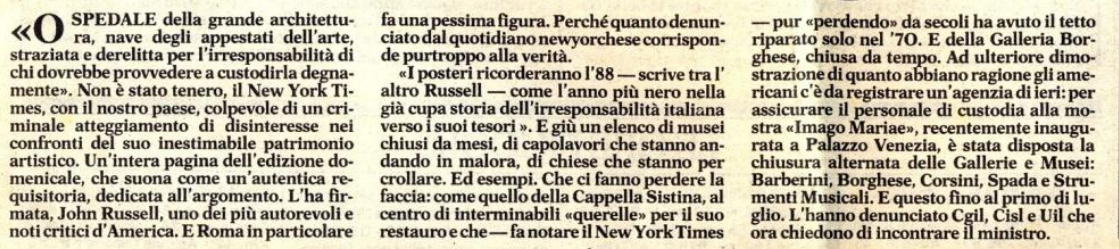

centro di interminabili «querellew per il sue

C HE sia il più importante re-
maiauro di questo secolo or-
mai l'hanno capito tutti. Da quando sono cominciati i lavori,
otto anni fa, la pulitura degli af freschidella Cappella Sistina, madi Michelangelo Buonarroti, hascatenato reazioni di ognigeterminabili "querelle" e stupopi, che hanno riempito pagine e gine digiornali. Finoal recentissimo collegamento televisivo zie al quale il pubblico di ques ultima ha potuto seguire diretta-

Qual è la storia di questo eccezionale lavoro, e perché ha suscitato tante polemiche? «Tutto
ècominciatonel 1964 -racconta Fabrizio Mancinelli, direttore stina-quando Deoclecio Red de Camposavviòla campagna da due cicli di affreschi lateral le storie di Mosè e di Cristo, de Quattrocento. Già la pulitura d delle chiavi» del Perugino e la "Punizione di Korah, Dathan Abiron» di Botticellif fece un cer-
to scalpore. Nel 1974, si proce-
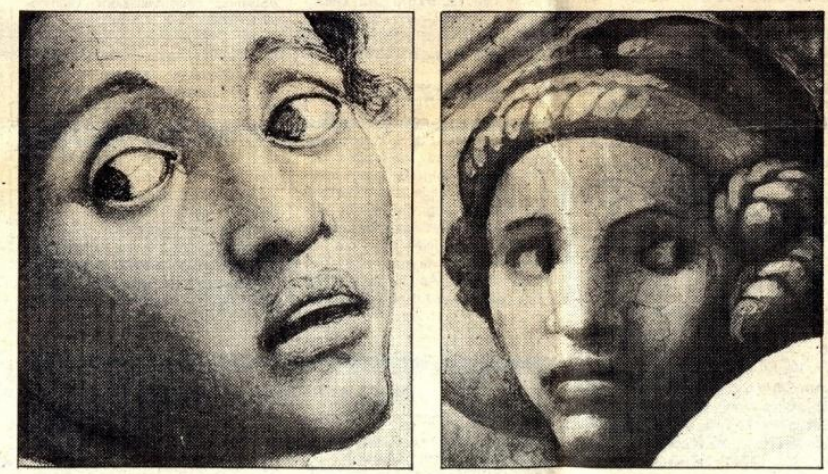

Accantoe inalto
alcuni

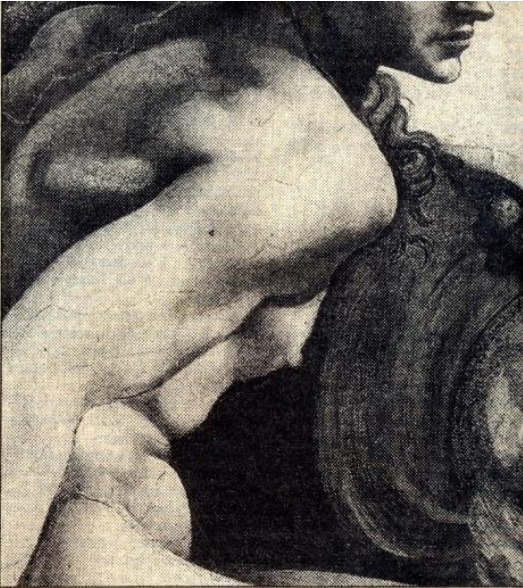

\section{Unacolla-killerperMichelangelo} di LUDOVICO PRATESI

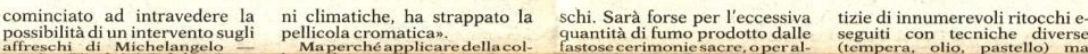
alcuni
particolari degli
affreschi della affreschi della
Cappella Cappella
Sistina

plicata con un pennello sulla s mane a contatto per 3 minu dopodichevienerimossaelas perficie trattata viene lavataco completo viene ripetuto una s completo viene ripetuto una
conda volta a distanza di 24 or La reintegrazione cromatic viene invere esclusivamente ad acquarelic Cappella Sistina secondo la tecnica del rigatin il restauro in corso tolyn. Oggi, le lunette e tre quar nate arisplendere come quand
Michelangelo più di quattro La storia infinita dei danni subiti dal capolavoro

cento annifa, le dipinse: una \& etí e sibille avvolti in panneg dalle tintesmaltate, luminosis me, cangianti, che aprono
strada al Manierismo ind do una precisa via da seguire
pittori come Andrea del Sart In quattrohannolavorato, d metriquadratidiaffreschi (120 dall' inquinamento sono previs definita Argan, popolata di pro Per proteggere gli affresch 


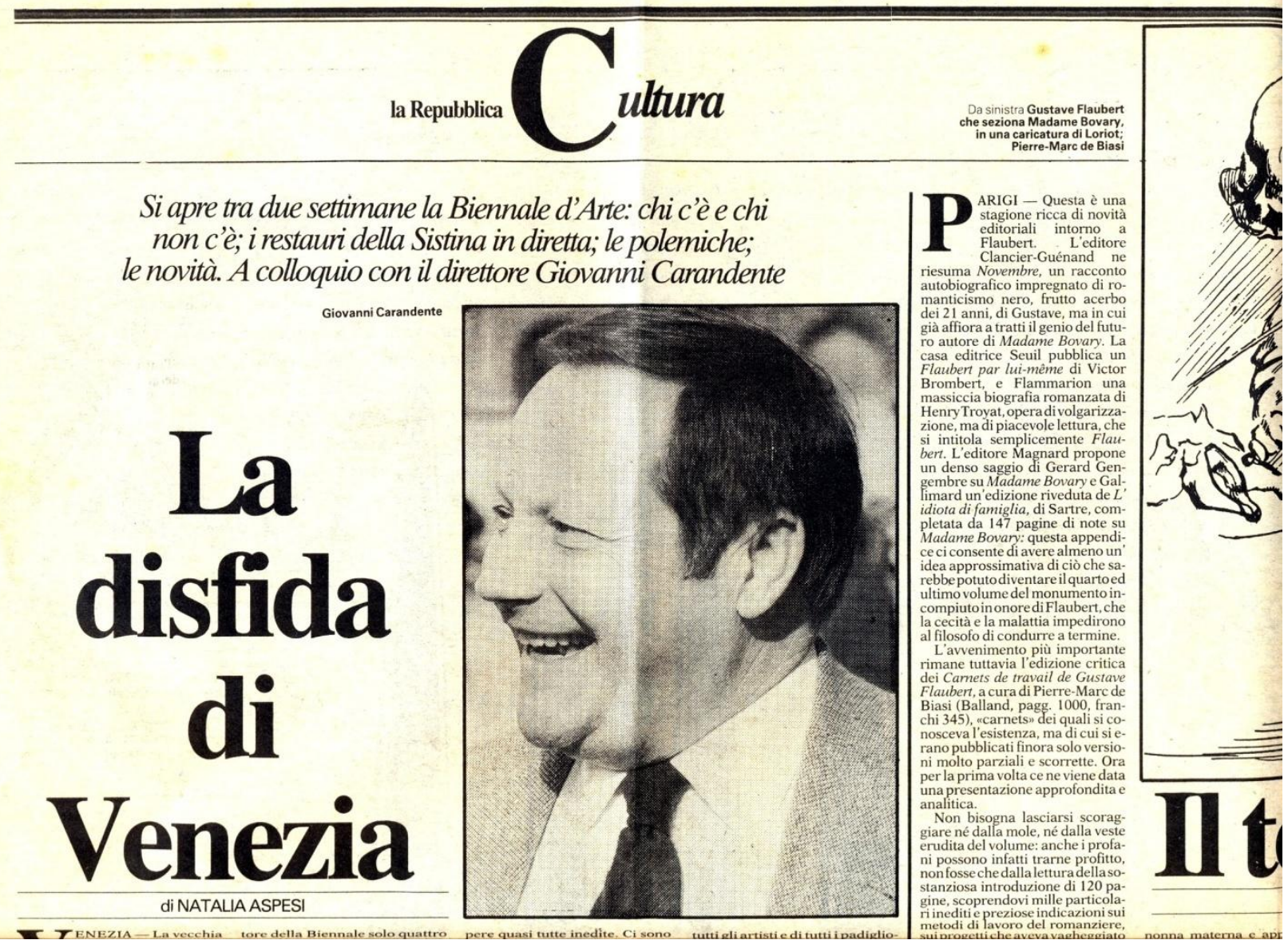




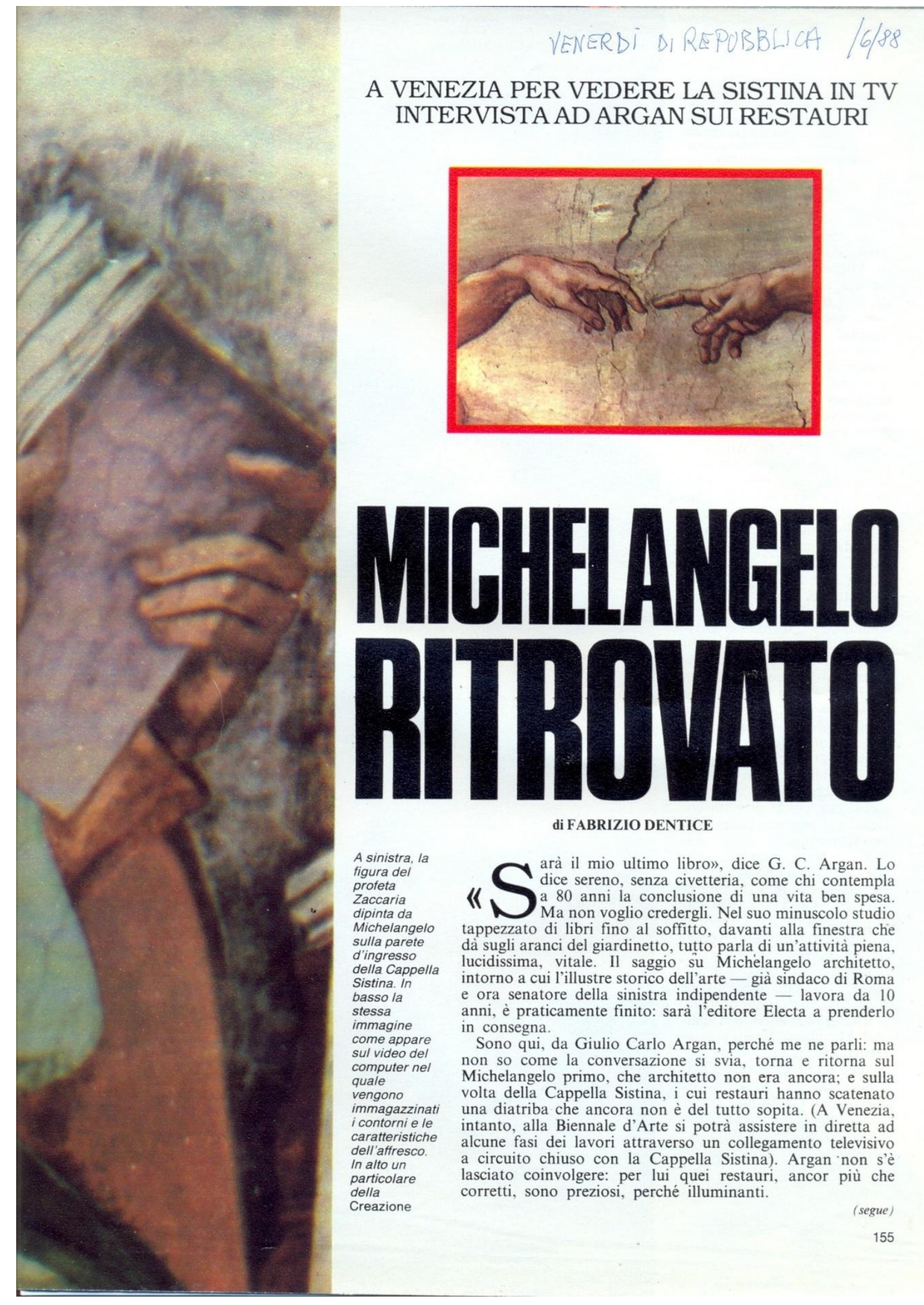




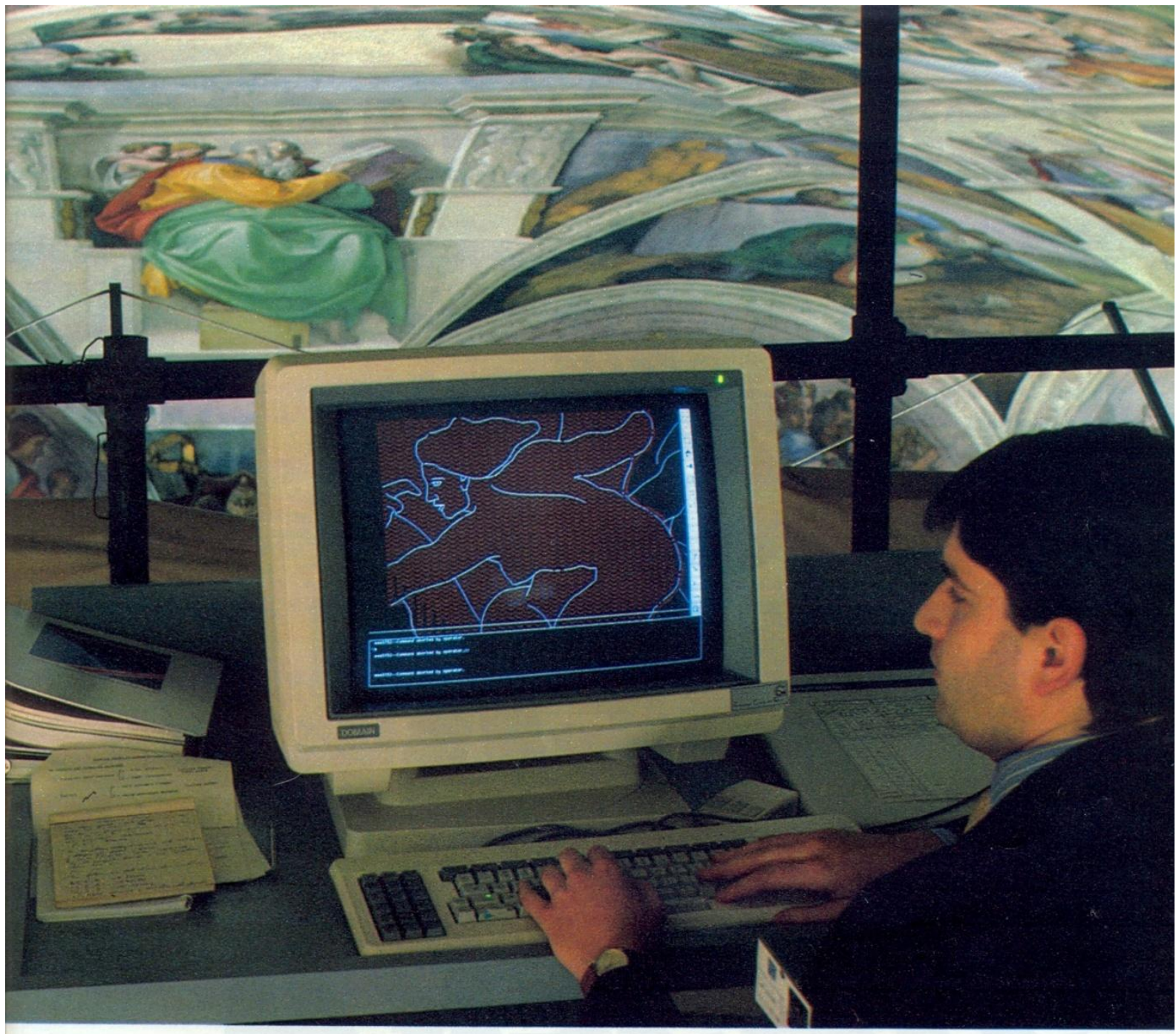

È finito il Rinascimento. «Michelangelo non è il Rinascimento. Non lo è mai stato. È il creatore del manierismo come primo momento della crisi dell'arte. Per lui larte è espressione della crisi esistenziale: il contrario del Rinascimento come è espresso in Raffaello, in Leonardo. Al fondo di tutto c’è il contrasto fra la loro idea di Rinascimento, inteso come risveglio di una cultura dormiente, e la sua idea neoplatonicocristiana, che l'intende come resurrezione di una cultura morta».

Non era questa certo l'idea di Leonardo.

"Michelangelo è in polemia costante, radicale, con
Leonardo. Polemica sulla concezione del mondo, della natura, della vita... Se scruto bene nel mio profondo vi trovo una grằnde antipatia per Michelangelo e una grandissima simpatia per Leonardo. Ma non sussiste dubbio su chi avesse ragione: chi ha visto fino in fondo la tragedia dell'essere è Michelangelo. In Leonardo c'è l'incredibile illusione di una scienza che nasce dall'arte come arte: una concezione rimasta su un binario morto, senza seguito. E sempre Leonardo è l'artista per cui il mistero si chiama "problema" e il miracolo si chiama "fenomeno". In Michelangelo non c'è niente di fenomenico, niente che imiti natura. E neppure di titanico, di poderoso, di demiurgico... La sua arte, e qui torniamo dove siamo partiti, è una "visio intellectualis". È l'opera di un artista filosofo che interviene sulla realtà esistente con un processo di risemantizzazione».

\section{In che senso?}

«Nel senso che interviene sull'esistente per cambiarne radicalmente il significato istituzionalizzato o storicamente consacrato. Questo si vede più che mai nell'architettura. Michelangelo non è mai stato architetto, non ha quasi ma costruito un edificio concependolo dalle fondamenta. Lavorava sul costruito, confrontandosi con la realtà esi- stente. Si è confrontato col Brunelleschi a Firenze, in San Lorenzo. A Roma, a palazzo Farnese, cambiando la forma del cornicione ha cambiato radicalmente il significato della costruzione del Sangallo. Sempre a Roma, c'imbattiamo nel suo capolavoro. Che non si realizza, come si potrebbe credere, in Campidoglio, ma in Santa Maria degli Angeli. Si pensi! Qui con un solo spostamento d'asse fa delle Terme di Diocleziano una chiesa. E per completare la trasformazione gli basta questa scritta: "Erat idolum: nunc est templum Virginis". Non sembra un gesto alla Duchamp?».

Fabrizio Dentice 


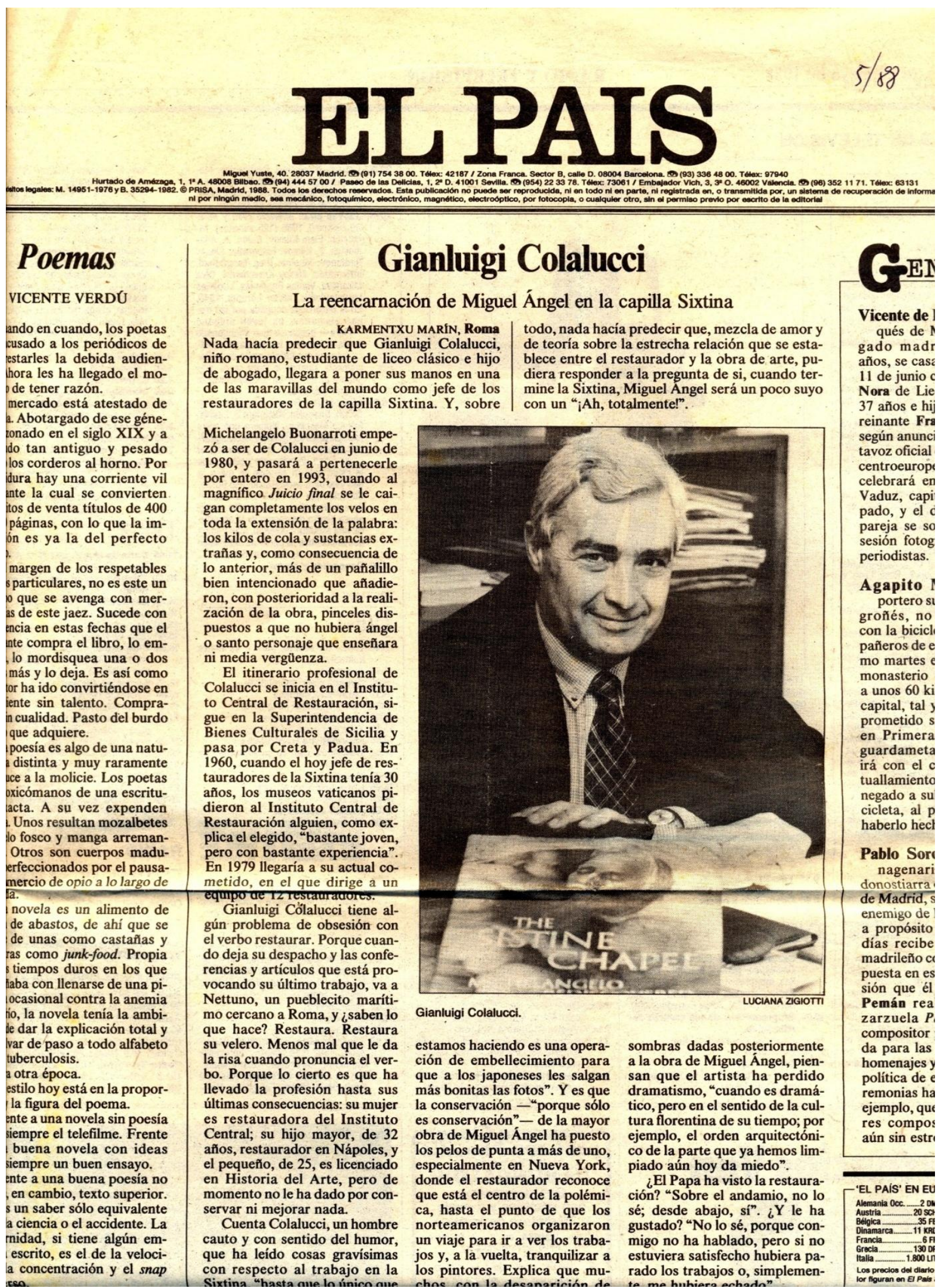




\section{EL PAIS}

\section{Poemas}

CENTE VERDO

do en cuando, los poetas ado a los periódicos de arles la debida audienra les ha llegado el moe tener razón.

rcado está atestado de Abotargado de ese géneado en el siglo XIX y a $\tan$ antiguo y pesado $s$ corderos al horno. Por ra hay una corriente vil e la cual se convierte nvierten de 400 ginas, con lo que la im es ya la del perfecto

argen de los respetables articulares, no es este un ue se avenga con merde este jaez. Sucede con que $\mathrm{e}$ compra el libro, lo em mordisquea una o do ás y lo deja. Es así como ha ido convirtiéndose en te sin talento. Compraualidad. Pasto del burdo te adquiere. esía istinta y muy raramente a la molicie. Los poetas cómanos de una escritu-

\section{Gianluigi Colalucci}

La reencarnación de Miguel Ángel en la capilla Sixtina

KARMENTXU MARÍN, Roma | todo, nada hacía predecir que, mezcla de amor y Nada hacía predecir que Gianluigi Colalucci, de teoría sobre la estrecha relación que se estaniño romano, estudiante de liceo clásico e hijo blece entre el restaurador y la obra de arte, pude abogado, ilegara a poner sus manos en una

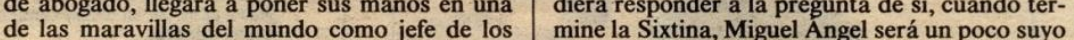
restauradores de la capilla Sixtina. Y, sobre con un "iAh, totalmente!".

Michelangelo Buonarroti empezó a ser de Colalucci en junio de 1980 , y pasará a pertenecerle por entero en 1993, cuando al magnífico Juicio final se le caigan completam toda la extension de la palabra: los kilos de cola y sustancias extrañas y, como consecuencia de lo anterior, más de un pafialillo bien intencionado que añadieron, con posterioridad a la realización de la obra, pinceles dispuestos a que no hubiera ángel era ángel o santo personaje que enseñara ni media vergüenza.

El itinerario profesional de Colalucci se inicia en el Instituto Central de Restauración, sigue en la Superintendencia de Bienes Culturales de Sicilia y pasa por Creta y tauradores de la Sixtina tenía 30 años, los museos vaticanos pi-

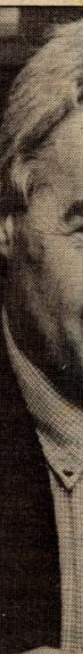
pas0 por Creta y Padua. En
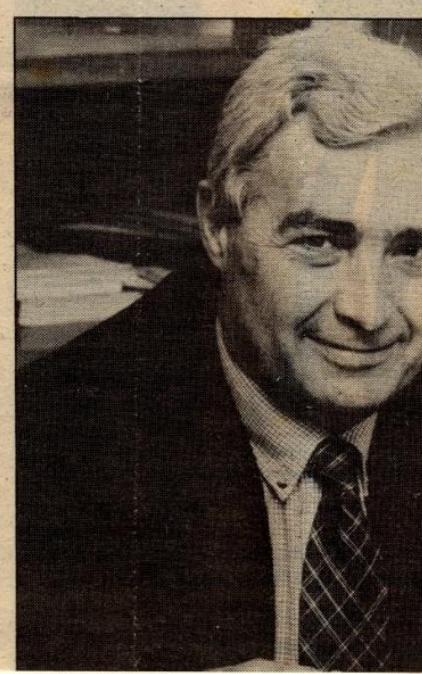

JOSE MARIA PEREZ GONZALEZ

AROUITECTO

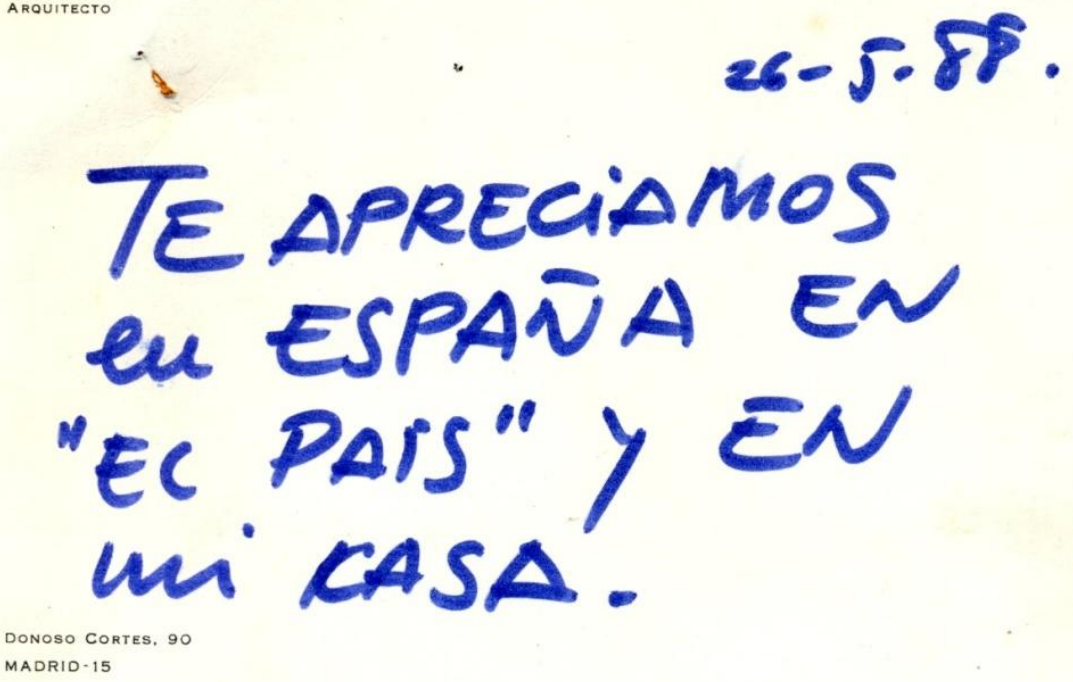

oriel

\section{y} G $G_{\text {EI }}$

Vicente de qués de 1 gado madi gado madi años, se cas 11 de junio Nora de Lie 37 años e hi reinante Fra según anunc centroeurop celebrará er Vaduz, capi pado, y el pareja se sc sesión fotog periodistas.

Agapito 1 portero si portero s
groñés, no grones, no
con la bicicl pañeros de e mo martes monasterio a unos $60 \mathrm{ki}$ capital, $\mathrm{tal}$ prometido s prometido s guardameta guará con el $c$ tuallamientc negado a su cicleta, al $\mathrm{p}$ haberlo hec

Pablo Sor nagenari donostiarra de Madrid, a propósito días recibe madrileño $\mathrm{c}$ puesta en es sión que él Pemán rea Pemán rea
zarzuela $P$ compositor da para las homenajes ] política de ? remonias ha remonias he \begin{tabular}{l|l}
$\begin{array}{l}\text { en el sentido de la cul- } \\
\text { itina de su tiempo; por }\end{array}$ & $\begin{array}{l}\text { ejemplo, qui } \\
\text { res compo: }\end{array}$ \\
el orden arquitectóni- & aún sin estr
\end{tabular} \begin{tabular}{l|l}
$\begin{array}{l}\text { en el sentido de la cul- } \\
\text { itina de su tiempo; por }\end{array}$ & $\begin{array}{l}\text { ejemplo, qui } \\
\text { res compo: }\end{array}$ \\
el orden arquitectóni- & aún sin estr
\end{tabular} el orden arquitectóniarte que ya hemos limt hoy da miedo".

pa ha visto la restaurabre el andamio, no lo abajo, sín. ¿Y le ha "No lo sé, porque con1a hablado, pero si no satisfecho pero rabajos 0 , simplemen- 


\section{The Netw Hork Eimes

\section{taly Reclaims Its Treasures From the P}

\begin{tabular}{|c|}
\hline Ву JOHN RUSSELL \\
\hline $\begin{array}{l}\text { OSTERITY MAY SEE THE YEAR } 1988 \text { AS } \\
\text { one in which there was at last a turn for the } \\
\text { better in the long and grim story of Italy's } \\
\text { irresponsibility toward her patrimony. As a } \\
\text { repository of great art and a living museum of } \\
\text { at architecture, Italy has few rivals, past or present. } \\
\text { also, and above all since World War II, it has doubled, } \\
\text { hat regard, as a hospital for great architecture and a } \\
\text { gue ship for great art. } \\
\text { Everyone who knows Italy well can think of great } \\
\text { seums that have been closed for months or even years } \\
\text { ther, great works of art that have been allowed to } \\
\text { triorate, and churches that are visibly coming apart. } \\
\text { say that there is any general improvement in this } \\
\text { lid be premature, but at least we have lately seen } \\
\text { jor and successful restorations of work by four great } \\
\text { sts - Michelangelo and Raphael in Rome, Masaccio } \\
\text { Donatello in Florence - together with the beginining } \\
\text { inew science of diagnostics that may help to make } \\
\text { h things common form in the future. } \\
\text { To begin with, we can say that in the ongoing and }\end{array}$ \\
\hline espite controversy, \\
\hline sveral major restorations \\
\hline Ive uncovered glories \\
\hline dden for centuries. \\
\hline $\begin{array}{l}\text { running process of the restoration of Michelangelo's } \\
\text { coes in the Sistine Chapel, work has just been com- } \\
\text { en on what may well be the most celebrated image in } \\
\text { tern painting - the "“Creation of Adam." } \\
\text { This critic happened to be in Rome last winter when } \\
\text { maveable scaffolding had just been put beneath the } \\
\text { eation of Adam." Like many another interested ob- }\end{array}$ \\
\hline
\end{tabular}
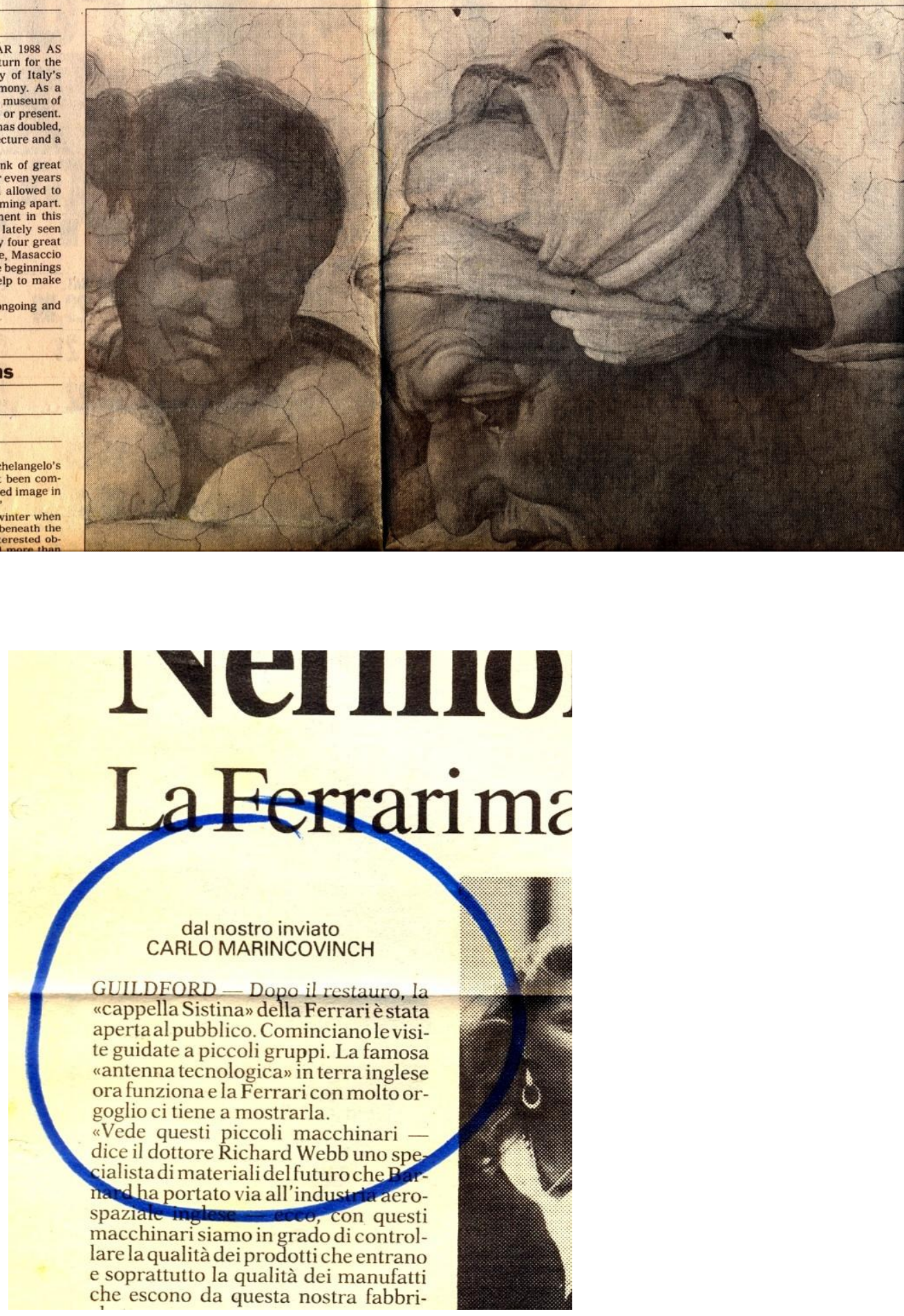


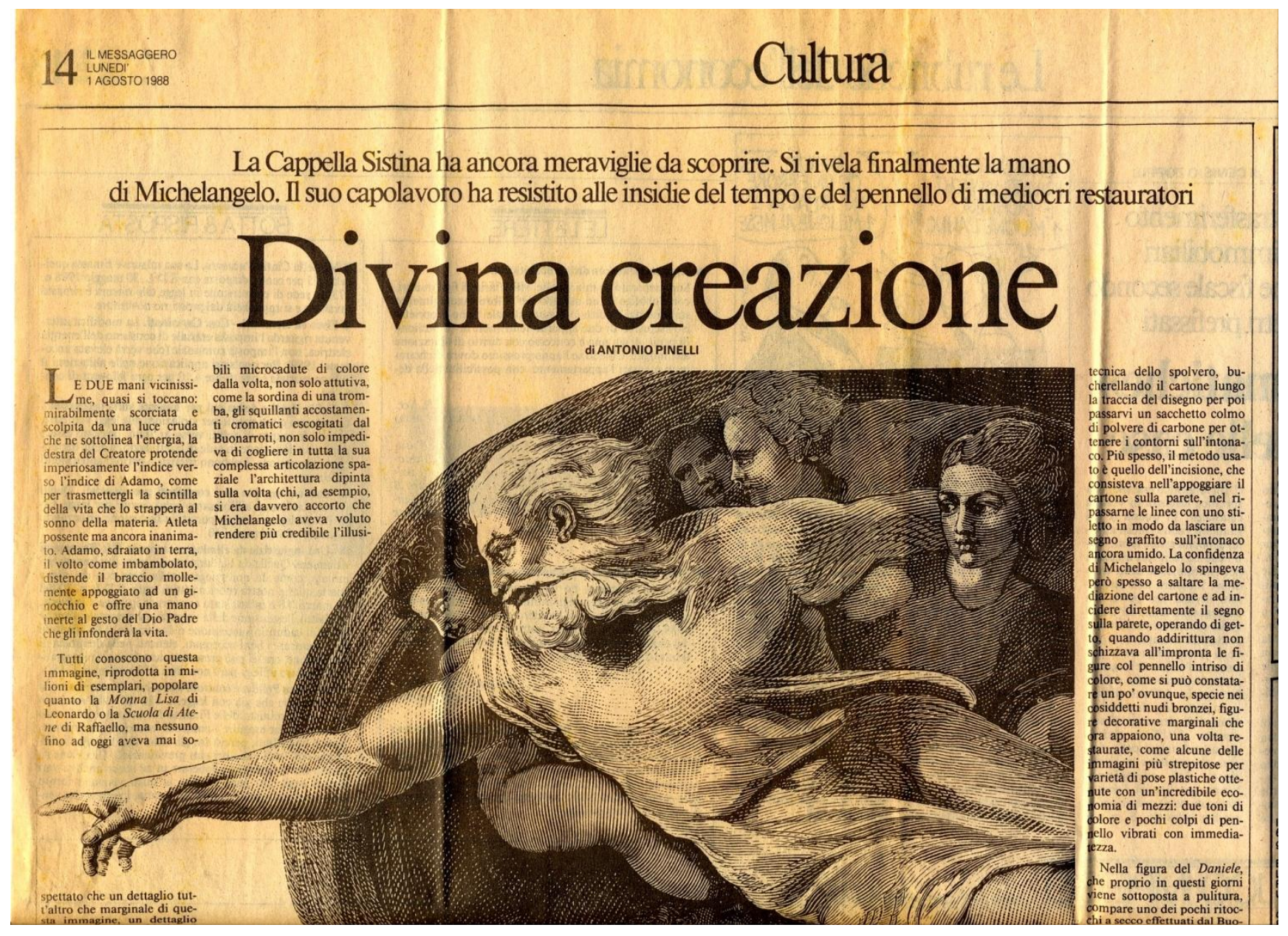




\section{Los restauradores de la Capilla Sixtina ignoran aún si fueron destruidos o no los desnudos de Miguel Ángel}

En 1989 se iniciará un estudio para comprobar el estado real de los frescos de 'El juicio final'

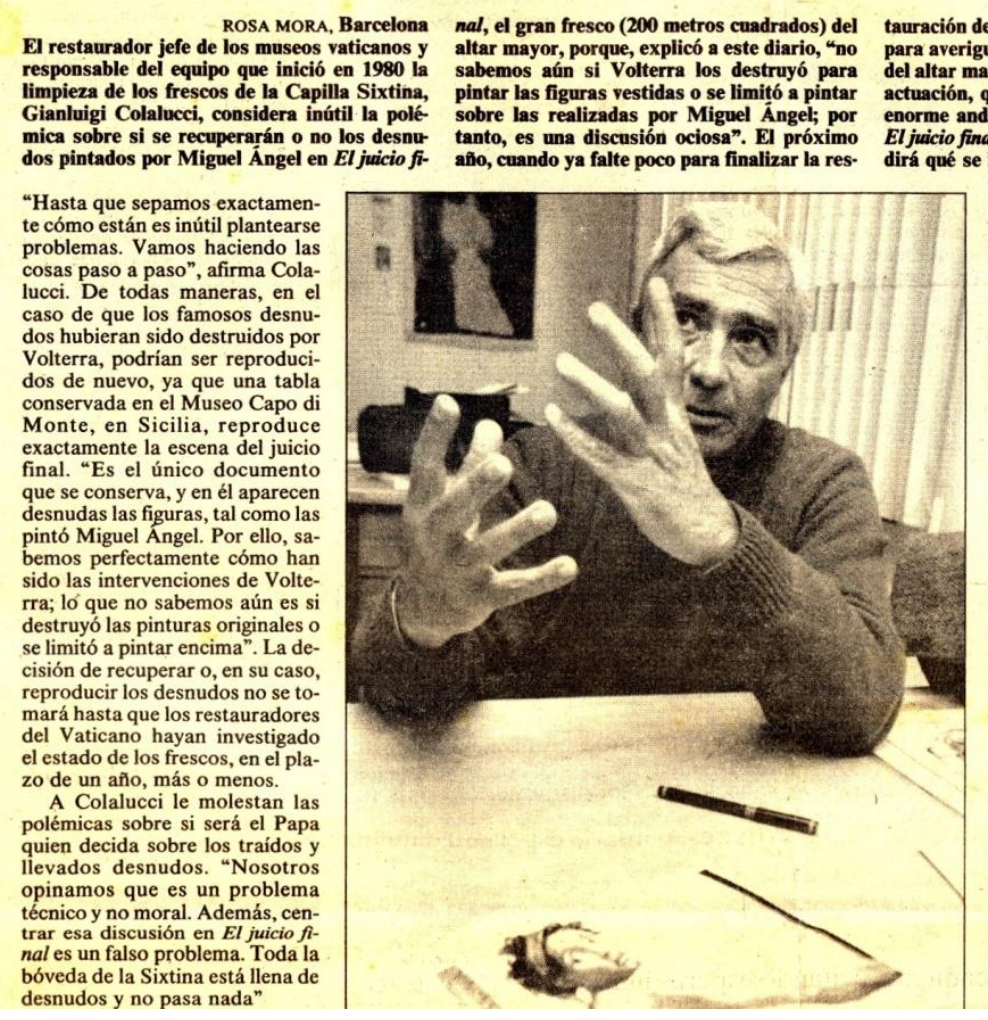

uración de la boveda, se realizará un estudio enstrucción de un alamio vertical para la limpieza de qué se hace con los famosos desnudos.

Hasta que sepamos exactamen(a) caso de que los famosos desnudos hubieran sido destruidos por el Museo Capo di en Sicilia, reproduce (a) "Es el único documento se conserva, y en él aparece ngel. Por ello, saido desnudos y no pasa nada" no se han tocado jamás; la imagen de que se rozan, con todos los significados metafisicos que se han dado al hecho, es producto de la imaginación En 1565 surgieron las primera grietas en la bóveda y se produjo una primera intervención. "Se produjo un movimiento en la bóeda, y cayeron pequenos trozos de los fres, quedaron afectados, por ejemplo, los dedos de don. Carnevale fue el encargages de Adán, y las pintó siguienges de Adan, y las pintó siguienreproduciendo original de Miguel Ángel. Los dedos pintados por Car dos pintados por Carnevale, exactos a los de Miguel Angel, no del Padre Eterno". Así fue y as queda tras la restauración actual.

\section{Un caso patológico}

"La Capilla Sixtina", explica Colalucci, "es un caso patológico; 1 a mayor parte de la gente ve lo que quiere ver, que los dedos se tocan. Y no es cierto. De todas maneras, no es grave. ya que demasiado y los turistas podrán seguir soñando"

La decisión de restaurar la
Cuestión de gustos

R. M., Barcelona La polémica sobre la conveniencia de realizar la resta ración de la Capilla Sixtina ha remitido bastante, aunque, según Colalucci, "volverá abrirse en cuanto finalice limpieza de la bóveda". "En fondo", añade, "es cuestión de gustos". Hay quien prefiere ver mugre enganchada co una vieja capa de cola, opin Colalucci, creyendo que ah esta todo el misterio, todas las sombras del pintor, a un $\mathrm{M}$ guel Ángel auténtico, lleno de color.

Tras la restauración, la Sixtina parecerá más amplia explica Colalucci. "La primera impresión será la del color, el gran descubrimiento del color de Miguel Ángel. Después de la limpieza, se podrán ver las intervenciones arquitectonicas de Miguel Angel en la bóveda y que no se veian causa de la suciedad. Y el rerecerá tener más espacio".

La polémica, recuerda La le ción, se inició en 1983 . Un pintor norteamericano, que se decía muralista, me envió un carta acompañada de un hoja de una revista en la que se reproducía una luneta restaurada. Sobre ella había colocado un papel transparente. lleno de flechas e indicaciones: Aqui habia una sombra ha desaparecido; aquí habia tal detalle y ahora ya no está. $\mathrm{y}$ asi, guiándose solo por el recorte de una revista. Le contesté que era muy complicado 
isogna sottolineare la 《 diversità fra questi Non è facile per i benpensanti capire Michelangelo. Attraverso il recupero degli affreschi dell Sistina vi è la possibilità di ricostruire la teoria del colore di Michelangelo. Era molto legato alla cultura e alla filosofia fiorentina neoplatonica; nella casa $d i$ Lorenzo il Magnifico, dove fu ospite, da ragazzo, fu in contatto con Botticelli, Marsilio Ficino Pico della Mirandola, Poliziano. Leonardo era, in un certo senso, l'antitesi di quel pensiero: aveva una veduta logico-analitica, de scrittiva e naturalistica. Michelangelo conosceva Leonardo e lo ammirava, ma idealmente era $\mathrm{i}$ suo antagonista, la sua concezione del mondo e dell'arte era opposta.»

«Probabilmente la volta della Sistina è stata dipinta in diretta polemica a Leonardo: una risposta fiorentina alla 'cena' di Milano, che era la più famosa delle pitture murali del tempo. Michelangelo non conobbe direttamente la Cena di Leonardo e non immaginava che la tecnica usata avrebbe portato il dipinto come lo vide il Vasari: poco più di una macchia.»

«Leonardo era un avversario del movimento neoplatonico. Non aveva mai legato con quel gruppo. Ciò spiega la sua fuga da Firenze per recarsi a Milano: una città in cui già vigeva una cultura tecnologica e pragmatica. Infatti si presentò ai signor di Milano come ingegnere-idraulico,»

«Leonardo e Michelangelo avevano già avuto in passato il modo di confrontarsi nella pittura murale: il dipinto di Leonardo rovinò prima di essere compiuto, del suo Michelangelo disegnò solo i cartoni. Meno di cinque anni dopo, nella Sistina volle dimostrare che sul muro si poteva dipingere solo a buon fresco.»

Problemi come questo del restauro mettono in gioco altre questioni: per esempio quello della copertura finanziaria. Per questo motivo si è scelta la via della sponsorizzazione, da molti ritenuta una iniziativa spregiudicata. La Nippon television network oggi aiuta il Vaticano a riscoprire Michelangelo e i suoi meravigliosi dipinti, ma è come se fosse momentaneamente in possesso di questi affreschi. In effetti possiede l'esclusiva delle riproduzioni fotografiche.

«Qualche tempo fa ho scritto un articolo molto duro sul problema delle sponsorizzazioni», ricorda Argan che mi parla allo che cadono a pezzi. E sono meno celebri, ma sempre storicamente notevoli.»

«Naturalmente non protesto per la sponsorizzazione della Sistina, in particolare, da parte dei giapponesi: il Vaticano, del resto, è uno stato estero; quando critico l'intervento privato mi riferisco alla condizione italiana. Per motivi morali, più che tecnici, preferisco che ad occuparsi del patrimonio artistico sia lo Stato, con gli storici dell'arte delle soprintendenze invece che munifici, ma non del tutto disinteressati, benefattori.

«Francamente nel generalizzarsi delle sponsorizzazioni vedo un pericolo: già si fanno avanti privati per sponsorizzare musei, mostre magari domani anche università $\mathrm{Si}$ innesca così un processo di privatizzazione della cultura che per me è regressivo. In realtà il problema c'è, mancano i fondi, visto che lo Stato ha sempre dato cifre irrisorie per il sempre dato cifre irrisorie per il patrimonio artistico. Più volte degli stanziamenti governativi e qualche cosa si è ottenuto, ma per spendere più soldi occorrono strutture tecniche più forti.»

Al posto, allora, di grandi imprenditori dovrebbero essere gli storici dell'arte a segnalare quali cicli di affreschi siano da restaurare. «Gli storici hanno senz'altro un peso, perché si interessano, sono invitati ad andare a vedere le opere in corso. In questo caso della volta della Sistina, la direzione dei Musei Vaticani ha chiesto l'avviso di molti studiosi italiani e stranieri. Lo stato italiano dispone di un ottimo strumento, l'Istituto centrale del restauro, dove gli storici dell'arte collaborano con chimici e fisici; ma lo costringe a vivere in povertà. Anche dal punto di vista metodologico gli storici, essendo degli specialisti, sono i soli, veri responsabili del restauro. Mi vanto di essere il fondatore di quell'Istituto che poi, diretto da Cesare Brandi, ha avuto fama internazionale ed è stato un vero modello. Lo storico dell'arte in Italia è già molto impegnato in questo, ma dovrebbe avere più potere decisionale rispetto alla burocrazia ministeriale.»

Tornando alla Sistina bisogna ammettere che si rimane perplessi, oggi, davanti ai dipinti michelangioleschi della Sistina, appena ripuliti. Si sono rivelati dopo essere stati per secoli coperti da sostanze le più varie. Sembra che i restauratori per primi siano rimasti colpiti da ciò che si è guadagnato in splendore. Forse nessuno si aspettava 

84.88

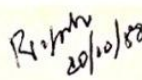

Arts \& Entertainment

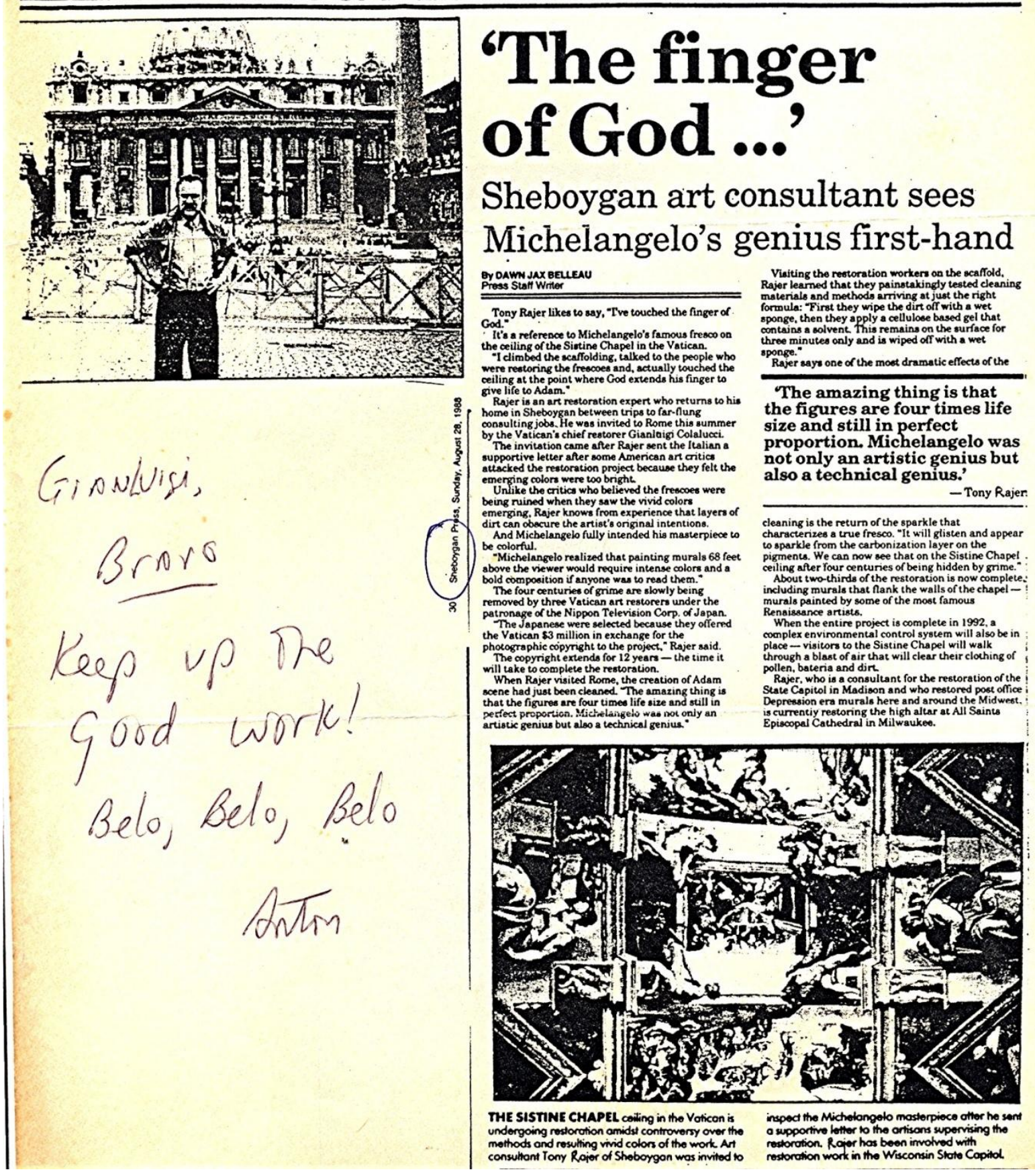




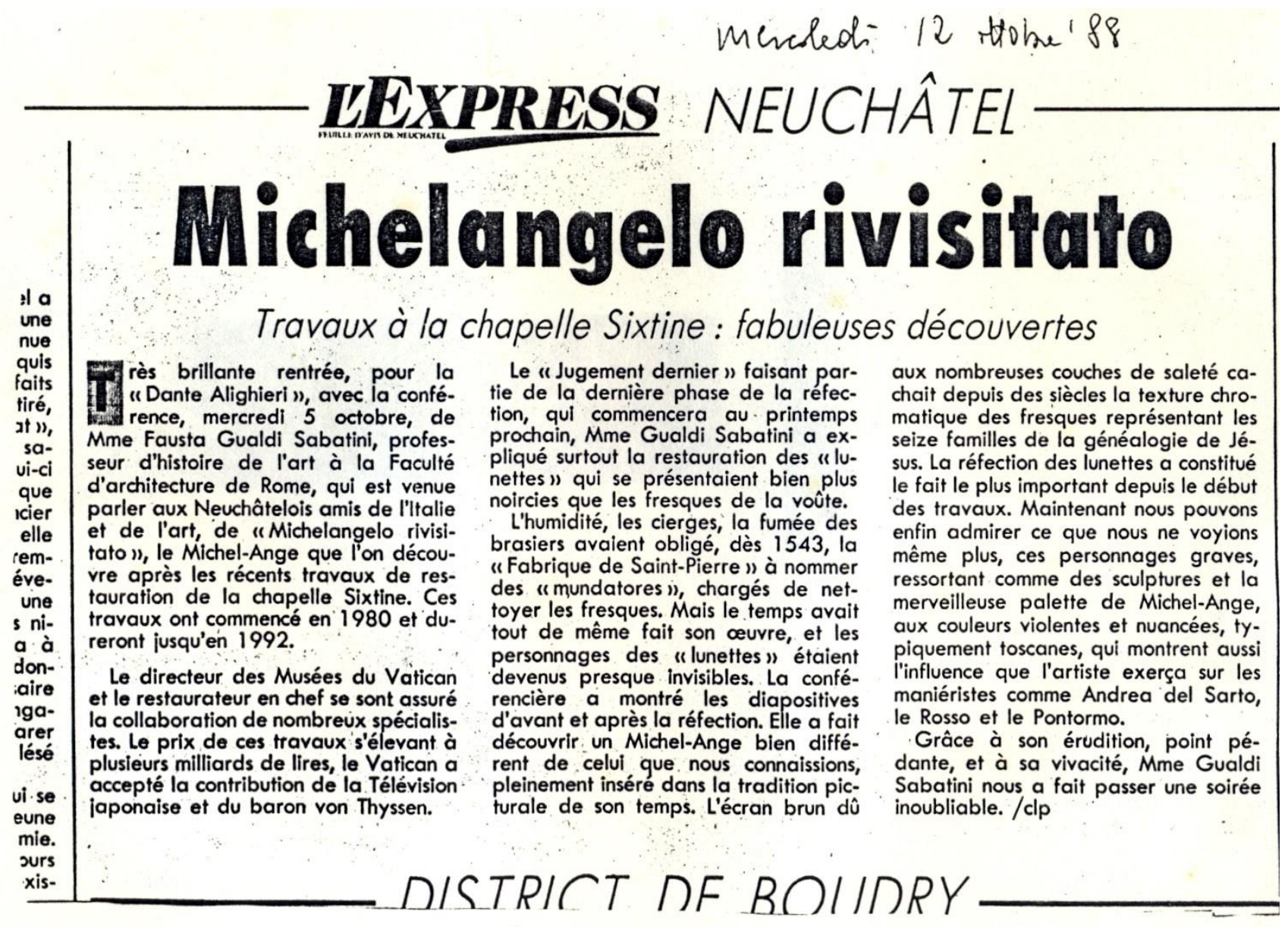




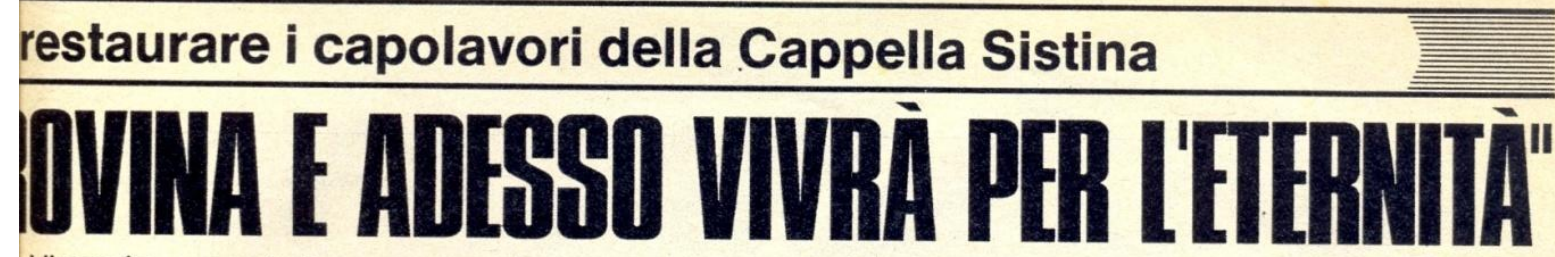

"Vivendo a contatto con questa immensa opera d'arte, abbiamo scoperto un Michelangelo grande di quanto si pensasse» «Nel 1990 inizieremo la pulitura del "Giudizio Universale" "

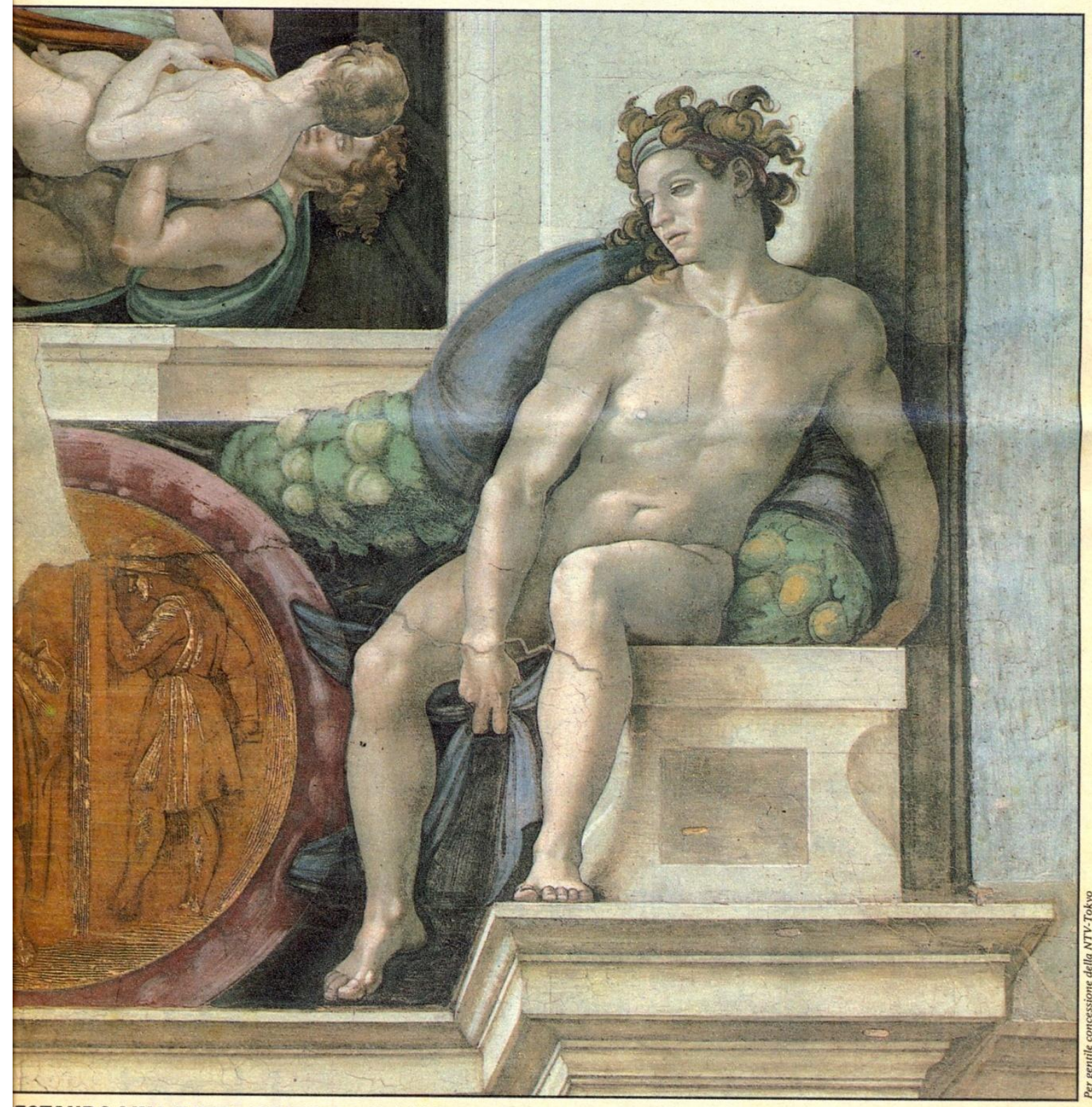

ESTAURO L'HA FATTO RIVIVERE Città del Vaticano. Ecco ora, un poco più ingrandita, la stessa parte del "Nudo", affrescato da Micheanluigi Colalucci. Il lavoro di restauro ha riportato alla luce i veri colori di Michelangelo, molto più chiari e vibranti di gusanto vaticani diretta dal profesla patina scura che si era creata nel tempo, l'affresco ha così ritrovato $i$ toni festosi che aveva in origine. Il restauro della volta della Cappella Sistina, iniziato 80, si concluderà l'anno prossimo. Subito dopo si inizierà il restauro dell'altro capolavoro dipinto da Michelangelo nella Sistina, il "Giudizio Universale". 


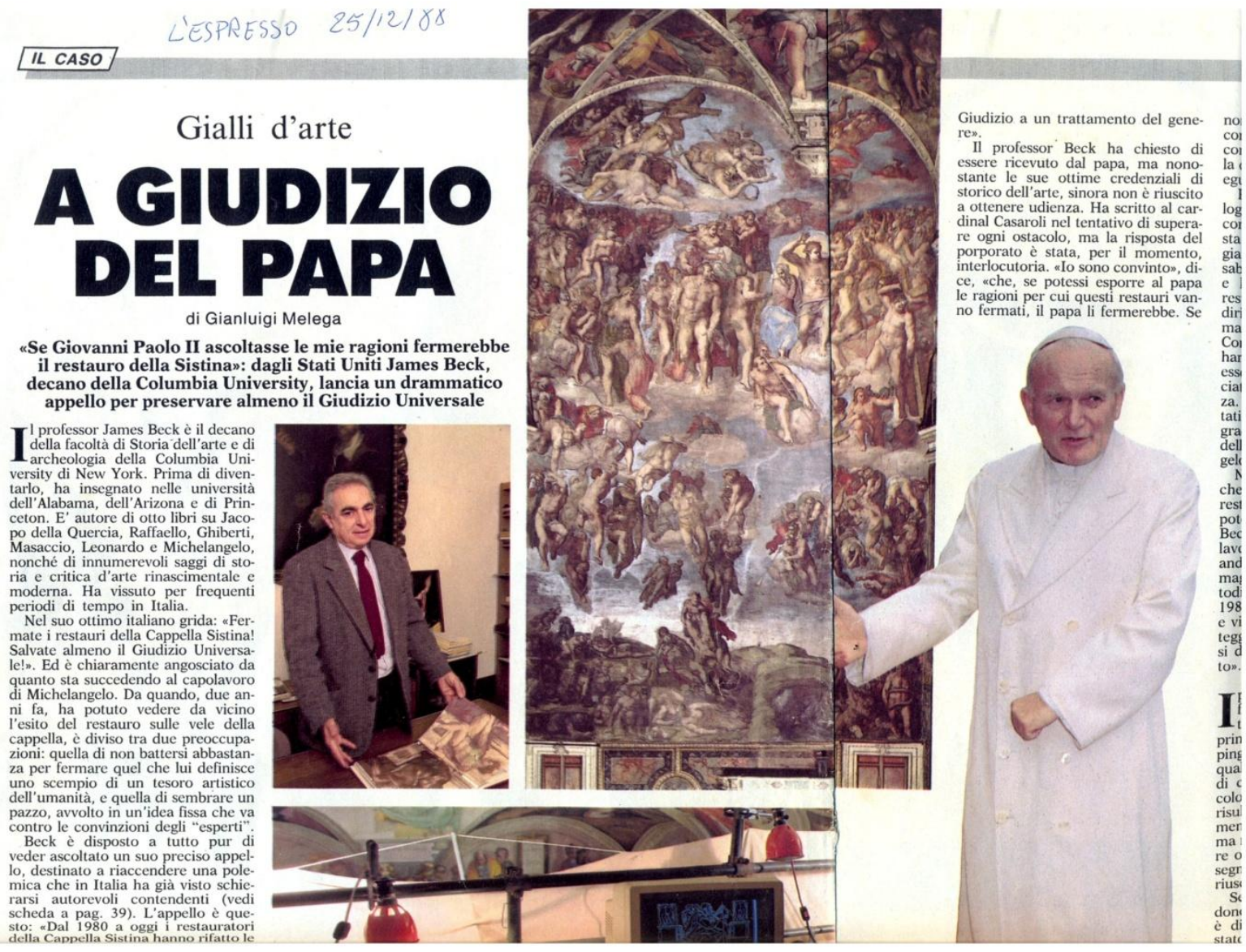




\section{L'ESPRESSO 2T/12/88}

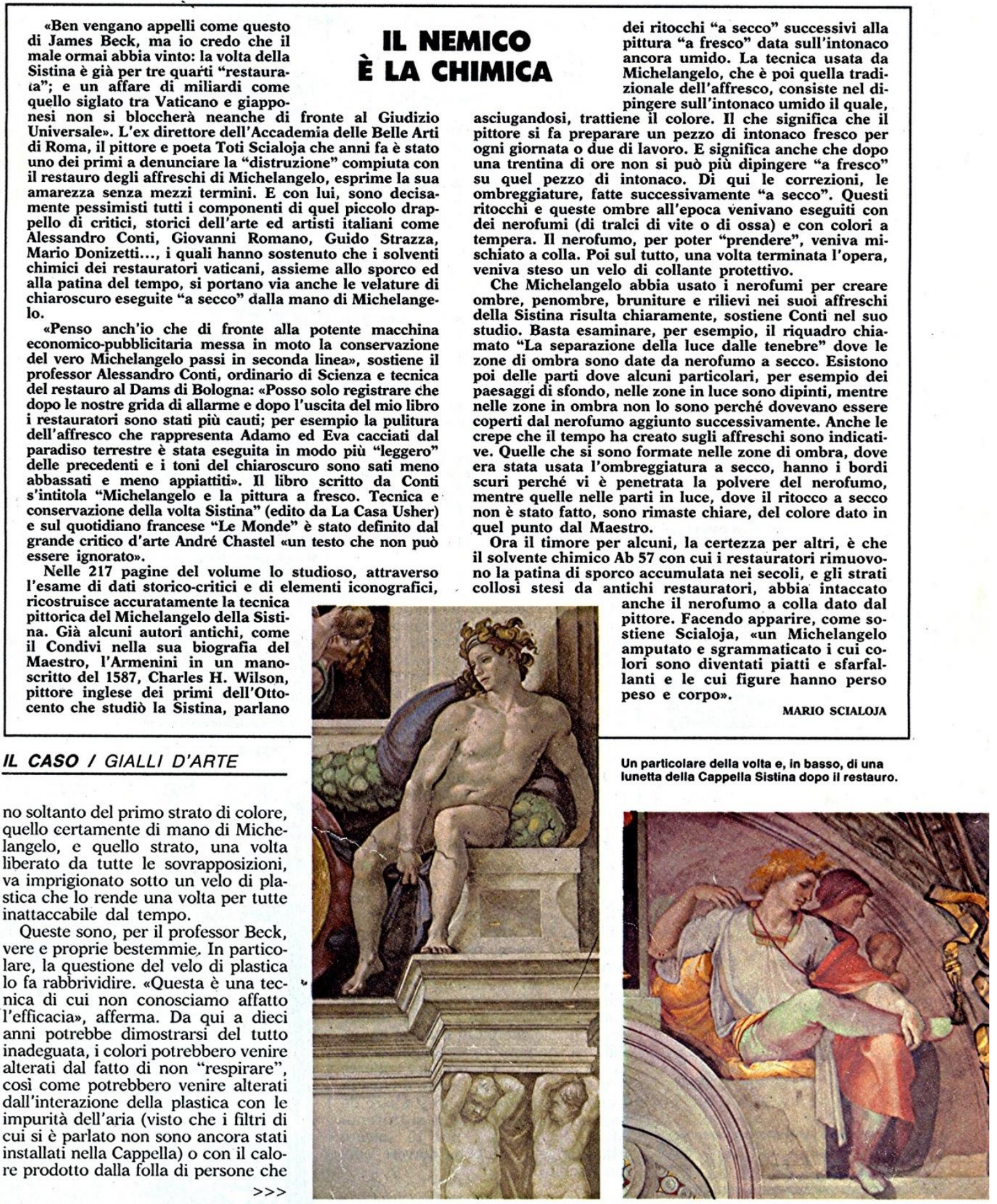

L'ESPRESSO - 25 DICEMBRE 1988 - 39 


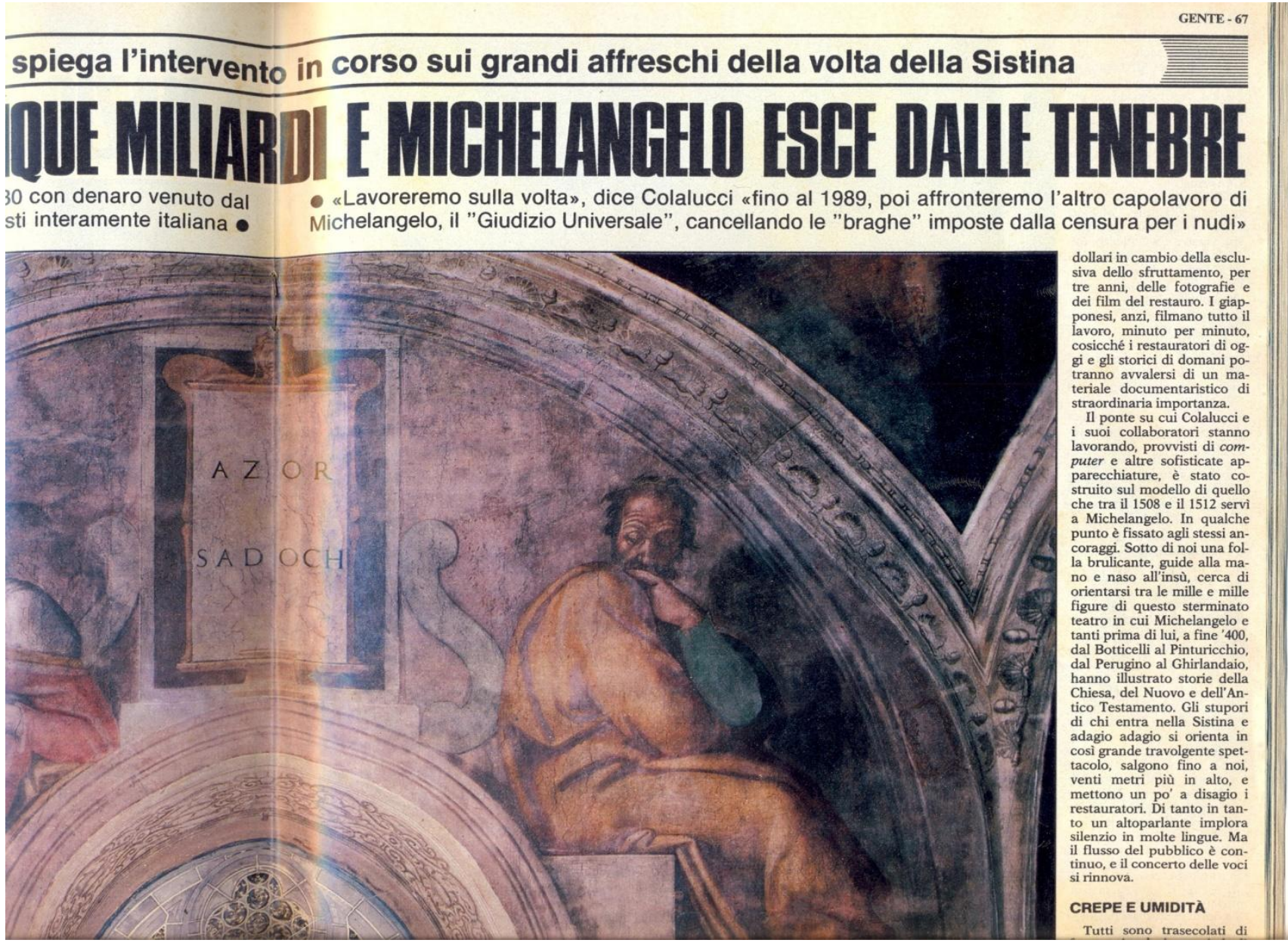


LAVANGVARDIA 31-1-11994-BARCELONA-CATALONIA- SPHIN La restauración de los frescos de la capilla Sixtina finaliza tras catorce años de trabajos
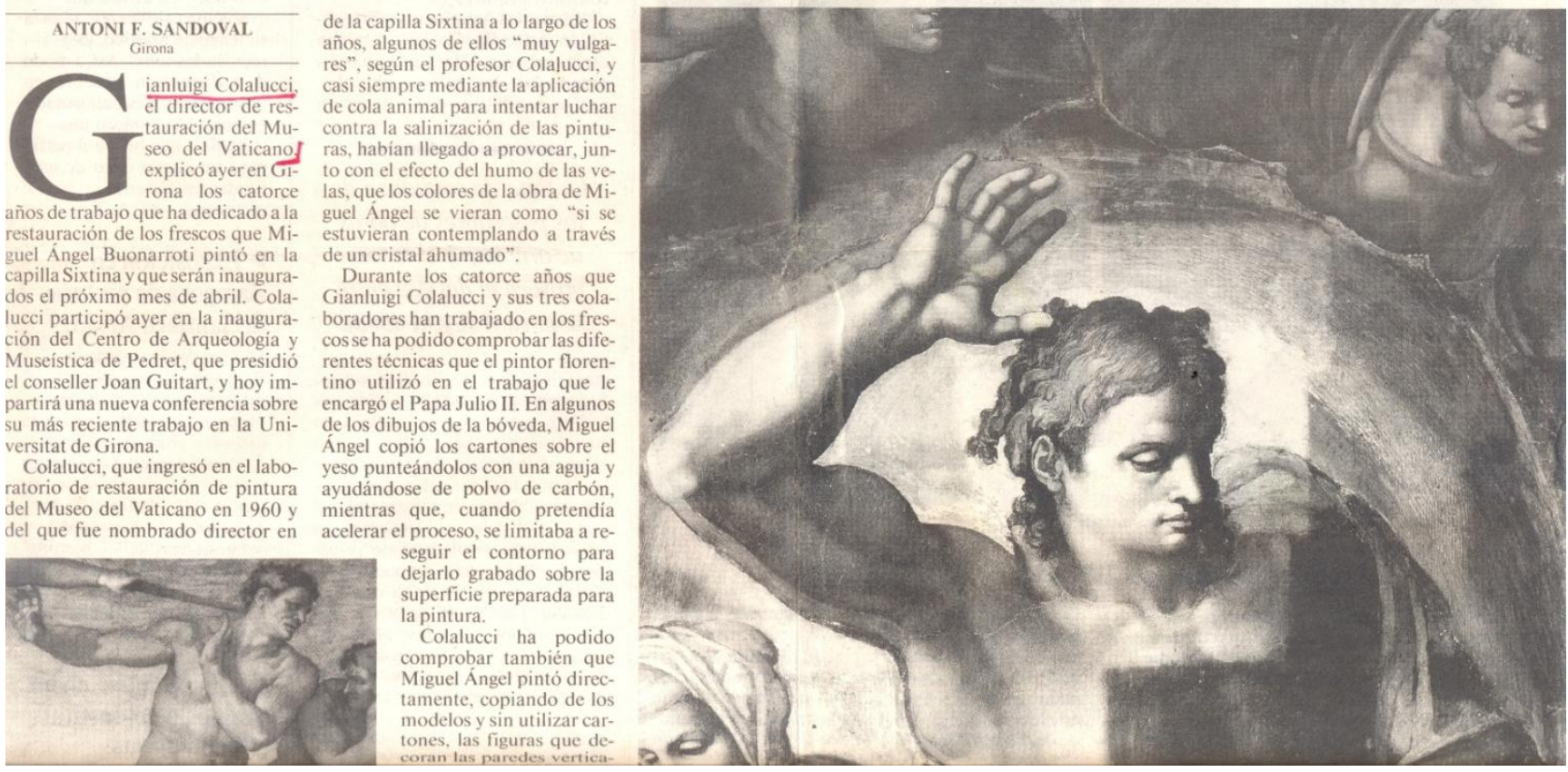


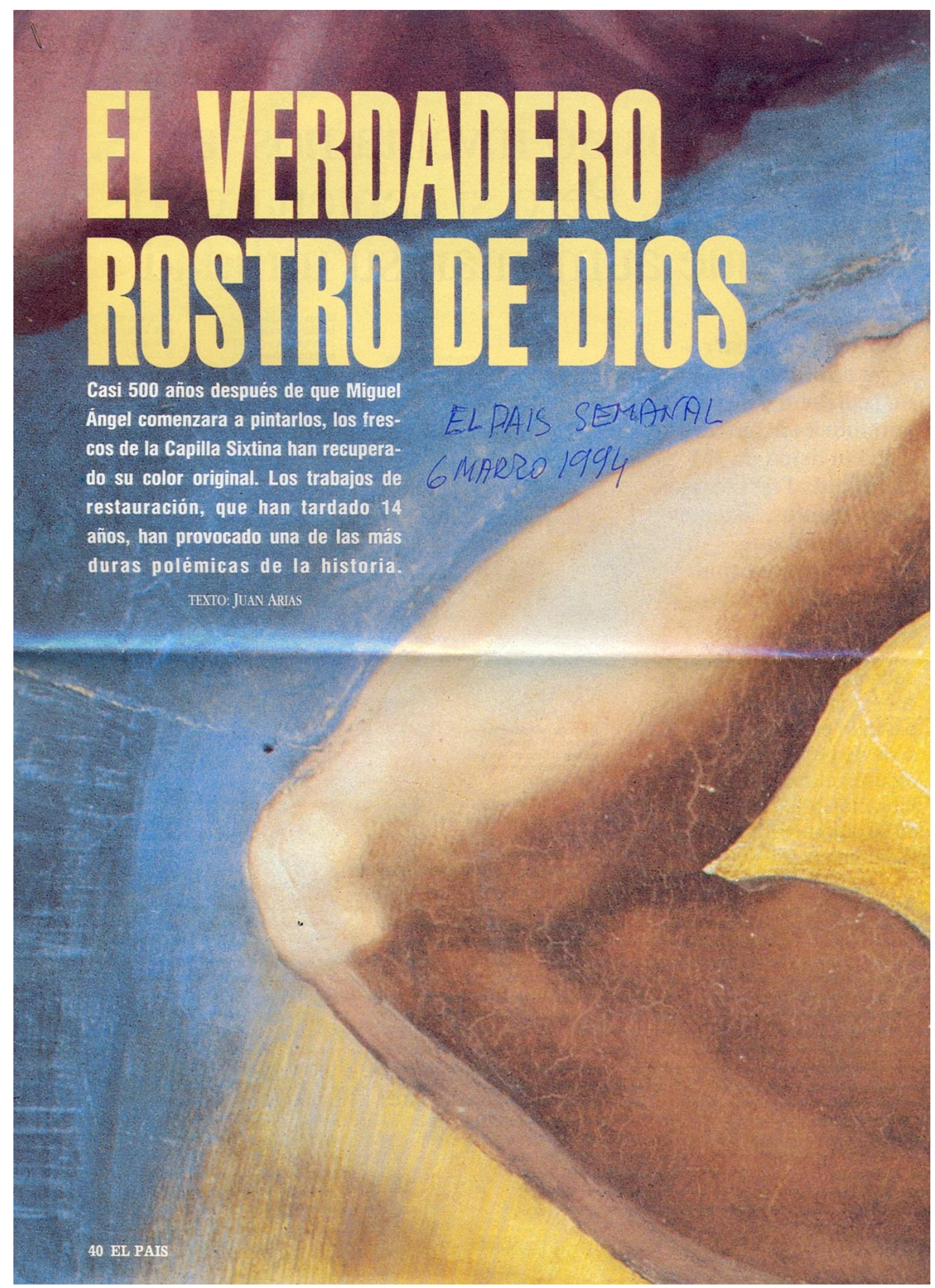




\section{RENAISSANCE}

Le 8 avril, le public pourra enfin revoir la fresque majeure de Michel-Ange, retravaillée à l'abri des regards depuis quatre ans. Les derniers travaux de la «restauration du siècle»

\section{Devant le «Jugement dernier» de la Sixtine, comme au premier jour}
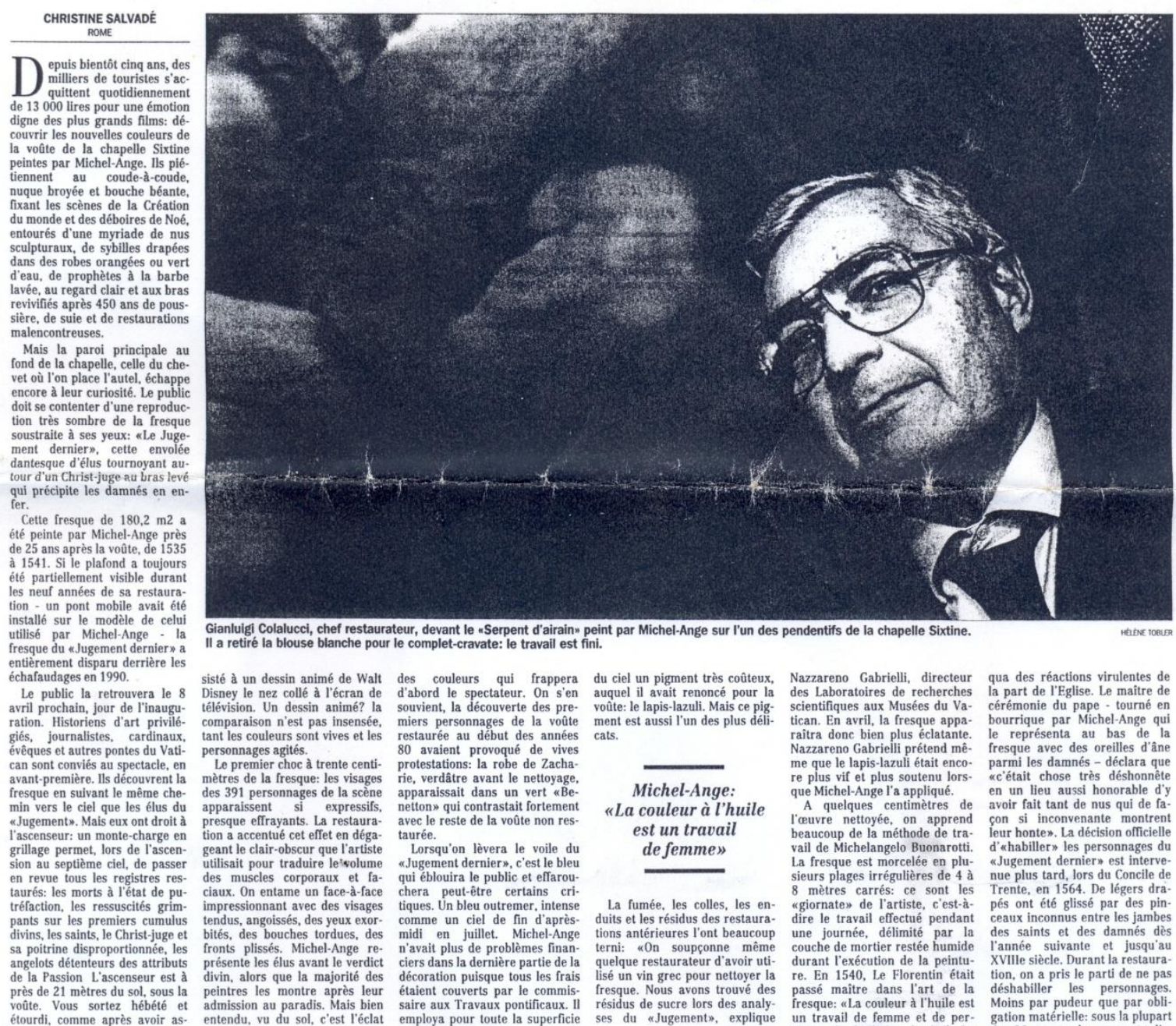

Gianluigi Colalucci, chef restaurateur, devant le "Serpent d'airain" peint par Michel-Ange sur I'un des pendentifs de la chapelle Sixtine. sisté à un dessin animé de Walt des couleurs qui frappera du ciel un pigment très coûteux,
Disney le nez collé à l'écran de

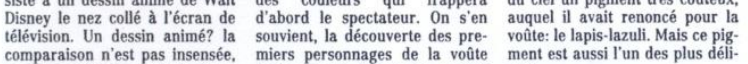
ant les couleurs sont vives et les Lo premier choc à trente centimètres de la fresque: les visages
des 391 personnages de la scene apparaissent si expressifs,
presque effrayants. La restaurpresque effrayants. La restaura-
tion a accentué cet effet en dégation a accentué cet effet en déga
geant le clair-obscur que l'artiste geant le clair-obscur que Partiste
utilisait pour traduire le'volume des muscles corporaux et fa-
ciaux. On entame un face-a-face tendus, angoissés, des yeux exor- cormme un ciel de fin d'aprèsfronts plissés. Michel-Ange re- midi en juillet. Michel-Ange
f'avait plus de problèmes finanprésente les élus avant le verdict ciers dans la dernière partie de la
divin, alors que la majorité des décoration puisque tous les frais pin, alors que la majorité des décoration puisque tous les frais
peintres les montre après leur étaient couverts par le commismiers personnages de la voûte
restaurée au début des années
80 avaient provoqué de vives protestations: la robe de Zacha-
rie, verdâtre avant le nettoyage. rie, verdâtre avant le nettoyage.
apparaissait dans un vert «Be. netton» qui contrastait fortement
avec le reste de la voute non rescats.

$$
\text { Mi }
$$

Michel-Ange: "La couleur à l'huile est un travail de femme»

La fumée, les colles, les entions antérieures l'ont bea terni: «On soupçonne mêm quelque restaurateur d'avoir ut-
lisé un vin grec pour nettoyer fresque. Nous avons trouvé
résidus de sucre lors des analy$\begin{array}{lll}\text { dmission au paradis. Mais bien } & \text { saire aux Travaux pontificaux. Il résidus de sucre lors des analy- } \\ \text { entendu, vu du sol, c'est l'éclat } & \text { employa pour toute la superficie } & \text { ses du «Jugement», expliqu }\end{array}$

\section{Quatorze ans de travail à quatre}
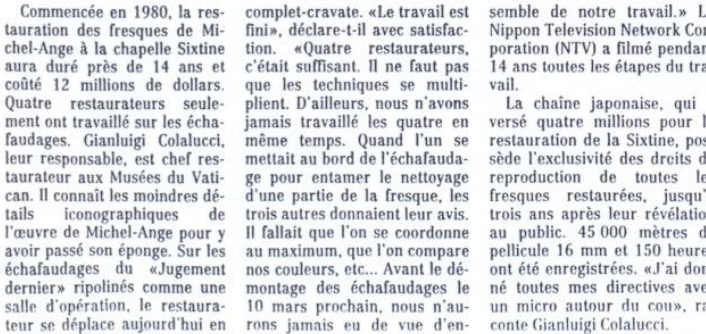

Le travail des restaurateur inis, déclare-t-il avec satisfac- Nippon Television Network Co tion. "Quatre restaurateurs, poration (NTV) a filmé penda 'est résumé à un nettoyage mi que les techniques se multi. va plient. D'ailleurs, nous n'avons La chaine japonaise, qui a
jamais travaillé les quatre en versé quatre millions pour même temps. Quand l'un se restauration de la Sixtine, po ge pour entamer le nettoyage reproduction de toutes les d'une partie de la larequue, les fresques restaurées, jusqua
drois autres donnaient leur avis. trois ans après leur révélatio trois autres donnaient leur avis. au maximum, que l'on compare dernier" ripolinés comme une montage des échafaudages
salle d'opération, le restaura. 10 mars prochain, nous nau-
teur se déplace aujourd hui en rons jamais ell de vue d'enau public. 45000 mètres ont été enregistrées. «J 'Jai dorconditionné et de filtrage d'at d'at nêt micro aut directives avec mosphère a été installé dans 1 a un micro autour du coum,
conte Gianluigi Colalucci.
Nazzareno Gabrielli, directeur scientifiques aux Musées du $\mathrm{Va}$ raitra done bien plus éclatan
retan Nazzareno Gabrielli prétend me. re plus vif et plus soutenu lorsque Michel-Ange l'a appliqué. l'auvre nettoyée, on apprend beaucoup de la méthode de tra. La fresque est morcelée en plu-
sieurs plages irrégulières de 4 a 8 mètres carrés: ce sont les "giornate" de l'artiste, c'est-à-
dire le travail effectué pendant une journée, délimité par la durant l'exécution de la peintupassé maitre dans l'art de fresque: «La couleur à l'huile est un travail de femme et de per-
sonne de facilitén, disait-il. La restauration menée durant ces treize dernières années aura
prouvé son talent de technicien: $\begin{gathered}\text { Dans quelques semaines, la } \\ \text { pas une couleur à base de plomb }\end{gathered}$ Sixtine se dévoilera completeni de céruse, réputée très oxy. ment. Le public et les critiques, dable, n'a été appliquée à comme en 1541 , rendront leur
fresque. Le soin apporté par Mi- verdict. Aprés l'avis des scienti-
chele. chel-Ange à ses préparations a fiques de l'échafaudage, ce sera permis de redécouvrir les cou- précipite les restaurateurs qu leurs presque inatierees sous Outre les pointillés et les inciapparaissent sur le mur tous les Michel-Ange ou par des interve. nants ajouts, les fameuses ubrachey
(cache-sexe) qui ont suscite beaucoup de discussions au dé. fresque. La présentation du \&Ju qua des réactions virulentes de cérémonie du pape - tourné en le représenta au bas de la parmi les damnés - déclara que avoir fall tant de nus qui de fa. con si inconvenante montrent whabiller» les personnages du nue plus tard, lors du Concile de pés ont été alissé legers dra作 lannée suivante et jusqu'au tion, on a pris le parti de ne pas (les personnages. . (ation enfer d'autres paradis picturaux. $\triangle$ LAUSANNE, mercredi 2 mars 20 h. Université, salle B 106. tauration du "Jugement der. nier», de Michel-Ange, dans la
chapelle Sixtine», conference de Gianluigi Colalucci et Nazzan ratoire de conservation de la pierre à I'EPFL et la Sociêt
Dante Alighieri de Genéve. 


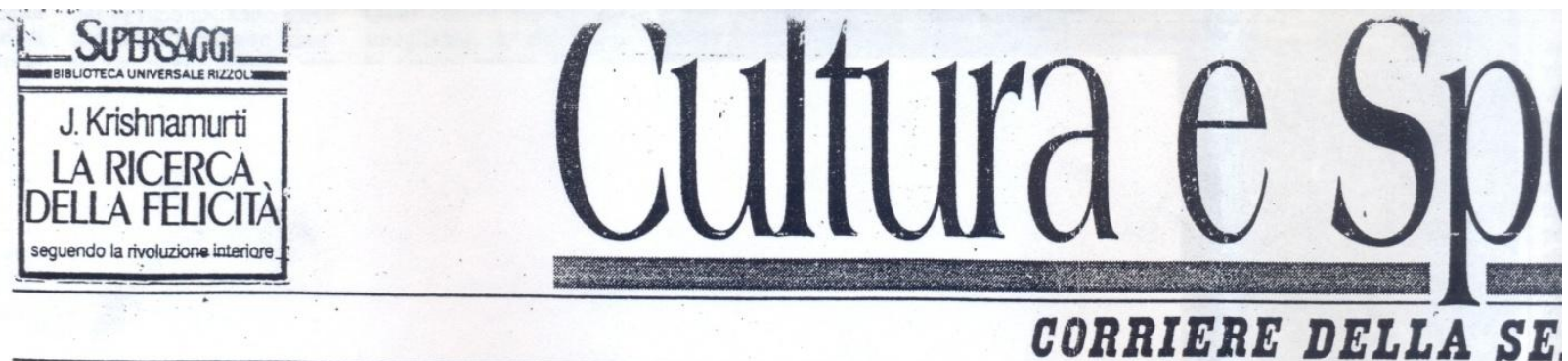

MONDOVISIONE Leri è stato presentato il restauro del «Giuddizio Universale» nella Cappe

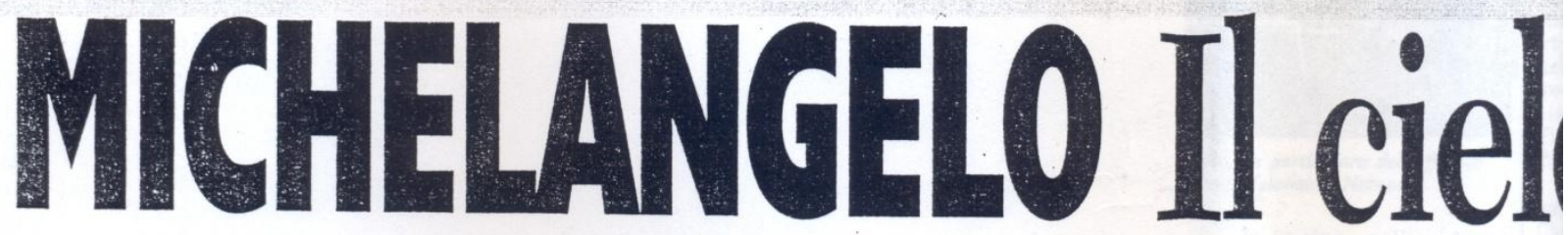

Beatit e danninatiti un popolo di giganti in lotta abbagliati dal gesto terribile di Cristo

\section{di EMLLOT TRONII}

4

orse non è ugrandezza", la prima pa rola che viene in mente quando si parla, oggi, dell'Italia. E forse è anche vero che la parola grandezza può addirittura evocare cose orribili come voglia di prevarica zione, odio per l'altro, zione, odio per l'altro,
sfiatata retorica, turpe vasfiatata retorica, turpe vanità. E gli italiani di una certa età ne sanno qualcosa per esperienza diretta.

Ma gli affreschi di Michelangelo nella Cappella Sistina mostrano che può anche parlare sensatamente di grandezza e di grandezza vera, concreta - per qualcosa che grazie al cielo, ha in qual che modo a che fare con che modo a che fare con Italia. to anche il restauro del "Giudizio finale", questa è una verità che si affer ma da sola, e clamorosamente.

"Il bello", scrive Rilke in una delle «elegie di Duino", "Il bello e il terribile al suo inizion. Forse perché il bello si dispone perché il bello si dispone rità. E nella apertura, nel "vuoto" di quella disponibilità non può non ir. rompere il terribile. Cer

to, il bello che appare ne-

gli affreschi di Michelan-

gelo nella Cappella Sisti-

na è quel bello lì. Tragi-

co. E noi proviamo piace

re e insieme siamo emo- menso sembra essere la contrasto, quel bagliore fatica, una grande fatica evocasse qualche oscurita di muscoli e di pensieri. sterminata.

Come se. davvero, il sen- Forza del colore, certo. so potesse darsi soltanto Quel colore smagliante in quella specie di destino che il restauro ha riporta eroico che conduce l'uo- to alla luce. Il colore che mo a vivere in rivolta era stato nascosto, prima mo a vivere in rivolta era stato nascosto, prima contro linsensatezza del di tutto, dalla vernice apNiente della morte. Che plicata nel Settecento, e quella insensatezza il va- con gli anni. Il colore, pelore, infondato, del suo raltro che prima del recorpo, mosso dalla vo- stauro si mostrava, eviGià, dal desiderio.

Gli affreschi della Cap pella Sistina, e le sculture dei «Prigioni», sono fors il momento più alto vissuto da quella figura che potremmo chiamare «la figura del corpo sotto sforzo", che compare per

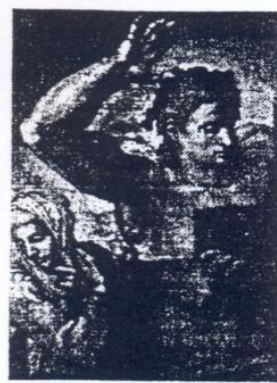

la prima volta in Grecia nel quinto secolo avant Cristo, nelle sculture di Fidia - proprio quando in Grecia si inventa la tragedia a teatro - e ch sopravvive. attraversando fatica, adesso, non serve

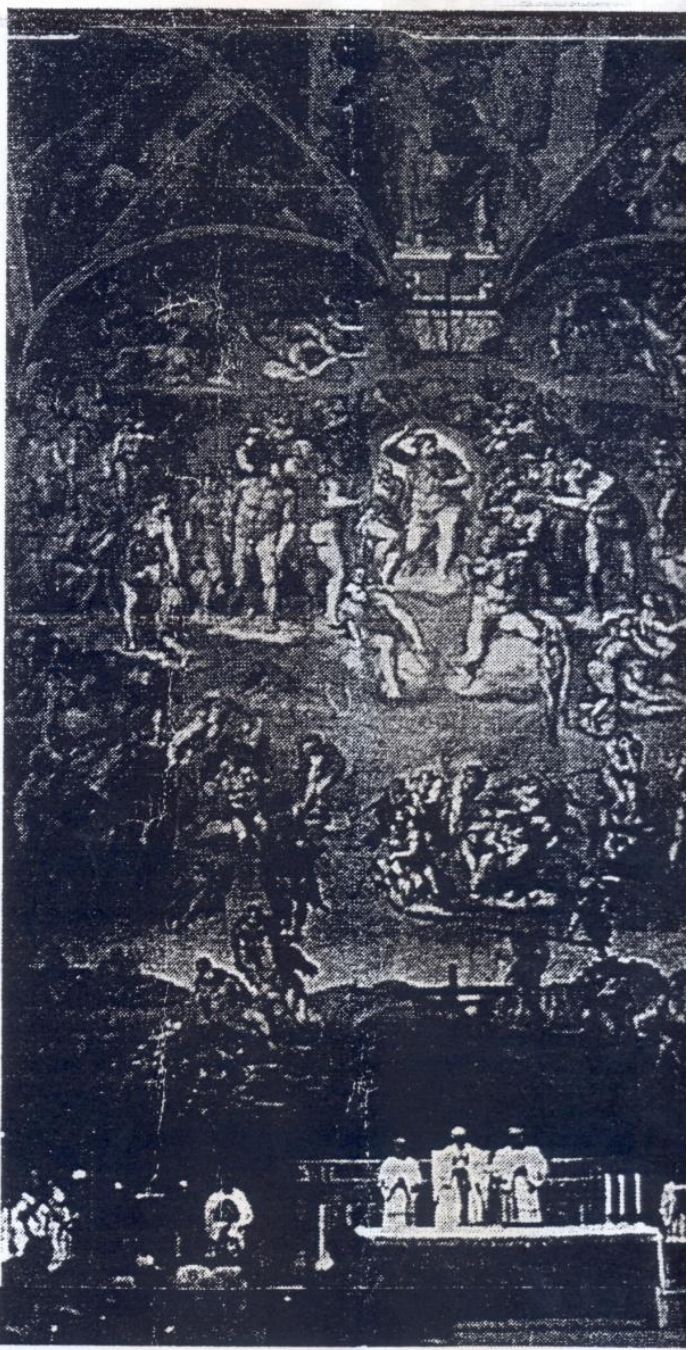

Veduta d'insieme della Cappella Sistina dopo i restauri; ai lati, un partico Veduta d'insieme della Cappella Sistina dopo i restauri; ai lati, un partico
durante (sinistra) e dopo il restauro (Cortesia della Ntv Nippon Television più». La fine del tempo è 
Iniversale» nella Cappella Sistina. Emozioni e polemiche per un capolavoro ritrovato
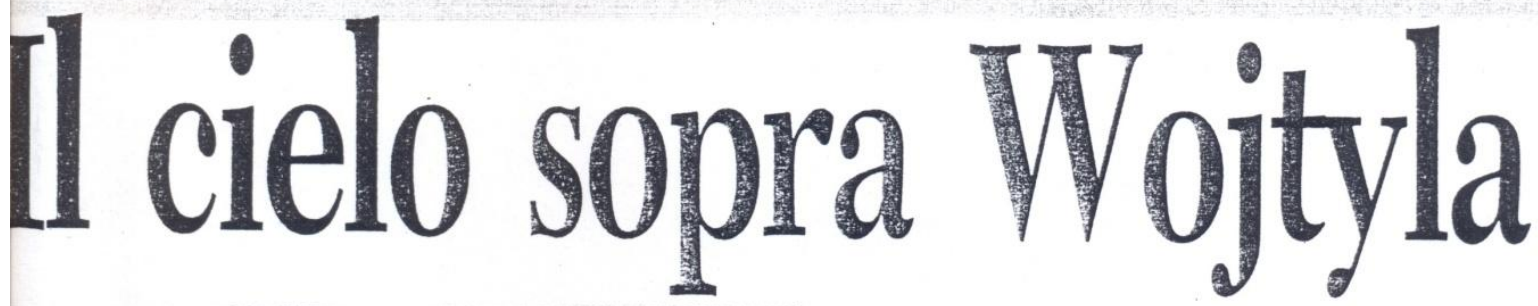

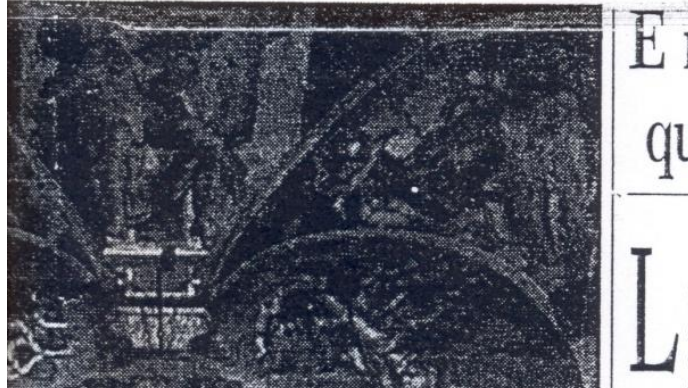

E nella gloria qualcuno conta le "braghe» cancellate

T ROMA immersa nel grigiastro di una mattinata di pioggia, le lampade sono state spente dopo la Messa papale, clamoroso vermissage in Mondovisione. Eppure i colori
del Giudizio Universale del Giudizio Universale quasi gridano, il Cristo è il luminoso motore di un perferto meccanismo pittorico. E soprattutto il blu del cielo, i lapislazzuli acquistati a Venezia e triturati, a risplendere quasi di una luce propria.

Alberto Arbasino è in mezzo alla folla dei primi visitatori. Se ne sta a testa in su: "Ecco il vero Michelangelo, non ho dubbi. Io sono un profano ma parto da un semplice ragionamento: la Sistina è un ambiente oscuro, con quelle povere finestrine lassù. Michelangelo progettò sicuramente qualcosa di chiaro, mente qualcosa di chiaro, non voleva mica realizzare una cripta". Riaffiora un ricordo di qualche anno fa, quando sali sui ponteggi che sorreggevano i restauratori al lavoro sulla volta e si commosse scoprendo i ripensamenti del Buonarroti sulla fronte di Adamo: "Prima piú bassa, poi più alta, forse era incerto se rappresentare un uomo intelligente o una bestiam. E davanti al Giudizio: «E Michelangelo che ha visto Tiziano e quasi annuncia Tintoretto e il Greco".
Inevitabile. La fine del Inevitabile. La fine del
unghissimo restauro sulla

\section{di PAOLO CONTI}

trangeli, alimentate «da un fiche: le «mutande» erano piccolo gruppo di storici in tutto 40 , quindi il 10 per dell'arte e di artisti" che cento delle quattrocento uper una curiosa contrad- figure che coprono i 180 dizione hanno assai rara- metri quadrati del Giudimente e solo fugacemente zio. Quelle di Daniele da visitato il cantiere». L'allu- Volterra e le altre più antivisitato il cantiere». L'allu- Volterra e le altre più anti-
sione è chiara: si tratta, per che sono rimaste tutte. Ne esempio, del professor Ja- sono state cancellate 17, le mes Beck della Columbia più «moderne", cioè setteUniversity e dell'italiano centesche. Il muscoloso Toti Scialoja che gridarono Sant'Andrea, proprio alla (e gridano) al massacro sinistra della Madonna, ha Anche Giovanni Caran- perso il panneggio che ha dente, ex direttore del set- coperto per secoli le sue dente, ex direttore del set- coperto per secoli le sue tore arti visive della Bien robuste natiche. Nudo è nale di Venezia, se ne sta a tomato il disperato «Orgotesta in su: "Ma quando glioso che scruta la tenemai lo sporco ha fatto par- bra eterna in arrivo e si cote della storia dell'arte... pre il volto con ta mano siLo dissi anche a Beck in nistra. Altrettanto nudi, diretta, durante una di- con le loro virilità in primo scussione ir tv: siate più piano, i due risorgenti sulla seri, frequentate di più i sinistra e diversi dannati . $\quad \begin{aligned} & \text { già scesi dalla barca di Ca- } \\ & \text { ronte. }\end{aligned}$

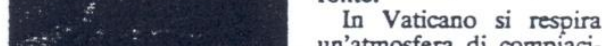
F un'atmosfera di compiacimento e di sollievo, una mento e di sollievo, una specie di sbarco sulla Luna
il giomo dopo. Felicissimo ì giorno dopo. Felicissimo man della Nippon Televi. sion Network Corporation, lo sponsor giapponese che ha finanziato l'operazione e ora tiene signorilmente a precisare come i ricavi dalla vendita delle riproduzioni, cioè libri e foto abbiano coperto «solo in minima parte la grande spesaw perché la soddisfazione morale «supera ogni tornaconto economico".

Per niente soddisfatto è Per niente soddisfatto è,
invece, il pittore Toti Scaloja: «Un orrore. L'ho già detto e lo ripeto: roba da 


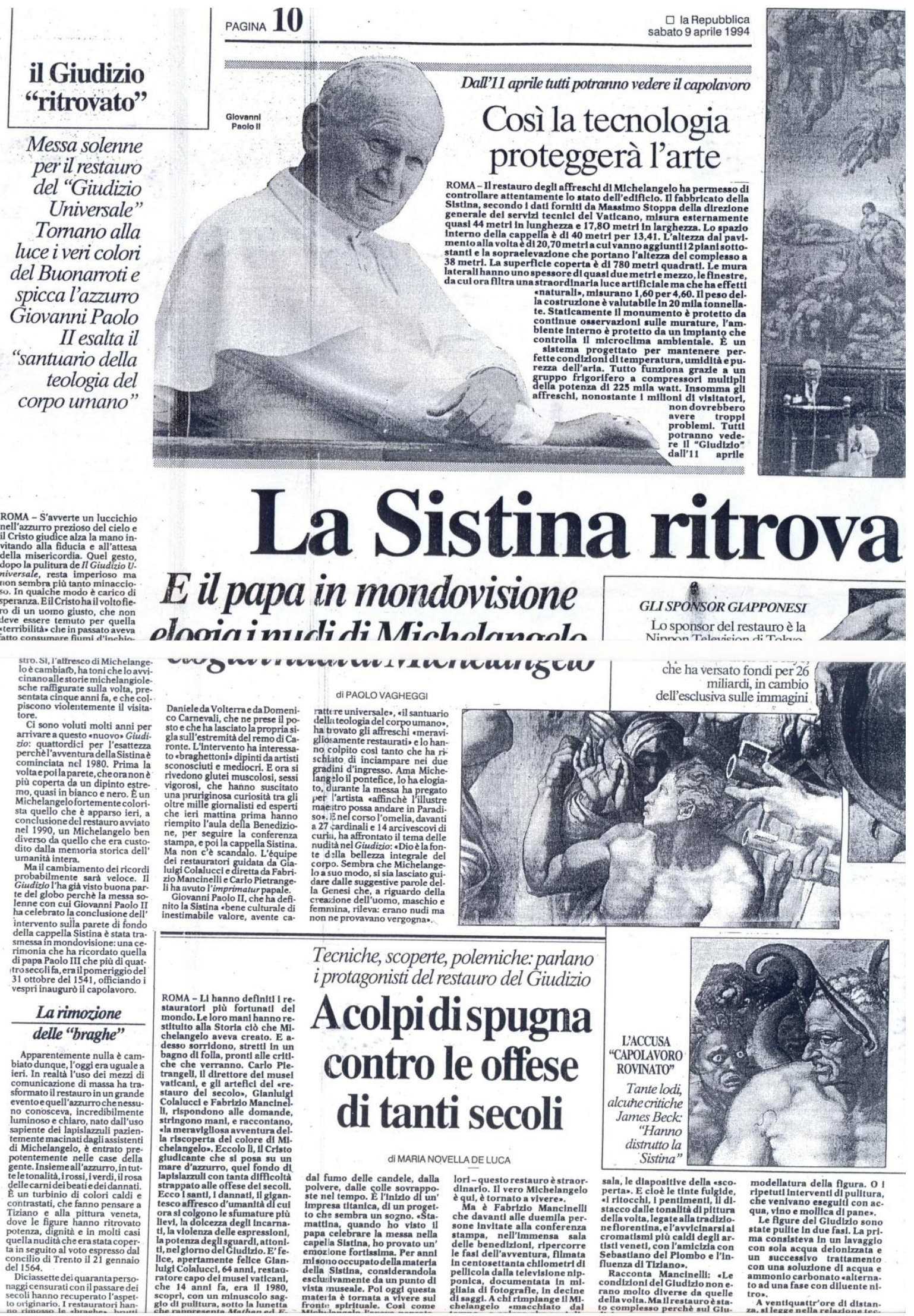




\section{LA NUOVA SISTINA}

\section{'8 aprile 1994 questa data, termine uffi- ciale dei lavori di restauro de- gli affreschi che Michelan-}

gelo eseguì oltre 4 secoli fa nella Cappella Sistina, verrà registrata nei libri di storia accanto a quella del 31 ottobre 1541, in cui papa Paolo III s trovò per la prima volta davanti al Giudizio universale, l'affresco posto dietro l'altare della Cappella Sistina che Michelangelo aveva appena finito di dipingere. Dopo quasi 4 anni di lavori - tanto è durato il restauro del Giudizio - il famoso affresco che racconta la fine del mondo torna a nuova vita. Caduta la gigantografia con la riproduzione dell'originale che dal ' 90 a oggi ha coperto agli occhi dei visitatori 180 metri quadrati del dipinto, dall' 11 aprile potremo tutti vedere il risultato del lavoro di restauro effettuato dall'équipe dei Musei Vaticani, composta da Gianluigi Colalucci, capo restauratore, maestri di restauro Maurizio Rossi, Pier Giorgio Bonetti, Bruno Baratti, il direttore del settore arte medievale e moderna, Fabrizio Mancinelli, e il direttore delle ricerche scientifiche, Nazareno Gabrielli.

Candele e fuliggine. È un nuovo Giudizio, quello che ci troveremo di fronte, nel senso che negli ultimi secoli i visitatori della Sistina hanno visto laffresco velato da una spessa patina prodotta dal fumo delle candele, dalla polvere, dalla fuliggine dei sistemi di riscaldamento. Il restauro ha anche tolto parte dei famosi drappi che nel corso dei diversi interventi censori sono stati sovrapposti alle nudità dei corpi michelangioleschi. Non tutti, perché, in base a un criterio oggi universalmente accettato, si tende a conservare di un dipinto anche ciò che fa parte della sua storia. Di conseguenza, delle "aggiunte» volute da diversi papi preoccupati di difendere il comune senso del pudore, sono stati

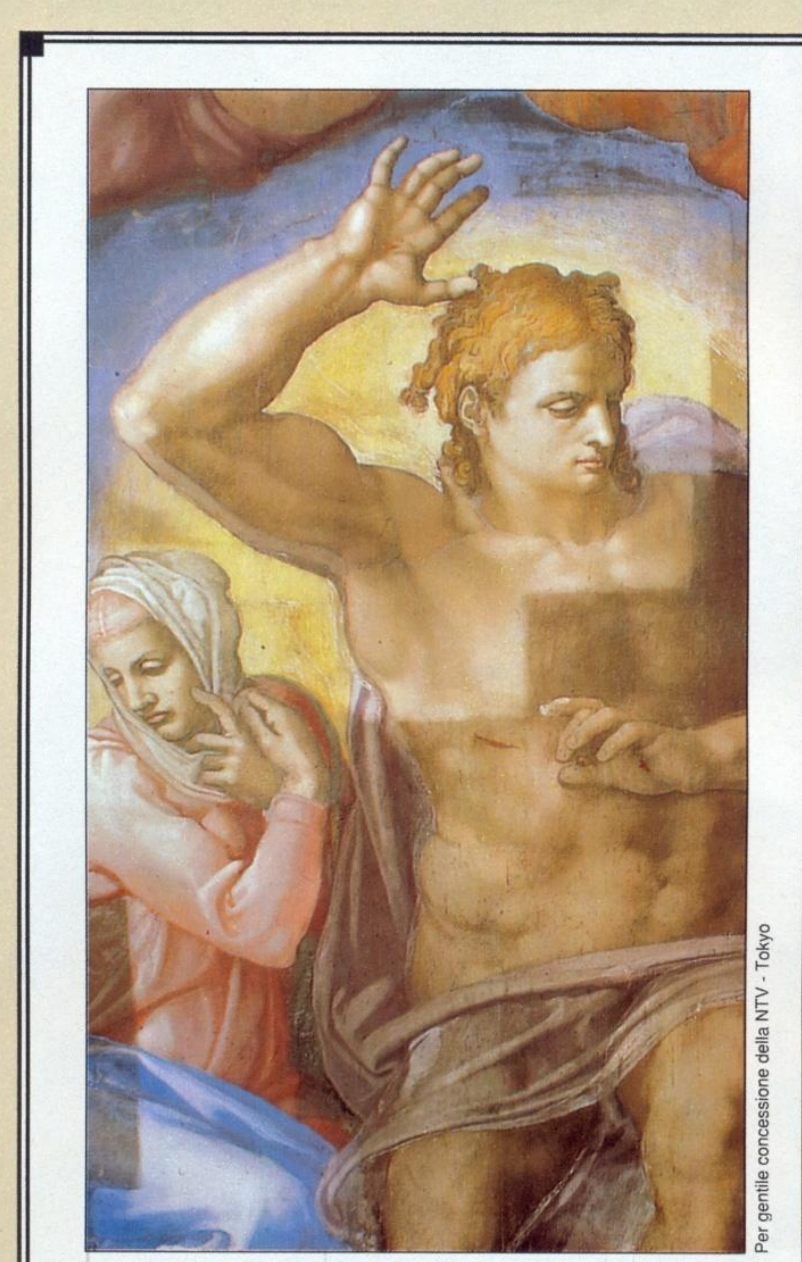

\section{AL GENTRO: GRISTO GTUDICE}

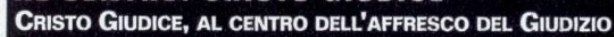

UnIVERSALE. SOPRA: DURANTE LA PULITURA. A FIANCO: DOPO

IL RESTAURO. IL COSTO TOTALE DEL RESTAURO NON SI CONO.

SCE ANCORA. UNO DEGLI SPONSOR, LA TIVÙ GIAPPONESE NTV,

HA CONTRIBUITO CON OLTRE SEI MILIARDI E MEZZO DI LIRE.

$$
*
$$

Gianluigı Co-

LALUCCI, CAPO

RESTAURATORE

DEI MUSEI VATI-

CANI: HA GUIDA-

TO L'ÉQUIPE CHE

HA «RIMESSO $A$

NUOVO" GLI AF-

FRESCHI.

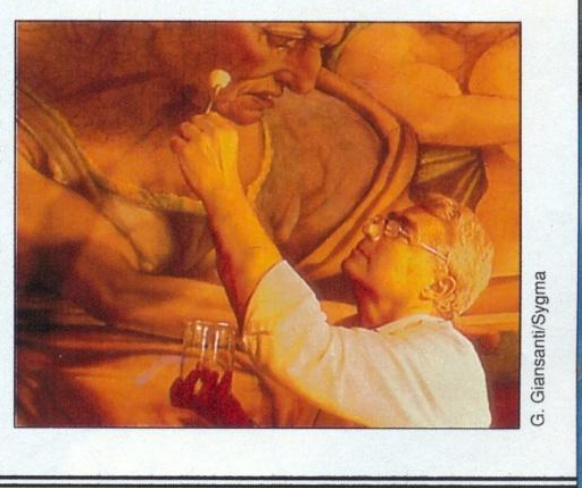

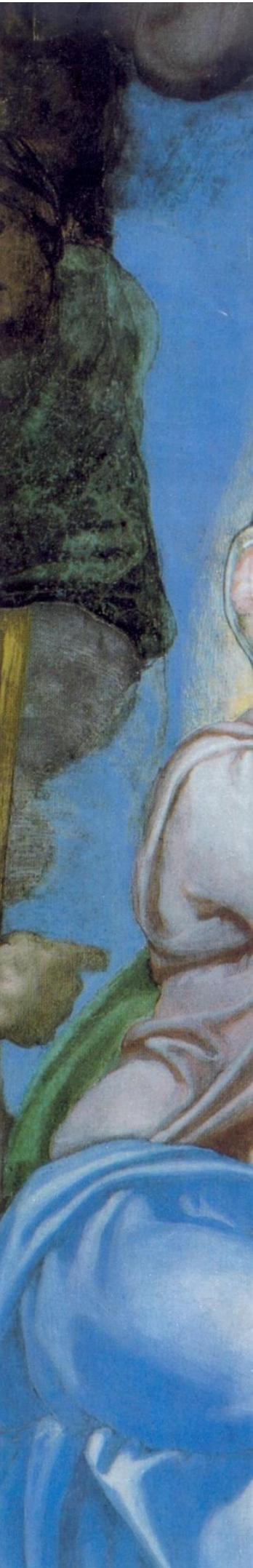




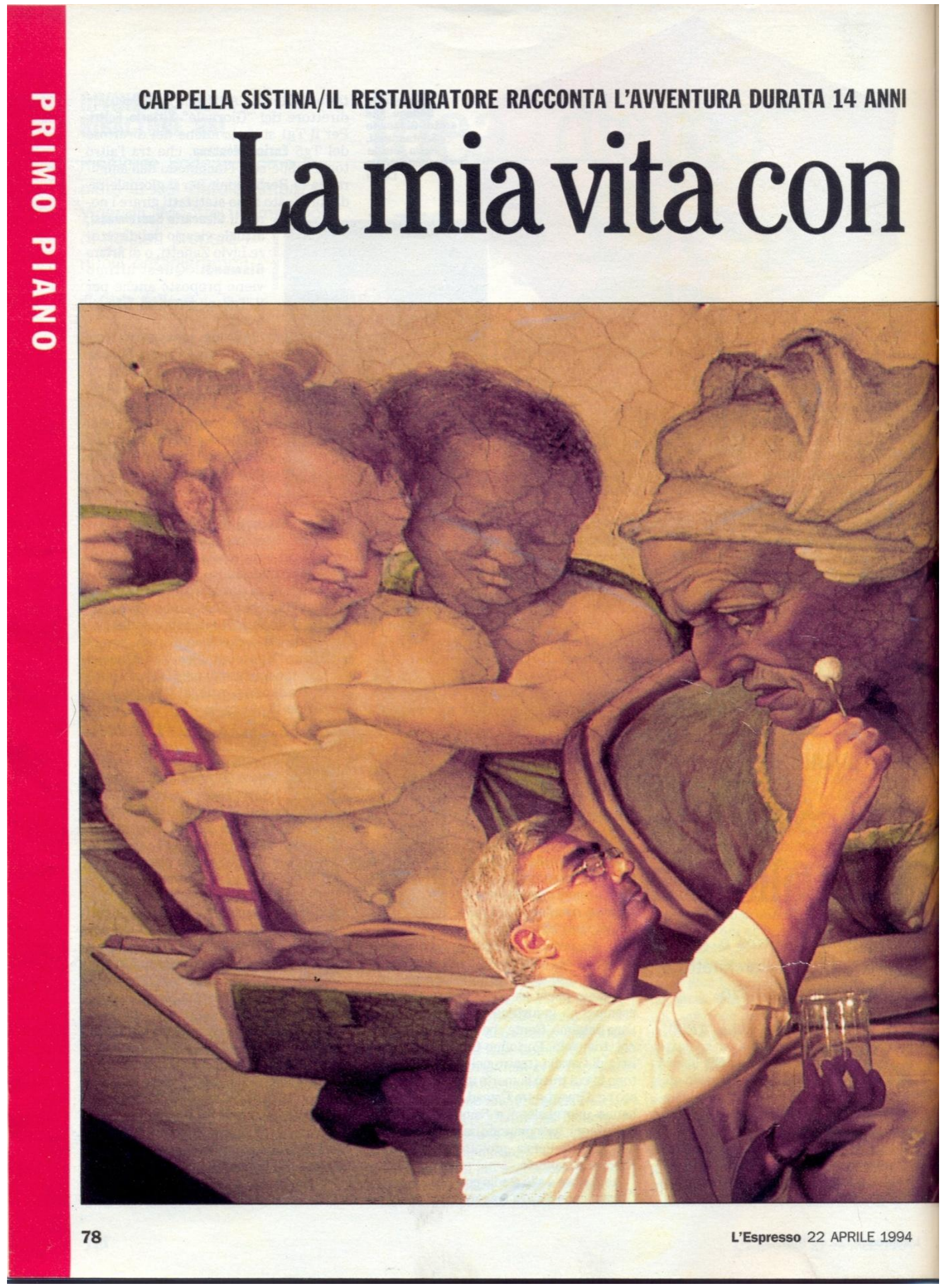



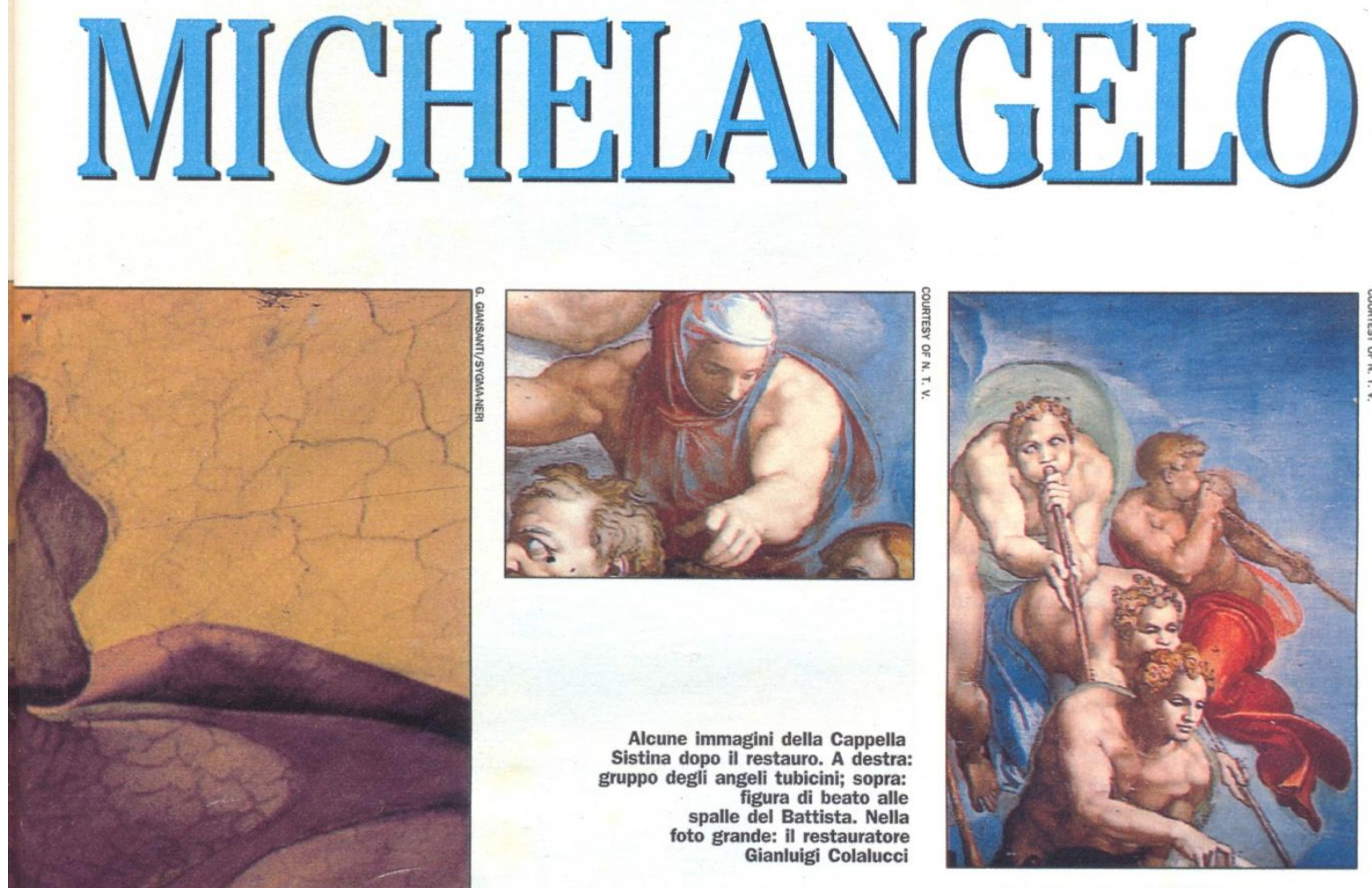

colloquio con Gianluigi Colalucci - di Alessandra Mammi

QUATTORDICI ANNI FA IL MAESTRO RESTAUratore Gianluigi Colalucci aveva cinquant'anni e una vita piena di soddisfazioni. Era uno specialista del restauro di antiche tavole, conosciuto e stimato dai medievalisti e dagli addetti ai lavori. Amava il suo la-

L'uomo che sotto velature e colle del '700 ha ritrovato $i$ colori originali del Giudizio Universale confessa tutto: i dubbi, le angosce, la rabbia di anni di lavoro. Fino alla scoperta della vera anima del maestro...

L'Espresso 22 APRILE 1994 re per sempre la Sistina di Michelangelo. Della tecnica di questo grande restauro sappiamo tutto, o quasi. Molto si è detto e molto si scriverà ancora. Ma delle emozioni, dei dubbi, dei problemi, della vicenda umana vissuta da lei e dai suoi collaboratori nessuno ha parlato. Può raccontarci la "sua Sistina" maestro Colalucci? «E' una storia che comincia molto prima del 1980. Forse nel Sessanta, quando entrai ai musei Vaticani. Ogni anno si faceva la spolveratura del Giudizio Universale in nome di una antica tradizione che risaliva addirittura al mundator istituito da Paolo III, subito dopo l'esecuzione della Sistina. Mi sono sempre offerto di fare questa operazione. Era un momento molto particolare per me andare a 
vedere l'affresco da vicino, studiarlo, cercare di capire anno dopo anno questa strana cosa, perché dal punto di vista tecnico il Giudizio era davvero una strana cosa...".

Cosa c'era di tanto strano?

«Non si capiva di cosa fosse fatto, per tutte le sovrapposizioni di sostanze messe dai restauratori del passato, per i troppi tentativi di pulirlo, per i tanti risultati insoddisfacenti che avevano costretto a sporcare di nuovo quel che era stato pulito. Insomma, salivo lassù e ci restavo un'intera giornata, fino alla sera spolverando il Giudizio con pennelli morbidi e una coda di volpe, scattando fotografie e continuando a interrogarmi sul perché fosse tanto discontinuo con cose bellissime accanto a cose orribilin.

Da qui nacque I'idea di ripulire la Sistina? «Non proprio. Intorno al "79 il direttore generale professor Pietrangeli decise $\mathrm{d}$ restaurare il ciclo di affreschi del ' 500 nella parete di ingresso della Sistina e quello quattrocentesco dei pontefici, in alto. Era un'occasione per vedere da vicino anche la volta. Abbiamo alzato i ponteggi tanto da toccare gli affreschi di Michelangelo e ci siamo resi conto quanto fossero coperti da una massa enorme di colla animale, polveri, fuliggine. Fu cosi che proponemmo un saggio di pulituram. $E$ che cosa è successo?

«Una cosa sorprendente. Sotto uno strato di color marrone, come la parte più scura di una tartaruga, è venuto fuori un rosso squillante, talmente vivo da suscitare il dubbio che Michelangelo non era quello che avevamo sempre creduto".

Avete pensato a che cosa poteva succedere ripulendo tutta la Sistina? Non avete avuto paura?

"Abbiamo a lungo meditato se non fosse opportuno risporcare il campione e lasciare le cose come stavano. Ma poi si decise di proseguire e di pulire un'intera lunetta. Quando abbiamo tolto le protezioni per presentare il lavoro alla stampa $e$ per la prima volta ho visto dal basso i colori, gli effetti cangianti, la luminosità di Michelangelo ho capito che tutto sarebbe cambiato di brutto. E ho avuto paura. Cominciò così....".

Anche le polemiche cominciarono coši? «No. Quelle violente arrivarono più tardi. Intorno al 1986, a metà del progetto. Eravamo a buon punto della volta. Stavamo rispettando le tabelle di marcia del mio progetto: quattro anni per le lunette, quattro per la volta, quattro per il giudizio. E avevamo seguito il consiglio di un nostro prestigioso consulente: l'ex direttore dell'Istituto centrale Pasquale Rotondi, purtroppo oggi scomparso, che visti i risultati e l'enorme salto di qualità fra lo sporco e il pulito, suggerì di accom-

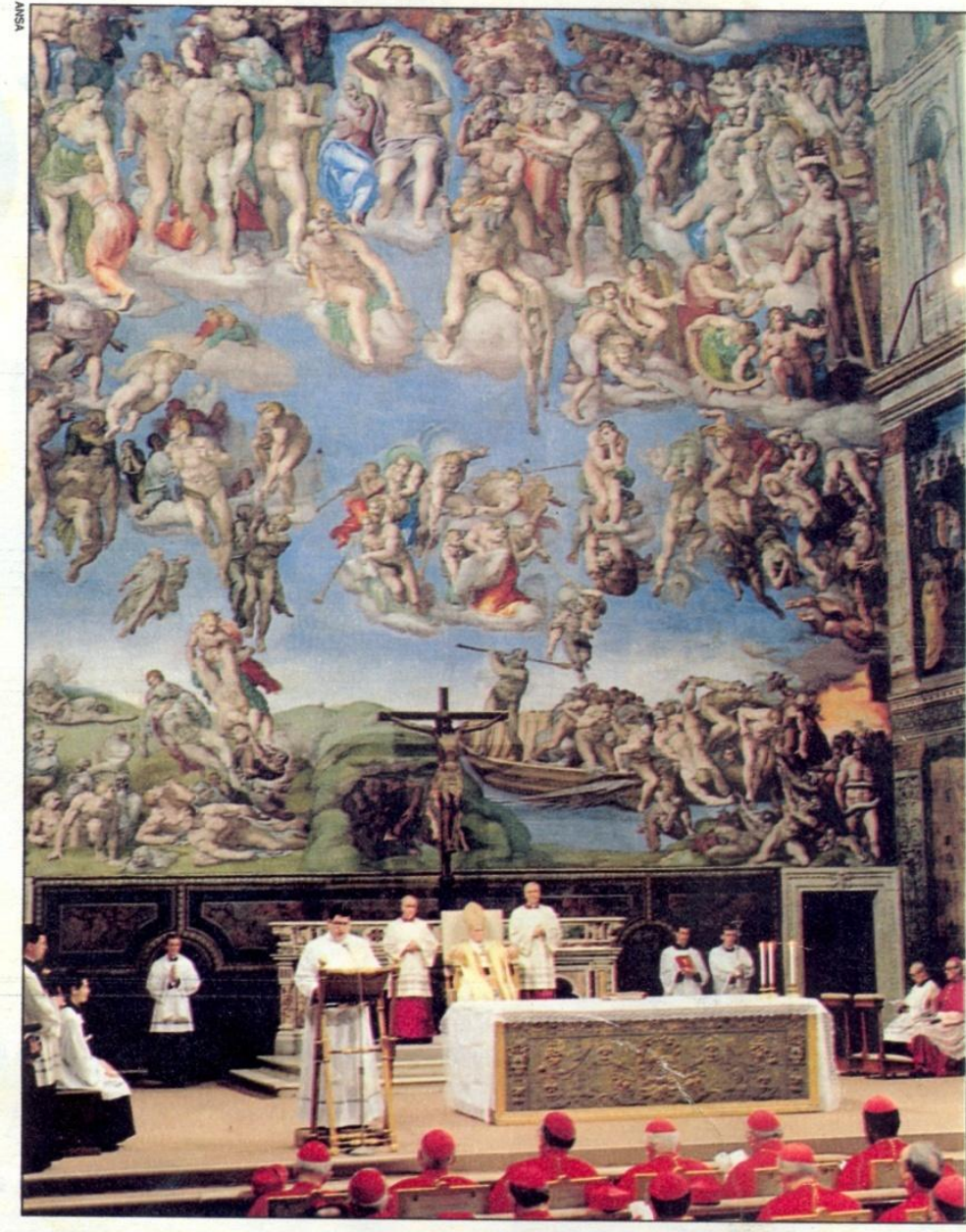

pagnare la documentazione fotografica con una cinematografica in tempo reale. I primi metri li ho girati da solo, col mio super8. Ma fu un disastro, per questo abbiamo cercato dei professionisti e arrivò la Ntv, una televisione di Tokyom.

Che c'entrano i giapponesi con le polemiche scatenate, se non sbaglio, dagli americani?

«Loro niente, sono stati sempre una presenza molto professionale e discreta. Ma le immagini cominciarono a circolare e le foto pubblicate da un mensile newyorkese scatenarono la suscettibilità di un pittore americano, un certo Mason che scrisse al Papa scongiurandolo di fermare il restauro. La foto di un'opera, lo disse bene Cesare Brandi, è un falso documento. E col senno di poi credo che fu un errore divulgarle».

Ci sono altri errori che si rimprovera?

«Errori di ingenuità, di non aver saputo capire i media. Di aver dovuto subire ac- cuse dolorose e ingiuste, di non essere riuscito a rispondere. Nel pieno delle polemiche ero davvero depresso. Alla radio la mattina la rassegna stampa diceva che stavo distruggendo questo, massacrando quest'altro e qualcuno mi chiamava persino criminale. Sono un restauratore, non un politico. Non ero pronto ad af frontare tutto questo. Mi sentivo sconfortato, ma i miei più stretti collaboratori mi ripetevano che eravamo nel giusto bisognava restare sereni. Oggi so che avevano ragione».

E sul restauro nessuna autocritica?

«A cose fatte no, perché l'autocritica è stata continua durante. Ho tenuto conto di tutte le accuse, di tutte le polemiche a tutti dicevo che le loro preoccupazion erano anche le nostre e li invitavo a salire sui ponteggi per verificare di persona. E' venuto anche James Beck [storico dell'arte americano, tra i più feroci accusatori del restauro della Sistina, ndr.], ha 

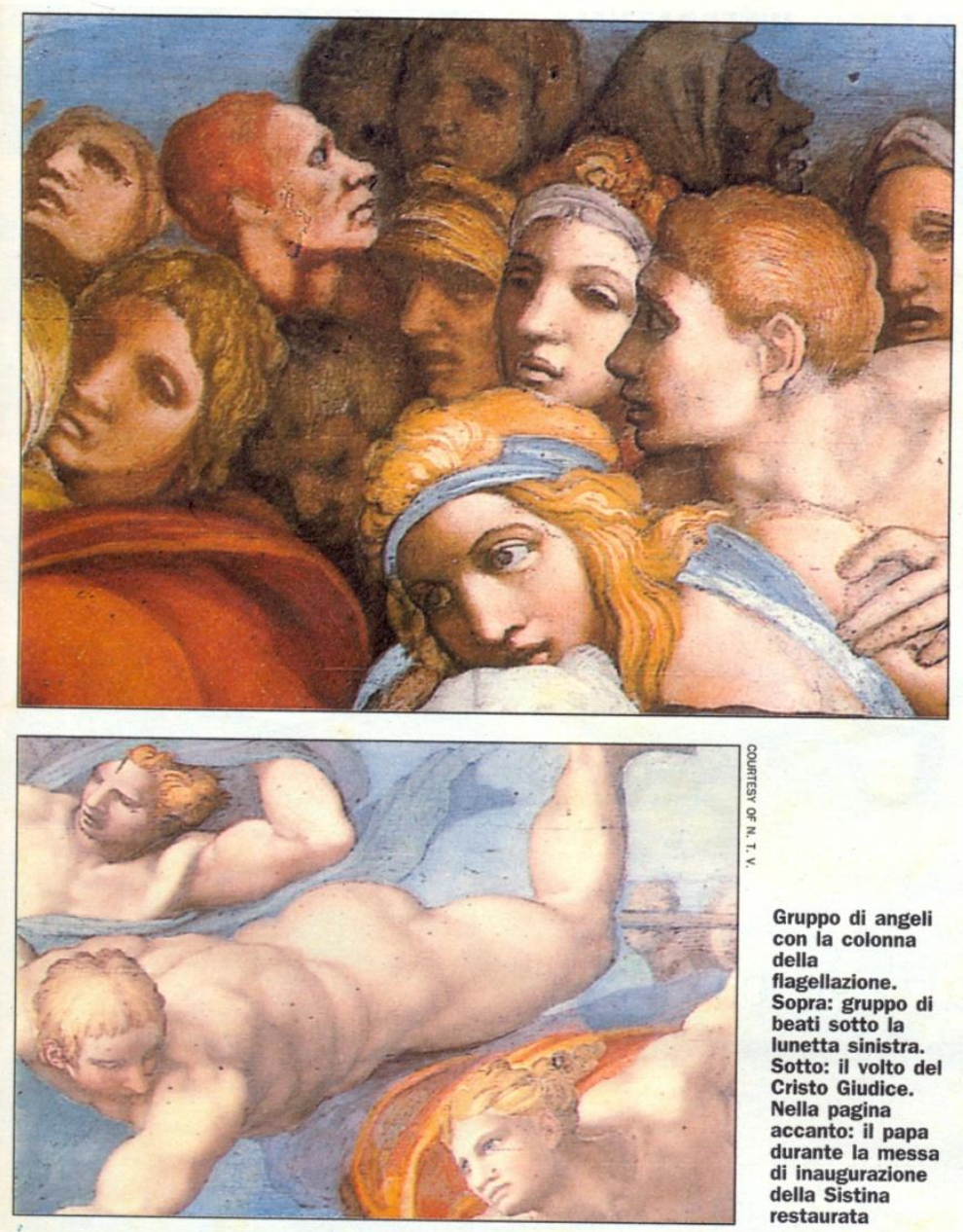

Gruppo di angeli con la colonna della flagellazione. Sopra: gruppo di beati sotto la lunetta sinistra. Sotto: il volto de Cristo Giudice. Nella pagina accanto: il papa durante la messa di inaugurazione della Sistina restaurata

visitato tutto e, salutandomi, mi ha fatto persino i complimenti. Poi è tornato in America ad animare false polemiche. E' un uomo sleale e quel che è peggio è un dilettante che si nasconde dietro un linguaggio pseudo-scientifico».

Ma se la sente di smentire Beck e di escludere al 100 per cento che neanche una traccia di Michelangelo è stata tolta con questa pulitura?

«Sì. Al 100 per cento. Anche hoi siamo saliti sulla volta della Sistina convinti di trovare della pittura a secco perché così sapevamo, così era stato tramandato. $\mathrm{Ma}$ Michelangelo ha dipinto tutto in affresco, anche le velature. Poteva permetterselo perché aveva tra le mani una grande tradizione tecnica e soprattutto perché era scultore del marmo, abituato a non sbagliare, a calibrare i suoi gesti, senza la consolazione di un ripensamento. Non vorrei sembrare presuntuoso, ma durante questo lavoro credo di aver capito a fondo la pittura di Michelangelom.

Se non I'ha capita lei, che I'ha toccata ogni giorno per quattordici anni..

«Sì. Ma non solo per questo. Anche perché durante la pulitura della Sistina ho restaurato i tre affreschi di Tiziano a $\mathrm{Pa}$ dova. Ho avuto il privilegio di lavorare su due capolavori straordinari e metterli a confronto. $\mathrm{E}$ allora là dove Tiziano è la pittura stessa, generosa, abbondante, Michelangelo mi sembrava sempre più freddo, calcolato, compassato. Anzi dirò che passando dalle spontaneità delle lunette alla rigidità della volta ho persino provato una leggera delusione».

\section{che Michelangelo l'ha delusa?}

«Mi lasci spiegare. In quel momento, mentre mi dividevo fra Roma e Padova, a confronto con Tiziano lo trovai timido, trattenuto e mi chiedevo perché. Poi ho capito. Sono giunto alla conclusione che la pittura di Michelangelo non era pittura ma architettura, dove tutto era studiato al centimetro, tutto era carico di contenuto, niente era concesso all'abbandono, alla sensualità della pittura. La pittura di Michelangelo è difficile, inquietante, mai distensiva. Bisogna attrezzarsi per capirla e la patina di sporco, il velo nero che abbiamo tolto era come un cuscinetto, un ammortizzatore fra questa pittura e lo spettatore. Le polemiche attribuiscono a noi la colpa di aver rovinato la Sistina, ma il problema non è il mio restauro, è proprio la difficoltà di capire Michelangelo. Chi protesta deve saperlo».

Si è mai interrogato però sulla responsabilità di aver intaccato un'immagine che apparteneva alla memoria del mondo?

"Certo che me lo sono chiesto. Anzi è l'unica, fra le critiche che mi sono state fatte, che ancora oggi mi fa riflettere. Ma so che la cultura è in perenne movimento, lo dimostra proprio la storia della Sistina che ha cambiato faccia molte volte nei secoli. Non è stata forse ripulita drasticamente nel Settecento, ricoperta di colla, rimaneggiata e ritoccata a tutto spiano nel corso della storia?».

E la sua vita con il restauro della Sistina è cambiata?

«Enormemente. Dal punto di vista professionale è peggiorata, $\mathrm{mi}$ ha fatto più male che bene, sono diventato un restauratore eccezionale. Come si può chiedere quest'uomo di toccare qualcosa di meno che un Michelangelo? Così invece dei restauri mi offrono conferenze in tutto il mondo e a volte la folla è tanta che devo ripeterle il giorno dopo. E poi le interviste, la televisione... Non mi ero mai reso conto di che cosa fosse la Sistina per l'immaginario collettivo. Sinceramente vorrei tornare al mio lavoro, al mio laboratorio, a curare quadri, a occuparmi di pittori. D'ora in poi, possibilmente, sconosciuti ai più». 


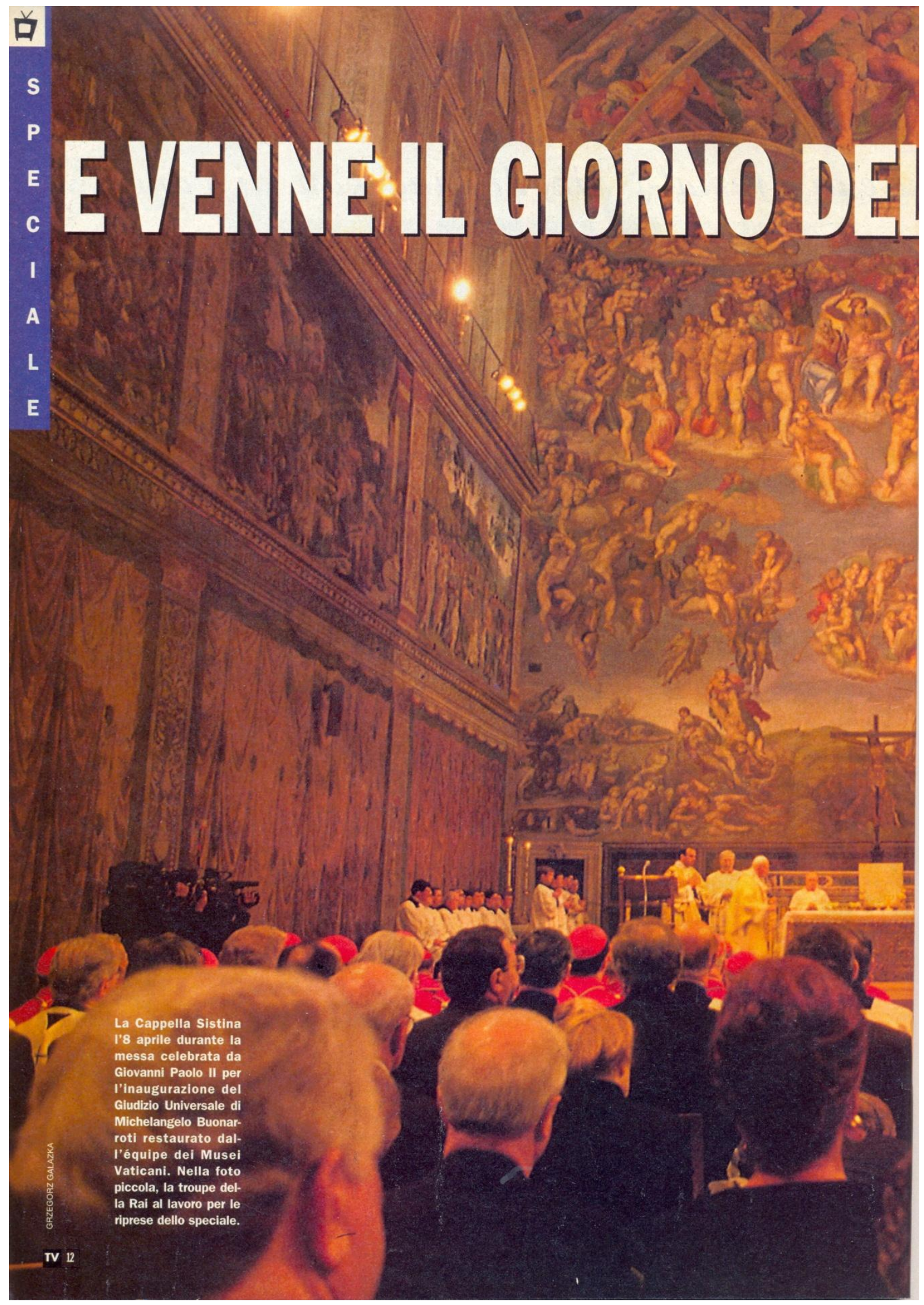




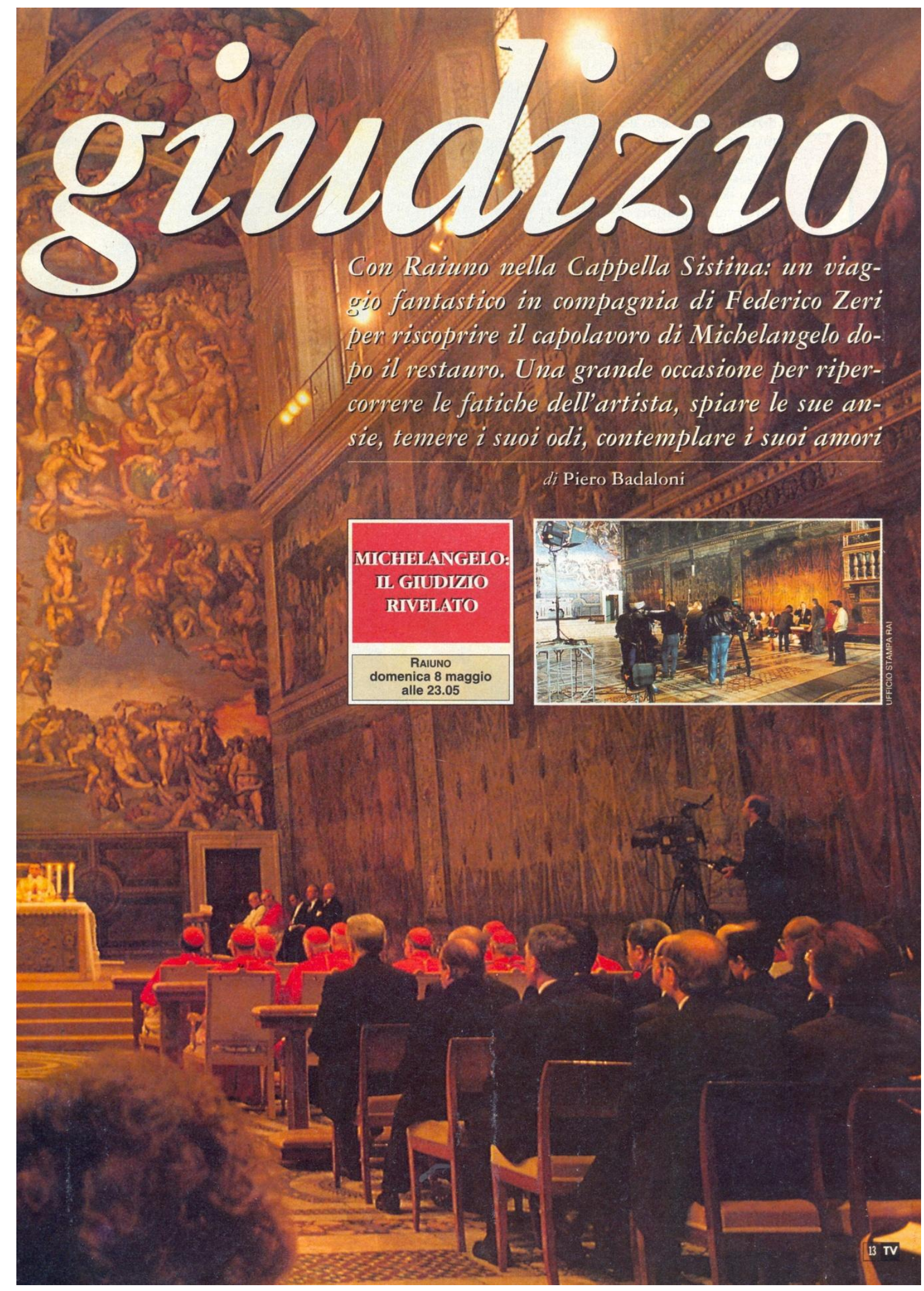




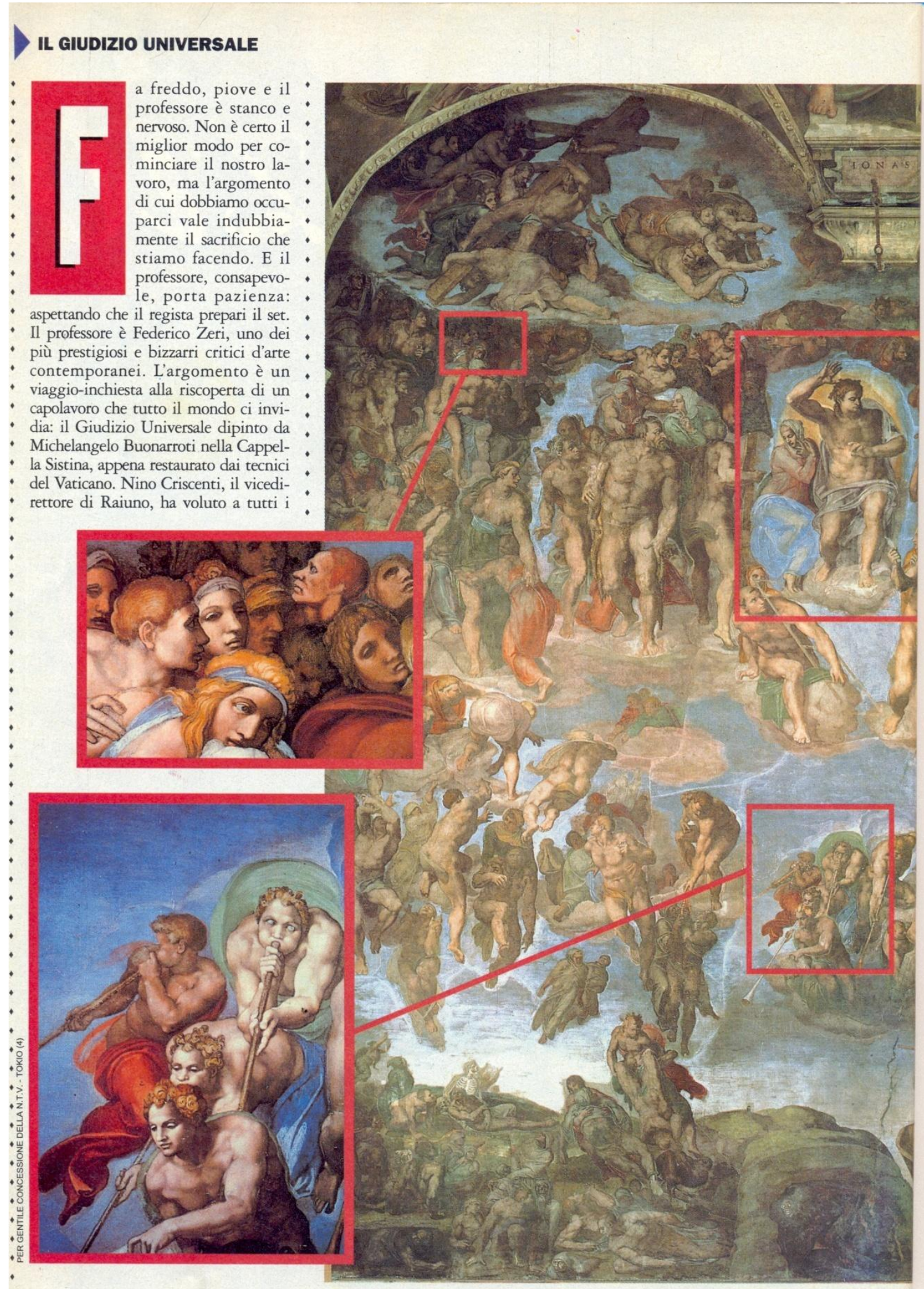

IV 14 


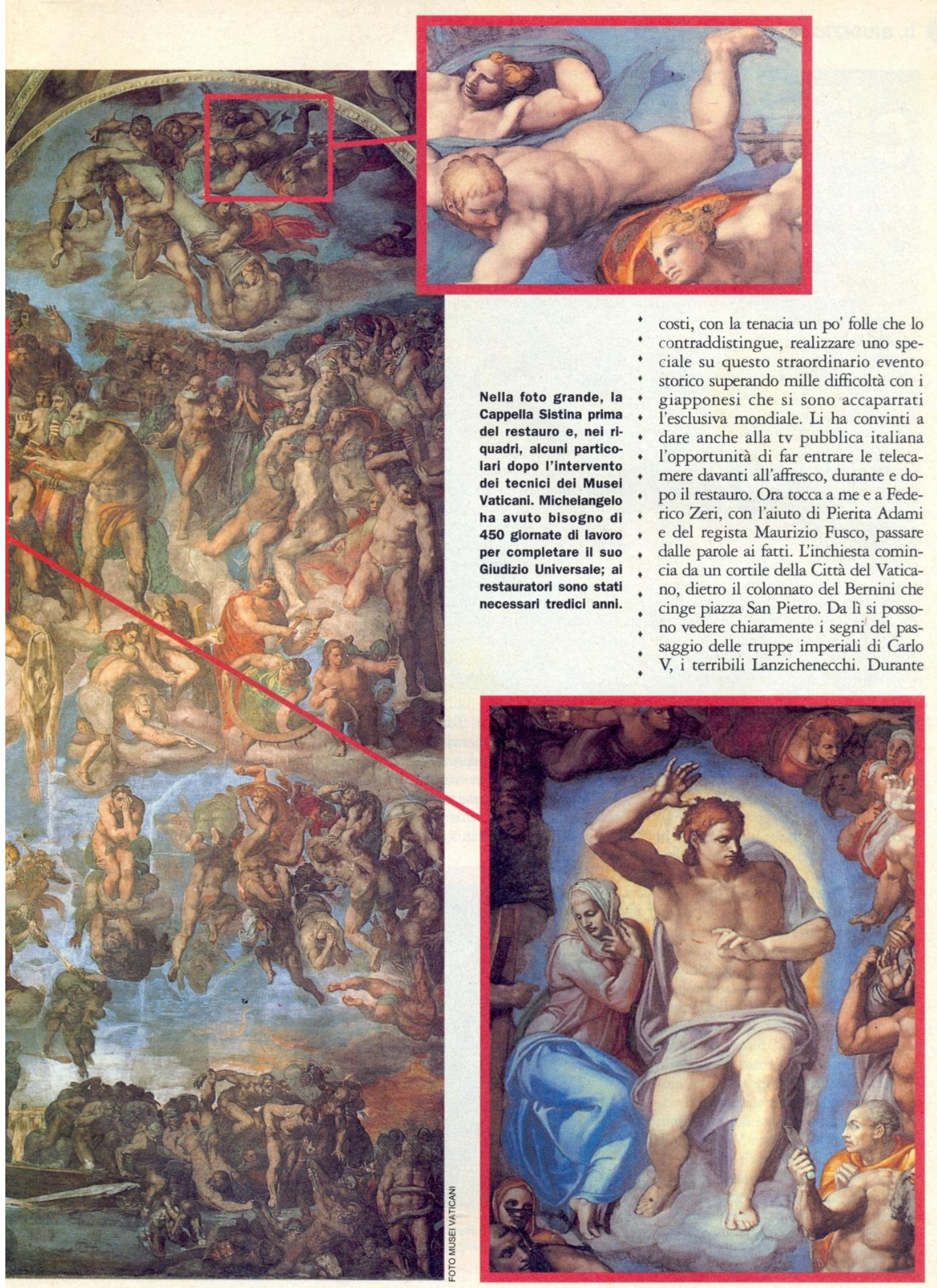




\section{IL GIUDIZIO UNIVERSALE}

$\begin{array}{ll}\text {. } & \\ \text {. } & \\ . & \end{array}$ dieci anni fa con la trasmissione dello Speciale $T g 1$ Il Michelangelo ritrovato. Nella primavera dell'84 salivo per le ripide scale dell'impalcatura insieme con l'operatore Angelo Pieroni. Il permesso era arrivato dopo un lungo negoziato con $i$ giapponesi della NTV, titolari di un'esclusiva miliardaria su tutte le immagini del restauro. Eravamo in tanti su quello stretto ponteggio addossato alla parete sinistra della Cappella. Oltre a noi c'erano la troupe della NTV e il grande fotografo d'arte Takashi Okamura, e $i$ restauratori, alle prese con le lunette su cui Michelangelo aveva raffigurato gli antenati di Cristo.

Con $i$ giapponesi $i$ patti erano stati chiari: noi avremmo fatto un'inchiesta giornalistica senza inquadrare gli affreschi a nudo. Quello che ci interessava era vedere come si suolgeva il restauro: con quali metodi, con quali controlli, con quali risultati. Una grande impresa culturale era in corso nel nostro Paese e mi sembrava che la Rai non potesse non raccontarla. Le polemiche non erano ancora esplose. In un'in-

il famoso sacco di Roma, il 6 maggio del 1527, all'alba, spararono diverse decine di colpi di archibugio contro Papa Clemente VII, che cercava di fuggire verso Castel S. Angelo, passando proprio sopra il cortile detto degli svizzeri. Le pallottole sgretolarono in più punti il muro, come si può vedere

- ancora oggi, ma il Papa riuscì a passare

indenne. Torniamo al cortile: dopo

un'ora di preparativi, il regista fa ac-

cendere le telecamere, riparandole dal-

la pioggia, alla meno peggio, con un

ombrello. Zeri è pronto a raccontare il

primo episodio, l'antefatto, il prologo

di un'appassionante storia che potrete **

- seguire domenica 8 maggio alle 23,05 *

- appunto su Raiuno. Cosa c'entrano .

- quei colpi rimasti sul muro del cortile .

- con il Giudizio Universale? È la do-

- manda da cui parte l'inchiesta. E il cri-

- tico, con pazienza, risponde: proprio in .

- quel momento Clemente VII decise di

- voler fissare nella parete della Cappella

- Sistina, come una memoria storica in-

delebile, la struggente sensazione pro-

- vata di fronte al sacco di Roma. L'affre-

- sco avrebbe dovuto ricordare ai cristia-

- ni la presenza di un Dio troppo spesso

- dimenticato nell'euforia dell'Umanesiesprimeva in termini molto positivi sul restauro che avrebbe costretto - sottol neava - a rivedere molti giudizi su Mi chelangelo pittore

Salimmo più volte in un arco di tre mesi su quel ponteggio per documentare la prima riscoperta dei colori di Michelangelo e nell'autunno dell'84, terminati $i$ lavori di restauro delle lunette, il programma andò in onda.

Nel 1990, quando viene scoperta la volta, $i$ telespettatori trovano su Raitre, dove allora lavoravo, un programma condotto da Corrado Augias, tutto girato dentro la Sistina diventata per l'occasione il nostro studio televisivo.

Appuntamento conclusivo adesso con Piero Badaloni, questa volta di nuovo su Raiuno e con un narratore d'eccezione, Federico Zeri. Avremmo voluto trasmettere questo programma a fine marzo, quando la parete del Giudizio è stata restituita al pubblico, ma nel palinsesto di Raiuno è stato difficile trovare spazio per raccontare come $\mathrm{Fa}$ brizio Mancinelli e Gianluigi Colalucci ci abbiano ridato Micbelangelo dopo quattordici anni di lavoro.

Nino Criscent (Vicedirettore di Raiuno)

mo. A dipingerlo, il Papa aveva già chiaro in testa chi chiamare: Michelangelo, lo scorbutico maestro fiorentino.

Ma Buonarroti non aveva alcuna voglia di assumersi questo faticoso incarico, perché nella Sistina aveva già lavorato trenta anni prima, dipingendo-

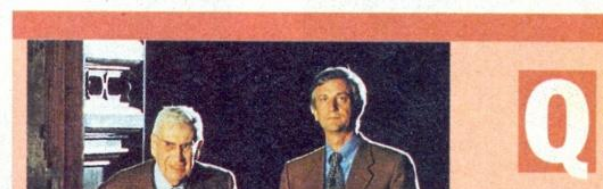

Q.

uando bo varcato la soglia della Sistina bo provato in un rimo momento una grande sorpresa, poi una grande emozione quando sono riuscito a vedere bene l'affresco pulito, completamente diverso da quello che mi aspettavo, nel senso che io sapevo che le figure sarebbero state più chiare una volta liberate dalla patina di polvere, di grassi e di cattivi restauri.

Però non mi aspettavo il fondo azzurro così intenso, né mi aspettavo che verso il basso quell'azzurro lapislazzulo cedesse ad una specie di cielo non si sa se di alba o di tramonto, ciò̀ quel crepuscolo sul quale si stagliano la Resurrezione dei morti e l'inferno.

Mi ba fatto una grandissima impressione, bo scoperto nell'affresco dei 


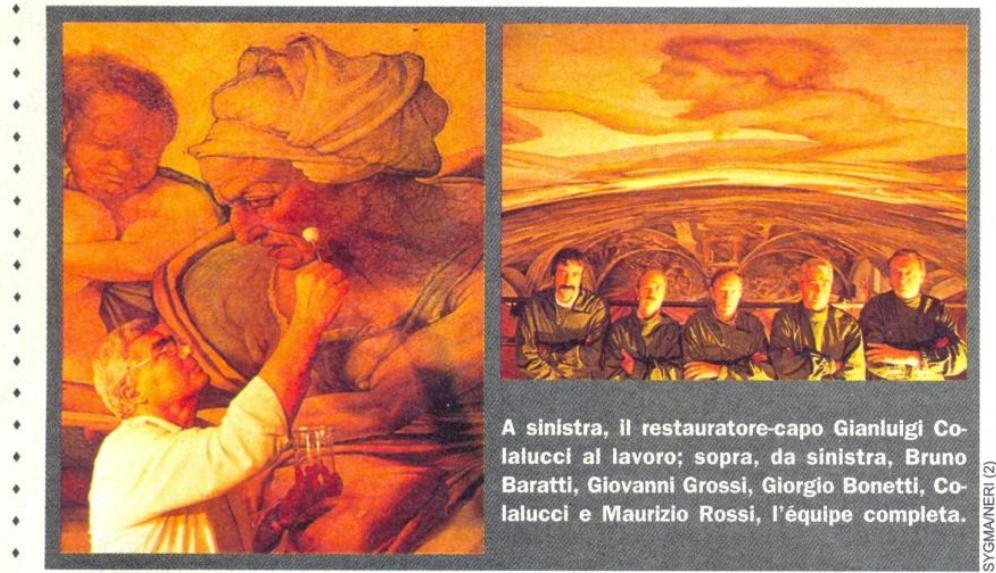

- briche pontificie meticolosamente gli - rese conto di ogni scudo uscito dalle - casse vaticane, anche per mettersi al ri- paro da eventuali accuse di tangenti o cose simili, da parte di qualche antenato del giudice Di Pietro.

I tempi dei pagamenti per il ponteggio, ad esempio, ci hanno confermato quello che il biografo di Michelangelo, Vasari, aveva scritto e che rap- presentò la prima grossa difficoltà in - cui si imbatté l'artista: una violenta lite con quello che fino ad allora era stato il suo più caro amico, Sebastiano del Piombo.

Narra il Vasari che Sebastiano aveva convinto Paolo III a far eseguire il giudizio con la tecnica ad olio. «Non dicendo Michelangelo né sì né no, stette senza metter mano all'opera alcuni mesi. Sollecitato, alla fine disse che - non voleva farla se non a fresco e che il

\section{FEDERICO ZERI}

valori cromatici che prima non si riu scivano a vedere. Ora c'è una composizione, ci sono degli spazi e c'è un rapporto tra le figure e il fondo e tra figura e figura, con il restauro si riesce a leggere un grandissimo capola voro, uno dei più grandi capolavori dell'arte di tutti $i$ tempi.

Micbelangelo ba creato in tutte le figure della Sistina dei capolavori assoluti soprattutto nelle figure degli Ante nati delle lunette, ma nel Giudizio c'è un altro Michelangelo, un Michelange lo che adesso è più maturo e diverso nel senso che partecipa alla figurazio ne con una profondità spirituale che prima non esisteva.

Poi bo trovato nel Giudizio soprattutto uno scultore, un grandissimo scultore che si rivela nella plasticità $e$ lore di grande luminosità, che il restauro ha finalmente riportato all'antico splendore.

Secondo alcuni storici, Michelangelo impiegò 450 giornate per completare la pittura di 180 metri quadri di parete. Quasi quattrocento, alla fine, le figure dipinte.

$E$ dal restauro è emersa una conferma alle tesi degli studiosi: l'artista ri- * toccò e corresse parecchi dettagli di • queste figure, a partire da quella principale, il Cristo. Li hanno chiamati "pentimenti». Lo faceva raschiando il * colore, mai l'intonaco. A volte spostava • addirittura la posizione delle figure rispetto a quella fissata sul cartone.

L'obiettivo era sempre lo stesso: $\mathrm{mi}-$. gliorare la prospettiva. Alcune delle fi- * gure secondarie, inoltre, soprattutto nella parte alta della parete, vennero dipinte successivamente, per dare alla struttura compositiva, via via, maggiore profondità. Ad aiutarlo, un solo al- . lievo, quasi esclusivamente nell'abbozzo delle figure.

Il 31 ottobre del 1541, il Papa finalmente fece scoprire l'affresco ter- * minato durante una solenne cerimo- . nia. I romani fecero la fila per poter . contemplare l'opera di Michelangelo. . La loro reazione, annota il Vasari, fu . di «stupore e meraviglia». Ma presto . cominciarono le polemiche sulla nu- • dità delle figure: indecente l'esposi- . zione di organi genitali, nella rappresentazione di Santi e Angeli, disse per . primo Pietro l'Aretino, il quale aveva . un conto in sospeso con Michelangelo, avendo l'artista fiorentino ignorato i suoi suggerimenti sulla costruzione . del Giudizio. E Paolo IV, appena elet- • to, mandò a dire al Buonarroti che . avrebbe dovuto rendere più decente . l'affresco. «Pensi ad acconciare il . nella fisicità dei corpi.

Trovo che il restauro fatto dai $\mathrm{Mu}$ sei Vaticani è eseguito in modo perfetto, a mio avviso, e non credo a tutte le critiche che sono state espresse sia per la Volta che per il Giudizio. Il restauro $c i$ ba restituito un capolavoro che $c i$ consente di scoprire dei dettagli che prima non esistevano sia nelle figure che nelle espressioni, ora si vede che Michelangelo dipinse il Giudizio dopo essere stato a Venezia, influenzato dalla pittura di Tiziano.

Insomma mi ba talmente interessato fare questo programma che lo rifarei, e vorrei anche esprimere una proposta dalle colonne di questo giornale: meno programmi scemi e più programmi culturali. - mondo", rispose con amarezza Michelangelo, «che le pitture si accon- . - ciano presto». Pochi mesi dopo, moriva. Ci pensarono altri ad eseguire . l'ordine del Papa. Alla fine, in epoche . successive, fino al settecento, quasi - quaranta figure furono coperte con le . - «braghe». La metà sono state tolte. dai restauratori del Vaticano. Una de- . - cisione storica, avallata da Giovanni . Paolo II: «Soltanto dinnanzi agli oc- . - chi di Dio il corpo umano può rimanere nudo e conservare intatto il suo splendore e la sua bellezza»: con que- . ste parole, il Papa, quattrocentocin- . quant'anni dopo, ha chiuso la polemica, dando ragione al grande artista fiorentino. Meglio tardi che mai.

Piero Badaloni 
Addio alla Cappella Sistina? Parla il direttore dei restauri replicando alle pesanti accuse dello studioso americano Beck
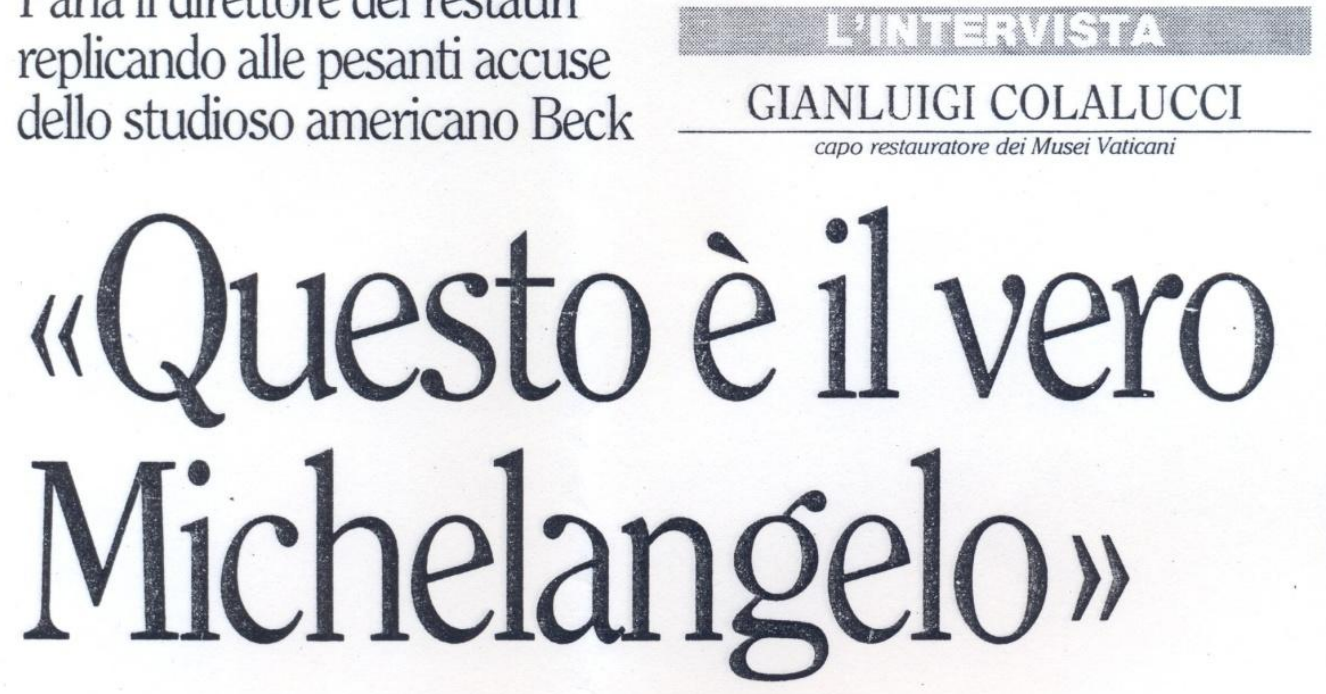

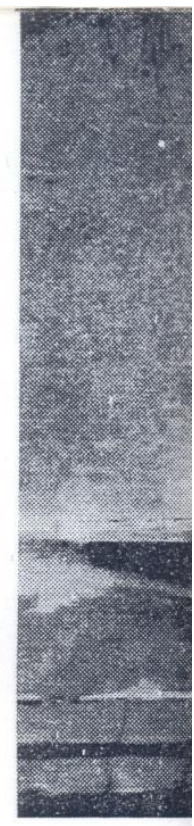

«Mai ci siamo sognati di asportare neanche un frammento di pittura di mano di Michelangelo. A volte abbiamo tenuto anche ridipinture non sue». Gianluigi Colalucci ribatte alle accuse che James Beck, autore d'un polemico saggio sul "business dei restaurin, ha reiterato domenica nell'intervista a l'Unità. Così il capo restauratore dei Musei Vaticani, punto su punto, difende la "sua» Cappella Sistina.

\section{CARLO ALBERTO BUCCI}

ci, 64 anni, è il capo restauratore dei Musei Vaticani 1980 lavora ai celebri affreschi di Michelangelo sulla volta di Michelang sulla volta del Giudizio Universale sulla parete ovest della Cappella Sistina. Un'impresa titanica quella affrontata dallo staff dei restauratori vaticani, sia per la vastità sia per l'importanza dei dipinti. Nonostante i suoi indiscutibili titoli scientifici, gli storici dell'arte accusano Colalucci di aver fatto sparire un bel po' della pittura di Michelangelo quando ha fatto togliere dalla superficie affrescata il nero fumo delle candele. Certo mente il più mente detrattori e James Beck, della Columbia University di New a Siegmund Ginzberg per l"Unità, pubblicata il 2 gennaio in occasione dell'uscita da noi del suo libro Restauri, capolavori \& affari, l'americano ha ridato voce alla sua antica polemica nei confronti dei restauratori "sistini", rei, sostiene, aver rovinato per sempre le pitture di Michelangelo.

Professor Colalucci, come mai solo oggi lei si decide rispondere alle gravi accuse che le vengono d'oltre ocea no?

In realtà lo abbiamo fatto da subito e, nonostante i lavori non fossero ultimati, abbiamo pubblicato libri, tenuto conve gni, allestito mostre. $\mathrm{E}$ ora accingiamo, siamo già alle bozze, a far uscire il Rapporto sul restauro nel quale sono documentati dettagliatamente avori sulle pitture della volta dove, voglio sperare, il profes sor Beck potrà trovare ennesime risposte alle sue solite accuse. Se oggi scelgo di difendere il nostro lavoro anche atraverso le pagine di un quotidiano è perché di fronte $a$ in vettive tanto , di fronte anche i lettori del giomale sappiano come stanno realmente le cose.

Unia delle accuse che le muove Beck, spalleggiato dal professor Charles Hope, è di non aver tenuto conto che Michelangelo non dipingeva
solo a "frescon - stendendo il colore sull'intonaco bagnato entro le 6 ore che ne precedono l'essiccamento ma che, come tutti i pittori del tempo, reinterveniva sul muro asciutto, cioè con una pittura a useccon.

Quando noi siamo saliti per la prima volta sui ponteggi abbiamo pensato che sotto quella spessa coltre di sporcizia vi osse soltanto pittura a "secco». mmaginavamo, allora, che la scarsa conoscenza delle tecniche pittoriche avesse indotto Michelangelo, fino al 1508 soprattutto noto come scultore priuturo cotore, niflute la tradizionale tecnica dell affresco. Questo per dire quanto abbiamo tenuto in
considerazione l'ipotesi di in-

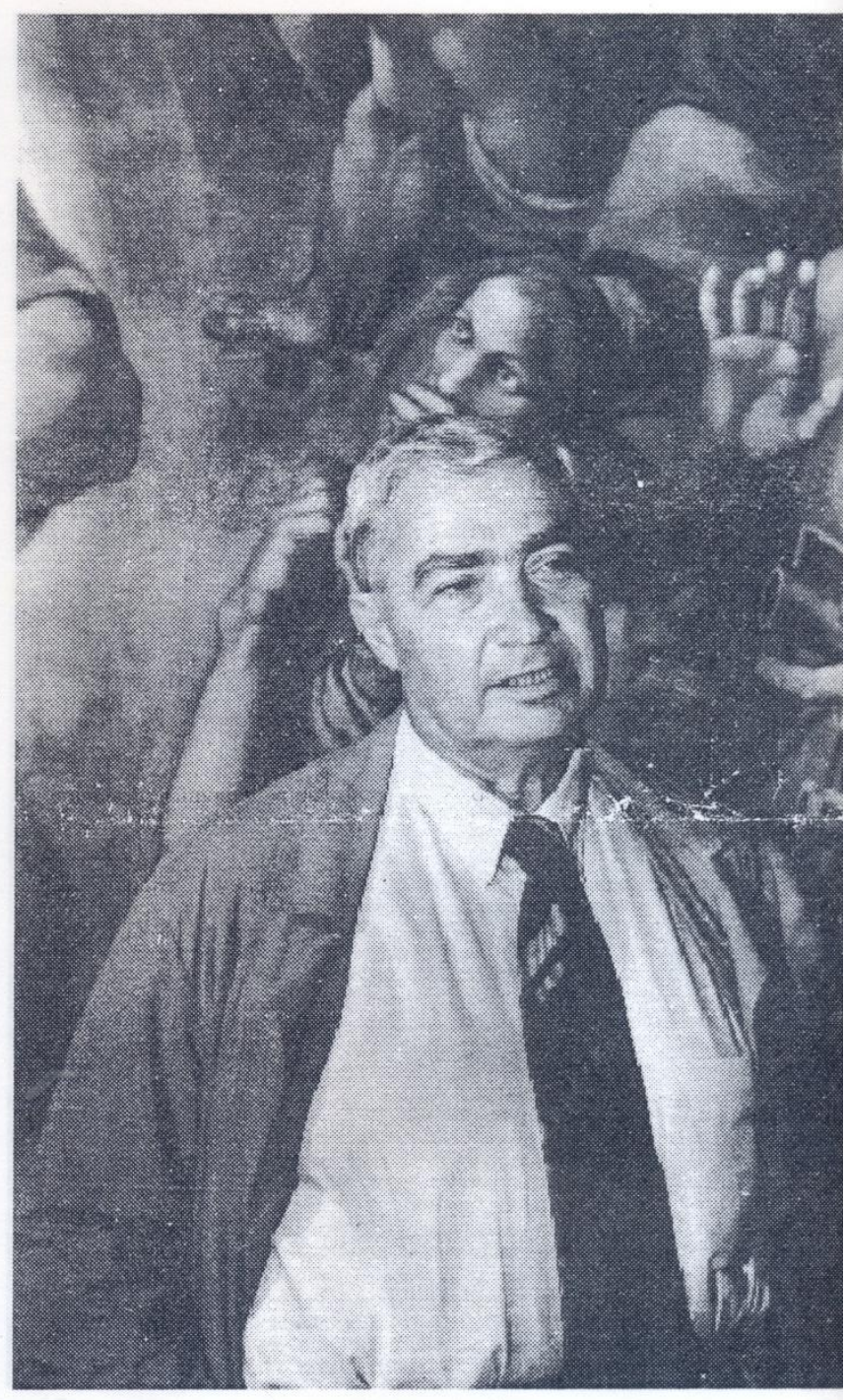




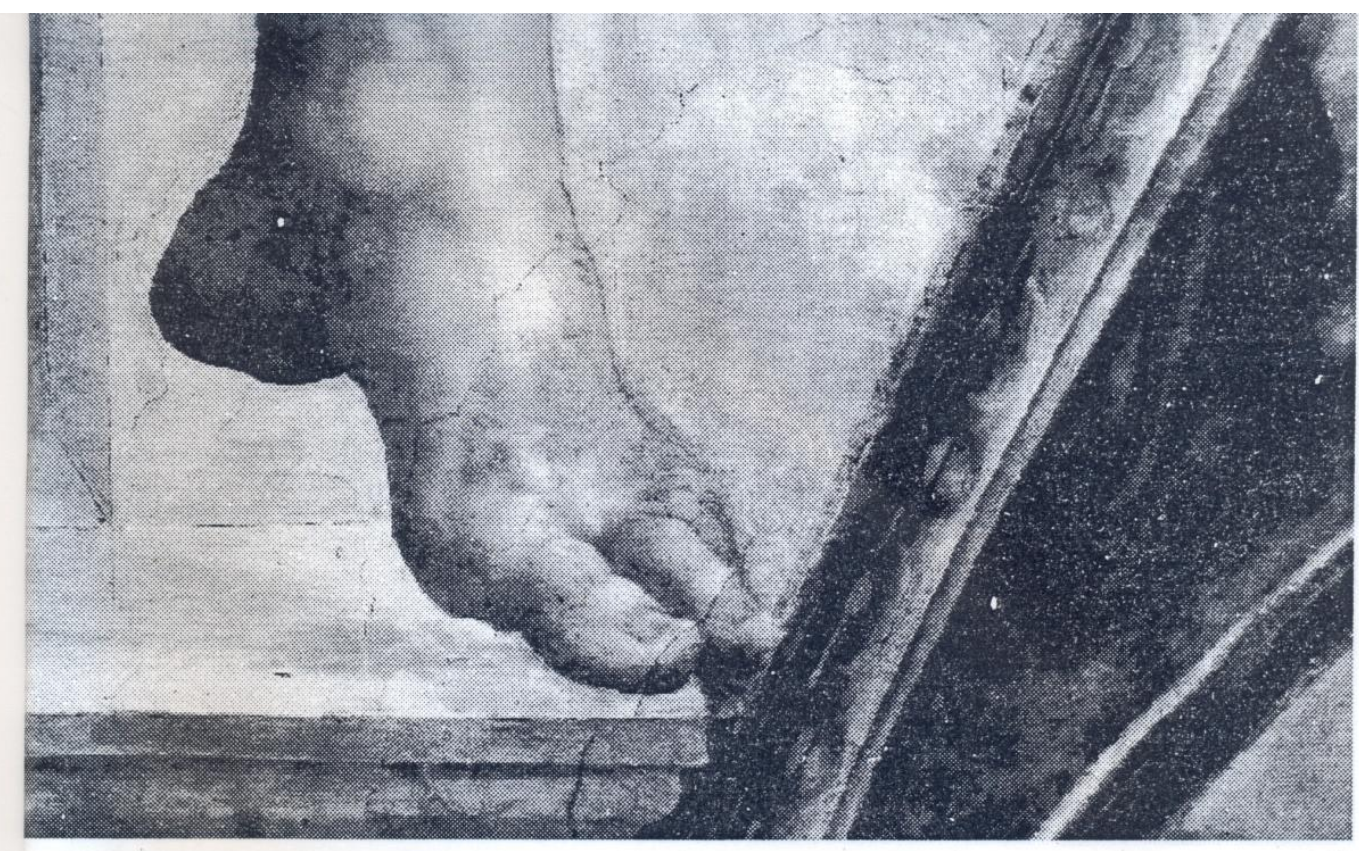

Gianluigi Colalucci di fronte al «Giudizio Universale». Sopra, dagli affreschi della volta della Sistina il piede del profeta Giona La macchia nera sulla destra testimonia lo stato dell'affresco prima della pulitura

terventi a "secco".

Allora Michelangelo ha usato una tecnica tradizional come l'affresco senza apportare sostanziali cambiamenti?

Proprio come uno dei più navigati pittori del tempo ha realiz zato un ottimo fresco reinte venendo a "secco" per eseguire delle piccole correzioni sulle figure. Esigue porzioni di pittura che sono chiaramente individuabili anche sotto lo strato di sporcizia: a occhio nudo con l'ausilio della lampada con lausilio della lampada Wood e anche perché eseguite con pigmenti differenti rispetto a quelli usati per l'affresco. Questo è l'Abc per un restauratore.

Beck sostiene che voi ci siete andati giù un po' pesanti con il solvente AB57 e che con il solvente ABst e che porta via unete pittura a "secco" originale.

È assolutamente falso. Si deve tenere conto che una volta fatta la mappa dello stato di conservazione della porzione di affresco su cui ci accing ad into sure ad intervenire e, dopo un'accurata indagine tecnica e chmica, individuate le parti "secco" - che siano di Michelangelo, o quelle eseguite da Carnevali nel 1566, o dal Mazzuoli nel 1710 oppure da altri meno noti venuti dopo - in somma, in tutti questi casi no innanzitutto proteggiamo zone a *secco" con una sostan- za impermeabile e solo dopo aver ultimato la pulitura di tutte le parti a "fresco" decidiamo se intervenirci sopra e rimuoverle: comunque mai ci siamo sognati di asportare neanche un frammento di pittura di mano di Michelangelo e, a volte abbiamo tenuto anche le ridipinture non sue.

Comunque vi accusano di aver scambiato i ritocchi Michelangelo per quelli successivi.

La differenza fra la tecnica pittorica di Michelangelo (parlo proprio del modo di segnare con il pennello la parete) quella grossolana di chi è in quella grossolana di chi è intervenuto dopo è evidente più, delle fotografie in cui si ve de come le ridipinture siano sovrapposte all'affresco michelangiolesco e, di seguito, alle stuccature che turano le alle stuccature che
crepe nella muratura.

Altra accusa: sotto i colpi del solvente aveite asportato anche le colle animali che servono, sostengono gli studioi cis amere le accentuare il gioco dei chiaroscuris.

Altra sciocchezza. Le colle animali che abbiamo trovato sono quelle usate dai restaurator per ravvivare i toni delle pitture che si erano appassiti. Ma Miche si erano appassiti. Ma Mi-
chelangelo non ha applicato chelangelo non ha applicato colle animali. Anche perche esse sono soggette a un rapido sco si impreziosisce col tempo. In più: all'interno di una stuccatura eseguita nel 1566 dal Carnevali per tappare dappare la di uno dei nudi, abbiamo ritrovato un pezzo di intonaco afvato un pezzo di intonaco af-
frescato usato allora per riemfrescato usato allora per niem-
pire la falla. Ebbene, su questo frammento dell'affresco originale, che si è preservato intatto per secoli, non c'è nessuna traccia di colla animale. Non solo, ma il colore è identico quello che noi abbiamo ritrovato pulendo le altre parti del corpo dell'ignudo. E quando corpo dellignudo. E quando o fuccio pariama le indagini sul pigmento ma le indagini sul pigmento elaborate da Nazareno Gabrielli e dagli altri chimici nell'attrezzato laboratorio dei Musei Vaticani che, per alcun analisi particolari, si avvale an'Università di Roma e dell'Istituto centrale del restauro.

Cosa mi dice a proposito de fatto che con le vostre puliture avreste attenuato, fin a fario quasí scomparire, il contrasto netto e potente tra ombre e luci creato da Mi. chelangelo?

Questa è un'accusa che può ormulare solo chi non conosce, nel profondo, la pittura del grande toscano. Quelle macchie nere che alcuni tanto rimpiangono non sono altro che il frutto della fossilizzazione dello sporco. Tolto il quale ne dello sporco. Tolto il quale e venuto fuori un tratteggio sapientissimo di linee di divers colori intrecciando le quali Michelangelo giungeva alla formulazione di un'ombra cromatica e non di una macchia bituminosa.

A proposito di ombre, cosa mi dice di quella proiettata sulla parete dal piede del profeta Giona?

Sì, ho letto nell'intervista che Beck sostiene che non si vede più. E lo dice, e cito l'intervista, aguidandoci nello scomere "guidandoci nello scorrere le illustrazioni che accompagnano l'edizione inglese del libro è che quando Beck stato cun noi sui pontejgi non ha espresso quei dubbi, a proposito dello svanito plasticismo, che poi ha avuto, ne chiuso del suo studio, dinanzi alle foto degli affreschi. Ma le fotografie, per quanto fatte be ne, non possono niprodurre esattamente il dipinto perché hanno bisogno, almeno in questo ambiente, di luce eletrica. Guardi ad esempio il busto nudo di Giona con questo th di colon frecdi segnano i muscoli. Spe gnamo il faretto puntato sopra, vede ora come la poca luce naturale ricompatti le linee separate in una tenue fusione chiaroscurale di masse e volumi?

Ma l'ombra del piede?

Dunque, Beck il piede l'ha visto da vicino e sa benissimo che in quella porzione di muro c'è stato un attacco forte di silicati (dovuti alle infiltrazion d'ati) (he hanno corroso d'acqua) che hanno corroso colore partendo da dentro muro e che, quindi, avrebber distrutto le eventuali parti "secco" di Michelangelo. E ne '700 sui silicati il restauratore ha ridipinto tutto. Quello che rimane oggi, quindi, è l'ombra originaria in affresco, più morbida di quella nera delle ridipinture che peraltro, abbiamo pintunte in un campione sporco.

Insomma lei non ha dubbi.

Non è vero. lo di dubbi ne ho avuti tanti. E sono gli stessi che ha ancora oggi James Beck Ma li ho superati attraverso la prassi corrente secondo la quale prima di mettere man su ogni singola porzione di affresco si deve spendere tanto tempo ad analizzare il pigmento, a studiare la tecnica, individuare le diverse man che sono intervenute sull'opera. E poi, fortunatamente, supero i problemi insieme, superof problemi insieme allo staff di chimici, di restaurator e con il professor Mancineil. storico deil arte responsab:e del progetto. Comunque sì, sono convinto che abbiamo operato le scelte giuste restituendo l'opera di Michelangelo nella sua luce più vera. Nonostante danni provocati dall'acqua dal tempo e dagli uomini. 
Biografia Professionale di Gianluigi Colalucci relativa ai lavori svolti per le Soprintendenze dal 1953 al 1987

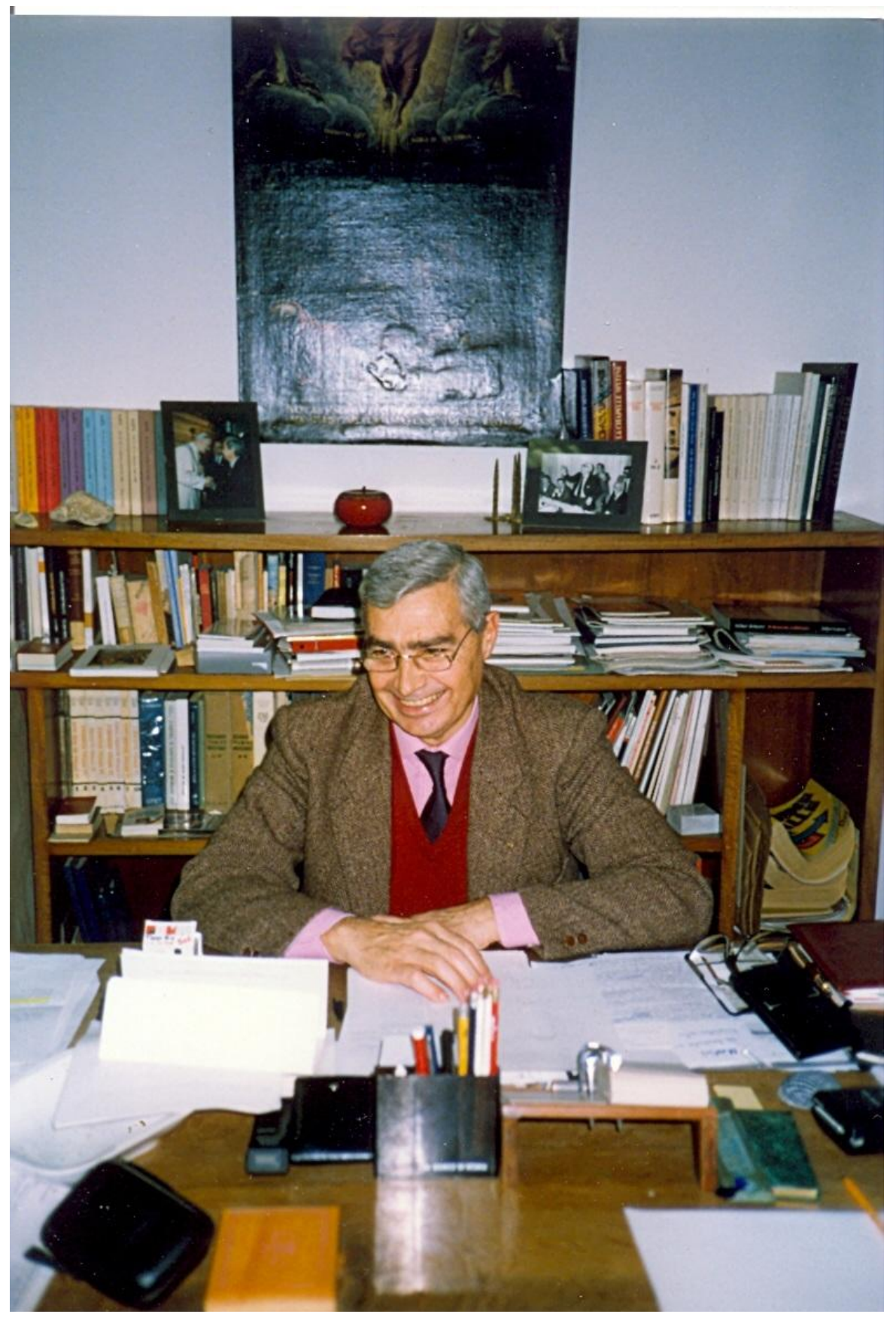

Gianluigi Colalucci nel suo ufficio ai Musei Vaticani 
1953 Palermo-Galleria di Palazzo Abatellis-

Maestro del polittico di trapani
Seguace di P.Novelli
sc.di A. De Crescenzio
\[ 1953 \text { Monreale (Pa)-Duomo- } \]
Filippo Paladino

Martirio di San Placido

olio su tela

$\mathrm{cm} .406 \times 311$

1954 Petralia Sattana (Pa)-Chiesa Madre-

Maestro delle Madonie ?

Madonna tra i Santi Pietro e Paolo

temp.su tav.

$\mathrm{cm} .216 \times 143$

1955 Erice (Tr)-Chiesa di Sant'Antonio

epoca basiliana

Santo vescovo

affresco

$\mathrm{cm} .200 \times 70$

1956 Creta-Museo di Eraclion

epoca minoica

affresco detto dei gigli

affresco

1956 Palermo-Galleria di Palazzo Abatellis

Tommaso de Vigilia

Madonna della catena

1957 Palermo -Galleria di Palazzo Abatellis

an.sec.XVII

sc. Del Novelli

Deposizione dalla Croce

Madonna del Rosario

F.Potenzano

La lavanda dei piedi

an.

P. d'Asaro detto il Monocolo

Circoncisione

an.sec.XVII

Natività

Sant'Ignazio in estasi

V. De Pavia

Deposizione dalla Croce

an.

Arcangelo Michele

1957 Palermo-Chiesa del Noviziato
G. Mercurio
II trionfo della Chiesa
an.
San Stanislao

olio su tela

$\mathrm{cm} .430 \times 300$

olio su tela

$\mathrm{cm}, 220 \times 141$

1957 Palermo- Museo Dicesano

an. sec. XVIII

Vergine col Bambino e Santo

olio su tela

1957 Agira (En)-Chiesa di Santa Maria Maggiore

an.

Crocifisso dip.su due lati

temp.su tav.

$\mathrm{cm} .390 \times 247$

1957 Agira (En)-Chiesa dell'immacolata

sc. catalana

Crocifisso

temp.su tav

$\mathrm{cm} .385 \times 286$

1957 Agira (En)-Chiesa di San Pietro 
1957 Castelvetrano (Tr)- Chiesa Madre-

an.

stucchi

oli su muro

oli su tela

1957 Castroreale (Me)-Chiesa di Santa Marina

an.

an. Fiammingo

an.

an.
Son Lorenzo

Adorazione dei Mogi

Crocifisso

Madonna con Santi e leone temp.gr.su tav.

olio su tav.

temp. su tav.

temp.gr.su tav. $\mathrm{cm} .185 \times 103$

$\mathrm{cm} .136 \times 190$

$\mathrm{cm} .240 \times 193$

$\mathrm{cm} .165 \times 110$ $\mathrm{cm} .232 \times 104$

San Leonardo

temp.gr.su tav.

temp.gr.su tav.

$\mathrm{cm} .360 \times 235$

Ognissonti

1957 Troina -Chiesa Madre

an

Arcangelo

an. sec. XVI

Madonna col Bambino

1958 Palermo-Galleria di Palazzo Abatellis

P. Novelli

sc.di V. De Pavia

Annunciazione

P. Novelli

Morte della Vergine

v. Carrera

Vergine col Battisto e Santi

San Raimondo

temp.su tav.

cm.115x89

temp.gr.su tav.

$\mathrm{cm} .110 \times 81$

olio su tela

$\mathrm{cm} .380 \times 204$

temp.gr.su tav.

olio su tela

olio su tela

cm. $238 \times 138$

1958 Butera (Ag)-Chiesa di San Francesco di Paola

an.

Madonna del Rosario

olio su tela

$\mathrm{cm} .263 \times 184$

olio su tela

$\mathrm{cm} .275 \times 207$

1958 Butera (Ag)-Chiesa Madre

an.

Madonna, Bambino SS. Pietro e Paolo tem.su tav.

$\mathrm{cm} .198 \times 193$

F. Paladino

Immacolata e Santi

olio su tela

$\mathrm{cm} .300 \times 200$

1958 Caltagirone (Rg)-Chiesa del Collegio

F. Paladino

Deposizione

alio su tela

$\mathrm{cm} .300 \times 200$

Polidoro da Caravaggio

Adorazione dei Pastori e Annunciazione olio su tav.

$\mathrm{cm} .278 \times 154$

1958 Castroreale (Me)-Chiesa della Candelora

an.

an.

maestro del polittico di Trapani
Circoncisione

Dormitio Virginis

Scene della vita dello Vergine temp.su tav.

cm. $267 \times 205$

temp.su tav.

$\mathrm{cm} .222 \times 221$

temp.su tav. 
1958 Castroreale (Me)-Chlesa del Salvatore-

$\begin{array}{ll}\text { an. } & \text { Trinitò e Ognissanti } \\ \text { an. } & \text { Angeli e IHS } \\ \text { an. } & \text { Incoronazione e Assunzione } 2 \text { lunette }\end{array}$

1958 Cesard (Me)-Chiesa Madre-

an.

1958 Enna-Chiesa di San Francesco-

an.

$$
\text { Crocefisso dipinto su due lati }
$$

temp.su tav.

$\mathrm{cm} .359 \times 255$

1958 Enna -Chiesa di San Cataldo-

an.

Crocefisso

temp.su tav.

$\mathrm{cm} .250 \times 200$

1958 Ficarra (Me)- Chiesa Madrean.

Madonna con i Santi Pietro e Paolo

temp.gr.su tav.

$\mathrm{cm} .288 \times 248$

1958 Montalbano Elicona (Me)- Chiesa Madre-

an.

$$
\text { Crocefisso }
$$

scultura lignea

1958 Molino (Me)-Chiesa Madre-

A. Riccio

Madonna di Loreto e Santi

temp.gr.su tav.

1958 Naro (Ag) -Chiesa di San Francesco-

V. d'Anna

Immocolato

olio su tela

cm. $325 \times 200$

1958 Venetico (Me)-Chiesa Madre-

sc.di C.da Sesto
sc.di C.da Sesto
an.sec.XV

1958 Trapani - Museo Pepoli

P.d'Asaro detto il Monocolo
A. Carreca
A. Carreca
sc. siciliana sec.XVII
an.sec.XVII
an.sec.XVIII
La Bruna
sc. del Tintoretto
sc. del Novelli
A. Carreca
La Bruna
sc. fiamminga sec.XVII
V. d'Anna ?

Adorazione dei magi replica
Redentore
Crocifisso

$\begin{array}{ll}\text { olio su tav. } & \mathrm{cm} .326 \times 270 \\ \text { olio su tav. } & \mathrm{cm} .78 \times 78 \\ \text { temp.gr.su tav. } & \end{array}$

$\begin{array}{ll}\text { Resurrezione } & \text { olio su tela } \\ \text { Annunciazione } & \text { olio su tela }\end{array}$

cm. $284 \times 180$

olio su tela

cm. $127 \times 195$

$\mathrm{cm} .100 \times 178$

$\mathrm{cm} .100 \times 129$

$\mathrm{cm} .74 \times 98$

$\mathrm{cm} .121 \times 98$

cm.67×57

$\mathrm{cm} .220 \times 180$

cm. $225 \times 167$

cm. $300 \times 210$

cm. $285 \times 178$

cm. $295 \times 200$ 
A. Carreca

an.

an. fiammingo

M. Stanzioni
Madonna del Rosario

Testa di vecchio

Testa con cappello piumato

Sant'Apollonio olio su tela

affresco

olio su tav.

olio su tela

temp.gr.su tav.

Nativitd

1958 Ragusa lbla (Rg)- Chiesa dei Cappuccini-

Guinaccia ?

1958 Racalmuto (Ag)-Chiesa del Carmine-

P. d'Asaro detto il Monocolo

Sacra Famiglia

P. d'Asaro detto il Monocolo

Crocifissione e Santi

1958/59 Nicosia (En)-Chiesa Madre-

P. Novelli

an.

1958/59 Francofonte (5r)- Chiesa Madre-

an. sec. XV

Madonna Miracolosa col Bambino

1958/59 Roccavaldina (Me)-Chiesa Madre-

an. sec. $\mathrm{XV}$

Crocifisso

1958/59 Randazzo (Ct)- Chiesa Madre-

an. sec. XVII

Martirio di san lorenzo

1958/59 Santa Lucia del Mela (Me)-Chiesa Madre-

P. Novelli

sc. siciliana del sec.XVII

San Biagio in adorazione

Madonna del Rosario

an.

an.sec.XVII

an.sec.XVII

an.sec.XVII

an.sec.XVII

an.sec.XVII

an.sec.XVII

Guinaccia

an.

1959/60 Trapani-Museo Pepoli-

G. Ruoppolo

A. Sabatini

A. Caroselli ?

an. caravaggesco

B. Cavallino

M. Pino
San Sebostiono

Modonna con S.Antonio e S.Simeone

Madonna del Cormelo

San Pietro e San Paolo

Madonna con San Gregorio

Madonna della presentazione

Assunzione

Natura morta

Dio Padre e angeli

La testa del Battisto ad Erodiade

Tobiolo el'Angelo

San Francesco e $/ /$ Crocefisso

Deposizione
San Mauro olio su tela

$\mathrm{cm} .220 \times 154$

olio su tela

$\mathrm{cm} .380 \times 275$

olio su tela

$\mathrm{cm} .207 \times 154$

olio su tela

cm. $228 \times 193$

temp.gr.su tav.

temp.su tav

olio su tela

$\begin{array}{ll}\text { olio su tela } & \mathrm{cm} .309 \times 206 \\ \text { olio su tela } & \mathrm{cm} .305 \times 205 \\ \text { olio su tela } & \mathrm{cm} .380 \times 230 \\ \text { olio su tela } & \mathrm{cm} .322 \times 218 \\ \text { olio su tela } & \mathrm{cm} .330 \times 202 \\ \text { olio su tela } & \mathrm{cm} .305 \times 205 \\ \text { olio su tela } & \mathrm{cm} .326 \times 205 \\ \text { olio su tela } & \mathrm{cm} .314 \times 213 \\ \text { olio su tela } & \mathrm{cm} .600 \times 400 \\ \text { termp.gr.su tav. } & \mathrm{cm} .237 \times 157 \\ \text { affresco } & \end{array}$

olio su tela

cm.49x65

temp.gr.su tav. $\quad \mathrm{cm} .40 \times 84$

olio su tela

$\mathrm{cm} .83 \times 80$

olio su tela

olio su tela

$\mathrm{cm} .81 \times 69$

olio su tav.

$\mathrm{cm} .41 \times 23$ 

A. Vaccaro
Adorazione dei Magi
olio su tela
cm. $98 \times 128$
V. Carrera
San Raimondo
olio su tela
$\mathrm{cm} .238 \times 138$
L. Coccorante
Mare in tempesta con rovine
olio su tela
cm. $125 \times 99$
M. Stanzioni
Sant'Agata
olio su tela
$\mathrm{cm} .46 \times 35$
H. Rigaut ?
Ritratto di Luigi XIN
olio su tela
$\mathrm{cm} .63 \times 46$
P. Porpora
Natura morta
olio su tela
$\mathrm{cm} .113 \times 72$

1965 Roma- Chiesa di Santa Maria in Montesanto-Sacrestia della Cappella Montioni-

L. Geminiani

stucchi

oli su muro

olio su tela

1967 Roma- Chiesa di San Salvatore in Lauro-

Peruzzini

P. L. Ghezzi

A. Turchi
Trasporto della Sonto Casa

Santi marchigiani

San Carlo Borromeo e la Vergine olio su tela

olio su tela

olio su tela cm.318x185

olio su tela

$320 \times 220$

olio su tela

cm. $277 \times 152$
Madonna della Misericordio

Gesu e San Gioacchino

olio su tela

cm.220x115

Sassoferrato

Madonna del Rosario

lunetta

olio su tela

cm.200x97

F. Vanni

Morte di santa Cecilia

Circoncisione

olio su tela

$\mathrm{cm} .70 \times 90$

1967 Roma-Chiesa di San Tommaso ai Cenci-

Giotto giovane o Maestro d'Isacco Crocefisso

temp.gr.su tav. camot.

cm. $250 \times 176$

1967 Anguillara (Rm)-Collegiata-

an. sec. XVII

$$
\text { Cristo in croce }
$$

olio su tela

$\mathrm{cm} .257 \times 149$

1967/69 Roma -Chiesa di Gesù e Maria-
L. Baldi
G. Brandi

Madonna col Bambino

Sacra Famiglia

olio su tela

$\mathrm{cm} .236 \times 145$

olio su tela

$\mathrm{cm} .247 \times 173$

1967/69 Roma-Chiesa di San Salvatore in Lauro-

an. sec. XVI

Crocefisso

scultura

temp.gr.su tav.

cm. $176 \times 140$ 
1967/69 Roma-Chiesa di Sant'Angelo in Pescheria-

1967/69 Roma-Chiesa di Santa Maria in Campo Marzio-

1967/69 Roma-Chlesa del Nome di Maria-

an. sec. XIII

Madonna col Bambino

\section{7/69 Roma- Chiesa di San Giovanni Decollato}

G. Vasari

G. Baldueci

Decollazione del Battista

G. Balducci

J. Zucchi

J. Zucchi

1. Zucchi

an.sec.XVI

an.sec.XVI

an.sec.XIV-XV

C. Roncalli

B. Naldini

M. Monanni

copia da Lanfranco

Resurrezione di Lazzaro

Predica del Battista

Nascita del Battisto

Vergine in gloria

Due Santi (due pannelli)

Decollazione del Battisto

Crocifissione

Madonna col Bambino

Visitazione

Morte di San Giovanni

Battesimo di Cristo

Andata al Calvario

1967/69 Roma-Chiesa dei SS. Apostoli-
A. Romano?
Madonna col Bambino

1967/69 Roma-Chiesa di Sant'lvo alla Saplenza-
P. da Cortona
Sant'lvo Avvocato

1967/69 Roma-Chlesa di Sant'Andrea della Valle-Cappella Barberini-

Passignano
Passignano
Passignano

1967/69 Roma-Castel Sant'Angelo-

sc. fiorentina sec. XV

F. di Lorenzo

P. del Vaga

B. Montagna

N. Alunno

S. del Piombo
Visita di Santa Elisabetta

Noscita della Vergine

Annunciazione

Madonna col Bambino e Santi

San Sebastiono

Sala della Giustizia

Madonno col Bambino

San Sebastiano e san Giovanni

Cristo portacroce

$\begin{array}{lll}\text { olio su tav. } & & \mathrm{cm} .320 \times 200 \\ \text { olio su tela } & & \mathrm{cm} .288 \times 192 \\ \text { olio su tela } & \mathrm{cm} .319 \times 385 \\ \text { olio su tela } & & \mathrm{cm} .344 \times 237 \\ \text { olio su tela } & & \mathrm{cm} .245 \times 178 \\ \text { olio su tela } & \text { cad. } & \mathrm{cm} .176 \times 57 \\ \text { olio su tela } & & \mathrm{cm} .293 \times 193 \\ \text { olio su tela } & & \mathrm{cm} .240 \times 131 \\ \text { affresco } & \text { (staccato) } & \mathrm{cm} .84 \times 56 \\ \text { olio su tela } & & \mathrm{cm} .348 \times 238 \\ \text { olio su tela } & & \mathrm{cm} .335 \times 230 \\ \text { olio su tela } & & \mathrm{cm} .310 \times 385 \\ \text { olio su tela } & \mathrm{cm} .209 \times 115\end{array}$

temp.gr.su tav.

crn. $179 \times 129$

olio su tela

$\mathrm{cm} .825 \times 375$

olio su muro

$\mathrm{cm} .278 \times 410$

olio su muro

cm. $260 \times 420$

olio su muro

cm.260x425

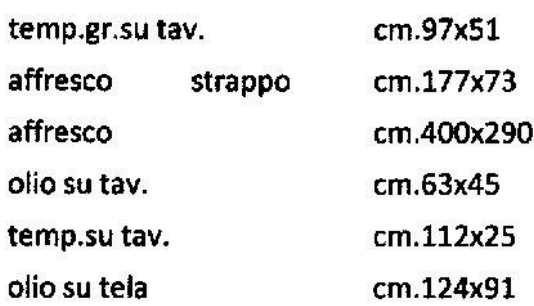


1967/69 Velletri (Rm)-Cattedrale di San Clemente-

an. senese sec.XIV

Madonna delle Grazie

temp.su tav

$\mathrm{cm} .153 \times 70$

1967/69 Velletri (Rm)-Chiesa di San Pietro e san Simone-

an. sec. XV

Madonna del Gonfolone

olio su tav.

$\mathrm{cm} .98 \times 59$

1967/69 Caprarola (RM)- Duomo-

an. sec.X VIII

Madonna in Gloria e Santi

olio su tela

$\mathrm{cm} .326 \times 219$

1967/69 Tivoll (Rm)- Chiesa dl Santa Maria Maggiore-

falso del sec.XVII

Madonna Avvocata

temp.su tav.

$\mathrm{cm} .102 \times 65$

1967/69 Salice (Me)- Chiesa di Santo Stefano-

an.

Le Sonte Lucia,Agato e Santa Famiglia

olio su tav.

1970 Roma-Chiesa di San Domenico e Sisto-

$\begin{array}{lllll}\text { Lanfranco } & \text { Crocifissione } & \text { centinata } & \text { olio su tela } & \mathrm{cm} .313 \times 146 \\ \text { an. sec. XIII } & \text { Croefisso } & & \text { temp. su tav. } & \mathrm{cm} .206 \times 169\end{array}$

1970 Roma-Castel Sant'Angelo-

Zavattari

L. Lotto

Poussin

Spansotti

P. Bordone

Giampietrino

an.

Madonna in Trono e Santi trittico

San Girolamo nella selva

Baccanale

Pietà

Cristo portacroce

Cristo portacroce

Sala dei Festoni

fregio

temp.gr.su tav

cm142x174.

temp.su tav.

olio su tela

olio su tav.

olio su tela

olio su tav.

affreschi

$\mathrm{cm} .80 \times 61$

cm.71x51

cm. $84 \times 69$

$\mathrm{cm} .43 \times 35$

m. $0,98 \times 22$

1970 Anguillara (Rm)-Chiesa di Santa Maria Assunta-

an. $\sec . X V$

Madonna col Bambino

trasporto

temp. gr.su tav.

$\mathrm{cm} .157 \times 63$

1970 Soriano al Cimino (Rm)- Chiesa della SS.Trinità-

an. sec. XIV

Madonna in Trono

temp. gr. su tav.

cm.117 $\times 73$

1970 Scandriglia (Ri)-Chiesa di san Nicola-

an. $\sec$. XIII

San Nicola in Trono

temp.su tav.

$\mathrm{cm} .168 \times 68$

1971 Roma- Castel Sant'Angelo-
L. Romano
L. Romano
P. del Vaga
an.

1971 Roma-Chlesa di Sant'Andrea della Valle-

\author{
Sala del Delfino \\ Sala della Cicogna \\ Corridoio della Sala della Cicogno \\ Sala della Cagliostra
}

affreschi

affreschi

affreschi

affreschi

mq.164

olio su tela

$\mathrm{cm} .348 \times 220$ 
1971 Roma- Chiesa di Sant'Ambrogio della Massima-

an. Sec. XIII

Crocefisso

temp.su tav.

$\mathrm{cm} .225 \times 160$

1971 Roma- Chiesa di San Claudio-
G. Francisci
Madonna col Bambino
centinata
olio su tav.
$\mathrm{cm} .92 \times 44$

1971 Rocca di Papa (Rm)- Chiesa dell'Assunta-

an. sec.XV

P. del Vaga? attr.

Modonna col Bambino

Redentore

1971 Alatri (Fr)-Curia Vescovile-

an. sec.XV|

Sacra Famiglia

1971 Tivoli (RI)-Chiesa di Santa Maria Maggiore-

A. Romano

Sant'Antonio da Padova

1971 Vinciano (Fr)

frammenti antichi rid. nel sec. XIX

Madonna del Corpinello

1971 Maranola (Fr)- Chlesa di Santa Maria dei Martiri-

sc. romana/napoletana sec.XVI

Madonna in Trono con Bamb.e Santi

1972/74 Roma- Chiesa di San Glovanni Decollato-

an. sec. XVI

Incredulitò di San tommaso

1972/74 Roma-Chiesa di san domenico e Sisto-

L. Vanni

Madonna col Bambino e Santi

1973/74 Roma Castel Sant'Angelo-

P. del Vaga e P. Tibaldi

Salo Paolina

Sacra Conversazione

L. Lotto

San Girolamo

C. Crivelti

Redentore

sc. lombarda sec.XVI

Dama con llocorno

E. Grandi

Deposizione

1973/74 Bracciano (Rm)-Colleglata di Santo Stefano-
D. e G. d'Arezzo
Redentore

1973/74 Rometta (Me)-Chiesa dell'Immacolata-

D. Guinaccia

Trasfigurazione temp.gr.su tav

cm. $218 \times 264$

affresco

$\mathrm{cm} .260 \times 180$

olio su tav.

$\mathrm{cm} .125 \times 68$

olio su tav.

$\mathrm{cm} .127 \times 69$

olio su tav.

$\mathrm{cm} .45 \times 60$

temp.gr.su tav.

cm. $188 \times 63$

olio su tela

cm.149x70

temp.gr.su tav

$\mathrm{cm} .159 \times 208$

cm.79x106

cm. $34 \times 27$

cm. $34 \times 27$

cm.132x98

cm. $84 \times 174$ olio su tav.

olio su tav.

$\mathrm{cm} .148 \times 114$

1973/74 Piedimonte Etneo (Me)-Santuario della Madonna della Venaan. sec. XII

Madonna col Bambino

temp.su tav.

$\mathrm{cm} .175 \times 66$ 
1973/74 Savoca (Me)-Chiesa di Santa Lucia-

an. sec. XIV

1973/74 Monreale (Pa)-Palazzo del Comune-

1975 Roma-Chiesa di San Silvestro al Quirinale-

1975 Gaeta (Lt)-Duomo-

1975 Palermo-Chiesa di San Giovanni dei Lebrosi-

1975 Termini Imerese (Pa)-Chiesa della Misericordia-
G. da Pesaro
Trittico della Misericordia

temp.gr.su tav.

cm.198x198

1976/77 Roma- Galleria Borghese-

F. Galizia

Garofalo

Garofalo

Garofalo

M. Pino

D. Ciampelli

1976/77 Roma-Castel Sant'Angelo-

L. Luzi e D. Zaga
an. sec.XVI
an. sec. XVI
P.del Vaga
P.del Vaga
P.del Vaga

1977 Castronuovo (Pa)-Chiesa Madre-

an. sec. XVI

Crocefisso

1978 Roma- Chiesa di Santa Maria sopra Minerva-Chiostroan. sec. XVI

Giuditta con la testa di Oloferne

Madonna col Bambino e cardellino

Madonna col Bambino e Santi

Santa Caterina d'Alessandria

Resurrezione

Cristo nel Sepolcro

Sala d'Apollo

Loggia di Paolo III

Vestibolo della Biblioteco

Stufetta di Clemente VII

Fregio della Sala del Perseo

Fregio della Sala di Amore e Psiche olio su tela

temp.gr.su tav.

temp.gr.su tav.

temp.gr.su tav.

olio su tav.

olio su tela

affreschi

affreschi

affreschi

affreschi e stucchi

affreschi

affreschi

scultura lignea policr.
1978 Roma-Galleria Borghese-

I. da Imola
seguace del
Garofalo
Garofalo
Garofalo
L. Cranach
B. di Dosso
B.di Dosso
D. Dossi

I. da Imola

seguace del Garofalo

Garofalo

Garofalo

Garofalo
Ritratto femminile

Resurrezione di Lazzaro

Sacra Famiglia

Pianto del Cristo

Flagellazione

Venere e Amore

Riposo dopo la fuga in Egitto

Presepio

Adorazione del Bambino temp.gr.su tav.

temp.gr.su tav.

temp.gr.su tav.

temp.gr.su tav.

temp.gr.su tav.

temp.gr.su tav.

temp.gr.su tav.

temp.gr.su tav.

temp.gr.su tav. cm.124x93

cm. $35 \times 39$

cm. $50 \times 32$

cm. $132 \times 98$

cm.125x103 $\mathrm{cm} .78 \times 58$

cm.66×45

$\mathrm{cm} .65 \times 42$

$\mathrm{cm} .55 \times 32$

cm. $71 \times 40$

cm169×67

cm.46x59

cm. $44 \times 29$

cm.56×32 
1978 Roma -Palazzo Falconieri-

\begin{tabular}{|c|c|c|}
\hline $\begin{array}{l}\text { F. Borromini } \\
\text { an. sec. XVIII-XIX }\end{array}$ & Sala 106 e Sala 107 & $\begin{array}{l}\text { stucchi } \\
\text { temp.su muro }\end{array}$ \\
\hline
\end{tabular}

1978 Palermo-Museo Diocesano-

an. sec.XV

Santi Cosma e Damiano

temp.gr.su tav.

cm.170x121

\section{9/81 Roma-Galleria Borghese-}

Brescianino
sc. romana
seguace di B. Luin
A. del Sarto
sc. fiorentina
D. Puligo
J. Dal Conte
Bachiacca
Bachiacca
Bachiacca
Bachiacca
Garofalo
M. Basaiti
M. Basaiti
P. Tibaldi
Baglione
Parmigianino

Venere tra due amorini

olio su tav.

cm. $151 \times 66$

Madonna col Bambino

olio su tav.

cm. $36 \times 47$

Sant'Agata

temp.gr.su tav.

cm. $40 \times 29$

Madonna col Bambino e S. Giovannino

temp.gr.su tav.

cm.154x101

Madonna col Bambino e S. Goivannino

olio su tav. tondo

cm. $72 \times 72$

Modonna col Bambino e S. Giovannino

temp.gr.su tav.

$\mathrm{cm} .86 \times 64$

Ritratto di Vittoria Farnese

Ricerca della coppa rubata

olio su lavagna

$\mathrm{cm} .106 \times 83$

temp.gr.su tav.

$\mathrm{cm} .26 \times 34$

temp.gr.su tav.

$\mathrm{cm} .26 \times 34$

temp.gr.su tav.

$\mathrm{cm} .26 \times 36$

Giuseppe venduto dai fratelli

temp.gr.su tav.

cm. $26 \times 36$

temp.gr.su tav.

temp.gr.su tav.

$\mathrm{cm} .152 \times 85$

temp.gr.su tav.

$\mathrm{cm} .152 \times 85$

olio su tela

$\mathrm{cm} .157 \times 107$

olio su tela

olio su tav.

cm. $54 \times 44$

1981 Roma-Chiesa della Trinità del Pellegrini-

G. Reni

Crocefissione con la Trinitò

olio su tela

cm. $564 \times 301$

1981 Roma- Convento di Sant'Alberto-

an.sec. XIII?

Crocifissione

temp. su tav.

$\mathrm{cm} .190 \times 145$

1980/81 Roma-Chiesa del Gesù- Cappella della Madonna della Strada-
G. Valeriano e S. Pulzone
Sposalizio della Vergine
G. Valeriano e S. Pulzone
Visita di Sant'Anna
G. Valeriano e S. Pulzone
Presentazione al Tempio
G. Valeriano e S. Pulzone
Annunciazione
G. Valeriano e S. Pulzone
Madonna in Gloria
G. Valeriano e S. Putzone
Assunzione
G. Valeriano e S. Pulzone
Natività

olio su tav.

cm.230x117

olio su tav.

cm. $230 \times 119$

olio su tav.

$\mathrm{cm} .232 \times 117$

olio su tav.

$\mathrm{cm} .233 \times 207$

olio su tav.

$\mathrm{cm} .230 \times 168$

olio su tav.

$\mathrm{cm} .234 \times 171$

olio su tav.

$\mathrm{cm} .231 \times 117$

1981 Roma-Palazzo Spada-

an. sec. XVI

Gallerio della Meridiano

pittura a calce su muro

1981 Cerro al Volturno (Is)-Chiesa Parrocchlale-

an. sec.XVI

Trasporto della Santa Casadi loreto

olio su tav.

$\mathrm{cm} .178 \times 210$ 
1981 Cremona- Battistero-

an. sec. XIV

1981 Ostiglia (Mn)-Chiesa Parrocchiale-

an.

Modonna in Trono col Bambino

Nativito

an.

Adorazione del Bambino

1981 Esperia (Fr)-Chiesa di Santa Maria Maggiore-

M. Mazzaroppi

Discesa dello Spirito Santo

1981 Vallemaio (Fr)-Chiesa dell'Annunclata-

attr. C. Martucci sec. XVI

L'Annunciazione

trittico

1982/85 Roma-Galleria Borghese-

Bassano
Palma il Vecchio
Raffaellino da Reggio
Guercino
D. Dossi
A. del Sarto
Mazzolino
sc. tedesca
copia da Rubens
F. Francia
P. Batoni
Savoldo
Caravaggio
G. della Porta

$1982 / 85$ Roma-Castel Sant'Angelo-
P. del Vaga
P. del Vaga
P. del Vaga
P. del Vaga

Pecore

Ritratto di giovane

Tobiolo e l'Angelo

Sansone offre un favo ai genitori

Apollo e Dafne

Storie di Gesù

San Tommaso

Ritratto di Ludovico $X$

Adorazione

San Francesco

Madonna col Bombino

Figura di giovane

San Girolamo

Crocifissione olio su tav.

$\mathrm{cm} .200 \times 280$

olio su tela

olio su tela

olio su tela

olio su tav.

olio su carta

olio su tav.

cm. $31 \times 44$

temp.gr.su tav.

cm. $30 \times 23$

olio su tela

olio su tela

temp.gr.su tav.

olio su tav.

olio su tav.

olío su marmo

olio su tav.

olio su tela

olio su tela

olio su tela

cera su lavagna

cm.107×73

cm. $148 \times 103$

cm.191×116

cm. $26 \times 173$

cm. $37 \times 31$

cm. $43 \times 35$

$\mathrm{cm} .45 \times 38$

cm. $58 \times 43$

cm. $66 \times 50$

cm. $50 \times 40$

cm. $116 \times 153$

cm. $69 \times 48$

\section{2/85 Cremona- Cattedrale-}

G. Campi

Assunta

stendardo

olio su seta

$\mathrm{cm} .257 \times 166$

1982/85 Verona- Museo di Castelvecchio-

J. Bellini

Cristo in Croce

temp.su tela

$\mathrm{cm} .314 \times 190$ 
1982/85 Padova-Scuola del Santo- Sala Capitolare-

Tiziano

Tiziano

Tiziano

F. Vecellio

F. Vecellio

G. Tessari
II miracolo del neonato

II miracolo del piede

II miracolo del marito geloso

II miracolo della mula

II miracolo del forziere

II neonato salvato dall'acqua affresco

cm. $325 \times 333$

affresco

affresco

affresco

affresco

affresco $\mathrm{cm} .325 \times 215$

cm. $325 \times 215$

$\mathrm{cm} .325 \times 335$

$\mathrm{cm} .325 \times 320$

$\mathrm{cm} .325 \times 432$
Arcangelo Michele

Arcangelo Michele

scultura in bronzo

scultura in marmo

1985/87 Roma- Castel Sant'Angelo_

Verrschaffelt

Raffaello da Montelupo 